\title{
RECEIVED
}

FFR 061998

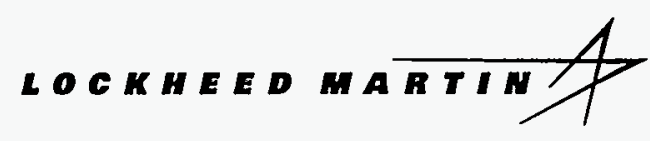

ENVIRONMENTAL RESTORATION PROGRAM

\author{
OSTI \\ ES/ER/TM-227/Pt1B
}

\section{Nuclear Facility Decommissioning and Site Remedial Actions: A Selected Bibliography, Vol. 18}

\author{
Part 1B. Citations with Abstracts \\ Sections 10 Through 16
}

This document has been approved by the East Tennessee Technology Park Technical Information Office for release to the public. Date: $9-18-97$ 


Information International Associates, Inc.
contributed to the preparation of this document and should not be
considered an eligible contractor for its review.

This report has been reproduced directly from the best available copy.

Available from the Remedial Action Program Information Center, 138 Mitchell Road, Oak Ridge, TN 37830-7918, phone: 423-576-6500, fax: 423-576-6547, e-mail: rapic@ornl.gov. 
ES/ER/M-227/Pt1B

\title{
Nuclear Facility Decommissioning and Site Remedial Actions: A Selected Bibliography, Vol. 18
}

\author{
Part 1B. Citations with Abstracts \\ Sections 10 Through 16
}

Date Issued—September 1997

\author{
Prepared by \\ Remedial Action Program Information Center \\ and \\ Information International Associates, Inc. \\ Oak Ridge, Tennessee \\ under subcontract 70K-GAM66 \\ Prepared for the \\ U.S. Department of Energy \\ Office of Environmental Management \\ under budget and reporting code EW 20
}

\section{LOCKHEED MARTIN ENERGY SYSTEMS, INC.}

managing the

Environmental Management Activities at the

East Tennessee Technology Park Paducah Gaseous Diffusion Plant

Oak Ridge Y-12 Plant Portsmouth Gaseous Diffusion Plant

Oak Ridge National Laboratory

under contract DE-AC05-84OR21400

for the

U.S. DEPARTMENT OF ENERGY 


\section{DISCLAIMER}

Portions of this document may be illegible electronic image products. Images are produced from the best available original document. 


\section{PREFACE}

This report, Nuclear Facility Decommissioning and Site Remedial Actions: A Selected Bibliography, Vol. 18 (ES/ER/TM-227), was prepared for the U.S. Department of Energy, Office of Environmental Restoration. This work was performed under Activity Data Sheet OR HQ 447. Publication of this document meets a Headquarter-controlled milestone of September 30, 1997.

This document is intended to serve a variety of information needs for individuals with an interest or involvement in environmental restoration activities, nuclear facility decontamination and decommissioning, uranium mill tailings management, and site remedial actions.

In addition to the main bibliographic text with abstracts, indexes of authors, author affiliations, selected title phrases, selected title words, publication descriptions, geographic locations, and keywords are provided. 


\section{CONTENTS}

PART 1A. CITATIONS WITH ABSTRACTS-SECTIONS 1 THROUGH 9

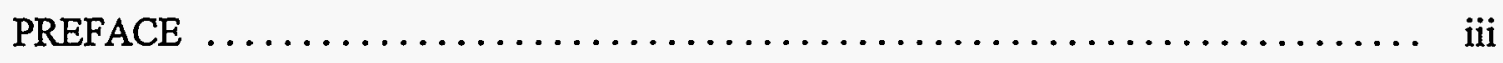

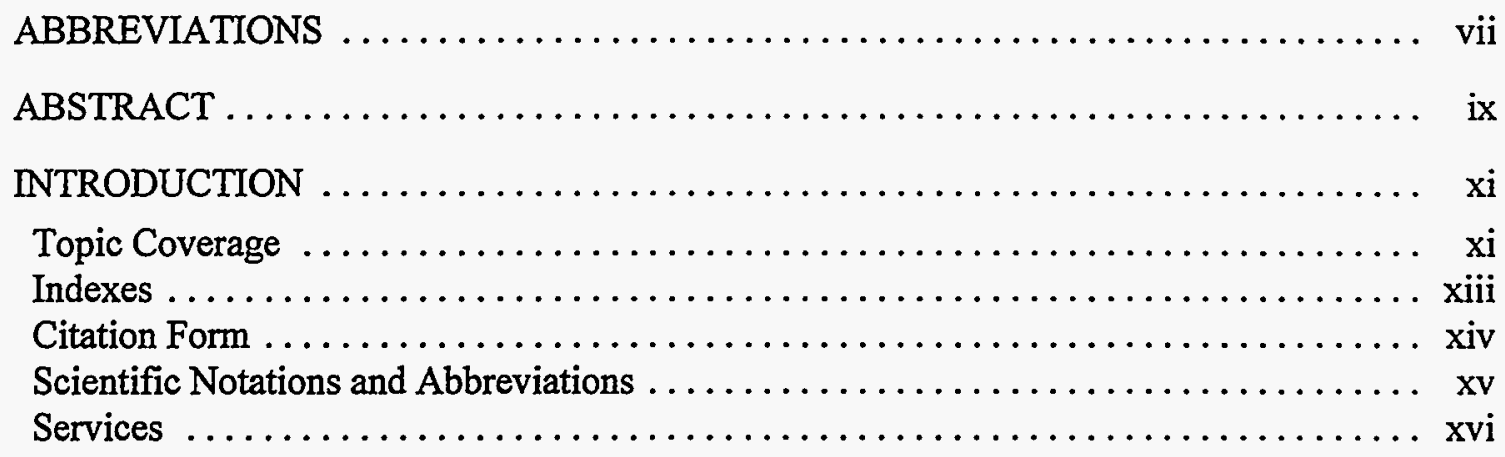

\section{SECTION HEADINGS}

DOE Environmental Restoration Program $\ldots \ldots \ldots \ldots \ldots \ldots \ldots \ldots \ldots \ldots \ldots, \quad 1$

DOE Decontamination and Decommissioning (D\&D) Program $\ldots \ldots \ldots \ldots \ldots \ldots .21$

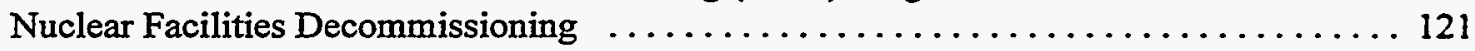

DOE Formerly Utilized Sites Remedial Action Program (FUSRAP) $\ldots \ldots \ldots \ldots \ldots \ldots 245$

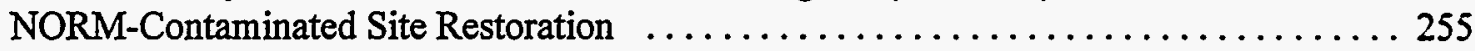

DOE Uranium Mill Tailings Remedial Action (UMTRA) Project $\ldots \ldots \ldots \ldots \ldots \ldots 263$

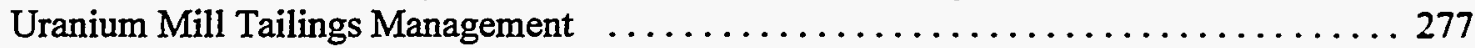

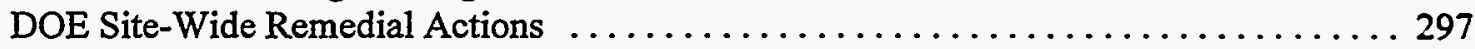

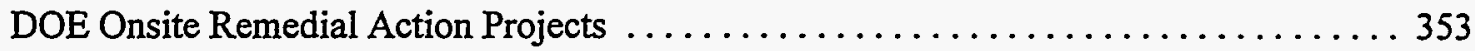

\section{PART 1B. CITATIONS WITH ABSTRACTS-SECTIONS 10 THROUGH 16}

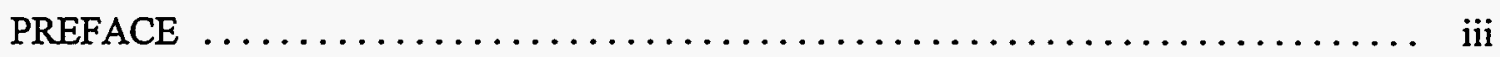

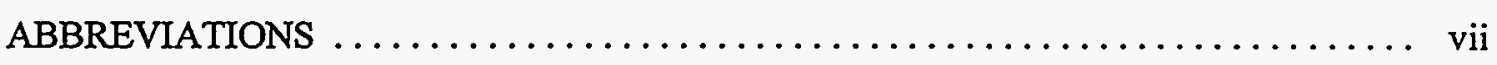

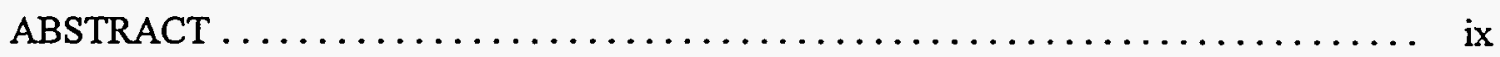

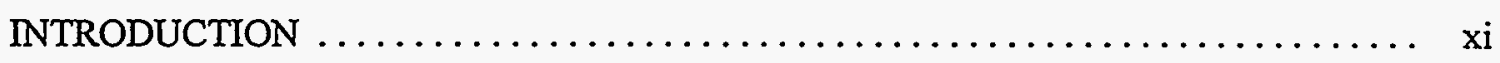

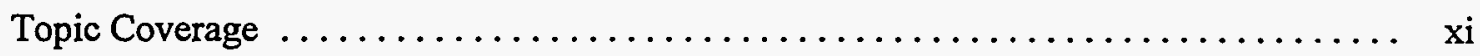

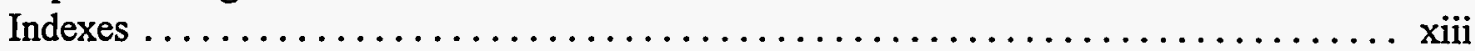

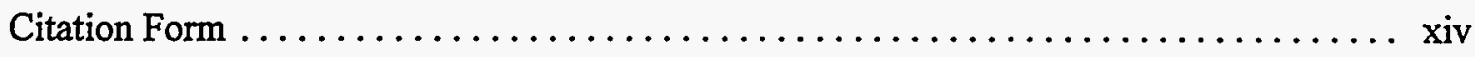

Scientific Notations and Abbreviations $\ldots \ldots \ldots \ldots \ldots \ldots \ldots \ldots \ldots \ldots \ldots \ldots \ldots \ldots, \quad \mathrm{xv}$

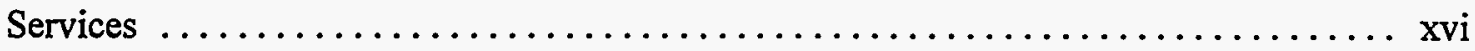




\section{SECTION HEADINGS}

Contaminated Site Remedial Actions . .......................... 433

DOE Underground Storage Tank (UST) Remediation ................... 513

DOE Technology Development, Demonstration, and Evaluation $\ldots \ldots \ldots \ldots \ldots \ldots . \ldots 51$

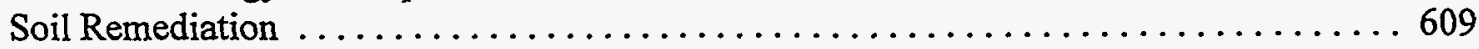

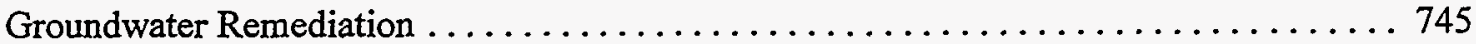

Environmental Measurements, Analysis, and Decision-Making $\ldots \ldots \ldots \ldots \ldots \ldots 845$

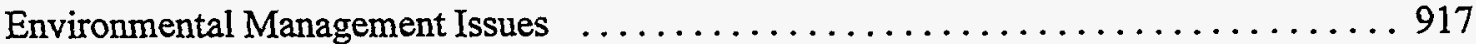

\section{PART 2. INDEXES}

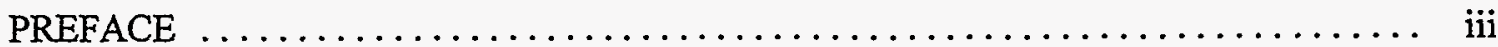

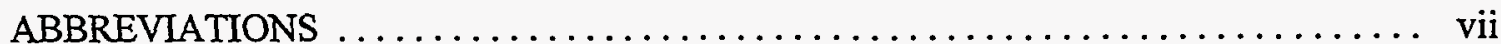

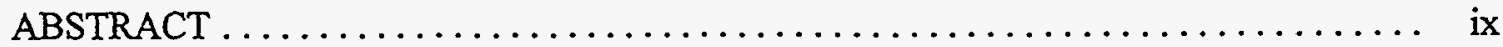

INTRODUCTION $\ldots \ldots \ldots \ldots \ldots \ldots \ldots \ldots \ldots \ldots \ldots \ldots \ldots \ldots \ldots \ldots \ldots \ldots \ldots \ldots \ldots$

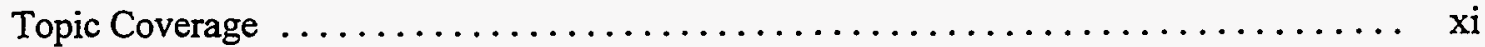

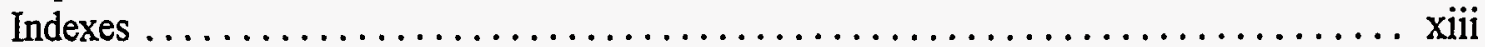

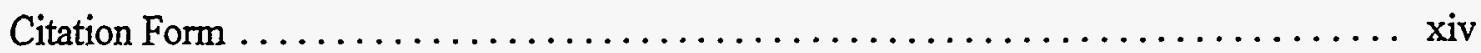

Scientific Notations and Abbreviations $\ldots \ldots \ldots \ldots \ldots \ldots \ldots \ldots \ldots \ldots \ldots \ldots \ldots \ldots$

Services $\ldots \ldots \ldots \ldots \ldots \ldots \ldots \ldots \ldots \ldots \ldots \ldots \ldots \ldots \ldots \ldots \ldots \ldots \ldots \ldots \ldots \ldots \ldots \ldots$

\section{INDEXES}

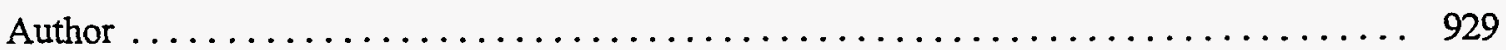

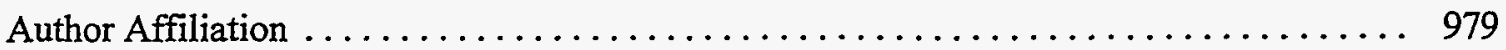

Selected Title Phrase ................................... 1027

Selected Title Word. . . . . . . . . . . . . . . . . . . . . . . . . 1037

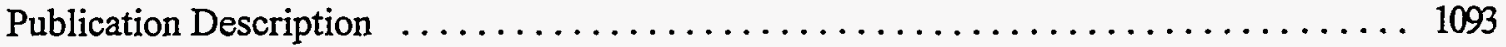

Geographic Location . . . . . . . . . . . . . . . . . . . . . . . . 1251

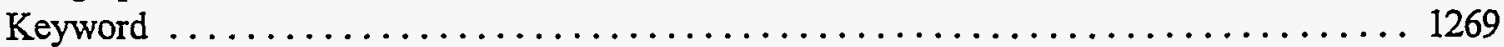




\section{ABBREVIATIONS}

\begin{tabular}{|c|c|}
\hline AEC & U.S. Atomic Energy Commission \\
\hline BRC & below regulatory concern \\
\hline BWR & boiling water reactor \\
\hline CERCLA & Comprehensive Environmental Response, Compensation, and Liability Act \\
\hline D\&D & decontamination and decommissioning \\
\hline DNAPL & dense nonaqueous phase liquid \\
\hline DOD & U.S. Department of Defense \\
\hline DOE & U.S. Department of Energy \\
\hline EPA & U.S. Environmental Protection Agency \\
\hline ER & environmental restoration \\
\hline FS & feasibility study \\
\hline FUSRAP & Formerly Utilized Sites Remedial Action Program \\
\hline FY & fiscal year \\
\hline GAO & U.S. General Accounting Office \\
\hline HEPA & high-efficiency particulate air \\
\hline IAEA & International Atomic Energy Agency \\
\hline LWR & light-water reactor \\
\hline NAPL & nonaqueous phase liquid \\
\hline NEPA & National Environmental Policy Act \\
\hline NORM & naturally occurring radioactive materials \\
\hline NPL & National Priorities List \\
\hline NPP & nuclear power plant \\
\hline NRC & U.S. Nuclear Regulatory Commission \\
\hline OTD & U.S. Office of Technology Development \\
\hline OU & operable unit \\
\hline PCB & polychlorinated biphenyl \\
\hline PWR & pressurized-water reactor \\
\hline QA & quality assurance \\
\hline $\mathrm{R} \& \mathrm{D}$ & research and development \\
\hline RAPIC & Remedial Action Program Information Center \\
\hline RCRA & Resource Conservation and Recovery Act \\
\hline RDDT\&E & research, development, demonstration, testing, and evaluation \\
\hline $\mathrm{RI}$ & remedial investigation \\
\hline RI/FS & remedial investigation/feasibility study \\
\hline ROD & Record of Decision \\
\hline SARA & Superfund Amendments and Reauthorization Act of 1986 \\
\hline SITE & Superfund Innovative Technology Evaluation \\
\hline TRU & transuranic \\
\hline TSCA & Toxic Substances Control Act \\
\hline UMTRA & Uranium Mill Tailings Remedial Action \\
\hline UMTRCA & Uranium Mill Tailings Radiation Control Act \\
\hline VOC & volatile organic compound \\
\hline WAG & waste area grouping \\
\hline
\end{tabular}




\begin{abstract}
This bibliography contains 3638 citations with abstracts of documents relevant to environmental restoration, nuclear facility decontamination and decommissioning (D\&D), uranium mill tailings management, and site remedial actions. This report is the eighteenth in a series of bibliographies prepared annually for the U.S. Department of Energy (DOE) Office of Environmental Restoration. Citations to foreign and domestic literature of all types-technical reports, progress reports, journal articles, symposia proceedings, theses, books, patents, legislation, and research project descriptions-have been included in Part 1 of the report. The bibliography contains scientific, technical, financial, and regulatory information that pertains to DOE environmental restoration programs. The citations are separated by topic into 16 sections, including (1) DOE Environmental Restoration Program; (2) DOE D\&D Program; (3) Nuclear Facilities Decommissioning; (4) DOE Formerly Utilized Sites Remedial Action Program; (5) NORM-Contaminated Site Restoration; (6) DOE Uranium Mill Tailings Remedial Action Project; (7) Uranium Mill Tailings Management; (8) DOE Site-Wide Remedial Actions; (9) DOE Onsite Remedial Action Projects; (10) Contaminated Site Remedial Actions; (11) DOE Underground Storage Tank Remediation; (12) DOE Technology Development, Demonstration, and Evaluation; (13) Soil Remediation; (14) Groundwater Remediation; (15) Environmental Measurements, Analysis, and Decision-Making; and (16) Environmental Management Issues. Within the 16 sections, the citations are sorted by geographic location. If a geographic location is not specified, the citations are sorted according to the document title. In Part 2 of the report, indexes are provided for author, author affiliation, selected title phrase, selected title word, publication description, geographic location, and keyword.

This bibliography is published annually by the Remedial Action Program Information Center (RAPIC), which selects, analyzes, and disseminates information on environmental restoration, D\&D, and site remedial actions. RAPIC staff and resources are available to meet a variety of information needs. Contact the center at (423) 576-6500 or by e-mail at rapic@ornl.gov. For updates to this publication, please access RAPIC 's site on the web at http://www.em.doe.gov/rapic.
\end{abstract}




\section{INTRODUCTION}

This bibliography is published by the Remedial Action Program Information Center (RAPIC). RAPIC is funded by the U.S. Department of Energy (DOE) Office of Environmental Restoration, Program Integration Division, to provide technical information support to DOE Environmental Restoration Program activities.

RAPIC serves as a central clearinghouse for information, derived from both foreign and domestic publications, that concerns the scientific, technical, regulatory, and socioeconomic aspects of environmental restoration at contaminated facilities and sites. Environmental restoration encompasses activities such as the following:

- performing characterization surveys of contaminated facilities or sites,

- conducting ongoing security and surveillance programs,

- performing preventive maintenance actions to ensure the containment of contamination until permanent facility disposition,

- assessing the environmental and engineering aspects of proposed remediation alternatives,

- drafting detailed project plans and procedures for remediation,

- performing decommissioning and remedial actions to make facilities or sites available for restricted or unrestricted use,

- developing technologies, and

- complying with applicable laws and regulations.

The 3638 citations with abstracts in this report constitute the 18th annual publication with the same title and topic coverage. The contents of all 18 volumes of this bibliography are stored in an on-line database that undergoes frequent updating. The bibliography is intended for use as a "first-line" reference tool. RAPIC can perform on-line searches of the entire database to identify recent additions to the database or to conduct a comprehensive search.

\section{TOPIC COVERAGE}

The major topics covered by this bibliography are presented in 16 sections: (1) DOE Environmental Restoration Program; (2) DOE Decontamination and Decommissioning (D\&D) Program; (3) Nuclear Facilities Decommissioning; (4) DOE Formerly Utilized Sites Remedial Action Program (FUSRAP); (5) NORM-Contaminated Site Restoration; (6) DOE Uranium Mill Tailings Remedial Action (UMTRA) Project; (7) Uranium Mill Tailings Management; (8) DOE Site-Wide Remedial Actions; (9) DOE Onsite Remedial Action Projects; (10) Contaminated Site Remedial Actions; (11) DOE Underground Storage Tank Remediation; (12) DOE Technology Development, Demonstration, and Evaluation; (13) Soil Remediation; (14) Groundwater Remediation; (15) Environmental Measurements, Analysis, and Decision-Making; and 
(16) Environmental Management Issues. The topic coverage of each section is explained in the following pages.

The first section, DOE Environmental Restoration Program, cites programmatic planning and management documents prepared by or for the DOE Office of Environmental Restoration. Documents that affect or relate to DOE's environmental restoration effort as a whole are included here.

The DOE Decontamination and Decommissioning (D\&D) Program section includes citations pertaining to the D\&D of buildings and structures located primarily on federal reservations.

The section on Nuclear Facilities Decommissioning presents citations relating to D\&D at non-DOE nuclear facilities, including those outside the United States.

The DOE Formerly Utilized Sites Remedial Action Program (FUSRAP) section cites documents generated by or related to the DOE FUSRAP program. FUSRAP sites were used by the Manhattan Engineer District or by the Atomic Energy Commission from the 1940s through the 1960 s for the processing, handling, storage, or shipment of radioactive materials.

The section on NORM-Contaminated Site Restoration contains citations of documents about remediation efforts at non-DOE sites contaminated with naturally occurring radioactive materials (NORM).

The DOE Uranium Mill Tailings Remedial Action (UMTRA) Project section cites information pertinent to UMTRA project management or to the 24 UMTRA sites, located primarily in the western United States. These sites are inactive uranium mill sites that were operated under government contract.

The section on Uranium Mill Tailings Management includes citations to foreign and domestic mill tailings documents and basic and applied mill tailings research reports that are not part of UMTRA.

The section on DOE Site-Wide Remedial Actions is composed of citations on remediation issues that affect an individual DOE facility or the entire DOE reservation.

The section on DOE Onsite Remedial Action Projects contains citations to documents about cleanup activities at operable units, waste area groupings, or other specific sites within a DOE facility or environmental contamination originating from a DOE facility.

The section on Contaminated Site Remedial Actions presents citations relating to remedial actions on environmental areas that are not a part of DOE's Environmental Restoration Program. These sites may include other governmental agencies, private sector, or countries other than the United States.

The DOE Underground Storage Tank Remediation section contains citations to documents relevant to the characterization and remediation of the underground storage tanks and tank contents awaiting final disposition at $\mathrm{DOE}$ sites.

The section on DOE Technology Development, Demonstration, and Evaluation cites documents originating from or directly relating to DOE Office of Technology Development 
programs for research and development, demonstration, testing, and evaluation of new technologies for environmental restoration and waste management.

The Soil Remediation section consists of citations to studies relating to characterizing, monitoring, and remediating soil contaminated with radioactive or hazardous materials.

The Groundwater Remediation section consists of citations to studies relating to characterizing, monitoring, and remediating groundwater contaminated with radioactive or hazardous materials.

The section titled Environmental Measurements, Analysis, and Decision-Making includes citations to documents on instrumentation for measuring radioactive or hazardous materials; sampling protocols; methods for data collection, validation, and analysis; quality assurance; risk assessment; and models for evaluating environmental restoration projects.

The final section, Environmental Management Issues, contains citations to requirements or regulatory drivers affecting DOE's remediation activities. Also included is information relevant to the conduct of program activities.

\section{INDEXES}

The indexes found in Part 2 of this report are color-coded to assist the user in identifying documents of interest. The numbers that appear after each listing in the indexes are the sequential numbers of the individual citations in Part 1A, Sections 1 through 9, and Part 1B, Section 10 through 16. The indexes appear as follows:

- Pink pages-the Author Index lists all authors for each citation

- Blue pages-the Author Affiliation Index is an alphabetical listing of the institutions with which the authors are affiliated

- Salmon pages-the Selected Title Phrase Index is an index of selected significant phrases in document titles

- Yellow pages - the Selected Title Word Index provides an index of selected significant words in document titles

- Green pages-the Publication Description Index alphabetically lists all journal citations, conference descriptions, report numbers, or other unique document descriptions that identify the publication. The title of the document is listed below each entry in the publication description index

- Gold pages - the Geographic Location Index provides an alphabetical listing of the geographic descriptions of sites referenced in the bibliography; these are divided into domestic sites and foreign sites

- Buff pages-the Keyword Index is an index of descriptors selected from a controlled thesaurus to characterize specific concepts in each record. 


\section{CITATION FORM}

Each citation in this volume of the bibliography is numbered sequentially. Within each section, the citations are grouped by geographic location. For example, in the section on DOE Site-Wide Remedial Actions, all citations concerning the Hanford Site are grouped together. Within these geographic groupings, the citations are listed alphabetically by the document title. Citations that do not refer to a specific geographic location appear at the end of each section and are sorted by the title.

Under the citation number, the document title appears in bold print. Author(s) of the document, are listed next, followed by the corporate affiliation(s) of the author(s). Finally, publication description, publication date, and the abstract are listed. A sample citation with abstract is shown below.

\section{SAMPLE CITATION WITH ABSTRACT}

This is an example of the format for the descriptive fields used in this bibliography:

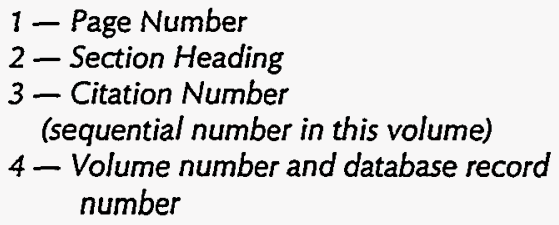
number

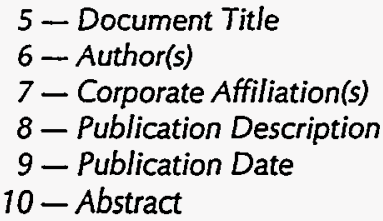

${ }^{2}$ DOE Onsite Remedial Action Projects

${ }^{5}$ Summary of Hydrogeologic Controls on Groundwater Flow at the Nevada Test Site, Nye County, Nevada

${ }^{6}$ Laczniak, F.J.; Cole, J.C.; Sawyer, D.A.; Trudeau, D.A.

${ }^{7}$ U.S. Geological Survey, Carson City, NV

${ }^{8}$ DOE/NV/11040-T1; 128 pp. ${ }^{9}(1996)$

${ }^{10}$ The underground testing of nuclear devices has generated substantial volumes of radioactive and other chemical contaminants below ground at the Nevada Test Site (NTS). Many of the more radioactive contaminants are highly toxic and are known to persist in the environment for thousands of years. In response to concerns about potential health hazards, the U.S. Department of Energy, under its Environmental Restoration Program, has made NTS the subject of a long-term investigation. Efforts will assess whether byproducts of underground testing pose a potential hazard to the health and safety of the public and, if necessary, will evaluate and implement steps to remediate any of the identified dangers. Unique to the hydrology of NTS are the effects of the underground testing, which severely alter local rock characteristics and affect hydrologic conditions throughout the region. This report summarizes what is known and inferred about groundwater flow throughout the NTS region. The report identifies and updates what is known about some of the major controls on groundwater flow, highlights some of the uncertainties in the current understanding, and prioritizes some of the technical needs as related to the Environmental Restoration Program. 


\section{SCIENTIFIC NOTATIONS AND ABBREVIATIONS}

Below is an explanation of scientific notations and abbreviations used in the text of this bibliography:

1. $\mathrm{X}$ sub t means $\mathrm{X}_{\mathrm{t}}$ or $\mathrm{X}$ subscript $\mathrm{t}$.

2. For chemical compounds and elements, $\mathrm{NaIO} 3$ means $\mathrm{NaIO}_{3}$.

3. $10(E+3)$ or $X(E-3)$ (E denoting exponent) means $10^{3}$ or $X^{-3}$, respectively.

4. Cubic or square dimensions of measurements are shown as $6 \mathrm{cu} \mathrm{cm}$ (for 6 cubic centimeters) or $3 \mathrm{sq} \mathrm{km}$ (for 3 square kilometeres).

5. The following prefixes have been used to indicate multiples or subdivisions of units of measurement:

$\begin{array}{llllll}\text { a } & \text { atto } & \left(10^{-18}\right) & \text { da } & \text { deca } & \left(10^{1}\right) \\ \text { f } & \text { femto } & \left(10^{-15}\right) & \mathrm{h} & \text { hecto } & \left(10^{2}\right) \\ \text { p } & \text { pico } & \left(10^{-12}\right) & \mathrm{k} & \text { kilo } & \left(10^{3}\right) \\ \mathrm{n} & \text { nano } & \left(10^{-9}\right) & \mathrm{M} & \text { mega } & \left(10^{6}\right) \\ \mathrm{u} & \text { micro } & \left(10^{-6}\right) & \mathrm{G} & \text { giga } & \left(10^{9}\right) \\ \mathrm{m} & \text { milli } & \left(10^{-3}\right) & \mathrm{T} & \text { tera } & \left(10^{12}\right) \\ \mathrm{c} & \text { centi } & \left(10^{-2}\right) & \mathrm{P} & \text { peta } & \left(10^{15}\right) \\ \mathrm{d} & \text { deci } & \left(10^{-1}\right) & \mathrm{E} & \text { exa } & \left(10^{18}\right)\end{array}$

6. The following abbreviations have been used for unit measurements:

$\begin{array}{llll}\mathrm{a} & \text { acre } & \mathrm{l} & \text { liter } \\ \mathrm{A} & \text { ampere } & \mathrm{lb} & \text { pound } \\ \mathrm{Bq} & \text { becquerel (activity of source) } & \mathrm{m} & \text { meter } \\ \mathrm{C} & \text { Celsius } & \mathrm{MeV} & \text { megaelectronvolt } \\ \mathrm{cd} & \text { current density } & \mathrm{min} & \text { minute } \\ \mathrm{Ci} & \text { curie } & \mathrm{mol} & \text { mole (amount) } \\ \mathrm{cpm} & \text { counts per minute } & \mathrm{N} & \text { newton } \\ \mathrm{cps} & \text { counts per second } & \mathrm{oz} & \text { ounce } \\ \mathrm{deg} & \text { degree } & \mathrm{Pa} & \text { Pascal } \\ \mathrm{dpm} & \text { disintegrations per minute } & \mathrm{ppb} & \text { parts per billion } \\ \mathrm{dps} & \text { disintegrations per second } & \mathrm{ppm} & \text { parts per million } \\ \mathrm{F} & \text { Fahrenheit } & \mathrm{R} & \text { roentgen (gamma exposure) } \\ \mathrm{ft} & \text { feet } & \mathrm{rad} & \text { radiation absorbed dose } \\ \mathrm{g} & \text { gram } & \mathrm{rem} & \text { roentgen-equivalent-man } \\ \text { gal } & \text { gallon } & \mathrm{s} & \text { second } \\ \mathrm{Gy} & \text { gray (absorbed radiation dose) } & \mathrm{Sv} & \text { sievert (dose equivalent) } \\ \text { ha } & \text { hectare } & \mathrm{t} & \text { tonne (mass) } \\ \mathrm{hr} & \text { hour } & \mathrm{V} & \text { volt } \\ \mathrm{Hz} & \text { hertz } & \mathrm{W} & \text { watt } \\ \text { in. inch } & \text { inchical) } \\ \mathrm{J} & \text { joule } & \mathrm{W}(\mathrm{e}) & \text { watt (electrical) } \\ \mathrm{K} & \text { Kelvin } & \mathrm{W}(\mathrm{t}) & \text { watt (thermal) } \\ \mathrm{keV} & \text { kiloelectron volt } & \mathrm{yd} & \text { yard } \\ & & \mathrm{yr} & \text { year }\end{array}$




\section{SERVICES}

Copies of most documents cited in this bibliography can be obtained through either the National Technical Information Service, 5285 Port Royal Road, Springfield, Virginia 22161, or the Office of Scientific and Technical Information, U.S. Department of Energy, P.O. Box 62, Oak Ridge, Tennessee 37831-0062.

RAPIC offers information support to researchers involved in many fields of environmental restoration. Services that are free of charge to DOE Environmental Restoration staff and their subcontractors include providing information from RAPIC resources, searching computerized databases, and assisting in locating and obtaining copies of documents cited in the RAPIC bibliographies. All inquiries about these and other RAPIC services should be addressed to:

Park T. Owen, Manager

Remedial Action Program Information Center

138 Mitchell Road

Oak Ridge, Tennessee 37830-7918

Telephone: (423)576-6500

Fax: (423)576-6547

E-Mail: rapic@ornl.gov

Web Site: http://www.em.doe.gov/rapic 


\section{CONTAMINATED SITE REMEDIAL ACTIONS}


1720

V18/023679

Cape Lisburne Long Range Radar Station, Alaska, Quality Program Plan, Addendum for Interim Remedial Actions

ASRC Contracting Company, Inc., Sacramento, CA

Report; 222 pp. (December 1996)

The Air Force is conducting interim remedial actions at Cape Lisbume Long Range Radar Station (LRRS) as part of the Installation Restoration Program. These actions are based on the results of the Remedial Investigation/Feasibility Ștudy conducted from 1993 to 1995 . The remedial actions are to be conducted at Sites LF01, 5503, SSO8, and SSO9.

\section{1}

V18/022998

United States Air Force 611th Air Support Group/Civil Engineering Squadron, Elmendorf AFB, Alaska Interim Remedial Action Report: Cape Lisburne Radar Installation, Alaska - Final Report, May-November 1995

Karmi, $\mathrm{S}$.

ICF Technology, Inc., Fairfax, VA

Report; 182 pp. (February 5, 1996)

No abstract available.

\section{2}

V18/023003

United States Air Force 611th Civil Engineer Squadron, Elmendorf AFB, Alaska - Cape Lisburne Long Range Radar Station, Alaska: Quality Program Plan, Addendum for Interim Remedial Actions - Final

ASRC Contracting Company, Inc., Sacramento, CA

Report; 206 pp. (December 1996)

The Air Force is conducting interim remedial actions at Cape Lisbume Long Range Radar Station (LRRS) as part of the Installation Restoration Program (IRP). The remedial actions are to be conducted at Sites LFOI (Landfill and Waste Accumulation Area No. 2/Dump No. 1), SSO3 (White Alice Site), SS08 (Upper Camp Transformer Building) and SSO9 (Lower Camp Transformer Building). This Quality Program Plan (QPP) Addendum is site-specific to work at the Cape Lisbume LRRS and is an addendum to the Program Quality Program Plan dated June 1995. This QPP Addendum includes: Construction Quality Plan (includes Waste Plan); Health and Safety Plan; and Sampling and Analysis Plan, including Quality Assurance Project Plan and Field Sampling Plan.

1723

\section{V18/021068}

Environmental Implications of Explosive Ordnance Disposal Open Burn/Open Detonation Operations

Steen, C.; Seutter, C.C.

EMCON Alaska, Inc., Anchorage, AK; Explosive Disposal Engineering and Technology, Wasilla, $A K$

CONF-940499 (Vol. 1); Proceedings of the 1994 Federal

Environmental Restoration III and Waste Minimization II Conference and Exhibition, New Orleans, LA, April 27-29, 1994. Hazardous Materials Control Resources Institute, Rockville, MD, Vol. 1, 783 pp.; (pp. 366-372) (1994)
The United States Army created their first Explosive Ordnance Disposal (EOD) teams in 1941, primarily to deal with the possibility of unexploded ordnance in occupied areas. Training with the British, who had developed a strong EOD program in response to the air raids on their cities and military installations, the Army teams concentrated on the safety of the technician and the local population. The gradual advent of Environmental laws since the 1970 s was largely unnoticed by the EOD community, whose operatives continued to value safety over environmental considerations. The Resource Conservation and Recovery Act (RCRA) took effect in 1980. Explosives, clearly a reactive waste by RCRA definition, were covered under the open burn/open detonation $(O B / O D)$ requirements, although various exemptions were allowed on existing firing ranges and disposal areas on Federal Facilities. Although the technicians were still taught strict procedures for all explosive operations, environmental policies were not included in the training. Now, the Army is faced with sites throughout the country that were used as EOD areas or impact areas that need to be investigated and decontaminated before installations are turned over for public use. Records of the OB/OD activities conducted on these ranges are often sketchy or nonexistent, since the personnel performing the work were not required to keep detailed records. To develop the site investigation or initiate closure plans needed to clean these areas, it is necessary to know how EOD operations historically have been conducted. The specific methods which have been used by EOD technicians for the past 50 years vary by the types of explosives available and the types of munitions to be disposed of. The residues left by the operation would therefore vary, which would change the methods by which a site investigation should be conducted.

\section{$1724 \quad$ V18/021235}

Risk Mitigation Techniques Employed in the Remediation Contracting Process for the Environmental Cleanup of Fort Ord, California

Schumitz, R.W.

\section{U.S. Navy, Naval Postgraduate School, Monterey, CA}

Thesis (M.S.); 97 pp. (December 1995)

When Fort Ord, Califormia, was designated for closure in 1991 by the Base Realignment and Closure (BRAC) Commission, the U.S. Army became responsible for the total remediation of Fort Ord's properties. The effort represents a large-scale, complex remediation project to remove both surface and sub-surface hazardous and toxic wastes. The U.S. Army Corps of Engineers (Corps), Sacramento District is using the Total Environmental Restoration Contracts (TERC) method as the principal tool to facilitate the required remediation. This thesis identifies and analyzes the risk mitigation efforts, from acquisition planning through contract administration, employed by the Corps in its contracting efforts. The objective of this thesis is to identify the unique risk mitigation strengths and weaknesses of the Corps efforts and to recommend future risk mitigation efforts for large-scale HTRW remediation efforts.

1725 V18/022610

Superfund Record of Decision (EPA Region 9): Fresno Municipal Sanitary Landfill, Fresno, CA, (Final Remedial Action), September 30, 1996 
U.S. Environmental Protection Agency, Office of Emergency and Remedial Response, Washington, DC

EPA/ROD/R09-96/150; 50 pp. (December 1996)

This Record of Decision (ROD) presents the selected final remedial action for the Fresno Sanitary Landfill Superfund site (the Site) in

Fresno Califomia. This operable unit is the final action of two operable units for the site. The first operable unit at the site involved a landfill cover, a landfill gas collection and treatment system, and storm water runoff collection system. This action addresses the groundwater.

\section{$1726 \quad$ V18/023496}

Superfund Record of Decision (EPA Region 9): Operating Industries, Inc., Landfill, Monterey Park, CA, (Final Remedial Action), September 30, 1996

U.S. Environmental Protection Agency, Office of Emergency and Remedial Response, Washington, DC

EPA/ROD/R09-96/152; 144 pp. (December 1996)

This decision document presents the selected remedial action for the Operating Industries, Inc. (OII) Site, in Monterey Park, Califomia. This Record of Decision (ROD) addresses liquids control and contaminated groundwater as well as long-term operation and maintenance of all environmental control facilities at the landfill, excluding those facilities covered under the Gas Migration Control and Landfill Cover ROD, as amended (EPA), 1990a (PB91-921493); originally the Gas Migration Control ROD (EPA, 1988b (PB89-196687)).

\section{7}

\section{V18/021690}

Combining Post-Remediation Monitoring and Baseline Ecological Risk Assessment at an Environmentally Contaminated Site

Mire, J.; Baker, J.; Gleason, M.; Sootkoos, B.; Russo, S. CONF-9511137; Global Environmental Protection: Science, Politics, and Common Sense, Proceedings of the Second Society of Environmental Toxicology and Chemistry (SETAC) World Congress and 16th Annual Meeting, Vancouver, British Columbia, Canada, November 5-9, 1995. Society of Environmental

Toxicology and Chemistry, Pensacola, FL, 378 pp.; (pp. 231-232) (1995)

Post-remediation monitoring, habitat restoration, and baseline ecological risk assessment are being integrated at an environmentally contaminated Navy installation in San Francisco Bay. Remedial and restoration actions were performed in some areas following a record of decision, but adjacent areas were not evaluated for potential ecological risks. Because the contaminated area included critical habitat of endangered species, only a portion of the area was excavated; the remediated and non-remediated areas are the subject of a long term monitoring program to track potential migration of contaminants across the site and to validate the effectiveness of the remediation. The monitoring program combines chemical, toxicological, and tissue residue sampling. Data from the monitoring efforts form the foundation for the baseline assessment by highlighting contaminants, ecological receptors, and exposure pathways of potential concem for remediated, restored, and monitoring areas. Areas not yet assessed for ecological risk are being evaluated by focused chemical sampling, toxicity testing, and tissue residue analysis, Chemical concentrations in tissues of clams, rodents, and plants collected during monitoring efforts will be supplemented by tissue residue analysis of benthic invertebrates and used in the baseline assessment to model potential exposure and effects and to evaluate potential risks to high trophic level receptors. Finally, the monitoring protocol will be reevaluated based on the results of the baseline assessment to ensure that the monitoring strategy adequately targets areas of greatest ecological concern, The concurrence of the monitoring, habitat restoration, and baseline assessment efforts provides a unique opportunity to validate risk management decisions concerning remediation and restoration of a critical wetlands habitat.

1728

V18/023175

Initiating the Cleanup of the Rocky Mountain Arsenal

Gabel, D.; Lowrey, J.; Lytle, R.; Berry, E.

Ebasco Environmental, Lakewood, CO; U.S. Army Program Managers Office for the Rocky Mountain Arsenal, Commerce City, $\mathrm{CO}$

CONF-9210194; Proceedings of an International Symposium on Environmental Contamination in Central and Eastern Europe, Budapest, Hungary, October 12-16, 1992, 968 pp.; (pp. 46-47) (1992)

The U.S. Army's Rocky Mountain Arsenal, located outside of Denver, Colorado, covers more than 70 square kilometers and is one of the largest hazardous waste sites in the United States. The facility was used from the 1940 s to the 1980 s as a chemical manufacturing facility: by the U.S. Army for the manufacture of various chemical munitions, including incendiaries and blister and nerve agents, and by several private companies for the manufacture of various chemicals - primarily herbicides and pesticides. Prior handling and disposal of the chemicals and waste products created more than 180 individual contamination sites ranging in size from less than one hectare to the 38-hectare site that was Basin F, an evaporation basin used for 25 years to dispose of liquid wastes from chemical manufacturing activities. Cleanup of the Arsenal is a complex and long-term process. In an effort to mitigate the greatest potential threats to human health and the environment, 13 interim response actions (IRAs) were identified for implementation prior to the final remedy. IRAs, which use standardized and rapid remediation techniques where feasible, have been implemented to mitigate as expeditiously as possible threats of contaminant migration, infiltration, or potential exposures to human health and the environment prior to the selection of final remedial actions. The IRA associated with the contaminated liquids, sludges, and soils at Basin $F$ is the largest and most complex of these actions and the focus of this paper. The procedures used to expedite the cleanup and rapidly contain the most hazardous portions may be a good example to follow for cleanup of former military bases or other large industrial facilities in Central and Eastern Europe.

\section{9}

V18/023207

Use of Innovative Technologies During the Cleanup of the Denver Radium Site

Zanowick, M.; Brink, J.; Fliniau, H.; Rehder, T.; Nyberg, P.; Goldfarb, J.; Pennock, S. 
U.S. Environmental Protection Agency, Denver, CO CONF-9210194; Proceedings of an International Symposium on Environmental Contamination in Central and Eastern Europe, Budapest, Hungary, October 12-16, 1992, 968 pp.; (pp. 373-375) (1992)

Contaminated soil from the Denver Radium Site is contaminated with both radioactive and non-radioactive residues and thus may not meet the acceptance criteria of existing commercial disposal facilities. During the site investigation phase of cleanup, in-situ vitrification (ISV) was identified as a technology which could provide a permanent solution to the mixed waste on site. A bench scale test was conducted to determine if the ISV process was appropriate to the specific soil-waste mixture at the site. The test affimed the feasibility of ISV although an altemative remedy was selected due to cost considerations and site conditions.

1730 V18/022113

World War I Chemical Weapons Bunker Engineering Evaluation and Cost Analysis

Crotteau, C.A.

U.S. Army Corps of Engineers, Huntsville, AL CONF-951139 (Vol. 1); Superfund 16: Proceedings of a Hazardous Waste Conference and Exhibition, Washington, DC, November 6-8, 1995. E.J. Krause and Associates, Bethesda, MD, Vol. 1, 828 pp.; (pp. 178-186) (1994)

This paper provides a review of the U.S. Army Corps of Engineers development and execution of a CERCLA chemical weapons and soil removal from two World War I underground test bunkers. The non-time critical removal action was completed from October 1994 to January 1995 in conjunction with Operation Safe Removal, Spring Valley, Washington, D.C.

\section{1}

V18/023709

\section{Palatka Decommissioning}

Powell, C.

\section{Florida Power \& Light Company, Miami, FL}

CONF-961032; Proceedings of the 1996 TLG Decommissioning Conference, Captiva Island, FL, October 13-16, 1996. TLG Services, Inc., Bridgewater, CT, 478 pp.; (17 pp.) (1996)

These viewgraphs present an overview of decommissioning activities at the Palatka Fossil Fuel Plant in Florida. They include alternatives explored, demolition project planning, project phases and lessons learned.

\section{2 \\ V18/023614}

Horizontal Groundwater Extraction Modeling and Remediation at a Metal-Plating Site

Tobin, R.J.; Newhert, G.; Powell, G. CONF-951023 (Vol. 8); WEFTEC '95, Proceedings of the 68th Annual Conference and Exposition of the Water Environment Federation, Miami Beach, FL, October 21-25, 1995. Water Environment Federation, Alexandria, VA, Vol. 8, 498 pp.; (p. 23) (1995)

The U.S. Environmental Protection Agency (U.S. EPA) conducted a full-scale removal action at the Manasota Plating Superfund Site in Sarsota, Florida. An electroplating business operated at the site since the late 1950s, until operations ceased in May 1992. Initial site assessments were performed in the Fall of 1992. As part of this removal action, the Response Engineering and Analytical Contract (REAC), under the direction of the U.S. EPA Environmental Response Team (ERT), conducted a hydrogeologic survey and an engineering evaluation of the site. Work included well installation, groundwater characterization, contaminant plume modeling, dewatering system design, groundwater treatability studies, and preliminary groundwater treatment system design. In the span of one year, the project was taken from the installation of groundwater monitoring wells to the design and operation of the groundwater treatment system during the contaminated soil excavation. Approximately 400,000 gallons of contaminated groundwater was treated during soil excavation activities. (Complete text).

\section{$1733 \quad$ V18/023500}

Superfund Record of Decision (EPA Region 9): Schofield Barracks (US Army), Operable Unit 4, Oahu, HI, (Final Remedial Action), September 26, 1996

U.S. Environmental Protection Agency, Office of Emergency and Remedial Response, Washington, DC

EPA/ROD/R09-96/155; 88 pp. (December 1996)

This report documents the response action plan for Operable Unit (OU) 4 at Schofield Army Barracks (Schofield Barracks), Island of Oahu, Hawaii. The Schofield Barracks OU 4 consists of the Former Schofield Barracks Landfill (Former Landfill) on the Main Post of Schofield Barracks.

\section{4}

\section{V18/021343}

Vertical Profiling of Hydrogeology of the Snake River Plain Aquifer with Geophysical Well Logs, Idaho National Engineering Laboratory, Idaho

Morin, R.H.; Paillet, F.; Taylor, T.; Barrash, W.

U.S. Geological Survey, Denver, CO; Idaho Department of Health and Welfare, Boise, ID

Proceedings of the American Geophysical Union 1992 Spring Meeting, Montreal, Quebec, Canada, May 12-16, 1992; (pp. 124-125) (1992)

A geophysical logging program has been undertaken to evaluate vertical changes in geologic layering and movement of groundwater in the Snake River Plain aquifer underlying the Idaho National Engineering Laboratory in southeastern Idaho. A preliminary effort in the fall of 1991 focussed on three wells located near the Idaho Chemical Processing Plant that penetrate interbedded basalt and sediment in the upper $200 \mathrm{ft}$ of the aquifer. The geophysical logs obtained in these wells included caliper, temperature, thermal flowmeter (before and during pumping), natural gamma, neutron porosity, gamma-gamma density, gamma spectral, and borehole televiewer. The nuclear logs effectively delineate a stratified series of basalt flows where dense flow centers are bounded by zones of high porosity and low density that correlate closely with attendant caliper logs and televiewer images of the borehole wall. Thermal flowmeter measurements obtained under static conditions reveal the presence of two flow regimes in each well that define borehole 
circulation parterns generated by differences in hydraulic head across individual basalt flows. Flowmeter measurements obtained during pumping show that intervals of high permeability correspond to most of the high-porosity zones between basalt flows. Flow measurements were combined with drawdown data to evaluate the vertical distribution of transmissivity. Results indicate that the majority of the transmissivity is restricted to the uppermost $140 \mathrm{ft}$ of the aquifer penetrated by these three wells.

\section{5}

V18/023497

Superfund Record of Decision (EPA Region 5): Yeoman Creek Landfill, Waukegan, $\mathbb{U}$, (Final Remedial Action), September 30, 1996

U.S. Environmental Protection Agency, Office of Emergency and Remedial Response, Washington, DC

EPA/ROD/R05-96/308; 172 pp. (December 1996)

This decision document represents the selected Final Remedial Action for the Yeoman Creek Landfill Site in Waukegan, Illinois. This final action includes containment of landfilled wastes, excavation and on-site containment of contaminated soils and sediments, collection and treatment of leachate entering Yeoman Creek, and recovery and treatment of landfill gases. This final action also addresses releases of leachate to groundwater, surface water, surface sediments, and wetlands; and release of landfill gases to air.

\section{6}

\section{V18/023315}

Modeling Exposure to Depleted Uranium in Support of Decommissioning at Jefferson Proving Ground, Indiana Ebinger, M.H.; Oxenberg, T.P.

Los Alamos National Laboratory, Environmental Science Group, Los Alamos, NM; U.S. Army Test and Evaluation Command, Aberdeen Proving Ground, $\mathrm{MD}$

LA-UR-96-3907; CONF-970335; Waste Management '97: Working Towards a Cleaner Environment, Proceedings of a Conference on HLW, LLW, Mixed Wastes and Environmental Restoration, Tucson, AZ, March 2-6, 1997; (9 pp.) (1997)

Jefferson Proving Ground was used by the U.S. Army Test and Evaluation Command for testing of depleted uranium (DU) munitions and closed in 1995 under the Base Realignment and Closure Act. As part of the closure of JPG, assessments of potential adverse health effects to humans and the ecosystem were conducted. This paper integrates recent information obtained from site characterization surveys at JPG with environmental monitoring data collected from 1983 through 1994 during DU testing. Three exposure scenarios were evaluated for potential adverse effects to human health: an occasional use scenario and two farming scenarios. Human exposure was minimal from occasional use, but significant risk were predicted from the farming scenarios when contaminated groundwater was used by site occupants. The human health risk assessments do not consider the significant risk posed by accidents with unexploded ordnance. Exposures of white-tailed deer to DU were also estimated in this study, and exposure rates result in no significant increase in either toxicological or radiological risks. The results of this study indicate that remediation of the DU impact area would not substantially reduce already low risks to humans and the ecosystem, and that managed access to IPG is a reasonable model for future land use options.

1737

V18/023499

Superfund Record of Decision (EPA Region 5): Continental Steel Superfund Site, Kokomo, Howard County, IN, (Interim Remedial Action), August 16, 1996

U.S. Environmental Protection Agency, Office of Emergency and Remedial Response, Washington, DC

EPA/ROD/R05-96/310; 94 pp. (December 1996)

This decision document presents the selected interim remedy for the Continental Steel Superfund site in Kokomo, Howard County, Indiana. This interim remedy addresses the contamination detected inside the deteriorated Main Plant buildings and in the Main Plant building basements.

1738

V18/022098

Treatability Studies Performed in Support of an Engineering Evaluation/Cost Analysis

Myers, J.M.; Mueller, J.P.; Sundquist, J.A.; Moore, G.W. Ecology and Environment, Inc., Dallas, TX; Ecology and Environment, Inc., Buffalo, NY; U.S. Environmental Protection Agency, Dallas, TX

CONF-951139 (Vol. 2); Superfund 16: Proceedings of a Hazardous Waste Conference and Exhibition, Washington, DC, November 6-8, 1995. E.J. Krause and Associates, Bethesda, MD, Vol. 2, 817 pp.; (pp. 716-725) (1994)

The Southem Shipbuilding Corporation (SSC) site is located on 54 acres of wooded land adjacent to Bayou Bonfouca, approximately 1.8 miles downstream of the Bayou Bonfouca National Priorities List (NPL) Superfund site in Slidell, St. Tammany Parish, Louisiana. The SSC site is bordered to the north and west by Bayou Bonfouca, to the east by wooded acreage, and to the south by a residential community. Six miles downstream from the site, Bayou Bonfouca empties into Lake Pontchartrain, the largest lake in Louisiana and is used as a drinking water supply by the city of New Orleans. Two one-acre, unlined surface impoundments on the SSC site were used to store wastes generated from vessel cleaning. Wastes stored in the impoundments are migrating into Bayou Bonfouca, which empties into Lake Pontchartrain. In addition, the impoundments are frequently invaded by flood waters. The U.S. EPA Emergency Response Branch (EPA-ERB) performed a site investigation which indicated that the majority of the contamination is petroleum-related and that the compounds of concern are Polycyclic Aromatic Hydrocarbons (PAHs). The wastes are generally contained within the two impoundments and surrounding soils. As part of an Engineering Evaluation/Cost Analysis (EE/CA) of potential response action alternatives, four treatability studies were performed. A thermal treatment (incineration) study was performed at the EPA's Incineration Research Facility (IRF). Biodegradation remedy selection feasibility assessment was conducted on-site. A remedy screening soil washing study was also performed by TAT. A solidification/stabilization (S/S) study was conducted through EPA's Risk Reduction Engineering Laboratory (RREL) to ascertain if the PAHs could be immobilized within a solid matrix. Experimental objectives, design, methodology and conclusions for these studies are presented as they relate to potential response actions being evaluated at the SSC site. 
1739

$\mathrm{V} 18 / 021136$

Characterization of DU Contamination at the Transonic Range at Aberdeen Proving Ground

Parrish, B.R.; Urbani, D.; Cardenuto, R.A.; Corpuz, R.; Wiherle, M.G.

General Physics Corporation, Columbia, MD; U.S. Army, Aberdeen Proving Ground, MD

CONF-960212; Waste Management '96: Working Towards a Cleaner Environment, Proceedings of a Conference on HLW, LLW, Mixed Wastes and Environmental Restoration, Tucson, $A Z$, February 25-29, 1996; (16 pp.) (1996)

A characterization study of radioactive contamination, hazardous waste and unexploded ordnance (UXO) at the Depleted Uranium (DU) testing area of the Transonic Range at the Aberdeen Proving Ground (APG) was conducted in the fall 1995 through the winter of 1996. DU penetrators were tested at a site located at the Transonic Range from 1973 through 1979. Although outdoor testing of DU penetrators ceased in 1979 at the 12 acre site, the need to release the site for nonradioactive use has become the goal of the U.S. Army Research Laboratory (ARL), and the APG Health Physics Office. APG is a Test and Evaluation Command installation within the United States Army Material Command. The mission of the installation is to develop and test military materials and to train officers and enlisted personnel in the use and maintenance of munitions. The installation was established in 1917 as two separate military reservations, APG and Edgewood Arsenal. Both were consolidated into APG in 1971. APG is located in northeast Maryland, has approximately 73,000 acres of land and water and has approximately 55 tenant organizations, many of whom are engaged in munitions development and testing. This paper discusses development of the characterization strategy, the health and safety plan, a quality assurance project plan and the work plan. Also presented are the results of the interviews with personnel responsible for the outdoor DU testing activities, test supervisors and test technicians. Results of the surface survey for UXO and preliminary radiological data are presented.

\section{$1740 \quad$ V18/022893}

Unexploded Ordnance Issues at Aberdeen Proving Ground: Background Information

Rosenblatt, D.H.

Argonne National Laboratory, Argonne, IL

ANL/EAD/TM-58; 60 pp. (November 1996)

This document summarizes currently available information about the presence and significance of unexploded ordnance (UXO) in the two main areas of Aberdeen Proving Ground: Aberdeen Area and Edgewood Area. Known UXO in the land ranges of the Aberdeen Area consists entirely of conventional munitions. The Edgewood Area contains, in addition to conventional munitions, a significant quantity of chemical-munition UXO, which is reflected in the presence of chemical agent decomposition products in Edgewood Area groundwater samples. It may be concluded from current information that the UXO at Aberdeen Proving Ground has not adversely affected the environment through release of toxic substances to the public domain, especially not by water pathways, and is not likely to do so in the near future. Nevertheless, modest but periodic monitoring of groundwater and nearby surface waters would be a prudent policy.

\section{$1741 \quad$ V18/021013}

Contamination Source Review for Building E5032, Edgewood Area, Aberdeen Proving Ground, Maryland

Booher, M.N.; O'Reilly, D.P.; Smits, M.P.; Brubaker, K.L.; Dougherty, J.M.; Tome, C.; Draugelis, A.K.; Rueda, J.; Zimmerman, R.E.

Argonne National Laboratory, Center for Environmental Restoration Systems, Argonne, II

ANL/ESD/TM-102; 120 pp. (September 1995)

This report was prepared by Argonne National Laboratory (ANL) to document the results of a contamination source review of Building E5032 at the Aberdeen Proving Ground (APG) in Maryland. The report may be used to assist the U.S. Army in planning for the future use or disposition of this building. The review included a historical records search, physical inspection, photographic documentation, geophysical investigation, and review of available records regarding underground storage tanks associated with Building E5032. The field investigations were performed by ANL during 1994 and 1995.

1742

V18/022326

Focused Feasibility Study for Surface Soil at the Main Pits and Pushout Area, J-Field Toxic Burning Pits Area, Aberdeen Proving Ground, Maryland

Patton, T.L.; Benioff, P.A.; Biang, C.; Butler, J.P.; Davies, W.; Haffenden, R.; Hayse, J.; Hlohowskyj, I.; Martino, L.E.; Poch, L.; Portante, E.; Quinn, J.J.; Yuen, C.Y.; Wang, Y.Y.; Williams, $\mathrm{G}$.

Argonne National Laboratory, Environmental Assessment Division, Argonne, IL

ANL/EAD/TM-61; 365 pp. (June 1996)

The Environmental Management Division of Aberdeen Proving Ground (APG), Maryland, is conducting a remedial investigation and feasibility study of the J-Field area at APG pursuant to the Comprehensive Environmental Response, Compensation, and Liability Act, as amended (CERCLA). J-Field is located within the Edgewood Area of APG in Harford County, Maryland. Since World War II, activities in the Edgewood Area have included the development, manufacture, testing, and destruction of chemical agents and munitions. These materials were destroyed at J-Field by open burning/open detonation. Portions of J-Field continue to be used for the detonation and disposal of unexploded ordnance (UXO) by open burning/open detonation under authority of the Resource Conservation and Recovery Act.

1743

V18/023677

Public Health Assessment for U.S. Army Materials Technology Laboratory, Watertown, Middlesex County, Massachusetts, Region 1, CERCLIS No. Ma0213820939

Agency for Health Care Policy and Research, Rockville, MD Report; 95 pp. (February 21, 1997) 
The U.S. Army Materials Technology Laboratory (MTL) was added to the U.S. Environmental Protection Agency's Superfund National Priorities List (NPL) on May 30, 1994. The Agency for Toxic Substances and Disease Registry (ATSDR) evaluated the environmental information for all properties comprising the original Watertown Arsenal. The authors identified three situations where people currently could be exposed to contaminants, could be exposed to site contaminants in the future, or could have been exposed to site contaminants in the past. These exposure situations relate to: (1) contaminated subsurface soil and building remnants on the FUDS parcel; (2) fish contamination in the Charles River, and; (3) past air releases of depleted uranium. Other situations were evaluated where exposures might result from future use of properties that are currently contaminated.

\section{$1744 \quad$ V18/023501}

Superfund Record of Decision (EPA Region 1): Materials Technology Laboratory Site (US Army), Soils and Groundwater Operable Unit, Watertown, MA, September 26, 1996

U.S. Environmental Protection Agency, Office of Emergency and Remedial Response, Washington, DC

EPA/ROD/R01-96/124; 248 pp. (January 1997)

This decision document presents the U.S. Army's selected remedial action for soils and groundwater at the Army Materials Technology Laboratory (MTL), Watertown, Massachusetts. This remedial action addresses long-term residential and commercial exposure to contaminated soil. It consists of excavating the contaminated soil and transporting the soil for off-site disposal and/or reuse.

Excavations are to be backfilled with clean soil. Once contaminated soil is removed, the bottom and sidewalls of the excavation areas will be sampled and analyzed to ensure that site cleanup goals are met.

\section{5 \\ V18/023391}

Superfund Record of Decision (EPA Region 7): Weldon Spring Former Army Ordnance Works, Operable Unit 1, Soils and Pipeline, St. Charles County, MO, September 26, 1996

U.S. Environmental Protection Agency, Office of Emergency and Remedial Response, Washington, DC

EPA/ROD/R07-96/087; 84 pp. (March 1997)

This decision document presents the selected remedial action for Operable Unit 1 at the Former Weldon Spring Ordnance Works (wSOW), in Weldon Spring, Missouri. The selected remedy for Operable Unit 1 incorporates both treatment and containment technologies for remediation of soil and pipeline media at the site. The remedy includes incineration of nitroaromatics-contaminated soils and wooden pipeline, stabilization and on-site landfill of lead-contaminated soils, and on-site landfill of construction debris separated from the contaminated soils. These proven technologies will substantially reduce risks associated with the contaminated materials that represent the principal threat at the site, and provide for permanent destruction of the nitroaromatics contamination. The selected remedy also eliminates a source of nitroaromatics to the groundwater.

\section{V18/020806}

Remedial Action Suitability for the Cornhusker Army Ammunition Plant Site

Nonavinakere, S.; Rappa, P., III

Plexus Scientific Corporation, Annapolis, MD

CONF-9507204; Hazardous and Industrial Wastes, A.K. Sengupta (ed.), Proceedings of the 27th Mid-Atlantic Industrial Waste Conference, Bethlehem, PA, July 9-12, 1995. Technomic Publishing Company, Lancaster, PA, 973 pp.; (pp. 129-134) (1995)

Numerous Department of Defense (DOD) sites across the nation are contaminated with explosive wastes due to munitions production during World War II, the Korean Conflict and the Vietnam Conflict. Production activities included explosives manufacturing, loading, packing, assembling, machining, casting and curing. Contaminants often present at these sites include TNT, ROX, HNX, Tetryl 2,4-DNT, 2,6-DNT, 1,3-DNB, 1,3,5-TNB and nitrobenzene. The Cornhusker Army Ammunition Plant (CAAP) is one such DOD site that has been determined to be contaminated with explosives. The CAAP is located approximately 2 miles west of the City of Grand Island in Hall County, Nebraska. The plant produced artillery, bombs, boosters, supplementary charges and various other experimental explosives. The purpose of this paper is to provide an overview of the site background, review of the remedial alternatives evaluation process and the rationale behind the selection of present remedial action.

\section{$1747^{\circ} \quad \mathrm{V} 18 / 021056$}

Remedial Design Services for Montclair/West Orange and Glen Ridge Superfund Sites

Urbaniak, T.F.; Tomiczek, P.W., Jr.

U.S. Army Corps of Engineers, Kansas City, MO; BechteI National, Inc., Oak Ridge, TN

CONF-940499 (Vol. 1); Proceedings of the 1994 Federal

Environmental Restoration III and Waste Minimization II Conference and Exhibition, New Orleans, LA, April 27-29, 1994. Hazardous Materials Control Resources Institute, Rockville, MD, Vol. 1, 783 pp.; (pp. 569-575) (1994)

The Montclair/West Orange and Glen Ridge Superfund Sites are located 12 miles west of New York City in Essex County, New Jersey. The sites are contaminated with waste materials from radium-processing facilities which operated in the area during the early 1900 's. The waste materials, containing radium and other radioactive isotopes were placed in three separate landfill sites. As the towns were developed, homes and streets were constructed on or near the disposal areas. Some of the contaminated material was also used as backfill in basements and in yards. There are 769 residential and commercial properties, having a combined area of approximately 210 acres, included in the two Superfund Sites. The principal contaminant is radium 226, with lesser concentrations of thorium, uranium, and lead. Major public health risks are indoor radon gas build-up and indoor/outdoor gamma radiation. In the early 1980's the United States Environmental Protection Agency, Region II (EPA) and the New Jersey Department of Environmental Protection (NJDEP) began a series of surveys, investigations, and studies to determine the boundaries of the contaminated areas. In 
1985 , NJDEP began a pilot study to remediate the properties by excavation and off-site disposal of contaminated material. The study was interrupted when the disposal permit to the off-site disposal facility was revoked. Residents of four partially remediated homes were left in temporary accommodations for nearly five additional years, while a new disposal facility could be identified and utilized. In 1989, the EPA issued a Record of Decision (ROD) which chose excavation and off-site disposal of contaminated material as the preferred alternative. Additionally, through an Interagency Agreement, the EPA engaged the Kansas City District of the U.S. Army Corps of Engineers (USACE) to perform the remedial design. Bechtel National, Inc. (BNI) was selected by the Kansas City District Corps of Engineers to perform the extensive field investigations and provide the detailed engineering designs for the remedial work. The purpose of this presentation is to highlight key elements of the design process for the remedial action at Montclair. Those key elements are as follows: (1) Meeting community relations challenges; (2) Measuring radioactive contamination; (3) Developing plans and specifications; (4) Packaging of remedial action contracts; and (5) Continually improving both the process and the designs.

\section{8 \\ V18/024303}

Full-Scale Soil Washing System Remediates Superfund Site

Hazardous Waste Consultant 11(6):1.1-1.3 (November-December 1993)

One of the first full-scale soil washing systems in the United States is currently being used to remediate the King of Prussia (KOP) Technical Corporation Superfund site (Winslow Township, New Jersey). The soil washing facility began operating at the site in June 1993. About 20,300 tons of soil require remediation, and operations were expected to be completed in October 1993. The soil washing process was supplied by Alternative Remedial Technologies, Inc. (ART) of Tampa, Florida, a 50-50 joint venture of Geraghty Miller, Inc. and the Dutch company, Heidemij Realisatie. Heidemij developed the process and has been involved with hazardous soil washing in the Netherlands for about ten years.

V18/025432

Draft Environmental Impact Statement: Disposal and Reuse of Naval Weapons Industrial Reserve Plant Calverton, New York

U.S. Navy, Naval Facilities Engineering Command, Northern Division, Philadelphia, PA

Report; 513 pp. (February 1997)

As a result of Northrop Grumman Corporation's decision to vacate the site, the US Navy has determined that it will consider disposal of the Naval Weapons Industrial Reserve Plant (NWIRP) Calverton, located in the towns of Riverhead and Brookhaven on Long Island, New York, by transferring the facility to the town of Riverhead's Community Development Agency (CDA). The transfer of this property has been authorized by special legislation. The proposed disposal of NWIRP Calverton is considered a major federal action, therefore an Environmental Impact Statement (EIS) must be prepared.

\section{$1750 \quad$ V18/023834}

Low Temperature Thermal Treatment Letterkenny Army Depot Case Study

CONF-9306269; HazMat '93 Intemational, Proceedings of the Eleventh Annual Environmental Management and Technology Conference and Exhibition, Atlantic City, NJ, June 9-11, 1993. Advanstar Expositions, Glen Ellyn, II, 731 pp.; (pp. 619-627) (1993)

The Letterkenny Army Depot (LEAD) is located near Chambersburg in south central Pennsylvania. LEAD is the owner/operator of two Industrial Wastewater Treatment Plant (IWTP) lagoons, classified by the Pennsylvania Department of Environmental Regulation (PADER) as hazardous waste surface impoundments. The IWTP lagoon sludges were classed as F006-listed waste, a category including wastewater treatment sludges from electroplating operations. Williams Environmental Services, Inc. (WILLIAMS) recently completed the low temperature thermal treatment of contaminated soil at the site. This landmark project marks the first use of a mobile low temperature thermal treatment unit (LTTTU) in Pennsylvania. The plan for closure of the lagoons required removal of the concrete liners and piping, excavation and treatment of 25,000 tons of contaminated soil below the impoundments, sampling and testing of the processed material to verify adequate contamination reduction, replacement and compaction of the material, and final capping of the lagoons. The U.S. Department of the Amy, Corps of Engineers, contracted with Associated Chemical and Environmental Services (ACES) to manage the overall closure operations. This case study details the thermal treatment system and its successful operation at Letterkenny.

1751 V18/024341

Superfund Record of Decision (EPA Region 3): Austin Avenue Radiation Site, Delaware County, PA, September 27, 1996

U.S. Environmental Protection Agency, Office of Emergency and Remedial Response, Washington, DC

EPA/ROD/R03-96/238; 34 pp. (April 1997)

This Record of Decision (ROD) presents the selected remedy for Operable Unit No. 2, groundwater, at the Austin Avenue Radiation Site, Delaware County, Pennsylvania (Site). EPA has determined that no remedial action is necessary to ensure protection of human health and the environment. No five-year review is required for this remedy since no hazardous substances or pollutants or contaminants remain at this Operable Unit above levels that allow for unlimited use and unrestricted exposure.

1752

V18/022660

Planning for Environmental Restoration in the Slovak Republic

Slavik, O.; Moravek, J.

Nuclear Power Plant Research Institute, Tmava, Slovakia

Spravodajca -Vyskumny Ustav Jadrovych Elektrami 12(1):1-12 (December 1995)

Remediation efforts in the Slovak Republic are concerned with 
contaminated soil banks from waste water disposal from the Bohunice Nuclear Power Plant. The identified contamination, consisting mainly of Cs-137, is a result of two accidents at the $\mathrm{CO}$-cooled and heavy water-moderated NPP Bohunice-A1 unit of the NPP Bohunice complex. Two types of radiation risk scenarios, namely the bank use and contaminated soil (from bank) use scenarios were investigated in relation to decision making for restoration of the contaminated banks. Results of dose assessments and the approach to planning for restoration of contaminated banks are summarized in the paper. Some details about the proposed technical design of the contaminated soil removal and its safe disposal in a near surface isolated basin are also discussed. (This document is in Slovak).

\section{3}

\section{V18/024294}

Remediation of Petroleum Hydrocarbon-Contaminated Groundwater in the Vicinity of a Jet-Fuel Tank Farm, Hanahan, South Carolina

Vroblesky, D.A.; Robertson, J.F.; Petkewich, M.D.; Chapelle, F.H.; Bradley, P.M.

U.S. Geological Survey, Water Resources Division, Columbia, SC

USGS/WRI-96-4251; 83 pp. (1997)

The purpose of this report is to present the evaluation results of groundwater remediation in the study area. The investigation examined groundwater hydrology, chemistry, and microbiology in the northern part of the facility and in parts of Gold Cup Springs subdivision, north of the facility. This investigation included the installation of monitoring wells; the collection of sediment samples for chemical and microbial evaluation, and lithologic description; the extensive collection of groundwater samples for chemical analyses; and the monthly collection of water-level data, as well as continuously recorded water-ievel data from two monitoring wells. In addition, data obtained during previous investigations at the facility were collected, compiled, and evaluated to provide historical information regarding site conditions, as well as to provide useful information to be integrated with data collected during this investigation.

\section{4}

\section{V18/020951}

Development of a Model Decommissioning/Interim Measures Plan for an Industrial Facility: A Case Study

Dechert, S.F.; Moore, B.M.; Moore, R.A.; Barron, S.E. Nuclear Fuel Services, Inc., Erwin, TN

CONF-960212; Waste Management '96: Working Towards a Cleaner Environment, Proceedings of a Conference on HLW, LLW, Mixed Wastes and Environmental Restoration, Tucson, $A Z$, February 25-29, 1996; (9 pp.) (1996)

Many industrial facilities are faced with remediation of contaminated environmental media. For these facilities, workplans may be required by more than one regulatory agency prior to beginning clean-up activities. For sites regulated by multiple agencies, the development of multiple documents to satisfy all regulatory authorities may be a lengthy, expensive, and difficult process. A nuclear materials fabrication facility located in East Tennessee is regulated by, among other agencies, the
Environmental Protection Agency (EPA), the Nuclear Regulatory Commission (NRC), the State of Tennessee Division of Solid Waste Management (DSWM), and the State of Tennessee Division of Radiological Health (DRH). As presented in this case study, a single remediation plan was developed to satisfy the requirements of each regulatory agency. An overview of the development of the multi-purpose remediation plan, a discussion of the benefits and limitations of the multi-purpose approach, and applicability of the multi-purpose approach to other industrial facilities is presented.

1755

V18/024352

Superfund Record of Decision: Memphis Defense Depot (DLA), AKA, Defense Depot, Operable Unit 1, Memphis, TN, (Interim Remedial Action), May 1, 1996

U.S. Environmental Protection Agency, Office of Emergency and Remedial Response, Washington, DC

EPA/ROD/R04-96/278; 57 pp. (April 1997)

This decision document (Record of Decision [ROD]) presents the selected interim remedial action (IRA) for the Defense Depot site, Memphis, Tennessee. The major components of the selected IRA for Operable Unit 1 (OU-1) include: evaluation of aquifer characteristics, which may include installation of a pump test well; installation of additional monitoring wells to locate the western edge of the groundwater plume; installation of recovery wells along the leading edge of the plume; obtaining a discharge permit for disposal of recovered groundwater to the T.E. Maxson Wastewater Treatment Plant, a publicly owned treatment works (POTW), or a municipal sewer system; operation of the system of recovery wells until the unit risk associated with the contaminants is reduced to acceptable leveis or until the final remedy is in place; and chemical analysis to monitor the quality of the discharge in accordance with the city discharge permit requirements. The permit will include parameters to be monitored and frequency.

1756

V18/024651

Insitu Slurry-Phase Bioremediation Case with Emphasis on Selection and Design of a Pure Oxygen Dissolution System

Bergman, T.J., Jr.; Greene, J.M.; Davis, T.R.

Praxair, Inc., Tarrytown, NY; ENSR Consulting and Engineering, Houston, TX; French Limited Project, Crosby, TX

Bioremediation of Pollutants in Soil and Water, B.S. Schepart (ed.), Proceedings of a Symposium, Fort Worth, TX, October 14-15, 1993. American Society for Testing and Materials (ASTM), Philadelphia, PA, 265 pp.; (pp. 117-134) (May 1995)

A field-scale, in-situ, slurry-phase bioremediation demonstration was conducted at the French Limited Superfund Site in Crosby, Texas. As part of this study, several aeration technologies were compared, based on reliability, organic chemical emissions levels, mixing, and oxygenation characteristics. An economic and technical comparison was drawn between these technologies and several high-purity oxygen-based technologies, including Praxair's (formerly, Union Carbide Industrial Gases) Mixflo [TM] system. Based on cost and air emissions, the Mixflo [TM] system was selected, and a field-scale system was designed for French Limited Site. This system is currently operating. 
1757

V18/021676

Assessment of Radiation Contamination at an Abandoned Tin Smelter Facility in Galveston County, Texas

Cornelius, J.M.; Laiche, T.P.; Zehner, W.B.

Ecology and Environment, Inc., Houston, TX; Ecology and Environment, Inc., Albuquerque, NM; U.S. Environmental Protection Agency, Houston, TX

CONF-950209 (Vol. 2); VIP-47, Proceedings of the Fourth Intemational Symposium on Field Screening Methods for Hazardous Wastes and Toxic Chemicals, Las Vegas, NV, February 22-24, 1995. Air and Waste Management Association, Pittsburgh, PA, Vol. 2, 701 pp.; (pp. 1173-1181) (1995)

The Region 6 U.S. Environmental Protection Agency (EPA) and Technical Assistant Team (TAT) contractor, Ecology and Environment, Inc. (E\&E), conducted a site assessment to determine the nature and extent of radiation contamination at an abandoned tin smelter facility in Texas City, Galveston County, Texas. Rapid, field-screening, radiation surveys were conducted, and four slag storage areas were located with gamma radiation levels above background levels. Comprehensive radiation surveys were performed at these locations with Global Positioning System (GPS) assistance for accurate location determination. Approximately 1500 data points were collected from 10 acres. Accurate contour maps of gamma radiation levels were developed using geostatistical modeling and kriging. Radiation exposure levels ranged from background [less than 10 microroentgen per hour to more than 500 microroentgen per hour. Gamma spectroscopic analysis was performed on soil and slag samples using a field-portable, multichannel analyzer (MCA) system. Equilibrium activities of bismuth-214 and thallium-208 were measured as high as 100 picocuries per gram. Ten percent of all samples were sent to an independent radiochemistry laboratory for confirmation analysis. Laboratory and field screening results corresponded closely. Insitu radon emanation rates were measured with large area charcoal collectors (LACCs). Measured rates were less than one picocurie per square meter per second.

\section{8 \\ V18/021011}

Background Chemistry for Chemical Warfare Agents and Decontamination Processes in Support of Delisting Waste Streams at the U.S. Army Dugway Proving Ground, Utah

Rosenblatt, D.H.; Small, M.J.; Kimmell, T.A.; Anderson, A.W.

Argonne National Laboratory, Energy Systems Division, Argonne, IL; Argonne National Laboratory, Environmental Assessment Division, Argonne, IL

ANL/EAD/TM-56; 75 pp. (April 1996)

The State of Utah, Department of Environmental Quality (DEQ), Division of Solid and Hazardous Waste (DSHW), has declared residues resulting from the demilitarization, treatment, cleanup, and testing of military chemical agents to be hazardous wastes. These residues have been designated as corrosive, reactive, toxic, and acute hazardous (Hazardous Waste No. F999). The RCRA regulation (40 Code of Federal Regulations [CFR] 260-280), the Utah
Administrative Code (R-315), and other state hazardous waste programs list specific wastes as hazardous but allow generators to petition the regulator to "delist" if it can be demonstrated that such wastes are not hazardous. The U.S. Army Test and Evaluation Command (TECOM) believes that certain categories of F999 residues are not hazardous and has obtained assistance from Argonne National Laboratory (Argonne) to make the delisting demonstration. The objective of this project is to delist chemical agent decontaminated residues resulting from materials testing activities and to delist a remediation residue (e.g., contaminated soil). To delist these residues, it must be demonstrated that the residues (1) do not contain hazardous quantities of the listed agents; (2) do not contain hazardous quantities of constituents listed in 40 CFR Part 261, Appendix VIII; (3) do not exhibit other characteristics that could define the residues as hazardous; and (4) do not fail a series of acute toxicity tests. The first phase will focus on a subset of the F999 wastes generated at the U.S. Army Dugway Proving Ground (DPG), where the Army tests the effects of military chemical agents and agent-decontamination procedures on numerous military items. This effort is identified as Phase I of the Delisting Program. Subsequent phases will address other DPG chemical agent decontaminated residues and remediation wastes and similar residues at other installations.

1759

V18/021259

Installation Restoration Activities at Dugway Proving Ground, Utah

Campbell, B.A.; Oluic, S.

U.S. Army Environmental Center, Installation Restoration Division, Aberdeen Proving Ground, MD

CONF-940499 (Vol. 2); Proceedings of the 1994 Federal Environmental Restoration III and Waste Minimization II Conference and Exhibition, New Orleans, LA, April 27-29, 1994. Hazardous Materials Control Resources Institute, Rockville, MD, Vol. 2, 858 pp.; (pp. 796-801) (1994)

The United States Amy is completing installation restoration activities over 170 Solid Waste Management Units (SWMUs) on Dugway Proving Ground (DPG), Utah. Efforts are focused on closure activities at $\mathbf{4 2}$ SWMUs in accordance with a State of Utah-mandated Resource Conservation and Recovery Act (RCRA) Stipulation and Consent Order, as well as RCRA Facility Investigation activities at over 130 SWMUs in accordance with the RCRA Part B Permit. Technical and administrative aspects of these requirements and the approach the U.S. Army has taken to meet these requirements are discussed. Additionally, unique aspects of performing environmental work at an installation involved with the testing and development of chemical and biological weapons are described. Particular discussions focus on schedule, health and safety requirements, laboratory screening and analytical requirements, and the logistical challenges associated with mobilizing field crews at a remote military installation. "Lessons leamed" based on actual experiences to date are mentioned.

1760

V18/021666

Base Realignment and Closure (BRAC) Cleanup Plan: Woodbridge Research Facility, Woodbridge, Virginia Version 1 
Earth Technology Corporation, Alexandria, VA

Report; 178 pp. (March 1994)

This Base Realignment and Closure (BRAC) Cleanup Plan (BCP) describes the status, management and response strategy, and action items related to ongoing environmental restoration and associated compliance programs at the Woodbridge Research Facility (WRF). These programs support restoration of the installation, which is necessary to meet the requirements for property disposal and reuse activities associated with the closure of the installation. The scope of the BCP considers the following regulatory mechanisms: the BRAC; National Environmental Policy Act (NEPA); Comprehensive Environmental Response, Compensation, and Liability Act (CERCLA) as amended by the Community Environmental Response Facilitation Act (CERFA); Resource Conservation and Recovery Act (RCRA); and other applicable laws. The BCP is a planning document, and the information and assumptions presented may not necessarily have complete approval from the U.S. Army and/or federal and state regulatory agencies. The BCP is a dynamic document that will be updated regularly to reflect the current status and strategies of remedial actions. This document is the first in a series of updates/modifications and represents conditions and strategies as of 24 February 1994.

1761 V18/022092

Ecological Risk Screening to Prioritize Sites for Cleanup at Yorktown Naval Weapons Station: A Case Study

Pehrman, D.G.; Rowles, L.K.; Thomson, R.

Black and Veatch Waste Science, Inc., Philadelphia, PA; U.S. Environmental Protection Agency, Philadelphia, PA

CONF-951 139 (Vol. 1); Superfund 16: Proceedings of a Hazardous Waste Conference and Exhibition, Washington, DC, November 6-8, 1995. E.J. Krause and Associates, Bethesda, MD, Vol. 1, 828 pp.; (pp. 97-105) (1995)

Federal facilities pose a unique and difficult problem for the Superfund process in that most federal facilities have a large number of suspect areas that require some form of environmental investigation to determine the potential risk these areas present to human health and the environment. Because federal facilities are, on the average, larger than private Superfund sites, not all of the identified suspect areas of contamination have gone through the preliminary assessment/site inspection (PA/SI) evaluation. Thus, some mechanism for evaluating the potential risk presented by these suspect areas is needed to determine which areas should continue in the risk assessment process, thereby allowing the remedial investigation (RI) process to focus on areas presenting the greatest threat to human health and/or the environment. Developing an ecological risk screening methodology for an area with known or suspect contaminated media is an integral part in assessing and characterizing existing and potential overall threat presented to the environment. Sites which indicate risk in the screening phase may be prioritized and carried into the RI process. Alternately, sites which indicate minimal risk in the screening process may be characterized for limited ecological investigation or possibly eliminated from further evaluation. This paper presents a case study of the ecological risk screening process used at the Naval Weapons Station (NWS), Yorktown, Virginia, a National Priorities
List (NPL) site, to assess the effects of organic contamination to sensitive ecological receptors with habitats encompassing Lee Pond, a freshwater pond tributary to the York River Estuary. Lee Pond has been impacted by several contaminant source areas found at the NWS facility and has, therefore, become a secondary source of contamination. This discussion will inciude the use of the ecological risk screening process at the facility as a method of prioritizing and directing environmental restoration activities at those areas determined to have a potential threat to human health or the environment.

1762

V18/021042

Remedial Design and Construction of the Silver Mountain Mine Site

Fonda, K.D.

Brown and Caldwell, San Diego,CA

CONF-940499 (Vol. 1); Proceedings of the 1994 Federal Environmental Restoration III and Waste Minimization II Conference and Exhibition, New Orleans, LA, April 27-29, 1994. Hazardous Materials Control Resources Institute, Rockville, MD, Vol. 1, 783 pp.; (pp. 719-726) (1994)

This paper focuses on design considerations and computer modeling used to develop the remedial design of the closure of the Silver Mountain Mine Superfund site as well as construction quality control measures that were used to ensure a lasting closure that would protect the environment and the public health. Information will be presented on the clay cap systems, biotic barrier, final cover, erosion controls and impermeable liner that were used in the remedial design. Sampling strategies as well as other construction methods used and lessons learned during execution of the remedial design will also be discussed. The objective of this paper is to give the design engineer the basic knowledge needed to prepare a remedial design for the closure of a mining site.

\section{3} V18/021047

Environmental Readiness Pilot Study at the Badger Army Ammunition Plant, Baraboo, Wisconsin

Mays, D.; Bhinge, D.; Patel, J.; Jones-Bateman, L.; Resnick, E.

U.S. Army Environmental Center, Aberdeen Proving Ground, MD; Science Applications International Corporation, McLean, VA

CONF-940499 (Vol. 1); Proceedings of the 1994 Federal Environmental Restoration III and Waste Minimization II Conference and Exhibition, New Orleans, LA, April 27-29, 1994. Hazardous Materials Control Resources Institute, Rockville, MD, Vol. 1, 783 pp.; (pp. 612-617) (1994)

The Badger Army Ammunition Plant (BAAP) has been on standby status since the mid-1970s, prior to the enactment of the majority of Federal environmental regulations. As a result, BAAP is unprepared to begin production without the implementation of pollution prevention and treatment measures. The Army contracted SAIC to conduct a pilot study to develop an environmental readiness plan for $\mathrm{BAAP}$ in the event that the plant is reactivated to produce explosives and propellants for ammunition requirements during mobilization. This paper describes the process developed by 
SAIC to conduct this pilot study at BAAP and the relationship between this effort and the Army's overall environmental mission.

\section{4}

V18/020821

Acoustic Barrier Separator

Goforth, R.R.; Ohkawa, T.

General Atomics, San Diego, CA

U.S. Patent 05419877; 22 pp. (May 30, 1995)

A large number of Superfund applications require remediation of contaminated soil. Where these applications require handling of soils, as in excavation, thermal treatment or deposition, engineers are faced with the problem of control of particulate emissions. In this invention, high temperature gas emissions from industrial power plant or environmental clean-up processes are subjected to an acoustic waveform having second harmonic content and appropriate second harmonic phase shift to impart a net acoustic Oseen force on particulate matter contained in the gas for removal of said matter. Particulate matter of 1 micron radius is positively excluded, while smaller particles are agglomerated by the sound wave. The acoustic waveform further enhances both sorption of injected sorbent particles for removal of sulfur oxides, and the efficiency of an in-line catalytic converter for removal of nitrogen oxides. The invention improves overall removal efficiency, can operate at very high temperatures, and does not produce any secondary waste, such as filters.

\section{5}

V18/022797

Activities on the International Atomic Energy Agency in Environmental Restoration Technology

Clark, D.E.

International Atomic Energy Agency, Vienna, Austria CONF-960804 (Vol. 3); Spectrum '96: Nuclear and Hazardous Waste Management, Proceedings of an International Topical Meeting, Seattle, WA, August 18-23, 1996. American Nuclear Society, La Grange Park, IL, Vol. 3, 841 pp.; (pp. 1707-1711) (1996)

The International Atomic Energy Agency (IAEA), an autonomous intergovernmental organization representing 123 countries, has an active project to assist its Member States in the environmental restoration of radioactively contaminated sites. In this paper, the current and projected activities of the IAEA in the area of environmental restoration technology are discussed. These activities include gathering and publishing information and data on key technical aspects of environmental restoration; promoting and supporting research; providing technical assistance and training; and developing an international registry of radioactively contaminated sites in Member States. The project's current and near-term focus is on the available technology for cleanup and remediation; site characterization methodologies; important considerations in the formulation of strategies for environmental restoration; planning and management options for the cleanup of contaminated groundwater; and post-restoration monitoring of decommissioned sites. Details of this project, including information on the technical reports to be published through the year 1999, are presented.

\section{Amperometric Biosensors for the Determination of} Heavy Metals

Compagnone, D.; Palleschi, G.; Varallo, G.; Imperiali, P.L.

Universita di Napoli-Federico II, Naples, Italy; Ente

Nazionale per l'Energia Elettrica, Centro Ricerca

Valorizzazione e Trattamento Residui, Brindisi, Italy; ISMES SpA, Bergamo, Italy

CONF-9506232; Environmental Monitoring and Hazardous Waste Site Remediation, T. Vo-Dinh and R. Niessner (eds.), Proceedings of a Conference of the Society of Photo-Optical Instrumentation Engineers, Munich, Germany, June 19-23, 1995. International Society for Optical Engineering, Bellingham, WA, 613 pp.; (pp. 141-151) (1995)

A bioelectrochemical method for the determination of heavy metal ions has been developed. This method is based on the inhibition effect of metal ions on the enzymatic activity of oxidase enzymes. The enzymatic activity was determined with an amperometric hydrogen peroxide probe. The inhibition effect on enzymes in solution and covalently immobilized on polymeric supports has been evaluated. $\mathrm{Hg}$ (II) was the metal ion that inhibited almost all the enzymes, particularly glycerol-3-P oxidase. $\mathrm{Hg}(\mathrm{II})$ was detected in the $0.05 / 0.5 \mathrm{ppm}$ range with the enzyme in solution. Calibration curves for $\mathrm{Hg}$ (II) were also obtained with the other oxidase enzymes in the $0.5 / 10 \mathrm{ppm}$ range. The other metal ions tested inhibited the enzymes more specifically. The metal ion/enzyme systems which gave the best inhibition were Se(TV)/glutathione oxidase. $\mathrm{Ni}(\mathrm{II}) / \mathrm{sarcosine}$ oxidase, $\mathrm{V}(\mathrm{V}) / \mathrm{glutathione}$ oxidase, $\mathrm{Cu}(\mathrm{II}) / \mathrm{al}$ cohol oxidase from Pichia Pastoris and Cd(II)/D-aminoacid oxidase All these metal ions were detected in the $0.1 / 10$ range using the enzymes in solution or covalently immobilized.

\section{$1767 \quad$ V18/021050}

Appropriate Techniques to Decommission (Abandon) Wells and Boreholes

McJunkin, R.D.

Califomia Environmental Protection Agency, Department of Toxic Substances Control, Sacramento, CA

CONF-940499 (Vol. 2); Proceedings of the 1994 Federal Environmental Restoration III and Waste Minimization II Conference and Exhibition, New Orleans, LA, April 27-29, 1994. Hazardous Materials Control Resources Institute, Rockville, MD, Vol. 2, 858 pp.; (pp. 1333-1337) (1994)

Wells and boreholes that are no longer needed or lost drive casing in an open borehole from drilling operations should always be properly sealed with impervious material. More importantly, in addition to the well, borehole, or lost drill casing being physically sealed, hydraulic integrity of subsurface geologic materials should be restored to a pre-drilling condition. The focus of decommissioning activities should always be to effectively seal subsurface geologic materials and prevent cross contamination of water-bearing zones or aquifers. In most sedimentary environments, geologic materials that should be sealed are low permeability silts and clays (aquitards). Essentially decommissioning should be to locate and seal aquitards to prevent cross contamination in the subsurface. Sealing permeable geologic materials (i.e., sand or gravel) should not be the focus of decommissioning operations and in most situations should be avoided. 


\section{8}

V18/021671

Assessment and Remediation of Contaminated Sediments (ARCS) Program: Estimating Contaminant Losses from Components of Remediation Alternatives for Contaminated Sediments: Report for March 1991-April 1994

Myers, T.E.; Averette, D.E.; Olin, T.J.; Palermo, M.R.; Reible, D.D.

U.S. Environmental Protection Agency, Great Lakes National Program Office, Chicago, II

EPA/905/R-96/001; 302 pp. (March 1996)

Industrial and municipal point-source discharges and nonpoint source pollution from agricuitural and urban areas over many years have contaminated bottom sediments in the rivers, harbors, and nearshore areas of the Great Lakes. Areas in the Great Lakes that remain seriously impaired have been designated as areas of concern (AOCs) under the Great Lakes Water Quality Agreement.

1769

V18/023177

Assessment of the Soil/Water/Air Contamination in Operating Petrochemical Plants: The Italian Experience

Ganapini, W.; Milani, A.; Carella, F.

Lombardia Risorse, Milan, Italy

CONF-9210194; Proceedings of an International Symposium on

Environmental Contamination in Central and Eastern Europe, Budapest, Hungary, October 12-16, 1992, 968 pp.; (pp. 182-185)

In Italy regional governments have been delegated the authority by the Italian Ministry of Environment to conduct investigations, prioritize sites, and develop remediation plans for sites contaminated with hazardous materials. The Agip oil refinery, in Rho, northwest of Milan, is one of the most important Italian cases related to the assessment of subsurface and groundwater contamination. It is located in a very high-risk area due to heavy industrial pollution. This plant occupies an area of $1.3 \mathrm{sq} \mathrm{km}$ and currently employs about 500 workers. The plant will be shut down in 1993 due to the potential risk of a release in a highly populated area. The Italian Ministry of Environment has adopted the methodology used from the investigation of the Agip facility as a precedent for future hazardous site investigations. The site investigation was initially performed using twenty sampling points (both drillings and piezometric wells) selected at random. A high level of subsurface contamination, due to both aromatic compounds (as high as $100 \mathrm{mg} / \mathrm{kg}$ ) and aliphatic hydrocarbons $(780 \mathrm{mg} / \mathrm{kg}$ ) in the central area of the plant, at depths ranging from 5 to 15 meters, was detected. Concentrations of benzene in the shallow aquifer reached about $18 \mathrm{mg} / \mathrm{l}$. In order to estimate the rate of migration of benzene toward the public water supply of Milan (located about 4 $\mathrm{km}$ from the refinery) a hydrodynamic and transport model was used. The rate of propagation of the benzene plume was estimated at about 150 meters/year. Hydrocarbon levels in the air attributed to the Agip refinery were assessed using mathematical models, and samples confirmed the values of about 1,000 to $1,500 \mathrm{ug} / \mathrm{cubic}$ meter. To prevent contaminant migration, a line of drainage wells was proposed. The testing of an "in situ" cleanup technology (soil venting and biodegradation) was suggested for a limited area while the refinery is still operating. Precautionary measures to prevent vapor escape during transfer of materials were also recommended.

1770

V18/023498

Beneficial Reuse of Treated Media from Remediation at an Industrial Site

Erdman, D.E.; Weston, A.F.; Morrissey, B.J.

Smith Environmental Technologies, Plymouth Meeting, PA; Occidental Chemical Corporation, Niagara Falls, NY; Occidental Chemical Corporation, Houston, TX

CONF-9606300; HazMat International '96, Proceedings of the 14th Annual Environmental Management and Technology International Conference, Atiantic City, NJ, June 18-20, 1996. Advanstar Expositions, Duluth, MN, 527 pp.; (pp. 445-452) (1996)

Remediation at an active polyvinyl chloride (PVC) resin manufacturing plant in southeastem Pennsylvania has involved closure of lagoons under a Resource Conservation and Recovery Act (RCRA) plan and design of a groundwater pump and treat program under the Comprehensive Environmental Response, Compensation, and Liability Act of 1980 (CERCLA). Both the CERCLA and RCRA programs involve beneficial reuse of the treated media, which in effect has offset some costs of the remediation. The lagoons were used to settle the PVC residual material from wastewater generated by the facility. Analysis of the residual material showed that the polymer content would allow it to be used as a low-grade PVC resin after drying. The treatment process selected for the RCRA lagoon closure involved indirect steam stripping and filter pressing which produced a filter cake that was both nonhazardous and marketable. Approximately 6,000 tons of product was sent to market from the lagoons. The groundwater, which will be remediated at the site, contains trichlorethylene (TCE), vinyl chloride monomer (VCM), and other volatile organic compounds. An average $400 \mathrm{gpm}$ of groundwater will be extracted and treated by carbon absorbents and an air stripper. The groundwater will be used by the plant in the production process after it is treated by the CERCLA remediation system.

1771

V18/024681

Bioremediation Engineering: Design and Application

Cookson, J.T., Jr.

International Network for Environmental Training, Inc., Potomac, MD

Bioremediation Engineering: Design and Application, G.F. Nalven (ed.), McGraw-Hill, Inc., New York, NY, 539 pp. (1995)

The purpose of this book is to provide the fundamentals that support the degradation of hazardous compounds coupled with design and operational techniques for bioremediation systems. The book is intended for design engineers, regulatory officials, project managers, and students interested in remediation. It is assumed that they have some knowledge of conventional methods of wastewater treatment, design of biological processes, water chemistry, and microbiology. The title, Bioremediation Engineering: Design and Application, was chosen to emphasise the engineering aspects of using microorganisms for the remediation of contaminated soil, sludge, and groundwater. This book has its origins in the author's 
application of biological processes to industrial wastewater treatment for the past 30 years, and bioremediation during the last 8 years. The contents reflect the author's teaching approach to technology transfer as a professor of environmental engineering for 10 years, and a practical approach to implementation from 18 years as head of an environmental engineering firm. The text integrates the scientific fundamentals with experience gained by many professionals in bioremediation. Bioremediation has grown from an insignificant level to over 15 percent of all site remediations within 5 years. This growth highlights the need for a coherent and comprehensive presentation of the subject. A text of this nature is not only necessary for the application of bioremediation but is important for the acceptance of this technology. Individual chapters are also indexed separately in the RAPIC database.

1772 V18/024696

\section{Bioremediation and Government Oversight, Chapter 10}

Devine, $\mathrm{K}$.

DEVO Enterprises, Inc., Washington, DC

Bioremediation, K.H. Baker and D.S. Herson (eds.), McGraw-Hill, Inc., New York, NY, 404 pp.; (pp. 343-362) (1994)

This is a chapter from the book titled, Bioremediation. While sometimes used interchangeably by those not in the government, each of the terms legislation, regulation, and policy has a unique meaning. Legislation refers to law, which is enacted by Congress and which gives mandates or general direction to the particular govemment entity(ies) having jurisdiction over the activity(ies) at which the legislation is directed. Government organizations enact the legislation guidance or directives through the promulgation of regulations. Regulations are first released as "proposed" to the public for comment. The purpose of a proposed regulation is to allow the public, both the target regulated community and public interest groups and other interested parties, the opportunity to comment. Comments are taken into account, with the final regulation reflecting such comments or defending the government's stance for not incorporating certain comments. Policies are interpretations of existing regulations or legislation issued by a government body, and as such, they do not carry strict legal authority. The extent to which the target community may respond and adhere to such guidance can vary, in many cases heeding the written direction as if it were a regulation. Some policies provide the states with the ultimate interpretive authority. Policy statements can be released as a proposed work for public comment, with a final statement issued after comments have been reviewed by the government issuing the proposal.

1773 V18/024648

\section{Bioremediation of Oil Tar-Contaminated Soil}

Hyzy, J.B.; Schepart, B.S.

Waste Stream Technology, Buffalo, NY

Bioremediation of Pollutants in Soil and Water, B.S. Schepart (ed.), Proceedings of a Symposium, Fort Worth, TX, October 14-15, 1993. American Society for Testing and Materials (ASTM), Philadelphia, PA, 265 pp.; (pp. 61-74) (May 1995)

Oil tar is a heterogeneous mixture of petroleum compounds, including polycyclic aromatic hydrocarbons (PAHs). These are a significant health concern because many are suspected and known carcinogens. An oil gasification facility in Pt. Stanley, Ontario, Canada, deposited residual oil tars into two onsite lagoons. Using landfarm bioaugmentation technology, Waste Stream Technology was commissioned to remediate $40,000 \mathrm{cu}$ m of contaminated soil and accompanying groundwater. Bioremediation was performed in a $150 \mathrm{MX} 60 \mathrm{M}$ biopad, confined with an impermeable clay liner and berm. Soil was excavated and stockpiled in a contained pretreatment area, then loaded into the biopad as $4000-5000$ cu M "lifts." WST Bioblend M- 5 was used for soil remediation by daily culturing in six $1300 \mathrm{~L}$ bioreactors, followed by soil inoculation and rototiling. Soil was treated daily to achieve a viable microbial concentration of approximately $10(\mathrm{E}+4)$ colony forming units per gram of soil. Groundwater and rainwater run off was treated in six 10,000 liter fixed film bioreactors supplemented with CAP [TM]. Treated water was discharged onto the stockpiled, pretreatment soil. Analytical data showed that the water PAH content was reduced from greater than $900 \mathrm{ppb}$ initially, to below detectable limits. Solid phase bioremediation resulted in the reduction of soil PAHs, from an average initial concentration of $1000 \mathrm{ppm}$ total PAH (TPAH) and $100 \mathrm{ppm}$ Benzo(a)Pyrene, to less than $100 \mathrm{ppm}$ TPAH and less than 10 ppm Benzo(a)Pyrene.

\section{$1774 \quad$ V18/024580}

Bioremediation of Petroleum Contaminated Sites Riser-Roberts, E.

Bioremediation of Petroleum Contaminated Sites, C.K. Smoley, Chelsea, MI, 464 pp. (1992)

This book provides background information on the major aspects of technologies and related research dealing with the use of biodegradation for treatment of environmental contamination by toxic organic substances. It is intended to serve as a broad reference base for development of a program for in-situ biorestoration of fuel-contaminated soil and groundwater. The book is organized as follows: Sections 1-7 contain the main text, which is an overview of the many different subject areas involved in bioremediation. This summary is intended for managers and others who wish to learn about the technology without having to confront technical details. The Appendix is a Supplementary Text, which contains the technical information for readers who need indepth coverage. Three of the chapters are indexed separately in the RAPIC database.

1775 V18/023491

Bioremediation of Solvent Hydrocarbons: Laboratory and Insitu Field Studies

Peck, P.C.; Rhodes, S.H.; Anderson, B.N.; Henkler, R.D.

Minenco Pty. Limited, Bioremediation Services, North Sydney, Australia; RMIT University, Department of Chemical and Metallurgical Engineering, Melbourne, Victoria, Australia; ICI Paints (Europe), Berkshire, United Kingdom

CONF-960730 (Vol. 3); Technologies Critical to a Changing World, Volume III: Emerging Energy Technologies, Clean Technologies, Remediation and Emission Control Fuels, and Petrochemicals, Proceedings of the Fith World Congress of Chemical Engineering, San Diego, CA, July 14-18, 1996. American Institute of Chemical Engineers, New York, NY, Vol. 3, 1118 pp.; (pp. 737-742) (1996) 
A multidisciplinary international site assessment and remediation project has been undertaken for an operating paint manufacturing site in Germany, with specialist input from collaborating research centers and remediation consultants from both Australia and Germany. After a detailed chemical and hydrogeological investigation revealed areas of contamination with aromatic and aliphatic solvent hydrocarbons, soil and groundwater samples were collected for detailed microcosm-based studies to demonstrate the potential for biodegradation of the contaminants of concem. In situ biodegradation rates in the unsaturated zone were established by a field test program involving air injection testing, tracer testing and in situ respiration studies.

\section{6}

\section{V18/024660}

Bioremediation: Environmental Regulations and Resulting Market Opportunities, Chapter 2

\section{Bakst, J.S.; Devine, K.}

Bakst Environmental, Chapel Hill, NC; DEVO Enterprises, Inc., Washington, DC

Bioremediation: Field Experience, P.E. Flathman, D.E. Jerger and J.H. Exner (eds.), Lewis Publishers, Boca Raton, FL, 560 pp.; (pp. 11-48) (1994)

Environmental degradation of our nation's air, water, and land has created the need for responsible environmental solutions, such as the development and use of innovative treatment technologies. The federal government also has enacted environmental regulations to reduce, control, and eliminate such pollution and has developed programs that further the potential of technologies already in the field or under development. Efforts to use bioremediation, an innovative treatment technology, involve conducting the research needed to improve and expand applications of the technology and successfully applying it in full-scale operations. Regulations have three competing impacts on the use and application of innovative treatment technologies. They create markets for their use, impose barriers to their application in the environment, and encourage their development through innovative research and development programs. This chapter explains the key statutes, regulations, policies, and programs that potentially affect the bioremediation industry, by imposing barriers to the use of the technology, by creating potential business opportunities for the technology's application, and by fostering the development of applications of the technology not yet realized at the commercial level. This chapter is from the book entitled Bioremediation: Field Experience.

\section{7}

\section{V18/024354}

\section{CEBAF: Environmental Protection Program Plan}

Southeastern Universities Research Association, Inc., Continuous Electron Beam Accelerator Facility, Newport News, VA

DOE/ER/40150-681; 76 pp. (October 1, 1995)

An important objective in the successful operation of the Continuous Electron Beam Accelerator Facility (CEBAF) is to ensure protection of the public and the environment. To meet this objective, the Southeastern Universities Research Association, Inc., (SURA) is committed to working with the US Department of Energy (DOE) to develop, implement, and manage a sound and workable environmental protection program at CEBAF. This environmental protection plan includes information on environmental monitoring, long-range monitoring, groundwater protection, waste minimization, and a pollution prevention awareness program plan.

1778

V18/021236

Case Study of Manufactured Gas Plant Site

Remediations Using Thermal Desorption: Topical Report - December 1994-October 1995

Slimon, K.F.; Unites, D.F.; Howard, M.C.

Atiantic Environmental Services, Inc., Colchester, CT

Report; 55 pp. (October 1995)

This case study presents an evaluation of thermal desorption at the five SoCal Gas former MGP sites. The remediations are evaluated in terms of material handling and processing, equipment operations and reliability, effective reduction of contaminant levels, air emissions, regulatory compliance, and overall cost.

1779

V18/022644

Case Study of an Approved Corrective Action Integrating Active Remediation with Intrinsic Remediation

Teets, D.B.; Guest, P.R.; Blicker, B.R.

Parsons Engineering Science, Inc., Denver, $\mathrm{CO}$

CONF-960393 (Part 2); Contaminated Soils and Goundwater: Analysis, Fate, Environmental and Public Health Effects, and Remediation, Proceedings of the Sixth Annual West Coast Conference, Newport Beach, CA, March 11-14, 1996. Association for the Environmental Health of Soils, Amherst, MA, Part 2, 226 pp.; (p. 66) (1996)

Parsons Engineering Science, Inc., performed UST removals and/or site assessments at UST system locations at a former US Air Force Base (AFB) in Denver, Colorado. Four UST systems, incorporating 17 USTs, were located within the petroleum, oils, and lubricants bulk storage yard (POL Yard) of the former AFB. During the tank removals and subsequent site investigations, petroleum hydrocarbon contamination was found in soils at each site. Significant releases from two of the UST systems resulted in a dissolved benzene, toluene, ethylbenzene, and xylenes (BTEX) plume in the groundwater, and smear-zone contamination of soils beneath the majority of the POL Yard. Because of the close proximity of the UST systems, and the presence of the groundwater plume beneath the POL Yard, a corrective action plan (CAP) was prepared that encompassed all four UST systems. An innovative, risk-based CAP integrated active remediation of petroleum-contaminated soils with intrinsic remediation of groundwater. A natural attenuation evaluation for the dissolved BTEX was performed to demonstrate that natural attenuation processes are providing adequate remediation of groundwater and to predict the fate of the groundwater plume. BTEX concentrations versus distance were regressed to obtain attenuation rates, which were then used to calculate BTEX degradation rates using a one-dimensional, steady-state analytical solution. Additionally, electron acceptor concentrations in groundwater were compared to BTEX concentrations to provide evidence that natural attenuation of BTEX compounds was occurring. The natural attenuation 
evaluation was used in the CAP to support the intrinsic remediation with long-term monitoring alternative for groundwater, thereby avoiding the installation of an expensive groundwater remediation system. A full-scale bioventing system with six venting wells was designed and installed to remediate vadose zone soils and eliminate the potential long-term source of fuel hydrocarbons.

\section{$1780 \quad$ V18/025447}

Cesium-137 and Strontium-90 Buildup by Fruit-and-Berry Cultures at Different Density of Soil of Contamination

Savel'ev, V.V.; Piskunov, V.S.; Rubanova, R.V.

CONF-9309496; Proceedings of the Radiobiological Congress, Abstracts, Part 3, A.I. Gaziev (ed.), Kiev, Ukraine, September 20-25, 1993. Pushchinskij Nauchnyj Tsentr, Pushchino, Russian Federation, 399 pp.; (pp. 877-878) (1993)

Short communication. No abstract available. (This document is in Russian).

\section{$1781 \quad$ V18/021689}

Changes in Chemical Contaminant Body Burden and Biological Effects in Mussels Adjacent to a Marine Remediation Site

Kagley, A.N.; Snider, R.G.; Inouye, L.S.; Casillas, E.

National Oceanic and Atmospheric Administration, National Marine Fisheries Service, Seattle, WA

CONF-9511137; Global Environmental Protection: Science, Politics, and Common Sense, Proceedings of the Second Society of Environmental Toxicology and Chemistry (SETAC) World Congress and 16th Annual Meeting, Vancouver, British Columbia, Canada, November 5-9, 1995. Society of Environmental Toxicology and Chemistry, Pensacola, FL, 378 pp.; (p. 234) (1995)

Eagle Harbor is a creosote-polluted marine site currently undergoing initial environmental remediation. Highly contaminated sediments were capped with a layer of sediment from a minimally contaminated area. Mussels (Mytilus edulis complex) in the vicinity of the creosote plant were collected before, during, and after the initial remediation process, for monitoring body burdens of polycyclic aromatic hydrocarbons (PAH) as well as cellular effects indicative of biological damage. Mussels from this area have previously been shown to exhibit an elevated body burden of high molecular weight PAHs, as well as substantial changes in subcellular structures and functions, characteristic of mussels from chemically contaminated environments. Following capping, the body burden of high molecular weight PAHs was substantially reduced early in the restoration process yet mussel contaminant body burdens were approaching pre-cap levels one year after the end of the remediation project. Changes in mussel health were assessed by measuring selected aspects of lysosomal function as well as levels of enzymes and anti-oxidants involved in detoxifying organic chemical contaminants. Substantial improvement throughout capping occurred in lysosomal stability and cytochrome P450 reductase activity in digestive gland, and anti-oxidant status in gill tissue when compared to initial findings. In contrast, increased levels of neutral lipid and lipofuscin in digestive glands indicated that mussels were still suffering biological impairment as a result of chemical contaminant exposure. Overall, indigenous mussels near the marine remediation project showed temporary improvement in tissue body burden of chemical contaminants and some decrease in biological effects.

1782 V18/021294

Changes in Community Structure and Physiological Status of a Bacterial Consortia During Degradation of Trichloroethylene

Nold, S.; Lackey, L.W.; Ringelberg, D.B.; White, D.C. University of Tennessee, Center for Environmental Biotechnology, Knoxville, TN

CONF-9205212; Proceedings of the 1992 General Meeting of the American Society for Microbiology, New Orleans, LA, May 26-30, 1992, 383 pp.; (p. Q-283) (1992)

In situ bioremediation of hazardous waste relies on an understanding of microbial community structure and physiology. Analysis of microbial signature fatty acid biomarkers and endogenous storage lipids allows determination of changes in microbial community structure and physiology. This study correlates changes in microbial community structure and physiological status of a consortia with the degradation of TCE. The phospholipid fatty acid (PLFA) profile and poly-beta-hydroxyalkanoate (PHA) content of a microbial consortia derived from a TCE contaminated site was analyzed in a growth experiment as the consortia utilized propane and degraded TCE. Changes in fatty acid profiles were determined by (1) multivariate cluster analysis (2) dissection of signature fatty acid biomarkers with the profile. PHA content was determined by GCMS and volatile hydrocarbons were quantified by $G C$. Arthrobacter and propane utilizing species biomarkers increased as TCE and propane decreased. Changes in Pseudomonas sp. biomarkers did not correlate with changes in TCE and propane. Microbially synthesized PHA increased as TCE was degraded. Multivariate cluster analysis differentiated samples by growth phase, but did not separate the treated from the control consortia. PLFA and PHA analysis provided a mechanism to study the community structure and physiological status of a diverse microbial consortia. (Complete Text),

1783

V18/023733

City of Chicago Brownfields Initiative

Bower, J.

City of Chicago Department of Planning and Development, Chicago, IL

CONF-960741; DOE Pollution Prevention in the 21st Century, Proceedings of the Twelfth Annual DOE Pollution Conference, Chicago, IL, July 9-11, 1996; (3 pp.) (1996)

The following is a discussion of the progress made to date by the City of Chicago Brownfields Initiative. Brownfields are properties that are abandoned or idle because of the presence or suspected presence of environmental contamination. Beginning in October 1993, the City of Chicago assembled an interdepartmental team to address the complexities of the Brownfields problem. The team developed a three-tiered approach to the Brownfields problem: Cleanup and redevelopment of pilot sites; Policy development forum; Economic analysis of brownfields vs. greenfield 
development. Lessons leamed from these pilot projects are given.

1784

$$
\text { V18/024667 }
$$

Closure of an RCRA Surface Impoundment by Employing a Modified Biological Treatment Approach, Chapter 11

Portier, R.J.; Christiansen, J.A.

Louisiana State University, Institute of Environmental Studies, Baton Rouge, LA; Environmental Remediation, Inc., Baton Rouge, LA

Bioremediation: Field Experience, P.E. Flathman, D.E. Jerger and J.H. Exner (eds.), Lewis Publishers, Boca Raton, FL, 560 pp.; (pp. 225-233) (1994)

This chapter describes specialized biological reactors used for the treatment of marginally soluble, viscous organics trapped in porous soil matrices and associated groundwater at a petrochemical facility. A remediation design for the effective biological treatment of phenols, cumene, and related aromatics in a surface impoundment at a chemical plant situated along the Mississippi River was approved and implemented under RCRA. The impoundment, containing $30,0000 \mathrm{sq}$ yds (23,000 cu m) of contaminated soils/sludges, was closed in an 18-month timeframe using a protocol involving the construction and operation of a temporary treatment unit within the confines of the plant. This chapter is from the book entitled Bioremediation: Field Experience.

1785 V18/021617

Concepts of Chemical and Biological Remediation of Acidic, Iron-Containing Lakes in Mining Areas

Fischer, R.; Guderitz, T.

Technische University, Institute fuer Wasserchemie und Chemische Wassertechnologie, Dresden, Germany; Biologisch Analytisches Umweitlabor, IDUS GmbH, Ottendorf-Okrilla, Germany

Wissenschaftiche Zeitschrift der Technischen Universitaet Dresden 45(2):85-89 (1996)

The extensive lowering of groundwater connected with intensive lignite mining in the areas concemed produces problems with water balance and with water quality. The latter is a result of pyrite and markasite materials weathering. When using mining drainage water, the issues of remediation of mining lakes and of prediction of groundwater quality are of increasing importance. The extremeiy low $\mathrm{pH}$ level and high percentage of iron considerably restricts the utilization of mining lakes in the Lusatian and Central Lignite Mining Districts as recreational and fishing waters as well as for the production of drinking water. The authors present efficient and implementable concepts of remediation based on neutralization, hydrolysis and precipitation. The bases of the concepts are laboratory tests for the neutralization of strongly acidic mining lakes by means of soil drainage and percolation through buffering soil successions (mixtures of soil material, lime, and possibly alkaline wastes). In addition, direct input of neutralization material (lime, caustic soda) into the mining lake is considered. The prognosis for the funtre chemical and biological water quality of the mining lakes with regard to the quantity and quality of influent and effluent water is an important consideration. As a result of remediation the water quality should meet the demands of the European Union (EU) guidelines for recreational and fishing waters. (This document is in German).

1786

V18/021231

Consequences of Chernobyl: What Do We know 10 Years After the Accident

Bauchinger, M.; Bayer, A.; Biko, J.; Grosche, B.; Heinemann, G.; Heinemann, K.; Hill, P.; Hille, R.; Hillebrandt, S.; Karthein, R.; Kaul, A.; Mueller, W.U.; Narrog, J.

GSF, Institute fuer Strahlenbiologie, Oberschleissheim, Germany; Bundesamt fuer Strahlenschutz, Institut fuer Strahlenhygiene, Oberschleissheim, Germany; University Wuerzburg, Nuklearmedizin, Germany; PreussenElektra AG, Tanklager Stadesand, Stade, Germany; Forschungszentrum Juelich GmbH, Juelich, Germany; Universtaetsklinikum Essen, Institut fuer Medizinische Strahlenbiologie, Germany; TUEV Rheinland e.V., Institut fuer Kerntechnik und Strahlenschutz, Koeln, Germany; Bundesamt fuer Strahlenschutz, Salzgitter, Germany; Umweltministerium Baden-Wuerttemberg, Stuttgart, Germany

StrahlenschutzPraxis (Koeln) 2(1):3-38 (1996)

This report is a survey provided by 22 scientists in 12 articles about what is happening at Chernobyl. It includes the current situation in the most affected countries of the former Soviet Union and in Germany, and also the consequences of the accident. The report contains information about the measurement activities of the German Federal Republic and the project of GAST called, 'scientists help the children of Chemobyl'. The following topics are also included: A survey of epidemiological studies in Germany; a presentation of regulations and professional help as a consequence from the accident; and finally, an evaluation of the media and their part in the proliferation of information. (This document is in German).

\section{7 \\ V18/020815}

Considerations on Some Radioactive Areas in Romania Potential Subjects for Environmental Restoration

Sandru, $P$,

Institute of Atomic Physics, Bucharest, Romania

LAEA-TECDOC-865; CONF-9310459 (Vol. 1); Planning for Environmental Restoration of Radioactively Contaminated Sites in Central and Eastern Europe, Volume 1: Identification and Characterization of Contaminated Soils, Proceedings of a Workshop on Environmental Restoration in Central and Eastem Europe, Budapest, Hungary, October 4-8, 1993. International Atomic Energy Agency, Vienna, Austria, Vol. 1, 356 pp.; (pp. 217-230) (February 1996)

Radioactive substances started to be used in Romania practically at the same time with most of Eastern European countries, at first in the medical education fields, as well as minor technical applications; radium was the main radioactive element that was used. After 1950 , artificial radioactive substances have been imported; the exploitation of radioactive ores also began. By 1957 , the 
radioactive substances national production exhausted the existing radioactive sources. Subsequent to the nuclear field development, various nuclear regulations and appropriate authorizing and control mechanisms have been established, as well as environmental radioactivity supervision by national networks. The radioactive waste question has been relatively well controlled, as far as medical and industrial waste is concemed. For some time its collection and dumping was not made in optimal conditions. This problem was solved by decommissioning the improvised dumping site, treating the waste in a special installation, and depositing the confined and concentrated waste in a deep geological formation. Generally speaking, in Romania there are no areas of uncontrolled disposal of radioactive wastes, which could be taken as starting points for environmental restoration programs. Some incidents which resulted in the contamination of small areas have been resolved, with no environmental restoration being required today. The main characteristics of the radioactive contaminated areas arising as a consequence of radioactive ore exploration and exploitation as well as from the concentration of natural radioactive substances in fertilizer facilities or coal thermocentrales indicate that these could be potential subjects for inclusion in the environmental restoration program. One of the conclusions is that the environmental restoration program initiated by the IAEA as well as international co-operation for its achievement is necessary and opportune.

\section{$1788 \quad$ V18/023924}

Consortium for Site Characterization Technology: A Testing and Verification Program

Billets, S.; Koglin, E.N.

U.S. Environmental Protection Agency, National Exposure Research Laboratory, Las Vegas, NV

CONF-951048 (Vol. 50, Pt. 2); ISA/95: Advances in Instrumentation and Control, Proceedings of an International Conference and Exhibition, New Orleans, LA, October 1-6, 1995. Instrument Society of America, Research Triangle Park, NC, Vol. 50, Pt. 2, 764 pp.; (pp. 163-170) (1995)

The goal of the Consortium for Site Characterization Technology is to increase the use of new characterization and monitoring technologies in assessing and remediating contaminated sites. To attain this goal, the Consortium will: (1) identify, demonstrate, evaluate, verify, and transfer information about innovative and alternative monitoring, measurement, and site characterization technologies to developers, users, and regulators; and (2) define and demonstrate a process for verifying the performance of innovative site characterization technologies. By developing this process the Consortium will facilitate independent testing and demonstration that can generate the data necessary to evaluate and verify performance. This paper describes the need for establishing this program and the process which will be used to achieve this goal.

1789

\section{V18/023324}

Contaminated Land: Reclamation, Redevelopment and Reuse in the United States and the European Union Meyer, P.B.; Williams, R.H.; Yount, K.R.

Contaminated Land: Reclamation, Redevelopment and Reuse in the United States and the European Union, Ashgate Publishing,

Brookfield, VT (December 1995)
A framework is constructed within which to compare US and EU policies on contaminated land, thus widening the discussion from its usual national context. Specific aspects and issues, including the nature and extent of contaminated land, legal implications, regulations, overall environmental policy, and integrated analysis are compared. Among the findings are that making polluters pay may work better in Europe, and subsidies better in the US.

1790

V18/023320

Contaminated Sites and Environmental Cleanup: International Approaches to Prevention, Remediation, and Reuse

Page, G.W.

Contaminated Sites and Environmental Cleanup: Intemational Approaches to Prevention, Remediation, and Reuse, Academic Press, New York, NY, 230 pp. (January 1, 1997)

This book presents international policy approached to prevent toxic contamination, to perform environmental cleanup of contaminated sites, and to redevelop these sites for productive uses. The book will be useful for students and professionals in academia, industry, and government who are concerned with soil and groundwater contamination, remediation strategies, and environmental policy making. Chapters include: $\mathrm{Ch}$. 1 . The Problem of Contamination and Environmental Cleanup; Ch. 2. Remediation; Ch. 3. Public Health Implications of Contaminated Sites and Environmental Cleanup; Ch. 4. Policies to Prevent Additional Contaminated Sites; Ch. 5. Legal Aspects of the Contamination and Environmental Cleanup Problem; Ch. 6. Economic, Spatial, and Social Aspects of Contamination and Environmental Cleanup; Ch. 7. Contamination and Environmental Cleanup in Developing Countries; Ch. 8. The Superfund Program in the United States; Ch. 9. Contamination and Environmental Cleanup in Western Europe; Ch. 10. The Netherlands Case Study; Ch. 11. Contaminated Sites and Environmental Cleanup in the United Kingdom; Ch. 12. Contamination and Environmental Cleanup in Central and Eastem Europe; and Ch. 13. Concluding Comments on Contamination and Environmental Cleanup Issues.

1791 V18/022615

Control and Remediation of Solvent Pollution in the Dry Cleaning Industry: A Technological Assessment Johnston, J.R.; Hanna, G.P., Jr.; Tchobanoglous, G. Califormia State University, Fresno, CA ; University of California, Department of Civil and Environmental Engineering, Davis, $\mathrm{CA}$

CONF-9505206; Proceedings of the 50th Industrial Waste Conference, R.F. Wukasch (ed.), West Lafayette, IN, May 8-10, 1995. Ann Arbor Press, Inc., Chelsea, MI, 861 pp.; (pp. 555-564) (1996)

Perchloroethylene (PCE) is classified as a toxic air pollutant and it has been found in groundwater in many locations. Dry cleaning establishments have been identified as a source of fugitive atmospheric emissions and it is thought that dry cleaners are an important contributor to groundwater contamination in many locations. Recognizing the environmental problems associated with the dry cleaning industry, the Califomia legislature enacted Assembly Bill 2370 in 1992, which created the California Dry 
Cleaning Industry Task Force. A technical background report on the pollution problems of Califomia's dry cleaning industry was prepared for the Task Force by researchers from Califomia State University Fresno and the University of California, Davis. This paper is extracted from that report. The paper discusses the dry cleaning process and equipment, potential sources of PCE pollution, source controls, remediation of historical pollution, and prevention of future PCE pollution.

\section{2}

\section{V18/022602}

Control of Water Infiltration into Near-Surface, Low-Level Waste-Disposal Units in Humid Regions

O'Donnell, E.; Ridky, R.W.; Schulz, R.K.

U.S. Nuclear Regulatory Commission, Washington, DC; University of Maryland, College Park, MD; University of California, Berkeley, CA

CONF-941 124; Insitu Remediation: Scientific Basis for Current and Future Technologies, G.W. Gee and N.R. Wing (eds.), Proceedings of the 33rd Hanford Symposium on Health and the Environment, Pasco, WA, November 7-11, 1994. Battelle Press, Columbus, OH, Part 1, 704 pp.; (pp. 295-324) (1994)

This study's objective is to assess means for controlling water infiltration through waste-disposal unit covers in humid regions. Experimental work is being performed in large-scale lysimeters (75 $\mathrm{ft} \times 45 \mathrm{ft} \times 10 \mathrm{ft}$ ) at Beltsville, Maryland. Results of the assessment are applicable to disposal of low-level radioactive waste (LLW), uranium mill tailings, hazardous waste, and sanitary landfills. Three kinds of waste-disposal unit covers or barriers to water infiltration are being investigated: (1) resistive layer barrier, (2) conductive layer barrier, and (3) bioengineering management. The resistive layer barrier consists of compacted earthen material (e.g., clay). The conductive layer barrier consists of a conductive layer in conjunction with a capillary break. As long as unsaturated flow conditions are maintained, the conductive layer will wick water around the capillary break. Below-grade layered covers such as (1) and (2) will fail if there is appreciable subsidence of the cover, and remedial action for this kind of failure will be difficult. A surface cover, called bioengineering management, is meant to overcome this problem. The bioengineering management surface barrier is easily repairable if damaged by subsidence; therefore, it could be the system of choice under active subsidence conditions. The bioengineering management procedure also has been shown to be effective in dewatering saturated trenches and could be used for remedial action efforts. After cessation of subsidence, that procedure could be replaced by a resistive layer barrier or, perhaps even better, by a resistive layer barrier/conductive layer barrier system. The latter system would then give long-term effective protection against water entry into waste without institutional care.

1793

$$
\text { V18/022421 }
$$

\section{Cost of Lead-Paint Removal}

King, W.R.

Owens-Coming Corporation, Toledo, $\mathrm{OH}$

Cost Engineering 38(9):31-32 (September 1996)

To many construction managers, paint removal is one of those little annoyances that must be dealt with in the course of a tough day. It doesn't require a lot of thought, other than making sure that the paint comes off in some fashion. However, if managers had a better idea about the dangers associated with paint removal and the costs involved, they might take the job more seriously. The U.S. Occupational Safety and Health Administration's 1993 Lead Exposure Mandate, as published in the U.S. Government's Code of Federal Regulations, requires workers to be protected from airborne lead. This necessitates lead paint removal in preparation for cutting, welding, or burning. Two techniques, chemical stripping and chipping with high-efficiency particulate air vacuuming (HEPA), keep exposure below the lead action level and exempt a general contractor from most worker protection regulations.

\section{4}

\section{V18/025511}

Cost of Public Involvement Lessons Learned: How We Can Reinvest in the Future

Baranski, S.C.; McMullin, K.M.

Equinox Environmental, Inc., Shushan, NY; Equinox Environmental, Inc., Ballston Spa, NY

CONF-960804 (Vol. 2); Spectrum '96: Nuclear and Hazardous Waste Management, Proceedings of an Intemational Topical Meeting, Seattle, WA, August 18-23, 1996. American Nuclear Society, La Grange Park, IL, Vol. 2, 873 pp.; (pp. 1700-1703) (1996)

Throughout the history of environmental remediation and restoration projects, education programs have been viewed as something to develop when the financial climate is good, and something to eliminate when the financial picture declines. Technology and risk are issues that citizens and interested community members have come to be concerned about regardless of the purpose of the project. Many times the public response to an environmental remediation effort is unanticipated. Government and industry representatives often forget that even a "cleanup" effort can cause unrest in a community. Past education and public involvement efforts have been costly, from both a financial perspective and from a public policy and programmatic perspective. Money alone cannot provide education and public involvement opportunities that will enable a project to go forward to completion. Investment in environmental programs and projects for education, public involvement and communication activities has been substantial, from a financial point of view. Investment, from a policy and program success perspective, has not yielded high returns on the investment. One must examine past and current education and public involvement "investments" and where emphasis has been place in development of the programs. In this review, the authors suggest the need to look at the level of investment from the following perspectives: (1) financial, (2) educational opportunity, (3) public involvement opportunity, (4) policy and programmatic success, (5) evaluation of cost and resulting benefit, and (6) reinvesting our financial commitments for the future.

1795 V18/023797

Criteria for Implementing Non-Attainment Zones

Morse, S.I.; Gervason, R.C.; Makdisi, R.S.

Regional Water Quality Control Board, Oakland, CA; Stellar Environmental Solutions, Berkeley, CA

CONF-9504134; HAZMACON '95, T. Bursztynsky and M.L. Loss 
(eds.), Proceedings of the Twelfth Hazardous Materials Management Annual Conference and Exhibition, San Jose, $C A$, April 4-6, 1995. Association of Bay Area Govemments, Oakland, CA, 790 pp.; (pp. 383-393) (1995)

Management and closure of contaminated sites in Califormia may be easier and achievable in the near future through the use of Non-Attainment Zones (NAZ) for groundwater. The two main contaminant classes which are most likely to be subject to the NAZ management strategy are volatile organic compounds (VOC) and total petroleum hydrocarbons (TPH). The NAZ application to VOC sites is a recognition of the technical and economic infeasibility of achieving groundwater cleanup goals in a reasonable time frame. At the fuel Underground Storage Tank (UST) sites NAZ also recognizes those TPH sites where natural attenuation and/or biodegradation may be allowed under certain criteria to be managed rather than be required to continue aggressive cleanup. While several Regional Water Quality Control Boards (RWQCB) have adopted varieties of NAZ, in January 1995 the State Water Resources Control Board (SWRCB) proposed to amend their groundwater cleanup policy (SWRCB Res. No. 92-49) to implement the NAZ concept and to promote state-wide consistency in its application. The draft SWRCB policy amendment is similar to the RWQCBs' proposals, especially those originally developed at the San Francisco Bay (SF Bay) RWQCB. The SWRCB has presented their implementation of the NAZ concept utilizing two scenarios: Category $A$ - an approved fully implemented cleanup plan has resulted in extracted groundwater contaminant concentrations reaching asymptotic levels above the water quality objectives and further reductions in groundwater concentrations cannot be reasonably achieved; and Category B - sites with limited water quality, environmental and human health risks, where cleanup to water quality objectives cannot be reasonably achieved, remedies have been evaluated and implemented to the extent reasonable, and residual soil and groundwater pollution are contained and managed. Category A sites will typically be associated with higher-risk sites or the more persistent VOC contaminants while Category B sites would typically be contaminated by TPH. Experiences implementing NAZ, NAZ case studies for a VOC Category A site and a TPH Category B. site, and opportunities to optimize NAZ are presented.

\section{6}

V18/022020

\section{Plasma Arc Melter Technology for Waste} Vitrification

Hamilton, R.A.; Wittle, J.K.; Trescot, J.

Electro-Pyrolysis, Inc., Wayne, PA; Kennedy Van Saun, Danville, PA

CONF-9510125 (Vol. 1); Plasma Systems and Applications, P.W. Mayne and J.A. Mulholland (eds.), Proceedings of an International Symposium on Environmental Technologies, Atlanta, GA, October 8-11, 1995. Georgia Institute of Technology, Atlanta, GA, Vol. 1, 335 pp.; (pp. 67-76) (1995)

This paper describes the features and benefits of a breakthrough DC Arc Melter for the permanent treatment of all types of solid wastes including nonhazardous, hazardous and radioactive. This DC Arc Furnace system, now commercially available, is the low cost permanent solution for solid waste pollution prevention and remediation. Concern over the effective disposal of wastes generated by our industrial society; worldwide, has prompted development of technologies to address the problem. For the most part these technologies have resulted in niche solutions with limited application. The only solution that has the ability to process almost all wastes, and to recover/recycle metallic and inorganic matter, is the group of technologies known as melters. Melters have distinct advantages over traditional technologies such as incineration because melters operate at higher temperatures, are relatively unaffected by changes in the waste stream, produce a vitrified stable product, and have the capability to recover/recycle slag, metals, and gas. The system, DC Plasma Arc Melter, has the lowest capital, maintenance and operating cost of any melter technology because of its patented DC Plasma Arc with graphite electrode. DC Plasma Arc Melter systems are commercially available in sizes from 50 $\mathrm{kg} / \mathrm{batch}$ or $250-3,000 \mathrm{~kg} / \mathrm{hr}$ on a continuous feed basis. This paper examines the design and operating benefits of a DC Plasma Arc Melter System.

\section{7 \\ V18/023579}

\section{DOD, DOE Clean-Up Efforts Promising}

Rose, D.

Environmental Protection 5(1):58-64 (January 1994)

Scattered across the United States are federal facilities that were used to help defend this country and develop its energy resources. Now that those strategies have changed, the Departments of Defense and Energy have tapped new technologies to remediate numerous sites.

1798

V18/022739

Decontamination and Remediation of an Industrial Forest: Case Study in Belarus

Grebenkov, A.J.; Jouve, A.; Arapis, G.; Solovjov, V.N. Academy of Sciences, Institute of Power Engineering Problems, Minsk, Belarus; Institut de Protection et de Surete Nucleaire, Cadarache, France; Agricultural University of Athens, Athens, Greece

CONF-960804 (Vol. 1); Spectrum '96: Nuclear and Hazardous Waste Management, Proceedings of an International Topical Meeting, Seattle, WA, August 18-23, 1996. American Nuclear Society, La Grange Park, IL, Vol. 1, 887 pp.; (pp. 878-884) (1996)

Pilot and demonstrative scale in situ trials of several decontamination technologies proposed were carried out in a real forest contaminated as a result of the Chernobyl Accident. The data obtained have proved that industrial scale decontamination of various types of forest land is feasible in some specific cases of concern. The management of radioactive waste arising from decontamination techniques can be provided by ecologically sound and cost effective technologies.

\section{9}

\section{V18/022404}

\section{Decontamination in a Russian Settlement}

Roed, J.; Lange, C.; Andersson, K.G.; Prip, H.; Olsen, S.; Ramzaev, V.P.; Ponamarjov, A.V.

Risoe National Laboratory, Roskilde, Denmark

RISO-R-870(EN); 105 pp. (March 1996)

Decontamination was carried out in and around three houses in 
Novo Bobovichi, Russia, in the autumn of 1995. It was demonstrated that significant reductions in the dose rate both indoor $(\mathrm{DRF}=0.34$ ) and outdoor $(\mathrm{DRF}=0.20)$ can be achieved when a careful cleaning is undertaken. This report describes the decontamination work carried out and the results obtained. The roofs of the houses were swept and cleaned by special roof cleaning equipment. The soil around the houses was removed by hand while carefully monitoring the ground for residual contamination. By monitoring the decline in the dose rate during the different stages of the work the dose reducing effect of each action has been estimated. This report also describes a test of a triple digging method that reduces the dose rate without generating waste. In the appendices of the report the measurement data is available for further analysis.

1800

V18/022798

Decontamination of the Populated Areas Contaminated as a Result of Nuclear Accident

Voronik, N.I.; Davydov, Y.P.; Shatilo, N.N.

Academy of Sciences, Institute of Radioecological Problems, Minsk, Belarus

CONF-960804 (Vol. 3); Spectrum '96: Nuclear and Hazardous Waste Management, Proceedings of an International Topical Meeting, Seattle, WA, August 18-23, 1996. American Nuclear Society, La Grange Park, II, Vol. 3, 841 pp.; (pp. 1712-1716) (1996)

Decontamination tests on urban surfaces contaminated by the Chemobyl accident have shown that Chernobyl fallout behaves differently from fallout from nuclear weapons tests and contamination on surfaces in nuclear power plant. The variety of physical and chemical properties of materials, the form of radionuclide contamination, different depth of spread of radionuclides inside of materials and other things demand use of a wide gamut of technologies, methods and special technical means for effective decontamination. The objective of this paper is to report the results of laboratory and field experiments on various decontamination methods for removing Chernobyl fallout from the surfaces of urban buildings and machinery.

\section{1}

V18/020926

\section{Decontamination of the Territory of Belarus} Contaminated with Radionuclides as a Result of the Chernobyl Accident

Sharovarov, G.A.; Bykov, A.I.; Veretennikov, V.G.; Yatsko, S.I.; Antsypov, G.V.; Shaternik, R.A.

Academy of Sciences, Institute of Radioecological Problems, Minsk, Belarus; Ministry for Emergencies and Protection of the Population, Minsk, Belarus

CONF-960212; Waste Management '96: Working Towards a Cleaner Environment, Proceedings of a Conference on $\mathrm{HLW}$, LLW, Mixed Wastes and Environmental Restoration, Tucson, $A Z$, February 25-29, 1996; (23 pp.) (1996)

The total area of the territory of Belarus contaminated with radionuclides amounts to 46.5 thousand sq kilometers. It is more than $20 \%$ of the whole territory. There are 3668 populated areas in it. After the Chemobyl accident Belarus has become a zone of ecological disaster. On the basis of the special features of the accident, the following conclusions should be made: (1) In Belarus the tactics of observation and changing the residence have been mainly carried out. The large-scale decontamination of the territories has not been carried out. (2) The scale of decontamination is to be determined by cost-benefit analysis methods. The criteria of the density of decontamination, dose rates, etc., are only the internal parameters of the methods. They do not determine the expediency of the decontamination works. (3) Taking into account the high cost of decontamination, it is advisable to create international standard computational programs for "cost-benefit" analysis. (4) It is necessary to unite international efforts for development of the efficient technologies on clean-up of the soil, forest areas and water systems. (5) It is advisable to create an intemational data base on technologies and methods of decontamination of large territories.

\section{2}

\section{V18/024853}

Defense Environmental Restoration Program: Annual Report to Congress for Fiscal Year 1995: Volume 1 of 2

\section{U.S. Department of Defense, Washington, DC}

Report; 65 pp. (March 11, 1996)

As stewards of nearly 25 million acres of land in the United States, and with daily operations and activities that affect the quality of the nation's air, water, soil, and cultural treasures, the Department of Defense (DoD) takes seriousily its responsibility to protect the environment and use natural resources wisely. DoD's extensive environmental efforts and initiatives reflect the Department-wide commitment to cleaning up sites contaminated by past operations. Because DoD's ultimate mission is to protect the nation, protecting natural resources and preserving public health must be an intrinsic and vital part of every DoD effort. DoD's stewardship approach has evolved in recent years, and the goals of the environmental restoration program have been clarified to ensure the best use of precious resources and the greatest possible protection of human health and the environment. This volume provides narrative examples of how DoD is getting the job done and institutionalizing the restoration program within the framework of the planning, programming, and budgeting system process.

1803 .

$$
\text { V18/024854 }
$$

Defense Environmental Restoration Program: Annual Report to Congress for Fiscal Year 1995: Volume 2 of 2 U.S. Department of Defense, Washington, DC Report; 54 pp. (May 15, 1996)

FY95 was a year of transition for prioritizing work and measuring progress using the relative risk site evaluation methodology. Initial baseline relative risk data are presented in this report. In fiscal year 1995 (FY95), the Department of Defense (DoD) made significant strides in its environmental restoration program. Volume 1 of the Defense Environmental Restoration Program Annual Report to Congress for FY95 provides an in-depth discussion of the current state and future outlook of the program. Volume 1 also examines how DoD is making an investment in environmental restoration and maximizing the retum on that investment. This volume of the FY95 Annual Report presents highlights from Volume 1 and also presents quantitative information and analysis conceming the funding, status, and progress of the program, along with the 
installation-specific narratives and data tables.

1804

V18/021523

Designing Successful Remediation Programs at Unique Sites

Golightly, W.D.

Kleinfelder, Inc., Sacramento, CA

CONF-951124; HazMat West '95, Proceedings of the Eleventh Annual Environmental Management and Technology Conference and Exhibition, Long Beach, CA, November 7-9, 1995. Advanstar Expositions, Duluth, MN, 597 pp.; (pp. 377-385) (1995)

Successful environmental remediation programs have three common components: (1) adequate characterization of the extent of the problem, (2) selection of an effective remedial approach, and (3) appropriate design of a remediation system. Without all three components, even the most straightforward remediation program can encounter time delays, budget overruns, and technologic failure. This paper presents a retrospective view of a petroleum hydrocarbon remediation project at a fueling facility where failure to adequately characterize the nature and extent of contamination resulted in the oversight of unique site characteristics. Budget limitations early in the project prevented the performance of several tasks that would have yielded valuable data regarding unique characteristics of the site and the extent and nature of the contamination. These data could have been used to design a more appropriate remediation system which would have addressed the unique circumstances at the site. Additional contamination encountered during the confirmatory sampling activities prevented the site from attaining regulatory closure and elevated regulatory agency involvement.

\section{5}

\section{V18/023213}

Determining Effective Technology Transfer Mechanisms: A Case Study in the Russian Federation Colangelo, R.V.; Reistroffer, E.; Edgar, D.E.; Johnson, D.O. Environmental Planning Group, Inc., Elk Grove Village, IL; Argonne National Laboratory, Argonne, IL

CONF-9210194; Proceedings of an International Symposium on Environmental Contamination in Central and Eastern Europe, Budapest, Hungary, October 12-16, 1992, 968 pp.; (pp. 404-406) (1992)

In order to transfer technology efficiently, it is essential to define the cultural context in which the technologies have been developed and currently reside. As a participant in the International Technology Exchange Program (ITEP), the Environmental Planning Group, Inc. (EPG), had the opportunity to study environmental and energy programs in Russia. EPG found that the unstable political situation in Russia, the inadequate funding in the Russian scientific community, and the withdrawal of government support for research have created new opportunities for accessing technology. EPG concluded that knowledge of the structure of the government and the organization of the scientific community and an understanding of current business practices are fundamental to the creation of successful technology transfer mechanisms.
Development of International Criteria for the Clean-Up of Contaminated Areas

Gnugnoli, G.; Linsley, G.; Stegnar, P.

International Atomic Energy Agency, Vienna, Austria

CONF-970335; Waste Management '97: Working Towards a Cleaner Environment, Proceedings of a Conference on $\mathrm{HLW}$, LLW, Mixed Wastes and Environmental Restoration, Tucson, AZ, March 2-6, 1997; (5 pp.) (1997)

In the past, radiation protection has been concerned primarily with establishing the conditions that should be applied to the introduction of new practices and the management of continuing practices. There are two other types of situations which may need to be considered. These are contamination from past practices, which may be discovered well after a practice is discontinued at a particular site, or when an accident occurs that leads to chronic exposures due to the resulting contamination. In order to bring such environmental contamination situations to a state in which they can be safely occupied and utilized, some remedial actions may be necessary, such as removal, cover and/or mixing of radioactive materials in soil, treatment of ground and surface waters, and the decontamination of structures. Over the last three years, an IAEA working group has been developing radiological principles for use in decisions related to the clean-up of contaminated areas. More specifically, it has been attempting to establish an approach to developing radiological criteria for clean-up and to recommend ranges of generically applicable numerical values. The draft guidance produced by this working group is about to be circulated within the international community of experts in this field for comment.

1807

V18/021672

Development of Treatment Trains for a Remediation Demonstration Project at Former Missile Sites

Avotins, J.; Kokars, V.; Ouellette, L.; Whittaker, H.

Environment Canada, Ottawa, Ontario, Canada; Rizhskij Politekhnicheskij Institute, Riga, Latvia; Environment Canada, Emergencies Engineering Division, Ottawa, Ontario, Canada

CONF-9606262; Proceedings of the 13th Technical Seminar on Chemical Spills, Calgary, Alberta, Canada, June 10-11, 1996. Environment Canada, Ottawa, Ontario, Canada, 396 pp.; (pp. 1-9) (1996)

The remediation of a former missile site in Latvia is discussed. Soil and water at the coastal site were contaminated with toxic chemicals, and a large scale clean-up operation was required to return the land to safe use. A joint project between Canada and Latvia was set up to conduct an environmental assessment of the area. Concentrations of the xylidine-based missile fuel SAMIN were found to reach a few thousand ppm, while oil products were found to reach estimated levels of $6,000-7,000 \mathrm{ppm}$. Xylidine is toxic at concentrations as low as $2 \mathrm{ppm}$ by inhalation and skin contact. $A$ pilot-scale treatment train was built and is planned for use during a remediation pilot project to be conducted in August 1996. The technologies studied included soil washing, solvent extraction, and low temperature thermal desorption. Steam stripping and advanced oxidation were considered to rehabilitate the contaminated groundwater. The materials and methods for each technology are described. A new multi-stage treatment process for 
xylidine-contaminated soil and water was developed, in which the outputs were xylidine salts, cleaned water and cleaned soil.

1808

\section{V18/022041}

Disposable Cuvette Test for Enzymatic Determination of Heavy Metals

Wolfbeis, O.S.; Preininger, C.

Karl-Franzens University, Institute of Organic Chemistry, Graz, Austria

CONF-9506232; Environmental Monitoring and Hazardous Waste Site Remediation, T. Vo-Dinh and R. Niessner (eds.), Proceedings of a Conference of the Society of Photo-Optical Instrumentation Engineers, Munich, Germany, June 19-23, 1995. International Society for Optical Engineering, Bellingham, WA, 613 pp.; (p. 140) (1995)

We report on an optical cuvette test for total heavy metals based on the inhibition of the enzyme urease by metals ions including silver(I), mercury(II), copper(II), nickel(II), cobalt(II), and cadmium(II). The enzymatic action is monitored using an optical ammonia transducer deposited on the wall of a disposable cuvette. This results in a rapid and inexpensive single-shot device for heavy metal sensing. A solution of urease and buffer is placed in the cuvette with the ammonium sensor membrane fixed on one of its walls. Enzymatic action starts after addition of a defined quantity of urea. This is indicated by the increase in the absorption of the ammonia sensor membrane whose color changes from yellow to blue. The slope of the increase in signal is the information for the un-inhibited reaction. After several minutes, the sample (containing the heavy metal) is added to the cuvette. Heavy metal ions inhibit the enzyme (by binding to the sulfhydryl groups) and cause a decrease in the slope. The ratio of slopes of un-inhibited and inhibited reactions is a direct parameter for detecting and calculating total heavy metals. The optimum $\mathrm{pH}$ was a trade-off between optimum enzyme activity ( $\mathrm{pH} 7$ at 25 degrees $\mathrm{C}$ ) and the relative signal change of the ammonia-sensor (highest at pH 8). pH 7.5 was found to be optimal. The system was calibrated at optimized activities of urease (1.5 $u)$ and an optimized urea concentration (0.5 mmol). Heavy metals inhibit in the following order: $\mathrm{Ag}(\mathrm{I})$ more than $\mathrm{Hg}$ (II) more than $\mathrm{Cu}$ (II) much much more than Ni(II) more than $\mathrm{Co}$ (II) more than $\mathrm{Cd}(\mathrm{II})$ more than $\mathrm{Fe}$ (III) more than $\mathrm{Pb}$ (II) or $\mathrm{Zn}(\mathrm{II})$. The following concentrations that cause $50 \%$ inhibition were found: $\mathrm{Ag}(\mathrm{I})(0.1 \mathrm{ppm}), \mathrm{Hg}(\mathrm{II})(0.5 \mathrm{ppm}), \mathrm{Cu}(\mathrm{II})(0.5 \mathrm{ppm})$, $\mathrm{Ni}(\mathrm{II})(7 \mathrm{ppm}), \mathrm{Co}$ (II) (30 ppm), Cd(II) (95 ppm), Fe(III) (50 $\mathrm{ppm}), \mathrm{Zn}(\mathrm{II})(85 \mathrm{ppm})$ and $\mathrm{Pb}$ (II) (210 ppm). We also studied the inhibitory effect of combinations of metal ions, the influence of ionic strength, and the effect of incubation time.

1809

\section{V18/024059}

Disposal of Waste from the Cleanup of Large Areas Contaminated as a Result of a Nuclear Accident

International Atomic Energy Agency, Vienna, Austria

IAEA Technical Reports Series No. 330; 69 pp. (1992)

The purpose of this report is to give guidance to Member States on the means for safe loading, transport and disposal of large volumes of contaminated material which could arise from the cleanup of areas contaminated as a result of a serious accident at a nuclear facility.
1810

V18/021363

Division of Solid Waste Management (DSWM) Addresses Its Application of Health-Based Levels

Goddard, J.A.; Thomas, G.S.; McCarty, W.L.

Bass, Berry and Sims, Environmental Law Department, Nashville, TN

Environmental Law Letter 8(2):16 (March 1996)

This memorandum is intended to provide guidance to the State of Tennessee Division of Solid Waste Management's Field Offices regarding the application of RCRA Facility Investigation Health Based Criteria to establish "no further action" leveis for remediation sites. These levels are being utilized by the Division in accordance with the December 4, 1995, clarification of policy memo issued by the Director of the Division. The memorandum gives a brief summary of the steps involved in determining the appropriate level of contamination that may be left in place at a site with no adverse health or environmental impact.

1811

V18/021364

Division of Solid Waste Management (DSWM) Revises Policy Concerning Remediation Levels Goddard, J.A.; Thomas, G.S.; McCarty, W.L.

Bass, Berry and Sims, Environmental Law Department, Nashville, TN

Environmental Law Letter 8(2):15 (March 1996)

This memorandum is a Statement of Policy regarding the State of Tennessee Division of Solid Waste Management's remediation levels for media contaminated by hazardous constituents. Since 1988, the Division has been utilizing the RCRA Facility Investigation Health Based Criteria (EPA document \#530/SW-89-031, Chapter 8, published May 1989), to establish "no further action" levels for remediation sites. The Division's State Remediation Section (SRS) routinely updates a listing of the available levels. When contaminants are encountered that are not in the listing, the SRS should be contacted and they will work with EPA's Region IV Toxicology Section to establish the appropriate level.

1812

V18/024343

Dock Sud Environmental Remediation and Pollution Abatement Project: Final Report - Volume 8, Annexes 2 and 3

Brown and Caldwell, Pleasant Hill, CA

Report; 328 pp. (February 1, 1997)

The objectives of this study are to evaluate the extent of infrastructural and environmental impacts, identify potential regulatory standards and technical solutions, and evaluate the feasibility of proposed solutions for the remediation and abatement of pollution in the Dock Sud area. Volume 8 contains Annexes II and III to the main report.

1813 V18/024344

Dock Sud Environmental Remediation and Pollution Abatement Project: Final Report - Volume 7, Annex 1 
Brown and Caldwell, Pleasant Hill, CA

Report; 134 pp. (February 1, 1997)

The objectives of this study are to evaluate the extent of infrastructural and environmental impacts, identify potential regulatory standards and technical solutions, and evaluate the feasibility of proposed solutions for the remediation and abatement of pollution in the Dock Sud area. Volume 7 is Annex I to the main report.

1814

V18/024345

Dock Sud Environmental Remediation and Pollution Abatement Project: Final Report - Volume 6, Chapters 6 and 7

Brown and Caldwell, Pleasant Hill, CA

Report; 80 pp. (February 1, 1997)

The objectives of this study are to evaluate the extent of infrastructural and environmental impacts, identify potential regulatory standards and technical solutions, and evaluate the feasibility of proposed solutions for the remediation and abatement of pollution in the Dock Sud area. Volume 6 includes Chapter 6 and Chapter 7. Chapter 6 covers the following topics: (1) Financial Strategies; (2) Project Financing Alternatives; (3) Financial Model for the Environmental Regulatory Agency; and (4) Fines and Financing Design of the Regulator. Chapter 7 contains the following sections: (1) Infrastructure Evaluation and Requirements and (2) Environmental Projects.

\section{5}

\section{V18/024346}

Dock Sud Environmental Remediation and Pollution Abatement Project: Final Report - Volume 5, Chapter 5 and Appendix D

Brown and Caldwell, Pleasant Hill, CA

Report; 163 pp. (February 1, 1997)

The objectives of this study are to evaluate the extent of infrastructural and environmental impacts, identify potential regulatory standards and technical solutions, and evaluate the feasibility of proposed solutions for the remediation and abatement of pollution in the Dock Sud area. Volume 5 includes: (1) Pollution Prevention, (2) Remediation, and (3) Appendix D.

\section{6}

V18/024347

Dock Sud Environmental Remediation and Pollution Abatement Project: Final Report - Volume 4, Chapters 3 and 4 and Appendix $C$

Brown and Caldwell, Pleasant Hill, CA

Report; 193 pp. (February 1, 1997)

The objectives of this study are to evaluate the extent of infrastructural and environmental impacts, identify potential regulatory standards and technical solutions, and evaluate the feasibility of proposed solutions for the remediation and abatement of pollution in the Dock Sud area. Volume 4 contains Chapter 3 , Chapter 4, and Appendix C. Chapter 3 sections include: (1) Risk-Based Criteria; (2) Hazard Identification; (3) Exposure Assessment; (4) Ecological Risk Assessment; and (5) Cost/Benefit Analysis. Chapter 4 sections are: (1) Regulatory Recommendations and (2) Media-Specific Recommendations.

1817 V18/024348

Dock Sud Environmental Remediation and Pollution Abatement Project: Final Report - Volume 3, Chapter 2 and Appendix B

Brown and Caldwell, Pleasant Hill, $\mathrm{CA}$

Report; 263 pp. (February 1, 1997)

The objectives of this study are to evaluate the extent of infrastructural and environmental impacts, identify potential regulatory standards and technical solutions, and evaluate the feasibility of proposed solutions for the remediation and abatement of pollution in the Dock Sud area. Volume 3 contains Chapter 2 and Appendix B. Chapter 2 is divided into the following sections: (1) Study Area Characterization; (2) Facility Profile Development; (3) Field Investigation Activities; and (4) Field Investigation Results. Appendix B includes laboratory results, chain of custody, groundwater sample collection records, and summary results tables.

1818

V18/024349

Dock Sud Environmental Remediation and Pollution Abatement Project: Final Report - Volume 2, Chapter 1 and Appendix $A$

Brown and Caldwell, Pleasant Hill, CA

Report; 263 pp. (February 1, 1997)

The objectives of this study are to evaluate the extent of infrastructural and environmental impacts, identify potenual regulatory standards and technical solutions, and evaluate the feasibility of proposed solutions for the remediation and abatement of pollution in the Dock Sud area. Volume 2 contains Chapter I and Appendix A. Chapter 1 is divided into the following secuons (1) Regulatory Initiatives; (2) Comparison of the Provincial and Federal Environmental Management Programs; (3) Comparison of the Provincial System to Intemational Environmental Programs; (4) Remediation of Contaminated Soil and Groundwater; and (5) Monitoring, Compliance, and Enforcement. Appendix A contains the Legislation Report.

1819

V18/024350

Dock Sud Environmental Remediation and Pollution Abatement Project: Final Report - Volume 1, Executive Summary

Brown and Caldwell, Pleasant Hill, CA

Report; 63 pp. (February 1, 1997)

The objectives of this study are to evaluate the extent of infrastructural and environmental impacts, identify potential regulatory standards and technical solutions, and evaluate the feasibility of proposed solutions for the remediation and abatement of pollution in the Dock Sud area. Volume 1 is divided into: (1) Introduction; (2) Summary of Recommendations; and (3) Summary of Findings.
1820
V18/025467

Ecological Risk Assessment for Radionuclides and Metals: A Radiological and Chemical Approach 
Mahini, X.; Mahini, R.; Fan, A.

Ogden Environmental and Energy Services Company, San Francisco, CA; Electric Power Research Institute, Palo Alto, $\mathrm{CA}$; California Environmental Protection Agency, Berkeley, $\mathrm{CA}$

CONF-961149; SETAC 17: Partnerships for the Environment Science, Education, and Policy, Proceedings of the 17th Annual Meeting of the Society of Environmental Toxicology and Chemistry, Washington, DC, November 17-21, 1996. Society of Environmental Toxicology and Chemistry, Pensacola, FL, 378 pp.; (pp. 96-97) (1995)

In response to the regulatory concem over the adverse effects of depleted uranium (DU) on ecological receptors at two sites contaminated with DU and metals, an ecological risk assessment (ERA) was performed, in conjunction with a radiological/chemical human health risk assessment (HRA). To date, most research on the harmful effects of radiation has focused only on humans. With regard to radiation protection of the environment, national and international radiation protection advisory committees have concluded that levels protecting human health should be sufficient to protect the environment as well. To select chemicals of potential ecological concern, a qualitative ERA was first performed by comparing chemical stressor concentrations in abiotic media with various benchmarked criteria. The results indicate that, as with the case of human health, DU was the ecological risk-driving chemical at these sites. Both radiological and chemical effects posed by $D U$ were then estimated for the bald eagle, an endangered species that represents the assessment end point of the quantitative ERA. Abiotic media and food webs evaluated were: soils, surface water, plants, terrestrial (both mammalian and avian) species, and aquatic species. The results of the quantitative ERA indicate that the decision to cleanup DU contamination at these sites can solely be based on human health effects as limiting criteria. The risk assessments were well received by the regulatory agencies overseeing the project.

V18/024174

\section{Ecological Risk Assessment of a Decommissioned} Military Base

Starodub, M.E.; Feniak, N.A.; Willes, R.F.; Moore, C.E.; Mucklow, L.; Marshall, L.

CanTox, Inc., Mississauga, Ontario, Canada; CanTox, Inc., Halifax, Nova Scotia, Canada

CONF-961149; SETAC 17: Partnerships for the Environment Science, Education, and Policy, Proceedings of the 17th Annual Meeting of the Society of Environmental Toxicology and Chemistry, Washington, DC, November 17-21, 1996. Society of Environmental Toxicology and Chemistry, Pensacola, FL, 378 pp.; (pp. 300-301) (1996)

The ecological health risks to selected terrestrial animals at a decommissioned military base in Atlantic Canada have been assessed. Areas of the base varied in terms of terrain, ground cover, as well as types and extent of contamination, dependent on former uses of the sites. Analysis of surficial soils, sediments, water and fish tissue at the base indicated contamination by metals, PCBs, and various petroleum products and their constituents. Identification of chemicals of concem was based on these analyses, in conjunction with detailed chemical selection procedures. Exposures to chemicals of concern for ecological receptors were assessed in one of two ways. The exposures of moose, snowshoe hare and meadow vole were estimated in areas with surficial contamination, based on expected exposures to environmental media via oral inhalation, and dermal routes of exposure. For two top predators (mink and bald-headed eagle), exposures to bioaccumulative chemicals (cadmium, lead, mercury and $\mathrm{PCBs}$ ) via transport through the aquatic and/or terrestrial food chain were estimated. A toxicological assessment was conducted for the chemicals of concern to yield exposure limits derived from governmental regulations or developed based on no-observed-effect-levels (NOELs) reported in scientifically sound toxicological assays in relevant species. The risk evaluation of each chemical of concern was conducted as a comparison of the estimated total exposures to the exposure limits derived for the selected ecological receptors.

1822

V18/022790

Ecological-Commerce (ECO-COM) Zone Concept for Developing Biomass Energy from Contaminated Resources: A New Demonstration Zone for the Republic of Belarus

McCarn, D.W.; Dubovik, L.; Iakoushev, A.; Grebenkov, A.J.

Innovative Projects International, Albuquerque, NM; Committee on Energy Efficiency and Control, Minsk, Belarus; Academy of Sciences, Institute of Power Engineering Problems, Minsk, Belarus

CONF-960804 (Vol. 2); Spectrum '96: Nuclear and Hazardous Waste Management, Proceedings of an International Topical Meeting, Seattle, WA, August 18-23, 1996. American Nuclear Society, La Grange Park, IL, Vol. 2, 873 pp.; (pp. 1417-1424) (1996)

Following the Chernobyl Accident, about 17,000 sq km of forested area in the Gomel Oblask of Belarus was contaminated with radioactive material. Remediation and productive utilization of these resources is proposed through the use of the forest biomass as a source of energy. A short list of projects is presented at the end of this report that meet basic infrastructural, economic, industrial, and energy savings activities permitting the rapid payback of investments. This list was compiled for ECO-COM and recommended by the Ministry of Energy Savings in the framework of the Energy Efficiency 2000 (EE 2000) Demonstration Zone program adopted for Belarus.

1823

V18/023321

Ecotoxicity and Human Health: A Biological Approach to Environmental Remediation

Ecotoxicity and Human Health: A Biological Approach to Environmental Remediation, F.J. De Serres and A.D. Bloom (eds.), Lewis Publishers, Inc., Chelsea, MI, 336 pp. (September 1, 1995)

No abstract available.

1824 V18/024656

Elda Center - An Innovative Concept in Soil Recycling Using Bioremediation

Hater, G.R.; Gillenwater, P.S.; Li, A.Y.; Start, J. 
Waste Management Inc. Biosites, Cincinnati, OH; Rust Environment \& Infrastructure, Naperville, IL

Bioremediation of Pollutants in Soil and Water, B.S. Schepart (ed.), Proceedings of a Symposium, Fort Worth, TX, October 14-15, 1993. American Society for Testing and Materials (ASTM), Philadelphia, PA, 265 pp.; (pp. 227-232) (May 1995)

The ELDA Soil Center, operated by Waste Management, Inc., uses soil pile bioremediation to treat and destroy non-RCRA petroleum contamination in soils. Soil pile bioremediation is a simple and cost-effective method for remediating contaminated soils. This bioremediation Technology uses vacuum to provide continuous aeration to contaminated soil that has been excavated and inoculated with nutrients and contaminant-specific bacterial cultures. The center, which is located at a solid waste landfill in Cincinnati, Ohio, produces clean soils that can be recycled either as daily cover at the landfill or as backfill at off-site locations. To date, two soil piles, each with 15,000 cu yd capacity, have been constructed at the ELDA landfill. The Soil Center is capable of recycling in excess of 250,000 tons per year of petroleum contaminated soils. This cost-competitive off-site remediation alternative was designed to meet the needs of customers with contaminated soil resulting from leaking underground petroleum storage tanks. Current EPA estimates are that one-third of these tanks are leaking nationwide. The ELDA Soil Center provides the low-cost solution that is needed to treat the large quantities of organic contaminated soil generated by these leaking tanks.

\section{5}

V18/024302

Enhanced $U$ and Th Concentrations in Soils from a Wet Marshland Washed by Contaminated Riverwaters

Martinez-Aguirre, A.; Garcia-Orellana, I.; Garcia-Leon, M. Seville University, Facultad de Fisica, Seville, Spain CONF-9510424; Proceedings of an International Committee for Radionuclide Metrology Conference on Low-Level Measurement Techniques, Seville, Spain, October 2-6, 1995; Applied Radiation and Isotopes 47(9-10):1081-1087 (September-October 1996)

A study of the presence of $U$ and $T h$ isotopes in soil samples from a saline wet marshland located close to a phosphoric acid production factory is presented. The samples were collected during low tide in areas washed by water during high tide. The incoming Odiel riverwaters, which directly receive the wastes from this factory, provokes the enhancement of radioactivity in certain zones of the studied area. Comparison of radionuclide concentrations between the fine particle fraction (greater than or equal to $63.5 \mathrm{um}$ ) and the total soil fraction has given some hint on the processes by which contamination takes place.

\section{6 \\ V18/021064}

Ensuring Environmentally Clean Disposal of Energetics Johnson, M.B.; Bacon, D.P.

U.S. Army, Dugway Proving Ground, Utah

CONF-940499 (Vol. 1); Proceedings of the 1994 Federal

Environmental Restoration III and Waste Minimization II

Conference and Exhibition, New Orleans, LA, April 27-29, 1994.

Hazardous Materials Control Resources Institute, Rockville, MD, Vol. 1, 783 pp.; (pp. 313-320) (1994)
The Department of Defense, recognizing the need to dispose of munitions without injuring the environment, has developed a testing system to characterize the emissions produced by open-air burning of propellants and detonation of explosives. This system, which has been successfully audited by the U.S. Environmental Protection Agency (U.S. Environmental Protection Agency), employs a unique assembly of leading technologies and has proven to be sensitive, accurate, rapid, and relatively inexpensive. Although specifically designed for testing energetic munitions, it holds considerable potential for use in characterizing the combustion products of a wide variety of government and commercial energetic and nonenergetic waste products. This paper describes the system's evolution, components, and enhancement for the testing of shrapnel-producing munitions; a synopsis of testing programs; other potential applications; and anticipated inclusion of future testing-system developments in the Federal technology-transfer program.

V18/023341

Environmental Concerns, Public Policies, and Remediation Technologies: Proceedings of the Third Annual Conference, American Society of Environmental Sciences, September 24-25, 1993, Baton Rouge, LA

Environmental Concerns, Public Policies, and Remediation Technologies, Proceedings of the Third Annual Conference, American Society of Environmental Sciences, September 24-25, 1993, Baton Rouge, LA; 310 pp. (1993)

No abstract available.

\section{8 \\ V18/021701}

Environmental Protection: Status of Defense Initiatives for Cleanup, Compliance, and Technology

U.S. General Accounting Office, National Security and International Affairs Division, Washington, DC

GAONSIAD-96-155; 34 pp. (August 2, 1996)

The Department of Defense (DOD) is responsible for managing and caring for thousands of military installations and defense sites throughout the United States and overseas. Its operations are subject to the same environmental, safety, and health laws and regulations as private industry, as well as additional requirements for federal facilities. The day-to-day operations and activities of a typical military installation generally mirror those of a small city. As a result, DOD installations face most of the same environmental problems confronting our nation's industrial and commercial sectors. To achieve its environmental mission, DOD organized its $\$ 5$ billion environmental program into five elements: cleanup, compliance, conservation, pollution prevention, and technology. This report addresses three of these elements: cleanup (remediation), which includes identification, investigation, and cleanup of contamination from hazardous substances and waste on active and formerly used DOD land (cleanup has been funded primarily through centralized accounts for defense environmental restoration and for Base Realignment and Closure (BRAC); compliance with environmental laws and regulations of federal, state, and local jurisdictions; and technology, under which DOD invests in research, development, demonstration, and validation of 
new technologies to support the other elements of its program.

1829

V18/022296

Environmental Radiation Measurements at the Former Soviet Union's Semipalatinsk Nuclear Test Site and Surrounding Villages

Shebell, P.; Hutter, A.R.

Environmental Measurements Laboratory, New York, NY

EML-584; 34 pp. (July 1996)

Two scientists from the U.S. Department of Energy's Environmental Measurements Laboratory served as scientific experts to the International Atomic Energy Agency's (IAEA) Mission to Kazakhstan: Strengthening Radiation and Nuclear Safety Infrastructures in Countries of the former USSR, Special Task Preassessment of the radiological situation in the Semipalatinsk and western areas of Kazakhstan. The former Soviet Union's largest nuclear test site was located near Semipalatinsk, Kazakhstan, and following Kazakhstan's independence, the IAEA committed to studying the environmental contamination and the resulting radiation exposure risk to the population due to 346 underground, 87 atmospheric and 26 surface nuclear detonations performed at the site between 1949 and 1989. As part of an 11-member team, environmental radiation measurements were performed during 2 weeks in July 1994. Approximately 30 sites were visited both within the boundaries of the Semipalatinsk nuclear test site as well as in and around surrounding villages. Specifically, the objectives of the EML team were to apply independent methods and equipment to assess potential current radiation exposures to the population. Towards this end, the EML scientists collected in-situ gamma-ray spectra, performed external gamma dose rate measurements using pressurized ionization chambers, and collected soil samples in order to estimate the inventory and to determine the depth distribution of radionuclides of interest. With the exception of an area near an "atomic lake" and a $1 \mathrm{sq} \mathrm{km}$ area encompassing ground zero, all the areas visited by the team had external dose rates that were within typical environmental levels. The measurements taken within a 15 $\mathrm{km}$ radius of ground zero had elevated levels of Cs-137 as well as the activation products Eu- 152 and $\mathrm{Co}-60$. The dose rate within a $1 \mathrm{~km}$ radius of ground zero ranged from 500 to $30000 \mathrm{nGy} \mathrm{h-1.}$

\section{$1830 \quad$ V18/022222}

Environmental Remediation and Waste Management in the United States

Muntzing, L.M.; Person, J.C.

Associacao Brasileira de Direito Nuclear, Rio de Janeiro, Brazil; International Nuclear Law Association (INLA), Brussels, Belgium

CONF-930943; Nuclear Inter Jura'93: Nuclear Energy and Sustainable Development - The Role of the Law, Proceedings of the Congress of the International Nuclear Law Association, Rio de Janeiro, Brazil, September 12-17, 1993. Forense, Rio de Janeiro, Brazil, 639 pp.; (pp. 531-538) (1995)

Environmental remediation of radioactively and chemically contaminated sites represents one of the most complex challenges of our age. From a practical viewpoint, if contaminated sites can not be successfully remediated, the future of the nuclear industry and of other industries could be challenged. From a moral standpoint, this generation has an obligation to remedy the harmful by-products of the otherwise necessary and beneficial activities in which it has engaged. The task is challenging for several reasons. First, standards governing remedial action are complex and constantly evolving. Second, unless contaminated material is to be stabilized in place, it must be removed and sent to another facility for storage and ultimate disposal. Yet, there is a shortage of such facilities and it is becoming increasingly difficult to develop additional ones. Third, the task is technically demanding. Fourth, the challenge is a risky one; those who seek to remediate past contamination may find themselves exposed to expanding and unfair allegations of liability for that very contamination. Finally, there is often a basic crisis of public confidence regarding remediation efforts which overshadows and permeates the foregoing considerations.

1831

V18/025440

Environmental Response Training Program: Schedule of Courses - September 1, 1997-September 30, 1998

U.S. Environmental Protection Agency, Office of Emergency and Remedial Response, Washington, DC

EPA/540/R-97/014; OSWER-9285.9-31B; 80 pp. (June 1997)

As part of EPA's comprehensive program for protecting the public and the environment from hazardous materials, the Emergency Response Division of the Office of Emergency and Remedial Response (OERR) has developed the Environmental Response Training Program (ERTP). The courses in this program are designed for personnel who respond to emergencies or who investigate and clean up abandoned hazardous waste sites Training is provided in safety and health as well as in the various technical operations needed to identify, evaluate, and control hazardous substances that have been released.

\section{$1832 \quad$ V18/020636}

Environmental Restoration Program

U.S. Department of Defense, Office of the Under Secretary of Defense, Washington, DC

DODI-4715.7; 15 pp. (April 22, 1996)

This Instruction implements DoD Directive 4715.1 with respect to the Defense Environmental Restoration Program (DERP) and the Base Realignment and Closure (BRAC) environmental restoration program. It implements and refines policies, assigns responsibilities, and prescribes procedures for the DERP, funded by the environmental restoration accounts; and the BRAC environmental restoration program, funded by the BRAC account. This Instruction assigns responsibilities for planning, programming, budgeting, executing, and reporting for the DERP and the BRAC environmental restoration programs. It implements the Fast-Track Cleanup (FTC) Program and establishes the Environmental Security Cleanup Committee (ESCC).

1833

V18/024351

Environmental Restoration Project, Peer Review Process Assessment

Schantz, P.A.

U.S. Air Force Institute of Technology, School of 
Engineering, Wright-Patterson Air Force Base, $\mathrm{OH}$ AFIT/GEE/ENV/96D-18; 218 pp. (December 1996)

To ensure Installation Restoration projects are risk based, technically sound, and cost effective, the Air Force instituted a peer review program in 1992. The objective of this research is to describe and analyze the peer review process. Through triangulation of data from interviews, observations, official and academic documents, and surveys, seven constructs were discovered: focus, agenda, facilitator, written preparation, oral presentation, team characteristics, and reviewer characteristics. A questionnaire was used to gather perceptions of peer review effectiveness-the criterion variable-and of the seven constructs. Linear regression is next used to assess the predictiveness of the seven constructs. Oral presentation and focus predict $68 \%$ of the variance in peer review effectiveness; no other constructs were significant. Variation in the peer review process between major commands is explored. Lastly, recommendations are made to improve the current peer review process.

\section{4}

$\mathrm{V} 18 / 022560$

Evaluation and Application of Cost Estimates for Hazardous Waste Remediation

LeBoeuf, E.J.; Roberts, P.V.; McCarty, P.L.

University of Michigan, Department of Civil and Environmental Engineering, Ann Arbor, MI; Stanford University, Department of Civil Engineering, Stanford, CA

CONF-9505206; Proceedings of the 50th Industrial Waste Conference, R.F. Wukasch (ed.), West Lafayette, IN, May 8-10, 1995. Ann Arbor Press, Inc., Chelsea, MI, 861 pp.; (p. 764) (1996)

The remediation of sites contaminated by hazardous wastes is often a very difficult and fustrating task for all parties involved. The public rightfully demands quick elimination of possible health threats caused by the contamination of the subsurface with hazardous chemicals. The government demands the same, but is also concemed with permanence of the remediation process, and ensuring the potentially responsible parties (PRP) are held fully liable for the cleanup. Finally, the PRP is concerned about all of the aforementioned factors, its reputation, and costs. It is this final aspect of hazardous waste remediation projects that has caused the largest concern. Because business and govermment often evaluate costs with differing criteria, it is necessary that both parties understand each other's position, and especially the limitations and uncertainties associated with the preparation or preliminary remediation project cost estimates. Often it is these preliminary estimates that are used to determine which available technology will be employed at a specific site. The purpose of this paper is to describe the development of remediation cost estimates, evaluate available cost assessment programs, and finally compare remediation technologies using the US Environmental Protection Agency's Cost of Remedial Action (CORA) program in an actual remedial action case study.

1835

V18/021970

Evaluation and Selection of Innovative Remedial Technology

Hansen, B.J.
H2 Technology, Inc., Arvada, CO

CONF-9509139; Emerging Technologies in Hazardous Waste Management VI, D.W. Tedder (ed.), Proceedings of the Seventh American Chemical Society Industrial and Engineering Chemistry Division Special Symposium, Atlanta, GA, September 17-20, 1995. American Chemical Society, Washington, DC, 1291 pp.; (pp. 561-563) (1995)

We in the United States have embarked on a major undertaking: that of cleaning up after ourselves. The major portion of the money to be spent cleaning up contaminated sites will be spent on federal facilities, particularly Department of Energy ( $\$ 200$ to $\$ 300$ billion) and Department of Defense ( $\$ 30$ to $\$ 40$ billion). The cost to clean up nonfederal superfund sites will be an additional $\$ 50$ to $\$ 100$ billion. And, that is just part of the story. At the same time, Americans are faced with increasing costs in the areas of crime prevention, health care, education and replacing rapidly aging infrastructure. We must become more efficient in implementing environmental clean up. We must be more selective in the targets that we choose to clean up. We must apply reasonable clean-up criteria to the sites that we do elect to clean up. We must become more efficient in evaluating site conditions and in selecting clean-up technology. Finally, we must select technology that will work and that does not have unintended negative consequences. This paper discussed some of the factors involved in a successful remedial design or waste treatment project. The importance of problem definition and systematic study is emphasized. Many problems encountered in remediation projects result from lack of problem definition and incomplete communication of the significance of the site and waste characterization studies. By adopting an integrated engineering approach, a professional team can evaluate and select innovative technology with confidence.

1836 V18/021754

Evaluation of Alternative Cleaning Methods for Removing an Organic Contaminant from a Stainless Steel Part

Boyd, J.L.

Carnegie Mellon University, Pittsburgh, PA

WAPD-T-3103; 80 pp. (August 1994)

As of December 1995, the manufacture of Freon, along with many other chlorofluorocarbons (CFCs), was prohibited by the Clean Air Act of 1990 (CAA). The ban of CFC solvents has forced manufacturers across the country to search for altemative metal cleaning techniques. The objective of this study was to develop a thorough, scientific based approach for resolving one specific manufacturer's problem of removing organic contamination from a stainless steel part. This objective was accomplished by an approach that involved: (1) defining the problem, (2) identifying the process constraints, (3) researching alternate cieaning methods, (4) researching applicable government regulations, (5) performing a scientific evaluation, and (6) drawing conclusions. The research documented herein indicates that there is a wide range of alternative methods to consider. This wide range of alternatives, combined with a vast array of government environmental safety regulations, made the selection of a new cleaning method very complex. Because of this complexity, only one small aspect of the selected cleaning problem was addressed in this study. Furthermore, the research 
indicates that most manufacturers have selected replacement cleaning methods in an ad hoc or subjective manner. Consequently, this evaluation met an additional challenge by developing a systematic method for ranking cleaning process alternatives. The method was modeled after the "house of quality", which is the basic design tool of the Quality Function Deployment (QFD) management approach that originated in Japan in the 1970's. The evaluation results confirm that altemate solvent cleaning methods are the most viable short term option for removing organic contamination from stainless steel in this application. A comprehensive list of alternate solvents was generated, many of which were tested in a laboratory experiment to determine their solvency and evaporation characteristics. The top three ranked solvents, Borothene, Bioact 145 and Navy Solv 77, based on the "scores" determined by the quantified ranking method, were selected as promising candidates for the new part cleaning process. It is recommended that more extensive and equipment-specific tests be performed on the top three solvents before making a final cleaning system decision. As a long range plan, it is recommended that additional development on plasma and laser surface cleaning techniques be explored.

1837

V18/024339

Evaluation of Early Phase Nuclear Accident Clean-Up Procedures for Nordic Residential Areas

Andersson, K.G.

Risoe National Laboratory, Roskilde, Denmark; Nordisk Kernesikkerhedsforskning, Roskilde, Denmark

NKS-EKO-5(96)-18; 93 pp. (December 1996)

The work reported was carried out as a part of the EKO-5 project under the framework of the Nordic co-operative NKS program. The project is aimed at giving guidelines relating to Nordic conditions for the reduction of external doses in the early phase of a major accidental airbome nuclear contamination situation in urban areas, with Cs-137 being the primary concern. The material in this report describes the expected effects, in terms of immediate dose rate reduction and of reduction of the integrated doses over 70 years, of implementation of the methods which were considered to be feasible for early phase treatment of contaminated urban surfaces. Also given are estimates of the integrated doses if no action were taken. The given estimates were based on the experience obtained through large amounts of in situ measurements on different types of surfaces, mainly since the Chemobyl accident in 1986. The computer model URGENT, was used to apply the information on the migration of the radioactive material with time, together with the results of Monte Carlo photon transport calculations, for the time-integrated dose estimates. Sixty six data sheets describe the beneficial effects, costs and disadvantages of application of a feasible method for cleanup in the early phase of a specific type of surface in one of five different urban or suburban environments. These data form the foundation for the recommendations on guidelines, which are the ultimate goal of the EKO-5 project. References are given to recommended supplementary reading.

1838

$\mathrm{V} 18 / 023814$

Evaluation of Metal Removal and Toxicity Reduction in a Low Sulfate Mine Drainage by Constructed Wetlands
Farmer, G.H.; Updegraff, D.M.; Lazorchak, J.M.; Bates, E.R.

PRC Environmental Management, Inc., Denver, CO; Colorado School of Mines, Golden, CO; U.S. Environmental Protection Agency, Cincinnati, $\mathrm{OH}$

CONF-9506226 (Vol. 1); Decades Later: A Time for Reassessment, G.E. Schuman and G.F. Vance (eds.), Proceedings of the Annual Meeting of the American Society for Surface Mining and Reclamation, Gillette, WY, June 3-8, 1995. American Society for Surface Mining and Reclamation, Princeton, WV, Vol. 1, 494 pp.; (pp. 78-89) (1995)

A pilot-scale demonstration using two constructed wetlands cells is being conducted to evaluate the potential removal of metal contamination, primarily zinc, from mine drainage. The drainage from the Burleigh Tunnel, Silver Plume, $\mathrm{CO}$, contains low levels of sulfate $(350-450 \mathrm{mg} / \mathrm{L})$ that may limit the production of hydrogen sulfide by sulfate-reducing bacteria; thus, limiting metal removal by the system. Total metals, anions, and field parameters in the mine drainage and the constructed wetlands effluents were routinely analyzed over 10 months. In addition, the wetlands compost was analyzed for metals sulfate-reducing bacteria and acid volatile sulfides. Zinc removal in the upflow wetlands was in excess of 99 percent (average influent zinc concentration of $56.4 \mathrm{mg} / \mathrm{L}$ ) during most of the 10-month period. Further, sulfate-reducing bacteria in the wetlands substrate compost ranged from $10(6)$ to $10(8)$ colony forming units per gram of compost. Finally, 48-hour toxicity testing with fish (fathead minnows) and invertebrates (Ceriodaphnia dubia) found that 100 percent of both wetlands effluents had no significant acute toxicity.

\section{9 \\ V18/021065}

Evaluation, Design and Implementation of an Air Pollution Control System for VOC Emissions

Mastriano, J.A.; Traister, M.; Towers, D.S.

O'Brien \& Gere Engineers, Inc., Syracuse, NY

CONF-940499 (Vol. 1); Proceedings of the 1994 Federal Environmental Restoration III and Waste Minimization II Conference and Exhibition, New Orleans, LA, April 27-29, 1994. Hazardous Materials Control Resources Institute, Rockville, MD, Vol. 1, 783 pp.; (pp. 328-336) (1994)

The evaluation, design, and cost-effective implementation of an air pollution control system requires not only technical knowledge of possible control alternatives, but a thorough understanding of state air regulations and the potential long-term implications of the Clean Air Act Amendments of 1990 (CAAA). With many manufacturers breaking into the market, an engineered solution is needed to evaluate alternatives and effectively manage emissions from an industrial facility. An engineered approach was used to implement a cost-effective replacement air pollution control system at an industrial facility in Central New York, saving the facility approximately $\$ 100,000$ in construction costs. As part of an air emissions inventory conducted at the facility, it was found that the facility operates six lithographic printing presses and dryers that generate an average of 13,000 standard cubic feet per minute (scm) and up to $14,610 \mathrm{scfm}$ of volatile organic compound (VOC)-laden air consisting primarily of hydrotreated middle distillates. A review of state and federal air regulations indicated that 
the new air pollution control system to replace an existing outdated system, should be designed to meet air permit constraints of $4.8 \mathrm{lbs}$ VOCs/hr and remove $94 \%$ of influent VOC from the lithographic press operations under maximum operating conditions. Results of an : evaluation of remedial technologies identified cataiytic oxidation as the most cost-effective technology for implementation at the facility. As part of the design, technical specifications required that the new catalytic oxidation system be designed to remove VOC-laden air at maximum (16,000 scfm) and minimum (971 scfm) flow conditions. The new system consisted of two catalytic oxidation combustion chambers (each capable of treating 8,000 scfm of VOC-laden air) and electrical, instrumentation, and control necessary for a complete, automatic operational system. Following removal of the old catalytic oxidation system and installation of a new catalytic oxidation system during a two-week shutdown as part of construction in 1993, stationary source testing was conducted on the catalytic oxidation system in accordance with 40 CFR Part 60 , Appendix A-Environmental Protection Agency (EPA) Reference Methods 1,2,3,4 and 25A. The facility utilized the test results to confirm that the unit is operating as designed, destroying $94 \%$ of the VOC-laden air influent to the catalytic oxidation system. Approximate project cost, including engineering and construction, was $\$ 500,000$.

\section{0 \\ V18/024360}

Expedited Remedial Action Program (SB 923): A California Brownfields Initiative

\section{Cambridge, M.; Wolfenden, A.K.}

Califomia Environmental Protection Agency, Department of Toxic Substances Control, Sacramento, $\mathrm{CA}$

CONF-9611118; HazMat West '96, Proceedings of an International Environmental Management and Technology Conference and Exhibition, November 5-7, 1996. Advanstar Expositions, Duluth, MN, 544 pp.; (pp. 147-155) (1996)

Califomia's Expedited Remedial Action Program (ERAP) created a comprehensive program that promotes an equitable and expedited approach for redevelopment of properties contaminated with hazardous substances. This bill embodies an emerging trend in environmental policy that permits flexibility, cooperation and creativity without compromising protection to public health or the environment. Within the California Environmental Protection Agency, the Department of Toxic Substances Control (DTSC) is promoting a number of programs to facilitate the restoration of contaminated properties as part of its Brownfields initiative. ERAP represents a potentially more efficient process to remediate sites by minimizing economic risks through a clearly identified liability scheme, indemnifying future owners through a covenant not to sue, and providing risk-based cleanups that are based on the permanent use of the site.

\section{$1841 \quad$ V18/024361}

Expedited Remedial Action Program: A Case Study The Alhambra Front Street Manufactured Gas Plant Site

Padleschat, J.A.; McMahon, T.D.

CONF-9611118; HazMat West '96, Proceedings of an International Environmental Management and Technology Conference and
Exhibition, November 5-7, 1996. Advanstar Expositions, Duluth, MN, 544 pp.; (pp. 171-184) (1996)

Early in 1995, the Department of Toxic Substances Control asked Southem Califomia Gas Company (SoCalGas) to enter one of its manufactured gas plant (MGP) sites into the new Expedited Remedial Action Program (ERAP). SoCalGas initially was not enthusiastic about the new program. Nevertheless, SoCalGas submitted an application for its Alhambra MGP site to be selected for the ERAP. The Alhambra Site was accepted into ERAP in November 1995, and was the furst ERAP site to have orphan shares. MGP sites are well suited to the ERAP. They often involve few potentially responsible parties and can be expected to have the same primary contaminants: polycyclic aromatic hydrocarbons (PAH), which are a byproduct of the gas manufacturing process, and petroleum hydrocarbons from the crude oil feedstock used to manufacture the gas.

\section{$1842 \quad$ V18/024359}

Expedited Remedial Action: A Promising Opportunity at Your Doorstep

Newman, E.R.

CONF-9611118; HazMat West '96, Proceedings of an International Environmental Management and Technology Conference and Exhibition, November 5-7, 1996. Advanstar Expositions, Duluth, MN, 544 pp.; (pp. 163-169) (1996)

The Expedited Remedial Action Program (ERAP) carries great promise and is limited to no more than 30 sites. There are a number of slots now available, and the legislature will soon be considering a reauthorization of the full state Superfund program, which expires in June 1998. The program is reportedly based to a great extent on the ERAP model. The ERAP provides for: (1) the early identification of fair and equitable shares of liability, including an orphan share, where appropriate, to be paid by the state; (2) the elimination of all joint and several liability; (3) cleanup levels and remedies based on the foreseeable planned use of the site; (4) site specific risk assessments based on the latest risk assessment protocols; (5) use of an arbitrator to quickly resolve all significant liability and technical disputes; and (6) broad and timely releases from future liability upon completion of cleanup.

1843 V18/023918

Extraction and Processing for the Treatment and Minimization of Wastes: Proceedings of the Second Interaational Symposium, Scottsdale, AZ, October 27-30, 1996

CONF-961018; Extraction and Processing for the Treatment and Minimization of Wastes, V. Ramachandran and C.C. Nesbitt (eds.), Proceedings of the Second International Symposium, Scottsdale, AZ, October 27-30, 1996. The Minerals, Metals, \& Materials Society, Warrendale, PA, 856 pp. (1996)

This volume contains 71 papers presented at the Symposium which was held at the Fall Extractive Metallurgy Meeting of the Minerals, Metals \& Materials Society in Scottsdale, AZ, October 27-30, 1996. The papers deai with management of wastes generated as a result of processing in the metals industry or management of wastes containing metals. Removal, stabilization and chemical and thermal treatments are explored. Characterization and monitoring studies 
are included as well as regulatory and compliance papers.

1844

$\mathrm{V} 18 / 021674$

Field Analytical Support During Superfund Site Remediation

Goldschmidt, W.L.; Catherman, D.R.

Environmental Resources Management, Inc., Exton, PA

CONF-950209 (Vol. 2); VIP-47, Proceedings of the Fourth International Symposium on Field Screening Methods for Hazardous Wastes and Toxic Chemicals, Las Vegas, NV, February 22-24, 1995. Air and Waste Management Association, Pittsburgh, PA, Vol. 2, 701 pp.; (pp. 735-742) (1995)

ERM-FAST (R) Services has provided cost-effective and critical field analytical support for a wide variety of investigatory and remedial projects over the past four years. Two recent projects involving soils remediation at Superfund sites exemplify the power of real time field analytical support in reducing time and expense during a project's remedial phase. ERM-FAST's on-site analytical facilities were able to meet, in a real time scenario, all data quality objectives (DQOs), all regulatory agency requirements, and satisfied the client's needs. ERM-FAST made this possible through the development of unique analytical strategies, the proper selection of analytical technologies, and by streamlining the analytical methodologies. Both of these remedial efforts offer illustrations of the effectiveness of field analysis for vastly differing site contaminants. This case study focuses on the use of portable Gas Chromatography (GC) instrumentation as a tool for providing analytical support during a CERCLA site remediation program. The project discussed provides an example of how low cost portable analytical instrumentation can be utilized in a field setting to meet analytical DQOs consistent with CERCLA compliance and to meet the requirements for remedial activity cost control. Substantial savings were realized both by reducing total project analytical cost, and by efficient and effective process and schedule management.

\section{5}

V18/024657

Field Application of Solid Oxygen Source for Bioremediation

Davis-Hoover, W.J.; Murdoch, L.C.; Vesper, S.J.

U.S. Environmental Protection Agency, Risk Reduction Engineering Laboratory, Cincinnati, OH; University of Cincinnati, Department of Civil and Environmental Engineering, Cincinnati, $\mathrm{OH}$

Bioremediation of Pollutants in Soil and Water, B.S. Schepart (ed.), Proceedings of a Symposium, Fort Worth, TX, October 14-15, 1993. American Society for Testing and Materials (ASTM), Philadelphia, PA, 265 pp.; (pp. 233-242) (May 1995)

A contaminated field site was created in the subsurface soil by introducing propylene glycol (PPG). The soil at the site is an overconsolidated silty clay of very low permeability (hydraulic conductivity about $10(\mathrm{E}-7) \mathrm{cm} / \mathrm{sec})$. After a period of acclimation, the soil was hydraulically fractured using a mixture of sand, encapsulated sodium percarbonate, and IBDU slow-release fertilizer. In the vicinity of the fractures, microbial metabolic rate increases were observed as well as increases in the microbial population of 10 to 100 fold. The PPG was observed at lower concentrations near the fractures compared to above the fractures by the end of the incubation. After four months in the soil, the rate of oxygen release from the fracture layer was still 2.6 percent of its initial rate of oxygen release.

1846

V18/021673

Field Implementation Complexities of EPA Developmental Methods During Remediation at Hazardous Waste Sites: Case Study

Green, E.L.; Cunningham, E.A.; Grabinski, C.

Eagle Environmental Health, Inc., Houston, TX; Tenneco, Inc., Houston, TX; Joslyn Corporation, Chicago, IL CONF-950209 (Vol. 2); VIP-47, Proceedings of the Fourth International Symposium on Field Screening Methods for Hazardous Wastes and Toxic Chemicals, Las Vegas, NV, February 22-24, 1995. Air and Waste Management Association, Pittsburgh, PA, Vol. 2, 701 pp.; (pp. 818-822) (1995)

The objective of this presentation is to provide insight into the complexities of field implementation of Environmental Protection Agency developmental methods for polynuclear aromatic hydrocarbons, pentachlorophenol, particulates and metals at hazardous waste site remediations. A remedial action plan developed for the site called for the development and subsequent execution of an air monitoring plan during the removal of affected subsurface soils. Ambient air monitoring for polynuclear aromatic hydrocarbons, pentachlorophenol, total particulates and arsenic, chromium and copper was conducted from February through May, 1992. After May, sampling for arsenic, chromium and copper was dropped from the plan because of the extremely low levels of metals associated with the soils. Real-time monitoring for total suspended particulates was conducted from February through September, 1992.

1847

V18/024680

Field Pilot-Scale Vapor-Phase Treatment of Styrene Using Biofiltration, Chapter 24

Togna, A.P.; Skladany, G.J.

Envirogen, Inc., Princeton Research Center, Lawrenceville, NJ

Bioremediation: Field Experience, P.E. Flathman, D.E. Jerger and J.H. Exner (eds.), Lewis Publishers, Boca Raton, FL, 560 pp.; (pp. 507-520) (1994)

The biological treatment of volatile organic compounds (VOCs) offers an attractive alternative to many of the drawbacks of traditional abatement systems. One commercially available vapor-phase biological treatment technology is biofiltration. Biofiltration uses microorganisms immobilized in the form of a biofilm on a porous substrate such as soil, compost, or peat. As a contaminated vapor stream passes through the filter bed, contaminants are transferred from the vapor phase to a thin water layer covering the microorganisms. The dissolved contaminants then pass from the liquid layer into the microorganisms, where the chemicals are metabolized to carbon dioxide, water, additional biomass, and benign metabolic products. The field pilot-scale study described in this chapter was intended to expand on previously published work and was specifically designed to determine whether a 
biofiltration system could successfully operate under real-world conditions at a functioning manufacturing facility. In this study, the treatment of styrene-contaminated air discharged from a spray booth operation was investigated using a field pilot-scalè biofilter containing $0.85 \mathrm{cu} \mathrm{m}(30 \mathrm{cu} \mathrm{ft})$ of packing. The results of the demonstration provide strong support for the use of biofiliters for treatment of emissions. An average removal efficiency of greater than $95 \%$, as measured with on-line total hydrocarbon analyzers, was consistently achieved over the 4 month operating period at a vapor residence time of $30 \mathrm{sec}$. At a vapor residence time of 15 sec, between $85 \%$ and $95 \%$ removal efficiencies were achieved. This chapter is from the book entitled Bioremediation: Field Experience.

\section{8}

\section{V18/022556}

\section{Future of Regulatory Policy in California}

Giannopoulos, J.G.

California State Water Resources Control Board, Sacramento, $\mathrm{CA}$

CONF-960393 (Part 3); Contaminated Soils and Groundwater: Analysis, Fate, Environmental and Public Health Effects, and Remediation, Proceedings of the Sixth Annual West Coast Conference, Newport Beach, CA, March 11-14, 1996. Association for the Environmental Health of Soils, Amherst, MA, Part 3, 366 pp.; (p. 10) (1996)

In 1996 the Califomia State Water Resources Control Board (State Board) must decide how to respond to the recommendations from its contractor, the Lawrence Livermore National Laboratory (LLNL), and the Senate Bill 1764 Advisory Committee, a panel of experts appointed by the State Board. The LLNL, in a report dated October 16,1995, recommended changes in the regulation of leaking underground fuel tank (LUFT) cleanup. The SB 1764 Advisory Committee will issue recommendations on the same subject by January 31, 1996. This paper discusses the existing regulatory setting and explores the State Boards' future options.

\section{9 \\ V18/025483}

Generic Protocol for Conducting Environmental Audits of Federal Facilities: Volume 1, Phase 1 - Auditing for Compliance, Volume 2, Phase 2 and 3 - Auditing Environmental Management Systems, Third Edition U.S. Environmental Protection Agency, Office of Federal Facilities Enforcement, Washington, DC

EPA/300/B-96/012A; EPA/300/B-96/012B; 1446 pp. (December 1996)

This 1996 revision includes a discussion and reference to EPA's 1995 audit policy. Material is intended to assist in conducting environmental audits and environmental assessments. Volume I emphasizes compliance with federal environmental requirements, both regulatory and non-regulatory. Volume II provides detailed procedures for environmental management system audits of facility-specific programs and overall programs managed at the agency's headquarters.

V18/023329

Geoenvironment 2000: Characterization, Containment,
Remediation, and Performance in Environmental Geotechnics, Proceedings of an American Society of Civil Engineers Specialty Conference, New Orleans, LA, February 22-24, 1995

Acar, Y.B.

CONF-950225; GeoEnvironment 2000: Characterization, Containment, Remediation, and Performance in Environmental Geotechnics, D.E. Daniel (ed.), Proceedings of an American Society of Civil Engineers (ASCE) Specialty Conference, New Orleans, LA, February 22-24, 1995, ASCE, New York, NY, 1856 pp. (February 1995)

The proceedings of Geoenvironment 2000, an ASCE Specialty Conference held in New Orleans, February 1995, outline the trends, developments, and varied tasks undertaken by civil engineers working in geoenvironmental engineering. Some 100 peer-reviewed and invited review papers cover characterization/speciation, fate and transport, landfills and containment barriers, and remediation. Topics range from the onsite analysis of organic compounds using field screening techniques to analytical models for cumulative mass column testing; hydraulic recovery/containment-vacuum extraction; stabilization; and bioremediation.

\section{$1851 \quad \mathrm{~V} 18 / 023737$}

Geologic Remote Sensing - Practical Solutions for Real World Problems: Proceedings of the Eleventh Thematic Conference, Vol. 1, Las Vegas, NV, February 27-29, 1996

CONF-960203 (Vol. 1); Geologic Remote Sensing - Practical Solutions for Real World Problems, Proceedings of the Eleventh Thematic Conference, Las Vegas, NV, February 27-29, 1996. Environmental Research Institute of Michigan, Ann Arbor, MI, Vol. 1, 730 pp. (1996)

These proceedings contain papers presented at the Eleventh Thematic Conference on Applied Geologic Remote Sensing, held 27-29 February 1996, in Las Vegas, Nevada. The meeting was convened to discuss practical solutions for real-world problems as well as research and development activities working to increase the future capabilities of this technology. Presentations in these volumes address the following topics: (1) Mineral Exploration; (2) Future Commercial Satellite Technologies; (3) Regional Geology and Tectonics; (4) Mining and Minerals; (5) Environment and Hydrology; (6) GIS and Data Integration; (7) Great Basin Applications; (8) Applications of New Sensor Technologies; (9) Petroleum Case Histories; (10) Image Processing and Spectral Analysis; and (11) Geo-Hazards - Nature's Revenge.

1852 V18/023739

Geologic Remote Sensing - Practical Solutions for Real World Problems: Proceedings of the Eleventh Thematic Conference, Vol. 2, Las Vegas, NV, February 27-29, 1996 CONF-960203 (Vol. 2); Geologic Remote Sensing - Practical Solutions for Real World Problems, Proceedings of the Eleventh Thematic Conference, Las Vegas, NV, February 27-29, 1996. Environmental Research Institute of Michigan, Ann Arbor, MI, Vol. 2, 723 pp. (1996)

These proceedings contain papers presented at the Eleventh Thematic Conference on Applied Geologic Remote Sensing, held 27-29 February 1996, in Las Vegas, Nevada. The meeting was 
convened to discuss practical solutions for real-world problems as well as research and development activities working to increase the future capabilities of this technology. Presentations in these volumes address the following topics: (1) Mineral Exploration; (2) Future Commercial Satellite Technologies; (3) Regional Geology and Tectonics; (4) Mining and Minerals; (5) Environment and Hydrology; (6) GIS and Data Integration; (7) Great Basin Applications; (8) Applications of New Sensor Technologies; (9) Petroleum Case Histories; (10) Image Processing and Spectral Analysis; and (11) Geo-Hazards - Nature's Revenge.

1853

V18/020920

Global Environmental Protection - Science, Politics, and Common Sense: Proceedings of the Second Society of Environmental Toxicology and Chemistry (SETAC) World Congress and the 16th Annual Meeting, Vancouver, British Columbia, Canada, November 5-9, 1995 [Book of Abstracts]

CONF-9511137; Global Environmental Protection: Science, Politics, and Common Sense, Proceedings of the Second Society of Environmental Toxicology and Chemistry (SETAC) World Congress and 16th Annual Meeting, Vancouver, British Columbia, Canada, November 5-9, 1995. Society of Environmental Toxicology and Chemistry, Pensacola, FL, 378 pp. (1995)

This book is comprised of the abstracts of the presentations for the platform and poster sessions of the Second World Congress of the Society of Environmental Toxicology and Chemistry (SETAC). The abstracts are reproduced as accepted by the Program Committee and appear in numerical order. Abstracts of presentations considered to be within the scope of this database are indexed individually.

\section{4}

\section{V18/021087}

\section{Great Plains - Rocky Mountain Hazardous Substance Research Center: Annual Report 1994}

Kansas State University, Hazardous Substance Research Center, Farrell Library, Manhattan, KS

Great Plains-Rocky Mountain Hazardous Substance Research Center Annual Report, D.L. Tillison, L.E. Erickson, and S.C. Grant (eds.), Great Plains-Rocky Mountain Hazardous Substance Research Center, Kansas State University, Manhattan, KS, 93 pp. (November 1994)

Kansas State University (KSU) leads the nine-institution consortium comprising the Great Plains - Rocky Mountain Hazardous Substance Research Center, which serves EPA Regions 7 and 8 . The Center was established in February 1989 to conduct research pertaining to the identification, treatment and reduction of hazardous substances resulting from agriculture, forestry, mining, mineral processing and other activities of local interest. The Center provides a focal point for hazardous substances research, training and technology transfer in the Great Plains and Rocky Mountain areas. A long-term goal is to serve the needs of the 10-state area using as many of the available resources within the region-pair as possible. For instance, training and technology transfer events offered by consortium universities and other institutions are listed in the quarterly newsletter HazTech Transfer. Through personal visits, the newsletter, telephone calls and direct mailings, Center staff have emphasized inclusiveness and the idea of "working together for a better environment." Center personnel have made visits to all of the consortia universities, several other universities, the EPA regional offices, and other state and federal offices. A variety of professional gatherings and conferences have been sponsored and attended. Approximately 10,000 individuals have benefited directly through center activities. This report contains research project descriptions, training and technology transfer project descriptions and a bibliography of publications and workshops by consortium members.

\section{5 \\ V18/021707}

Guidance Manual for Developing Site-Specific Soil Quality Remediation Objectives for Contaminated Sites in Canada

Cureton, P.M.; Ouellet, S.

Canadian Council of Ministers of the Environment, National Contaminated Sites Remediation Program, Ottawa, Ontario, Canada; Environment Canada, Program Evaluation Branch, Ottawa, Ontario, Canada

Report; 45 pp. (March 1996)

This report was compiled within the framework of the Canadian Council of Ministers of the Environment (CCME)-initiated National Contaminated Sites Remedial Program, to provide general guidance to government environmental officers and site managers on the various common scientific tools available for contaminated site assessment and remediation. The report includes guidance for developing site-specific environmental objectives, sampling and analytical procedures for different contaminants commonly found at contaminated sites, and guidance on the proper management of collected data. A glossary of terms is also included.

\section{6}

\section{V18/021751}

\section{Guide to Documenting Cost and Performance for Remediation Projects}

Federal Remediation Technologies Roundtable, Washington, DC

\section{EPA/542/B-95/002; 60 pp. (March 1995)}

The purpose of this Guide is to foster the use of consistent procedures to document cost and performance information for projects involving treatment of contaminated media. In short, it provides site remediation project managers with a standardized set of parameters to document completed remediation projects. Standard reporting of data will broaden the utility of the information, increase confidence in the future effectiveness of remedial technologies, and enhance the organization, storage, and retrieval of relevant information. Through greater coordination, Federal Agencies hope to improve data collection and dissemination, and thus to increase the effectiveness of hazardous waste cleanups.

\section{V18/023895}

HazMat West '95: Proceedings of the Eleventh Annual Environmental Management and Technology Conference and Exhibition, Long Beach, CA, November $7-9,1995$ 
CONF-951 124; HazMat West '95, Proceedings of the Eleventh Annual Environmental Management and Technology Conference and Exhibition, Long Beach, CA, November 7-9, 1995. Advanstar Expositions, Duluth, MN, 597 pp. (1995)

This conference was held November 7-9, 1995 in Long Beach, Califomia as part of the Environmental Management and Technology and Exhibition/West. The purpose of this conference was to provide a multidisciplinary forum dealing with state-of-the-art methods and site characterization technologies for environmental monitoring and remedial action planning of hazardous materials. Appropriate individual papers have been processed separately for inclusion in the RAPIC data base.

1858

V18/023950

Hazardous Waste Site Remediation: Participant's Manual

InterTech Environmental, Oak Ridge, TN

Report; 235 pp. (April 1997)

This document is a compilation of viewgraph-like materials that cover the contents of an introductory course in site assessment and remediation technologies. Course modules are divided into three main topics: (1) site characterization, (2) remediation technologies, and (3) technology selection. Basic hydrogeology and contaminant characteristics are covered within the site characterization section. The remediation technologies section presents the main features of a broad range of technologies divided into the following subsections: containment, removal methods, exsitu separation, exsitu disposal, exsitu destruction, and in situ treatment. The technology selection section presents several site assessment issues, such as monitoring well installation and purging methods, and discusses the factors driving technology selection.

\section{9 \\ V18/025337}

Health and Safety: Working Smarter, Faster, and Cheaper in Environmental Restoration Activities

Burns, S.E.; Brown, J.L.

Jacobs Engineering Group Inc., Oak Ridge, TN; Environmental \& Infrastructure Technologies, Inc., Knoxville, TN

CONF-970335; Waste Management '97: Working Towards a Cleaner Environment, Proceedings of a Conference on HLW, LLW, Mixed Wastes and Environmental Restoration, Tucson, AZ, March 2-6, 1997; (7 pp.) (1997)

Tightening budgets in the DOE complex are requiring contractors to accomplish more productive work at less cost in every functional area. The health and safety function in environmental restoration work is not immune to this pressure: contractor health and safety groups need to work smarter, faster, and cheaper than they have in the past, showing good cost-effectiveness for their efforts. One way to succeed in this is by applying the "necessary and sufficient" or "work smart" process to the health and safety functions. This can have the benefit of focusing health and safety efforts clearly on those areas of concern to a particular program or project, thereby maximizing the use of personnel, materials, and funds. However, proper use of this process requires careful analysis and sound technical judgment to avoid errors in identifying the applicable health and safety concerns and regulations for a particular project or effort. The best results can be seen in an integrated team approach, where health and safety staff interact with the other functional groups on each project from initial planning to completion. The Jacobs Environmental Management Team in Oak Ridge uses just such an approach in its work. Experience over the past two years has developed a "lesson leamed" list of things to do and things to avoid to achieve a successful integrated approach to "work smarter" in health and safety.

1860

V18/023767

Health, Safety and Environment in Oil and Gas Exploration and Production: Proceedings of the Third International Conference, Vol. 1, New Orleans, LA, June 9-12, 1996

CONF-960623 (Vol. 1); Proceedings of the Third International Conference on Health, Safety and Environment in Oil and Gas Exploration and Production, New Orleans, LA, June 9-12, 1996. Society of Petroleum Engineers (SPE), Inc., Richardson, TX, Vol. 1, 941 pp. (1996)

This conference was sponsored by the Society for Petroleum Engineers and contains papers which examine health, safery and environmental issues within the oil and gas exploration and production industry. Safety management, HSE training; risk assessment; environmental effects, remote medical care, and HSE management issues. Geographic coverage is international in scope and includes offshore issues. Papers within the scope of the RAPIC database are indexed separately.

\section{$1861 \quad$ V18/023650}

Heavy Metal Concentration in Bay Sediments of Japan Fukue, M.; Kato, Y.; Nakamura, T.; Yamasaki, S.

Tokai University, Shimizu, Japan; Aoki Marine Company, Fukushima, Osaka, Japan

CONF-9406413; Dredging, Remediation, and Containment of Contaminated Sediments, K.R. Demars, G.N. Richardson, R.N. Yong and R.C. Chaney (eds.), Proceedings of a Symposium, Montreal, Quebec, Canada, June 23-24, 1994, 343 pp.; (pp. 58-73) (1995)

Because industry discharges wastes into the sea, marine sediments can be contaminated with various kinds of hazardous and toxic substances. This study discusses how the degree of pollution by heavy metals affects the marine sediments from Osaka Bay and Tokyo Bay. In this study, the concentrations of various metals, such as manganese, iron, aluminum, titanium, vanadium, copper, phosphorus, etc., were measured from sediment samples obtained from different sites in the bays. The results had to be corrected because background concentrations for each metal differ with site location and grain size characteristics. The large difference between background and individual concentrations at various soil depths indicates that the surface layers of the seabed are significantly polluted with some species of heavy metal and other elements.

\section{$1862 \quad$ V18/023777}

Historic Contamination Along Oakland Inner Harbor Bird, J.C.; Shafer, D.L. Versar, Inc., Alameda, CA; PRC Environmental 
Management, Inc., Rancho Cordova, CA

CONF-9504134; HAZMACON '95, T. Bursztynsky and M.L. Loss (eds.), Proceedings of the Twelfth Hazardous Materials Management Annual Conference and Exhibition, San Jose, CA, April 4-6, 1995. Association of Bay Area Govemments, Oakland, CA, 790 pp.; (pp. 79-91) (1995)

As part of the ongoing remedial investigations (RI) at the Navy's Fleet and Industrial Supply Center, Oakland (FISCO) - Alameda Facility/Alameda Annex (the facility), FISC Oakland, and NAS Alameda, the presence of widespread historic chemical contaminants along the interface between the fill material and the former marshland deposits has been discovered. The historic contaminants are believed to have accumulated within the marshland areas prior to the filling activities along the Oakland Inner Harbor. The historic contaminants consists of heavy petroleum hydrocarbons, aromatic hydrocarbons, and polynuclear aromatic hydrocarbons (PAH), apparently generated by the former industries in the area.

1863

\section{V18/023388}

Identification and Assessment of Trace Contaminants Associated with Oil and Gas Pipelines Abandoned in Place

Thome, W.E.R.; Basso, A.C.; Dhol, S.K.

Biophilia, Inc., Calgary, Alberta, Canada

CONF-9505127 (Vol. 2); IPC '96: Pipelining in a Changing Competitive Environment, M. Yoon, M. Mensik and M. Mohitpour (eds.), Proceedings of the First International Pipeline Conference, Calgary, Alberta, Canada, June 9-14, 1996, Vol. 2, 772 pp.; (pp. 1263-1270) (1996)

As more Alberta oil and gas fields become depleted, attention is being given to development of economically and environmentally sound abandonment procedures. The objective of this study was to identify and assess residual internal and extemal contaminants associated with abandoned pipelines, particularly those to be abandoned in place. Circumstances which might increase the risk of contaminant release and other issues relating to residual pipeline contaminants were also identified. It was found that there are thousands of different substances which could potentially be associated with abandoned pipelines. A wide range in the potential quantities of residual contaminants was also found. Of the issues identified, the effectiveness of pipeline pigging and cleaning procedures prior to abandonment was the most critical determinant of the potential quantities of residual contaminants. However, a number of trace contaminants, such as PCBs and naturaliy occurring Radioactive Materials (NORM) may remain after thorough cleaning. A brief review of the legislation and regulations from a number of jurisdictions shows that pipeline abandonment has only recently become an issue of concem. Regulations specific to abandonment are lacking, and more general regulations and guidelines are being applied on a contaminant-specific basis, or in terms of waste disposal requirements.

\section{4 \\ V18/020809}

Identification and Characterization of Radioactively Contaminated Sites in Russia

Nechaev, A.F.; Vasiliev, I.A.
St. Petersburg State Institute of Technology, St. Petersburg, Russian Federation

IAEA-TECDOC-865; CONF-9310459 (Vol. 1); Planning for Environmental Restoration of Radioactively Contaminated Sites in Central and Eastern Europe, Volume 1: Identification and Characterization of Contaminated Soils, Proceedings of a Workshop on Environmental Restoration in Central and Eastern Europe, Budapest, Hungary, October 4-8, 1993. International Atomic Energy Agency, Vienna, Austria, Vol. 1, 356 pp.; (pp. 231-260) (February 1996)

The presented material is devoted to the description of the nuclear and radiation legacy of the Russian Federation. The paper contains classification of radioactively contaminated sites in Russia and their characterization, including history, sources of contamination, surface areas, proximity to population centers, levels of radioactivity and spreading of contamination. It is noted that corresponding information is rather limited, and there is much scope for further evaluation and detailed elaboration of quantitative data.

\section{5 \\ V18/020743}

\section{Identification and Radiological Characterization of Contaminated Environment in Ukraine}

Rudy, C.

Ministry for Environmental Protection of Ukraine, Kiev, Ukraine

IAEA-TECDOC-865; CONF-9310459 (Vol. 1); Planning for Environmental Restoration of Radioactively Contaminated Sites in Central and Eastern Europe, Volume 1: Identification and Characterization of Contaminated Soils, Proceedings of a Workshop on Environmental Restoration in Central and Eastern Europe, Budapest, Hungary, October 4-8, 1993. International Atomic Energy Agency, Vienna, Austria, Vol. 1, 356 pp.; (pp. 319-348) (February 1996)

As a result of the Chernobyl accident, 1779 towns and settlements all over the Ukraine were contaminated with level of surface contamination exceeding $1 \mathrm{Ci} / \mathrm{sq} \mathrm{km}$ of Caesium-137. In general, the Chernobyl accident affected 18 Ukrainian regions. Currently officially registered in the Ukraine are 104,802 radioisotopic devices that are used by 2,641 organizations. There are also 550 gamma-flow detectors, 78 installations of gamma-therapy and 6 medical isotopic units. Average annual radioactive inventory of open isotopes used in the Ukraine comes to $327,166 \mathrm{Ci}$. Radioactive inventory for closed isotopes is equal to 991 kg-equivalent of Radium. Activity of radioactive wastes disposed annually in the Ukraine falls within $14,000-22,000 \mathrm{Ci}$ (NPP wastes are not inciuded). All this creates a considerable potential for release of radioactivity into the environment and contamination of soil, water and biota. A critical radioecological situation was created in the areas of uranium mining and milling in the South of the Ukraine, mainly in the Kirovograd and Dnipropetrovsk regions. Significant volumes of tailings and depleted uranium ore waste piles have accumulated in the region. To coordinate all activities in the area of environmental restoration, and as a response to IAEA Technical Co-operation project RER/9/022, the Ministry for Environmental Protection of Ukraine recently started the development of the National Environmental Restoration Program 
(NERP), which as a first step includes systematic characterization of the current radiological situation in Ukraine.

\section{6}

\section{V18/020597}

\section{Identification and Radiological Characterization of} Contaminated Sites in Slovak Republic

Slavik, O.; Moravek, J.

Nuclear Power Plant Research Institute, Trnava, Slovakia

IAEA-TECDOC-865; CONF-9310459 (Vol. 1); Planning for Environmental Restoration of Radioactively Contaminated Sites in

Central and Eastem Europe, Volume 1: Identification and Characterization of Contaminated Soils, Proceedings of a Workshop on Environmental Restoration in Central and Eastern Europe, Budapest, Hungary, October 4-8, 1993. International Atomic Energy Agency, Vienna, Austria, Vol. 1, 356 pp.; (pp. 261-282) (February 1996)

This paper mainly deals with the methods and results of a detailed radiological survey in the vicinity of NPP Bohunice. In the Slovak Republic, only one site has been positively identified as being contaminated with Cs-137. This is namely the smaller rated water canal-river system taking out the waste water from the shut down and decommissioning Al-Nuclear Power Plant of Bohunice NPP complex. A detailed radiological survey showed that along practically the entire length of this $18 \mathrm{~km}$ water way the lower parts of the grassy banks are contaminated mainly by Cs-137 and $\mathrm{Sr}-90$ (but the $\mathrm{Sr}-90$ activity in contaminated soils is lower by two orders of magnitude). The overall contaminated area along the polluted shores is approximately $55,000 \mathrm{sq} \mathrm{m}$ and the average Cs-137 activity in the top soil layer $(10 \mathrm{~cm})$ is $6,1000 \mathrm{~Bq} / \mathrm{kg}$. On the canal banks contaminated hot-spots were identified with a maximum Cs-137 activity about $250,000 \mathrm{~Bq} / \mathrm{kg}$. The dose rates on the contaminated banks does not exceed the value of $1.5[\mathrm{mu}] \mathrm{Sv} / \mathrm{h}$. The Cs-137 surface and depth distribution analysis results, as well as the radiological characteristics of the site, are presented and discussed in the paper.

\section{7}

\section{V18/020812}

\section{Identification and Radiological Characterization of Contaminated Sites in Canada}

Whitehead, W.G.

Atomic Energy Control Board, Ottawa, Ontario, Canada LAEA-TECDOC-865; CONF-9310459 (Vol. 1); Planning for Environmental Restoration of Radioactively Contaminated Sites in Central and Eastern Europe, Volume 1: Identification and Characterization of Contaminated Soils, Proceedings of a Workshop on Environmental Restoration in Central and Easterm Europe, Budapest, Hungary, October 4-8, 1993. International Atomic Energy Agency, Vienna, Austria, Vol. 1, 356 pp.; (pp. 65-89) (February 1996)

Several instances of localized site contamination as a consequence of past practices involving radioactive materials (in particular, the mining and processing of radioactive ores) have occurred in Canada. In general, these situations evolved over several decades, and originated with historical practices which predate the current climate of environmental consciousness and commensurate regulatory controls. Although such practices included storage, handling or disposal in accordance with methods and standards considered acceptable at the time, subsequent developments, including observed impacts and increased societal expectations, have rendered many of these standards and methods unacceptable to current generations. Consequently, since the early 1970 's, Canadian government and industry have become increasingly active in initiatives to identify and remediate contaminated sites, and to prevent similar recurrences. This paper describes specific instances of contamination, past and present. Relevant details such as histories of occurrences, descriptions of contaminated sites and contaminants, and descriptions of pending or completed remedial programs are provided.

1868 V18/020814

Identification and Radiological Characterization of Contaminated Sites in the United Kingdom

Fellingham, L.R.

AEA Technology, Harwell Laboratory, Engineering Services Division, Didcot, Oxfordshire, United Kingdom

IAEA-TECDOC-865; CONF-9310459 (Vol. 1); Planning for Environmental Restoration of Radioactively Contaminated Sites in Central and Eastern Europe, Volume 1: Identification and Characterization of Contaminated Soils, Proceedings of a Workshop on Environmental Restoration in Central and Eastern Europe, Budapest, Hungary, October 4-8, 1993. International Atomic Energy Agency, Vienna, Austria, Vol. 1, 356 pp.; (pp. 349-354) (February 1996)

The United Kingdom has a large number of sites on which radioactive materials are used and hence where there is potential for radioactive contamination to occur. It has several power generating reactors with supporting facilities for fuel enrichment and fabrication, spent fuel reprocessing, waste conditioning and low-level waste disposal. It has a nuclear defense capability with a submarine nuclear propulsion program. It is also a major producer and supplier of radioisotopes and associated products. This paper briefly addresses the types, nature and extent of contamination at these sites and the approaches to characterizing the contamination. The problems of radioactive contamination of sites in the UK have generally been very much more limited in number and scale than those experienced in the USA, the former USSR and many of the other countries of Central and Eastem Europe. This has been due to a strict regulatory and planning framework, the location and limited size of the major nuclear sites with the consequent need for more effective operational and waste management practices and the absence of uranium mining and nuclear weapons test facilities within the UK.

1869

V18/020799

Identification and Radiological Characterization of Sites Contaminated Due to Mining and Milling: Methods and Criteria Applied in Germany

Ettenhuber, E.; Roehnsch, W.

Federal Office for Radiation Protection, Berlin, Germany IAEA-TECDOC-865; CONF-9310459 (Vol. 1); Planning for Environmental Restoration of Radioactively Contaminated Sites in Central and Eastern Europe, Volume 1: Identification and Characterization of Contaminated Soils, Proceedings of a 
Workshop on Environmental Restoration in Central and Eastern Europe, Budapest, Hungary, October 4-8, 1993. International Atomic Energy Agency, Vienna, Austria, Vol. 1, 356 pp.; (pp. 143-150) (February 1996)

Conventional mining and milling has been in place in certain parts of Germany for centuries. As the mined ores are frequently accompanied by uranium minerals, radiation protection problems can be associated with such conventional waste. After World War II intensive uranium mining and milling was started, resulting in significant environmental contamination and radiation exposure of the public. Decisions on restoration and remediation of radioactive contaminated sites require systematic investigation and objective evaluation of the existing radiation exposure. On behalf of the Federal Ministry for the Environment, Nature Conservation and Reactor Safety the project is guided by the Federal Office for Radiation Protection (BES). The primary objective of the project is the evaluation of the radiological relevance of contaminated sites and their contribution to radiation exposure. The economic development of the regions concerned is to be taken into account and the public will be informed. In view of the large number and scattering of contaminated sites, a gradual procedure for radiological characterization had to be developed.

\section{0}

\section{V18/022043}

Immunosensing of 2,4-Dichlorophenoxy Acetic Acid Using Biochemical Amplification: Influence of Organic Solvent on Binding Observed by Evanescent Field Technology

Bier, F.F.; Stoecklein, W.F.M.; Ehrentreich-Foerster, E.; Scheller, F.W.

University of Potsdam, Institute for Biochemistry and Molecular Physiology, Berlin-Buch, Germany

CONF-9506232; Environmental Monitoring and Hazardous Waste Site Remediation, T. Vo-Dinh and R. Niessner (eds.), Proceedings of a Conference of the Society of Photo-Optical Instrumentation Engineers, Munich, Germany, June 19-23, 1995. International Society for Optical Engineering, Bellingham, WA, 613 pp.; (pp. 153-157) (1995)

In conventional trace analysis pretreatment of a sample serves to enrich the substance to be detected. Some compounds poliuting the environment are hydrophobic and stick to the soil matrix: therefore organic solvents often are used to prepare samples for environmental analysis. In biochemical analysis the enrichment step may be incorporated in the detection process. The most effective method is the use of immunochemistry; the matrix bound antibodies collect the analyte out of a highly diluted sample. Immunoassays therefore have been introduced successfully for environmental monitoring during the last decade; e.g for pesticides many immunoassays have been developed and some of them are now commercially available. However, despite the fact that selectivity and sensitivity of immunoreactors is high, the capability of producing directly useful signals is poor. Many attempts have been made to overcome this limitation by the use of physical, chemical or biochemical labels. But still there is need for more sensitivity than most immunoassays can achieve. On the other hand immunoassays usually are performed under physiological conditions and only rare data are available about antigen/antibody binding in non-aqueous systems.
1871
V18/022130

Improvement of Characteristics of Solidified Radioactive Waste Forms with Polymer-Concrete Layer

Grebenkov, A.J.; Trubnikov, V.P.; Verzhynskaja, A.B.; Nikolajev, V.A.; Kapustina, I.B.

Academy of Sciences, Institute of Power Engineering Problems, Minsk, Belarus; Academy of Sciences, Institute of Radiation and Physical Chemistry Problems, Minsk, Belarus

CONF-941075; Proceedings of the 18th International Symposium on the Scientific Basis for Nuclear Waste Management, Part 2, T. Murakami, E. Matsuryama and R.C. Ewing (eds.), October 23-27, 1994. Materials Research Society, Pittsburgh, PA, Vol. 353, 690 pp.; (pp. 929-934) (1995)

Within the framework of the Belarus National Program, Institute of Power Engineering Problems (IPEP) is performing research on the immobilization of low level radioactive waste after decontamination and remediation of the Chemobyl Zone. The goal of the R\&D program is to develop a composite matrix for embedding these wastes using special encapsulation technology and a reinforced and hydro-resisting polymer-concrete layer on solidified waste blocks to minimize the amount of cement for conditioning of waste.

1872

V18/023772

\section{Improving Federal Facilities Cleanup: Report of the Federal Facilities Policy Group}

Federal Facilities Policy Group, Office of Management and Budget, Council on Environmental Quality, Washington. DC Report; 57 pp. (October 1995)

This report presents the analysis, conclusions, and recommendations of the Federal Facilities Policy Group (FFPG). convened by the Director of the Office of Management and Budget (OMB) and the chair of the Council on Environmental Quality (CEQ) to review the current stanus and future course of environmental response and restoration at Federal facilities. Specifically, this report identifies area of management and regulatory reform essential to protect public health and restore the environment as well as assure effective, efficient use of resources as the effort to clean up Federal facilities proceeds.

1873

V18/022176

Insitu Vitrification and Removal of Lead-Based Paint for Steel Structures

Covey, S.; Lattimore, L.; Kumar, A.

U.S. Army, Construction Engineering Research Laboratories, Champaign, II

CONF-9509182; Advances in Thermal Spray Science and Technology, C.C. Berndt and S. Sampath (eds.), Proceedings of the Eighth National Thermal Spray Conference, Houston, TX, September 11-15, 1995, ASM International, Materials Park, OH, 795 pp.; (pp. 605-614) (1995)

The feasibility of in-situ vitrification of lead oxide contained in red lead based organic coatings was investigated. The removal of organic lead-based primers and paints has been achieved by a flame spray process that uses a glass/ceramic compound designed for high 
lead solubility and resistance to devitrification. The glass/ceramic compounds were prepared by fusing, fritting, and ball milling to produce the desired powder. The result powder was collected and used to flame spray previously prepared samples containing a commonly used red lead primer. Oxyacetylene flame spray technology was used to apply the glass compound to the steel substrate. The resulting glass waste was collected and analyzed for lead content using Energy Dispersive Spectroscopy (EDS) and $\mathrm{X}$-Ray Diffraction analysis. The lead cation leachability rates were determined by the US Environmental Protection Agency (EPA) approved Toxicity Characteristic Leaching Procedure (TCLP). The designer glass waste form that exhibited the best results was a borosilicate glass with iron oxide additions. The iron silicate glass waste form leached approximately 1 ppm of lead during the TCLP, far below the current $5 \mathrm{ppm}$ limit for hazardous waste.

\section{4}

\section{V18/022094}

Insitu Treatment of Landfill Leachate and Wastes Using Bioventing Technology [November 1995]

Barr, K.D.; O'Flanagan, B.D.; Newman, W.A.; Julik, J.K.; Wetzstein, D.W.

Delta Environmental Consultants, Inc., St. Paul, MN; Minnesota Pollution Control Agency, St. Paul, MN

CONF-951139 (Vol. 2); Superfund 16: Proceedings of a Hazardous Waste Conference and Exhibition, Washington, DC, November 6-8, 1995. E.J. Krause and Associates, Bethesda, MD, Vol. 2, 817 pp.; (pp. 882-891) (1994)

The effectiveness of in-situ, aerobic biodegradation of landfill leachate has been tested by applying bioventing at a closed municipal solid waste landfill in Minnesota. A pilot test was conducted with air injection into a field of six bioventing wells for a six month period, creating an aerobic biotreatment zone for leachate as it migrates to groundwater. Results show that an effective aerobic treatment zone can be established and maintained with organic compounds actively biodegraded and dissolved inorganic compounds, such as metals, oxidized and immobilized. Groundwater contaminants also showed decreasing concentrations during the pilot test. This approach may, ultimately, obviate the need for groundwater removal and treatment.

\section{$1875 \quad$ V18/024363}

Incorporation of Toxicity Testing in Site Assessment and Remediation

Birkholz, D.A.; Rogers, R.; Goudey, J.S.; Sevigny, J.; Calder, L.; Mersereau, $B$.

Enviro-Test Laboratories, Edmonton, Alberta, Canada; Toxcon Inc., Edmonton, Alberta, Canada; HydroQual Laboratories, Calgary, Alberta, Canada; Komex International Limited, Calgary, Alberta, Canada; Shell Canada Products Limited, Calgary, Alberta, Canada; Canadian Turbo Inc., Calgary, Alberta, Canada

CONF-961149; SETAC 17: Partnerships for the Environment Science, Education, and Policy, Proceedings of the 17th Annual Meeting of the Society of Environmental Toxicology and Chemistry, Washington, DC, November 17-21, 1996. Society of Environmental Toxicology and Chemistry, Pensacola, FL, 378 pp.; (p. 178) (1995)
Site remediation for contaminated sites may be conducted following chemical analyses of soil and groundwater for specified chemical parameters. These parameters are defined by regulatory agencies and include analyses for metals, mono-, polyaromatic-, and chlorinated hydrocarbons, phenolic and miscellaneous organic and inorganic compounds. Following analyses, data are scored and regulatory exceedances noted. A site remediation plan may be developed using regulatory guideline criteria (chemical-specific endpoints) or a risk assessment. From an environmental protection point of view, such an approach raises a number of concerns. A limitation of criteria-based approaches revolves around the fact that the number of pollutants identified by the regulatory agencies is very small compared to the number of known chemicals. Therefore cleanup to chemical-specific endpoints raises questions as to the presence of toxic chemicals that may not be listed by the regulatory agencies and which should be included in a site remediation plan. An altemative to the regulatory chemical-specific approach is to use a toxicity-based approach. In addition to collecting regulatory agency chemical-specific data for contaminated groundwater samples from a contaminated site, toxicity identification evaluations were performed. Chemicals of concem identified using the chemical-specific approach were monoaromatic hydrocarbons, whereas the toxicity based approach revealed that the major contributor to toxicity was t-butylphenol. Follow up investigations, revealed that the t-butylphenol was part of an operation that had been missed during the Phase 1 audit of the site.

1876 V18/023401

Indian Tribal View of the Back End of the Nuclear Fuel Cycle: Historical and Cultural Lessons

Tano, M.L.; Reuben, J.H.; Powaukee, D.L.; Lester, A.D.

Radwaste Magazine 3(2):44-47 (March 1996)

Indian tribes of the westem United States, including the Nez Perce Tribe, the Confederated Tribes of the Umatilla Indian Reservation, and the Yakama Indian Nation, have entered into cooperative agreements with the U.S. Department of Energy to oversee the cleanup of the Hanford Reservation, in Washington state. These and other tribes considering involvement in nuclear waste management programs have been subjected to severe criticism from some Indians and non-Indians, accusing them of aiding and abetting the violation of Mother Earth by acquiescing in the contamination of lands by radioactive wastes. We'd like to suggest that this view of the Indian relationship to nature and the environment is too narrow. While the purpose of this article is not to suggest that Indian beliefs support the location of waste management facilities on Indian lands, we will describe aspects of Indian religion and culture that support tribal involvement in radioactive waste management and environmental restoration, and participation in radioactive waste management decision making.

\section{7}

\section{V18/024335}

Influence of Decontamination Wastes Concentrated in Chernobyl Exclusion Zone and Its Evaluation

Ledenev, A.I.; Shirokov, L.V.; Mishunina, I.B.

Virobniche Ob'jednannya Chemobyl's'ka AES, Chernobyl', Ukraine; Ministerstvo Ukrainy po Delam Zashchity Naseleniya ot Posledstvij Avarii na Chemobyl'skoj AEhS, 
Kiev, Ukraine

INIS-UA-026/A; CONF-960002; Chemobyl 96: Results of 10 Years Work on ChNPP Accident Mitigation, Proceedings of the Fifth International Scientific-Technical Conference, N.P. Arkhipov (ed.), Zelenyj Mys, Ukraine, 1996, 526 pp.; (pp. 220-221) (1996)

Short communication. No abstract available. (This document is in Russian).

\section{8}

V18/024650

Insitu Bioremediation Pilot Study at a Former Manufactured Gas Plant Site

English, D.A.; Nelson, J.R.; Hargens, D.A.

Black and Veach Waste Science and Technology Corporation, Kansas City, MO; IES Industries, Inc., Cedar Rapids, IA

Bioremediation of Pollutants in Soil and Water, B.S. Schepart (ed.), Proceedings of a Symposium, Fort Worth, TX, October 14-15, 1993. American Society for Testing and Materials (ASTM), Philadelphia, PA, 265 pp.; (pp. 91-113) (May 1995)

A one-year in situ bioremediation pilot study was implemented in January 1992 at a site contaminated with polynuclear aromatic hydrocarbons, benzene, ethyl benzene, toluene, and xylenes from former manufactured gas plant operations. The objective of the study was to evaluate the effectiveness of in situ bioremediation on high molecular weight hydrocarbons under site conditions. The pilot study involved injecting treated groundwater amended with nutrients and oxygen (in the form of hydrogen peroxide) into the subsurface via an injection well, extracting groundwater through a downgradient extraction well, and periodically monitoring the system using monitoring wells and soil borings. Results indicate that the site hydrogeology, the high concentrations of target and non-target organics, and the presence of pure-phase coal tar in the subsurface limit the cost-effective application of in situ bioremediation at this site.

\section{9}

V18/024687

\section{Insitu Bioremediation, Chapter 7}

Cookson, J.T., Jr.

International Network for Environmental Training, Inc., Potomac, $\mathrm{MD}$

Bioremediation Engineering: Design and Application, G.F. Nalven (ed.), McGraw-Hill, Inc., New York, NY, 539 pp.; (pp. 241-303) (1995)

This is a chapter in the book titled Bioremediation Engineering: Design and Application. In situ treatment is the enhancement of in-place biodegradation of organic compounds within the subsurface or existing waste-holding lagoons. This chapter presents the principles for engineering subsurface in situ treatment systems. In situ bioremediation has several advantages. One is that site disturbance is minimized. This is particularly important when the contaminated plume has moved under permanent structures. Although site characterization and monitoring requirements are more extensive and costly, the cost of removing contaminated material for surface treatment is frequently greater. The biggest limitation of in situ bioremediation has been the inability to deal effectively with metal contaminants mixed with organic compounds. New technologies such as electrokinetic techniques may prove effective when combined with in situ bioremediation in addressing this deficiency. In the past year, the combining of soil venting with in situ bioremediation, bioventing, has gained popularity. Using combinations of new techniques, sites contaminated with volatile compounds can be cleaned up in a shorter time at reduced cost. The major engineering challenge is the design of a delivery and recovery system that provides for a responsive control of the subsurface environment, and a monitoring system that provides data for process optimization.

1880

\section{V18/024666}

Insitu Liquid/Solids Treatment of Petroleum Impoundment Sludges: Engineering Aspects and Field Applications, Chapter 10

Coover, M.P.; Kabrick, R.M.; Stroo, H.F.; Sherman, D.F.

Remediation Technologies, Inc., Seattle, WA; Remediation Technologies, Inc., Austin, TX; Remediation Technologies, Inc., Billings, MT

Bioremediation: Field Experience, P.E. Flathman, D.E. Jerger and J.H. Exner (eds.), Lewis Publishers, Boca Raton, FL, 560 pp.; (pp. 197-224) (1994)

Liquids/solids treatment (LST) is recognized as a competitive technology for bioremediation of petroleum refinery sludges. The process is similar to activated sludge treatment of municipal and industrial wastewater but is conducted at substantially higher suspended solids and organic substrate concentrations. LST is applicable to remediation of impoundments containing petroleum or petrochemical sludges under Superfund or Resource Conservation and Recovery Act (RCRA) programs. Primary and Secondary refinery sludges (i.e., F037 and F038) are listed hazardous wastes under the RCRA program and have established treatment standards that are applicable when land disposal of the treated material is anticipated. These are referred to as Best Demonstrated and Available Technology (BDAT) standards. Data are presented in this chapter that indicate that BDAT standards can, under certain conditions be achieved by LST. Nonlisted refinery wastes can be characteristically hazardous if they fail the Toxicity Characteristic Leaching Procedure (TCLP) test. The parameter of greatest concern in the application of TCLP criteria is benzene, which has a regulated concentration of $0.5 \mathrm{mg} / \mathrm{L}$. Benzene and associated volatile organics can be removed during SLT through a combination of biological treatment and physical or thermal unit operations (e.g., carbon adsorption of off-gas combustion). LST technology has been used successfully for the closure of an impoundment containing toxicity characteristic waste by treating the material to nonhazardous levels. LST technology can be applied using tank-based systems or in situ treatment for remediation of impoundments. The focus of this chapter is on the application of LST technology in situ. A discussion of strategies for implementing LST in situ treatment is provided, and important field applications of the technology are briefly reviewed. The case history of a one million gallon ( 3.8 million L) LST pilot-demonstration project is presented. This chapter is from the book entitled Bioremediation: Field Experience.

1881 V18/020602

Installation Restoration Program: Surveillance and Oversight of Remedial Actions at Site 2 and Site 4 - 
Completion Report for Alpena Combat Readiness Training Center, Alpena Michigan

Montgomery Watson, Novi, MI

Report; 261 pp. (February 1996)

This report documents remediation activities through completion at Site 2 and Site 4 of the Alpena Combat Readiness Training Center (CRTC) in Ajpena, Michigan. Contaminated soils were remediated from May 1995 through August 1995 using a combination of stabilization, in-situ bioremediation, and exsitu bioremediation technologies. Remediation activities were completed by Unico Construction Company, Inc. (the general contractor) and CCC Group, Inc. (a subcontractor) both of San Antonio, Texas.

\section{2}

\section{V18/021698}

Installation Restoration Research Program: Review of the Utility of Natural Attenuation for Remediating Contaminated Army Sites

Balasco, A.A.; Bowen, R.C.; Cahill, K.R.; Mahannah, J.L.

Arthur D. Little, Inc., Cambridge, MA

WES-CR-IRRP-96-1; 134 pp. (August 1996)

Natural attenuation, or intrinsic bioremediation, was investigated as an innovative approach to site remediation. This process, based on the concept that contamination in groundwater, soils, and surface water can be reduced to environmentally benign levels through natural processes, is becoming increasingly popular with both regulators and the parties responsible for remediation. A review was conducted of the available scientific literature for sites at which natural attenuation has been observed or selected for implementation, including several database searches. In addition, Federal and state regulators were interviewed to identify the conditions necessary for regulatory acceptance of natural attenuation. The final phase of the study involved assessing the available technical data to support the selection of natural attenuation at contaminated Army sites. The study results demonstrate reasonable potential for implementation of natural attenuation at Army sites, provided that site-specific characteristics support its selection. Laboratory studies and field demonstrations are recommended to assess the potential for biodegradation of military unique compounds such as explosives and energetics, since these materials have not been demonstrated to be as susceptible to natural attenuation via biodegradation.

1883

\section{$\mathrm{V} 18 / 021424$}

Integrated Chemical/Biological Treatment of a Paint Stripper Mixed Waste: Metals Toxicity and Separation

Vanderberg-Twary, L.; Grumbine, R.K.; Foreman, T.M.; Hanners, J.L.; Brainard, J.R.; Sauer, N.N.; Unkefer, P.J.

Los Alamos National Laboratory, Chemical Science and Technology Division, Los Alamos, NM

CONF-950877; Mixed Waste, A.A. Moghissi, B.R. Love and R.K. Blauvelt (eds.), Proceedings of the Third Biennial Symposium, Baltimore, MD, August 7-10, 1995, 545 pp.; (pp. 11.7.1-11.7.6) (1995)

The U.S. Department of Energy (DOE) complex has generated vast quantities of complex heterogeneous mixed wastes. Paint stripper waste (PSW), is a complex waste that arose from decontamination and decommissioning activities. It contains paint stripper, cheesecloth, cellulose-based paints with $\mathrm{Pb}$ and $\mathrm{Cr}$, and suspect $\mathrm{Pu}$. Los Alamos National Laboratory has $150-200$ barrels of heterogeneous waste. Few technologies exist that can treat this complex waste. Our approach to solving this problem is the integration of two established technologies: biodegradation and metals chelation. Bioremediation of hazardous organics found in paint stripper has been demonstrated in our laboratory. A defined consortium ( $1 \mathrm{~g} / \mathrm{L}$ dry weight cells) in minimal salts medium mineralized $50 \mathrm{ppm}$ each of dichloromethane (DCM), toiuene, and acetone simultaneously in $24 \mathrm{~h}$. At higher concentrations of solvents, this mixture was degraded within $48 \mathrm{~h}$. Analytical techniques included head space analysis by gas chromatography-mass spectrometry and spectrophotometry. Actively growing cultures of individual consortium members were exposed to $\mathrm{Cr}(\mathrm{VI})(1-100 \mathrm{ppm})$ as $\mathrm{K} 2 \mathrm{CrO} 4, \mathrm{Cr}(\mathrm{III})(5-500 \mathrm{ppm})$ as $\mathrm{CrN3O9}$ (9H2O), or $\mathrm{Pb}(50-1000 \mathrm{ppm}$ ) as $\mathrm{Pb}(\mathrm{NO} 3) 2$ for $24 \mathrm{~h}$. Expected concentrations of metals in PSW are: $\mathrm{Cr}$ (combined) less than $100 \mathrm{ppm}, \mathrm{Pb} 200-1000 \mathrm{ppm}, \mathrm{Pu}$ much less than $100 \mathrm{ppm}$. Concentrations of $1 \mathrm{ppm} \mathrm{Cr(VI)} \mathrm{and} 500 \mathrm{ppm} \mathrm{Cr}$ (III) resulted in $95 \%$ toxicity to the bacterial cuitures as determined by dilution plating. $\mathrm{Pb}(1000 \mathrm{ppm})$ caused a $50 \%$ reduction in growth. Various types and combinations of metal chelators were ineffective at sequestering metals from microbes. Combining bioremediation and metals chelation results in an environmentally benign, cost effective technology to treat PSW. This technology may also prove applicable to a variety of other complex waste streams.

\section{$1884^{\cdot} \quad \mathrm{V} 18 / 023353$}

International PCB Remediation: The Scarification of $15,000 \mathrm{sq} \mathrm{m}$ Facility in Finland

Electricity Today 8(10):35,46 (November-December 1996)

The decontamination of 165,000 square feet of concrete floor in a former transformer manufacturing plant in Vaasa, Finland is discussed. Waste Management International (WMI) was contracted to remove PCBs beyond detectable limits and to collect the contaminated concrete, all within a two month period. Initial attempts to remove the PCBs by power washing techniques were unsuccessful. Actual physical removal by scarifying the concrete was used instead, utilizing Pentek's mechanical scabbling robot, the Moose. The Moose removed and captured the contaminated concrete to the required depth with pneumatically driven tungsten carbide tipped bits. The project was completed three weeks ahead of schedule.

\section{$1885 \quad$ V18/023211}

International School of Innovative Technology for Cleaning the Environment - Ettore Majorana Centre for Scientific Culture, Erice, Sicily, Italy

Ragaini, R.C.

Lawrence Livermore National Laboratory, Livermore, CA CONF-9210194; Proceedings of an International Symposium on Environmental Contamination in Central and Eastern Europe, Budapest, Hungary, October 12-16, 1992, 968 pp.; (pp. 398-400) (1992)

The International School of Innovative Technology for Cleaning 
the Environment was founded at the Ettore Majorana Centre for Scientific Culture (EMCSC), the seat of the World Laboratory Mediterranean Branch, in 1989. The School primarily organizes and hosts training courses and advanced study courses addressing state-of-the-art technologies to clean the environment, minimize waste generation, prevent pollution, and identify strategies to choose environmentally resilient sites and processes for new industrial installations. The School also participates in facilitating multi-national research projects for developing countries under the auspices of the World Laboratory and other sponsoring agencies.

\section{6}

V18/021693

\section{Intrinsic Remediation of an Industrial Waste Impoundment}

Swindoll, C.M.; Lee, M.D.; Wood, K.N.; Hartten, A.S.; Bishop, A.L.; Connor, J.M.

CONF-9511137; Global Environmental Protection: Science, Politics, and Common Sense, Proceedings of the Second Society of Environmental Toxicology and Chemistry (SETAC) World Congress and 16th Annual Meeting, Vancouver, British Columbia, Canada, November 5-9, 1995. Society of Environmental Toxicology and Chemistry, Pensacola, FL, 378 pp.; (p. 236) (1995)

Intrinsic remediation, also known as natural restoration, was evaluated as a potential corrective action alternative for an industrial surface impoundment previously used for the disposal of waste treatment biosolids, organic wastes, and fly ash. Organic waste constituents included chlorobenzene, aniline, xylenes, benzene, toluene, acetone, p-cresol, 2-butanone, fluorene, and ethylbenzene. The evaluation demonstrated that the impoundment contains an active microbial community including aerobic, denitrifying, sulfate-reducing, and methanogenic microbes, and that environmental conditions were favorable for their growth. Laboratory studies confirmed that these microbes could biodegrade the organic waste constituents under varying redox conditions. The sorptive properties of the residual biosolids and fly ash contribute to the immobilization of chemical constituents and may enhance biodegradation by sequestering chemicals onto surfaces where microbes grow. Based on this field and laboratory evaluation, it was concluded that intrinsic remediation offers significant environmental benefits over other corrective action alternatives that would not allow these natural restoration processes to continue in the surface impoundment.

\section{7 V18/020807}

Investigation and Remediation of a Chlorobenzene Spill: A Case Study

Donovan, E.J., Jr.; Sparrow, L.A.

HydroQual, Inc., Mahwah, NJ

CONF-9507204; Hazardous and Industrial Wastes, A.K. Sengupta (ed.), Proceedings of the 27th Mid-Atlantic Industrial Waste Conference, Bethlehem, PA, July 9-12, 1995. Technomic Publishing Company, Lancaster, PA, 973 pp.; (pp. 918-927) (1995)

During the remedial investigation of an industrial facility, an area containing elevated concentrations of chlorobenzene in the soil and groundwater was identified. No record of chlorobenzene use or reference to a spill could be found at the site, which had recently been shut down after more than 80 years of operation. The lack of historical information suggested that the spill occurred at least 20 years prior. The area, located in New Jersey, was adjacent to railroad tracks frequented by chemical tanker cars. The site has been under an Administrative Consent Order (ACO) with the New Jersey Department of Environmental Protection (NJDEP) since 1988 to investigate and remediate contamination at the site. Except for the chlorobenzene, only minor amounts of volatile organics had been found elsewhere on the site.

1888

V18/021725

Investigation of Procedures and Economics of Spill Site Remediation in Southeast New Mexico

Abbott, D.; Hillard, J.D.

CONF-950433; Proceedings of a Society of Petroleum Engineers Production Operations Symposium, Oklahoma City, OK, April 2-4, 1995. Society of Petroleum Engineers, Richardson, TX, 992 pp.; (pp. 391-394) (1995)

A pilot field study was initiated to evaluate the feasibility of remediating produced water and hydrocarbon contaminated soils along produced water gathering lines and disposal facilities in Southeast New Mexico. The soils were contaminated by leaks occurring adjacent to gathering lines and along Right-of-Ways over a 30 year time frame.

1889

V18/021043

Jet Fuel Investigation at an Abandoned Tank Farm at Nas Adak, Alaska

Sagstad, S.R.; Boehike, C.M.; Lovely, A.W.; Hortwitz, S. EMCON Northwest, Inc., Bothell, WA; U.S. Navy, EFA Northwest, Silverdale, WA

CONF-940499 (Vol. 1); Proceedings of the 1994 Federal Environmental Restoration III and Waste Minimization II Conference and Exhibition, New Orleans, LA, April 27-29, 1994. Hazardous Materials Control Resources Institute, Rockville, MD, Vol. 1, 783 pp.; (pp. 695-702) (1994)

An investigation was performed to evaluate petroleum hydrocarbon impacts to soil and groundwater in a former tank farm area located at Naval Air Station (NAS) Adak, Adak Island, Alaska. This mountainous volcanic island lies approximately midway down the Aleutian Island chain, off the west coast of mainland Alaska. A portion of the island has been used as a military installation since 1942. NAS Adak currently occupies the northern half of Adak island; the southem half of the island is a national wildlife refuge. EMCON Northwest, Inc. (EMCON), was contracted to perform a Release Investigation in the Tank Farm A area of NAS Adak. The investigation focused on abandoned tanks, pipelines, known or suspected leaks, and releases. The study area included the former Tank Farm A fuel storage area and an area near the southern end of Runway 18-36. EMCON is working closely with the Navy to identify an initial remedial system to remove fuel plumes and to prevents sheens in an adjacent fisheries stream. Several potential interim remedial actions have been identified. They include removal of floating product in monitoring wells, use of floating booms to absorb product on surface water, and controlling drawdowns in surface water bodies. The possible diversion of contaminated surface 
water into engineered wetlands is also being explored.

1890

$$
\text { V18/024034 }
$$

\section{LLNL Finds Nature Can Help California Cleanup} Leaking Underground Fuel Tanks

TIE Quarterly 5(2):13 (Fall 1996/Winter 1997)

A Lawrence Livermore National Laboratory (LLNL) study found billions of dollars can be saved and thousands of acres can be returned for beneficial use if California adopts new approaches to cleaning up its leaking underground fuel tanks (LUFTs). The study was a collaborative effort by a team of LLNL and University of California, Los Angeles, Santa Barbara, Davis, and Berkeley scientists. The study was performed for the Califormia State Water Resources Control Board which regulates cleanup of the LUFTs.

\section{1}

V18/021668

Legal Aspects of Abandoned Facilities

\section{Ratliff, R.A.}

Texas Bureau of Radiation Control, Austin, TX

CONF-9505336; Proceedings of the 27th Annual National Conference on Radiation Control, San Antonio, TX, May 7-10, 1995, Conference of Radiation Control Program Directors, Inc., Frankfort, KY, 364 pp.; (pp. 68-70) (1995)

This paper outlines the basic regulatory requirements needed to identify radioactive material licensee owners/operators. Basic actions that must be taken once a radioactive material site is abandoned are also listed. Two such actions in Texas are briefly described. Civil suits requesting penalties, injunctive relief for decontamination, and recovery of response costs pursuant to the Texas regulatory acts have been filed against the potentially responsible parties.

\section{2}

\section{V18/024689}

\section{Liquid-Phase Bioremediation, Chapter 9}

Cookson, J.T., Jr.

International Network for Environmental Training, Inc., Potomac, MD

Bioremediation Engineering: Design and Application, G.F. Nalven (ed.), McGraw-Hill, Inc., New York, NY, 539 pp.; (pp. 359-432) (1995)

This is a chapter in the book titled Bioremediation Engineering: Design and Application. Liquid-phase bioremediation is the application of surface bioreactors to the treatment of water contaminated with hazardous chemicals. They support the growth and retention of desired microorganisms under optimized process conditions. Reactor design requires the integration of biological concepts with reaction kinetics, mass transfer, and the flow characteristics of the contacting unit. The design principles for liquid-phase bioremediation originate with municipal and industrial wastewater treatment. The application of biological processes to the treatment of hazardous chemicals frequently necessitates changes in equipment and process configuration. It is not the intent to provide the theory and principles of bioreactor design in this text. Texts are available that address design principles for suspended and fixed-film biological reactors. A review is provided on the kinetics and predictive models for bioreactor design. The objective of this chapter is to emphasise differences in design when applying biological processes to hazardous chemicals in groundwater versus municipal-industrial wastewater. Available information is provided to design criteria and system performance for bioremediation of hazardous chemicals.

V18/022099

Low Cost, High Performance Remotely Controlled Backhoe/Excavator

Rizzo, J.

Benthos Inc., North Falmouth, MA

CONF-951139 (Vol. 1); Superfund 16: Proceedings of a Hazardous Waste Conference and Exhibition, Washington, DC, November 6-8, 1995. E.J. Krause and Associates, Bethesda, MD, Vol. 1, 828 pp.; (pp. 709-713) (1994)

This paper addresses a state of the art, low cost, remotely controlled backhoe/excavator system for remediation use at hazardous waste sites. The all weather, all terrain, Remote Dig-It is based on a simple, proven construction platform and incorporates state of the art sensors, control, telemetry and other subsystems derived from advanced underwater remotely operated vehicle systems. The system can be towed to a site without the use of a trailer, manually operated by an on board operator or operated via a fiber optic or optional RF communications link by a remotely positioned operator. A proportional control system is piggy backed onto the standard manual control system. The control system improves manual operation, allows rapid manual/remote mode selection and provides fine manual or remote control of all functions. The system incorporates up to 4 separate video links, acoustic obstacle proximity sensors, and stereo audio pickups and an optional differential GPS navigation. Video system options include electronic panning and tilting within a distortion-corrected wide angle field of view. The backhoe/excavator subsystem has a quick disconnect interface feature which allows its use as a manipulator with a wide variety of end effectors and tools. The Remote Dig-It was developed to respond to the need for a low-cost, effective remediation system for use at sites containing hazardous materials. The prototype system was independently evaluated for this purpose by the Army at the Jefferson Proving Ground where it surpassed all performance goals. At the time of this writing, the Remote Dig-It system is currently the only backhoe/excavator which met the Army's goals for remediation systems for use at hazardous waste sites and it costs a fraction of any known competing offerings.

\section{4}

\section{V18/021079}

Low-Level Radioactive Waste Management: Proceedings of the 17th Annual U.S. DOE Waste Management Conference, Phoenix, AZ, December 12-14, 1995

CONF-951209; Proceedings of the 17th Annual U.S. Department of Energy Low-Level Radioactive Waste Management Conference, D. Lake (ed.), Phoenix, AZ, December 12-14, 1995, 480 pp. (1995)

The goal of the US DOE Low-Level Radioactive Waste Management Conference is to provide an opportunity for information exchange between representatives of the commercial and defense related low-level radioactive waste management 
communities. Attendees and participants represent the DOE and their contractors, other Federal agencies, State and compact officials, generators (e.g., utilities, hospital research groups, and manufacturing), and public interest groups such as local citizens advisory groups. Papers considered to be within the scope of this database are indexed separately.

\section{$1895 \quad$ V18/025659}

Malsch Toxic Waste Dump: Potential Dangers and Impact and Goals and Concepts for Remedial Action

Guenther, K.; Huba, R.P.

Sondermuellbetriebsgesellschaft mbH, Fellbach-Schmiden, Germany; Wasser- und Abfalltechnik Ingenieurgesellschaft mbH und Company KG, Karlsruhe, Germany

Wasser und Boden 48(12):55-58 (1997)

The contents of a filled toxic waste dump in Malsch were physically and chemicaily characterized, and emissions from the dump were quantified. A remedial action plan was subsequently prepared and carried out. The project was completed in the spring of 1996 with a total investment of 100 million German marks. Definition of the project goals is explained using groundwater as an important example of the resources to be protected. (This document is in German).

\section{6}

V18/024682

\section{Managing a Bioremediation Project, Chapter 2}

Cookson, J.T., Jr.

International Network for Environmental Training, Inc., Potomac, $\mathrm{MD}$

Bioremediation Engineering: Design and Application, G.F. Nalven (ed.), McGraw-Hill, Inc., New York, NY, 539 pp.; (pp. 27-50) (1995)

This is a chapter in the book titled Bioremediation Engineering: Design and Application. Groundwater and soil remediation are both a technical and management challenge. Although this can be said for any engineering project, bioremediation of hazardous substances demands the highest of skills. The number of scientific and technical disciplines that must be coordinated with several regulatory agencies and citizens requires the best that management can deliver. For a successful project, management is as important as technology, and they are so tightly integrated that it is sometimes difficult to separate their components. A successful project is the net result of four major components: good negotiation, good project management, good engineering, and good implementation of field operations. In this section, the project management of bioremediation is discussed. The balance of this text addresses the engineering and field operations. The project manager orchestrates the necessary inputs from many disciplines. This requires adequate technical knowledge on bioremediation so appropriate limits are placed on the scope of each effort, while ensuring adequate data for successful design and operation. From a discussion standpoint, a bioremediation project can be grouped in the following phases: defining the project and goals, assembling the project team, initial review of remediation options, screening and selecting remediation alternatives for detail evaluation, developing a design concept, developing the supporting elements of the project, designing and conducting laboratory treatability testing, designing and conducting field pilot testing, revising process design, obtaining final approvals, performing field remediation activities, and obtaining site closure.

1897

V18/023646 Mercury-Contaminated Sludge Treatment by Dredging
in Minamata Bay

Yoshinaga, $\mathrm{K}$.

Ministry of Transport, Niigata, Japan

CONF-9406413; Dredging, Remediation, and Containment of Contaminated Sediments, K.R. Demars, G.N. Richardson, R.N. Yong and R.C. Chaney (eds.), Proceedings of a Symposium, Montreal, Quebec, Canada, June 23-24, 1994, 343 pp.; (pp. 182-191) (1995)

To eradicate Minamata Disease, caused by the discharge of sewage containing methyl mercury and its accumulation in fish and shellfish through the food cycle, a large-scale sediment disposal project was conducted with special care taken to prevent new pollution resulting from the project itself. The basic approach to sediment disposal was to construct a highly watertight revetment to reclaim the inner area of the bay and then confine sediment dredged from the remaining contaminated area in the reclamation area through surface treatment. Before sediment disposal, boundary nets were installed to enciose the work area to prevent the mixing of contaminated and noncontaminated fish. Dredging work was successfully carried out by using four cutterless suction dredgers, newly developed in advance for minimizing resuspension of sediments. Dredged material was discharged into the reclamation area, filled up to sea level, and covered.with a sandproof membrane, lightweight volcanic ash earth, and mountain soil.

1898

V18/021585

Methods and Techniques Used to Rehabilitate Radioactively Contaminated Sites in the United Kingdom

Fellingham, L.R.; Moreton, A.D

AEA Technology, Harwell Laboratory, Engineering Services Division, Didcot, Oxfordshire, United Kingdom

IAEA-TECDOC-865; CONF-9412128 (Vol. 3); Planning for Environmental Restoration of Radioactively Contaminated Sites in Central and Eastern Europe, Volume 3: Technologies for, and the Implementation of Environmental Restoration of Contaminated Sites, Proceedings of a Workshop on Environmental Restoration in Central and Eastern Europe, Rez, Czech Republic, December 12-16, 1994. International Atomic Energy Agency, Vienna, Austria, Vol. 3, 356 pp.; (pp. 281-287) (May 1996)

In the early years of radioactive materials use, the quality of control and waste management practices were of a considerably lower standard than those acceptable today. As a consequence a large number of sites in the United Kingdom (UK) became contaminated to varying degrees with radioactive materials. The vast majority of these sites were very small in size and were linked to either radium or thorium operations or research applications. The net consequence has been that the vast majority of the rehabilitation work in the UK has been on a small scale and has not merited the use of innovative techniques. However, a number of innovative remediation techniques are under development in the UK for future 
cleanup programs and some have attained full-scale application. These will be described in this paper. Three development areas are described in detail, namely, (1) the application of separation process from minerals processing; (2) the BNFL 'Cacitox' process; and (3) electroremediation.

1899

V18/020598

Methods of Planning and Preparation for Restoration of Belarus Territories Contaminated with Radionuclides as a Result of the Chernobyl Accident

Sharovarov, G.A.

Academy of Sciences, Minsk, Belarus

IAEA-TECDOC-865; CONF-9404316 (Vol. 2); Planning for Environmental Restoration of Radioactively Contaminated Sites in Central and Eastern Europe, Volume 2: Planning for Environmental Restoration of Contaminated Sites, Proceedings of a Workshop on Environmental Restoration in Central and Eastem Europe, Piestany, Slovakia, April 11-15, 1994. Intemational Atomic Energy Agency, Vienna, Austria, Vol. 2, 248 pp.; (pp. 25-41) (March 1996)

Up to 1994, the restoration of contaminated territories has not been practically carried out. The problems of carrying out the restoration, methods of planning and preparation for it based on the "cost-benefit" analysis are considered. Technical and economic aspects of the restoration of contaminated territories are analyzed. It is shown that the combined methods of clean-up are the most promising. Determination of the advisability of clean-up is carried out on the basis of an economic evaluation of risk when a person is chronically exposed to $1 \mathrm{man}$-rem, with allowance for risk factors: premature death, shortening of lifetime, loss of ability to work, reduction in life standards. It should be recognized that restoration must be done in coordination with several regions, as the isolated clean-up of a single region can Iead to its secondary contamination. Determination of the clean-up consequences of the affected regions is an important problem. In addition, common criteria and methods should be worked out for all countries with contaminated territories. It would be advisable to create an united financial center and an international group of executors. 10 refs, 5 figs, 1 tab.

\section{$1900 \quad$ V18/024685}

Microbial Detoxification of Specialty Chemicals, Chapter 5

Cookson, J.T., Jr.

International Network for Environmental Training, Inc., Potomac, MD

Bioremediation Engineering: Design and Application, G.F. Naiven (ed.), McGraw-Hill, Inc., New York, NY, 539 pp.; (pp. 165-203) (1995)

This is a chapter in the book titled Bioremediation Engineering: Design and Application. The microbial degradation of many organic compounds are discussed in Chapter 4. They respond similarly to microbial degradation for each chemical category. They also are found present as a mixture on many contaminated sites. There are a few chemicals that for one or more reasons don't fall into a generalized discussion. This may result from the uniqueness of their chemical structure or from their use patterns by society and interaction with the environment. This category includes the specialty chemicals that are designed for very specific uses. They are the pesticides and their subcategories of insecticides, herbicides and fungicides, polychlorinated biphenyls, and azo dyes. Several chemicals of each are examined with regard to their treatability by bioremediation.

\section{$1901 \quad$ V18/024683}

Microbial Systems of Bioremediation, Chapter 3

Cookson, J.T., Jr.

International Network for Environmental Training, Inc., Potomac, MD

Bioremediation Engineering: Design and Application, G.F. Nalven (ed.), McGraw-Hill, Inc., New York, NY, 539 pp.; (pp. 51-93)

This is a chapter in the book titled Bioremediation Engineering: Design and Application. This chapter discusses the basic microbial systems and requirements for successful bioremediation. It covers the principles of microbial metabolism, enzyme catalyzed reactions, and requirements for biological processes important to bioremediation. It discusses the nature of biochemical reactions and the mechanisms by which microorganisms mediate degradation of hazardous compounds.

1902

V18/021230

Microbiological Method for Purification of Radioactive and Chemically Polluted Water from the Ronneburg Sanitation Site: Part 1, Laboratory Method - Final Report of the Preliminary Phase

Glombitza, F.; Hummel, A.; Loeffler, R.

C\&E Consulting und Engineering $\mathrm{GmbH}$, Sektion Umweltmikrobiologie, Chemnitz, Germany:

Report; 58 pp. (December 15, 1994)

This project investigated the depolymerization/bioconversion potential of fungi of different ecophysiological groups for native coals and selected coal model structures (with characteristic coal structure elements: Condensed aromatic hydrocarbons, ether bridges, short aliphatic sections between aromatic structure). Fungi were investigated because they are the only systems that can efficiently attack aromatic macromolecules (e.g. lignine) by means of extracellular enzyme systems. (This document is in German).

1903

V18/023968

Military Munitions Rule: RCRA Information Brief EH-411-097/0002; 4 pp. (April 1997)

On February 12, 1997, the Environmental Protection Agency (EPA) issues the final version of Military Munitions Rule: Hazardous Waste Identification and Management; Explosives Emergencies; Manifest Exemption for Transport of Hazardous Waste on Right-of-Ways on Contiguous Properties. The rule identifies when conventional and chemical military munitions become a hazardous waste under the Resource Conservation and Recovery Act (RCRA), and provides for the safe storage and transport of these wastes. The rule also amends existing regulations regarding emergency responses involving both military and 
non-military munitions and explosives. In addition, the rule exempts all generators who have contiguous properties divided by public right-of-ways from the RCRA manifest and transporter Hazardous Waste Identification requirements when transporting hazardous waste between or along the border of their contiguous properties. The rule does not finalize provisions regarding the solid waste status of military munitions on closed and transferred ranges. EPA has decided to postpone action for further analysis of comments received on the proposed Military Munitions Rule and an analysis of the Department of Defense (DOD) Range Rule. The DOD Range Rule will govern the cleanup of munitions on closed, transferring, and transferred ranges.

\section{4}

V18/023504

\section{Minimizing Waste in Environmental Restoration [June} 1996]

Thuot, J.R.; Moos, L.P.

Argonne National Laboratory, Argonne, IL

CONF-9606116; Proceedings of an American Nuclear Society

(ANS) Annual Meeting, Reno, NV, June 16-20, 1996. ANS, La Grange Park, IL; Transactions of the American Nuclear Society $74: 89$ (1996)

Environmental restoration, decontamination and decommissioning, and facility dismantlement projects are not typically known for their waste minimization and pollution prevention efforts. Typical projects are driven by schedules and milestones with little attention given to cost or waste minimization. Conventional wisdom in these projects is that the waste already exists and cannot be reduced or minimized; however, there are significant areas where waste and cost can be reduced by careful planning and execution. Waste reduction can occur in three ways: beneficial reuse or recycling, segregation of waste types, and reducing generation of secondary waste.

\section{5}

\section{V18/023657}

Modeling the Washoff of Sr-90 and Cs-137 from an Experimental Plot Established in the Vicinity of the Chernobyl Reactor

Nair, S.K.; Hoffman, F.O.; Thiessen, K.M.; Konoplev, A.V. SENES Oak Ridge, Inc., Oak Ridge, TN; Institute of Experimental Meteorology, Obninsk, Russian Federation

Health Physics 71(6):896-909 (December 1996)

After the Chemobyl event, a large area of land was contaminated following the deposition of radionuclides. This area became a continuing source of radionuclides to natural waters and aquatic ecosystems. In 1986 an experimental plot was constructed in a contaminated area near the Chemobyl Nuclear Power Plant to study the washoff of radionuclides by surface runoff. Concentrations of Cs-137 and Sr-90 were measured in the top $10 \mathrm{~cm}$ of the soil prior to the experiments. During two separate experiments, intense artificial rainfall was applied to the plot. A washoff scenario was prepared with site-specific information on initial soil contamination, duration and quantities of rainfall and runoff, physicochemical properties of the topsoil, and some climatological data. Modelers were asked to predict: (a) the vertical distributions of the initial concentrations of $\mathrm{Cs}-137$ and $\mathrm{ST}-90$ in various chemical forms in the topsoil, (b) concentrations of these radionuclides in various chemical forms in the runoff water during each experiment, and (c) the total amounts of these radionuclides in various chemical forms in the runoff water during each experiment, and (c) the total amounts of these radionuclides that were washed off during each experiment. A vertical, one-dimensional, multiphase, multispecies transport model was then developed to simulate the movement of contaminants in the topsoil during the 160 day period between the Chernobyl event and the experiments as well as the washouts of contaminants by runoff during the experiments and during the 24 hour period thereafter. The model provided very good predictions of the vertical distributions of total contaminant concentrations in the top $10 \mathrm{~cm}$ of the soil; however, the concentrations in individual chemical forms were not predicted as accurately. The complete modeling approach and comparisons of model predictions with measurements and with predictions from other modelers are presented.

\section{6}

\section{V18/023226}

Monitoring Program for the Evaluation of the Pollution Level of the Italian Harbour Sediments: I - General Description

Caricchia, A.M.; Chiavarini, S.; Cremisini, C.; Morabito, R.; Brondi, A.; Vitali, M.

Energie Nucleare e delle Energie Alternative (ENEA), Centro Ricerche Energia, Casaccia, Rome, Italy; Universita di Roma La Sapienza, Instituto di Igiene, Rome, Italy

CONF-9210194; Proceedings of an International Symposium on Environmental Contamination in Central and Eastem Europe, Budapest, Hungary, October 12-16, 1992, 968 pp.; (pp. 537-539) (1992)

One hundred twenty sediment cores were sampled in the main Italian harbour basins, obtaining a total of 360 samples (three subsamples at different depth levels for each core). All the samples were analyzed for several parameters including physical characteristics, microbiological contamination indices, inorganic pollutants. Thirty six selected samples were analyzed for organic micropollutants as well. In particular PCB, chlorinated pesticides, polycyclic aromatic hydrocarbons $(\mathrm{PAH})$ and organotin compounds were considered. A general description of the whole project as well as a description of the sampling sites were reported. This paper gives a description of the overall sampling program, sampling locations, and the analyte suite.

V18/023227

Monitoring Program for the Evaluation of the Pollution Level of the Italian Harbour Sediments: II - Analytical Methods

Bernabei, M.; Caricchia, A.M.; Chiavarini, S.; Cremisini, C.; Martini, F.; Morabito, R.

Energie Nucleare e delle Energie Alternative (ENEA), Centro Ricerche Energia, Environmental Chemistry Division, Casaccia, Rome, Italy

CONF-9210194; Proceedings of an International Symposium on Environmental Contamination in Central and Eastem Europe, Budapest, Hungary, October 12-16, 1992, 968 pp.; (pp. 540-542) 
One hundred twenty sediment cores were sampled in the main Italian harbour basins, obtaining a total of 360 samples (three subsamples at different depth levels for each core). All the samples were analyzed for several parameters including physical characteristics, microbiological contamination indices, inorganic pollutants. Thirty six selected samples were analyzed for organic micropollutants as well. In this paper analytical methodologies for PCBs, chlorinated pesticides, polycyclic aromatic hydrocarbons (PAHs) and organotin compounds are described.

\section{8}

VI8/023228

Monitoring Program for the Evaluation of the Pollution Level of the Italian Harbour Sediments: III - Results

Caricchia, A.M.; Chiavarini, S.; Cremisini, C.; Fantini, M.; Morabito, R.

Energie Nucleare e delle Energie Alternative (ENEA), Centro Ricerche Energia, Environmental Chemistry Division, Casaccia, Rome, Italy

CONF-9210194; Proceedings of an International Symposium on Environmental Contamination in Central and Eastern Europe, Budapest, Hungary, October 12-16, 1992, 968 pp.; (pp. 542-544)

(1992)

One hundred twenty sediment cores were sampled in the main Italian harbour basins, obtaining a total of 360 samples (three subsamples at different depth levels for each core). All the samples were analyzed for several parameters including physical characteristics, microbiological contamination indices, inorganic pollutants Thirty six selected samples were analyzed for organic micropollutants as well. In this paper the results obtained for PCBs, chlorinated pesticides, polycyclic aromatic hydrocarbons (PAHs) and organotin compounds are reported and discussed with reference to international legislative requirements.

1909

V18/023546

Multibarrier Insitu Confinement of Radioactive Wastes: An Option for Long-Term Management?

Craig, D.R.

AEA Technology, Dounreay Site, Thurso, Caithness, Scotland, United Kingdom

CONF-941124; Insitu Remediation: Scientific Basis for Current and Future Technologies, G.W. Gee and N.R. Wing (eds.), Proceedings of the 33rd Hanford Symposium on Health and the Environment, Pasco, WA, November 7-11, 1994. Battelle Press, Columbus, OH, Part 1, 704 pp.; (pp. 37-59) (1994)

AEA Technology has two intermediate-level waste facilities on the Dounreay Site which are currently the subject of options studies for future waste management. Their suitability is being assessed in terms of risk, doses, and costs. The projects have the aim of identifying the most cost-effective, safe option for ultimate disposal of each facility and its wastes. Each project considered three options, including: (1) in-situ confinement of the wastes within the existing facility structure, (2) fully engineered in-situ confinement of the wastes within a modified facility structure, and (3) retrieval of the wastes, followed by decommissioning of the facility and return to a "green field" site. In each option we examined engineering methods and solutions to achieve the option, and risks to doses unexpected, both in the short and long term, to operators and to the public. Reference designs for each confinement option were considered in terms of resistance to coastal erosion and resistance to groundwater penetration. The latter was evaluated by using engineered multibarrier protection to condition the wastes chemically in order to prevent leaching of radionuclides, and to engineer a long-term solution to minimize groundwater penetration of the facility until it no longer mattered. Final recommendations are currently being considered and are not yet certain. The final option will most likely be determined by national UK policy on intermediate-level waste. Nevertheless, in-situ confinement of intermediate-level wastes has been shown to be a viable option for their long-term management.

\section{0 \\ V18/022600}

Multilayered Landfill Covers: Field Data on the Water Balance and Liner Performance

Melchior, S.; Berger, K.; Vielhaber, B.; Miehlich, G.

University of Hamburg, Institute fuer Bodenkunde, Hamburg, Germany

CONF-941124; Insitu Remediation: Scientific Basis for Current and Future Technologies, G.W. Gee and N.R. Wing (eds.), Proceedings of the 33rd Hanford Symposium on Health and the Environment, Pasco, WA, November 7-11, 1994. Battelle Press, Columbus, OH, Part 1, 704 pp.; (pp. 411-425) (1994)

The water balance and long-term performance of different covers have been monitored on the Georgswerder landfill (Hamburg, Germany) since 1988. Evapotranspiration and drainage above the liners are the major components of the water balance. The liners tested performed very differently. The compacted soil liners have lost their efficiency due to desiccation and shrinkage. The flexible membrane liners (used in combination with compacted soil liners) and an extended capillary barrier performed very well. A slight periodical desiccation due to thermally induced water transport was observed within the soil liners below the flexible membranes. Finally, the authors discuss the suitability of compacted soil liners in landfill covers and the use of other, proposed systems with an intrinsic ability for control.

\section{$1911 \quad$ V18/022439}

National Contaminated Sites Remediation Program: 1994/95 Annual Report

Canadian Council of Ministers of the Environment, Winnipeg, Manitoba, Canada

Report (1996)

In October 1989, CCME initiated the five-year, $\$ 250$ million National Contaminated Sites Remediation Program (NCSRP). The program was aimed at dealing with properties across the country that had been polluted with hazardous materials originating from industrial or commercial activities. This is the fifth and final annual report on activities under the program's two principal components: orphan site remediation and technology development. The report outlines for each province or territory, by site or by project, progress made through cost-sharing agreements signed under the NCSRP. 


\section{National Review of Corps Environmental Restoration} Projects

Muncy, J. D.; Fischenich, J. C.

U.S. Army Corps of Engineers, Institute for Water

Resources, Fort Belvoir, VA

IWR-96-R-27; 234 pp. (November 1996)

The purpose of this report is to describe management measures, principally engineering features, explored and selected from a cross section of Corps districts and divisions. One or more management measures or engineering features can make up an alternative. The report responds to a need expressed by various study managers, project managers, engineers, water resource planners and managers, and others for descriptive information as to what management measures other district and division offices are considering when formulating environmental projects.

\section{3}

V18/023505

\section{National Review of Non-Corps Environmental} Restoration Projects

Shreffler, D.K.; Thom, R.M.; Scott, M.J.; Wellman, K.F.; Walters, M.A.

U.S. Army Corps of Engineers, Institute for Water Resources, Fort Belvoir, VA

IWR-95-R-12; 179 pp. (December 1995)

This report was prepared under the Engineering Environmental Investments: Formulating Inputs and Monitoring Effectiveness Work Unit of the Evaluation of Environmental Investments Research Program. This interim report is part of a series of reports to help build into the Prototype Information Tree for Environmental Restoration Plan Formulation and Cost Estimation, IWR Report 95-R-3. Compiled and compared in this report are management measures, engineering features, monitoring techniques, and detailed costs for a representative sample of non-Corps environmental projects or engineering projects with environmental features.

\section{$1914 \quad$ VI8/023682}

Natural Bioventing Remediation from Tidal Wave Action at a Field Site

Kampbell, D.H.; Hansen, J.E.; Kittel, J.A.

U.S. Environmental Protection Agency, National Risk

Management Research Laboratory, Ada, OK; U.S. Air Force

Center for Environmental Excellence, Brooks Air Force Base, TX; Battelle Memorial Institute, Columbus, $\mathrm{OH}$

CONF-9605266; Proceedings of the 1996 Hazardous Substance Research Center/Waste-Management Education and Research Consortium Joint Conference on Environment, L.E. Erickson, S.C. Grant, D.L. Tillison and J.P. McDonald (eds.), Albuquerque, NM, May 21-23, 1996. Great Plains-Rocky Mountain Hazardous Substance Research Center, Kansas State University, Manhattan, KS, 706 pp.; (pp. 670-672) (1996)

A remediation research study has been implemented at a jet fuel spill site on an island airport. $A$ buried pipeline fracture several years ago resulted in a fuel spill exceeding 160,000 gallons. The site hydrogeology is a fragmented coral matrix with fresh water overlying more dense salt water. Water table fluctuations of about two feet occur once every twelve hours from tidal action. The research approach being pursued is to recover free-phase floating petroleum liquid using vacuum-mediated subsurface skimming wells. The vacuum will create an active vadose zone aeration to enhance aerobic biodegradation processes and vaporization of fuel. Once the floating fuel is removed, a natural bioventing action caused by tidal oscillations will complete remediation of the spill site.

1915

V18/020805

Natural and Active Chemical Remediation of Toxic Metals, Organics, and Radionuclides in the Aquatic Environment

McPherson, G.; Pintauro, P.; O'Connor, S.

Tulane University, Center for Bioenvironmental Research, New Orleans, LA

DOE/EW/53023-T14; Hazardous Materials in Aquatic Environments of the Mississippi River Basin, Annual Technical Report, January 1-December 31, 1995, 129 pp.; (pp. 58-69) (May 2, 1996)

This project focuses on the chemical aspects of remediation, with the underlying theme that chemical remediation does occur naturally. Included are studies on the fate of heavy metal and organic contaminants discharged into aquatic environments; accurate assay of metal contaminants partitioned into soils, water and tissue; development of novel polymeric membranes and microporous solids for the entrapment of heavy metals; and the development of hybrid chemo-enzymatic oxidative schemes for aromatics decontamination.

\section{$1916 \quad$ V18/024358}

New Alternatives Advanced for Financing Site Remediation

Hazardous Waste Consultant 13(2):1.13-1.15 (March-April 1995)

In the current worldwide economic market there is considerable competition for public and private investment expenditures. Compared to the endless number of other opportunities to invest, hazardous waste site remediation is rarely considered an attractive investment. Private parties are not inclined to invest in contaminated properties, and adequate public funds are often unavailable for required cleanups. Unfortunately, many contaminated sites pose risks to human health and the environment. As a result, there is a need to develop systems that prioritize site cleanups, place rational limits on cleanup programs, and attract competing public and private investments.

1917

V18/023344

\section{New Remediation Technology in the Changing} Environmental Arena

New Remediation Technology in the Changing Environmental Arena, B.J. Scheiner, T.D. Chatwin, H. El-Shall, S.K. Kawatra and A.E. Torma (eds.), Society for Mining, Metallurgy, and Exploration, Inc., Littleton, CO, 235 pp. (1995)

This proceedings volume is an aid to remediate past problems and formulate a plan for elimination of future environmental cleanup problems. Every mining professional needs this valuable 
information for successful and efficient alleviation of environmental problems now and in the future.

\section{$1918 \quad \mathrm{~V} 18 / 023194$}

New United Kingdom Guidance on the Remediation of Contaminated Sites

Smith, M.A.

Clayton Environmental Consultants, Limited, Berkhamsted, United Kingdom

CONF-9210194; Proceedings of an International Symposium on Environmental Contamination in Central and Eastem Europe, Budapest, Hungary, October 12-16, 1992, 968 pp.; (pp. 289-291) (1992)

New guidance on the remediation of contaminated sites is being prepared by the Construction Industry Research and Information Association (CIRIA). Subjects to be covered will include: site investigation, development of remediation strategies, engineering methods (e.g., in-ground barriers, hydrological control measures), in-situ and exsitu treatment methods, the legal background, specification and procurement, and management of the remediation process. The work, which is due to be completed early in 1993, is jointly funded by the Department of the Environment and industry. The work draws directly on the results of the NATO/CCMS study on innovative clean-up technologies and is an example of the practical value of such studies. It is primarily intended to be of use to those who might need to commission investigations and remediation of contaminated sites. In the United Kingdom, these are mainly private sector activities arising from efforts to regenerate old urban and industrial areas, but they are also of increasing importance to companies with operating sites. The report should also be of value to regulators in local govemments.

\section{9}

\section{V18/021811}

Nuclear Contamination from Weapons Complexes in the Former Soviet Union and the United States

Bradley, D.J.; Frank, C.W.; Mikerin, Y.

Pacific Northwest National Laboratory, Richland, WA; U.S. Department of Energy, Washington, DC; Ministry of Atomic Energy of the Russian Federation, Moscow, Russian Federation

Physics Today (April 1996):40-45 (April 1996)

In developing the largest nuclear weapons complexes in the world, the United States and the Former Soviet Union (FSU) also created the world's largest inventories of radioactive waste. Although some of this waste has been stored in safely managed systems, significant amounts of it have been released to the environment. This article focuses primarily on these weapons-related discharges because of their size and less-well known nature. In both regions the reprocessing of nuclear fuel from reactors used to produce weapons materials has been the cause of most of the environmental contamination, either through abnormal events or planned discharges. Reprocessing creates several types of waste streams, including high-level waste that contains most of the fission products. During the cold war, the Soviet Union discharged substantially larger amounts of radioactivity into the environment than did the US. Soviet waste management practices in the early years included direct discharges into lakes and rivers as well as large scale injection of waste into the ground. Furthermore, Russian has continued to reprocess spent fuel from production reactors. In contract, the US has not operated a production reactor or reprocessing plant since 1988 . This paper provides a comprehensive review of the contamination in both regions.

1920

V18/021384

\section{Old Glory Goes Green}

Coleman, D.G.; Roland, S.J.; Seavy, P.R.

O'Brien \& Gere Engineers, Inc., Syracuse, NY

O'Brien \& Gere Newsletter 18(1):3-5 (Spring 1994)

Until the 1970 s there were no laws or regulations that addressed the disposal of hazardous waste. As a result most parties, including DOD, followed practices that are unacceptable by today's standards. With more than 25 million acres of U.S. territory under its command, the DOD is doing its part in this broad-based environmental cleanup campaign. There's a strong commitment and a shared focus. The fallout are new practices and creative solutions. The targets are an estimated 18,000 military sites-U.S. and abroad. Currently, remedial activities are being conducted at about 3500 locations.

\section{$1921 \quad$ V18/024333}

One Decade After Chernobyl

Harrison, J.R.

National Radiological Protection Board, Chilton, United Kingdom

Radiological Protection Bulletin 184:33-40 (December 1996)

The European Commission, the International Atomic Energy Agency and the World Health Organization, in cooperation with other international organizations, sponsored a major conference in Vienna in April 1996. The conference, One Decade After Chernobyl: Summing Up the Consequences of the Accident, was attended by more than 800 delegates from over 70 countries and organizations. The increasing incidence of childhood thyroid cancer and the major psychological stress reaction of the relocated populations show that the aftermath of the accident is not yet at an end. Nevertheless, the conference was an excellent opportunity for politicians and scientists of the affected republics to report on these issues and for the overall consequences to be put into perspective.

1922

V18/023680

One Decade After Chernobyl: Summing Up the Consequences

Kaul, A.; Landfermann, H.; Thieme, M.

Health Physics 71(5):634-640 (November 1996)

During the week 8-12 April 1996, an international conference summing up the consequences of the Chemobyl disaster after one decade took place in Vienna. Organizers were the European Commission (EC), the International Atomic Energy Agency (IAEA) and the World Health Organization (WHO). One of the authors presented the outcome of the conference as given in this paper at the IPRA 9 congress, which was held in Vienna the following week. Two caveats have to be mentioned here: firstly, 
only facts actually reported and reviewed at the conference can be accounted for, and, secondly, according to the ground rules of the conference, the deadline for the background papers of the conference was 9 February 1996, meaning that facts materializing after that time are not covered in this paper. The same applied to information given at the conference that was not properly reviewed and published. Reports, for example, given at the conference on an observed increase of thyroid cancers and leukemia among liquidators and of diabetes mellitus among children are not yet substantiated and are, therefore, not yet recognized as consequences. If corroborated, and it is obvious that all higher exposed groups should be closely monitored in the future, an update on the consequences will be considered.

1923

\section{V18/020601}

Operational Concerns Regarding Chemical Biological Decontamination of Fixed Sites

Fleisch, D. L.

U.S. Navy, Naval War College, Newport, RI

Report; 21 pp. (June 14, 1996)

Existing U.S. military doctrine and practice are deficient regarding CBW decontamination capabilities and procedures for fixed sites. Currently, responsibility for decontamination is left to each service component and focused on individual unit requirements. Further, joint doctrine splits the responsibility for all phases of decontamination between the theater commander and the services. Recommendations include: Doctrinal changes to emphasize realistic CBW consequences, practical solutions, and eliminate confusion regarding fixed site responsibility; OPLAN development more specific with respect to fixed sites; Additional units must be trained and equipped to provide fixed site decontamination.

\section{4}

\section{V18/024684}

Optimizing Microbial Transformation of Hazardous Chemicals, Chapter 4

Cookson, J.T., Jr.

International Network for Environmental Training, Inc., Potomac, MD

Bioremediation Engineering: Design and Application, G.F. Nalven (ed.), McGraw-Hill, Inc., New York, NY, 539 pp.; (pp. 95-164) (1995)

This is a chapter in the book titied Bioremediation Engineering: Design and Application. The feasibility of bioremediation for the cleanup of contaminated sites starts with an assessment of the degradation potential of the contaminants. This assessment includes the ease of difficulty of degradation, the ability to achieve total mineralization, as well as the environmental conditions necessary for mineralization. A review of pertinent degradation pathways provides information on intermediates and insight on where the reaction sequence may be blocked. Knowledge of these intermediates is necessary to address health concerns and monitor the degree of bioremediation. Monitoring intermediate compounds during transformation can provide insight on rate-limiting factors during the mineralization process. Microbial transformations of organic compounds are frequently described by the terms detoxification, degradation, and mineralization. Detoxification is the transformation of the compound to some intermediate form that is less toxic. Degradation means that the parent compound no longer exists. Mineralization refers to the complete conversion of the organic structure to inorganic forms. Thus detoxification and degradation are necessary consequences of mineralization. The goal of this chapter is to provide information on the general nature of the most needed transformations in bioremediation. Fortunately microorganisms frequently use similar degradation pathways for chemicals of similar structure. The chapter is organized to support engineering design and applications according to chemical categories that are frequently found in contaminated sites. For this reason, all metabolism modes and the responding transformations are presented for each hazardous chemical category. Compounds that differ significantly from these generalized categories, that pose special environmental problems, or that has specific commercial applications are presented in Chapter 5. These includes pesticides, polychlorinated biphenyls, and dyes.

\section{5}

V18/024356

\section{Overview of BRAC: Base Realignments and Closures}

Wang, $\mathrm{D}$.

CONF-9611118; HazMat West '96, Proceedings of an International Environmental Management and Technology Conference and Exhibition, November 5-7, 1996. Advanstar Expositions, Duluth, MN, 544 pp.; (pp. 129-146) (1996)

This presentation focuses on the socio-economic impact of base realignment and closures, as well as the environmental challenges involved in closing military installations. The environmental factors include the following: hazardous waste management and cleanup; underground storage tanks and fuel lines; air quality issues; radioactive wastes; unexploded ordnance; water and sewer systems; landfills; asbestos, pesticides, and lead-based paints; endangered species, wetlands, coastal protection, tidal lands, and historic and cultural resources.

1926

V18/023192

\section{Overview of Canada's National Contaminated Sites Remediation Program}

Hill, G.H.

Environment Canada, Burlington, Ontario, Canada

CONF-9210194; Proceedings of an International Symposium on Environmental Contamination in Central and Eastern Europe, Budapest, Hungary, October 12-16, 1992, 968 pp.; (pp. 284-289) (1992)

Canada is a federal state, comprising the federal government, 10 provincial governments, and two territorial governments. In general, the provinces and territories have primary jurisdiction in environmental matters, but there is a large degree of cooperation between the three levels of government. The Canadian Council of Ministers of the Environment (CCME) provides one of the forums for this cooperation. In October of 1989, the CCME formally recognized the need for a consistent national approach for the classification and cleanup of contaminated sites in Canada by establishing the National Contaminated Sites Remediation Program (NCSRP). 


\section{7}

V18/021521

Overview of New Policies and Technologies for Site Remediation

Cornelius, J.

State Water Resources Control Board, Division of Clean Water Programs, Sacramento, CA

CONF-951124; HazMat West '95, Proceedings of the Eleventh Annual Environmental Management and Technology Conference and Exhibition, Long Beach, CA, November 7-9, 1995. Advanstar Expositions, Duluth, MN, 597 pp.; (pp. 169-187) (1995)

In this presentation, the new State of California legislation, regulations, policies, and guidelines for site remediation are discussed. Site remediation activities of the California Department of Toxic Substances Control (DTSC), the State Water Resources Control Board (SWRCB), and the nine Califomia Regional Water Quality Control Boards (RWQCBs) are also described. Federal Superfund reauthorization is briefly addressed.

\section{8 \\ V18/024658}

Oxygen Dissolution Technologies for Bioremediation Applications

Storms, G.E.

Praxair, Inc., Tarrytown Technical Center, Tarrytown, NY

Bioremediation of Pollutants in Soil and Water, B.S. Schepart (ed.), Proceedings of a Symposium, Fort Worth, TX, October 14-15, 1993. American Society for Testing and Materials (ASTM), Philadelphia, PA, 265 pp.; (pp. 243-251) (May 1995)

For aerobic biotreatment processes, oxygen transfer and volatile organic chemical (VOC) emissions can be important operational limitations. By using industrially pure oxygen rather than air as the dissolved oxygen source, higher oxygen transfer rates and significantly lower volatile emissions rates can be achieved. In addition pure oxygen can eliminate foam formation, reduce the evaporative cooling effects, eliminate dependence on electrical power for aeration, and allow for greater oxygen demand variations. Due to the cost of oxygen, it is generally more cost effective to use mixing technologies that have higher oxygen transfer efficiencies (and higher mixing energy costs) than are usually used with air-based aeration. These are usually mechanical mixing technologies, rather than diffusion technologies. Several such approaches are discussed.

1929

V18/024649

PAH Impact on the Sediment Bacterial Community

Pikett, S.F.; McEldowney, S.; Knights, B.

University of Westminster, School of Biological and Health Science, London, United Kingdom

Bioremediation of Pollutants in Soil and Water, B.S. Schepart (ed.), Proceedings of a Symposium, Fort Worth, TX, October 14-15, 1993. American Society for Testing and Materials (ASTM), Philadelphia, PA, 265 pp.; (pp. 75-89) (May 1995)

The potential for bioremediating polycyclic aromatic hydrocarbons (PAHs), the major constituents of creosote, will depend on the response of the sediment bacterial community. The microbial community in sediments from a creosote-polluted freshwater lake was studied. The aim of this study was to assess the impact of PAH contamination on the sediment bacterial community. Sediment samples were taken at selected sites around the lake and upstream at an unpolluted site. Samples were analyzed for selected PAH concentrations. The numbers of aerobic heterotrophic bacteria isolated after growth on peptone yeast extract agar, peptone yeast extract with added creosote agar, and minimal media with added creosote agar were determined for each site. The response of different bacterial physiological types to PAH contamination in sediment ecosystems was assessed through the use of a gel-stabilized model system. It was apparent that the PAH contamination had a marked effect on the bacterial community of these freshwater sediments. Such effects may influence the cycling of nutrients within sediments, e.g., the nitrogen and sulfur cycle, and the potential for in situ bioremediation.

\section{0}

\section{V18/022270}

PETRO-SAFE '96: Proceedings of a Conference Held as Part of the Energy Week ' 96 Conferences and Exhibition, Houston, TX, January 29-February 2, 1996

CONF-960154; PETRO-SAFE '96, Proceedings of a Conference Held as Part of the Energy Week ' 96 Conference and Exhibition, Houston, TX, January 29-February 2, 1996. PennWell Conferences and Exhibitions, Houston, TX, 291 pp. (1996)

This proceedings consists of seven volumes titled as follows: (1) Environmental Issues, (2) Process Safety Management, (3) Waste \& Remediation Issues, (4) Business Risk Management, (5) Safety Issues (Technical), (6) Health, Safety \& Environmental Training Issues, and (7) Emergency Response \& Spill Control. Individual papers cover a broad range of topics including naturally-occurring radioactive materials, risk-based cleanup standards, remediation technologies, and training. Papers within the scope of this database have been indexed separately.

1931 V18/023648

Partnering for Environmental Restoration: The Port Hope Harbour Remedial Action Plan (RAP)

Weston, S.M.C.

Environment Canada, Toronto, Ontario, Canada

CONF-9406413; Dredging, Remediation, and Containment of Contaminated Sediments, K.R. Demars, G.N. Richardson, R.N. Yong and R.C. Chaney (eds.), Proceedings of a Symposium, Montreal, Quebec, Canada, June 23-24, 1994, 343 pp.; (pp. 297-305) (1995)

A Remedial Action Plan (RAP) is being developed for Port Hope Harbour, one of 43 Areas of Concem (AOCs) identified by the International Joint Commission (IJC). The RAP, when implemented, will lead to the restoration and protection of desirable water conditions in Port Hope Harbour. The environmental concern associated with the harbor can be best viewed as a historical contaminated sediment problem. Approximately $90,000 \mathrm{cu} \mathrm{m}$ of sediment located in Port Hope Harbour's tuming basin and west slip are contaminated by uranium and thorium series radionuclides, heavy metals, and PCBs. There are several groups contributing to the development of the RAP. All of these groups have the common goal of developing an environmentally sound plan that reflects the views of the community. Strategic partnerships have been established that recognize the need to integrate and coordinate the 
efforts of all agencies, stakeholders, and the community. The objective is to develop an environmentally sound remediation plan through an efficient and effective management framework.

\section{2}

V18/024169

Paying for the Change: Can the Federal Energy Regulatory Commission (FERC) Force Dam Decommissioning at Relicensing

Swiger, M.A.; Southwick, A.P.; Mairs, S.L. Energy Law Joumal 17(1):163-190 (1996)

Hydroelectric dam decommissioning has become a sensitive issue since the Federal Energy Regulatory Commission (FERC) has responded favorably to the river restoration movement. The legal aspects of what conditions the FERC can impose during the re-licensing process are examined.

\section{3}

V18/021451

Phylogenetic Analysis and Development of Probes for Differentiating Methylotrophic Bacteria

Brusseau, G.A.; Bulygina, E.S.; Hanson, R.S.

University of Minnesota, Gray Freshwater Biological Institute, Navarre, MN

Report; 20 pp. (1993)

Small-subunit rRNAs from methylotrophic bacteria have been sequenced. Phylogenetic trees were constructed using 16S rRNA sequences from 36 methylotrophic bacteria and 10 representative organisms from subdivisions within the class Proteobacteria on the basis of sequence similarities by using a weighted least-mean-square difference method. The methylotrophs were separated into coherent clusters in which bacteria shared physiological characteristics. The clusters distinguished bacteria which used either the ribulose monophosphate (RuMP) or serine pathways for carbon assimilation. In addition, methanotrophs and methylotrophs which do not utilize methane were found to form distinct clusters with these groups. Five new deoxyoligonucleotide probes were designed, synthesized, labeled with digoxigenin-11-ddUTP and tested for the abilities to hybridize to RNA extracted from the bacteria represented in the unique clusters. The nonradioactive detection system performed reliably at concentrations of RNA as low as $1 \mathrm{ng}$.

\section{4 \\ V18/022117}

Pilot Project Decontamination of Radon-Polluted Dwellings: Final Report

Stadtverwaltung City Administration, Schneeberg, Germany; Bundesministerium fuer Umwelt, Naturschutz und Reaktorsicherheit, Bonn, Germany

BMU-1996-464; 214 pp. (1996)

The aim of this project was to test the value of different decontamination methods, in order to draw general conclusions for future decontamination projects. The measures taken ranged from simple immediate actions such as cellar aeration, instailing gas-tight doors, sealing of walls and floors, and ventilation-technical measures to sophisticated complete decontaminations as a combination of sealing measures and underpressure. Testing included both complete area decontaminations and partial area decontaminations.

\section{5}

V18/020599

Planning for Environmental Restoration in Slovak Republic

Slavik, O.; Moravek, J.

Nuclear Power Plant Research Institute, Tmava, Slovakia

IAEA-TECDOC-865; CONF-9404316 (Vol. 2); Planning for Environmental Restoration of Radioactively Contaminated Sites in Central and Eastern Europe, Volume 2: Planning for Environmenta Restoration of Contaminated Sites, Proceedings of a Workshop on Environmental Restoration in Central and Eastem Europe, Piestany, Slovakia, April 11-15, 1994. Intemational Atomic Energy Agency, Vienna, Austria, Vol. 2, 248 pp.; (pp. 183-196) (March 1996)

The restoration in the Slovak Republic concerns the contaminated banks of the Maniver canal - Dudvah River system which receives waste water from the Bohunice NPP. The identified contamination, consisting of mainly Cs-137, is a result of two accidents on the $\mathrm{CO} 2$-cooled and heavy water moderated NPP-Al unit of NPP Bohunice complex. Two types of radiation risk scenarios, namely the bank use and contaminated soil (from bank) use scenario were investigated in relation to decision making on the planning for restoration of the contaminated banks. Results of dose assessments and the approach to planning for restoration of contaminated banks are summarized in the paper. Some details from the technical design for removing contaminated soil from the banks and its safe disposal in a subsurface isolated basin are introduced in the paper also.

1936

V18/020632

Planning for Environmental Restoration of Radioactively Contaminated Sites in Central and Eastern Europe - Identification and Characterization of Contaminated Sites: Proceedings of a Workshop on Environmental Restoration in Central and Eastern Europe, Vol. 1, Budapest, Hungary, October 4-8, 1993

IAEA-TECDOC-865; CONF-9310459 (Vol. 1); Planning for Environmental Restoration of Radioactively Contaminated Sites in Central and Eastern Europe, Volume 1: Identification and Characterization of Contaminated Soils, Proceedings of a Workshop on Environmental Restoration in Central and Eastem Europe, Budapest, Hungary, October 4-8, 1993. International Atomic Energy Agency, Vienna, Austria, Vol. 1,356 pp. (February 1996)

The radioactive contaminant materials resulting from diverse activities in relation to the nuclear fuel cycle, defense related operations, and various industries in addition to medical and research facilities represent perhaps the most severe and immense pollution left from a past era. The political changes in central and eastem Europe (CEE) not only brought some disclosure of the radioactively contaminated sites, but also resulted in a political condition in which this region became receptive to co-operation from a range of outside countries. The subject of the first workshop held in Budapest, 4-8 October 1993, was the identification and characterization of radioactively contaminated sites in the region.

1937

V18/021686

Planning for Environmental Restoration of 
Radioactively Contaminated Sites in Central and

Eastern Europe - Technologies for, and the

Implementation of, Environmental Restoration of Contaminated Sites: Proceedings of a Workshop, Vol. 3, " Rez, Czech Republic, December 12-16, 1994

IAEA-TECDOC-865; CONF-9412128 (Vol. 3); Planning for Environmental Restoration of Radioactively Contaminated Sites in Central and Eastem Europe, Volume 3: Technologies for, and the Implementation of, Environmental Restoration of Contaminated Sites, Proceedings of a Workshop on Environmental Restoration in Central and Eastem Europe, Rez, Czech Republic, December 12-16, 1994. International Atomic Energy Agency, Vienna, Austria, Vol. 3, 356 pp. (May 1996)

The radioactive contaminant materials resulting from diverse activities in relation to the nuclear fuel cycle, defense related operations, and various industries in addition to medical and research facilities represent perhaps the most severe and immense pollution left from a past era. The political changes in Central and Eastem Europe (CEE) not only brought some disclosure of the radioactively contaminated sites, but also resuited in a political condition in which this region became receptive to co-operation from a range of outside countries. The subject of the first workshop held in Budapest, 4-8 October 1993, was the identification and characterization of radioactively contaminated sites in the region. The second part of the project and the second workshop (Piestany, Slovak Republic, 12-16 April 1994) involved planning and preparing the identified sites for restoration. This included items such as the restoration objectives, dose and environmental assessment, cost analysis, strategy and prioritization. Eventually, the third part of the project covered technologies for, and the implementation of, environmental restoration. The third and final workshop was held in Rez, Czech Republic, 12-16 December 1994.

\section{8}

V18/023492

Planning for Environmental Restoration of the Contaminated Banks near Bohunice, Nuclear Power Plant (NPP)

Slavik, O.; Moravek, J.; Vladar, $\mathrm{M}$.

Nuclear Power Plant Research Institute, Trnava, Slovakia; Slovenska Lekarska Spolocnost, Spolocnost Nuklearnej Mediciny a Radiacnej Hygieny, Bratislava, Slovakia CONF-9511264; Proceedings of the 19th Radiation Hygiene Days Conference, Jasna Pod Chopkim, Slovakia, November 20-23, 19915; Journal of Radioanalytical and Nuclear Chemistry 209(2):381-385 (1996)

The $18 \mathrm{~km}$ long banks of the Bohunice Nuclear Power Plant (NPP) waste water recipient are contaminated by $\mathrm{Cs}-137$ as a result of two accidents at the CO2 cooled NPP-A1 unit in 1976 and 1977. Contamination acceptance limits 6 or $8 \mathrm{~Bq} / \mathrm{g}$ for Cs-137 in soil, depending on contaminated area size, were derived on the basis of developed principles and approved by the authorities. Removal and safe burial of $1100 \mathrm{cu} \mathrm{m}$ of contaminated soil from a steep area and a $15 \mathrm{~cm}$ thick clean soil covering on about 1 ha of a flat area of the contaminated banks is planned for the re-considered restoration project implementation in 1995/96.

1939
Plant Protection Under Considerations of Radioactive Contamination of Agricultural Lands

Filipas, A.S.; Oulianenko, L.N.; Pimenov, E.P.

Russian Institute of Agricultural Radiology and Agroecology, Moscow, Russian Federation

CONF-950917 (Vol. 2); ICEM '95, Proceedings of the Fifth International Conference on Radioactive Waste Management and Environmental Remediation, Vol. 2: Management of Low-Level Waste and Remediation of Contaminated Sites and Facilities, $S$. Slate, R. Baker and G. Benda (eds.), Berlin, Germany, September 3-7, 1995. American Society of Mechanical Engineers, New York, NY, 913 pp.; (pp. 1487-1488) (1995)

Increasing influence of anthropogenic contaminants as well as substantiated risk of the action of ionizing radiation on agroecosystems suggest the necessity of studying both the state of separate components of cenosis and the search for methods on retention of ecosystem stability as a whole. It should be taken into account that by 'retention of resistance of living organisms to the action of stress agents' is meant not only genetically conditioned potential, but induction of protective reactions at the expense of ecogene action as well. Protection of agricultural plants in the areas subjected to radioactive contamination from the Chernobyl Nuclear Power Plant accident presents a series of problems, one of which is a need for minimizing pesticide use. Ordinarily, pesticide discontinuance would lead to crop loss and quality decline, but it is possible to solve this problem by introducing measures to increase plant resistance to unfavorable environmental factors. Applying natural.and synthetic biologically active substances (BAS) for incrustation of seeds is one possibility. For rehabilitating radionuclide contaminated areas, such preventive treatments for chemical and biological protection of crop sowings takes on special significance because it is directly connected with the problem of radiation burden on workers in the agroindustrial complex.

1940

V18/022022

Plasma Activities in Russia and in the Newly Independent States

Vursel, P.B.; Camacho, S.L.

Plasmasil Company Limited, Moscow, Russian Federation; Plasma Technology Corporation, Raleigh, NC

CONF-9510125 (Vol. 1); Plasma Systems and Applications, P.W. Mayne and J.A. Mulholland (eds.), Proceedings of an International Symposium on Environmental Technologies, Atlanta, GA, October 8-11, 1995. Georgia Institute of Technology, Atlanta, GA, Vol. 1, 335 pp.; (pp. 35-43) (1995)

In addition to plasma technologies designed and applied in Russia and NIS, several new technologies had been explored and found practical application within last few years: (1) wastes (W) treatment (solid W - in plasma furnaces, liquid radioactive W - in HF plasma, gaseous $\mathrm{W}$ in flue gas and atmospheric impurities - in nonequilibrium plasma (NEP)); (2) deposition of films and coatings for different purposes in NEP; (3) production of powders with ordered properties; (4) surface modification in NEP; (5) improvement of traditional technologies for increasing of ecological, economical, technical characteristics. 
1941

V18/022024

Plasma Arc Technology Development for Application to Demilitarization of Pyrotechnic Ordnance

Mescavage, G.; Filius, K.

U.S. Army, Armament Research, Development, and Engineering Center, Picatinny Arsenal, NJ; MSE, Inc., Butte, MT

CONF-9510125 (Vol. 2); Plasma Systems and Applications, P.W. Mayne and J.A. Mulholland (eds.), Proceedings of an Intemational Symposium on Environmental Technologies, Atlanta, GA, October 8-11, 1995. Georgia Institute of Technology, Atlanta, GA, Vol. 2, 392 pp.; (pp. 597-608) (1995)

An initial investigation into the use of a plasma arc furnace for demilitarization of completely assembled, small-caliber, hand-emplaced pyrotechnic, smoke, and dye ordnance was conducted at the Department of Energy's Westem Environmental Technology Office, located in Butte, Montana. This technology is being pursued as an alternative to open burning/open detonation (OB/OD), which is the method of demilitarization traditionally used for these items, as increasingly more stringent environmental regulations have discouraged and disallowed the use of $O B / O D$. Problems have been experienced with the use of existing incinerators for demilitarization of these items. Varying quantities of 19 different types of live, completely assembled, small pyrotechnic, smoke, and dye items were processed in a pilot-scale Retech, Inc., Plasma Arc Centrifugal Treatment System. This testing demonstrated that a plasma arc furnace equipped with pollution abatement equipment can safely demilitarize these items in compliance with applicable environmental regulations. In addition, the process encapsulates heavy metals and other hazardous constituents into a solid, low-leachable slag product that passes Federally established tests as a nonhazardous material. This provides an advantage over standard incineration which yields a hazardous ash. The process also is able to overcome problems reported with standard incinerators. In addition, gas flows are significantly lower than those in standard incinerators, allowing smaller pollution abatement equipment to be used. However, operational problems and inefficiencies were identified that need to be resolved before fuil-scale implementation. A follow-on effort is currently underway to resolve previously identified problems and inefficiencies, develop a design specification for a full-scale system specifically designed for processing pyrotechnic ordnance, and procure and install the full-scale system at an Army site. Several studies, modification of the existing pilot system, and extensive testing on the modified system will be conducted to resolve operational problems and inefficiencies and acquire data needed to develop the design specification. In addition to testing the modified pilot system, a small-scale plasma furnace (SSPF) is available and is being used to conduct preliminary evaluations of processing parameters before they are used in the modified pilot system testing. SSPF testing is currently underway, and the test plans for the testing required on the modified pilot unit are being developed. Preliminary configuration recommendations have been developed for the final full-scale system and will be further developed into a design specification based on the results of testing the modified pilot system. This design specification will be used to procure the production plasma arc system.
1942

$\mathrm{V} 18 / 022021$

Plasma Arc Torch: Its Electrical and Thermal Characteristics

Camacho, S.L.

Plasma Technology Corporation, Raleigh, NC

CONF-9510125 (Vol. 1); Plasma Systems and Applications, P.W. Mayne and J.A. Mulholland (eds.), Proceedings of an International Symposium on Environmental Technologies, Atlanta, GA, October 8-11, 1995. Georgia Institute of Technology, Atlanta, GA, Vol. 1, 335 pp.; (pp. 45-65) (1995)

The plasma arc torch is a very effective heating device. Plasma arc heating technology is very appropriate and essential for product manufacture and for remediating and protecting the environment. The plasma torch initiates and maintains a length of arc column, similar to a lightning bolt, and the electrically-conducting column is used in the conversion of electricity into heat energy. The format of the heat energy delivery is a low-mass, high enthalpy gas. Heat energy is delivered by the plasma torch with a minimum of mass only about $2.3 \%$ of the mass delivery from a combustion heater that is delivering the same heat enthalpy. This virtually mass-less heat is ideal for promoting very rapid physical changes and chemical changes in the material being heated. It is ideal for the pyrolysis (or gasification) of organic materials and for the vitrification (or melting) of inorganic materials - processes that are desirable for new product manufacture and for environmental remediation and protection. Plasma arc heating technology has been perfected by industry during the last 20-30 years, and the industrial sector today is employing this unique heating source in product manufacture and, lately, in environmental remediation and protection processes. It is a cost-effective industrial heat source. The primary objective of this paper is to familiarize you with plasma heaters and their operating characteristics. The essential elements of the plasma arc torch: Electrodes, Insulators, Gas Injectors, Water-cooling, Electrical Connectors, etc., are described and the Electrical and Thermal Characteristics of this novel heating device are highlighted. An overview of today's employment of plasma heating technology and a sample of some of today's applications of the technology in the industrial sector in the United States and around the world are presented.

1943

\section{V18/022023}

\section{Plasma/Arc Melter Review for Vitrification of Mixed} Wastes: Results

Eddy, T.L.; Soelberg, N.R.; Raivo, B.D.

MeltTran, Inc., Idaho Falls, ID

CONF-9510125 (Vol. 2); Plasma Systems and Applications, P.W. Mayne and J.A. Mulholland (eds.), Proceedings of an International Symposium on Environmental Technologies, Atlanta, GA, October 8-11, 1995. Georgia Institute of Technology, Atlanta, GA, Vol. 2, 392 pp.; (pp. 35-43) (1995)

In October of 1994, the Idaho Waste Treatment Program (IWTP) sponsored a workshop to review the results of a plasma/arc melter system preliminary design for treating mixed waste. The design activity compared current DOE sponsored melter system demonstration units and proposed overall system design recommendations to three subcommittees of international experts. 
Government personnel, vendors, and other interested parties were also invited to the review, attended by approximately 60 people. The subcommittees focused on: (1) the melter design, (2) the offgas system design, and (3) the overall system design. The inclusion of feed preparation and handling systems, as well as monitoring and control systems, were considered premature until decisions regarding the melter and offgas treatment were resolved. The evaluation was based on the constraints of the transuranic-contaminated mixed waste in the Radioactive Waste Management Complex (RWMC) at the Idaho National Engineering Laboratory (INEL). Major factors are the retention of the transuranics in the basaltic slag, maintenance in a radioactive environment, reliability of components to prevent any major problems, upsets, or safety concerns, and the collection, elimination, or reduction of hazardous materials for appropriate stabilization. Several modifications were recommended by the group at large, discussed by the subcommittees, and accepted as the preferred options by the design team. Though all questions were not answered, the preferred systems for mixed waste treatment were the arc melters with graphite electrode systems with appropriate cooling which reduced maintenance and the possibility of eruptions that have occurred with plasma torches. Arc melters can also result in the minimum footprint and shielding. The preferred offgas systems were the wet/dry systems, that essentially eliminate the formation of carcinogenic compounds so they do not have to be destroyed down stream. This system also puts all of the particulate matter into one stream, instead of two.

\section{4}

V18/021974

\section{Plutonium Weathering on Johnston Atoll}

Wolf, S.F.; Bates, J.K.; Buck, E.C.; Dietz, N.L.; Fortner, J.A. Argonne National Laboratory, Chemical Technology Division, Argonne, II

CONF-9509139; Emerging Technologies in Hazardous Waste Management VII, D.W. Tedder (ed.), Proceedings of the Seventh American Chemical Society Industrial and Engineering Chemistry Division Special Symposium, Atlanta, GA, September 17-20, 1995. American Chemical Society, Washington, DC, 1291 pp.; (pp. 21-24) (1995)

Johnston Atoll (JA), a group of four coral islands located $1330 \mathrm{~km}$ WSW of Honolulu, was the site of a series of atmospheric nuclear weapons tests in 1962. These tests, along with the presence of four aborted nuclear devices carrying Thor missiles, caused the area to be contaminated with transuranic elements, particularly plutonium. Initial cleanup operations removed debris that was detected either visually or by using alpha radiation detectors. Growth of the Pu-241 decay product, Am-241, has since permitted isolation of "hot particles" using gamma-ray detection. Ground surveys and analyses of contaminated particles, performed in 1980, indicated that most of the contamination outside the launch area was in the form of these discrete hot particles. Since then, JA has been the site of an extensive soil remediation program that focused on the removal of these hot particles from the soil. However, many areas also contained a low-level continuum of activity, and subsurface contamination has been detected. This led to the suggestion that contamination had migrated from the hot particles to the surrounding environment. We characterized discrete hot particles and contaminated soil to determine whether the spread of activity on JA was caused by weathering. We used a variety of analytical techniques, including gamma spectrometry, alpha spectrometry, and inductively coupled plasma-mass spectrometry (ICP-MS) to determine transuranic elemental and isotopic composition. We have used ultrafiltration and small-particle handling techniques to isolate individual particles. Optical microscopy, scanning electron microscopy (SEM), analytical transmission electron microscopy (TEM), energy dispersive X-ray spectroscopy (EDS), and electron energy loss spectroscopy (EELS) were used to characterize individual particles.

\section{5}

\section{V18/025505}

Pollution: Causes, Effects and Control

Harrison, R.M.

University of Birmingham, Institute of Public and Environmental Health, School of Chemistry, Birmingham, United Kingdom

Pollution: Causes, Effects and Control, Royal Society of Chemistry, Cambridge, United Kingdom, 501 pp. (1996)

The book contains twenty chapters written by experts in the field and aims to provide a basic textbook covering the more important aspects of pollution and pollution control. Chapter headings are: chemical pollution of the aquatic environment by priority pollutants and its control; chemistry and pollution of the marine environment; drinking water quality and health; water pollution biology; sewage and sewage sludge treatment; the treatment of toxic wastes; air pollution; sources, concentrations and measurement; chemistry of the troposphere; chemistry and pollution of the stratosphere; atmospheric dispersal of pollutants and the modeling of air pollution; the health effects of air pollution; effects of gaseous pollutants on crops and trees; control of pollutant emissions from road traffic; soil pollution and land contamination; solid waste management; the environmental behavior of toxic organic chemicals; radioactivity in the environment; health effects of environmental chemicals; the legal control of pollution; and integrated pollution control and waste minimization. Chapters within the scope of this data base have been indexed separately.

\section{6}

V18/024856

\section{Potential Blaster Liability Under CERCLA}

Kliche, C.A.; Rickenbach, J.C.

South Dakota School of Mines and Technology, Rapid City, $\mathrm{SD}$

CONF-970224; Proceedings of the 23rd Annual Conference on Explosives and Blasting Techniques, Las Vegas, NV, February 2-5, 1997. International Society of Explosives Engineers, Cleveland, OH, 660 pp.; (pp. 207-220) (1997)

The Comprehensive Environmental Response, Compensation and Liability Act of 1980 (CERCLA) established a national program for responding to releases of hazardous substances into the environment. The funding mechanism for this program is the Hazardous Substance Response Trust Fund (commonly referred to as Superfund), which provides funding for the implementation of removal and remedial response actions. The Liability portion of CERCLA gives the EPA authority to affix proportions of responsibility for cleanup of a Superfund site. In one recent instance, a blaster under contract to drill and blast a trench for a 
storm sewer line drilled into an old underground storage tank of waste material from a coal gasification piant that contained hazardous substances. The blaster, along with other possible Responsibie Parties, was sued by the EPA to recover the costs of cleanup of the site. The liability for cleanup was affixed through litigation and arbitration to the current owners of the site, the past owners of the site, the city and the blasting contractor in various proportions.

\section{7}

V18/020634

Potential of Imaging Spectrometry (DAIS 7915) for the Monitoring of Recultivation Activities in Mining Areas

Mueller, A.; Lehmann, F.; Rothfuss, H.

DLR, Institute for Optoelectronics, Oberpfaffenhofen, Germany

CONF-960203 (Vol. 2); Geologic Remote Sensing - Practical Solutions for Real World Problems, Proceedings of the Eleventh Thematic Conference, Las Vegas, NV, February 27-29, 1996. Environmental Research Institute of Michigan, Ann Arbor, MI, Vol. 2, 723 pp.; (pp. II350-II357) (1996)

The airbome Daedalus-ATM scanner and the new Digital Airborne Imaging Spectrometer (DAIS 7915) developed by DLR were used to map the area of a former uranium mining site in Eastern Germany. The spectral reflectance and temperature images derived after the calibration and atmospheric correction of the data are very helpful in assessing potential environmental risks related to this site. Mapping of temperature anomalies and differentiation of surface materials - relevant for the recultivation of the site and the assessment of the hydrological situation - are activities that are addressed in this study. Preliminary results show that the radiometric quality of the DAIS in combination with its spectral coverage allows a better discrimination of surface materials and an improved understanding of effects in the thermal wavelength range.

\section{8}

\section{V18/024669}

Powdered Activated Carbon Treatment of Aqueous Wastes at Superfund Sites, Chapter 13

Randall, T.L.; Copa, W.M.; Berrigan, J.K., Jr.

Zimpro Environmental, Inc., Rothschild, WI

Bioremediation: Field Experience, P.E. Flathman, D.E. Jerger and J.H. Exner (eds.), Lewis Publishers, Boca Raton, FL, 560 pp.; (pp. 259-283) (1994)

The powdered activated carbon treatment (PACT [R]) system has been applied to the treatment of municipal and industrial wastewaters, leachates, and contaminated groundwater. The PACT $[R]$ wastewater treatment system involves the addition of powdered activated carbon (PAC) to biological treatment systems. In most applications, the biological treatment system is a suspended growth system, such as the activated sludge system. The combination of physical adsorption and biological oxidation/assimilation is particularly effective in treating wastewaters that vary in concentration and composition, are highly colored, or contain contaminants that are toxic to biological growth. Recently, the PACT $[R]$ system achieved high quality effluent standards requiring extremely low concentrations of hazardous organic constituents. This chapter describes the PACT [R] treatment system and its application for site remediation. Included are summaries of two bench-scale PACT $[R]$ treatability studies. The first treatability study was performed on landfill leachate and the second on contaminated groundwater. The results of a demonstration-scale, PACT [R] system study performed on leachate are also summarized. The treatment results from two full-scale PACT [R] system installations are discussed in detail. This chapter is from the book entitled Bioremediation: Field Experience.

1949

V18/022200

Present Concept on Current Water Protection and Remediation Activities for the Areas Contaminated by the 1986 Chernobyl Accident

Voitsekhovitch, O.; Prister, B.; Nasvit, O.; Los, I.; Berkovski, V.

Health Physics 71(1):19-28 (July 1996)

The results of radiation monitoring data and migration pathway analysis of water bodies within areas affected by the 1986 Chernobyl accident provide a unique opportunity for decision-makers working in other extensively contaminated regions to optimize their approaches to surface and groundwater protection. Most engineering measures within the Chernobyl $30-\mathrm{km}$ exclusion zone were focused on preventing secondary contamination of surface and groundwater from entering the Pripyat River and the Kiev Reservoir. However, implementation of these measures required huge financial and human resources. Therefore, lessons about post-accident water protection activities can be leamed from the Chẹnobyl example.

1950

V18/022957

\section{Procedures for Partial Deletions at NPL Sites}

U.S. Environmental Protection Agency, Washington, DC OERR Directive 9320.2-11; EPA/540/R-96/014; 25 pp. (April 30, 1996)

The purpose of this guidance is to define the requirements for partial deletions at National Priorities List (NPL) sites. The Partial Deletions rule, which allows EPA to delete releases at portions of NPL sites, provided that deletion criteria are met, was published in the Federal Register on November 1, 1995. Previous EPA policy had been to delete releases only after evaluation of the entire site. However, while total cleanup may take many years, portions of the site may have been cleaned up and be available for productive use. Therefore, EPA decided to delete portions of sites as appropriate.

\section{1}

\section{V18/023488}

\section{Proceedings of Japan-Germany Workshop of} Bioremediation

New Energy and Industrial Technology Development Organization, Tokyo, Japan

NEDO-GET-9540-2; 59 pp. (December 4, 1995)

The Japan-Germany Workshop on Bioremediation was held on December 4 and 5, 1995. The keynote lectures included: (1) Environmental preservation using biotechnology given by Professor Karube of the University of Tokyo and (2) Environmental technology in Germany: status, achievements, and problems given by Professor R.D.Schmid of the University of Stuttgart. In the oral 
session 7 papers were presented on the microbiological aspects of bioremediation, 10 papers on environmental monitoring, and 6 papers on the engineering aspects of bioremediation. This workshop was sponsored by the German Federal Ministry for Education, Science and Technology, New Energy and Industrial Technology Development Organization, and Research Institute of Innovative Technology for the Earth. According to the lecture by Professor Karube, key technologies for environmental preservation include biotechnologies such as the culture of fine algae with high $\mathrm{CO} 2$ concentration resistant properties using a solar light condenser, production of effective substances from $\mathrm{CO} 2$, and production of organic fertilizer from the sediments of lakes and seas. (This document is in Japanese).

\section{2}

\section{V18/023503}

Proceedings of an American Society of Mechanical Engineers (ASME) Heat Transfer and Fluids Engineering Divisions 1995 International Mechanical Engineering Congress and Exhibition: Fluid Mechanics and Heat Transfer in Sprays - Heat, Mass and Momentum Transfer in Environmental Flows Measurement Techniques in Mutiphase Flow Multiphase Transport in Porous Media, San Francisco, CA, November 12-17, 1995

Hoyt, J.W.; O'Hern, T.J.; Presser, C.

San Diego State University, San Diego, CA; Sandia National Laboratories, Albuquerque, NM; National Institute of Standards and Technology, Gaithersburg, MD

CONF-951135; Proceedings of an American Society of Mechanical Engineers (ASME) Heat Transfer and Fluids Engineering Divisions 1995 Intemational Mechanical Engineering Congress and Exhibition: Fluid Mechanics and Heat Transfer in Sprays - Heat, Mass and Momentum Transfer in Environmental Flows Measurement Techniques in Mutiphase Flow - Multiphase Transport in Porous Media, J.W. Hoyt, T.J. O'Hem and C. Presser (eds.), San Francisco, CA, November 12-17, 1995. ASME, New York, NY, 761 pp. (1995)

The papers in the Fluid mechanics and heat transfer in sprays section have application to combustion sprays, spray cooling for fire fighting, cooling towers, and fuel atomization. The papers in the Heat, mass and momentum transfer in environmental flows symposium are related to air pollution transport, air infiltration to building envelopes, climatic change, radionuclide transport, power plant stack plumes, flow through geologic repositories of radioactive wastes, and intake flow to cooling towers. There are papers which discuss measurement techniques in multiphase flow. The symposium on Multiphase transport in porous media contains papers related to enhanced recovery of petroleum, remedial action of soil and groundwater, and hydrogen storage as hydrides. Papers within the scope of this database have been indexed separately.

\section{3}

V18/023928

Proceedings of the 1993 Electric Power Research Institute (EPRD) International Low-Level Waste Conference, Monterey, CA, November 10-12, 1993 (Session November 11)

Proceedings of the 1993 Electric Power Research Institute (EPRD)
Intemational Low-Level Waste Conference (Papers presented Thursday, November 11, 1993), Monterey, CA, November 10-12, 1993, 345 pp. (1993)

The 1993 International Low-level Waste Conference held November 10-12, 1993, in Monterey, Ca attracted low-level waste (LLW) professionals from US nuclear utilities along with representatives of foreign utilities, suppliers, consultants, researchers, engineers, regulators and educators. The objective of the conference was to provide up-to-date $L L W$ information and describe advanced technology related to processing, storage, and disposal issues. The conference included papers along with exhibit booths, manned by suppliers of LLW technical equipment and services. Sessions focused on the nuclear industry and EPRI LLW projects update, interim storage experiences, liquid, wet and dry active waste, improved processing and technology, pretreatment for and vitrification, mixed waste, foreign $L L W$ practice, steam generator replacement, decontamination, ion-exchange advancements, disposal site status, building public trust and licensing and regulatory issues. A volume has been published for each day of the conference, containing the papers presented during that day's sessions.

1954

V18/023929

Proceedings of the 1993 Electric Power Research Institute (EPRD) International Low-Level Waste Conference, Monterey, CA, November 10-12, 1993 (Session November 12)

Proceedings of the 1993 Electric Power Research Institute (EPRD) International Low-Level Waste Conference (Papers presented Friday, November 12, 1993), Monterey, CA, November 10-12, 1993, 125 pp. (1993)

The 1993 International Low-level Waste Conference held November 10-12, 1993, in Monterey, Ca attracted low-level waste (LLW) professionals from US nuclear utilities along with representatives of foreign utilities, suppliers, consultants, researchers, engineers, regulators and educators. The objective of the conference was to provide up-to-date LLW information and describe advanced technology related to processing, storage, and disposal issues. The conference included papers along with exhibit booths, manned by suppliers of LLW technical equipment and services. Sessions focused on the nuclear industry and EPRI LLW projects update, interim storage experiences, liquid, wet and dry active waste, improved processing and technology, pretreatment for and vitrification, mixed waste, foreign $L L W$ practice, steam generator replacement, decontamination, ion-exchange advancements, disposal site status, building public trust and licensing and regulatory issues. A volume has been published for each day of the conference, containing the papers presented during that day's sessions.

1955

\section{V18/023811}

Proceedings of the 1995 Electric Power Research Institute (EPRD) International Low-Level Waste Conference, Orlando, FL, July 10-12, 1995

EPRI-TR-105569; CONF-950718; Proceedings of the 1995 Electric Power Research Institute (EPRI) International Low-Level Waste Conference, Orlando, FL, July 10-12, 1995, 600 pp. (November 1995) 
EPRI's 1995 Intemational Low Level Waste Conference held July 10-12, 1995, in Orlando, Florida, attracted 110 low level waste (LLW) professionals from US nuclear utilities along with almost 200 representatives of foreign utilities, suppliers, consultants, researchers, engineers, regulators, and educators. The conference included 72 papers along with 40 exhibit booths, manned by suppliers of LLW technical equipment and services. Sessions focused upon the nuclear industry and EPRI LLW projects update, interim storage experiences, liquid, wet and dry active waste, improved processing and technology, pretreatment for and vitrification, mixed waste, foreign $L L W$ practices, steam generator replacement, decontamination, ion-exchange advancements, disposal site status, building public trust and licensing and regulatory issues. The ASME-EPRI Workshop for utility LLW professional immediately followed the conference.

\section{$1956 \quad$ V18/023926}

Proceedings of the 211th American Chemical Society National Meeting, New Orleans, LA, March 24-28, 1996, Book of Abstracts, Pt. 1

CONF-960376 (Part 1); Proceedings of the 211th American Chemical Society (ACS) National Meeting, New Orleans, LA, March 24-28, 1996. ACS, Washington, DC, Part 1, 1172 pp. (1996)

These two volumes contain the abstracts of presentations and poster sessions at the American Chemical Society meeting. Many topics in chemistry are covered, but the main coverages are petroleum chemistry, nuclear chemistry, environmental chemistry, fuels chemistry, analytical chemistry, and inorganic chemistry. Individual abstracts within the scope of the RAPIC database are indexed separately.

\section{7}

\section{V18/023927}

Proceedings of the 211th American Chemical Society National Meeting, New Orleans, LA, March 24-28, 1996, Book of Abstracts, Pt. 2

CONF-960376 (Part 2); Proceedings of the 211th American Chemical Society (ACS) National Meeting, New Orleans, LA, March 24-28, 1996. ACS, Washington, DC, Part 2, 1115 pp. (1996)

These two volumes contain the abstracts of presentations and poster sessions at the American Chemical Society meeting. Many topics in chemistry are covered, but the main coverages are petroleum chemistry, nuclear chemistry, environmental chemistry, fuels chemistry, analytical chemistry, and inorganic chemistry. Individual abstracts within the scope of the RAPIC database are indexed separately.

\section{8}

\section{V18/024855}

Proceedings of the 23rd Annual Conference on Explosives and Blasting Techniques, Las Vegas, NV, February 2-5, 1997

CONF-970224; Proceedings of the 23rd Annual Conference on Explosives and Blasting Techniques, Las Vegas, NV, February 2-5, 1997. Intemational Society of Explosives Engineers, Cleveland, OH, 660 pp. (1997)
This edition of the proceedings is the twenty third in a series published by the International Society of Explosives Engineers and made available as part of a collection known as the Blasters Library. The proceedings contains a large number of papers on a broad range of subjects relevant to blasting techniques. Papers within the scope of this data base have been indexed separately.

1959

V18/024331

Programme and Sequence of Extraordinary Actions on Chernobyl Accident Mitigation

Murachev, A.I.; Baladinskij, V.L.

Kievskij Politekhnicheskij Institute, Kiev, Ukraine; Ministerstvo Ukrainy po Delam Zashchity Naseleniya ot Posledstvij Avarii na Chernobyl'skoj AEhS, Kiev, Ukraine

INIS-UA-026/A; CONF-960002; Chernobyl 96: Results of 10 Years Work on ChNPP Accident Mitigation, Proceedings of the Fitth Intemational Scientific-Technical Conference, N.P. Arkhipov (ed.), Zelenyj Mys, Ukraine, 1996, 526 pp.; (pp. 222-223) (1996)

Short communication. No abstract available. (This document is in Russian).

$1960 \quad$ V18/020808

Project Carried Out in Italy to Secure a Site Contaminated by Cs-137 of Unknown Origin [Vol. 2]

Cochi, C.; Mastino, G.

Ente per le Nuove Tecnologie, l'Energia e l'Ambiente, Rome, Italy

IAEA-TECDOC-865; CONF-9404316 (Vol. 2); Planning for Environmental Restoration of Radioactively Contaminated Sites in Central and Eastern Europe, Volume 2: Planning for Environmental Restoration of Contaminated Sites, Proceedings of a Workshop on Environmental Restoration in Central and Eastern Europe, Piestany, Slovakia, April 11-15, 1994. International Atomic Energy Agency, Vienna, Austria, Vol. 2, 248 pp.; (pp. 135-144) (March 1996)

The present paper examines the intermediate phases of the work described in the workshop held in Budapest to secure an industrial waste disposal site radioactively contaminated by $\mathrm{Cs}-137$ of unknown origin. In particular, the lecture focuses on the planning and preparation of the work undertaken for the environmental restoration, the constitution of a Technical Committee, the share of tasks and costs, the rationale for remedy, the restoration objectives and, eventually, the project for the intervention.

1961 V18/021685

Project Carried Out in Italy to Secure a Site Contaminated by Cs-137 of Unknown Origin [Vol. 3]

Cochi, C.; Mastino, G.

Energie Nucleare e delle Energie Alternative (ENEA), Rome, Italy

IAEA-TECDOC-865; CONF-9412128 (Vol. 3); Planning for Environmental Restoration of Radioactively Contaminated Sites in Central and Eastern Europe, Volume 3: Technologies for, and the Implementation of, Environmental Restoration of Contaminated Sites, Proceedings of a Workshop on Environmental Restoration in 
Central and Eastern Europe, Rez, Czech Republic, December 12-16, 1994. International Atomic Energy Agency, Vienna, Austria, Vol. 3, 356 pp.; (pp. 173-180) (May 1996)

This paper describes the final phase of the works carried out to secure the industrial waste disposal site situated near Brescia (Italy) contaminated by Cs-137 of unknown origin, and represents the logical continuation of the papers presented at the Budapest and Piestany Workshops. After the campaign survey undertaken to evaluate the amount of the radioactivity on the surface of the. facility, the deposition of a first coating, in order to temporarily stabilize and immobilize radioactive contamination, and the drilling campaign undertaken to investigate the quantity and the distribution of the contamination inside the mass of waste, the whole surface of the waste disposal facility was eventually coated with a physical cover and protected with an erosion control net. In particular, the lecture focuses on the technologies involved, the description of the works undertaken and the results obtained.

1962

V18/023314

Project Carried Out in Italy to Secure a Site Contaminated by Cs-137 of Unknown Origin [Vol. 1]

Cochi, C.; Mastino, G.

Ente per le Nuove Tecnologie, l'Energia e l'Ambiente, Rome, Italy

IAEA-TECDOC-865; CONF-9310459 (Vol. 1); Planning for

Environmental Restoration of Radioactively Contaminated Sites in

Central and Eastem Europe, Volume 1: Identification and

Characterization of Contaminated Soils, Proceedings of a

Workshop on Environmental Restoration in Central and Eastern

Europe, Budapest, Hungary, October 4-8, 1993. International

Atomic Energy Agency, Vienna, Austria, Vol. 1, 356 pp.; (pp.

157-181) (February 1996)

This paper describes the main phases of work carried out to secure a site consisting of an industrial waste disposal facility contaminated by Cs-137 of unknown origin. A campaign survey to evaluate the amount of radioactivity on the surface of the storage waste plant was undertaken; then, a complex process was set up and carried out, taking into consideration the environmental conditions, the characteristics of the waste involved and of the materials added to it, the waste transport conditions, the structure and management of the waste storage plant, in order to realize Cs-137 ions mobility and diffusion in that peculiar situation. A first sealing of the surface was carried out to secure the site at least for some months, in order to let technicians and vehicles go freely and safely on the surface of the plant taking samples for laboratory analysis. A special drilling system, capable of picking up contaminated samples from the depth of the mass of waste without any (or almost any) contact with the environment, was then performed. As conclusion of that investigation, an "on-site" security action was decided, in consideration of the great amount of waste involved and in order to avoid that some contaminated waste could come in contact with the environment. The radiological survey, the interim actions for a temporary securing of the site, the drilling campaign and the system used to pick up samples, as well as the results of laboratory analysis are described in the lecture.
Public Participation in Environmental Law Relating to Investment in Central and Eastern Europe: Six Country Examples

Stec, S.

Budapest, Hungary

CONF-9210194; Proceedings of an International Symposium on Environmental Contamination in Central and Eastem Europe, Budapest, Hungary, October 12-16, 1992, 968 pp.; (pp. 328-338) (1992)

The environmental recovery of Central and Eastern Europe critically depends upon well-reasoned and fair decisions by authorities with respect to all activities affecting the environment, taking into account their short- and long-term impacts. Experience in the West has proven that the best way for decision makers to avoid mistakes based on lack of information is for the public to actively participate in the decision-making process. It is equally important to those involved in the re-development of the countries in the region that the wishes and concerns of the public be anticipated and addressed at an early stage of the process, to promote efficiencies, to avoid delays and to increase certainties. The right to the public to truly participate in decision making must be guaranteed by law. Many of the states of Central and Eastern Europe and the former Soviet Union have some existing legal basis for public participation in decision making, for example the People's Councils. But in past practice, these institutions usually rubber-stamped decision from above. They may provide the structure, however, for the future growth of public participation rights. In addition, lessons leamed from Westem cultures may be adaptable to these countries in transition. Public participation covers a broad area, from the right to create legislation through initiative to citizen enforcement of laws and obligations of officials to the right to be heard as part of the decision-making process. This paper addresses only one aspect of public participation - the right of the public to take part in decisions affecting development of the man-made environment - but it is a critically important one today, as the region experiences rapid transformation and focuses its efforts on refitting its economy.

\section{4}

V18/024874

Quantitative Comparisons of Insitu Microbial Biodiversity by Signature Biomarker Analysis

White, D.C.; Stair, J.O.; Ringelberg, D.B.

University of Tennessee, Center for Environmental Biotechnology, Knoxville, TN; Oak Ridge National Laboratory, Environmental Sciences Division, Oak Ridge, TN; University of Tennessee, Department of Microbiology, Knoxville, TN

Journal of Industrial Microbiology 17:185-196 (1996)

Microscopic examinations have convinced microbial ecologists that the culturable microbes recovered from environmental samples represent a tiny proportion of the extant microbiota. Methods for recovery and enzymatic amplification of nucleic acids from environmental samples have shown that a huge diversity exists in situ, far exceeding any expectations which were based on direct microscopy. It is now theoretically possible to extract, amplify and sequence all the nucleic acids from a community and thereby gain a comprehensive measure of the diversity as well as some insights 
into the phylogeny of the various elements within this community. Unfortunately, this analysis becomes economically prohibitive if applied to the multitude of niches in a single biome let alone to a diverse set of environments. It is also difficult to utilize polymerase chain reaction (PCR) amplification on nucleic acids from some biomes because of co-extracting enzymatic inhibitors. Signature biomarker analysis which potentially combines gene probe and lipid analysis on the same sample, can serve as a complement to massive environmental genome analysis in providing quantitative comparisons between microniches in the biome under study. This analysis can also give indications of the magnitude of differences in biodiversity in the biome as well as provide insight into the phenotypic activities of each community in a rapid and cost-effective manner. Applications of signature lipid biomarker analysis to define quantitatively the microbial viable biomass of portions of an Eastern USA deciduous forest, are presented.

\section{5}

\section{V18/021696}

Quantum Mechanical Contribution to Cation Selectivity by 12-Crown- 4 and Related Polyethers

Hill, S.E.; Feller, D.F.

Pacific Northwest National Laboratory, Richland, WA

CONF-960376 (Part 2); Proceedings of the 211th American Chemical Society (ACS) National Meeting, New Orleans, LA, March 24-28, 1996. ACS, Washington, DC, Part 2, 1115 pp.; (p. 1523, Paper PHYS 235) (1996)

Trends in binding preferences of crown ethers to metal cations are generally attributed to simple electrostatic interactions and relative ring cavity/cation radius dimensions. For larger, more polarizable cations - and possibly transition metals - the binding mechanisms for gaseous complexes are not clearly established. Using ab initio computational methods, we report binding energies and enthalpies of metal cations with 12-crown-4 and other representative fragment ethers. The aim is to anticipate alterations in classical complexation trends by such factors as electron correlation and charge transfer. (Complete text).

\section{$1966 \quad$ V18/022139}

Quarterly Report for the NGA FFCA Project - July 1-September 30, 1994

National Govemors' Association, Washington, DC DOE/EW/30330-T2; 40 pp. (1994)

Summaries are presented of activities and meetings related to the National Governor's Association (NGA) Federal Facilities Compliance Act (FFCA) project. The objective of this project is the management of mixed radioactive and hazardous wastes. Activities include: (1) execution of grants to states to fund a review and development of site treatment plans; (2) determination of interest in a proposed cost model to be developed by EG\&G; (3) determination of the major issues that need to be addressed prior to the release of the Draft Site Treatment Plans; and (4) development of a draft Commercial Mixed Waste Issue Paper which was distributed for review and comments.

\section{Remediation of Contaminated Sites}

Beaulieu, $M$.

Environment Canada, Ottawa, Ontario, Canada; Quebec Ministere de l'Environnement, Ste-Foy, Quebec, Canada

CONF-9509397; Towards a Sustainable Future: Waste Minimization - New Solutions for Challenging Times, Proceedings of the 17th Canadian Waste Management Conference, Quebec, Quebec, Canada, September 11-14, 1995. Canadian Environmental Industry Association, Winnipeg, Manitoba, Canada, 750 pp.; (10 pp.) (1995)

The Province of Quebec first introduced its policy on the remediation of contaminated sites in 1988. After seven years of application, the policy is being evaluated and revised. The new policy is about to undergo public consultation. The origin and initial objectives of the 1988 policy were presented and its principal accomplishments were reviewed. Modifications to the policy were also discussed. The initial policy had three principal objectives. They were: 1) to protect new users of contaminated sites, (2) to re-use contaminated sites, and (3) to establish safety standards for the management of contaminated sites. The new policy will also include prevention as an objective, to forestall the re-occurrence of events which in the past have led to serious ground contamination problems. (This document is in French).

1968 V18/022146

RCRA, Superfund and EPCRA Hotline Training Module: Introduction to RCRA Enforcement and Compliance Updated July 1996

Booz-Allen \& Hamilton, Inc., Bethesda, MD

EPA/530/R-96/040; 20 pp. (July 1996)

The module describes enforcement procedures, cites the statutory authority, and describes the two different types of enforcement (i.e., administrative and judicial). It explains when and how EPA can enforce the RCRA regulations in authorized states. It describes the enforcement mechanisms available to EPA. It states the differences between enforcement at interim status and permitted facilities. It describes enforcement at federal facilities and identifies relevant resource documents.

1969

V18/025480

RCRA, Superfund and EPCRA Hotline Training Module: Introduction to the Superfund Response Program

U.S. Environmental Protection Agency, Office of Emergency and Remedial Response, Washington, DC

EPA/540/R-97/022; OSWER-9205.5-14; 44 pp. (June 1997)

The module will enable readers to: (1) demonstrate familiarity with the statutory and regulatory framework of the Superfund program, and quickly reference pertinent sections in the statue and the National Contingency Plan (NCP); (2) explain the basic steps of the Superfund response process, from initial site discovery until site cleanup has been completed; (3) describe the function of the CERCLIS database, the archived list, and the National Priorities List (NPL); (4) locate and cite the Hazard Ranking System (HRS); (5) briefly explain the NPL, the HRS, and their relationship; (6) provide information about special types of sites, such as federal facilities, mining sites, Resource Conservation and Recovery Act 
(RCRA) sites, pesticide sites, and radioactive sites; (7) understand the factors that contribute to the selection of a remedy; and (8) understand the role of the states in the Superfund process.

1970

V18/025453

Radiation Assessment of Contaminated Sites of Peat Mining and Peat Bricks Used as Fuel by the Population of Zhitomir Area of the Ukraine

Semenyuk, N.D.; Shabunina, N.D.; Voloshchenko, V.O.; Troyan, L.V.; Salenko, K.A.; Berezhnaya, T.I.

CONF-9309496; Proceedings of the Radiobiological Congress, Abstracts, Part 3, A.I. Gaziev (ed.), Kiev, Ukraine, September 20-25, 1993. Pushchinskij Nauchnyj Tsentr, Pushchino, Russian Federation, 399 pp.; (pp. 903-904) (1993)

Short communication. No abstract available. (This document is in Russian).

1971

V18/021667

Radiation Control: Proceedings of the 27th Annual National Conference, San Antonio, TX, May 7-10, 1995

CONF-9505336; Proceedings of the 27th Annual National Conference on Radiation Control, San Antonio, TX; May 7-10, 1995, Conference of Radiation Control Program Directors, Inc., Frankfort, KY, 364 pp. (1995)

A wide variety of topics related to radiation control are presented in the papers selected for the database. Topics covered include: radioactive soil cleanup standards, low-level radioactive waste, Licensing State Designation program, health physics, radioactive contamination of scrap metal, radioactive contamination of food, U.S. Nuclear Regulatory Commission materials licensing program, high and pulsed dose rate medical therapy, licensing of a commercial mixed waste facility, radioactive sewer discharge regulations, air emission standards for radionuclides, and regulation of naturally occurring radioactive materials in oil and gas fields. Other topics covered, but not selected for the database, are primarily related to medical x-ray programs.

1972

V18/020681

Radiation Heritage: The Remediation of Contamination from WISMUT is Eastern Germany's Biggest Environmental Project

Lenk, U.

Beratende Ingenieure 25(6):28-30 (June 1995)

No other enterprise of the former German Democratic Republic is and has been so much in the focus of public interest as the WISMUT company. What was once discussed in secret is being portrayed by environmentalists and concerned citizens after the collapse of the eastem regime as the greatest environmental catastrophe in German history. (This document is in German).

\section{3}

V18/021233

Radiation Site Cleanup Regulations: Technical Support Document for the Development of Radionuclide Cleanup Levels for Soil - Appendices A-O, Review Draft Wolbarst, A.B.; Mauro, J.J.; Anigstein, R.; Back, D.; Bartlett, J.W.
U.S. Environmental Protection Agency, Office of $A$ ir and Radiation, Washington, DC

EPA/402/R-96/011B; EPA/402/R-96/011C; 797 pp. (September 26, 1994)

Table of Contents: Appendix A - Footnotes for Table 1-2; Appendix B - Parameter Values Used in Pathway/Risk Modeling; Appendix C - Modified RAGS/HHEM Equations; Appendix D Description of Terminology Used by the Census Bureau; Appendix E - Methodology for Deriving Population Impacts; Appendix F Comparison of Health Risks Arising from the Radiological and Chemical Toxicity of Uranium; Appendix G - PRESTO-CPG Input Parameters; Appendix $\mathrm{H}$ - Results of RESRAD Parameter Sensitivity Analyses; Appendix I - RAGS/HHEM Monte Carlo Uncertainty Analysis; Appendix J - Analysis of Aerial Radiological Surveys; Appendix K - Risk Based Results of Reference Site Analyses; Appendix L - Graphical Results of Reference Site Analyses; Appendix M - Dose Based Resins of Reference Site Analyses; Appendix N - Population Model Results of Reference Site Analyses; and Appendix O - Background Radiation and Lower Limits of Detection.

1974

V18/021234

Radiation Site Cleanup Regulations: Technical Support Document for the Development of Radionuclide Cleanup Levels for Soil - Review Draft

Wolbarst, A.B.; Mauro, J.J.; Anigstein, R.; Back, D.; Bartlett, J.W.

U.S. Environmental Protection Agency, Office of Radiation and Indoor Air, Washington, DC

EPA/402/R-96/011A; 395 pp. (September 24, 1994)

This report presents EPA's approach to assessing some of the beneficial and adverse radiation health effects associated with various possible values for an annual dose limit. In particular, it discusses the method developed to determine how the choice of cleanup criterion affects (1) the time-integrated numbers of non-fatal and fatal radiogenic cancers averted among future populations, (2) the occurrence of radiogenic cancers among remediation workers and the public caused by the cleanup process itself, and (3) the volume of contaminated soil that may require remediation.

1975

V18/020810

Radiation Situation in the Republic of Kazakhstan, Its Control and Measures on Liquidation of Radioactive Pollution

Dzhunusov, A.; Bayadilov, E.

Atomic Energy Agency of the Republic of Kazakhstan, Kazakhstan

IAEA-TECDOC-865; CONF-9310459 (Vol. 1); Planning for Environmental Restoration of Radioactively Contaminated Sites in Central and Eastem Europe, Volume 1: Identification and Characterization of Contaminated Soils, Proceedings of a Workshop on Environmental Restoration in Central and Eastern Europe, Budapest, Hungary, October 4-8, 1993. Intemational Atomic Energy Agency, Vienna, Austria, Vol. 1, 356 pp.; (pp. 183-192) (February 1996) 
The report describes procedures of supervision and control of the radiation situation in the Republic of Kazakhstan, its general conditions, and some methods used in practice of recultivation of polluted territories. The report describes the main sources of radioactive pollution and conducted measures, which prevent the distribution of radioactive contamination. It is shown that the main part of the contaminated territories is supervised and if it is necessary, deactivated. The work of revealing unknown pollution is regularly carried out.The report also gives radiation safety regulations on liquidation of uranium enterprises and some problems connected with waste handling in the Republic.

\section{6 \\ V18/020688}

Radioactive Contamination of Agriculture Plants: Chapter 5

Zabolotnyj, A.I.

Akadehmiya Navuk Belarusi, Institut Ehksperymental'naj Bataniki imya V.F. Kuprehvicha, Minsk, Belarus

Radioactive Contamination of the Plants of Belarus (as a Result of the Chernobyl Accident), V.I. Parfenov (ed.), Navuka i Tehkhnika, Minsk, Belarus, 582 pp.; (pp. 237-274) (1995)

The contamination of arable lands of the Republic of Belarus and the accumulation of radionuclides by both vegetative and reproductive bodies of plants via the level of soil contamination and conditions of cultivation are described. The influence of external and internal irradiation on the vital functions of plants is discussed. The physiobiochemical characteristic of seeds grown on the contaminated soils are given. The possibility of decontamination of soils by plants and chemical methods is explored. (This document is in Russian).

\section{7}

\section{V18/022504}

\section{Radioactive Wood Waste Treatment in the Chernobyl} Zone

Savushkin, I.A.; Grebenkov, A.J.; Solovjov, V.N.; Luchkin, B.G.

Academy of Sciences, Institute of Power Engineering Problems, Minsk, Belarus

CONF-960804 (Vol. 1); Spectrum '96: Nuclear and Hazardous Waste Management, Proceedings of an International Topical Meeting, Seattle, WA, August 18-23, 1996. American Nuclear Society, La Grange Park, IL, Vol. 1, 887 pp.; (pp. 25-31) (1996) The large volume of radioactive wood waste generated on forested areas in Belarus after the Chemobyl Accident requires a special strategy of forestry production and contaminated wood treatment. If this activity is supplied with wood utilization technologies, the probability of recovering some of the costs of decontamination and remediation of the forest will be realised.

\section{8}

V18/024336

Radiochemical Contamination of Soil, Grass and Ground Layer of the Air of Lublin (Poland)

Chibowski, S.; Zygmunt, J.

Uniwersytet Marii Curie-Sklodowskiej, Lublin, Poland

Polish Joumal of Environmental Studies 4(4):25-32 (1995)
The contamination of the city of Lublin, Poland by gamma emitters and radionuclides in the ground layer of air were studied. A heterogeneous distribution of radiocesium was found in soils, due chiefly to the Chernobyl power plant accident. The contribution of after-Chemobyl radiocesium to the total amount of this radioelement in the surface layer of the soil averages $85 \%$. Compared with so-called uncontaminated areas, there is an elevated level of the natural nuclides $\mathrm{Ra}-226, \mathrm{Ra}-224, \mathrm{Ac}-228, \mathrm{~Pb}-212$ and $\mathrm{Bi}-212$ in the city. However, $\mathrm{K}-40$, whose contribution averages about $65 \%$ of total activity, is the main gamma emitter found in Lublin soil. In grass samples, the contribution of $\mathrm{K}-40$ averages as high as $85 \%$. Substantial amounts of Ra-226 and Ra-224 were also found in grass. Radiocesium activity in grass ranges from 0.6 to 11 $\mathrm{Bq} / \mathrm{kg}$ of dry matter and the transfer factor of Cs-137 from soil to grass ranges from 0.07 to 0.85 . The radioactivity of the ground layer of air was as low as $1.2-3.4 \mathrm{mBq} / \mathrm{cu} \mathrm{m}$.

1979

V18/020603

Radioecological Problems of the Republic of Belarus After the Chernobyl Accident and the Ways of Their Solution

Sharovarov, G.A.

Academy of Sciences, Minsk, Belarus

IAEA-TECDOC-865; CONF-9310459 (Vol. 1); Planning for Environmental Restoration of Radioactively Contaminated Sites in Central and Eastem Europe, Volume 1: Identification and Characterization of Contaminated Soils, Proceedings of a Workshop on Environmental Restoration in Central and Eastern Europe, Budapest, Hungary, October 4-8, 1993. International Atomic Energy Agency, Vienna, Austria, Vol. 1, 356 pp.; (pp. 31-41) (February 1996)

The data on the scale of radionuclide contamination in Belarus after the Chernobyl accident are given. The overall contaminated areas with radiation density of caesium- 137 exceeding $3.7 \times 10(E+4)$ $\mathrm{Bq} / \mathrm{sq} \mathrm{km}$ amount to 46,5 thousands of square kilometers. It is shown, that in 1993 the radioactivity at the territory of Belarus accounts for more than $3.7 \times 10(E+16) \mathrm{Bq}$. The paper presents the characteristics of the main contributors to the radiological situation. The characterization of the patterns of contamination of soil, water systems, and forests is considered. The paper gives the organizing structure of control over the processes remediating the post-effects of the Chemobyl accident. The need for urgent development of the project for changing contaminated territories into ecologically safe areas is indicated. Suggestions on organizing the International Safety System against accidents at potentially hazardous industrial enterprises are given.

1980

V18/022993

Radon Manual: Radon Monitoring in the United Kingdom - Second Edition

Radon Council Limited, Middlesex, United Kingdom INIS-GB-681; 7 pp. (1996)

This second edition to the Radon Manual provides a guide to the detection and measurement of natural radon levels in the United Kingdom, and is published by the Radon Council, an independent self-regulatory body for the radon industry. The document also 
details appropriate remedial measures to mitigate radiation exposure effects and methods of monitoring the success of such measures.

\section{1}

\section{V18/021295}

Reaction Products and Mass Balances from Irradiated TCE Vapor

Matthews, S.M.; Wang, F.T.; Mill, T.; Su, M.; Yao, C.C.D. Lawrence Livermore National Laboratory, Livermore, CA; SRI International, Menlo Park, CA

CONF-9409178; Emerging Technologies in Hazardous Waste Management VI, Proceedings of the Sixth American Chemical Society Industrial and Engineering Chemistry Division Special Symposium, Atlanta, GA, September 19-21, 1994. American Chemical Society, Washington, DC; (p. 10) (1994)

Trichloroethylene (TCE) vapor, at a concentration of $3000 \mathrm{ppmv}$ in synthetic air, was sealed in Tedlar bags and irradiated with a 3.7 $\mathrm{MeV}$ electron beam. Bags of dry vapor and vapor at $90 \%$ relative humidity were irradiated. Doses up to 11 megarads (11 MR) were applied. Each bag was chemically analyzed for reaction products and a mass balance of the chlorine and carbon was obtained within the $11 \mathrm{MR}$ dose range. The results of these radiolysis experiments and chemical analysis show that, given the proper treatment, the TCE concentration is reduced to below detection limit and the reaction products of the organic carbon and chlorine are carbon monoxide (CO), carbon dioxide ( $\mathrm{CO} 2)$, chlorine gas $(\mathrm{Cl} 2)$, and hydrochloric acid $(\mathrm{Hcl})$. No detectable amounts of dichloroacetyl chloride (DCAC) or phosgene (PG) remained in the sample after proper treatment. DCAC and PG were found only as intermediary oxidation products of the TCE. High energy ionizing radiation, as electron beams and bremsstrahlung, is a new treatment technology for destroying toxic compounds and hazardous wastes. A demonstration of complete destruction of organic products, using this treatment at standard temperature and pressure, is expected to help implement the use of this technology. (Complete Text).

\section{2}

\section{V18/023048}

\section{Recycling and Reuse of Industrial Wastes}

Smith, L.; Means, J.; Barth, E.

Battelle Memorial Institute, Columbus, OH; U.S.

Environmental Protection Agency, Washington, DC

Report; 100 pp. (1995)

The intent of this handbook is to assist pollution prevention efforts by encouraging recycling and reuse of wastes found on Superfund or Resource Conservation and Recovery Act (RCRA) Corrective Action sites. This handbook outlines specific technologies for recycling and reuse of materials that require remediation at contaminated sites. Case studies within the handbook document applications of these technologies to real-world conditions. A broad range of organic and inorganic waste types are covered. Chapter 2 contains a summary table of applicable technologies arranged by waste type. Chapter 3 contains brief descriptions of individual technologies, with information on such matters as process maturity, applicable wastes, and advantages and disadvantages. Chapter 4 discusses product quality specifications, and Chapter 5 presents case studies.
1983

V18/023337

\section{Remediation Engineering: Design Concepts}

Suthersan, S.S.

Remediation Engineering: Design Concepts, Lewis Publishers, Inc., Chelsea, MI (December 1996)

This book contains the actual design of systems for waste remediation. It covers all forms of hazardous waste remediation and draws upon the experience of the entire remediation engineering program at the environmental firm of Geraghty \& Miller, Inc. It features realistic cost-benefit analyses within the changing regulatory framework; discusses the evolution and evaluates the applicability of numerous remediation technologies; offers "rules of thumb" for dealing with emerging remediation technologies that are based on empirical knowledge; and contains 175 figures that describe various technologies.

1984

V18/024620

Remediation Planning, Chapter 12

Boulding, J.R.

Eastern Research Group, Inc., Lexington, MA

Soil, Vadose Zone, and Groundwater Contamination Assessment, Prevention, and Remediation, Lewis Publishers, Boca Raton, FL, 947 pp.; (pp. 695-729) (1995)

This is a chapter in the book titied: Practical Handbook of Soil, Vadose Zone, and Groundwater Contamination by J. Russell Boulding. Remediation Planning is part of the section on Prevention and Remediation. Subsurface remediation includes: (1) identifying, quantifying, and controlling contaminant source(s); (2) considering cleanup levels required for each medium (air, soil, and groundwater) to protect human health and the environment; and (3) selecting treatment technologies based on information obtained concerning source(s) and cleanup levels. The challenge is to effectively relate site characterization activities to selecting the most appropriate remediation technologies for contaminated soils and groundwater at hazardous waste sites. Effectively relating these activities with technology selection improves the efficiency, purpose, and results of both site characterization and remediation technique selection. This chapter addresses specific subsurface physical, chemical, and biological processes that have been discussed in Part I within the context of (1) site characterization requirements, (2) evaluation and selection of remediation techniques and treatment trains utilizing several techniques, and (3) design of monitoring programs. Specific soil and aquifer remediation techniques are addressed in more detail in Chapters 13 (Remediation of Contaminated Soil) and 14 (Remediation of Contaminated Groundwater) which are also indexed in the RAPIC database.

1985 V18/021699

Remediation of Contaminated Media at U.S. Coast Guard Facilities

Kikkeri, S.R.; Hagerty, E.P.; Ness, E.R.; Fitzpatrick, M.

Coast Guard Research and Development Center, Groton, CT CGRDC-16/95; 74 pp. (June 1996)

This document summarizes data in tabular form, on remediation 
technologies practiced at U.S. Coast Guard (USCG) facilities. Abbreviated information concerning the site, media treated, contaminants, matrix characteristics, operating parameters, cost, and other pertinent information is organized by technology type as identified in the Remediation Technologies Screening Matrix and Reference Guide (EPA/542/B-94/013). The document structure matches that of Tables 3-4 through 3-16 in Section 3 of the Guide, and review of USCG data should be done using the Guide as a companion/reference text.

\section{$1986 \quad$ V18/022220}

Remediation of Explosive Materials

NERAC, Inc., Tolland, CT

Bibliography (October 1996)

The bibliography contains citations from the Energy Science and Technology Database (EDB) concerning the reclamation of sites, both civilian and military, polluted with munitions waste. Articles discuss the remediation and degradation of such materials as trinitrotoluene (TNT), red water, pink water, propellants, explosives, and other energetic materials. Techniques used to clean up these waste products include composting, incineration, fungal degradation, activated carbon, and natural biological/chemical decomposition.

\section{7}

V18/022616

Remediation of Hazardous Effluent Emitted from Beneath Newly Constructed Road Systems and Clogging of Underdrain Systems

Siddiqui, A.A.; Wukasch, R.F.

Purdue University, West Lafayette, IN

CONF-9505206; Proceedings of the 50th Industrial Waste Conference, R.F. Wukasch (ed.), West Lafayette, IN, May 8-10, 1995. Ann Arbor Press, Inc., Chelsea, MI, 861 pp.; (p. 778) (1996)

The Indiana Department of Transport used No. 53 recycled concrete for construction and repair of sections of I-70, I-65 and I-465. Effluents from beneath these sections were found to have a $\mathrm{pH}$ as high as 12 which is beyond the allowable limits. In addition, precipitates forming in the effluent were clogging some of the screens and water was backing up. It is also possible that similar scales are forming in the underdrain filter cloth and clogging the drains. The objective of the project is to determine the source and composition of the high $\mathrm{pH}$ water and determine the chemical mechanisms involved in the forming of the water, the precipitates and the deposits and the extent of the problem, i.e., the long-term leachability of the material. The project will further look at the various treatment options available to eliminate the high $\mathrm{pH}$ of water, cleanup of the clogged screens and develop methods for prevention of the problem in the future.

\section{8}

\section{V18/023678}

Remediation of Hazardous Effluent Emitted from

Beneath Newly Constructed Road Systems and Clogging of Underdrain Systems: Final Report

Wukasch, R.F.; Siddiqui, A.A.

Purdue University, Joint Highway Research Project, West Lafayette, $\mathbb{N}$
FHWA/NN/JHRP-96/13; 84 pp. (November 1996)

The Indiana Department of Transportation uses recycled concrete pavement as aggregate for the construction of highways. The effluent from these pavements has a high $\mathrm{pH}$. The high $\mathrm{pH}$ effluent can cause clogging of drains and vegetative kill around the outlet. This project looks into the source of the effluent water, its chemical composition, and the approximate duration the problem can be expected to persist. The project also investigates possible methods for reduction of the problem in future installation. The approximate additional cost of these solutions and the problems associated with them are discussed as well.

\section{9}

V18/020600

Remediation of Mercury Pollution [Latest Citations from the Energy Science and Technology Database]

NERAC, Inc., Tolland, $C T$

Bibliography; 50 pp. (June 1996)

The bibliography contains 50-250 citations concerning the clean-up of mercury contaminated environmental systems. Articies cited address remedial action for soils, groundwater, sludges, and waste water specifically for mercury and more generally for heavy metals. Citations discuss in-situ fixation and vitrification, reclamation and recycling of mercury, soil washing, analysis, and site characterizations. The bibliography includes a subject term index and title list.

1990

V18/023338

\section{Remediation of PCB Spills}

Erickson, M.D.

Remediation of PCB Spills, Lewis Publishers, Inc., Chelsea. MI (April 1993)

No abstract available.

\section{1 \\ V18/021715}

Remediation of PCB-Contaminated Sediments, in Lake Jaernsjoen, River Emaan, Sweden: Monitoring and Results

Troedsson, B.; Helgee, A.

Municipality of Hultsfred, Hultsfred, Sweden

CONF-9511137; Global Environmental Protection: Science, Politics, and Common Sense, Proceedings of the Second Society of Environmental Toxicology and Chemistry (SETAC) World Congress and 16th Annual Meeting, Vancouver, British Columbia, Canada, November 5-9, 1995. Society of Environmental Toxicology and Chemistry, Pensacola, FL, 378 pp.; (pp. 233-234) (1995)

Lake Jaemsjoen is a small lake in the Emaan river system which is considered to be one of the most valuable watercourses in Sweden. River Emaan is known for its high diversity of fish species. The river and its valley are of national interest from the viewpoints of both nature conservation and cultural history. Remediation implies certain hazards for the environment and substantial environmental monitoring is necessary for managing of the work in order to minimize damage to the environment. The content of $\mathrm{PCB}$ in the sediments of Jaernsjoen was estimated at about $400 \mathrm{~kg}$ and was the 
most important source for spreading of PCB in River Emaan. Remediation of the contaminated sediments took place during 1993 and 1994. It was carried out using a horizontal auger suction dredger. During dredging, the area with the most contaminated sediments was closed off by a silt curtain in order to protect River Emaan from release of suspended solids and PCB. The environmental monitoring during remediation included measuring of PCB, turbidity, suspended solids, total organic carbon, nitrogen, and phosphorus. Turbidity was measured automatically and registered continuously while samples for analysis of suspended solids and PCB were collected automatically and combined to form daily (suspended solids) and weekly (PCB) average samples. Turbidity, suspended solids and $\mathrm{PCB}$ were measured to certify that requirements in the contract for the work and from the authorities were fulfilled. Comparisons between monitoring stations upstream and downstream Lake Jaemsjoen show that the remediation has not influenced the River Emaan negatively.

\section{2}

\section{V18/025556}

Remediation of Syncrude's Edmonton Research Center Evans, P; Ziervogel, H.; Mueller, P.; Parraguez, C. EBA Engineering Consultants Limited, Edmonton, Alberta, Canada; Syncrude Canada Limited, Edmonton், Alberta, Canada; Alberta Environmental Protection, Edmonton, Alberta, Canada; Canadian Geotechnical Society, Montreal, Quebec, Canada

CONF-9609351; Frontiers of Geotechnology, Proceedings of the 49th Canadian Geotechnical Conference, St. John's, Newfoundland, Canada, September 23-25, 1996. Canadian Geotechnical Society, Montreal, Quebec, Canada, 961 pp.; (pp. 1-9) (1996)

Decommissioning of the old Syncrude Research Center and remediation of the site is discussed. Decommissioning and site remediation were carried out based on the "National Guidelines for Decommissioning Industrial Sites" issued by the Canadian Council of Ministers of the Environment (CCME). It was the first large industrial site to have been successfully decommissioned and given a certificate of compliance by Alberta Environmental Protection. Details of the CCME Guidelines, modifications made to the recommended procedures in this case, the specific steps taken, the contaminants found at each location and the volume of contaminated materials removed from each location are described. Remediation work at the site began in August 1992 and was completed in December 1995.

\section{3 \\ V18/023490}

Remediation of an Abandoned Radium-Contaminated Site: The French Approach

Ladsous, D.

ANDRA, Chatenay-Malabry, France

CONF-961103; Decommissioning, Decontamination, and Reutilization Worldwide Experience: DD\&R, What Does It Mean, M.G. White, R.G. Thomas and R.F. Ranellone (eds.), Proceedings of an Embedded Topical Symposium of an American Nuclear Society Winter Meeting, Washington, DC, November 10-14, 1996. American Nuclear Society, Inc., La Grange Park, IL, 328 pp.; (1996)
In 1949, a company called Radium Light, with a workshop, was set up for the manufacture and application of radioluminescent paint on clock dials and hands. Such paint is based on radium bromide, and the yearly dose is about $200 \mathrm{mCi}$. That radionuclide was used by the clock industry between 1906 and 1964, when tritium first appeared. Radium Light closed in 1988, and its judicial liquidation has been in process since then. That company operated on two different sites. These areas have been rehabilitated. These sites were recorded in the national waste inventory in 1993, 1994, and 1995. Setting up that inventory (a public document) is one of the National Radioactive Waste Management Agency's (ANDRA's) regulatory assignments. Indeed, ANDRA checks all sites containing radioactive waste. The author describes the procedure followed in the remediation of one of these sites. The paper touches on site survey, mapping, specification creation, pricing, safety planning, financing, and finally soil and vegetation removal to a temporary storage facility.

1994

V18/024362

Removal Response to Radiation Sites: Reference Document

U.S. Environmental Protection Agency, Office of Emergency and Remedial Response, Washington, DC

EPA/540/R-94/038; 32 pp. (October 1996)

The purpose of this document is to provide references and a planning guide for removal actions involving radioactive materials. This document includes: information on the differences between a radiation site and a hazardous waste site without radioactive contamination; a statement of the relevant issues for responding to a radiation release and references to detailed technical information; a guide to the response planning process as it relates to radiation; assistance available to on-scene coordinators and site managers in dealing with radiation sites; and information about radiation-related training.

\section{$1995 \quad$ V18/022210}

Residual Radioactivity in the Soil of the Semipalatinsk Nuclear Test Site in the Former USSR

Yamamoto, M.; Tsukatani, T.; Katayama, Y.

Kanazawa University, Ishikawa, Japan; Kyoto University, Kyoto, Japan

Health Physics 71(2):142-148 (August 1996)

This paper deals with efforts to survey residual radioactivity in the soil sampled at the Semipalatinsk Nuclear Test Site and at off-site areas in Kazakhstan. The soil was sampled at the hypocenter, where the first Soviet nuclear explosion was carried out on 29 August 1949 , and at the bank of the crater called "Bolapan, "which was formed by an underground nuclear detonation on 15 January 1965 along the Shagan River. As a comparison, other soil was also sampled in the cities of Kurchatov and Almaty. These data have allowed a preliminary evaluation of the contemporary radioactive contamination of the land in and around the test site. At the first nuclear explosion site and at Bolapan higher than background levels of $\mathrm{Pu}-239$ and $\mathrm{Pu}-240$ (from weapons-grade plutonium) were detected together with fission and activation products such as Cs-137, Co-60, Eu-152, and Eu-154. 
1996

V18/021661

Restoration Work on the Hungarian Uranium Mining Area

Juhasz, L.; Lendvai, Z.S.; Csicsak, J.; Csovari, M.

National Research Institute for Radiobiology and

Radiohygiene, Budapest, Hungary; Mecsek Ore Mining

Company, Pecs, Hungary

IAEA-TECDOC-865; CONF-9412128 (Vol. 3); Planning for

Environmental Restoration of Radioactively Contaminated Sites in Central and Eastern Europe, Volume 3: Technologies for, and the Implementation of, Environmental Restoration of Contaminated Sites, Proceedings of a Workshop on Environmental Restoration in Central and Eastern Europe, Rez, Czech Republic, December 12-16, 1994. International Atomic Energy Agency, Vienna, Austria, Vol. 3, 356 pp.; (pp. 161-171) (May 1996)

In Hungary uranium mining and milling activities are close to shut-down, so planning for restoration work and implementation of different remedial actions has been undertaken in the last years.

Restoration planning and work was begun in 1992-93, and as a first step the mining piles have been restored. The main goal is that the restored residues on the mining and milling areas are fitted into the surrounding topographic features, and other important aspects, like radiological situation, water management and revegetation are also taken into account. The plan for pile 3 incorporates the experiences of the earlier restored piles, so it takes into consideration the optimization of pile relocation and sloping, mining cavities, and activities and hydrography.

\section{7}

\section{V18/020595}

Restoration of Radioactively Contaminated Sites in the Republic of Croatia [Vol. 2]

Subasic, D.; Schaller, A.; Barisic, D.; Lulic, S.; Vekic, B.; Kovac, J.; Lokobauer, N.; Marovic, G.

APO Hazardous Waste Management Agency, Zagreb, Croatia; Institute of Ruder Boskovic, Zagreb, Croatia; Institute for Medical Research and Occupational Health, Zagreb, Croatia

IAEA-TECDOC-865; CONF-9404316 (Vol. 2); Planning for Environmental Restoration of Radioactively Contaminated Sites in Central and Eastern Europe, Volume 2: Planning for Environmental Restoration of Contaminated Sites, Proceedings of a Workshop on Environmental Restoration in Central and Eastern Europe, Piestany, Slovakia, April 11-15, 1994. International Atomic Energy Agency, Vienna, Austria, Vol. 2, 248 pp.; (pp. 55-79) (March 1996)

In accordance with the scope of work, which was presented and fundamentally accepted at the First Workshop in Budapest, progress has been made in project implementation. First, the highest priorities have been identified. They are related to two out of four listed groups where higher radiation doses could be expected: (1) sites containing coal/ash piles (INA-VINIL plant in Kastel Sucurac, coal-fired power plant PLOMIN); and (2) sites containing phosphates and phospho-gypsum remaining from fertilizer industry (INA-PETROKEMIJA in Kutina). The most sensitive site is INA-VINIL plant in Kastel Sucurac, since there is (1) considerable population (some 250,000 residents) living within a radius of $10 \mathrm{~km}$ around the site; (2) besides radiation there is additional, non-radioactive contamination generated by the plant (mercury, vinyl-chloride-monomer etc.); and (3) the site is situated at the seaside in the close, densely populated Bay of Kastela. Sampling and detailed measurements at all three sites are under way.

Radiochemical analysis using radium 226 will be done from water samples (from piezometers) and wells in surrounding populated area. Working level for radon 222 daughters will also be determined. TLDs and "diffusion chambers" were set up at desired places. In addition to the previousiy involved Institute Ruder Boskovic, another institution, the Institute for Medical Research and Occupational Health from Zagreb has been included in the project. It is worth mentioning that we are simultaneously running the project for site selection for a radioactive waste repository in Croatia, and a few preferred (candidate) sites are scheduled to be identified and verified by the end of the year. Namely it is assumed that some of the contaminated materials involved in the project will be eventually disposed at the radioactive waste repository.

1998

V18/020811

Restoration of Radioactively Contaminated Sites in the Republic of Croatia [Vol. 1]

Saler, A.; Barisic, D.; Vekic, B.; Lulic, S.

APO Hazardous Waste Management Agency, Zagreb, Croatia; Institute of Ruder Boskovic, Zagreb, Croatia

IAEA-TECDOC-865; CONF-9310459 (Vol. 1); Planning for Environmental Restoration of Radioactively Contaminated Sites in Central and Eastem Europe, Volume 1: Identification and Characterization of Contaminated Soils, Proceedings of a Workshop on Environmental Restoration in Central and Eastem Europe, Budapest, Hungary, October 4-8, 1993. International Atomic Energy Agency, Vienna, Austria, Vol. 1, 356 pp.; (pp. 91-112) (February 1996)

In March 1993 Croatia joined the LAEA Technical Co-operation Project on Environmental Restoration in Central and Eastern Europe. The proposed project structure was fully accepted, i.e., the project implementation in Croatia is supposed to be carried out through three stages: (1) identification and characterization of radioactively contaminated sites; (2) preparation for restoration; and (3) restoring radioactively contaminated sites. The Hazardous Waste Management Agency from Zagreb has been appointed to be the project co-ordinator in Croatia. Through contacts with experts from the IAEA who are responsible for the international project implementation, the general structure of the project performance in Croatia was defined with respect to the specific situation in our country, i.e., regarding the types of radioactively contaminated sites. There are four groups of radioactively contaminated sites in Croatia: (1) sites containing coal slag/ash piles; (2) sites containing phosphates and phospho-gypsum from fertilizers industry; (3) geothermal springs and gas/oil drillings; and (4) sites containing natural radioactive materials.

1999

V18/021679

Restoration of Radioactively Contaminated Sites in the Republic of Croatia [Vol. 3]

Subasic, D.; Schaller, A.; Barisic, D.; Lulic, S.; Vekic, B.; Kovac, J.; Lokobauer, N.; Marovic, G. 
APO Hazardous Waste Management Agency, Zagreb, Croatia; Institute of Ruder Boskovic, Zagreb, Croatia; Institute for Medical Research and Occupational Health, Zagreb, Croatia

IAEA-TECDOC-865; CONF-9412128 (Vol. 3); Planning for Environmental Restoration of Radioactively Contaminated Sites in Central and Eastem Europe, Volume 3: Technologies for, and the Implementation of, Environmental Restoration of Contaminated Sites, Proceedings of a Workshop on Environmental Restoration in Central and Eastem Europe, Rez, Czech Republic, December 12-16, 1994. Intemational Atomic Energy Agency, Vienna, Austria, Vol. 3, 356 pp.; (pp. 87-119) (May 1996)

This report brings results of performed investigations and analyses, but also shows information of relevant past researches referring to three highly prioritized sites: INA-VINIL Plant, PLOMIN Power Plant and INA-PETROKEMIJA Plant. This information serves as a suitable starting point for further investigations, which are, according to the programme schedule, foreseen to be completed by the end of 1997. The report also gives some recommendations for the personnel of INA-PETROKEMIJA Plant, being in this way useful for everyday practice in the only fertilizer factory in Croatia.

2000

V18/023784

\section{Returning Property to the Tax Rolls: A Case Study}

Aveggio, J.

SHN Consulting Engineers \& Geologists, Eureka, CA

CONF-9504134; HAZMACON '95, T. Bursztynsky and M.L. Loss (eds.), Proceedings of the Twelth Hazardous Materials Management Annual Conference and Exhibition, San Jose, CA, April 4-6, 1995. Association of Bay Area Governments, Oakland, CA, 790 pp.; (pp. 182-191) (1995)

The interiors of many cities contain former industrialized areas that have fallen into disrepair. Many of these areas have been incorporated into redevelopment zones as cities attempt to recapture retail and light industrial commercial enterprises that have been exiting cities for outlying suburban areas. A major deterrent to the redevelopment of these intercity areas is the high cost associated with mitigating residual soil and groundwater contamination resulting from years of industrial activities. If the properties remain undeveloped, their revenue to the local taxing authority remains at minimal levels. It is not unreasonable to assume that a redeveloped property would increase 10 to 100 times in assessed value. In California, the local taxing authority bases its tax assessment as a percentage of the assessed value. Therefore, it is in the taxing authority's best interest to encourage and provide incentives for redevelopment. The City of Eureka and Price-Costco combined to remediate a contaminated property, build a Costco store, provide jobs, and return a property to the tax rolls. The effort was accomplished through the negotiation of site specific cleanup levels for petroleum hydrocarbons and remediation of approximately 16,000 tons of soil by thermal desorption. Site specific cleanup levels were established by using a leachate procedure to establish the contaminant concentration in soil that would impact groundwater, and through an economic analysis of cleanup level versus benefit. Petroleum contaminated soil was excavated from 11 source areas and transported to an on-site thermal desorber for treatment. The soil contained the full spectrum of petroleum hydrocarbons, from gasoline to heavy oils. The thermal desorber was able to consistently treat this wide variety of contamination to nondetectable levels. Following treatment, the soil was backfilled and compacted into the excavations. The entire cleanup was complete in approximately 2 months and was performed concurrently with the construction of the store. This paper will present the details of how project was successfully completed.

2001 V18/024338

Risk Assessment Approach to Evaluating Potential Remedial Actions at the Diemerzeediji Hazardous Waste Site

Heida, H.; Van Den Berg, M.; Olie, $\mathrm{K}$.

OMEGAM-Environmental Research Institute, Amsterdam, Netherlands; University of Utrecht, Utrecht, Netherlands; University of Amsterdam, Amsterdam, Netherlands Hazardous Waste and Hazardous Materials 12(1):1-14 (Winter 1995)

As a result of the former burning of hazardous chemical wastes in the open air along the border of lake IJmeer, located southeast of Amsterdam, the surrounding environment was contaminated with a variety of organic substances. The major contaminants detected were solvents, volatile aromatics, organochlorine pesticides, arsenic, polychlorinated biphenyls (PCBs), polycyclic aromatic hydrocarbon (PAHs), and dioxins and furans. For the purpose of risk assessment, several pathways for the migration of hazardous substances were identified. Both site-specific and total-lifetime cancer risk amounted to more than $98 \%$. It is concluded that without remedial action neither the total-lifetime carcinogenic risk nor the total acceptable daily intake would satisfy the minimum health protection goals of $10(\mathrm{E}-6)$ and $300 \%$, respectively. Complete removal of the residues from burning and of the adjacent lake sediments tumed out to be the remedial action plan offering the greatest degree of public health protection.

\section{$2002 \quad$ V18/024353}

Role of CSGWPPs in EPA Remediation Programs

U.S. Environmental Protection Agency, Office of Emergency and Rémedial Response, Washington, DC

EPA/540/F-95/084; OSWER-9283.1-09; 13 pp. (April 4, 1997)

This directive recommends that Environmental Protection Agency (EPA) remediation programs be familiar with Comprehensive State Ground Water Protection Programs (CSGWPPs) and utilize them as a means of giving more flexibility to a State for management of groundwater resources.

2003

V18/022675

Role of Cometabolism in Reductive Dehalogenation of Aromatics

Sathish, N.; Young, J.C.

C.C. Johnson \& Malhotra, P.C., Detroit, MI; Pennsylvania State University, Department of Civil and Environmental Engineering, University Park, PA

CONF-941 124; Insitu Remediation: Scientific Basis for Current and Future Technologies, G.W. Gee and N.R. Wing (eds.), Proceedings 
of the 33rd Hanford Symposium on Health and the Environment, Pasco, WA, November 7-11, 1994. Battelle Press, Columbus, $\mathrm{OH}$, Part 2, 605 pp.; (pp. 167-193) (1994)

Anaerobic reactions are sequential, so that the effective transformation of chemicals is brought about by the combined action of several different groups of bacteria. Reductive dehalogenation reactions are the first step in the anaerobic degradation of toxic halogenated pollutants, but these reactions alone do not provide the carbon necessary for bacterial growth. Complete removal of the halogen atoms from the aromatic ring is required for these compounds to support growth under anaerobic conditions. The study described in this paper addresses the reductive dehalogenation of several polychlorinated phenols under anaerobic conditions. The tests provided clear evidence of the existence of cometabolic reactions in which the enzymes responsible for the dehalogenation reactions were developed during prior growth on organic cosubstrates. The cometabolic sequential dehalogenation reactions were modeled using a comprehensive toxicity model which takes into account the presence of parent compounds, intermediates, and final products.

\section{4}

\section{V18/021040}

\section{Scrap Metal Recycling for Waste Minimization at Rocky} Mountain Arsenal

Rondinella, M.A.; Harris, V.; Anderson, G.M.

U.S. Army, Rocky Mountain Arsenal, Commerce City, CO

CONF-940499 (Vol. 2); Proceedings of the 1994 Federal

Environmental Restoration III and Waste Minimization II

Conference and Exhibition, New Orleans, LA, April 27-29, 1994.

Hazardous Materials Control Resources Institute, Rockville, MD, Vol. 2, 858 pp.; (pp. 1054-1062) (1994)

The U.S. Army Rocky Mountain Arsenal is a former munitions and pesticide production, storage and demilitarization facility. Two large manufacturing complexes remain at the facility. All production activities ceased in 1982, and the Arsenal is now a National Priorities List (NPL) site undergoing environmental restoration. The U.S. Army is now removing tanks, piping and equipment from the manufacturing areas. The paper addresses the Army's use of recycling to minimize wastes that would otherwise be land disposed during these removal operations. The advantages of recycling and the problems and pitfalls will be addressed. This paper will focus primarily on scrap metal from areas that did not produce or store chemical warfare agents. The special case of recycling of containers and equipment associated with chemical warfare agents will also be briefly addressed.

\section{5}

V18/024661

Selection of Bioremediation for Site Cleanup: Decision Factors, Chapter 3

Kaufman, A.K.

RESNA Industries, Inc., Los Angeles, CA

Bioremediation: Field Experience, P.E. Flathman, D.E. Jerger and J.H. Exner (eds.), Lewis Publishers, Boca Raton, FL, 560 pp.; (pp. 51-57) (1994)

Environmental specialists frequently face a dilemma associated with making the appropriate selection for site remediation. Often, they must rely on information obtained by others, and that information is consequently subject to differences of interpretation. More often than not, additional information must be obtained even before remedial action can be addressed. Sometimes, so much information regarding a site's characteristics is available that focusing on the key factors for making a decision appears almost impossible. For the applicability of biological treatment, however, there are a number of general parameters which can be useful in the construction of a remedial action "decision tree." Prior to addressing the physiochemical and biological concerns associated with prospective implementation of biological treatment at a specific site (most often referred to as the treatability study), a determination must be made as to the feasibility of implementing bioremediation at that site. In general, this assessment is based upon a review of site-specific physical features, contamination characteristics, hydrogeology, time and economic constraints, and regulatory considerations. Unless feasibility of biological treatment can be affirmed at the outset of the project, subsequent work devoted to biological remediation would not likely be prudent. This chapter discusses how the general factors listed above influence the feasibility of successfully using biological treatment for site remediation. This chapter is from the book entitled Bioremediation: Field Experience.

2006

V18/023223

\section{Severe Contamination of Soils by Heavy Metals near Gyoengyoes, Hungary}

Turcsanyi, M.; Kovacs, S.; Buettner, K.; Penksza, M.; Guely, E.; Czinege, E.

Agricultural University, Department of Botany and Plant Physiology, Goedoelloe, Hungary

CONF-9210194; Proceedings of an International Symposium on Environmental Contamination in Central and Eastem Europe, Budapest, Hungary, October 12-16, 1992, 968 pp.; (pp. 515-517) (1992)

Severe soil contamination by heavy metals was discovered alongside the Toka brook in Gyoengyoes, Hungary, downstream of a mining area, at the end of 1990 . In different layers of a garden soil $116-196 \mathrm{mg} / \mathrm{kg} \mathrm{As}, 5.02-28.50 \mathrm{mg} / \mathrm{kg} \mathrm{Cd}, 107-181 \mathrm{mg} / \mathrm{kg} \mathrm{Cu}$, $796-1145 \mathrm{mg} / \mathrm{kg} \mathrm{Pb}$, and $289-3807 \mathrm{mg} / \mathrm{kg} \mathrm{Zn}$ were detected. Subsequent investigations revealed that about a $12 \mathrm{~km}$ long strip alongside the brook is inhomogeneously contaminated by the mentioned heavy metals. In most samples of vegetables taken from the gardens the $\mathrm{Cd}$ content, and in some samples also the $\mathrm{Pb}$ content, exceeded the concentration limits permitted by the Hungarian environmental standards for foods. Unfortunately, instead of a detailed estimation of the hazards of the garden owners, most of the available money has been spent for the verification of the statement that the guilt of the mining company cannot be proven.

\section{$2007 \quad$ V18/021691}

\section{Site Remediation Strategy with Cost Analysis}

Tabatebaei, A.M.

Environment Canada, Ottawa, Ontario, Canada; McGill

University, Department of Mining and Metallurgical

Engineering, Montreal, Quebec, Canada 
CONF-9509397; Towards a Sustainable Future: Waste Minimization - New Solutions for Challenging Times, Proceedings of the 17th Canadian Waste Management Conference, Quebec, Quebec, Canada, September 11-14, 1995. Canadian Environmental Industry Association, Winnipeg, Manitoba, Canada, 750 pp.; (15 pp.) (1995)

The remedial action taken at a landfill site north of Montreal, which was declared an environmental risk by the Quebec Ministry of the Environment, is described. An industrial waste treatment plant was charged with improper sealing of dangerous substance containers, and with exceeding the government's waste treatment limit of 100,000 tons per year. The hydrogeology of the area consists of two water tables, one of which is on a clay layer, while the other is beneath the clay layer and is the main source of potable water for the Blainville and Sainte Therese urban area. The present case of insufficient sealing poses a potential risk to the main water source. Two scenarios for remediation were proposed. The first included remedial processes to be done on the whole site. The second included remedial processes to be done on one cell at a time. The cost for remedial action per unit operation for different types of slurry walls is presented, along with a cost analysis for each remedial action technique.

\section{8}

V18/022704

\section{Site Remediation in Downtown Vancouver}

Conlin, B.; Livingstone, D.; Boyle, B.

Golder Associates Limited, Victoria, British Columbia, Canada

Environmental Science \& Engineering 9(5):25, 27 (November 1996)

Development of 'Pacific Place', site of Expo '86' in downtown Vancouver, and the remediation actions taken prior to development, are described. The development will include high value condominium apartment buildings and park areas. Schools and social housing are planned for a later stage. Remediation planning included characterization and delineation of the soil and groundwater contamination employing risk assessment and risk management methods. To date remediation has been initiated and/or completed in six of the nine parcels of land included in the project. The project as a whole is considered to be an excellent example of the problems and challenges involved in transforming a former industrial area in the downtown section of a major city into a highly desirable residential community.

2009

V18/025640

\section{Site Remediation with Insitu Air Sparging}

Lord, D.; Lei, J.; Sansregret, J.L.

Biogenie, Inc., Sainte-Foy, Quebec, Canada; Department of the Environment, Environmental Protection Service, Ottawa, Ontario, Canada

CONF-951086; Proceedings of the Fifth Annual Symposium on Groundwater and Soil Remediation, Toronto, Ontario, Canada, October 2-6, 1995. Environment Canada - Environmental Protection Service, Hull, Quebec, Canada, 566 pp.; (pp. 529-530) (1995)

Remediation of a 30,000 square miles petroleum depot located in the Port of Quebec, which is heavily contaminated by hydrocarbons, is discussed. Work on the project began in 1993. Based on the results of a laboratory study, air injection and nutrient addition were chosen as the treatment methods. During full-scale treatment the site was divided into four zones that function independently. A total of 119 injection wells were installed. Three sampling operations have been undertaken since the beginning of the full-scale treatment project. Results show a 33 per cent decrease in mineral oil and grease levels and a constant decrease in benzene, toluene, ethylbenzene, and xylenes (BTEX) concentrations in both the soil and the water. In terms of microbiological, physical and chemical parameters there was a significant increase in the concentration of dissolved oxygen, and there were increases in total and specific microbial populations. Specific microbial populations were found to vary with the level of contamination.

2010 V18/024688

Solid- and Slurry-Phase Bioremediation, Chapter 8

Cookson, J.T., Jr.

International Network for Environmental Training, Inc., Potomac, MD

Bioremediation Engineering: Design and Application, G.F. Nalven (ed.), McGraw-Hill, Inc., New York, NY, 539 pp.; (pp. 305-358) (1995)

This is a chapter in the book titled Bioremediation Engineering: Design and Application. The biological treatment of municipal waste solids and sludges is not a new concept. It has been practiced worldwide for at least two centuries and for thousands of years in China. During the treatment technology advances of the 1960s and early 1970s, microbial systems received only secondary attention compared with physical-chemical systems. By the late 1970 s interest was renewed in biological treatment of solid wastes. Physical-chemical processes were judged by some as environmentally unacceptable or too expensive. The need to clean up soil and lagoon sludges contaminated with hazardous substances has rekindled solid-phase biological treatment. This chapter presents treatment concepts for aboveground degradation of hazardous chemicals in solids and slurries. There is not clear distinction between slurry and liquid wastes. Slurries are sometimes referenced as solid wastes that have been suspended in water to enhance handling and treatment without any regard to water content. Others consider wastes with water contents of 95 percent or more as liquids. For the discussion of treatment modes here, slurries are defined as water suspensions that are impractical to treat by the liquid reactor technologies discussed in Chapter 9. These typically are mixtures with less than 90 to 98 percent water by weight. A 98 percent water content is typical of unthickened sludges from liquid biological processes. The solid-phase treatment processes for hazardous compounds consist of: land farming; composting - windrow system, static pile system, and in-vessel system; and slurry reactors.

2011

V18/021271

Sour Gas Plant Remediation Technology Research and Demonstration Project: Topical Report - January 1, 1993-December 31, 1993

Stepan, D.J.; Kuehnel, V.; Schmit, C.R.

University of North Dakota, Energy and Environmental 
Research Center, Grand Forks, ND

DOEMC/10637-3827; 75 pp. (February 1994)

Recognizing the potential impacts of sour gas plant operations on the subsurface environment, the Canadian Association of Petroleum Producers (CAPP) and Environment Canada initiated a multiphase study focusing on research related to the development and demonstration of remedial technologies for soil and groundwater contamination at these facilities. Research performed under this project was designed to supplement and be coordinated with research activities being conducted at an operational sour gas plant located in Rocky Mountain House, Alberta, Canada. These research tasks included hydrogeological site characterization, subsurface contaminant characterization, exsitu treatment of groundwater, and subsurface remediation of residual contamination in the unsaturated zone. Exsitu treatment of groundwater included evaluations of air stripping, steam stripping, advanced oxidation, and biological treatment, as well as the development of an artificial freeze crystallization process. Soil vapor extraction was evaluated as a technique to address residual contamination in the unsaturated zone.

\section{2}

V18/021272

Sour Gas Plant Surface Remediation Technology Research and Demonstration Project: Quarterly Technical Progress Report - January 1, 1994-March 31, 1994

Stepan, D.J.; Kuehnel, V.

University of North Dakota, Energy and Environmental Research Center, Grand Forks, ND

\section{DOE/MC/30098-3915; 9 pp. (April 1994)}

Recognizing the potential impacts of sour gas plant operations on the subsurface environment, the Canadian Association of Petroleum Producers (CAPP), formerly the Canadian Petroleum Association (CPA), and Environment Canada initiated a multiphase study focusing on research related to the development and demonstration of remedial technologies for soil and groundwater contamination at these facilities. The first phase of the project was completed in 1990 , and consisted of a comprehensive review of all soil and groundwater monitoring data submitted to Alberta Environment by sour gas plants in accordance with the Clean Water Act (1980). That review indicated that all but one of the 45 sour gas plants for which data were available exhibited some form of impact on soil and groundwater quality. The study identified the most frequently occurring contamination situations at the site and classified them by source, type of contaminant, and the hydrogeological characteristics of the contaminated setting. The project steering committee subsequently selected the Strachan Gas Plant, located near Rocky Mountain House, Alberta, Canada, as a field research and remediation technology demonstration site. Research to be performed under this agreement is for activities in the areas of soil vapor extraction (SVE), bioventing, and bioremediation, all focusing on residual contamination in the unsaturated, or vadose, zone at the site, as well as evaluations of biological treatment of groundwater and exsitu soil remediation using solvent extraction in conjunction with photooxidation, solvent extraction in conjunction with microwave irradiation, and low-temperature thermal desorption.
Spectrum ' 96 - Nuclear and Hazardous Waste

Management: Proceedings of an International Topical Meeting, Vol. 1, Seattle, WA, August 18-23, 1996

CONF-960804 (Vol. 1); Spectrum '96: Nuclear and Hazardous Waste Management, Proceedings of an International Topical Meeting, Seattle, WA, August 18-23, 1996. American Nuclear Society, La Grange Park, IL, Vol. 1, 887 pp. (1996)

These volumes are the proceedings from the sixth biennial International Topical Meeting on Nuclear and Hazardous Waste Management, otherwise known as Spectrum '96. The Spectrum conference series is conducted under the auspices of the American Nuclear Society (ANS), but since its inception in 1986, it has been organized to highlight the accomplishments of a hosting U.S.

Department of Energy (DOE) Site and to provide a national forum for components of DOE's National Environmental Management Program. The objectives of the organizers, sponsors, and participating customer groups of Spectrum ' 96 are: (1) to make available information on Hanford (the hosting DOE site) and National Program's progress and accomplishments to regional and national audiences; (2) to increase domestic and intemational industry understanding of U.S. and international cleanup opportunities; (3) to achieve high-quality technology exchanges on new technologies; operating experience and new management tools across Federal sites, industry and other countries; (4) to provide for technical and business exchanges between Federal and domestic and international industry representatives; and (5) to involve secondary and university-level environmental education programs from the region. This Spectrum ' 96 technical program clearly has a strong emphasis on activities related to the DOE Environmental Management program. Nearly $50 \%$ of the 500 presentations/papers are by DOE staff or contractors, and many of the papers from industry and universities reflect DOE work or issues. The Department is also sponsoring several special sessions and working side meetings to review and coordinate a number of nationwide and international initiatives. This international emphasis is designed to accomplish integration or exchanges of information across DOE sites and programs, but it is also intended to inform domestic industry, universities, and the international community on the opportunities within this multi-billion dollar environmental program. Over 100 presentations are being provided by domestic industry and universities, and approximately 130 papers are being presented by representatives from over 30 countries. The Spectrum ' 96 program is designed to promote productive interactions among this diverse set of participants. Volume 1 contains 129 papers covering these major topics: low and intermediate level waste; risk assessment and analysis, and, new approaches for EM. 28 of these papers are cited separately in this database.

\section{4}

\section{V18/021749}

Spectrum ' 96 - Nuclear and Hazardous Waste Management: Proceedings of an International Topical Meeting, Vol. 2, Seattle, WA, August 18-23, 1996

CONF-960804 (Vol. 2); Spectrum '96: Nuclear and Hazardous Waste Management, Proceedings of an International Topical Meeting, Seattle, WA, August 18-23, 1996. American Nuclear Society, La Grange Park, IL, Vol. 2, 873 pp. (1996)

These volumes are the proceedings from the sixth biennial International Topical Meeting on Nuclear and Hazardous Waste 
Management, otherwise known as Spectrum '96. The Spectrum conference series is conducted under the auspices of the American Nuclear Society (ANS), but since its inception in 1986, it has been organized to highlight the accomplishments of a hosting U.S. Department of Energy (DOE) Site and to provide a national forum for components of DOE's National Environmental Management Program. The objectives of the organizers, sponsors, and participating customer groups of Spectrum ' 96 are: (1) to make available information on Hanford (the hosting DOE site) and National Program's progress and accomplishments to regional and national audiences; (2) to increase domestic and international industry understanding of U.S. and international cleanup opportunities; (3) to achieve high-quality technology exchanges on new technologies; operating experience and new management tools across Federal sites, industry and other countries; (4) to provide for technical and business exchanges between Federal and domestic and intemational industry representatives; and (5) to involve secondary and university-level environmental education programs from the region. This Spectrum ' 96 technical program clearly has a strong emphasis on activities related to the DOE Environmental Management program. Nearly $50 \%$ of the 500 presentations/papers are by DOE staff or contractors, and many of the papers from industry and universities reflect DOE work or issues. The Department is also sponsoring several special sessions and working side meetings to review and coordinate a number of nationwide and international initiatives. This international emphasis is designed to accomplish integration or exchanges of information across DOE sites and programs, but it is also intended to inform domestic industry, universities, and the international community on the opportunities within this multi-billion dollar environmental program. Over 100 presentations are being provided by domestic industry and universities, and approximately 130 papers are being presented by representatives from over 30 countries. The Spectrum ' 96 program is designed to promote productive interactions among this diverse set of participants. Volume 2 contains 132 papers covering these major topics: soil and groundwater; international technology transfer; packaging and transportation; and public participation. Sixty-two of these papers are cited separately in this database.

\section{5}

\section{V18/021750}

Spectrum ' 96 - Nuclear and Hazardous Waste Management: Proceedings of an International Topical Meeting, Vol. 3, Seattle, WA, August 18-23, 1996 CONF-960804 (Vol. 3); Spectrum '96: Nuclear and Hazardous Waste Management, Proceedings of an International Topical Meeting, Seattle, WA, August 18-23, 1996. American Nuclear Society, La Grange Park, IL, Vol. 3, 841 pp. (1996)

These volumes are the proceedings from the sixth biennial International Topical Meeting on Nuclear and Hazardous Waste Management, otherwise known as Spectrum '96. The Spectrum conference series is conducted under the auspices of the American Nuclear Society (ANS), but since its inception in 1986, it has been organized to highlight the accomplishments of a hosting U.S. Department of Energy (DOE) Site and to provide a national forum for components of DOE's National Environmental Management Program. The objectives of the organizers, sponsors, and participating customer groups of Spectrum ' 96 are: (1) to make available information on Hanford (the hosting DOE site) and
National Program's progress and accomplishments to regional and national audiences; (2) to increase domestic and intemational industry understanding of U.S. and international cleanup opportunities; (3) to achieve high-quality technology exchanges on new technologies; operating experience and new management tools across Federal sites, industry and other countries; (4) to provide for technical and business exchanges between Federal and domestic and international industry representatives; and (5) to involve secondary and university-level environmental education programs from the region. This Spectrum ' 96 technical program clearly has a strong emphasis on activities related to the DOE Environmental Management program. Nearly $50 \%$ of the 500 presentations/papers are by DOE staff or contractors, and many of the papers from industry and universities reflect DOE work or issues. The Department is also sponsoring several special sessions and working side meetings to review and coordinate a number of nationwide and international initiatives. This international emphasis is designed to accomplish integration or exchanges of information across DOE sites and programs, but it is also intended to inform domestic industry, universities, and the international community on the opportunities within this multi-billion dollar environmental program. Over 100 presentations are being provided by domestic industry and universities, and approximately 130 papers are being presented by representatives from over 30 countries. The Spectrum '96 program is designed to promote productive interactions among this diverse set of participants. Volume 3 contains 133 papers covering these major topics: decontamination and decommissioning; and high level waste and spent fuel. Fifty of these papers are cited separately in this database.

\section{$2016 \quad$ V18/022225}

\section{Stabilization of Lead-Contaminated Municipal Ash on} Johnston Atoll

Lear, P.R.; Gemar, D.W.; Ingoglia, M.

OHM Remediation Services Corporation, Findlay, $\mathrm{OH}$; OHM Remediation Services Corporation, Pleasanton, CA; Pacific Air Forces, Honolulu, HI

CONF-951139 (Vol. 2); Superfund 16: Proceedings of a Hazardous Waste Conference and Exhibition, Washington, DC, November 6-8, 1995. E.J. Krause and Associates, Bethesda, MD, Vol. 2, 817 pp.; (pp. 1339-1346) (1994)

Johnston Atoll is located approximately 700 nautical miles southwest of the Hawaiian Islands. Johnston Atoll is an unincorporated territory of the United States with operational control administered by the Defense Nuclear Agency (DNA). The atoll serves as a storage and destruction site for chemical munitions under the Johnston Atoll Chemical Agent Disposal System (JACADS). Previously, the atoll served as a site high and low altitude nuclear testing and more recently, principal overseas base to support the Nation Nuclear Readiness Program's Safeguard C, which required the capability to promptly resume nuclear testing. The Solid Waste Burn Pit (SWBP) is located on the northwest end of Johnston Island (J) and was utilized to burn refuse generated during the daily operation of the island. Part of the SWBP remains active and is still in use. In the inactive portion, hazardous materials such as batteries, paints, and solvents were bumed in the past. This paper addresses the remediation of the inactive portion of the SWBP only. 
2017

V18/023923

Standards for Site Assessment and Characterization

Ross, D.

Camtec Environmental Consultants, Carisbad, CA

CONF-951048 (Vol. 50, Pt. 2); ISA/95: Advances in Instrumentation and Control, Proceedings of an Intemational Conference and Exhibition, New Orleans, LA, October 1-6, 1995. Instrument Society of America, Research Triangle Park, NC, Vol. 50, Pt. 2, 764 pp.; (pp. 151-160) (1995)

Legislation that brought the "Superfund", the Federal law covering liability and remediation of unsupervised hazardous waste sites, was initiated in the 1980's. Yet, standards for conducting site assessments and characterization lagged until the 1990's when the Environmental Protection Agency (EPA) authorized the American Society of Testing and Materials (ASTM) to prepare standards that direct how the work is to accomplished. The author presents the Instrument Society of America (ISA) in ASTM subcommittees for Phase I and II site assessments and Phase III remediation. This paper details many standards for conducting site assessments and analytical methodologies including those developed by ASTM and those embodied in EPA standards such as SW 846. New developments that are discussed include EPA's program for verification of new technologies for field screening.

2018 V18/021004

Status of R\&D of Thermal Plasma Applications in Japan

Inaba, $T$.

Chuo University, Department of Electric and Electronics Engineering, Tokyo, Japan

CONF-9510125 (Vol. 1); Plasma Systems and Applications, P.W. Mayne and J.A. Mulholland (eds.), Proceedings of an International Symposium on Environmental Technologies, Atlanta, GA, October 8-11, 1995. Georgia Institute of Technology, Atlanta, GA, Vol. 1, 335 pp.; (pp. 13-34) (1995)

Commercial use of smail scale plasma devices of several $\mathrm{kW}$ is well established. On the other hand a few large scale plasma heaters were primarily imported in the metal industry, and the steel industry became the world leader in the use of plasma heating of steel in tundishes or reservoirs in the tops of metals molds. Now even several MW plasma heaters can be produced. Other plasma developments are being piloted to treat incinerator ash, low level radioactive wastes and so on in the many industrial fields and municipal bodies.

2019 V18/021708

Study of Allowable Residual Contamination Levels Estimation Method for Radioactive-Contaminated Soil

Keqiang, L.; Zhiming, W.; Guoqing, J.

China Nuclear Information Centre, Beijing, China; Ministry of Nuclear Industry, Institute of Radiation Protection, Taiyuan, China

CNIC-01055; CIRP-0013; 7 pp. (April 1996)

The estimation method for allowable residual contamination levels
(ARCL) in radioactive-contaminated soil near nuclear facilities under decommissioning or to be decommissioned is discussed. The estimation method would help determine the regulatory limit for remedial actions for a given site. The methodology of estimating $A R C L$, the related models, and the parameters used for estimation of maximum annual dose are described. As an example, a contaminated factory site is considered. The maximum individual doses and ARCL values for various radionuclides are estimated. It must be pointed out that the determination of ARCL is also based on the acceptable dose limit. Thus, a cost-effectiveness anaiysis is necessary in determining the actual acceptable dose limit.

2020

V18/021675

Subsurface Assessment Handbook for Contaminated Sites

Barker, J.F.; Nicholson, R.V.; Smyth, D.J.A.; Greenhouse, J.P.; Gudjurgis, P.J.; Rudolph, D.L.; Molson, J.W.; Frind, E.O.; Sudicky, E.A.

Canadian Council of Ministers of the Environment, National Contaminated Sites Remediation Program, Ottawa, Ontario, Canada; Environment Canada, Environmental Protection Service, Ottawa, Ontario, Canada; Waterloo University, Institute for Groundwater Research, Ontario, Canada

Report; 293 pp. (March 1994)

A program was developed by the Canadian Council of Ministers of the Environment (CCME) to remediate high-risk contaminated sites that threaten the environment or human health. The program provides necessary resources to remediate those sites where a responsible party cannot be identified. This handbook provides the essentials of a consistent national approach for subsurface assessment of contaminated sites, using expertise from the disciplines of geology, chemistry, mathematics and biology. The intended audience are those who commission, conduct, and evaluate assessments of the subsurface at contaminated sites. Suggested actions are not meant to be considered absolute requirements; alternative approaches that are as good or better than those suggested, especially for site-specific conditions, are acceptable. The handbook is divided into seven sections: (1) approach to subsurface assessment, (2) gathering and evaluating existing information, (3) advantages and limitations of geophysical methods, (4) hydrogeological site assessment methods, (5) chemical hydrogeology to evaluate the distribution of contaminants, (6) groundwater flow and contaminant transport models, and (7) subsurface remedial approaches and assessment requirements. $A$ useful glossary of terms and references to additional information are also provided.

2021

V $18 / 022100$

Successful Pond Closure Utilizing Novel Solidification/Stabilization Technology

Donnelly, J.R.; Webster, W.C.

Davy International, San Francisco, CA; Webster and Associates, Auburn, AL

CONF-951139 (Vol. 1); Superfund 16: Proceedings of a Hazardous Waste Conference and Exhibition, Washington, DC, November 6-8, 1995. E.J. Krause and Associates, Bethesda, MD, Vol. 1, 828 pp.; (pp. 672-680) (1994) 
Davy International, in joint venture with Intemational Technology Corporation (IT-Davy), has recently completed the RCRA closure of wastewater impoundments at a major gulf coast refinery. These surface impoundments contained a mixture of petroleum waste sediments, free water and standing oil. Insitu solidification/stabilization (solidification) was used to produce a material which met the regulatory criteria of: (a) achieving a bearing capacity sufficient to support earth moving equipment, the final multi-layer cap and the soil cover, and (b) immobilizing contaminants of concern namely; benzene, toluene, chrysene, naphthalene, I-methyl naphthalene, chromium and lead. Exsitu solidification was specified in the initial bid documents to meet the above criteria. Solidified material was to achieve an unconfined compressive strength of greater than 20 pounds per square inch (psi) and a permeability of less than $1 \times 10(E-5)$ centimeters per second after 7 days of curing. During the project design for insitu solidification which reduced the estimated project cost by approximately $\$ 10$ million (or 33 percent). IT-Davy was awarded a contract for engineering design and implementation of an approved closure plan based on the insitu approach. IT-Davy's approach was confirmed during the engineering phase of the project. Field closure activities included; dewatering of the impoundments, demolition of existing structures and pipeways, solidification of waste sediments and contaminated media in the impoundments, placement of non-hazardous fill material to bring the impoundments up to final grade, construction of a multi-layer cap and cover, and the associated surface drainage facilities around the impoundments. Approximately 500,000 cubic yards of material were solidified and a 28 acre cap/cover was installed.

2022

V18/025642

Summary of Three Dimensional Pump Testing of a Fractured Rock Aquifer in the Western Siberian Basin

Nichols, R.L.; Looney, B.B.; Eddy-Dilek, C.A.; Drozhko, E.G.; Glalolenko, Y.V.; Mokrov, Y.G.; Ivanov, I.A.; Glagolev, A.V.; Vasil'kova, N.A.

Westinghouse Savannah River Company, Aiken, SC; P.A. Mayak, Chelyabinsk, Russian Federation; P.S.A. Hydrospetzgeologiya, Moscow, Russian Federation WSRC-TR-96-0350; 74 pp. (October 30, 1996)

A group of scientists from the Savannah River Technology Center and Russia successfully completed a 17 day field investigation of a fractured rock aquifer at the MAYAK PA nuclear production facility in Russia. The test site is located in the western Siberian Basin near the floodplain of the Mishelyak river. The fractured rock aquifer is composed of orphyrites, tuff, tuffbreccia and lava and is overlain by $0.5-12$ meters of elluvial and alluvial sediments. A network of 3 uncased wells $(176,1 / 96$, and 2/96) was used to conduct the tests. Wells 176 and $2 / 96$ were used as observation wells and the centrally located well 1/96 was used as the pumping well. Six packers were installed and inflated in each of the observation wells at a depth of up to 85 meters. The use of 6 packers in each well resulted in isolating 7 zones for monitoring. The packers were inflated to different pressures to accommodate the increasing hydrostatic pressure. A straddle packer assembly was installed in the pumping well to allow testing of each of the individual zones isolated in the observation wells. A constant rate pumping test was run on each of the 7 zones. The results of the pumping tests are included in Appendix A. The test provided new information about the nature of the fractured rock aquifers in the vicinity of the Mishelyak river and will be key information in understanding the behavior of contaminants originating from process wastes discharged to Lake Karachi. Results from the tests will be analyzed to determine the hydraulic properties of different zones within the fractured rock aquifer and to determine the most cost effective clean-up approach for the site.

2023

V18/021677

Summary of the Experience Gained from the Emergencies Science Division Role in the Remediation Effort at Canadian Coast Guard Facilities in Newfoundland

Lambert, P.; Goldthorp, M.; Ackerman, F.; Fingas, M.F. Environment Canada, Emergencies Engineering Division, Ottawa, Ontario, Canada; Goldthorp Consulting, Nepean, Ontario, Canada

CONF-9606262; Proceedings of the 13th Technical Seminar on Chemical Spills, Calgary, Alberta, Canada, June 10-11, 1996. Environment Canada, Ottawa, Ontario, Canada, 396 pp.; (pp. 205-235) (1996)

Several environmental site investigations at Canadian Coast Guard facilities in Newfoundland and Labrador were carried out to determine chemical contamination. The survey included testing for motor oils, fuels, polycyclic aromatic hydrocarbons (PAH), polychlorinated biphenyls (PCB), and metals (lead, zinc and mercury). Field and laboratory analyses were performed on a portion of the samples. Field screening for oil contamination was done using a portable flame ionization detector, and immunoassay test kits were used to measure PAH, PCB and total petroleum hydrocarbon. Field measurement of metals was done with a portable $\mathrm{X}$-ray fluorescence meter. Laboratory testing was carried out by an independent contractor employing standard methodologies. Field results were compared with laboratory results. It was found that the amount of contamination at a particular site was dependent on the age, size and location of the station. Fuel contamination of the soil was the most common concern. Spills were usually near the drain/fill valves of storage tanks and were a result of improper handling practices.

\section{4 \\ V18/021032}

Superfund 16 - New Frontiers in Hazardous Waste: Proceedings of the 16th Hazardous Waste Conference and Exhibition, Vol. 1, Washington, DC, November 6-8, 1995

CONF-951139 (Vol. 1); Superfund 16: Proceedings of a Hazardous Waste Conference and Exhibition, Washington, DC, November 6-8, 1995. E.J. Krause and Associates, Bethesda, MD, Vol. 1, 828 pp. (1995)

This conference was held November 6-8, 1995 in Washington, DC. The purpose of the meeting was to provide a multidisciplinary forum for dealing with state-of-the-art methods and site characterization technologies for environmental monitoring and remedial action planning of hazardous wastes. Volume I of these proceedings includes presentations on the following topics: public involvement; legislative issues; property redevelopment; ecological 
effects; federal facilities; RU/FS and corrective actions; analytical issues; costs/economics; Superfund - PRP's; Superfund studies; RCRA issues; and site remediation. Individual papers within the scope of the RAPIC data base have been abstracted and indexed separately.

2025

\section{V18/021033}

Superfund 16 - New Frontiers in Hazardous Waste: Proceedings of the 16th Hazardous Waste Conference and Exhibition, Vol. 2, Washington, DC, November 6-8, 1995

CONF-951 139 (Vol. 2); Superfund 16: Proceedings of a Hazardous Waste Conference and Exhibition, Washington, DC, November 6-8, 1995. E.J. Krause and Associates, Bethesda, MD, Vol. 2, 817 pp. (1995)

This conference was held November 6-8, 1995 in Washington, DC. The purpose of the meeting was to provide a multidisciplinary forum for dealing with state-of-the-art methods and site characterization technologies for environmental monitoring and remedial action planning of hazardous wastes. Volume 2 of these proceedings includes presentations on the following topics: treatment technologies, including in-situ and thermal treatment, PCB's and landfill issues; innovative technologies such as biotreatment, soil vapor extraction, air sparging and bioventing, metals recovery and physical treatment; and, hydrogeologic issues including DNAPLs, mathematical modeling, and groundwater monitoring, sampling and other issues.

\section{6 \\ V18/020816}

Superfund Post Remediation Accomplishments: Uses of the Land and Environmental Achievements - Volume 2

U.S. Environmental Protection Agency, Office of Emergency and Remedial Response, Washington, DC

EPA/540/R-96/021; OSWER-9202.1-21A; 644 pp. (April 1996)

There are 224 Fact Sheets on National Priorities List (NPL) sites with construction completion as of March 1994. These include sites that were dropped out of the analysis in Volume 1 because they were No Action sites, or sites that did not include the land surface. In addition, 76 fact sheets describe removal actions at NPL and non-NPL sites that were not completed sites at the time the report was being compiled.

\section{$2027 \quad$ V18/020817}

Superfund Post Remediation Accomplishments: Uses of the Land and Environmental Achievements - Volume 1

U.S. Environmental Protection Agency, Office of Emergency and Remedial Response, Washington, DC

EPA/540/R-94/007; OSWER-9202.1-21; 105 pp. (April 1996)

The primary purpose of the study was to examine some of the benefits achieved by completing construction to clean up the sites on the National Priorities List (NPL) and examine the uses of sites after cleanup and the factors that affect these uses. In addition, the study lays a foundation for future studies that may evaluate other economic benefits not addressed here, such as changes in property values. The study looks at a relatively narrow set of accomplishments, and is not a comprehensive analysis of all the benefits of the Superfund program. For the study, the analysis was directed at the 228 sites on the Construction Completion List (CCL) as of March 1994. Benefits examined included benefits to human health and the environment such as protecting drinking water aquifers and the economic and noneconomic beneficial use of properties.

\section{$2028 \quad$ V18/024332}

Support System for Adoption of Solutions on Chernobyl Accident Mitigation

Borodastov, G.V.; Valuev, D.I.; Vysotskij, S.K.

Innovatsionno-inzhiniringovoe predpriyatie Vozrozhdenie', Moscow, Russian Federation; Ministerstvo Ukrainy po Delam Zashchity Naseleniya ot Posledstvij Avarii na Chernobyl'skoj AEhS, Kiev, Ukraine

INIS-UA-026/A; CONF-960002; Chernobyl 96: Results of 10 Years Work on ChNPP Accident Mitigation, Proceedings of the Fifth International Scientific-Technical Conference, N.P. Arkhipov (ed.), Zelenyj Mys, Ukraine, 1996, 526 pp.; (p. 225) (1996)

Short communication. No abstract available. (This document is in Russian).

2029

V18/021053

System Case Studies for the Removal of Heavy Metals from Landfill Leachate

Kimball, P.V.; Sargavakian, K.L.

Wheelabrator/Memtek Corporation, Billerica, MA

CONF-940499 (Vol. 1); Proceedings of the 1994 Federal

Environmental Restoration III and Waste Minimization II

Conference and Exhibition, New Orleans, LA, April 27-29. 1994.

Hazardous Materials Control Resources Institute. Rockville. MD.

Vol. 1, 783 pp.; (pp. 175-184) (1994)

The purpose of this paper is to present proven technologies used in the treatment of solid waste landfill leachates. The design considerations include the type of landfill and its contents, leachate collection, leachate water characteristics and effluent limitations. The three technologies presented will include precipitation followed by conventional gravity settling, precipitation followed by crossflow microfiltration and treatment by ion exchange processes. Three case studies will be presented to illustrate the design process and application of the technologies, along with the capital and operating costs.

2030

V18/021232

Task 1.6 - Mixed Waste: Topical Report - April 1994-September 1995

Rindt, J.R.; Jones, F.A.

University of North Dakota, Grand Forks, ND

DOE/MC/30097-5162; 391 pp. (January 1996)

For fifty years, the United States was involved in a nuclear arms race of immense proportions. During the majority of this period, the push was always to design new weapons, produce more weapons, and increase the size of the arsenal, maintaining an advantage over the opposition in order to protect U.S. interests. Now that the Cold War is over, the U.S. is faced with the imposing tasks of dismantling, cleaning up, and remediating the wide variety of 
problems created by this arms race. The ability to understand the problems encountered when dealing with radioactive waste, both from a scientific standpoint and from a legislative standpoint, requires knowledge of treatment and disposal subject areas. This required the accumulation of applicable information. A literature database was developed; site visits were made; and contact relationships were established. Informational databases from government agencies involved in environmental remediation were ordered or purchased, and previously established private sector relationships were used to develop an information base. An appendix contains 482 bibliographic citations that have been integrated into a Microsoft Access [R] database.

\section{1}

V18/020594

Technical Support for the EPA Cleanup Rule on Radioactively Contaminated Sites

Hull, H.B.; Newman, A.; Wolbarst, A.B.; Doehnert, M.; Mauro, J.J.; Ralston, L.

U.S. Environmental Protection Agency, Washington, DC; Sanford Cohen \& Associates, Inc., McLean, VA

CONF-951209; Proceedings of the 17th Annual U.S. Department of Energy Low-Level Radioactive Waste Management Conference, D. Lake (ed.), Phoenix, AZ, December 12-14, 1995, 480 pp.; (11 pp.) (1995)

The U.S. Environmental Protection Agency (EPA) is developing a radiation site cleanup regulation for the protection of the public from radionuclide contamination at sites that are to be cleaned up and released for public use. The regulation will apply to sites under the control of Federal agencies, and to sites licensed by the Nuclear Regulatory Commission (NRC) or NRC Agreement States. The agency is therefore conducting a comprehensive technical analysis aimed at developing information that will be used to support the rule. This presentation describes the regulation and the approach developed to determine how radiological health impacts and volumes of soil requiring remediation vary as functions of the possible cleanup dose or risk level.

2032

\section{V18/021684}

\section{Technologies for Environmental Restoration in Ukraine}

Rudy, C.; Avdeev, O.; Soroka, Yu.; Perepeliatnikov, G.; Saversky, S.

Ministry for Environmental Protection of Ukraine, Kiev, Ukraine; R\&D Institute for Decontamination and Waste Management, Zovti Vody, Ukraine; R\&D Institute for Industrial Technologies, Zovti Vody, Ukraine; R\&D Institute for Agricultural Radiology, Zovti Vody, Ukraine; Scientific Department of the Restricted Zone Administration, Ukraine IAEA-TECDOC-865; CONF-9412128 (Vol. 3); Planning for Environmental Restoration of Radioactively Contaminated Sites in Central and Eastern Europe, Volume 3: Technologies for, and the Implementation of, Environmental Restoration of Contaminated Sites, Proceedings of a Workshop on Environmental Restoration in Central and Eastern Europe, Rez, Czech Republic, December 12-16, 1994. Intemational Atomic Energy Agency, Vienna, Austria, Vol. 3, 356 pp.; (pp. 243-279) (May 1996)

This paper provides examples of restoration approaches in the
Ukraine for contaminated sites of various nature and origin. Advantages and disadvantages of such approaches are also described. Forestation proved to be the most effective counter measure to bind radionuclides in-situ and prevent resuspension mechanics in the Chernobyl restricted zone. Another protective measure in this zone is the erection of dams to prevent contamination spreading floods. The restoration program in living ores mainly includes upper soil removal; demolition and removal of roofs, fences and wall plasters; asphalting; and transportation of secondary wastes to the wastes disposal site. Additional measures to reduce internal exposures include agrochemical measures and milk filtration. Such aspects are described in detail in this paper. A separate section deals with restoration of sites contaminated by uranium mining and milling activities.

2033

$\mathrm{V} 18 / 021681$

Technologies for Restoration of Environment Contaminated with Radionuclides in Belarus

Sharovarov, G.A.

Academy of Sciences, Minsk, Belarus

IAEA-TECDOC-865; CONF-9412128 (Vol. 3); Planning for Environmental Restoration of Radioactively Contaminated Sites in Central and Eastem Europe, Volume 3: Technologies for, and the Implementation of, Environmental Restoration of Contaminated Sites, Proceedings of a Workshop on Environmental Restoration in Central and Eastern Europe, Rez, Czech Republic, December 12-16, 1994. International Atomic Energy Agency, Vienna, Austria, Vol. 3, 356 pp.; (pp. 37-49) (May 1996)

The state of work on creation of technologies for clean-up of the territories of Belarus contaminated as a result of the Chemobyl accident is considered in the report. Technologies for decontamination of pre-school, medical and prophylactical institutions, schools, zones for recreation, industrial, and agricultural objects are used in Belanus. On the whole, the strategy of changing the residence of population and supervision over the radiological situation is carried out in the Republic. Clean-up of contaminated soils of large territories is not realized in the Republic on an industrial scale. Presently, methods have been developed for radiation forecast and determination of advisable extent of decontamination. The description of worked out technologies for decontamination, waste management and disposal is given. The need for development of industrial methods for the soil clean-up is shown.

\section{4}

\section{V18/021490}

Technologies for and Implementation of Environmental Restoration Projects in the Slovak Republic

Slavik, O.; Moravek, J.; Vladar, M.

Nuclear Power Plant Research Institute, Trnava, Slovakia; Research Institute of Preventive Medicine, Bratislava, Slovakia

IAEA-TECDOC-865; CONF-9412128 (Vol. 3); Planning for Environmental Restoration of Radioactively Contaminated Sites in Central and Eastern Europe, Volume 3: Technologies for, and the Implementation of, Environmental Restoration of Contaminated Sites, Proceedings of a Workshop on Environmental Restoration in Central and Eastem Europe, Rez, Czech Republic, December 12-16, 
1994. Intemational Atomic Energy Agency, Vienna, Austria, Vol. 3, 356 pp.; (pp. 211-223) (May 1996)

This paper represents the logical continuation of those presented at the Budapest and Piestany Workshops. After finishing the monitoring activities in the contaminated site near Bohunice Nuclear Plant, the need for reconsidering the old restoration project arose. To resolve this task, new principles for the evaluation of remedial measures were developed in close cooperation with the national hygiene authorities. These principles as well as the resulting evaluation and proposal of a justified scope for the contaminated banks restoration project are described and discussed in the paper. The re-evaluated scope of the banks restoration project included removing and safe burial of about 1100 cubic meters of contaminated soil, and overlaying with clean soil cover, about 10,000 square meters of contaminated flat area of these banks. The total cost can be estimated to be about US $\$ 100,000$.

$$
\mathrm{V} 18 / 021680
$$

Technologies for and Implementation of Environmental Restoration Projects in Slovenia

Krizman, M.J.; Logar, Z.

Jozef Stefan Institute, Ljubljana, Slovenia; Rudnik Zirovsky, Gorenja, Slovenia

LAEA-TECDOC-865; CONF-9412128 (Vol. 3); Planning for Environmental Restoration of Radioactively Contaminated Sites in Central and Eastern Europe, Volume 3: Technologies for, and the Implementation of, Environmental Restoration of Contaminated Sites, Proceedings of a Workshop on Environmental Restoration in Central and Eastern Europe, Rez, Czech Republic, December 12-16, 1994. International Atomic Energy Agency, Vienna, Austria, Vol. 3, 356 pp.; (pp. 225-236) (May 1996)

Not all environmental restoration technologies have been tested and evaluated in Slovenia and implementation of environmental restoration projects will not start before 1995. Information is presented in this paper on Slovenia's state-of-the-art in this field. The state, design and implementation of rehabilitation works are briefly described. Particular emphasis is given to the following aspects: regulations, planning, research, investigations and implementation.

\section{6}

V18/021683

Technologies for and Implementation of Environmental Restoration Projects

Laraia, $\mathrm{M}$.

International Atomic Energy Agency, Waste Management Section, Vienna, Austria

IAEA-TECDOC-865; CONF-9412128 (Vol. 3); Planning for Environmental Restoration of Radioactively Contaminated Sites in Central and Eastern Europe, Volume 3: Technologies for, and the Implementation of, Environmental Restoration of Contaminated Sites, Proceedings of a Workshop on Environmental Restoration in Central and Eastern Europe, Rez, Czech Republic, December 12-16, 1994. International Atomic Energy Agency, Vienna, Austria, Vol. 3, 356 pp.; (pp. 7-35) (May 1996)

This paper represents the logical continuation of those presented at the Budapest and Piestany Workshops. It covers practical methods and techniques to decontaminate radioactively contaminated sites. A great deal of experience is available related to the cleanup of small and medium sized land areas. A variety of techniques and equipment are available for the cleanup of contaminated areas and for the transportation and disposal of wastes arising from such cleanups. The selection of methods and technical procedures for environmental restoration will be governed by criteria such as: external dose rates and the mixture of radionuclides present, the nature of the location and of items requiring cleanup, mechanical properties of the materials requiring treatment, the availability of different methods of cleanup and the technical facilities for applying them, and the availability of trained staff. Although a great deal is known about such cleanups, further work is required, especially on the decontamination of urban areas. Most of the information provided in this paper is based on IAEA's Technical Report Series No. 300, Cleanup of Large Areas Contaminated as a Result of a Nuclear Accident, 1989.

\section{$2037 \cdot \quad \mathrm{V} 18 / 021682$}

Technologies for and Implementation of Environmental Restoration in Canada

Pollock, R.W.; Feasby, D.G.

Low-Level Radioactive Waste Management Office, Gloucester, Ontario, Canada; Canada Centre for Mineral and Energy Technology, Ottawa, Ontario, Canada

IAEA-TECDOC-865; CONF-9412128 (Vol. 3); Planning for Environmental Restoration of Radioactively Contaminated Sites in Central and Eastern Europe, Volume 3: Technologies for, and the Implementation of, Environmental Restoration of Contaminated Sites, Proceedings of a Workshop on Environmental Restoration in Central and Eastem Europe, Rez, Czech Republic, December 12-16, 1994. International Atomic Energy Agency, Vienna, Austria, Vol. 3, 356 pp.; (pp. 59-85) (May 1996)

This paper discusses the technologies for, and implementation of, environmental restoration at three types of sites present in Canada: at a historic low-level radioactive waste (LLRW) site, resulting from the early years of the radium and uranium industry in Canada which are the responsibility of the Low-Level Radioactive Waste Management Office (LLRWMO); the Chalk River Laboratories (CRL) site of Atomic Energy of Canada Limited (AECL); and decommissioning and waste management at uranium mining and milling sites. The latter section deals primarily with sites for which the uranium production companies are responsible for decommissioning. It has been included to describe Canadian experience in this area since, from a technical perspective, there are many factors in common with restoration programs at inactive or abandoned sites.

\section{8}

\section{V18/021687}

Technologies of Environmental Restoration in Russia Nechaev, A.F.; Projaev, V.V.

St. Petersburg State Institute of Technology, St. Petersburg, Russian Federation

IAEA-TECDOC-865; CONF-9412128 (Vol. 3); Planning for Environmental Restoration of Radioactively Contaminated Sites in Central and Eastern Europe, Volume 3: Technologies for, and the Implementation of, Environmental Restoration of Contaminated 
Sites, Proceedings of a Workshop on Environmental Restoration in Central and Eastern Europe, Rez, Czech Republic, December 12-16, 1994. International Atomic Energy Agency, Vienna, Austria, Vol. 3, 356 pp.; (pp. 189-210) (May 1996)

In the present study an attempt is made to compile, systematize, and analyze the data on technologies of radioactively contaminated sites restoration. Principal attention is paid to the methods and tools already employed in the practical activities. Some generalized considerations and suppositions on the subject are also presented.

\section{V18/021044}

Testing and Removal of Lead Based Paint, What Works and What Doesn't

Goldstein, L.S.; Kesner, J.; Stoll, R.K.

URS Consultants, Inc., Seattle, WA; U.S. Navy, Naval Facilities Engineering Command, Poulsbo, WA

CONF-940499 (Vol. 1); Proceedings of the 1994 Federal

Environmental Restoration III and Waste Minimization II Conference and Exhibition, New Orleans, LA, April 27-29, 1994. Hazardous Materials Control Resources Institute, Rockville, MD, Vol. 1, 783 pp.; (pp. 679-686) (1994)

Lead-based paints (LBP) have become a health and environmental concern and have been the focus of several regulatory agencies including the U.S. Environmental Protection Agency (EPA) and the Department of Housing and Urban Development (HUD). Until 1978 , lead was used as an additive to paint to make it more durable. As a result of this use, lead has become pervasive in the environment and is of special concem in homes. LBP is considered by HUD to be the leading contributor to childhood lead poisoning. Section 302 of the Lead Based Paint Poisoning Prevention Act (1) requires public housing authorities and Indian housing authorities to inspect painted surfaces and abate LBP. The threshold level established by HUD for a painted surface to be considered a LBP is 0.5 percent lead $(5,000 \mathrm{ppm})$ or $1.0 \mathrm{mg} / \mathrm{sq} \mathrm{cm}$. The Residential Lead-Based Paint Hazard Reduction Act of 1992, commonly referred to as Title $\mathrm{X}$, expands the requirement for abatement to housing owned by the Department of Defense (DoD). Beginning January 1, 1995, DoD housing that is sold requires a LBP survey for units built prior to 1978 , and units built prior to 1960 must have the LBP abated. This paper will focus on two issues associated with LBP: (1) the advantages and disadvantages associated with sampling methods used to test for LBP and (2) disposal options for the LBP or LBP coated surfaces that are removed.

\section{$2040 \quad$ V18/023509}

Town of Hague Landfill Reclamation Study:

Researching Ways to Increase Waste Heating Value and Reduce Waste Volume: Final Report

Visalli, J.R.; Reis, J.F.; Belden, D.; Salemi, E.; Richard, T.

New York State Energy Research and Development Authority, Albany, NY; Town of Hague, Hague, NY; SSB

Environmental, Inc., Albany, NY; Cornell University, Ithaca, NY

NYSERDA 97-1; 35 pp. (January 1997)

Monitored composting was studied as a method for reducing the quantity of waste requiring disposal from a landfill reclamation project. After each of two re-screening steps, composted "soil" from a single long window of varying depths and moisture content was subjected to analytical testing to determine its suitability to remain as backfill in a reclaimed landfill site. The remaining uncomposted waste was combusted at a waste-to-energy facility to determine if Btu values were improved. Results indicate that a full-scale composting operation would result in a net decrease of approximately 11 percent in disposal costs. The Btu value of the reclaimed waste was calculated to be 4,500 to $5,000 \mathrm{Btw} / \mathrm{ib}$. The feasibility of composting reclaimed waste at other landfill reclamation projects will depend upon site-specific technical and economic factors, including size and nature of the organic fraction of the waste mass, local processing costs, and the cost of waste disposal alternatives.

2041 V18/023578

Transmittal of Revised Model Comfort Letter Clarifying NPL Listing, Uncontaminated Parcel Determinations, and CERCLA Liability Involving Transfers of Federally Owned Property

Laws, E.P.

U.S. Environmental Protection Agency, Office of Solid Waste and Emergency Response, Washington, DC

Report; 9 pp. (January 19, 1996)

This model letter provides a template that closing installations can use to clarify liability issues for potential buyers to help facilitate the transfer of property at installations that have been listed on the NPL. The letter addresses some common misunderstandings about such listing and liability under CERCLA and highlights certan provisions governing the transfer of Federally ouned propert. The letter also emphasizes that whether property is part of an NPL site has no effect on liability under CERCLA. By clarifying these issues, installations may help ease potential buyers' concerns about liability.

2042 V18/020819

Transportable Electron Beam System and Method Schonberg, P.R.; Hoberg, G.G.; Shonberg, R.G.; Fadness, D.R.

Zapit Technology, Inc., Santa Clara, CA U.S. Patent 05357291; 16 pp. (October 18, 1994)

The invention is a transportable and reconfigurable system and method designed for on-site conversion of toxic substances to nontoxic forms. Influents consisting of gases, vapors, aerosols, and suspended particulates enter a reaction chamber into which a beam of electrons is injected. These electrons interact with the influent to chemically transform compounds into elements or other compounds. The invention includes an electron beam generator, a reaction chamber and effluent post-processing modules mounted on a carrier for transporting the system from site to site.

\section{3 \\ V18/021045}

Trenchless Installation of an HDPE Barrier for Liquid Control: A Case History

Mickelson, B.B.; Dunn, K.E. 
Gundle Lining Systems, Inc., Houston, TX

CONF-940499 (Vol. 2); Proceedings of the 1994 Federal

Environmental Restoration III and Waste Minimization II

Conference and Exhibition, New Orleans, LA, April 27-29, 1994.

Hazardous Materials Control Resources Institute, Rockville, MD,

Vol. 2, 858 pp.; (pp. 1318-1322) (1994)

This case history summarizes a liquid containment project in Fernandina Beach, Florida where an HDPE vertical barrier was installed into an existing dike without excavation. The dike separated two lagoons that contained process chemicals for a pulp and paper mill. During normal plant operations, the liquid level in the lagoons could vary by several feet. The clay core of the dike proved to be incapable of preventing the cross contamination of the lagoons caused by this differential gradient. Concems associated with this project were not limited to finding a suitable barrier to stop the contamination of the process chemicals. The continued operation of the mill was of prime importance. Because of this the lagoons could not be drained to facilitate construction. Also, the construction activities would have to be confined to as small an area as possible. Due to the many project constraints, the feasibility of several barrier technologies was studied. A slurry wall and steel sheet piling were among the technologies reviewed and discarded. It was determined that the best solution would be a barrier incorporating the low permeability high chemical resistance properties of a geomembrane. The barrier selected by ITT Rayonier and their engineer, CH2M Hill, was a high density polyethylene barrier called Gundwall.

\section{4}

\section{V18/020680}

Turnkey Environmental Remediation in Eastern Europe Dougherty, B.; Emery, J.M.

Foster Wheeler Environmental Corporation, Clinton, NJ CONF-951021; Proceedings of the 1995 Environment Conference, Halifax, Nova Scotia, Canada, October 24-26, 1995. Canadian Pulp and Paper Association, Montreal, Quebec, Canada, 151 pp.; (pp. 17-20) (October 1995)

MMC, a U.S.-based multinational manufacturing company, which was expanding its business throughout Eastem Europe, commissioned Foster Wheeler Environmental to conduct an environmental assessment of certain Hungarian state-owned facilities. In two of three instances, extensive contamination was encountered in both groundwater and soils. An environmental assessment was aiso conducted in Greece. Four distinct phases of environmental work by Foster Wheeler for MMC were described, using their largest project in Budapest, Hungary, as an example. The four phases were remedial investigation, remedial design, remedial construction, and regulatory negotiation. MMC believed environmental issues were important considerations when evaluating direct international investment ventures. Many methods exist for conducting turnkey environmental work abroad and this experience showed that confronting these environmental issues outside familiar frameworks can be managed satisfactorily.

V18/023681

U.S. Army Chemical Demilitarization and Remediation Activity Non-Stockpile Monitoring Approach

Queen, J.; Miskelly, P.; Chatfield, M.J.
Oak Ridge National Laboratory, Oak Ridge, IN

ORNL/M-4315; CONF-9409370; Analytical Methods for Environmental Sampling of Chemical Warfare Agents and Their Degradation Products, A.P. Watson and S. Kistner (eds.), Proceedings of a Conference, Aberdeen, MD, September 20-21, 1994, 180 pp.; (pp. 19-24) (June 1995)

In Section 176 of Public Law (PL) 102-484, the 1993 Defense Authorization Act, Congress directed the U.S. Army to submit a report identifying the locations, types, and quantities of non-stockpile chemical material (NSCM). As part of that report, published in the Survey and Analysis Report for the Non-Stockpile Chemical Material Program, five categories of NSCM were addressed. These included buried chemical warfare material (CWM); recovered chemical weapons; and miscellaneous CWM. To better define the scope of CWM burial sites, four separate types of sites were discussed-chemical agent identification set (CAIS) burials, smail CWM burial sites with no explosives, small CWM burial sites with explosives, and large CWM burial sites (with and without explosives). A total of 215 potential CWM burial sites, distributed throughout 33 states, the U.S. Virgin Islands, and the District of Columbia, were identified. This article describes the rapid response system (RRS); CAIS characterization and disposal; monitoring during RRS operations; monitoring standards, and the non-stockpile monitoring program.

\section{6}

\section{V18/024668}

Use of Submerged Fixed-Film Bioreactors to Treat Aqueous Wastes, Chapter 12

Skladany, G.J.

Envirogen, Inc., Princeton Research Center, Lawrenceville, NJ

Bioremediation: Field Experience, P.E. Flathman, D.E. Jerger and J.H. Exner (eds.), Lewis Publishers, Boca Raton, FL, 560 pp.; (pp. 237-258) (1994)

Many organic chemicals considered to be environmentally hazardous are readily amenable to treatment using biological processes. Efficient biological treatment of contaminated groundwater, industrial process waters, and landfill leachates relies on the successful teaming of metabolically capable microorganisms with an appropriately engineered bioreactor system designed to create favorable microbial growth conditions. To date, much attention in the biotreatment field has been paid to elucidating and understanding the microbiological and biochemical processes involved with bioremediation. Less attention has been devoted to the design and testing of suitable bioreactor systems for remediation work. This chapter presents an introduction to the theory, design, and benefits of using aerobic submerged fixed-film bioreactors for the treatment of aqueous wastes. Described are the "growth-mode" version of this bioreactor design, which has been used successfully to treat influent organic concentrations ranging from 50 to 10,000 $\mathrm{mg} / \mathrm{L}$ (parts per million, or ppm) of Biochemical Oxygen Demand (BOD), and the "decay-mode" reactor version, used to treat influent organic concentrations of 1 to $20 \mathrm{mg} / \mathrm{L}$ actual concentration. Attainable effluent concentrations are typically less than $50 \mathrm{ug} / \mathrm{L}$ (parts per billion, or $\mathrm{ppb}$ ) actual concentration for specific organics with the growth-mode system, and less than $10 \mathrm{ug} / \mathrm{L}$ actual concentration with the decay-mode bioreactor. Specific 
contaminant destruction rates of greater than 95 percent are possible with these systems. Several case studies documenting the successful full-scale field use of submerged fixed-film bioreactors are also presented. This chapter is from the book entitled Bioremediation: Field Experience.

Voluntary Cleanups - Gaining Momentum

Stevens, M.A.; Bergman, J.B.; Carter, R.M.

Roy F. Weston, Inc., Lakewood, CO; City and County of Denver, Denver, $C O$

CONF-951139 (Vol. 1); Superfund 16: Proceedings of a Hazardous Waste Conference and Exhibition, Washington, DC, November 6-8, 1995. E.J. Krause and Associates, Bethesda, MD, Vol. 1, 828 pp.; (pp. 568-574) (1994)

The authors are currently conducting a voluntary cleanup in Colorado under the state's Voluntary Cleanup and Redevelopment Act of 1994. This paper details the plan approval process and implementation at the Smith Road Jail Site, which is owned by the City and County of Denver (CCOD). The site was the location of historical dumping of potentially hazardous materials. $\mathrm{CCOD}$ agreed to develop property near the site into a controlled access facility upon aiport closure. To expedite remediation efforts and therefore redevelopment, to ensure that remediation plans met with approval of the Colorado Department of Public Health and the Environment and to ensure that plans would provide for adequate protection of human health and the environment, the City submitted a Voluntary Cleanup Plan under Colorado's new law. This remediation plan, which includes an innovative biosparge system, is the third application out of nine submitted and is the fourth approved in Colorado. Significant lessons have been learned about: establishing cleanup levels; hazardous waste regulation barriers; forecasting potential future land use; and the process for plan approval. New federal legislation could streamline the voluntary process by addressing the applicability of the Corrective Action Management Unit (CAMU) concept to voluntary cleanups; including an option for risk assessment; and proposing an exemption from land disposal restrictions for remediation wastes. As Superfund is reevaluated in the 104th Congress, amendments are being proposed that address this rapidly developing concept. At least 20 states have developed voluntary remediation programs; salient parts of state laws could be combined to produce effective national legislation. Benefits of voluntary remediation programs are innumerable (a "No Further Action Letter" reduces liability and encourages redevelopment). However, there are obstacles in the process that must be removed for this new concept to be effective.

\section{8 \\ V18/021522}

Voluntary Program Promotes Equitable and Expedited Remediation of Contaminated Properties

Wolfenden, A.K.; Cambridge, M.

California Environmental Protection Agency, Department of Toxic Substances Control, Sacramento, CA

CONF-951124; HazMat West '95, Proceedings of the Eleventh Annual Environmental Management and Technology Conference and Exhibition, Long Beach, CA, November 7-9, 1995. Advanstar Expositions, Duluth, MN, 597 pp.; (pp. 113-119) (1995)
In Califomia, the California Environmental Protection Agency (Cal/EPA) has developed a more equitable and expedited approach for the redevelopment of sites contaminated with hazardous substances. Senate Bill 923, enacted in 1994, established the Expedited Remedial Action Program (ERAP) under Chapter 6.85 of the Califomia Health and Safety Code. This bill responds to a nationwide demand to reform Superfund laws and promote the restoration of blighted and contaminated parcels - often referred to as Brownfields. The program was designed as an alternative to CERCLA, which has come under criticism for being inefficient, unfair, and for restricting opportunities for effective cleanups. Cal/EPA's Department of Toxic Substances Control will implement this pilot program. This pilot program, which will eventually comprise 30 sites, provides incentives for voluntary remediation by addressing key economic issues associated with the remediation and redevelopment of contaminated properties.

\section{9}

\section{V18/022573}

Washington State Environmental Radiation Standard Erickson, J.L.; Wells, D.; Jaquish, R.E.

Washington State Department of Health, Olympia, WA CONF-9607135; Proceedings of the 41st Annual Meeting of the Health Physics Society, Seattle, WA, July 21-25, 1996; Health Physics 70(6):54b (June 1996)

The Department of Health is in the process of establishing new environmental radioactivity cleanup regulations. The scope of these regulations will encompass all radionuclides and will apply to soils, sediments, and groundwater. The requirements of these regulations will be part of license terminations for those nuclear facilities licensed by the state. Non-licensees which leave residual radioactivity in the environment will also be affected because the requirements of these regulations will be incorporated as applicable, relevant, and appropriate regulations in the Model Toxics Control Act administered by the State Department of Ecology. The motivation for establishing these new regulations is the need for cleanup guidance for a number of sites across the state and, except for uranium mills, the absence of soil, sediment, and groundwater radioactivity cleanup standards. Establishment of these standards will close the only major gaps in environmental radioactivity cleanup regulations and fulfill the Department of Health's statutory requirements to protect public health from environmental radiation exposure. Development of the standard is following the state rule-making process. An Issues Paper was distributed for public comment in November 1994. Current activities include an environmental impact statement, a small business impact statement, and preparation of the draft rule.

2050

$\mathrm{V} 18 / 021318$

Waste Contaminants at Military Bases Working Group: 1994 Annual Report

Western Govemors' Association, Denver, CO; Federal Advisory Committee to Develop Onsite Innovative Technologies, Washington, DC

Report; 25 pp. (December 1994)

The Working Group continues to promote expedited development and commercialization of acceptable innovative technologies. 
Utilizing a consensus-based decision-making approach at its four 1994 meetings, the working group benefited by active participation of a variety of stakeholders. Phase I demonstrations enlisted the support of site-based stakeholders and regional expertise. The working group also explored Phase II activities to test new approaches to procurement, and investigated ways to incorporate institutional changes into DOD and WGA processes. The Working Group approved four demonstration programs, implementation of which is contingent upon securing financial resources and active state and federal participation. Activities for 1995 were expected to include: (1) Improving site-based stakeholder involvement in facility cleanup, reuse, and technology decision-making; (2) Improving regional stakeholder participation in demonstration design and implementation; (3) Improving and standardizing cost/performance evaluation protocols to improve technology selection decision-making; (4) Implementing new forms of interstate regulatory cooperation, reciprocity, and interstate technology acceptance; and (5) Increasing the procurement and commercialization of innovative technologies.

\section{1}

\section{V18/021457}

\section{Waste Management Education and Research Consortium 1994-1995 [Annual Report]}

New Mexico State University, Las Cruces, NM

Report; 16 pp. (1994/1995)

The research presented here represents the environmental projects and several educational outreach programs of the Waste-management Education and Research Consortium (WERC) during 1994-95. Work towards solutions to some of the most perplexing and difficult environmental challenges continues through a unique consortium of universities, industries, national laboratories and federal and state agencies. Work on risk, environmental remediation. waste management, assessment, education and retraining continues to reach the demonstration and application stages on the local, regional and national level. Projects highlighted in this report focus on the following areas: groundwater, petroleum waste management, thermal waste destruction, sensors for waste management, hazardous waste management, robotics, bioremediation, site assessment, radioactive waste management, air quality, soil remediation, nuclear waste storage and educational outreach.

\section{2}

V18/021702

Where is New York State Relative to Cleanup Standards for Soils Contaminated with Radioactive Materials?

Merges, P.J.

New York State Department of Health, Bureau of Radiation, Albany, NY

CONF-9505336; Proceedings of the 27th Annual National Conference on Radiation Control, San Antonio, TX, May 7-10, 1995, Conference of Radiation Control Program Directors, Inc., Frankfort, KY, 364 pp.; (pp. 20-25) (1995)

In September 1993, New York State adopted a cleanup guideline for radioactively contaminated sites being remediated for unrestricted release. This paper reviews this cleanup guideline and discusses its implementation by Bureau of Radiation staff. A cleanup guideline has been adopted by the State of New York which applies to residual radiological contamination on sites undergoing remediation for unrestricted use. The guideline is flexible and allows for alternative site cleanup approaches. The application of this guidance by radiation control program staff is discussed herein. There may be a need to revisit properties that were felt to be "clean" previously but fail to meet the new guidance.

\section{3 \\ V18/021140}

\section{Zero Accidents in the Remediation Business}

Thomas, B.R.

OHM Remediation Services Corporation, Findlay, OH CONF-960212; Waste Management '96: Working Towards a Cleaner Environment, Proceedings of a Conference on HLW, LLW, Mixed Wastes and Environmental Restoration, Tucson, AZ, February 25-29, 1996; (9 pp.) (1996)

While many industrial hygiene concerns are encountered at a hazardous wastes site during characterization and remediation activities, experience indicates that these problems can be controlled adequately. Personal exposure to airborne chemicals are effectively controlled primarily because a plan is prepared to review the chemical hazards that are likely to be encountered. Unfortunately, the hazards that are likely to represent a concern are safety issues including slips, trips, and falls. Consequently, it is injuries to employees that are the principal concern. This presentation describes the elements of a "Zero Accident" program and the improved statistics resulting from its implementation. At the beginning of 1994, the Midwest Region of OHM Remediation Services Corp. (OHM) implemented a program to supplement the existing industrial hygiene program to reduce accidents at work sites. The management of the Midwest Region made a commitment to promote and support the philosophy of zero accidents and established that goal as part of the Region's business plan. The Regional Safety Management Review Committee was established and identified the key elements that were necessary to accomplish the goal of zero accidents. These were management commitment, training for employees, job safety analysis, accident investigation, and employee recognition program. While each of these elements existed before January 1994, the "Zero Accident Program" emphasized the importance of and the relationship between these elements in eliminating injuries at a job site. The "Zero Accident Program" provided a baseline for supporting the interaction of these elements. The program also provided a vehicle to communicate the ground rules for effective and safe job performance. The program was communicated throughout the Region in a variety of ways including training classes for site supervisors and foremen to review their roles in achieving zero accidents. The emphasis on zero accidents has paid off already. The current OHM OSHA recordable injuries rate is down by $52 \%$ from 1994 and $63 \%$ over the last 3 years. This has produced an estimated cost savings of $\$ 213,000$ for 1994 and $\$ 1,274,000$ for the last 3 years. The Experience Modification Rate has dropped by $45 \%$ from 1994 and is down $72 \%$ over the last 3 years. The number of job sites that achieved zero injuries in 1994 was up by 54\% from 1993. With the.continued implementation of the "Zero Accident Program," this effort will continue to improve each year and clearly demonstrates that a goal of zero accidents for all remediation job sites is realistic and achievable. 


\section{U.S. DEPARTMENT OF ENERGY (DOE) UNDERGROUND STORAGE TANK REMEDIATION}


2054

\section{V18/025343}

Replacement of Underground Storage Tanks Rocky Flats Environmental Technology Site

Campbell, R.P.; Ferrari, M.R.

Rocky Mountain Remediation Services, LLC, Golden, CO; Kaiser-Hill Company, Golden, CO

CONF-970335; Waste Management '97: Working Towards a Cleaner Environment, Proceedings of a Conference on $\mathrm{HLW}$, LLW, Mixed Wastes and Environmental Restoration, Tucson, $A Z$, March 2-6, 1997; (8 pp.) (1997)

Twenty-two underground petroleum storage tanks (USTs) at the Rocky Flats Environmental Technology Site (RFETS) were replaced with eighteen aboveground storage tanks (ASTs) and five USTs. The old USTs were closed-in-place by filling with an inert polyurethane closed-cell foam. ASTs were selected in most cases to avoid interferences with existing structures and utilities, and minimize excavation in areas with potential hazardous and radioactive contamination. The tanks were closed-in-place with significant cost savings due to avoidance of excavation and generation of soils requiring management. Geoprobe sampling was used to verify subsurface soils were not contaminated from tank leakage. The closed-in-place tanks were filled with foam rather than concrete to facilitate future removal if required.

\section{5}

V18/022784

Development and Demonstration of a Stabilization System for Buried Mixed Waste Tanks: Initial Results of the Tank V-9 Hot Demonstration

Matthern, G.E.; Kuhns, D.J.; Meservey, R.H.; Farnsworth, R.K.

Idaho National Engineering Laboratory, Idaho Falls, ID CONF-960804 (Vol. 2); Spectrum '96: Nuclear and Hazardous Waste Management, Proceedings of an International Topical Meeting, Seattle, WA, August 18-23, 1996. American Nuclear Society, La Grange Park, IL, Vol. 2, 873 pp.; (pp. 1366-1370) (1996)

This paper describes a systematic approach for the stabilization of buried mixed waste tanks and presents the status of an application of this approach to a specific hot waste tank demonstration to be performed in FY-96. The approach uses the cradle-to-grave concept and includes technical, health and safety, and regulatory considerations and requirements. It starts with the identification of the tank and continues to the final disposition and monitoring of the tank.

\section{6 \\ V18/022860}

Building 310 Retention Tanks: Characterization Report Sholeen, C.M.; Geraghty, D.C.

Argonne National Laboratory, Argonne, IL ANL/ESH-HP-96/04; 210 pp. (December 1996)

The Health Physics Section of ANL performed a characterization of the Building 310 Service Floor Retention Tank Facility during the months of July and August, 1996. The characterization included measurements for radioactivity, air sampling for airborne particles and sampling to determine the presence and quality of hazardous materials requiring remediation. Copies of previous lead and asbestos sampling information was obtained from ESH-IH. The facility consists of ten retention tanks located in rooms, A-062A, A-050A, $A-038 \mathrm{~A}, \mathrm{~A}-026 \mathrm{~A}$, and an entry room $\mathrm{A}-068 \mathrm{~A}$ which contained miscellaneous pumps and other scrap material. Significant contamination was found in each room except room A-068A which had contaminated spots on the floor and a discarded contaminated pump.

2057

V18/025547

Closure Report: Nevada Test Site Underground Storage Tank (UST) Number 25-3123-1 - Nevada Division of Emergency Management Case Number H940825D Corrective Action Unit 450

U.S. Department of Energy, Nevada Operations Office, Las Vegas, NV; Bechtel Nevada Corporation, Las Vegas, NV

DOE/NV/11718-091; 263 pp. (January 1997)

This document has been prepared as a final closure report documenting the assessment and corrective actions taken for the petroleum hydrocarbon release associated with underground storage tank (UST) UST25-3123-1. UST25-3123-1 was located at Area 25 within the Nevada Test Site. The UST was identified as abandoned to be closed under the U.S. Department of Energy/Nevada Operations Office Environmental Restoration Division Program during Fiscal Year 1994. The scope of work for closure of the UST included evaluating site conditions and closing the tank in accordance with all applicable regulations. Site evaluation analytic results of a soil sample collected below the tank showed a diesel concentration of $120 \mathrm{mg} / \mathrm{kg}$ at a depth of 3 meters. During remedial excavation, approximately 3.8 cubic meters of hydrocarbon impacted soil was removed. Laboratory analysis of the soil sample collected from the excavation bottom confirms that total petroleum hydrocarbon concentrations greater than $100 \mathrm{mg} / \mathrm{kg}$ are no longer present. Therefore, it is requested that the site be closed without further action.

2058

V18/021608

Corrosion of Mild Steel in Simulated Cesium Elution Process Solutions

Elmore, M.R.

Pacific Northwest National Laboratory, Richland, WA

PNNL-11284; 19 pp. (September 1996)

The West Valley Support Project is being conducted to meet technology needs for the West Valley Demonstration Project and to provide support to the site cleanup and stabilization activities, which involves removing residual Cs in Tank 8D-1 after waste retrieval. In-tank oxalic acid elution of Cs-loaded zeolite is being evaluated. The work reported here involved evaluating the potential for increased comosion of Tank 8D-1 during Cs elution because oxalic acid is corrosive to carbon steel. This included corrosion tests with mild steel (A516 Grade 55) at 27-50 C with 4 and 8 wt\% oxalic acid, for 2, 4, and 6 days. Results agreed with Sept. 1995 tests at 50 $C$ for $1-3$ weeks. The corrosion rate of $A 516$ Grade 55 mild steel in oxalic acid is quite high (about $150 \mathrm{mils} / \mathrm{y}$ or $3.8 \mathrm{~mm} / \mathrm{y}$ ). Corrosion increased three or fourfold going from 27 to $50 \mathrm{C}$. Although the tests resulted in a very rough surface appearance, indicating a 
potential for localized corrosion, eg., pitting and crevice corrosion, the exposure times used were apparently too short to initiate pitting.

\section{9}

V18/020923

Investigating the Feasibility of Using Oxalic Acid to Clean Carbon Steel High-Level Waste Tanks

Sills, J.; King, C.; Westcott, D.; Schiffhauer, M.; Patello, G.K

Pacific Northwest National Laboratory, Richland, WA; West Valley Nuclear Services Company, Inc., West Valley, NY

CONF-960212; Waste Management '96: Working Towards a Cleaner Environment, Proceedings of a Conference on $\mathrm{HLW}$, LLW, Mixed Wastes and Environmental Restoration, Tucson, AZ, February 25-29, 1996; (20 pp.) (1996)

As a result of former reprocessing operations, two types of high-level radioactive waste (HLW) were generated at the Western New York Nuclear Service Center (WNYNSC) located in West Valley, NY. These were plutonium uranium extraction (PUREX) waste and thorium extraction (THOREX) waste. In 1980, the West Valley Demonstration Project (WVDP) Act was passed authorizing the Department of Energy (DOE) to conduct a HLW management project at the WNYNSC. As part of the Act, the approximate two million liters of $\mathrm{HLW}$ generated are to be processed and solidified by vitrification. As a result of vitrification operations, residual amounts of the HLW described above and cesium (Cs)-loaded zeolite, a high-activity ion exchange waste stream generated from vitrification pretreatment operations, will be present in underground carbon steel tanks located in an on-site Tank Farm. Research is currently being conducted at the Pacific Northwest National Laboratory (PNNL) on the use of oxalic acid, which has been proposed to facilitate the removal of residual amounts of these high-level and high-activity wastes. Laboratory-scale tests performed by PNNL have been used to determine the optimum conditions in terms of acid-to-waste ratio, contact time, and the temperature of acid. In addition, the effects of multiple contacts, long-term contacts, the presence of corrosion products, the lack of agitation, and the temperature of tank contents were evaluated. The objectives of this research are to maximize the removal of the residual wastes from the carbon steel tanks, minimize the dissolution of iron, minimize corrosion, and provide a feed that is compatible with the current vitrification waste form specification.

2060

V18/025662

\section{Counter Current Decantation Washing of HLW Sludge}

Brooke, J.N.; Peterson, R.A.

Westinghouse Savannah River Company, Aiken, SC

WSRC-MS-97-0048; CONF-970321; Proceedings of a National Spring Meeting and Petrochemical Exposition of the American Institute of Chemical Engineers (AIChE) and the Second Plant Operations and Design Conference, Houston, TX, March 10-13, 1997; (15 pp.) (1997)

The Savannah River Site (SRS) has 51 High Level Waste (HIW) tanks with typical dimensions 25.9 meters ( 85 feet) diameter and 10 meters ( 33 feet) high. Nearly 114 million liters ( $30 \mathrm{M}$ gallons) of $\mathrm{HLW}$ waste is stored in these tanks in the form of insoluble solids called sludge, crystallized salt called salt cake, and salt solutions. This waste is being converted to waste forms stable for long term storage. High costs and operational concerns with the current washing process prompted DOE and the Westinghouse Savannah River Company (WSRC) to seek an improved washing method. A new method should take full advantage of the physical/chemical properties of sludge, experience from other technical disciplines, processing rate requirements, inherent process safety, and use of proven processes and equipment. Counter current solids washing is a common process in the minerals processing and chemical industries. Washing circuits can be designed using thickeners, filters, or centrifuges. Realizing the special needs of nuclear work and the low processing rates required, a Counter Current Decantation (CCD) circuit is proposed using small thickeners and fluidic pumps.

\section{1}

V18/022193

Rheology of Savannah River Site Tank $\mathbf{4 2}$ Radioactive Sludges [Rev. 1]

Ha, B.C.; Bibler, N.E.

Westinghouse Savannah River Company, Aiken, SC

WSRC-MS-95-0371 (Rev. 1); CONF-9609234; Proceedings of an American Chemical Society Special Symposium on Industrial Engineering Chemistry, Birmingham, AL, September 9-12, 1996; (5 pp.) (1995)

Knowledge of the rheology of the radioactive sludge slurries at the Savannah River Site (SRS) is necessary in order to ensure that they can be retrieved from waste tanks and processed for final disposal. At Savannah River Site (SRS), Tank 42 sludge represents one of the first high-level waste (HLW) radioactive sludges to be vitrified in the Defense Waste Processing Facility (DWPF). The rheological properties of unwashed Tank 42 sludge slurries at various solids concentrations were measured remotely in the Shielded Cells at the Savannah River Technology Center (SRTC) using a modified Haake Rotovisco viscometer. Rheological properties of Tank 42 radioactive sludge were measured as a function of weight percent total solids to ensure that the first DWPF radioactive sludge batch can be pumped and processed in the DWPF with the current design bases. The yield stress and consistency of the sludge slurries were determined by assuming a Bingham plastic fluid model.

\section{2 \\ V18/021614}

Cesium Removal Demonstration for Treatment of the Department of Energy Underground Storage Tank, High-Salt Content Liquid Wastes

Walker, J.F., Jr.; Birdwell, J.F.; Kent, T.E.

Oak Ridge National Laboratory, Oak Ridge, TN

CONF-960376 (Part 1); Proceedings of the 211 th American Chemical Society (ACS) National Meeting, New Orleans, LA March 24-28, 1996. ACS, Washington, DC, Part 1, 1172 pp.; (p. 954, Paper I EC 189) (1996)

Removal of cesium from the liquid waste in the Department of Energy (DOE) underground storage tanks is complicated by the high-salt content of the waste in these tanks. Current adsorbents are not efficient at removing cesium from liquid wastes containing high-salt concentrations, and their use to treat existing DOE liquid waste would require large capital expenditures. As a result, DOE is 
funding work to develop and test more cost effective adsorbents for removal of cesium from these high-salt content wastes. This paper describes a cesium removal demonstration (CsRD) being conducted at ORNL which supports the DOE effort by (1) providing full-scale operating data for removal of radioactive cesium from actual wastes, (2) evaluating the feasibility of using modular, mobile equipment for treatment of high-activity wastes, (3) evaluating the ability to decontaminate mobile systems for hands-on maintenance, and (4) showing the relationship between bench-scale and full scale performance of cesium removal systems. Results of adsorbent transport and hydraulic studies as well as the design of the CsRD system will be discussed. (Complete text).

\section{$2063 \quad$ V18/023941}

Risk Characterization Data Manual for Category D Inactive Liquid Low-Level Waste Tank Systems at Oak Ridge National Laboratory, Oak Ridge, Tennessee

U.S. Department of Energy, Washington, DC; Oak Ridge National Laboratory, Oak Ridge, TN

DOE/OR/01-1168\&D3; 75 pp. (April 1997)

This manual reports the results of a risk characterization of Category $D$ inactive liquid low-level radioactive waste (LLLW) at the Oak Ridge National Laboratory (ORNL). The risk characterization is required by the Federal Facility Agreement between the Department of Energy, Oak Ridge Operations Office; the Environmental Protection Agency, Region IV; and the Tennessee Department of Environment and Conservation. The intent of the risk characterization is to determine relative priorities for assessment and remediation. Each tank was scored on a scale of 1 to 5 on the basis of three criteria: (1) leak characteristics, (2) location, and (3) toxicological characteristics of residual sludges and residues.

\section{4}

\section{V18/023608}

Insitu Radiation Measurements of the $\mathrm{C} 1$ and $\mathrm{C} 2$ Waste Storage Tank Vault

Yong, L.K.; Womble, P.C.; Weems, L.D.

Oak Ridge National Laboratory, Oak Ridge, TN

ORNL/TM-13295; 46 pp. (September 1996)

In August of 1996, the Applied Radiation Measurements Department (ARMD) of the Waste Management and Remedial Action Division (WMRAD) at Oak Ridge National Laboratory (ORNL) was tasked with characterizing the radiation fields in the $\mathrm{Cl}$ and C2 Liquid Low Level Waste (LLLW) tank vault located at ORNL. These in-situ measurements were made to provide data for evaluating the potential radiological conditions for personnel working in or around the vault during future planned activities. This report describes the locations where measurements were made, the types of radiation detection instruments used, the methods employed, the problems encountered and resolved, and discusses the results obtained.

Completion Report for the Isolation and Remediation of Inactive Liquid Low-Level Radioactive Waste Tanks LA-104, WC-7, and 4501-P at Oak Ridge National
Laboratory, Oak Ridge, Tennessee

Oak Ridge National Laboratory, Oak Ridge, TN; Advanced

Sciences, Inc., Oak Ridge, TN

ORNL/ER-388; 5 pp. (December 1996)

The Federal Facility Agreement (FFA) among the U.S. Environmental Protection Agency (EPA), the Tennessee Department of Environment and Conservation (TDEC), and the U.S. Department of Energy (DOE) requires that all liquid low-level waste (LLLW) tanks at Oak Ridge National Laboratory (ORNL) that have been removed from service, designated in the FFA as Category $D$, to be remediated in accordance with Comprehensive Environmental Response, Compensation, and Liability Act (CERCLA) requirements. A human health risk analysis was conducted on inactive tanks LA-104, WC-7, and 4501-P to determine the method for remediating the tanks. Risk analysis results indicated that the health risk associated with these tanks were within or below the EPA range of concern of $1 \times 10(E-4) x$ $1 \times 10(\mathrm{E}-6)$. On the basis of these results and with regulators approval, it was determined that either no action or in-place stabilization of the tanks would satisfy risk-based remediation goals. Therefore, a decision was made and approved by DOE to remediate these tanks as a maintenance action rather than an action under the CERCLA process. Letters documenting these decisions were approved by DOE and submitted to TDEC and EPA.

2066

V18/022398

Completion Report for the Isolation and Remediation of Inactive Liquid Low-Level Radioactive Waste Tanks 7562, H-209, and T-30 at Oak Ridge National Laboratory, Oak Ridge, Tennessee

Oak Ridge National Laboratory, Oak Ridge. IN: Advanced Sciences, Inc., Oak Ridge, IN

ORNL/ER-389; 15 pp. (December 1996)

The Federal Facility Agreement (FFA) among the U.S. Environmental Protection Agency (EPA), the Tennessee Department of Environment and Conservation (TDEC), and the U.S. Department of Energy (DOE) requires that all liquid low-level waste (LLLW) tanks at Oak Ridge National Laboratory (ORNL) that have been removed from service, designated in the FFA as Category $\mathrm{D}$, to be remediated in accordance with Comprehensive Environmental Response, Compensation, and Liability Act (CERCLA) requirements. A human health risk analysis was conducted on inactive tanks $7562, \mathrm{H}-209$, and T-30 to determine the method for remediating the tanks. Risk analysis results indicated that the health risk associated with these tanks were within or below the EPA range of concern of $1 \times 10(E-4) \times 1 \times 10(E-6)$. On the basis of these results and with regulators approval, it was determined that either no action or in-place stabilization of the tanks would satisfy risk-based remediation goals. Therefore, a decision was made and approved by DOE to remediate these tanks in-place as a maintenance action. Letters documenting these decisions were approved by DOE and submitted to TDEC and EPA.

1996 Structural Integrity Assessments for the Category C Liquid Low-Level Waste Tank Systems at Oak Ridge National Laboratory, Oak Ridge, Tennessee 
International Waste Management Systems, Knoxville, TN; Vista Research, Inc., Mountain View, CA; Oak Ridge National Laboratory, Oak Ridge, TN

DOE/OR/01-1512\&D2; 145 pp. (September 1996)

This document provides a report of the efforts made to satisfy the Federal Facility Agreement (FFA) for the structural integrity certification of ten Category C Liquid Low Level Waste (LLLW) tank systems on the Oak Ridge Reservation (ORR) in Oak Ridge, Tennessee. This report is developed as an update to the 1995 Structural Integrity Assessment Report (DOE/OR/01-1385\&D2). DOE/OR/01-1385\&D2 included the assessment of 14 Category C tank systems. Four tank systems have since been removed from Category C classification. These systems include 2026A, WC-7, and WC-19. Each of these four systems has been removed from service and has been given a Category $\mathrm{D}$ classification. Within this document, each Category $C$ tank system is described including the associated pipeline segments evaluated as a part of those tank systems. A separate structural integrity assessment was conducted for each of the LLLW Tank Systems, four of which are located in Melton Valley, and six of which are located in Bethel Valley. The results of the structural integrity assessments are reported herein. The assessments are based on: (1) a review of available tank design drawings; (2) a qualitative assessment of corrosion on the tank and pipelines; and primarily (3) leak testing program results.

\section{8 \\ V18/020670}

Alkaline-Side Extraction of Technetium from Tank Waste Using Crown Ethers and Other Extractants

Bonnesen, P.V.; Moyer, B.A.; Presley, D.J.; Armstrong, V.S.; Haverlock, T.J.; Counce, R.M.; Sachleben, R.A.

Oak Ridge National Laboratory, Oak Ridge, TN

ORNLTM-13241; 105 pp. (June 1996)

The chemical development of a new crown-ether-based solvent-extraction process for the separation of (Tc) from alkaline tank-waste supernate is ready for counter-current testing. The process addresses a priority need in the proposed cleanup of Hanford and other tank wastes. This need has arisen from concerns due to the volatility of Tc during vitrification, as well as Tc-99's long half-life and environmental mobility. The new process offers several key advantages: direct treatability-no adjustment of the waste composition is needed; economical stripping with water; high efficiency-few stages needed; non-RCRA chemicals-no generation of hazardous or mixed wastes; co-extraction of Sr-90; and optional concentration on a resin. A key concept advanced in this work entails the use of tandem techniques: solvent extraction offers high selectivity, while a subsequent column sorption process on the aqueous stripping solution serves to greatly concentrate the Tc. Optionally, the stripping solution can be evaporated to a small volume. Batch tests of the solvent-extraction and stripping components of the process have been conducted on actual Melton Valley Storage Tank (MVST) waste as well as simulants of MVST and Hanford waste. The tandem process was demonstrated on MVST waste simulants using the three solvents that were selected as the final candidates for the process. The solvents are $0.04 \mathrm{M}$ (bis-4,4'5')[(tert-butyl)cyclohexano]-18-crown-6 (abbreviated di-t-BuCH18C6) in a 1:1 vol/vol blend of tributyl phosphate and Isopar [R] M (an isoparaffinic kerosene); $0.02 \mathrm{M}$ di-t-BuCH18C6 in
$2: 1 \mathrm{vol} / \mathrm{vol}$ TBP/lsopar $M$ and pure TBP. The process is now ready for counter-current testing on actual Hanford tank supernates.

2069

$\mathrm{V} 18 / 022190$

Comprehensive Supernatant Treatment

Egan, B.Z

Oak Ridge National Laboratory, Oak Ridge, TN

PNNL-SA-27105; CONF-960158; Efficient Separation and Processing Crosscutting Program, Proceedings of the 1996 Technical Exchange Meeting, Gaithersburg, MD, January 16-19, 1996, 52 pp.; (pp. 73-75) (1996)

This task involves the testing of sorbent materials for removing cesium, strontium, and technetium from the saline solutions in DOE storage tank supernatant at Oak Ridge and other sites. Staff at Oak Ridge National Laboratory (ORNL) are recovering and treating the liquid (supematant) portions of Melton Valley Storage Tank (MVST) waste in a hot cell to separate and remove the radionuclides. Batch tests will be used to evaluate and select the most promising materials for supernatant treatment to reduce the amount of waste for final disposal. Smail column tests will be made on selected sorbents to verify the batch data and to obtain additional data for process design. Efforts will be made to obtain samples of tank supematant from Hanford for comparison.

2070

V18/025469

Design Assessment for the Melton Valley Storage Tanks Capacity Increase at Oak Ridge National Laboratory Under the Federal Facility Agreement, Oak Ridge, Tennessee

Oak Ridge National Laboratory, Oak Ridge, TN

DOE/OR-01-1424\&D1; ORNL/M-4900; 35 pp. (November 1995)

This project was initiated to find ways to increase storage capacity for the liquid low-level waste (LLLW) system at the Oak Ridge National Laboratory and satisfy the Federal Facility Agreement (FFA) requirement for the transfer of LLW from existing tank systems not in full FFA compliance.

2071

$\mathrm{V} 18 / 021613$

Sorption Studies on the Removal of Cesium, Strontium, and Technetium from Supernatants from Underground Storage Tanks at ORNL

Collins, J.L.; Egan, B.Z.; Anderson, K.K.; Chase, C.W.

Oak Ridge National Laboratory, Oak Ridge, TN

CONF-960376 (Part 1); Proceedings of the 211th American Chemical Society (ACS) National Meeting, New Orleans, LA, March 24-28, 1996. ACS, Washington, DC, Part 1, 1172 pp.; (p. 941, Paper I EC 147) (1996)

Bench scale batch equilibration tests have been conducted with supernatants from several tanks at the Melton Valley Storage Tank (MVST) Facility at Oak Ridge National Laboratory (ORNL) to evaluate and compare the effectiveness of selected ion exchangers for removing cesium, strontium, and technetium. The MVST supernatants are similar in composition to some of the supernatants stored in the Hanford tanks, and these data should prove useful in the overall evaluation of the ion exchangers for applications to 
Hanford and other U.S. Department of Energy sites. Eight sorbents were evaluated for cesium removal, ten for strontium removal, and six for technetium removal. Kinetic and isotherm data, as well as data showing the effects of the concentrations of cesium and potassium on the removal of cesium from the supernatants, will be presented. Kinetic and isotherm data for the removal of strontium and technetium will be given. A test to determine the solubility of strontium in one of the supernatants will be described. (Complete text)

\section{2}

\section{V18/022881}

Safety Analysis Report for the North Tank Farm, Tank W-11, and the Gunite and Associated Tanks: Treatability Study, Oak Ridge National Laboratory, Oak Ridge, Tennessee

Oak Ridge National Laboratory, Oak Ridge, TN

ORNL/ER-382; 140 pp. (February 1997)

The North Tank Farm (NTF) tanks consist of eight underground storage tanks (Tanks W-1, W-1A, W-2, W-3, W-4, W-13, W-14, and $W-15$ ). Four of the tanks (W-1, W-2, W-3, and W-4) were constructed using an in-place gunite construction process. An aggregate-free concrete (gunite) was sprayed in layers onto rebar skeletons to form the tanks in place. The other four tanks (W-1A, $\mathrm{W}-13, \mathrm{~W}-14$, and $\mathrm{W}-15$ ) are constructed of stainless steel. Built in the 1940s, the underground storage tanks have since been removed from service because of age and changes in liquid waste system needs and requirements. Tanks W-11 is a 1500-gal gunite tank located in the Bethel Valley South Tank Farm. The underground tank was constructed in 1943 to serve as a waste collection and monitoring tank for research laboratories in Building 3550. Tank W-11 has been removed from service because of age and changes 9 in liquid waste system needs and requirements. The Gunite and Associated Tanks (GAAT) Treatability Study involves the demonstration of sludge removal techniques and equipment for use in other waste storage tanks throughout the DOE complex. Sludges in Tanks W-3 and $W-4$ in the NTF will be the subject of the study and will be dislodged and transferred between tanks. A technique known as confined sluicing, which uses a high-pressure, low-volume water jet integrated with a jet pump, will be demonstrated and thoroughly evaluated. Two deployment options are considered in the Treatability Study for the confined sluicing. The first is a Modified Light Duty Utility Arm (MLDUA), which is a remotely controlled robotic arm that can be used to position and manipulate the sluicing equipment. The second is a remotely operated vehicle.

\section{3}

\section{V18/024844}

Addendum 2: Old Hydrofracture Facility Tanks Sampling and Analysis Plan

Oak Ridge National Laboratory, Oak Ridge, TN; CDM Federal Programs Corporation, Oak Ridge, TN

ORNL/RAP/LTR-88/24 (Addendum 2); 23 pp. (December 1995)

This plan is designed to guide sampling and analysis at the five inactive tanks associated with the Old Hydrofracture Facility (OHF). All sampling and analysis activities will be conducted under the direction of the Waste Management and Remedial Action Division (WMRAD) and will follow WMRAD procedures. This plan is Addendum 2 to the ORNL Inactive Waste Tanks Sampling and
Analysis Plan [SAP (ORNL/RAP/LTR-88/24), Energy Systems 1988b], which directed sampling of 33 inactive tanks managed by the Oak Ridge National Laboratory (ORNL) Environmental Restoration Program. Addendum I covers additional sampling at the Gunite and Associated Tanks at ORNL. The five tanks associated with the OHF Facility contain liquid supernate and sludge material having high curie loading (estimated to total approximately 30,000 $\mathrm{Ci}$ for all tanks). The sampling and information-gathering activities covered by this plan will provide information needed to support removal of tank contents and closure of the tanks, which are necessary to protect public health and the environment. The sections of this plan provide background on the OHF Facility and associated tanks, and discuss the objectives of this sampling endeavor.

\section{4 \\ V18/022395}

Addendum 3: Supplemental Sampling and Analysis Plan for the Old Hydrofracture Facility Tanks

Oak Ridge National Laboratory, Oak Ridge, TN; CDM Federal Programs Corporation, Oak Ridge, TN

ORNL RAP/LTR-88/24 (Addendum 3); 35 pp. (November 1996)

This Sampling and Analysis Plan (SAP) is designed to guide a supplemental sampling and analysis project at the Old Hydrofracture Facility (OHF) tanks. There are five tanks, all of which are inactive and located underground. Sampling and analysis activities will be conducted under the direction of the Waste Management and Remedial Action Division (WMRAD) and will follow its procedures. This plan is Addendum 3 to the ORNL Inactive Waste Tanks Sampling and Analysis Plan, which directed sampling of 33 inactive tanks managed by the Oak Ridge National Laboratory (ORNL) Environmental Restoration Program. Addendum 1 was developed in August 1994 for additional sampling at the gunite and associated tanks. Addendum 2 was developed in December 1995 for additional sampling at the OHF tanks.

\section{5}

$$
\text { V18/022390 }
$$

Contingency Plan for the Old Hydrofracture Facility Tanks Sluicing Project at Oak Ridge National Laboratory, Oak Ridge, TN

Oak Ridge National Laboratory, Oak Ridge, TN; CDM Federal Programs Corporation, Oak Ridge, TN

ORNL/ER-383; 50 pp. (October 1996)

Lockheed Martin Energy Systems, Inc. (Energy Systems), plans to begin a sluicing (flushing) and pumping project to remove the contents from five inactive, underground storage tanks at the Old Hydrofracture Facility (OHF) at the Oak Ridge National Laboratory (ORNL) in Oak Ridge, Tennessee. The tank contents will be transferred to the Melton Valley Storage Tanks, which are part of the active waste treatment system at ORNL. The purpose of the project is to minimize the risk of leaking the highly radioactive material to the environment. The five OHF tanks each contain a layer of sludge and a layer of supernatant. Based on a sampling project undertaken in 1995, the sludge in the tanks has been characterized as transuranic and mixed waste and the supematants have been characterized as mixed waste. The combined radioactivity of the contents of the five tanks is approximately $29,500 \mathrm{Ci}$. 


\section{6}

V18/022885

Evaluation and Monitoring Plan for Consolidation Tanks: Gunite and Associated Tanks Operable Unit, Waste Area Grouping 1, Oak Ridge National Laboratory, Oak Ridge, Tennessee

Vista Research, Inc., Oak Ridge, TN; Oak Ridge National Laboratory, Oak Ridge, TN

ORNL/ER-396; 30 pp. (February 1997)

This report describes the results of an integrity evaluation of Tanks W-8 and W-9, part of the Gunite and Associated Tanks (GAAT), in the South Tank Farm at Oak Ridge National Laboratory (ORNL), together with a plan for monitoring those tanks for potential releases during the GAAT CERCLA treatability study and waste removal activities. This work was done in support of an ORNL plan to use W-8 and W-9 as consolidation tanks during remediation of the other tanks in the North and South Tank Farms. The analysis portion of the report draws upon both tank-internal measurements of liquid volume change and tank-external measurements of the change in electrical conductivity of the groundwater in the dry wells adjacent to each tank. The results of the analysis show that both W-8 and W-9 are liquid-tight and are suitable for use as consolidation tanks. The recommended monitoring plan will utilize the dry well conductivity monitoring method as the primary release detection tool during the CERCLA activities. This method is expected to be able to detect releases of less than $0.5 \mathrm{gal} / \mathrm{h}$ with a $95 \%$ probability of detection, most of the time. The results described here validate three prior independent efforts: a liquid integrity assessment made in 1995, a structural integrity assessment made in 1995 by experts in the field of gunite tanks, and a structural integrity assessment made in 1994 using a three-dimensional, finite-element computer model. This work, along with the three prior efforts, shows that Tanks W-8 and W-9 are structurally sound and liquid-tight. Based upon this work it is concluded that these tanks are suitable for use as consolidation tanks during the GAAT CERCLA treatability study and waste removal actions and it is recommended that the tanks be monitored for potential releases during this period using the methods described in this report.

\section{7}

\section{$\mathrm{V} 18 / 021423$}

Leaching studies and Miscellaneous Data for the Gunite and Associated Tanks at Oak Ridge National

Laboratory, Oak Ridge, Tennessee

Giaquinto, J.M.; Keller, J.M.; Mills, T.P.

Oak Ridge National Laboratory, Chemical and Analytical Sciences Division, Oak Ridge, TN

ORNL/ER-364; 30 pp. (March 1996)

This report provides the Environmental Restoration Program with analytical results for toxicity characteristic leaching procedure (TCLP) and Kd (distribution coefficient) determinations performed on the Gunite and Associated Tanks (GAAT) W-03, W-04, W-06, W-07, and W-10 at the Oak Ridge National Laboratory (ORNL). Also included are the analyses of chips found in sludge grab samples from tanks W-05 and W-06 and gunite wall samples removed from tanks W-05 and W-08. Analytes determined for each procedure include (1) principle radionuclides, (2) Resource Conservation and Recovery Act metals listed by the US EPA that exceed TCLP regulatory limits by a factor of 20 in the total metals analysis of the sludges, (3) total uranium and thorium, and (4) some physical properties. Information provided in this report forms part of the technical basis for criticality safety, systems safety, engineering design, and waste management as they apply to the GATT treatability study and remediation.

\section{8}

V18/021437

Preliminary Engineering Report: Waste Area Grouping 5 Old Hydrofracture Facility Tanks Content Removal Project, Oak Ridge National Laboratory, Oak Ridge, Tennessee

CDM Federal Programs Corporation, Oak Ridge, TN; Lockheed Martin Energy Systems, Inc., Environmental Restoration Division, Oak Ridge, TN

ORNL/ER-372; 135 pp. (June 1996)

Five inactive liquid low-level waste tanks located at the Old Hydrofracture (OHF) Facility in the Melton Valley area of Oak Ridge National Laboratory have been evaluated and are now entering the remediation phase. Before the final remediation is implemented, the OHF Tanks Content Removal Project will be conducted to remove the current liquid and sludge contents of each of the five tanks. It was concluded in the Engineering Evaluation/Cost Analysis for the Old Hydrofracture Facility Tanks that sluicing and pumping the contaminated liquid and sludge from the five OHF tanks was the preferred removal action. This removal action consists of removing transuranic mixed waste from the $\mathrm{OHF}$ Facility underground storage tanks and transporting the waste via pipeline to the Melton Valley Storage Tank Facility. The removal action will be accomplished using existing sluicing technologies coupled with providing a tie-in to the existing pipeline where needed to perform the material transfer. The purpose of this document is to establish a technical approach that will achieve the mission objectives, provide a baseline for defining the design scope and product, provide an adequate technical basis for a conceptual level cost estimate, and identify any "fatal flaws" to the approach.

$$
\text { V18/023311 }
$$

Project Health and Safety Plan for the Gunite and Associated Tanks at Oak Ridge National Laboratory, Oak Ridge, Tennessee

Abston, J.P.

Oak Ridge National Laboratory, Life Sciences Division, Oak Ridge, TN

ORNL/ER-397; 95 pp. (April 1997)

The purpose of this PHASP is to define the interfaces and responsibilities for ensuring H\&S for the GAAT Remediation Project, to briefly describe the types of hazards involved, and to define the methodology for implementing H\&S requirements that mitigate and/or eliminate those hazards for each organization involved. This PHASP has been created using site characterization data and process knowledge to determine potential hazards. The objective of this PHASP is to provide safe and healthful working conditions at the project site. This plan explains project $H \& S$ requirements in addition to those in referenced procedures. This PHASP shall be available for inspection and review by all personnel before they enter the project site. 


\section{0}

V18/020851

Project Management Plan for Waste Area Grouping 5 Old Hydrofracture Facility Tanks Content Removal at Oak Ridge National Laboratory, Oak Ridge, Tennessee Oak Ridge National Laboratory, Engineering Division, Oak Ridge, TN; CDM Federal Programs Corporation, Oak Ridge, TN

\section{ORNL/ER-375; 15 pp. (July 1996)}

The purpose of the Old Hydrofracture Facility (OHF) tanks content removal project is to transfer inventory from the five OHF tanks ( $T-1, T-2, T-3, T-4$, and $T-9$ ) located in Waste Area Grouping (WAG) 5 at Oak Ridge National Laboratory (ORNL) to the Melton Valley Storage Tanks (MVST) liquid low-level (radioactive) waste (LLLW) storage facility, and remediate the remaining OHF tank shells. The major activities involved are identified in this document along with the organizations that will perform the required actions and their roles and responsibilities for managing the project.

\section{$2081 \quad$ V18/021422}

Results of Fall 1994 Sampling of Gunite and Associated Tanks at the Oak Ridge National Laboratory, Oak Ridge, TN

Bechtel National, Inc., Oak Ridge, TN; Oak Ridge National Laboratory, Oak Ridge, TN

ORNL/ER/Sub/87-99053/74; 55 pp. (June 1995)

This technical memorandum (TM) documents the August-November 1994 sampling and analysis of 12 underground radioactive waste tanks at Oak Ridge National Laboratory (ORNL). These tanks are part of the Gunite and Associated Tanks (GAAT) Operable Unit (OU), and the sampling campaign is part of the ongoing GAAT remedial investigation/feasibility study (RI/FS) process. This TM reports both field observations (e.g., liquid and sludge depths) and analytical results. Analytical results are also available from the Oak Ridge Environmental Information System (OREIS) data base under the project name GAAT (PROJ_Name = WAG 1 Gunite and Associated Tanks OU 1). Information provided in this report forms part of the technical basis for criticality safety, systems safety, engineering design, and waste management as they apply to the GATT treatability study and remediation. This TM is organized as a brief discussion followed by series of appendices that include field measurements, analytical results, and narratives. This TM does not attempt to analyze the data; a follow-up document is scheduled for that purpose.

\section{2 \\ V18/020996}

Root Cause Analysis for Waste Area Grouping 1 Batch I, Series 1 Tank T-30 Project at Oak Ridge National Laboratory Oak Ridge, Tennessee

Oak Ridge National Laboratory, Oak Ridge, TN; MACTEC, Oak Ridge, TN

ORNL/ER-359; 15 pp. (August 1996)

Four inactive liquid low-level waste ( $L L L W)$ tanks were scheduled for remedial actions as the Batch L Series I Tank Project during fiscal year (FY) 1995. These tanks are 3001-B, 3004-B, T-30, and 3013. The initial tank remediation project was conducted as a maintenance action. One project objective was to gain experience in remediation efforts (under maintenance actions) to assist in conducting remedial action projects for the 33 remaining inactive LLLW tanks. Batch I, Series 1 project activities resulted in the successful remediation of tanks 3001-B, 3004-B, and 3013. Tank $\mathrm{T}-30$ remedial actions were halted as a result of information obtained during waste characterization activities. The conditions discovered on tank T-30 would not allow completion of tank removal and smelting as originally planned. A decision was made to conduct a root cause analysis of Tank T-30 events to identify and, where possible, correct weaknesses that, if uncorrected, could result in similar delays for completion of future inactive tank remediation projects. The objective of the analysis was to determine why a portion of expected project end results for Tank T-30 were not fully achieved. The root cause analysis evaluates project events and recommends beneficial improvements for application to future projects. This document provides the background, problem statement, results, and methodology for Tank T-30 root cause investigation. The problem investigated was stated as, "Tank T-30 was not removed under a maintenance action as originally planned." The investigation was conducted to identify and, where possible, correct weaknesses to avoid similar delays in future inactive tank remediation projects.

\section{$2083 \quad$ V18/024286}

Simulation Tools for Hazardous Waste Removal

Bills, K.C.; Love, L.J.

Oak Ridge National Laboratory, Oak Ridge, TN; Oak Ridge Institute for Science and Education, Oak Ridge, TN

CONF-970464; Proceedings of the Seventh American Nuctear Society (ANS) Topical Meeting on Robotics and Remote Systems, Augusta, GA, April 27-May 1, 1997. ANS, La Grange Park, IL; (7 pp.) (1997)

The primary mission of Oak Ridge National Laboratory (ORNL) during World War 2 was the processing of pure plutonium metal in support of the Manhattan Project. By-products of this process include radioactive cesium-137 and strontium-90. Between 1943 and 1951, the Gunite and Associated Tanks (GAAT) at ORNL were built to collect, neutralize, and store these by-products. Currently, twelve gunite tanks and four stainless steel tanks are located on the ORNL complex. Characterization studies of these tanks in 1994 indicated that the structural integrity of some of the tanks is questionable. These risks provided the motivation for remediation and relocation of waste stored in the ORNL tanks. A number of factors complicate the remediation process. The material stored in these tanks ranges from liquid to sludge and solid and is composed of organic materials, heavy metals, and radionuclides. Furthermore, the tanks, which range from 12 to 50 ft in diameter, are located below ground and in the middle of the ORNL complex. The only access to these tanks is through one of three access ports that are either 12 or 24 in. in diameter. These characteristics provide a daunting challenge: how can material be safely removed from such a confined structure This paper describes the existing strategy and hardware projected for use in the remediation process. This is followed by a description of an integrated hardware system model. This investigation has isolated a few key areas where further work may be needed. 


\section{4}

V18/022884

Summary Review of the Chemical Characterization of Liquid and Sludge Contained in the Old Hydrofracture Tanks, Oak Ridge National Laboratory, Oak Ridge, Tennessee

Francis, C.W.; Herbes, S.E.

Oak Ridge National Laboratory, Oak Ridge, IN

ORNL/ER-395; 45 pp. (February 1997)

This report presents analytical data developed from samples collected from the five inactive tanks located at the Old Hydrofracture Facility (OHF) at the Oak Ridge National Laboratory (ORNL) in Oak Ridge, Tennessee. The samples were collected during December 1995 and January 1996. The purpose of the sampling and analysis project was to: (1) determine whether the tank contents meet Treatment Systems, Waste Evaluation Criteria, WM-WMCO-201; (2) to determine various physical properties of the tank contents that would affect the design of a sludge mobilization system; and (3) to gather information to support a baseline risk assessment. The report focuses on the analytical results used to evaluate the tank contents with regard to nuclear criticality safety requirements and to regulatory waste characterization.

\section{5}

\section{V18/022389}

Treatability Study Operational Testing Program and Implementation Plan for the Gunite and Associated Tanks at the Oak Ridge National Laboratory, Oak Ridge, Tennessee [Rev. 1]

Oak Ridge National Laboratory, Oak Ridge, TN; XI Associates, Inc., Oak Ridge, TN

ORNL/ER-361/R1; 75 pp. (September 1996)

To support future decision making of the Gunite and Associated Tanks (GAAT) Operable Unit (OU) remedy selection, the Department of Energy (DOE) is performing a Treatability Study (TS), consistent with the U.S. Environmental Protection Agency (EPA) guidance for Comprehensive Environmental Response, Compensation, and Liability Act (CERCLA) treatability studies. The study will inform stakeholders about various waste removal technologies and the cost of potential remediation approaches, particularly the cost associated with sluicing and the reduction in risk to human health and the environment from tank content removal. As part of the GAAT OU remedy, a series of studies and technology tests will be performed. These may address one or more of the following areas: characterization, removal, treatment, and transfer of wastes stored in the GAAT OU.

\section{6}

\section{V18/021304}

Treatment, Storage, and Disposal Alternatives for the Gunite and Associated Tanks at Oak Ridge National Laboratory, Oak Ridge, Tennessee

DePew, R.E.; Redus, K.S.; du Mont, S.P.; Lewis, B.E.; DePaoli, S.M.; Van Hoesen, S.D., Jr.

Advanced Systems Technology, Inc., Oak Ridge, TN; MACTEC, Oak Ridge, TN; Hazardous and Medical Waste Services, Inc. Oak Ridge, TN; Oak Ridge National Laboratory, Oak Ridge, TN
ORNL/ER-356; 65 pp. (May 1996)

Potential altematives for the treatment, storage, and disposal (TSD) of the wastes in the inactive Gunite and Associated Tanks (GAAT) at the Oak Ridge National Laboratory have been reviewed and evaluated. This effort is an extension of an initial study of various waste treatment and tank stabilization alternatives. Potential waste storage and disposal options were identified and treatment options developed based on the waste acceptance criteria for selected disposal options. Screening criteria were developed to assist in the selection of the most viable individual TSD options. The individual TSD options that did not meet the screening criteria were eliminated. The remaining TSD options were then combined to create a number of systematic approaches (TSD system alternatives) for the final disposal of the GAAT waste. Evaluation criteria were developed to assist in the selection of the most viable TSD system alternatives. Each TSD system alternative was then described in terms of key evaluation criteria. Rough order-of-magnitude cost information for the selected treatment and stabilization alternatives are also provided.

2087

V18/025017

W-12 Valve Pit Decontamination Demonstration

Benson, C.E.; Parfith J.E.; Patton, B.D.

Oak Ridge National Laboratory, Oak Ridge, TN

ORNL/TM-13113; 13 pp. (December 1995)

Waste tank W-12 is a tank in the ORNL Low-Level Liquid Waste (LLLW) system that collected waste from Building 3525 . Because of a leaking flange in the discharge line from W-12 to the evaporator service tank (W-22) and continual inleakage into the tank from an unknown source, W-12 was removed from service to comply with the Federal Facilities Agreement requirement. The initial response was to decontaminate the valve pit between tank W-12 and the evaporator service tank (W-22) to determine if personnel could enter the pit to attempt repair of the leaking flange. The pit is located west of the Fourth Street (across the street from the southwest comer of Building 3525) and measures approximately $12 \mathrm{ft}$ long, $3 \mathrm{ft}$ wide, and $8 \mathrm{ft}$ deep. The $\mathrm{W}-12$ jet system occupies approximately one-half the length of the pit. Radiation levels taken previousily were approximately $15 \mathrm{R} / \mathrm{h}$ at the bottom of the pit. Due to the uncertainty of the radiation exposure in the pit, Health Physics lowered thermoluminescent dosimeters into the pit (approximately 6 in. from the bottom of the pit) to determine radiation exposure levels. The results of this measurement indicated radiation fields of $200 \mathrm{mR} / \mathrm{h}$ (skin) and $2 \mathrm{R} / \mathrm{h}$ (penetrating). Preventing the spread of radioactive contamination from the pit to the environment and to other waste systems was of concern during the decontamination. The drain in the pit goes to the process system; therefore, if high-level liquid waste were generated during decontamination activities, it would have to be removed from the pit by means other than the available liquid waste connection. In addition, the radioactive contamination had been present in the pit for a long time and could have been adsorbed into the concrete. It was questionable where surface decontamination could reduce the radiation exposure enough, given the proposed level of effort and limit on waste generated. However, decontamination could reduce the exposure to a level such that temporary shielding could be used to lower the exposure to a reasonable level for a person to enter the pit. 


\section{8}

V18/025015

Structural Integrity Assessments for the Category C Liquid Low-Level Waste Tank Systems at the Oak Ridge National Laboratory

Lockheed Martin Energy Systems, Inc., Oak Ridge, TN

DOE/OR/01-1385\&D1; 180 pp. (September 8, 1995)

This document provides a report of the efforts made to satisfy the Federal Facility Agreement (FFA) for the structural integrity certification of 14 Category C Liquid Low Level Waste (LLLW) Tank Systems on the Oak Ridge Reservation (ORR) in Oak Ridge,Tennessee. Within this document, each tank system is described including the associated pipeline segments evaluated as part of those tank systems. A separate structural integrity assessment was conducted for each of the LLLW Tanks Systems. The results are reported in summary form in Part $I$ and in detail in Part II of this document. This assessment has determined that all of the tank systems were generally designed and constructed with materials and methods appropriate to their intended usage. With the exception of one tank system, it was determined that corrosion is likely not to be a significant factor in the integrity of the systems. Certification results for each specific tank system are presented at the end of each tank section.

\section{9}

\section{V18/020985}

Technical Specification for Transferring Tank Construction Data to the Oak Ridge Environmental Information System (OREIS)

Lockheed Martin Energy Systems, Inc., Environmental Restoration Division, Oak Ridge, IN

ES/ER/TM-189; 30 pp. (June 1996)

The purpose of this technical specification report is to address the consolidated environmental data requirements of the Federal Facility Agreement (FFA) and the In February 1996, a team was formed to develop, document, and implement technical specifications for transmitting tank construction data to the Oak Ridge Environmental Information System (OREIS). This document describes the requirements, responsibilities, criteria, and format for transmitting tank construction data to OREIS as determined by the Tank Technical Specification Team. The primary goal of this technical specification is to meet the consolidated environmental data requirements defined by the Federal Facility Agreement (FFA) and the Tennessee Oversight Agreement as they pertain to tank construction data maintained in Oak Ridge, Tennessee, by the US Department of Energy's Maintenance and Operations contractor Lockheed Martin Energy Systems, Inc., and prime contractors to the Department of Energy. This technical specification describes the organizational responsibilities for loading tank construction data into OREIS, describes the logical and physical data transfer files, addresses business rules and submission rules, addresses configuration control of this technical specification, and addresses required changes to the current OREIS data base structure based on site requirements. This technical specification addresses the tank construction data maintained by the $\mathrm{Y}-12, \mathrm{~K}-25$, and ORNL sites that will be sent to OREIS. The initial submission of data will include only inactive Environmental Restoration tanks as specified by the FFA.
2090

V18/024275

Site Status Monitoring Report and Site Ranking Form for Underground Storage Tank 2331-U at Building 9201-1

Oak Ridge Y-12 Plant, Oak Ridge, TN; Science Applications International Corporation, San Diego, CA

Y/SUB-96-99069C/Y22/3; 44 pp. (May 1996)

The purpose of this document is to present potentiometric, groundwater quality and vapor monitoring data required for site status monitoring of underground storage tank (UST) $2331-\mathrm{U}$ at the Building 9201-1 Site. Site status monitoring has been conducted at the site as part of a Monitoring Only program approved by the Tennessee Department of Environment and Conservation (TDEC) based on review and approval of Site Ranking (Site Ranking Form approved May 23, 1994). This document presents the results of the fourth semiannual site status monitoring that was performed in April 1996. Site status monitoring and preparation of this report have been conducted in accordance with the requirements of TDEC Rule 1200-1-15 and the IDEC UST Reference Handbook, Second Edition (TDEC 1994) Technical Guidance Document (TGD) 007. This document is organized into three sections with two Appendices. Section 1 presents introductory information relative to the site including the regulatory initiative and a site description. Section 2 includes the results of measurement and sampling of monitoring wells GW-193, GW-657, GW-707, GW-708, GW-808, GW-809, and GW-810. Section 3 presents data from vapor monitoring conducted in subsurface utilities present at the site. Appendix A contains the original analytical laboratory results for environmental and quality control samples.

\section{1}

V18/023461

Site Status Monitoring Report for Underground Storage Tank 0134-U at Building 9204-2

Oak Ridge Y-12 Plant, Oak Ridge, IN; Science Applications International Corporation, Oak Ridge, IN

Y/SUB-96-99069 C/Y22/2; 34 pp. (March 1996)

This document presents potentiometric, groundwater quality, and vapor monitoring data required for site status monitoring of underground storage tank (UST) 0134-U at the Oak Ridge Y-12 Plant Building 9204-2 Site. The monitoring was conducted as part of a Monitoring Only program approved by Tennessee Department of Environment and Conservation. Results are given of the second semiannual site status monitoring performed in March 1996. Site ranking was also performed using the March 1996 groundwater data. The site was the location of a gasoline UST used to fuel an emergency generator at Building 9204-2; the tank was excavated and removed from the site.

\section{V18/023022}

Mobilization Plan for the Y-12 9409-5 Tank Storage Facility RCRA Closure Plan: Final Report [Rev. 1]

Oak Ridge Y-12 Plant, Oak Ridge, TN; Science Applications International Corporation, Oak Ridge, TN

Y/ER-139/Rl; 20 pp. (November 1993)

This mobilization plan identifies the activities and equipment 
necessary to begin the field sampling for the Oak Ridge Y-12 9409-5 Diked Tank Storage Facility (DT-SF) Resource Conservation and Recovery Act (RCRA) closure. Elements of the plan outline the necessary components of each mobilization task and identify whether Science Applications International Corporation (SAIC) or the Martin Marietta Energy Systems, Inc. Y-12 Environmental Restoration Division will be responsible for task coordination. Field work will be conducted in two phases: mobilization phase and soil sampling phase. Training and medical monitoring, access, permits and passes, decontamination/staging area, equipment, and management are covered in this document.

2093

V18/021069

Summary of Closure of the 9409-5 Tank Storage Facility at the Oak Ridge Y-12 Plant Under Rules Governing Hazardous Waste Management in Tennessee Oak Ridge Y-12 Plant, Oak Ridge, TN

Y/ER-266; 1300 pp. (June 1996)

In February 1995, the RCRA Closure Plan for the 9409-5 Tank Storage Facility at the Y-12 Plant, Oak Ridge, TN, Y/ER-5R1, was submitted to the Tennessee Department of Environment and Conservation (TDEC) for review and approval. The plan was approved by the TDEC in November 1995, and the described closure activities have been completed. This Summary of Closure of the 9409-5 Tank Storage Facility at the Oak Ridge Y-12 Plant Under Rules Governing Hazardous Waste Management in Tennessee, Y/ER-266, was prepared in accordance with the rules governing hazardous waste management in the state of Tennessee. This document contains descriptions of the steps taken to remove the waste from the site, sampling and analysis of the environs around the site, and evaluation of the site's suitability for release. This document is largely a compilation of previously issued reports related to the disposition of the 9409-5 Tank Storage Facility.

2094

V18/024276

Comprehensive Monitoring Report for Underground Storage Tanks 0439-U, 0440-U, 2073-U, 2074-U, and 2075-U at the East End Fuel Station, Buildings 9754 and 9754-2, Oak Ridge Y-12 Plant, Oak Ridge, Tennessee

Oak Ridge Y-12 Plant, Oak Ridge, TN; Science Applications International Corporation, San Diego, CA

Y/SUB-96-99069C/Y22/5; 61 pp. (June 1996)

The purpose of this document is to provide hydrogeologic, geochemical, and vapor monitoring data required for comprehensive monitoring of underground storage tanks (UST) 0439-U, 0440-U, 2073-U, 2074-U, and 2075-U at the East End Fuel Station. Comprehensive monitoring was conducted at the site in May 1996 at the direction of the Tennessee Department of Environment and Conservation (TDEC) based on review and notice of deficiencies in the Site-specific Standard Request. This document is organized into three sections. Section 1 presents introductory information relative to the site including regulatory initiative and a description of the site. Section 2 includes the results of water level measurement and sampling of monitoring welis at the site. Section 3 presents data from vapor monitoring conducted in subsurface utilities present at the site. Appendix A contains the original analytical laboratory results for environmental and quality control samples collected during comprehensive monitoring.

2095

V18/024234

Data Quality Objectives for Regulatory Requirements for Hazardous and Radioactive Air Emissions Sampling and Analysis

Mulkey, C.H.; Markillie, K.D.

Westinghouse Hanford Company, Richland, WA; Stone and Webster Engineering Corporation, Richland, WA

WHC-SD-WM-DQO-021; 87 pp. (November 1995)

This data quality objective (DQO) document was developed using the Tank Waste Remediation System Data Quality Objectives Strategy, which is based on the U.S. EPA's DQO guidelines. This $D Q O$ document identifies state and federal requirements associated with toxic hazardous and/or radiological air emissions under the jurisdiction of Hanford Tank Farm Transition Projects. It includes lists of analytes compiled from chemical inventories, process knowledge, vapor space characterization data, and gases that may be generated by chemical and/or radiological activities. It outlines decision identification, decision inputs, study boundaries, decision rules, decision limits of errors, and sampling and analysis designs for obtaining data.

2096

V18/021609

Extensive Separations Pretreatment Alternative Engineering Data Package for the Tank Waste Remediation System Environmental Impact Statement Jansen, G., Jr.; Knutson, B.J.; Allen, G.K.; Lauerhass, L. Westinghouse Hanford Company, Richland, WA; Pacific Northwest Laboratory, Richland, WA.

WHC-SD-WM-EV-100; 973 pp. (September 22, 1995)

This engineering data package provides supporting data for preparation of the Tank Waste Remediation System (TWRS) Environmental Impact Statement (TWRS EIS). Data in this document addresses specifically the Extensive Separations Altemative. Engineering data packages addressing the other altematives to be evaluated in the TWRS EIS are the No Disposal Action Alternative, In Situ Disposal Alternative, Tri-Party Agreement, and the No Separations Alternative. The Waste Retrieval and Transfer Engineering Data Package and the Closure Engineering Data Package provide additional data addressing the Tri-Party Agreement Altemative. Data provided in this document relate to impacts from construction, operations (including startup, and decontamination and decommissioning), resource operations (including startup, and decontamination and decommissioning), resource utilization, transportation, and radiation dose to workers. Processes and activities addressed in this data package include radionuclide removal, low-level waste vitrification, low-level waste disposal, high-level waste vitrification, on-site interim storage of the vitrified high-level waste product, and transportation of the vitrified high-level waste product to a geologic repository. Environmental impacts associated with disposal of high-level waste in a geologic repository are not within the scope of the TWRS EIS and not addressed in this document, other than accounting for the repository disposal fee in order to equitably compare aitematives. 
2097

V18/023462

Facility Design Philosophy: Tank Waste Remediation System Process Support and Infrastructure Definition

Leach, C.E.; Galbraith, J.D.; Grant, P.R.; Francuz, D.J.; Schroeder, P.J.

Westinghouse Hanford Company, Richland, WA; Fluor Daniel, Inc., Richland, WA

WHC-SD-W378-ES-002; 538 pp. (November 1995)

This report documents the current facility design philosophy for the Tank Waste Remediation System (TWRS) process support and infrastructure definition. The Tank Waste Remediation System Facility Configuration Study (FCS) initially documented the identification and definition of support functions and infrastructure essential to the TWRS processing mission. Since the issuance of the FCS, the Westinghouse Hanford Company (WHC) has proceeded to develop information and requirements essential for the technical definition of the TWRS treatment processing programs.

\section{8}

V18/021728

Immobilization of Separated Tc and Cs/Sr in Synroc

Hart, K.P.; Vance, E.R.; Day, R.A.; Begg, B.D.; Angel, P.J.; Jostsons, A.

ANSTO, Menai, New South Wales, Australia

CONF-951155; Scientific Basis for Nuclear Waste Management, W.M. Murphy and D.A. Knecht (eds.), Proceedings of a Materials Research Society Fall Meeting and Symposium, Boston, MA, November 27-December 1, 1995. Materials Research Society, Pittsburgh, PA, Vol. 412, 957 pp.; (pp. 281-287) (1996)

In some radwaste applications, such as immobilization of Hanford Tank wastes using vitrification, $\mathrm{Tc}$ and $\mathrm{Cs} / \mathrm{Sr}$ are likely to be separated out from high-level waste supernates. Simplified Synroc preparations can be devised for the immobilization of separated $T_{c}$ and $\mathrm{Cs} / \mathrm{Sr}$, either together or individually. Under suitably reducing processing conditions, Tc can be immobilized as metal or Tc4. The volatility of $\mathrm{Tc}$ and $\mathrm{Cs} / \mathrm{Sr}$ in Synroc processing is very restricted. In Synroc-C, designed for Purex high-level reprocessing wastes, Tc exists as a metal alloy. In air-saturated water, normalized MCC-1 type total differential leach rates at $90 \mathrm{C}$ decreased with leaching time and after 90 days were less than $10(E-4) \mathrm{g} / \mathrm{sq} \mathrm{m} / \mathrm{d}$, decreasing by a factor of approximately 100 in anoxic conditions. The corresponding results in a $\mathrm{pH}=6.1$ buffer solution were fairly similar to those in deionized water, but in anoxic conditions, the leach rates were higher in the buffer solution than in the deionized water. A single perovskite phase was loaded with ca $40 \mathrm{wt} \%$ of $\mathrm{TcO} 2$ to form CaTc0.5-Ti0.5-03 by a combination of graphite-die hot-pressing and heating in argon. Rutile, intended to be doped with about $35 \mathrm{wt} \% \mathrm{TCO} 2$, was fabricated by bellows hot-pressing at 1,200 degrees $\mathrm{C}$; approximately $75 \%$ of the $\mathrm{Tc}$ formed a solid solution with rutile, but some metallic Tc was also present due to imperfect redox control. Results of both MCC-1 and PCT-type leach tests are presented on a preparation containing $70 \mathrm{wt} \%$ hollandite $+20 \mathrm{wt} \%$ perovskite $+10 \mathrm{wt} \%$ rutile containing about $5 \mathrm{wt} \%$ of $\mathrm{Cs}$ and $\mathrm{Sr}$ respectively. Phase distributions resulting from incorporating $\mathrm{Cs}$ and $\mathrm{Sr}$ in Synroc-B precursor were studied.
2099

V18/021727

Models and Strategies for Blending Nuclear Wastes to Minimize Immobilized Waste Volume

Hoza, M.

Pacific Northwest National Laboratory, Richland, WA

CONF-951155; Scientific Basis for Nuclear Waste Management, W.M. Murphy and D.A. Knecht (eds.), Proceedings of a Materials Research Society Fall Meeting and Symposium, Boston, MA, November 27-December 1, 1995. Materials Research Society, Pittsburgh, PA, Vol. 412, 957 pp.; (pp. 517-524) (1996)

Hanford tank waste will be separated into high-level and low-level portions; each portion will then be vitrified to produce a stable glass form for disposal. Because of the wide variability in the tank waste compositions, blending is being considered as a way to reduce the number of distinct compositions that must be vitrified and to minimize the resultant volume of vitrified waste. This paper discusses several approaches to blending and models developed to formulate blends for each approach. The models produce optimized blends which minimize the volume of glass required such that all composition and property constraints on the glass are satisfied. The paper will discuss several blending strategies and will provide the results of calculations comparing the approaches and strategies. Finally, an overall strategy for retrieving, blending, and vitrifying Hanford tank waste will be briefly discussed. Results of the calculations for high-level waste show that an effective blending strategy can greatly reduce the volume of glass required to immobilize the waste.

2100 V18/021599

Oxidative Dissolution of Chromium from Hanford Tank Sludges Under Alkaline Conditions

Rapko, B.M.; Lumetta, G.J.; Wagner, M.J.

Pacific Northwest Laboratory, Richland, WA

PNNL-11233; 19 pp. (July 1996)

Because of the expected high cost of vitrifying and disposing of high-level waste at the U.S. Department of Energy's Hanford Site, pretreatment processes are being developed to reduce the anticipated volume of borosilicate glass. Sludge washing and caustic leaching, the baseline sludge pretreatment process, is expected to leach out a substantial portion of the Cs-137, possibly other radionuclides, and a significant portion of such major nonradionuclides as $\mathrm{Al}$ or $\mathrm{P}$. The decontaminated solution will be routed to the low-level waste stream, where it will be immobilized in a glass matrix. The leached solids, which will contain the transuranic elements and $\mathrm{Sr}-90$, will be handled as high-level waste. Previous studies indicate that poor removal of chromium in the +3 oxidation state $\mathrm{Cr}(\mathrm{III})$ occurs during baseline pretreatment. Because the concentration of $\mathrm{Cr}$ allowed in high level waste glass is low, a relatively small amount of $\mathrm{Cr}$ in the sludge can have a relatively large impact on the volume of high level waste glass produced. For this reason, additional leach steps to remove $\mathrm{Cr}$ would be desirable, and oxidative alkaline leaching has been proposed as a simple addition to the baseline sludge pretreatment. This report describes small-scale screening tests on the oxidative alkaline leaching of $\mathrm{Cr}$ performed with actual Hanford tank sludges. 
2101

V18/022191

Selective Crystallization of Tank Supernatant Liquid

Herting, D.L.

Pacific Northwest National Laboratory, Richland, WA

PNNL-SA-27105; CONF-960158; Efficient Separation and Processing Crosscutting Program, Proceedings of the 1996 Technical Exchange Meeting, Gaithersburg, MD, January 16-19, 1996, 52 pp.; (pp. 109-111) (1996)

The objective of this task is to demonstrate the feasibility of selectively removing sodium nitrate (NaNO3) from Hanford Site tank waste by a large-scale fractional crystallization process. Two thirds of all the nuclear waste stored in Hanford's underground storage tanks is sodium nitrate (mass basis, excluding water). Fractional crystallization can remove essentially nonradioactive NaNO3 and other sodium salts from the waste, thereby reducing the volume of low-level waste glass by as much as 90 percent.

2102 V18/021601

Summary of FY-95 NIR Moisture Measurement Development and Implementation Activities

Reich, F.R.; Rebagay, T.V.; Dodd, D.A.; Lopez, T.; Watts, J.K.

Westinghouse Hanford Company, Richland, WA

WHC-SD-WM-RPT-191; 76 pp. (September 29, 1995)

This report summarizes the work completed in FY-95 in preparing a nonionizing radiation (NIR) moisture probe for early hot cell deployment. This work was completed by a team from Westinghouse Hanford Company's Process Analytical Labs and Tank Technology Projects organizations and was funded by EM- 50 office of Technology Development and EM-30's Tank Waste Remediation Systems Programs.

\section{$2103 \quad$ V18/022605}

TWRS Privatization - Phase I: Waste Characterization Data Evaluation for the Request for Proposal

Patello, G.K.; Wiemers, K.D.

Pacific Northwest National Laboratory, Richland, WA PNNL-11109; 107 pp. (September 1996)

Radioactive wastes have been stored in large underground tanks at Hanford since 1944. In 1991, The Tank Waste Remediation System (TWRS) program was established to manage, retrieve, treat, immobilize, and dispose of these wastes in a safe, effective manner. DOE believes that it is feasible to privatize portions of the TWRS program. Under the Privatization strategy embodied in the request for proposal, DOE will purchase services from a contractor-owned, contractor-operated facility under a fixed-price type of contract. Phase I is a proof-of-concept/commercial demonstration-scale effort. The method used to achieve the objective of producing a technically reviewed inventory is outlined. Organic speciation and physical properties data were gathered for the tank wastes and may be found in the individual tank section of this document. Reference reviews and tank volume and sampling summary graphs are also provided for each tank.
2104

V18/022192

Tank Leak Detection Using Electrical Resistance Methods

Ramirez, A.L.; Daily, W.D.; Binley, A.; LaBrecque, D.J.

Lawrence Livermore National Laboratory, Livermore, CA; Lancaster University, Lancaster, United Kingdom; University of Arizona, Tucson, $A Z$

CONF-960477; SAGEEP '96, R.S. Bell and M.H. Cramer (eds.), Proceedings of the Ninth Annual Symposium on the Application of Geophysics to Engineering and Environmental Problems, Denver, CO, April 15-May 1, 1996. Environmental and Engineering Geophysical Society, Wheat Ridge, CO, 1353 pp.; (pp. 763-772) (1996)

Two field experiments were performed to evaluate the performance of electrical resistance tomography (ERT) as a leak detection method under metal underground storage tanks (UST). This paper provides a summary of the field experiments performed under a 15 m diameter steel tank mockup located at the Hanford Reservation, Washington. Two different leak events were created. About 3800 liters of saline solution were first released along a portion of the tank's edge and another 1900 liters were later released near the tank's center. The release rate averaged about 26 liters/hour for the leak on the tank's side and about 3.0 liters/hour for the center leak. Two and three dimensional tomographs were calculated using data collected before, during and after each spill. The tomographs show that, as the solution penetrated the soil, readily detectable resistivity decreases appeared where the associated plume was expected. The results indicate that the plume associated with these releases could be reliably detected after approximately 190 liters were released. Results are also shown where the metal tank is used as a large electrode.

2105

V18/021602

Tank Waste Remediation System Heat Stress Control Program Report - 1995

Carls, D.R.

Westinghouse Hanford Company, Richland, WA

WHC-SD-WM-RPT-190; 79 pp. (September 28, 1995)

Protecting employees from heat stress within tank farms during the summer months is challenging. Work constraints typically experienced in tank farms complicate the measures taken to protect employees from heat stress. TWRS-Industrial Hygiene (IH) has endeavored to control heat stress injuries by anticipating, recognizing, evaluating and controlling the factors which lead or contribute to heat stress in Tank Farms. The TWRS Heat Stress Control Program covers such areas as employee training, communication of daily heat stress alerts to tank farm personnel, setting work/rest regimens, and the use of engineering and personal protective controls when applicable. The program has increased worker awareness of heat stress and prevention, established provisions for worker rest periods, increased drinking water availability to help ensure worker hydration, and allowed for the increased use of other protective controls to combat heat stress. The TWRS Heat Stress Control Program is the comerstone for controlling heat stress among tank farm employees. The program has made great strides since it's inception during the summer of 
1994. Some improvements can still be made to enhance the program for the summer of 1996 , such as (1) procurement and use of personal heat stress monitoring equipment to ensure appropriate application of administrative controls, (2) decrease the need for use of containment tents and anti-contamination clothing, and (3) providing a wider variety of engineering and personal protective controls for heat stress prevention.

\section{6}

\section{V18/022822}

\section{Remote Integrity Assessment of a Radioactive} Hazardous Waste Tank System

McCoy, M.W.; Knight, T.

Pacific Northwest National Laboratory, Richland, WA; Inuktun Services, Limited, Cedar, British Columbia, Canada

CONF-960804 (Vol. 3); Spectrum '96: Nuclear and Hazardous Waste Management, Proceedings of an International Topical Meeting, Seattle, WA, August 18-23, 1996. American Nuclear Society, La Grange Park, IL, Vol. 3, 841 pp.; (pp. 1860-1867) (1996)

In 1987 the State of Washington received authorization under the Resource Conservation and Recovery Act to regulate radioactive waste tanks as part of the state hazardous waste management program. This change in regulation required an integrity assessment of all radioactive hazardous waste tanks. Some of these tanks stored highly radioactive waste and were located in vaults that precluded standard integrity assessment techniques. Such assessments commonly require visual inspection and nondestructive examination of the tank system, including ancillary equipment and secondary containment structures. Four commercially available robots were used to transport and position video camera systems within the vault containing a radioactive hazardous tank system. Spotter robots and a telepresence video camera system were used to aid in precise robot navigation. Before the inspection, existing information on the tank system was assembled and used to create a computer simulation and full-scale mockup of the vault and tank system.

\section{7}

V18/022401

Acquire Commercial Technology for Retrieval Fiscal Year 1996 Summary and Highlights, September 1996

Berglin, E.J.; McDaniel, L.B.; Young, J.A.

SGN Eurisys Services Corporation, Richland, WA; Numatec Hanford Corporation, Richland, WA; Pacific Northwest Laboratory, Richland, WA

\section{WHC-SD-RPT-269; 35 pp. (October 1996)}

The US DOE is currently committed to retrieving the waste from all 149 single-shell tanks (SSTs) at the Hanford Site. The Acquire Commercial Technology for Retrieval (ACTR) program element was established in June 1995 in an effort to understand the costs and risks associated with retrieval and to reduce the risk to planned privatization efforts. The ACTR effort is designed to identify and test innovative, commercially available or adaptable retrieval system equipment, concepts, and contracting strategies that will add to existing Hanford Site technology and significantly reduce cost and/or risk as compared with the baseline retrieval approach of sluicing the waste from SSTs onsite. This document provides an overview of the program including: vendor survey; information databases; test and activities summary; alternative technology tests; and, double-shell tank waste retrieval. The appendices contain the test descriptions and information sources.

2108

V18/022086

Calculation of Radiation Fields for Hanford Tank Riser Modifications

Schwarz, R.A.; Carter, L.L.; Hillesland, K.E.

Westinghouse Hanford Company, Richland, WA

CONF-941148 (Vol. 2); DDER-'94: Decommissioning, Decontamination, and Environmental Restoration at Contaminated Nuclear Sites, M.G. White (ed.), Proceedings of an Embedded Topical Symposium of the American Nuclear Society Winter Meeting, Washington, DC, November 13-18, 1994. American Nuclear Society, Inc., La Grange Park, IL, Vol. 2, 241 pp.; (pp. 345-349) (1994)

Work is in progress at the Hanford Site to characterize the dose rates associated with waste tank operations. It is necessary to predict the dose rates likely to be encountered when pumps or other apparatus are installed or removed. A visualization process has been created to animate the dose rates from radiation sources as the source and shielding configuration are modified. This process has been illustrated with the removal of a mixer pump from a Hanford Site waste tank.

\section{9}

\section{V18/021607}

Mechanisms of Gas Generation from Simulated SY Tank Farm Wastes: FY 1995 - Progress Report

Barefield, E.K.; Boatright, D.; Deshpande, A.; Doctorovich, F.; Liotta, C.L.; Neumann, H.M.; Seymore, S.

Pacific Northwest Laboratory, Richland, WA

PNNL-1 1247; 86 pp. (July 1996)

The objective of this work is to develop a better understanding of the mechanism of formation of flammable gases in the thermal decomposition of metal complexants such as HEDTA and sodium glycolate in simulated SY tank farm waste mixtures. This report summarizes the results of work done at the Georgia Institute of Technology (GIT) in fiscal year 1995. Topics discussed are (1) long-term studies of the decomposition of HEDTA in simulated waste mixtures under an argon atmosphere at 90 and 120 degrees $C$, including time profiles for disappearance of HEDTA and appearance of products and the quantitative analysis of the kinetic behavior; (2) considerations of hydroxylamine as an intermediate in the production of nitrogen containing gases by HEDTA decomposition; (3) some thoughts on the revision of the global mechanism for thermal decomposition of HEDTA under argon; (4) preliminary long-term studies of the decomposition of HEDTA in simulated waste under an oxygen atmosphere at 120 degrees $C ;(5)$ estimation of the amount of NH3 in the gas phase above HEDTA reaction mixtures; and (6) further examination of the interaction of aluminum with nitrite ions using Al-27 NMR spectroscopy. Section 2 of this report describes the work conducted over the last three years at GIT. Section 3 contains a discussion of the kinetic behavior of HEDTA under argon; Section 4 discusses the role of hydroxylamine. Thermal decomposition of HEDTA to ED3A is the 
subject of Section 5, and decomposition of HEDTA in simulated waste mixtures under oxygen is covered in Section 6 . In Section 7 the authors estimate ammonia in the gas phase; the role of aluminum is discussed in Section 8.

\section{0}

V18/021539

Modeling Needs Assessment for Hanford Tank Farm Operations: Vadose Zone Characterization Project at the Hanford Tank Farms

Rust Geotech, Inc., Grand Junction, CO

DOE/DD/12584-252; 51 pp. (April 1996)

This report presents the results of a modeling needs assessment conducted for Tank Farm Operations at the Hanford Site. The goal of this project is to integrate geophysical logging and subsurface transport modeling into a broader decision-based framework that will be made available to guide Tank Farm Operations in implementing future modeling studies. In support of this goal, previous subsurface transport modeling studies were reviewed, and stakeholder surveys and interviews were completed (1) to identify regulatory, stakeholder, and Native American concerns and the impacts of these concerns on Tank Farm Operations; (2) to identify technical constraints that impact site characterization and modeling efforts; and (3) to assess how subsurface transport modeling can best be used to support regulatory, stakeholder, Native American, and Tank Farm Operations needs. This report is organized into six sections. Following an introduction, Section 2.0 discusses background issues that relate to Tank Farm Operations. Section 3.0 summarizes the technical approach used to appraise the status of modeling and supporting characterization. Section 4.0 presents a detailed description of how the technical approach was implemented. Section 5.0 identifies findings and observations that relate to implementation of numerical modeling, and Section 6.0 presents recommendations for future activities.

\section{1}

\section{V18/022734}

\section{Privatization of Hanford's Tank Waste Remediation} System: A Progress Report

Kinzer, J.E.; Sohn, C.L.; Kearns, P.K.

U.S. Department of Energy, Richland Operations Office, Richland, WA; Pacific Northwest National Laboratory, Richland, WA

CONF-960804 (Vol. 1); Spectrum '96: Nuclear and Hazardous Waste Management, Proceedings of an International Topical Meeting, Seattle, WA, August 18-23, 1996. American Nuclear Society, La Grange Park, Il, Vol. 1, 887 pp.; (pp. 742-746) (1996)

The U.S. Department of Energy (DOE) is in the process of procuring privatized services for the cleanup of a portion of the highly radioactive tank waste (waste) contained in large underground storage tanks at the Hanford Site near Richland, Washington. This RCRA regulated cleanup activity is governed under the Hanford Federal Facility Agreement and Consent Order, otherwise known as the Tri-Party Agreement. Under the Tri-Party Agreement, DOE, the U.S. Environmental Protection Agency, and the Washington State Department of Ecology have agreed to a timetable for cleanup of the Hanford Site. The tank waste was generated from the production of plutonium for the nation's nuclear defense programs and has been accumulating at Hanford since 1944. Currently, there are approximately 55 million gallons of waste, containing an estimated 240,000 tons of process chemicals and 177 megacuries of radioactive elements, stored in 177 underground tanks. These caustic wastes are in the form of liquids, slurries, saltcakes, and sludge. In 1991, DOE established the Tank Waste Remediation System (TWRS) program to ensure that these wastes are managed, retrieved, treated, immobilized, and disposed of in a safe, environmentally sound, and cost-effective manner. The TWRS mission is to conceptualize, develop, design, construct, and operate the physical system and technologies necessary to retrieve the waste from the tanks and convert it into an immobilized form, such as vitrified waste, suitable for ultimate disposal.

\section{2}

V18/022923

Probabilistic Safety Assessment for Hanford High-Level Waste Tanks

MacFarlane, D.R.; Stack, D.W.; Kindinger, J.P.; Deremer, R.K.

Lawrence Livermore National Laboratory, Livermore, CA; PLG, Inc., Washington, DC

CONF-951006; Proceedings of an American Nuclear Society (ANS)

Winter Meeting, San Francisco, CA, October 29-November 1, 1995. ANS, La Grange Park, IL, 522 pp.; Transactions of the American Nuclear Society 73:52-53 (1995)

This paper gives results from the first comprehensive level-3 probabilistic safety assessment (PSA), including consideration of external events, for the Hanford tank farm (HTF). This work was sponsored by the U.S. Department of Energy/Environmental Restoration and Waste Management Division (DOE/EM). At the HTF, there are 177 underground tanks in 18 separate tank farms containing accumulated liquid/sludge/saltcake radioactive wastes from 50 years of weapons materials production activities. The total waste volume is approximately 60 million gallons, containing approximately 200 million $\mathrm{Ci}$ of radioactivity.

\section{3 \\ V18/021594}

Tank Waste Remediation System, Hanford Site, Richland, Washington: Final Environmental Impact Statement - Volume 5 (Appendices G, H, I, J, K)

U.S. Department of Energy, Richland Operations Office, Richland, WA; Washington State Department of Ecology, Waste Reduction, Recycling and Litter Control Program, Olympia, WA

DOE/EIS-0189 (Vol. 5); 475 pp. (August 1996)

This appendix describes the air dispersion modeling that was performed to assess the impacts on air quality resulting from normal operations associated with the various Tank Waste Remediation System (TWRS) alternatives. The analyses were conducted to accomplish the following objectives: (1) Compare the analyzed impacts of potential criteria pollutant releases against National Ambient Air Quality Standards and applicable Washington State regulations; (2) Compare the analyzed impacts of emissions of toxic and hazardous air pollutants against applicable Washington State regulations; and (3) Compare the analyzed impacts of emissions of radionuclides against applicable Washington State and Federal standards. This appendix contains sections which describe the proposed Hanford Site TWRS alternatives and discuss the dispersion 
models used in the analyses. The remaining sections describe the methodology of the modeling approach, the data used as input to the model (meteorology, source, and receptor parameters), and the results of the modeling effort.

\section{4 \\ V18/021595}

Tank Waste Remediation System, Hanford Site, Richland, Washington: Final Environmental Impact Statement - Volume 2 (Appendices A, B, C)

U.S. Department of Energy, Richland Operations Office, Richland, WA; Washington State Department of Ecology, Waste Reduction, Recycling and Litter Control Program, Olympia, WA

DOE/EIS-0189 (Vol. 2); 293 pp. (August 1996)

This appendix provides the inventory of waste addressed in this Environmental Impact Statement (EIS). The inventories consist of waste from the following four groups: (1) tank waste; (2) cesium (Cs) and strontium (Sr) capsules; (3) inactive miscellaneous underground storage tanks (MUSTs); and (4) anticipated future tank waste additions. The major component by volume of the overall waste is the tank waste inventory (including future tank waste additions). This component accounts for more than 99 percent of the total waste volume and approximately 70 percent of the radiological activity of the four waste groups identified previously. Tank waste data is available on a tank by tank basis, but the accuracy of this data is suspect because it is primarily based on historical records of transfers between tanks rather than statistically based sampling and analyses programs. However, while the inventory of any specific tank may be suspect, the overall inventory for all of the tanks combined is considered more accurate. The tank waste inventory data is provided as the estimated overall chemical masses and radioactivity levels for the single-shell tanks (SSTs) and double-shell tanks (DSTs). The tank waste inventory data is broken down into tank groupings or source areas that were developed for analyzing groundwater impacts.

\section{$2115 \quad$ V18/021596}

Tank Waste Remediation System, Hanford Site, Richland, Washington: Final Environmental Impact Statement - Volume 4 (Appendices E, F)

U.S. Department of Energy, Richland Operations Office, Richland, WA; Washington State Department of Ecology, Waste Reduction, Recycling and Litter Control Program, Olympia, WA

DOE/EIS-0189 (Vol. 4); 667 pp. (August 1996)

This appendix describes the current safety concerns associated with the tank waste and analyzes the potential accidents and associated potential health effects that could occur under the alternatives included in this Tank Waste Remediation System (TWRS) Environmental Impact Statement (EIS).
2116
V18/021597

Tank Waste Remediation System, Hanford Site, Richland, Washington: Final Environmental Impact Statement - Volume 3 (Appendix D)

U.S. Department of Energy, Richland Operations Office,
Richland, WA; Washington State Department of Ecology, Waste Reduction, Recycling and Litter Control Program, Olympia, WA

DOE/EIS-0189 (Vol. 3); 658 pp. (August 1996)

This appendix describes the analysis of anticipated risk for the Tank Waste Remediation System (TWRS) Environmental Impact Statement (EIS). Risk is defined as the number or degree of human health or ecological effects from exposure to radiation and chemicals resulting from TWRS activities during and after remediation. The mission of TWRS is to manage and dispose of TWRS waste, including current and future tank waste, associated inactive miscellaneous underground storage tanks (IMUST), and cesium (Cs) and strontium (Sr) capsules in an environmentally sound, safe, secure, and cost-effective manner. Sections D.1.0 through D.5.0 of this appendix address the methodology and results of the human health risk assessment. Section D.6.0 presents the methodology and results of the ecological risk assessment. Section D.7.0 presents the methodology and results of the assessment of risks from inadvertent human intrusion into the residual waste after remedial actions are complete.

2117 V18/021598

Tank Waste Remediation System, Hanford Site, Richland, Washington: Final Environmental Impact Statement - Volume 1

U.S. Department of Energy, Richland Operations Office, Richland, WA; Washington State Department of Ecology, Waste Reduction, Recycling and Litter Control Program, Olympia, WA

DOE/EIS-0189 (Vol. 1); 638 pp. (August 1996)

This document analyzes the potential environmental consequences related to the Hanford Site Tank Waste Remediation System (TWRS) alternatives for management and disposal of radioactive, hazardous, mixed waste and the management and disposal of approximately 1,930 cesium and strontium capsules located at the Hanford Site. This waste is currently or projected to be stored in 177 underground storage tanks and approximately 60 miscellaneous underground storage tanks. This document analyzes the following altematives for remediating the tank waste: No Action, Long-Term Management, In Situ Fill and Cap, In Situ Vitrification, Ex Situ Intermediate Separations, Ex Situ No Separations, Ex Situ Extensive Separations, Ex Situ/In Situ Combination 1, and Ex Situ/ln Situ Combination 2. This document also addresses a Phased Implementation alternative (the DOE and Ecology preferred altemative for remediation of tank waste). Alternatives analyzed for the cesium and strontium capsules include: No Action, Onsite Disposal, Overpack and Ship, and Vitrify with Tank Waste. The DOE and Ecology preferred alternative for the cesium and strontium capsules is the No Action Altemative.

2118

V18/022869

Vadose Zone Characterization Project at the Hanford Tank Farms: BY Tank Farm Report

U.S. Department of Energy, Grand Junction Office, Grand Junction, $C O$

GJO-96-2-TAR; GJO-HAN-6; 240 pp. (February 1997) 
The U.S. Department of Energy Grand Junction Office (GJO) was tasked by the DOE Richland Operations Office (DOE-RL) to perform a baseline characterization of the contamination distributed in the vadose zone sediment beneath and around the single-shell tanks (SSTs) at the Hanford Site. The intent of this characterization is to determine the nature and extent of the contamination, to identify contamination sources, and to develop a baseline of the contamination distribution that will permit future data comparisons. This characterization work also allows an initial assessment of the impacts of the vadose zone contamination as required by the Resource Conservation and Recovery Act (RCRA). This characterization project involves acquiring information about the vadose zone contamination with borehole geophysical logging methods and documenting that information in a series of reports. Data from boreholes surrounding each tank are compiled into individual Tank Summary Data Reports. The data from each tank farm are then compiled and summarized in a Tank Farm Report. This document is the Tank Farm Report for the BY Tank Farm. Prepared as a part of this characterization project, the BY Tank Farm Report is the final document that presents an overall perspective of the vadose zone contamination in the entire BY Tank Farm. This report describes the vadose zone contamination with empirical three-dimensional models of the contamination developed from the log data and places the information into the appropriate geotechnical context.

\section{$2119 \quad$ V18/022944}

SX Tank Farm Report: Vadose Zone Characterization Project at the Hanford Tank Farms

Rust Geotech, Inc., Grand Junction, $C O$

DOE/ID/12584-268; GJPO-HAN-4; 225 pp. (September 1996)

The U.S. Department of Energy Grand Junction Projects Office (GJPO) was tasked by the DOE Richland Operations Office (DOE-RL) to perform a baseline characterization of the contamination distributed in the vadose zone sediment beneath and around the single-shell tanks (SSTs) at the Hanford Site. The intent of this characterization is to determine the nature and extent of the contamination, to identify contamination sources, and to develop a baseline of the contamination distribution that will permit future data comparisons. This characterization work also allows an initial assessment of the impacts of the vadose zone contamination as required by the Resource Conservation and Recovery Act (RCRA). This characterization project involves acquiring information about the vadose zone contamination with borehole geophysical logging methods and documenting that information in a series of reports. Data from boreholes surrounding each tank are compiled into individual Tank Summary Data Reports. The data from each tank farm are then compiled and summarized in a Tank Farm Report. This document is the Tank Farm Report for the SX Tank Farm.

2120

V18/024846

Comprehensive Analysis of Contaminant Transport in the Vadose Zone Beneath Tank SX-109

Ward, A.L.; Gee, G.W.; White, M.D.

Pacific Northwest National Laboratory, Richland, WA

PNL-1 1463; 45 pp. (February 1997)

The Vadose Characterization Project is currently investigating the subsurface distribution of gamma-emitting radionuclides in S and SX Waste Management Area (WMA-S-SX) located in the 200 West Area of the U.S. Department of Energy's Hanford Site in southeastern Washington State. Spectral-gamma logging of boreholes has detected elevated Cs-137 concentrations as deep as 38 $m$, a depth considered excessive based on the assumed geochemistry of Cs-137 in Hanford sediments. Routine groundwater sampling under the Resource Conservation and Recovery Act (RCRA) has also detected elevated levels of site-specific contaminants downgradient of WMA-S-SX. The objective of this report is to explore the processes controlling the migration of Cs-137, Tc-99, and $\mathrm{NO}\left(3^{-}\right)$though the vadose zone of WMA-S-SX, particularly beneath tank SX-109. A series of hypothetical cases was simulated using STOMP, a multi-dimensional flow and transport simulator. Since information concerning actual values of many input parameters is mostly lacking, a wide range of possibilities is examined to provide a range of possible outcomes. A parametric analysis is used to isolate the most critical parameters so that these parameters can be studied further.

\section{1}

V18/021600

Ferrocyanide Safety Project: Ferrocyanide Aging Studies - Final Report

Lilga, M.A.; Hallen, R.T.; Alderson, E.V.
Pacific Northwest Laboratory, Richland, WA
PNNL-11211; 78 pp. (June 1996)

This final report gives the results of the work conducted by Pacific Northwest National Laboratory (PNNL) from FY 1992 to FY 1996 on the Ferrocyanide Aging Studies, part of the Ferrocyanide Safety Project. The Ferrocyanide Safety Project was initiated as a result of concern raised about the safe storage of ferrocyanide waste intermixed with oxidants, such as nitrate and nitrite salts, in Hanford Site single-shell tanks (SSTs). In the laboratory, such mixtures can be made to undergo uncontrolled or explosive reactions by heating dry reagents to over 200 degrees C. In 1987, an Environmental Impact Statement (EIS), published by the U.S. Department of Energy (DOE), "Final Environmental Impact Statement, Disposal of Hanford Defense High-Level Transuranic and Tank Waste, Hanford Site, Richiand, Washington," included an environmental impact analysis of potential explosions involving ferrocyanide-nitrate mixtures. The EIS postulated that an explosion could occur during mechanical retrieval of saltcake or sludge from a ferrocyanide waste tank, and concluded that this worst-case accident could create enough energy to release radioactive material to the atmosphere through ventilation openings, exposing persons offsite to a short-term radiation dose of approximately $200 \mathrm{mrem}$. Later, in a separate study (1990), the General Accounting Office postulated a worst-case accident of one to two orders of magnitude greater than that postulated in the DOE EIS. The uncertainties regarding the safety envelope of the Hanford Site ferrocyanide waste tanks led to the declaration of the Ferrocyanide Unreviewed Safety Question (USQ) in October 1990.

Gas Release During Salt Well Pumping: Model Predictions and Comparisons to Laboratory Experiments Peurrung, L.M.; Caley, S.M.; Bian, E.Y.; Gauglitz, P.A. 
Pacific Northwest National Laboratory, Richland, WA

PNNL-11310; 75 pp. (September 1996)

The Hanford Site has 149 single-shell tanks (SSTs) containing radioactive wastes that are complex mixes of radioactive and chemical products. Some of these wastes are known to generate mixtures of flammable gases, including hydrogen, nitrous oxide, and ammonia. Nineteen of these SSTs have been placed on the Flammable Gas Watch List (FGWL) because they are known or suspected, in all but one case, to retain these flammable gases. Salt well pumping to remove the interstitial liquid from SSTs is expected to cause the release of much of the retained gas, posing a number of safety concerns. Research at the Pacific Northwest National Laboratory (PNNL) has sought to quantify the release of flammable gases during salt well pumping operations. This study is being conducted for Westinghouse Hanford Company as part of the PNNL Flammable Gas Project. Understanding and quantifying the physical mechanisms and waste properties that govern gas release during salt well pumping will help to resolve the associated safety issues.

\section{3}

V18/021606

Remediation and Cleanout Levels for Hanford Site Single-Shell Tanks

Boothe, G.F.

Westinghouse Hanford Company, Richland, WA WHC-SD-WM-TI-711; 126 pp. (1995)

The Hanford Federal Facility Agreement and Consent Order (Tri-Party Agreement), requires the retrieval of 99 percent of the Hanford Site single-shell tank (SST) waste. Retrieval of the waste requires the completion of saltwell pumping and then the sluicing of all 149 tanks, at a cost of over $\$ 3$ billion. The retrieved waste is to be processed and vitrified for ultimate disposal as glass. This document shows that the intent of the Tri-Party Agreement can be met by sluicing the waste from only 86 tanks, after the completion of saltwell pumping. This partial retrieval option will result in a cost savings of over $\$ 600$ million in construction and operation alone, and will significantly reduce the volume of glass requiring disposal.

\section{$2124 \quad$ V18/022606}

Summary of Tank Information Relating Salt Well Pumping to Flammable Gas Safety Issues

Caley, S.M.; Mahoney, L.A.; Gauglitz, P.A.

Pacific Northwest National Laboratory, Richland, WA

PNNL-1 1335; 74 pp. (September 1996)

The Hanford Site has 149 single-shell tanks (SSTs) containing radioactive wastes that are complex mixes of radioactive and chemical products. Active use of these SSTs was phased out completely by November 1980 , and the first step toward final disposal of the waste in the SSTs is interim stabilization, which involves removing essentially all of the drainable liquid from the tank. Stabilization can be achieved administratively by jet pumping to remove drainable interstitial liquid or by supernatant pumping. To date, 116 tanks have been declared interim stabilized; 44 SSTs have had drainable liquid removed by salt well jet pumping. Of the 149 SSTs, 19 are on the Flammable Gas Watch List (FGWL) because the waste in these tanks is known or suspected, in all but one case, to generate and retain mixtures of flammable gases, including hydrogen, nitrous oxide, and ammonia. Salt well pumping to remove the drainable interstitial liquid from these SSTs is expected to cause the release of much of the retained gas, posing a number of safety concerns. The scope of this work is to collect and summarize information, primarily tank data and observations, that relate salt well pumping to flammable gas safety issues. While the waste within FGWL SSTs is suspected of involving flammable gases, the effect of salt well pumping on the waste behavior is not well understood. This study is being conducted for the Westinghouse Hanford Company as part of the Flammable Gas Project at the Pacific Northwest National Laboratory (PNNL). Understanding the historical tank behavior during and following salt well pumping will help to resolve the associated safety issues.

2125

V18/021386

\section{Hanford Tank Initiative: A Joint EM-30/EM-50 Effort}

Wodrich, D.

U.S. Department of Energy, Richland Operations Office, Richland, WA

Fostering the Needed Partnerships: Doing the Necessary Science to Support Technology Development, Commercialization, Deployment, E.L. Helminski (ed.), Proceedings of the Seventh Annual Western Governors' Association/Weapons Complex Monitor Applied Research and Cleanup Technology Colloquium, Phoenix, AZ, April 29-May 2, 1996. Exchange/Monitor Publications and Forums, Lake Bluff, IL, 500 pp.; (25 pp.) (April 1996)

This presentation focuses on the technologies and costs to remove single-shell tank waste to the extent needed for tank closure. These viewgraphs and outline highlight the need for a demonstration program by examining the following areas: the problems involved in removal; technical and programmatic objectives; the scope of the demonstration, plans for accomplishing the demonstration; and anticipated results.

\section{6 \\ $\mathrm{V} 18 / 024280$}

241-SY-101 Strain Concentration Factor Development via Nonlinear Analysis: Volume 1 of 1

Los Alamos National Laboratory, Los Alamos, NM; Advent Engineering Services, Inc., San Ramon, CA

LA-SUB-93-260; 133 pp. (1997)

The 241-SY-101 waste storage tank at the Hanford-Site has been known to accumulate and release significant quantities of hydrogen gas. An analysis was performed to assess the tank's structural integrity when subjected to postulated hydrogen deflagration loads. The analysis addressed many nonlinearities and appealed to a strain-based failure criteria. The model used to predict the global response of the tank was not refined enough to confidently predict local peak strains. Strain concentration factors were applied at structural discontinuities that were based on steel-lined reinforced-concrete containment studies. The discontinuities included large penetrations, small penetrations, springline geometries, stud/liner connections, and the $1 / 2$ inch to $3 / 8$ inch liner thickness transition. The only tank specific strain concentration factor applied in the evaluation was for the $1 / 2$ inch to $3 / 8$ inch liner thickness change in the dome. Review of the tank 
drawings reveals the possibility that a 4 inches Sch. 40 pipe penetrates the dome thickness transition region. It is not obvious how to combine the strain concentration factors for a small penetration with that of a thickness transition to arrive at a composite strain concentration factor. It is the goal of this effort to make an approximate determination of the relative significance of the 4 inch penetration and the $1 / 2$ inch to $3 / 8$ inch thickness transition in the 241-SY-101 dome geometry. This is accomplished by performing a parametric study with three general finite-element models. The first represents the thickness transition only, the second represents a 4 inch penetration only, and the third combines the thickness transition with a penetration model.

\section{7}

V18/022719

Ion Exchange Removal of Cesium from Stimulated and Actual Hanford Tanks 241-SY-101 and 241-SY-103

Kurath, D.E.; Brown, G.N.; Herting, D.L.

Pacific Northwest Laboratory, Richland, WA; Westinghouse Hanford Company, Richland, WA

CONF-960804 (Vol. 1); Spectrum '96: Nuclear and Hazardous Waste Management, Proceedings of an Intemational Topical Meeting, Seattle, WA, August 18-23, 1996. American Nuclear Society, La Grange Park, IL, Vol. 1, 887 pp.; (pp. 222-228) (1996)

Several Cs ion exchange process cycles were conducted using simulant and actual wastes from Hanford tanks 241-SY-101 and 24I-SY-103. The experiments were conducted using single small columns containing approximately $12 \mathrm{~mL}$ of CS-100, a Cs-selective phenol-formaldehyde resin purchased from Rhom and Haas. Simulants were developed on the basis of available analytical data and tested before the actual wastes. Process steps included loading, washing, elution, and regeneration. Loading and elution profiles for cesium and a number of minor waste components are presented.

\section{8}

V18/021605

Development of In-Structure Design Spectra for Dome Mounted Equipment on Underground Waste Storage Tanks at the Hanford Site

Julyk, L.J.

Westinghouse Hanford Company, Richland, WA; ICF Kaiser Hanford Company, Richland, WA

WHC-SD-WM-TI-713; 61 pp. (September 1995)

In-structure response spectra for dome mounted equipment on underground waste storage tanks at the Hanford Site are developed on the basis of recent soil-structure-interaction analyses.

Recommended design spectra are provided for various locations on the tank dome.

2129

VI8/025543

Estimated Heat Load Using the Average Vapor Space Temperatures for the Hanford Site Underground Storage Tanks

Crowe, R.D.; Maassen, D.P.; Parra, S.A.

Westinghouse Hanford Company, Richland, WA

CONF-960804 (Vol. 3); Spectrum '96: Nuclear and Hazardous Waste Management, Proceedings of an International Topical
Meeting, Seattle, WA, August 18-23, 1996. American Nuclear Society, La Grange Park, IL, Vol. 3, 841 pp.; (pp. 2371-2375) (1996)

A better method for estimating the heat load from the Hanford Site underground high-level radioactive waste storage tanks has been developed. This method is based on correlating the seasonal atmospheric temperature variations to the measured vapor space waste temperatures inside the tank. The seasonal variations in the atmospheric temperature can be used to estimate the thermal conductivity of the soil surrounding the underground tank. The daily surface temperature oscillations, from day to night, do not affect the soil more than $1 \mathrm{~m}$ below the surface while the yearly temperature oscillations, from summer to winter, affects the soil up to depths of $20 \mathrm{~m}$. By evaluating the amplitude or the phase shifts from the atmospheric temperature variations with respect to the vapor space temperature variations, the thermal conductivity of the soil surrounding the underground storage tanks can be determined. Using the thermal conductivity of the soil and geometrical properties of the tanks, the total heat load for each underground storage tank can be estimated.

V18/021610

Estimating Heel Retrieval Costs for Underground Storage Tank Waste at Hanford

DeMuth, S.F.

Los Alamos National Laboratory, Technology and Safety Division, Energy and Environmental Analysis Group, Los Alamos, NM

LA-UR-96-3038; 17 pp. (December 1996)

Approximately 100 million gallons (approx. $400,000 \mathrm{cu} \mathrm{m}$ ) of existing U.S. Department of Energy (DOE) ouned radioactive waste stored in underground tanks can not be disposed of as lou-level waste (LLW). The current plan for disposal of UST waste which can not be disposed of as LLW is immobilization as glass and permanen storage in an underground repository. Disposal of LLW generally can be done sub-surface at the point of origin. Consequently, LLW is significantly less expensive to dispose of than that requiring an underground repository. Due to the lower cost for LLW disposal, it is advantageous to separate the 100 million gallons of waste into a small volume of high-level waste (HLW) and a large volume of LLW.

2131

V18/025540

Functions and Requirements for the Light-Duty Utility Arm Integrated System [Rev. 1]

Kiebel, G.R.

Westinghouse Hanford Company, Richland, WA

WHC-SD-TD-FRD-003 (Rev. 1); 34 pp. (January 25, 1996)

The Light Duty Utility Arm (LDUA) Integrated System is a mobile robotic system designed to remotely deploy and operate a variety of tools in uninhabitable underground radiological and hazardous waste storage tanks. The system primarily provides a means to inspect, survey, monitor, map and/or obtain specific waste and waste tank data in support of the Tank Waste Remediation System (TWRS) mission at Hanford and remediation programs at other U.S. Department of Energy (DOE) sites. 


\section{2}

V18/021612

Investigation into the Chemical, Thermal and Radiological Changes of Organic Chemicals Added to the Underground Storage Tanks at Hanford

Samuels, W.D.; Camaioni, D.M.; Clauss, S.A.; Linehan, J.C. Pacific Northwest Laboratory, Richland, WA

CONF-960376 (Part 1); Proceedings of the 211th American Chemical Society (ACS) National Meeting, New Orleans, LA, March 24-28, 1996. ACS, Washington, DC, Part 1, 1172 pp.; (p. 936, Paper I EC 129) (1996)

Uranium and plutonium production at the Hanford Site produced large quantities of radioactive by-products and contaminated process chemicals that are presently stored in underground tanks awaiting treatment and disposal. Having been made strongly alkaline and then subjected to successive water evaporation campaigns to increase storage capacity, the wastes now exist in the physical forms of salt cakes, metal oxide sludges, and saturated aqueous brine solutions. Those waste storage tanks containing organic process chemicals mixed with nitrate/nitrite salt wastes are thought to be at risk for fuel-nitrate combustion accidents. To support resolution of this potential hazard, we are studying how organic chemicals added to the tanks may have aged or changed under storage conditions. Simulated wastes have been irradiated with gamma rays at temperatures between ambient and 90 degrees $C$ and subsequently analyzed quantitatively. The presentation will report findings on the rates and products of organic degradation. Reaction mechanisms and implications of the findings will be discussed. (Complete text)

\section{3 \\ V18/025544}

Results of Modeling and Experimental Measurements for the Design of a Neutron Surface Moisture Measurement Sensor

Watson, W.T.; Harris, M.D.; Todd, A.K.

Westinghouse Hanford Company, Richland, WA

CONF-960804 (Vol. 2); Spectrum '96: Nuclear and Hazardous Waste Management, Proceedings of an International Topical Meeting, Seattle, WA, August 18-23, 1996. American Nuclear Society, La Grange Park, IL, Vol. 2, 873 pp.; (pp. 1257-1262)

(1996)

Computer modeling and experimental testing have been performed to produce a design for a neutron-moderation-based surface moisture sensor. Results indicate that this sensor should be capable of providing information about the moisture concentration profile in the top $15 \mathrm{~cm}$ of material. Tests show that the sensor should be capable of operating in the expected high temperature and gamma exposure rate fields within the Hanford Site tanks. A field-ready sensor and an in-tank deployment system are now being readied for application of this technology to the Hanford Site tank farms.

\section{$2134 \quad$ V18/024277}

Tank Waste Remediation System Characterization Project Programmatic Risk Management Plan

Baide, D.G.; Webster, T.L.

Westinghouse Hanford Company, Richland, WA; TRW, Inc., Redondo Beach, CA
WHC-SD-WM-PMP-019; 24 pp. (December 1995)

The Tank Waste Remediation System (TWRS) Characterization Project has developed a process and plan in order to identify, manage and control the risks associated with tank waste characterization activities. The result of implementing this process is a defined list of programmatic risks (i.e., a risk management list) that is used by the Project as management tool. This concept of a risk management process is a commonly used systems engineering approach which is being applied to all TWRS program and project elements. The Characterization Project risk management plan and list are subsets of the overall TWRS risk management plan and list.

2135 V18/023025

Tank Waste Remediation System Characterization Project Quality Policies [Rev. 1]

Trimble, D.J.

Westinghouse Hanford Company, Richland, WA WHC-SD-WM-QAPP-025 (Rev. 1); 71 pp. (October 2, 1995)

These Quality Policies (QPs) describe the Quality Management System of the Tank Waste Characterization Project (hereafter referred to as the Characterization Project), Tank Waste Remediation System (TWRS), Westinghouse Hanford Company (WHC). The Quality Policies and quality requirements described herein are binding on all Characterization Project organizations. To achieve quality, the Characterization Project management team shall implement this Characterization Project Quality Management System.

\section{6 \\ V18/023023}

Tank Waste Remediation System Programmatic Risk Management Plan

Seaver, D.A.

Westinghouse Hanford Company, Richland, WA WHC-SD-WM-PMP-018; 21 pp. (October 31, 1995)

This risk management plan defines the approach to be taken to managing risks in the Tank Waste Remediation System (TWRS) program. It defines the actions to be taken at the overall program level, and the risk management requirements for lower-level projects and other activities. The primary focus of this plan is on programmatic risks, i.e., risks with respect to the cost, schedule, and technical performance of the program. The plan defines an approach providing managers with the flexibility to manage risks according to their specific needs, yet creates the consistency needed for effectiveness across the program. The basic risk management approach uses a risk management list for the program, each project, and additional lower-level activities. The risk management list will be regularly reviewed and updated by appropriate level of management. Each list defines key risks, their likelihood and consequences, risk management actions to be taken, responsible individuals, and other management information.

Tank Waste Remediation System Risk Management List

Collard, L.B. 
Westinghouse Hanford Company, Richland, WA WHC-SD-WM-RPT-201; 77 pp. (October 31, 1995)

The Tank Waste Remediation System (TWRS) Risk Management List and it's subset of critical risks, the Critical Risk Management List, provide a tool to senior Richland Operations (RL) and Westinghouse Hanford Company (WHC) management (Level-1 and -2) to manage programmatic risks that may significantly impact the TWRS program. The programmatic risks include cost, schedule, and performance risks. Performance risk includes technical risk, supportability risk (such as maintainability and availability), and extemal risk (i.e., beyond program control, for example, changes in regulations). The risk information includes a description, its impacts, as evaluation of the likelihood, consequences and risk value, possible mitigating actions, and responsible $R L$ and WHC managers. The issues that typically form the basis for the risks are presented in a separate table and the affected functions are provided on the management lists.

\section{$2138 \quad$ V18/025541}

Technetium in Alkaline, High-Salt, Radioactive Tank Waste Supernate: Preliminary Characterization and Removal

Blanchard, D.L., Jr.; Brown, G.N.; Conradson, S.D.

Pacific Northwest National Laboratory, Richland, WA

PNNL-11386; 51 pp. (January 1997)

This report describes the initial work conducted at Pacific Northwest National Laboratory to study technetium (Tc) removal from Hanford tank waste supernates and Tc oxidation states in the supernates. Filtered supernate samples from four tanks were studied: a composite double shell slurry feed (DSSF) consisting of $70 \%$ from Tank AW-101, 20\% from AP-106, and 10\% from AP-102; and three complexant concentrate (CC) wastes (Tanks AN-107, SY-101, ANS SY-103) that are distinguished by having a high concentration of organic complexants. The work included batch contacts of these waste samples with Reillex [TM]-HPQ (anion exchanger from Reilly Industries) and ABEC 5000 (a sorbent from Eichrom Industries), materials designed to effectively remove Tc as pertechnetate from tank wastes. A short study of Tc analysis methods was completed. A preliminary identification of the oxidation state of non-pertechnetate species in the supernates was made by analyzing the technetium $\mathrm{x}$-ray absorption spectra of four $\mathrm{CC}$ waste samples. Molybdenum (Mo) and rhenium (Re) spiked test solutions and stimulants were tested with electrospray ionization-mass spectrometry to evaluate the feasibility of the technique for identifying Tc species in waste samples.

V18/023027

Technology Development in Support of the Tank Waste Remediation System (TWRS) Process Flowsheet [Rev. 1]

Washenfelder, D.J.

Westinghouse Hanford Company, Richland, WA

WHC-SD-WM-DT- P-033 (Rev. 1); 168 pp. (October 11, 1995)

The Tank Waste Remediation System is to treat and dispose of Hanford's Single-Shell and Double-Shell Tank Waste. The TWRS Process Flowsheet document described a flowsheet based on a large number of assumptions and engineering judgments that require verification or further definition through process and technology development activities. This document takes off from the TWRS Process Flowsheet to identify and prioritize tasks that should be completed to strengthen the technical foundation for the flowsheet.

2140

V18/023460

Ultimate Hanford Challenge: Radioactive Waste Management of High-Level Radioactive Wastes Stored in Underground Tanks

Berriochoa, $M$.

Radwaste Magazine 3(3):18-24 (May 1996)

A pioneering project is underway to obtain samples of highly radioactive waste from giant underground storage tanks on the Hanford Reservation. The sampling is essential to clean up more than 55 million gallons of the waste stored for decades. The waste in the 177 storage tanks represents America's single largest environmental cleanup challenge. This article describes the history, the design challenges for sampling and how they were overcome, and the current status: full characterization of 10 tanks and samples from 121 of the 177 tanks.

\section{$2141 \quad$ V18/021611}

Washing and Caustic Leaching of Hanford Tank Sludges: Results of FY 1996 Studies

Lumetta, G.J.; Rapko, B.M.; Wagner, M.J.; Liu, J.; Chen, Y.L.

Pacific Northwest National Laboratory, Richland, WA

PNNL-1 1278; 115 pp. (August 1996)

During the past few years, the primary mission of the US DOE Hanford Site has changed from producing plutonium to restoring the environment. Large volumes of high-level radioactive wastes (HLW) generated during past Pu production and other operations are stored in underground tanks on site. The current plan for remediating the Hanford tank farms consists of waste retrieval, pretreatment, processing (immobilization), and disposal. The HLW will be immobilized in a borosilicate glass matrix, and the resulting glass canisters will then be disposed of in a geologic repository. Because of the expected high cost of HLW vitrification and geologic disposal, pretreatment processes will be implemented to reduce the volume of borosilicate glass in disposing of the tank wastes. This report describes the sludge washing and caustic leaching tests conducted at Pacific Northwest National Laboratory in FY 1996. These tests supported the development of the baseline Hanford tank sludge pretreatment flowsheet.

V18/021603

Work Plan for Defining a Standard Inventory Estimate for Wastes Stored in Hanford Site Underground Tanks

Kupfer, M.J.

Westinghouse Hanford Company, Richland, WA WHC-SD-WM-WP-311; 30 pp. (September 29, 1995)

This work plan addresses the methodology for defining a tank waste database that will provide a best basis estimate of waste characteristics for each underground storage tank. The resulting database is expected to be in place in a network accessible electronic 
form by September 1996.

$2143 \quad$ V18/023026

Life Management/Aging: 1995 Annual Report [Rev. 1]

Lindsay, D.C.

Westinghouse Hanford Company, Richland, WA

WHC-SD-WM-PRS-013 (Rev. 1); 17 pp. (October 5, 1995)

This report provides the 1995 status of the Life Management/Aging Management Program and the activities over the current fiscal year. It relates to the Tank Waste Remediation System and to the double shell tanks.

\section{$2144 \quad$ V18/025538}

Functional Design Criteria for the Self-Installing Liquid Observation Well [Rev. 3]

Parra, S.A.

Westinghouse Hanford Company, Richland, WA WHC-SD-WM-FDC-042 (Rev. 3); 21 pp. (January 1996)

This document presents the functional Design Criteria for installing liquid observation wells (LOWs) into single-shell tanks containing ferrocyanide and organic wastes. The LOWs will be designed to accommodate the deployment of gamma, neutron, and electromagnetic induction probes and to interface with the existing tank structure and environment.

\section{5 \\ V18/022718}

Hanford Single-Shell Underground Storage Tank Waste Retrieval Risk Reduction Through Leak Detection, Monitoring, and Mitigation

Peters, B.; Treat, R.; Iwatate, D.

Foster Wheeler Environmental Corporation, Richland, WA; Westinghouse Hanford Company, Richland, WA CONF-960804 (Vol. 1); Spectrum '96: Nuclear and Hazardous Waste Management, Proceedings of an Intemational Topical Meeting, Seattle, WA, August 18-23, 1996. American Nuclear Society, La Grange Park, IL, Vol. 1, 887 pp.; (pp. 214-221) (1996)

A trade study was performed to evaluate and compare leakage detection, monitoring, and mitigation (LDMM) technologies. The technologies were evaluated for feasibility of application at the Hanford Site, life-cycle cost of application, contribution to risk reduction (effectiveness), and the resulting cost-benefit of each technology.

\section{6 \\ V18/024278}

Tank Waste Remediation System Inactive Miscellaneous Underground Storage Tanks Program Plan

Gustavson, R.D.

Westinghouse Hanford Company, Richland, WA WHC-SD-WM-PD-046; 74 pp. (December 1995)

The Program Management Plan (PMP) describes the approach that will be used to manage the Tank Waste Remediation System (TWRS) Inactive Miscellaneous Underground Storage Tank
(IMUST) Program. The plan describes management, technical, and administrative control systems that will be used to plan and control the IMUSTs Program performance. The technical data to determine the IMUSTs status for inclusion in the Single Shell Tank Farm Controlled Clean and Stable (CCS) Program. The second is to identify and implement surveillance, characterization, stabilization, and modifications to support CCS prior to final closure.

\section{7}

\section{V18/025542}

Organic Tank Safety Project: Effect of Water Partial Pressure on the Equilibrium Water Contents of Waste Samples from Hanford Tank 241-BY-108

Scheele, R.D.; Bredt, P.R.; Sell, R.L.

Pacific Northwest National Laboratory, Richland, WA PNNL-11401; 43 pp. (February 1997)

Water content plays a crucial role in the strategy developed by Webb et al. to prevent propagating or sustainable chemical reactions in the organic-bearing wastes stored in the 20 Organic Tank Watch List tanks at the US Department of Energy's Hanford Site. Because of water's importance in ensuring that the organic-bearing wastes continue to be stored safely, Duke Engineering and Services Hanford commissioned the Pacific Northwest National Laboratory (PNNL) to investigate the effect of water partial pressure $(\mathrm{P}-\mathrm{H} 2 \mathrm{O})$ on the water content of organic-bearing or representative wastes. Of the various interrelated controlling factors affecting the water content in wastes, $\mathrm{P}-\mathrm{H} 2 \mathrm{O}$ is the most susceptible to being controlled. Hanford Site's environmental conditions, if necessary, could be managed to maintain the water content at an acceptable level or could be used to adjust the water content back to an acceptable level. Of the various waste types resulting from weapons production and waste-management operations at the Hanford Site, Webb et al. determined that saltcake wastes are the most likely to require active management to maintain the wastes in a Conditionally Safe condition. A Conditionally Safe waste is one that satisfies the waste classification criteria based on water content alone or a combination of water content and either total organic carbon (TOC) content or waste energetics. To provide information on the behavior of saltcake wastes, two waste samples taken from Tank 241-BY-108 (BY-108) were selected for study, even though BY-108 is not on the Organic Tanks Watch List, because of their ready availability and their similarity to some of the organic-bearing saltcakes.

\section{$2148 \quad$ V18/022488}

Application of Insitu Vitrification to DOE Underground Storage Tanks

Geosafe Corporation, Richland, WA

Report; 12 pp. (December 1995)

Within the U.S. Department of Energy (DOE) complex, 332 underground storage tanks (USTs) have been used to process radioactive and chemical mixed wastes generated from weapon materials production. Together, these tanks hold more than 100 million gallons of high-level and low-level radioactive liquid waste. The waste typically consists of several physical forms: sludge, supernate, and salt cake. Most of the waste is alkaline and contains the following chemical constituents: nitrate and nitrite salts (approximately half of the total wastes), hydrated metal oxides, 
phosphate precipitates, and ferrocyanides. A total of 640 million curies of radionuclides composed of transuranic (TRU) elements and fission products, primarily strontium- 90 and cesium-137, are distributed in these wastes. Radiation fields in these tanks can be as high as $10,000 \mathrm{rad} / \mathrm{h}$, which is 20 times the lethal exposure limit.

\section{9}

\section{V18/021615}

Batch and Column Tests of Novel Cesium Sorbents for the Remediation of Alkaline Tank Supernate

Hunt, R.D.; Bray, L.A.

Oak Ridge National Laboratory, Oak Ridge, TN; Pacific Northwest Laboratory, Richland, WA

CONF-960376 (Part 1); Proceedings of the 211th American Chemical Society (ACS) National Meeting, New Orleans, LA, March 24-28, 1996. ACS, Washington, DC, Part 1, 1172 pp.; (p. 954, Paper I EC 188) (1996)

Since most of the radioactivity from the supernate is due to Cs-137, the Department of Energy (DOE) sites with alkaline high level waste tanks have identified Cs removal as a very high priority need. Each of the currently implemented Cs removal processes has at least one inherent weakness such as a low Kd or potential vitrification problems. In response, a major technology development effort by the DOE and private industry has produced several new Cs sorbents that may be safer and more cost effective. These new sorbents such as SuperLig 644, resorcinol-formaldehyde, crystalline silicotitanate, and potassium cobalt hexacyanoferrate have been evaluated through batch and column tests at Oak Ridge National Laboratory and Pacific Northwest Laboratory. These test results and the plans for the 25,000-gal Cs Removal Demonstration at Oak Ridge will be discussed. (Complete text)

\section{$2150 \quad \mathrm{~V} 18 / 020606$}

Case Study to Remove Radioactive Hazardous Sludge from Long Horizontal Storage Tanks

Hylton, T.D.; Youngblood, E.L.; Cummins, R.L.

Oak Ridge National Laboratory, Oak Ridge, TN

CONF-9507119; Proceedings of the Summer National Meeting of the American Institute of Chemical Engineers, Boston, MA, July 30-August 2, 1995; (22 pp.) (1995)

The removal of radioactive hazardous sludge from waste tanks is a significant problem at several U.S. Department of Energy (DOE) sites. The use of submerged jets produced by mixing pumps lowered into the supematant/siudge interface to produce a homogeneous slurry is being studied at several DOE facilities. The homogeneous slurry can be pumped from the tanks to a treatment facility or altemative storage location. Most of the previous and current studies with this method are for flat-bottom tanks with vertical walls. Because of the difference in geometry, the results of these studies are not directly applicable to long horizontal tanks such as those used at the Oak Ridge National Laboratory. Mobilization and mixing studies were conducted with a surrogate sludge (e.g., kaolin clay) using submerged jets in two sizes of horizontal tanks. The nominal capacities of these tanks were $0.87 \mathrm{cu} \mathrm{m}(230 \mathrm{gal})$ and 95 cu $\mathrm{m}(25,000 \mathrm{gal})$. Mobilization efficiencies and mixing times were determined for single and bidirectional jets in both tanks with the discharge nozzles positioned at two locations in the tanks.
Approximately $80 \%$ of the surrogate sludge was mobilized in the 95 cu $\mathrm{m}$ tank using a fixed bidirectional jet (inside diameter $=0.035 \mathrm{~m}$ ) and a jet velocity of $6.4 \mathrm{~m} / \mathrm{s}(21 \mathrm{ft} / \mathrm{s})$.

2151

V18/024282

Cesium Removal Flow Studies Using Ion Exchange

Lee, D.D.; Walker, J.F., Jr.; Taylor, P.A.

Oak Ridge National Laboratory, Oak Ridge, TN; Westinghouse Hanford Company, Richland, WA

CONF-970321; Proceedings of a National Spring Meeting and Petrochemical Exposition of the American Institute of Chemical Engineers (AIChE) and the Second Plant Operations and Design Conference, Houston, TX, March 10-13, 1997; (40 pp.) (1997)

Cesium and strontium radionuclides are a small fraction of the mainly sodium and potassium salts in underground storage tank supernatant at US Department of Energy (DOE) sites at Hanford, Oak Ridge, Savannah River, and Idaho that DOE must remediate. Cesium-137 is the primary gamma radiation source in the dissolved tank waste at these sites, and its removal from the supernatant can reduce the hazard and waste classification of the treated waste reducing the further treatment and disposal costs. Several cesium removal sorbents have been developed by private industry and the US DOE's Office of Science and Technology. Several of these removal technologies have been previously tested in small batch and column tests using simulated and actual supernatant under DOE's Environmental Management (EM) programs, including the Tanks Focus Area (TFA) and the Efficient Separations and Processing (ESP) Cross-Cutting Program.

\section{2 \\ V18/022818}

Closure of Underground Storage Tanks at the Rocky Flats Environmental Technology Site: Looking Beyond the Obvious

Madel, R.E.; Gappa, R.M.; Anderson, M.A.; Warbington, C.P.

Rocky Mountain Remediation Services, LLC, Golden, CO; Roy F. Weston, Inc., Lakewood, CO

CONF-960804 (Vol. 3); Spectrum '96: Nuclear and Hazardous Waste Management, Proceedings of an Intemational Topical Meeting, Seattle, WA, August 18-23, 1996. American Nuclear Society, La Grange Park, IL, Vol. 3, 841 pp.; (pp. 1832-1838) (1996)

The Rocky Flats Environmental Technology Site (RFETS) is in the process of replacing and closing 22 Underground Storage Tanks (USTs) currently in use for fuel storage. The tank closures are in response to Federal and State Regulations requiring tank upgrades or replacement by December 22, 1998, to meet new requirements for leak detection and spill prevention. This paper presents the basis for determining the most cost effective program for closing the USTs. Presented herein is general information relevant to closure altematives as well as evaluation criteria that can be used to assess the various alternatives. A decision tree for choosing among tank closure alternatives using the evaluation criteria is then discussed. Finally, a summary of the results of the decision process for each of the 22 tank sites is presented. The closure altematives, the evaluation criteria, and the decision trees are non-site specific which 
enables the decision process that is presented in this paper to be used at other similar sites.

\section{$2153 \quad$ V18/022186}

Comparison of Organic and Inorganic Ion Exchange Materials for Removal of Cesium and Strontium from Tank Waste

Brown, G.N.

Pacific Northwest National Laboratory, Richland, WA

PNNL-SA-27105; CONF-960158; Efficient Separation and Processing Crosscutting Program, Proceedings of the 1996 Technical Exchange Meeting, Gaithersburg, MD, January 16-19, 1996, 52 pp.; (pp. 95-98) (1996)

This work is part of an Efficient Separation and Processing (ESP) task to develop high-capacity, selective, solid extractants for cesium, strontium, and technetium from nuclear wastes. Pacific Northwest National Laboratory (PNNL) staff are investigating novel ion exchangers for use in nuclear waste remediation (groundwater, high-level waste [HLW], and low-level waste [LLW]). Waste components targeted for remediation include cesium, strontium, and technetium.

\section{4 \\ V18/025477}

Complexities of Conducting a Successful Large Scale LUST Remediation Project: A Case Study

Westerby, G.; Gable, S.

CONF-9611165; Underground and Aboveground Storage Tanks: Complying, Purchasing, Designing, Installing, Managing, Replacing and Remediating Underground and Aboveground Storage Tanks, Proceedings of a Canadian Institute Conference, Toronto, Ontario, Canada, November 21-22, 1996. The Canadian Institute, Toronto, Ontario, Canada, 300 pp.; (12 pp.) (1996)

A case study of a large scale leaking underground storage tank (LUST) remediation project at the remote Kashechewan First Nation community, located on the James Bay Lowlands, was presented. Field measurements from a site assessment showed that petroleum hydrocarbons were present in excess of federal limits. The source for the contamination was leaky oil tanks and pipes. Of particular concern was the migration of hydrocarbon vapors into the school. Results of air monitoring and laboratory analyses showed that remedial action would be needed. A long list of remedial actions were reviewed based on technical appropriateness, their cost, and their difficulty of operation. Criteria for remediation method selection were described. Remedial actions chosen included in-situ containment using an impermeable membrane with passive venting, excavation and replacement of leaky pipes, removal of contaminated soil and backfilling with clean soil, installation of clay collar and oil/water separator in each drain line to trench.

\section{$2155 \quad$ V18/025479}

Complying, Purchasing, Designing, Installing, Managing, Replacing and Remediating Underground and Aboveground Storage Tanks: Proceedings of a Canadian Institute Conference, Ontario, Canada, November 21-22, 1996

CONF-9611165; Underground and Aboveground Storage Tanks:
Complying, Purchasing, Designing, Installing, Managing, Replacing and Remediating Underground and Aboveground Storage Tanks, Proceedings of a Canadian Institute Conference, Toronto, Ontario, Canada, November 21-22, 1996. The Canadian Institute, Toronto, Ontario, Canada, 300 pp. (1996)

The focus of this conference was on underground and above-ground storage tanks, the relevant regulatory environment, and on the importance of managing a tank system life cycle that would minimize liability, ensure saleability of goods stored, and reduce costs. Methods of designing underground and above-ground storage tanks to improve their impermeability were described and environmental concerns relating to leaky storage systems were addressed. Individual papers within the scope of this data base have been indexed separately.

\section{6 \\ V18/024284}

Control Issues Related to Bilateral Teleoperation of Long-Reach, Flexible Manipulators

Love, L.J.

Oak Ridge National Laboratory, Oak Ridge, TN

CONF-970464; Proceedings of the Seventh American Nuclear Society (ANS) Topical Meeting on Robotics and Remote Systems, Augusta, GA, April 27-May 1, 1997. ANS, La Grange Park, IL; (8 pp.) (1997)

A challenging problem presently being addressed by the Department of Energy (DOE) is the extraction of large volumes of hazardous waste from underground waste storage facilities. The nature of the material requires the use of robotic and teleoperated systems. Furthermore, the constraints of the storage tanks require the use of long reach manipulators. These robots are characterized by their large workspace and reduced mass. Unfortunately, this reduction in mass increases structural compliance, making these robots susceptible to vibration. Until recently, no attempt has been made to provide the operator any type of force reflection due to the compliance of the slave robot. This paper addresses the control of bilateral teleoperation systems that use long-reach, flexible manipulators. Analysis and experiments show that the compliance of the slave robot directly affects the stability of the teleoperation system. This study suggests that this may be controlled by increasing the damping on the master robot. However, this increase in target damping increases the energy an operator must exert during the execution of a task. A new teleoperation strategy adapts the target impedance of the master robot to variations in the identified impedance of the remote environment coupled to the slave robot. Experiments show increased performance due to a decrease in the energy the operator must provide during task execution.

V18/025476

Corrosion Control Methods for Underground Storage Tanks

Gummow, R.

Correng Consulting Service Inc., Canada

CONF-9611165; Underground and Aboveground Storage Tanks: Complying, Purchasing, Designing, Installing, Managing, Replacing and Remediating Underground and Aboveground Storage Tanks, 
Proceedings of a Canadian Institute Conference, Toronto, Ontario, Canada, November 21-22, 1996. The Canadian Institute, Toronto, Ontario, Canada, 300 pp.; (30 pp.) (1996)

Steel storage tanks and their susceptibility to corrosion was discussed. Several corrosion control solutions that can be applied to storage tank systems were described. The Canadian government has introduced legislation making it mandatory that new tank installations incorporate corrosion control equipment and that existing tanks and piping be upgraded. Control methods for both above-ground and underground storage systems encompass: (1) material selection, such as choosing between steel or fiberglass reinforced plastic; (2) environmental control, such as backfilling the tank with appropriate backfill material; (3) use of inhibitors, some of which (e.g., alkaline sodium nitrite) can actually inhibit internal corrosion in domestic fuel oil tanks; (4) use of coatings of epoxy and urethane; and (5) use of cathodic protection, the only corrosion control technique that can be applied to both new and existing underground storage systems.

\section{$2158 \quad$ V18/022106}

\section{Cost Effectiveness of Risk-Based Closures at UST Sites}

Scruton, K.M.; Baker, J.N.

Parsons Engineering Science, Inc., Denver, $\mathrm{CO}$

CONF-951139 (Vol. 1); Superfund 16: Proceedings of a Hazardous Waste Conference and Exhibition, Washington, DC, November 6-8, 1995. E.J. Krause and Associates, Bethesda, MD, Vol. 1, 828 pp.; (pp. 489-494) (1994)

Risk-based closures have been achieved at Underground Storage Tank (UST) sites throughout the country for a major transportation company. The risk-based closures were cost-effective because a streamlined risk-based approach was used instead of the generic baseline risk assessment approach. U.S. Environmental Protection Agency has recently provided guidance encouraging the use of risk-based methodology for achieving closure at UST sites. The risk-based approach used in achieving the site closures involved an identification of potential human and ecological receptors and exposure pathways, and a comparison of maximum onsite chemical concentrations to applicable or relevant and appropriate requirements (ARARs). The ARARs used in the evaluation included Federal and/or State Maximum Contaminant Levels (MCLs) for groundwater and risk-based screening levels for soils. If the maximum concentrations were above the screening levels, a baseline risk assessment was recommended. In several instances, however, the risk-based approach resulted in a regulatory agency acceptance of a "no further action" altemative at UST sites which did not pose a significant threat to human health and the environment. The cost of the streamlined risk-based approach is approximately $\$ 3,500$, while a baseline risk assessment for the same UST site could cost up to $\$ 10,000$ or more. The use of the streamlined risk-based approach has proven to be successful for achieving a "no further action" outcome for the client at a reasonable cost. This approach also resulted in significant cost savings for the client at low priority sites, allowing assets normally expended to be redirected toward site investigations and remediations of sites with environmental concerns.
DOE Underground Storage Tank Waste Remediation Chemical Processing Hazards, Part I: Technology Dictionary

DeMuth, S.F.

Los Alamos National Laboratory, Los Alamos, NM

LA-UR-96-3883; 33 pp. (October 1996)

This document has been prepared to aid in the development of regulating guidelines for the privatization of Hanford underground storage tank waste remediation. The document has been prepared in two parts. Part II is the primary focus of this effort in that it describes the technical basis for established and potential chemical processing hazards associated with Underground Storage Tank (UST) nuclear waste remediation across the DOE complex. The established hazards involve those at sites for which Safety Analysis Reviews (SARs) have already been prepared. Potential hazards are those involving technologies currently being developed for future applications. Part I of this document outlines the scope of Part II by briefly describing the established and potential technologies. In addition to providing the scope, Part I can be used as a technical introduction and bibliography for regulatory personnel new to UST waste remediation, and in particular, the privatization effort. Part II of this document is not intended to provide examples of a SAR Hazards Analysis, but rather provide an intelligence gathering source for regulatory personnel who must eventually evaluate the Privatization SAR Hazards Analysis.

2160

V18/022839

Data Quality Objectives Lessons Learned for Tank Waste Characterization

Eberlein, S.J.; Banning, D.L.

Westinghouse Hanford Company, Richland, WA

CONF-960804 (Vol. 3); Spectrum '96: Nuclear and Hazardous Waste Management, Proceedings of an Intemational Topical Meeting, Seattle, WA, August 18-23, 1996. American Nuclear Society, La Grange Park, IL, Vol. 3, 841 pp.; (pp. 1984-1987) (1996)

The tank waste characterization process is an integral part of the overall effort to control the hazards associated with radioactive wastes stored in underground tanks at the Hanford Reservation. The programs involved in the characterization of the waste are employing the Data Quality Objective (DQO) process in all information and data collection activities. The DQO process issued by the programs to address an issue or problem rather than a specific sampling event. Practical limits (e.g., limited number and location of sampling points) do not always allow for precise characterization of a tank or the full implementation of the DQO process. Because of the flexibility of the DQO process, it can be used as a planning tool for sampling and analysis of the underground waste storage tanks. The iterative nature of the DQO process allows it to be used as additional information is obtained or "lessons are learned" concerning an issue or problem requiring sampling and analysis of tank waste. In addition, the application of the DQO process forces alternative actions to be considered when precise characterization of a tank or the full implementation of the DQO process is not practical. 


\section{1}

V18/022179

Development and Testing of Inorganic Sorbents for Radionuclide and Heavy Metál Separations

Collins, J.L.

Oak Ridge National Laboratory, Oak Ridge, TN

PNNL-SA-27105; CONF-960158; Efficient Separation and Processing Crosscutting Program, Proceedings of the 1996 Technical Exchange Meeting, Gaithersburg, MD, January 16-19, 1996, 52 pp.; (pp. 81-83) (1996)

The objectives of this task are to develop, prepare, and test microspheres and granular forms of inorganic ion exchangers to remove radionuclides and heavy metals from waste streams occurring at various sites. Several inorganic materials, such as hexacyanoferrates, titanates, phosphates, and oxides have high selectivities and efficiencies for separating and removing radionuclides such as uranium, technetium, cesium and strontium, and metals such as cobalt, silver, zinc, and zirconium from aqueous waste streams. However, these sorbents frequently exist only as powders and consequently are not readily adaptable to continuous processing such as column chromatography.

\section{2}

V18/024146

Development of a Waste Dislodging and Retrieval System for Use in the Oak Ridge National Laboratory Gunite Tank

Randolph, J.D.; Burks, B.L.; Rinker, M.W.; Summers, D.; Blank, J.; Lloyd, P.D.; Johnson, M.A.; Mullen, D.; Alberts, D.

Oak Ridge National Laboratory, Oak Ridge, TN; Pacific Northwest National Laboratory, Richland, WA; University of Missouri, Rolla, MO; Advanced Systems Technology, Inc., Knoxville, TN; Waterjet Technology, Inc., Kent, WA CONF-970464; Proceedings of the Seventh American Nuclear Society (ANS) Topical Meeting on Robotics and Remote Systems, Augusta, GA, April 27-May 1, 1997. ANS, La Grange Park, IL; (pp. 894-906) (1997)

As part of the Gunite and Associated Tanks (GAAT) Treatability Study, the Oak Ridge National Laboratory (ORNL) has developed a tank waste retrieval system capable of removing wastes varying from liquids to thick sludges. This system is also capable of scarifying concrete walls and floors. The GAAT Treatability Study is being conducted by the Department of Energy, Oak Ridge Environmental Restoration Program. Much of the technology developed for this project was cosponsored by the DOE Office of Science and Technology through the Tanks Focus Area (TFA) and the Robotics Technology Development Program. The waste dislodging and conveyance (WD\&C) system was developed jointly by ORNL and participants from the TFA. The WD\&C system is comprised of a four degree-of-freedom arm with backdriveable motorized joints, a cutting and dislodging tool, a jet pump and hose management system for conveyance of wastes, confined sluicing end-effector, and a control system, and must be used in conjunction with a robotic arm or vehicle. Other papers have been submitted to this conference describing the development and operation of the arm and vehicle positioning systems. This paper will describe the development of the WD\&C system and its application for dislodging and conveyance of ORNL sludges from the GAAT tanks. The confined sluicing end-effector relies on medium pressure water jets to dislodge waste that is then pumped by the jet pump through the conveyance system out of the tank. This paper will describe the results of cold testing of the integrated system. At the conference presentation there will also be results from the field deployment. ORNL has completed fabrication of the WD\&C system for waste removal and is full-scale testing, including testing of the confined sluicing end-effector.

2163

V18/022604

\section{Durability of Polymers for Containment Barriers}

Heiser, J.H.; Milian, L.W.; Clinton, J.N.; Colombo, P.

Brookhaven National Laboratory, Environmental and Waste Technology Center, Upton, NY

CONF-941124; Insitu Remediation: Scientific Basis for Current and Future Technologies, G.W. Gee and N.R. Wing (eds.), Proceedings of the 33rd Hanford Symposium on Health and the Environment, Pasco, WA, November 7-11, 1994. Battelle Press, Columbus, $\mathrm{OH}$, Part 1, 704 pp.; (pp. 61-86) (1994)

Brookhaven National Laboratory has been involved in several tasks to develop, demonstrate, and implement advanced polymer materials for use in subsurface barriers throughout the US Department of Energy complex. Binders investigated as barrier composites include polyester styrenes, vinylester styrenes, high-molecular-weight acrylics, sulfur polymer cement, bitumen, and a furfuryl-alcohol-based furan polymer. These materials have been extensively used in many commercial applications, e.g., in sewage and brine handling systems and electrolytic baths. They have also been used by the US Army Corps of Engineers to repair dams and canal locks, and by the Federal Highway Administration for bridge deck and highway repairs. Their impermeability to gases and liquids, combined with resistance to radiation and to acidic and alkaline environments, make polymer grouts candidates for high-quality, durable barriers. Laboratory testing and evaluation of polymer composites has been ongoing since early 1992. A series of resistance tests were used to determine the performance and durability characteristics of a variety of polymer composites. This paper details the results of this characterization that pertain to the Hanford Site underground storage tanks. Testing includes wet-dry cycling, chemical resistivity to groundwater, base, solvent and a surrogate nitrate tank brine, resistance to irradiation, and hydraulic conductivity. Performance values indicate that polymers can meet the requirements for containment barriers for underground storage tanks at the Hanford tank farm, including the high-heat tanks. Appropriate choices of binder and aggregate, followed by appropriate, site-specific compatibility testing will result in a durable, high-strength, low-permeability barrier.

\section{4}

\section{V18/024287}

Effect of Moisture Dependent Anisotropy and Enhanced Recharge Around Underground Storage Tanks

Kline, N.W.; Khaleel, R.

Westinghouse Hanford Company, Richland, WA

CONF-950420; Proceedings of the International Conference on Mathematics and Computations, Reactor Physics, and Environmental Analyses, Portland, OR, April 30 - May 4, 1995. 
American Nuclear Society, Inc., La Grange Park, IL, 1629 pp.; (pp. 181-191) (1995)

Numerical simulations have been performed to demonstrate and quantify enhancement of recharge due to shedding of infiltrating precipitation from the dome of an underground storage tank. Anisotropy induced by soil layering and varying moisture content is shown to strongly influence both the magnitude and lateral extent of recharge enhancement. Simulations of flow and transport from hypothetical leakage along a row of underground tanks show that both moisture-dependent anisotropy and enhanced recharge are important in determining arrivals of solute transport at the underlying water table. Validity of the model results is established by matching simulated volumetric moisture content to field observation.

\section{5}

V18/022187

\section{Electrically Controlled Cesium Ion Exchange}

Lilga, M.A.

Pacific Northwest National Laboratory, Richland, WA

PNNL-SA-27105; CONF-960158; Efficient Separation and Processing Crosscutting Program, Proceedings of the 1996 Technical Exchange Meeting, Gaithersburg, MD, January 16-19, 1996, 52 pp.; (pp. 47-52) (1996)

Several sites within the DOE complex (Savannah River, Idaho, Oak Ridge and Hanford) have underground storage tanks containing high-level waste resulting from nuclear engineering activities. To facilitate final disposal of the tank waste, it is advantageous to separate and concentrate the radionuclides for final immobilization in a vitrified glass matrix. This task proposes a new approach for radionuclide separation by combining ion exchange $(\mathrm{XX})$ and electrochemistry to provide a selective and economic separation method.

\section{6 \\ V18/022433}

Environmental Code of Practice for Aboveground Storage Tank Systems Containing Petroleum Products

Canadian Council of Ministers of the Environment, Winnipeg, Manitoba, Canada

Report; 56 pp. (1994)

While National Fire Code and Canadian Standards Association requirements have been used in Canada for the installation and operation of aboveground storage tanks containing petroleum products, these codes were written primarily from a fire prevention perspective and, historically, have not prevented the contamination of groundwater supplies from leaking storage tanks. The CCME code of practice addresses this shortcoming. This code of practice is a model set of technical requirements designed to protect the environment from leaking aboveground storage tank systems. It promotes environmentally sound management, and complements the approaches which focus on fire safety and prevention. It provides guidance on: requirements for registration; design and installation of new systems, including recommendations concerning secondary containment, storage tanks, piping, product transfer areas, and associated equipment; upgrading of existing systems; proper operation and maintenance; and requirements for closure and withdrawal from service.
V18/022434

Environmental Code of Practice for Underground Storage Tank Systems Containing Petroleum Products and Allied Petroleum Products

Canadian Council of Ministers of the Environment, Winnipeg, Manitoba, Canada

Report; 53 pp. (1993)

This code of practice presents minimum requirements for environmental protection from existing or new underground storage tank systems containing petroleum products or allied petroleum products. It promotes environmentally sound management, and complements approaches which focus on fire safety and prevention. It provides guidance on: requirements for registration; classification of prospective sites; design and installation of new systems, including tanks, piping, and associated equipment; upgrading of existing systems; proper operation and maintenance; and requirements for closure and withdrawal from service.

\section{8} V18/022841

Fly-By Robotic Tank Inspection End Effector for Waste Storage Tank

Gittleman, M.M.; Robertson, B.; Lee, B.; Gaseor, T.; Wightman, B.; Hughes, G.

Oceaneering Space Systems, Houston, TX; Oceaneering International, Inc., Aberdeen, Scotland, United Kingdom CONF-960804 (Vol. 3); Spectrum '96: Nuclear and Hazardous Waste Management, Proceedings of an International Topical Meeting, Seattle, WA, August 18-23, 1996. American Nuclear Society, La Grange Park, IL, Vol. 3, 841 pp.; (pp. 1996-2008) (1996)

A robotic end effector has been developed that is capable of performing fly-by, electromagnetic non-destructive evaluation (NDE) and visual inspection of the inside of the U.S. Department of Energy's waste storage tanks. Furthermore, the system is also capable of sizing defects through its unique NDE technique, Alternating Current Field Measurement (ACFM). The NDE data is recorded and logged electronically and is tagged with the position data from the deploying manipulator, allowing a complete mapping of the tank walls and future return to defect sites.

\section{9}

\section{V18/024086}

Gaseous Analytes of Concern at Hanford Tank Farms: Topical Report - March 1, 1996

Northrop Grumman Corporation, Electronic Sensors and Systems Division, Pittsburgh, PA

DOE/MC/32087-5374; 45 pp. (March 1996)

Large amounts of toxic and radioactive waste materials are stored in underground tanks at DOE sites. When the vapors in the tank headspaces vent to the open atmosphere a potentially dangerous situation can occur for personnel in the area. An open-path atmospheric pollution monitor is being developed for DOE to monitor the open air space above these tanks. In developing this monitor, it is important to know what hazardous gases are most likely to be found in dangerous concentrations. These gases are called the Analytes of Concern. At the present time, measurements 
in eight tanks have detected thirty-one analytes in at least two tanks and fifteen analytes in only one tank. In addition to these gases, carbon tetrachloride is considered to be an Analyte of Concem because it permeates the ground around the tanks. These Analytes are described and ranked according to a Hazard Index which combines their vapor pressure, density, and approximate danger level. The top sixteen ranked analytes which have been detected in at least two tanks comprise an "Analyte of Concern Test List" for determining the system performance of the atmospheric pollution monitor under development. A preliminary examination of the infrared spectra, barring atmospheric interferences, indicates that the pollution monitor will detect all forty seven analytes.

\section{0}

V18/024135

\section{Hanford Tank SY-102 Remediation Project}

Los Alamos National Laboratory, Los Alamos, NM

LALP-95-173; 1 p. (1995)

Los Alamos researchers have developed and tested a functional flowsheet that combines an array of proven remediation technologies. This particular flowsheet focuses on remediating waste found in Hanford Tank SY-102, but it is flexible enough to have other applications if appropriately modified. The flowsheet and equipment are designed to use a combination of in-tank processing, existing facilities, or compact processing units. The volume in tank SY-102 will be recovered by treating the waste and preparing it for storage in an appropriate repository. Because the SY-102 flowsheet does not assume that either the high- or low-level vitrification plants are operating, it does not require additional separation steps to remove components that degrade glass performance. This characteristic minimized the complexity of the flowsheet and allows greater flexibility in deploying the technology.

\section{1}

V18/021030

High Level Control and Data Acquisition System for Robotic Characterization of Hazardous Waste in Underground Storage Tanks

Callow, D.S.; Palmquist, R.D.; Weatherby, J.R.; Fugelso, D.

Sandia National Laboratories, Intelligent Systems and Robotic Center, Albuquerque, NM; Ray Rashkin and Associates, Albuquerque, NM

CONF-960212; Waste Management '96: Working Towards a Cleaner Environment, Proceedings of a Conference on $\mathrm{HLW}$, LLW, Mixed Wastes and Environmental Restoration, Tucson, AZ, February 25-29, 1996; (14 pp.) (1996)

The U.S. Department of Energy (DOE) has significant amounts of radioactive waste stored in underground single-shell storage tanks. Many of these storage tanks have reached their design life and are deteriorating structurally. The wastes are chemically and radiologically hazardous with radiation levels ranging from slightly above background to hundreds of rads/hr. The consistency of the waste ranges from pumpable liquids and slurries to thick sludges and large crystalline masses. A priority mission of the DOE is to retrieve the waste from its present storage and process it for final disposal. The Light Duty Utility Arm (LDUA), a robotic system being developed by the DOE's Office of Science and Technology, will be used to gather information about the waste and the tanks in which it is stored to better plan and execute the clean-up mission. The LDUA will become operational at the Hanford Site in 1996, making it the first robotic system to be deployed in a radioactive underground storage tank. Sandia National Laboratories is developing both a Supervisory Control System (SCS) and a Supervisory Data Acquisition System (SDAS) for use on the IDUA. The SCS is based on graphical programming and model-based control which allow previewing of programmed robot motion by the operator before actual robot motion is performed; this advanced capability is needed for robot safety in the hazardous environment. The SDAS is an integral part of the robotic system; it collects data from several end-effectors and controls both video storage and end-effector operations. SDAS uses a client/server architecture which allows multiple programs to receive data in real time including an operator interface, an expert system, and a data logger. This paper discusses the design and architecture of both the SCS and SDAS systems.

2172

V18/022189

Hot Demonstration of Proposed Commercial Nuclide Removal Technology

Lee, D.W.

Pacific Northwest National Laboratory, Richland, WA; Oak Ridge National Laboratory, Oak Ridge, TN

PNNL-SA-27105; CONF-960158; Efficient Separarion and Processing Crosscutting Program, Proceedings of the 1996 Technical Exchange Meeting, Gaithersburg, MD, Januan 16-19. 1996, 52 pp.; (pp. 77-80) (1996)

This task covers the development and operation of an expenmental test unit located in a Building 4501 hot cell within Building 4501 at Oak Ridge National Laboratory (ORNL). This equipment is designed to test radionuclide removal technologies under continuous operation on actual ORNL Melton Valley Storage Tank (ANST) supernatant, Savannah River high-level waste supernatant, and Hanford supernatant. The latter two may be simulated by adding the appropriate chemicals and/or nuclides to the MVST supematant

2173

V18/021029

Houdini: Reconfigurable In-Tank Robot

White, D.W.; Slifko, A.D.; Thompson, B.R.

RedZone Robotics, Inc., Pittsburgh, PA

CONF-960212; Waste Management '96: Working Towards a Cleaner Environment, Proceedings of a Conference on $\mathrm{HLW}$, LLW, Mixed Wastes and Environmental Restoration, Tucson, AZ, February 25-29, 1996; (11 pp.) (1996)

Across the DOE complex, hundreds of above and below ground storage tanks contain large amounts of high-level waste. The Femald Environmental Management Project, a site within the DOE complex, contains four, above-ground, domed, concrete waste tanks. Some structural deterioration has been noted in the walls and domes of the tanks, resulting in concerns about leakage of their contents. Waste retrieval for final remediation must begin in 1997. RedZone Robotics, Inc. and Camegie Mellon University (CMU) are developing a tethered mobile robot, Houdini, to work inside waste storage tanks in support of the Department of Energy's Environmental Restoration and Waste Management (EM) Program. 
The development of Houdini is funded by the DOE's Office of Science and Technology through the Morgantown Energy Technology Center. Houdini will first be deployed at Fernald in support of the waste retrieval for final remediation of the K-65 waste silos. Femald personnel are active members of the development team. Houdini is a tethered, hydraulically powered, track driven, teleoperated, work machine with an expandable frame chassis that allows it to fit through confined entries as small as 0.57 meters (22.5 in.) in diameter. The Houdini system performs heel removal, waste retrieval, waste mobilization, waste size reduction, and other tank waste retrieval and decommissioning tasks. It is equipped with an articulated plowing blade and a manipulator with exchangeable end effector tooling. Tooling consists of a gripper, scoop, shear, vacuum suction hose grip, and spray-down nozzle. The system can locomote over and through a variety of waste forms, and can operate fully submerged. An operations trailer houses Houdini's primary operator interface console. Joysticks, switches, and remote-viewing monitors allow the operator to control the system from a remote location. A second, portable control station provides the capability for local operations, on-site debugging, system checkout, and emergency recovery. A navigation system developed at Oak Ridge National Labs (ORNL) provides the operator with feedback on the vehicle's position and orientation inside the tank. Robotic systems are needed to work inside waste storage tanks in support of the DOE's EM activities. As a technology for supporting the DOE's EM program and in comparison or collaboration with other competing technologies, Houdini provides many benefits. The Houdini system is designed to eliminate or reduce potential public and operational health risks associated with work on DOE tanks. The system provides fully-contained remote operation, reducing the risk of spreading contamination outside of the tanks. Because of Houdini's similarity to bulldozers and backhoes from the construction industry, it provides simple, intuitive, and efficient waste handling techniques. Houdini's transportation, installation, deployment, and removal operations are simple due to its compact size. Houdini's simplicity and operational capability lead to cost efficiency with respect to development, operation, and maintenance. The Houdini concept was developed specifically in response to the needs at Fernald, but is useful at a number of other DOE sites where tank remediation projects are planned. Upon successful completion of the development program, in late 1996, RedZone will make the results of this program commercially available.

\section{4}

V18/023511

Inactive Tanks Remediation Program Strategy and Plans for Oak Ridge National Laboratory, Oak Ridge, Tennessee [Rev. 1]

Step, Inc., Oak Ridge, TN; Oak Ridge National Laboratory, Oak Ridge, TN

ORNL/ER-297/R1; 25 pp. (March 1997)

This report presents plans and strategies for remediation of the liquid low-level waste ( $L L L W)$ tanks that have been removed from service (also known as inactive tanks) at Oak Ridge National Laboratory (ORNL) in Oak Ridge, Tennessee. These plans and strategies will be carried out by the Environmental Restoration Program's Inactive LLLW Tank Program at ORNL. These tanks are defined as Category $D$ tanks because they are existing tank systems without secondary containment that are removed from service. The approach to remediation of each tank or tank farm must be adapted in response to the specific circumstances of individual tank sites. The approach will be tailored to accommodate feedback on lessons leamed from previous tank remediation activities and will not be a rigid step-by-step approach that must be conducted identically for every tank system. However, the approach will follow a multistep decision process. The overall objective of the Inactive Tank Program is to remediate all LLLW tanks that have been removed from service to the extent practicable in accordance with the FFA requirements. The Inactive Tank Program will focus on the remediation of the tank residues (i.e., contents after tank has been emptied) and tank shell. This strategy is discussed in detail in this report.

2175

V18/023607

\section{Infrared Pyrometry for Waste Characterization}

Macy, J.

New Mexico State University, Department of Mechanical Engineering, Las Cruces, NM

CONF-9605266; Proceedings of the 1996 Hazardous Substance Research Center/Waste-Management Education and Research Consortium Joint Conference on Environment, L.E. Erickson, S.C. Grant, D.L. Tillison and J.P. McDonald (eds.), Albuquerque, NM, May 21-23, 1996. Great Plains-Rocky Mountain Hazardous Substance Research Center, Kansas State University, Manhattan, KS, 706 pp.; (pp. 424-432) (1996)

The objective of this research is the development of two methodologies by which heat sources contained in underground storage tanks (USTs) can be remotely characterized. A problem statement is established based upon the restrictions of UST robotic capabilities and basic infrared (IR) pyrometer operation. The first analysis is designed to provide real time information to a robot operator about the UST interior. The other analysis is designed to calculate an estimated temperature distribution using a least-squares solution after a data survey. A mock UST designed by Sandia National Laboratories and New Mexico State University was built to provide a test bed for data collection. Two data sets are graphically presented to show the positions of known heat sources and their thermal responses. The results of the two analyses on the data sets are graphically presented to illustrate the correlation between known heat sources and estimated thermal targets. In conclusion, the estimated temperature distribution provides a higher resolution image of the UST surface, as compared to the measured temperature distribution, such that individual heat sources may be located.

\section{6 \\ V18/025475}

Leak Detection, Repair and Remediation: Advantages and Limitations of Various Methods

Veska, E.

Jacques Whitford Environment Limited, Markham, Ontario, Canada

CONF-9611165; Underground and Aboveground Storage Tanks: Complying, Purchasing, Designing, Installing, Managing, Replacing and Remediating Underground and Aboveground Storage Tanks, Proceedings of a Canadian Institute Conference, Toronto, Ontario, Canada, November 21-22, 1996. The Canadian Institute, Toronto, 
Ontario, Canada, 300 pp.; (26 pp.) (1996)

The rationale and background of some of the more common methods for leak detection and repair in both underground and above-ground storage tank systems was presented. Tank management programs should strive to minimize liability by maintaining a cost effective operation that protects the environment and human health. Several technological advances have been made to improve the impermeability of storage tanks. Significant improvements have been made in leak monitoring methods, including tests for tightness, internal and external leak monitoring, volumetric methods, and pressure tests. The advantages and limitations of these methods were described. The most common method for the remediation of hydrocarbon contamination in soils in the past has been "the dig and haul" approach. However, new techniques such as bioventing, bioremediation, and low temperature thermal desorption are gaining greater acceptance.

\section{7}

V18/021238

Light Duty Utility Remote Manipulator for Underground Storage Tank Inspection and Characterization

Kruse, P.W.; Cunliffe, G.; Carteret, B.A.

Spar Aerospace Limited, Avon, CT; Spar Aerospace Limited, Brampton, Ontario, Canada; Westinghouse Hanford Company, Richland, WA

CONF-941148 (Vol. 1); DDER-'94: Decommissioning, Decontamination, and Environmental Restoration at Contaminated Nuclear Sites, M.G. White (ed.), Proceedings of an Embedded Topical Symposium of the American Nuclear Society Winter Meeting, Washington, DC, November 13-18, 1994. American Nuclear Society, Inc., La Grange Park, IL, Vol. 1, 323 pp.; (pp. 153-159) (1994)

The Light Duty Utility Arm (LDUA) is a remote manipulator system which is being designed and fabricated to perform surveillance and characterization activities in support of the remediation of underground storage tanks at the Hanford site as well as other DOE sites. The LDUA is a highly dexterous manipulator which utilizes an advanced control system to safely and reliably deploy a series of sensors to characterize underground storage tanks. The electrical components of the in tank system are radiation hardened and the mechanical components are designed to operate in the corrosive environment which exists in the tanks. The use of this system will allow the U.S. Department of Energy to sample and characterize the waste material in the tanks prior to the initiation of waste retrieval operations. In addition to its use for inspecting and characterizing underground storage tanks, the system has the potential to be used in other environments where accessibility is limited and where high radiation levels exist.

\section{$2178 \quad$ V18/020772}

Low-Level Tank Waste Simulant Data Base

Lokken, R.O.

Pacific Northwest National Laboratory, Richland, WA

PNNL-11116; 42 pp. (April 1996)

The majority of defense wastes generated from reprocessing spent N-Reactor fuel at Hanford is stored in underground Double-Shell
Tanks (DST) and in older Single-Shell Tanks (SST) in the form of liquids, slurries, sludiges, and salt cakes. The tank waste Remediation System (TWRS) Program has the responsibility of safely managing and immobilizing these tank wastes for disposal. This report discusses three principle topics: the need and basis for selecting target or reference low level waste (LLW) simulants; tanks waste analyses and simulants that have been defined, developed, and used for the Gaseous Diffusion Plant (GDP); and activities in support of preparing and characterizing simulants for the current LLW vitrification project. The procedures and the data that were generated to characterize the $L L W$ vitrification simulants were reported and are presented in this report. The final section of this report addresses the applicability of the data to the current program and presents recommendations for additional data needs including characterization and simulant compositional variability studies.

2179

V18/022177

Membrane-Based Separation Technologies for Cesium, Strontium, and Technetium

Kafka, T.M.

Pacific Northwest Laboratory, Richland, WA

PNNL-SA-27105; CONF-960158; Efficient Separation and Processing Crosscutting Program, Proceedings of the 1996 Technical Exchange Meeting, Gaithersburg, MD, January 16-19, 1996, 52 pp.; (pp. 99-100) (1996)

This work is one of two parallel projects that are part of an Efficient Separation and Processing (ESP) task to develop high-capacity, selective, solid extractants for cesium, strontium, and technetium from nuclear wastes. In this subtask, Pacific Northwest National Laboratory (PNNL) is collaborating with 3M, St. Paul, Minnesota, working in cooperation with IBC Advanced Technologies, American Fork, Utah.

2180 V18/021074

Microwave Dissolution in a Highly Radioactive Cell Greenop, D.; Dilworth, I.J.

British Nuclear Fuels plc, Sellafield, Cumbria, United Kingdom; University of Essex, Essex, United Kingdom CONF-9509204; Proceedings of a Conference on Microwave and High Frequency Heating, Cambridge, United Kingdom, September 17-21, 1995; (pp. D2.1-D2.3) (1995)

Fission product waste from nuclear reprocessing activities is concentrated and stored temporarily in tanks whilst the separated plutonium and uranium are retained for future use. The fission products are highly radioactive and are vitrified for long term storage. Characterization of the fission product feed is necessary for efficient operation of the vitrification process. Determination of the mixed transition metals, lanthanides and actinides provides the required information. Before the advent of microwave techniques sodium peroxide fusion followed by spectroscopic measurement was used for the characterization. There are several unsatisfactory features of sodium peroxide fusion; it is time consuming, liable to sample contamination or analyte loss and it generates considerable volumes of waste. In contrast, microwave dissolution in a sealed vessel offers reduced preparation time and avoidance of the contamination and analyte loss problems. The success of 
microwaves in dissolving a large variety of matrices is well documented and the feasibility of applying microwave technology to the dissolution of highly active storage tank liquor (HAST) is supported by the successful dissolution of granite and sedimentary rocks.

\section{$2181 \quad$ V18/024056}

OST Dovetails Technologies for Remote Tank Cleanup Initiatives in Environmental Technology Investment 4(April 1997):2-4 (April 1997)

The U.S. Department of Energy's Office of Science and Technology has successfully dovetailed several of its technologies, demonstrating how they can be used together for remote retrieval of radioactive liquid and sludge from underground storage tanks. During December and January, Oak Ridge National Laboratory hosted open-house demonstrations of three remotely operated technologies: the Modified Light Duty Utility Arm, Houdini, and a waste dislodging and conveyance system.

2182

V18/020604

Potential Enhancements to Addressing Programmatic Risk in the Tank Waste Remediation System (TWRS) Program

Brothers, A.J.; Fassbender, L.L.; Bilyard, G.R.; Levine, L. Pacific Northwest Laboratory, Richland, WA

PNNL-1 1068; 57 pp. (April 1996)

Pacific Northwest National Laboratory (PNNL) conducted a Tank Waste Remediation System (TWRS) Risk Management methodology development task. The objective of this task was to develop risk management methodology focused on (1) the use of programmatic risk information in making TWRS architecture selection decisions and (2) the identification/evaluation/selection of TWRS risk-handling actions. Methods for incorporating programmatic risk/uncertainty estimates into trade studies are provided for engineers/analysts. Methods for identifying, evaluating, and selecting risk-handling actions are provided for managers. The guidance provided in this report is designed to help decision-makers make difficult judgments. Current approaches to architecture selection decisions and identification/evaluation/selection of risk-handling actions are summarized. Three categories of sources of programmatic risk (parametric, external, and organizational) are examined. Multiple analytical approaches are presented to enhance the current alternative generation and analysis (AGA) and risk-handling procedures. Appendix A describes some commercially available risk management software tools and Appendix B provides a brief introduction to quantification of risk attitudes. The report provides three levels of analysis for enhancing the AGA Procedure: (1) qualitative discussion coupled with estimated uncertainty ranges for scores in the alternatives-by-criteria matrix; (2) formal elicitation of probability distributions for the alternative scores; and (3) a formal, more structured, comprehensive risk analysis. A framework is also presented for using the AGA programmatic risk analysis results in making better decisions. The report also presents two levels of analysis for evaluation and selection of risk-handling actions: (1) qualitative analysis and judgmental rankings of alternative actions, and (2) Simple Multi-Attribute Rating Technique (SMART).
2183

V18/021604

Radioactive Tank Waste Remediation Focus Area

U.S. Department of Energy, Office of Environmental Management, Office of Science and Technology, Washington, $\mathrm{DC}$

DOE/EM-0295; 128 pp. (August 1996)

The Department of Energy's Office of Environmental

Management's Office of Science and Technology has established the Tank Focus Area (TFA) to manage and carry out an integrated national program of technology development for tank waste remediation. The TFA is responsible for the development, testing, evaluation, and deployment of remediation technologies within a system architecture to characterize, retrieve, treat, concentrate, and dispose of radioactive waste stored in the underground tanks and to stabilize and close the tanks. The goal is to provide safe and cost-effective solutions that are acceptable to both the public and regulators. Within the DOE complex, 335 underground storage tanks have been used to process and store radioactive and chemical mixed waste generated from weapon materials production and manufacturing. Collectively, these tanks hold over 90 million gallons of high-level and low-level radioactive liquid waste in sludge, saltcake, and as supernate and vapor. Very little has been treated and/or disposed or is in final form. This report provides overviews of a large number of developmental tank remediation technologies under the follow section headings: (1) Characterization and Safety, (2) Waste Retrieval and Tank Closure, (3) Pretreatment, (4) Waste Immobilization, (5) Crosscutting Programs, and (6) Site Specific Technology Development.

2184

V18/022717

Rapid Characterization of Mixed Waste by FTIR-Fiber Optic Method

Rebagay, T.V.; Lopez, T.; Cash, R.J.; Reich, F.R.: Dodd, D.A.; Watts, J.K.

Westinghouse Hanford Company, Richland, WA CONF-960804 (Vol. 1); Spectrum '96: Nuciear and Hazardous Waste Management, Proceedings of an International Topical Meeting, Seattle, WA, August 18-23, 1996. American Nuclear Society, La Grange Park, IL, Vol. 1, 887 pp.; (pp. 196-203) (1996)

Tank waste characterization requires various analytical systems to identify and quantify the chemical composition and water content of Hanford Site high-level waste. Safe long-term storage of the waste depends on its chemical and physical data. An analytical database is also the key to the design and implementation of pre-treatment and disposal processes. To provide a faster, cheaper, and safer technique to monitor the moisture content of tank waste, two types of near-infrared (NIR) diffuse reflectance fiber optic probes interfaced to a Fourier transform infrared (FTIR) spectroscopy system were studied. Lower absorptivities in the NIR region enable longer pathlengths to be used leading to easier nondestructive sampling. Both overtone and combination bands of water can be used for moisture measurements. While a previous report provides evidence for the feasibility of using fiber optic probes, the results were strictly qualitative. In this study, the fiber optic probe is installed in a hot ceil making it possible to characterize highly radioactive mixed waste rapidly and 
quantitatively. In seeking a strategy to identify individual species in the waste with minimal sample preparation, a modular transfer optic system equipped with a mid-infrared diffuse reflectance sampler was assessed. Light pipes were used to present the sample to the FTIR spectrometer. Its performance for obtaining rapid, high quality mid-infrared (MR) spectra of mixed waste is compared with FTIR-photoacoustic spectroscopy.

\section{$2185 \quad$ V18/022385}

Recommendations to Improve the Cleanup Process for California's Leaking Underground Fuel Tanks (LUFTs)

Rice, D.W.; Dooher, B.P.; Cullen, S.J.; Everett, L.G.; Kastenberg, W.E.; Grose, R.D.; Marino, M.A.

University of California, Los Angeles, CA; University of California, Santa Barbara, CA; University of California, Berkeley, CA; University of California, Davis, CA

UCRL-AR-121762; 40 pp. (October 16, 1995)

This document summarizes the findings, conclusions, and recommendations resulting from an 18 month review of the regulatory framework and cleanup process currently applied to California's leaking underground fuel tanks (LUFT). This review was conducted by the Lawrence Livermore National Laboratory (LLNL) and the University of Califomia at Berkeley, Davis, Los Angeles, and Santa Barbara at the request of the State Water Resources Control Board (SWRCB), Underground Storage Tank Program. The recommendations are made to improve and streamline the LUFT cleanup decision-making process.

\section{$2186 \quad$ V18/022608}

Recommendations to Improve the Cleanup Process for California's Leaking Underground Fuel Tanks (LUFTs)

Rice, D.W.; Dooher, B.P.; Cullen, S.J.; Everett, L.G.; Kastenberg, W.E.; Grose, R.D.; Marino, M.A.

Lawrence Livermore National Laboratory, Livermore, CA; University of California, Los Angeles, CA; University of California, Santa Barbara, CA; University of California, Berkeley, CA; University of California, Davis, CA CONF-960393 (Part 1); Contaminated Soils and Groundwater: Analysis, Fate, Environmental and Public Health Effects, and Remediation, Proceedings of the Sixth Annual West Coast Conference, Newport Beach, CA, March 11-14, 1996. Association for the Environmental Health of Soils, Amherst, MA, Part 1, 257 pp.; (p. 13) (1996)

This document summarizes the findings, conclusions, and recommendations resulting from an 18 month review of the regulatory framework and cleanup process currently applied to California's leaking underground fuel tanks (LUFT). This review was conducted by the Lawrence Livermore National Laboratory (LLNL) and the University of California at Berkeley, Davis, Los Angeles, and Santa Barbara at the request of the State Water Resources Control Board (SWRCB), Underground Storage Tank Program. The recommendations are made to improve and streamline the LUFT cleanup decision-making process.

2187 V18/025478

Remediation Alternatives
Ola, $\mathrm{S}$.

CONF-9611165; Underground and Aboveground Storage Tanks: Complying, Purchasing, Designing, Installing, Managing, Replacing and Remediating Underground and Aboveground Storage Tanks, Proceedings of a Canadian Institute Conference, Toronto, Ontario, Canada, November 21-22, 1996. The Canadian Institute, Toronto, Ontario, Canada, 300 pp.; (34 pp.) (1996)

Leaky storage tanks have resulted in the contamination of thousands of sites across Canada, most of which are located in urban communities. Methods used to remediate subsurface contamination were described. They fall into four broad classes: (1) passive remediation, (2) containment and isolation, (3) removal for treatment, and (4) in-situ treatment. Each of these treatment methods was briefly described. Within each class there are finer remedial techniques such as physical barriers, immobilization, stabilization, encapsulation, soil washing, thermal techniques, incineration, on-site aeration, groundwater extraction, bioventing, air sparging, landfarming, and bioremediation. The advantages and disadvantages of each technique were listed.

\section{8}

\section{V18/024285}

\section{Remote Viewing End Effectors for Light Duty Utility} Arm Robot

Heckendorn, F.M.; Robinson, C.W.; Haynes, H.B.; Anderson, E.K.; Pardini, A.F.

Westinghouse Savannah River Company, Aiken, SC; Westinghouse Hanford Company, Richland, WA

WSRC-MS-96-0720; CONF-970464; Proceedings of the Seventh American Nuclear Society (ANS) Topical Meeting on Robotics and Remote Systems, Augusta, GA, April 27-May 1, 1997. ANS, La Grange Park, IL; (15 pp.) (November 4,1996)

The Robotics Development Groups at the Savannah River Site (SRS) and at the Hanford site have developed remote video and photography systems for deployment in underground radioactive-waste storage tanks at the Department of Energy (DOE) sites as a part of the Office of Science and Technology (OST) program within DOE. Viewing and documenting the tank interiors and their associated annular spaces is an extremely valuable tool in characterizing their condition and contents and in controlling their remediation. Several specialized video/photography systems and robotic End Effectors have been fabricated that provide remote viewing and lighting. All are remotely deployable into and out of the tank, with all viewing functions remotely operated. Positioning all control components away from the facility prevents the potential for personnel exposure to radiation and contamination. Only the remote video systems are discussed in this paper.

2189

V18/025664

Review of the Integrated Thermal and Nonthermal Treatment System Studies

North Dakota University, Energy and Environmental Research Center, Grand Forks, ND

DOE/MC/31388-5318; 147 pp. (October 1, 1996)

This report contains a review and evaluation of three systems analysis studies performed by LITCO on integrated thermal 
treatment systems and integrated nonthermal treatment systems for the remediation of mixed low-level waste stored throughout the US Department of Energy weapons complex. The review was performed by an independent team of nine researchers from the Energy and Environmental Research Center, Science Applications International Corporation, the Waste Policy Institute, and Virginia Tech. The purpose of this review was to: (1) determine whether the assumptions of the studies were adequate to produce an unbiased review of both thermal and nonthermal systems, (2) to identify the critical areas of the studies that would benefit from further investigation, and (3) to develop a standard template that could be used in future studies to assure a sound application of systems engineering.

\section{0}

\section{V18/025474}

\section{Risk Assessment - Insurance Coverage and Financial} Responsibility

Davis, J.L.

CONF-9611165; Underground and Aboveground Storage Tanks: Complying, Purchasing, Designing, Installing, Managing, Replacing and Remediating Underground and Aboveground Storage Tanks, Proceedings of a Canadian Institute Conference, Toronto, Ontario, Canada, November 21-22, 1996. The Canadian Institute, Toronto, Ontario, Canada, 300 pp.; (99 pp.) (1996)

The total cleanup costs associated with site contamination in Canada due to leaky storage tanks has been estimated at $\$ 30$ billion. This presentation focussed on the financial responsibility, risk assessment and legislative and common law financial liability exposures as they relate to damages and cleanup costs. Liability coverage is available and is designed to address the needs of storage tank owners and operators. Proof of insurance may be necessary for certain commercial transactions. With billions of dollars at stake, risk assessment through environmental audits has become a growing industry. Examples of policy wordings were presented. Text of relevant legislative and regulatory instruments were appended.

\section{1}

V18/022942

Second Biannual Recalibration of Two Spectral Gamma-Ray Logging Systems Used for Baseline Characterization Measurements in the Hanford Tank Farms: Vadose Zone Characterization Project at the Hanford Tank Frams

Koizumi, C.J.

Rust Geotech, Inc., Grand Junction, CO

DOE/ID/12584-281; GJPO-HAN-5; 30 pp. (August 1996)

The U.S. Department of Energy's (DOE) Grand Junction Projects Office (GJPO) is establishing an initial, or baseline, characterization of gamma-ray-emitting contaminants in the subsurface of the Tank Farms at the DOE Hanford Site in the State of Washington. These baseline data are gathered by logging existing monitoring boreholes with two high-resolution passive spectral gamma-ray logging systems (SGLSs) informally known as Gamma 1 and Gamma 2. Calibration of the logging systems is crucial to the assurance of data quality. The project document Vadose Zone Monitoring Project at the Hanford Tank Farms, Spectral Gamma-Ray Borehole Geophysical Logging Characterization and Baseline Monitoring Plan for the Hanford Single-Shell Taniks specifies that both systems must be recalibrated, using the calibration standards at the Hanford borehole logging calibration center, every 6 months. This document presents the data for the second biannual recalibrations.

2192

V18/024045

Selective Separation of Europium Using Polymer-Enhanced Ultrafiltration

Norton, M.V.; DiGiano, F.A.; Hallen, R.T.

Gray and Osborne, Inc., Seattle, WA; University of North Carolina, Chapel Hill, NC; Pacific Northwest Laboratory, Richland, WA

Water Environment Research 69(2):244-254 (March 1997)

The U.S. Department of Energy (DOE) is actively pursuing new and improved separation techniques for the cleanup of past nuclear defense production sites. Research and production activities at DOE's Hanford Site in Richland, WA have created large volumes of waste streams containing hazardous and toxic chemicals along with radioactive materials. Many of these wastes will require processing for segregation into high-level, transuranic, and/or low-level waste for permanent disposal. A process to selectively remove actinides, such as americium, from liquid radioactive waste was investigated for potential use at Hanford and other contaminated DOE sites. The objective of this research was to determine the effectiveness of polymer binding followed by ultrafiltration for removal of europium (Eu), a nonradioactive surrogate for trivalent actinides such as americium. A commercially available polyacrylic acid (PAA) and a Pacific Northwest Laboratory (PNL) synthesized copolymer were tested. Both polymers significantly increased Eu removal. A cation exchange mechanism was implied by examination of the Eu-to-RCO2-functional groups that comprise the acrylic acid monomer. The weight ratios of Eu-to-polymer needed to achieve $85 \%$ rejection of Eu were $1: 6$ for PAA and $1: 10$ for the PNL copolymer. Addition of sodium to the feed solution at a concentration three orders of magnitude greater than Eu did not adversely affect rejection of Eu; this showed the high selectivity of both polymers for Eu. Polymer binding of metals followed by ultrafiltration also has potential applications for selective separation of metals from various industrial process streams. The formation of metal hydroxide precipitates is also a possibility unless $\mathrm{pH}$ is controlled; these could be separated as well by ultrafiltration but defeat the intent of polymer addition. For the polymers tested, $\mathrm{pH}$ had to be above the $\mathrm{pKa}(4.25)$ of the ionizing functional groups but below a pH of 6 where precipitation may interfere.

\section{3}

V18/024134

Separating Technetium from Hanford Waste

Los Alamos National Laboratory, Los Alamos, NM

LALP-95-174; 1 p. (1995)

Approximately $1800 \mathrm{~kg}$ of technetium are present in the Hanford waste tanks. Technetium's potential to migrate in groundwater and its long half-life ( $\mathrm{t} 1 / 2=213,000$ years) make it a major contributor to the long-term hazard associated with the storage of Hanford low-level waste. This hazard is being mitigated by developing a process to remove $99 \%$ of the technetium from this waste. This process uses anion exchange, an "off-the-shelf" technology, with a new resin, Reillex [TM] HPQ. Flow data is currently being obtained on large columns that can be used for a full-scale processing design 
that will remediate Hanford tank waste.

2194

V18/023817

Separation and Quantitation of Radionuclides in Hanford Environmental and Waste Tank Samples Using IC-ICP/MS Techniques

Farmer, O.T., III; Smith, M.R.; Wyse, E.J.; Barinaga, C.J.; Koppenaal, D.W.

Pacific Northwest Laboratory, Richland, WA

CONF-960113; Proceedings of the 1996 Winter Conference on Plasma Spectrochemistry, Fort Lauderdale, FL, January 8-13, 1996, 378 pp.; (p. 96) (1996)

The use of shielded ICP/MS instrumentation to characterize radioactive material has seen marked growth over the past few years. With a lower limit of detection now in the $\mathrm{fg} / \mathrm{mL}$ range for newer units, ICP/MS has become the method of choice for many studies requiring rapid, isotopic analysis of both stable elements and radionuclides with half-lives greater than 102-103 years. However, despite its sensitivity and versatility, ICP/MS has heretofore had some notable limitations in certain radiological applications. For example, Hanford waste tank samples contain a variety of nuclides with altered isotopic abundances, which complicate identification of these nuclides. Even if a nuclide can be identified, conventional quantitation using vendor-supplied software assumes natural, or knowledge of, isotopic abundance. Difficult sample matrices like those obtained from the Hanford tanks can further complicate interpretation and quantitation. On-line chromatography (IC) has been recently employed to mitigate some of these problems. By sequentially separating elements, isobars can be resolved, thereby permitting the unequivocal determination of isotopic abundances. But even though the technique resolves isobaric interferences and is effective in reducing matrix problems, IC does not easily lend itself to quantitation. Internal standards, which are crucial for quantitation during a prolonged ICP/MS analysis with varying eluant matrices, are separated or affected as any indigenous element is using standard IC methodology.

\section{$2195 \quad$ V18/022402}

Sluicing Nozzle Test Report: Volume 1

Packer Engineering, Inc., Naperville, IL WHC-SD-WM-TD-013; 20 pp. (July 1996)

The Westinghouse Hanford Company (WHC) is exploring various options for retrieving waste materials from the underground storage tanks at the Hanford Site in Richland, Washington. One option under investigation is the use of a commercially available sluicing nozzle manufactured by Bristol Equipment Company (BEC). A test program was recently conducted under Purchase Order Number MKJ-SVW-400385 to determine the performance of the sluicing nozzle against several waste simulants developed by WHC. The purpose of the test program was to establish a performance baseline against which to compare other competing technologies. The sluicing nozzle performance was determined as a function of nozzle diameter, nozzle pressure, and standoff. The test program was divided into two test groups: Load Cell Tests and Waste Simulant Reaction Tests. The approved Work Plan is included in Appendix A and the approved Test Procedure is included in Appendix B for reference. A photograph log is included as a separate volume to this report (Volume II). Four videotapes have also been submitted as part of the test program documentation (Volume III).

2196

V18/022188

Solvent Extraction of Radionuclides from Aqueous Tank Waste

Bonnesen, P.V.; Sachleben, R.A.; Moyer, B.A.

Pacific Northwest National Laboratory, Richland, WA; Oak Ridge National Laboratory, Oak Ridge, TN

PNNL-SA-27105; CONF-960158; Efficient Separation and Processing Crosscutting Program, Proceedings of the 1996 Technical Exchange Meeting, Gaithersburg, MD, January 16-19, 1996, 52 pp.; (pp. 43-46) (1996)

The purpose of this task is to develop an efficient solvent-extraction and stripping process to remove the fission products Tc-99, Sr-90, and Cs-137 from alkaline tank waste, such as those stored at Hanford and Oak Ridge. As such, this task expands on FY 1995's successful development of a solvent-extraction and stripping process for technetium separation from alkaline tank-waste solutions. This process now includes the capability of removing both technetium and strontium simultaneously. In this form, the process has been named SRTALK and will be developed further in this program as a prelude to developing a system capable of removing technetium, strontium, and cesium.

2197 V18/021806

\section{Spotlight on the Tanks Focus Area}

Initiatives in Environmental Technology Investment 3 (June 1996):4-5 (June 1996)

The Tanks Focus Area, or TFA, planned 21 demonstrations for fiscal year 1996 ranging from bench- to full-scale. The following technologies are discussed in this paper: Mobile evaporator, Light duty utility arm, Sorbents, Near infrared spectroscopy. In addition to technologies, other activities of the TFA are also discussed including: Stakeholder involvement, the Collaborative treatability study, the Mid-year review, and the Hanford tanks guide.

\section{8}

\section{V18/024283}

Strategies for Redundancy Resolution of Dual-Arm Systems with Passive Elements for Tank Waste Removal

Dubey, R.; Love, L.J.

University of Tennessee, Department of Mechanical Engineering, Knoxville, TN; Oak Ridge Institute for Science and Education, Oak Ridge, TN; Oak Ridge National Laboratory, Oak Ridge, TN

CONF-970464; Proceedings of the Seventh American Nuclear Society (ANS) Topical Meeting on Robotics and Remote Systems, Augusta, GA, April 27-May 1, 1997. ANS, La Grange Park, IL; (8 pp.) (1997)

The work described in this paper focuses on the coordination and control of two manipulators coupled by passive elements operating in a confined space. An example of one such system is the hardware used for the environmental response treatability study funded by the Department of Energy at Oak Ridge National Laboratory (ORNL). The motivation for this project is to establish the methodology 
necessary to extract large volumes of hazardous waste from underground storage facilities. The hardware used at ORNL consists of two long-reach manipulators. The first robot, the Modified Light Duty Utility Arm (MLDUA), is an 8-degree-of-freedom long-reach manipulator. The second arm, the Hose Management Arm (HMA), has two active degrees-of-freedom and provides hardware to break up and extract materials from the tank. Current strategies call for the MLDUA to grasp a combined sluicing end-effector attached by a long flexible hose to the HMA. The MLDUA will then move the combined system through the waste, extracting material. This paper describes many of the issues related to redundancy resolution and the coordinated control of these two robots. First, the authors provide a brief outline of the project and the existing hardware. This is followed by a description of existing redundancy resolution techniques and the impact redundancy has on the success of the project. Finally, preliminary simulation results show the effect cooperative control has on the level of forces generated between the dual-arm systems when coupled by an elastic exhaust hose. These results show a significant reduction in forces when both arms are active and have a combined manipulation strategy.

\section{9}

V18/020641

Systematic Look at Tank Waste Remediation System Privatization

Holbrook, J.H.; Duffy, M.A.; Vieth, D.L.; Sohn, C.L. Pacific Northwest National Laboratory, Richland, WA PNNL-10937; 172 pp. (January 1996)

The mission of the Tank Waste Remediation System (TWRS) Program is to store, treat, immobilize, and dispose, or prepare for disposal, the Hanford radioactive tank waste in an environmentally sound, safe, and cost effective manner. Highly radioactive Hanford waste includes current and future tank waste plus the cesium and strontium capsules. In the TWRS program, as in other Department of Energy (DOE) clean-up activities, there is an increasing gap between the estimated funding required to enable DOE to meet all of its clean-up commitments and level of funding that is perceived to be available. Privatization is one contracting/management approach being explored by DOE as a means to achieve cost reductions and as a means to achieve a more outcome-oriented program.

Privatization introduces the element of competition, a proven means of establishing true cost as well as achieving significant cost reduction.

V18/020608

TWRS Privatization Bibliography [Rev. 2]

Pacific Northwest National Laboratory, Richland, WA

PNNL-10969 (Rev. 2); 80 pp. (April 1996)

The purpose of this bibliography is to present a select set of documents that may be of interest to the Offeror, covering a variety of subject areas related to the TWRS Privatization Project. This bibliography is not, nor is it intended to be, exhaustive or complete. It was prepared with the intent of providing a sampling of representative documents potentially helpful to Offerors. This bibliography is organized by subject area. The subjects covered are: waste characterization; pre-treatment; high-level waste immobilization; low-level waste immobilization; low-level waste melter test program; performance assessment; general; and safety.
2201

V18/024281

Tank Focus Area Pretreatment Activities

McGinnis, C.P.; Welch, T.D.; Manke, K.L.

Oak Ridge National Laboratory, Oak Ridge, IN; Pacific Northwest National Laboratory, Richland, WA

CONF-970321; Proceedings of a National Spring Meeting and Petrochemical Exposition of the American Institute of Chemical Engineers (AIChE) and the Second Plant Operations and Design Conference, Houston, TX, March 10-13, 1997; (20 pp.) (1997)

Plans call for the high-level wastes to be retrieved from the tanks and immobilized in a stable waste form suitable for long-term isolation. Chemistry and chemical engineering operations are required to retrieve the wastes, to condition the wastes for subsequent steps, and to reduce the costs of the waste management enterprise. Pretreatment includes those processes between retrieval and immobilization, and includes preparation of suitable feed material for immobilization and separations to partition the waste into streams that yield lower life-cycle costs. Some of the technologies being developed by the Tank Focus Area (TFA) to process these wastes are described. These technologies fall roughly into three areas: (1) solid/liquid separation (SLS), (2) sludge pretreatment, and (3) supemate pretreatment.

2202

$\mathrm{V} 18 / 021745$

Tank Waste Remediation System, Hanford Site, Richland, Washington: Final Environmental Impact Statement - Volume 6 (Appendix L: Draft EIS Comments and Agency Responses)

U.S. Department of Energy, Richland Operations Office, Richland, WA; Washington State Department of Ecology, Waste Reduction, Recycling and Litter Control Program, Olympia, WA

DOE/EIS-0189 (Vol. 6); 397 pp. (August 1996)

The U.S. Department of Energy and the Washington State Department of Ecology added Appendix L, Response to Public Comments, to the Tank Waste Remediation System (TWRS) Environmental Impact Statement (EIS) to fully address and respond to public comments on the Draft EIS. In addition, DOE considered public comments, along with other factors such as programmatic need, short- and long-term impacts, technical feasibility, and cost, in arriving at DOE's preferred alternative. During the public comment period for the Draft EIS, more than 350 individuals, agencies, Tribal Nations, and organizations provided comments. This volume represents a broad spectrum of private citizens; businesses; local, State, and Federal officials; Tribal Nations; and public interest groups.

\section{V18/021019}

Tank Waste Remediation System, Hanford Site, Richland, Washington: Final Environmental Impact Statement - Summary

U.S. Department of Energy, Richland Operations Office, Richland, WA; Washington State Department of Ecology, Waste Reduction, Recycling and Litter Control Program, Olympia, WA 


\section{DOE/EIS-0189 (Summary); 60 pp. (August 1996)}

This appendix analyzes the potential environmental consequences related to the Hanford Site Tank Waste Remediation System (TWRS) alternatives for management and disposal of radioactive, hazardous, and mixed waste, and the management and disposal of approximately 1,930 cesium and strontium capsules located at the Hanford Site. This waste is currently or projected to be stored in 177 underground storage tanks and approximately 60 miscellaneous underground storage tanks. This document analyzes the following alternatives for remediating the tank waste: No Action, Long-Term Management, In Situ Fill and Cap, In Situ Vitrification, Ex Situ Intermediate Separations, Ex Situ No Separations, Ex Situ Extensive Separations, Ex Situ/In Situ Combination 1, and Ex Situ/In Situ Combination 2. This document also addresses a Phased Implementation alternative (the DOE and Ecology preferred alternative for remediation of tank waste). Alternatives analyzed for the cesium and strontium capsules include: No Action, Onsite Disposal, Overpack and Ship, and Vitrify with Tank Waste. The DOE and Ecology preferred alternative for the cesium and strontium capsules is the No Action alternative.

\section{4}

V18/020607

Test Plan for Fauske and Associates to Perform Tube Propagation Experiments with Simulated Hanford Tank Wastes [Rev. 1]

Carlson, C.D. ; Babad, H.

Pacific Northwest Laboratory, Richland, WA; Westinghouse Hanford Company, Richland, WA

PNNL-10970 (Rev. 1); 53 pp. (May 1996)

This test plan, prepared at Pacific Northwest National Laboratory for Westinghouse Hanford Company, provides guidance for performing tube propagation experiments on simulated Hanford tank wastes and on actual tank waste samples. Simulant compositions are defined and an experimental logic tree is provided for Fauske and Associates (FAD) to perform the experiments. From this guidance, methods and equipment for small-scale tube propagation experiments to be performed at the Hanford Site on actual tank samples will be developed. Propagation behavior of wastes will directly support the safety analysis (SARR) for the organic tanks. Tube propagation may be the definitive tool for determining the relative reactivity of the wastes contained in the Hanford tanks. FAI have performed tube propagation studies previously on simple two- and three-component surrogate mixtures. The simulant defined in this test plan more closely represents actual tank composition. Data will be used to support preparation of criteria for determining the relative safety of the organic bearing wastes.

\section{5}

V18/025320

Treatment of Hazardous and Radioactive Waste from Underground Storage Tanks Using Insitu Vitrification

Seacord, T.F.

Clarkson University, Department of Civil and Environmental Engineering, Potsdam, NY

CONF-970335; Waste Management '97: Working Towards a Cleaner Environment, Proceedings of a Conference on HLW,
LLW, Mixed Wastes and Environmental Restoration, Tucson, $A Z$, March 2-6, 1997; (11 pp.) (1997)

An interdisciplinary student design team produced a conceptual design and project plan for the safe and cost effective treatment of hazardous and radioactive wastes which reside in four different underground storage tanks. To treat these wastes, it was decided that an exsitu treatment would cause unnecessary risk of exposure to radiation and hazardous chemicals. For this reason, in-situ vitrification (ISV) was chosen to treat the site. Legal and regulatory requirements were identified and actions were taken for compliance. Legal and regulatory requirements included: community relations, OSHA training for workers, environmental regulations for off-gas treatment and leachate analysis, and disposal of secondary waste from the off-gas treatment system. Overburden soil was added or taken away from the site of each tank to provide adequate shielding from radiation while achieving optimum conditions for vitrification. A health and safety plan was produced which provided for optimal worker and community safety by monitoring radiation levels and establishing an emergency action plan. A community relations plan was implemented early in the design process. A sample community was assembled and accepted the proposal of using ISV. Their concerns were identified and incorporated into the design. A plan for communication was established which involved meetings, brochures, and an 800 number to provide further information and address concerns. An economic assessment and business plan indicated that ISV was far superior to exsitu treatment and disposal noting that disposal costs alone were greater than the entire ISV operation.

\section{6 \\ V18/022846}

Underground Storage Tank Waste Retrieval Strategies Using a High-Pressure Waterjet Scarifier

Hatchell, B.K.; Smalley, J.T.

Pacific Northwest National Laboratory, Richland, WA CONF-960804 (Vol. 3); Spectrum '96: Nuclear and Hazardous Waste Management, Proceedings of an International Topical Meeting, Seattle, WA, August 18-23, 1996. American Nuclear Society, La Grange Park, IL, Vol. 3, 841 pp.; (pp. 2347-2354) (1996).

The Retrieval Process Development and Enhancements Program (RPD\&E) is sponsored by the U.S. Department of Energy Office of Science and Technology to investigate existing and emerging retrieval processes suitable for the retrieval of high-level radioactive waste inside underground storage tanks. This program, represented by industry, national laboratories, and academia, seeks to provide a technical and cost basis to support site-remediation decisions. Part of this program has involved the development of a high-pressure waterjet dislodging system and pneumatic conveyance integrated as a scarifier. Industry has used high-pressure waterjet technology for many years to mine, cut, clean, and scarify materials with a broad range of properties. The scarifier was developed as an alternate means of retrieving waste inside Hanford single-shell tanks, particularly hard, stubbom waste. Simulant materials representative of tank waste have been used to test the performance of the scarifier over a wide range of waste types. This technology has been shown to mobilize and convey the waste simulants at desired retrieval rates while operating within the space envelope and the dynamic loading constraints of proposed deployment devices. A 
testing program has been initiated to investigate system deployment techniques to determine appropriate mining strategies, level of control, sensor requirements, and address integration issues associated with deploying the scarifier by a long robotic manipulator arm. A test facility denoted the Hydraulics Testbed (HTB) is being constructed to achieve these objectives and to allow longer-duration, multiple-pass tests on large waste fields using a versatile gantry-style manipulator. Mining strategy tests with materials simulating salt cake and sludge waste forms will be conducted to evaluate the effectiveness of mining strategies, forces related to scarifier and conveyance line, and retrieval rate. This paper will describe the testbed facility and testing program and present initial test results to date.

\section{7 \\ V18/025546}

Use of Compact Processing Units for DOE High-Level Waste Tank Remediation

Geiser, D.W.; Fadullon, F.S.; Nenninger, L.L.

U.S. Department of Energy, Germantown, MD; Science Applications International Corporation, Gaithersburg, MD CONF-960804 (Vol. 3); Spectrum '96: Nuclear and Hazardous Waste Management, Proceedings of an International Topical Meeting, Seattie, WA, August 18-23, 1996. American Nuclear Society, La Grange Park, IL, Vol. 3, 841 pp.; (pp. 2510-2515) (1996) ${ }^{\text {' }}$

Compact processing is a concept developed at Pacific Northwest National Laboratory for rapidly deploying technologies for the treatment of DOE's stored waste. The concept envisions small, modular, mobile "Compact Processing Units" (CPUs), deployed near waste storage tanks to perform waste treatment at a rate of two to five gallons per minute. The small scale units provide process flexibility and avoid the need to build large, costly treatment plants. They can be taken from design, construction, and testing through hot operations in eighteen months, which allows for rapid utilization, improvement, and innovation. Compact processing units could be designed for a variety of waste characterization, retrieval, and treatment operations. This paper discusses the first generation of CPUs, currently being tested by the Tanks Focus Area. They include units for radionuclide extraction, evaporation, and waste retrieval. After demonstration and testing they will be transferred to EM-30 and EM-40's continuing operations.

2208 V18/020605

Vitrification Technology for Hanford Site Tank Waste Weber, E.T.; Calmus, R.B.; Wilson, C.N. Westinghouse Hanford Company, Richland, WA WHC-SA-2862; CONF-950401; Proceedings of the American Ceramic Society 97th Annual Meeting, Cincinnati, OH, April 30-May 1, 1995; (17 pp.) (April 1995)

The U.S. Department of Energy's (DOE) Hanford Site has an inventory of $217,000 \mathrm{cu} \mathrm{m}$ of nuclear waste stored in 177 underground tanks. The DOE, the U.S. Environmental Protection Agency, and the Washington State Department of Ecology have agreed that most of the Hanford Site tank waste will be immobilized by vitrification before final disposal. This will be accomplished by separating the tank waste into high- and low-level fractions. Capabilities for high-capacity vitrification are being assessed and developed for each waste fraction. This paper provides an overview of the program for selecting preferred high-level waste melter and feed processing technologies for use in Hanford Site tank waste processing.

V18/025545

Waste Retrieval System Development and Demonstration

Bamberger, J.A.; Rinker, M.W.

Pacific Northwest National Laboratory, Richland, WA

CONF-960804 (Vol. 3); Spectrum '96: Nuclear and Hazardous Waste Management, Proceedings of an Intemational Topical Meeting, Seattle, WA, August 18-23, 1996. American Nuclear Society, La Grange Park, IL, Vol. 3, 841 pp.; (pp. 1921-1928) (1996)

Waterjet technologies are being developed and applied to radioactive waste retrieval, processing, and system decontamination. Benefits from this approach include control of waste dilution and dissolution, the ability to clean tank surfaces, and selective removal of surface contaminants. Systems under development include: (1) pulsed air mixers as an alternative to mixer pumps to maintain slurries in suspension; (2) borehole miner with an extendible nozzle as an enhancement of sluicing; (3) confined sluicing end effector with jet pump retrieval for breakup and removal of sludges and solids; and (4) scarifier with pneumatic conveyance for fracture and removal of sludges and harder solids without water accumulation or appreciable waste dilution and surface decontamination. Two systems are being developed for demonstration in radioactive tanks in Fiscal Year 1997: the confined sluicing end effector for retrieval of waste from tanks W3 and W4 at Oak Ridge National Laboratory and extendible nozzle for zeolite, heel breakup at Savannah River Site tank 19. 


\section{U.S. DEPARTMENT OF ENERGY (DOE) TECHNOLOGY DEVELOPMENT, DEMONSTRATION, AND EVALUATION}




\section{0}

\section{V18/023900}

Progressive DOE Superfund Site Cleanup with Advanced Technologies

Ziagos, J.; Aines, R.; Blake, R.G.; Folsom, E.; Hoffman, F.; Isherwood, B.; Knapp, R.B.; Knauss, K.; Newmark, R.L.; Peterson, B.; Ragaini, R.C.; Yow, J.L., Jr.; Younker, L.W. Lawrence Livermore National Laboratory, Livermore, CA

CONF-951124; HazMat West '95, Proceedings of the Eleventh Annual Environmental Management and Technology Conference and Exhibition, Long Beach, CA, November 7-9, 1995. Advanstar Expositions, Duluth, MN, 597 pp.; (pp. 251-266) (1995)

Lawrence Livermore National Laboratory proposes to apply advanced technologies for site remediation to achieve negotiated closure of the Livermore Superfund site. This new LLNL approach integrates scientific, technical, operational, and regulatory project components to save decades of work and hundreds of millions of dollars over realistic current life-cycle cleanup estimates. Overall savings for DOE will be amplified if this integrated approach is applied across the defense complex. The LLNL site cleanup will apply new in situ remediation technologies to destroy contaminant sources and intercept migrating plumes. These technologies will be focused where significant amounts of contaminant (greater than 50 parts per billion) reside in the subsurface. Focusing the most aggressive cleanup methods on these targets will cut the volume of soil to be treated from an original estimate of about $50 \mathrm{M} \mathrm{cu} \mathrm{m}$ to about $3 \mathrm{M}$ cu $\mathrm{m}$ - a factor of over 15 in volume reduction. While the new technologies are fielded and operated, advanced pump-and-treat methods employed at the site perimeter will control off-site movement of contaminants.

\section{1 \\ V18/021393}

Stakeholders, Key Players in Successful Technology Demonstration - Overview of the SCAPS Demo

Sauerwein, $R$.

Oxnard Plain Restoration Advisory Board, Oxnard, CA

Fostering the Needed Partnerships: Doing the Necessary Science to Support Technology Development, Commercialization, Deployment, E.L. Helminski (ed.), Proceedings of the Seventh Annual Western Governors' Association/Weapons Complex Monitor Applied Research and Cleanup Technology Colloquium, Phoenix, AZ, April 29-May 2, 1996. Exchange/Monitor Publications and Forums, Lake Bluff, IL, 500 pp.; (10 pp.) (April 1996)

This paper describes the Site Characterization and Analysis Penetrometer System (SCAPS) Laser Induced Fluorescence (LIF) demonstration program at Oxnard Plain. SCAPS-LIF is a real-time, cost-effective technique for in-situ detection of subsurface contamination due to petroleum products which combines an LIF spectroscopic system with a cone penetrometer truck. The objectives of the demonstration program were to promote acceptance of the technology by involving multiple stakeholders and improving regulatory participation. The viewgraphs for the presentation include a technology overview, demonstration milestones, key players, keys to a successful public forum, and a comprehensive list of lessons learned.

\section{2}

V18/021440

Directional Drilling and Remediation Applications at the Idaho National Engineering Laboratory

Hubbell, J.M.

Idaho National Engineering Laboratory, Idaho Falls, ID

Report; 22 pp. (September 1992)

This study was conducted to determine if directional drilling techniques are applicable for use at the INEL and to survey potential INEL sites that could use directional drilling to access contaminated sites and to facilitate characterization and remediation activities. Since a similar project was being performed at the Savannah River Site (SRS), it was decided to terminate the field investigations at the INEL and become involved with the Savannah River Integrated Demonstration (SRID) Project to obtain information on the feasibility of horizontal drilling and remediation (OTD) program to transfer the directional drilling technology to the INEL. Under the SRID program the INEL has been represented on the Directional Drilling Technical Support Group. This paper discusses the three major directional drilling techniques and examines sites at INEL where directional drilled wells could be used for characterization and remediation activities. The guided boring system (thrust boring) has the greatest potential for use at the INEL for sampling within sediments beneath disposal areas for characterization activities. The river crossing technique appears to be the best developed technique for drilling long horizontal wells within sediments where sampling is not required. The petroleum drilling technique appears to be best developed to perform drilling/sampling in basalt and for drilling and sampling within sediments where horizontal distances greater than $400 \mathrm{ft}$ are not required.

\section{$2213 \quad$ V18/021126}

Results and Cost Savings from Radiological Surveys of Buried Drain Lines with the Pipe Explorer [TM] System Cremer, C.D.; Kendrick, D.T.; Cramer, E.; Lowry, W.E. Science and Engineering Associates, Inc., Albuquerque, NM CONF-960212; Waste Management '96: Working Towards a Cleaner Environment, Proceedings of a Conference on $\mathrm{HLW}$, LLW, Mixed Wastes and Environmental Restoration, Tucson, AZ, February 25-29, 1996; (17 pp.) (1996)

Science and Engineering Associates, Inc. (SEA) has developed a unique and versatile method of transporting characterization tools into pipes, drain-lines, and ducts. The system, called the Pipe Explorer [TM], uses a pressurized inverting membrane to tow sensors such as radiation detectors, video cameras, and pipe locator beacons through pipes. In addition to towing characterization tools, such as a radiation detector, the membrane also lines the pipe to provide a clean conduit through which the detector travels. This protects expensive sensors by preventing removable contamination from coming into contact with them. Cross contamination is thus eliminated allowing the system to obtain a true measurement of contaminant activity as a function of distance. The system is currently capable of transporting detectors up to 250 feet in pipes 2 inches in diameter and greater. It can also negotiate multiple elbows and obstructions. The DOE Morgantown Energy Technology Center sponsored the development of this technology as a 
characterization tool to support the decommissioning and decontamination of DOE nuclear process facilities. Recently the system was demonstrated at a site being remediated under the DOE Formerly Utilized Sites Remedial Action Program (FUSRAP). The Pipe Explorer [TM] successfully characterized a total of 8, 4-inch diameter buried drain-lines, over lengths as long as 120 feet. The interior surfaces of the drain-lines were coated with a thick oily sludge that contained residual amounts of $U-238$. The drain-lines were continuously characterized over the entire lengths and were found to have contamination levels ranging from below 3000 $\mathrm{dpm} / 100$ square centimeters to over $1,000,000 \mathrm{dpm} / 100$ square centimeters. By using the Pipe Explorer [TM] system the DOE FUSRAP was able to save in excess of $\$ 1,000,000$ in this single demonstration. These cost savings were realized through reduction of secondary waste and by avoiding more labor intensive and less accurate survey methods. A description of the system and samples of the data obtained from the FUSRAP site are presented. In addition, data substantiating the cost savings by the DOE are included.

\section{4}

\section{V18/021322}

\section{Pipe Explorer Squeezes into Tight Spots}

\section{SEA, Albuquerque, NM}

Initiatives in Environmental Technology Investment 3(February 1996):8-9 (February 1996)

During recent testing, Pipe Explorer, a sensor for detecting radiation inside pipes, saved the U.S. Department of Energy about $\$ 1.5$ million in avoided costs. The testing was conducted at a DOE Formerly Utilized Sites Remedial Action Program site, now used by General Motors as an automobile plastics factory. Use of the Pipe Explorer avoided drain-line excavation and plant impacts, such as the cost of relocating portions of the active factory. The savings is nearby three times the amount invested in Pipe Explorer's development.

\section{5 \\ V18/022837}

Technology Used in the Cleanup of a Difficult-to-Remediate Facility

Ramachandran, $\mathrm{N}$.

Bechtel National, Inc., Oak Ridge, TN

CONF-960804 (Vol. 3); Spectrum '96: Nuclear and Hazardous Waste Management, Proceedings of an Intemational Topical Meeting, Seattle, WA, August 18-23, 1996. American Nuclear Society, La Grange Park, IL, Vol. 3, 841 pp.; (pp. 1974-1976) (1996)

New technologies were used to cost-effectively remediate several hundred feet of radioactively contaminated subsurface drain pipes at the General Motors site in Adrian, Michigan, and to conduct post-remedial verification surveys. Supplemental cleanup criteria were applied to inaccessible areas of the project, and inexpensive treatment technology was used to treat wastewater generated. Application of these methods resulted in substantial cost savings.

\section{6}

\section{V18/022603}

Evaluation of Two New Grouts for Constructing Subsurface Barriers
Voss, C.F.; Einberger, C.M.; Matalucci, R.V.

Golder Associates, Inc., Redmond, WA; Sandia National Laboratories, Albuquerque, NM

CONF-941124; Insitu Remediation: Scientific Basis for Current and Future Technologies, G.W. Gee and N.R. Wing (eds.), Proceedings of the 33rd Hanford Symposium on Health and the Environment, Pasco, WA, November 7-11, 1994. Battelle Press, Columbus, OH, Part 1, 704 pp.; (pp. 113-134) (1994)

This paper presents the results of laboratory and field tests to evaluate two new grout materials for creating low-permeability barriers in unconsolidated soils. The grout materials of interest are a particulate grout developed in Germany, consisting of a naturally occurring wax (montan wax), water, and bentonite, and a glyoxal-modified sodium silicate chemical grout developed in France. The test program assesses the suitability of the grout for creating subsurface containment barriers in contaminated soils over a range of soil and contaminant conditions. Laboratory activities are described that evaluated permeability reductions achieved by . grout placement within a range of soil types and assessed the compatibility of the grouts with a variety of waste forms. A series of single-borehole injection tests are described that were conducted at the Mixed Waste Landfill Integration Demonstration site at Sandia National Laboratories to evaluate the grout performance and permeation distances under field-scale conditions. Injection and monitoring methods are described, and the results of the single-borehole tests are reviewed.

\section{7 \\ V18/020667}

Development and Application of Engineered Proteins for Bioremediation

Trewhella, J.

Los Alamos National Laboratory, Los Alamos, NM

LA-UR-96-1767; CONF-9509364 (Exec. Summ.); Development and Application of Engineered Proteins for Bioremediation, Proceedings of a Symposium, Los Alamos, NM, September 26, 1995, 56 pp. (September 26, 1995)

Clean up of the toxic legacy of the Cold War is projected to be the most expensive domestic project the nation has yet undertaken. Remediation of the Department of Energy and Department of Defense toxic waste sites alone are projected to cost approximately $\$ 1$ trillion over a 20-30 year period. New, cost effective technologies are needed to attack this enormous problem. Los Alamos has put together a cross-divisional team of scientists to develop science-based bioremediation technology to work toward this goal. In the team there is expertise in: (1) molecular, ecosystem and transport modeling; (2) genetic and protein engineering; (3) microbiology and microbial ecology; (4) structural biology; and (5) bioinorganic chemistry. This document summarizes talks at a workshop of different aspects of bioremediation technology including the following: Introducing novel function into a Heme enzyme: engineering by excavation; cytochrome $\mathrm{P}-450$ : ideal systems for bioremediation; selection and development of bacterial strains for in situ remediation of chlorinated solvents; genetic analysis and preparation of toluene ortho-monooxygenase for field application in remediation of trichloroethylene; microbial ecology and diversity important to bioremediation; engineering haloalkane dehalogenase for bioremediation; enzymes for oxidative 
biodegradation; indigenous bacteria as hosts for engineered proteins; performance of indigenous bacteria, hosting engineered proteins in microbial communities.

\section{8 \\ V18/020668}

EPA Speeds Technology Implementation

Hightower, M.M.

Sandia National Laboratories, Environmental Programs

Center, Albuquerque, NM

Chemtech 26(4):73-75 (April 1996)

Common barriers block the use of innovative remediation technologies. The Innovative Treatment Remediation Demonstration (ITRD) Program at the U.S. Department of Energy's (DOE) Sandia National Laboratories was initiated in 1993 in cooperation with the U.S. Environmental Protection Agency's (EPA) Technology Innovation Office in an attempt to reduce these barriers and accelerate the implementation of innovative remediation technologies. The innovative technologies considered for evaluation by the ITRD program lack the cost and performance information that would otherwise permit their full consideration as remedial altematives. These technologies have often shown promise in pilot-scale applications but have limited full-scale data. Some examples in this category include: bioremediation, in situ dynamic stripping, soil washing and soil flushing, solvent and surfactant extraction and chemical treatment, in situ passive treatment, and advanced physical separation techniques. Currently, three ITRD projects are under way. ITRD sites are generally small, and most are characterized sites already scheduled for remediation. Thus, each project can be initiated quickly; additional program costs are minimized; and overall site remediation is accelerated. ITRD projects tend to target sites with typical soil and groundwater contamination problems. Contaminants at such sites include chlorinated solvents and petroleum products; pesticides, polychlorinated biphenyls (PCBs), and dioxins; heavy metals; explosives; and complex or multiconstituent contamination. The paper describes the activities at these three projects located at Pinellas, Mound Laboratory, and Fernald.

\section{9}

V18/022175

Application of Dig-Face Monitoring During Excavation of a Radioactive Plume

Josten, N.E.; Gehrke, R.J.; Stanley, R.; MacMahan, K.

Idaho National Engineering Laboratory, Idaho Falls, ID; EG\&G Mound Applied Technologies, Inc., Miamisburg, OH CONF-960477; SAGEEP '96, R.S. Bell and M.H. Cramer (eds.), Proceedings of the Ninth Annual Symposium on the Application of Geophysics to Engineering and Environmental Problems, Denver, CO, April 15-May 1, 1996. Environmental and Engineering Geophysical Society, Wheat Ridge, CO, 1353 pp.; (pp. 1135-1156) (1996)

Dig-face characterization is a concept for improving the safety and efficiency of hazardous waste retrieval. A dig-face characterization system consists of onsite hardware for collecting detailed information on the changing chemical, radiological, and physical conditions in the subsurface during the entire course of a hazardous site excavation. The dig-face characterization concept originated at the Idaho National Engineering Laboratory and has been under development there since 1992. During August 1995, a prototype dig-face system was taken to Mound Laboratory, Ohio, for a first attempt at monitoring a hazardous excavation. Mound Area 7 was the site of historical disposals of Th-232, Ac-227, and assorted debris. The dig-face characterization system was used to monitor a 20-ft $\times 20$-ft $\times 5$-ft-deep excavation aimed at removing Ac-227 contaminated soils. Radiological, geophysical, and topographic sensors were scanned across the excavation dig-face at four successive depths as soil was removed in 1-ft to 2-ft lifts. The geophysical and topographic sensors located metallic debris and mapped the dig-face topography in great detail as the excavation advanced. The radiation sensors produced high-fidelity images showing the location of radioactive contaminants and clearly identified and delineated separate Th-232 and Ac-227 plumes. By combining the radiation data from all four levels, a three-dimensional image of the contamination plumes was developed. The radiation sensor data indicated that only a small portion of the excavated soil volume was contaminated. The spatial information produced by the dig-face system was used to direct the excavation activities into the area containing the Ac-227 and to evaluate options for handling the separate Th-232 plume.

\section{0}

V18/022173

Environmental Measurement While Drilling Gamma Ray Spectrometer (EMWD-GRS) System Technology Demonstration Plan for Use at the Savannah River Site F-Area Retention Basin

Williams, C.V.; Lockwood, G.J.; Normann, R.A.; Gruebel, R.D.

Sandia National Laboratories, Albuquerque, NM; Tech Reps, Inc., Albuquerque, NM

SAND96-2019; 180 pp. (August 1996)

The Environmental Measurement-While-Drilling-Gamma Ray Spectrometer (EMWD-GRS) system represents an innovative blend of new and existing technology that provides the capability of producing real-time environmental and drillbit data during drilling operations. This demonstration plan presents information on the EMWD-GRS technology, demonstration design, Cs-137 contamination at the Savannah River Site F-Area Retention Basin, responsibilities of demonstration participants, and the policies and procedures for the demonstration to be conducted at the Savannah River Site F-Area Retention Basin. The EMWD-GRS technology demonstration will consist of continuously monitoring for gamma-radiation contamination while drilling two horizontal boreholes below the backfilled retention basin. These boreholes will pass near previously sampled vertical borehole locations where concentrations of contaminants are known. Contaminant levels continuously recorded by the EMWD-GRS system during drilling will be compared to contaminant levels previously determined through quantitative laboratory analysis of soil samples.

2221 V18/021446

Evaluation of PAWS System for On-Line Monitoring of Off-Gas Concentrations: Evaluation Report for PAWS Off-Gas

Frye, G.C. 
Sandia National Laboratories, Albuquerque, NM

Report; 8 pp. (September 30, 1992)

This report summarizes the results of a project to develop and demonstrate a portable acoustic wave sensor (PAWS) system for real-time, on-line monitoring of volatile organic contaminants in off-gas lines at the Savannah River ID Site. System development was done in collaboration with two other OTD programs: On-Line Monitoring of Volatile Organics for Waste Minimization and PAWS Down Hole Liquid/Vapor Phase. A description of the basic sensor capabilities including a patented dual output technique for molecular discrimination is given in an accompanying article entitled "Portable Acoustic Wave Sensor Systems for On-Line Monitoring of Volatile Organics" published in the International Journal of Environmentally Conscious Manufacturing, 1 (1992) 37. This article also gives a description of the PAWS system and its basic capabilities. Additional information is provided in the accompanying text entitled "Input for the Interim Monitoring Summary Report: Savannah River Integrated Demonstration Program."

\section{2}

V18/021413

Insitu Bioremediation: Cost Effectiveness of a Remediation Technology Field Tested at the Savannah River Integrated Demonstration Site

Saaty, R.P.; Booth, S.R.

Los Alamos National Laboratory, Los Alamos, NM

LA-UR-94-1714; 75 pp. (November 1994)

The purpose of this report is to study the cost effectiveness of Insitu Bioremediation (ISBR) with horizontal wells as tested at the Savannah River Integrated Demonstration (SRID) site in Aiken, South Carolina. ISBR is an innovative new remediation technology for the removal of chlorinated solvents from contaminated soils and groundwater. The principal contaminant at the SRID is the volatile organic compound (VOC), trichloroethylene (TCE). A 384 day test nun at Savannah River, sponsored by the U.S. Department of Energy, Office of Development (EM-50), furnished information about the performance and applications of ISBR.

\section{3}

\section{V18/021421}

Insitu Permeable Flow Sensor: A Device for Measuring Groundwater Flow Velocity

Ballard, S.; Barker, G.T.; Nichols, R.L.

Sandia National Laboratories, Albuquerque, NM; Savannah River Technology Center, Aiken, SC

SAND93-2765; 37 pp. (March 1994)

A new technology called the Insitu Permeable Flow Sensor has been developed at Sandia National Laboratories. These sensors use a thermal perturbation technique to directly measure the direction and magnitude of the full three dimensional groundwater flow velocity vector in unconsolidated, saturated, porous media. The velocity measured is an average value characteristic of an approximately 1 cubic meter volume of the subsurface. During a test at the Savannah River Site in South Carolina, two flow sensors were deployed in a confined aquifer and the well was pumped at four different pumping rates. In this situation horizontal flow which is radially directed toward the pumping well is expected. The flow sensors measured horizontal flow which was directed toward the pumping well, within the uncertainty in the measurements. The observed magnitude of the horizontal component of the flow velocity increased linearly with pumping rate, as predicted by theoretical considerations. The measured horizontal component of the flow velocity differed from the predicted flow velocity, which was calculated with the assumptions that the hydraulic properties of the aquifer were radially homogeneous and isotropic, by less than a factor or two. Drawdown data obtained from other well near the pumping well during the pump test indicate that the hydraulic properties of the aquifer are probably not radially homogeneous but the effect of the inhomogeneity of the flow velocity field around the pumping well as not modeled because the degree and distribution of the inhomogeneity are unknown. Grain size analysis of core samples from wells in the area were used to estimate the vertical distribution of hydraulic conductivity. Vertical components of groundwater flow observed with the flow sensors are qualitatively consistent with the vertical distribution of horizontal hydraulic conductivity estimated from grain size analysis but are significantly larger in magnitude than predicted. This is likely due to the creation of a vertical conduit of increased hydraulic conductivity during emplacement of the probes. Overall, the flow sensors performed very well.

2224

V18/021419

Insitu Permeable Flow Sensors at the Savannah River Integrated Demonstration: Phase I Results

Ballard, S.

Sandia National Laboratories, Albuquerque, NM

SAND92-1952; 35 pp. (October 1992)

The Insitu Permeable Flow Sensor, a new technology which uses a thermal perturbation technique to directly measure the 3-dimensional groundwater flow velocity vector at a point in permeable, unconsolidated geologic formations, has been used to monitor changes in the groundwater flow regime around an experimental air stripping waste remediation activity. While design flaws in the first version of the technology, which were used during the experiment being reported here, precluded measurements of the horizontal component of the flow velocity, measurements of the vertical component of the flow velocity were obtained. Results indicate that significant changes in the vertical flow velocity were induced by the air injection system. One flow sensor, MHM6, measured a vertical flow velocity of $4 \mathrm{~m} / \mathrm{yr}$ or less when the air injection system was not operating and $25 \mathrm{~m} / \mathrm{yr}$ when the air injection system was on. This may be caused by air bubbles moving past the probes or may be the result of the establishment of a more widespread flow regime in the groundwater induced by the air injection system. In the latter case, significantly more groundwater would be remediated by the air stripping operation since groundwater would be circulated through the zone of influence of the air injection system. Newly designed flow sensors, already in the ground at Savannah River to monitor Phase II of the project, are capable of measuring horizontal as well as vertical components of flow velocity. When the Phase II results become available, it should be possible to resolve this issue.

2225

V18/021420

Insitu Permeable Flow Sensors at the Savannah River Integrated Demonstration: Phase II Results 
Ballard, S.

Sandia National Laboratories, Albuquerque, NM

SAND94-1958; 19 pp. (August 1994)

A suite of Insitu Permeable Flow Sensors was deployed at the site of the Savannah River Integrated Demonstration to monitor the interaction between the groundwater flow regime and air injected into the saturated subsurface through a horizontal well. One of the goals of the experiment was to determine if a groundwater circulation system was induced by the air injection process. The data suggest that no such circulation system was established, perhaps due to the heterogeneous nature of the sediments through which the injected gas had to travel. The steady state and transient groundwater flow patterns observed suggest that the injected air followed high permeability pathways from the injection well to the water table. The preferential pathways through the essentially horizontal impermeable layers appear to have been created by drilling activities at the site.

\section{6}

V18/021439

Integration of Raman Spectrometry and Cone Penetration Technology to Characterized Chlorinated Hydrocarbon Contaminant Plumes

Bratton, W.L.; Shinn, J.D., II; Haas, J.W., III; Carrabba, M.M.

Applied Research Associates, Inc., South Royalton, VT; EIC Laboratories, Inc., Norwood, MA

Report; 100 pp. (March 30, 1994)

A new hazardous waste site characterization tool that combined Raman Scattering Spectroscopy and Cone Penetration Technologies (CPT) was developed. The primary objective of the project was to develop a minimally intrusive, rapid and cost effective method for locating and identifying nonaqueous phase liquids (NAPLs) in the subsurface. Applied Research Associates was responsible for integrating the Raman system into the cone penetrometer test system and performing a field demonstration of the completed Raman-CPT system. EIC Laboratories was tasked to develop a field portable system suitable for integration with the CPT, perform a laboratory evaluation of the system, assist in system integration and participate in a two-week demonstration of the Raman-CPT system at the U.S. Department of Energy's (DOE) Savannah River Site (SRS). Contaminants targeted specifically included trichloroethylene (TCE) and tetra-chloroethylene (perchloroethylene, PCE) dense NAPLs (DNAPLs), and fuels such as gasoline and diesel, which are light NAPLs (LNAPLs). These hazards were expected to be present at the selected demonstration site of the DOE Savannah River Site. The completed system was demonstrated at SRS during August, 1993. This report documents the system development from all stages through the demonstration and subsequent data analysis.

Numerical Simulations in Support of the Insitu Bioremediation Demonstration at Savannah River Travis, B.J.; Rosenberg, N.D.

Los Alamos National Laboratory, Los Alamos, NM

LA-12789-MS; 58 pp. (June 1994)
This report assesses the performance of in-situ bioremediation technology demonstrated at the Savannah River Integrated Demonstration (SRID) site in 1992-1993. The goal of the technology demonstration was to stimulate naturally occurring methanotrophic bacteria at the SRID site with injection of methane, air and air-phase nutrients (nitrogen and phosphate) such that significant amounts of the chlorinated solvent present in the subsurface would be degraded. Our approach is based on site-specific numerical simulations using the TRAMP computer code. In this report, we discuss the interactions among the physical and biochemical processes involved in-situ bioremediation. We also investigate improvements to technology performance, make predictions regarding the performance of this technology over longer periods of time and at different sites, and compare in-situ bioremediation with other remediation technologies.

V18/021444

Pilot Plant Test of the Brayton Cycle Solvent Recovery Heat Pump for Site Remediation at the Savannah River Site [Draft]

Priebe, S.

Idaho National Engineering Laboratory, Idaho Falls, ID

Report; 25 pp. (1993)

The Savannah River Site operated fuel rod fabrication shops in the M-Area HWMF for about 30 years. For about 20 years of that time, a waste water outfall was allowed to drain onto the ground approximately one half mile from the facility. The waste water was contaminated primarily with trichloroethylene (TCE), and perchloroethylene (PCE), but contained small amounts of 1,1,1-trichloroethane (TCA), 1,2-dichloroethylene, and chloroform. In 1984, a survey of the extent of soil and groundwater contamination was performed. The solvents have contaminated the soil vadose zone in an area of approximately $0.1 \mathrm{sq} \mathrm{mi}$. Contaminated groundwater has spread to an area of about $1 \mathrm{sq} \mathrm{mi.} \mathrm{A}$ feasibility study showed that carbon adsorption followed by regeneration using a decoupled Brayton cycle heat pump is an economically competitive technology for recovering solvents from the extraction well at the A-014 outfall at Savannah River. Operation of a pilot plant Brayton cycle solvent recovery heat pump demonstrated the technical feasibility of the system to recover clean, dry solvent with a recovery efficiency of $97 \%$. Based on these results, a conceptual design of a full-scale system for recovery of solvents from the SRS site remediation project was prepared.

2229

V18/023312

Roadmap for the Integrated Demonstration for Cleanup of Organics in Soils and Groundwater at Non-Arid Sites at the Savannah River Site

Westinghouse Savannah River Company, Aiken, SC SRT-EMP-92-0204; 31 pp. (June 30, 1992)

This document discusses two major phases of the roadmap planning process: Assessment and Analysis. The roadmap provides a comprehensive overview of the Integrated Demonstration (ID) plans and identifies issues and the resulting needs of the ID at Savannah River Site (SRS). During the Assessment Phase, the status and background information regarding the ID are identified. The 
assessment phase includes the creation of an assumptions document, a regulatory requirements document, a milestone document and activity diagrams. In the Analysis Phase, key issues that could impact the program are identified, and a schedule for resolution of these issues is provided. The analysis phase includes defining and addressing issue statements, needs statements, activity statements, and issue resolution schedules. A third phase called Issue Resolution and Planned Activity Integration that is usually included in a roadmap was excluded because it did not enhance this particular roadmap. The objective of this roadmap for the Savannah River Site (SRS) Integrated Demonstration (ID) is to provide the Integrated Demonstration Planning Group with a document that focuses on the identification, root-cause analysis, and resolution of issues that may adversely impact the ID.

\section{$2230 \quad \mathrm{~V} 18 / 021410$}

SEAMIST [TM] Depth Discrete Sampling and Monitoring of the Vadose Zone at the Savannah River Site [DRAFT]

Lowry, W.E.; Dunn, S.D.

Science and Engineering Associates, Inc., Santa Fe, NM

SEASF-FR-93-005; 28 pp. (February 2, 1993)

The work described in this report was performed in M Area at the Savannah River Integrated Demonstration Site. Science and Engineering Associates, Inc. (SEA) provided and installed three instrumented SEAMIST [TM] membranes for vapor sampling, pressure measurements, and air permeability measurements at up to ten discrete elevations in each hole. This report describes the systems, the field installations results of the initial permeability tests, and improvements in the system design recommended as a result of this project.

2231

V18/022025

Arc Heater Capabilities at AEDC

Hom, D.D.; Bruce, W.E., III

Micro Craft Technology, Amold Air Force Base, TN

CONF-9510125 (Vol. 1); Plasma Systems and Applications, P.W. Mayne and J.A. Mulholland (eds.), Proceedings of an International Symposium on Environmental Technologies, Atlanta, GA, October 8-11, 1995. Georgia Institute of Technology, Atlanta, GA, Vol. I, 335 pp.; (pp. 307-31) (1995)

The USAF/Amold Engineering Development Center (AEDC), located near Tullahoma, Tennessee, has a wide range of arc heater capabilities. Test facilities include a 25-MW segmented arc heater (HI) and a 40-MW Huels-type arc heater (HR). These facilities operate at pressures up to $12 \mathrm{MPa}(120 \mathrm{~atm})$ and exhaust to atmosphere, providing low Mach number flows ( $M$ greater than 3.5). The HR arc heater is also used as the driver for the arc-heated wind tunnel $(\mathrm{H} 2)$ which has a test cabin 3 meters (10 feet) in diameter and is provided with a subatmospheric exhaust to accommodate higher Mach number flows $(M=4$ to 8$)$ and flow fields up to a diameter of 0.6 meters (24 in.). A new larger scale 60-MW segmented arc heater (H3), which is in the final year of a six year development effort at AEDC, will significantly increase the size and performance of the existing facilities. The $\mathrm{H} 3$ heater has been demonstrated at chamber pressures up to $10.3 \mathrm{MPa}(103 \mathrm{~atm})$ and a power of $58 \mathrm{MW}$. AEDC has a wide range of plant utilities available for arc facility operations and development, including a 60-MW direct-current power supply, a $27 \mathrm{MPa}$ (4,000 psi) high-pressure air supply capable of flow rates up to $9 \mathrm{~kg} / \mathrm{sec}(20$ $\mathrm{lbm} / \mathrm{sec}$ ), and cooling water systems which provide up to $190 \mathrm{~kg} / \mathrm{sec}$ $(3,000 \mathrm{gpm})$ at a minimum pressure of $7 \mathrm{MPa}(1,000 \mathrm{psi})$. A state-of-the-art analytical capability has also been developed over the past 10 years at AEDC to better understand arc heater performance and behavior. Developers of large-scale commercial plasma systems have an opportunity to utilize the facilities and experience available at AEDC.

2232

V18/021578

Decontamination Systems Information and Research Program - Literature Review in Support of Development of Standard Test Protocols and Barrier Design Models for Insitu Formed Barriers Project

National Research Center for Coal and Energy, Morgantown, WV

DOE/MC/29467-5042; 158 pp. (December 1994)

The US Department of Energy is responsible for approximately 3,000 sites in which contaminants such as carbon tetrachloride, trichlorethylene, perchlorethylene, non-volatile and soluble organic and insoluble organics (PCBs and pesticides) are encountered. In specific areas of these sites radioactive contaminants are stored in underground storage tanks which were originally designed and constructed with a 30-year projected life. Many of these tanks are now 10 years beyond the design life and failures have occurred allowing the basic liquids ( $\mathrm{pH}$ of 8 to 9 ) to leak into the unconsolidated soils below. Nearly one half of the storage tanks located at the Hanford Washington Reservation are suspected of leaking and contaminating the soils beneath them. The Hanford site is located in a semi-arid climate region with rainfall of less than 6 inches annually, and studies have indicated that very little of this water finds its way to the groundwater to move the water down gradient toward the Columbia River. This provides the government with time to develop a barrier system to prevent further contamination of the groundwater, and to develop and test remediation systems to stabilize or remove the contaminant materials. In parallel to remediation efforts, confinement and containment technologies are needed to retard or prevent the advancement of contamination plumes through the environment until the implementation of remediation technology efforts are completed. This project examines the various confinement and containment technologies and protocols for testing the materials in relation to their function in-situ.

\section{3 \\ V18/021325}

Microorganisms Recruited for Hanford Cleanup

Waste Policy Institute, Blacksburg, VA

Initiatives in Environmental Technology Investment 3(April 1996):1-3 (April 1996)

Deep underground at the Hanford Site in southeastern Washington state, an army of microorganisms has been drafted by the U.S. Department of Energy's Pacific Northwest National Laboratory. The microorganisms' mission is to clean soils and groundwater tainted with nitrate and carbon tetrachloride, an industrial solvent 
and a suspected carcinogen.

$$
2234 \quad \text { V18/022598 }
$$

Phase III ResonantSonic [R] Report

Newcomer, D.R.; Last, G.V.; Friley, J.R.; Strope, L.A.; Johnston, B.V.

Pacific Northwest National Laboratory, Richland, WA

PNNL-1 1321; 42 pp. (September 1996)

The ResonantSonic [R] drilling system was tested at the Hanford

Site in the fiscal year 1991-1992 under the auspices of the Drilling Technology Development Program and the Environmental Restoration Program. The purpose of that program was to develop, test, and demonstrate drilling methods that are environmentally acceptable, safe, efficient, and cost effective when drilling and sampling in hazardous and radioactive waste sites. The cable tool method has historically been the primary drilling method employed for characterization and remediation projects at the Hanford site. The cable tool method can be used reliably in a wide variety of geologic conditions and yields continuous, relatively intact core samples. however, the disadvantages of this method are that the penetration rates are slow relative to most other drilling techniques. This report represents the completion of the ResonantSonic drilling program test activities. A brief description of the ResonantSonic drilling program is given. Phases I and II activities are also presented. Phase III activities are outlined. The conclusions drawn from the results and recommendations for further work to improve the drilling technology are discussed.

\section{$2235 \quad$ V18/023954}

1996 Laboratory Directed Research and Development: Annual Report

Meyers, C.E.; Harvey, C.L.; Lopez-Andreas, L.M.; Chavez, D.L.; Whiddon, C.P.

Sandia National Laboratories, Albuquerque, NM

SAND97-0579; 308 pp. (1996)

This report summarizes progress from the Laboratory Directed Research and Development (LDRD) program during fiscal year 1996. In addition to a programmatic and financial overview, the report includes progress reports from 259 individual $R \& D$ projects in seventeen categories. The Energy and Environmental Science and Technology section contains reports on several innovative characterization technologies, e.g., portable detection equipment and spectroscopic techniques, as well as a report on electrokinetic remediation of uranium-contaminated soils.

\section{6}

V18/023955

3D Electromagnetic Inversion for Environmental Site Characterization

Alumbaugh, D.L.; Newman, G.A.

Sandia National Laboratories, Albuquerque, NM

SAND97-0480C; CONF-970344; SAGEEP '97, R.S. Bell and M.H. Cramer (eds.), Proceedings of the Tenth Annual Symposium on the Application of Geophysics to Environmental and Engineering Problems, Reno, NV, March 23-26, 1997. Environmental and Engineering Geophysical Society, Wheat Ridge, CO; (pp. 407-416)
(1997)

A 3-D nonlinear electromagnetic inversion scheme has been developed to produce images of subsurface conductivity structure from electromagnetic geophysical data. The solution is obtained by successive linearized model updates where full forward modeling is employed at each iteration to compute model sensitivities and predicted data. Regularization is applied to the problem to provide stability. Because the inverse part of the problem requires the solution of 10's to 100's of thousands of unknowns, and because each inverse iteration requires many forward models to be computed, the code has been implemented on massively parallel computer platforms. The use of the inversion code to image environmental sites is demonstrated on a data set collected with the Apex Parametrics 'MaxMin I-8S' over a section of stacked barrels and metal filled boxes at the Idaho National Laboratory's 'Cold Test Pit.' The MaxMin is a loop-loop frequency domain system which operates from $440 \mathrm{~Hz}$ up to $56 \mathrm{kHz}$ using various coil separations; for this survey coil separations of 15,30 , and 60 feet were employed. The out-of-phase data are shown to be of very good quality while the in-phase are rather noisy due to slight mispositioning errors, which cause improper cancellation of the primary free space field in the receiver. Weighting the data appropriately by the estimated noise and applying the inversion scheme is demonstrated to better define the structure of the pit. In addition, comparisons are given for single coil separations and multiple separations to show the benefits of using multiple offset data.

2237 . V18/025403

Accelerating the Use of Innovative Remediation Technologies Through Cooperative Partnerships Hightower, M.M.

Sandia National Laboratories, Albuquerque, NM

CONF-970335; Waste Management '97: Working Towards a Cleaner Environment, Proceedings of a Conference on HLW, LLW, Mixed Wastes and Environmental Restoration, Tucson, AZ, March 2-6, 1997; (3 pp.) (1997)

To accelerate the adoption and implementation of new and innovative remediation technologies, the Innovative Treatment Remediation Demonstration (ITRD) Program was created by the Department of Energy's (DOE) Environmental Restoration Program Office (EM40) as a public-private partnership in cooperation with the Environmental Protection Agency's (EPA) Technology Innovation Office (TIO). Coordinated for the DOE by Sandia National Laboratories, the ITRD Program directly involves government, industry, and regulatory agencies in the assessment, implementation, and validation of innovative technologies. DOE facilities participating in this program work with technical experts from DOE, EPA, industry, the national laboratories, and state and federal regulatory agencies to identify and evaluate innovative technologies applicable to the clean-up of their sites. This cooperative approach reduces many of the common barriers to the implementation of innovative remediation technologies, creating a nonadversarial relationship between participants where innovative technology issues can be openly discussed and addressed in a technical dialogue. There are currently five projects underway within the DOE using this process. Though conducted at DOE sites, each of the projects that has been initiated is designed to address a 
major industrial contamination concern, such as organic or heavy metal contamination of either soil or groundwater. At each of the facilities involved, the innovative technologies selected for implementation are to be used to fully remediate representative areas at each site. This generates the full-scale and real-world operating, treatment performance, and cost data needed to validate the technologies and gain wider acceptance by industry and regulatory agencies nationwide.

\section{$2238 \quad \mathrm{~V} 18 / 020911$}

Alternative Landfill Cover Demonstration - Stakeholder and Regulator Involvement

Snow, $\mathrm{H}$.

New Mexico Energy, Minerals and Natural Resources Department, Santa Fe, NM

Fostering the Needed Partnerships: Doing the Necessary Science to Support Technology Development, Commercialization, Deployment, E.L. Helminski (ed.), Proceedings of the Seventh Annual Western Govemors' Association/Weapons Complex Monitor Applied Research and Cleanup Technology Colloquium, Phoenix, AZ, April 29-May 2, 1996. Exchange/Monitor Publications and Forums, Lake Bluff, IL, 500 pp.; (8 pp.) (1996)

This paper consists of viewgraphs for a presentation given at the Western Governors' Association / Weapons Complex Research and Technology Colloquium. The alternative landfill cover demonstration was developed as two phases and the timeline for each is discussed. The technologies for each phase are described. Phase I covers included a soils cover for solid waste (RCRA subtitle D), a clay cover for hazardous waste (RCRA Subtitle C), and a geosynthetic clay liner. Phase II covers included an anisotropic barrier, capillary barrier and an enhanced evapotranspiration soil cover. Site team activities and regulatory and stakeholder enhancements are described. An evaluation of the process and lessons learned is included.

2239 V18/020940

Analysis of Gas Phase Effluents from a Pilot Scale Plasma Torch

Lindner, J.S.; Guice, J.D.; Lynn, B.; Scoggin, J.; Toghiani, Zheng, Y.; Miller, G.P.; Winstead, C.; Green, R.; Okhuysen, W.; Costley, R.; Shepard, W.S.

Mississippi State University, Diagnostic Instrumentation and Analysis Laboratory, Mississippi State, MS

CONF-960212; Waste Management '96: Working Towards a Cleaner Environment, Proceedings of a Conference on HLW, LLW, Mixed Wastes and Environmental Restoration, Tucson, AZ, February 25-29, 1996; (14 pp.) (1996)

Plasma torches and joule-heated melters are two technologies which have been selected for mixed waste stream remediation demonstrations by the US DOE. The work here concerns the characterization of gas streams arising from plasma torch processing of a surrogate waste. Evaluations of gas stream compositions and products of incomplete waste conversion are valuable for screening and controlling remediation processes. In this work, the effluent from a pilot scale plasma torch processing a surrogate waste has been analyzed by conventional gas analyzers, gas chromatography, GC/MS and FTIR spectroscopy. Initial studies on the use of on-line Air ICP are discussed along with development efforts for an instrument capable of quantifying polychlorinated organics (PCB's dioxins) on-line. Results from the surrogate processing studies indicate a reduced oxygen gas stream along with the presence of. The formation of $\mathrm{NOCl}$ (from the $\mathrm{HCI}$ arising from PVC destruction and the NO generated from the plasma torch) is accompanied by the liberation of chlorine, The $\mathrm{HCl}, \mathrm{NOCl}$ and $\mathrm{C} 2$ represent a corrosive gas stream and attention is needed in the design of APCD systems for plasma torch units. Results from the on-line Air ICP indicated the presence of copper which was not a component of the surrogate feed and has been traced to the torch electrode. GC/MS experiments using surrogate waste spiked with hexachlorobenzene indicated a DRE of at least $99.99 \%$. The results obtained thus far indicate the instruments employed for the measurements should be suitable for routine analysis and may find application in torch facility controls.

\section{0}

V18/023718

Analysis of the Directional Drilling Technique for Laying Polyethylene Pipes

Delorme, P.; Homand, F.

GDF Research and Development Division, Laboratoire de Geomecanique, Nancy, France

CONF-9603151; Intemational NO-DIG '96: Proceedings of an International Society and North American Society for Trenchless Technology (ISTT/NASTT) Conference and Exhibition, New Orleans, LA, March 31-April 3, 1996. NASTT, Chicago, IL, 687 pp.; (pp. 408-417) (1996)

The use of trenchless techniques for laying or renovating pipelines has evolved in France over the last few years. Among these techniques, directional drilling for the laying polyethylene (PE) pipes has recently undergone considerable development. Polyethylene pipes (owing to such specific qualities, as flexibility and ease of use) are very well suited for pipelaying without the need for digging trenches. However, their low surface resistance (possibility of scratch and damage) and their specific mechanical and rheological behavior (visco-elasto-plastic deformation) demand a precise understanding of their use to avoid long-term damage.

2241 V18/022751

Application of Laser-Induced Breakdown Spectroscopy to the Field-Based Characterization of Nuclear and Hazardous Wastes

Cremers, D.A.; Ferris, M.J.

Los Alamos National Laboratory, Los Alamos, NM

CONF-960804 (Vol. 2); Spectrum '96: Nuclear and Hazardous Waste Management, Proceedings of an Intemational Topical Meeting, Seattle, WA, August 18-23, 1996. American Nuclear Society, La Grange Park, IL, Vol. 2, 873 pp.; (pp. 1021-1025) (1996)

Laser-induced breakdown spectroscopy (LIBS) is a highly versatile tool for the rapid, field-based analysis of materials to determine elemental composition. Because of this versatility, it has many potential applications to the analysis of toxic materials under conditions not possible using conventional analysis methods. In this 
paper we discuss several analysis scenarios using LIBS that are adaptable to the determination of the elemental composition of nuclear and hazardous wastes.

\section{2}

V18/022597

Applying High-Energy Physics Instrumentation to Environmental Restoration

Brodzinski, R.L.

Pacific Northwest Laboratory, Richland, WA

CONF-931044; Proceedings of a Fall Meeting of the Division of Nuclear Physics of the American Physical Society, Pacific Grove, CA, October 20-23, 1993; Bulletin of the American Physical Society 38(9):1800.a (October 1993)

This communication will deal with the application of instruments originally designed for executing physics experiments to the characterization, monitoring, and restoration of contaminated environments. Detectors developed to track particles in supercollider experiments are being used to clean up uranium contaminated soils at a processing facility; detectors used to analyze the soil on Mars are being used to characterize effluents from chemical waste landfills; and detectors developed to measure lepton nonconserving double-beta decay processes are being used to measure fallout from nuclear weapons-testing. In nearly all cases where physics experiments are being applied to environmental problems, the major virtue of the original detectors was their ability or design to measure the "needle in a haystack." These unique measurement capabilities have proven to be invaluable in performing unique, cost effective measurements in difficult environmental circumstances. Discussions will include applications of alpha, beta, gamma, neutron, and charged particle detectors to environments ranging from macadamia nuts contaminated with Chemobyl fallout to management of high-level liquid radioactive waste tanks.

\section{3}

VI8/023198

Assessing Environmental Technology Needs

Brown, E.W.; Whitehurst, C.A.; Plumblee, H.E.

Lockheed Environmental Systems and Technology

Company, Houston, TX

CONF-9210194; Proceedings of an International Symposium on Environmental Contamination in Central and Eastern Europe, Budapest, Hungary, October 12-16, 1992, 968 pp.; (pp. 307-309)

It is absolutely necessary to adapt, develop, or create and rapidiy implement new technologies that comply with all applicable regulations to successfully achieve a long-range cleanup goal with the lowest possible cost. This paper describes a planning process derived from the aerospace industry, which has been used to define an environmental research and development program with very specific objectives. The Lockheed Corporation supports an internal research and development $(R \& D)$ policy designed to keep the corporation at the leading edge of technology readiness. The R\&D program supporting this policy is defined through a technology planning process that assesses both short- and long-range technology needs of major programs. It brings the practitioner together with the technologist in a disciplined workshop environment. The planning process described in this paper was used to define $R \& D$ projects to support the development of such complex systems as the F-22 Advanced Tactical Fighter. The keys to success are the continuous development of new technologies, the successful transfer of that technology to engineering design teams, and the emphasis of maximizing the performance of new systems. These success factors are built into the planning process used in developing high-tech systems. They have now been modified for use in the definition of technology development programs for the hazardous waste remediation industry, with initial emphasis directed toward the U.S. Department of Energy (DOE). Results from a Lockheed planning session are compared with the results of an extensive $R \& D$ survey conducted under the auspices of the DOE.

2244

V18/020669

Assessment of Barrier Containment Technologies: A Comprehensive Treatment for Environmental Remediation Applications

O'Donnell, S.A.; Rumer, R.R.; Mitchell, J.K.

Peripheral Vision, Buffalo, NY

Proceedings of an International Containment Technology Workshop, Baltimore, MD, August 29-31, 1995, 454 pp. (August 1995)

This international workshop on containment technology was organized into small working sessions, each dealing with a particular aspect of barrier containment technologies. This provided the opportunity for the invited participants to share information, exchange opinions, and achieve consensus on what was known, what was not known, and what was needed conceming the application of containment technologies in remediation. The working sessions dealt with a range of topics, including: design and construction of vertical barrier walls (including sheet piles); barrier floors (indigenous and artificial); caps; geomembrane applications; barrier materials (soil-based and chemical-based); permeable reactive barriers; contaminant transport modeling; performance monitoring; and emplacement verification. The publication contains the edited summary reports for each working session.

2245

V18/022180

Autonomous Biomorphic Robots as Platforms for Sensors

Tilden, M.; Hasslacher, B.; Mainieri, R; Moses, J.

Los Alamos National Laboratory, Los Alamos, NM

LA-UR-96-3222; 6 pp. (1996)

The idea of building autonomous robots that can carry out complex and nonrepetitive tasks is an old one, so far unrealized in any meaningful hardware. One of the authors has shown recently that there are simple, processor-free solutions to building autonomous mobile machines that continuously adapt to unknown and hostile environments, are designed primarily to survive, and are extremely resistant to damage. These devices use smart mechanics and simple (low component count) electronic neuron control structures having the functionality of biological organisms from simple invertebrates to sophisticated members of the insect and crab family. These devices are paradigms for the development of autonomous machines that can carry out directed goals. The machine then becomes a 
robust survivalist platform that can carry sensors or instruments. These autonomous roving machines, now in an early stage of development (several proof-of-concept prototype walkers have been built), can be developed so that they are inexpensive, robust, and versatile carriers for a variety of instrument packages. Applications are immediate and many, in areas as diverse as prosthetics, medicine, space, construction, nanoscience, defense, remote sensing, environmental cleanup, and biotechnology.

\section{6 \\ V18/021226}

Autostereoscopic Display (3D Without Glasses) Suitable for Telerobotic Radioactive Waste Remediation

Eichenlaub, J.B.

Dimension Technologies, Inc., Rochester, NY; Electric Power Research Institute, Palo Alto, CA; Paul Williams and Associates, Medina, $\mathrm{OH}$

EPRI-TR-105569; CONF-950718; Proceedings of the 1995 Electric Power Research Institute (EPRD) International Low-Level Waste Conference, Orlando, FL, July 10-12, 1995, 600 pp.; (pp. 62.1-62.10) (November 1995)

An autostereoscopic video display ideal for telerobotic operations is described. The display creates stereoscopic images using input from two cameras in such a way that the observer does not have to wear special glasses or other headgear to see the images, and can also see the images from across a wide area. The display is being used in nuclear waste remediation and other telerobotic applications.

2247

V18/021346

B\&W NESI - Innovative Technologies: Advanced Bioremediation Technology

B\&W Nuclear Environmental Services, Inc., Lynchburg, VA

Brochure; 2 pp. (June 1995)

Bioremediation has proven to be a reliable, low-cost, and environmentally friendly technology for the remediation of petroleum hydrocarbon contaminated soil and groundwater. Recent advances in the field are now making this technology applicable to a broader range of contaminates including chlorinated solvents, polychlorinated biphenyls, and explosives. In 1994 a series of experiments was successfully conducted utilizing specialized cultues of selected aerobic, facultative, and anaerobic bacteria and specially engineered nutrient formulations in conjunction with conventional radioactive waste processing to remediate mixed waste forms that contain gasoline, diesel, benzene and other organics.

2248

V18/021345

B\&W NESI - Innovative Technologies: Cyclone Vitrification Technology

B\&W Nuclear Environmental Services, Inc., Lynchburg, VA

Brochure; 2 pp. (June 1995)

The B\&W Alliance Research Center (ARC) in Ohio, a B\&W NESI affiliate, developed the cyclone vitrification technology. This innovative thermal technology offers advantages in treating soils, liquids, and sludges containing organics, heavy metals, and/or radionuclide contaminants. This technology is designed to achieve high heat release rates, temperatures, and turbulence. It can also produce on-site electrical power, thereby recovering operating costs. It achieves better than $99.99 \%$ destruction of organic contaminants, and captures $97 \%$ of the input soil in a glassy slag that passes EPA's Toxicity Characteristic Leaching Procedure (TCLP) tests.

2249

V18/023319

\section{Barrier Containment Technologies for Environmental Remediation Applications}

Barrier Containment Technologies for Environmental Remediation Applications, A. Bodocsi and M.E. Ryan (eds.), John Wiley \& Sons, New York, NY, 170 pp. (September 1, 1995)

This book is the final report of a study conducted by the DuPont Corporation and the State University of New York, Buffalo, into methods of containing pollution where it lies in the soil or groundwater when the current technology cannot sufficiently remediate or remove it. The report evaluates the cutting edge in containment technologies presently practiced in remediation applications. It is designed to assess the advantages, limitations and performance of each containment component, individually as well as in combination. This comprehensive review examines the state of knowledge, constructability and performance of the three main barrier types of containment: vertical, bottom, and surface. It includes a glossary without pronunciation. The report was released in November 1993 and has been slightly revised for publication.

2250

$\mathrm{V} 18 / 024851$

Barrier. Technologies for Environmental Management: Summary of a Workshop

National Research Council, Washington, DC

CONF-950868; ER '95: Committed to Results, Proceedings of a U.S. Department of Energy Environmental Remediation Conference, Denver, CO, August 13-18, 1995; Barrier Technologies for Environmental Management, National Academy Press, Washington, DC, 188 pp. (1997)

Remediation of radioactive and mixed waste located in the U.S. Department of Energy (DOE) nuclear weapons complex will require increased use of physical barriers to prevent the spreading of contaminants during interim periods of cleanup and the migration of contaminants left behind upon completion of the cleanup. To raise the level of awareness of available technologies and to provide information on the current knowledge of barrier performance through technology development and actual installation, the Committee on Remediation of Buried and Tank Wastes and representatives of the DOE Office of Environmental Restoration organized a 1-day workshop on engineered barriers. Participants in this workshop included government researchers and contractors, as well as barrier designers and builders from private industries. This summary report is a synthesis of the oral discussions at the workshop. Sections of the report within the scope of this data base have been indexed separately.

2251

V18/022928

Behavior-Based Cooperative Robotics Applied to Multi-Target Observation

Parker, L.E. 


\section{Oak Ridge National Laboratory, Oak Ridge, TN}

CONF-9609318; Dagstuhl Seminar 9636: Modeling and Planning for Sensor-Based Robot Systems, Proceedings of a Conference, Dagstuhl, Germany, September 1-6, 1996. World Scientific, Inc., Singapore, Singapore; (18 pp.) (1996)

An important issue that arises in the automation of many security, surveillance, and reconnaissance tasks is that of monitoring (or observing) the movements of targets navigating in a bounded area of interest. A key research issue in these problems is that of sensor placement - determining where sensors should be located to maintain the targets in view. In complex applications involving limited-range sensors, the use of multiple sensors dynamically moving over time is required. In this paper, we investigate the use of a cooperative team of autonomous sensor-based robots for the observation of multiple moving targets. We focus primarily on developing the distributed control strategies that allow the robot team to attempt to minimize the total time in which targets escape observation by some robot team member in the area of interest. Our initial efforts on this problem address the aspects of distributed control in homogeneous robot teams with equivalent sensing and movement capabilities working in an uncluttered, bounded area. This paper first formalizes the problem, discusses related work, and then shows that this problem is NP-hard. We then present a distributed approximate approach to solving this problem that combines low-level multi-robot control with higher-level control. The low-level control is described in terms of force fields emanating from the targets and the robots. The higher level control is presented in the ALLIANCE formalism, which provides mechanisms for fault tolerant cooperative control, and allows robot team members to adjust their low-level actions based upon the actions of their teammates. We then present the results of the ongoing implementation of our approach, both in simulation and on physical robots. To our knowledge, this is the first paper addressing this research problem that has been implemented on physical robot teams.

\section{2}

V18/021948

\section{Biodecontamination of Concrete}

Rogers, R.D.

Idaho National Engineering Laboratory, Idaho Falls, ID CONF-951209; Proceedings of the 17th Annual U.S. Department of Energy Low-Level Radioactive Waste Management Conference, D. Lake (ed.), Phoenix, AZ, December 12-14, 1995, 480 pp.; (1 p.) (1995)

This paper describes the development and results of a demonstration for a continuous bioprocess for mixed waste treatment. A key element of the process is a unique microbial strain, which tolerates high levels of aromatic solvents and surfactants. This microorganism is the biocatalysis of the continuous flow system designed for processing stored liquid scintillation wastes. During the past year, a process demonstration has been conducted on commercial formulations of liquid scintillation cocktails (LSC). Based on data obtained from this demonstration, the Ohio Environmental Protection Agency granted the Mound Applied Technologies Laboratory a treatability permit allowing the limited processing of actual mixed waste. Since August 1994 , the system has been successfully processing stored "hot" LSC waste. This paper discusses the bioprocess, rates of processing, effluent, and implications of bioprocessing for mixed waste management. (Complete text)

2253

V18/022015

Characterization of Plasma Processes in the Destruction of Volatile Organic Compounds

Green, D.S.; Sieck, L.W.; Herron, J.T.

Stanford University, Department of Mechanical Engineering, Stanford, CA; National Institute of Standards and

Technology, Gaithersburg, MD

CONF-9510125 (Vol. 1); Plasma Systems and Applications, P.W. Mayne and J.A. Mulholland (eds.), Proceedings of an Intermational Symposium on Environmental Technologies, Atlanta, GA, October 8-11, 1995. Georgia Institute of Technology, Atlanta, GA, Vol. 1, 335 pp.; (pp. 87-99) (1995)

The nature of chemical mechanisms for non-thermal plasma degradation of toluene in dilute humid air streams has been investigated both theoretically and experimentally. This study focuses on processes subsequent to the initiating electron-molecule collisions, and on the role of water vapor in determining the final products. A plausible destruction mechanism based on both free radical and ion-molecule reactions is considered and compared with experimental data. The computational model consists of a select set of ion and neutral kinetics and predicts the temporal behavior of a multicomponent reacting system during a single pulse of an electrical discharge. Experiments are performed using a compact pulsed electron-beam, a coaxial wire pulsed corona discharge, and a dc corona torch. Evolution of the ion-neutral interactions is investigated using pulsed electron beam high-pressure mass spectrometry. Temporal and spatial behavior of radical chemistry in the electrical discharges is probed by means of in situ laser-based diagnostics.

\section{$2254 \quad$ V18/022727}

Characterization, Monitoring and Sensor Technology Program: Technology Solutions and Remaining DOE Characterization Problems

Roelant, D.F.; Purdy, C.B.

BDM Federal, Inc., Gaithersburg, MD; U.S. Department of Energy, Washington, DC

CONF-960804 (Vol. 1); Spectrum '96: Nuclear and Hazardous Waste Management, Proceedings of an International Topical Meeting, Seattle, WA, August 18-23, 1996. American Nuclear Society, La Grange Park, II, Vol. 1, 887 pp.; (pp. 648-652) (1996)

The U.S. Department of Energy (DOE) is required to characterize approximately 3,700 contaminated sites, 1.6 million barrels of stored waste, 385,000 cubic meters of high-level radioactive waste in tanks, and between 1,700 and 7,000 facilities before site remediation, waste treatment, and facility deactivation and decontamination (D\&D) operations commence. DOE has spent billions of dollars for site and waste characterization activities. To reduce these costs innovative characterization technologies are being developed to address five major problem areas: (1) mixed waste treatment; (2) facility D\&D; (3) mapping and treatment of contaminant plumes in soil and groundwater; (4) landfill 
stabilization, retrieval and remediation, and (5) retrieval and treatment of high-level radioactive waste from underground storage tanks. The Office of Science and Technology within DOE's Office of Environmental Management (DOE/EM) has focused on these problems and has created organizations known as Focus Areas to address technology development for each of these problem areas. Described below are: the need for innovative technologies accepted by users and regulators; the Characterization, Monitoring and Sensor Technology Crosscutting Program (CMST-CP) within DOE's Office of Science and Technology (OST); a portfolio of characterization technologies developed by DOE/OST; and DOE characterization problems still requiring technology development. This CMST-CP description includes the program's: mission, collaborations with technology development and technology user groups, process for helping Focus Areas define technology development needs, and peer review process for selecting new projects and reviewing on-going projects. The section on characterization and monitoring technologies contains examples of some innovative technologies, the problems they address, their status, and a list of other technologies developed for similar problems. The last section details characterization needs requiring additional technology development identified by the five Focus Area organizations.

\section{5} V18/021591

\section{Characterization, Monitoring, and Sensor Technology} Crosscutting Program

U.S. Department of Energy, Office of Environmental Management, Office of Science and Technology, Washington, DC

DOE/EM-0298; 154 pp. (August 1996)

The purpose of the Characterization, Monitoring, and Sensor Technology Crosscutting Program (CMST-CP) is to deliver appropriate characterization, monitoring, and sensor technology (CMST) to the Office of Waste Management (EM-30), the Office of Environmental Restoration (EM-40), and the Office of Facility Transition and Management (EM-60).

\section{6}

\section{V18/022252}

Commercial Treatability Study Capabilities for Application to the U.S. Department of Energy's Anticipated Mixed Waste Streams

International Technology Corporation, Albuquerque, NM INEL-96/0249; 108 pp. (July 1996)

According to the data developed for the proposed site treatment plans, the U.S. Department of Energy (DOE) mixed low-level and mixed transuranic waste inventory was estimated at 181,000 cubic meter comprised of approximately 2,000 waste streams. Many of these streams are unique and require new technologies to facilitate compliance with Resource Conservation and Recovery Act (RCRA) disposal requirements. Because almost all waste streams are unique, a demonstration of the selected technologies is justified. Evaluation of commercially available or innovative technologies in a treatability study is a cost-effective method of providing a demonstration of the technology and supporting decisions on technology selection. This document provides DOE waste managers with a list of commercial providers with mixed-waste treatability study capabilities and the technologies available at those facilities.
The list was compiled by a survey of commercial providers using available databases and a Commerce Business Daily announcement. The survey identified 107 treatment processes offered by 34 commercial providers. The technologies address 21 general treatment categories and include straightforward application of standard technologies (such as pyrolysis) as well as proprietary technologies developed specifically for mixed waste.

2257

V18/021729

Commercialization of Microwave Vitrification

Golden, J.; Morgan, R.D.

Electric Power Research Institute, Palo Alto, CA; CENTEC-21, Inc., Santa Clara, CA; Clean Earth Technologies, St. Louis, MO

EPRI-TR-106079; CONF-951244; Vitrification of Low-Level Waste: The Process and Potential, M.D. Naughton and K. Sullivan (eds.), Proceedings of an Electric Power Research Institute (EPRn) Meeting, San Antonio, TX, December 5-6, 1995, 368 pp.; (pp. 14.1-14.3) (March 1996)

A new company, Clean Earth Technologies, L.L.C. (CET), is being formed as a spin-off of Berkeley Research Associates, Inc. with the goal of commercializing microwave vitrification as the industrial partner with the Rocky Flats Environmental Technology Site. Based on the Department of Energy's development program at Rocky Flats, microwave vitrification has been shown to be an effective and economical method of treatment for several types of wastes. CET will begin operation of a pilot-scale plant $(50 \mathrm{~kg} / \mathrm{hr})$ for treatment formulation studies during Winter, 1996. It is expected that systems with comparable production rates will be offered for delivery during summer, 1996. Scaling of microwave vitrification systems to the $200-500 \mathrm{~kg} / \mathrm{hr}$ level is underway, and CET plans to manufacture portable, standalone, $200-500 \mathrm{~kg} / \mathrm{hr}$ systems. These systems will be complete, integrated front-to-back systems including waste pre-treatment, off-gas and waste water treatment, and automated monitoring and operation. A field demonstration is being planned for early 1997.

V18/021209

Comparison of Photoacoustic Radiometry to Gas Chromatography/Mass Spectrometry Methods for Monitoring Chlorinated Hydrocarbons

Sollid, J.E.; Trujillo, V.L.; Limback, S.P.; Woloshun, K.A. Los Alamos National Laboratory, Los Alamos, NM

LA-UR-96-100; CONF-9606125; Proceedings of the Air and Waste Management (AWM) 1996 Annual Meeting, Nashville, TN, June 23-28, 1996; (17 pp.) (1996)

A comparison of two methods of gas chromatography mass spectrometry (GCMS) and a nondispersive infrared technique, photoacoustic radiometry (PAR), is presented in the context of field monitoring a disposal site. First is presented an historical account describing the site and early monitoring to provide an overview. The intent and nature of the monitoring program changed when it was proposed to expand the Radiological Waste Site close to the Hazardous Waste Site. Both the sampling methods and analysis techniques were refined in the course of this exercise. 
2259

V18/022204

\section{Cone Penetrometer: Innovative Technology Summary Report}

U.S. Department of Energy, Office of Environmental Management, Office of Science and Technology, Washington, DC

DOE/EM-0309; 24 pp. (April 1996)

Cone penetrometer technology (CPT) provides cost-effective, real-time data for use in the characterization of the subsurface. Recent innovations in this baseline technology allow for improved access to the subsurface for environmental restoration applications. The technology has been improved by both industry and government agencies and is constantly advancing due to research efforts. The U.S. Department of Energy (DOE) Office of Science and Technology (formerly Technology Development) has contributed significantly to these efforts. This report focuses on the advancements made in conjunction with DOE's support but recognizes Department of Defense (DOD) and industry efforts.

2260

V18/021143

Considerations for the Implementation of Partnering Agreements for Technology Transfer Related to Department of Energy Programs

Kuykendall, T.A.

Parsons Engineering Science, Inc., Denver, CO

CONF-960212; Waste Management '96: Working Towards a Cleaner Environment, Proceedings of a Conference on HLW, LLW, Mixed Wastes and Environmental Restoration, Tucson, $A Z$, February 25-29, 1996; (10 pp.) (1996)

The Department of Energy (DOE), and the DOE national laboratories in particular, have developed numerous processes and technologies that have the potential to be of practical use to both the government and commercial market sectors in areas such as environmental remediation, waste management, applied physics, remote handling, etc. For effective commercial application, these technologies must be transferred to private enterprise for further development, tailoring for specific functions and uses, and full development and targeting of potential markets. This transfer will require the skills, interfaces, and business relationships of a consortium of organizations with appropriate specialized experience and expertise. In order to develop and implement effective technology transfer programs, it is beneficial for the DOE site or laboratory to enter into partnering arrangement with engineering/technology firms, universities and academia, private industry, other government agencies, and specialized business entities to support the identification, development and transfer of emerging technologies developed and/or adapted by a laboratory or research and development (R\&D) organization which can be applied to address ongoing or future needs for environmental management. The key elements of the partnering agreement are: long term commitment; equality among partnering members; a mutually supportive relationship; encouragement of innovation; a commitment to continual improvement; insurance of continuity of resources; and the promotion of a 'win-win' atmosphere. The ultimate measure of success will be the demonstrated improvement of the ability of the consortium to identify currently available technologies useful to the private sector, and the expediting of technology transfer available for commercialization. The development of a partnering arrangement between DOE and a consortium of organizations with complementary skills can lead to an orderly and efficient mechanism for introducing DOE technologies to the common industrial market.

Control of Water Infiltration into Near Surface LLW Disposal Units: Progress Report on Field Experiments at a Humid Region Site, Beltsville, Maryland

Schulz, R.K.; Ridky, R.W.; O'Donnell, E.

U.S. Nuclear Regulatory Commission, Division of Regulatory Applications, Washington, DC; University of Califomia, Los Angeles, CA; University of Maryland, College Park, MD; University of Maryland, Department of Chemistry, College Park, MD

NUREG/CR-4918 (Vol. 9); 30 pp. (August 1996)

This study's objective is to assess means for controlling water infiltration through waste disposal unit covers in humid regions. Experimental work is being performed in large-scale lysimeters $21.34 \mathrm{~m} \times 13.72 \mathrm{~m} \times 3.05 \mathrm{~m}$ ( $70 \mathrm{ft} \times 45 \mathrm{ft} \times 10 \mathrm{ft}$ ) at Beltsville, Maryland. Results of the assessment are applicable to disposal of low-level radioactive waste ( $L L W$ ), uranium mill tailings, hazardous waste, and sanitary landfills. Three kinds of waste disposal unit covers or barriers to water infiltration are being investigated: (1) resistive layer barrier, (2) conductive layer barrier, and (3) bioengineering management. The resistive layer barrier consists of compacted earthen material such as clay. The conductive layer barrier consists of a conductive layer in conjunction with a capillary break. As long as unsaturated flow conditions are maintained, the conductive layer will wick water around the capillary break. Below-grade layered covers such as (1) and (2) will fail if there is appreciable subsidence of the cover, and remedial action for this kind of failure will be difficult. A surface cover, called bioengineering management, is meant to overcome this problem. The bioengineering management surface barrier is easily repairable if damaged by subsidence; therefore, it could be the system of choice under active subsidence conditions. The bioengineering management procedure also has been shown to be effective in dewatering saturated trenches and could be used for remedial action efforts. After cessation of subsidence, that procedure could be replaced by a resistive layer barrier or, perhaps even better, by a resistive layer barrier/conductive layer barrier system. The latter system would then give long-term effective protection against water entry into waste without institutional care.

\section{$2262 \quad$ V18/022803}

Control of a Self Guided Tracked Vehicle for Hazardous Waste Removal Using GPS Positioning and Ultrasonic Collision Avoidance

Roy, B.; Lokhorst, D.; Fung, P.; Rice, P.

RSI Research Limited, Victoria, British Columbia, Canada; Spar Aerospace Limited, Brampton, Ontario, Canada; Lockheed Martin Idaho Technologies Company, Idaho Falls, ID

CONF-960804 (Vol. 3); Spectrum '96: Nuclear and Hazardous 
Waste Management, Proceedings of an Intemational Topical Meeting, Seattle, WA, August 18-23, 1996. American Nuclear Society, La Grange Park, IL, Vol. 3, 841 pp.; (pp. 1749-1756) (1996)

In 1994 a large hydraulic telerobotic tracked transport vehicle (TTV) was built for Lockheed Idaho Technologies by a team of companies consisting of RAHCO International of Spokane, Spar Aerospace of Toronto and RSI Research of Victoria. The TTV was developed as a part of the Department of Energy's Buried Waste Integrated Demonstration Program to transport low level transuranic waste in a safe, dust-free manner minimizing the potential spread of airborne contaminants. The TTV was controlled from a remote control station by an operator relying on video and sensor feedback. This paper describes the control system of SGTV, a self guided version of the TTV developed in 1995 to travel autonomously between loading and off-loading points while automatically avoiding obstacles in its path. Self-guidance is divided between a supervisory Mission Planning and Control computer (MPC) and an on-board system of five networked computers.

\section{$2263 \quad$ V18/022419}

Cost Effectiveness of Sonic Drilling

Masten, D.; Booth, S.R.

Los Alamos National Laboratory, Los Alamos, NM

LA-UR-96-1328; 40 pp. (March 1996)

Sonic drilling is an innovative environmental technology being developed in cooperation with the DOE-sponsored Arid-Site Volatile Organic Compounds (VOCs) Integrated Demonstration at Hanford and the Mixed Waste Landfill Integrated Demonstration (MWLID) at Sandia National Laboratory. The principal developer of the technology is Water Development Corporation (WDC) of Woodland, California under the service mark ResonantSonic [TM]. This report studies the cost effectiveness of sonic drilling based on performance data from the above mentioned demonstrations and estimates of expected performance. The baseline technologies are cable-tool (the primary drilling technology used at Hanford hazardous sites) and mud rotary (popular for fast drilling and used at Sandia). The primary benefit of sonic, as compared to the baseline technologies, is its ability to drill in all types of formations without introducing a circulating medium; as a result, little secondary waste is generated at hazardous sites. Early demonstrations of sonic drilling were plagued by downtime due to drill string and drill head failures. Later tests indicate that the drill head problems have, for the most part, been solved. Some improvements have been made to increase drill-string life. However, additional research and technology developments are necessary to mitigate this problem. Even so, based on the scenario results in this report, sonic appears to be a superior, cost-effective technology when compared to cable-tool for drilling in both hazardous and "clean" sites. It is also superior to mud rotary in hazardous sites. For the scenario based on ideal estimates of sonic drill rates, it appears that sonic also may be able to effectively compete with mud rotary in clean sites.

2264

V18/022420

Cost Studies of Thermally Enhanced Insitu Soil

Remediation Technologies

Bremser, J.P.; Booth, S.R.
Los Alamos National Laboratory, Los Alamos, NM

LA-UR-96-1683; 65 pp. (May 1996)

This report describes five thermally enhanced technologies that may be used to remediate contaminated soil and water resources. The standard methods of treating these contaminated areas are Soil Vapor Extraction (SVE), Excavate \& Treat (E\&T), and Pump \& Treat (P\&T). Depending on the conditions at a given site, one or more of these conventional altematives may be employed; however, several new thermally enhanced technologies for soil decontamination are emerging. These technologies are still in demonstration programs which generally are showing great success at achieving the expected the expected remediation results. The cost savings reported in this work assume that the technologies will ultimately perform as anticipated by their developers in a normal environmental restoration work environment. The five technologies analyzed in this report are Low Frequency Heating (LF or Ohmic, both 3 and 6 phase AC), Dynamic Underground Stripping (DUS), Radio Frequency Heating (RF), Radio Frequency Heating using Dipole Antennae (RFD), and Thermally Enhanced Vapor Extraction System (TEVES). In all of these technologies the introduction of heat to the formation raises vapor pressures accelerating contaminant evaporation rates and increases soil permeability raising diffusion rates of contaminants. The physical process enhancements resulting from temperature elevations permit a greater percentage of volatile organic compound (VOC) or semi-volatile organic compound (SVOC) contaminants to be driven out of the soils for treatment or capture in a much shorter time period.

2265

V18/024270

Cost Uncertainty for Different Levels of Technology Maturity

DeMuth, S.F.; Franklin, A.L.

Los Alamos National Laboratory, Los Alamos, NM; Pacific Northwest National Laboratory, Richland, WA

LA-UR-96-2786; 8 pp. (August 7, 1996)

It is difficult at best to apply a single methodology for estimating cost uncertainties related to technologies of differing maturity. While highly mature technologies may have significant performance and manufacturing cost data available, less well-developed technologies may be defined in only conceptual terms. Regardless of the degree of technical maturity, a cost estimate relating to application of the technology may be required to justify continued funding for development. However, a cost estimate without its associated uncertainty lacks the information required to assess economic risk. For this reason, it is important for the developer to provide some type of uncertainty along with a cost estimate. This study demonstrates how different methodologies for estimating uncertainties can be applied to cost estimates for technologies of different manurities. For a less well-developed technology an uncertainty analysis of the cost estimate can be based on a sensitivity analysis. On the other hand, an uncertainty analysis of the cost estimate for a well-developed technology can be based on an error propagation technique from classical statistics. It was decided to demonstrate these uncertainty estimation techniques with (1) an investigation of the additional cost of remediation due to beyond baseline, nearly complete, waste heel retrieval from 
underground storage tanks (USTs) at Hanford; and (2) the cost related to the use of crystalline silico-titanate (CST) rather than the baseline CS100 ion exchange resin for cesium separation from UST waste at Hanford.

\section{6}

V18/021412

Cost-Effectiveness Analysis of the SEAMIST [TM] Membrane System Technology

De Piante Henriksen, A.; Booth, S.R.

Los Alamos National Laboratory, Los Alamos, NM

LA-UR-93-3750; 49 pp. (1993)

This report describes the cost and performance characteristics of SEAMIST [TM], an innovative technology that facilitates measurements of contaminants in both vertical and horizontal vadose zone boreholes. This new technology consists of an airtight membrane liner that is pneumatically emplaced inside the borehole. The positive air pressure inside the liner maintains the integrity of the borehole structure. Sampling ports with attached tubing, absorbent collectors, or various in-situ measuring devices can be fabricated into the liner and used for monitoring volatile organic compounds (VOCs), semivolatile organic compounds (SVOCs), pesticides, herbicides, polynuclear aromatic hydrocarbons, polychlorinated biphenyls, or radioactive substances. In addition, small instruments can be guided through the lined borehole and measurements taken inside at specified intervals. The SEAMIST [TM] technology is simple in its concept and design. In some of its applications it replaces significantly more complicated and more costly methods of obtaining the same information. In other applications, SEAMIST [TM] performs tasks and obtains information in ways that have no simple baseline technology for comparison. The purpose of this study is to analyze the cost and performance effectiveness of this new technology. To do so, we constructed four hypothetical scenarios in which utilization of the SEAMIST [TM] system can address various needs of the Department of Energy's environmental remediation program. Two of the scenarios involve vertical boreholes (or vertical instrument configurations) and two involve horizontal boreholes (or horizontal instrument configurations). The four scenarios jointly address contamination by VOCs, SVOCS, various water-soluble toxic substances, and low-level radioactive waste.

\section{7}

V18/023308

Cost-Effectiveness of the Integrated Spectroscopic System for Environmental Contaminant Speciation

Heskett, J.C.; Booth, S.R.

Los Alamos National Laboratory, Los Alamos, NM

LA-UR-93-4054; 15 pp. (November 2, 1993)

The Integrated Spectroscopic System for Environmental Contaminant Speciation (ISSECS), is a new approach in the characterization of harmful contaminants to identify the optimal means of pollution remediation. By examining a sample at the molecular level, ISSECS can determine speciation in a contaminant, e.g., uranium. Speciation information can then be used to determine the most effective remediation strategy. A detailed discussion of ISSECS follows a description of the methodology for this cost-effectiveness study. Evaluating a new environmental technology normally entails a performance evaluation and an economic evaluation in which the new technology is compared to a standard, or baseline, technology. Immediately and rightfully, the "apples and oranges" objection arises. In order to resolve this issue, we take a descriptive approach which details a baseline technology or cluster of technologies with approximately the same capabilities as the new technology. In this fashion, we can offer an analogous solution to the problem that the new technology addresses and then compare cost and performance.

2268

V18/021037

Crosswell Seismic Imaging of an Insitu Air Stripping Waste Remediation Process

Elbring, G.J.

Sandia National Laboratories, Geophysics Department, Albuquerque, NM

SAND92-2312C; CONF-9304109; SAGEEP '93, Proceedings of a Symposium on the Application of Geophysics to Environmental and Engineering Problems, San Diego, CA, April 18-21, 1993; (pp. 55-63) (1993)

The restoration of environmentally contaminated sites at DOE facilities has become a major effort in the past several years. The variety of wastes involved and the differing characteristics have driven the development of new restoration and monitoring technologies. One of the new remediation technologies is being demonstrated at the Savannah River Site near Aiken, South Carolina. In conjunction with this demonstration, a new technology for site characterization and monitoring of the remediation process has been applied by Sandia National Laboratories. The remediation technology being demonstrated involves the in-situ air stripping of contaminated soils and groundwater. The geology at the site consists of horizontally-layered unconsolidated sands, clayey sands, sandy clays, and clays. A leaking process sewer line contaminated the area under study with chlorinated volatile organic compounds (CVOC's) primarily trichloroethylene (TCE) and tetrachloroethylene (PCE). To remove the contaminants, two horizontal wells were drilled, an upper level vapor extraction well and a lower level injection well. Air was injected into the lower well beneath the water table and a vacuum was applied to the upper well to extract the injected air. For maximum resolution of the subsurface, a crosshole tomographic imaging approach was selected. This method reduces the effect of surface noise sources and attenuation problems associated with near-surface materials. In addition, the source and receiver are both near the area of interest giving shorter travel paths and less loss of high frequency energy. With these conditions in mind, crosswell S-wave surveys were conducted both before and during the first phase of the air stripping experiment in 1991, and similar crosswell P-wave surveys were conducted during the second phase of the air stripping in 1992.

2269

V18/022599

Cryogenic Drilling: A New Drilling Method for Environmental Remediation

Simon, R.D.; Cooper, G.A.

University of Califomia, Berkeley, CA

Groundwater Monitoring and Remediation 16(3):79-85 (Summer 1996) 
Cryogenic drilling is a technique developed at the University of Califomia (UC), Berkeley, for drilling in unstable sediments for environmental monitoring, for characterizing, and for remediation wells. The method uses standard air rotary drilling techniques, but with cold nitrogen rather than ambient air as the circulating fluid in order to freeze and stabilize the borehole wall. Several laboratory and full-scale field tests have been performed. A 52-foot-deep (16 $\mathrm{m})$ soil boring and 24-foot $(7 \mathrm{~m})$ monitoring well have been drilled as part of the Lawrence Berkeley Laboratory Site Characterization Project. Continued testing and refinement of the equipment and operational method are in progress. The method has been proposed for use as part of the Department of Energy (DOE) weapons site cleanup at locations with unstable sediments such as Hanford, Sandia, and Idaho National Engineering Laboratory (INEL).

\section{0}

V18/022424

\section{Cyclone Melting System Puts Mixed Waste Through} the Spin Cycle

Initiatives in Environmental Technology Investment 3(October 1996):1-2 (October 1996)

A washing machine uses centrifugal force to separate water from clothes by spinning the laundry at high speed. The Cyclone Melting System works in much the same manner. CMS spins molten mixed waste at high-speed, slinging the material out to the walls of the chamber, separating gas from molten glass. The resulting product is a solid glass form that is suitable for storing in non-hazardous landfills, recycling, or processing into glass products.

\section{1}

V18/021060

\section{DETOX [SM]: An Innovative Mixed Waste Treatment} Method

Rogers, T.W.; Dhooge, P.M.

Delphi Research, Inc., Albuquerque, NM

CONF-940499 (Vol. 1); Proceedings of the 1994 Federal

Environmental Restoration III and Waste Minimization II

Conference and Exhibition, New Orleans, LA, April 27-29, 1994.

Hazardous Materials Control Resources Institute, Rockville, MD,

Vol. 1, 783 pp.; (pp. 200-208) (1994)

The accumulation of mixed wastes has resulted in a large volume of mixed wastes at federally operated facilities. The implementation of the Federal Facilities Compliance Act and amendments to the Land Disposal Restrictions have resulted in an urgent need to develop, demonstrate, and apply innovative technologies which are capable of treating mixed wastes in a manner which will result in significant volume reduction of radionuclide contaminates, yet will destroy organic constituents in compliance with state and federal regulatory requirements. Delphi Research, Inc. has developed and tested a catalyzed wet oxidation process, DETOX [SM], which is capable of oxidizing a broad range of organic compounds and concentrating heavy metals and radionuclides. The process utilizes iron $(\mathrm{Fe} 3+$ ) as a primary catalyst, and ruthenium (Ru3+) and platinum ( $\mathrm{Pt} 4+$ ) as the co-catalysts in an acid medium. Extensive laboratory testing and bench-scale testing has been performed to establish the destruction efficiency and cation solubilities in the DETOX [SM] solution. Organic constituents tested have included polychlorinated biphenyls (PCB's), trichloroethylene, Hydrocount [TM], Ready Value [TM], paper, polyethylene, wood, n-butyl acetate, picric acid, pentachloropyridine, tetrachlorothiophene, and poly(vinyl) chloride. Solubility studies on the selected cations have been performed and include chromium, lead, mercury, barium, beryllium, cadmium, nickel, vanadium, and arsenic. Cerium and neodymium were used as surrogates to represent the chemical and physical properties of uranium and plutonium respectively. A summary of results obtained in these studies are presented and observations noted regarding the limitations and/or unusual solubility characteristics of potential metal contaminants. An overview of on-going development and engineering work being performed for the U.S. Department of Energy (DOE-METC), Los Alamos National Laboratory (LANL), and EG\&G Rocky Flats Plant (RFP) is presented.

2272

V18/021390

DOE's Technology Application Program - What It Has, What It Needs to Attract Industry

Dabrowski, T.E.

Rust Federal Services, Inc., Golden, $\mathrm{CO}$

Fostering the Needed Partnerships: Doing the Necessary Science to Support Technology Development, Commercialization, Deployment, E.L. Helminski (ed.), Proceedings of the Seventh Annual Westem Governors' Association/Weapons Complex Monitor Applied Research and Cleanup Technology Colloquium, Phoenix, AZ, April 29-May 2, 1996. Exchange/Monitor Publications and Forums, Lake Bluff, IL, 500 pp.; (10 pp.) (April 1996)

The outline and viewgraphs for this presentation highlight the following areas: DOE's value as a customer, the unique needs of DOE, how industry can help DOE drive down costs, and hou DOE and industry can improve the technology application improvement process.

2273

V18/021227

DOE, Russia Pursue Nuclear Cleanup Technologies

Lobsenz, G.

Energy Daily, Washington, DC

Energy Daily 22(160):2 (August 22, 1994)

U.S. DOE began discussions on establishing Russian companies that can provide promising nuclear cleanup technology for DOE environmental programs and broader commercial applications. The meeting with Russian officials is to identify 50 cleanup technologies most suitable for commercialization.

2274

V18/022304

Decontamination Systems Information and Research Program: Quarterly Report - October-December 1995

West Virginia University, Department of Civil and Environmental Engineering, Morgantown, WV; U.S. Department of Energy, Morgantown Energy Technology Center, Morgantown, WV

DOE/MC/29467-5177; 265 pp. (December 1995)

The projects reported for the WVU Cooperative Agreement are categorized into the following three areas: 1.0 In Situ Remediation Process Development, 2.0 Advanced Product Applications Testing, 
and 3.0 Information Systems, Public Policy, Community Outreach, and Economics. Summaries of the significant accomplishments for the projects reported during the period October 1, 1995 through December 31, 1995 are presented.

\section{$2275 \quad$ V18/022332}

Decontamination Systems Information and Research Program: Quarterly Report - April-June 1995

West Virginia University, Morgantown, WV; U.S. Department of Energy, Morgantown Energy Technology Center, Morgantown, WV

DOE/MC/29467-4091; 335 pp. (July 1995)

The projects reported for the Cooperative Agreement are categorized into the following three areas: $1.0 \mathrm{In}$ Situ Remediation Process Development, 2.0 Advanced Product Applications Testing, and 3.0 Information Systems, Public Policy, Community Outreach, and Economics. Summaries of the significant accomplishments for the projects reported during period April 1, 1995 through June 30, 1995 are presented.

\section{6}

V18/022896

Decontamination and Decommissioning Focus Area: 1996 Annual Report

Federal Energy Technology Center, Morgantown, WV DOE/FETC-97/1041; 20 pp. (1996)

Established by the U.S. Department of Energy's Environmental Management (DOE-EM) program through its Office of Science and Technology (OST), the Decontamination and Decommissioning (D\&D) Focus Area is working to develop answers for problems that hinder EM's extensive cleanup efforts. From recycling radioactive stainless steel to robotically dismantling reactor systems, projects emerging from this program offer innovative solutions that are more effective, less costly and more protective of worker safety. Focus Area efforts are directed toward three primary activities: facility deactivation, facility decontamination, and facility dismantlement including material disposition.Technical challenges range from chemical and radiological characterization to remote dismantlement of systems, and from plutonium separations to contaminant removal and materials recycling.

\section{$2277 \quad$ V18/023547}

Demonstration of Ground Freezing for

Radioactive/Hazardous-Waste Disposal

Peters, $\mathbf{R}$.

Scientific Ecology Group, Inc., Oak Ridge, TN

CONF-941124; Insitu Remediation: Scientific Basis for Current and Future Technologies, G.W. Gee and N.R. Wing (eds.), Proceedings of the 33rd Hanford Symposium on Health and the Environment, Pasco, WA, November 7-11, 1994. Battelle Press, Columbus, OH, Part 1, 704 pp.; (pp. 103-112) (1994)

The U.S. Department of Energy's Office of Environmental Restoration and Waste Management, through the Office of Technology Development, is performing a subsurface ground-freezing demonstration at Scientific Ecology Group facilities in Oak Ridge, Tennessee. The primary goal of the demonstration is to display a technology that can be easily installed to form an impermeable barrier. This method can be used at sites of radioactive and other hazardous contaminants to prevent migration of contaminants. This technology uses, as an underground barrier, a zone of frozen soil that can be removed at a later date, after the contamination problem is remediated.

2278

V18/022249

Demonstration of a VOC Insitu Fiber Optic Sensor for Use with a Penetrometer Analysis System

Hartenstein, S.D.; Moore, G.; Nelson, B.; Kane, J.; Lowe, M.

Idaho National Engineering Laboratory, Idaho Falls, ID; GEO-CENTERS, Inc., Newton Center, MA

INEL-96/00037; CONF-960848; Denver 96: Advanced

Technologies for Environmental Monitoring and Remediation, T. Vo-Dinh (ed.), Proceedings of the First Society of Photo-Optical Instrumentation Engineers (SPIE) Conference on Space Processing of Materials, Denver, CO, August 4-9, 1996. SPIE, Bellingham, WA, 294 pp.; (10 pp.) (1996)

Researchers at the Idaho National Engineering Laboratory with their industrial CRADA partner GEO-CENTERS demonstrated a fiber optic based VOC sensor at the Army Environmental Center (AEC) technology demonstration at Dover Air Force Base. The sensor used during the demonstration was a single fiber optic cable coupled to an in situ sensor element contained in a cone penetrometer tip. The sensor's fluorescence response was measured at the surface using an optical breadboard-based instrument. Results from this demonstration showed that the sensor provided semi-quantitative results for total VOCs comparable to the historical values of VOCs. In addition, the demonstration identified several technical challenges for improvement of the sensor. This paper describes the analytical properties of the reversible sensing materials, construction of an improved sensor system, and the planned demonstration of the modified in-siru VOC sensor system. This sensor system is tentatively scheduled for demonstration at the Army Environmental Center's Aberdeen Proving Ground Test site. Improvements to the VOC sensor system include an optical configuration that will correct for soil matrix interferences and multiple sensing substrates to leam whether VOC selectivity can be achieved.

\section{$2279 \quad$ V18/021406}

Depleted Uranium Concrete Container Feasibility Study

Haelsig, R.T.

Idaho National Engineering Laboratory, Idaho Falls, ID

EGG-MS-11400; 65 pp. (September 1994)

The purpose of this report is to consider the feasibility of using containers constructed of depleted uranium aggregate concrete (DUCRETE) to store and transport radioactive materials. The method for this study was to review the advantages and disadvantages of DUCRETE containers considering design requirements for potential applications. The author found that DUCRETE is a promising material for onsite storage containers, provided DUCRETE vessels can be certified for one-way transport 
to disposal sites. The author also found that DUCRETE multipurpose spent nuclear fuel storage/transport packages are technically viable, provided altered temperature acceptance limits can be developed for DUCRETE.

\section{$2280 \quad$ V18/023715}

Design Guidelines and Procedures for Guided Horizontal Drilling

Kirby, M.J.; Kramer, S.R.; Pittard, G.T.; Mamoun, M. Jason Consultants International, Inc., Washington, DC; Maurer Engineering, Inc., Houston, TX; Gas Research Institute, Chicago, IL

CONF-9603151; International NO-DIG '96: Proceedings of an International Society and North American Society for Trenchless Technology (ISTT/NASTT) Conference and Exhibition, New Orleans, LA, March 31-April 3, 1996. NASTT, Chicago, IL, 687 pp.; (pp. 2-35) (1996)

Jason Consultants International, Inc., under the sponsorship of the Gas Research Institute (GRI), has developed guidelines, procedures and software for the installation of polyethylene gas pipe using guided horizontal drilling. Jason was aided in this development by two key subcontractors: Mauer Engineering who wrote the software and NICOR Technologies who reviewed the software and guidelines from a utility perspective. This program resulted in the development of commercially viable software for utilities, contractors, engineering firms, and others involved with the installation of pipes using guided horizontal drilling. The software is an interactive design tool that allows the user to enter ground elevation data, alignment information and pipe data. The software aids the engineer in designing a drill path and provides plan and profile views along with tabular data for pipe depth and surface profile. Finally, the software calculates installation loads and pipe stresses, compares these values against the pipe manufacturer's recommendations, and provides this information graphically and in tabular form.

2281

V18/022017

Design of Thermal Plasma Reactors for Long Reactant Residence Times and Enhanced Mixing

Han, Q.Y.; Zhuang, D.; Huang, P.C.; Heberlein, J.; Pfender, E.

University of Minnesota, Department of Mechanical Engineering, ERC for Plasma-Aided Manufacturing, Minneapolis, MN

CONF-9510125 (Vol. 1); Plasma Systems and Applications, P.W. Mayne and J.A. Mulholland (eds.), Proceedings of an International Symposium on Environmental Technologies, Atlanta, GA, October 8-11, 1995. Georgia Institute of Technology, Atlanta, GA, Vol. 1, 335 pp.; (pp. 193-204) (1995)

Efficient destruction of hazardous materials requires sufficiently long residence times at high temperatures and good mixing of the reactants with the plasma gas. While it is easy to obtain high temperatures in thermal plasma reactors, mixing on a microscopic scale is usually difficult for fluids of strongly differing densities and viscosities, and residence times are usually in order of milliseconds. We have studied the mixing of two dissimilar fluids for the cases of a plasma jet issuing into a cold gas ambient (mixing by turbulent entrainment), and for the case of a jet of atomized liquid droplets being injected into a plasma jet in a counter-flow arrangement. Numerical calculations and measurements have been performed. In the first case, it has been apparent that the turbulent entrainment provides good mixing on a macroscopic scale, but that the entrained gases remain in the form of unmixed cold bubbles for a relatively long time, i.e. for more than five nozzle diameters. In the case of counter-flow injection, we have found a very fast evaporation of the liquid droplets and very efficient mixing on a microscopic scale. Waste destruction experiments involving several hazardous liquids including PCBs have demonstrated the mandated destruction and removal efficiencies. Moreover, the counter-flow reactor can be modified to allow the generation of valuable co-products.

\section{2}

V18/023815

Design of a Tailing Liner and Cover to Mitigate Potential Acid Rock Drainage: A Geochemical Engineering Project

Wildeman, T.; Gusek, J.J.; East, D.R.; de Villiers, A.

Colorado School of Mines, Department of Chemistry and Geochemistry, Golden, CO; Knight Piesold \& Company, Denver, $\mathrm{CO}$

CONF-9506226 (Vol. 2); Decades Later: A Time for Reassessment, G.E. Schuman and G.F. Vance (eds.), Proceedings of the Annual Meeting of the American Society for Surface Mining and Reclamation, Gillette, WY, June 3-8, 1995. American Society for Surface Mining and Reclamation, Princeton, WV, Vol. 2, 362 pp.; (pp. 681-687) (1995)

In design for closure of a mining facility, both the physical and chemical factors that lead to the desired result should be taken into account. In mining operations, this usually entails flow of water through rocks, soils, or tailing materials and chemical reactions of these solid materials with the water. Design and problem solving associated with water - rock - soil interactions can be considered geochemical engineering. These principles were applied to the recent design of a tailing facility to be placed in a mountainous region of western United States where there is an excess of net precipitation. Because the tailing material gave all indications that it would be acid producing, the design issue was to build the facility and reclamation cap to eliminate oxidation and thereby mitigate potential acid production by sulfide minerals. It was assumed that some small amount of underdrainage would occur and the liner design emphasized complete collection of this water and discharge through the foot of the dam into a monitoring sump. Special considerations in the design of the geomembrane liner included providing a cushion for construction equipment, and protection from damage by freezing and UV radiation. Because the underdrain water may require some treatment, special provisions were made to separate the water flowing across the tailing system from that flowing from the underdrain. Operation and closure of the facility is based on subaqueous deposition and storage. The reclamation cap design maintains saturated tailing without a permanent lake. Rather, a permanent water table is maintained near surface and above the tailing, within the multi-layered reclamation cap. To affect surface runoff, a mild sloping final surface was designed with a wetland along the center of the facility for flow control. The water level would be maintained above an organic rich soil layer that would facilitate 
removal of all dissolved oxygen. Careful control of the hydraulic conductivity of the soil layers in the reclamation cap will help to maintain greater flow of direct precipitation and run-on from an adjacent hillside across the cap instead of vertical flow through the tailings. What little water that does reach the tailings will geochemically interact with the reclamation cap soils such that all oxygen is removed. Acid production from the tailings would thus be minimized.

\section{3 \\ V18/022018}

Destruction of Hazardous Waste Material Using Plasma Arc Technology

Brooman, E.W.; Patun, R.J.; Qazi, M.A.; Kanaras, L. National Defense Center for Environmental Excellence, Johnstown, PA; U.S. Army Environmental Center, Aberdeen Proving Ground, MD; Concurrent Technologies Corporation, Johnstown, PA

CONF-9510125 (Vol. 1); Plasma Systems and Applications, P.W. Mayne and J.A. Mulholland (eds.), Proceedings of an International Symposium on Environmental Technologies, Atlanta, GA, October 8-11, 1995. Georgia Institute of Technology, Atlanta, GA, Vol. 1, 335 pp.; (pp. 205-217) (1995)

This paper gives an overview of Plasma Arc Technology (PAT), how it works, and whether it is a pyrolysis or combustion process. Arc generators and their applications are described along with examples of successful waste treatment applications. This paper also evaluates the economic impact and the advantages of using PAT systems. This paper concludes with a description of a PAT system that is being used to destroy military wastes, and describes the task plan, the selection process for the waste materials, and the Plasma Arc Centrifugal Treatment (PACT-2) system.

\section{$2284 \quad$ V18/025485}

Development of a Decision Support System for the Department of Energy's Selection of Waste Site Remediation Technologies

Ralston, B.E.

U.S. Air Force Institute of Technology, Wright-Patterson Air Force Base, $\mathrm{OH}$

AFIT/GOR/ENS/96M-12; 136 pp. (March 1996)

This research focused on developing a decision support system to aid the decision maker in selecting the best strategy of remediation technologies. A decision analysis model was developed which incorporates life cycle cost data, risk information, and user input, to analyze the technology choices. The research outlined the use of multiple attribute utility theory using exponential attribute utility functions with a simple additive objective function. The best available data was used to demonstrate the capabilities of the model. The model provides the decision maker with estimates of the cost and time distributions and the associated utility. Cumulative and frequency distributions illustrate the dominance of technology choices and the variance in the results. Cost and time plots allow the decision maker to see the tradeoffs inherent in the utility functions. The model also allows for sensitivity analysis in the form of rainbow and tomado diagrams to display the effects of changes in the values of the input variables.

\section{5 \\ V18/021992}

Development of a Precision Cleaning and Processing System

Kohli, R.; Schueller, K.J.; Pasupathi, V.

Battelle Memorial Institute, Columbus, $\mathrm{OH}$; Battelle Memorial Institute, Oak Ridge Operations, Oak Ridge, TN

CONF-9509139; Emerging Technologies in Hazardous Waste Management VII, D.W. Tedder (ed.), Proceedings of the Seventh American Chemical Society Industrial and Engineering Chemistry Division Special Symposium, Atlanta, GA, September 17-20, 1995. American Chemical Society, Washington, DC, 1291 pp.; (pp. 206-209) (1995)

Battelle has developed a highly versatile, non-solvent precision cleaning and processing system, BattelleClean [TM], which can be used for a variety of applications in commercial industries. The primary driver for the development of this system has been the increased emphasis on the minimization of the amount of hazardous waste generated. Possible applications are in the aerospace, automotive, chemical, defense, electronics, environmental, food, medical and robotics industries. The versatility of the system allows it to be used for a number of different operations resulting in both cost savings and pollution prevention. Some examples of the operations include: surface decontamination to remove hazardous materials; recycle and recovery of precious materials by precise and selective removal of components containing these materials; removal of coatings; demarking; precise drilling and cutting of hazardous components; and general surface cleaning.

\section{6 \\ V18/021223}

Development of a Scintillation Flow-Cell Detection System for Environmental Restoration and Waste Management Applications

DeVol, T.A.; Branton, S.D.; Fjeld, R.A.

Clemson University, Department of Environmental Systems Engineering, Clemson, SC; South Carolina Universities Research and Education Foundation, Strom Thurman Institute, Clemson, SC

DOE/MC/29115-96/C0691; CONF-960212; Waste Management '96: Working Towards a Cleaner Environment, Proceedings of a Conference on $\mathrm{HLW}, \mathrm{LLW}$, Mixed Wastes and Environmental Restoration, Tucson, AZ, February 25-29, 1996; (9 pp.) (1996)

A flow-cell detection system was developed utilizing a coincidence circuit and tested with $\mathrm{BaF} 2, \mathrm{CaF} 2$ :Eu and scintillating glass. The coincidence detection system reduced the background from approximately $200 \mathrm{cps}$ to approximately $0.5 \mathrm{cps}$. The detection efficiencies for these cells ranged from 0.38 to 0.66 for $\mathrm{Ca}-45$ beta particles $(E[s u b \max ]=0.257 \mathrm{MeV}$ ) and from 0.45 to 0.52 for U-233 alpha particles ( $E[$ sub [alpha]] $=4.8 \mathrm{MeV}$ ). The minimum detectable activity was calculated for a $30 \mathrm{~s}$ count time and determined to be in the range of $1-2 \mathrm{~Bq}$.

Development of a Supercritical Fluid Extraction System for the Remediation of Toxic Metal Contaminated Environmental Matrices 
Smart, N.G.; Elshani, S.; Wai, C.M.; Carleson, T.; Fox, R.

British Nuclear Fuels plc, Preston, United Kingdom;

University of Idaho, Moscow, ID; Idaho National

Engineering Laboratory, Idaho Falls, ID

CONF-960804 (Vol. 2); Spectrum '96: Nuclear and Hazardous Waste Management, Proceedings of an International Topical Meeting, Seattle, WA, August 18-23, 1996. American Nuclear Society, La Grange Park, IL, Vol. 2, 873 pp.; (pp. 967-973) (1996)

Interest in supercritical fluids (SF), particularly carbon dioxide as a solvent for use in extraction processes has been driven by increased environmental legislation restricting the use of conventional solvents. Recently, the use of SFs modified by the addition of complexing agents has been utilised in the extraction of metal ions from various solid and liquid matrices. In this study, the authors investigated the use of a range of commercially available reagents for the extraction. The feasibility of using Kelex 100, Cyanex 301, 302,272 and D2EHTPA as reagents for the supercritical fluid extraction of toxic heavy metals has been demonstrated. High extraction efficiencies are observed for a range of heavy metals using Cyanex 302, 301 and D2EHTPA ligands from a variety of matrices and from samples of high acidity. Extraction efficiencies increased with increasing pressure. Temperature was found to have little effect on extraction efficiencies. Kelex 100 was found to be very selective for the extraction of $\mathrm{Cu} 2+$ using $\mathrm{SF} \mathrm{CO} 2$.

\section{8 \\ V18/021224}

Development of an Insitu XRF Probe for Down Well Characterization of Waste Sites Containing Heavy Metals

Shepard, C.L.; Brodzinski, R.L.; Reeves, J.H.; Conroy, T.J.

Pacific Northwest Laboratory, Richland, WA; Lockheed Idaho Technologies Company, Idaho Falls, ID; Idaho State University, Pocatello, ID

CONF-951091; Proceedings of the Fourth Conference on Nondestructive Assay and Nondestructive Examination Waste Characterization, Salt Lake City, UT, October 24-26, 1995, 550 pp.; (pp. 431-442) (1995)

The United States Department of Energy (DOE) and other federal and state agencies have a need for the rapid and inexpensive characterization of waste depository sites which have been developed over the last century. Examples of such sites include both industrial and federal landfills as well as mining sites and estraries. Characterization involves a host of tests and includes in many cases soil testing for the presence of high atomic number elements, most notably heavy metals. Standard methods of characterization include sampling followed by laboratory analysis using accepted techniques. These methods are costly and time consuming and in some cases generate secondary waste. Pacific Northwest Laboratory (PNL) is developing an $x$-ray fluorescence (XRF) probe with the goal of reducing characterization costs by providing analysis for heavy metals in real time and without sampling. The probe is about 120 $\mathrm{cm}$ in length and $3.2 \mathrm{~cm}$ in diameter, which is small enough to fit within the bore of a cone penetrometer. It is designed to be operated in unlined (or only lined with a thin air bladder) test wells drilled or pushed into the waste sites.

\section{Directional Drilling}

Cooper, G.A.

University of California, Berkeley, CA

Scientific American 270(5):56-61 (May 1994)

This paper provides an overview of directional drilling. It discusses development of the technology for use in the oil and gas industry and the extension of these techniques to applications in the cable and pipeline industry and remedial action procedures. The directional drilling assembly equipment is described along with well and borehole design and configuration. In addition to describing developments within the petroleum industry, specific examples of uses of the technology for river crossings and clean-up operations are provided along with problems encountered unique to these settings.

\section{$2290 \quad$ V18/021794}

Divide and Conquer is ESP's Strategy

Initiatives in Environmental Technology Investment 3(June 1996):10-12 (June 1996)

The U.S. Department of Energy's Office of Science and Technology created the efficient separations and processing (ESP) crosscutting area because new separations technologies and processes have the potential to save billions of dollars in cleanup costs. By removing the most hazardous or most radioactive portions of a waste stream, new separations technologies could reduce the complexity of treatments and the volume of waste slated for expensive high-level waste treatment and disposal. In addition to reducing costs, ESP has also been challenged to design separations processes that minimize risks to plant personnel and the public. Another goal is minimizing secondary wastes, which are additional wastes from the reagents used to carry out the separations. The ESP program really came into being to support the tanks focus area. Now tank support is slowly giving way to ESP support for the mixed waste, decontamination and decommissioning, and subsurface contaminants focus areas. Esp has categorized its inventory of $R \& D$ projects into four product lines to address short-lived radionuclides, long-lived radionuclides, heavy metals, and waste processing and treatment. Success is measured in transfers of technologies to meet customers' needs.

2291

V18/022760

EM-40 Technology Initiatives: Achieving a Common Goal

Warren, S.W.; Breck, M.

U.S. Department of Energy, Washington, DC; Booz-Allen \& Hamilton, Inc., Germantown, MD

CONF-960804 (Vol. 2); Spectrum '96: Nuclear and Hazardous Waste Management, Proceedings of an International Topical Meeting, Seattle, WA, August 18-23, 1996. American Nuclear Society, La Grange Park, IL, Vol. 2, 873 pp.; (pp. 1146-1149) (1996)

The U.S. Department of Energy's Office of Environmental Restoration has a number of initiatives underway which are designed to infuse improved/innovative technologies into the Environmental Management Program. These initiatives are intended to help expedite cleanup by defining problem sets across the sites (i.e., the field), identifying appropriate technologies, assisting technology 
development, breaking down barriers to technology implementation, providing a standardized method for reporting technology cost and performance information, and allowing the marketplace to suggest the best technologies for doing the job.

\section{$2292 \quad$ V18/021592}

Efficient Separations Processing Crosscutting Program

U.S. Department of Energy, Office of Environmental Management, Office of Science and Technology, Washington, $\mathrm{DC}$

\section{DOE/EM-0294; 155 pp. (August 1996)}

The Efficient Separations and Processing Crosscutting Program (ESP) was created in 1991 to identify, develop, and perfect chemical and physical separations technologies and chemical processes which treat wastes and address environmental problems throughout the DOE complex. The ESP funds several multiyear tasks that address high-priority waste remediation problems involving high-level, low-level, transuranic, hazardous, and mixed (radioactive and hazardous) wastes. The ESP supports applied research and development (R\&D) leading to the demonstration or use of these separations technologies by other organizations within the Department of Energy (DOE) Office of Environmental Management. This report provides overviews of a large number of technologies under the following section headings: (1) Short-Lived Radionuclides, (2) Long-Lived Radionuclides, (3) Heavy Metals, (4) Waste Processing and Treatment.

\section{$2293 \quad$ V18/021580}

Electrokinetic Applications for Environmental

Restoration, Waste Volume Reduction, and

Contaminant Containment Systems

Lomasney, H.L.; Lomasney, C.A.

Isotron Corporation, New Orleans, LA

CONF-960306 (Vol. 5); ICONE-4 (Vol. 5), Proceedings of an American Society of Mechanical Engineers/Japanese Society of Mechanical Engineers (ASME/JSME) International Conference Nuclear Engineering, Radioactive Waste Disposal, Decontamination and Decommissioning, Aging Assessment and License Renewals, Global Advances in Nuclear Codes and Standards, Major Component Reliability, A.S. Rao, R.B. Duffey and D. Elias (eds.), New Orieans, LA, March 10-13, 1996. ASME, New York, NY, Vol. 5, 525 pp.; (pp. 157-161) (1996)

In the US and all over the world, following over 50 years of nuclear arms production operations, the magnitude of resultant environmental damage is only beginning to surface. The US Department of Energy estimates that by the year 2070, the total volume of high-level waste, transuranic waste, low-level waste, and low-level mixed waste, generated as a result of past and current nuclear activities, will exceed 20 million cubic meters. In Russia, it is reported that more than $30 \%$ of all groundwater is contaminated with agricultural and industrial chemical waste. Government agencies today are faced with the responsibility of developing technologies that are suitable for dealing with severe environmental contamination and accumulating waste inventories. In response to this demand, applications of electrokinetics have emerged in the field of environmental waste management as alternatives for environmental decontamination and ecological protection.
Electrokinetics involves the movement of charged species under the influence of an applied electric field and is applicable in several areas of environmental waste management, including cleanup of soil and groundwater, barrier detection, and emergency or protective fencing. The worldwide interest in this technology has steadily escalated over the past decade. Today, state-of-the-art applications of electrokinetics have been demonstrated in the US, the Netherlands, Russia, the Ukraine, and India. This paper addresses the latest advances in the various applications of this technology as well as the most significant breakthroughs in the history of electrokinetics.

\section{4}

V18/020934

Electrolytic Decontamination of Stainless Steel Materials in a Sodium Nitrate Electrolyte for Hazardous Waste Management

Wedman, D.E.; Martinez, H.E.; ONelson, T.

Los Alamos National Laboratory, Los Alamos, NM

CONF-960212; Waste Management '96: Working Towards a Cleaner Environment, Proceedings of a Conference on $\mathrm{HLW}$, LLW, Mixed Wastes and Environmental Restoration, Tucson, AZ, February 25-29, 1996; (14 pp.) (1996)

Electrolytic decontamination of plutonium and americium from stainless steel and uranium surfaces has been demonstrated. This decontamination process is similar to industrial electropolishing processes but is carried out in a sodium nitrate electrolyte from which the metals can be precipitated. The separation of the metals from the electrolyte allows for recycle of the electrolyte; hence, no aqueous waste stream is produced. The generated waste is in the form of a precipitate and is therefore very minimal and compact. An example application is a "can-out" process for the decontamination of radioactive material storage containers being developed at Los Alamos National Laboratory. This process utilizes electrolytic decontamination as its primary component. The "can-out" decontamination system and the underlying chemistry is outlined. Other successful applications of this technology are the in-situ decontamination of gloveboxes and highly enriched uranium.

2295

V18/024074

Electromagnetic Integrated Demonstration at the Idaho National Engineering Laboratory Cold Test Pit

Pellerin, L.; Alumbaugh, D.L.; Pfeifer, M.C.

Lawrence Berkeley National Laboratory, Berkeley, CA; Sandia National Laboratories, Albuquerque, NM; Idaho National Engineering Laboratory, Idaho Falls, ID

SAND97-0904C; 12 pp. (1997)

The electromagnetic integrated demonstration (EMID) is a baseline study in electromagnetic (EM) exploration of the shallow subsurface (less than $10 \mathrm{~m}$ ). Eleven distinct EM systems, covering the geophysical spectrum, acquired data on a grid over the Idaho National Engineering Laboratory (NNEL) Cold Test Pit (CTP). The systems are investigated and evaluated for the purpose of identifying and reviewing existing geophysical characterization instrumentation (commercial and experimental), integrating those technologies with multi-dimensional interpretational algorithms, and identifying gaps in shallow subsurface EM imaging technology. 
The EMID data, are valuable for testing and evaluating new interpretational software, and developing techniques for integrating multiple data sets. The experimental field techniques shows how the acquisition of data in a variety of array configurations can considerably enhance interpretation. All data are available on the world wide web (http://vetem.lbl.gov). Educators and students are encouraged to use the data for both classroom and graduate studies. The purpose of this paper is to explain why, where, how and what kind of data were collected. It is left to the reader to assess the value of a given system for their particular application. Information about the EMID is organized into two general categories: survey description and system evaluation.

\section{6 \\ V18/021407}

Emerging Technologies for Environmental Characterization and Monitoring

Wang, P.W.; Purdy, C.B.; Lightner, E.M.

Ames Laboratory, Ames, IA; U.S. Department of Energy, Germantown, MD

Fostering the Needed Partnerships: Doing the Necessary Science to Support Technology Development, Commercialization, Deployment, E.L. Helminski (ed.), Proceedings of the Seventh Annual Western Governors' Association/Weapons Complex Monitor Applied Research and Cleanup Technology Colloquium, Phoenix, AZ, April 29-May 2, 1996. Exchange/Monitor Publications and Forums, Lake Bluff, II, 500 pp.; (7 pp.) (April 1996)

The Characterization, Monitoring, and Sensor Technology Crosscutting Program (CMST-CP) is primarily responsible for developing technologies for use in site/waste characterization as well as in monitoring of waste removal/treatment/disposition operations. This paper summarizes past, current, and future CMST-CP activities with an emphasis on those technologies ready for use or planned for field evaluation and testing. By publicizing this information, the DOE aims to achieve wider use of new technologies in DOE cleanup operations as well as in commercial applications.

\section{$2297 \quad$ V18/022770}

Emerging Technologies for Environmental Characterization and Monitoring

Wang, P.W.; Purdy, C.B.; Lightner, E.M.

Ames Laboratory, Ames, IA; U.S. Department of Energy, Germantown, MD

CONF-960804 (Vol. 2); Spectrum '96: Nuclear and Hazardous Waste Management, Proceedings of an International Topical Meeting, Seattle, WA, August 18-23, 1996. American Nuclear Society, La Grange Park, IL, Vol. 2, 873 pp.; (pp. 1234-1242) (1996)

The Characterization, Monitoring, and Sensor Technology Crosscutting Program (CMST-CP) is primarily responsible for developing technologies for use in site/waste characterization as well as in monitoring of waste removal/treatment/disposition operations. This paper summarizes past, current, and future CMST-CP activities with an emphasis on those technologies ready for use or planned for field evaluation and testing. By publicizing this information, the DOE aims to achieve wider use of new technologies in DOE cleanup operations as well as in commercial applications.

2298

V18/022876

Engineered Photocatalysts for Detoxification of Waste Water

Majumder, S.A.; Prairie, M.R.; Shelnutt, J.A.; Ryba, G.N.; Miller, J.E.; Garino, T.J.; Khan, S.U.M.

Sandia National Laboratories, Albuquerque, NM; Duquesne University, Pittsburgh, PA

SAND96-2925; 118 pp. (December 1996)

This report describes progress on the development of engineered photocatalysts for the detoxification of water polluted with toxic organic compounds and heavy metals. We examined a range of different oxide supports (titania, alumina, magnesia and manganese dioxide) for tin uroporphyrin and investigated the efficacy of a few different porphyrins. A water-soluble octaacetic-acid-tetraphenylporphyrin and its derivatives have been synthesized and characterized in an attempt to design a porphyrin catalyst with a larger binding pocket. We have also investigated photocatalytic processes on both single crystal and powder forms of semiconducting $\mathrm{SiC}$ with an ultimate goal of developing a dual-semiconductor system combining $\mathrm{TiO} 2$ and $\mathrm{SiC}$. Mathematical modeling was also performed to identify parameters that can improve the efficiency of SiC-based photocatalytic systems. Although the conceptual $\mathrm{TiO} / \mathrm{SiC}$ photodiode shows some promises for photoreduction processes, $\mathrm{SiC}$ itself was found to be an inefficient photocatalyst when combined with TiO2. Alternative semiconductors with bandgap and band potentials similar to $\mathrm{SiC}$ should be tested in the future for further development and a practical utilization of the dual photodiode concept.

2299

V18/022400

Engineering-Scale Insitu Vitrification Tests of Simulated Oak Ridge National Laboratories Buried Wastes

Oak Ridge National Laboratory, Oak Ridge, TN; Battelle Memorial Institute, Richland, WA

ORNL/ER-384; 144 pp. (October 1996)

This report presents the results of a series of in-situ vitrification (ISV) tests designed to assess the potential of ISV for remediating buried waste trenches in WAG 6 . The tests were conducted at the Pacific Northwest National laboratory Engineering-Scale ISV Facility in Richland, Washington. A series of 10 tests were performed that included investigation of the merits of dynamic compaction prior to ISV. Dynamic compaction reduces the volume of waste and breaches any containers in the waste. Also, the use of the bottom-up approach to ISV was examined with some of the tests. This approach initiates the melt below the waste. Details on the series of tests are provided in this report.
2300
V18/025460

Enhanced Research in Ground-Penetrating Radar and Multisensor Fusion with Application to the Detection and Visualization of Buried Waste: Final Report

Devney, A.J.; DiMarzio, C.; Kokar, M.; Miller, E.L.; Rappaport, C.M.; Weedon, W.H. 
Northeastern University, Center for Electromagnetics Research, Boston, MA

DOE/ID/13395-T1; 112 pp. (May 14, 1996)

Recognizing the difficulty and importance of the landfill remediation problems faced by $D O E$ and the fact that no one sensor alone can provide complete environmental site characterization, a multidisciplinary team approach was chosen for this project. The authors have developed a multisensor fusion approach that is suitable for the wide variety of sensors available to DOE. The approach allows separate detection algorithms to be developed and custom-tailored to each sensor. This approach is currently being applied to the Geonics EM-61 and Coleman step-frequency radar data. High-resolution array processing techniques were developed for detecting and localizing buried waste containers. A soil characterization laboratory facility was developed using a HP-8510 network analyzer and near-field coaxial probe. Both internal and extemal calibration procédures were developed for de-embedding the frequency-dependent soil electrical parameters from the measurements. Dispersive soil propagation modeling algorithms were also developed for simulating wave propagation in dispersive soil media. A study was performed on the application of infrared sensors to the landfill remediation problem, particularly for providing information on volatile organic compounds (VOC) in the atmosphere. A dust-emission lidar system is proposed for landfill remediation monitoring. Design specifications are outlined for a system which could be used to monitor dust emissions in a landfill remediation effort. The detailed results of the investigations are contained herein.

\section{1}

V18/024271

Enhancing Technology Acceptance: The Role of the Subsurface Contaminants Focus Area External Integration Team

Kirwan-Taylor, H.; McCabe, G.H.; Lesperancè, A.M.; Kauffman, J.; Serie, P.; Dressen, L.

Battelle Seattle Research Center, Seattle, WA; Pacific Northwest National Laboratory, Richland, WA

PNNL-1 1334; BSRC-800/96/013; 153 pp. (September 1996)

The US DOE is developing and deploying innovative technologies for cleaning up its contaminated facilities using a market-oriented approach. This report describes the activities of the Subsurface Contaminant Focus Area's (SCFA) Extemal Integration Team (EIT) in supporting DOE's technology development program. The SCFA program for technology development is market-oriented, driven by the needs of end users. The purpose of EIT is to understand the technology needs of the DOE sites and identify technology acceptance criteria from users and other stakeholders to enhance deployment of innovative technologies. Stakeholders include regulators, technology users, Native Americans, and environmental and other interest groups. The success of this national program requires close coordination and communication among technology developers and stakeholders to work through all of the various phases of planning and implementation. Staff involved must be willing to commit significant amounts of time to extended discussions with the various stakeholders.
Environmental Management Technology Demonstration and Commercialization: Semi-Annual Report - April 1, 1995-October 31, 1995

Hawthome, S.B.

University of North Dakota, Energy and Environmental Research Center, Grand Forks, ND

DOE/MC/31388-5252; 265 pp. (November 1995)

Several field-portable (e.g., gas chromatrography [GC], gas chromatography-mass spectrometry [GC-MS]) instruments are available for the measurement of organic pollutants. However, solid samples such as soils, sludges, and sediments must first be extracted before analysis can be performed. Conventional extraction methods based on liquid solvent (e.g., Soxhlet extraction) are not practical in the field because of the large volumes of solvents required as well as clumsy apparatus and glassware. However, supercritical fluid extraction (SFE) has been demonstrated in several studies by the Energy Environmental Research Center (EERS) to extract a broad range of organic pollutants from soils and sediments successfully. Of the approximately 100 major organic pollutants identified as problems for the US Department of Energy (DOE) sites, the SFE laboratory has demonstrated efficient SFE recoveries for about half, and published literature has addressed an additional $40 \%$. SFE in the off-line mode (i.e., collection of extracted organics in a small volume of liquid solvent) has also been demonstrated to be easily performed in the field with only generator electrical power for support. Recent advances in flow restrictor design have virtually eliminated the mechanical problems previously associated with the performance of SFE in the field.

\section{3}

\section{V18/022703}

Environmental Management Technology

Demonstration and Commercialization: Semi-Annual Report - November 1995-March 1996

Hawthome, S.B.

North Dakota University, Energy and Environmental Research Center, Grand Forks, ND

DOE/MC/31388-5251; 191 pp. (April 1996)

This document describes activities in the following tasks associated with a project on environmental management technology for decontamination and commercialization: (1) commercialized version of a field-portable instrument for performing supercritical fluid extraction (SFE) with on-line Fourier transform infrared (FT-IR) detection; (2) pyrolysis of plastic wastes associated with mixtures of radioactive wastes; (3) management and reporting activities; (4) centrifugal membrane filtration with application to tank waste remediation; and (5) technology development integration activities associated with remedial action and waste management.

\section{$2304 \quad$ V18/024840}

Environmental Management Technology

Demonstration and Commercialization: Task 3, Pyrolysis of Plastic Waste - Semiannual Report, November 1, 1995-March 31, 1996

Ness, R.O.; Aulich, T.R.

University of North Dakota, Energy and Environmental 
Research Center, Grand Forks, ND

DOE/MC/31388-5251 (Task 3); 26 pp. (April 1996)

Over the last 50 years, the U.S. Department of Energy (DOE) has produced a wide variety of radioactive wastes from activities associated with nuclear defense and nuclear power generation. These wastes include low-level radioactive solid wastes, mixed wastes, and transuranic (TRU) wastes. A portion of these wastes consists of high-organic-content materials, such as plastics and other polymers, synthetic and natural rubbers, resins, and cellulosic-based materials, as well as oils, organic solvents, and chlorinated organic solvents. Options for dealing with high-organic-content radioactive waste include volume reduction and storage. The University of North Dakota Energy \& Environmental Research Center is developing a process for efficient, complete separation of radionuclides from high-organic-content radioactive waste. The process is a low-temperature thermal decomposition-separation technology that will yield a small volume of particulate solids product containing radioactive species, a nonradioactive organic condensate product, and a nonradioactive hydrocarbon-rich gas product. This document summarizes the research project and reports laboratory test results using surrogates for radionuclides.

\section{$2305 \quad$ V18/024841}

Environmental Management Technology

Demonstration and Commercialization: Task 8, Management and Reporting - Semiannual Report, November 1, 1995-March 31, 1996

Daly, D.J.; Steadman, E.N.

University of North Dakota, Energy and Environmental Research Center, Grand Forks, ND

DOE/MC/31388-5251 (Task 8); 10 pp. (April 1996)

The task of restoring nuclear defense complex sites under the U.S. Department of Energy (DOE) Environmental Management (EM) program presents an unprecedented challenge to the environmental restoration community. Effective and efficient cleanup requires the timely development or modification of novel cleanup technologies applicable to radioactive wastes. Fostering the commercialization of these innovative technologies is the mission of EM-50, the EM Program Office of Science and Technology. DOE's Morgantown Energy Technology Center (METC) pursues activities integral to the EM-50 mission through a cooperative agreement with the EM Office of Science and Technology. The Energy \& Environmental Research Center (EERC), a not-for-profit, contract-supported organization focused on research, development, demonstration, and commercialization (RDD\&C) of energy and environmental technologies, is in the second year of a cooperative agreement with METC. The following activities, along with program management, comprise the four program areas of the METC-EERC EM Cooperative Agreement (EMCA): Technology Commercialization, Systems Engineering, Technology Integration, and Management and Reporting. This report is focused on the accomplishments of the Management and Reporting program area, which corresponds to Task 8 under EMCA.

2306

V18/024842

Environmental Management Technology Demonstration and Commercialization: Task 9,
Centrifugal Membrane Filtration - Semiannual Report, November 1, 1995-March 31, 1996

Stepan, D.J.; Kurz, M.D.

University of North Dakota, Energy and Environmental Research Center, Grand Forks, ND

DOE/MC/31388-5251 (Task 9); 10 pp. (April 1996)

Work under this task is designed to establish the utility of a novel centrifugal membrane filtration technology for the remediation of liquid mixed waste streams at the U.S. Department of Energy (DOE) facilities in support of the DOE Environmental Management (EM) program. The Energy \& Environmental Research Center (EERC) has teamed with SpinTek Membrane Systems, Inc., a small business and owner of the centrifugal membrane filtration technology, to establish the applicability of the technology to DOE site remediation and the commercial viability of the technology for liquid mixed waste stream remediation. The technology is a uniquely configured process that utilized ultrafiltration and centrifugal force to separate suspended and dissolved solids from liquid waste streams, producing a filtered water stream and a low-volume contaminated concentrate stream. This technology has the potential for effective and efficient waste volume minimization, the treatment of liquid tank wastes, the remediation of contaminated groundwater plumes, and the treatment of secondary liquid waste streams from other remediation processes, as well as the liquid waste stream generated during decontamination and decommissioning activities.

2307

V18/024843

Environmental Management Technology

Demonstration and Commercialization: Task 10, Technology Development Integration - Semiannual Report, November 1, 1995-March 31, 1996

Hendrikson, J.H.; Daly, D.J.

University of North Dakota, Energy and Environmental Research Center, Grand Forks, ND

DOE/MC/31388-5251 (Task 10); 140 pp. (April 1996)

The Energy \& Environmental Research Center (EERC) in conjunction with the Waste Policy Institute (WPI) will identify and integrate new technologies to meet site-specific environmental management (EM) requirements at contaminated sites appropriate to U.S. Department of Energy (DOE) interests. EM technologies offered by developers will be evaluated to determine their complementary contribution to new cleanup systems focused on particular characterization and remediation problems at specific EM sites. The technology clusters identified will provide EM cleanup capabilities that are significantly faster, better, safer, and cheaper than systems that are currently available. Work will be performed under the DOE-EERC EM Cooperative Agreement (CA), which includes provisions "to develop, demonstrate, and commercialize technologies that address environmental management needs of contaminated sites" together with "management activities which accelerate transfer of technologies." The effort began July 1, 1995. Task 10 develops new approaches for evaluating technology focus areas and other research and development technical programs and activities. This section reviews accomplishments in technology integration during the reporting period. Appendices present WPI monthly reports for the reporting period. 


\section{8}

V18/024091

Environmental Management Technology Leveraging Initiative: Topical Report - October 1994-September 1995

Global Environment and Technology Foundation, Annandale, VA

DOE/MC/31179-5309; 35 pp. (1997)

The deployment of innovative DOE-EM technologies could provide more cost-effective treatments than remediation technologies and methods currently in use. By building partnerships between the public and private sectors, the technological expertise of federal researchers and engineers and the commercial incentive of industrialists and other non-government interests can combine to help move these technologies "off the shelf" and toward the use at contaminated sites. The Global Environmental Technology Enterprise (GETE) approach to achieving this end is to: (1) develop a process which identifies and assesses DOE-developed technologies from the perspective of commercial marketability, assists in bringing these technologies to the attention of the private sector, and aids in business planning and start-up activities; (2) establish a state-of-the-art electronic communications system, the Global Network of Environment \& Technology (GNET), to disseminate information on DOE-developed technologies, as well as information on capital and financing availability, regulatory matters, and commercialization objectives to potential business partners and others; and (3) undertake public participation and outreach activities designed to address barrier reduction and public acceptance issues.

\section{9 \\ V18/024136}

Environmental Problem-Solving Through Science and Technology

Los Alamos National Laboratory, Los Alamos, NM

Report; 155 pp. (February 1997)

This document contains one-page technology summary sheets for a broad range of technologies under development at the Los Alamos National Laboratory. Technologies are related to environmental restoration, waste management, and pollution prevention. The summary sheets contain technical information as well as information on partnering opportunities and contacts. Information is also available on a World Wide Web site (http://www-emtd.lanl.gov). Summaries within the scope of this database have been indexed separately.

\section{$2310 \quad$ V18/022403}

Environmental Restoration Remediation Technology Requirements Definition: Volume 1, Version 0.2

Report; 125 pp. (June 17, 1996)

The purpose of this report is to: (1) assist the Technology Focus Areas in budget formulation and priority setting by identifying remediation problem sets and how problem sets are addressed by the marketplace, and (2) rank technology gaps and areas where existing technology can be improved. The project scope is limited to Environmental Restoration remedial action problem sets and to plumes/landfill technologies. The present report is the first of a series that will analyze problem sets in the Environmental Restoration Program and the commercially available technologies for addressing them. The analyses provide initial answers to four questions: What problem sets confront the ER Remedial Action Program; Where are there no technologies provided by the marketplace; Where can technologies be improved; and, What problem sets are satisfied by technologies available in the marketplace.

2311 V18/021417

Evaluation of an Air Drilling Cuttings Containment System

Westmoreland, J.

Sandia National Laboratories, Albuquerque, NM

SAND94-0214; 58 pp. (April 1994)

Drilling at hazardous waste sites for environmental remediation or monitoring requires containment of all drilling fluids and cuttings to protect personnel and the environment. At many sites, air drilling techniques have advantages over other drilling methods, requiring effective filtering and containment of the retum air/cuttings stream. A study of current containment methods indicated improvements could be made in the filtering of radionuclides and volatile organic compounds, and in equipment like alarms, instrumentation or pressure safety features. Sandia National Laboratories, Department 6111 Environmental Drilling Projects Group, initiated this work to address these concerns. A look at the industry showed thas asbestos abatement equipment could be adapted for containment and filtration of air drilling returns. An industry manufacturer was selected to build a prototype machine. The machine was leased and put through a six-month testing and evaluation period at Sandia National Laboratories. Various materials were vacuumed and filtered with the machine during this time. In addition, it was used in an actual air drive drilling operation. Results of these tests indicate that the vacuum/filter unit will meet or exceed our drilling requirements. This vacuum/filter unit could be employed at a hazardous waste site or any site where drilling operations require cuttings and air containment.

2312 V18/021416

Final Report for SNL/NM Environmental Drilling Project

Wemple, R.P.; Meyer, R.D.; Staller, G.E.; Layne, R.R. Sandia National Laboratories, Albuquerque, NM; Charles Machine Works, Inc., Perry, OK

SAND94-2388; 75 pp. (November 1994)

Concern for the environment and cost reduction are the driving forces for a broad effort in government and the private sector to develop new, more cost-effective technologies for characterizing, monitoring and remediating environmental sites. Secondary goals of the characterization, monitoring and remediation (CMR) activity are: minimize secondary waste generation, minimize site impact, protect water tables, and develop methods/strategies to apply new technologies. The Sandia National Laboratories (SNL) project in directional boring for CMR of waste sites with enhanced machinery from the underground utility installation industry was initiated in 1990. Preliminary activities included surveying the directional 
drilling access needs of various DOE sites, identifying an existing class of machinery that could be enhanced for environmental work through development, and establishing a mutually beneficial working relationship with an industry partner. Since that time the project has tested a variety of prototype machinery and hardware built by the industrial partner, Charles Machine Works (CMW), and SNL at several sites (Savannah River Site (SRS), Hanford, SNL, Kirtland Air Force Base (KAFB), CMW), successfully installed usable horizontal environmental test wells at SRS and SNL/KAFB, and functioned as a clearing house for information regarding application of existing commercial machinery to a variety of governmental and commercial sites. The project has continued to test and develop machinery in FY 94. DOE-OTD funding concludes in FY 94. The original goal of cost-effectiveness is being met through innovation, adaptation, and application of fundamental concepts. Secondary goals are being met via a basic philosophy of "cut/thrust and compact cuttings without adding large quantities of fluid" to an environmental problem site. This technology will not be universally applicable to all geologies, but will be very cost effective where applicable. The industry partnership with $\mathrm{CMW}$ has been extended through FY 95 and will be continued to wrap up the project, to respond to requests for information, and for limited participation in demonstration opportunities. Technology transfer and commercialization by $\mathrm{CMW}$ is ongoing and will continue into FY 95. Technology transfer to the private sector is ongoing and reflected in increasing machinery sales to environmental contractors. Education of regulatory agencies resulting in restructuring of appropriate regulatory standards for specification of the horizontal drilling techniques continues to be a long-range goal.

2313 V18/024096

Flexible Ultrasonic Pipe Inspection Apparatus

Jenkins, C.F.; Howard, B.D.

Westinghouse Hanford Company, Richland, WA

U.S. Patent A8312644; 21 pp. (1994)

The present invention relates to pipe inspection apparatus. In particular, the present invention relates to a modular ultrasonic pipe inspection apparatus that flexes to negotiate severe bends in small diameter piping systems. The apparatus has a plurality of modules carried by a flexible shaf, including a nose section, a tail section, at least on rotatable ultrasonic transducer, a motor/gear unit, and a position/signal encoder. The modules are connected by flexible joints that enable the apparatus to negotiate bends in piping by allowing each module to change its relative orientation with respect to the neighboring modules. The motor unit rotates the transducer about the longitudinal axis of the apparatus for scanning the inner surface of a pipe.

\section{4}

V18/022181

Full-Scale Technology Demonstration of a Polyethylene Encapsulation Process for Radioactive, Hazardous, and Mixed Wastes

Kalb, P.D; Lageraaen, P.R; Wright, S.

Brookhaven National Laboratory, Upton, NY; Ames

Laboratory, Ames, IA

Journal of Environmental Science and Health, Part A -

Environmental Science \& Engineering 31(7):1767-1780 (August
1996)

A full-scale technology demonstration of a polyethylene encapsulation process, sponsored by the U.S. Department of Energy (DOE) Office of Technology Development, was held at the Environmental and Waste Technology Center at Brookhaven National Laboratory (BNL) in September 1994. Polyethylene encapsulation has been developed and tested at BNL as an alternative solidification technology for improved treatment of low-level radioactive (LLW), hazardous, and mixed wastes. Although originally developed for treatment of DOE-generated wastes through waste management and environmental restoration activities, polyethylene encapsulation has application within the commercial sector. A fully equipped, production-scale system, capable of processing over $900 \mathrm{~kg} / \mathrm{hr}(2000 \mathrm{lb} / \mathrm{hr})$, has been installed at BNL. The demonstration covered all facets of the integrated processing system including pre-treatment of aqueous wastes, precise feed metering, extrusion processing, on-line quality control monitoring, and process control. Following the demonstration, waste-form testing was conducted to confirm performance of the final waste form.

\section{5}

V18/021401

\section{Global Environmental Technology Enterprise (GETE)}

Meacham, S.A.

Global Environment and Technology Foundation, Annandale, VA

Fostering the Needed Partnerships: Doing the Necessary Science to Support Technology Development, Commercialization, Deployment, E.L. Helminski (ed.), Proceedings of the Seventh Annual Western Governors' Association/Weapons Complex Monitor Applied Research and Cleanup Technology Colloquium, Phoenix, AZ, April 29-May 2, 1996. Exchange/Monitor Publications and Forums, Lake Bluff, II, 500 pp.; (12 pp.) (April 1996)

This presentation discusses the GETE mission which is to increase commercial availability and deployment of EM-relevant, DOE supported technologies by providing assistance to focus areas, the private sector and site technology coordination groups. These viewgraphs provide information on GETE information, facilitation and communication including descriptions of programs, services and activities, particularly the GNET - Global Network for Environmental Technology.

\section{$2316 \quad$ V18/023017}

Graphical Programming of Telerobotic Tasks

Small, D.E.; McDonald, M.J.

Sandia National Laboratories, Albuquerque, NM

SAND96-2419C; CONF-9610197; Proceedings of the 1996 Deneb User Group Conference, Troy, MI, October 9, 1996; (4 pp.) (1996)

With a goal of producing faster, safer, and cheaper technologies for nuclear waste cleanup, Sandia is actively developing and extending intelligent systems technologies through the US Department of Energy Office of Technology Development (DOE OTD) Robotic Technology Development Program (RTDP). Graphical programming is a key technology for robotic waste cleanup that Sandia is developing for this goal. Graphical programming uses 
simulation such as TELEGRIP 'on-line' to program and control robots. Characterized by its model-based control architecture, integrated simulation, 'point-and-click' graphical user interfaces, task and path planning software, and network communications, Sandia's Graphical Programming systems allow operators to focus on high-level robotic tasks rather than the low-level details. Use of scripted tasks, rather than customized programs minimizes the necessity of recompiling supervisory control systems and enhances flexibility. Rapid world-modelling technologies allow Graphical Programming to be used in dynamic and unpredictable environments including digging and pipe-cutting. This paper describes Sancho, Sandia's most advanced graphical programming supervisory software. Sancho, now operational on several robot systems, incorporates all of Sandia's recent advances in supervisory control. Graphical programming uses 3-D graphics models as intuitive operator interfaces to program and control complex robotic systems. The goal of the paper is to help the reader understand how Sandia implements graphical programming systems and which key features in Sancho have proven to be most effective.

\section{7}

\section{V18/021584}

\section{Graphite Electrode Arc Melter Demonstration: Phase 2} Test Results

Soelberg, N.R.; Chambers, A.G.; Anderson, G.L.; O'Connor, W.K.; Oden, L.L.; Turner, P.C.

Idaho National Engineering Laboratory, Idaho Falls, ID

INEL-95/0502; 283 pp. (June 1996)

Several U.S. Department of Energy organizations and the U.S. Bureau of Mines have been collaboratively conducting mixed waste treatment process demonstration testing on the near full-scale graphite electrode submerged arc melter system at the Bureau's Albany (Oregon) Research Center. An initial test series successfully demonstrated arc melter capability for treating surrogate incinerator ash of buried mixed wastes with soil. The conceptual treatment process for that test series assumed that buried waste would be retrieved and incinerated, and that the incinerator ash would be vitrified in an arc melter. This report presents results from a recently completed second series of tests, undertaken to determine the ability of the arc melter system to stably process a wide range of "as-received" heterogeneous solid mixed wastes containing high levels of organics, representative of the wastes buried and stored at the Idaho National Engineering Laboratory (INEL). The Phase 2 demonstration test results indicate that an arc melter system is capable of directly processing these wastes and could enable elimination of an up-front incineration step in the conceptual treatment process.

\section{8}

V18/021579

\section{Hard Surface Remediation}

\section{Durrett, $\mathbf{R}$.}

Blue Planet Technologies, Inc., Channelview, TX CONF-960154; PETRO-SAFE '96, Proceedings of a Conference Held as Part of the Energy Week ' 96 Conference and Exhibition, Houston, TX, January 29-February 2, 1996. PennWell Conferences and Exhibitions, Houston, TX, 291 pp.; (pp. 144-145) (1996)

The emphasis in this paper is to define the term "Hard Surface
Remediation" and to discuss a unique means of environmental cleaning as it relates to the variety of surfaces available. Most applications of interest herein deal with equipment and motor pool areas in refineries and the petrochemical plants. The term, "Hard Surface," implies a variety of substrates including concrete and its many variations. Asphalt and its many forms as well as non-porous surfaces such as steel, ceramics, and other non-ferrous metals must be included in any discussion. With specific reference to concrete surface areas, the utilization of bioremediation products offers a solution to removing hydrocarbon contaminants completely from the substrate. Examples of sites best suited for bioremediation include: auto dealerships, parking facilities, warehouse and product storage areas, and chemical loading and transfer areas. However, this is only a small portion of what is potentially an unlimited source of "Hard Surface" sites. External sites around chemical storage tanks, laden with rock or gravel subjected to chemical spillage or other types of contamination are additional examples of "Hard Surface" areas. Internally, these same storage tanks offer unique opportunities for bioremediation. The cleaning of chemical storage tanks has become a rather complicated task based on specific responsibilities in the handling of the sludige or waste residues. Confined space entry problems occur with delays encountered in attempts to expedite the return of the tank to service. With safety considerations as a primary concem, there exists a way to assist in returning the tank to service by reducing the lower explosive limit (LEL) using a combination of chemical and biological processes.

2319 V18/021006

High-Energy Corona for Destruction of Volatile Organic Contaminants in Process Off-Gases

Virden, J.W.; Heath, W.O.; Goheen, S.C.; Miller, M.C.; Mong, G.M.; Richardson, R.L.

Pacific Northwest Laboratory, Richland, WA

PNL-SA-20741; CONF-920851 (Vol. 1); Spectrum '92: Nuclear and Hazardous Waste Management, Proceedings of an Intemational Topical Meeting, Boise, ID, August 23-27, 1992, Vol. 1, 848 pp.; (pp. 670-673) (April 1992)

A small (2 scfm) High-Energy Corona (HEC) reactor was developed to produce a non-equilibrium plasma in a concentric-cylinder geometry. A volume-filling plasma was produced in a packed bed, and initial tests have demonstrated the ability to destroy up to 1500 ppm trichloroethylene at a flow rate of $1.4 \mathrm{scfm}$, with greater than $99 \%$ destruction observed. Destruction efficiency is examined as a function of inlet TCE concentration, bed height (residence time) and applied voltage. Hydrochloric acid appears to be the primary chlorinated byproduct, and can be removed by conventional wet or dry scrubbing.

\section{0}

V18/021774

\section{How Many Mixed Waste Streams Can DETOX Handle?}

Robertson, D.T.

Initiatives in Environmental Technology Investment 3(August 1996):12-13 (August 1996)

The U.S. Department of Energy's Office of Science and Technology is interested in developing treatment systems that can handle a wide variety of the department's mixed waste streams. In mid-August 1996 , OST's mixed waste focus area plans to begin a demonstration 
to test the feasibility and applicability of one such technology - a chemical wet oxidation method. DETOX, developed and patented by Delphi Research, Inc. of Albuquerque, New Mexico, has the potential to destroy hazardous organics and concentrate heavy metals and radionuclides in a process solution while controlling releases of hazardous air pollutants.

\section{1}

\section{V18/021141}

\section{ISV Technology Transfer from Battelle/PNNL to} Geosafe Corporation to ISV Japan

Hansen, J.E.; McElroy, J.L.

Geosafe Corporation, Richland, WA

CONF-960212; Waste Management '96: Working Towards a Cleaner Environment, Proceedings of a Conference on HLW, LLW, Mixed Wastes and Environmental Restoration, Tucson, AZ, February 25-29, 1996; (14 pp.) (1996)

The In Situ Vitrification (ISV) technology was invented by Battelle Pacific Northwest National Laboratory (PNNL) for the U.S. Department of Energy (DOE) in 1980. The technology involves the electric melting of contaminated soil and debris, in situ, for purposes of destroying organic contaminants and permanently immobilizing hazardous and radioactive heavy metals. The ISV technology has been developed and demonstrated on a broad range of contaminants, soil types, and waste materials and debris. Geosafe Corporation (Geosafe) offers ISV remediation and waste treatment services on a large-scale commercial basis, and has recently completed its third major site remediation project. The ISV technology was transferred from Battelle/PNNL to Geosafe starting in 1988. Subsequently, Geosafe has transferred the technology to a new company, ISV Japan, Limited (ISVJ) starting in 1995. This paper reviews the technology development and commercialization chronologies for the ISV technology, and then discusses the technology transfer processes that were performed during that time. Eight (8) basic elements of the technology transfer process are presented, including: (1) license rights, (2) technical information, (3) laboratory test/demonstration know-how, (4) commercial production technology know-how, (5) provision of experienced staff members, (6) continuing technical assistance, (7) financial/investment support, and (8) shareholder positioning. The two technology transfer events (Battelle/PNNL to Geosafe, and Geosafe to ISVJ) are contrasted relative to these eight elements. The authors believe that the technology transfer model represented by the 8-elements listed above, is very effective. It is noted that one weakness of the process lies in the area of estimating the time and costs associated with translating a laboratory demonstrated technology into a commercial production technology. It is recognized that technical operating know-how is critical to the success of effective technology transfer; and provisions must be made to ensure that knowledgeable staff are made available to the recipient of a technology transfer, until such time that they possess the needed know-how themselves. In the Battelle/PNNL to Geosafe technology transfer, this need was met by Battelle's provision of full-time experienced technical and business development staff to Geosafe. In the Geosafe to ISVJ technology transfer, this need is being satisfied by provision of knowledgeable Geosafe staff on an as needed basis under a technical assistance contract. Lastly, the paper identifies a continuing financial involvement between the parties as an important element of effective technology transfer.
2322

V18/021952

Identification and Assessment of Site Treatment Plan Implementation Opportunities for Emerging Technologies

Bernard, E.A.

Sandia National Laboratories, Environmental Programs Development Office, Germantown, MD

CONF-951209; Proceedings of the 17th Annual U.S. Department of Energy Low-Level Radioactive Waste Management Conference, D. Lake (ed.), Phoenix, AZ, December 12-14, 1995, 480 pp.; (8 pp.) (1995)

The Department of Energy (DOE), in response to the 1992 Federal Facility Compliance Act, has prepared Site Treatment Plans (STP) for the approximately 2000 waste streams identified within its mixed waste inventory. Concurrently, emerging mixed waste treatment technologies are in final development. This paper defines a three-phase process to identify and assess implementation opportunities for these emerging technologies within the STP. It highlights the first phase, functional matching of expected treatment capabilities with proposed treatment requirements. Matches are based on treatment type, regulated contaminant and waste matrix type, for both capabilities and requirements. Results identify specific waste streams and volumes that could be treated by each emerging technology. A study of Plasma Hearth Process. Delphi DETOX [SM], Supercritical Water Oxidation and Vitrification shows that about 200,000 cu m of DOE's mixed waste inventory can potentially be treated by one or more of these emerging technologies. Actual implementations are small fractions of the treatable inventory. Differences between potential and actual implementations must be minimized to accrue optimum benefit from implementation of emerging or alternative treatment technologies. Functional matching is the first phase in identifying and quantifying benefits, addressing technology system and treatment issues, and providing, in part, the basis for STP implementation decisions. DOE, through EM's Office of Technology Development, has funded this work.

2323

V18/022391

Insitu Modular Waste Retrieval and Treatment System Walker, M.S.

Oak Ridge National Laboratory, Oak Ridge, TN; Machine Kinetics Corporation, Knoxville, IN

ORNL/ER-338; 20 pp. (October 1996)

This report describes a conceptual design for an In Situ Modular Waste Retrieval and Treatment System able to excavate, shred, and process buried waste on site with minimum disturbance and distribution of dust and debris into the air. The proposed equipment design consists of a modular train configuration with an excavation module followed by other units consistent with the types of waste expected and other local conditions. The system would be sized to enter a waste trench at one end and proceed down its length, characterizing and processing waste as it is encountered. The equipment would provide containment, since all waste processing activities would occur within the system, and thus would prevent the release of contaminants and the exposure of workers. The system would substantially reduce the volume of the wastes as well as the 
eliminate of most of its volatile contents. The system would bring appropriate levels of treatment to the waste and addresses the fact that much of the waste buried in the DOE complex does not require exotic treatment technology. In many cases a stabilized waste form and increased containment are all that is required. The processed waste would be encapsulated and left in place in the trench or moved to a more appropriate site. The system would have immediate application in areas wherever systematic burial in fairly consistently sized long trenches was practiced. The size of the system would address the problem of large landfills by providing a means for faster remediation. The system would also be very useful in existing civic or commercial sanitary landfills by performing a recduction in volume, leachate, and release of volatiles. Unit costs on the order of $\$ 300 /$ cubic yard could be achieved. While this equipment would require a very substantial capital investment, the result would certainly be competitive with current remediation costs and would achieve remediation at a rate beyond any current means.

\section{4}

V18/021394

\section{Innovative Field Assessment Technologies}

\section{Barker, C.I.}

Massachusetts Department of Environmental Protection, Boston, MA

Fostering the Needed Partnerships: Doing the Necessary Science to Support Technology Development, Commercialization, Deployment, E.L. Helminski (ed.), Proceedings of the Seventh Annual Western Governors' Association/Weapons Complex Monitor Applied Research and Cleanup Technology Colloquium, Phoenix, AZ, April 29-May 2, 1996. Exchange/Monitor Publications and Forums, Lake Bluff, IL, 500 pp.; (15 pp.) (April 1996)

This presentation focused on field assessment technologies in the state of Massachusetts, first establishing the need for and then the barriers to the use of innovative technologies. The Massachusetts Strategic Environtechnology Partnership (STEP) was described and the following areas discussed: Goals, Technical stage services, Commercial stage services, the STEP assessment process, and STEP results. Two handouts are also included in the conference materials:

(1) How the New 21E Program is Measuring Up is a progress report which documents the success of the Department of Environmental Protection (DEP) efforts to revamp the waste site cleanup program and (2) STEP - The Massachusetts Strategic Environtechnology Partnership describes the effort to promote the growth of new environmental and energy-efficiency technologies in Massachusetts.

2325 V18/025509

Innovative Remote Monitoring of Plant Health for Environmental Applications: A Joint Effort Between Epcot [R] and the DOE

Robitaille, H.; Capelle, G.; Di Benedetto, J.

Walt Disney World Resort, Lake Buena Vista, FL; Special Technologies Laboratory, Santa Barbara, CA

CONF-960804 (Vol. 2); Spectrum '96: Nuclear and Hazardous Waste Management, Proceedings of an International Topical Meeting, Seattle, WA, August 18-23, 1996. American Nuclear Society, La Grange Park, IL, Vol. 2, 873 pp.; (pp. 982-989) (1996)
In September of 1994, the US Department of Energy (DOE), Environmental Management, Office of Science and Technology for (OST) and Epcot [R] in the WALT DISNEY WORLD [R] Resort (Epcot) signed an agreement to cooperate on the research, development, and public communication and display of environmental technologies. Although Epcot and OST have distinctive missions, certain areas of their respective research and development efforts are common, including the integration of remote sensors with robotics platforms, airbome surveys for environmental characterization and monitoring, and ground based measurements of vegetation stress. The first area of cooperative $R \& D$ pursued under the agreement is the evaluation of laser-induced fluorescence imaging (LIFI), a technology developed by OST and proven effective for uranium detection. This paper describes the efforts being conducted under the Epcot-OST agreement and presents initial results. An appendix describing LIFI technology is also included.

\section{6}

\section{V18/021088}

Innovative Treatment Technologies: Annual Status Report (Seventh Edition) - Applications of New Technologies at Hazardous Waste Sites

U.S. Environmental Protection Agency, Washington, DC EPA/542/R-95/008 (No. 7, Revised); 60 pp. (September 1995)

This yearly report documents and analyzes the selection and use of innovative treatment technologies in the EPA Superfund Program and at some non-Superfund sites subject to corrective action under the RCRA Program, and those being addressed by DoD, and DOE. The report updates the status of all the projects and includes projects for which innovative technologies were selected in Superfund Records of Decision (ROD) signed during fiscal year 1994. The information will improve communication between experienced technology users and those who are considering innovative technologies to clean up contaminated sites. In addition, the information will enable technology vendors to evaluate the market for innovative technologies at Superfund sites for the next several years. Altemative treatment technologies are altematives to land disposal. Innovative treatment technologies are altemative treatment technologies the use of which at Superfund and similar sites is inhibited by lack of data on cost and performance. This report documents the use of the following innovative treatment technologies to treat groundwater (in situ), soils, sediments, sludge, and solid-matrix wastes: Soils Technologies including: (1) Bioremediation (exsitu); (2) Bioremediation (in situ); (3) Contained Recovery of Oily Wastes (CROW [TM]); (4) Cyanide oxidation; (5) Dechlorination; (6) In situ flushing; (7) In situ vitrification; (8) Plasma high temperature metals recovery; (9) Phyto-treatment; (10) Soil vapor extraction; (11) Soil washing; (12) Solvent extraction; (13) Thermal desorption. Groundwater Technologies including: (1) Air sparging; (2) Bioremediation (in situ); (3) Dual-phase extraction; (4) In situ oxidation; (5) Passive treatment walls; (6) Surfactant flushing.

2327

V18/021706

Innovative Vitrification for Soil Remediation [December 1995]

Jetta, N.W.; Patten, J.S.; Hnat, J.G. 
Electric Power Research Institute, Palo Alto, CA; CENTEC-21, Inc., Santa Clara, CA; Vortec Corporation, Collegeville, $\mathrm{PA}$

EPRI-TR-106079; CONF-951244; Vitrification of Low-Level Waste: The Process and Potential, M.D. Naughton and K. Sullivan (eds.), Proceedings of an Electric Power Research Institute (EPRI) Meeting, San Antonio, TX, December 5-6, 1995, 368 pp.; (pp. 6.1-6.13) (March 1996)

The objective of this DOE demonstration program is to validate the performance and operation of the Vortec Cyclone Melting System (CMS) for the processing of LLW contaminated soils found at DOE sites. This DOE vitrification demonstration project has successfully progressed through the first two phases. Phase 1 consisted of pilot scale testing with surrogate wastes and the conceptual design of a process plant operating at a generic DOE site. The objective of Phase 2, which is scheduled to be completed the end of FY 95 , is to develop a definitive process plant design for the treatment of wastes at a specific DOE facility. During Phase 2, a site specific design was developed for the processing of $L L W$ soils and muds containing ISCA organics and RCRA metal contaminants. Phase 3 will consist of a full scale demonstration at the DOE gaseous diffusion plant located in Paducah, KY. Several DOE sites were evaluated for potential application of the technology. Paducah was selected for the demonstration program because of their urgent waste remediation needs as well as their strong management and cost sharing financial support for the project.

\section{$2328 \quad$ V18/023323}

Insitu Treatment Technology

Nyer, E.K.; Palmer, P.L.; Suthersan, S.S.; Fam, S.; Johns, F., II; Kidd, D.F.; Crossman, T.; Boettcher, G.

Geraghty \& Miller, Inc., Tampa, FL; Geraghty \& Miller, Inc., Phoenix, $\mathrm{AZ}$

Insitu Treatment Technology, E.K. Nyer (ed.), Lewis Publishers, Inc., Chelsea, MI, 352 pp. (April I, 1996)

This book details various available in situ technologies for remediation, stressing geological foundations and the limitations of each of the technologies, including chapters on areas such as bioremediation, vapor extraction, sparging, and vacuum-enhanced recovery, with coverage of laboratory and pilot plant studies, full-scale design, operation and maintenance, and cost analysis, and case histories. It discusses emerging technologies including phytoremediation, temperature-enhanced extraction, and reactive zones, as well as non-in situ design.

\section{9}

V18/023979

Insitu, Subsurface Monitoring of Vapor-Phase TCE Using Fiber Optics

Rossabi, J.; Colston, B., Jr.; Brown, S.; Milanovich, F.P.; Lee, L.T., Jr.

Westinghouse Savannah River Company, Aiken, SC; Lawrence Livermore National Laboratory, Environmental Sciences Division, Livermore, CA; U.S. Army Corps of Engineers, Waterways Experiment Station, Geotechnical Laboratory, Vicksburg, MS

WSRC-MS-92-247; 10 pp. (March 5, 1993)
A vapor-phase, reagent-based, fiber optic trichloroethylene (TCE) sensor developed by Lawrence Livermore National Laboratory (LLNL) was demonstrated at the Savannah River Site (SRS) in two configurations. The first incorporated the sensor into a down-well instrument bounded by two inflatable packers capable of sealing an area for discrete depth analysis. The second involved an integration of the sensor into the probe tip of the Amy Corps of Engineers Waterways Experiment Station (WES) cone penetrometry system. Discrete depth measurements of vapor-phase concentrations of TCE in the vadose zone were successfully made using both configurations. The fiber optic TCE sensor consists of three basic components: the chemical reagent, the electro-optic measurement device, and the sensor. This instrument is capable of measuring vapor-phase concentrations below $200 \mathrm{ppbv}$; this concentration is below the theoretical vapor-phase concentration in equilibrium with water contaminated at the maximum contaminant level drinking water standard. The upper detection limit is greater than $500 \mathrm{ppmv}$ depending on the chemistry of the reagent.

2330

V18/023716

Installation Loading and Stress Analysis Involved with Pipelines Installed by Horizontal Directional Drilling

Huey, D.P.; Hair, J.D.; McLeod, K.B.

Stress Engineering Services, Inc., Houston, TX; J.D. Hair \& Associates, Inc., Tulsa, $\mathrm{OK}$

CONF-9603151; International NO-DIG '96: Proceedings of an International Society and North American Society for Trenchless Technology (ISTT/NASTT) Conference and Exhibition, New Orleans, LA, March 31-April 3, 1996. NASTT, Chicago, IL, 687 pp.; (pp. 36-60) (1996)

Pipelines installed by horizontal directional drilling (HDD) are subject to a combination of tension, bending, and external pressure. These installation loads, either individually or in combination, can be more severe than operational loads and may govern drilled path design or pipe specification. This is particularly true as the state of the art in horizontal directional drilling is advanced to larger pipe diameters and longer drilled lengths. This paper presents methods for calculating installation loads, including pulling forces, and analyzing combined stresses in steel pipe during installation and operation. Pipe to soil frictional and fluidic drag forces are discussed. A method for analyzing the effect of bends on pulling force is presented. Methods of analysis are illustrated with example calculations. The paper resuits from work done under the sponsorship of the Pipeline Research Committee at the American Gas Association and is taken from an engineering design guide produced specifically for $\mathrm{HDD}$ pipeline installation.

V18/021452

Integrated Thermal Treatment Systems Study: U.S. Department of Energy Internal Review Panel Report

Cudahy, J.J.; Escarda, T.; Gimpel, R.F.; Huffman, G.L.; Kolts, J.H.; Musgrave, B.C.; Peters, R.D.; Seeker, W.R.; Swartz, V.; Torbert, M.M.; Vavruska, J.S.

Focus Environment, Inc., Knoxville, TN; California Department of Toxic Substances Control, Sacramento, CA; Fernald Environmental Restoration Management Corporation, Cincinnati, OH; U.S. Environmental Protection 
Agency, Risk Reduction Engineering Laboratory, Cincinnati, OH; U.S. Department of Energy, Idaho Operations Office, Idaho Falls, ID; BCM, Inc., Los Alamos, NM; Pacific Northwest Laboratory, Richland, WA; Energy and Environmental Research Corporation, Irvine, CA; Swartz and Associates, Inc., Golden, CO; U.S. Department of Energy, Oak Ridge Operations Office, Oak Ridge, TN; Equinox Limited, Santa Fe, NM

DOE/EM-0268-96003365; 95 pp. (April 1995)

The U.S. Department of Energy's (DOE's) Office of Technology Development (OTD) commissioned two studies to uniformly evaluate nineteen thermal treatment technologies. These studies were called the Integrated Thermal Treatment System (ITTS) Phase I and Phase II. With the advice and guidance of the DOE Office of Environmental Management's (EM's) Mixed Waste Focus Group, OTD formed an ITTS Internal Review Panel, composed of scientists and engineers from throughout the DOE complex, the U.S. Environmental Protection Agency (EPA), the California EPA, and private experts. The Panel met from November 15-18, 1994, to review and comment on the ITTS studies, to make recommendations on the most promising thermal treatment systems for DOE mixed low level wastes (MLLW), and to make recommendations on research and development necessary to prove the performance of the technologies on MLLW. This report shares the findings of the Panel and includes technology evaluation, cost implications and recommendations.

\section{V18/020908}

Integrated Thermal and Non-Thermal Systems Studies Results

\section{Cooley, C.R.}

U.S. Department of Energy, Office of Environmental Management, Office of Science and Technology, Washington, DC

Fostering the Needed Partnerships: Doing the Necessary Science to Support Technology Development, Commercialization, Deployment, E.L. Helminski (ed.), Proceedings of the Seventh Annual Westem Governors' Association/Weapons Complex Monitor Applied Research and Cleanup Technology Colloquium, Phoenix, AZ, April 29-May 2, 1996. Exchange/Monitor Publications and Forums, Lake Bluff, IL, 500 pp.; (13 pp.) (1996)

This paper consists of viewgraphs for a presentation given at the Western Govemors' Association/Weapons Complex Research and Technology Colloquium. The following topics were discussed: System evaluation of thermal and nonthermal technologies to identify major technology differences, advantages and disadvantages; Operating assumptions for the study; Development of final requirements and measurements for comparative evaluations; Sample flow sheets; Non-thermal systems studied; Thermal systems studied; and life cycle costs and cost distribution comparisons.

\section{3}

\section{V18/024085}

Intelligent Mobile Sensor System for Drum Inspection and Monitoring: Topical Report - October 1, 1993-April 22, 1995

Lockheed Martin Astronautics, Littleton, CO
DOE/MC/29112-5399; 125 pp. (1997)

The objective of the Intelligent Mobile Sensor System (IMSS) project is to develop an operational system for monitoring and inspection activities for waste storage facility operations at several DOE sites. Specifically, the product of this effort is a robotic device with enharced intelligence and maneuverability capable of conducting routine inspection of stored waste drums. The device is capable of operating in a the narrow free aisle space between rows of stacked drums. The system has an integrated sensor suite for problem-drum detection, and is linked to a site database both for inspection planning and for data correlation, updating, and report generation. The system is capable of departing on an assigned mission, collecting required data, recording which portions of its mission had to be aborted or modified due to environmental constraints, and reporting back when the mission is complete. Successful identification of more than $96 \%$ of drum defects has been demonstrated in a high fidelity waste storage facility mockup. Identified anomalies included rust spots, rust streaks, areas of corrosion, dents, and tilted drums. All drums were positively identified and correlated with the site database. This development effort is separated into three phases of which phase two is now complete. The first phase demonstrated an integrated system (maturity level IVa) for monitoring and inspection activities for waste storage facility operations. This demonstration system was quickly fielded and evaluated by leveraging technologies developed from our previous NASA and ARPA contracts and internal research. The second phase demonstrated a prototype system appropriate for operational use in an actual storage facility. The prototype provides an integrated design that considers operational requirements, hardware costs, maintenance, safety, and robustness. The final phase will demonstrate commercial viability using the prototype vehicle in a pilot waste operations and inspection project. This report summarizes the design and evaluation of new IMSS Phase 2 system and vehicle. Several parts of the IMSS Phase 1 Topical (Final) Report, which describes the requirements, design guidelines, and detailed design of the Phase 1 IMSS vehicle, are incorporated here, with modifications to reflect the changes in the design and the new elements added during the Phase 2 work. The new vehicle design can only be meaningfully described in the context of the foundational Phase I design material. Thus, this report serves as a repository for all requirements and design materials for the IMSS Phase 2 vehicle. Phase 2 evaluation and performance results are also reported here.

2334

V18/023210

International Environmental Technology Transfer from the U.S. Department of Energy's R\&D Laboratories Mayfield, T.L.

Martin Marietta Energy Systems, Inc., Office of Technology Transfer, Oak Ridge, TN

CONF-9210194; Proceedings of an International Symposium on Environmental Contamination in Central and Eastem Europe, Budapest, Hungary, October 12-16, 1992, 968 pp.; (pp. 389-398) (1992)

This document consists of a series of viewgraphs that present various aspects of the U.S. Department of Energy's (DOE) international environmental technology transfer program. Topics 
shown include: (1) DOE and DOE contractor organizations, (2) technology transfer-related legislation, (3) and overviews of the intemational technology exchange program missions and status over the past several years. Mechanisms for implementing the program are presented, with particular emphasis on cooperative research and development agreements (CRADA). Finally, program benefits are summarized.

\section{5}

V18/023714

International NO-DIG '96: Proceedings of an International Conference and Exhibition of Trenchless Technology, Chicago, IL, March 31-April 3, 1996

CONF-9603151; International NO-DIG '96: Proceedings of an Intemational Society and North American Society for Trenchless Technology (ISTT/NASTT) Conference and Exhibition, New Orleans, LA, March 31-April 3, 1996. NASTT, Chicago, IL, 687 pp. (1996)

This international conference, jointly organized by the International Society for Trenchless Technology and the North American Society for Trenchless Technology explored research, applications and case studies related to trenchless technology. Presentations were organized into the following sessions: Horizontal directional drilling; Rehabilitation of water pipelires; Microtunneling research; Sewer rehabilitation case histories; Gas pipeline rehabilitation; Microtunneling case histories; Gas pipeline rehabilitation systems evaluation; Unique horizontal directional drilling applications; Design and evaluation of sliplining rehabilitation systems/motivating research and development; Design considerations; Research and design of sewer and water rehabilitation systems; Microtunneling design; and, Case histories involving large pipes, mapping and water distribution. Those individual papers within the scope of the RAPIC database are indexed separately.

\section{6}

V18/022793

International School of Innovative Technologies for Cleaning the Environment

Ragaini, R.C.

Lawrence Livermore National Laboratory, Livermore, CA CONF-960804 (Vol. 2); Spectrum '96: Nuclear and Hazardous Waste Management, Proceedings of an Intemational Topical Meeting, Seattle, WA, August 18-23, 1996. American Nuclear Society, La Grange Park, IL, Vol. 2, 873 pp.; (pp. 1478-1479) (1996)

The Intemational School of Innovative Technologies for Cleaning the Environment was established in 1989. This School is located at the Ettore Majorana Centre for Scientific Culture in Erice, Sicily, Italy. The School primarily organizes and hosts training courses, technical conferences and advanced study workshops addressing state-of-the-art technologies to clean the environment, minimize waste generation, prevent pollution, and identify strategies for sustainable development. The most recent workshop, "Risk Management Strategies Applied to Environmental Cleanup in Central and Eastem Europe (CEE), " will be discussed in detail.
Torches for Hazardous Waste Treatment

Phoenix Solutions Company, Minneapolis, MN

CONF-9510125 (Vol. 1); Plasma Systems and Applications, P.W. Mayne and J.A. Mulholland (eds.), Proceedings of an International Symposium on Environmental Technologies, Atlanta, GA, October 8-11, 1995. Georgia Institute of Technology, Atlanta, GA, Vol. 1, 335 pp.; (pp. 77-86) (1995)

Studies have been carried out previously to obtain the performance and scaling characteristics of arc heaters. However, the scaling laws derived from these investigations are only for certain types of arc heaters operated in air, helium, and hydrogen. Due to different applications and the large variety of plasma gases that can be used for hazardous waste treatment, further study of the performance and scaling characteristics is needed. A developmental testing model has been formulated to investigate the performance and scaling characteristics of reverse-polarity, well-type electrode plasma torches in comparison with the operating characteristics of a 300 $\mathrm{kW}$ plasma torch. The results show that the model can give good prediction of the performance characteristics of plasma torches with hollow electrodes used for hazardous waste treatment. It can, therefore, be employed to scale plasma systems to different power levels with different plasma gases.

V18/021586

Ion Exchange Properties of Low Rank Coals on Actinides and Other Heavy Metals

Wong, A.S.; Stalnaker, N.D.; Lafferty, C.J.; Robertson, J.D.; Kuhr, J.H.

Los Alamos National Laboratory, Los Alamos, NM; University of Kentucky, Lexington, KY

CONF-960376 (Part 1); Proceedings of the 211th American Chemical Society (ACS) National Meeting, New Orleans, LA, March 24-28, 1996. ACS, Washington, DC, Part 1, 1172 pp.; (p. 844, Paper FUEL 133) (1996)

The removal of heavy metal and low-level radioactive waste from the environment and their subsequent immobilization in an appropriate repository is one of the major environmental challenges facing the United States. The scope and magnitude of the contamination at many DOE and Superfund sites are such that successful remediation will require the development of new, inexpensive technologies which remove, in an environmentally acceptable manner, the heavy metal and radioactive wastes from contaminated soil and water. In this paper, the preliminary data is presented on the viability of using low rank coals, or lignites, as a novel, inexpensive material to remove actinides. (Complete text)

2339

V18/021582

Knowledge Assistant for Robotic Environmental Characterization

Feddema, J.T.; Rivera, J.; Tucker, S.; Matek, J. Sandia National Laboratories, Albuquerque, NM SAND96-1995; 39 pp. (August 1996)

A prototype sensor fusion framework called the Knowledge Assistant has been developed and tested on a gantry robot at Sandia 
National Laboratories. This Knowledge Assistant guides the robot operator during the planning, execution, and post-analysis stages of the characterization process. During the planning stage, the Knowledge Assistant suggests robot paths and speeds based on knowledge of sensors available and their physical characteristics. During execution, the Knowledge Assistant coordinates the collection of data through a data acquisition "specialist." During execution and post analysis, the Knowledge Assistant sends raw data to other "specialists", which include statistical pattern recognition software, a neural network, and model-based search software. After the specialists retum their results, the Knowledge Assistant consolidates the information and returns a report to the robot control system where the sensed objects and their attributes (e.g., estimated dimensions, weight, material composition, etc.) are displayed in the world model. This report highlights the major components of this system.

\section{0 \\ V18/022763}

Laboratory - Performance Criteria for Insitu Waste-Stabilization Materials

Shaw, P.; Weidner, J. Idaho National Engineering Laboratory, Idaho Falls, ID CONF-960804 (Vol. 2); Spectrum '96: Nuclear and Hazardous Waste Management, Proceedings of an International Topical Meeting, Seattle, WA, August 18-23, 1996. American Nuclear Society, La Grange Park, II, Vol. 2, 873 pp.; (pp. 1159-1165) (1996)

The Department of Energy (DOE) Landfill Stabilization Focus Area is investigating a variety of in situ placement methods, grout materials, and characterization techniques for the stabilization of buried low-level transuranic-contaminated waste at Department of Energy sites. In situ stabilization involves underground injection or placement of substances to isolate, treat, or contain buried contaminants. Performance criteria were developed to evaluate various candidate stabilization materials for both long-term stabilization and interim stabilization or retrieval. The criteria are go/no-go, ready, and preliminary. The criterion go/no-go eliminates technologies that are not applicable for in situ treatment of buried waste. The criterion ready indicates that the technology is sufficiently developed and proven to be field demonstrated full-scale. The criterion preliminary indicates the prospective technologies to be potentially applicable to in situ buried waste stabilization, but further development is needed before the technology is ready for field-scale demonstration.

2341

\section{V18/021730}

Life Cycle Benefit-Cost Analysis of Alternatives for Deployment of the Transportable Vitrification System

Sexton, J.L.; Dole, L.R.

Oak Ridge National Laboratory, Oak Ridge, TN

ES/WM-80; 149 pp. (July 1996)

The U.S. Department of Energy's (DOE) Oak Ridge Reservation (ORR) occupies almost 37,000 acres in and around the city of Oak Ridge, Tennessee. In the rapid effort to produce a working atomic bomb, three plants were constructed: Oak Ridge Gaseous Diffusion Plant (K-25), now the Oak Ridge K-25 Site and the Center for
Environmental Technology and Waste Management; Clinton Laboratories (now the Oak Ridge National Laboratory [ORNL]); and the Oak Ridge Y-12 Plant. Following the end of the Cold War and the resulting reduction in nuclear weapons production, the DOE faced an unprecedented task of safely managing, storing, and treating legacy waste while, at the same time, cleaning up the contaminated areas within its sites in 33 states in a manner that uses the most cost-effective methods in conjunction with its responsibility to protect human health and the environment. The Transportable Vitrification system (TVS), an alternative waste treatment technology, has been developed by the DOE Office of Technology Development (EM-50). EM-50, or OTD, is the DOE program concerned with developing, demonstrating, and deploying new methods for environmental restoration and waste management and, as such, has provided the majority of the funding for the development of the TVS. This study reports the results of life cycle benefit-cost-risk analyses of the TVS for a series of use-scenarios proposed for treating mixed low-level waste (MLLW) streams on the ORR in accordance with the Office of Management and Budget (OMB) guidelines contained in OMB Circular 94. The system is designed to produce about $300 \mathrm{lb}$ of glass per hour at its maximum capacity and is capable of processing wet, dry, or slurried waste. When formed into glass by the TVS, MLLW streams meet the Resource Conservation and Recovery Act (RCRA) land disposal requirements (LDR) and can potentially be disposed of as low-level wastes (LLW).

2342

V18/022736

Life Cycle Planning for Technology Development: A Strategic and Tactical Method for Global Environmental Problem Solving

Lederer, $\mathrm{L}$.

Los Alamos National Laboratory, Los Alamos, NM

CONF-960804 (Vol. 1); Spectrum '96: Nuclear and Hazardous Waste Management, Proceedings of an International Topical Meeting, Seattle, WA, August 18-23, 1996. American Nuclear Society, La Grange Park, IL, Vol. 1, 887 pp.; (pp. 809-829) (1996)

Defense laboratories face new challenges in the wake of the Cold War. Evolving missions with an emphasis on global competitiveness, environmental technology, and industrial ecology demand broad cultural change. Recent recommendations from the Secretary of Energy Advisory Board stated, "The laboratories could, and should, make a significant contribution to the integration of energy, raw materials, technology, and environmental science throughout the nation's economy, and the development of the field of industrial ecology. However, the Advisory Board believes that "Neither the [Department of Energy (DOE)] or the laboratories are organized or managed to support this R\&D area," and encourages the Department to work with the laboratories to develop an integrated plan to support "this important area of research." To respond effectively to this recommendation, DOE and the laboratories must identify and implement alternative approaches to program technology development. By emphasizing technology exchange, rather than transfer, collaborations with academia, industry, and other government agencies could better leverage their respective expertise and address the legacy wastes, regulatory pressures, and liabilities that have created the multibillion-dollar environmental dilemma. 
2343

V18/021332

\section{Light for Heavy Work - Industrial Lasers}

U.S. Department of Energy, Office of Environmental Restoration, Washington, DC

TIE Quarterly 4(4):4 (Spring 1996)

DOE's Energy Technology Engineering Center (ETEC) is developing new roles for lasers and fiber optics in deactivation and decommissioning (D\&D) projects. ETEC, located near Los Angeles, is operated for DOE by the Rocketdyne division of Rockwell International Corporation. During the last 30 years, ETEC has used both conventional and advanced dismantlement and size-reduction technologies during D\&D of former nuclear facilities at its Santa Susana Field Laboratory (SSFL) and elsewhere. In parallel, Rocketdyne has also been involved in a variety of advanced laser projects for the U.S. Air Force at SSFL. This proximity of activities and corporate relationship lets ETEC evaluate the suitability of an industrial version of one of these laser technologies for D\&D applications.

2344

\section{V18/024102}

Living Machines: Unsupervised Work in Unstructured Environments

Los Alamos National Laboratory, Los Alamos, NM

LALP-94-263; 1 p. (1994)

Dependable machines capable of working in unstructured, unpredictable environments can readily conduct a number of operations, including monitoring, security, cleanup, and maintenance. These machines can work without rest in environments hazardous to humans. These new types of machines consist of a patented, new control paradigm for robotic control called Nervous Nets, which is based on minimal, elegant, non-linear, analog electromechanics. Keyed on fundamental principles of Artificial Life, BIOMORPH robots exhibit characteristics that allow them to solve real-world problems in a biological manner - in essence, to adapt to an ever-changing environment. Adaptive robot swarms can be configured to carry sensors or tools under local or remote operations.

\section{5}

\section{V18/022730}

\section{MAG*SEP [SM] Process Technology Demonstration at} SRS

Sliger, E.K.; Wilkey, M.L.

Selentec, Atlanta, GA; Argonne National Laboratory, Argonne, IL

CONF-960804 (Vol. 1); Spectrum '96: Nuclear and Hazardous Waste Management, Proceedings of an International Topical Meeting, Seattle, WA, August 18-23, 1996. American Nuclear Society, La Grange Park, IL, Vol. 1, 887 pp.; (pp. 695-699) (1996)

Selective Environmental Technologies, Inc. (Selentec) has been involved in laboratory and pilot scale demonstration testing of its patented MAG*SEP [SM] technology. This technology is being considered for eventual application at sites involving groundwater contaminated with heavy metals and/or radionuclides. A prototype scale demonstration test of the MAG*SEP [SM] technology has shown that the process is capable of removal of heavy metal contaminants in the presence of significant concentrations of competing ions. For example, nickel ion concentrations were reduced from approximately $1000 \mathrm{ppb}$ to less than $100 \mathrm{ppb}$ in the presence of significant concentrations of competing ions, specifically aluminum ( $50 \mathrm{ppm})$, magnesium $(40 \mathrm{ppm})$, and calcium $(60 \mathrm{ppm})$. This work has been carried out with a project team consisting of Selentec, B\&W Nuclear Technologies (magnetic filter supplier), RUST Environment and Infrastructure (design support), Argonne National Laboratory (contract management), and Westinghouse Savannah River Company (site support). Laboratory testing and analytical support were provided by the Savannah River Technology Center (SRTC) and the pilot scale demonstration was carried out at the Savannah River D Area Coal Pile Runoff Basin.

2346

V18/020909

\section{Managing the Technology Maturation Process}

Fiori, M.P.

U.S. Department of Energy, Savannah River Operations Office, Aiken, SC

Fostering the Needed Partnerships: Doing the Necessary Science to Support Technology Development, Commercialization, Deployment, E.L. Helminski (ed.), Proceedings of the Seventh Annual Western Governors' Association/Weapons Complex Monitor Applied Research and Cleanup Technology Colloquium, Phoenix, AZ, April 29-May 2, 1996. Exchange/Monitor Publications and Forums, Lake Bluff, IL, 500 pp.; (12 pp.) (1996)

This paper consists of viewgraphs for a presentation given at the Westem Govemors' Association/Weapons Complex Research and Technology Colloquium. The presentation described the steps necessary for successful technology development. Steps included basic research, applied R\&D, engineering, pilot demonstrations and deployment. The importance of addressing customer needs as part of the development process was also emphasized.

2347

V18/022072

Methodology and Comparative Risk Assessment of Supercritical Water Oxidation (SCWO) and Incineration for the Treatment of Liquid Mixed Waste Dehmel, J.C.; Hong, G.T.

Sanford Cohen \& Associates, Inc., McLean, VA; MODAR, Inc., Natick, MA

CONF-941148 (Vol. 2); DDER-'94: Decommissioning, Decontamination, and Environmental Restoration at Contaminated Nuclear Sites, M.G. White (ed.), Proceedings of an Embedded Topical Symposium of the American Nuclear Society Winter Meeting, Washington, DC, November 13-18, 1994. American Nuclear Society, Inc., La Grange Park, II, Vol. 2, 241 pp.; (pp. 424-432) (1994)

Nuclear facilities generate various radioactive wastes, including liquid mixed waste. Such wastes are generated during normal operations and during decontamination and decommissioning (D\&D) activities, by both the commercial and Federal sectors. The Department of Energy (DOE) and Department of Defense (DOD) have initiated D\&D programs involving the cleanup of operating facilities and those that were used in past weapons and civilian nuclear programs. These D\&D activities will generate large amounts of mixed waste. 
The commercial sector and Federal agencies will be considering the merits and various treatment options to process these wastes. In this paper two treatment options are evaluated, incineration and supercritical water oxidation (SCWO), both assumed to be used for treating liquid mixed waste. A risk assessment analysis was performed to evaluate the relative merits of each technology by comparing radiation doses and risks from stack emissions. The results reveal annual dose (EDE) estimates of $3.5(\mathrm{E}-04) \mathrm{mrem}$ (3.5[E-03] $\mathrm{mu} \mathrm{Sv}$ ) for incineration and 6.6(E-05) mrem (6.6[E-04] $\mathrm{mu}$ Sv) for SCWO for systems with the same stack heights. With varying parameters, doses were noted to span one order of magnitude. For incineration, the doses vary from $1.7(\mathrm{E}-03)$ to $4.8(\mathrm{E}-05) \mathrm{mrem} / \mathrm{y}$ (1.7[E-02] to 4.8[E-04] mu Sv/y. For SCWO, the doses range from $8.9(\mathrm{E}-05)$ to $6.4(\mathrm{E}-04) \mathrm{mrem} / \mathrm{y}(8.9[\mathrm{E}-04]$ to $6.4(\mathrm{E}-03) \mathrm{mu} \mathrm{Sv} / \mathrm{y}$. Both treatment systems present unique aspects in modelling radionuclide behavior. Key parameters governing stack emissions include the selection of partition factors for the SCWO system, performance of the incinerator given varying composition of mixed waste, and the type of exhaust system to treat stack effluents.

\section{8}

\section{V18/024018}

\section{Methods for Evaluating Investment Strategies for} Environmental Technologies

Showalter, W.E.; Booth, S.R.; Hardie, W.

Los Alamos National Laboratory, Los Alamos, NM

Remediation 5(4):17-27 (Autumn 1995)

Environmental technology development, like other ventures, requires decisions regarding where to invest scarce capital. The investment option that offers the greatest benefit relative to the cost should be chosen. The problem is to determine a way to analyze the project and apply a useful measure for comparison to other investment opportunities. In this article, three methods of analysis are presented: return on investment, benefit-to-cost ratio, and payback period. Formulas are developed for each of the methods, and a case study illustrates their application.

\section{9 \\ V18/020854}

Microbial Degradation of Low-Level Radioactive Waste: Final Report

Rogers, R.D.; Hamilton, M.A.; Veeh, R.H.; McConnell, J.W., Jr.

Idaho National Engineering Laboratory, Idaho Falls, ID NUREG/CR-6341; NEL-95/0215; 100 pp. (June 1996)

The Nuclear Regulatory Commission stipulates in 10 CFR 61 that disposed low-level radioactive waste (LLW) be stabilized. To provide guidance to disposal vendors and nuclear station waste generators for implementing those requirements, the NRC developed the Technical Position on Waste Form, Revision 1. That document details a specified set of recommended testing procedures and criteria, including several tests for determining the biodegradation properties of waste forms. Information has been presented by a number of researchers, which indicated that those tests may be inappropriate for examining microbial degradation of cement-solidified LLW. Cement has been widely used to solidify LLW; however, the resulting waste forms are sometimes susceptible to failure due to the actions of waste constituents, stress, and environment. The purpose of this research program was to develop modified microbial degradation test procedures that would be more appropriate than the existing procedures for evaluation of the effects of microbiologically influenced chemical attack on cement-solidified LLW. The procedures that have been developed in this work are presented and discussed. Groups of microorganisms indigenous to LLW disposal sites were employed that can metabolically convert organic and inorganic substrates into organic and mineral acids. Such acids aggressively seact with cement and can ultimately lead to structural failure. Results on the application of mechanisms inherent in microbially influenced degradation of cement-based material are the focus of this final report. Data-validated evidence of the potential for microbially influenced deterioration of cement-solidifed LLW and subsequent release of radionuclides developed during this study are presented.

2350

V18/022757

Minimum Detection Thresholds for Insitu Measurements of Contaminants by Neutron Activation

George, D.C.; Wilson, R.D.; Burnham, J.L.; Conaway, J.; Mikesell, J.

U.S. Department of Energy, Grand Junction Office, Grand Junction, CO; Los Alamos National Laboratory, Los Alamos, NM; U.S. Geological Survey, Denver, CO CONF-960804 (Vol. 2); Spectrum '96: Nuclear and Hazardous Waste Management, Proceedings of an International Topical Meeting, Seattle, WA, August 18-23, 1996. American Nuclear Society, La Grange Park, IL, Vol. 2, 873 pp.; (pp. 1106-1111) (1996)

An experiment was performed to determine the minimum concentration of certain elements that could be detected in the environment of a borehole surrounded by uniformly contaminated soil. A full-scale model was constructed with removable disks of concrete that contained the elements of interest $(\mathrm{Hg}, \mathrm{Cd}, \mathrm{Cl}, \mathrm{Gd}$, and $\mathrm{Sm}$ ). A prototype borehole sonde was assembled with a $14-\mathrm{MeV}$ pulsed neutron generator and a high-resolution gamma-ray detector. The detection thresholds were determined to be $33 \mathrm{ppm}$ for $\mathrm{Hg}, 1.4$ ppm for $\mathrm{Cd}, 86 \mathrm{ppm}$ for $\mathrm{Cl}, 0.9 \mathrm{ppm}$ for $\mathrm{Gd}$, and $1.2 \mathrm{ppm}$ for $\mathrm{Sm}$. Improvements in the hardware and in the data reduction process could improve these thresholds.

\section{1 \\ V18/021062}

Mixed Waste Integrated Program Emerging Technology Development

Berry, J.B.; Hart, P.W.

Oak Ridge National Laboratory, Oak Ridge, TN; U.S.

Department of Energy, Washington, DC

CONF-940499 (Vol. 2); Proceedings of the 1994 Federal

Environmental Restoration III and Waste Minimization II

Conference and Exhibition, New Orleans, LA, April 27-29, 1994.

Hazardous Materials Control Resources Institute, Rockville, MD, Vol. 2, 858 pp.; (pp. 228-236) (1994)

The U.S. Department of Energy (DOE) is responsible for the management and treatment of its mixed low-level wastes (MLLW). MLLW are regulated under both the Resource Conservation and 
Recovery Act and various DOE orders. Over the next 5 years, DOE will manage over 1.2 cubic meters of $\mathrm{MLLW}$ and mixed transuranic (MTRU) wastes. In order to successfully manage and treat these mixed wastes, DOE must adapt and develop characterization, treatment, and disposal technologies which will meet performance criteria, regulatory approvals, and public acceptance. Although technology to treat MLLW is not currently available without modification, DOE is committed to developing such treatment technologies and demonstrating them at the field scale by FY 1997. The Office of Research and Development's Mixed Waste Integrated Program (MWIP) within the DOE Office of Environmental Management (EM), Office of Technology Development, is responsible for the development and demonstration of such technologies for MLLW and MTRU wastes. MWIP advocates and sponsors expedited technology development and demonstrations for the treatment of MLLW. MWIP is expediting the development of a suite of technologies to process heterogeneous waste. One robust process is the fixed-hearth plasma-arc process that is being developed to treat a wide variety of contaminated materials with minimal characterization. Additional processes include steam reforming and a catalytic extraction process that uses molten metal technology. Both processes are being demonstrated by the commercial developer of the technology. Advanced off-gas systems are also being developed. Vitrification technologies are being demonstrated for the treatment of homogeneous wastes such as incinerator ash and sludge. An altemative to conventional evaporation for liquid removal-freeze crystallization-is being investigated. Since mercury is present in numerous waste streams, mercury-removal technologies are being developed.

\section{2}

V18/021782

Modeling of Silent Discharge Plasma for the Destruction of Hazardous Organic Compounds

Greene, A.E.; Bechtold, L.A.; Coogan, J.J.; Rosocha, L.A.

Los Alamos National Laboratory, Los Alamos, NM

LA-UR-92-2685; CONF-9209189; Proceedings of the Course and Workshop on Industrial Applications of Plasma Physics, Varenna, Italy, September 2-12, 1992; (1 p.) (June 2, 1992)

The destruction of hazardous organic wastes by means of advanced oxidation processes has been demonstrated on a laboratory scale. This method involves the generation of highly reactive oxyradicals and their reaction with organic compounds to produce nonhazardous compounds such as $\mathrm{CO} 2$ and $\mathrm{H} 2 \mathrm{O}$. A promising method for producing these reactive free radicals is based on the silent electrical discharge that has proven to be industrially dependable for the generation of large quantities of ozone. The Los Alamos National Laboratory is engaged in a project to develop the silent discharge plasma (SDP) process as a prototype demonstration of this hazardous compound destruction technique. In parallel with this experimental effort, we are developing a coupled plasma kinetics and chemical kinetics model of this process. We feel that such a modeling effort will prove important to optimize the destruction of hazardous compounds and to make this process economically viable. This paper will discuss details of this modeling effort and present comparisons with our laboratory experiments. The plasma in the SDP consists of a large number of microdischarges which are fractions of a millimeter in diameter and last for only a few nanoseconds. We are attempting to model the life of a microdischarge with a time dependent, $2-D$, particle-in-cell code to which elastic, inelastic, and charge exchange collisions have been added. The status of this effort will also be discussed.

2353

V18/023309

Multi-Attribute Technology Evaluation

Kidman, R.B.

Los Alamos National Laboratory, Los Alamos, NM

LA-UR-93-1334; 40 pp. (1993)

A common method for combining disparate attributes (multi-attribute decision theory) is applied to environmental technology evaluation. Several different evaluation programs are reviewed. Appropriate criteria, scoring, and weighting are selected to form a technology evaluation paradigm for use by the National Low-Level Waste Program (NMLLWP) and the Mixed Waste Integrated Program (MWIP). The paradigm was initially developed for, and tested at, the Advanced Waste Treatment Program (AWTP) at Los Alamos National Laboratory.

\section{4}

V18/022392

Multi-Point Injection Demonstration for Solidification of Shallow Buried Waste at Oak Ridge Reservation, Oak Ridge, Tennessee

Oak Ridge National Laboratory, Oak Ridge, TN; Ground Environmental Services, Inc., Alpharetta, GA

ORNL/ER-378; 65 pp. (August 1996)

A proprietary jet delivery system, termed multi-point injection (MPI) was demonstrated for Lockheed Martin Energy Systems and Jacobs Engineering Group as part of a treatability study for Environmental Restoration Program activities at the Lockheed Martin Energy Systems Y-12 Plant (Y-12), in which in situ solidification of shallow buried waste is a preferred alternative for remediating the site. The MPI system is a remotely-installed, remotely-operated delivery system which has mostly low-cost, disposable equipment (plastic casing, rubber hoses, stub sections of steel pipe) which comes into direct contact with any contamination. Workers and major capital equipment are situated in the support zone.

\section{$2355 \quad \mathrm{~V} 18 / 021400$}

National Institute for Environmental Renewal: Providing Links to Academic Expertise and Non-Federal Markets for Environmental Technology

Graeffe, H.G.

National Institute for Environmental Renewal, Harrisburg, PA

Fostering the Needed Partnerships: Doing the Necessary Science to Support Technology Development, Commercialization, Deployment, E.L. Helminski (ed.), Proceedings of the Seventh Annual Westem Governors' Association/Weapons Complex Monitor Applied Research and Cleanup Technology Colloquium, Phoenix, AZ, April 29-May 2, 1996. Exchange/Monitor Publications and Forums, Lake Bluff, II, 500 pp.; (12 pp.) (April 1996)

This presentation describes the National Institute for 
Environmental Renewal (NIER) programs and mission. The NIER was established as an enterprise to apply DOE technologies to national environmental problems using northeastern $P A$ as a laboratory. The technologies are to be demonstrated, applied and commercialized. This approach is intended to restore the environmental and economic viability of industrial sites, while creating a new regional economic development model. The viewgraphs and outline highlight the following areas: The purpose and mission of the Institute, partnerships with industry, regulatory gateways for environmental technologies, specific programs, the Carbondale enterprise zone, and future plans and international business opportunities.

\section{$2356 \quad V 18 / 021399$}

National Risk Management Research Laboratory

Gatchett, A.M.

U.S. Environmental Protection Agency, Washington, DC

Fostering the Needed Partnerships: Doing the Necessary Science to Support Technology Development, Commercialization, Deployment, E.L. Helminski (ed.), Proceedings of the Seventh Annual Western Governors' Association/Weapons Complex Monitor Applied Research and Cleanup Technology Colloquium, Phoenix, AZ, April 29-May 2, 1996. Exchange/Monitor Publications and Forums, Lake Bluff, IL, 500 pp:; (15 pp.) (April 1996)

The viewgraphs and outline from this presentation provide information on the technology development program within the National Risk Management Research Laboratory (NREL). The NREL project solicitation protocol and objectives are discussed including: Process guidance for procurement and implementation of technology demonstrations which provides for stakeholder involvement, regulatory cooperation and private sector participation; Mixed waste working group, solicitation subgroup objectives; Products to meet the objectives of industry involvement, expedited procurement/technology commercialization, stakeholder involvement, and interstate technology and regulatory cooperation. The basic elements of project selection, project implementation, project evaluation and technology deployment are covered and completed tasks are outlined.

\section{$2357 \quad$ V18/021385}

New Approaches Towards Promoting the Application of Innovative Bioremediation Technologies

Kaback, D.S.

Colorado Center for Environmental Management, Denver, $\mathrm{CO}$

Fostering the Needed Partnerships: Doing the Necessary Science to Support Technology Development, Commercialization, Deployment, E.L. Helminski (ed.), Proceedings of the Seventh Annual Western Govemors' Association/Weapons Complex Monitor Applied Research and Cleanup Technology Colloquium, Phoenix, AZ, April 29-May 2, 1996. Exchange/Monitor Publications and Forums, Lake Bluff, IL, 500 pp.; (2 pp.) (April 1996)

This document consists of the outline of a paper focused on utilization of bioremediation technologies. Areas discussed include barriers to deploying innovative technologies quickly, selecting the most effective technology, identifying the most suitable contaminants, state encouragement of new technologies, and intergovemmental working groups.

$2358 \quad$ V18/021392

\section{New Initiatives to Address Focus Area Technology Needs}

Bedick, R.C.

U.S. Department of Energy, Morgantown Energy Technology Center, Morgantown, WV

Fostering the Needed Partnerships: Doing the Necessary Science to Support Technology Development, Commercialization, Deployment, E.L. Helminski (ed.), Proceedings of the Seventh Annual Westem Governors' Association/Weapons Complex Monitor Applied Research and Cleanup Technology Colloquium, Phoenix, AZ, April 29-May 2, 1996. Exchange/Monitor Publications and Forums, Lake Bluff, IL, 500 pp.; (10 pp.) (April 1996)

This presentation covered the Morgantown Energy Technology Center's (METC's) goal to involve the private sector in developing, demonstrating, and implementing improved technologies that address the needs of the Focus Areas through Govermment contracting mechanisms. These viewgraphs highlight the following areas: the solicitation process, stages of technology development. near-term planned opportunities, FY 97-98 technology: requirements, and the METC/OST Research Opportunin Announcement (ROA) purpose and objectives. Specific research areas include subsurface contamination, mixed waste. tanks. D\&D. and crosscutting research.

\section{9}

V18/022016

New Temperature and Metals Emissions Monitoring Technologies for Furnaces

Woskov, P.P.; Cohn, D.R.; Rhee, D.Y.; Thomas, P.: Surma, J.E.; Titus, C.H.

Massachusetts Institute of Technology, Plasma Fusion Center, Cambridge, MA; Pacific Northwest Laboratory, Richland, WA; T\&R Associates, Wayne, PA

CONF-9510125 (Vol. 1); Plasma Systems and Applications, P.W. Mayne and J.A. Mulholland (eds.), Proceedings of an International Symposium on Environmental Technologies, Atlanta, GA, October 8-11, 1995. Georgia Institute of Technology, Atlanta, GA, Vol. 1, 335 pp.; (pp. 101-111) (1995)

New technologies have been successfully tested for continuous real time monitoring of temperature and hazardous metals emissions in a DC graphite electrode arc furnace that is being evaluated for mixed waste processing. An active millimeter-wave pyrometer with rotatable graphite waveguide/mirror optics inside the furnace has proven to be a robust, spatially resolved temperature monitor of the molten slag and refractory surfaces even during waste feeding operations when dense smoke is present. The active probe beam provides additional information on surface emissivities. A microwave plasma torch constructed of refractory materials has been implemented as part of the furnace exhaust duct up stream of 
the scrubbers to sample high temperature, greater than 500 degrees $C$, undiluted exhaust gases. It has proven to be a robust gas excitation device for sensitive in situ atomic emission spectroscopy (in the part per billion range) of metals entrained in the exhaust emissions.

2360

V18/022145

Opportunities for Industry Participation in DOE's Environmental Management Technology Development Program

Bedick, R.C.; Waiker, J.S.

U.S. Department of Energy, Morgantown Energy Technology Center, Morgantown, WV; U.S. Department of Energy, Office of Environmental Management, Office of Science and Technology, Washington, DC

DOE/METC/C-96/7241; CONF-9609234; Proceedings of the American Chemical Society Special Symposium on Industrial Engineering Chemistry, Birmingham, AL, September 9-12, 1996; (6 pp.) (1996)

The Morgantown Energy Technology Center (METC) has managed about 85 research, development, and demonstration projects on behalf of DOE-EM's Office of Science and Technology. The projects encompass each of the four major environmental remediation and waste management problem areas: subsurface contaminants (radionuclides, heavy metals, dense nonaqueous phase liquids); decontamination and decommissioning of facilities; high-level waste tank remediation; and mixed waste characterization/treatment/disposal. All projects within the Industry Programs are phased or have optional tasks at specific go/no-go decision points, allowing DOE to make investment decisions at various points in the technology development cycle to ensure meeting the technology development goals and the needs of the customer or end-user. This decision making process is formalized in a Technology Investment Decision Model. A brief summary is given of R \& D requirements (technology needs) in each of the above-mentioned four problem areas.

2361

VI $8 / 023212$

Overview of Regional and International Networks and Clearinghouses

Johnson, S.W.; Pastel, C.M.; Harrington, M.W.

U.S. Department of Energy, Germantown, MD; Waste Policy Institute, Germantown, MD; Sandia National Laboratories, Albuquerque, NM

CONF-9210194; Proceedings of an International Symposium on Environmental Contamination in Central and Eastern Europe, Budapest, Hungary, October 12-16, 1992, 968 pp.; (pp. 401-403) (1992)

The International Technology Exchange (ITE) Division of the United States Department of Energy is responsible for the identification and evaluation of international environmental restoration and waste management technologies and their subsequent transfer to areas where needed. Efficient transfer of these technologies will improve operational effectiveness, reduce environmental restoration and waste management costs, and/or reduce the time spent implementing environmental restoration and waste management programs. A principal method for accomplishing these goals is through efficient dissemination of information. An international technology transfer information system having the capability of identifying worldwide needs and linking them to both available and developmental technologies will encourage a mutually beneficial technological exchange between countries. International technological options will become viable through the establishment of a mechanism for transferring technologies from national . laboratories, private industries, and universities to world-wide markets. World-wide contacts will be identified and participation in international cooperative programs and integrated demonstrations will be expedited. ITE has established the information system EnviroTRADE as a mechanism through which international sites in need of environmental remediation can be matched with appropriate technologies.

2362

V18/022943

PO*WW*ER Mobile Treatment Unit Process Hazards Analysis: Grand Junction Projects Office Mixed-Waste Treatment Program

Rust Geotech, Inc., Grand Junction, $\mathrm{CO}$

DOE/ID/12584-272; GJPO-MWTP-31; 145 pp. (June 1996)

In response to the need for increased mixed-waste treatment capability, the Department of Energy (DOE) Albuquerque Operations Office (AL) organized a Treatment Selection Team to match mixed wastes with treatment options and develop a strategy for treatment of its mixed waste. The strategy developed by the Treatment Selection Team was to use off-site commercial treatment facilities where available, and for those wastes which could not be treated using commercial treatment facilities, to develop mobile treatment capability to treat the wastes at the DOE-AL sites where the wastes were generated, eliminating the necessity for shipment of wastes from one site to another. Responsibility for development of several of these technologies was assigned to the DOE Grand Junction Projects Office (GJPO) under the Mixed-Waste Treatment Program (MWTP). One of the waste-treatment technologies assigned to GJPO was evaporative oxidation (EO), which is used primarily in the treatment of aqueous wastes containing hazardous organic compounds. Rust Geotech, contractor to DOE-GJPO, conducted pilot scale EO treatability testing using the patented $\mathrm{PO}^{*} \mathrm{WW}$ ER process. Information obtained from the treatability testing was used to design a full-scale mobile treatment unit (MTU). A Process Hazards Analysis (PHA) is required for each MTU being developed. The objective of the PHA and this report is to demonstrate that a thorough assessment of the risks associated with the operation of the MTU has been performed and documented.

2363

V18/022373

PROTECH Version 3.0: The Prospective Technology Communication System

Pacific Northwest Laboratory, Richland, WA

PNL-9366; 15 pp. and $43.5^{n}$ diskettes for Macintosh (February 1994)

ProTech, the Prospective Technology Communication System, describes innovative environmental cleanup technologies funded through the Department of Energy's (DOE) Office of Technology 
Development (OTD). ProTech's goal is to provide a practical communication tool to help an informed, non-technical audience understand and provide input on the acceptability of innovative cleanup technologies funded by OTD. Information is provided on several topics to allow the user to evaluate a technology's acceptability. Some of these topics include performance, cost, regulatory issues, estimated impacts on humans and the environment, and socioeconomic interests. Protech allows users to learn about innovative technologies from technology fact sheets. Users can also compare innovative technologies with established baseline technologies, and with other comparable innovative technologies. Fact sheets include both a description and a diagram of the technology. This copy of ProTech is in Macintosh format and consists of 4 installation disks. A users manual is included.

\section{4}

V18/020910

\section{Partnerships to Deploy Technologies to Meet Client} Needs

Bechtel, T.F.

\section{U.S. Department of Energy, Morgantown Energy Technology Center, Morgantown, WV}

Fostering the Needed Partnerships: Doing the Necessary Science to Support Technology Development, Commercialization, Deployment, E.L. Helminski (ed.), Proceedings of the Seventh Annual Western Governors' Association/Weapons Complex Monitor Applied Research and Cleanup Technology Colloquium, Phoenix, AZ, April 29-May 2, 1996. Exchange/Monitor Publications and Forums, Lake Bluff, $\mathbb{I L}, 500$ pp.; (12 pp.) (1996)

This paper consists of viewgraphs for a presentation given at the Western Govemors' Association / Weapons Complex Research and Technology Colloquium. The presentation focused on the elements involved in developing appropriate technology to support Environmental Management activities. The following topics were discussed: Commitment to customer satisfaction; Delivering quality products to customers; Successful partnering; METC's EM technology development goals, Government's role in technology development, Prioritizing and decision making; and, Critical issues.

\section{5}

\section{V18/021334}

\section{Past Experience Brings Future Benefits}

U.S. Department of Energy, Office of Environmental Management, Washington, DC

TIE Quarterly 4(4):5 (Spring 1996)

The Energy Technology Engineering Center (ETEC) and its operating contractors, Rockwell International Corporation, have worldwide experience in deactivating and decommissioning (D\&D) nuclear facilities and performing In-Service Inspections (ISI) of commercial light water reactor vessels. This experience base includes decommissioning four nuclear power plants and eight research and training reactor facilities, D\&D of 19 other nuclear facilities, and the release of 18 facilities for unrestricted use. These activities also included the development and use of robotic or remote tooling and other equipment to perform work in hazardous environments to minimize radiation exposures to workers and the public. This experience is not currently being leveraged to develop technology or provide hardware for dismantling a number of DOE cold war legacy facilities. Recently, DOE's Office of Environmental
Management (EM initiated a D\&D Focus Area program to develop and demonstrate a remotely operated Standardized Dismantlement System for the size-reduction of metal reactor vessels and other similar structures. A dismantlement system now being developed at ETEC is planned for deployment at one of the research reactors at the Idaho National Engineering Laboratory. Plans have been made to demonstrate the prototype system at a shutdown research reactor at Oak Ridge National Laboratory in FY 1997. ETEC has the lead role in developing the system.

\section{6}

V18/021335

\section{Perfect Strip Act}

Ames Laboratory, Ames, IA

TIE Quarterly 4(4):3 (Spring 1996)

Ames Laboratory has been studying the application of lasers to surface decontamination since 1991. The Office of Science and Technology Development supplied funds for the initial studies (1991-1993) at WINCO/Lockheed Martin Idaho Technologies (LMII). The Laboratory now can field flexible, efficient, automated, and fast laser decontamination systems. This laser decontamination system is currently being patented jointly by Ames Laboratory and LMIT.

\section{7}

\section{V18/023953}

Performance Planning and Measurement for DOE EM-International Technology Integration Program Jordan, G.B.; Reed, J.H.; Wyler, L.D. Sandia National Laboratories, Albuquerque, NM SAND96-2953; 20 pp. (March 1997)

This report describes the process and results from an effort to develop metrics for program accomplishments for the FY 1997 budget submission of the U.S. Department of Energy Environmental Management International Technology Integration Program (EM-ITI). The four-step process included interviews with key EM-ITI staff, the development of a strawman program logic chart, and all day facilitated workshop with EM-ITI staff during which preliminary performance plans and measures were developed and refined, and a series of follow-on discussions and activities including a cross-organizational project data base. The effort helped EM-ITI crystallize and develop a unified vision of their future which they can effectively communicate to their own management and their internal and external customers. The effort sets the stage for responding to the Govemment Performance and Results Act. The metrics developed may be applicable to other international technology integration programs. Metrics were chosen in areas of eight general performance goals for 1997-1998: (1) number of forums provided for the exchange of information, (2) formal agreements signed, (3) new partners identified, (4) customers reached and satisfied, $(5,6)$ dollars leveraged by EM technology focus area and from foreign research, (7) number of foreign technologies identified for potential use in remediation of DOE sites, and (8) projects advanced through the pipeline.

2368

$\mathrm{V} 18 / 021263$

Perspectives of Use of Ozone Treatment in Clearing of Radioactive Run-Offs 
Prokudina, S.A.; Tkachenok, S.V.; Shashkova, I.L.

Belarusian State Economic University, Minsk, Belarus; General and Inorganic Chemistry Institute, Minsk, Belarus

CONF-950917 (Vol. 2); ICEM '95, Proceedings of the Fifth International Conference on Radioactive Waste Management and Environmental Remediation, Vol. 2: Management of Low-Level Waste and Remediation of Contaminated Sites and Facilities, $S$. Slate, R. Baker and G. Benda (eds.), Berlin, Germany, September 3-7, 1995. American Society of Mechanical Engineers, New York, NY, 913 pp.; (pp. 1421-1424) (1995)

In an earlier paper, we show the expediency of ozone treatment for surfactant removal from radioactive run-offs before an evaporation process at nuclear power plants' chemical shops. This treatment will: (1) Significantly increase the evaporators' work efficiency; (2) Improve the condensate quality; and (3) Lengthen the ion-exchange filters' service life. The current paper describes an investigation of ozone treatment to remove complexons (for example, Trilon B), formed during decontamination, from radioactive run-offs. Use of ozone treatment for forming modified ion-exchange materials on a base of fibrous active carbons, for sorption of radionuclides, was also investigated.

\section{9}

\section{V18/022409}

Phase I Implementation Plan for PROTECH: The Prospective Technology Communication System

Zakian, P.; McCabe, G.H.; Lesperance, A.M.; Stein, S.

Battelle Seattle Research Center, Seattle, WA; Pacific Northwest Laboratory, Richland, WA

Report; 80 pp. (January 1993)

ProTech, the Prospective Technology Communication System, describes innovative environmental cleanup technologies funded through the Department of Energy's (DOE) Office of Technology Development (OTD), to non-technical stakeholders. These stakeholders are individuals and/or groups who are interested in or concerned about waste management activities at each Integrated Demonstration (ID) site. ProTech's goal is to provide three main benefits. First, ProTech functions as a communication tool which can greatly enhance ID public involvement activities. Second, ProTech describes innovative technologies to varied stakeholders with the intent of soliciting input on technology acceptance. It is structured to identify regulatory and public acceptability issues. Finally, ProTech will increase national exposure for technologies and enhance technology transfer activities. ProTech's secondary goals include providing management support to Integrated Demonstration Coordinators (TDCs) and DOE-OTD personnel and increasing communication between people involved in technology development activities at ID sites across the country.

\section{0}

V18/022754

Pipe Explorer [TM]: Overview, Applications, and Recent Developments

Kendrick, D.T.; Cremer, C.D.

Science and Engineering Associates, Inc., Albuquerque, NM

CONF-960804 (Vol. 2); Spectrum '96: Nuclear and Hazardous

Waste Management, Proceedings of an Intemational Topical

Meeting, Seattle, WA, August 18-23, 1996. American Nuclear
Society, La Grange Park, IL, Vol. 2, 873 pp.; (pp. 1038-1045) (1996)

As the Department of Energy (DOE) continues to dismantle its nuclear process facilities, site managers throughout the complex must employ the safest and most cost effective means of disposing or remediating hundreds of miles of potentially contaminated piping and duct work. Much of this is buried or encased, making quantification of contamination levels inside the pipes extremely difficult. Without adequate characterization, it is usually necessary to assume the piping is contaminated and to extract and dispose of it accordingly. For buried drain lines this approach can cost on the order of $\$ 1,200 / \mathrm{ft}$ and is often unnecessary as residual contamination levels are below free release criteria. The Science \& Engineering Associates, Inc. (SEA) Pipe Explorer [TM] technology offers a simple and effective approach of transporting characterization tools into pipes and ducts so that these costs can be avoided. The system uses a pneumatically operated tubular membrane to tow radiation detectors and video cameras into pipes while simultaneously providing a clean conduit for the sensors to travel through. This paper describes the operation of the system, the DOE sites where it has been used, and the cost savings that have resulted from its use. In addition, recently added features to the technology, such as the ability to perform alpha and video surveys, are discussed.

2371

\section{V18/023813}

\section{Plasma Hearth Process Vitrification of DOE Low-Level} Mixed Waste

Gillins, R.L.; Geimer, R.M.

Science Applications International Corporation, Idaho Falls, ID

EPRI-TR-105569; CONF-950718; Proceedings of the 1995

Electric Power Research Institute (EPRI) Intemational Loh-Leve) Waste Conference, Orlando, FL, July 10-12, 1995, 600 pp.; (pp. 60.1-60.7) (November 1995)

The Plasma Hearth Process (PHP) demonstration project is one of the key technology projects in the Department of Energy (DOE) Office of Technology Development Mixed Waste Focus Area. The PHP is recognized as one of the more promising solutions to DOE's mixed waste treatment needs, with potential application in the treatment of a wide variety of DOE mixed wastes. The PHP is a high temperature vitrification process using a plasma arc torch in a stationary, refractory lined chamber that destroys organics and stabilizes the residuals in a nonleaching, vitrified waste form. This technology will be equally applicable to low-level mixed wastes generated by nuclear utilities. The final waste form will be volume reduced to the maximum extent practical, because all organics will have been destroyed and the inorganics will be in a high-density, low void-space form and little or no volume-increasing glass makers will have been added. Low volume and high integrity waste forms result in low disposal costs. This project is structured to ensure that the plasma technology can be successfully employed in radioactive service. The PHP technology will be developed into a production system through a sequence of tests on several test units, both non-radioactive and radioactive. As the final step, a prototype PHP system will be constructed for full-scale radioactive waste treatment demonstration. 


\section{2}

V18/022011

Plasma Pyrolysis Vitrification (PPV) Technology Demonstration Program as Applied to the Defense National Stockpile of Thorium Nitrate

Hermes, W.H.; Hoffmann, D.P.; Gibson, L.V.; Ryn, F.V.; Harris, L.A.; Lee, H.T.; Camacho, S.L.; Circeo, L.J.; Laird, D.; Suris, A.L.

Oak Ridge K-25 Site, Oak Ridge, IN; Midwest Technical, Inc., Oak Ridge, TN; Oak Ridge Institute for Science and Education, Oak Ridge, TN; Plasma Technology Corporation, Raleigh, NC; Georgia Institute of Technology, Atlanta, GA; Science Ventures, Inc., San Diego, CA; Moscow Academy of Chemical Engineering, Moscow, Russian Federation

CONF-9510125 (Vol. 2); Plasma Systems and Applications, P.W. Mayne and J.A. Mulholland (eds.), Proceedings of an International Symposium on Environmental Technologies, Atlanta, GA, October 8-11, 1995. Georgia Institute of Technology, Atlanta, GA, Vol. 2, 392 pp.; (pp. 369-380) (1995)

Thorium (Th-232) can be utilized as fuel in breeder style nuclear reactors. Th-232 is considered a fertile nuclide since it can be fissioned by high energy (greater than $1 \mathrm{MeV}$ ) neutrons to produce fissile uranium (U-233). The Defense National Stockpile Center (DNSC) currently has Th-232 in storage in the chemical form of thorium nitrate, Th(NO3) 4 center dot $4 \mathrm{H} 2 \mathrm{O}$. The potential use of Th-232 is being phased out and hence there is a need to mitigate any potential future environmental or exposure hazards associated with this material. Since Th-232 has a long half-life $(1.41[\mathrm{E}+10]$ yrs), the current program is evaluating treatment methodologies to safely produce the less leachable oxide. The more chemically stable oxide will be lower in mass and volume and exhibit low leachability characteristics making it optimized for licensed long-term storage. This paper will discuss some work completed and the experiments which are planned for completion at the $\mathrm{Ga}$ Tech Plasma Application Research Facility (PARF). This paper will also present the types of experiments being considered using actual thorium nitrate and how they will be used to support the evaluation of plasma processing application to the thorium nitrate inventory. The experiments at Georgia Tech are planned for September 1995 and will utilize non-radiological surogates for the thorium oxide. Although the early publishing date of this paper precludes the incorporation of any actual results, the planned poster session will include all verified data collected to date.

2373

$\mathrm{V} 18 / 021590$

\section{Plutonium Focus Area: Technology Summary}

U.S. Department of Energy, Office of Environmental Management, Office of Science and Technology, Washington, $\mathrm{DC}$

\section{DOE/EM-0297; 117 pp. (August 1996)}

To ensure research and development programs focus on the most pressing environmental restoration and waste management problems at the U.S. Department of Energy (DOE), the Assistant Secretary for the Office of Environmental Management (EM) established a working group in August 1993 to implement a new approach to research and technology development. As part of this new approach, EM developed a management structure and principles that led to the creation of specific Focus Areas. These organizations were designed to focus the scientific and technical talent throughout DOE and the national scientific community on the major environmental restoration and waste management problems facing DOE. The Focus Area approach provides the framework for intersite cooperation and leveraging of resources on common problems. After the original establishment of five major Focus Areas within the Office of Technology Development (EM-50, now called the Office of Science and Technology), the Nuclear Materials Stabilization Task Group (EM-66) followed the structure already in place in EM-50 and chartered the Plutonium Focus Area (PFA). This report outlines the scope and mission of the EM, EM-60, and EM-66 organizations as related to the PFA organizational structure and presents a large number of overviews of technologies that are under development. Technologies described are divided into the following groupings: (1) Standards Development, (2) Stabilization Process Development, (3) Packaging, (4) Surveillance and Monitoring; (5) Transportation and Remediation Infrastructure, and (6) Core Technology Program.

\section{$2374 \quad$ V18/021796}

Polymer Filtration Process Extracts Metals

Initiatives in Environmental Technology Investment 3(June 1996):12-13 (June 1996)

The US DOE's Efficient Separations and Processing (ESP) cross-cutting area is evaluating polymer filtration, a new separation technology developed by Los Alamos National Laboratory to remove valuable or regulated metals from aqueous waste streams. In order to pinpoint these metals, specialized water-soluble polymers are added to contaminated waste, where they create a bond with the targeted metais. This bonded complex forms a much larger compound that can then be separated from the waste stream. The key to this new process is a water-soluble chelating polymer that has at least two sites to bind to a specific metal ion. By having two or more binding sites, the polymer has the potential to bind more strongly and more selectively. The technology has succeeded in several demonstrations. While minimizing waste volumes, this new process may help companies lower disposal costs and comply with stringent federal discharge regulations.

2375

V18/021038

Portable Acoustic Wave Sensor Systems for Real-Time Monitoring of Volatile Organic Compounds

Cernosek, R.W.; Frye, G.C.; Gilbert, D.W.

Sandia National Laboratories, Microsensor Research and Development, Albuquerque, NM

CONF-9305187; ISE '93, Ideas in Science and Electronics, Proceedings of an IEEE Conference, Albuquerque, NM, May 11, 1993. Institute of Electrical and Electronics Engineers, Piscataway, NJ; (8 pp.) (1993)

Portable acoustic wave sensor (PAWS) systems are being developed for real-time, on-line and in situ monitoring of volatile organic compounds (VOCs). These systems are built around surface acoustic wave (SAW) devices coated with visco-elastic polymers. Two independent responses of the SAW sensor, wave velocity and attenuation, are measured to provide information about the chemical species sorbed by the coating. Sensing is rapid and 
reversible, and coatings can be optimized for particular chemical selectivity and sensitivity. The complete PAWS system consists of two SAW devices (a sensor and a reference), RF oscillator electronics to drive the devices, digital interface/communications electronics, gas handling hardware to sample the environment, and a notebook computer to control the hardware and display responses in real-time. These systems have been demonstrated for on-line monitoring of exhaust stack vapors in environmentally conscious manufacturing (ECM) applications, for real-time documentation of off-gas contaminants from vacuum extraction processes at $D O E$ remediation sites, and for down-hole sensing of volatile organics in vadose zone (above the groundwater level) monitoring wells.

V18/021402

Providing Links to Academic Expertise, the Next Generation of Technologists and Non-Federal Markets for Environmental Technology - Local and University-Based Institutions

Ebadian, M.A.

Florida International University, Hemispheric Center for Environmental Technology, Miami, FL

Fostering the Needed Partnerships: Doing the Necessary Science to Support Technology Development, Commercialization, Deployment, E.L. Helminski (ed.), Proceedings of the Seventh Annual Western Governors' Association/Weapons Complex Monitor Applied Research and Cleanup Technology Colloquium, Phoenix, AZ, April 29-May 2, 1996. Exchange/Monitor Publications and Forums, Lake Bluff, IL, 500 pp.; (15 pp.) (April 1996)

These are the view graphs for a presentation describing the programs of the Florida International University (FIU) Hemispheric Center for Environmental Technology (HCET). Areas discussed include: The vision and mission of the HCET; University R\&D centers; HCET-FIU's Latin American and Caribbean Center connections; HCET's full-service plan for industry and technology transfer; HCETs research and development capabilities, including D\&D and work for DOE; HCET's interactions with industry; International activities; and, future directions.

\section{7}

V18/021137

Quantitative Assessment of Insitu Microbial Communities Affecting Nuclear Waste Disposal

White, D.C.; Ringelberg, D.B.

University of Tennessee, Center for Environmental Biotechnology, Knoxville, TN; Oak Ridge National Laboratory, Oak Ridge, TN

CONF-960212; Waste Management '96: Working Towards a Cleaner Environment, Proceedings of a Conference on HLW, LLW, Mixed Wastes and Environmental Restoration, Tucson, AZ, February 25-29, 1996; (10 pp.) (1996)

Microbes in the environments surrounding nuclear waste depositories pose several questions regarding the protection of the surrounding communities. Microbes can facilitate microbially influenced corrosion (MC), mobilize and facilitate the transport of nuclides as well as produce gaseous emissions which can compromise containment. We have developed an analysis of the extant microbiota that is independent of quantitative recovery and subsequent growth, based on signature biomarkers analysis (SBA). Polar lipids exist in all organisms that have intact cell membranes and intact cell membranes are a requirement for life. Extraction and measurement of polar lipids indicates the biomass of the microbes that are viable but may or may not be culturable. Phospholipid ester-linked fatty acids (PLFA) give a measure of the microbial community containing intact membranes. Phospholipids are often transformed into diglycerides by endogenous phospholipases in injured cells which retain for a time the characteristic signature profiles of the fatty acids and thus provide a measure of the viable cells with intact membranes and recently non-viable (lysed) cells. The lipid patterns of PLFA and other lipid classes also reflect exposures of the cells to nutritional imbalances, toxicity, and various stresses thereby providing phenotypic insight into the condition of the community. The lipid extraction procedure also allows recovery of the cellular DNA for probing with or without enzymatic amplification that adds extraordinary specificity for analysis for specific organisms, groups of organisms or potential enzyme activities. Specific signature lipid patterns of PLFA, steroids, respiratory quinones and lipopolysaccharide hydroxy fatty acids of the lipid $A$ of gram negative bacteria allow detection of many groups of microbes with a quantitative definition of the community composition. Utilizing the SBA it has been possible to show that there are viable microbial communities in the host rock of potential subsurface waste deposit sites like Yucca Mountain. Research has shown that the viable biomass, community composition and nutritional status of the extant microbial community shifts with contamination, pollution, and disturbance. With SBA it has been possible to document that MIC is related in time and space to the corrosion process and to define which microbial communities are most likely to facilitate localized corrosion. Specific organism involved in uranium reduction can be identified by SBA. With the insight gained with SBA, predictions of potential effects microbial communities may have on the containment of nuclear wastes can be made.

2378 V18/021063

Quantum-CEP [TM] for Mixed Waste Processing Nahass, P.; Sekula-Moise, P.A.; Chanenchuk, C.A. Molten Metal Technology, Inc., Waltham, MA

CONF-940499 (Vol. 1); Proceedings of the 1994 Federal Environmental Restoration III and Waste Minimization II Conference and Exhibition, New Orleans, LA, April 27-29, 1994. Hazardous Materials Control Resources Institute, Rockville, MD, Vol. 1, 783 pp.; (pp. 237-245) (1994)

No commercially available technology exists to effectively treat the hundreds of thousands of tons of mixed waste stored and generated in the United States and worldwide. Catalytic Extraction Processing (CEP) is an innovative flexible recycling technology which has inherent advantages for processing mixed wastes in a wide variety of chemical and physical forms. CEP uses a molten metal bath to completely dissociate feeds and recombine them with selected reactants to form useful products. Dissolved carbon in the metal bath creates a reducing atmosphere, readily converting hydrocarbons to synthesis gas, metals to alloys in their reduced state, and inorganics to an engineered ceramic phase. Process conditions can be manipulated to strongly favor partitioning of 
select radionuclides to a nonleachable vitreous phase, ready for final form disposal. Molten Metal Technology has adapted its CEP technology for radioactive processing and has delivered Quantum-CEP [TM] units to cûstomers for demonstration of mixed waste processing leading to commercial-scale installations for reducing both private and government inventories. Agreements have also been reached to build commercial CEP facilities to recycle hazardous and industrial wastes.

\section{9}

\section{V18/021225}

\section{Radioactive Scrap Metal Decontamination Technology} Assessment Report

Buckentin, J.M.; Damkroger, B.K.; Schlienger, M.E.

Sandia National Laboratories, Liquid Metal Processing Laboratory, Albuquerque, NM

SAND96-0902; 39 pp. (April 1996)

Within the DOE complex there exists a tremendous quantity of radioactive scrap metal. As an example, it is estimated that within the gaseous diffusion plants there exists in excess of 700,000 tons of contaminated stainless steel. At present, valuable material is being disposed of when it could be converted into a high quality product. Liquid metal processing represents a true recycling opportunity for this material. By applying the primary production processes towards the material's decontamination and re-use, the value of the strategic resource is maintained while drastically reducing the volume of material in need of burial. Potential processes for the liquid metal decontamination of radioactively contaminated metal are discussed and contrasted. Opportunities and technology development issues are identified and discussed. The processes compared are: surface decontamination; size reduction, packaging and burial; melting technologies; electric arc melting; plasma arc centrifugal treatment; air induction melting; vacuum induction melting; and vacuum induction melting and electroslag remelting.

\section{0}

V18/020964

Rapid Site Characterization and Monitoring Systems Using Surface Acoustic Wave/Gas Chromatography Staples, E.J.; Pappas, G.A.; Watson, G.W.; McGuire, D. Amerasia Technology, Inc., Westlake Village, CA CONF-960212; Waste Management '96: Working Towards a Cleaner Environment, Proceedings of a Conference on $\mathrm{HLW}$, LLW, Mixed Wastes and Environmental Restoration, Tucson, $A Z$, February 25-29, 1996; (13 pp.) (1996)

This paper describes the development of a surface acoustic wave/ (SAW) technology for the rapid characterization of waste site radiation emissions. Developed under an EM-50 Department of Energy contract, the system was designed to rapidly assess contamination in field conditions. The new technology allows capture, identification and analysis of Volatile Organic Compounds (VOCs), Non-VOCs, Dioxins, PCBs, and Energetics. This is done within water and soil matrices, within real time, on-site with parts per billion accuracy. The system has been modification capability to detect mixed waste containment, in radioactive environments. The ability to detect to picogram or ppb levels of compounds using fast chromatograph columns has been demonstrated for a wide range of materials. The application of SAW/GC technology will lead to the manufacturing of low cost, field portable products for waste site characterization and monitoring. The design theory and development of the technology will be presented as well as the test results from the Savannah River Facility field demonstration. The SAW sensor has demonstrated high specificity and sensitivity for trace analysis screening at DOE remediation sites. Also, the results demonstrate significant cost savings when compared to reference laboratory analysis. The related deployment strategies for the various mixed waste sites and product maintainability issues will also be noted.

\section{1 \\ V18/020938}

\section{Reconditioning Contaminated Gravel}

Walsh, H.; Bowers, J.; Cadwell, K.

Lawrence Livermore National Laboratory, Hazardous Waste Management Division, Livermore, CA

CONF-960212; Waste Management '96: Working Towards a Cleaner Environment, Proceedings of a Conference on $\mathrm{HLW}$, LLW, Mixed Wastes and Environmental Restoration, Tucson, AZ, February 25-29, 1996; (15 pp.) (1996)

Lawrence Livermore National Laboratory (LLNL) has developed a portable screening system that will recondition radioactively contaminated gravel in the field. The separation technique employed by this system removes dirt, contaminated debris, and other fine particles from gravel. The separation process can be used on gravel or other comparable material ranging in size up to $2.5-\mathrm{cm}$ (1-in.) in diameter. The particle size of dirt and debris removed is variable. For pea gravel, the particles removed can vary from 38 $\mathrm{mm}-1 \mathrm{~cm}(3 / 8 \mathrm{in}$.). At LLNL, gravel is used in conjunction with the experimental testing of explosives to reduce shock wave propagation. The gravel surrounds the experimental device and buffers the energy generated from the explosion. During an explosion, some of the gravel is broken down into small particles and mixed with contaminants. Contaminants in the used gravel originate from metal sheathing and other parts comprising the experimental device. These contaminants may consist of radionuclides (primarily depleted uranium) and metals (e.g., beryllium, copper, and zinc) that are considered hazardous by the State of Califomia when disposed. The small particles generated during the explosion mix with the gravel and collect in the void space between the gravel. The removal of void spaces increases the aggregate material compressive strength and reduces the gravel's effectiveness for shock wave reduction. Reconditioning removes the small particles and some contaminants and restores the gravel's effectiveness for shock wave reduction. The paper presents the process that conveys contaminated material into the screener system, sprays the material with recycled water or other mild cleaning chemicals, and separates the particles based on size. Particles greater than a specified size are discharged out of the screener separator and recycled back into use, thereby reducing the amount of mixed waste generated and minimizing the need for new gravel. An array of smaller particles are discharged into drums and, if desired, reused in other applications. The fines or silt are flushed out of the separator with the water and are removed from the water and consolidated into a drum with the use of a hydrocyclone separator and drum decant system. Because the water in the spray system is recycled, minimal makeup water is needed. The system 
monitors pH and total dissolved solids (TDS) and, when undesired levels of $\mathrm{pH}$ or TDS are reached or when suspended solids could result in clogs, the spray system can be purged and refilled.

\section{2}

$\mathrm{V} 18 / 022250$

Recovery of Iron, Carbon and Zinc from Steel Plant Waste Oxides Using the AISI-DOE Postcombustion Smelting Technology

Sarma, B.; Downing, K.B.; Aukrust, E.

Praxair, Inc., Tarrytown Technical Center, Tarrytown, NY; Fluor Daniel, Inc., Greenville, SC; E. Aukrușt, Pittsburgh, PA

INEL-96/00081; CONF-960317; Proceedings of the 79th

Steelmaking and the 55th Ironmaking Conference, Pittsburgh, PA, March 24-27, 1996; (pp. 667-684) (1996)

In November 1988, the American Iron and Steel Institute (AISI) and the United States Department of Energy (DOE) began a collaborative program to define an energy-efficient and environmentally-friendly technology for the production of hot metal for steelmaking directly from coal and iron ore pellets, without incurring the high capital costs and environmental problems associated with traditional coke and blast fumace technology. The five year $\$ 60.3$ million research and development program, including pilot plant operations, laboratory research, and an independent study of the results, confirmed the technical feasibility of the postcombustion smelting technology developed for this purpose.

\section{3}

\section{V18/021067}

Reformulation/Reuse of Explosives and Propellants Burch, D.; Sims, K.

U.S. Navy, Naval Surface Warfare Center, Crane Division, Crane, IN

CONF-940499 (Vol. 1); Proceedings of the 1994 Federal

Environmental Restoration III and Waste Minimization II Conference and Exhibition, New Orleans, LA, April 27-29, 1994. Hazardous Materials Control Resources Institute, Rockville, MD, Vol. 1, 783 pp.; (pp. 355-359) (1994)

The Department of Defense (DoD) faces many environmental issues and concerns in the demilitarization and disposal of obsolete, excess and unserviceable munition items. For many munition items the only method of disposal is Open Burning/Open Detonation (OB/OD) which not only creates pollutants, but destroys potentially valuable materials. Increased concem for the protection of the environment has mandated that DoD must pursue improved methods of munitions demilitarization while maximizing ingredient recovery. Removal technology has already been demonstrated for the majority of explosive and propellant loaded items, but the reclaimed energetic material is being destroyed by OB/OD or other destruction technologies. For the past few years, Crane Division, Naval Surface Warfare Center (NAVSURFWARCENDIV Crane) has concentrated on reclaiming the valuable energetics with subsequent reformulation for commercial applications. Technology Development Inc. (TDI), Rolla, MO and TPL, Inc. (TPL), Albuquerque, NM under the Small Business Innovation Research (SBIR) program have demonstrated the feasibility, on a lab/bench scale, of using reclaimed military explosives as commercial blasting agents. TDI's efforts have concentrated on the reformulation for the purpose of producing a commercial mining explosive, while TPL has concentrated on use as a metal brazing explosive. In both cases, reclaimed PBXs and other explosives have been formulated and tested to produce explosives of equal or superior performance to current commercial explosives. Work has also been initiated to recover $R D X$ and $H M X$ from military explosives and propellants and qualification of the RDX and HMX for commercial applications. Test results conducted by TPL, Inc. (Phase I SBIR) indicate that a feed supplement for ruminant animals and a slow nitrogen release fertilizer can be generated from surplus Navy gun propellants. The feasibility of using surplus gun propellants in a novel oil and gas well stimulation process was also demonstrated. A Phase II SBIR contract has been awarded and work is currently being performed to further develop and evaluate these programs.

\section{4}

V18/022715

Remotely Controlled Vehicles and Systems for Integrated Remediation of Buried TRU Wastes

Tucker, H.J.; Ballantyne, J.; Rife, G.; Fung, P.

Spar Space Systems, Brampton, Ontario, Canada

CONF-960804 (Vol. 1); Spectrum '96: Nuclear and Hazardous Waste Management, Proceedings of an International Topical Meeting, Seattle, WA, August 18-23, 1996. American Nuclear Society, La Grange Park, IL, Vol. 1, 887 pp.; (pp. 50-57) (1996)

This paper describes the design, implementation and testing of remotely controlled vehicle systems developed for cooperative retrieval and transportation of Transuranic (TRU) buried wastes. The systems described are for the control of a Remote Excavator (REMEX), a Self Guided Transfer Vehicle (SGTV), a Remotely Controlled Materials Handling System and a Virtual Environment for Remote Operations (VERO), using imaging by a 3D Laser Camera.

\section{$2385 \quad$ V18/021771}

Removing Cesium and Strontium from a Radioactive Brew

Initiatives in Environmental Technology Investment 3(June 1996):1-3 (June 1996)

The material on top of the sludge in waste tanks is a nasty brew. It's called supernate, and it is a fluid containing, among other things, cesium and strontium. High-level tank waste is a byproduct of nuclear material processing and a major concern in the U.S. Department of Energy cleanup efforts. Inorganic ion exchangers and molecular recognition technology are two ways researchers are improving separation techniques. Both technologies are being commercialized by private industry in collaboration with DOE and have been successfully tested in the DOE complex. Both can be remotely operated to reduce worker exposure to radionuclides in the field. Sandia National Laboratories, UOP Molecular Sieves and Texas A\&M University have collaborated to develop an inorganic ion exchange material called crystalline silicotitanate, or CST. Already commercially available in a powder form, the material has been successfully tested with both simulated and real wastes. IBC Advanced Technologies, Inc. has developed a molecular recognition material called SuperLig and is working with $3 \mathrm{M}$ and Pacific 
Northwest National Laboratory to commercialize it for tank waste remediation.

2386

V18/022309

Report of the Technical Review Team on the Catalytic Extraction Process

U.S. Department of Energy, Office of Environmental Management, Office of Science and Technology, Washington, DC

DOE/EM-0314; 60 pp. (March 1996)

During a technical review on January 23 and 24, 1996, the DOE Technical Review Team (TRT) was impressed with the amount and quality of work that has been done since the last review in January 1995 by a DOE Technical Review Panel (TRP). Molten Metals Technologies (MMT) has been responsive to recommendations of the TRP made in 1995. MMT has made good progress in addressing the special concerns of the TRP for the processing of DOE mixed low-level waste (MLLW) as required by the present PRDA contract. Advancement of the technology has been accomplished on the R\&D front as well as the actual implementation of the Catalytic Extraction Process (hereinafter, "CEP") technology through its subsidiary with partner Lockheed Martin Corporation, called M4 Environmental, L.P. (or "M4"), at Oak Ridge, TN. The M4 facilities, now operating on actual radioactive waste, exemplify the capability of private industry to take the initiative and move forward to design and construct facilities using technical results from DOE-funded R\&D activities.

2387

V18/025533

Road Transportable Analytical Laboratory (RTAL) System

Finger, S.M.; Malhotra, J.L.; Herman, D.L.

Engineering Computer Optecnomics, Inc., Annapolis, MD;

U.S. Department of Energy, Morgantown Energy

Technology Center, Morgantown, WV; Fernald

Environmental Restoration Management Corporation,

Cincinnati, $\mathrm{OH}$

CONF-960804 (Vol. 2); Spectrum '96: Nuclear and Hazardous Waste Management, Proceedings of an International Topical Meeting, Seattle, WA, August 18-23, 1996. American Nuclear Society, La Grange Park, IL, Vol. 2, 873 pp.; (pp. 1578-1583) (1996)

Remediation of DOE sites requires extensive sampling to determine the extent of the contamination, to monitor clean-up and remediation progress, and for post-closure monitoring of facilities. The DOE would benefit greatly if it had reliable, road transportable, fully independent laboratory systems that could perform on-site a full range of analyses meeting high levels of quality assurance and control. Such systems would accelerate and thereby reduce the cost of clean-up and remediation efforts by: (1) providing critical analytical data more rapidly and (2) eliminating the handling, shipping, and manpower associated with sample shipments. The goals of the Road Transportable Analytical Laboratory (RTAL) Project are the development and demonstration of a system to meet the unique needs of the DOE for rapid, accurate analysis of a wide variety of hazardous and radioactive contaminants in soil, groundwater, and surface waters. This laboratory system is designed to provide the field and laboratory analytical equipment necessary to detect and quantify radionuclides, organics, heavy metals and other inorganic parameters. The laboratory system consists of a set of individual laboratory modules deployable independently or as an interconnected group to meet each DOE site's specific needs.

2388 $\mathrm{V} 18 / 021142$

Roadmap Process for Commercialization and Use of

Emerging Characterization and Monitoring Technologies

Wang, P.W.; Zachry, T.A.; Anderson, M.S.; Paladino, J.B.

U.S. Department of Energy, Washington, DC; Ames

Laboratory, Ames, IA

CONF-960212; Waste Management '96: Working Towards a Cleaner Environment, Proceedings of a Conference on $\mathrm{HLW}$, LLW, Mixed Wastes and Environmental Restoration, Tucson, AZ, February 25-29, 1996; (11 pp.) (1996)

A roadmap process designed to facilitate acceptance of emerging technologies by users and commercial vendors has been developed for use by the U.S. Department of Energy (DOE) Characterization, Monitoring, and Sensor Technology Crosscutting Program (CMST-CP) to transfer its portfolio of technologies. The CMST-CP technology transfer roadmap consists of six main sections: needs assessment, identification of technologies for transfer, a managing-technology-for-development (MTD) process, a technology de-risking process, a technology verification (and/or certification) process, and a "hands-on" technical assistance process. Through the use of this roadmap process, many barriers that impede acceptance of new technologies have been identified and mitigated.

2389

V18/023898

Robotic Sludge Removal System for Efficient Tank, Pit, and Pond Cleanout

Palowitch, A.W.

Oceaneering International, Inc., Upper Marlboro, MD

CONF-951124; HazMat West '95, Proceedings of the Eleventh Annual Environmental Management and Technology Conference and Exhibition, Long Beach, CA, November 7-9, 1995. Advanstar Expositions, Duluth, MN, 597 pp.; (pp. 161-168) (1995)

A fully robotic sludge removal system has been developed and is now operating at various refineries cleaning heavy crude sludges from above ground storage tanks. The system, controlled by a single operator at a console located outside of the tank, uses hydraulic mechanical control and a fiber optic image data link. Designed for petrochemical industry use, the system is electrically certified as explosion proof. Use of the system within the harshest chemical or explosive atmospheres eliminates the need to send teams of men into tanks to accomplish cleaning activities. The savings to industrial customers from reduced manning, increased production rates, and elimination of personnel injury risk has made the robotic sludge removal system a requirement for the most hazardous tank cleaning jobs.

2390

V18/025506

Robotic Tooling for DOE Environmental Management: 
Annual Report - September 29, 1995-September 28, 1996 Wang, S.L.

North Carolina Agricultural and Technical State University, Greensboro, NC

DOE/SR/18544-2; 49 pp. (December 18, 1996)

The Department of Energy (DOE) has created nuclear weapons for defense for over forty years. During this time, hazardous and nuclear wastes have accumulated, and contamination of soils and groundwater have occurred throughout the US, as environmental stewardship was not fully appreciated until recent times. Thousands of sites require clean up, and hundreds of facilities require decontamination and decommissioning. The Office of Technology Development (OTD) assists this mission by developing new technology that is safer, more efficient, and less expensive than current processes. The OTD has focused upon five primary areas where robotics technology can help. These five areas are: Tank Waste Retrieval, Contaminant Anaiysis Automation, Decontamination and Dismantlement, Mixed Waste Operations, and the Plutonium Focus Area. This report details work on the robotic opening of waste drums and end-effector design for non-destructive drum opening.

\section{1 \\ V18/022311}

Robotics Crosscutting Program, Technology Summary

U.S. Department of Energy, Office of Environmental Management, Office of Science and Technology, Washington, DC

DOE/EM-0299; 108 pp. (August 1996)

The Robotics Technology Development Program (RTDP) is a needs-driven effort developed from an assessment of needed robotics applications at all DOE sites. The assessment revealed several common threads running through the sites: Tank Waste Retrieval (TWR), chemical Analysis Automation (CAA), and Decontamination \& Dismantlement (D\&D). The RTDP also realized that some of the technology development in these three areas had common needs, for example, computer control and sensor interface protocols. This led to the formation of a fourth application area: Crosscutting and Advanced Technology (CC\&AT) development. Each application area is coordinated by a DOE contractor at a site/laboratory chosen for its unique expertise or situation as paradigmatic of an EM problem. This document contains detailed discussions of each technical application area.

\section{$2392 \quad$ V18/023557}

Role of Plants in Isolation Barrier Systems

Link, S.O.; Waugh, W.J.; Downs, J.L.

Pacific Northwest Laboratory, Richland, WA; Rust Geotech, Inc., Grand Junction, $\mathrm{CO}$

CONF-941124; Insitu Remediation: Scientific Basis for Current and Future Technologies, G.W. Gee and N.R. Wing (eds.), Proceedings of the 33rd Hanford Symposium on Health and the Environment, Pasco, WA, November 7-11, 1994. Battelle Press, Columbus, $\mathrm{OH}$, Part 1, 704 pp.; (pp. 561-592) (1994)

Surface barriers are used to isolate buried wastes from the environment; most have been built for short-term isolation.
Effective isolation of radioactive and hazardous wastes from the environment requires that the functional integrity of a barrier be maintained for much longer periods of time (i.e., thousands of years). Barrier function depends strongly on vegetation. While plants reduce wind and water erosion and minimize drainage, they may transport contaminants if roots extend into buried wastes. Our review of the function of plants in surface barriers focuses on the role of plants across mesic to arid environments and gives special consideration to studies at the Hanford Site. The Hanford Barrier Development Program's goal is to design and test an earthen cover system to inhibit water infiltration, plant and animal intrusion, and wind and water erosion, while isolating buried wastes for at least 1000 year. Studies at Hanford have shown that plants significantly interact with the barrier; they transpire soil water back into the atmosphere. Deep-rooted perennials recycle water best, whereas soil water may drain through the root zone of shallow-rooted annuals. Lysimeter studies indicate that a surface layer of fine soil with deep-rooted plants preciudes drainage even with three times normal precipitation. The presence of vegetation greatly reduces water and wind erosion, but deep-rooted plants pose a threat of biointrusion and contaminant transport. The Hanford barrier includes a buried rock layer and an asphalt layer to (among other purposes) prevent biointrusion.

\section{V18/024055}

\section{Rolling Out the Carpet for Concrete Decontamination}

Initiatives in Environmental Technology Investment 4(April 1997):5-6 (April 1997)

The U.S. Department of Energy (DOE) estimates there are 600 million square feet of concrete in need of decontamination.across the DOE complex. ISOTRON Corporation has developed a decontamination technology that uses electrokinetics and a carpet-like pad to remove contaminants from concrete without damaging it. ISOTRON's ELECTROSORB " $\mathrm{C}^{n}$ ("C" for concrete) technology offers an alternative to physical abrasion for cleaning up contaminated concrete. Abrasion creates airborne contaminated particles that must be contained to protect workers. Because the technology doesn't create dust, ELECTROSORB " $\mathrm{C}$ " can be operated near other activities without disturbing them. The secondary waste generated by ELECTROSORB " $\mathrm{C}$ " is contained in the electrolyte solution and ion-sorbent materials, such as ion-exchange media, which can be safely and easily disposed of.

\section{4 \\ V18/021017}

\section{SEAMIST [TM] - Innovative Technology Summary Report}

U.S. Department of Energy, Office of Environmental Management, Washington, DC

Report; 15 pp. (September 1995)

SEAMIST [TM] has been demonstrated and deployed as an innovative tool to better access the subsurface for characterization monitoring of contaminants in both vertical and horizontal boreholes. The technology has been developed by industry with assistance from DOE's Office of Technology Development to ensure it meets the needs of the environmental restoration market. 


\section{SEAMIST [TM] Cuts Contamination Cleanup Costs}

Locke, $\mathrm{T}$.

Sandia National Laboratories, Albuquerque, NM

SAND96-0905; Inside Sandia (April 1996): 8-9 (April 1996)

SEAMIST [TM] (Science and Engineering Associates Membrane Instrumentation and Sampling Technique) was invented by Science Engineering Associates, Inc. Its functionality has been further developed and demonstrated through collaboration with Sandia environmental scientists. The basis of SEAMIST (TM) is an impermeable membrane liner that is installed directly into a borehole. Fluid sampling devices attached to the outside of the liner are positioned as the liner is installed. The SEAMIST (TM) liner provides stability to the borehole and protects workers from exposure to contaminants. Devices that the liner can deliver to the borehole include gas sample lines, fiber optics, and chemical, hydrologic, and radiologic sensors.

\section{6 \\ V18/021361}

SEG's Metal Recycling Program for Beneficial Reuse of Radioactively Contaminated Scrap Metal

Large, D.E.

Scientific Ecology Group, Inc., Oak Ridge, TN

CONF-940798; Proceedings of the Workshop on Radioactively Contaminated Scrap Metal, University of Tennessee, Energy, Environment and Resources Center, Knoxville, TN, July 12-14, 1994; (9 pp.) (July 12, 1994)

More than a million tons of radioactively contaminated metals, considered scrap and waste, have been identified at the many sites under the purview of the Department of Energy and many more with the Department of Defense and in the commercial sector. Several concerns exist regarding the disposition of existing inventories and potential generations of contaminated scrap metals. In the past, good potentially reusable metal has been buried as waste. Time has come, and is much overdue, for that practice to cease. Capability to process these scraps to needed products exists, and responding facilities are in operation. In the late eighties, the Department of Energy's Oak Ridge Operations Office pioneered the move to involve private industry in dealing with the contaminated scrap metal under its purview. Consequently, SEG emerged as a leader in processing contaminated metal for beneficial reuse. Using effective technologies and techniques for processing radioactively contaminated metals, the Scientific Ecology Group, Inc. (SEG) has built with private funds and has in operation in Oak Ridge, Tennessee a Metal Processing Facility (MPF). This MPF is used to process radioactively contaminated metals, rid them of the majority of contamination, and form them into customized shield blocks and other beneficial items. Significant volume reduction for scrap metals (estimated to be in excess of 20 to 1 ) is achieved with metal melting services.

\section{7}

V18/023925

Savannah River Environmental Technology Field Test Platform

Rossabi, J.; Riha, B.D.

Westinghouse Savannah River Company, Aiken, SC; Oak Ridge Institute for Science and Education, Aiken, SC
CONF-951048 (Vol. 50, Pt. 2); ISA/95: Advances in Instrumentation and Control, Proceedings of an International Conference and Exhibition, New Orleans, LA, October 1-6, 1995. Instrument Society of America, Research Triangle Park, NC, Vol. 50, Pt. 2, 764 pp.; (pp. 171-182) (1995)

The principal goal in the development of new technologies for environmental monitoring and characterization is transferring them to organizations and individuals for use in site assessment and compliance monitoring. The Savannah River Technology Center (SRTC) has been developing a program to rigorously field test promising environmental technologies that have not undergone EPA equivalency testing. The infrastructure and staff expertise developed as part of the activities of the Savannah River Integrated Demonstration Program allows field testing of technologies without the difficulties of providing remote field support. By providing a well-characterized site and a well-developed infrastructure, technologies are tested in actual field scenarios to determine their appropriate applications in environmental characterization and monitoring activities. The field tests provide regulatory organizations, potential industrial partners, and potential users with the opportunity to evaluate the technology's performance and its utility for implementation in environmental characterization and monitoring programs. This program has resulted in the successful implementation of several new technologies.

\section{8}

\section{V18/021758}

\section{Scannerless Terrain Mapper}

Sackos, J.; Bradley, B.; Diegert, C.; Ma, P.; Gary, C.

Sandia National Laboratories, Exploratory Systems Development and Parallel Science Computing Centers, Albuquerque, NM; National Aeronautics and Space Administration, Ames Research Center, Photonics Group, Moffett Field, CA

SAND96-2073C; CONF-960848; Denver 96: Advanced Technologies for Environmental Monitoring and Remediation, $T$. Vo-Dinh (ed.), Proceedings of the First Society of Photo-Optical Instrumentation Engineers (SPIE) Conference on Space Processing of Materials, Denver, CO, August 4-9, 1996. SPIE, Bellingham, WA, 294 pp.; (11 pp.) (1996)

NASA-Ames Research Center, in collaboration with Sandia National Laboratories, is developing a Scannerless Terrain Mapper (STM) for autonomous vehicle guidance through the use of virtual reality. The STM sensor is based on an innovative imaging optical radar technology that is being developed by Sandia National Laboratories. The sensor uses active flood-light scene illumination and an image intensified $\mathrm{CCD}$ camera receiver to rapidly produce and record very high quality range imagery of observed scenes. The STM is an all solid-state device (containing no moving parts) and offers significant size, performance, reliability, simplicity, and affordability advantages over other types of 3-D sensor technologies, such as scanned laser radar, stereo vision, and structured lighting. The sensor is based on low cost, commercially available hardware, and is very well suited for affordable application to a wide variety of military and commercial uses, including: munition guidance, target recognition, robotic vision, automated inspection, driver enhanced vision, collision avoidance, site security and monitoring, and facility surveying. This paper reviews the 
sensor technology, discusses NASA's terrain mapping applications, and presents results from the initial testing of the sensor at NASA's planetary landscape simulator.

\section{9}

\section{V18/020737}

Selecting Remediation Technologies Through a

"Technical Risk" Index: An Application of Multi-Attribute Utility Theory

Timmerman, T.J.; Kloeber, J.M; Jackson, J.A.; Deckro, R.F. U.S. Air Force Institute of Technology, Wright-Patterson Air Force Base, $\mathrm{OH}$

CMSATR/96-01; 87 pp. (January 20, 1996)

This study applies multi-attribute utility theory to the DOE's problem of selecting the least risky technologies to develop. It focuses on two aspects of the technical risks involved with emerging technologies: the risk of successful development (measured by the likelihood of successful R\&D completion within seven years) and the risk of successful implementation in the field (measured by the likelihood of the technology performing as anticipated). Three experienced contractors working with the Landfill Stabilization Focus Area served in the roles of DOE technology managers. Their preferences, expressed as MAUT utility functions, were assessed for al! seven functional remediation processes. These utilities are plotted as three-dimensional surfaces over a plane formed by the two technical risk measures, graphically depicting the trade-offs each 'decision maker' felt was appropriate between the two measures. Their utility surfaces for treatment technologies were then used with a set of ten treatment methods for which expert estimates of the two risk measures were available. The resulting rankings of technologies are analyzed to examine the suitability of the methodology. Recommendations for the use of this approach with real Department of Energy managers are presented.

2400 .

V18/021783

Silent Discharge Plasma Destruction of Hazardous Wastes

Coogan, J.J.; Anderson, G.K.; Kang, M.; Rosocha, L.A.

Los Alamos National Laboratory, Chemical and Laser Sciences Division, Los Alamos, NM

CONF-930273; Proceedings of the Electric Power Research Institute (EPRI) Symposium on Environmental Applications of Advanced Oxidation Technologies, San Francisco, CA, February 22-24, 1993; (1 p.) (1993)

Aл innovative plasma oxidation treatment technology is being developed at Los Alamos for the destruction of hazardous organics. Silent discharge plasmas (SDP) have been demonstrated in the laboratory to be effective in destroying hazardous organic compounds, particularly halocarbons. These compact systems offer an alternative to existing post-incineration treatments. The conventional approach to organic destruction is through combustion of the material and the chemistry is dependent on the generation of free radicals such as $\mathrm{O}(3 \mathrm{P}), \mathrm{OH}$, and $\mathrm{H}$. SDP generates very energetic ( $1-10 \mathrm{eV}$ ) electrons, which efficiently create reactive free radicals without adding the enthalpy associated with very high gas temperatures. Thus, increased reaction rates can be realized while the actual gas temperatures remain near ambient.
Non-equilibrium plasmas can be very energy efficient for waste destruction because most of the work goes into enhancing the chemistry without significantly raising the gas temperature and without adding additional fuel to the process.

2401

V18/022415

Sonsub [R]: The Innovators of Remote Systems

Technology

Sonsub, Inc., Houston, TX

Report; 35 pp. (1996)

Sonsub Environmental Services is an engineering and field services contractor with unique abilities and experience in the design and use of remotely operated equipment to retrieve and stabilize hazardous and radioactive materials at remote sites. Son sub routinely uses remotely operated equipment at locations ranging from water depths of 5,000 feet to desert areas. Sonsub designs and provides specialized equipment and provides field site crews to remotely operate the equipment. Designs, practices, management and crew training have been shown to meet US EPA requirements including RCRA regulations, and US DOE requirements for handling radioactive materials and wastes. This document is a compilation of information about the company, its products, projects and services. Material consists of company brochures, reprints of papers from waste management conferences and journals, and articles from the popular press.

\section{$2402 \quad$ V18/021772}

Spotlight on the Characterization, Monitoring, and Sensor Technology Crosscutting Program

Initiatives in Environmental Technology Investment 3(August 1996):6-7 (August 1996)

Since it began in 1990, the characterization, monitoring, and sensor technology crosscutting program has funded and managed many technology development activities across government laboratories, the private sector, and universities. Many technologies have been fully developed and commercialized and are now in use. Many more technologies are being developed that are close to being implemented. This article gives an overview of the following technologies and updates their development: RCL monitor, Waste Inspection Tomography (WIT), SAW sensor, Continuous emissions monitors (CEMs).

2403

V18/022413

\section{Spotlight on the Subsurface Contaminants Focus Area}

Initiatives in Environmental Technology Investment 3(December 1996):6-8 (December 1996)

The subsurface contaminants focus area is the newest focus area, formed in late September 1996 when the contaminant plumes containment and landfill stabilization focus areas merged. SCFA's mission is to develop, demonstrate, and deploy innovative systems for containing and isolating buried waste and remediating subsurface contaminants, including dense non-aqueous phase liquids, metals, and radionuclides. SCFA technologies will reduce risk and the cost of remediation while meeting compliance requirements. Opportunities for SCFA-developed technologies to improve DOE's environmental management mission are significant because of the enormous 
magnitude of the environment problem. Initial estimates of the cost and time to address this environmental management problem were as great as $\$ 230$ billion over 75 years. The SCFA program develops technologies that will allow completion of the environmental restoration and solid waste management portions of this program more quickly and cost effectively.

\section{4 \\ V18/020962}

Stabilization and Containment of Buried Waste Sites Using Jet Grouting of Acrylic Polymers

Loomis, G.G.; Heiser, J.H.

Idaho National Engineering Laboratory, Idaho Falls, ID; Brookhaven National Laboratory, Upton, NY

CONF-960212; Waste Management '96: Working Towards a Cleaner Environment, Proceedings of a Conference on $\mathrm{HLW}$, LLW, Mixed Wastes and Environmental Restoration, Tucson, AZ, February 25-29, 1996; (12 pp.) (1996)

A full-scale field demonstration of an innovative subsurface stabilization technique was performed on simulated transuranic waste pits at the Idaho National Engineering Laboratory. The demonstration involved jet grouting simulated buried transuranic waste pits with an acrylic polymer. The jet grouting created a monolith out of the buried waste pits. The monolith can either be considered for in situ disposal of the buried waste with improved confinement or can actually enhance the contamination control of the transuranic material during a hot-spot retrieval effort by agglomerating the contaminants into courser less aerosolizable materials. The demonstration involved pit construction, two-component jet grouting for the polymer pit, destructive examinations of the polymer pit, and evaluation of the contamination-control aspects of using the polymer material to bind the contaminants.

2405

V18/024092

Steerable/Distance Enhanced Penetrometer Delivery System - Phase I: Topical Report - August 1994-August 1995

Amini, A.; Shenhar, J.

UTD, Inc., Newington, VA

DOE/MC/31178-5307; 62 pp. (August 1995)

Penetrometers play an important role in detection, mapping, and remediation of underground contaminated sites. At present, penetrometer applications are restricted mainly to vertical pushes. This is due to a technology gap that exists in tracking and steering of the penetrometer tip. In the past five years, UTD Incorporated has worked to close this technology gap by developing an accurate and efficient position location system referred to as the POLO (POsition LOcation) device. The prototype POLO device was developed under a Program Research and Development Announcement (PRDA) contract sponsored by the Department of Energy (DOE), Morgantown Energy Technology Center (METC), Office of Science and Technology. At the completion of this contract, for the first time the penetrometer operator had the capability to know the position of the tip of the penetrometer in real-time. Building on this capability, UTD Incorporated was awarded a follow-on three-phase contract under a Research
Opportunity Announcement (ROA) program. The objectives of the new contract are to develop a steerable distance enhanced penetrometer delivery system, and to integrate POLO into a commercial penetrometer truck.

2406

V18/024093

Steerable/Distance Enhanced Penetrometer Delivery System - Phase II: Topical Report

Amini, A.; Shenhar, J.; Lum, K.D.

UTD, Inc., Newington, VA

DOE/MC/31178-5308; 46 pp. (May 1996)

Penetrometers play an important role in detection, mapping, and remediation of underground contaminated sites. At present, penetrometer applications are restricted mainly to vertical pushes. This is due to a technology gap that exists in tracking and steering of the penetrometer tip. In the past five years, UTD Incorporated has worked to close this technology gap by developing an accurate and efficient position location system referred to as the POLO (POsition LOcation) device. The prototype POLO device was developed under a Program Research and Development Announcement (PRDA) contract sponsored by the Department of Energy (DOE), Morgantown Energy Technology Center (METC), Office of Science and Technology. At the completion of this contract, for the first time the penetrometer operator had the capability to know the position of the tip of the penetrometer in real-time. Building on this capability, UTD Incorporated was awarded a follow-on three-phase contract under a Research Opportunity Announcement (ROA) program. The objectives of the new contract are to develop a steerable distance enhanced penetrometer delivery system, and to integrate POLO into a commercial penetrometer truck.

2407

V18/020771

Streamlined Environmental Remediation

Characterization Using Remote Sensing Techniques:

Case Studies for the U.S. Department of Energy, Oak Ridge Operations

Carden, D.M.; Nalezny, C.L.; Smyre, J.L.; Evers, T.K.; King, A.L.

U.S. Department of Energy, Oak Ridge Operations Office, Oak Ridge, TN; U.S. Department of Energy, Office of Environmental Management, Washington, DC; Oak Ridge National Laboratory, Oak Ridge, TN

CONF-9607107; Proceedings of the 18th International Society for Photogrammetry and Remote Sensing Congress, Vienna, Austria, July 9-19, 1996; (13 pp.) (1996)

This paper provides an overview of the DOE Oak Ridge Operations Remote Sensing Program and discusses how data from this program have assisted the environmental restoration program in streamlining site-characterization activities. Three case studies are described where remote sensing imagery has provided a more focused understanding of site problems with a resultant reduction in the need for costly and time-consuming, ground-based sampling approaches. 


\section{Subsurface Contaminants Focus Area}

U.S. Department of Energy, Office of Environmental Management, Office of Science and Technology, Washington, DC

\section{DOE/EM-0296; 296 pp. (August 1996)}

The US Department of Energy (DOE) Subsurface Contaminants Focus Area is developing technologies to address environmental problems associated with hazardous and radioactive contaminants in soil and groundwater that exist throughout the DOE complex, including radionuclides, heavy metals, and dense non-aqueous phase liquids (DNAPLs). More than 5,700 known DOE groundwater plumes have contaminated over 600 billion gallons of water and 200 million cubic meters of soil. Migration of these plumes threatens local and regional water sources, and in some cases has already adversely impacted off-site resources. In addition, the Subsurface Contaminants Focus Area is responsible for supplying technologies for the remediation of numerous landfills at DOE facilities. These landfills are estimated to contain over 3 million cubic meters of radioactive and hazardous buried waste. Technology developed within this specialty area will provide effective methods to contain contaminant plumes and new or alternative technologies for development of in-situ technologies to minimize waste disposal costs and potential worker exposure by treating plumes in place. While addressing contaminant plumes emanating from DOE landfills, the Subsurface Contaminants Focus Area is also working to develop new or alternative technologies for the in-situ stabilization and nonintrusive characterization of these disposal sites. This report presents overviews of a large number of new technologies under development within the following product lines: Organics, DNAPLs, Metals and Radionuclides, Subsurface Access, Transuranic/Mixed Waste in Arid Environments, Transuranic/Mixed Waste in Humid Environments, Low-Level Waste/Other Contaminants in Arid Environments, Low-Level/Other Contaminants in Humid Environments, and Crosscutting Programs.

2409

V18/022892

Summary Proceedings of a Workshop on Bioremediation and Its Societal Implications and Concerns (BASIC), Airlie Center, Warrenton, VA, July 18-19, 1996

Drell, D.W.; Metting, F.B., Jr.

U.S. Department of Energy, Germantown, MD; Pacific Northwest Laboratory, Richland, WA

LBNL-39583; CONF-9607165; Bioremediation and Its Societal Implications and Concerns (BASIC), L.D. Way (ed.), Proceedings of a Conference, Warrenton, VA, July 18-19, 1996, 220 pp. (1996)

The Department of Energy (DOE), Office of Health and Environmental Research held a workshop in support of its new fundamental scientific program in Natural and Accelerated Bioremediation Research (NABIR) on July 18-19, 1996 near Warrenton, Virginia. In all, 45 invited participants from govemment, academia, non-profit institutions, trade organizations and the business community met to discuss ethical, legal, and social issues (ELSI) associated with the new NABIR program. The objectives of the workshop were to: (1) explore what some of the societal, public policy, educational and other issues attendant to the
NABIR Program might be; (2) to begin a process of public involvement; and (3) to develop an initial set of recommendations for creating a program in Bioremediation and Its Societal Issues and Concems (BASIC) within NABIR. Participants engaged in a very lively discussion of a broad range of specific topics. A number of direct and provocative ideas were offered. Some of these are included in the body of these proceedings. General consensus was that DOE was to be lauded for this attempt to institute a novel approach to a long-standing need to enhance public participation in the scientific enterprise. Viewgraphs of the presentations are included.

\section{$2410 \quad$ V18/021456}

Surface Acoustic Wave Sensing of VOCs in Harsh Chemical Environments

Pfeifer, K.B.; Martin, S.J.; Ricco, A.J.

Sandia National Laboratories, Albuquerque, NM

SAND93-0070; 75 pp. (June 1993)

The measurement of VOC concentration in harsh chemical and physical environments is a formidable task. A surface acoustic wave (SAW) sensor has been designed for this purpose and its construction and testing are described in this paper. Included is a detailed description of the design elements specific to operation in $300 \mathrm{deg} \mathrm{C}$ steam and $\mathrm{Hcl}$ environments including temperature control, gas handling, and signal processing component descriptions. In addition, laboratory temperature stability was studied and a minimum detection limit was defined for operation in industrial environments. Finally, a description of field tests performed on stream reforming equipment at Synthetica Technologies, Inc. of Richmond, $\mathrm{CA}$ is given including a report on destruction deficiency of $\mathrm{CCl} 4$ in the Synthetica moving bed evaporator. Design improvements based on the field tests are proposed.

2411 V18/023717

System for Comparison of Boring Parameters of Mini-HDD Machines

Gunsaulis, F.R.

Oklahoma State University, Department of Biosystems and Agricultural Engineering, Stillwater, OK

CONF-9603151; International NO-DIG '96: Proceedings of an International Society and North American Society for Trenchless Technology (ISTT/NASTT) Conference and Exhibition, New Orleans, LA, March 31-April 3, 1996. NASTT, Chicago, IL, 687 pp.; (pp. 61-77) (1996)

A system has been developed to accurately evaluate changes in performance of a mini-horizontal drilling (HDD) system in the backreaming/pullback portion of a bore as the parameters influencing the backream are changed. Parameters incorporated in the study include spindle rotation rate, rate of pull, fluid flow rate, and backreamer design. The boring system is able to run at variable, operator-determined rates of spindle rotation and pullback speed utilizing electronic feedback controls for regulation. Spindle torque and pullback force are continuously measured and recorded giving an indication of the performance of the unit. A method has also been developed to measure the pull load on the installed service line to determine the effect of the boring parameters on the service line. 
Variability of soil along the bore path is measured and quantified using a soil sampling system developed for the study. Sample results obtained with the system are included in the report.

\section{2}

V18/022184

Technology Integration Project: Environmental Restoration Technologies Department Sandia National Laboratories

Williams, C.V.; Burford, T.D.; Allen, C.A.

Sandia National Laboratories, Environmental Restoration

Technologies, Albuquerque, NM; Tech Reps, Inc., Albuquerque, NM; Sandia National Laboratories, Albuquerque, NM

SAND96-2001; 156 pp. (August 1996)

Sandia National Laboratories Environmental Restoration Technologies Department is developing environmental restoration technologies through funding from the US Department of Energy's (DOE's) Office of Science and Technology. Initially, this technology development has been through the Mixed Waste Landfill Integrated Demonstration (MWLID). It is currently being developed through the Contaminant Plume Containment and Remediation Focus Area, the Landfill Stabilization Focus Area, and the Characterization, Monitoring, and Sensor Cross-Cutting Program. This Technology Integration Project (TIP) was responsible for transferring MWLD-developed technologies for routine use by environmental restoration groups throughout the DOE complex and commercializing these technologies to the private sector. The MWLID's technology

transfer/commercialization successes were achieved by involving private industry in development, demonstration, and technology transfer/commercialization activities; gathering and disseminating information about MWLID activities and technologies; and promoting stakeholder and regulatory involvement. From FY91 through FY95, 30 Technical Task Plans (TTPs) were funded. From these TTPs, the MWLID can claim 15 technology transfer/commercialization successes. Another seven technology transfer/commercialization successes are expected. With the changeover to the focus areas, the TIP continued the technology transfer/commercialization efforts begun under the MWLID.

\section{$2413 \quad$ V18/023899}

Technology Transfer from the Superfund Basic Research Program

Chang, D.P.Y.; Comelius, J.

University of Califomia, Davis, CA; State Water Resources Control Board, Division of Clean Water Programs, Sacramento, CA

CONF-951124; HazMat West '95, Proceedings of the Eleventh Annual Environmental Management and Technology Conference and Exhibition, Long Beach, CA, November 7-9, 1995. Advanstar Expositions, Duluth, MN, 597 pp.; (pp. 197-212) (1995)

In the Spring of 1995, The National Institute of Environmental Health Sciences (NIEHS) sponsored a two-day Symposium on "Transfer of Basic (Superfund) Research to Waste Site Remediation" in collaboration with the Department of Defense's (DOD) Environmental Education Demonstration Grant Program, the US Environmental Protection Agency (U.S. Environmental Protection Agency), the Califomia Environmental Protection Agency (Cal EPA) and the Lawrence Berkeley and Livermore National Laboratories (LBL and LLNL). The Symposium's purpose was three-fold: (1) to familiarize DOD environmental managers with the multi-disciplinary research approach of the NIEHS Superfund Basic Research Program; (2) to exchange information on DOD research priorities; and (3) to identify issues with and recommend remedies for converting technological advances from the laboratory to actual practice. The purpose of this paper is to provide a brief description of the NIEHS Superfund Basic Research Program (SBRP) and to summarize selected discussions and issues identified regarding technology transfer.

\section{$2414 \quad$ V18/022858}

Technology Transfer to DOE Environmental Management: Subsurface Science Program

U.S. Department of Energy, Office of Energy Research, Washington, DC

Report; 30 pp. (October 1995)

The Department of Energy faces environmental restoration challenges resulting from 50 years of energy development and nuclear weapons production. Some 10,000 individual sites in need of cleanup have been identified. The volume, broad distribution, and complexity of DOE's contaminated subsurface sediments and groundwater pose a unique and formidable long-term challenge. The Office of Health and Environmental Research (OHER), in collaboration with EM and its predecessor offices, has analyzed the fundamental scientific requirements for a successful environmental restoration program that focuses on DOE site needs. Most recently, SSP assisted EM-50 in planning its "new approach," which identified the Plumes, Landfills, and Tanks Focus Areas. Basic research in subsurface science has resulted in the acquisition of a body of fundamental knowledge that: (1) supports the development of innovative site characterization and cleanup technologies that reduce cost and risk, and (2) provides information to address problems for which there are no curent technical solutions.

\section{$2415 \quad$ V18/022862}

Thermoplastic Encapsulation of Waste Surrogates by High-Shear Mixing

Lageraaen, P.R.; Kalb, P.D.; Patel, B.R.

Brookhaven National Laboratory, Upton, NY

BNL-63712; 35 pp. (December 1995)

Brookhaven National Laboratory (BNL) has developed a robust, extrusion-based polyethylene encapsulation process applicable to a wide range of solid and aqueous low-level radioactive, hazardous and mixed wastes. However, due to the broad range of physical and chemical properties of waste materials, pretreatment of these wastes is often required to make them amenable to processing with polyethylene. As part of the scope of work identified in FY95 "Removal and Encapsulation of Heavy Metals from Ground Water," EPA SERDP\#387, that specifies a review of potential thermoplastic processing techniques, and in order to investigate possible pretreatment alternatives, BNL conducted a vendor test of the Draiswerke Gelimat (thermokinetic) mixer on April 25, 1995 at their test facility in Mahwah, NJ. The Gelimat is a batch operated, 
high-shear, high-intensity fluxing mixer that is often used for mixing various materials and specifically in the plastics industry for compounding additives such as stabilizers and/or colorants with polymers. Test objectives were to gauge the success of this process for mixing different waste materials with thermoplastic and to produce a molten product that can either be discharged directly into a waste container or can be fed to an extruder. In the latter case, the extruder would serve to further mix the materials, act as a melt pump for processing the materials through a die, and to create a continuous encapsulation process. For this test, a series of surrogate wastes including mixed incinerator ash, hearth ash, nitrate salts, sawdust and wood chips were mixed with pelletized virgin and recycled low-density polyethylene (LDPE), recycled flake high-density polyethylene (HDPE), recycled flake poly(ethylene terephthalate) (PET), or a combination of these polymers.

\section{$2416 \quad$ V18/021784}

Treatment of Hazardous Organic Wastes Using Silent Discharge Plasmas

Rosocha, L.A.; Anderson, G.K.; Bechtold, L.A.; Coogan, J.J.; Heck, H.G.; Kang, M.; McCulla, W.H.; Tennant, R.A.; Wantuck, P.J.

Los Alamos National Laboratory, Los Alamos, NM

LA-UR-92-2037; CONF-920967; Non-Thermal Plasma Techniques

for Pollution Control, Proceedings of an Advanced Research

Workshop, Cambridge, England, September 21-25, 1992; (3 pp.)

(1992)

The conventional approach for the destruction of organic compounds is combustion. Although the generation of bond-cleaving free radicals is usually accomplished by thermal methods (i.e., high temperatures) or the photolysis of ozone or hydrogen peroxide, it can also be efficiently accomplished by non-thermal electrical discharge plasmas. Copious quantities of reactive free radicals can be produced in a gaseous waste stream by dissociating molecular oxygen with energetic electrons in a discharge. With some water present, the primary radicals are $\mathrm{OH}$ and $\mathrm{O}(3 \mathrm{P})$. One promising technology for non-thermal plasma processing is based upon the "silent electrical discharge" that has proven to be industrially dependable for the generation of large quantities of ozone. Initial experimental and theoretical work on the use of these discharges for oxidation of $\mathrm{SO} 2$ and NOx in moist air and the destruction of selected hydrocarbons and halocarbons has been quite successful.

2417

V18/021795

\section{U.S. Department of Commerce Announces Private-Sector RCI Participants}

Initiatives in Environmental Technology Investment 3(June 1996):1,3 (June 1996)

The private sector players in the Rapid Commercialization Initiative ( $R C I$ ) have been chosen. Nine companies will join state and federal partners in the $\mathrm{RCI}$ team to cooperatively seek ways to streamline the commercialization of environmental technologies. $\mathrm{RCl}$ will help the chosen companies overcome three barriers to successful marketing of their environmental technologies: finding test beds, verifying performance and costs, and obtaining permits from regulatory agencies. From a field of 36 proposals, 10 projects were selected on the basis of technology readiness and innovation, promising market outlook and clear commercialization plans, sufficient pre-arranged funding, and organization commitment. Lessons learned from the partnership will be used to develop and implement better technology policies and strategies for the commercialization process. The 10 selected projects are described in this article.

\section{$2418 \quad$ V18/022905}

Update on Plasma Arc Centrifugal Treatment

Haun, R.E.; Shuey, M.W.; Eschenbach, R.C.

Retech, Inc., Ukiah, CA

CONF-961108; Proceedings of the 1996 Annual Meeting of the American Institute of Chemical Engineers (AIChE), Chicago, IL, November 10-15, 1996; (8 pp.) (1996)

Over the last ten years, Retech has developed a plasma system for destroying organics and stabilizing metal oxides in a non-leaching slag. The system, termed Plasma Arc Centrifugal Treatment (PACT), can handle a variety of waste streams such as contaminated soils, sludges, ion-exchange resins, incinerator residue, fly-ash, and drummed waste among others. This paper will review recent commercial applications of the technology. Three Plasma Arc Centrifugal Treatment systems having an eight-foot diameter centrifuge (PACT-8) are in the construction or checkout phase. One will be used in the Lockheed-Martin Advanced Environmental Systems (LMAES) installation for remediating Pit 9 at the Idaho Engineering Laboratory (INEL). A second unit will be located at the Retech plant in Ukiah, California. The third unit will be located at a site in Munster, Germany. Two PACT-2 units (two foot diameter centrifuge) have been installed within the last two years. The French nuclear agency, CEA, has been using one to study the destruction of surrogate low-level radioactive waste. Retech has been investigating the destruction of hazardous waste for the U.S. Ammy through a contract from Concurrent Technologies Corp. of Johnstown, PA. Retech's PACT-2 has also been used to develop feeding techniques and to improve refractory and torch life.

\section{9}

\section{V18/021588}

\section{Use of Carbon Aerogel Electrodes for Environmental Cleanup}

CONF-960376 (Part 1); Proceedings of the 211th American Chemical Society (ACS) National Meeting, New Orleans, LA, March 24-28, 1996. ACS, Washington, DC, Part 1, 1172 pp.; (p. 847, Paper FUEL 144) (1996)

A process for the capacitive deionization (CDI) of water with a stack of carbon aerogel electrodes has been developed by Lawrence Livermore National Laboratory (LLNL). Earlier versions of CDI use activated carbon as electrodes. Aqueous solutions with various anions and cations are passed through a stack of carbon aerogel electrodes, each having a very high specific surface area (400 to $1100 \mathrm{sq} \mathrm{m} / \mathrm{g}$ ). After polarization, non-reducible and non-oxidizable ions are removed from the electrolyte by the imposed electric field and held in electric double layers formed at the surfaces of electrodes. As desired, the effluent from the cell is purified water. This process is also capable of simuitaneously removing a variety of other impurities. Dissolved heavy metals and suspended colloids can be removed by electrodeposition and electrophoresis, respectively. 
CDI has several potential advantages over other more conventional technologies. Unlike ion exchange, no acids, bases, or salt solutions are required for regeneration of the system. Regeneration is accomplished by electrically discharging the cell. Therefore, no secondary waste is generated. In contrast to thermal processes such as evaporation, $\mathrm{CDI}$ is much more energy efficient. Since no membranes or high pressure pumps are required, $\mathrm{CDI}$ offers operational advantages over electrodialysis and reverse osmosis (RO). Carbon aerogel capacitive deionization can produce a continuous flow of product water by operating two stacks of carbon aerogel electrodes in parallel. One stack purifies while the other is electrically regenerated. This mode of operation is called potential swing and also enables energy recovery. For example, energy released during the discharge of one stack of electrodes (regeneration) can be used to charge the other stack (deionization). Such synchronous operation requires user-friendly automation. This level of automation and sophistication has been incorporated into the demonstration process now available at LLNL. (Complete text)

\section{0}

V18/021036

Utilization of Polymer Viscoelastic Properties to Enhance Acoustic Wave Sensor Performance

Frye, G.C.; Martin, S.J.

Sandia National Laboratories, Microsensor Research and Development, Albuquerque, NM

CONF-9305124; SAND92-2450C; Chemical Sensors II, M. Butler, A. Ricco and N. Yamazoe (eds.), Proceedings of a Symposium, Honolulu, HI, May 16-21, 1993. The Electrochemical Society, Pennington, NJ, Vol 97-3, 864 pp.; (pp. 51-58) (1993)

Polymer films are commonly used as the sorptive layer for preparing chemical sensors using surface acoustic wave (SAW) devices. Absorption of chemical species into these polymer coatings results in plasticization (i.e., softening) of the polymer. We have demonstrated that SAW devices are sensitive to the resulting changes in viscoelastic properties, especially due to the onset of a film resonance. This film resonance occurs when the inertial phase lag across the film approaches $\mathrm{p} / 2$. Based on understanding these acoustic wave/polymer film interactions and the resulting changes in wave velocity and attenuation, device sensitivity can be significantly increased and the ability to utilize both responses to discriminate between isolated chemical species with a single SAW device can be improved.

\section{$2421 \quad$ V18/022870}

\section{VAC ${ }^{\star}$ TRAX Mobile Treatment Unit Process Hazards Analysis}

Rust Geotech, Inc., Grand Junction, CO; U.S. Department of Energy, Grand Junction Office, Grand Junction, $C O$

GJPO-MWTP-19; 170 pp. (April 1996)

In response to the need for increased mixed-waste treatment capability, the Department of Energy (DOE) Albuquerque Operations Office (AL) organized a Treatment Selection Team to match mixed wastes with treatment options and develop a strategy for treatment of its mixed waste. The strategy developed by the Treatment Selection Team was to use available off-site commercial treatment facilities and develop mobile treatment capability to treat wastes at the DOE-AL sites where wastes are generated. One of the technologies assigned to the DOE Grand Junction Projects Office (GJPO) for development was thermal desorption (TD). Rust Geotech, contractor to DOE-GJPO, conducted pilot-scale TD treatability testing with the Rust-patented VAC ${ }^{*} T R A X$ process. Information gained from the treatability testing was used to design a full-scale VAC*TRAX mobile treatment unit (MTU). The VAC*TRAX MTU uses an indirectly heated, batch vacuum dryer to thermally desorb organic compounds. The objective of this report is to demonstrate that a thorough assessment of the risks associated with the operation of the VAC*TRAX MTU has been performed and documented.

\section{2 \\ $\mathrm{V} 18 / 021323$}

VAC*TRAX Puts the Heat on Mixed Waste

Rust Federal Services, Inc., Grand Junction, $\mathrm{CO}$

Initiatives in Environmental Technology Investment 3(April 1996):8-9 (April 1996)

The U.S. Department of Energy facility operated by Rust Geotech Inc. in Grand Junction, Colorado is building a large-scale VAC*TRAX vacuum dryer unit for testing by mid-1996. The VAC*TRAX technology was developed by Rust Federal Services Inc. at the Clemson Technical Center in South Carolina under a 1992 Announcement issued by the DOE Office of Science and Technology. VAC*TRAX separates contaminants such as semivolatile and volatile organic compounds, polychlorinated biphenyls, and radioactive materials from soils, sludges, and solid trash. The products of the VAC*TRAX treatment are then ready for further treatment or disposal. The system is still in the demonstration stage. Several pilot tests using small-scale units have been successfully performed at DOE sites, such as Rocky Plats Environmental Technology Site.

\section{$2423 \quad$ V18/025532}

\section{VETEM: A Very Early Time Electromagnetic System -} Year 2

Pellerin, L.; Pfeifer, M.C.; Labson, V.F.

Lawrence Berkeley National Laboratory, Berkeley, CA; Idaho National Engineering Laboratory, Idaho Falls, ID; U.S. Geological Survey, Denver, CO

CONF-960804 (Vol. 2); Spectrum '96: Nuclear and Hazardous Waste Management, Proceedings of an International Topical Meeting, Seattle, WA, August 18-23, 1996. American Nuclear Society, La Grange Park, II, Vol. 2, 873 pp.; (pp. 1243-1248) (1996)

The Very Eariy Time Electromagnetic (VETEM) system is designed to ascertain the conductivity and dielectric properties of the shallow subsurface in conductive terrains. Hence, the one-dimensional (1-D) and three-dimensional (3-D) numerical modeling algorithms, developed in the first year of the project, contain the full solution to the EM problem including both displacement and conduction currents. The VETEM system fills a gap between electromagnetics (EM) and ground penetrating radar (GPR), but all three methods are necessary to successfully image the shallow subsurface. To achieve the goal of fully 3-D subsurface imaging, the VETEM project is hosting the Electromagnetic Integrated Demonstration (EMID) at the Idaho National Engineering Laboratory's Cold Test Pit (INEL's CTP). Over a dozen EM systems will acquire data over the same 
survey area for interpretation in conjunction with the VETEM team. The prototype time-domain instrument employs a magnetic dipole transmitter and receiver and operates from 10 nano-second to a micro-second. The USGS high frequency sounder (HFS), which served as the VETEM proof-of-concept, uses the same antenna geometry as the time-domain instrument and acquires data from 30 $\mathrm{kHz}$ to $30 \mathrm{MHZ}$. The first VETEM survey was recently conducted at the INEL's CTP as a part of the EMID. The electromagnetic migration technique is being investigated for interpretation of the VETEM data.

\section{4}

\section{V18/022463}

Valuing the Promise of Innovative Technology: Estimating Savings in the Environmental Restoration Program

Dahling, $P$.

Project Performance Corporation, Sterling, VA CONF-950868; ER '95: Committed to Results, Proceedings of a U.S. Department of Energy Environmental Remediation Conference, Denver, CO, August 13-18, 1995; (11 pp.) (1995)

The mission of the Office of Environmental Restoration (EM-40) in the U.S. Department of Energy (DOE) is to characterize and address environmental contamination problems primarily created by 40 years of daily operation of the nuclear weapons manufacturing complex. These contamination problems range from large areas of contaminated soil or groundwater to thousands of containers of stored waste material. The projected cost of addressing these problems is indicative of the large number of individual, identifiable contamination problems and the technical complexity of addressing those problems. The 1995 Baseline Environmental Management Report (BEMR) (DOE/EM-0232) projected life cycle cost of the EM-40 program at $\$ 105$ billion (in constant 1995 dollars unadjusted for productivity), of which $\$ 71$ billion was for environmental remediation or decommissioning activities. The prospect of funding a program of this magnitude over the next 50 years led to increased efforts to identify opportunities for cost savings, including the application of innovative remediation technologies.

\section{5 \\ V18/022740}

Variable Geometry Truss Manipulators: A New Type of Robot for Site Inspection and Remediation

Naccarato, F.

Dynacon Enterprises, Limited, North York, Ontario, Canada CONF-960804 (Vol. 2); Spectrum '96: Nuclear and Hazardous Waste Management Proceedings of an International Topical Meeting, Seattle, WA, August 18-23, 1996. American Nuclear Society, La Grange Park, II, Vol. 2, 873 pp.; (pp. 907-914) (1996)

A new type of robotic manipulator has been developed that offers many potential advantages over conventional robot arms for site inspection and remediation. This new robot is based on the variable geometry truss manipulator (VGTM) concept which combines the structural properties of a truss with the dexterous capabilities of a manipulator. By substituting linear actuators for some of the fixed-length members within a truss, the structure can be made to change its overall shape. By coordinating the motion of these actuators appropriately, a VGTM can perform tasks that are relevant to hazardous waste clean-up, including deployment through curved ducts, probing into crevices and obstacle avoidance. Trussarm [TM], a prototype VGTM with twelve degrees-of-freedom, has been constructed by Dynacon Enterprises Limited.

\section{$2426 \quad$ V18/021035}

Velocity and Attenuation Effects in Acoustic Wave Chemical Sensors

Frye, G.C.; Martin, S.J.

Sandia National Laboratories, Microsensor Research and Development, Albuquerque, NM

CONF-931045; Proceedings of an Ultrasonics Symposium, Baitimore, MD, October 31-November 3, 1993, Institute of Electrical and Electronic Engineers, Piscataway, NJ, 1650 pp.; (pp. 379-383) (1993)

A variety of chemical sensors have been developed using surface acoustic wave (SAW) devices coated with sorptive films. Chemical update into the coating results in a change in the coating's physical properties. Typically, only the velocity response is used and responses are interpreted gravimetrically. Polymers are commonly used as the sorptive coatings due to the ease of forming thin films and to the wide range of chemical affinities that can be obtained. We have shown that viscoelastic properties play a significant role in polymer-coated SAW sensors, especially due to the onset of a film resonance when the inertial phase lag across the film approaches pi/2. This film resonance causes enhanced absorption of acoustic energy from the wave and a dramatic effect on device response. Based on understanding these acoustic wave/polymer film interactions and the resulting changes in both wave velocity and attenuation, device sensitivity can be significantly increased and the ability to utilize both responses to discriminate between isolated chemical species with a single SAW device can be improved.

\section{7 \\ V18/022012}

Waste Destruction with $500 \mathrm{~kW}$ Three Phase AC Plasma Torch

Polovtsev, I.S.

Scientific Utilization, Inc., Decatur, AL

CONF-9510125 (Vol. 2); Plasma Systems and Applications, P.W. Mayne and J.A. Mulholland (eds.), Proceedings of an Intemational Symposium on Environmental Technologies, Atlanta, GA, October 8-11, 1995. Georgia Institute of Technology, Atlanta, GA, Vol. 2, 392 pp.; (pp. 355-361) (1995)

Experiments for gas destruction with the help of the new three phase AC plasma generator were performed. Advantages of the new type plasma generator were studied. It was shown that this generator can be successfully used for destruction of hazardous waste. Tests of methane, freon and malathion destruction were performed. Results of the tests shows complete destruction of the injected gases.

2428

V18/022895

Western Environmental Technology Office (WETO), Butte, Montana: Technology Summary

Western Environmental Technology Office, Butte, MT 
DOE/EM-0278; 61 pp. (March 1996)

OST manages an aggressive national program for applied research, development, demonstration, testing and evaluation (RDDT\&E). This program develops high-payoff innovative technologies to clean up the inventory of DOE nuclear component manufacturing sites and to manage DOE-generated waste faster, safer, and cheaper than current, or baseline, environmental cleanup technologies. OST programs are designed to make new, innovative, and more effective technologies available for transfer to potential users through progressive development. Technologies are demonstrated, tested, and evaluated in an effort to produce effective solutions to current problems. The transition of technologies into more advanced stages of development is based upon stringent technological, regulatory, economic, and institutional criteria. New technologies are made available for use in eliminating radioactive, hazardous, and other wastes in compliance with regulatory mandates. The main goal is to protect human health and prevent further contamination. OST technologies focus on three principal areas: (1) groundwater and soils cleanup, (2) waste retrieval and processing, and (3) pollution prevention. These problems are not unique to DOE, but are also associated with other Federal agency and industry sites. Thus, technical solutions developed within OST programs will benefit DOE and should offer applications to outside markets. This document has been prepared to highlight these activities. The information presented in this document has been assembled from recently produced OST documents that highlight technology development activities within each of the OST program elements and Focus Areas.

\section{9 \\ V18/025531}

Westinghouse Savannah River Site Vendor Forum: An Innovative Cooperative Technology Development Success

Sturm, H.F., Jr.

Westinghouse Savannah River Company, Aiken, SC

CONF-960804 (Vol. 2); Spectrum '96: Nuclear and Hazardous Waste Management, Proceedings of an International Topical Meeting, Seattle, WA, August 18-23, 1996. American Nuclear Society, La Grange Park, IL, Vol. 2, 873 pp.; (pp. 1457-1464) (1996)

The Westinghouse Savannah River Company (WSRC) Supplier Environmental and Waste Management Information Exchange Fonum was held August 31 -September 1, 1993. The forum, which was planned and conducted in concert with the Department of Energy Savannah River Operations Office (DOE-SROO), was held to foster a technical exchange in which new, innovative technologies were proposed by suppliers, to identify more cost-effective methods to apply to future and on-going activities, to increase use of the private sector, and to promote partnerships with other industries. The two day forum provided the opportunity for WSRC and DOE-SR to review program activities and challenges in five major areas. Each attendee was then invited to submit pre-proposals relative to the abstracts presented in The Special Consolidated Solicitation for Environmental and Waste Management Basic and Applied Research and Research-Related Development and/or Demonstration No. E10600-E1 document. Twenty-five contracts totaling $\$ 12$ million were awarded. Twenty-four contracts have now been completed. This paper provides an overview of the pre-forum activities, the forum, post-forum and proposal review process, and most importantly a description of the technologies demonstrated, the benefits and savings derived, and future use potential from a DOE perspective, as well as technology transfer and industrial partnership potential.

2430

V18/021389

What It Will Take to Have Client "Buy-In" on Deploying Innovative Cleanup Technologies: A Client's Perspective

Owendoff, J.M.

U.S. Department of Energy, Office of Environmental Restoration, Washington, DC

Fostering the Needed Partnerships: Doing the Necessary Science to Support Technology Development, Commercialization, Deployment, E.L. Helminski (ed.), Proceedings of the Seventh Annual Westem Govemors' Association/Weapons Complex Monitor Applied Research and Cleanup Technology Colloquium, Phoenix, AZ, April 29-May 2, 1996. Exchange/Monitor Publications and Forums, Lake Bluff, II, 500 pp.; (5 pp.) (April 1996)

These viewgraphs and outline highlight the major topics covered in this discussion which was the keynote address at the conference. Topics include: Resolving problems through technology screening; Gathering and consolidating data; Screening technologies and results; Implementation analysis; Technology acquisition strategy; and Environmental restoration technology implementation goals.

2431

V18/021397

What are the Unsolved Problems in Site Characterization?

Purdy, C.B.

U.S. Department of Energy, Office of Environmental Management, Office of Science and Technology, Washington, DC

Fostering the Needed Partnerships: Doing the Necessary Science to Support Technology Development, Commercialization, Deployment, E.L. Helminski (ed.), Proceedings of the Seventh Annual Western Governors' Association/Weapons Complex Monitor Applied Research and Cleanup Technology Colloquium, Phoenix, AZ, April 29-May 2, 1996. Exchange/Monitor Publications and Forums, Lake Bluff, IL, 500 pp.; (20 pp.) (April 1996)

This presentation explores the development of site characterization procedures and technologies. It provides background information on the characterization program and delineates the changing history of the program. Old methods are compared with new methods in the areas of field geosciences, field analytics, subsurface monitors and field work-plan flexibility. Ongoing challenges are identified and DOE efforts in promoting the development and utilization of new technologies are discussed. 


\section{SOIL REMEDIATION}


- .....

. 
2432

V18/021000

\section{Biodegradation of Oil Refinery Wastes Under OPA and CERCLA}

Banipal, B.S.; Myers, J.M.; Fisher, C.W.

Ecology and Environment, Inc., Dallas, TX; U.S.

Environmental Protection Agency, Dallas, TX

CONF-951139 (Vol. 2); Superfund 16: Proceedings of a Hazardous Waste Conference and Exhibition, Washington, DC, November 6-8, 1995. E.J. Krause and Associates, Bethesda, MD, Vol. 2, 817 pp.; (pp. 1028-1035) (1995)

Land treatment of oil refinery wastes has been used as a disposal method for decades, More recently, numerous laboratory studies have been performed attempting to quantify degradation rates of more toxic polycyclic aromatic hydrocarbon compounds (PAHs). This paper discusses the results of the full-scale aerobic biodegradation operations using land treatment at the Macmillan Ring-Free Oil refining facility. The tiered feasibility approach in the evaluation of using biodegradation as a treatment method to achieve site-specific cleanup criteria including pilot scale biodegradation operations is included in an earlier paper. Analytical results of biodegradation indicate that degradation rates observed in the laboratory can be met and exceeded under field conditions and that the site-specific cleanup criteria can be attained within a proposed project time. Also presented are degradation rates and half-lives for PAHs for which cleanup criteria has been established. PAH degradation rates and half-life values are determined and compared with the laboratory degradation rates and half-life values which used similar oil refinery wastes by other investigators.

2433

V18/023905

Insitu Bioremediation Under High Saline Conditions

Bosshard, B.; Raumin, J.; Saurohan, B.

Kleinfelder, Inc., San Diego, CA; Bechtel National, Inc., San Diego, CA

CONF-951124; HazMat West '95, Proceedings of the Eleventh Annual Environmental Management and Technology Conference and Exhibition, Long Beach, CA, November 7-9, 1995. Advanstar Expositions, Duluth, MN, 597 pp.; (pp. 421-444) (1995)

An in situ bioremediation treatability study is in progress at the Salton Sea Test Base (SSTB) under the NAVY CLEAN 2 contract. The site is located in the vicinity of the Salon Sea with expected groundwater saline levels of up to $50,000 \mathrm{ppm}$. The site is contaminated with diesel, gasoline and fuel oils. The treatability study is assessing the use of indigenous heterotrophic bacteria to remediate petroleum hydrocarbons. Low levels of significant macro nutrients indicate that nutrient addition of metabolic nitrogen and Orthophosphate are necessary to promote the process, requiring unique nutrient addition schemes. Groundwater major ion chemistry indicates that precipitation of calcium phosphorus compounds may be stimulated by air-sparging operations and nutrient addition, which has mandated the remedial system to include pneumatic fracturing as an option. This presentation is tailored at an introductory level to in situ bioremediation technologies, with some emphasis on innovations in sparge air delivery, dissolved oxygen uptake rates, nutrient delivery, and pneumatic fracturing that should keep the expert's interest.

\section{$2434 \quad$ V18/022063}

Study to Assess the Applicability of Particle-Size Separation Technology to the Remediation of Hunter's Point Annex: Parcel E Contaminated with Radium-226 Luminous Sources

Richardson, W.S., III; Phillips, C.R.; Burchett, R.T.; Dean, S.M.; Cox, C.; Lloyd, V.D.

Sanford Cohen \& Associates, Inc., Montgomery, AL; U.S. Environmental Protection Agency, San Francisco, CA; U.S. Environmental Protection Agency, Montgomery, AI

CONF-941148 (Vol. 2); DDER-'94: Decommissioning, Decontamination, and Environmental Restoration at Contaminated Nuclear Sites, M.G. White (ed.), Proceedings of an Embedded Topical Symposium of the American Nuclear Society Winter Meeting, Washington, DC, November 13-18, 1994. American Nuclear Society, Inc., La Grange Park, IL, Vol. 2, 241 pp.; (pp. 314-320) (1994)

A preliminary treatability study was conducted to assess the applicability of particle-size separation technology to the remediation of the Hunter's Point Annex, Parcel E site where radium-226 luminous sources were disposed. Three soil samples ( $A$, $B$, and $C$ ) were studied to determine their radionuclide content and particle-size and radionuclide distributions. After examination of the results from those samples, ten more samples (D-M) were collected for study to obtain a better understanding of the distribution of radium-226 in the soil particle-sizes, determine if large radium-226 sources or their fragments are present among the soil particles, and determine if significant contamination is present in soil away from the immediate source location. Results show that eight of the ten samples that were collected away from a source contain background concentrations of radium-226, indicating they may represent a significant volume of the soil at the Parcel E site. Remediation of the site might be accomplished, therefore, by selective removal of soil in the vicinity of identifiable sources. Overall, the limited number of samples considered in these studies suggest that a significant volume of the Hunter's Point Annex, Parcel E site could potentially be remediated by a combination of selective removal of soil in the vicinity of identifiable sources and removal of the source from the soil by particle-size separation.

2435

V18/020966

Advances in Soil Decontamination Methods for Rocky Flats Soils

Kochen, R.L.; Navratil, J.D.

Rust Federal Services, Inc., Golden, CO

CONF-960212; Waste Management '96: Working Towards a Cleaner Environment, Proceedings of a Conference on HLW, LLW, Mixed Wastes and Environmental Restoration, Tucson, AZ, February 25-29, 1996; (9 pp.) (1996)

Improved separation methods are needed to remove contaminants selectively and efficiently from soils at the Rocky Flats Environmental Technology Site (RFETS). The methods must meet appropriate state and federal regulations for residual contaminant concentrations, and to minimize waste generation, the radioactive contaminants need to be incorporated in as small a waste volume as 
possible. To meet these needs, advances have been made for decontaminating soils at the RFETS. Based on recent decontamination studies with Rocky Flats (RF) soils, the americium and plutonium in the greater than 0.5 -millimeter soil fraction (greater than $90 \mathrm{wt}$ \%) can be lowered to less than 5 picocuries per gram of soil via wet sieving/size separation and rotary scrubbing/soil dispersion. The benefit of utilizing established wet screening technology is high volume soil decontamination. The contaminated fine fraction (clays) can be treated to further reduce the volume of contaminated soil.

\section{6}

V18/020956

Valuation of Solvent Extraction for Removal of Radionuclides from Soil and Vegetation

Armstead, C.E.; Riese, A.C.; Weimer, L.D.

Harding Lawson Associates, Denver, CO; Resources Conservation Company, Ellicott City, MD

CONF-960212; Waste Management '96: Working Towards a Cleaner Environment, Proceedings of a Conference on $\mathrm{HLW}$, LLW, Mixed Wastes and Environmental Restoration, Tucson, AZ, February 25-29, 1996; (20 pp.) (1996)

A solvent extraction bench-scale treatability study was performed for the U.S. Department of Energy (DOE) Rocky Flats Environmental Technology Site (RFETS) in Golden, Colorado by Resources Conservation Company (IONICS RCC) and Harding Lawson Associates (HLA) using IONIC RCC's patented Basic Extraction Solvent Technology (B.E.S.T. [R]) and additional process technologies for which patents are pending. The bench-scale treatability study was performed in two phases. Each phase was designed to address feasibility study data needs regarding the effectiveness of solvent extraction to remove radionuclides from RFETS soil and vegetation. Two surficial soil samples and one vegetation sample were collected from three separate areas downgradient of the 903 pad in Operable Unit Number 2 (OU 2). Before treatment, soil sample No. 1, soil sample No. 2, and the vegetation sample contained the following plutonium concentrations: 740 picocuries per gram ( $\mathrm{pCi} / \mathrm{g}), 1200 \mathrm{pCi} / \mathrm{g}$, and $640 \mathrm{pCi} / \mathrm{g}$, respectively. During the time this treatability study was performed, cleanup levels were not yet established. Therefore, the effectiveness of this technology was primarily evaluated on the basis of the percent of total plutonium-239 and plutonium-240 removed from each soil and vegetation sample following treatment. The most favorable results of the bench-scale study showed plutonium concentrations in soil sample No. 1, soil sample No. 2, and the vegetation sample were reduced to $83 \mathrm{pCi} / \mathrm{g}(89$ percent removed), $102 \mathrm{pCi} / \mathrm{g}$ ( 92 percent removed), and $23 \mathrm{pCi} / \mathrm{g}$ (97 percent removed), respectively. The plutonium was concentrated in a residual solvent sidestream that was estimated to be a small fraction of the original contaminated soil and vegetation sample weight. The success of the bench-scale treatability study indicates that plutonium can be removed from RFETS soil and vegetation effectively. After cleanup goals for the radionuclides have been established, a pilot-scale study should be performed to refine the process parameters and costs for full-scale application.
Gianotto, D.F.; Anderson, I.R.

Idaho National Engineering Laboratory, Idaho Falls, ID INEL-95/00040; CONF-950209 (Vol. 2); VIP-47, Proceedings of the Fourth International Symposium on Field Screening Methods for Hazardous Wastes and Toxic Chemicals, Las Vegas, NV, February 22-24, 1995. Air and Waste Management Association, Pittsburgh, PA, Vol. 2, 701 pp.; (10 pp.) (February 1995)

Use of an X-ray fluorescence spectrometer was used in a multiphased approach to analyze soil samples for lead contamination. The objectives of this investigation were to characterize the spatial distribution of lead contamination, identify soil areas with elevated lead concentrations (hot-spots), and quantify subsurface soil contamination at the hot-spots to evaluate the vertical migration of lead. Phase I consisted of using non-site-specific standards to calibrate the XRF instrument to qualitatively and semi-quantitatively assess lead contamination (Type I XRF analysis). Phase II involved selecting soil samples for off-site SW-846 analysis and using the results to develop a calibration model based on site-specific calibration standards (SSCS). The XRF was used in Phase III to obtained quantitative results (Type II XRF analysis).

\section{8}

\section{V18/023660}

Verifying the Integrity of Annular and Back-filled Seals for Vadose-Zone Monitoring Wells

Dunnivant, F.M.; Porro, I.; Bishop, C.; Hubbell, J.M.; Giles, J.R.; Newman, M.E.

Idaho National Engineering Laboratory, Integrated Earth Sciences Group, Idaho Falls, D

Groundwater 35(1):140-148 (January-February 1997)

Monitoring the movement of contaminants throughout the vadose zone requires the use of wells, and the credibility of a monitoring program depends on obtaining an adequate seal between the well casing and borehole wall. The credibility of monitoring well installation was evaluated during the Idaho National Engineering Laboratory's Large Scale Pumping and Infiltration Test. Wells were drilled in and around a 6.5 acre infiltration basin with an air rotary rig using a downhole hammer, cased with polyvinyl chloride (PVC) or steel, and the annual space back-filled with alternating layers of bentonite and sand. The purpose of completing the wells in this manner was to isolate fractured intervals (subvertical and subhorizontal interflow zones) in order to observe water movement during the infiltration test. Bentonite was used between sand intervals to prevent the borehole (or annular space) from serving as a conduit for vertical water flow or tracer migration. Neutron probes were used to confirm the presence and locations of each completion interval (sand or bentonite) by distinguishing differences in background-water content of the back-filling materials. Upon flooding of the infiltration basin with water containing radioactive tracers, water flow and tracer transport were monitored using neutron probes and an in situ, downhole gamma spectroscopy system, respectively. Results confirm that each well was installed correctly; water and tracers flowed through natural fractures in the subsurface and arived at the monitoring sites located at sand completion zones. Significant water or tracer flow through the annular space between the well casing and borehole was not observed. 
2439

V18/025406

Engineered Barrier for the Stationary Low-Power Reactor No. 1 Burial Ground

Hiaring, C.M.; Jorgensen, D.K.; Rothermel, J.S.; Cotten, G.B.

Lockheed Martin Idaho Technologies Company, Idaho Falls, ID; Parsons Infrastructure \& Technology Group, Inc., Idaho Falls, ID

CONF-970335; Waste Management '97: Working Towards a Cleaner Environment, Proceedings of a Conference on $\mathrm{HLW}$, LLW, Mixed Wastes and Environmental Restoration, Tucson, AZ, March 2-6, 1997; (9 pp.) (1997)

The SL-1 burial ground at the Department of Energy (DOE) Idaho National Engineering Laboratory was constructed in 1961 to dispose of radioactively-contaminated debris, soils, and gravel generated by the destruction of a small nuclear reactor. The INEL was officially placed on the National Priorities List in November 1989. Consequently, remediation of the SL-1 burial ground falls under the purview of Comprehensive Environmental Response, Compensation, and Liability Act (CERCLA). The SL-1 burial ground consists of three excavations, in which a total volume of 99,000 cubic feet of contaminated material was deposited. The excavations ranged from 8 to 14 feet in depth, and at least 2 feet of clean backfill was placed over each excavation. Shallow mounds of soil over the excavations were added at the completion of cleanup activities in September 1962. Results of the baseline risk assessment indicate that the direct human exposure pathway dominates the overall risk for the burial grounds. The primary contributor to this risk is cesium-137 and its progeny. Based upon consideration of the requirements of CERCLA, on detailed analysis, and on public comments, the DOE, and the Environmental Protection Agency (EPA), and the State of Idaho have selected containment by capping with an engineered long-term barrier comprised primarily of natural materials as the preferred alternative. The cover will be designed to maintain effective long-term isolation of contaminants. The number and thickness of layers designed in the cover were dependent on local climatic and geographic conditions, including precipitation rate, freeze depth, indigenous plant and animal species, and local topography. The engineered lifetime of the cap is a minimum of 400 years. Surface water diversion measures, including contouring and grading, will be used as necessary to direct runoff away from the burial ground and into nearby naturally-occurring drainage formations.

2440 V18/022652

Insitu Decontamination of Sand and Gravel Aquifers by Chemically Enhanced Solubilization of Multiple-Component DNAPLs with Surfactant Solutions: Topical Report

INTERA, Inc., Austin, TX

DOE/MC/29111-5247; 190 pp. (January 1995)

Laboratory, numerical simulation, and field studies have been conducted to assess the potential use of micellar-surfactant solutions to solubilize chlorinated solvents contaminating sand and gravel aquifers. Laboratory studies were conducted at the State University of New York at Buffalo (SUNY), while numerical simulation and field work were undertaken by INTERA Inc. in collaboration with Martin Marietta Energy Systems Inc. at the Paducah Gaseous Diffusion Plant (PGDP) in Kentucky. Ninety-nine surfactants were screened for their ability to solubilize trichloroethene (TCE), perchloroethylene (PCE), and carbon tetrachloride (CTET). Ten of these were capable of solubilizing TCE to concentrations greater than $15,000 \mathrm{mg} / \mathrm{L}$, compared to its aqueous solubility of 1,100 $\mathrm{mg} / \mathrm{L}$. Four surfactants were identified as good solubilizers of all three chlorinated solvents. Of these, a secondary alcohol ethoxylate was the first choice for in situ testing because of its excellent solubilizing ability and its low propensity to sorb. However, this surfactant did not meet the Commonwealth of Kentucky's acceptance criteria. Consequently, it was decided to use a surfactant approved for use by the Food and Drug Administration as a food-grade additive. As a $1 \%$ micellar-surfactant solution, this sorbitan monooleate has a solubilization capacity of $16,000 \mathrm{mg}$ $\mathrm{TCE} / \mathrm{L}$, but has a higher propensity to sorb to clays than has the alcohol ethoxylate.

2441 V18/022000

Chelant Extraction and "Redox" Manipulation for Remediation of Heavy Metal Contaminated Soils

Peters, R.W.; Li, W.; Miller, G.; Patton, T.L.; Martino, L.E. Argonne National Laboratory, Argonne, IL CONF-9509139; Emerging Technologies in Hazardous Waste Management VII, D.W. Tedder (ed.), Proceedings of the Seventh American Chemical Society Industrial and Engineering Chemıstry Division Special Symposium, Atlanta, GA, September 17-20, 1995. American Chemical Society, Washington, DC, 1291 pp.: (pp 1125-1128) (1995)

The Toxic Burning Pits at J-Field on the Gunpowder Neck Peninsula at the Aberdeen Proving Ground, Maryland, were used to dispose of munitions, explosives, nerve and chemical agents, mustard gas, liquid smoke, chlorinated solvents, and radioactive chemicals. From soil gas measurements collected between 1987 and 1992 by the U.S. Geological Survey, contaminants identified included trichloroethylene, tetrachloroethylene, dichloroethylene, trichloroethane, phthalates, combined hydrocarbons, simple aromatics, and heavy aromatic hydrocarbons. The surface soil contained elevated levels of heavy metals, especially lead (up to 2.6 percent in places), mercury (up to $10 \mathrm{mg} / \mathrm{kg}$ ), and cadmium (up to $16.6 \mathrm{mg} / \mathrm{kg}$ ). Other contaminants include PCBs (up to $143,000 \mathrm{mu}$ $\mathrm{g} / \mathrm{kg}$ ), 1,1,2,2-tetrachloroethane (up to 3,270,000 $\mathrm{mu} \mathrm{g} / \mathrm{kg}$ ), and trichloroethene (up to $263,000 \mathrm{mu} \mathrm{g} / \mathrm{kg}$ ). The highest level of organic compounds were found at a depth of $6 \mathrm{ft}$. Argonne National Laboratory is conducting a Focused Feasibility Study to identify and evaluate remedial technologies that may be implemented to address contamination at the Toxic Buming Pits area. Several treatability studies were performed to collect additional data on potential technologies and determine their applicability on conditions specific to the TBP area.

\section{$2442 \quad$ V18/022773}

Soil Surface Stabilization Using an Insitu Plutonium Coating Technique at the Nevada Test Site

Lew, J.Y.; Snipes, R.; Tamura, T.

Lockheed Martin Energy Systems, Inc., Hazardous Waste 
Remedial Actions Program, Oak Ridge, TN

CONF-960804 (Vol. 2); Spectrum '96: Nuclear and Hazardous Waste Management, Proceedings of an International Topical Meeting, Seattle, WA, August 18-23, 1996. American Nuclear Society, La Grange Park, IL, Vol. 2, 873 pp.; (pp. 1275-1279) (1996)

The Hazardous Waste Remedial Actions Program (HAZWRAP), in collaboration with the University of Nevada at Reno (UNR), has developed and is investigating an in situ plutonium treatment for soils at the Nevada Test Site (NTS). The concept, conceived by Dr. $T$. Tamura and refined at HAZWRAP, was developed during the Nevada Applied Ecology Program investigation. In analyzing for plutonium in soils, it was noted that the aipha emanation of plutonium was greatly attenuated if traces of iron or manganese oxides were present in the final electroplating stage. The technique would reduce resuspension of alpha particles into the air by coating the contaminants in soils in situ with an environmentally compatible, durable, and nontoxic material. The coating materials reduce resuspension by providing a cementitious barrier against radiation penetration while retaining soil porosity. This technique not only stabilizes plutonium-contaminated soils, but also provides an additional protection from worker exposure to radiation during remediation activities. Additionally, the coating would decrease the water solubility of the contaminant and, thus, reduce its migration through soil and uptake by plants.

\section{$2443 \quad$ VI8/022203}

Insitu Electrical Heating for the Decontamination of Soil

Dev, H.; Phelan, J.M.

IIT Research Institute, Chicago, IL; Sandia National

Laboratories, Albuquerque, NM

CONF-960426; Proceedings of the 58th Annual Meeting of the American Power Conference, A.E. McBride (ed.), Chicago, $\mathbb{L}$, April 9-11, 1996. American Power Conference, Chicago, IL, Vol. 58-I, 767 pp.; (pp. 337-341) (1996)

Clean up of soil contaminated with hazardous organic substances is a common challenge faced by the environmental engineering profession. Two broad categories of organic chemicals are found in soil: low boiling volatile chemicais, many of which are chlorinated solvents; and heavier boiling hydrocarbons of various types that include fuels, manufactured gas plant (MGP) site wastes (including creosote, phenols, and polyaromatic hydrocarbons). Traditional methods of clean up have involved excavation of the contaminated soil followed by reburial in an approved landfill or high temperature incineration. In recent years new technologies have been developed for the in-situ treatment of the contaminated soil with minimal or no excavation. One process is called the in-situ radio frequency (RF) heating process which utilizes electromagnetic energy in the 2 to 13 MHz frequency range to heat soil to a temperature of 100 to 300 degrees $\mathrm{C}$. A second process utilizes $60 \mathrm{~Hz}$ ac power to heat soil up to the boiling point of water. The low frequency process is called the in-situ EM heating process. The RF process is aimed at the removal of high boiling chemicals in the unsaturated soil zone (the vadose zone) above the water table. The EM process is suitable when the soil contains VOCs in the vadose zone. Both processes can be used to increase the effective permeability of the soil to the flow of air. Thus, both can be used to enhance air flow rates through soils with low native permeability to air. The above processes were tested in a field experiment in which the Thermal Enhanced Vapor Extraction System was implemented at a chemical waste landfill located at Sandia National Laboratory, Albuquerque. The purpose of this test was to measure the enhancement of in-situ soil vapor extraction as a result of heating arid sandy silt. In this paper the Thermal Enhanced Vapor Extraction System is described along with the results of its field demonstration.

\section{$2444 \quad$ V18/022678}

Air Permeability Profiling of a Deep Vadose Zone Phelan, J.M.

Sandia National Laboratories, Albuquerque, NM

CONF-941124; Insitu Remediation: Scientific Basis for Current and Future Technologies, G.W. Gee and N.R. Wing (eds.), Proceedings of the 33rd Hanford Symposium on Health and the Environment, Pasco, WA, November 7-11, 1994. Battelle Press, Columbus, OH, Part 2, 605 pp.; (pp. 1155-1177) (1994)

The disposal of liquid organic solvents in unlined pits at the Sandia National Laboratories' Chemical Waste Landfill (CWL) has created an organic solvent vapor plume in the subsurface soils. Field measurements of air permeability in alluvial sediments over a 100 -ft-depth interval show a large variability, depending on the physical measurement. Five boreholes within a $10-\mathrm{m}$ radius were used to obtain air-permeability measurements using four different measurement techniques. A borehole membrane deployed method was used to obtain discrete zone measurements; a prototype borehole anemometer was used to evaluate air producing zones and infer air permeability; a straddle packer assembly was used to log the boreholes; and a large-scale transient drawdown test was performed. Steady-state and transient analytical solutions were used to estimate air-permeability values for each field measurement. The differences in measurement scale have a significant influence on the magnitude of the air-permeability value. It is hypothesized that the larger-scale measurements are dominated by the larger air-permeability pathways, and small, low-permeability regions are not identified. An order-of-magnitude change in low-permeability to high-permeability regions has implications for the ability of long screened vapor-extraction wells to adequately remove vapor-phase contamination. Without recognizing the heterogeneous nature of alluvial deposits, the analogous misfortunes of failed pump-and-treat remedial measures may be mirrored in vacuum vapor extraction systems.

2445 V18/022674

Similar-Media Scaling and Geostatistical Analysis of Soil Hydraulic Properties

Rockhold, M.L.; Rossi, R.E.; Gee, G.W.; Hills, R.G.

Pacific Northwest Laboratory, Earth and Environmental Sciences Center, Richland, WA; New Mexico State University, Department of Mechanical Engineering, Las Cruces, NM

CONF-941124; Insitu Remediation: Scientific Basis for Current and Future Technologies, G.W. Gee and N.R. Wing (eds.), Proceedings of the 33rd Hanford Symposium on Health and the Environment, Pasco, WA, November 7-11, 1994. Battelle Press, Columbus, OH, 
Part 2, 605 pp.; (pp. 1099-1129) (1994)

Similar-media scaling and geostatistical analyses are used to characterize the spatial variability of soil hydraulic properties at the Las Cruces Trench Site in New Mexico. Laboratory measurements of soil-water retention characteristics from 448 core samples are scaled and coalesced into an average or scale-mean curve. A reduction in the sum of squares for error in the fitted water retention function of over $50 \%$ is achieved. The spatial structure of the hydraulic properties is analyzed using scaling factors determined from water retention and in-situ hydraulic conductivity data. The two sets of scaling factors are shown to be spatially correlated over significant distances. A new method is described for conditioning the hydraulic properties used for unsaturated water flow and solute transport modeling, based on the spatial distributions of initial field-measured water contents and a set of scale-mean hydraulic parameters. This method is used to estimate hydraulic properties for numerical simulations of the latest field-scale water flow and solute transport experiment conducted at the Las Cruces Trench Site. Relatively good matches between the observed and simulated flow and transport behavior are obtained without model calibration. These resuits suggest that using similar-media scaling in conjunction with the described conditioning procedure could change the problem of simulating unsaturated flow and solute transport at the field scale from a stochastic to a more deterministic one.

2446 V18/025599

Vapor Extraction, Air Sparging, and Bioventing in Combination to Form a Technically and Cost Effective Scenario to Remediate Petroleum Hydrocarbons

Brown, D.A.; Baker, J.N.; Mailloux, M.P.

P.G. Parsons Engineering Science, Inc., Liverpool, NY; Chevron U.S.A. Products Company, Inc., Atlanta, GA; Department of the Environment, Environmental Protection Service, Ottawa, Ontario, Canada

CONF-951086; Proceedings of the Fifth Annual Symposium on Groundwater and Soil Remediation, Toronto, Ontario, Canada, October 2-6, 1995. Environment Canada - Environmental Protection Service, Hull, Quebec, Canada, 566 pp.; (p. 509) (1995)

Petroleum hydrocarbon-contaminated soil remediation at the former Gulf Terminal in Johnson City, NY, is described. Air sparging, vapor extraction, and bioventing were used in combination to accomplish the task. After a series of pilot studies with favorable results, the full-scale remediation system was installed in April 1995 to address both the vadose and phreatic zone contaminants. To date over 12,000 pounds of petroleum hydrocarbons, including 30 pounds of benzene, have been removed, at an estimated cost of $\$ 5.60$ per cubic yard.

2447

\section{V18/022446}

\section{Bench-Scale Solid Phase Biotreatment: Benfield}

Industries Superfund Site

Marlowe, M.W.; Harper, T.R.; Semenak, R.K.

Kiber Environmental Services, Inc., Atlanta, GA

CONF-951139 (Vol. 2); Superfund 16: Proceedings of a Hazardous Waste Conference and Exhibition, Washington, DC, November 6-8, 1995. E.J. Krause and Associates, Bethesda, MD, Vol. 2, 817 pp.; (pp. 1036-1043) (1995)

The Benfield Industries, Inc. Superfund site located in Hazelwood, North Carolina has been found to have approximately 15,000 cubic yards of polycyclic aromatic hydrocarbon (PAH) contaminated soil. Risk based clean up goals were specified at the site for eight target PAH compounds including benzo(a)anthracene, benzo(a)pyrene, benzo(b)fluoranthene, benzo(k)fluoranthene, chrysene, indeno(1,2,3-cd)pyrene, naphthalene, and pentachlorophenol. Treatability studies were performed to evaluate solid phase bioremediation, which includes exsitu and in-situ land treatment processes, for treatment of the site soil. All treatments were conducted using only indigenous microorganisms maintained under aerobic conditions. Two soil samples with different levels of PAH contamination were collected from the site for use in the treatability evaluations. The two soil samples were contaminated with total PAFs at concentrations of approximately 30 milligrams per kilogram (mg/kg) and $6000 \mathrm{mg} / \mathrm{kg}$, respectively. Three solid phase bioremediation studies were conducted over a one and one half year period using starting concentrations of total PAHs of approximately $30 ; 600$; and $6,000 \mathrm{mg} / \mathrm{kg}$. The objectives of the studies included the determination of: (1) if clean up goals could be achieved, (2) the approximate biodegradation rate of PAHs in the site soils, and (3) the optimum environmental conditions for biodegradation of the PAHs. Some of the environmental parameters which were varied during the testing included moisture levels, soil conditioners, nutrients and $\mathrm{pH}$. The results of the testing indicated that total and target PAHs can be reduced by up to 90 percent in less than $\mathbf{5 0}$ days, depending on environmental conditions maintained in the reactors. Clean up goals for all of the target compounds were achieved at some point during the study.

\section{8}

V18/022958

Soil Washing Treatability Study

Krstich, M.

Fernald Environmental Restoration Management Corporation, Cincinnati, $\mathrm{OH}$

FEMP-2504; 80 pp. (December 1995)

Soil washing was identified as a viable treatment process option for remediating soil at the FEMP Environmental Management Project (FEMP). Little information relative to the specific application and potential effectiveness of the soil washing process exists that applies to the types of soil at the FEMP. To properly evaluate this process option in conjunction with the ongoing FEMP Remedial Investigation/Feasibility Study (RI/FS), a treatability testing program was necessary to provide a foundation for a detailed technical evaluation of the viability of the process. The purpose of this treatability study was to generate data to support initial screening and the detailed analysis of alternatives for the Operable Unit 5 FS. The study consisted of a literature review followed by bench-scale and pilot-scale experiments.

\section{9 \\ V18/022917}

Saxton Soil Remediation Project

Holmes, R.D.

GPU Nuclear Corporation, Middletown, PA

CONF-951006; Proceedings of an American Nuclear Society (ANS) 
Winter Meeting, San Francisco, CA, October 29-November 1, 1995. ANS, La Grange Park, IL, 522 pp.; Transactions of the American Nuclear Society 73:59-60 (1995)

The Saxton Nuclear Experimental Facility (SNEF) consists of a 23-MW(thermal) pressurized light water thermal reactor located in south central Pennsylvania. The Saxton Nuclear Experimental Corporation (SNEC), a wholly owned subsidiary of the General Public Utilities (GPU) Corporation, is the licensee for the SNEF. Maintenance and decommissioning activities at the site are conducted by GPU Nuclear, also a GPU subsidiary and operator of the Three Mile Island and Oyster Creek nuclear facilities.

\section{0 \\ V18/022661}

Technologies for and Implementation of an Environmental Restoration Project in the Slovak Republic

Slavik, O.; Moravek, J.; Vladar, $M$.

Nuclear Power Plant Research Institute, Tmava, Slovakia; Research Institute of Preventive Medicine, Bratislava, Slovakia

Spravodajca -Vyskumny Ustav Jadrovych Elektrarni 12(1):13-23 (December 1995)

After completing monitoring activities at the contaminated site near the Bohunice Nuclear Power Plant, a need for reconsidering the old restoration project was recognized. For this task new principles for the evaluation of remedial measures were developed in close cooperation with the national hygiene authorities. These principles and the resulting evaluation of and proposal for a revised estimate of the extent of contaminated banks restoration are described. The re-evaluated extent of the banks restoration project includes removing and safe burial of about 1,100 cubic meters of contaminated soil and overlaying a clean soil cover on about 10,000 square meters of contaminated flat area on the banks. The total cost can be estimated by about US $\$ 100,000$. (This document is in Slovak).

\section{$2451 \quad$ V18/022217}

Bench-Scale Studies with Mercury Contaminated SRS Soil

Cicero, C.A.

Westinghouse Savannah River Company, Aiken, SC

WSRC-TR-95-0413; 24 pp. (1995)

Bench-scale studies with mercury contaminated soil were performed at the Savannah River Technical Center (SRTC) to determine the optimum waste loading obtainable in the glass product without sacrificing durability, leach resistance, and processability. Vitrifying this waste stream also required offgas treatment for the capture of the vaporized mercury. Four soil glasses with slight variations in composition were produced, which were capable of passing the Product Consistency Test (PCT) and the Toxicity Characteristic Leaching Procedure (TCLP). The optimum glass feed composition contained 60 weight percent soil and produced a soda-lime-silica glass when melted at $1,350 \mathrm{C}$. The glass additives used to produce this glass were 24 weight percent $\mathrm{Na} 2 \mathrm{CO} 3$ and 16 weight percent $\mathrm{CaCO3.} \mathrm{Volatilized} \mathrm{mercury} \mathrm{released} \mathrm{during} \mathrm{the} \mathrm{vitrification} \mathrm{process}$ was released to the proposed mercury collection system. The proposed mercury collection system consisted of quartz and silica tubing with a Na2S wash bottle followed by a $\mathrm{NaOH}$ wash bottle. Once in the system, the volatile mercury would pass through the wash bottle containing Na2S, where it would be converted to $\mathrm{Hg} 2 \mathrm{~S}$, which is a stable form of mercury. However, attempts to capture the volatilized mercury in a Na2S solution wash bottle were not as successful as anticipated. Maximum mercury captured was only about $3.24 \%$ of the mercury contained in the feed. Mercury capture efforts then shifted to condensing and capturing the volatilized mercury. These attempts were much more successful at capturing the volatile mercury, with a capture efficiency of $34.24 \%$ when dry ice was used to pack the condenser. This captured mercury was treated on a mercury specific resin after digestion of the volatilized mercury.

\section{$2452 \quad V 18 / 023481$}

Bench-Scale Studies with Mercury Contaminated Savannah River Site (SRS) Soil

Cicero, C.A.

Westinghouse Savannah River Company, Aiken, SC WSRC-MS-96-0413; 24 pp. (May 8, 1996)

The Savannah River Technology Center (SRTC) has been chartered by the Department of Energy (DOE) - Office of Technology Development (OTD) to investigate vitrification technology for the treatment of Low Level Mixed Wastes (LLMW). In fiscal year 1995, LLW streams containing mercury and organics were targeted. This report will present the resuits of studies with mercury contaminated waste. In order to successfully apply vitrification technology to LLMW, the types and quantities of glass forming additives necessary for producing homogeneous glasses from the wastes had to be determined, and the trearment for the mercur portion had to also be determined. The selected additives had to ensure that a durable and leach resistant waste form was produced. while the mercury treatment had to ensure that hazardous amounts of mercury were not released into the environment.

2453 V18/021719

Bioventing vs. Prepared Beds for Remediation of Petroleum Contaminated Soil

Hazen, T.C.; Lombard, K.H.; Kastner, J.R.

Westinghouse Savannah River Company, Savannah River Technology Center, Aiken, SC

CONF-960376 (Part 1); Proceedings of the 211 th American Chemical Society (ACS) National Meeting, New Orleans, LA, March 24-28, 1996. ACS, Washington, DC, Part 1, 1172 pp.; (p. 777, Paper ENVR 68) (1996)

Bioventing is an in-situ biostimulation technique that has become extremely popular recently for remediation of near-surface sediment (soil) contaminated with petroleum products. Prepared bed bioremediation of petroleum contaminated soil involves the use of a centralized controiled aboveground facility that uses contained land-farming techniques. Several sites at the U.S. DOE Savannah River Site have been evaluated and remediated using these two technologies. The characterization cost, capital costs, safety, implementation time, remediation rate, monitoring requirements, final disposition requirements, regulatory requirements, and public 
acceptance make these techniques better then any other conventional technology (e.g., incineration) and make it difficult to decide which of the two is the best altemative. New rapid site characterization and treatability techniques, e.g., laser induced fluorescence and microrespirometry, have allowed better decisions as to which of these two technologies is the most appropriate for a given site. (Complete text)

\section{4}

\section{V18/025518}

Demonstration of Plasma Insitu Vitrification at the K-Reactor Seepage Basin (904-65G)

Blundy, R.F.; Zionkowski, P.; Schumacher, R.F.; Herman, D.T.

Westinghouse Savannah River Company, Aiken, SC WSRC-TR-96-0390; 10 pp. (December 4, 1996)

The Savannah River Technology Center began investigating the possibility of utilizing a plasma torch for "bottoms up" in-situ vitrification and funded pilot plant scale testing at the Georgia Institute of Technology (GIT) and at Clemson University. By the spring of 1996 the GIT trials had indicated that the process was potentially viable for vitrification of Savannah River Site (SRS) soils, but that the process needed to be validated on a clean site at a near production scale before deployment into a radioactive environment could be contemplated. The Environmental Restoration Division organized this demonstration at a clean location adjacent to the 904-65G K-Reactor Seepage basin with the objectives of: (1) developing realistic cost-effectiveness data for evaluation of the process against other competing remediation technologies, such as soil grouting; (2) developing the engineering data necessary for possible subsequent full scale deployment at an SRS radiologically contaminated waste unit; and (3) evaluating commercially available non-intrusive subsurface monitoring techniques as potential methods for regulatory compliance verification. This Interim Technical Report provides a preliminary description of the demonstration with conclusions and recommendations based on observations made during the period of the demonstration. A detailed engineering report will be compiled in the near future providing all the data pertaining to the demonstration, together with the cost comparisons, product quality determinations and engineering recommendations for future actions.

2455

V18/021081

Molecular Environmental Diagnostics of TCE Contaminated Subsurface Environments

Jimenez, L.E.; Rosario, I.; Bowman, J.P.; Koh, S.C.; Sayler, G.S.

University of Tennessee, Department of Microbiology, Knoxville, TN

CONF-930482 (Vol. 2-1); Proceedings of the Second International Insitu and Onsite Bioreclamation Symposium, San Diego, CA, April 5-8, 1993; Bioremediation Series 2(1) - Bioremediation of Chlorinated and Polycyclic Aromatic Hydrocarbon Compounds, R.E. Hinchee, A. Leeson, L. Semprini and S.K. Ong (eds.), Lewis Publishers, Boca Raton, FL, 560 pp.; (pp. 392-396) (March 1994)

This investigation was undertaken to isolate DNA from TCE contaminated subsurface sites at the Savannah River Site (SRS) for molecular analysis and diagnosis, to study the distribution of catabolic genotypes in subsurface sites, and to use this knowledge for eventual optimization of the bioremediation process. One hundred sixty one subsurface sediment samples were obtained across the depth profile from 12 different boreholes before the injection of methane into the subsurface. Microbial DNA extracted from these sediments was hybridized with three different gene probes. Based upon the distributions across the depth profiles, it seems that the potential to degrade TCE is widespread across all sites at the SRS. Furthermore, methane enrichments from adjacent groundwater wells yielded 25 type II methanotrophic bacteria which showed high soluble MMO activity and high TCE degradation rates. On the basis of the gene distribution, high soluble MMO activity, and high TCE degradation rates, the authors conclude that subsurface methanotrophic bacterial communities at the SRS are an ideal choice for the in situ bioremediation of TCE contaminated sites.

2456

V18/024002

\section{Savanuah River Site A/M Area Cone Penetrometer Testing}

SEC Donohue Inc., Aiken, SC; Westinghouse Savannah River Company, Environmental Restoration Division, Aiken, SC

WSRC-TR-92-240; 175 pp. (October 1992)

The discharge of chlorinated solvents to the Savannah River Site (SRS) M-Area Settling Basin during M-Area manufacturing operations resulted in elevated levels of dissolved and free phase (dense non-aqueous phase liquids) volatile organic compounds (VOCs) in the subsurface. Residual dense non-aqueous phase liquids (DNAPLs) in the vadose and sanurated zones below the basin may be contributing to this groundwater contamination. In conjunction with the DNAPL Assessment Program, electric cone penetrometer testing (ECPT) was used to enhance characterization of the geology at $M$ Area and further determine geologic controls on the migration of DNAPLs in the area. Twenty six geotechnical test holes and two subsurface sampling holes were pushed to obtain groundwater and soil vapor samples. Additional locations were added to the scope, and multiple holes were tested at four locations following initial formation refusal. Resistivity, sleeve resistance/tip pressure, and pore pressure were measured for the sediments encountered to infer sediment type and the location of the watertable. Soil vapor and groundwater sampling were conducted to further evaluate and confirm the distribution of VOCs and to assess the sampling capabilities of the ECPT system.

2457

V18/021447

Baseline Characterization and Remediation-Induced Changes in TCE Degradative Potential Using Enrichment Techniques and DNA Probe Analysis

Brockman, F.J.; Sun, W.; Ogram, A.V.; Payne, W.; Workman, D.J.

Pacific Northwest Laboratory, Richland, WA

CONF-930482 (Vol. 2-1); Proceedings of the Second International Insitu and Onsite Bioreclamation Symposium, San Diego, CA, April 5-8, 1993; Bioremediation Series 2(1) - Bioremediation of Chlorinated and Polycyclic Aromatic Hydrocarbon Compounds, R.E. Hinchee, A. Leeson, L. Semprini and S.K. Ong (eds.), Lewis Publishers, Boca Raton, FL, 560 pp.; (pp. 397-403) (1993) 
In situ remediation of trichloroethylene (TCE) in deep unsaturated and saturated sediments is being conducted at the Savannah River Site, South Carolina, by injection of air and methane to stimulate the growth and activity of indigenous methanotrophs, which can degrade TCE via the methane monooxygenase enzyme. The objective of our research is to characterize the response of the microbial community to bioremediation activities using cultural approaches for select physiological groups that possess TCE-degradative ability, and using DNA probes specific for genes that identify TCE-degrading micro-organisms. Of particular interest is an assessment of how well the available probes correlate with degradation of TCE as observed in enrichment cultures and in field measurements of contaminant concentrations in sediment and groundwater. The use of both approaches allows a more comprehensive and defensible analysis of the success of bioremediation.

\section{8}

\section{V18/021442}

Design and Factory Test Report: Brayton Cycle Pilot Plant - Soil Remediation Project, Savannah River Site Enneking, J.C.

Nuclear Consulting Services, Inc., Columbus, $\mathrm{OH}$ NUCON 05EG831/01; 11 pp. (December 22, 1992)

A number of process improvements have been incorporated into the Brayton Cycle pilot plant being used for soil remediation technology demonstration at Savannah River. The design and factory test portions of the project have been completed. The pilot plant process design was changed from pressure mode to vacuum mode which represents a major improvement in simplicity and reduced energy consumption. In addition, equipment for providing compressed air, cooling water and $110 \mathrm{VAC}$ power were added to the trailer. The only site hook-ups now required are for $440 \mathrm{VAC}$ power and Solvent Laden Air (SLA). Factory tests were conducted at Nuclear Consulting Services, Inc. (NUCON) using trichloroethylene as the solvent. They showed that the new design can effectively remove solvent from an effluent air stream and recover it as liquid.

\section{9}

V18/020915

Field Experiences with a Multisorbent Arrayed Sampler for Insitu Collection of Vadose Zone Volatile Organic Compounds

Jenkins, R.A.; Higgins, C.E.; Gayle, T.M.; Allin, G.W.; Smith, R.R.

\section{Oak Ridge National Laboratory, Oak Ridge, TN}

CONF-950209 (Vol. 2); VIP-47, Proceedings of the Fourth International Symposium on Field Screening Methods for Hazardous Wastes and Toxic Chemicals, Las Vegas, NV, February 22-24, 1995. Air and Waste Management Association, Pittsburgh, PA, Vol. 2, 701 pp.; (pp. 1018-1024) (1995)

This presentation describes the development and initial field demonstrations of an arrayed, multisorbent sampler for in-situ collection of volatile species at depths up to 125 feet in the vadose zone. The sampler consists of an array of six traps each packed with sequential beds of sorbent materials. One end of each trap can be opened to a screened space. The sampler can be lowered by a single individual into a 4 inch diameter screened borehole and controlled from the surface. Air samples of nearly any volume and/or duration can be passed through the traps and the volatile organics retained. The arrayed sampler is then returned to the surface and the traps analyzed, either using field or laboratory based analytical procedures. Inflatable packers can be used to isolate the geologic zone being sampled if appropriate. The prototype system has been successfully deployed and demonstrated at the Department of Energy's Savannah River Integrated Demonstration Project site. Numerous vadose zone samples have been collected, sampling soil gas volumes sufficiently small so as not to disturb the subsurface equilibrium, even in non-porous strata. Data acquired during the sampling yielded a wide range of apparent soil gas concentrations, from 5-130,000 mu g/cubic meters of trichloroethylene. The current system configuration, although undergoing modification to permit interfacing with a wider variety of monitoring well designs, can provide time and spatially resolved chemical information concerning the impact, effectiveness, and zone of influence of candidate remediation technologies, for both target and non-target species in the deep vadose zone.

\section{$2460 \quad \mathrm{~V} 18 / 021441$}

Recovery of Volatile Organic Compounds from Soil Remediation Sites at the Savannah River Site (SRS) [Draft]

Engleman, V.S.; Hunter, L.L.

Science Applications International Corporation, San Diego, $\mathrm{CA}$

Report; 20 pp. (September 4, 1992)

This report presents the results of a comparative study of several alternative technologies for the recovery or destruction of volatile organic compounds. This comparative analysis was conducted as part of a project to study the technical and economic feasibility of using the Brayton cycle solvent recovery heat pump to recover VOCs from soil and groundwater remediation sites at the Savannah River Site. The present analysis is based on the results obtained from two previous vacuum extraction pilot tests conducted at the Savannah River Site. The two tests were conducted at the abandoned M-Area process sewer line. One test was conducted using vacuum only and the other test was conducted using an air assist. The results of the two earlier tests are summarized in a table. The major compounds found on the site were perchloroethylene (PCE) and trichloroethylene (TCE). The initial concentration of the chlorinated compounds was found to be in excess of $1,000 \mathrm{ppm}$. The concentration dropped rapidly, leveling off in the 200 to 300 ppm range.

2461 V18/021414

\section{Simulations of Insitu Air Stripping Demonstration at Savannah River}

Robinson, B.A.; Rosenberg, N.D.; Zyvoloski, G.A.; Viswanathan, $\mathrm{H}$.

Los Alamos National Laboratory, Los Alamos, NM

LA-12781-MS; 40 pp. (June 1994)

This report assesses the performance of the in-situ air stripping technology demonstrated at the Savannah River Integrated Demonstration (SRID) site. This technology is a combination of air 
injection below the water table and vacuum extraction in the vadose zone, using a pair of horizontal wells. Our approach is based on the construction of a site-specific numerical model using the FEHM flow and transport code. We use the model as a tool to investigate improvements of performance, to improve the prediction of the performance of this technology over longer periods of time and at different sites, and to compare performance with other remediation technologies.

2462

V18/021007

Six-Phase Soil Heating for Enhanced Removal of Contaminants: Volatile Organic Compounds in Non-Arid Soils Integrated Demonstration, Savannah River Site

Gauglitz, P.A.; Bergsman, T.M.; Caley, S.M.; Heath, W.O.; Miller, M.C.; Moss, R.W.; Roberts, J.S.; Schalla, R.; Schlender, M.H.; Jarosch, T.R.; Eddy-Dilek, C.A.; Looney, B.B.

Pacific Northwest Laboratory, Richland, WA; Westinghouse Savannah River Company, Aiken, SC

PNL-10184; 65 pp. (October 1994)

During November 1993, Pacific Northwest Laboratory (PNL) and Savannah River Site (SRS) personnel completed a field demonstration of six-phase soil heating (SPSH) at the Savannah River Site, Aiken, South Carolina. This demonstration was directed by the U.S. Department of Energy (DOE) Volatile Organic Compounds in Non-Arid Soils Integrated Demonstration (VOCs in Non-Arid Soils ID). Pacific Northwest Laboratory designed the SPSH systems for this demonstration, and Westinghouse Savannah River Company (WSRC) conducted drilling, soil sampling, construction, off-gas treatment, and contaminant analyses. The purpose of the project was to demonstrate a soil heating system that uses electricity to cost effectively heat soil and enhance the performance of conventional soil-venting techniques.

2463

\section{$\mathrm{V} 18 / 021270$}

Field Test of Six-Phase Soil Heating at the Savannah River Site

Gauglitz, P.A.; Roberts, J.S.; Bergsman, T.M.; Caley, S.M.; Heath, W.O.; Miller, M.C.; Moss, R.W.; Schalla, R.; Schlender, M.H.; Jarosch, T.R.; Eddy-Dilek, C.A.; Looney, B.B.

Pacific Northwest Laboratory, Richland, WA; Westinghouse Savannah River Company, Aiken, SC

CONF-941 124; Insitu Remediation: Scientific Basis for Current and Future Technologies, G.W. Gee and N.R. Wing (eds.), Proceedings of the 33rd Hanford Symposium on Health and the Environment, Pasco, WA, November 7-11, 1994. Battelle Press, Columbus, OH, Part 1, 704 pp.; (pp. 763-780) (1994)

Six-Phase Soil Heating (SPSH) was demonstrated as a viable technology for heating low permeability soils containing volatile organic contaminants as part of the Volatile Organic Compounds in Non-Arid Soils Integrated Demonstration (VOC Non-Arid ID) at the Savannah River Site. The soil at the integrated demonstration site is contaminated with perchloroethylene (PCE) and trichloroethylene (TCE); the highest soil contamination occurs in clay rich zones that are ineffectively treated by conventional soil vapor extraction due to the very low permeability of the clay. The SPSH demonstration sought to heat the clay zone and enhance the performance of conventional soil vapor extraction. Thermocouples at 30 locations quantified the areal and vertical heating within the treated zone. Results show successful heating of the targeted clay zone that contained the higher levels of soil contamination. The clay-zone temperatures increased to $100 \operatorname{deg} \mathrm{C}$ after 8 days of heating and were maintained near $100 \mathrm{deg} C$ for 17 days. Electrical heating removed $17,000 \mathrm{gal}$ of water from the soil as steam, with peak removal rate of $1,500 \mathrm{gpd}$ of condensed steam. After the initial start-up, electrical power was applied to the pattem at an average rate of $200 \mathrm{~kW}$. The total energy applied to the soil was $100,000 \mathrm{kWh}$. The volume of soil heated to above $70 \mathrm{deg} C$ is estimated to be 100 cubic meters giving an energy input of 90 $\mathrm{kWh} /$ cubic meters ( $70 \mathrm{kWh} /$ cubic yards). The average voltage (line to neutral) applied to the soil was $1000 \mathrm{~V}$. The voltages began at $250 \mathrm{~V}(\mathrm{~L}-\mathrm{N})$ during start-up and increased to $2400 \mathrm{~V}(\mathrm{~L}-\mathrm{N})$ at the end of the test. To quantify removal of PCE and TCE from the soil and soil drying, soil samples were taken (essentially every foot) from six wells prior to heating and adjacent to these wells after heating; analysis of these samples is ongoing.

2464

V18/025355

Large-Scale Treatability Testing of Insitu Vitrification Technology at ORNL WAG 7 Pit 1 Site: Challenges, Results, Status

Timmerman, C.L.; Spalding, B.P.; Tixier, J.S.

Geosafe Corporation, Richland, WA; Oak Ridge National Laboratory, Oak Ridge, TN; Pacific Northwest National Laboratory, Richland, WA

CONF-970335; Waste Management '97: Working Towards a . Cleaner Environment, Proceedings of a Conference on $\mathrm{HLW}$, LLW, Mixed Wastes and Environmental Restoration, Tucson, AZ, March 2-6, 1997; (12 pp.) (1997)

Large-scale treatability testing of the DOE-developed In Situ Vitrification (ISV) technology was performed at Oak Ridge National Laboratory's (ORNL) Waste Area Group (WAG) 7 Pit 1 site to generate data needed for completion of the RI/FS activity for the 6 remaining pits and trenches located at WAG 7. This paper discusses the unique challenges posed by the site, problems encountered, project results, and significance of test findings relative to future applications of ISV at WAG 7 and similar DOE sites. The ISV technology has been developed for DOE by the Pacific Northwest National Laboratory (PNNL) since its inception in 1980.

Collaboration on technology development and application began with ORNL in 1985. Geosafe Corporation, the commercial licensee of the technology, has also contributed heavily to the development of the technology since 1988 by transitioning it to a commercially viable production technology for a broad range of contaminated soil and waste/debris applications. Over 200 laboratory tests and experiments plus almost 100 large-scale field tests, demonstrations, and commercial melts have demonstrated the broad applicability of the technology for the destruction/removal of organic contaminants and permanent immobilization of inorganic and radionuclide contaminants within a high integrity vitrified product. Geosafe has successfully applied the technology since 1993 on a broad range of contaminated soil and buried waste and debris 
applications at U.S. Superfund sites and overseas sites.

\section{5}

\section{V18/020691}

Remediation of Hylebos Waterway (Tacoma, WA): A

Common Sense Approach to Determining

Contaminated Sediment Volumes

Fuglevand, P.; Revelas, G.; Striplin, B.; Striplin, P.

Dalton, Olmsted and Fuglevand, Inc., Bothell, WA; Striplin

Environmental Associates, Inc., Olympia, WA

CONF-9511137; Global Environmental Protection: Science, Politics, and Common Sense, Proceedings of the Second Society of Environmental Toxicology and Chemistry (SETAC) World Congress and 16th Annual Meeting, Vancouver, British Columbia, Canada, November 5-9, 1995. Society of Environmental Toxicology and Chemistry, Pensacola, FL, 378 pp.; (p. 229) (1995)

Hylebos Waterway is a three mile long industrial waterway located in Commencement Bay, Washington. A CERCLA program RI/FS, conducted in the mid-1980's, found that surface sediments $(0-2 \mathrm{~cm})$ were contaminated with chlorinated organics, PAHs, and metals. An ongoing pre-remedial design effort, initiated in 1993, is evaluating natural recovery and four sediment confinement options for sediments that exceed programmatic sediment quality objectives: confined aquatic disposal, near-shore disposal, upland disposal, and in-place capping. The first three confinement options require dredging of contaminated sediments which, in turn, requires accurate determination of the three dimensional distribution of contaminated sediments. To place a maximum depth boundary on the sediment sampling approach, isopach maps were created by contouring the difference between the deepest historic dredging depth and current depth along the entire waterway. These isopach maps revealed the pattem of post-industrial sediment deposition in the waterway. For example, in some areas, little or no sediment accumulation had occurred in the navigation channel. Conversely, significant accumulation had occurred along some channel edges and in near-shore areas as the result of deposition, bank sloughing and historic dredging/filling activities. The isopach maps were used to place a lower depth boundary on waterway-wide sediment contamination and to establish the maximum core sampling depth required to reach "native" sediments, i.e., those below the deepest historic dredging depth and believed to be uncontaminated. Subsequent geo-technical and chemical analyses of the core samples confimed the accuracy of the isopach approach. The data generated from this sampling effort are being used to estimate the areas and volumes of subtidal sediments requiring remedial action. (Complete text)

\section{6}

\section{V18/023912}

Accounting for the Effects of Soil Buttressing and Construction Loading in the Design of a Soil Veneer Cover System at the Delaware County Landfill

Sheridan, T.G.; Bolton, J.W., Jr.; Clark, D.

Tensar Environmental Systems, Inc., Spring Lake, NJ; Tensar Environmental Systems, Inc., Atlanta, GA; Clark Engineering, New Lebanon, NY

CONF-950177; Waste Tech '95, Proceedings of a Conference, New Orleans, LA, January 23-25, 1995. Environmental Industry News,
Washington, DC, 530 pp.; (pp. 61-69) (1995)

The intent of this paper is to outline the combination of design methods that were used to generate an optimal design that minimized the potential for sliding failure of the soil veneer cover at the Delaware County Landfill. The design not only addressed the long-term stability of the slope but also the critical short-term stability that occurs during construction loading. Special consideration was given to the selection of both construction equipment as well as the geosynthetic reinforcement based on specific design criteria.

2467

V18/022096

Acid Leaching and Stabilization Treatment Evaluations for Lead Contaminated Soil

Semenak, R.K.; Zarlinski, S.J.; Kingham, N.W.

Kiber Environmental Services, Inc., Atlanta, GA

CONF-951139 (Vol. 2); Superfind 16: Proceedings of a Hazardous Waste Conference and Exhibition, Washington, DC, November 6-8, 1995. E.J. Krause and Associates, Bethesda, MD, Vol. 2, 817 pp.; (pp. 768-772) (1994)

Lead contamination of soils represents a relatively large portion of hazardous waste sites currently requiring clean-up. Typically, lead contamination occurs at a broad range of sites, including but not limited to lead-acid battery reclamation, secondary lead smelting operations, and munitions manufacturing and disposal.

Traditionally, treatment of lead sites has focussed on encapsulation or fixation of the lead contaminated materials through the mechanisms of stabilization and solidification. Stabilization treatment has been established as an effective treatment for both organic and inorganic contaminants. Three primary applications of the stabilization technology include: (1) treatment of liquids and sludges for land disposal; (2) remediation of contaminated sites containing organic and inorganic contaminants; and (3) solidification of materials which are physically unstable. Stabilization treatment is identified in the national contingency plan as a permanent remedial alternative for treatment of organic and inorganic waste materials. Recently, innovative technologies have also been evaluated for treatment of lead sites. Acid leaching is an innovative technology that has been adapted from established applications in the mining industry in which valuable metals are leached from ore piles. Applications for the environmental field, however, have been limited to pilot-scale demonstrations. The scope of work outlined in this paper is designed to provide a generic approach to evaluating both acid leaching and stabilization technologies for treatment of lead contaminated soil. Specifically, this paper discusses: (1) detailed untreated waste characterization to evaluate contaminant levels and material types considered representative of site materials; (2) detailed analyses to evaluate potential material handling concerns, specifically with regard to full-scale acid leaching treatment, and (3) laboratory evaluations of the various treatment technologies. Prior to initiating laboratory testing, interviews with full-scale acid leaching vendors are performed to ensure accurate modelling of potential full-scale processes. Laboratory testing is then initiated to: (1) evaluate the identified treatment technologies including acid leaching and stabilization, and (2) determine potential full-scale operating requirements. Throughout the study, care is taken to ensure that sufficient data is obtained to accurately assess treatment 
effectiveness, implementability and cost for both selected technologies.

\section{8}

\section{V18/025437}

Advanced Fuel Hydrocarbon Remediation National Test Location - Biocell Treatment of Petroleum

Contaminated Soils

Heath, J.; Lory, E.

U.S. Navy, Naval Facilities Engineering Service Center, Port Hueneme, CA

TDS-2017-ENV-REV; 4 pp. (March 1997)

Biocells are engineered systems that use naturally occurring microbes to degrade fuels and oils into simpler, nonhazardous, and nontoxic compounds. Biocells are able to treat soils contaminated with petroleum based fuels and lubricants, including diesel, jet fuel, and lubricating and hydraulic oils. The microbes use the contaminants as a food source and thus destroy them. By carefully monitoring and controlling air and moisture levels, degradation rates can be increased and total treatment time reduced over natural systems.

\section{$2469 \quad$ V18/025436}

Advanced Fuel Hydrocarbon Remediation National Test Location - Biopile Remediation

Heath, J.; Lory, E.

U.S. Navy, Naval Facilities Engineering Service Center, Port Hueneme, $\mathrm{CA}$

NFESC-TDS-2018-ENV-REV; 4 pp. (March 1997)

Biopile remediation is an environmental cleanup technology that uses naturally occurring microbes such as bacteria and fungi to destroy organic contaminants in soil. Certain species of bacteria are able to consume organic pollutants as a food source, thus detoxifying the pollutants. Biopile remediation is effective in treating soils contaminated with petroleum hydrocarbons such as gasoline, grease, jet fuels, diesel fuels, and motor oil. The microbes "appetite" is enhanced by blowing air through the contaminated soil pile to provide oxygen and adding fertilizer to provide additional solid nutrients.

2470

V18/025435

Advanced Fuel Hydrocarbon Remediation National Test Location - Demonstration of Hot Air Vapor Extraction for Fuel Hydrocarbon Cleanup

Heath, J.; Lory, E.

U.S. Navy, Naval Facilities Engineering Service Center, Port Hueneme, CA

NFESC-TDS-2015-ENV-REV; 4 pp. (March 1997)

Hot air vapor extraction (HAVE) is a fast track, innovative environmental cleanup technology that uses a combination of thermal, heap pile, and vapor extraction techniques to remove and destroy hydrocarbon contamination in soil. This technology is very effective in cleaning soils contaminated with gasoline, diesel, heavy oil, and polycyclic aromatic hydrocarbons (PAH).
Advanced Fuel Hydrocarbon Remediation National Test Location - Site Characterization and Analysis Penetrometer System

Heath, J.; Lory, E.

U.S. Navy, Naval Facilities Engineering Service Center, Port Hueneme, $\mathrm{CA}$

NFESC-TDS-2016-ENV-REV; 3 pp. (March 1997)

The site characterization and analysis penetrometer system (SCAPS) with laser induced fluorescence (LIF) sensors is being demonstrated as a quick field screening technique to determine the physical and chemical characteristics of subsurface soil and contaminants at hazardous waste sites. SCAPS is a collaborative development effort of the Navy, Amy, and Air Force under the Tri-Service SCAPS Program. The current SCAPS configuration is designed to quickly and cost effectively distinguish areas contaminated with petroleum products (hydrocarbons) from unaffected areas.

\section{2 \\ V18/024131}

Advanced Remediation of Actinide-Contaminated Soils Los Alamos National Laboratory, Los Alamos, NM

LALP-95-34; 1 p. (1995)

The objective of this project is to develop effective extraction processes that remove uranium and other actinides from contaminated soils. We use selective chelators together with redox chemistry designed to take advantage of the specific coordination and redox properties of the target metals. The specific chelators that we use have some of the highest known binding constants for hard Lewis acid cations, such as $\mathrm{Pu}(4+)$ and $\mathrm{U}(4+)$, thereby making their application as extractants for actinides very attractive. The dissolution of solid metal phases occurs under such mild conditions that alteration of soil characteristics is minimized. Moreover, the secondary liquid waste stream that this process generates is easy to treat.

2473

V18/021722

Advances in Electrokinetic Soil Remediation

Gale, R.J.

Louisiana State University, Baton Rouge, LA

CONF-960376 (Part 1); Proceedings of the 211th American Chemical Society (ACS) National Meeting, New Orleans, LA, March 24-28, 1996. ACS, Washington, DC, Part 1, 1172 pp.; (p. 182, Paper ANYL 189) (1996)

Electrokinetic soil remediation, or electroreclamation, refers to a class of emerging techniques that use electricity to achieve decontamination, or chemical modification, of polluted soils or slurries. The EPA general classification, that they are in-situ phase separation techniques is somewhat restrictive since the number and types of these methodologies are growing to include micellar electrokinetic soil decontamination and electrokinetic bioremediation. Following a discussion of the classical theory of electroosmosis, an overview will be given of the principles and current status of electrokinetic soil remediation for toxic metals extraction with illustrative bench, pilot, and field results. Emerging techniques, such as micellar electroremediation and electrokinetic 
bioremediation will also be reviewed and illustrated. The problems that can occur in a natural site will be shown and the economics of these methodologies, compared to alternative and competitive processes, will be estimated. (Complete text)

\section{4}

V18/022682

Advances in Vacuum Extraction Technology for Effective Subsurface Remediation

Dodson, M.E.; Pezzullo, J.A.; Piniewski, R.J.

Terra Vac Corporation, Northwest Division, Seattle, WA; Terra Vac Corporation, Mid-Atlantic Division, West Trenton, NJ; Terra Vac Corporation, Midwest Division, Temperance, $\mathrm{MI}$

CONF-941124; Insitu Remediation: Scientific Basis for Current and Future Technologies, G.W. Gee and N.R. Wing (eds.), Proceedings of the 33rd Hanford Symposium on Health and the Environment, Pasco, WA, November 7-11, 1994. Battelle Press, Columbus, OH, Part 2, 605 pp.; (pp. 721-736) (1994)

Vacuum extraction technology has become one of the most widely acclaimed methods for remediating soils contaminated by petroleum hydrocarbons and volatile organic compounds. Removal of the source of contamination in the soil is often the first step in effective control of groundwater contamination. Though originally thought effective only for removal of light-end hydrocarbons from permeable vadose-zone soils, vacuum extraction can now be adapted to address situations of low-permeable soils, heavier-end hydrocarbons and groundwater contamination. This paper reviews four innovative modifications to the vacuum extraction process and how they solve a wide variety of subsurface contamination problems. The modifications, or processes, reviewed include: vacuum-extraction-enhanced bioremediation, groundwater sparging, pneumatic soil fracturing, and soil heating.

\section{5}

V18/021296

Aerobic Degradation of Trichloroethylene (TCE), Vinyl Chloride (VC), and Aromatic Compounds by Type IV Actinomycetes

Malachowsky, K.J.; Phelps, T.J.; White, D.C.

University of Tennessee, Center for Environmental Biotechnology, Knoxville, TN

CONF-9205212; Proceedings of the 1992 General Meeting of the American Society for Microbiology, New Orleans, LA, May 26-30, 1992, 383 pp.; (p. Q-281) (1992)

TCE and VC are EPA priority pollutants. Past studies have shown aerobic mineralization of VC but the conditions conducive to degradation have not been investigated. This study examined conditions that effected VC and TCE biodegradation and investigated the ability of the isolates to degrade other organic compounds. Two Type IV Actinomycete strains and Rhodococcus rhodochrous (ATCC \#21197) were found to mineralize TCE in growth VC was degraded by cell suspensions of isolate $\mathrm{Sm}-1$ grown on propan-1-ol, glucose, acetate, or yeast extract. Degradations, at a pH range of 5-10, and temperature of $4 \mathrm{deg}$ to $45 \mathrm{deg}$ C. The isolates were able to degrade mixtures of aromatic and chlorinated aliphatic solvents as well as utilize energy sources. A colorimetric assay showed the presence of a monooxygenase in cells grown on propane or glucose. We suggest that these organisms may have monooxygenase(s), which are broad in specificity giving the organisms the ability to degrade a variety of aliphatic and aromatic compounds. (Complete Text)

\section{$2476 \quad$ V18/024653}

Anaerobic Bioremediation of Munitions-Contaminated Soil

Daniel, B.P.; Korus, R.A.; Crawford, D.L.

University of Idaho, Department of Chemical Engineering, Moscow, ID; University of Idaho, Department of Microbiology, Molecular Biology, and Biochemistry, Moscow, ID

Bioremediation of Pollutants in Soil and Water, B.S. Schepart (ed.), Proceedings of a Symposium, Fort Worth, TX, October 14-15, 1993. American Society for Testing and Materials (ASTM), Philadelphia, PA, 265 pp.; (pp. 161-175) (May 1995)

The soil at many military sites in the United States is contaminated with 2,4,6-trinitrotoluene (TNT) and other munitions chemicals. Anaerobic biodegradation is one possible method of soil remediation. This paper reports the results of investigations about the effects of a number of parameters on anaerobic biodegradation of TNT. The method used had been previously applied to the herbicide 2-sec-butyl-4,6-dinitrophenol (dinoseb), which is also a nitroaromatic compound, and to a TNT-contaminated soil. It was based on the use of an aerobic bacterial consortium to consume dissolved oxygen and to force anaerobic conditions, and a methanogenic bacterial consortium previously acclimated to TNT to enhance degradation. It was determined that the initial steps of biodegradation of TNT in this soil were not affected by the presence of either of the consortia, and that INT degradation was slightly faster at $\mathrm{pH} 7.0$ than at $\mathrm{pH}$ 6.0. It was also determined that agitation during incubation increased the degradation rate of one of the intermediates of the degradation.

\section{$2477 \quad$ V18/025438}

Analysis of Remedial Actions Conducted on Contaminated Soils with Regard to the Success of Sanitation: Monitoring of Sanitized Hazardous Waste Sites

Doetsch, P.; Hotten, R.; Denker, M.; Dreschmann, P.

Umweltbundesamt, Berlin, Germany

UBA-FB-96-079; 539 pp. (September 1996)

Strategies for a standardized decision-making process applicable to all of Laender for cleanup of hazardous waste sites were developed. Areas covered were remedial investigations, project planning, implementation of remedial measures, and monitoring of remediation. Twenty five remedial measures were investigated. It is concluded that the experience gained and the approach chosen in these cases of remedial action were only applicable to a limited degree to other situations. The analysis of the particular circumstances and of the feasibility of a remedial measure is an essential precondition for the application of ecologically and economically appropriate procedures and techniques. (This document is in German). 
2478

V18/023820

Analysis of Soils Using Multivariate Signal Quantitation ICEP-OES

Salit, M.L.; Yates, D.A.

National Institute of Standards and Technology, Chemical Science and Technology Laboratory, Gaithersburg, MD; Perkin-Elmer Corporation, Norwalk, CT

CONF-960113; Proceedings of the 1996 Winter Conference on Plasma Spectrochemistry, Fort Lauderdale, FL, January 8-13, 1996, 378 pp.; (p. 127) (1996)

Multivariate analysis of spectra for ICP-OES signal quantitation offers the potential for signal-to-noise enhancement, background correction, and alleviation of spectral overlaps. The availability of high quality, simultaneous multichannel spectra from array-detector spectrometers makes these data processing approaches especially appealing. A simple multiple least-squares (MLS) approach will be applied to the determination of the elemental composition of a series of soil standard reference materials, and results characterized for precision and bias. MLS is a promising approach which performs successfully in well characterized, well controlled analytical situations. Performance limitations arise from several areas in practical applications. The underiying model profiles are subject to contamination, which jeopardizes the procedure by forcing a fit of the contaminant; when unmodeled components are present or when a modeled component is absent, the fit can degrade, forcing a poor fit of the components which are present; the procedure is sensitive with respect to wavelength drift; and noise artifacts in low signal-to-noise spectra can compromise the results. Determination of different elements in the soil reference materials represents different degrees of spectrochemical complexity, which will help to characterize the MLS approach.

2479

V18/023791

Analytical and Statistical Approaches to Validate Biological Treatment in Petroleum Hydrocarbons in Soil

Graves, D.; Chase, L.; Ray, J.

International Technology Corporation, Knoxville, TN; International Technology Corporation, Wilmington, CA; Konoike Transport and Engineering, Inc., Wilmington, $\mathrm{CA}$

CONF-9504134; HAZMACON '95, T. Bursztynsky and M.L. Loss (eds.), Proceedings of the Twelfth Hazardous Materials Management Annual Conference and Exhibition, San Jose, CA, April 4-6, 1995. Association of Bay Area Govemments, Oakland, CA, 790 pp.; (pp. 323-332) (1995)

A site in southem California, containing 50,000 cubic yards of petroleum contaminated soil, was remediated using land treatment. By using a combination of soil screening and land treatment, the total petroleum hydrocarbon content was reduced to less than the clean-up standard of $1,000 \mathrm{mg} / \mathrm{kg}$. Initial contaminant concentrations ranged between 4,000 and $5,000 \mathrm{mg} / \mathrm{kg}$ after screening to remove large globules of tar and pieces of asphalt. Biological treatment time was less than eight months. Simple parametric and nonparametric statistical methods were applied to results obtained from soil testing. Multiple analytical methods were used to determine the type of residual hydrocarbon and the relative environmental risk associated with the residual contamination. This combination of physical segregation, land treatment, and statistical and analytical methods resulted in soil remediation and permission to use the soil on site without restriction.

2480

V18/022247

Application of Air Sparging and SVE for Biotreatment of Soils at Delaware Air National Guard, Delaware

Garlanka, S.; Janiga, K.; Kirby, W.

Earth Technology, Inc., Alexandria, VA

CONF-951139 (Vol. 2); Superfund 16: Proceedings of a Hazardous Waste Conference and Exhibition, Washington, DC, November 6-8, 1995. E.J. Krause and Associates, Bethesda, MD, Vol. 2, 817 pp.; (pp. 1044-1053) (1994)

Site characterization at a defense facility in Delaware identified chlorinated hydrocarbons and benzene, toluene, ethylbenzene, and xylenes (BTEX) contamination in soils and groundwater. The subsurface geology at the site has complicated the migration, hence remediation of the contaminant. A multi-phase treatment approach was used to treat contaminated soils and groundwater under varying lithologic conditions. This paper will first discuss the facility history and former disposal practices that led to the release of contamination to the environment at the site. Then the paper will discuss the geology of the site. The paper will describe each of the three technologies used during the pilot-scale test. The paper will then discuss the pilot-scale testing at the site including the well configuration, the equipment set-up, and the operation of the test. The results from the pilot-scale tests will be summarized. A short discussion and conclusion section are provided at the end of the paper.

2481

V18/023897

Application of Immunoassay Testing to Monitoring of Bioremediation of Petroleum Contaminated Soil

Denham, D.; Carter, K.R.

EnSys Environmental Products, Inc., Research Triangle Park, $\mathrm{NC}$

CONF-951124; HazMat West '95, Proceedings of the Eleventh Annual Environmental Management and Technology Conference and Exhibition, Long Beach, CA, November 7-9, 1995. Advanstar Expositions, Duluth, MN, 597 pp.; (pp. 77-82) (1995)

Exsitu bioremediation continues to be a cost-effective remediation technology for petroleum contaminated soil. Its wide regulatory acceptance and proven technique has caused many clients to ask for a lump sum cost proposal for employing the technology. This in turn has raised the need to closely monitor the progress of the degradation process to keep operating costs as low as possible. Traditional laboratory costs for analysis of soils with hydrocarbons has become less expensive, but for 24 hour turnaround of results, costs are still subject to $100 \%$ mark-ups. Yet the ability to obtain the analysis rapidly can assist the environmental professional in modifying oxygen, nutrients and other components that are essential in the degradation process, therefore, minimizing the time required to accomplish the remediation project. This is why the use of immunochemistry-based field methods, which are rapid and cost-effective, are being employed by environmental professionals. 
2482

V18/023633

Application of Insitu Bioventing in the Remediation of Deep Soils at Arid Sites

Frishmuth, R.A.; Ratz, J.W.; Blicker, B.R.; Hall, J.F.

CONF-951023 (Vol. 8); WEFTEC '95, Proceedings of the 68th

Annual Conference and Exposition of the Water Environment Federation, Miami Beach, FL, October 21-25, 1995. Water Environment Federation, Alexandria, VA, Vol. 8, 498 pp.; (p. 325) (1995)

In situ bioventing, or low flow rate soil ventilation for the enhanced aerobic biodegradation of petroleum hydrocarbon contaminants, has been shown to be a cost-effective remedial alternative for vadose zone soils. The success of the technology relies on the ability of indigenous soil microorganisms to utilize hydrocarbon contaminants as a primary growth substrate. The rate of hydrocarbon biodegradation at a given site depends on a variety of factors, including the concentration of soil microorganisms present. Parsons Engineering Science, Inc. (Parsons ES) has conducted bioventing pilot tests at six U.S. Air Force sites in Arizona, Nevada, New Mexico, and Utah, where petroleum hydrocarbon contamination has migrated to depths ranging from 19.8 to 67 meters ( 65 to 220 feet) below ground surface (bgs). Test results demonstrated that bioventing can be a viable remedial alternative in deep soils in and regions. Petroleum biodegradation was shown to be occurring at significant rates at three of the six subject sites. Average oxygen consumption rates ranged from 4.6 to 12.8 percent per day during initial in situ respiration testing at these three sites. At five of the six sites, average soil total Kjeldahl nitrogen (TKN) concentrations ranged from 50 to 150 milligrams per kilogram $(\mathrm{mg} / \mathrm{kg}$ ), generally indicating that significant bacterial populations may exist in deep soils at these sites, and that enough nitrogen was present to support aerobic hydrocarbon biodegradation. At Site 35, located at Davis-Monthan Air Force Base (AFB) in Arizona, the average TKN concentration in soil was $16 \mathrm{mg} / \mathrm{kg}$ and the average oxygen consumption rate was 0.22 percent per day, demonstrating that the lack of a significant microbial population may contribute to the low hydrocarbon biodegradation rates estimated at this site. During these initial pilot tests, soil moisture was found to be present in adequate amounts at all subject sites to support aerobic petroleum hydrocarbon biodegradation.

Application of Petrographic and Radiochemical Analysis of Radioactive Soil Fractions to Stages of the RI/FS Process

Neiheisel, J.

U.S. Environmental Protection Agency, Office of Radiation Programs, Washington, DC

CONF-9210194; Proceedings of an International Symposium on Environmental Contamination in Central and Eastern Europe, Budapest, Hungary, October 12-16, 1992, 968 pp.; (pp. 510-512) (1992)

The Office of Radiation Programs has developed a soil characterization protocol for radioactive soils that has application to: (a) enhancement of the conceptional model of the sites, (b) improvement of baseline risk assessment, and (c) facilitate identification of potential remedial alternatives at radioactively contaminated Superfund sites. The protocol involves separation of the bulk samples into several size fractions with complete petrographic and radiochemical analysis of each size fractions. This procedure provides: (1) identification of activity levels versus grain size, (2) identification of the mineral/material composition and physical properties of radioactive contaminants, and (3) identification of differences between physical properties of contaminants and host materials. The data quality objectives gained by the soil characterization protocol are described for risk assessment and in remedial technology assessment for the radium contaminated soils of Montciair and Glen Ridge, New Jersey and for the thorium contaminated soils of Wayne and Maywood, New Jersey.

2484

V18/024645

Application of a Biotreatment Screening Test for Considering Bioremediation as a Treatment Option

Roy, M.; Gauger, W.K.; Rehage, J.A.

Radian Corporation, Austin, TX

Bioremediation of Pollutants in Soil and Water, B.S. Schepart (ed.), Proceedings of a Symposium, Fort Worth, TX, October 14-15, 1993. American Society for Testing and Materials (ASTM), Philadelphia, PA, 265 pp.; (pp. 19-33) (May 1995)

The purpose of this study was to validate a test procedure developed to be flexible but sufficiently focused to determine the biodegradation potential of organic contaminants in a waste. The biotreatability test provides a low cost screening tool to evaluate bioremediation as a treatment option for contaminated soil. The test measures microbial activity by collecting oxygen uptake and carbon dioxide evolution data. Pollutant removal is assessed by destructive sampling of the soil. We report the use of this test on hydrocarbon-contaminated silty sandy soil from an Air Force Station in central Alaska. Soils were incubated at $4 \mathrm{deg} C$ and at various oxygen levels which were expected to exist during in situ treatment conditions. The incubation period for the test was 90 days. Results indicated that the test conditions incubated at the reduced oxygen levels (2-14 percent) had the most vigorous oxygen uptake and efficient hydrocarbon removal.

\section{5 \\ V18/021726}

Applying Vitrification to Meet Customers' Value

Roy, B.

Electric Power Research Institute, Palo Alto, CA; CENTEC-21, Inc., Santa Clara, CA; Scientific Ecology Group, Inc., Oak Ridge, TN

EPRI-TR-106079; CONF-951244; Vitrification of Low-Level Waste: The Process and Potential, M.D. Naughton and K. Sullivan (eds.), Proceedings of an Electric Power Research Institute (EPRI) Meeting, San Antonio, TX, December 5-6, 1995, 368 pp.; (pp. 9.1-9.16) (March 1996)

Cost-effective waste management solutions that maximize customer value require a thorough and flexible evaluation and integration of approaches, technology applications, and disposal options. This is particularly true in the application of vitrification to low-level radioactive and mixed waste stabilization. Case-specific evaluations 
are required to determine the highest value, most cost-effective approaches.

\section{6}

$$
\text { V18/023663 }
$$

Arsenic Sorption and Redox Reactions: Relevance to Transport and Remediation

McGeehan, S.L.

University of Idaho, Moscow, ID

Joumal of Environmental Science and Health, Part A Environmental Science \& Engineering 31(9):2319-2336 (October 1996)

Sorption and redox reactions strongly influence the toxicity, bioavailability, and potential mobility of arsenic (As) in soils. The objective of this paper is to describe the impact of soil flooding on the sorption and oxidation state of As. Soils were flooded in a batch system, and aqueous-phase measurements including $\mathrm{Eh}, \mathrm{pH}$, and dissolved $\mathrm{Fe}, \mathrm{Mn}$, and $\mathrm{As}$ were recorded at the end of each flooding period. In addition, aqueous- and solid-phase arsenite and arsenate were determined by ion chromatography and $x$-ray absorption spectroscopy. Soil suspension Eh decreased rapidly during the initial two days of flooding, thereby establishing anaerobic conditions for the remainder of the flooding period. Dissolved $\mathrm{Fe}$ and $\mathrm{Mn}$ levels increased, suggesting reductive dissolution of $\mathrm{Fe}$ and $\mathrm{Mn}$ hydroxides occurred. Dissolved As decreased rapidly during the initial 24 hours of the experiment, most likely the result of sorption. Oxidation state measurements showed dissolved arsenate disappeared with a concurrent increase in dissolved arsenite. Furthermore, solid-phase arsenate declined with a concurrent increase in arsenite. These aqueous- and solid-phase observations indicate that arsenate is reduced to arsenite in flooded soils although it is not clear whether this reduction occurs in solution or on the soil particles.

\section{7}

V18/024647

Assessing Ex/Insitu Full Scale Soil Bioremediation Processes Through Laboratory Experiments: 2 Case Studies

Galvez-Cloutier, R; Yong, R.N.; Hadjinicolaou, J.

McGill University, Geotechnical Research Centre, Montreal, Quebec, Canada

Bioremediation of Pollutants in Soil and Water, B.S. Schepart (ed.), Proceedings of a Symposium, Fort Worth, TX, October 14-15, 1993. American Society for Testing and Materials (ASTM), Philadelphia, PA, 265 pp.; (pp. 49-57) (May 1995)

Bioremediation is considered an innovative technology, essentially because current knowledge concerning the fundamental mechanisms of biodegradation does not allow for a large and safe application of biotechnology. Pre-assay and ongoing monitoring of biotechnology in the laboratory can provide the basic scientific and technical information which assist to improve the efficiency in the field. Two soil bioremediation projects were implemented with parallel assistance of laboratory simulations: (1) the Soil Recycling Demonstration Plant at the Toronto Harbour and (2) the soil decontamination of a Montreal refinery site. The clean-up of the first site is complete while the second is still in progress. Both sites are highly contaminated with petroleum hydrocarbons (20-30 percent oil and grease) and heavy metals (e.g. greater than $600 \mathrm{ppm}$ of $\mathrm{Pb}$ ). The remediation techniques included combined physico/chemical and bioremediation processes in order to tackle both types of contamination. Biostimulation was simulated in large bench-scale reactors in both bio-slurry and solid state form depending on the requirements of the project. The bioremediation controlling parameters which have been assessed in these studies include: (a) screening of reagents, (b) optimization of nutrients and oxygen dosages (concentrations, mixing gradients, contact time), c) effects of hydrocarbon/soil ratios, (d) biodegradation pathways and persistence of products, and (e) microbe family strains and the effects of redox and $\mathrm{pH}$ on population growth. The results showed that valuable scientific and practical information can be obtained from laboratory experiments performed on actual contaminated soils. The major practical advantage being the greater flexibility they provide at lower expense.

\section{8}

V18/023479

Assisted Thermal Stripping (ATS) for Removal of PCBs from Contaminated Soils: Design of Experiments Modeling of the ATS Process

Krabbenhoft, H.O.; Webb, J.L.; Gascoyne, D.G.; Cawse, J.N.

General Electric Company, Corporate Research and Development Center, Schenectady, NY; GE Plastics, Pittsfield, MA

CONF-960807; Proceedings of the 212th American Chemical Society (ACS) National Meeting, Orlando, FL, August 25-30. 1996. ACS, Washington, DC; National Meeting - American Chemical Society, Division of Environmental Chemistry 36(2):7-10 (1996)

In a companion report, the Assisted Thermal Stripping (ATS) process for enhanced removal of PCBs from PCB-contaminated soil is described. In studies directed toward achieving residual PCB levels of less than $2 \mathrm{ppm}$, it was found that four factors were particularly important: (1) process temperature; (2) process time; (3) the amount of additive (for enhancing the removal of PCBs); and (4) steam flow rate. In order to optimize the ATS process, it was deemed crucial to ascertain the relative effect exerted by cach of those process factors and the reproducibility of the process. To accomplish that we have relied on the technique "Design of Experiments" (DOE) to mathematically model the ATS process. After considering the findings from our previous investigations, it was decided to employ formic acid as the additive for enhancing the removal of PCBs.

\section{$2489 \quad$ V18/021818}

Augers Separate Water from Soil: Unique Auger Sets Up Counterflow

Kuhlman, M.I.; Hall, R.

Tuboscope Vetco Environmental Services, Houston, TX Soil and Groundwater Cleanup (May 1995); 3 pp. (May 1995)

A new approach to soil washing is being offered by Tuboscope Vetco International Environmental Services Inc. of Houston. A countercurrent soil washing auger pushes the soil towards its left side, where pressure washing jets are aligned to scour soil up to 17 times with near boiling temperature, high pressure water. Wash water containing dispersed contaminants then flows 
countercurrently down the right side of the auger and out for further treatment. The flights of the auger are fabricated with openings that permit water to flow countercurrently. The auger is mounted in a covered metal trough with the injection jets mounted on top. The system consists of a large particle treatment auger, a fine particle system and a water recycle system that removes metals and hydrocarbons dissolved in process water. The system was used to close a site containing 4560 cubic meters of hydrocarbon and lead contaminated gravel in Prudoe Bay, Alaska. Hydrocarbon contamination was reduced from 5530 to $207 \mathrm{ppm}$, total lead down to $224 \mathrm{ppm}$ from $3330 \mathrm{ppm}$.

V18/024007

Automated Detection and Reporting of Volatile Organic Compounds (VOCs) in Complex Environments

Hargis, P.J., Jr.; Preppernau, B.L.; Osbourn, G.C.; Ricco, A.J.; Frye, G.C.

Sandia National Laboratories, Albuquerque, NM

SAND97-0509; 20 pp. (March 1997)

This paper describes results from efforts to develop VOC sensing systems based on two complementary techniques. The first. technique used a gated channeltron detector for resonant laser-induced multiphoton photoionization detection of trace organic vapors in a supersonic molecular beam. The channeltron was gated using a relatively simple circuit to generate a negative gate pulse with a width of $400 \mathrm{~ns}$ (FWHM), a 50 ns turn-on (rise) time, a 1.5 mu s turn-off (decay) time, a pulse amplitude of -1000 Volts, and a DC offset adjustable from zero to -1500 Volts. The gated channeltron allows rejection of spurious responses to UV laser light scattered directly into the channeltron and time-delayed ionization signals induced by photoionization of residual gas in the vacuum chamber. Detection limits in the part-per-trillion range have been demonstrated with the gated detector. The second technique used arrays of surface acoustic wave (SAW) devices coated with various chemically selective materials (e.g., polymers, self assembled monolayers) to provide unique response patterns to various chemical analytes. This work focused on polymers, formed by spin casting from solution or by plasma polymerization, as well as on seif assembled monolayers. Response from coated SAWs to various concentrations of water, volatile organics, and organophosphonates (chemical warfare agent simulants) were used to provide calibration data. A novel visual empirical region of influence (VERI) pattern recognition technique was used to evaluate the ability to use these response patterns to correctly identify chemical species. This investigation shows how the VERI technique can be used to determine the best set of coatings for an array, to predict the performance of the array even if sensor responses change due to aging of the coating materials, and to identify unknown analytes based on previous calibration data.

\section{$2491 \quad$ V18/021824}

Avoid Unnecessary Remediation: Give Attenuation a Chance

De Rose, $N$.

Langan Engineering and Environmental Services, Inc., Doylestown, PA

Soil and Groundwater Cleanup (October 1995); 4 pp. (October
1995)

Most petroleum products naturally attenuate in the environment.

This is largely due to the volatility of many of the lighter distillates, including petroleum based solvents and motor fuels, and the biodegradability of most of the simpler petroleum compounds which make up motor fuels and lighter heating oils. Recent experience with petroleum hydrocarbon releases from underground storage tank sites shows that completing an accurate and detailed Source Impact Zone Evaluation yields a functional characterization of the subtleties of the site as regards natural attenuation. Often, by completing an effective Source Impact Zone Evaluation and plume delineation, very little additional analysis is needed to demonstrate natural attenuation. Experience on many petroleum release sites has shown that natural attenuation can be demonstrated as the appropriate remediation by relying on basic characterization techniques. The need for complicated sampling and analytical programs is often not necessary or appropriate.

2492

V18/020822

Bacteria Isolated from Amoebae/Bacteria Consortium

Tyndall, R.L.

Martin Marietta Energy Systems, Inc., Oak Ridge, TN

U.S. Patent 05420035; 16 pp. (May 30, 1995)

New protozoan derived microbial consortia and method for their isolation are provided. Consortia and bacteria isolated therefrom are useful for treating wastes such as trichloroethylene and trinitrotoluene. Consortia, bacteria isolated therefrom, and dispersants isolated therefrom are useful for dispersing hydrocarbons such as oil, creosote, wax, and grease.

\section{V18/024315}

Bacterial Treatment System for the Remediation of Trichloroethylene: Final Report - November 1, 1992-December 31, 1994

Shields, M.S.

University of West Florida, Pensacola, FL

Report; 199 pp. (October 1996)

A genetically altered bacterium Burkholderia (Pseudomonas) cepacia PR123 and closely related genetic derivatives were tested for bioreactor and in situ trichloroethylene (TCE) degradation. PR123 was shown to degrade TCE in a plugged flow bioreactor, but failed to form a stable biofilm under test conditions at Hanscom AFB. Indigenous microorganisms dominated the reactors shortly after inoculation in every instance, despite changes in support matrix and primary carbon source. The continuous addition of the genetically altered bacterium did achieve a significant (greater than $80 \%$ ) removal of TCE and cis-dichloroethylene from the waste stream at concentrations of 500-800 ug/L, at $0.26 \mathrm{gpm}$, thus confirming the capacity of the constitutively expressed toluene ortho-monooxygenase (TOM) to cooxidize TCE under environmental conditions. For this reason the TOM constitutive plasmid, TOM31c (a kanamycin resistant derivative of TOM), was transferred to two superior biofilm forming bacteria, $P$. capacia 17616 and $\mathrm{P}$. sp JSI5O, and dominant aquifer bacterium from Wichita KS WS23. These transconjugants also constitutively degraded TCE, but were no more competitive in biofilm reactors 
than PR123. In column tests greater than $95 \%$ of the TCE was degraded in an 8 hour residence time.

\section{4}

V18/022653

Barometric Pumping With a Twist: VOC Containment and Remediation Without Boreholes - Phase I: Topical Report

Science and Engineering Associates, Inc., Santa Fe, NM DOE/MC/32109-5285; 126 pp. (August 1996)

The majority of the planned remediation sites within the DOE complex are contaminated with volatile organic compounds (VOCs). In many instances the contamination has not reached the water table, does not pose an immediate threat, and is not considered a high priority problem. These sites will ultimately require remediation of some type, either by active vapor extraction, bioremediation, or excavation and exsitu soil treatment. The cost of remediating these sites can range from $\$ 50 \mathrm{~K}$ to more than $\$ 150$ $\mathrm{K}$, depending on site characteristics, contaminants, and remediation method. Additionally, for many remediated sites, residual contamination exists which could not practically be removed by the applied remediation technology. These circumstances result in modest sites with contamination of limited risk, but by regulation they must still be controlled. A remediation solution being developed by Science and Engineering Associates, Inc. (SEA) for the Department of Energy serves as an in-situ containment and extraction methodology for sites where most or all of the contamination resides in the vadose zone soil. The approach capitalizes on the advective soil gas movement resulting from barometric pressure oscillations.

\section{5 \\ V18/022013}

Baseline Geoenvironmental Experiments for Insitu Soil Transformation by Plasma Torch

Beaver, J.R.; Mayne, P.W.

Georgia Institute of Technology, School of Civil and Environmental Engineering, Atlanta, GA

CONF-9510125 (Vol. 2); Plasma Systems and Applications, P.W. Mayne and J.A. Mulholland (eds.), Proceedings of an Intemational Symposium on Environmental Technologies, Atlanta, GA, October 8-11, 1995. Georgia Institute of Technology, Atlanta, GA, Vol. 2, 392 pp.; (pp. 617-630) (1995)

The advent of the nontransferred plasma arc torch has implicated a range of in-situ geoenvironmental applications that can revolutionize methods of ground modification and field remediation of contaminated sites. Historically, the use of high temperature methods for site improvement has been inhibited by difficulties in the control and application of high temperatures, uncertainties in the final effectiveness, and high costs. With reverse polarity nontransferred arc type plasma torches, temperatures at 4000 degrees $C$ to 7000 degrees $C$ can be directed at specific targets of contaminated soil or waste. At these extreme temperatures, all organic materials within the soil undergo pyrolysis, while the bulk composition is transformed into a magma that subsequently cools to form a vitrified mass resembling volcanic obsidian or a dense partially crystalline material resembling microcrystalline igneous rock. Preliminary experiments to evaluate the effectiveness of the plasma torch for in-situ transformation of soil, contaminated ground, and wastes have been funded by the National Science Foundation and the Federal Highway Administration. Simulations of in-situ transformation of soil have been conducted at the Georgia Institute of Technology using both $100-\mathrm{kW}$ and $240-\mathrm{kW}$ torches to alter clay, silty sand, and sand in chamber tests. Although these materials are primarily composed of silica and alumina oxides having melting temperatures of 1100 degrees $C$ to 1600 degrees $C$, the formation of a spheroidal magma core occurred within the first five minutes of exposure to the plasma flame. Experiments were conducted to quantify the improved engineering properties that occur after transformation and to demonstrate the relative effects of power level, water content, and soil type on the size and strength of the altered material. The ongoing research also serves as a baseline study for further experimentation that will focus on the in-situ remediation of soils with varied contaminants.

2496 V18/021711

Beginning Soil Cleaning

Laramee, $\mathrm{V}$.

Environnement Magazine 1547:29-31 (May 1996)

The cleaning of contaminated soils will start slowly. However, an acceleration has been expected for a long time by professional decontamination professionals who see a market of several hundred sites open in the next months. (This document is in French).

\section{7}

V18/020939

Bench- and Pilot-Scale Demonstration of Treatment of Mixed Waste Sediments by Thermal Desorption and Soil

Morris, M.I.; Grosse, D.W.; Alperin, E.S.; Sadler, K.G.; Shealy, S.E.

Lockheed Martin Energy Systems, Inc., Oak Ridge, TN; U.S. Environmental Protection Agency, Risk Reduction Engineering Laboratory, Cincinnati, OH; International Technology Corporation, Knoxville, TN

CONF-960212; Waste Management '96: Working Towards a Cleaner Environment, Proceedings of a Conference on HLW, LLW, Mixed Wastes and Environmental Restoration, Tucson, AZ, February 25-29, 1996; (17 pp.) (1996)

The 1992 Oak Ridge Reservation FFCA listed a number of mixed wastes, subject to LDR, for which no treatment method had been identified, and required DOE to develop strategies for treatment and ultimate disposal of those wastes. Thermal Desorption and soil washing are two emerging commercial technologies that have typically been used for removing hazardous organics and heavy metals from contaminated soils, sediments and sludges that are similar to many of these wastes. This paper presents the results of a program to demonstrate that these technologies can remove both organics, uranium and mercury from a mixed waste from the DOE Y-12 facility in Oak Ridge. TN. This mixed waste sediment from the plant storm sewer system contained mercury, uranium and PCBs. Leachable mercury exceeded TCLP and LDR criteria. This program included bench- and pilot-scale testing of thermal desorption technology. This study also included testing of a soil washing process using physical separation and carbonate extraction to remove uranium. The pilot-scale testing was supported by DOE and EPA through the SITE Emerging Technology Program. Results 
of the bench-scale testing of the thermal desorption technology showed that total mercury could be reduced to $120 \mathrm{ppm}$ by treatment at $600 \mathrm{deg} C$, which is at the high end of the temperature range for typical thermal desorption systems. Leachable (TCLP) mercury was less than $50 \mathrm{ppb}$ and PCBs were below $2 \mathrm{ppm}$. Mercury removal in the pilot-scale thermal desorption system was not as high, most likely due to kinetic effects of mercury oxide compound decomposition or inadequate flow of purge gas in the thermal desorber tube. Treated soil from the pilot test did pass TCLP for mercury. The pilot-scale thermal desorption treatment was effective in removing PCBs. The testing also provided information on the characteristics and quantities of residuals from the thermal desorption process. The soil washing process resulted in removal of roughly $50 \%$ of the uranium from the sediments and the carbonate extraction was only marginally effective, indicating that the thermal treatment converted uranyl compounds to less soluble species. This program demonstrated that thermal desorption was an effective technology for treating this material to meet waste acceptance criteria for uitimate disposal at a commercial facility.

\section{8}

\section{V18/025431}

\section{Bench-Scale Remediation Composting: Process} Principles and Protocol

Preston, K.T.; Seiden, S.; Ro, K.S.

U.S. Army Corps of Engineers, Waterways Experiment Station, Vicksburg, MS

WES-IR-RP-97-1; 99 pp. (February 1997)

The purpose of this report is to apply the principles of biochemical process kinetics, mass and heat transfer, and major process parameters in the design and application of bench-scale compost systems. The premise is that understanding the fundamentals of the system in the engineering sense will assist to provide a technical foundation for standard bench-scale composting protocols. Process kinetics as they relate to organic substrate use, overall, and the kinetics of explosive compound degradation/transformation are discussed. Also discussed are the physical, chemical, biological, and thermodynamic factors central to the application of bench-scale compost systems. Finally, the outline of a standard remediation composting protocol built on a foundation of fundamentals is provided. The approach described in this report is providing a basis for two currently ongoing bench-composting investigations.

2499

\section{V18/020695}

Bench-Scale Vitrification Studies with Savannah River Site Mercury Contaminated Soil

Cicero, C.A.; Bickford, D.F.

Westinghouse Savannah River Company, Aiken, SC WSRC-MS-95-0423; CONF-960212; Waste Management '96: Working Towards a Cleaner Environment, Proceedings of a Conference on HLW, LLW, Mixed Wastes and Environmental Restoration, Tucson, AZ, February 25-29, 1996; (13 pp.) (1995)

The Savannah River Technology Center (SRTC) has been chartered by the Department of Energy (DOE)--Office of Technology Development (OTD) to investigate vitrification technology for the treatment of Low Level Mixed Wastes (LLMW). In fiscal year 1995, mercury containing LLMW streams were targeted. In order to successfully apply vitrification technology to mercury containing LLMW, the types and quantities of glass forming additives necessary for producing homogeneous glasses from the wastes have to be determined and the treatment for the mercury portion must also be determined. Selected additives should ensure that a durable and leach resistant waste form is produced, while the mercury treatment should ensure that hazardous amounts of mercury are not released into the environment. The mercury containing LLMW selected for vitrification studies at the SRTC was mercury contaminated soil from the TNX pilot-plant facility at the Savannah River Site (SRS). Samples of this soil were obtained so bench-scale vitrification studies could be performed at the SRTC to determine the optimum waste loading obtainable in the glass product without sacrificing durability and leach resistance. Vitrifying this waste stream also required offgas treatment for the capture of the vaporized mercury.

2500

V18/022679

Bentonite Mat Demonstration: Field Performance Evaluation of an Alternative Geosynthetic Composite Cover System

Serrato, M.G.

Westinghouse Savannah River Company, Savannah River Technology Center, Aiken, SC

CONF-941124; Insitu Remediation: Scientific Basis for Current and Future Technologies, G.W. Gee and N.R. Wing (eds.), Proceedings of the 33rd Hanford Symposium on Health and the Environment. Pasco, WA, November 7-11, 1994. Battelle Press, Columbus, OH. Part 2, 605 pp.; (pp. 649-662) (1994)

The Savannah River Site is investigating an altemative RCRA closure cover system configuration for hazardous solid-waste landfills. The bentonite mat demonstration is a field performance test of an alternative composite geosynthetic material cover configuration. The bentonite mat demonstration consists of four test pads; each test pad is a compacted sandy clay layer $30 \mathrm{ft}$ wide, $80 \mathrm{ft}$ long, and $2 \mathrm{ft}$ deep. Three of the test pads will be blanketed with one of the commercially available bentonite mats (geosynthetic clay liner), then overlain by a flexible membrane liner to form the composite barrier. The remaining test pad will not contain any geosynthetic materials and will be used as the control pad for the demonstration. Each test pad will be constructed over a 4-ft sand layer. A series of access pipes will be embedded in the sand layer to provide a means for evacuating portions of the sand layer in order to create underlying cavities, thus inducing localized subsidence in the test pad. Material stress data will be collected to identify the composite barrier failure point. Infiltration data will be collected for each test pad to correlate permeability as a function of deflection. At the conclusion of the subsidence testing, the test pads will be dismantled to identify the failure mechanisms of the barriers. A finite-element analysis computer model is being developed to predict the structural behavior of the composite barrier system. The bentonite mat demonstration data will be used to verify this model, which will serve as a diagnostic tool for future designs. The formulation and execution of this demonstration is one element in achieving regulatory approval of the composite geosynthetic materials altemative cover system design configuration. 
BetaScint: Sniffing Out the Good, the Bad, and the Ugly

Initiatives in Environmental Technology Investment 3(June 1996):6-7 (June 1996)

Researchers are speeding the commercialization and use of an innovative fiber-based sensor that can analyze soils for uranium and strontium contamination. The sensor, known as BetaScint, was developed at Battelle's Pacific Northwest National Laboratory. It is portable and can provide on-site results within minutes which eliminates the risk and expense of transporting contaminated samples to an off-site laboratory where the waiting time may be weeks and costs can range from $\$ 100$ to $\$ 200$ per sample. Those costs are roughly two to five times higher than using BetaScint. This article highlights several government and private industry applications and efforts to commercialize the technology.

2502 V18/022648

Bio-Enhanced Thin-Spreading: A Low Cost Soil Remediation Alternative

Wong, G.; Pfarrer, R., III

Kohler Company, Kohler, WI

CONF-9505206; Proceedings of the 50th Industrial Waste

Conference, R.F. Wukasch (ed.), West Lafayette, IN, May 8-10, 1995. Ann Arbor Press, Inc., Chelsea, MI, 861 pp.; (pp. 513-526)

(1996)

Products manufactured at Kohler Company's Kohler, Wisconsin plant include a variety of plumbing fixtures, including vitreous china toilets and sinks, cast iron enameled sinks and tubs, electroplated faucets, assorted plumbing fittings, and small engines. This paper focuses on a soil remediation project performed at the Kohler Company's Kohler, Wisconsin facility. In order to implement this soil remediation project, close coordination and communication was required with many project entities including numerous company departments, contractors, regulatory agencies, and the general public. Using an innovative and cost-effective soil treatment method called bio-enhanced thin-spreading (BETS), over 5,000 cubic yards of kerosene-contaminated soils were successfully remediated. The purpose of this case study is: (1) to describe the technical aspects of the remediation project including the BETS soil treatment method; and (2) to discuss factors which can significantly influence the development, management, and implementation of environmental remediation projects at large manufacturing facilities.

\section{3}

V18/023191

Biodegradation/Bioventing Process for the Treatment of Organic Contamination in Soil

Pouliot, Y.; Sansregret, J.L.; Cyr, B.

Biogenie, Inc., Sainte-Foy, Quebec, Canada

CONF-9210194; Proceedings of an International Symposium on Environmental Contamination in Central and Eastern Europe, Budapest, Hungary, October 12-16, 1992, 968 pp.; (pp. 279-283) (1992)

The process consists of a solid reactor where the contaminated soil is placed in a pile with an aeration and an irrigation system. Depending on the quantity of volatile compounds in the soil, the aeration system is either equipped with an activated carbon filter (for low concentrations) or a biofilter. The system can be used for a large variety of organic compounds and allows for addition of surfactants, co-substrates, or acclimated bacteria, when needed. It is applicable either in a treatment centre where the contaminated soil is trucked in or for a specific site in which case mobile units are used. Clean-up criteria have been reached for soils contaminated with gasoline, jet fuel, diesel fuel (up to $60,000 \mathrm{ppm}$ ), insulating oil, motor oil, crude oil, and pentachlorophenol (up to $10,000 \mathrm{ppm}$ in wood chips). Results indicate that emission regulations were met and that overall treatment costs are considerably less than those for other types of remediation technologies for treating soils contaminated with organics.

2504

V18/021713

Biofluffing: Enhancing Biological Remediation of Near-Surface Spills by Augering

Stehmeier, L.; Ikeda-Cameron, K.; Francis, M.; Young, B.

Environment Canada, Ottawa, Ontario, Canada; Novacor Research and Technology Corporation, Calgary, Alberta, Canada

CONF-9606265; Proceedings of the 19th Arctic and Marine Oilspill Program (AMOP) Technical Seminar, Calgary, Alberta, Canada, June 12-14, 1996. Environment Canada, Ottawa, Ontario, Canada; (pp. 1283-1299) (1996)

A field site where a minor spill of hydrocarbon material had occurred was chosen to study the effects that augering would have on soil decontamination. The soil was impermeable moist clay. Therefore, remediation methods that rely on a porous soil would not have been appropriate in this case. Excavation was not considered feasible either, since studies have shown that during excavation more than $90 \%$ of the volatile components are released to the atmosphere, causing safety hazards. Efficient bioremediation needs the presence of nutrients and oxygen. Before the site was augered, nitrogen and phosphorous fertilizers were spread over the area. Augering allowed the percolation of nutrients to $90 \mathrm{~cm}$ depth, and increased the redox potential. It held the volatilization of hydrocarbons to less than $2 \%$ of the initial concentration. Total hydrocarbon contaminants were reduced by $78 \%$ in 116 days. It was concluded that augering was economical and that it protected the environment by minimizing the release of volatile compounds while enhancing soil remediation.

2505

V18/023795

Biofouling: A Critical Consideration for Evaluating Insitu Biotreatment Feasibility

Kaufman, A.K.

Consultant, Los Angeles, CA

CONF-9504134; HAZMACON '95, T. Bursztynsky and M.L. Loss (eds.), Proceedings of the Twelfth Hazardous Materials Management Annual Conference and Exhibition, San Jose, CA, April 4-6, 1995. Association of Bay Area Governments, Oakland, CA, 790 pp.; (pp. 358-362) (1995)

In situ bioremedial treatment continues to be utilized with greater frequency as a preferred method for the mitigation of hydrocarbon-impacted soil and/or groundwater due to associated technical, economic, and practical benefits. While numerous 
successful case histories and project completions have been reported, inappropriate application of in situ bioremedial treatment technologies have resulted in notable project failures, most of which could have been avoided if appropriate feasibility parameters had been addressed prior to process implementation. While site-specific microbiological and physicochemical constraints are certainly issues which require consideration in evaluating in situ feasibility, the potential for biofouling and associated events are aspects which, unfortunately, are too infrequently considered as feasibility parameters.

\section{6}

\section{V18/021998}

\section{Biological Degradation of TNT-Contaminated Soil}

Manning, J.F.; Boopathy, R.

Argonne National Laboratory, Argonne, IL CONF-9509139; Emerging Technologies in Hazardous Waste Management VI, D.W. Tedder (ed.), Proceedings of the Seventh American Chemical Society Industrial and Engineering Chemistry Division Special Symposium, Atlanta, GA, September 17-20, 1995. American Chemical Society, Washington, DC, 1291 pp.; (p. 528) (1995)

The concept of using biological siurry reactors to remediate soil contaminated with TNT has been investigated at the laboratory scale. Important parameters include an organic co-substrate and appropriate amounts of nitrogen and phosphorus added as nutrients. Normally, the degradation requires an organic co-substrate. The type of co-substrate can have a significant impact on the rate and extent of degradation. Succinate, malate, molasses, and glucose are all acceptable co-substrates. Molasses, or succinate with added yeast extract and/or peptone, provides superior rates of removal. Consortia of microorganisms isolated from various sites can also degrade TNT. To exploit the microbial system, laboratory scale soil slurry reactors have been operated, achieving reductions in TNT concentrations on the order of $90-99 \%$ from initial TNT concentrations of 7,000-10,000 mg/kg. Laboratory scale tests have shown that all of the intermediates can be removed by microbial degradation. Laboratory reactors operated with $15 \%$ volume replacement one, two, or three times a week achieved removal of $95-99 \%$ of the TNT in the feed soil. This system can reduce TNT concentrations to less than $20 \mathrm{mg} / \mathrm{kg}$ in treated soil. In particular, operation of the reactors in an aerobic-anoxic sequenced pattern promotes the conversion of TNT to $\mathrm{CO} 2$ and microbial biomass. Radiolabeling studies demonstrated that $50 \%$ of the TNT is mineralized, with $30 \%$ of the original labeled TNT being converted to microbial biomass. To take advantage of this technology, a field demonstration in which the soil slurry reactor is being used to degrade explosives-contaminated soil is currently being conducted. (Complete text)

\section{7}

\section{V18/023793}

Biological Forced Air Soil Treatment (BIOFAST [TM]) System: A Field Application

Anenson, T.B.

International Technology Corporation, Martinez, CA CONF-9504134; HAZMACON '95, T. Bursztynsky and M.L. Loss (eds.), Proceedings of the Twelfth Hazardous Materials Management Annual Conference and Exhibition, San Jose, CA,
April 4-6, 1995. Association of Bay Area Governments, Oakland, CA, 790 pp.; (pp. 344-353) (1995)

A biological forced air soil treatment (BIOFAST [TM]) system was constructed at the Beatrice/Hunt-Wesson site in Northem California to treat approximately 2,000 cubic yards of soil impacted with diesel fuel and heavy bunker oil. To determine if bioremediation was a feasible option, five soil samples were submitted for a bioassessment. The results indicated that the soils contained elevated levels of hydrocarbon-degrading bacteria and very low nutrient concentrations. The results also suggested that moisture and $\mathrm{pH}$ were variable and, in some cases, were outside the ideal range for bioremediation. The results were used to determine the full-scale design and operating parameters to treat the soil on site. The system began operation in early 1992. Results from periodic monitoring suggested that biodegradation was occurring. Hydrocarbons were reduced by more than 72 percent after the first few months of system operation. The target level of 1,000 parts per million (ppm) of hydrocarbons was attained using BIOFAST [TM] and the soil was transported off site for disposal.

2508 V18/024663

Biological Land Treatment of Diesel Fuel-Contaminated Soil: Emergency Response Through Closure, Chapter 7

Troy, M.A.; Berry, S.W.; Jerger, D.E.

OHM Remediation Services Corporation, Trenton, NJ; OHM Remediation Services Corporation, Findlay, $\mathrm{OH}$

Bioremediation: Field Experience, P.E. Flathman, D.E. Jerger and J.H. Exner (eds.), Lewis Publishers, Boca Raton, FL, 560 pp.; (pp. 145-160) (1994)

Land treatment is described as the managed treatment and ultimate disposal process that involves the regulated application of a waste to a soil or soil vegetation system. This type of treatment process is viewed as a series of unit operations that utilize the soil to breakdown, assimilate, transform, and immobilize certain waste components. Land treatment systems have been utilized for the disposal of a variety of industrial wastes, such as those from the food processing, organic chemical manufacturing, coke, textile, and pulp and paper industries. The objective of presenting this case study is to describe the biological land treatment techniques that were employed for the cleanup of approximately $8400 \mathrm{gal}(32,000$ L) of diesel fuel that had been spilled onto the soil from the dispensing nozzle of an underground storage tank at a warehouse in New Jersey. Biological land treatment of diesel fuel focuses on the breakdown of the petroleum hydrocarbon fractions by aerobic microorganisms in the layers of the soil where oxygen is made available. Metabolism by these microorganisms ultimately reduces the hydrocarbons to carbon dioxide ( $\mathrm{CO} 2)$, water, and biomass. This chapter is from the book entitled Bioremediation: Field Experience.

2509 V18/020826

Biological Process for Recovery of Plutonium from Contaminated Soils

Rusin, P.A.

Metallurgical and Biological Extraction Systems, Inc., Tucson, AZ 
U.S. Patent 05422268; 10 pp. (June 6, 1995)

This patent describes a biological process for recovering plutonium from soils using an iron-reducing bacterium, Bacillus circulans NRRL B-21037. A process for obtaining such bacteria is disclosed. The invention process gives upwards of about $88 \%$ yield of plutonium from soils. Further, pertinent gene(s) encoding enzymes obtainable from iron-reducing microbes can be used by placing such gene(s) on a suitable vector and transforming a competent host. The transformed host then can be used in the same manner as the native bacterium.

\section{$2510 \quad$ V18/023502}

Biological and Chemical Remediation of RDX and HMX Apblett, A.W.; Ensley, H.E.; Reinhardt, L.E.

Tulane University, New Orleans, LA

CONF-960807; Proceedings of the 212th American Chemical Society (ACS) National Meeting, Orlando, FL, August 25-30, 1996. ACS, Washington, DC; National Meeting - American Chemical Society, Division of Environmental Chemistry 36(2):12-14 (1996)

Contamination of water and soils by residual explosives and their byproducts at military sites throughout the world is quite common. Most remedial studies have focussed on TNT, but other military explosives such as RDX and HMX may also pose environmental hazards. For example, RDX has been used as a rat poison and it can cause epileptic seizures in humans. In this investigation, biological and chemical studies are combined to provide insight into the behavior (physical and biological) of RDX and HMX as they pass through wetland ecosystems as well as to develop technology for the remediation of these compounds.

\section{1 \\ V18/025377}

Biologically Mediated Dissipation of Polyaromatic Hydrocarbons in the Root Zone, Chapter 12

Schwab, A.P.; Banks, M.K.

Kansas State University, Department of Agronomy, Manhattan, KS; Kansas State University, Department of Civil Engineering, Manhattan, KS

Bioremediation Through Rhizosphere Technology, T.A. Anderson and J.R. Coats (eds.), American Chemical Society, Washington, DC, 249 pp.; (pp. 132-141) (1994)

Soil contaminated with petroleum sludge is often bioremediated by tillage and addition of nitrogen and phosphorus to stimulate microbial degradation of the hazardous compounds. This "landfarming" technique is effective in reducing concentrations of a variety of chemicals during the early stages of treatment, but degradation rates severely decline thereafter, especially for recalcitrant compounds such as polyaromatic hydrocarbons (PAHs). However, the presence of vegetation can enhance the degradation of these compounds. In a greenhouse experiment, the degradation of PAHs was greater in the presence of plants than in their absence. Target PAHs were detectable in the plant tissue, but the total quantity of uptake was insignificant. Enhanced microbial activity was apparently responsible for increased dissipation of target PAHs. Establishment of vegetation holds promise as an inexpensive yet effective means of passive remediation of sites contaminated with petroleum hydrocarbons. This chapter summarizes the work to date using mycorrhizal fungi in bioremediation studies.

2512

V18/025369

Bioremediation Through Rhizosphere Technology

Bioremediation Through Rhizosphere Technology, T.A. Anderson and J.R Coats (eds.), American Chemical Society, Washington, DC, 249 pp. (1994)

This book addresses the potential use of the rhizosphere for bioremediation. The book is divided into four sections. Overviews of bioremediation and rhizosphere microbiology are provided in the first section. The interactions between microorganisms, plants, and chemicals in the thizosphere are presented in six chapters contained in the second section. The degradation of industrial chemical in the rhizosphere, including polycyclic aromatic hydrocarbons and chlorinated phenols, is presented in the third section. Finally, the section on microbial degradation of pesticides in the rhizosphere contains chapters on herbicides as well as applications to pesticide contaminated sites. Individual papers within the scope of this data base have been indexed separately.

\section{3}

V18/022657

Bioremediation Using Composting or Anaerobic Treatment for Ordnance-Contaminated Soils

Tuomi, E.; Coover, M.P.; Stroo, H.F.

Remediation Technologies, Inc., Seattle, WA

CONF-960393 (Part 3); Contaminated Soils and Groundwater:

Analysis, Fate, Environmental and Public Health Effects, and Remediation, Proceedings of the Sixth Annual West Coast Conference, Newport Beach, CA, March 11-14, 1996. Association for the Environmental Health of Soils, Amherst, MA, Part 3, 366 pp.; (p. 33) (1996)

Govermment installations nationwide are faced with the problem of cleaning up soils contaminated with ordnance compounds. The materials have been introduced into the environment through the manufacture, use, storage, and disposal of explosives such as 2,4,6-trinitrotoluene (TNT),

octahydro-1,3,5,7-tetranitro-1-3-5-7-tetraazocine (HMX), and hexahydro-1,3,5-trinitro-1,3,5-triazine ( $R D X)$. The effectiveness of aerobic biological treatment (composting) for the remediation of nitroaromatics-impacted soils has been confirmed in several laboratory and field studies. Composting involves the incubation of contaminated soils with organic amendments under thermophilic conditions ( 40 to $70 \mathrm{C}$ ). Over the last several years, the remediation of nitroaromatics-contaminated soils has been demonstrated using the Simplot Anaerobic Bioremediation (SABRE[trademark]) process developed by the University of Idaho and the J.R. Simplot Company. Both processes were proven effective at the bench-scale for the remediation of two ordnance-contaminated soils from a local Naval Installation. This paper presents the results of the pilot-scale testing of these technologies conducted from December 1994 through March 1995 at the Bangor Naval Submarine Base (Silverdale, Washington). Goals of the pilot study were to provide cost and design information for the implementation of the full-scale remediation scheduled for mid 1996. 


\section{Bioremediation of Contaminated Sediments}

Hughes, J.B.; Jee, V.; Ward, C.H.

Rice University, Department of Environmental Science and Engineering, Houston, TX

EPA/600/R-95/012; CONF-9504110; Proceedings of the 21st Annual Risk Reduction Engineering Laboratory (RREL) Research Symposium, Cincinnati, OH, April 4-6, 1995. U.S. Environmental Protection Agency, Cincinnati, OH, 398 pp.; (pp. 236-242) (April 1995)

Contaminants in bottom sediments have historically been considered to have minimal environmental impact because they are buried, sorbed, or electrostatically bound to clay particles or incorporated into humus. However, resuspension of bottom sediments makes contaminants more available for dispersal into the marine environment. The focus of this research was to examine the relationship between resuspension and biodegradation of polycyclic aromatic hydrocarbons (PAH) in laboratory scale slurry reactors. The rate and extent of contaminant release from the sediments into an uncontaminated water column was determined, oxygen demand of initially anaerobic sediments was investigated, and the rate and extent of phenanthrene biodegradation was examined. It can be concluded from the experiments that resuspension of anaerobic sediments can affect the degradation of phenanthrene sorbed to them. Sediments with contamination levels of $50 \mathrm{ppm}$ phenanthrene were remediated in the laboratory reactor to the point that only trace phenanthrene was found after five days. Mixing and aeration were the only treatment used. However, due to the time required to see complete degradation, it is unlikely that mixing and aeration provided solely by dredging can be considered a remedial treatment. Potential exsitu and in situ constructed reactors are considered.

\section{5}

V18/025014

Bioremediation of PCBs: CRADA Final Report (CRADA ORNL 90-0039)

Klasson, K.T.; Abramowicz, D.A.

Oak Ridge National Laboratory, Oak Ridge, TN; General Electric Company, Corporate Research and Development Center, Niskayuna, NY

ORNL/TM-13242; 137 pp. (June 1996)

The Cooperative Research and Development Agreement was signed between Oak Ridge National Laboratory (ORNL) and General Electric Company (GE) on August 12, 1991. The objective was a collaborative venture between researchers at $G E$ and $O R N L$ to develop bioremediation of polychlorinated biphenyls (PCBs). The work was conducted over three years, and this report summarizes ORNL's effort. All planned tasks in the Cooperative Research and Development Agreement (CRADA) were not completed due to technical issues and funding limitations. A major accomplishments by ORNL, not previously demonstrated, was the utilization of existing bacterial consortia (obtained from GE) for PCB dechlorination in soils. The work conducted at ORNL has generated 15 publications and presentations. A significant achievement was reached by $G E$ when demonstrating the anaerobic $P C B$ dechlorination in a field study. During this study, it was found that field study results compared well results obtained in the laboratory on a much smaller scale.

2516

V18/025281

Bioremediation of Petroleum-Contaminated Soil on Kwajalein Island: Microbiological Characterization and Biotreatability Studies

Adler, H.I.; Jolley, R.L.; Donaldson, T.L.

Oak Ridge Associated Universities, Oak Ridge, TN; Oak Ridge National Laboratory, Chemical Technology Division, Oak Ridge, TN

ORNL/TM-11925; 72 pp. (May 1992)

Bioremediation technology is being evaluated for use on the Kwajalein Atoll, which is located in the Republic of the Marshall Islands. The study was undertaken by the Oak Ridge National Laboratory (ORNL) on behalf of the U.S. Army Kwajalein Atoll (USAKA). During February of 1991, a team from ORNL and The University of Tennessee (UT) visited the USAKA. In addition to making on-site observations regarding microbial abundance and distribution of petroleum contaminants, they brought back to Oak Ridge various soil and water samples for detailed analyses. This report documents the biological studies of these samples and presents observations made during the period from February to April 1991 by investigators at ORNL, UT, and the Oak Ridge Associated Universities.

\section{7}

\section{V18/020832}

Bioremediation of Polycyclic Aromatic Hydrocarbon-Contaminated Soil

Lee, S.G.; Cutright, T.J.

University of Akron, Akron, $\mathrm{OH}$

U.S. Patent 05427944; 13 pp. (June 27, 1995)

A mixed bacteria culture for biodegrading polycyclic aromatic hydrocarbon contaminants includes Achromobacter sp. and Mycobacterium sp. which have been grown together and gradually acclimated to utilize polycyclic aromatic hydrocarbons as a primary food source. The mixed bacteria culture can be utilized for in situ or exsitu bioremediation of contaminated soil, or in any of various conventional bioreactors to treat contaminated liquids such as landfill leachates, groundwater or industrial effluents. The bacteria, the nutrients used to sustain growth of the bacteria, and the products of the biodegradation of the polycyclic aromatic or other hydrocarbons are all substantially harmless to the environment. The mixed bacteria can be utilized in the presence of oxygen, or hydrogen peroxide can be used alone or in combination with oxygen as an effective altemative electron acceptor. The mixed bacteria culture of Achromobacter sp. and Mycobacterium sp. provides an environmentally safe and affordable means for rapidly and effectively eliminating a variety of polycyclic aromatic hydrocarbon contaminants from the environment.

\section{V18/022234}

Bioremediation of Soils Impacted by Chlorinated Pesticides/Herbicides and Nitroaromatics

Fisher, D.R.; Seech, A.G.; Bucens, P.G.

Grace Dearborn Inc., Mississauga, Ontario, Canada

CONF-951139 (Vol. 2); Superfund 16: Proceedings of a Hazardous 
Waste Conference and Exhibition, Washington, DC, November 6-8, 1995. E.J. Krause and Associates, Bethesda, MD, Vol. 2, 817 pp;; (pp. 1176-1179) (1994)

Chlorinated pesticide and herbicide manufacturing and application, coupled with the long natural half-lives of these compounds, has resulted in many incidents of soil contamination throughout the world. Soils impacted by nitroaromatics such as 2,4,6-trinitrotoluene (TNT), due largely to past military activities, are also common. The potential environmental and human health risks are spawning development of various technologies to remediate these impacted soils. Daramend [TM] bioremediation technology, developed by Grace Dearborn Inc. (Dearborn), has been proven effective at bench-, pilot- and full-scale for remediation of soils impacted by PAHs, petroleum hydrocarbons and chlorinated phenols. Research conducted by Daramend has extended application of Daramend bioremediation to chlorinated pesticide/herbicide and TNT impacted soils. This paper discusses this research.

\section{9}

V18/024693

Bioremediation of Surface and Subsurface Soils, Chapter 6

Baker, K.H.

Environmental Microbiology Associates, Inc., Harrisburg, PA

Bioremediation, K.H. Baker and D.S. Herson (eds.), McGraw-Hill, Inc., New York, NY, 404 pp.; (pp. 203-259) (1994)

This is a chapter from the book titled, Bioremediation. Contamination of soils can occur through the accidental release of materials on the surface or through the direct introduction of contaminants into the subsurface, as in the case of leaking underground storage tanks. From the perspective of remediation, the soil environment can be divided into two zones: shallow surface soils and subsurface (vadose) soils. Shallow surface soils usually include the upper 1 to $3 \mathrm{ft}$ of the soil environment. These soils represent the region of the environment typically included in the agronomic definition of soils. They are easily modified and are generally more amenable to remediation than deeper vadose soils. Operationally, surface soils can be defined as those soils which can be excavated or treated by surface amendments not requiring the installation of wells. Vadose soils are those soils which lie between the surface soils and the water table or aquifer. Vadose soils are generally unsaturated, although there may be pockets of water saturated soil within the vadose zone, particularly in the area of the root zone and in the capillary fringe at the surface of the water table. In addition, there may be inclusions of low permeability materials such as clay lenses within the vadose zone which can become saturated with water. Unlike surface soils, vadose soils are often not amenable to excavation or surface treatment; rather, modification of such soils usually involves the use of infiltration galleries, injection wells, or other engineered means for introducing materials. This chapter will briefly review the fate and transport of contaminants within the subsurface environment. Factors which limit microbial activity and hence biodegradation in soils will be covered briefly. Basic techniques for soil treatment both in situ and using engineered systems such as bioreactors will be reviewed. Emphasis will be given to field studies.
2520

V18/023883

Bioremediation of Trinitrotoluene [sic] by a Ruminal Microorganism

Lee, T.; Williamson, K.J.; Craig, A.M.

Oregon State University, Corvallis, OR

EPA/600/R-95/012; CONF-9504110; Proceedings of the 21st Annual Risk Reduction Engineering Laboratory (RREL) Research Symposium, Cincinnati, OH, April 4-6, 1995. U.S. Environmental Protection Agency, Cincinnati, OH, 398 pp.; (pp. 278-282) (April 1995)

2,4,6-trinitrotoluene (INT) has been widely used for the production of explosives because of its low boiling point, high stability, low impact sensitivity, and safe manufacture. More than 1,100 military facilities, each potentially contaminated with munitions waste, are expected to require treatment of more than one million cubic yards of contaminated soils. Recently, researchers have studied ruminal microorganisms in relation to their ability to degrade xenobiotic compounds. A TNT-degrading ruminal microorganism has been isolated from goat rumen fluid with successive enrichments on triaminotoluene (TAT) and TNT. The isolate, designated G.8, utilizes nitrate and lactate as the primary energy source. $G .8$ was able to tolerate and metabolite levels of TNT up to the saturation point of $125 \mathrm{mg} / 1$. Based on the results of previous studies, the present research was directed at understanding the process of TNT degradation by G.8. The isolate was incubated in serum bottles containing a variety of media. TNT and its breakdown products were measured by high performance liquid chromatography. Other products were measured with gas chromatography/mass spectroscopy or ion spectroscopy. The G.8 isolate was capable of reducing the TNT nitro group to an amino group and was also involved in deaminization as a co-metabolite, resulting in nitrogen free compounds such as toluene or o-cresol. Specific metabolites and transformation processes are discussed.

2521

V18/023719

Bioremediation of a Condensed Grease Trap Waste

Bentham, R.; NcClure, N.; Catcheside, D.

Flinders University, School of Biological Sciences, Bedford Park, South Australia

CONF-960730 (Vol. 3); Technologies Critical to a Changing World, Volume III: Emerging Energy Technologies, Clean Technologies, Remediation and Emission Control Fuels, and Petrochemicals, Proceedings of the Fifth World Congress of Chemical Engineering, San Diego, CA, July 14-18, 1996. American Institute of Chemical Engineers, New York, NY, Vol. 3, 1118 pp.; (pp. 777-782) (1996)

The bioremediation of condensed grease trap waste has been investigated. The waste is an oily emulsion resulting from chemical processing and condensation of grease trap wastes. The oil consists of a complex mix of hydrocarbons with significant fuel oil and lube oil fractions. Currently this waste is disposed of by incineration.

The feasibility of a biological process to remove a significant proportion of the hydrocarbons has been investigated.

2522

V18/022686

Bioslurping Technology Applications at Naval Fuel 
Remediation Sites

Hoeppel, R.E.; Goetz, F.; Zwick, T.C.; Kittel, J.A.; Julio, S.D.

U.S. Navy, Naval Facilities Engineering Service Center, Port Hueneme, CA; Battelle Memorial Institute, Columbus, $\mathrm{OH}$; California State University, Northridge, CA

CONF-960393 (Part 1); Contaminated Soils and Groundwater: Analysis, Fate, Environmental and Public Health Effects, and Remediation, Proceedings of the Sixth Annual West Coast Conference, Newport Beach, CA, March 11-14, 1996. Association for the Environmental Health of Soils, Amherst, MA, Part 1, 257 pp.; (p. 34) (1996)

Bioventing accelerates the biodegradation of both high and low volatility fuels immobilized in the vadose zone by satisfying the high oxygen demand of in situ microorganisms through forced aeration of subsurface soils. However, many Naval field sites have light non-aqueous phase liquid (LNAPL) residing at and above the groundwater table. In such cases biodegradation of the LNAPL may be a very slow process because bioemulsification and bioavailability are impeded. Biosiurper systems are designed to recover LNAPL via vacuum-assisted pumping, while simultaneously promoting the remediation of vadose zone soil contamination via bioventing. Biosiurping has been ongoing at Naval Air Station (NAS) Fallon, Nevada, for over three years and was initiated at Marine Corps Base Hawaii last summer. The sites have low volatility JP- 5 jet fuel on the groundwater table in low to medium permeability soils. An arid bioventing site at Twentynine $\mathrm{Palms}, \mathrm{CA}$, appears to be moisture limited. Subsurface irrigation of the $190 \mathrm{ft}$ vadose zone has increased mixed fuel biodegradation rates about 10 -fold but wetting the contaminated zone has been a slow process.

2523

V18/024334

\section{Botanical Cleanup Crews}

Adler, T.

Science News 150(3):42-43 (July 20, 1996)

This article discusses the use of plants to help remediate contaminated soil and water. Many international efforts are aimed at phytoremediation - the use of plants to absorb pollutants from air water and soil. Among the pollutants targeted are radioactive materials, lead, selenium, and oil. Many plants have an ability to bioaccumulate these contaminants. The article goes on to describe specific projects on uranium contaminated springs at Oak Ridge National Laboratory (ORNL), trichloroethylene used as a degreaser and drycleaning agent, selenium in wetlands which contain drainage water, and oil contamination.

\section{4 \\ V18/021694}

C-13 Nuclear Magnetic Resonance Spectroscopy Combined with Site-Specific C-13 Labeling: A Powerful Method for Examining Biodegradation Reactions

Bortiatynski, J.M.; Nanny, M.A.; Hatcher, P.G.

Pennsylvania State University, University Park, PA

CONF-960376 (Part 1); Proceedings of the 211 th American

Chemical Society (ACS) National Meeting, New Orleans, LA, March 24-28, 1996. ACS, Washington, DC, Part 1, 1172 pp.; (p. 776, Paper ENVR 64) (1996)
C-13 nuclear magnetic resonance spectroscopy (NMR) combined with site-specific $C-13$ labeled compounds has become a powerful method to examine biodegradation reactions. Identification and analysis of intermediate products, as well as covalent and non-covalent interactions with natural organic matter (NOM), are just a few of the data obtained by this method. Biodegradation reactions are typically monitored by measuring the mineralization rate of $\mathrm{C}-14$ labeled compounds, or by organic solvent extraction of the parent compound followed by a gas chromatography/mass spectrometry (GC/MS) analysis. In addition, GC/MS data depends upon sufficient compound volatility, or the ability to form volatile derivatives often difficult to achieve with hydrophilic compounds or compounds incorporated into NOM. Since aqueous solvents, as well as organic solvents, can be examined with NMR, hydrophilic or NOM incorporated compounds and reaction products are easily studied. We will present advances this NMR methodology has made in biodegradation studies, in addition to presenting our own research, demonstrating the ability of this method to identify polar or NOM incorporated products and to follow biodegradation reactions in heterogeneous matrices. (Complete text)

2525

V18/022879

CRADA with Beckman Instruments and Pacific Northwest National Laboratory (PNL-013): Development and Commercialization of the Unsaturated Flow Apparatus (UFA) Using Characterization of Aridisols Final Project Report

Wright, J.; Conca, J.L.

Pacific Northwest National Laboratory, Richland, WA PNNL-11389; 45 pp. (October 1996)

The objective of this Cooperative Research and Development Agreement (CRADA) was to develop and commercialize a technology conceived by scientists at Pacific Northwest National Laboratory (PNNL) and manufactured by Beckman Instruments, Inc. (Beckman), and to apply this technology to the characterization of arid soils. The technology is the Unsaturated Flow Apparatus (UFA). The UFA provides a highly efficient method of direct, rapid measurement of hydraulic conductivity and other flow properties according to Darcy-Buckingham principles because the operator controls both the fluid driving force, using an ultracentrifuge, and the flow into the sample while it is spinning, with a rotating seal assembly. The concept of using centrifugation to significantly decrease the time needed, from years or months to days, for study of subsurface transport, particularly under unsaturated conditions, was conceived by James Conca, Ph.D., and Judith Wright, $\mathrm{Ph} . \mathrm{D}$., in 1986. The prototype UFA was developed in 1988 because there was a need to rapidly and accurately determine transport parameters in soils, sediments, and rocks for the Grout Waste Disposal Program. Transport parameters are critical to modeling outcomes for site-specific solutions to environmental remediation and waste disposal problems.

2526

V18/021966

Capture and Destruction of Chlorinated Solvents Via Electrokinetic Pumping: The Lasagna [TM] Process

Salvo, J.J.; Ho, S.V.; Shoemaker, S.H.

General Electric Company, Corporate Research and 
Development Center, Schenectady, NY; Monsanto Company, St. Louis, MO; DuPont Engineering, Houston, TX

CONF-9509139; Emerging Technologies in Hazardous Waste Management VII, D.W. Tedder (ed.), Proceedings of the Seventh American Chemical Society Industrial and Engineering Chemistry Division Special Symposium, Atlanta, GA, September 17-20, 1995. American Chemical Society, Washington, DC, 1291 pp.; (p. 469) (1995)

Remediating soils and groundwater that have been contaminated with chlorinated solvents is a significant challenge for current environmental technology. Soils with a high proportion of fine silts and clays have been especially recalcitrant due to their low permeability. Recently, electrokinetics has shown great promise in gaining access to these contaminated zones that fail to yield traditional pumping methods. An integrated approach using electrokinetics combined with in situ capture and destruction zones (LASAGNA [TM]) is being developed and field tested by Monsanto, DuPont and GE under the auspices of the EPA's Remediation Technology Development Forum and with financial support from the Department of Energy. To speed implementation and encourage partnering, royalty-free cross-licensing of the developed technology is available to consortium members for use on their sites.

2527

V18/021705

Case Study of Shallow Soil Mixing and Soil Vacuum Extraction Remediation Project

Carey, M.J.; Day, S.R.; Piniewski, R.J.

Geo-Con, Inc., Monroeville, PA; Terra Vac Corporation, Midwest Division, Temperance, MI

CONF-960154; PETRO-SAFE '96, Proceedings of a Conference Held as Part of the Energy Week ' 96 Conference and Exhibition, Houston, TX, January 29-Febnary 2, 1996. PennWell Conferences and Exhibitions, Houston, TX, 291 pp.; (pp. 140-143) (1996)

Shallow Soil Mixing (SSM) and Soil Vacuum Extraction (SVE) are techniques which have been increasingly relied on for the in-situ remediation of contaminated soil. The primary applications of SSM have been to mix cement, bentonite, or other reagents to modify properties and thereby remediate contaminated soils or sludges. Soil vacuum extraction has been used at numerous applications for in-situ removal of contaminants from soils. At a recent project in southem Ohio, the two technologies were integrated and enhanced to extract volatile organic compounds (VOCs) from soils at a Department of Energy facility. Advantages of the integrated SSM/SVE technology over alternative technologies include a relatively rapid remediation compared to other in-situ techniques at a lower cost, less exposure of waste to the surface environment and elimination of off site disposal. These advantages led to the selection of the use of both technologies on the project in southem Ohio.

V18/020839

Cementitious Encapsulation of Waste Materials and/or Contaminated Soils Containing Heavy Metals to Render Them Immobile

Stark, J.N.

U.S. Patent 05439318; 13 pp. (August 8, 1995)

The present invention relates to the cementitious encapsulation of waste materials and/or contaminated soils containing heavy metals, to render them immobile, and particularly to the immobilization of metals, in regulated amounts, in such wastes. A waste product comprising the metals is provided. A mixture is prepared comprising the wastes and/or contaminated soils containing heavy metals, water, and a cementitious composition. The cementitious composition comprises magnesium oxide and magnesium chloride in proportions effective to produce, with said water, a magnesium oxychloride cement. The cementitious composition is present in an amount which, on setting, is effective to immobilize the metals in the waste and/or contaminated soils. The present invention is useful for the remedial treatment of landfill sites. Alternatively, introduction of a retarding agent into the cementitious composition will permit the transportation of the mixture to another site for use and deposition. The mixture can be pumped or forced into the site where it will set and harden. This application is useful in the creation of slurry wall grouting and the creation of slurry wall containment basins.

\section{V18/024047}

Central Composite Rotatable Analysis for the Catalyzed Hydrogen Peroxide Remediation of Diesel-Contaminated Soils

Spencer, C.J.; Stanton, P.C.; Watts, R.J.

Washington State University, Pullman, WA

Journal of the Air and Waste Management Association 46(11):1067-1074 (November 1996)

A central composite rotatable design was used to investigate the interactions between hydrogen peroxide concentration, slurry volume, initial contaminant concentration, and soil organic carbon content in the catalyzed hydrogen peroxide remediation of diesel-contaminated soil. Two separate experimental matrices were investigated: (1) high slurry volumes and low peroxide concentrations, and (2) low slurry volumes with high peroxide concentrations. The time required for the high volume/low concentration system to proceed to completion was approximately three weeks; the low volume/high concentration reactions were complete within three days. The results showed that the soil organic carbon content was an insignificant variable in the catalyzed peroxide treatment of diesel-contaminated soils. However, significant interactions were found for the remaining three variables. The data were analyzed for total petroleum hydrocarbon (TPH) degradation and treatment stoichiometry. Although both systems could achieve equal levels of treatment, the stoichiometry of the high volume/low concentration system was significantly more efficient; therefore, the high volume/low concentration was determined to be the most economical system for the remediation of diesel-contaminated soils.

\section{0 \\ V18/020697}

Cesium-137 Redistribution Along the Profile of Top Soils Under Effect Deep Processing Without Pushing Aside

Popova, G.E.; Malina, L.L.; Pimenov, E.P.; Belova, N.V. 
Gosudarstvennyj Komitet po Ispol'zovaniyu Atomnoj Ehnergii SSSR, Fiziko-Ehnergeticheskij Institut, Obninsk, Russian Federation

INIS-RU-416; CONF-9310457 (Vol. 1); Radioecological Problems in Nuclear Energetics and in Industry Conversion, Proceedings of Mendeleev's 15th Meeting on General and Applied Chemistry, Obninsk, Russian Federation, October 1993, Vol. 1, 310 pp.; (p. 257) (1993)

Short communication. No abstract available. (This document is in Russian).

2531

V18/025382

Characterization and Removal of Radionuclides from the Drainage Sediment

Hsu, T.B.; Pen, B.L.; Men, L.C.; Yang, C.H.

Tamkang University, Department of Water Sources and Environmental Engineering, Tamshui, Taiwan; Institute of Nuclear Energy Research, Chemical Analysis Division, Lung-Tan, Taiwan

CONF-970335; Waste Management '97: Working Towards a Cleaner Environment, Proceedings of a Conference on HLW, LLW, Mixed Wastes and Environmental Restoration, Tucson, AZ, March 2-6, 1997; (4 pp.) (1997)

The purpose of this study were to determine the characteristics of the chemical extraction for Co-60 and Cs-137 radionuclides in the slightly contaminated drainage sediment by Tessier's sequential extraction and to compare the radionuclides removal using the same solution among three simple processes: shaking method, column washing, and microwave treatment. The results obtained show that a significant part of the $C s-137$ radionuclide was found in the residual fraction of sediment, while the C0-60 was mostly associated with $\mathrm{Fe} / \mathrm{Mn}$ oxides fraction. The removing efficiencies in both microwave treatment and column washing are higher than that in sediment shaking treatment. However, the total removals for all three treatments have aimost the same values (approximately $70 \%$ ). The microwave treatment has advantages of easy operation, time saving, and less equipment required. These preliminary experimental results indicated that the microwave treatment might be considered as alternative method in the treatment of heavy-metal contaminated sediments.

\section{2 \\ V18/025627}

Characterization and Solubility Measurements of Uranium-Contaminated Soils to Support Risk Assessment

Elless, M.P.; Armstrong, A.Q.; Lee, S.Y.

Phytotech, Inc., Monmouth Junction, NJ; Oak Ridge

National Laboratory, Oak Ridge, TN

Health Physics 72(5):716-726 (May 1997)

Remediation of uranium-contaminated soils is considered a high priority by the US Department of Energy because these soils, if left untreated, represent a hazard to the environment and human health. Because the risk to human health is a function of the solubility of uranium in the soils, the objectives of this work are to measure the uranium solubility of two contaminated soils, before and after remedial treatment, and determine the health risk associated with these soils. Two carbonate-rich, uranium-contaminated soils from the US Department of Energy Fernald Environmental Management Project facility near Cincinnati, Ohio, as well as two nearby background soils were characterized and their uranium solubility measured in a 75-d solubility experiment using acid rain, groundwater, lung serum, and stomach acid stimulants. Results show that the soluble uranium levels of each soil by each simulant are greatly influenced by their contamination source term. Risk calculations and biokinetic modeling based on the solubility data show that the risks from the soil ingestion and groundwater ingestion pathways are the predominant contributors to the total carcinogenic risk, whereas the risk from the soil inhalation pathway is the smallest contributor to this risk. However, kidney toxicity was the greater health concern of the Femald Environmental Management Project soils, primarily from undiluted ingestion of the groundwater solution following contact with the contaminated soils. Sensitivity analyses indicate that uranium solubility is a key parameter in defining kidney toxicity; therefore, without proper consideration of the solubility of radionuclides/metals in untreated and treated soils, important factors may be overlooked which may result in soil cleanup goals or limits which are not protective of human health and the environment.

$2533 \quad$ V18/020679

Characterizing Risks in Emerging Soil Remediation Technologies

Timmerman, T.J.; Deckro, R.F.; Kloeber, J.M.; Jackson, J.A.

U.S. Air Force Institute of Technology, Wright-Patterson Air Force Base, $\mathrm{OH}$

AFIT-CMSATR/96-03; 250 pp. (March 1996)

The Department of Energy is focusing a long-term development effort on producing cheaper, safer, and faster state-of-the-art soil remediation technologies. To assist with the management of these innovative technology development projects, ways of quantifiably measuring technical risk were investigated through a detailed literature review. 'Technical risk' was defined in this study as the combination of the consequences of undesired events and their likelihood. Careful design of the inputs into a technology selection decision support system accounted for the uncertainty in forecasting final characteristics of remediation technologies still in the early phases of R\&D. Experts made subjective probability estimates of these cost, schedule, and performance factors. Examination of several measures of final cost and schedule risk focused on communicating the risks inherent in different technological alternatives to the technology manager for operational, not theoretical, use. These risk measures included subjective measures, using utility theory, and objective measures, using variation about an expected value. A new measure was developed, the expected unfavorable deviation, which is similar but superior to the semi-variance as a measure of downside risk. These simple risk measures can be used whenever uncertainty is expressed through probability distributions of cost, schedule, and performance characteristics. 
Richardson, W.S., III; Chambless, D.A.; Hudson, T.B.; Cox, C.; Lloyd, V.D.

Sanford Cohen \& Associates, Inc., Montgomery, AL; Aubum University, Montgomery, AL; U.S. Environmental Protection Agency, National Air and Radiation Environmental Laboratory, Washington, DC

CONF-960212; Waste Management '96: Working Towards a Cleaner Environment, Proceedings of a Conference on HLW, LLW, Mixed Wastes and Environmental Restoration, Tucson, AZ, February 25-29, 1996; (23 pp.) (1996)

Soil samples from a Superfund Site contained elevated concentrations of radium-226 and thorium-230. The soil allegedly was contaminated with mill tailings from a chemical processing plant that extracted radium from camotite ores. Chemical extraction studies of soil samples were performed using solutions containing nitric acid, hydrochloric acid, hexametaphosphate, or combinations of hydrochloric acid and sodium chloride in single, multiple, and sequential extractions. The extractions were examined under various conditions of time, concentration, liquid-to-solid ratio, temperature, and rotational velocity. The products were analyzed for radium-226 and thorium-230. A full quadratic model of the bench-scale extraction studies for pilot-plant design considerations was examined to determine any important interactions of temperature, concentration of extractant, and liquid-to-solid ratios. Chemical extraction studies of soil samples demonstrated that dilute nitric acid solutions are effective in removing over 90 percent of the radium and thorium activity. Dilute hydrochloric acid solutions remove over 90 percent of the radium but less thorium. However, a sequential extraction procedure, employing hydrochloric acid followed by hexametaphosphate solutions, is equally effective in removing both radium and thorium. Hydrochloric acid could be replaced by a hydrochloric acid/sodium chloride solution, reducing the hydrochloric acid requirements for the process. A full quadratic model of the bench-scale extraction studies data revealed several important interactions between temperature, concentration of extractant, and liquid-to-solid ratios. Optimal values for these significant variables were determined using the model. Physical separation of the whole-soil samples by particle sizing isolated a significant quantity of a soil fraction larger then 50 -mesh size $(0.30-\mathrm{mm})(+50)$ with radium-226 and thorium-230 concentrations less than $15 \mathrm{pCi} / \mathrm{g}$. This fraction was extracted under optimum conditions to assess chemical treatment as a remediation technology to reduce the concentration of the contaminants to less than $5 \mathrm{pCi} / \mathrm{g}$ above background. Chemical extraction of the +50 soil fraction containing less than $15 \mathrm{pCi} / \mathrm{g}$ radium-226 and thorium-230 using the sequential extraction method described above reduces the concentrations to approximately $5 \mathrm{pCi} / \mathrm{g}$. A combination of physical separation of whole soil followed by chemical extraction of a select particle-size fraction may offer a viable method for site remediation of radionuclide-contaminated sites by volume reduction.

\section{5}

\section{V18/021958}

\section{Chemical Oxidation of TCE Contaminated Soils}

Gates, D.D.; Siegrist, R.L.; Cline, S.R.

Oak Ridge National Laboratory, Environmental Sciences

Division, Oak Ridge, TN
CONF-9509139; Emerging Technologies in Hazardous Waste Management VII, D.W. Tedder (ed.), Proceedings of the Seventh American Chemical Society Industrial and Engineering Chemistry Division Special Symposium, Atlanta, GA, September 17-20, 1995. American Chemical Society, Washington, DC, 1291 pp.; (p. 339) (1995)

Chemical oxidation of contaminated soils and sediments has been evaluated as a potential in situ remediation technique. The objective of this research was to compare two potential chemical oxidants; hydrogen peroxide ( $\mathrm{H2O} 2)$ plus iron (Fenton's reagent) and potassium permanganate (KMnO4). The TCE reduction efficiency for both oxidants was determined during a series of bench-scale experiments. The persistance of the two oxidants in soil systems and the effect of the oxidants on bulk soil properties were also evaluated. In clay soil systems, $\mathrm{KMnO} 4$ was able to reduce the TCE content by $99 \%$ from an average initial concentration of $130 \mathrm{mg} / \mathrm{kg}$ to an average posttreatment concentration of $4 \mathrm{mg} / \mathrm{kg}$. TCE reductions achieved with $\mathrm{H} 2 \mathrm{O} 2$ were slightly lower (86\%) and appeared to depend on both the soil $\mathrm{pH}$ and the iron concentration. The results of the laboratory studies have been used as the basis for several completed and proposed field demonstrations of the in situ chemical oxidation of sites contaminated with volatile organic compounds including TCE. (Complete text.)

\section{6}

$$
\mathrm{V} 18 / 022010
$$

Chemical Oxidation-Enhanced Bioremediation

Liu, B.; Kelley, B.; Paterek, B.; Srivastava, V.J.

Institute of Gas Technology, Des Plaines, IL

CONF-9509139; Emerging Technologies in Hazardous Waste Management VII, D.W. Tedder (ed.), Proceedings of the Seventh American Chemical Society Industrial and Engineering Chemistry Division Special Symposium, Atlanta, GA, September 17-20, 1995. American Chemical Society, Washington, DC, 1291 pp; (p. 1137) (1995)

The Institute of Gas Technology (IGT) has developed and demonstrated a cost-effective soil remediation technology for contaminants present at former manufactured gas plant (MGP) sites. The technology is known as the MGP-REM process. This process is based on the enhancement and acceleration of indigenous biological activity and the application of chemical treatment to promote subsequent biological degradation of the chemically modified compounds. The chemical treatment uses hydrogen peroxide and iron salt (Fenton's Reagent) as an oxidant to oxidize polynuclear aromatic hydrocarbons (PAHs), making them more amenable to biological treatment. The MGP-REM process is faster and achieves a higher degree of cleanup than the conventional biological process alone, costs no more than conventional bioremediation, and is much cheaper than incineration. This integrated chemical/biological treatment can be applied to other contaminants such as PCBs and cyanide. The major benefit of this process is its ability to degrade those hard-to-degrade compounds without degenerating any harmful by-products. The treatment end-products of this process are carbon dioxide and water. IGT has successfully field tested this technology in landfarming mode between 1991 and 1993, and in soil-bioslurry mode during 1993-1994. Insitu field tests are expected to start in 1995. 
Chemically Enhanced Insitu Recovery

Sale, T.; Pitts, M.; Wyatt, K.

$\mathrm{CH} 2 \mathrm{M}$ Hill Inc., Denver, CO; Surtek, Inc., Golden, CO; Oak Ridge National Laboratory, Oak Ridge, TN

ORNL/TM-13305; Insitu Remediation of DNAPL Compounds in Low Permeability Media Fate/Transport, Insitu Control

Technologies, and Risk Reduction, 318 pp.; (pp. 11.1-11.17) (August 1996)

Chemically enhanced recovery is a promising alternative to current technologies for management of subsurface releases of organic liquids. Through the inclusion of surfactants, solvents, polymers, and/or alkaline agents to a waterflood, the transport of targeted organic compounds can be increased and rates of recovery enhanced. By far, the vast majority of work done in the field of chemically enhanced recovery has been at a laboratory scale. The following text focuses on chemically enhanced recovery from a field application perspective with emphasis given to chlorinated solvents in a low permeability setting. While chlorinated solvents are emphasized, issues discussed are also relevant to organic liquids less dense than water such as petroleum products. Topics reviewed include: (1) description of technology; (2) general technology considerations; (3) low permeability media considerations; (4) cost and reliability considerations; (5) commercial availability; and (6) case histories. Through this paper an appreciation is developed of both the potential and limitations of chemically enhanced recovery. Excluded from the scope of this paper is the in situ destruction of organic compounds through processes such as chemical or biological oxidation, chemically enhanced recovery of inorganic compounds, and exsitu soil treatment processes.

\section{8}

\section{V18/020674}

Clean-Up of Water Released During Soil Remediation Meeder, T.A.; Soczo, E.R.; de Ruiter, N.

Rijksinstituut voor de Volksgezondheid en Milieuhygiene, Bilthoven, Netherlands

RIVM-772404001; RIVM-772404; 142 pp. (January 1995)

The goal of the study is to compile well-documented information on the cleanup of water released during remediation of soil at Leidraad Bodembescheming. Additionally, the results of the study are meant to support the establishment of general regulations on cleanup of water from soil remediation operations and to describe cleanup technology for inclusion in the Handbook of Soil Remediation Technology. An evaluation of water cleanup during soil remediation was performed using a database of relevant information, and the information has been arranged and edited to meet the goals of the study. (This document is in Dutch).

2539

V18/022107

Cleanup of Contaminated Soil - Unreal Risk Assumptions: Contaminant Degradation

Schiffman, A.

New Jersey Department of Environmental Protection, Trenton, NJ; Schiffman Associates, LLC, Ewing, NJ
CONF-951139 (Vol. 1); Superfund 16: Proceedings of a Hazardous Waste Conference and Exhibition, Washington, DC, November 6-8, 1995. E.J. Krause and Associates, Bethesda, MD, Vol. 1, 828 pp.; (pp. 386-393) (1994)

Exposure assessments for development of risk-based soil cleanup standards of criteria assume that contaminant mass in soil is infinite and conservative (constant concentration). This assumption is not real for most organic chemicals. Contaminant mass is lost from soil and groundwater when organic chemicals degrade. Factors to correct for chemical mass lost by degradation are derived from first-order kinetics for 85 organic chemicals commonly listed by U.S. Environmental Protection Agency and state agencies. Soil cleanup criteria, based on constant concentration, are then corrected for contaminant mass lost. For many chemicals, accounting for mass lost yields large correction factors to risk-based soil concentrations. For degradation in groundwater and soil, correction factors range from greater than one to several orders of magnitude. The long exposure durations normally used in exposure assessments (25 to 70 years) result in large correction factors to standards even for carcinogenic chemicals with long half-lives. For the groundwater pathway, a typical soil criterion for TCE of $1 \mathrm{mg} / \mathrm{kg}$ would be corrected to $11 \mathrm{mg} / \mathrm{kg}$. For noncarcinogens, correcting for mass lost means that risk algorithms used to set soil cleanup requirements are inapplicable for many chemicals, especially for long periods of exposure.

2540 V18/023796

Combined Chemical and Biological Oxidation of Slurry Phase Polycyclic Aromatic Hydrocarbons

Brown, K.L.; Davila, B.; Sanseverino, J.

International Technology Corporation, San Bernardino, CA; U.S. Environmental Protection Agency, Cincinnati. OH: International Technology Corporation, Knoxville. TN CONF-9504134; HAZMACON' 95, T. Bursztynsky and M.L. Loss (eds.), Proceedings of the Twelfth Hazardous Materials Management Annual Conference and Exhibition, San Jose, CA, April 4-6, 1995. Association of Bay Area Govemments, Oakland, CA, 790 pp.; (pp. 363-369) (1995)

Polycyclic aromatic hydrocarbons (PAH) are characterized by high organic partition coefficients, low aqueous solubility, and low vapor pressures. These characteristics result in the highly sorptive nature of PAH and their subsequent limited availability to microbial populations. IT's past experience with PAH-contaminated soils indicated that contaminant desorption from soil is the rate limiting factor in bioremediation. Manipulation of a variety of parameters can be used to enhance the rate of desorption and thereby increase the rate of biodegradation. The optimum method of manipulating these parameters is in liquid/solids contact or bioslurry reactors. Bioslurry treatment of PAH-impacted soils was demonstrated under the Superfund Innovative Technologies Evaluation - Emerging Technologies Program (SITE ETP) as an extension of research previously funded by IT and additional investigations supported by the EPA. During this demonstration, innovative methods for the treatment of polycyclic aromatic hydrocarbons (PAH)-impacted soils were evaluated to determine their compliance with the mandates of CERCLA. This document reports the results from this demonstration. 


\section{1}

V18/020827

Combustion and Catalytic Remediation of Hydrocarbon Contaminated Soil

Orman, M.I.; Joy, M.J.

Newlandex Corporation, Ventura, CA

U.S. Patent 05424045; 10 pp. (June 13, 1995)

Combustible hydrocarbon gas from a contaminated zone of soil and/or water is abated by removing hydrocarbon gas from the zone, combusting a first portion of the hydrocarbon gas in an internal combustion engine to develop power and to produce hot exhaust gas, delivering a second portion of the hydrocarbon gas and the hot exhaust gas to a catalytic unit, passing the hot gas exiting the catalytic unit in countercurrent heat exchange relation to the second portion of the hydrocarbon gas before venting said exit gas and utilizing the power from said engine to remove hydrocarbon gas and contaminated water from the zone and to pump the gases throughout the system.

\section{2 \\ V18/025313}

Comparison of Acid and Base Leach for the Removal of Uranium from Contaminated Media

Duff, M.C.; Mason, C.F.V.; Musgrave, J.A.; Dunfrund, F.

Los Alamos National Laboratory, Chemical Science and Technology Division, Los Alamos, NM; U.S. Army, Yuma Proving Ground, Yuma, AZ

CONF-970335; Waste Management '97: Working Towards a Cleaner Environment, Proceedings of a Conference on HLW, LLW, Mixed Wastes and Environmental Restoration, Tucson, AZ, March 2-6, 1997; (9 pp.) (1997)

Over the past few years, several different leaching schemes have been developed for the removal of uranium from contaminated media such as soil. Studies using sulfuric acid (H2SO4) and carbonate leach solutions (with or without an oxidative pretreatment) have been proposed. These solutions have been used on environmental sites with varying degrees of success. However, at few of these sites have both acid and base leachings been evaluated using the same set of criteria. The lack of comparative studies on acid and base leaches has created confusion over the relative merits of the two approaches. A comparison of selected acid and base leaches with several U-contaminated soils will be discussed. Discussion will be given with supporting data on relative $U$ removal efficiencies for each leach solution and the other leached elemental concentrations. Conclusions of our research will assist in the decision-making processes concerned with the remediation of U-contaminated media. Preliminary studies suggest the removal efficiency of soil $U$ for each leach solution varies with the nature of the $U$ contamination in the soil. It is likely the form(s) of soil U such as reduced species, absorbed species and mineral forms influence the solubilization of $U$ by the leaching agents.

\section{3}

V18/022228

Comparison of Bioaugmentation and Intrinsic Insitu Bioremediation of a PAH Contaminated Site

Geddes, T.; Mortier, N.; Chaparian, M.

Blue Planet Technologies, Inc., Madison Heights, MI
CONF-951139 (Vol. 2); Superfund 16: Proceedings of a Hazardous Waste Conference and Exhibition, Washington, DC, November 6-8, 1995. E.J. Krause and Associates, Bethesda, MD, Vol. 2, 817 pp.; (pp. 1213-1221) (1994)

Polycyclic aromatic hydrocarbons (PAHs) are one of the most common environmental hazards, naturally occurring in petroleum and its by-products. They are encountered at neariy all UST sites, and present an impediment to the use of cost effective intrinsic in situ bioremediation due to their recalcitrant nature. Even bacteria isolated specifically for their ability to degrade PAHs in the laboratory have shown no significant degradative capabilities in the field. This is due to the unique balance that exists at every contaminated site between the microbial ecology, chemical, physical, and environmental factors. Therefore, bacteria indigenous to the site and acclimated to these environmental parameters should be well suited for use in bioaugmentation. Based on this assumption, a new and innovative approach to bioaugmentation has been developed which consists of a series of scientifically-sound, rational steps in the use of this technology. Initially, careful chemical and biological analyses of site samples are conducted using conventional analytical instrumentation and state-of-the-art microbiological, biochemical, and molecular biological techniques. Bacteria from site samples that demonstrate potential PAH degradative capability are isolated. The bacteria are then enriched in culture and re-introduced to the site with appropriate nutrients. Further, this approach encompasses the proposed guidelines for proving the efficacy of in situ bioremediation as set forth by the National Science Foundation. To demonstrate the effectiveness of this approach, data are presented here of a laboratory-scale trial of a PAH contaminated site.

V18/022596

Completed North American Innovative Remediation Technology Demonstration Projects

U.S. Environmental Protection Agency, Office of Solid Waste and Emergency Response, Washington, DC

EPA/542/B-96/002; 65 pp. (August 12, 1996)

The matrix is organized according to the media treated: soil, sludge, and sediment projects or groundwater projects. Of key interest to the reader are the type(s) of medium, type(s) of contaminant treated, and the description of the site activity, which enables the reader to find a technology that may fit specific remediation needs. Conversely, if the reader is appraising a remediation technology, the matrix can be used to identify other projects in which the technology has been used and the medium(s) and contaminant(s) treated. The agency technical report number is given so that the user can research the actual project demonstration for further information.

2545

V18/023775

Composition of TPH in Soil vs. Specific Organics

Marks, B.J.

International Technology Corporation, Martinez, CA CONF-9504134; HAZMACON '95, T. Bursztynsky and M.L. Loss (eds.), Proceedings of the Twelfth Hazardous Materials Management Annual Conference and Exhibition, San Jose, CA, 
April 4-6, 1995. Association of Bay Area Governments, Oakland, CA, 790 pp.; (pp. 61-70) (1995)

Measures of total petroleum hydrocarbons as diesel and gasoline (TPH-D and IPH-G, respectively) often are used to make clean-up decisions at contaminated sites. But these measures do not provide specific information regarding site-specific threats to the environment and human health. Using TPH results in remediation decision making generally involves assuming, either implicitly or explicitly, that: benzene, toluene, ethylbenzene, xylenes (BTEX) and polycyclic aromatic hydrocarbons (PAHs) are the only chemicals of concern; or, that the TPH in the soil has the same chemical composition as the parent fuel. This paper presents data on the specific composition of approximately $\mathbf{4 2 0}$ soil samples taken at 20 sites in California that provide more information on the potential chemical constituents in the soil that are measured as TPH. Samples with similar TPH concentration can have significantly different concentrations of the BTEX and PAH constituents. When the concentrations of TPH- $G$ and TPH-D were below detection (i.e., less than 1 to $10 \mathrm{mg} / \mathrm{kg}$ ), the concentrations of BTEX and PAH also were below detection or quite low (in the mu g/kg range). This suggests TPH is a good screening level measure. However, often the concentrations of BTEX and PAHs were low or undetectable although the concentrations of TPH were measurable. These samples were also relatively low in concentrations of the alkylbenzenes and nontarget PAHs. The non-BTEX and target PAH compounds most frequently detected were branched alkanes, cyclical alkanes, and oxygenated forms (i.e., alcohol, aldehyde, and ketone forms) of the alkanes and alkenes found in petroleum fuels. Many of these latter chemicals have relatively high water solubilities but they are highly toxic at environmental concentrations. These results suggest that assuming there are toxic chemicals in the soil when a sample contains a detectable concentration of TPH can be misleading regarding the potential significance of the threats to human health from a petroleum spill.

2546

V18/023635

Computer Model for Predicting Two-Phase

Groundwater Transport in the Soil Surrounding a Growing Melt in the Insitu Vitrification Process

Schreiber, W.C.

University of Alabama, Department of Mechanical Engineering, Tuscaloosa, AL

CONF-960815; Proceedings of the 31st National Heat Transfer Conference of the American Society of Mechanical Engineers (ASME), H.A. Hadim, M. Charmchi, R. Cochran, B. Ramaswamy and R.S. Figliola (eds.), Houston, TX, August 3-6, 1996, 158 pp.; (pp. 63-70) (1996)

Two different computer models are tested for their usefulness in predicting the water balance and pressure field surrounding a growing hemispherical In Situ Vitrification (ISV) melt. The melt is centered under the flat surface of a hemisphere of soil contained by an impervious wall. The control volume method is employed for balancing heat and mass in each model. The soil is considered a porous media; consequently, fluid velocity can be modeled by Darcy's equation. Both computer models employ grids which adapt to the transient boundary of the growing melt. Computational Grid I (CGI) adapts with the melt boundary by contracting in the radial direction only. In addition to adapting to the melt boundary, Computational Grid II (CGM) also adapts to the liquid-vapor interface which moves outward from the $1,700 \mathrm{C}$ melt in response to the formation of vapor. CGII has been devised in order to attempt to reduce, at a reasonable CPU cost, the numerical pressure oscillation which arises when the grid is too coarse. A very fine CGI is used as a benchmark to test CGII and a coarser version of CGI. Results from the two CGI and the one CGII cases are presented graphically to illustrate the mass flux of liquid and vapor water and the build-up in pressure as the melt boundary approaches the impermeable wall.

V18/020770

Conceptual Design for a Full-Scale VAC*TRAX Vacuum Thermal Desorption Unit: Final Report September 1992-December 1995

Palmer, C.R.

Rust Federal Services, Inc., Clemson Technical Center, Anderson, SC

DOE/MC/29105-5199; 135 pp. (April 1996)

Rust Federal Services is pleased to present this topical report on the results of our Phase II conceptual design work of the Program Research and Development Announcement (PRDA)

VAC*TRAX[SM] mobile vacuum thermal desorption technology demonstration program. Through the present Phase II conceptual design activities, Rust has developed an equipment design and permitting strategy that retains the flexibility of a mobile treatment system with the long term value and ease of access of a central facility. The process is designed to remove volatile matter from solid matrices by thermal desorption. The system is also designed with superior emission controls, making it an ideal system for the treatment of radioactive wastes.

2548 $\mathrm{V} 18 / 024035$

Cone Penetrometer Fluorescence Sensors Demonstrated in Poland

TIE Quarterly 5(2):14-15 (Fall 1996/Winter 1997)

The Ames Laboratory Expedited Site Characterization (ESC) team demonstrated site characterization technologies in May 1996 in the Katowice region of Poland at the Czechowice Oil Refinery. Technologies were selected by the ESC team to characterize the site, consisting of several acres of lagoons, storage tanks, and support facilities, and to compare state-of-the-practice and innovative technologies. Because of the petroleum-based contaminants at the site, primarily benzene, ethylbenzene, toluene, and xylene (BETX) and polycyclic aromatic hydrocarbons (PAHs), it was natural to demonstrate the powerful suite of technologies associated with cone penetration (CPT) systems, particularly those chemical sensors that rely on the fluorescence properties of these compounds. Laser-based systems, called laser-induced fluorescence (LIF) detectors, have proven value in tracking qualitatively subsurface plumes of BETX and PAHs. Nearly all the LIF systems transport the surface laser light by fiber optic cable downhole where it exits the push rod through a rugged window. The fiber optic cable also transports fluorescence to the surface detector. 
Containment, Stabilization and Treatment of Contaminated Soil Using Insitu Soil Mixing

Day, S.R.; Ryan, C.R.

Geo-Con, Inc., Monroeville, PA

CONF-950225; GeoEnvironment 2000: Characterization, Containment, Remediation, and Pefformance in Environmental Geotechnics, D.E. Daniel (ed.), Proceedings of an American Society of Civil Engineers (ASCE) Specialty Conference, New Orleans, LA, February 22-24, 1995, ASCE, New York, NY, 1856 pp.; (17 pp.) (1995)

Soil mixing is a technique which has increasingly been relied upon for the in situ remediation of contaminated soils. Depending on the application, large or small diameter (4 to 0.3 meter) mixing augers can be used to inject cement, bentonite or other reagents to modify soil properties and thereby remediate contaminated soils and sludges. A major advantage of the method is the capability to treat soils at depth (up to 35 meters deep) without excavation, shoring or dewatering. Recent advantages in soil mixing technology include lower permeability additives for groundwater barriers, additives for the fixation of waste-contaminated soils and the combination of soil mixing with hot air injection and vapor extraction technology to remove volatile organic chemicals. Advantages of soil mixing over altemative technologies include lower cost, less exposure of wastes to the surface environment and eliminating off-site disposal. These advantages have made soil mixing the technique of choice on many projects. The information presented in this paper is intended to provide engineers and owners with the level of understanding necessary to apply soil mixing technology to a specific site. The most important steps in implementing the technology are site investigation, feasibility estimate, selection of performance criteria, selection of appropriate materials, bench scale testing, and construction.

2550

\section{$\mathrm{V} 18 / 023872$}

Contaminants and Remedial Options at Selected Metals Contaminated Sites: A Technical Resource Document

Royer, M.D.; Smith, L.A.

U.S. Environmental Protection Agency, Edison, NJ; Battelle Memorial Institute, Columbus, $\mathrm{OH}$

EPA/600/R-95/012; CONF-9504110; Proceedings of the 21st Annual Risk Reduction Engineering Laboratory (RREL) Research Symposium, Cincinnati, OH, April 4-6, 1995. U.S. Environmental Protection Agency, Cincinnati, OH, 398 pp.; (pp. 166-171) (April 1995)

A technical resource document, Contaminants and Remedial Options at Selected Metals-Contaminated Sites, has been produced to assist site remediation managers to select treatment technologies for contaminated soils, sludges, sediments, and waste deposits at sites where inorganic arsenic (As), cadmium (Cd), chromium (Cr), mercury $(\mathrm{Hg})$, or lead $(\mathrm{Pb})$ are the primary contaminants of concern. These five metals have been addressed because of their toxicity, industrial use, and frequency of occurrence at Comprehensive Environmental Response, Compensation, and Liability Act (CERCLA) sites and in Resource Conservation and Recovery Act (RCRA) hazardous wastes. This document should prove useful to all remediation managers, whether their efforts fall under federal, state, or private authority, and whether they are applying standards from RCRA, CERCLA, and/or state programs. This paper describes the contents of the resource document and summarizes the state of treatment technologies for the above metals.

\section{$2551 \quad$ V18/023035}

Contaminated Site Remediation and Liability Issues

Wolowich, E.A.; Staniuk, J.D.

W.L. Wardrop and Associates Limited, Winnipeg, Manitoba, Canada

CONF-9610147; Sustainability: The Evolution of Waste Management to Pollution Prevention and Resource Recovery, Proceedings of the 18th Canadian Waste Management Conference, Winnipeg, Manitoba, Canada, October 7-10, 1996. Canadian Environmental Industry Association, Winnipeg, Manitoba, Canada, 600 pp.; (12 pp.) (October 1996)

Various remediation processes for contaminated sites were reviewed, and areas of concern in remediating a site that may give rise to future liabilities, were identified. Depending on the waste generated, different techniques could be used, such as digging and dumping, vapor extraction, bioremediation, or pumping and treating. Most remedial efforts leave behind some kind of residual contamination which cannot be removed with current technology. In Canada, the legal liability associated with improper or incomplete remediation of a site has two sources: statute law and common law. Some actions which could be taken to limit liabilities associated with contaminated sites were described.

\section{$2552 \quad \mathrm{~V} 18 / 020687$}

Contaminated Site Remediation with Moderation and in View of Specific Aims

Hulpke, H.; Mueller-Eisen, U.; Neumaier, H.

Bayer AG, WV Umweltschutz, Leverkusen, Germany

WLB Wasser Luft und Boden 40(1-2):55-58 (January-February 1996)

Contaminated site remediation and soil protection are in a phase of upheaval. Limited financial means for decontamination measures, the insight that decontamination mostly cannot lead to multifunctional use of a ground, and the latest draft proposal by ministry officials for a federal soil protection act have prompted far-reaching discussions on the future of contaminated site remediation and soil protection. The authors discuss the connections and interdependencies from the political, scientific and economic viewpoints, advocating a sober attitude. (This document is in German).

\section{$2553 \quad$ V18/022235}

Control Technologies for Soil Vapor Extraction at Petroleum Hydrocarbon Impacted Sites: Regulatory Challenges to System Operations

Cacossa, K.F.; Campbell, G.E.; Devine, K.

Groundwater and Environmental Services, Inc., Wall, NJ

CONF-951139 (Vol. 2); Superfund 16: Proceedings of a Hazardous Waste Conference and Exhibition, Washington, DC, November 6-8, 1995. E.J. Krause and Associates, Bethesda, MD, Vol. 2, 817 pp.; 
(pp. 1126-1134) (1994)

Soil vapor extraction (SVE) is frequently used to remediate soils impacted by petroleum hydrocarbons. Four technologies have proven to be viable methods to control the off-gas emissions from SVE systems, namely, internal combustion, thermal oxidation, catalytic oxidation, and granular activated carbon adsorption. The optimal range of influent vapor concentrations for system operation differs for each of the technologies. Over the past several years the authors have worked proactively with the state regulatory community to develop general, all inclusive air pollution control permits which allow for the potential use of all four technologies over the life of the permit. Private industry has similariy worked with the state regulators to develop a less labor intensive sampling/monitoring procedure. Actual system performances, which were monitored using summa canisters and field equipment, provided the basis for the new procedure. System performance data indicated that field sampling with portable hydrocarbon analyzers, such as flame ionization detectors (FID), was preferable over the use of summa canister sampling. In addition, to reduce the costs associated with the analysis of samples, the new SVE monitoring protocol also reduced the number of system monitoring visits. These reductions equated into a cost effective, yet environmentally sound SVE system monitoring program.

\section{4}

\section{V18/023555}

\section{Control of Eolian Soil Erosion from Waste-Site Surface} Barriers

Ligotke, M.W.

Pacific Northwest Laboratory, Richland, WA

CONF-941 124; Insitu Remediation: Scientific Basis for Current and Future Technologies, G.W. Gee and N.R. Wing (eds.), Proceedings of the 33rd Hanford Symposium on Health and the Environment, Pasco, WA, November 7-11, 1994. Battelle Press, Columbus, OH, Part 1, 704 pp.; (pp. 545-559) (1994)

Physical models were tested in a wind tunnel to determine optimum surface gravel admixtures for protecting silt-loam soil from erosion by wind and saltating sand stresses. The tests were performed to support the development of a natural-material surface barrier for arid waste sites. Plans call for a 2-m-deep, silt-loam, soil reservoir to retain infiltrating water from rainfall and snowmelt. The objective of the study was to develop a gravel admixture that would produce an erosion-resistant surface layer during periods of extended dry climatic stress. Thus, tests were performed using simulated surfaces representing dry, unvegetated conditions present just after construction, after a wildfire, or during an extended drought. Surfaces were prepared using silt-loam soil mixed with various grades of sand and gravel. Wind-induced surface shear stresses were controlled over the test surfaces, as were saltating sand mass flow rates and intensities. Tests were performed at wind speeds that approximated and exceeded local 100-yr peak gust intensities. Surface armors produced by pea gravel admixtures were shown to provide the best protection from wind and saltating sand stresses. Compared with unprotected silt-loam surfaces, armored surfaces reduced erosion rates by more than $96 \%$. Based in part on wind-tunnel results, a pea gravel admixture of $15 \%$ will be added to the top $1 \mathrm{~m}$ of soil in a prototype barrier under construction in 1994. Field tests are planned at the prototype site to provide data for comparison with wind-tunnel results.

\section{V18/022500}

Cost Effective Bioremediation Strategy Using Low Technology Resources for Reclamation of Dry Land Hydrocarbon Contamination: A Case Study

Robb, A.J., III; Hoggatt, P.R.

Mobil Exploration \& Producing US Inc., Houston, TX CONF-950333; SPE-29759; Government and Industry Working Together to Find Cost Effective Approaches to Protecting the Environment, Proceedings of the Society of Petroleum Engineers (SPE)/U.S. Environmental Protection Agency (EPA) Exploration Production Environmental Conference, Houston, TX, March 27-29, 1995. SPE, Richardson, TX, 797 pp.; (pp. 661-670) (1995)

Hydrocarbon containing soil was bioremediated at a combination wastewater and slop oil skim evaporation pond utilizing cost effective low technology resources. Fluids and sludges from the football field-sized pond were analysed using extraction procedure toxicity and purgeable organics procedures, and total petroleum hydrocarbon (TPH) concentrations determined. An impact risk analysis was performed, and a corrective action plan developed and implemented. The three year project was closely coordinated with the Kansas Cooperation Commission (KCC) and the Kansas Department of Health and Environment (KDHE) who established the closure level. The impacted soils at the pond were completely excavated and closure was immediately granted by KDHE for the excavated area. The 24,000 cubic yards of excavated soil were then surface spread on adjacent Mobil property. A nutrient and microbial base was applied to bioaugment the soil. The preapplication land surface and the subsequently land farmed soil was periodically disced and chiseled. A job safety plan including industrial hygiene measures to eliminate workforce exposure was developed and implemented. The final remediation cost analysis amounts to $\$ 1.48$ per cubic yard compared to the $\$ 30$ and $\$ 150$ per cubic yard industry estimates for similar projects. Several factors were critical in allowing costs to remain so low: (1) assessment and implementation by local in-house staff; (2) conservative remedial action plan and sampling strategy; (3) local contractors; (4) locally available soil amendment; and (5) effective regulatory coordination. The methods described can be used to cost effectively characterize and bioremediate other sites where hydrocarbon-impacted soils exist in similar dry-land environments.

\section{$2556 \quad$ V18/023482}

Creosote: Remediation and Degradation [Latest Citations from the Energy Science and Technology Database]

NERAC, Inc., Tolland, CT

Bibliography (March 1997)

The bibliography consists of citations on remediation and natural degradation of creosote contamination. Several remediation technologies are discussed, including thermal desorption, in-situ bioremediation, biosiurry reactors, soil washing, incineration, and supercritical extraction. Creosote toxicology, industrial hygiene, environmental impact and fate, analytical methodologies, and source identification are also included in database articles. 


\section{7}

V18/023639

Critical Analysis of Sediment Quality Criteria and Hazard/Risk Assessment Tools

Galvez-Cloutier, R.; Yong, R.N.; Chan, J.; Bahout, E.

Laval University, Department of Civil Engineering, Quebec City, Quebec, Canada; McGill University, Geotechnical Research Centre, Montreal, Quebec, Canada

CONF-9406413; Dredging, Remediation, and Containment of Contaminated Sediments, K.R. Demars, G.N. Richardson, RN. Yong and R.C. Chaney (eds.), Proceedings of a Symposium, Montreal, Quebec, Canada, June 23-24, 1994, 343 pp.; (pp. 306-316) (1995)

The Canadian Federal Environmental Assessment Review Office is funding the Geotechnical Research Centre to facilitate their participation in the analysis of the Environmental Impact Statement during the public hearings of the Lachine Canal decontamination project. A summary and critical analysis of recent research and practical experience in the interpretation and application of sediment quality criteria and hazard/risk assessment tools was prepared for use in a comparative examination for the Lachine project. This present survey shows that various approaches can be taken when establishing both sediment quality and remediation criteria in light of an increasing preference for flexible guidelines that can be adjusted according to specific site conditions and that will marry more than one approach. Depending on the complexity of the decontamination scenario, there exist different levels of application in the analysis of the hazard and risk. Simple and complex models are available, but their actual application in ongoing sediment decontamination projects is minimal due to lack of understanding of the basics of contaminant exposure assessment and exposure routes.

2558 V18/025326

\section{Cs-137 Removal from Contaminated Clay Soil by} Electrokinetics

Prozorov, L.B.; Martyanov, V.V.; Chtcheglov, M.Y.

Scientific and Industrial Association - Radon, Engineering Department of the Moscow Government, Moscow, Russian Federation

CONF-970335; Waste Management ' 97 : Working Towards a Cleaner Environment, Proceedings of a Conference on $\mathrm{HLW}$, LLW, Mixed Wastes and Environmental Restoration, Tucson, AZ, March 2-6, 1997; (8 pp.) (1997)

Electrokinetic methods are applied for removal of radionuclides and heavy metals from soil. With in situ methods the remediation of soil takes place on site without preliminary soil removal and processing. Electrokinetic methods are based on known processes. The application of electrokinetic methods is preferable for local sites with high levels of contamination. Since 1993 these methods have been used for soil cleaning of radionuclides at the Mos SIA "Radon" site. Earlier electrokinetic methods were applied to clear surfaces of SO4(2-) and residual uranium at the production enterprises.

\section{9 \\ V18/024858}

DOE's Office of Science and Technology
Phytoremediation Program

Levine, R.S.

U.S. Department of Energy, Office of Environmental Management, Office of Science and Technology, Washington, DC

CONF-960592; Proceedings of a Conference on Phytoremediation, Arlington, VA, May 8-10, 1996. International Business Communications, Southborough, MA, 388 pp.; (14 pp.) (1996)

This document consists of a series of viewgraphs that present the Department of Energy's phytoremediation program goals and approaches. Hydroponic and pot studies and soil field studies are summarized. Viewgraphs also cover aquatic phytoremediation by rhizofiltration and bioremoval. Program goals, approaches, accomplishments, and future studies are briefly described. Final viewgraphs present FY 96 objectives for phytoremediation or soils and water.

2560

V18/024320

Data Quality Objectives for Surface-Soil Cleanup Operation Using Insitu Gamma Spectrometry for Concentration Measurements

Fong, S.H.; Alvarez, J.L.

Georgia Institute of Technology, Atlanta, GA; International Technology Corporation, Englewood, CO

Health Physics 72(2):286-295 (February 1997)

In situ gamma spectrometry is an efficient method for monitoring the progress of cleanup activities for radioactive contaminants in surface soil and for evaluating the attainment of cleanup standards. However, desired data precision and accuracy must be specified for such a detection system prior to the operation to ensure that the level of uncertainty associated with the concentration measurements is acceptable. A method for developing data quality objectives is described in this paper for in situ gamma spectrometry to achieve numerical goals for data precision and accuracy for cleanup operations. Concentration measurement for a radionuclide at its cleanup level must have a precision commensurate with the importance of cleanup decisions. The $95 \%$ lower limit of detection of the system is suggested to be about one tenth the expected system response at the cleanup level. The count time required to achieve the preferred $95 \%$ lower limit of detection, and hence the desired precision, can then be determined. The accuracy error arises from the overall calibration factor, which relates the detector responses (e.g., count rate) to physical quantities of interest (e.g., radionuclide soil concentration). The major source of error for the calibration factor using in situ gamma spectrometry is the misidentification of the type of the depth profile of radionuciide concentration in soil. If surrogate radionuclides are used, such as Am-241 for plutonium, the variation in the concentration ratio would be another significant source of error. Soil sampling programs performed prior to a cleanup operation will greatly reduce the accuracy error for an in situ detection system, and the analysis of system errors may determine the degree of sampling required. The planning of such a program is discussed in the study.

2561

V18/023654

Data Requirements for Advancing Techniques to Predict 
Dredge-Induced Sediment and Contaminant Releases: A Review

Averette, D.E.

U.S. Army Corps of Engineers, Waterways Experiment Station, Vicksburg, MS

CONF-9406413; Dredging, Remediation, and Containment of Contaminated Sediments, K.R. Demars, G.N. Richardson, R.N. Yong and R.C. Chaney (eds.), Proceedings of a Symposium, Montreal, Quebec, Canada, June 23-24, 1994, 343 pp.; (pp. 128-135) (1995)

In many areas of the world, contaminated sediments are being considered a major factor in the redistribution of toxic chemicals in the environment. While removal of contaminated sediments from the aquatic environment is often the preferred alternative for reducing the potential impacts of contaminated sediment, regulatory agencies and the public often express concern about contaminant releases during dredging operations. The US Army Corps of Engineers continues to develop techniques for making a priori estimates of the sediment resuspension rates and contaminant releases during hydraulic and mechanical dredging activities. However, appropriate field data to verify and refine these techniques for a wide range of conditions are currently limited. Data needs include physical and operational characteristics of the dredge, waterway characteristics, sediment characteristics, sediment contaminant data, and water quality data collected during the dredging activity. This paper discusses key parameters required to improve the current predictive techniques and outlines the type of monitoring program needed to improve the comparability of the techniques to measured releases. The recommended monitoring program is derived from experiences with previous monitoring efforts. Planners of future dredging demonstrations are encouraged to collect similar data in order to advance the state of the art for predicting sediment and contaminant releases associated with dredging.

\section{2}

\section{V18/022667}

\section{Demonstrating the Efficacy of Bioventing Using} Radiotracers

Baker, R.S.; Ghaemghami, J.; Simkins, S.; Mallory, L.M. ENSR Consulting and Engineering, Acton, MA; University of Massachusetts, Department of Plant and Soil Sciences, Soil and Environmental Microbiology Laboratories, Amherst, MA

CONF-941124; Insitu Remediation: Scientific Basis for Current and Future Technologies, G.W. Gee and N.R. Wing (eds.), Proceedings of the 33rd Hanford Symposium on Health and the Environment, Pasco, WA, November 7-11, 1994. Battelle Press, Columbus, OH, Part 1, 704 pp.; (pp. 259-277) (1994)

Direct evidence to support the effectiveness of bioventing was obtained in columns simulating unsaturated zone dynamics. Fine sandy loam from the capillary fringe of a site contaminated with toluene and xylenes was packed into glass columns. Radiolabeled [U-ring-C14] toluene and [U-ring-C14] $\mathrm{m}$-xylene were separately added to gamma-irsadiated control columns and identical nonsterile columns. Toluene (or $\mathrm{m}-x y$ lene) and $\mathrm{CO} 2$ present in air drawn through the soil were continuously captured in organic vapor and $\mathrm{NaOH}$ traps, respectively. The addition of a radiotracer to all columns permitted an accounting of the contaminant mass balance among volatilized, biodegraded, residual, and leached fractions. During two trials involving C14-toluene and C14-m-xylene, 46 to $57 \%$ and 40 to $46 \%$, respectively, of the added C14 was oxidized to $\mathrm{C} 14 \mathrm{O} 2$ in the nonsterile columns, demonstrating that bioremediation had been effective. Volatilization of $75 \%$ of added C14-toluene and $54 \%$ of added C14-m-xylene occurred in the sterile controls, whereas the nonsterile columns experienced volatile losses of less than $0.4 \%$ and $0.7 \%$, respectively. As virtually no volatile hydrocarbons were detected in the offgas over the course of the bioventing tests from the nonsterile columns, despite the high airflow rate (15 to 20 pore volumes d[E-1]), offgas treatment may prove unnecessary during bioventing of some field sites.

$$
\text { V18/022722 }
$$

\section{Demonstration of Close-Coupled Barriers for} Subsurface Containment of Buried Waste

Dwyer, B.P.; Heiser, J.H.; Stewart, W.

Sandia National Laboratories, Albuquerque, NM; Brookhaven National Laboratory, Upton, NY; Applied Geotechnical Engineering and Construction, Inc., Richland, WA

CONF-960804 (Vol. 1); Spectrum '96: Nuclear and Hazardous Waste Management, Proceedings of an International Topical Meeting, Seattle, WA, August 18-23, 1996. American Nuclear Society, La Grange Park, II, Vol. 1, 887 pp.; (pp. 359-366) (1996)

The primary objective of this project is to develop and demonstrate a close-coupled barrier for the containment of subsurface waste or contaminant migration. A close-coupled barrier is produced by first installing a conventional cement grout curtain followed by a thin inner lining of polymer grout. The resultant barrier is a cement polymer composite that has economic benefits derived from the cement and performance benefits from the durable and resistant polymer layer. Close-coupled barrier technology is applicable for final, interim, or emergency containment of subsurface waste forms. Consequently, when considering the diversity of technology application, the construction emplacement and material technology maturity, general site operational requirements, and regulatory compliance incentives, the close-coupled barrier system provides an alternative for any hazardous or mixed waste remediation plan. This paper discusses the installation of a close-coupled barrier and the subsequent integrity verification. The demonstration was installed at a benign site at the Hanford Geotechnical Test Facility, 400 Area, Hanford, Washington. The composite barrier was emplaced beneath a 15,000 liter tank. The tank was chosen to simulate a typical DOE Complex waste form. The stresses induced on the waste form were evaluated during barrier construction. The barrier was constructed using conventional jet grouting techniques. Drilling was completed at a 45 degree angle to the ground, forming an ice cream cone shaped barrier with the waste form inside the cone. Two overlapping rows of cylindrical cement columns were grouted in a honeycomb fashion to form the secondary backdrop barrier layer. The primary barrier, a high molecular weight polymer manufactured by $3 \mathrm{M}$ Company, was then installed providing a relatively thin inner liner for the secondary barrier. The primary barrier was emplaced by panel jet grouting with a dual wall drill stem, two phase grouting system. 
Demonstrations and Commercial Applications of Innovative Sediment Removal Technologies

Pelletier, J.P.

Environment Canada, Toronto, Ontario, Canada

CONF-9406413; Dredging, Remediation, and Containment of Contaminated Sediments, K.R. Demars, G.N. Richardson, R.N. Yong and R.C. Chaney (eds.), Proceedings of a Symposium, Montreal, Quebec, Canada, June 23-24, 1994, 343 pp.; (pp. 112-127) (1995)

The Contaminated Sediment Removal Program (CSRP) of Environment Canada was founded in November 1990 following a request from the Great Lakes Cleanup Fund to the Environmental Protection Service-Ontario Region to provide the leadership in the identification of removal technologies and procedures for contaminated sediments in the Great Lakes. Following a request for proposal issued by the CSRP, proposals were received from vendors of innovative sediment removal technologies to conduct contaminated sediment removal demonstrations in different Areas of Concem (AOCs) on the Canadian side of the Great Lakes. In 1992, the CSRP conducted the demonstration of two innovative sediment removal technologies at three different sites. The Cable Arm 100E clamshell bucket was demonstrated in Toronto and Hamilton Harbors, while the Pneuma Pump was demonstrated in Collingwood Harbor. Those three demonstrations led to the first Canadian commercial applications of the Cable Arm 100E clamshell bucket in Pickering, Ontario, and of the Pneuma Pump in Collingwood, Ontario.

\section{5}

\section{V18/023658}

Depth of Fenton-Like Oxidation in Remediation of Surface Soil

Kakarla, P.K.C.; Watts, R.J.

Washington State University, Department of Civil and Environmental Engineering, Pullman, WA

Joumal of Environmental Engineering 123(1):11-17 (January 1997)

A series of soil columns was used to investigate the depth of Fenton-like reactions provided by the surface application of catalyzed hydrogen peroxide. Initial experiments examined the effect of four stabilizers (monobasic potassium phosphate, dibasic potassium phosphate, sodium tripolyphosphate, and silicic acid) on $\mathrm{H} 2 \mathrm{O} 2$ decomposition and the depth to which $\mathrm{H} 2 \mathrm{O} 2$ could be detected. The $\mathrm{H} 2 \mathrm{O} 2$ dynamics along the depth of the column showed that the addition of the most effective stabilizers, monobasic potassium phosphate, increased the depth of the detectable $\mathrm{H} 2 \mathrm{O} 2$ in the soil by three times the depth in soil columns without stabilization. The oxidation of sorbed hexadecane, a highly hydrophobic compound (log Kow $=9.07$ ), by Fenton-like reactions focused on the process variables of $\mathrm{H} 2 \mathrm{O} 2$ concentration, number of $\mathrm{H} 2 \mathrm{O} 2$ applications, and $\mathrm{pH}$. A single application of $15 \mathrm{M} \mathrm{H} 2 \mathrm{O} 2$ with $\mathrm{pH}$ governed by the buffering of $\mathrm{KH} 2 \mathrm{PO} 4$ provided maximum hexadecane oxidation. Minimal desorption (less than 10\%) in the soil columns was found in control experiments using deionized water in place of $\mathrm{H} 2 \mathrm{O} 2$, suggesting that hexadecane oxidation occurred in the sorbed phase. More detailed investigation of the process variables was conducted using central composite rotatable designs. The results showed that a $\mathrm{KH} 2 \mathrm{PO} 4$ concentration greater than 30 $\mathrm{mM}$ provided increased hexadecane oxidation while maintaining minimal $\mathrm{H} 2 \mathrm{O} 2$ decomposition relative to unstabilized $\mathrm{H} 2 \mathrm{O} 2$. For higher $\mathrm{KH} 2 \mathrm{PO} 4$ concentrations (60-75 mM), the central composite results documented greater than $90 \%$ hexadecane oxidation in the top $2 \mathrm{~cm}$ of the soil column and $20-40 \%$ oxidation in the $10-15 \mathrm{~cm}$ depths.
2566
V18/022236

Design and Analysis of a SVE System in a Shallow Water Table Application

Swingle, T.P.; Leachman, W.D.

Parsons Engineering Science, Inc., Winter Park, FL; Cummins Southeastern Power, Inc., Tampa, FL

CONF-951139 (Vol. 2); Superfund 16: Proceedings of a Hazardous Waste Conference and Exhibition, Washington, DC, November 6-8, 1995. E.J. Krause and Associates, Bethesda, MD, Vol. 2, 817 pp.; (pp. 1106-1115) (1994)

Cummins Southeastem Power, Inc. (CSPD) operates a diesel engine repair facility in Hialeah Gardens, FL. Parsons Engineering Science, Inc. (Parsons ES) was retained to design a treatment system to remediate soil contaminated with various light and mid-range hydrocarbons beneath the CSPI service building. Soil vapor extraction (SVE) followed by bioventing was selected as the most appropriate and cost effective approach. These activities were completed as part of CSPI's overall environmental program, which includes cleanup of any contamination that is encountered at their facilities and continual implementation of new measures to prevent future contamination from occurring. This paper presents a complete case history outlining the unique technical challenges associated with the CSPI site conditions. The methods utilized during completion and analysis of the pilot test are discussed and a description of how the pilot data was utilized for completion of the full-scale design is included. The paper presents the empirical analysis method which was developed during this design and shows how it can be applied to other SVE remediation applications.

\section{7}

V18/025389

Design and Conduct of Meaningful Soil Characterization and Treatability Studies Based on a Knowledge of Mineral Processing Technology

Richardson, W.S., III; Phillips, C.R.; Luttrell, G.H.; Cox, C. Auburn University, Montgomery, AL; Sanford Cohen \& Associates, Inc., Montgomery, AL; Virginia Polytechnic Institute and State University, Blacksburg, VA; U.S. Environmental Protection Agency, Montgomery, AL CONF-970335; Waste Management '97: Working Towards a Cleaner Environment, Proceedings of a Conference on $\mathrm{HLW}$, LLW, Mixed Wastes and Environmental Restoration, Tucson, $A Z$, March 2-6, 1997; (16 pp.) (1997)

Mineral processing technology has been in use for decades and can be applied to separation of radionuclide contaminants from their host soil matrix by exploiting differences in physical properties between them or these two constituents. A number of studies have been performed to assess the applicability and effectiveness of mineral processing technology for treatment of radionuclide-contaminated soils. Many of these studies have produced inconclusive results because of their incomplete scope and 
a lack of understanding of radionuclide contamination and its association with the host soil. Some of the past studies were limited by a lack of commitment of funds to develop the proper application of characterization and treatability studies to mineral processing and others by a lack of understanding of the necessary requisites for a definitive study. In order to select potential treatment process(es), a complete characterization study of both host soil and contaminant materials must be performed to determine their physical and chemical properties as well as their relative associations with each other. Full characterization must be followed by treatment studies to evaluate the performance of process units and to optimize separation by computer modeling. Process modeling can save time and is critical to the successful selection and design of a treatment process train. Most characterization and treatability studies performed to date on radionuclide-contaminated sites lack this completeness and applicability and, therefore, have not resulted in a successful process design. This paper describes the approach to the design and conduct of characterization and treatment studies and their relation to the conceptual and engineering design phase of the treatment process. Four important themes run throughout the paper: (1) the tiered approach to process selection, (2) the application of proven physical processes for treatment, (3) the importance of economic and practical comparison to other potential approaches to remediation, and (4) the importance of performing a complete, integrated, iterative, and reliable study of the contaminant and soil and the separation processes that are suitable for treatment and remediation.

\section{8}

V18/023661

Design and Performance Verification of a Soil-Bentonite Slurry Wall for the Hydraulic Isolation of Contaminated Sites

Hollenweger, R.; Martinenghi, L.

Swiss Federal Institute of Technology, Institute of Geotechnical Engineering, Zurich, Switzerland

CONF-9406413; Dredging, Remediation, and Containment of Contaminated Sediments, K.R. Demars, G.N. Richardson, R.N. Yong and R.C. Chaney (eds.), Proceedings of a Symposium, Montreal, Quebec, Canada, June 23-24, 1994, 343 pp.; (pp. 271-286) (1995)

The polluted ground of contaminated sites is often encapsulated by diaphragm walls, with concrete or concrete-stabilized earth being common construction materials in Europe. At the Institute of Geotechnical Engineering at the Swiss Federal Institute of Technology Zurich, new material mixtures that contain a high percentage of clay minerals have been developed over the past few years. Two experimental diaphragm walls, one in Switzerland and one in Germany, were constructed using such materials. A diaphragm wall $55 \mathrm{~m}$ deep using this mixture is currently being placed to encapsulate a contaminated landfill site in Germany. In this paper, an evaluation of the new mixture and results from both the experimental and full-scale walls, as well as complementary laboratory investigations, are presented and examined.

Designing Injectable Colloidal Silica Barriers for Waste Isolation at the Hanford Site
Persoff, P.; Moridis, G.J.; Apps, J.; Pruess, K.; Muller, S.J. Lawrence Berkeley National Laboratory, Berkeley, CA CONF-941124; Insitu Remediation: Scientific Basis for Current and Future Technologies, G.W. Gee and N.R. Wing (eds.), Proceedings of the 33rd Hanford Symposium on Health and the Environment, Pasco, WA, November 7-11, 1994. Battelle Press, Columbus, OH, Part 1, 704 pp.; (pp. 87-101) (1994)

Injectable barriers can be formed from colloidal silica, a gelling colloidal suspension. A particular problem associated with emplacement of colloidal silica barriers is uncontrolled rapid gelling due to chemical interaction between the grout and divalent ions in the soil. The authors discuss three techniques for solving this problem. Gel-time control can be achieved in Hanford sand by displacing the divalent ions away from the injected grout. This can be done by preceding the grout injection with a preflush of $4 \% \mathrm{NaCl}$ brine. For cases where preflushing is not permitted, displacement of divalent ions can also be achieved by starting the grout injection with diluted colloidal silica, which eventually gels due to its colloid content and accumulation of displaced divalent ions. Preliminary laboratory results support this strategy. A $13 \%$ solids colloid displaced divalent ions and did not gel during the injection period, while colloids with $20 \%$ or greater solids content gelled too rapidly. A second strategy to avoid preflushing is to use $\mathrm{NaF}$, rather than $\mathrm{NaCl}$, brine (or a mixture) to cause gelling of the first grout injected. The sodium ions caused displacement of divalent cations. The fluoride ion precipitates or complexes the major divalent cations, preventing premature gelling, but leaving enough cations to gel slowly. Hanford sand accelerates gelling of colloidal silica grout that has been prepared with $\mathrm{NaCl}$, but preliminary laboratory results show that if $\mathrm{NaF}$ is used instead of $\mathrm{NaCl}$, the Hanford sand delays gelling.

V18/023774

Detecting PCBs Using Soil Gas Pathfinders

Viellenave, J.H.; Harrington, P.A.

Northeast Research Institute LLC, Lakewood, CO

CONF-9504134; HAZMACON '95, T. Bursztynsky and M.L. Loss (eds.), Proceedings of the Twelfth Hazardous Materials Management Annual Conference and Exhibition, San Jose, CA, April 4-6, 1995. Association of Bay Area Govemments, Oakland, CA, 790 pp.; (pp. 51-60) (1995)

Thousands of contaminated sites have experienced enhanced characterization by using soil gas geochemical methods to focus invasive investigations and to identify a myriad of organic chemical constituents. The application of soil gas technologies has largely been restricted to detecting volatiles, although operators of passive methods have reported detection of semivolatiles. Accumulations of such non-volatile species as poly-chlorinated biphenyls (PCBs), pesticides, metals, etc., have largely gone undetected by soil gas methods except by fortuitous circumstances. However, an investigator with a sophisticated and intensive understanding of the chemistry of a mixture or of a process will discover associations of chemical species that allow the use of undetectable species. Pathfinders have been knowingly used in mineral and petroleum exploration for half a century; they are used in environmental site investigations as well, for example, as in the use of BTEX to track gasoline. In most cases, the use is still focused on the more volatile 
organic compounds and mixtures. Northeast Research Institute (NERD) has been approached a number of times with requests to detect non-volatile compounds or mixtures in difficult environments. While the first impression may be that such a compound or mixture cannot be detected by soil gas technologies, it is worth questioning the situation, and perhaps conducting a trial study, in order to determine if that conclusion is correct. Perhaps there is more potential than meets the eye at first glance. This notion was well tested when a case was brought forward involving the contamination of soils by PCBs.

\section{1 \\ V18/021973}

Detection of Organic and Heavy Metal Contaminants in Soils Using X-Ray Mapping and Microprobe Two-Step Laser Mass Spectroscopy

Bradley, J.P.; Clemett, S.; Zare, R.N.; Wood, T.B.V.; Zevenbergen, $\mathrm{C}$.

MVA, Inc., Norcross, GA; Stanford University, Department of Chemistry, Stanford, CA; IWACO, Rotterdam, Netherlands

CONF-9509139; Emerging Technologies in Hazardous Waste Management VII, D.W. Tedder (ed.), Proceedings of the Seventh American Chemical Society Industrial and Engineering Chemistry Division Special Symposium, Atlanta, GA, September 17-20, 1995. American Chemical Society, Washington, DC, 1291 pp.; (p. 17) (1995)

Inorganic and organic contaminants at bulk levels of parts-per-million are often localized at higher concentrations within specific components of soils. Automated scanning (and transmission) electron microscopes provide a means of mapping such local accumulations. The distribution and speciation of $\mathrm{Cr}, \mathrm{Zn}$, $\mathrm{Mo}, \mathrm{Pb}$, and $\mathrm{U}$ in soils have been determined, enabling mechanisms of heavy metal immobilization and remediation strategies to be evaluated. Organic compounds containing elemental "tags" (e.g. $\mathrm{Cl}$, $S, P$ ) have been mapped and, once located, their molecular compositions were determined using microprobe two-step laser desorption spectroscopy (muL2MS). With muL2MS, a pulsed infrared laser focused to a 40 mum diameter spot causes desorption of a plume of neutral molecules from individual soil grains. A second pulsed ultraviolet laser photo-ionizes the plume which is then injected into a time-of-flight mass spectrometer. The combination of automated electron microscopy and muL2MS have been applied to study the distributions of chlorinated compounds (e.g. PCB's) and $\mathrm{S}$ - and P-containing organic contaminants in soils. (Complete text)

\section{2}

V18/021710

Determination and Characterization of the Structure of a Pore Space from 3D Volume Images

Baldwin, C.A.; Sederman, A.J.; Mantle, M.D.; Alexander, P.; Gladden, L.F.

University of Cambridge, Cambridge, United Kingdom

Journal of Colloid and Interface Science 181(1):79-92 (July 15, 1996)

A new approach to the partitioning of the void space from volume images is presented. A variant of morphological thinning is used to partition the void space into a discrete and well-defined collection of individual pores. The approach leads to the identification of pores which are defined by criteria which are well established in the literature. Each pore is bounded by interfaces between the void space and solid matrix, and by planes erected where the hydraulic radius of the pore space exhibits local minima defined as pore necks. From the partitioned data various statistics are readily obtainable such as the pore-size and coordination distributions, and the distribution of pore surface area between interfaces with solid phase and those with neighboring pores. The authors also calculate two fractal dimensions related to the discrete pores which they suggest may represent an important method of characterizing the pore space. Although the method is illustrated by application to magnetic resonance imaging (MRI) data of a packed bed of uniform spheres, the algorithm is entirely general and may be applied to any fully sampled three-dimensional image or reconstructed porous medium.

2573

V18/022685

Developing a Carbon Dioxide/Oxygen Monitor for Cost Effective Field Use

Portnoff, M.A.; Hibner, J.L.; Jarrett, J.; Prusko, P.; Tabacchi, J.; Toth, T.

Carnegie Mellon Research Institute, Pittsburgh, PA

CONF-960393 (Part 1); Contaminated Soils and Groundwater: Analysis, Fate, Environmental and Public Health Effects, and Remediation, Proceedings of the Sixth Annual West Coast Conference, Newport Beach, CA, March 11-14, 1996. Association for the Environmental Health of Soils, Amherst, MA, Part 1, 257 pp.; (p. 21) (1996)

From concept to field prototype, this project was driven by two independent findings. The first was related to the trends in gas detection technology, and the second related to findings that high analytical costs were hindering effective site assessment and remediations at leaking underground storage tank (UST) sites. A design study was performed evaluating gas detection equipment already employed in soil gas surveying. Soil gas surveying is one of many field analysis techniques used for UST site investigative work. The test program was divided into the following phases: determine $\mathrm{CO} 2$ and $\mathrm{O} 2$ sensor requirements for leaking UST site assessment; develop a test protocol to objectively test gas sensors in simulated field environments; design and build a sensor test system based on the test protocol; and test and evaluate sensor performance.

2574

V18/022748

Development and Application of Statistical Techniques for the Detection of Discrete Contaminated Artifacts in a Soil Stream

Clement, C.H.; Stager, R.H.

Atomic Energy of Canada Limited, Port Hope, Ontario, Canada; SENES Consultants Limited, Richmond Hill, Ontario, Canada

CONF-960804 (Vol. 2); Spectrum '96: Nuclear and Hazardous Waste Management, Proceedings of an Intemational Topical Meeting, Seattle, WA, August 18-23, 1996. American Nuclear Society, La Grange Park, IL, Vol. 2, 873 pp.; (pp. 974-981) (1996)

The Low-Level Radioactive Waste Management Office (LLRWMO), in conjunction with SENES Consultants Limited, has 
developed a conveyor based system for the detection and segregation of discrete radium contaminated artifacts from a soil stream. The Soil Sorting Conveyor System (SSCS) is centered around a pair of high volume plastic scintillators in a steel housing through which soil containing gamma emitting artifacts passes. A computer monitors the readings from the scintillators and activates a pneumatic soil shunting gate to segregate any material for which the absence of above criterion discrete artifacts cannot be confirmed. The development of the statistical methods required to assess the scintillometer readings in real time are described, and the detection performance is investigated in some detail. One important result is that identification of individual artifacts containing $3.7 \mathrm{kBq}$ ( $0.1 \mathrm{mu} \mathrm{Ci)} 226 \mathrm{Ra}$ is possible with greater than $95 \%$ confidence, even with radon emanation factors of $(75+/-5) \%$.

\section{5}

V18/022238

Development of Soil Cleanup Standards for the Biological Treatment of Wood Preserving Wastes

Jerger, D.E.; LaGoy, P.K.

OHM Remediation Services Corporation, Findlay, $\mathrm{OH}$; OHM Remediation Services Corporation, Hopkinton, MA

CONF-951139 (Vol. 2); Superfund 16: Proceedings of a Hazardous Waste Conference and Exhibition, Washington, DC, November 6-8, 1995. E.J. Krause and Associates, Bethesda, MD, Vol. 2, 817 pp.; (pp. 1080-1083) (1994)

The primary goal of hazardous waste site remediation is to achieve a set of conditions that are environmentally safe for organismal receptors, and will prevent any further action on site. Establishing these conditions raises the issue of "how clean is clean" or "what concentration of a contaminant in soil is environmentally acceptable ${ }^{n}$ for contaminated sites. This debate is occurring on a national scale as part of the Superfund reauthorization. OHM Remediation Services Corp. (OHM) has recently completed the successful treatment of 14,000 tons of creosote-contained material at the Southeastern Wood Superfund Site in Canton,MS. Slurry phase biological treatment was the technology chosen to remediate the contaminated material classified as RCRA K001 criteria for CERCLA actions: protection of pubic health, welfare, and the environment.

\section{6}

\section{V18/023645}

Development of Solidification Technique for Dredged Sediments

Yamasaki, S.; Yasui, H.; Fukue, $M$.

Aoki Marine Company, Fukushima, Osaka, Japan; San O Company, Limited, Kyoto, Japan; Tokai University, Marine Science and Technology, Shimizu, Japan

CONF-9406413; Dredging, Remediation, and Containment of Contaminated Sediments, K.R. Demars, G.N. Richardson, R.N. Yong and R.C. Chaney (eds.), Proceedings of a Symposium, Montreal, Quebec, Canada, June 23-24, 1994, 343 pp.; (pp. 136-142) (1995)

The sediments deposited on the bottoms of seas, lakes, and rivers can be contaminated with hazardous and toxic substances as a result of the discharge of human activities. Therefore, since the natural remediation process cannot be expected, contaminated or polluted as well as highly organic sediments must be treated as waste and be properly disposed for human health and environmental protection. One method of disposal may be to remove the sediments by dredging and to treat them with a proper technique. The main problems in the dredging method are as follows: (1) since sediments usually have very high water content, it is necessary to decrease the volume and solidify them for the next procedure, e.g., landfill; (2) the leachates from the sediments should be treated also. It is required that the water to be discharged be kept at a quality satisfying the level of standards. This paper describes an experimental study using a solidification system performed for the cleanup of the bottom of a river. To promote the solidification of the system, several agents, such as lime, cement, polymer, resin, etc., were used. The results show that these agents strongly influence the solidification characteristics of the sediments and the quality of the leachate from the sediments.

2577

V18/023799

Development of a Continuously Monitoring Resistivity Probe for Free-Phase Petroleum Hydrocarbons

Shoop, S.; Berini, C.; Guyer, R.

U.S. Army, Cold Regions Research and Engineering Laboratory, Hanover, $\mathrm{NH}$

CONF-960477; SAGEEP '96, R.S. Bell and M.H. Cramer (eds.), Proceedings of the Ninth Annual Symposium on the Application of Geophysics to Engineering and Environmental Problems, Denver, CO, April 15-May 1, 1996. Environmental and Engineering Geophysical Society, Wheat Ridge, CO, 1353 pp.; (pp. 11-20) (1996)

An in-situ electrical resistivity probe was evaluated for use in monitoring the vertical distribution of petroleum hydrocarbon in contaminated soil. By installing the probe to intersect the water table, it continuously monitors the presence of free-phase hydrocarbons by detecting electrical resistivity changes corresponding to the degree of oil saturation in the sediment pores. At a field site where diesel contamination occurs within a fine-grained sand, the results from the probe were compared to chemical analysis of total petroleum hydrocarbons (TPH) of soil borings and measured free product, i.e., light non-aqueous phase liquid (LNAPL), thickness and groundwater level in wells. The resistivity probe was also used to study LNAPL behavior under fluctuating water table conditions in a controlled laboratory environment. Results from the resistivity probe reflect the distribution of the contaminant within the sediment on a continuous basis and more accurately than contaminant thickness measurements in wells.

2578

V18/023863

Development of a Multi-Level Protocol for Determination of Biodegradation Kinetics and Bioavailability of Organic Compounds to Enhance Insitu Bioremediation

Tabak, H.H.; Govind, R.; Fu, C.; Yan, X.; Pfanstiel, S.; Gao, C.

U.S. Environmental Protection Agency, Risk Reduction Engineering Laboratory, Cincinnati, OH; University of Cincinnati, Department of Chemical Engineering, Cincinnati, $\mathrm{OH}$ 
EPA/600/R-95/012; CONF-9504110; Proceedings of the 21st Annual Risk Reduction Engineering Laboratory (RREL) Research Symposium, Cincinnati, OH, April 4-6, 1995. U.S. Environmental Protection Agency, Cincinnati, OH, 398 pp.; (pp. 49-55) (April 1995)

Knowledge of biodegradation kinetics in soils is needed to understand the efficacy of in-situ and exsitu bioremediation technologies. Laboratory studies to determine biodegradation rates can be used as screening tests to determine the rate and extent of bioremediation that might be attained during remediation, and to provide design criteria. Traditionally, in-situ biodegradation kinetics have been determined using soil microcosms which are difficult to model mathematically. Laboratory studies involving slurry reactors have been reported by Bachmann et al., Kaplan and Kaplan, Milhelcic and Luthy, and Brunner et al. Currently there is no systematic methodology to quantitatively determine biodegradation kinetics of contaminants in compacted soil systems. Biodegradation in soil is a fairly complex process which involves diffusion of contaminants in the porous soil matrix, adsorption to the soil surface, biodegradation in the biofilms existing on the soil particle surface and in the large pores as well as in the bound and free water phase after desorption from the soil surface. In soil slurry reactors, biodegradation of contaminant occurs both in the liquid phase by soil microorganisms desorbed from the soil matrix and by the biofilms immobilized on the soil particle surface. In compacted soil systems, biodegradation occurs in the free and bound water phase primarily by the soil immobilized microorganisms and the contribution of water suspended microbiota is small due to low water content. In this paper a systematic protocol based on three types of bioreactors and one representative contaminant, phenol, has been developed to determine the biokinetic parameters of the suspended and immobilized microbiota and the transport parameters of contaminant and oxygen in the soil matrix.

V18/021985

\section{Development of a Prediction Tool for PCB} Bioremediation

Klasson, K.T.

Oak Ridge National Laboratory, Chemical Technology Division, Oak Ridge, TN

CONF-9509139; Emerging Technologies in Hazardous Waste Management VII, D.W. Tedder (ed.), Proceedings of the Seventh American Chemical Society Industrial and Engineering Chemistry Division Special Symposium, Atlanta, GA, September 17-20, 1995. American Chemical Society, Washington, DC, 1291 pp.; (pp. 1146-1147) (1995)

Polychlorinated biphenyls (PCBs) are a family of compounds produced as complex mixtures that have been employed extensively in transformers, capacitors, printing ink, paints, antidusting agents, pesticides, etc. The discovery of widespread environmental occurrence of these very stable compounds and their suspected carcinogenic effect in humans led to regulation of PCBs through the Toxic Substances Control Act of 1976. Although PCBs may seem inert, biological degradation by anaerobic dechlorination and aerobic oxidation is possible. The enzymes involved in the aerobic ring-cleavage have been studied extensively, but little is known about enzymes responsible for anaerobic dechlorination, mainly due to the difficulty in isolating an organism. The anaerobic dechlorination follows distinct dechlorination patterns, which refer to the type of chlorines removed, and varies from site to site. As the knowledge of microbial dechlorination and degradation increases, it may soon be possible to control the processes for optimal result. This work presents results of the development of a tool to aid in evaluation of $\mathrm{PCB}$ bioremediation possibilities through the development of a computer program based on the susceptibility of PCB congeners to undergo bacterial transformation. The mathematical model also incorporates data from literature to estimate the effects on humans.

2580

V18/022245

Development of an Indirectly Heated Thermal Desorption System for PCB Contaminated Soil

Maxymillian, N.A.; Pisanelli, A.J.

Maxymillian Technologies, Inc., Boston, MA

CONF-951139 (Vol. 2); Superfund 16: Proceedings of a Hazardous Waste Conference and Exhibition, Washington, DC, November 6-8, 1995. E.J. Krause and Associates, Bethesda, MD, Vol. 2, 817 pp.; (pp. 990-996) (1994)

Thermal Desorption is effective in removing organics to established cleanup standards from contaminated soils, sludges and sediments. Maxymillian Technologies, Inc. (MT) has developed the Indirect System, which is an indirectly heated thermal desorption system for decontaminating soils contaminated with PCBs. This innovative system is mobile and trailer-mounted for easy transport to remediation sites to treat contaminated soils. The system is designed to effectively decontaminate PCB soil to belou 2 ppm as a rate of 10 to 20 tons per hour. MT developed the Indirect System to meet a growing need for cost-effective, mobile, high-throughput technologies that effectively remediate soils contaminated with PCBs. To develop the Indirect System, Maxymillian Technologies entered into a Joint Development Agreement (JDA) with General Electric Corporation's Corporate Research and Development (GE $\mathrm{CRD}$ ) group. In this relationship, GE CRD provides the basic research and science upon which the technology is based, and MT provides the process and implementation. At the time of writing this paper, the Indirect System was scheduled to undergo a Research and Demonstration Test at a PCB contaminated site in New York in the fall of 1995. The results of this R\&D Test are expected to be presented at the Superfund XVI Conference in November of 1995.

2581

V18/024316

Development of an Injection System for Insitu Catalyzed Peroxide Remediation of Contaminated Soil

Ho, C.L.; Shebl, M.A.A.; Watts, R.J.

Washington State University, Pullman, WA

Hazardous Waste and Hazardous Materials 12(1):15-25 (Winter 1995)

In situ chemical oxidations have the potential for rapidly treating soils contaminated with toxic and persistent organic wastes. One mechanism for introducing strong oxidants into contaminated soils is the catalyzed decomposition of hydrogen peroxide $(\mathrm{H} 2 \mathrm{O} 2)$ to form hydroxyl radicals $(\mathrm{OH})$, commonly known as Fenton's reagent. The research presented in this paper investigated the injection of $\mathrm{H} 2 \mathrm{O} 2$ at depth for treating soil. A scale model injection 
system was designed and constructed to deliver the $\mathrm{H}_{2} \mathrm{O} 2$ at depth. The tests were conducted in a polyethylene test tank. A natural sand from southeastem Washington state was placed in the tank under controlled density conditions and saturated with nitrobenzene, a documented hydroxyl radical probe. $\mathrm{H} 2 \mathrm{O} 2$ was injected at a controlled flow rate through a Teflon rotary injection system. Bottom up injection was used for all tests. Pore fluid samples were extracted using thirty in-place glass sampling tubes placed at various depths and distances from the injection axis. Concentrations of nitrobenzene and $\mathrm{H} 2 \mathrm{O} 2$ were measured to evaluate the influence of flow rate and $\mathrm{H} 2 \mathrm{O} 2$ concentration on the effectiveness of the in situ delivery system.

\section{2}

\section{V18/024084}

Development of an Integrated, Insitu Remediation Technology: Task 7, Development of Degradation Processes - Topical Report, September 26, 1994-May 25, 1996

Brackin, M.J.; Heitkamp, M.A.; Ho, S.V.; Houston, Z.C.; Warikoo, V.; McCarty, P.L.

Monsanto Company, St. Louis, MO; Stanford University, Western Region Hazardous Substance Research Center, Stanford, CA

DOE/MC/31185-5495; 50 pp. (1997)

Contamination in low permeability soils poses a significant technical challenge to in situ remediation efforts. Poor accessibility to the contaminants and difficulty in delivery of treatment reagents have rendered existing in situ treatments such as bioremediation, vapor extraction, and pump and treat rather ineffective when applied to low permeability soils present at many contaminated sites. The Lasagna [TM] technology is an integrated in situ treatment in which established geotechnical methods are used to install degradation zones directly in the contaminated soil, and electro-osmosis is utilized to move the contaminants back and forth through those zones until the treatment is completed. The general concept of the technology is to use electrokinetics to move contaminants from the soils into "treatment zones" where the contaminants can be removed from the water by either adsorption or degradation. The focus of technical task \# 7 was to optimize the conditions required for electro-osmotic movement of contaminants and microbial degradation in the treatment zones. This topical report summarizes the results of aerobic microbial research performed to evaluate the feasibility of incorporating the chemical-degrading organisms into biotreatment zones in laboratory-scale electro-osmosis units and to demonstrate the combination of electrokinetics and aerobic microbial degradation for the removal of contaminants from clay. Also included in this report are the results of investigating microbial movement during electro-osmosis and studies involving the optimization of the microbial support matrix in the biozone.

\section{3}

\section{V18/024081}

Development of an Integrated, Insitu Remediation Technology: Task 11, Evaluation of TCE Contamination Before and After the Field Experiment - Topical Report, September 26, 1994-May 25, 1996

Hughes, B.M.; Ho, S.V.; Athmer, C.J.; Sheridan, P.W.;
Shoemaker, S.H.; Larson, J.R.; Clausen, J.L.; Zutman, J.L.

Monsanto Company, St. Louis, MO; E.I. du Pont de Nemours \& Company, Houston, TX; Lockheed Martin Energy Systems, Inc., Kevil, KY; Oak Ridge National Laboratory, Oak Ridge, TN

DOE/MC/31185-5496; 225 pp. (1997)

Contamination in low permeability soils poses a significant technical challenge to in-situ remediation efforts. Poor accessibility to the contaminants and difficulty in delivery of treatment reagents have rendered existing in-situ treatments such as bioremediation, vapor extraction, pump and treat rather ineffective when applied to low permeability soils present at many contaminated sites. This technology is an integrated in-situ treatment in which established geotechnical methods are used to install degradation zones directly in the contaminated soil and electroosmosis is utilized to move the contaminants back and forth through those zones until the treatment is completed. The present Topical Report for Task \# 11 summarizes the results of TCE analysis in soil and carbon before and after conducting the field experiment. In addition, a discussion of the TCE material balance demonstrates that the Lasagna [TM] process is effective in moving TCE from the contaminated soil into carbon treatment zones in the field experiment at DOE's Gaseous Diffusion Plant in Paducah, Kentucky.

\section{4}

\section{V18/025619}

Development of an Integrated, Insitu Remediation Technology: Task 2-4, Electrokinetic Modeling - Topical Report, September 26-May 25, 1996

Monsanto Company, St. Louis, MO

DOE/MC/31185-5391; 54 pp. (1997)

This report summarizes the work conducted in Tasks 2-4, which together make up the Electrokinetic Modeling carried out in this project. The modeling was divided into three main sections: thermal analysis, chemical species transport, and electrode geometry and soil heterogeneity issues. The thermal modeling consisted of development of the governing equations to incorporate Joule heating associated with electro-osmosis, heat conduction and convection, and temperature dependencies of electrical conductivity and electro-osmotic permeability. To model the transport of chemical species in the Lasagna [TM] process, a one-dimensional model was developed. This model is based on previous models, but includes additional mechanism to account for charge transfer in the double layer, $\mathrm{pH}$ buffering of the soil, and zeta potential dependency on $\mathrm{pH}$ and ionic strength. An analysis was also conducted to compare the use of cylindrical electrodes to the plate geometry used in Phase I. In summary, cylindrical electrodes may be appropriate for anodes, because the do not intercept the flow. If used as cathodes, a planar treatment zone in their vicinity would probably be required. An example of soil heterogeneity was investigated when it was discovered that a steel pit was buried in the vicinity of the pilot test. There is some distortion of the field near the pit, but its effects on the test zone between the electrodes are minimal.

2585

V18/024077

Development of an Integrated, Insitu Remediation Technology: Task 6, Lab-Scale Development of Microbial Degradation Process - Topical Report, 


\section{September 26, 1994-May 25, 1996}

Odom, J.M.

DuPont Company, Central Research \& Development, Wilmington, DE; Monsanto Company, St. Louis, MO DOE/MC/31185-5388; 20 pp. (1997)

Contamination in low permeability soils poses a significant technical challenge to in situ remediation efforts. Poor accessibility to the contaminants and difficulty in delivery of treatment reagents have rendered existing in situ treatments such as bioremediation, vapor extraction, and pump and treat rather ineffective when applied to low permeability soils present at many contaminated sites. The technology is an integrated in situ treatment in which established geotechnical methods are used to install degradation zones directly in the contaminated soil, and electro-osmosis is utilized to move the contaminants back and forth through those zones until the treatment is completed. The present Topical Report for Task \# 6 summarizes the results of a study of the potential for stimulating microbial reductive dehalogenation as part of the integrated in situ treatment process at the field experiment test site at DOE's Gaseous Diffusion Plant in Paducah, Kentucky. A series of "microcosm bottle tests" were performed on samples of contaminated soil and groundwater taken from the Paducah site and spiked with trichloroethene (TCE). A number of bottles were set up, each spiked with a different carbon source in order to enhance the growth of different microbial subpopulations already present within the indigenous population in the soil. In addition, a series of bottle tests were completed with samples of the granular activated carbon (GAC) treatment zone material retrieved from the test site during the Paducah field experiment. In these tests, the GAC samples were used in place of the soil. Results of the soil-groundwater microcosms yielded a negative indication of the presence of dechlorinating bacteria at the site. However, charcoal (GAC) samples from one location in the test plot exhibited marked dechlorination with conversion of TCE to dichloroethene.

\section{6}

V18/024094

Development of an Integrated, Insitu Remediation Technology: Tasks 12 and 13, Large Scale Field Test of the Lasagna Process - Topical Report, September 26, 1994-May 25, 1996

Athmer, C.J.; Ho, S.V.; Hughes, M.; Sheridan, P.W.; Brodsky, P.H.; Shapiro, A.P.; Thorton, R.F.; Salvo, J.J.; Schultz, D.S.; Landis, R.C.; Griffith, R.; Shoemaker, S.H.

Monsanto Company, St. Louis, MO; General Electric Company, Corporate Research and Development Center, Schenectady, NY; E.I. du Pont de Nemours \& Company, Houston, TX

DOE/MC/31185-5390; 148 pp. (1997)

Contamination in low permeability soils poses a significant technical challenge to in-situ remediation efforts. Poor accessibility to the contaminants and difficulty in delivery of treatment reagents have rendered existing in-situ treatments such as bioremediation, vapor extraction, pump and treat rather ineffective when applied to low permeability soils present at many contaminated sites. This technology is an integrated in-situ treatment in which established geotechnical methods are used to install degradation zones directly in the contaminated soil and electroosmosis is utilized to move the contaminants back and forth through those zones until the treatment is completed. This topical report summarizes the results of the field experiment conducted at the Paducah Gaseous Diffusion Plant in Paducah, KY. The test site covered 15 feet wide by 10 feet across and 15 feet deep with steel panels as electrodes and wickdrains containing granular activated carbon as treatment zones. The electrodes and treatment zones were installed utilizing innovative adaptation of existing emplacement technologies. The unit was operated for four months, flushing trichloroethylene (TCE) by electroosmosis from the soil into the treatment zones where it was trapped by the activated carbon. The scale up from laboratory units to this field scale was very successful with respect to electrical parameters as well as electroosmotic flow. Soil samples taken throughout the site before and after the test showed over $98 \%$ TCE removal, with most samples showing greater than $99 \%$ removal. This high degree of removal is remarkable since some of the pre-test soil samples indicated the presence of residual pure phase TCE (DNAPL). Analysis of the carbon samples retrieved from various treatment zone locations showed that overall about 50 percent of the TCE can be accounted for, which is quite good considering the difficulty in handling TCE and the highly non-uniform distribution of TCE in the soil. Monitoring TCE levels in the air during the test showed that only about $4 \%$ of the total TCE could have been lost through evaporation. As far as we know, this is the first time that an organic contaminant could be cleaned up so uniformly from an actual contaminated clayey site. The Lasagna [TM] process shows great promise as an in-situ soil remediation technology, especially for low permeability soils.

V18/024083

Development of an Integrated, Insitu Remediation Technology: Tasks 8 and 10, Laboratory and Pilot Scale Experiments of the Lasagna Process - Topical Report, September 26, 1994-May 25, 1996

Ho, S.V.; Athmer, C.J.; Sheridan, P.W.; Shapiro, A.P. Monsanto Company, St. Louis, MO; General Electric Company, Corporate Research and Development Center, Schenectady, NY

DOE/MC/31185-5375; 71 pp. (1997)

Contamination in low permeability soils poses a significant technical challenge to in-situ remediation efforts. Poor accessibility to the contaminants and difficulty in delivery of treatment reagents have rendered existing in-situ treatments such as bioremediation, vapor extraction, pump and treat rather ineffective when applied to low permeability soils present at many contaminated sites. This technology is an integrated in-situ treatment in which established geotechnical methods are used to install degradation zones directly in the contaminated soil and electro-osmosis is utilized to move the contaminants back and forth through those zones until the treatment is completed. This topical report summarizes the results of the lab and pilot sized Lasagna [TM] experiments conducted at Monsanto.

\section{$2588 \quad$ V18/021398}

Development of the Integrated Insitu Lasagna [TM] Process

Hughes, B.M. 


\section{Monsanto Company, St. Louis, MO}

Fostering the Needed Partnerships: Doing the Necessary Science to Support Technology Development, Commercialization, Deployment, E.L. Helminski (ed.), Proceedings of the Seventh Annual Western Govemors' Association/Weapons Complex Monitor Applied Research and Cleanup Technology Colloquium, Phoenix, AZ, April 29-May 2, 1996. Exchange/Monitor Publications and Forums, Lake Bluff, II, 500 pp.; (15 pp.) (April 1996)

This presentation provided an in-depth discussion of the soil remediation technology known as the in-situ Lasagna [TM] process. The discussion focused on the following topics: soil remediation technologies, the Lasagna [TM] concept, integrated in-situ remediation, steps for commercialization, history of development, organizational structure for phase 1 and phase 2 research, summary of field experiments and the proposed approach to integrated development. The benefits of an integrated government/industry approach to technology development are emphasized and lessons learned are discussed.

\section{9}

V18/023810

Dielectric Properties of Polluted Soils as a Potential Tool to Detect Low Level Organic Pollution in Unsaturated Soils

Porokhovoi, S.; du Mouza, J.; Reiter, M.

Centre de Geologie de l'Ingenieur, Paris, France; Houilleres de Bassin Centre-Midi, Francois-Margand, France

CONF-960477; SAGEEP '96, R.S. Bell and M.H. Cramer (eds.), Proceedings of the Ninth Annual Symposium on the Application of Geophysics to Engineering and Environmental Problems, Denver, CO, April 15-May 1, 1996. Environmental and Engineering Geophysical Society, Wheat Ridge, CO, 1353 pp.; (pp. 1237-1246) (1996)

The detection of organic pollution in soils is usually done by chemical analysis. Some geophysical methods are available to detect massive and transient pollution. But the standards used in Europe to define a non-polluted soil are very strict: some organic compounds (e.g., polycyclic aromatic hydrocarbons) have to be less than 10 ppm. Hence, a geophysical tool that allows prospecting large areas with low levels of organic pollution has to be developed. This work is the first step of the evaluation of a geophysical method based on the dielectric characteristics of soils, our final goal being in situ measurements of those parameters. Several geophysical methods are already used to monitor organic pollution of groundwater and soils. Both electric and dielectric properties of these pollutants can be used. This paper reports laboratory measurements of the dielectric properties of both polluted and non-polluted soils. The experiments used primarily artificial soils composed of pure siliceous sand and pure kaolinite. Various pollutants belonging to different structural classes were added to the soils, including acetone, heptane, xylene, benzene, and toluene. Two natural soils from a site polluted with polycyclic aromatic hydrocarbons were also measured.

\section{0}

V18/023473

Distribution and Extraction of $\mathrm{Pb}$ and $\mathrm{Zn}$ with Chelating Agents in Soils with Varying Pollution Level

Barona, A.; Etxebarria, B.
University of Basque Country, Bilbao, Spain

CONF-960730 (Vol. 3); Technologies Critical to a Changing World, Volume III: Emerging Energy Technologies, Clean Technologies, Remediation and Emission Control Fuels, and Petrochemicals, Proceedings of the Fifth World Congress of Chemical Engineering, San Diego, CA, July 14-18, 1996. American Institute of Chemical Engineers, New York, NY, Vol. 3, 1118 pp.; (pp. 576-581) (1996)

Three locations with different pollution levels were selected for soil sampling. After determining the general characteristics of the soils, total amounts of $\mathrm{Zn}$ and $\mathrm{Pb}$ were measured. A sequential extraction procedure was carried out in order to establish the distribution of these two metals in the operationally defined soil fractions. Ethylene diamine tetra-acetic (acid) (EDTA) was selected as a chelating agent to extract $\mathrm{Pb}$ from the studied soils. Similarly, diethylenetriaminepentaacetic acid (DTPA) was selected to extract the $\mathrm{Zn}$. Multiple regression analysis of data was performed in order to obtain a satisfactory equation that relates the $\mathrm{Pb}$ and $\mathrm{Zn}$ recovery with chelating agents to the amounts of these metals in each of the sequential fractions.

2591

V18/023652

Dredging, Remediation, and Containment of Contaminated Sediments

Demars, K.R.; Richardson, G.N.; Yong, R.N.; Chaney, R.C. CONF-9406413; Dredging, Remediation, and Containment of Contaminated Sediments, K.R. Demars, G.N. Richardson, R.N. Yong and R.C. Chaney (eds.), Proceedings of a Symposium, Montreal, Quebec, Canada, June 23-24, 1994, 343 pp.; (pp. 23-23) (1995)

This conference was held June 23-24, 1994 in Montreal, Canada. One purpose of this conference was to provide a multidisciplinary forum for exchange of state-of-the-art information on identifying tests, methods, procedures, and materials, used in support of dredging, treatment, and containment of contaminated sediments that are in need of standardization. Another objective was to provide a forum for discussion of past dredging practices and future directions, including the effects of sediment properties and behavior, equipment requirements, and the impact of regulations. Papers within the scope of this data base have been indexed separately.

V18/023807

EM Induction and Magnetic Surveys at Large Landfill Sites Using GPS for Positional Control

Hackworth, J.B.; Kirkpatrick, T.M.; Holtzciaw, D.R.

International Technology Corporation, Knoxville, TN

CONF-960477; SAGEEP '96, R.S. Bell and M.H. Cramer (eds.), Proceedings of the Ninth Annual Symposium on the Application of Geophysics to Engineering and Environmental Problems, Denver, CO, April 15-May 1, 1996. Environmental and Engineering Geophysical Society, Wheat Ridge, CO, 1353 pp.; (pp. 1157-1172) (1996)

Electromagnetic (EM) induction and magnetic surveys were conducted at two large landfill sites, totaling 76 acres, using a global positioning system (GPS) as the positional control method. The surveys were conducted at Tinker AFB in Oklahoma, as part of a Phase II Resource Conservation and Recovery Act (RCRA) facility 
investigation. The objectives of the investigation were to delineate the boundaries of known landfill trenches and determine whether features seen in aerial photographs represented previously unidentified trenches. The GPS method of survey control was chosen rather than the conventional local grid approach because site conditions included extremely rugged surface topography, thick vegetation, and several swampy areas that precluded the establishment of precisely spaced, straight lines. The alternative would have required civil surveying and extensive vegetation removal. The GPS allowed local navigation and re-orientation to avoid obstacles and field hazards while continuing to collect valid, accurately located geophysical data. The use of differentially corrected GPS data for this investigation proved to be an excellent way to obtain geophysical survey control at a reduced level of effort; however, it added complexity to the surveys that had to be planned for both in the field and during data processing. Specialized processing techniques were developed to overcome minor satellite signal "dropouts", and to allow for proper time-synchronization and merging of the geophysical and GPS data.

\section{3}

V18/023634

Effect of Redox Potential on the Electrokinetic Remediation of Mercury Contaminated Soils

Cox, C.D.; Shoesmith, M.A.; Ghosh, M.M.

University of Tennessee, Knoxville, TN

CONF-951023 (Vol. 8); WEFTEC '95, Proceedings of the 68th Annual Conference and Exposition of the Water Environment Federation, Miami Beach, FL, October 21-25, 1995. Water Environment Federation, Alexandria, VA, Vol. 8, 498 pp.; (p. 303) (1995)

An electrokinetic process for remediation of mercury contaminated soils using an iodine-iodide lixiviant was developed. In this process, reduced forms of insoluble mercury are oxidized by iodine. Iodide then reacts with mercury to form the highly soluble $\mathrm{HgI} 4(2-)$ complex, which in turn migrates toward the anode via electromigration. The objective was to determine the thermodynamic conditions under which mercury could be solubilized and transported from the soil. At the end of the electrokinetic treatment process, $\mathrm{pH}, \mathrm{pE}$, iodine, iodide, and soluble and total mercury were measured along the length of the soil. The process was tested on a soil contaminated with HgS (cinnabar) in the laboratory and a contaminated soil obtained from a hazardous waste site. Up to $99 \%$ overall removal of mercury could be achieved from the laboratory contaminated soil. Up to $84 \%$ of mercury was removed from some sections of the field contaminated soil, but overall removal was only $6 \%$. The presence of iodine in the soil pore water was found to be the most important factor in solubilization of mercury. Residual levels of soluble $\mathrm{Hg}$ remaining in soil after treatment were greater than allowed by current regulations and far in excess of the solubility of $\mathrm{Hg}$ compounds present in the untreated soil. (Complete text)

Effect of Thin Layer Caps on Cesium Contaminated Bed Sediment Remediation

Omojola, J.O.; Thibodeaux, L.J.; Novitsky, M.

Dillard University, New Orleans, LA
CONF-960376 (Part 1); Proceedings of the 211th American Chemical Society (ACS) National Meeting, New Orleans, LA, March 24-28, 1996. ACS, Washington, DC, Part 1, 1172 pp.; (p. 773, Paper ENVR 53) (1996)

An alternative to conventional in-situ capping of contaminated bed-sediment is being investigated. The method proposed entails periodically distributing (at 3-month intervals) a thin layer (about 1 $\mathrm{cm}$. in thickness) of silt particles onto the contaminated bed. Lake Swaytoe in Russia, contaminated with Cesium 137, is used for the case study using theoretical model calculations. Due to Cs-137 adsorption on the silt the cap acts as a barrier, reducing the concentration in the pore water. Burial of contaminated solids also occurs with subsequent application of layers. Over time bioturbation enhanced particle transport mixes clean sediment with contaminated sediment thereby reducing the effectiveness of the cap. Particle interchange is modeled over time to predict concentration levels and to adjust the appropriate time interval for putting on a new layer. The results indicate bed surface pore water Cs- 137 concentrations can be reduced by over $85 \%$ in the first year after four applications of thin layers. (Complete text)

\section{5}

V18/022417

Effectiveness of Purge-and-Trap for Measurement of Volatile Organic Compounds in Aged Soils

Askari, M.D.F.; Maskarinec, M.P.; Smith, S.M.; Beam, P.M.; Travis, C.C.

University of Tennessee, Knoxville, TN; U.S. Department of Energy, Washington, DC; Oak Ridge National Laboratory, Oak Ridge, TN

Analytical Chemistry 68(19):3431-3433 (October 1, 1996)

Purge-and-trap, the U.S. EPA-recommended method for measurement of trace levels of volatile organic compounds (VOCs) in soil, measures the readily desorbable organic contaminants from soil pore spaces and external soil surfaces. It does not, however, measure contamination that has diffused into intemal micropores of soil matrix. Thus, the purge-and-trap method measures only a small fraction of total soil contaminants, especially in long-contaminated soils, where approximately $90-99 \%$ of contamination may be in the interior of the soil matrix. We compared three methods for determination of VOCs in aged field samples: purge-and-trap, methanol immersion, and hot solvent extraction. Hot solvent extraction proved to be much more effective than the U.S. EPA-approved purge-and-trap technique. For three long-contaminated soils containing such VOCs as trichloroethene, benzene, toluene, chloroform, methylene chloride, and cis-1,1-dichloroethylene, recovery from purge-and-trap ranged between 1.5 and $41.3 \%$ that of hot solvent extraction. Our data show that purge-and-trap may not be the best methodology for measuring soil VOCs concentrations, particularly in aged soils. It is clear from this and previous studies that the best overall choice for soil VOCs measurements is hot solvent extraction. These results also indicate the inefficiency of purge-and-trap as a method for evaluating vapor extraction remediation technology. Our results suggest that the EPA should review the use of the purge-and-trap method for measuring VOCs concentrations in soils. 
Effects of Soil Chemistry on Electroremediation

Dzenitis, J.M.

Massachusetts Institute of Technology, Department of Mechanical Engineering, Cambridge, MA

CONF-9509139; Emerging Technologies in Hazardous Waste Management VII, D.W. Tedder (ed.), Proceedings of the Seventh American Chemical Society Industrial and Engineering Chemistry Division Special Symposium, Atlanta, GA, September 17-20, 1995. American Chemical Society, Washington, DC, 1291 pp.; (p. 456) (1995)

The chemical composition of the pore liquid throughout the treatment volume has a major impact on the electroremediation process. The chemical state affects both electromigration and electroosmosis contributions by controlling important parameters such as the conductivity, soil surface charge, and contaminant complexation. In general it is not appropriate to assume uniform chemical compositions, nor to neglect the chemical contribution of the soil matrix. An engineering approach to including soil chemistry in electroremediation transport modeling is presented. Specific chemical models for two clayey soils are discussed; it is shown that these chemical models are necessary to reconcile results of numerical simulations with those of laboratory experiments. Finally, some general guidelines and criteria for including soil chemistry are given. (Complete text).

2597

V18/021097

Electrical Resistance Tomography During Gas Injection at the Savannah River Site

Ramirez, A.L.; Daily, W.D.

Lawrence Livermore National Laboratory, Livermore, CA

UCRL-JC-114126; CONF-9309146; Emerging Technologies in

Hazardous Waste Management V, Proceedings of the Fifth

American Chemical Society Industrial and Engineering Chemistry

Division Special Symposium, Atlanta, GA, September 27-29, 1993.

American Chemical Society, Washington, DC, 903 pp.; (4 pp.)

(May 1993)

Electrical resistance tomography (ERT) is used to monitor some in situ remediation processes being evaluated for removal of volatile organic compounds from subsurface water and soil at the Integrated Demonstration for VOC's in Soils and Groundwater at Non Arid Sites, the Savannah River Site, near Aiken, South Carolina. Air was injected in the saturated zone and the entrained air was tomographically imaged by its effects on the formation electrical resistivity. We found that the flow paths are confined to a complex three dimensional network of channels, some of which extend as far as $30 \mathrm{~m}$ from the injection well. We conciude, based on these results, that the shape and extent of the air plume are controlled by spatial variations in the local gas permeability. These channels are somewhat unstable over a period of months and new channels appear to form with time.

\section{8}

V18/021080

Electrical Resistance Tomography During Insitu TCE Remediation at the Savannah River Site

Daily, W.D.; Ramirez, A.L.

Lawrence Livermore National Laboratory, Livermore, CA
UCRL-JC-112326; 25 pp. (April 1993)

Electrical resistance tomography (ERT) is used to monitor some of the in situ remediation processes being evaluated for removal of volatile, organic compounds from subsurface water and soil at the Integrated Demonstration for VOC's in Soils and Groundwater in Non Arid Sites, the Savannah River Site, near Aiken, South Carolina. Air was injected in the saturated zone and the entrained air was tomographically imaged by its effects on the formation electrical resistivity. We found that the flow paths are confined to a complex, three dimensional network of channels, some of which extend as far as $30 \mathrm{~m}$ from the injection well. We conclude based on these results that the shape and extent of air plume are controlled by spatial variations in the local gas permeability. These channels are not entirely stable over a period of months and new channels appear to form with time. Also the longer gas flows through the formation, the larger is the change in resistivity. One interpretation is that established channels are becoming dryer with use. Images of water infiltration from the surface support similar conclusions about the permeability in the vadose zone. The infiltration wetting front is confined to narrow channels which have a clear three dimensional structure. Here as in the saturated zone, fluid flow is controlled by local variations in the formation permeability. However, the temporal changes in these channels are minor; small scale permeability variations do not seem to be modified by continued infiltration.

2599

V18/020776

Electrokinetic (EK) Remediation of a Fine Sandy Loam: The Effect of Voltage and Reservoir Conditioning

Ramsey, J.; Reed, B.

West Virginia University, Department of Civil and Environmental Engineering, Morgantown, WV

CONF-9507204; Hazardous and Industrial Wastes, A.K. Sengupta (ed.), Proceedings of the 27th Mid-Atlantic Industrial Waste Conference, Bethlehem, PA, July 9-12, 1995. Technomic Publishing Company, Lancaster, PA, 973 pp.; (pp. 804-813) (1995)

Recently, attention has focused on developing cost effective in situ techniques to remove contaminants from soils. There is a need for cost effective and more efficient technologies that can be used to remediate low permeability soils in-situ. A candidate technology for this type of remedial measure is electrokinetic (EK) soil flushing. Recently, attention has focused on EK as a remediation technology. However, there is a need for experimentation on methods that may potentially enhance the effects and minimize the cost of EK soil flushing on the remediation of contaminated soil systems. Based on the fact that lead is a predominate constituent found in many Superfund sites across the United States, this research focused on applying the EK soil flushing process to removing lead from an artificially contaminated soil system. The objectives of this research were to determine the effect of voltage and reservoir conditioning on energy expenditure and time required for lead removal.

2600

V18/021993

Electrokinetic Characterization Techniques for Contaminated Soils 
Eykholt, G.R.; Hung, H.

University of Wisconsin, Department of Civil and

Environmental Engineering, Madison, WI

CONF-9509139; Emerging Technologies in Hazardous Waste Management VII, D.W. Tedder (ed.), Proceedings of the Seventh American Chemical Society Industrial and Engineering Chemistry Division Special Symposium, Atlanta, GA, September 17-20, 1995. American Chemical Society, Washington, DC, 1291 pp.; (pp. 452-455) (1995)

One important element to the success of electrokinetic remediation of contaminated soils may be the assessment and control of the soil surface chemistry. This is usually reflected by an operative zeta-potential or electroosmotic coefficient, keo, found by an electroosmosis test on a plug of contaminated soil. However, several researchers have shown that both the magnitude and uniformity of keo change over the course of testing, as does the electric field intensity and zeta-potential, two basic parameters of the fundamental driving force. The electric field intensity can be measured during the test, but it is more difficult to assess the zeta potential. Independent techniques are needed. A conventional technique is dilute electrophoresis, but this test may not be truly representative or convenient. Alternative techniques based on electroacoustic phenomena will be presented in conjunction with other electrokinetic tests on reference and contaminated soils.

2601

V18/023476

Electrokinetic Characterization of the Transport Behavior of Monoclonal Bacterial Populations in Porous Media

Glynn, J.R., Jr.; Amold, R.G.; Ogden, K.L.; Baygents, J.C.

University of Arizona, Department of Chemical and Environmental Engineering, Tucson, $\mathrm{AZ}$

CONF-960730 (Vol. 3); Technologies Critical to a Changing World, Volume III: Emerging Energy Technologies, Clean Technologies, Remediation and Emission Control Fuels, and Petrochemicals, Proceedings of the Fifth World Congress of Chemical Engineering, San Diego, CA, July 14-18, 1996. American Institute of Chemical Engineers, New York, NY, Vol. 3, 1118 pp.; (pp. 689-693) (1996)

Bacterial transport in porous media is central to a variety of contemporary environmental issues. For example, plumes of pathogenic microorganisms may threaten drinking water supplies after an unintentional injection of reclaimed wastewater to aquifers. Conversely, microorganisms with unusual metabolic capabilities can be introduced into the subsurface to remediate hazardous contaminants. This paper discusses the use of capillary electrophoresis measurements to help characterize bacterial adsorption, a key factor in bacterial transport.

\section{2 \\ V18/020840}

Electrokinetic Electrode System for Extraction of Soil Contaminants from Unsaturated Soils

Lindgren, E.R.; Mattson, E.D.

Sandia Corporation, Albuquerque, NM

U.S. Patent 05435895; 10 pp. (July 25, 1995)

There is presented an electrokinetic electrode assembly for use in extraction of soil contaminants from unsaturated soil in situ. The assembly includes a housing for retaining a liquid comprising an electrolyte solution, pure water, and soil water, the housing being in part of porous material capable of holding a vacuum. An electrode is mounted in the housing. The housing is provided with a vacuum orifice for effecting a vacuum within the housing selectively to control flow of soil water through the housing into the chamber and to control outflow of the liquid from the chamber. The assembly further includes conduit means for removing the liquid from the housing and returning the electrolyte solution to the housing, and a conduit for admitting pure water to the housing. There is further presented an electrode system and method for extraction of soil contaminants, the system and method utilizing at least two electrode assemblies as described above.

2603 V18/022009

Electrokinetic Injection of Ammonium and Sulfate for Insitu Bioremediation of Soils

Acar, Y.B.; Rabbi, M.F.; Gale, R.J.; Peters, R.W.; Brewster, M.D.

Louisiana State University, Department of Civil and Environmental Engineering, Baton Rouge, LA; Louisiana State University, Department of Chemistry, Baton Rouge, LA; Argonne National Laboratory, Energy Systems Division, Argonne, II

CONF-9509139; Emerging Technologies in Hazardous Waste Management VII, D.W. Tedder (ed.), Proceedings of the Seventh American Chemical Society Industrial and Engineering Chemistry Division Special Symposium, Atlanta, GA, September 17-20, 1995. American Chemical Society, Washington, DC, 1291 pp.; (p. 1136) (1995)

In situ biotreatment is a desirable and promising remediation technology. One limiting aspect of its successful implementation has been ineffective introduction of process nutrients into biologically active zones (BAZs). Key process additives are conventionally introduced by pumping a recirculated groundwater through the $\mathrm{BAZ}$ relying upon hydraulic gradients that could be induced across the BAZ. Uniform introduction of additives is often prevented by heterogeneities in the aquifer. Zones of higher permeability result in preferential flow paths and lead to incomplete biological treatment. All biological processes require that nutrient and electron acceptors be supplied at appropriate amounts, stoichiometric ratios, and application rates. Some systems also require specialty additives such as surfactants and cometabolites which are even more difficult to uniformly transport into the BAZs. Therefore, the need to uniformly introduce nutrients and cometabolites has been the principal bottleneck in successful implementation of in situ bioremediation.

\section{4}

V18/022207

Electrokinetic Remediation of Brine-Impacted Soil

Harris, T.; Davis, C.; Al-Mutairi, K.

U.S. Department of Energy, Washington, DC; Amoco Production Company, Houston, TX; Conoco, Inc., Stamford, $\mathrm{CT}$; University of Tulsa, Tulsa, $\mathrm{OK}$

CONF-9509296; Environmental Issues and Solutions in Petroleum Exploration, Production, and Refining, K.L. Sublette (ed.), 
Proceedings of the Second International Petroleum Environmental Conference, New Orleans, LA, September 25-27, 1995, 1078 pp.; (pp. 619-630) (1995)

The remediation of soil contaminated with oilfield brine is often necessary to prevent excessive erosion as well as contamination of nearby surface and groundwater supplies. In the present study the use of electrokinetic remediation was examined. With this technique, the soil is first saturated with water, and then a large potential is applied between two electrodes placed in the soil. The objective of the electrolysis is to enhance the rate of removal of sodium and chloride ions (relative to simply leaching the soil with water). Laboratory tests with a small cell indicate that the efficiency of water utilization is enhanced by the applied potential. However, changes in the soil structure brought about by the products of the electrolysis can have an adverse effect on the flow of water through the soil.

\section{5}

V18/020678

Electrokinetic Remediation of Mercury-Contaminated Soils Using Iodine/Lodide Lixiviant

Cox, C.D.; Shoesmith, M.A.; Ghosh, M.M.

University of Tennessee, Knoxville, TN

Environmental Science \& Technology 30(6):1933-1938 (June 1996)

Insitu remediation of mercury-contaminated soils, by electrokinetic or other means, is difficult because of the low solubility of mercury and its compounds. In this research, enhanced electrokinetic remediation of HgS-contaminated soils using $12 /(-1)$ lixiviant was investigated using bench-scale electrokinetic cells. The thermodynamic conditions under which the lixiviant could be effective were determined by constructing a $\mathrm{pE}$-pH diagram for the $\mathrm{Hg}$-S-I system. Introduced near the cathode, the lixiviant migrated through the soil to the anode by electromigration. Mercury, released by the oxidation of $\mathrm{HgS}$ compounds by $\mathrm{I}$, was complexed as HgI4(-2). The negative complex continued to electromigrate toward the anode. Up to $99 \%$ of the Hg present in laboratory-contaminated soils could be removed. Electrokinetic treatment of a field-contaminated soil, containing more organic matter than the laboratory-contaminated soil, occurred much slower. The critical issues in determining the efficacy of the process are the oxidation of reduced $\mathrm{Hg}$ by $\mathrm{I} 2$ and $\mathrm{I}(-1)$ and the transport of the resultant HgI4(-2) complex.

\section{$2606 \quad$ V18/021724}

Electrokinetic Remediation of Soil Contaminated with Oilfield Brine

Davis, C.; Harris, T.

University of Tulsa, Tulsa, $O K$

CONF-960376 (Part 1); Proceedings of the 211th American Chemical Society (ACS) National Meeting, New Orleans, LA, March 24-28, 1996. ACS, Washington, DC, Part 1, 1172 pp.; (p. 417, Paper CHED 209) (1996)

The contamination of soil with brine (salt water) is a common environmental problem associated with the onshore production of oil. The use of electrokinetic remediation to remove sodium chloride from soil is being investigated. Experiments are being conducted in a test cell that features a well containing a stainless steel electrode at either end. During an experiment distilled water is added incrementally to the cell, and that which accumulates in the wells is removed and analyzed. The removal of both chloride ion and sodium ion from the soil is enhanced at the anode well by the application of an applied potential. The addition of calcium sulfate to the soil eliminates the plugging off of soil porosity resulting from $\mathrm{pH}$ changes that occur in the vicinity of both electrodes. (Complete text)

2607

V18/022202

Electrokinetic Remediation of Soils Contaminated with Electroplating Wastes

Reddy, K.R.; Parupudi, U.S.; Devulapalli, S.

University of Illinois, Department of Civil and Materials Engineering, Chicago, IL; Patterson Associates, Inc., Chicago IL

CONF-960426; Proceedings of the 58th Annual Meeting of the American Power Conference, A.E. McBride (ed.), Chicago, IL, April 9-11, 1996. American Power Conference, Chicago, IL, Vol. 58-I, 767 pp.; (pp. 342-346) (1996)

Electrokinetic remediation of soils simulated with electroplating waste contamination was investigated in two soils, kaolin and glacial till. Soil samples were contaminated with nickel, cadmium and hexavalent chromium and subjected to an external electric field for four days. Results of these experiments revealed that the soil composition plays an important role in electrokinetic remediation. Due to induced electric potential, a distinct $\mathrm{pH}$ gradient was developed in kaolin; however, in glacial till alkaline conditions existed throughout the soil because of its high carbonate buffering capacity. The movement of cationic metallic contaminants, $\mathrm{Ni}(\mathrm{II})$ and $\mathrm{Cd}(\mathrm{II})$, from the anode to the cathode was significant in kaolin as compared to glacial till. Because of high $\mathrm{pH}$ conditions near the cathode, $\mathrm{Ni}(\mathrm{II})$ and $\mathrm{Cd}(\mathrm{II})$ were precipitated in kaolin. In glacial till, however, because of alkaline conditions throughout the soil, most of $\mathrm{Ni}(\mathrm{II})$ and $\mathrm{Cd}(\mathrm{II})$ precipitated without migration. Overall, this study demonstrates that anion exchange, cation exchange and precipitation were the significant fixation mechanisms of nickel, cadmium and chromium in soils.

2608

V18/022877

Electrokinetic Removal of Uranium from Contaminated, Unsaturated Soils

Booher, W.F.; Lindgren, E.R.; Brady, P.V.

International Technology Corporation, Albuquerque, NM; Sandia National Laboratories, Albuquerque, NM

SAND97-0122; 52 pp. (January 1997)

Electrokinetic remediation of uranium-contaminated soil was studied in a series of laboratory-scale experiments in test cells with identical geometry using quartz sand at approximately 10 percent moisture content. Uranium, when present in the soil system as an anionic complex, could be migrated through unsaturated soil using electrokinetics. The distance that the uranium migrated in the test cell was dependent upon the initial molar ratio of citrate to uranium used. Over 50 percent of the uranium was recovered from the test cells using the citrate and carbonate complexing agents over a 
period of 15 days. Soil analyses showed that the uranium remaining in the test cells had been mobilized and ultimately would have been extracted. Uranium extraction exceeded 90 percent in an experiment that was operated for 37 days. Over 70 percent of the uranium was removed from a Hanford waste sample over a 55 day operating period. Citrate and carbonate ligand utilization ratios required for removing 50 percent of the uranium from the uranium-contaminated sand systems were approximately 230 moles per mole uranium and 1320 moles ligand per mole uranium for the waste. Modifying the operating conditions to increasing the residence time of the complexants is expected to improve the utilization efficiency of the complexing agent.

2609

V18/024006

Electromagnetic Imaging of a Fuel Oil Spill at Sandia/CA

Bartel, L.C.

Sandia National Laboratories, Albuquerque, NM

SAND97-0914; 22 pp. (April 1997)

The multifrequency, multisource integral wave migration method commonly used in the analysis of seismic data is extended to electromagnetic (EM) data within the audio frequency range. The method is applied to the secondary magnetic fields produced by a borehole, vertical electric source (VES). The integral wave-migration method is a numerical reconstruction procedure utilizing Green's theorem where the fields are migrated (extrapolated) from the measuring aperture into the interior of the earth. To form the image, the approach used here is to Fourier transform the constructed image from frequency domain to time domain and set time equal to zero. The image is formed when the in-phase part (real part) is a maximum or the out-of-phase (imaginary part) is a minimum; i.e., the EM wave is phase coherent at its origination. In the application here, the secondary magnetic fields are treated as scattered fields. To determine the conductivity, the measured data migrated to a pixel location are equated to calculated data migrated to the same pixel. The conductivity is determined from solving a Fredholm integral equation of the first kind by solving a system of linear algebraic equations. The multifrequency, multisource integral wave-migration method is applied to calculated model data and to actual field data acquired to map a diesel fuel oil spill. For the application discussed here, a two dimensional resistivity slice is calculated from the solution to the Fredholm integral equation. The resistivity image of the fuel oil agrees with the known location.

\section{0 \\ V18/023510}

Electromagnetic Induction Method for Underground Target Detection and Characterization

Bartel, L.C.; Cress, D.H.

Sandia National Laboratories, Albuquerque, NM

SAND97-0054; 45 pp. (January 1997)

An improved capability for subsurface structure detection is needed to support military and non-proliferation requirements for inspection and for surveillance of activities of threatening nations. As part of the DOE/NN-20 program to apply geophysical methods to detect and characterize underground facilities, Sandia National
Laboratories (SNL) initiated an electromagnetic induction (EMI) project to evaluate low frequency electromagnetic (EM) techniques for subsurface structure detection. Low frequency, in this case, extended from kilohertz to hundreds of kilohertz. An EMI survey procedure had already been developed for borehole imaging of coal seams and had successfully been applied in a surface mode to detect a drug smuggling tunnel. The SNL project had focused on building upon the success of that procedure and applying it to surface and low altitude airborne platforms. Part of SNL's work has focused on improving that technology through improved hardware and data processing. The improved hardware development has been performed utilizing Laboratory Directed Research and Development (LDRD) funding. In addition, SNL's effort focused on: (1) improvements in modeling of the basic geophysics of the illuminating electromagnetic field and its coupling to the underground target (partially funded using LDRD funds) and (2) development of techniques for phase-based and multi-frequency processing and spatial processing to support subsurface target detection and characterization. The products of this project are: (1) an evaluation of an improved EM gradiometer, (2) an improved gradiometer concept for possible future development, (3) an improved modeling capability, (4) demonstration of an EM wave migration method for target recognition, and a demonstration that the technology is capable of detecting targets to depths exceeding 25 meters.

\section{$2611 \quad$ V18/024306}

Electroosmosis Remediation of DNAPLs in Low Permeability Soils

Ho, S.V.

Monsanto Company, St. Louis, MO; Oak Ridge National Laboratory, Oak Ridge, TN

ORNL/TM-13305; Insitu Remediation of DNAPL Compounds in Low Permeability Media Fate/Transport, Insitu Control Technologies, and Risk Reduction, 318 pp.; (pp. 5.1-5.14) (August 1996)

Electroosmosis is the movement of water through a soil matrix induced by a direct current (DC) electric field. The technique has been used since the 1930s for dewatering and stabilizing fine-grained soils. More recently, electroosmosis has been considered as an in-situ method for soil remediation in which water is injected into the soil at the anode region to flush the contaminants to the cathode side for further treatment or disposal. The major advantage of electroosmosis is its inherent ability to move water uniformly through clayey, silty soils at 100 to 1000 times faster than attainable by hydraulic means, and with very low energy usage. Drawbacks of electroosmosis as a stand-alone technology include slow speed, reliance on solubilizing the contaminants into the groundwater for removal, potentially an unstable process for long term operation, and necessary additional treatment and disposal of the collected liquid. Possible remediation applications of electroosmosis for DNAPLs would be primarily in the removal of residual DNAPLs in the soil pores by electroosmotic flushing. The future of electroosmosis as a broad remedial method lies in how well it can be coupled with complementary technologies. Examples include combining electroosmosis with vacuum extraction, with surfactant usage to deal with non-aqueous phase liquids (NAPLs) through enhanced solubilization or mobilization, with permeability 
enhancing methods (hydrofracturing, pneumatic fracturing, etc.) to create recovery zones, and with in-situ degradation zones to eliminate aboveground treatment.

\section{2}

V18/020969

\section{Energy Considerations and Soil Temperature Changes During Soil Vapor Extraction}

Casey, D.; Walton, J.; Anker, C.; LeMone, D.V.

University of Texas, El Paso, TX

CONF-960212; Waste Management ' 96 : Working Towards a Cleaner Environment, Proceedings of a Conference on HLW, LLW, Mixed Wastes and Environmental Restoration, Tucson, AZ, February 25-29, 1996; (13 pp.) (1996)

Soil vapor extraction (SVE) is a widely used remediation technology for sites contaminated with volatile organic compounds (VOCs). In addition to removing VOCs, SVE can produce secondary effects on soil temperature and moisture content. Soil temperature is important because it controls the vapor pressure of VOCs and the mass transfer rate out of stagnant, low permeability zones in the soil. Soil moisture content affects the removal efficiency of SVE by decreasing the permeability of the soil, by heating or cooling the soil in response to latent heat effects, and by affecting the partitioning of the VOCs. A comprehension of the importance of temperature and moisture content will result in a greater understanding of the energy fluxes associated with soil venting. This is crucial to the development of an optimal design. In this work, a simple model for the enthalpy balance during SVE was used to examine several processes leading to changes in soil temperature and moisture content.

\section{3}

\section{V18/025446}

Engineering Bulletin: Separation/Concentration Technology Alternatives for the Remediation of Pesticide-Contaminated Soil

Bennett, I.; McGraw, G.; Platt, J.S.

International Technology Corporation, Cincinnati, $\mathrm{OH}$

EPA/540/S-97/503; 17 pp. (May 1997)

This bulletin focuses on soils and current or soon-to-be available separation/concentration pesticide remedial technologies. The resource document contains site-specific information on pesticide contamination and the remediation techniques.

\section{4}

V18/022227

Enhanced Biodegradation of TPH and PAHs in Diesel Contaminated Soils Through Bioventing

Nickerson, D.A.; Baker, J.N.

Parsons Engineering Science, Inc., Denver, $\mathrm{CO}$

CONF-951139 (Vol. 2); Superfund 16: Proceedings of a Hazardous Waste Conference and Exhibition, Washington, DC, November 6-8, 1995. E.J. Krause and Associates, Bethesda, MD, Vol. 2, 817 pp.; (pp. 1231-1241) (1994)

A bioventing system was designed and installed to enhance the natural biodegradation of diesel fuel residuals in soils at an underground storage tank (UST) facility in Pittsburgh, Pennsylvania. This system was designed to operate in conjunction with a groundwater pump and treatment system which exposes the more heavily contaminated soils at the capillary fringe to ambient air supplied to the subsurface at a low flow rate from a single vertical injection point. Results of a pilot study conducted at the facility indicated that an initial average biodegradation rate of 2,100 milligrams of total petroleum hydrocarbons (TPH) per kilogram of soil per year could be achieved, making enhanced in situ biodegradation a feasible and cost-effective remedial altemative for soil cleanup. Oxygen (O2), carbon dioxide (CO2), and hydrocarbon vapor concentrations and pressure responses were measured in vapor monitoring points constructed at various depth intervals and varying distances from the central air injection point. Results indicate that the system is capable of providing sufficient oxygen to maintain microbial biodegradation of residual petroleum hydrocarbons within a radius of 70 feet of the injection point. Soil samples were collected during the installation of the vapor monitoring points and analyzed for TPH and PAH (Polynuclear Aromatic Hydrocarbon) concentrations to provide baseline analytical data from the areas of highest known contamination. A soil sampling program will be implemented to independently confirm the amount of TPH and PAH reduction that has occurred after the initial six-months of full-scale bioventing operation.

2615 V18/022673

Enhanced Insitu Bioremediation Using Six-Phase Electrical Heating

Heath, W.O.; Truex, M.J.

Pacific Northwest Laboratory, Richland, WA

CONF-941124; Insitu Remediation: Scientific Basis for Current and Future Technologies, G.W. Gee and N.R. Wing (eds.), Proceedings of the 33rd Hanford Symposium on Health and the Environment, Pasco, WA, November 7-11, 1994. Battelle Press, Columbus, OH, Part 2, 605 pp.; (pp. 781-797) (1994)

Laboratory tests were performed to determine whether moderate electrical heating could be used to accelerate in-situ biodegradation and to evaluate the suitability of six-phase electricity for this purpose. The tests were performed with and without electrical heating, using groundwater-saturated silica sand inoculated with facultative anaerobes. Denitrification conditions were used, with acetate as the electron donor. It was found that electrical heating to an optimum metabolic range of 30 to $40 \mathrm{C}$ accelerated denitrification rates by a factor of 2.2 compared to rates under simulated aquifer conditions ( $11 \mathrm{C}$ ). It was also found that the Arrhenius equation could be used to estimate the increase in metabolic rates due to six-phase heating. Six-phase electricity provided remarkably uniform heating, with in-situ temperatures varying a maximum of [ +-$] 4 \mathrm{C}$ as measured at six radial locations with the heated region and eleven depths along the centerline of the test reactor. Adjusting the six-phase electrode array to preferentially heat the bottom of the laboratory aquifer appeared to produce thermally driven mixing of the simulated groundwater, promoting temperature uniformity throughout the treatment region. Further work is recommended to optimize the vertical placement of electrodes within an aquifer to achieve the best temperature uniformity. A cost-benefit analysis is also recommended to quantify the net economic advantage of accelerating in-situ biological treatment processes with six-phase electrical heating. 
2616

V18/020675

\section{Enhanced Soil Bioremediation with Electric Fields}

Acar, Y.B.; Rabbi, M.F.; Gale, R.J.; Ozsu, E.E.;

Alshawabkeh, A.N.

Louisiana State University, Baton Rouge, LA

Chemtech 26(4):40-43 (April 1996)

Electrokinetic remediation is an in-situ remediation technique that uses low-level direct-current electric potential differences (on the order of volts per centimeter) or an electric current (on the order of milliamps per square centimeter of cross-sectional area between electrodes) applied across a soil mass by electrodes placed in an open- or closed-flow arrangement. In electrokinetic methods, the groundwater in the boreholes or an externally supplied fluid (processing fluid) is used as the conductive medium. Electrokinetic remediation technology for metal extraction is expected to decrease the cost of remediating contaminated soils to the lower end of the $\$ 100-\$ 1,000$ per cubic meter range. This would be a significant savings in the $\$ 350$ billion hazardous waste site cleanup and remediation market. The environmental restoration cost for the mixed (radioactive)-waste market is separately estimated to be $\$ 65$ billion. The potential of the electrokinetic remediation technique in remediating soils contaminated with radioactive mixed waste using depolarization agents and complexing agents is noteworthy. The authors have removed uranyl ions from spiked kaolinite using the technique.

\section{7}

\section{V18/022244}

Enhanced Thermal Desorption: Facile Removal of PCBs from Contaminated Soils

Krabbenhoft, H.O.; Webb, J.L.; Gascoyne, D.G.

General Electric Company, Corporate Research and Development Center, Environmental Laboratory, Schenectady, NY

CONF-951139 (Vol. 2); Superfund 16: Proceedings of a Hazardous Waste Conference and Exhibition, Washington, DC, November 6-8, 1995. E.J. Krause and Associates, Bethesda, MD, Vol. 2, 817 pp.; (pp. 980-989) (1994)

The use of certain organic and inorganic materials, when admixed with soils contaminated with polychlorinated biphenyls ( $\mathrm{PCBs}$ ), greatly facilitates the removal of PCBs by means of an exsitu thermal desorption process. Thus, for example, heating a soil (with an initial PCB concentration of approximately $700 \mathrm{ppm} \mathrm{A-1260)}$ from 25 degrees $C$ to 300 degrees $C$ over a 30-minute period provided remediated soil with a residual $\mathrm{PCB}$ level of $53 \mathrm{ppm}$ (92.4\% PCB removal). When the experiment was repeated using a sweep of steam (corresponding to a water delivery rate of 1.0 $\mathrm{mL} / \mathrm{min}$ ), the residual PCB level was $10 \mathrm{ppm}$ ( $98.6 \%$ PCB removal). And when steam was passed through the soil admixed with $5 \%$ sodium formate, the residual PCB level was only $0.9 \mathrm{ppm}(99.9 \%$ PCB removal). Several other additives (such as sodium acetate, ammonium carbamate, formic acid) have been shown to be efficacious for enhanced PCB removal via thermal desorption. A design of experiments study was carried out to optimize the process parameters of temperature, time, additive level, and steam flow. A logarithmic transformation of the data afforded a mathematical model (correlation coefficient 0.96 ) that allows one to employ the enhanced thermal desorption process in a cost-effective manner to remediate contaminated soil (with an initial PCB level of approximately $8000 \mathrm{ppm} A-1260$ ) such that residual PCB levels of less than equal to $2 \mathrm{ppm}$ ( $99.98 \%$ PCB removal) are routinely achieved.

\section{8 \\ V18/022672}

Enhanced Transport of Degradative Bacteria for Insitu Bioremediation

DeFlaun, M.F.; Condee, C.W.; Ensley, B.D.

Envirogen, Inc., Lawrenceville, NJ

CONF-941124; Insitu Remediation: Scientific Basis for Current and Future Technologies, G.W. Gee and N.R. Wing (eds.), Proceedings of the 33rd Hanford Symposium on Health and the Environment, Pasco, WA, November 7-11, 1994. Battelle Press, Columbus, OH, Part 1, 704 pp.; (pp. 249-258) (1994)

Insitu bioremediation requires that competent degradative bacteria penetrate soil or aquifer solids to reach the site of contamination. One of the major obstacles to bioaugmentation is that bacteria often adhere strongly to solid surfaces. In the absence of a strong hydrogeological gradient, the organisms remain localized at the origin of injection, resulting in fouling of wells and inadequate dispersion of degradative bacteria. The authors are developing two approaches to overcome this obstacle: (1) the use of adhesion-deficient degradative bacteria, and (2) the electrokinetic transport of these bacteria through aquifer solids. They have isolated nonadhesive variants of several different strains that are capable of degrading a suite of chlorinated organics commonly found as groundwater contaminants. These strains have displayed increased transport through model aquifers when compared to the wild type. These strains were also used to demonstrate directional transport of bacteria to test the feasibility of using electrokinetics as a tool for insitu bacterial dispersion. Bacteria are negatively charged in the environment and, as such, can be electrophoresed toward the anode in a DC electric field. Model aquifers were used to demonstrate transport rates of $1.5 \mathrm{~m} /$ day through aquifer solids representing a range of grain sizes and porosities. Using trichloroethylene (TCE) as a model chlorinated organic, the authors also demonstrated that adhesion-deficient degradative bacteria moving through contaminated aquifer material by electrokinetics were able to degrade TCE sorbed to the sediments.

\section{9}

\section{V18/020831}

\section{Enhanced Volatilization of Polychlorinated Biphenyl} Compounds

El-Shoubary, Y.; Shiling, N.Z.; Webb, J.L.

General Electric Company, Schenectady, NY

U.S. Patent 05430232; 7 pp. (July 4, 1995)

This invention is directed to decontamination of soils and other particulate materials such as soil, sand, gravel, crushed concrete, sludges, sediments and the like by removal of volatile and semivolatile organic compounds, particularly halogenated compounds such as polychlorinated biphenyl compounds. These are separated from soil by oil assisted desorption followed by vacuum stripping in presence of a sweep gas. More particularly, decontamination of such materials is accomplished by means of 
thermal desorption and volatilization of the contaminant compounds from the contaminated material in the presence of desorption promoting additives. Effective additives are hydrocarbons and oils which solubilize the contaminant or which promote desorption of the contaminant from the soil and volitilization of the target contaminant. Effective additives have boiling points below the boiling point of the contaminant to be removed.

Enhancement of Bioremediation of a Creosote-Contaminated Soil

Carriere, P.E.; Mesania, F.A.

West Virginia University, Department of Civil and Environmental Engineering, Morgantown, WV

CONF-951139 (Vol. 2); Superfund 16: Proceedings of a Hazardous Waste Conference and Exhibition, Washington, DC, November 6-8, 1995. E.J. Krause and Associates, Bethesda, MD, Vol. 2, 817 pp.; (pp. 1054-1062) (1994)

There is a growing concern in the U.S. about the increasing number of industrial sites containing concentration of polynuclear aromatic hydrocarbons (PAHs) in their soil and waste sludge above background levels. PAHs, neutral and non-polar organic compounds, consist of two or more fused benzene rings which are generated from industrial activities such as creosote wood treating, gas manufacturing, coke making, coal tar refining, petroleum refining, and aluminum smelting. Low molecular weight PAHs are generally considered as extremely toxic compounds, whereas the higher molecular weight PAHs are carcinogenic in nature. Bioremediation, a viable option for treatment of PAHs contaminated soil, can be enhanced by the use of surfactant. In this study a nonionic surfactant, Triton X-100, was investigated. Abiotic soil desorption experiments were performed to determine the kinetics of release of selected PAH compounds from the soil matrix to the aqueous phase. Respirometric experiments were also conducted to evaluate the effect of nonionic surfactant on biodegradation. The N-Con system respirometer was used to monitor the oxygen uptake by the microorganisms. The abiotic experiments results indicated that the addition of surfactant to soil/water systems increases the desorption of PAH compounds. The increase in PAHs availability to the microorganisms produced an increase in oxygen uptake.

\section{1}

\section{V18/021994}

Enhancement of Electrochemical Processing of Soils by Sorbents and Solubilizing Agents

Pamukcu, S.; Weeks, A.; Wittle, J.K.

Lehigh University, Department of Civil and Environmental Engineering, Bethlehem, PA; Electro-Petroleum, Inc., Wayne, PA

CONF-9509139; Emerging Technologies in Hazardous Waste Management VI, D.W. Tedder (ed.), Proceedings of the Seventh American Chemical Society Industrial and Engineering Chemistry Division Special Symposium, Atlanta, GA, September 17-20, 1995. American Chemical Society, Washington, DC, 1291 pp.; (p. 461) (1995)

In this paper, the efficacy of using natural adsorbents and solubilizing agents to enhance electrochemical processing of contaminated soils is presented. Past experience with electrokinetic treatment technology shows that the process is most effective when the transported substances are ionic, surface charged or in the form of small micelles with little drag resistance. Therefore, utilization of solubilizing agents that break apart molecules into their ionic constituents, or arrest existing ions so they are no longer available for precipitation and soil surface adsorption, or transform complex molecules into micro-micelles which are readily transportable with water advection, enhances greatly the success of electrokinetic treatment of contaminated soils. Utilization of products such as inorganic acids or organic compounds such as EDTA or EDA may require that they too be taken out of the ground since they may be harmful to the ecological make-up of the sub-surface. Poly Lactic Acid (PLA), a readily biodegradable by-product of com processing, was shown to be effective in solubilizing the metal constituents in contaminated soils during electrochemical/electrokinetic treatment. Natural sorbents such as zeolites, bentonite and glauconite and iron containing slag fines were utilized as filter beds to purify metal containing water in soils transported by electrokinetics. The method showed that selective removal or separation of metals can be accomplished using these natural sorbents in both in-situ and exsitu electrochemical processing of contaminated soils and sludges. The efficacy of a slurry cut-off wall of a sorbent material constructed in front of a electrokinetically driven plume of contaminated water was tested in the laboratory.

2622 V18/021963

Enhancing Petroleum Hydrocarbon Biodegradation in Soils with Surfactant/Nutrients

Nelson, E.C.; Walter, M.V.; Bossert, I.D.; Martin, D.G.

Texaco R\&D, Beacon, NY

CONF-9509139; Emerging Technologies in Hazardous Waste Management VII, D.W. Tedder (ed.), Proceedings of the Seventh American Chemical Society Industrial and Engineering Chemistry Division Special Symposium, Atlanta, GA, September 17-20, 1995. American Chemical Society, Washington, DC, 1291 pp.; (pp. 636-638) (1995)

Bioremediation of hydrocarbon contaminated soils is an attractive process for treating contaminated soils because it converts contaminants into harmless byproducts at low cost. However, the process is slow; rates of cleanup are typically measured in months or years. We are attempting to improve the process by developing additives that accelerate rates of biodegradation. Molecular surfactant/nutrients were synthesized and tested for their ability to enhance the biodegradation of petroleum hydrocarbon contaminants in soils. Rates of biodegradation of heavy hydrocarbons were evaluated using either oxygen and carbon dioxide respirometry in soil slurries, or periodic measurements of extractable hydrocarbon residues in unsaturated soil microcosms. Results show rate enhancements in both soil slurries and unsaturated soil microcosms that were treated with an anionic nitrogenous surfactant. 
Pattanayek, M.; Waldrop, V.C.; Stephens, M.D.; Allen, P.W.; Harper, F.; Cobb, G.P.

Clemson University, Institute of Wildlife and Environmental Toxicology, Clemson, SC

CONF-9511137; Global Environmental Protection: Science, Politics, and Common Sense, Proceedings of the Second Society of Environmental Toxicology and Chemistry (SETAC) World Congress and 16th Annual Meeting, Vancouver, British Columbia, Canada, November 5-9, 1995. Society of Environmental Toxicology and Chemistry, Pensacola, FL, 378 pp.; (p. 235) (1995)

Fire suppressant Fuelbuster (FB), a non ionic surfactant, was investigated for its ability to reduce particle emission from combustion activities, to increase rates of heat dissipation from fires, and to increase rates of PCB dissipation in soils. Smoke reduction was tested by aerosol application of FB to the flame of ignited toluene. By a hand held K-thermocouple, temperature changes were recorded before and after extinguishing the flame, to determine heat dissipation rates. This was compared to dissipation rates of other fire suppressants. FB showed increased heat dissipation rates and reduced particle emission. Remediation of PCB-contaminated soils was conducted by applying $6 \%$ FB to soil samples over a period of time. Preliminary results show increased PCB dissipation over a period of two months (data will be presented for a five month period). Remediated effluent is usually sent to a sanitary sewer for further treatment before it can be discharged. This event was simulated by petroleum hydrocarbon aerobic degradation using activated sludge and $6 \% \mathrm{FB}$. Surfactant action increased water solubility of hydrocarbons, facilitating degradation, which was determined by dissolved organic carbon content reduction over a period of 16 days.

\section{4}

\section{V18/023778}

Environmental Assessment of an Oil Field Prior to Redevelopment

Ferguson, E., Jr.; Smith, E.A.

McLaren/Hart Environmental Engineering, Irvine, CA CONF-9504134; HAZMACON '95, T. Bursztynsky and M.L. Loss (eds.), Proceedings of the Twelth Hazardous Materials Management Annual Conference and Exhibition, San Jose, CA, April 4-6, 1995. Association of Bay Area Governments, Oakland, CA, 790 pp.; (pp. 92-101) (1995)

A statistical and directed soil sampling approach, using "spot trenching" and GeoProbe techniques, to characterize an active oil field prior to redevelopment. As land uses change, environmental characterization of the subject area is often required to assess future development opportunities. This is evident in areas that have been historically used for oil production but declining oil production in the field has produced undeveloped land available for future development. The area discussed in this paper is a 63-acre section, within an oil field in Southern Califomia, expected to be developed in the next three to five years as a golf course. This study area is part of the City's Redevelopment Agency and is managed by a work group consisting of oil companies, city government, developers, and other private interests. The work group provides financial and strategic planning for environmental assessment and future reclamation of the oil field. The purpose of this remedial investigation was to assess the soil conditions and determine the most advantageous remediation techniques, if needed, for future land use. The methodology of the investigation needed to complement the redevelopment goals for an effective property transfer. Use of aerial photographs to identify potential source areas combined with aggressive investigation. Spot trenching and sampling of oil sumps and tank batteries identified on aerial photographs was used to identify the crude oil and benzene, toluene, ethylbenzene and xylenes (BTEX) aspect of the oil production. Statistical sampling using a "GeoProbe", an in situ sampling method, for the remainder of the site identified chemicals not commonly associated with oil production (organic compounds and metals). These techniques of sampling achieved a 90 percent confidence level that the entire site had characterized. The results allowed McLaren/Hart to determine impacted areas and volumes of soil affected, thus allowing the cost of development to be projected prior to development of the property.

\section{5 \\ V18/023809}

Environmental Geophysics and Sequential Air Photo Study at Sunfish Lake Twin Cities Army Ammunition Plant

Padar, C.A.; McGinnis, L.D.; Thompson, M.D.; Anderson, A.W.; Benson, M.A.; Stefanov, J.E.; Daudt, C.R.; Miller, S.F.

Argonne National Laboratory, Argonne, Il; Federal Cartridge Company, Minneapolis, MN

CONF-960477; SAGEEP '96, R.S. Bell and M.H. Cramer (eds.). Proceedings of the Ninth Annual Symposium on the Application of Geophysics to Engineering and Environmental Problems. Denver. CO, April 15-May 1, 1996. Environmental and Engineering Geophysical Society, Wheat Ridge, CO, 1353 pp.; (pp. 1217-1226) (1996)

Geophysical and air photo studies at the Twin Cities Amy Ammunition Plant (TCAAP), Minnesota, were conducted to establish a chronology of dumping and waste disposal. This study was undertaken to aid in the assessment of the amount of remediation needed to reclaim a wetland area. An integrated analysis of electromagnetic, magnetic and ground-penetrating RADAR (GPR) measurements over a 25-acre site, provided the information necessary to define waste disposal events. These events are observed on a sequence of aerial photos taken between 1940 and 1993. The former southwestern embayment of the lake, filled in during the original construction of the base, has been clearly defined. Two burn cages and their surrounding debris have been delineated. The areal extent of another waste site has been defined along the northem shoreline. Depth estimates determined from EM-61 analysis, and depths to original lake bottom, derived from GPR, have yielded volumetric estimates of the amount of material that would need removal if excavation is required. Magnetic and electromagnetic data have pin-pointed the locations of mounds, observed from historical air photos. Except for these areas along the northwestern shore, there is no evidence of waste disposal along the shoreline or within the present-day lake margins. The ability to date the anomalous regions is significant, in that different production demands upon TCAAP, during the time periods of WWII, the Korean War, and the Vietnam Conflict, have resulted in different types of waste. The ability to categorize areas with distinct time 
periods of operation and waste disposal can greatly aid the environmental cleanup effort with regard to the type of contaminants that might be expected at these poorly documented disposal sites.

\section{6}

\section{V18/024839}

Environmental Management Technology Demonstration and Commercialization: Task 2, Extraction and Analysis of Pollutant Organics from Contaminated Solids Using Off-Line Supercritical Fluid Extraction (SFE) and On-Line SFE-Infrared Spectroscopy - Semiannual Report, November 1, 1995-March 31, 1996

Hawthorne, S.B.

University of North Dakota, Energy and Environmental Research Center, Grand Forks, ND

DOE/MC/31388-5251 (Task 2); 5 pp. (April 1996)

This activity will result in a commercialized version of a field-portable instrument for performing supercritical fluid extraction (SFE) with on-line Fourier transform infrared (FT-IR) detection. The Energy \& Environmental Research Center (EERC) has developed an SFE field-portable method for quantitatively extracting organic pollutants (e.g., polycyclic aromatic hydrocarbons [PAHs], polychlorinated biphenyls [PCBs], total petroleum hydrocarbons [TPHs]) from soils and sludges under U.S. Environmental Protection Agency (EPA) funding. FT-IR is a detector that can yield quantitative and compound-class information for organic pollutants and is excellent for survey uses, since virtually all organic compound classes can be monitored. A laboratory prototype SFE-FT-IR instrument has been developed at the EERC and the University of North Dakota (UND) Department of Chemistry. The commercial instrument will be field-portable (requiring only generator electricity) and able to extract and measure organic pollutants from soils and siudges, identify the compound classes present, and provide quantitative or semiquantitative results at detection limits relevant to regulatory needs (e.g., parts per million to parts per billion). The SFE-FT-IR approach is particularly advantageous for very hazardous samples (e.g., determination of organics in solids contaminated with radioactive components), since SFE-FT-IR analysis generates no waste solvents. The instrument will also be configured to allow collection of "positive" extracts for analysis by other confirmatory (e.g., gas chromatography-mass spectroscopy [GC-MS]) methods.

V18/025529

Environmental Measurement While Drilling System for Real-Time Field Screening of Contaminants

Williams, C.V.; Lockwood, G.J.; Normann, R.A.

Sandia National Laboratories, Albuquerque, NM

CONF-960804 (Vol. 2); Spectrum '96: Nuclear and Hazardous Waste Management, Proceedings of an International Topical Meeting, Seattle, WA, August 18-23, 1996. American Nuclear Society, La Grange Park, IL, Vol. 2, 873 pp.; (pp. 1065-1072) (1996)

Sampling during environmental drilling is essential to fully characterize the spatial distribution and migration of subsurface contaminants. Real-time information on environmental conditions, drill bit location and temperature during drilling is valuable in many environmental restoration operations. This type of information can be used to provide field screening data and improved efficiency of site characterization activities. The Environmental Measurement-While-Drilling (EMWD) System represents an innovative blending of new and existing technology in order to obtain real-time data during drilling. The system consists of two subsystems. The down-hole subsystem (at the drill bit) consists of sensors, a power supply, a signal conditioning and transmitter board, and a radio-frequency (RF) coaxial cable. The up-hole subsystem consists of a battery pack/coil, pickup coil, receiver, and personal computer. The system is compatible with fluid miser drill pipe, a directional drilling technique that uses minimal drilling fluids and generates little to no secondary waste. As drilling is conducted, data is collected on the nature and extent of contamination, enabling on-the-spot decisions regarding drilling and sampling strategies. The EMWD system has been improved by the integration of a Gamma Ray Spectrometer (GRS). The GRS consists of a sodium iodide-thallium activated crystal coupled to a photomultiplier tube (PMT). The output of the PMT goes to a multichannel analyzer (MCA). The MCA data is transmitted to the surface via a signal conditioning and transmitter board similar to that used with the GMT. The EMWD system is described and the results of field tests and a field demonstration are presented.

\section{8}

V18/022908

Environmental Monitoring of Soil Contaminated with Heavy Metals Using Laser-Induced Breakdown Spectroscopy

Alexander, D.R.; Poulain, D.E.; Ahmad, M.U.; Kubik, R.D.; Cespedes, E.R.

University of Nebraska, Lincoln, NE; U.S. Army Corps of Engineers, Waterways Experiment Station, Vicksburg, MS CONF-940814 (Vol. 2); IGARSS '94: Surface and Atmospheric Remote Sensing - Technologies, Data Analysis and Interpretation, Proceedings of an International Geoscience and Remote Sensing Symposium, Pasadena, CA, August 8-12, 1994. Califomia Institute of Technology, Pasadena, CA, Vol. 2, 599 pp.; (pp. 767-769) (1994)

Research on the detection of heavy metals in soils and water using laser-induced breakdown spectroscopy (LIBS) has been carried out. LIBS is based on a Nd:YAG laser operating at $50-100 \mathrm{~mJ}$ at lambda $=1.06 \mathrm{mu} \mathrm{m}$. The beam is focused on the surface of the sample to produce a laser spark (plasma). The atomic emission lines are recorded using an optical multichannel analyzer (OMA) after specific gate delay times. Gating delay times of a few microseconds allow broadband emissions to decay before detecting heavy metal emission lines. This remote sampling technique has application in monitoring both land and ocean sites containing heavy metals. Research has been performed on the detection of $\mathrm{As}, \mathrm{Cd}, \mathrm{Cr}, \mathrm{Hg}$, $\mathrm{Pb}$, and $\mathrm{Zn}$. Resuits are reported on the detection levels of $\mathrm{Cr}$ in soil samples. In addition, computer software has been developed to automate the identification of atomic emission lines for mixed matrices of these heavy metals in background emissions from elements typically in soil. Future plans are to determine the minimum limits of detection for various heavy metals by a typical LIBS system based on a Nd:YAG laser and a fiber-optic collection 
system for the plasma emissions.

\section{$2629 \quad$ V18/024337 \\ Environmental Remediation Monitoring Using Chemical Sensors}

Dong, X.L.

Unocal Corporation, Brea, CA

CONF-960782; Proceedings of the Sixth International Meeting on Chemical Sensors, Gaithersburg, MD, July 22-25, 1996. U.S.

Department of Commerce, National Institute of Standards and Technology, Gaithersburg, MD, 313 pp.; (1 p.) (1996)

Monitoring is one of the most critical steps in environmental site remediation. However, the conventional technique of monitoring "inlet" and "outlet" of a process stream is no longer applicable in many in-situ remedial processes such as bioventing, biosparging, and intrinsic bioremediation. Traditional soil sampling and analysis is also unsuitable for monitoring biodegradation process because of chemical and biological inhomogeneity in soil. Soil gas measurement, on the other hand, is one of the few techniques available which is ideally suited for monitoring in-situ processes, since bioremediation processes involve gaseous components such as oxygen and carbon dioxide. In addition to oxygen and carbon dioxide, contaminant vapors and other trace gaseous components found in the pores of unsaturated soils also provide information on the spatial distribution and the extent of biodegradation. These gaseous components are very mobile, making them ideal analytes for chemical sensors. In this study, oxygen, carbon dioxide, and hydrocarbon subsurface chemical sensors were employed for monitoring in-situ bioremediation of petroleum hydrocarbon contaminated soils.

2630 V18/024049

Establishing and Evaluating the Risk Implications of Uniform Soil Remediation Goals

Labieniec, P.A.; Dzombak, D.A.; Siegrist, R.L.

Consultant, Chesterfield, VA; Carnegie Mellon University, Department of Civil and Environmental Engineering, Pittsburgh, PA; Colorado School of Mines, Environmental Science and Engineering Division, Golden, $\mathrm{CO}$

Joumal of the Air and Waste Management Association 46(12):1179-1 184 (December 1996)

There is growing interest in the establishment of uniform, concentration-based soil remediation goals to accelerate the cleanup of contaminated sites and to provide consistency in the extent of cleanup required for similar sites. It uniform goals are used in a region, post-remediation risk will vary across sites due to regional variability in site properties. Thus far, of the national and state agencies that have established or proposed uniform concentration guidelines, none have quantified the regional variability in risk that is likely to result with their use as remediation goals. This paper describes a methodology for evaluating regional cancer risk variability resulting from use of uniform, concentration-based soil remediation goals, presents and example application of the methodology, and examines its utility for establishing uniform goals for organic contaminants in soil. The methodology is based on the integrated transport, fate, exposure, and risk model SoilRisk. Also addressed is the issue of contaminants for which regional risk variability is expected to be large with use of uniform soil remediation goals. An approach is described for reducing such variability by development of alternative uniform contaminant concentration levels for categories of sites differentiated by site geographic location or by physical-chemical properties.

\section{1}

V18/025484

Estimating Risks in Emerging Soil Remediation Technologies

Timmerman, T.J.

U.S. Air Force Institute of Technology, Wright-Patterson Air Force Base, $\mathrm{OH}$

AFIT/GOA/ENS/96M-09; 253 pp. (March 1996)

The Department of Energy is focusing a long-term development effort on producing cheaper, safer, and faster state-of-the-art soil remediation technologies. To assist with the management of these innovative technology development projects, ways of quantifiably measuring technical risk were investigated through a detailed literature review. "Technical risk" was defined in this study as the combination of the consequences of undesired events and their likelihood. Careful design of the inputs into a technology selection decision support system accounted for the uncertainty in forecasting final characteristics of remediation technologies still in the early phases of R\&D. Experts made subjective probability estimates of these cost, schedule, and performance factors. Examination of several measures of final cost and schedule risk focused on communicating the risks inherent in different technological alternatives to the technology manager for operational, not theoretical, use. These risk measures included subjective measures, using utility theory, and objective measures, using variation about an expected value. A new measure was developed, the expected unfavorable deviation, which is similar but superior to the semi-variance as a measure of downside risk. These simple risk measures can be used whenever uncertainty is expressed through probability distributions of cost, schedule, and performance characteristics.

\section{$2632 \quad$ V18/022745}

Estimation Possibility of Cleaning from Radionuclides for the Coast Parts of Drainage System by the Soil Fractionating Method

Karlin, Y.V.; Chuikov, V.Y.; Belianina, N.G.; Barinov, A.S.

Scientific and Industrial Association - Radon, Sergiev Posad, Russian Federation; Scientific and Industrial Association Radon, Moscow, Russian Federation

CONF-960804 (Vol. 2); Spectrum '96: Nuclear and Hazardous Waste Management, Proceedings of an International Topical Meeting, Seattle, WA, August 18-23, 1996. American Nuclear Society, La Grange Park, Il, Vol. 2, 873 pp.; (pp. 956-962) (1996)

This paper considers the possibility using soil fractionating to remove radionuclides from the coast parts of the drainage system at the Moscow SIA "Radon". It is showed that this method cannot be used for the cleaning of the soils near flowing water (a river, a spring or a open drainage system) because the most part of the soil size-fractions is the fine fractions and the main contaminant 
radionuclide, Cesium 137, is distributed among the different soil components homogeneousiy.

\section{3}

\section{V18/023903}

Evaluation and Prevention of Explosions in Soil Vapor Extraction Systems

Hower, J.

Radian Corporation, El Segundo, CA

CONF-951 124; HazMat West '95, Proceedings of the Eleventh Annual Environmental Management and Technology Conference and Exhibition, Long Beach, CA, November 7-9, 1995. Advanstar Expositions, Duluth, MN, 597 pp.; (pp. 387-398) (1995)

Due to the widespread and long term use of petroleum derived fuels and solvents, many areas have subsurface soils contaminated with petroleum derivatives. This contamination can migrate to groundwater, which is frequently used to supply drinking water needs. A common method of cleaning up that contamination is soil vapor extraction (SVE). SVE is a technique where several extraction wells are installed in the contaminated area, with screens in the appropriate vertical locations. The soil vapors are extracted from the wells using a positive displacement blower. To prevent this subsurface contamination from becoming air pollution, the extracted vapors are then sent to a hydrocarbon removal device, such as a carbon adsorption system or a thermal oxidizer. The data used in this investigation were collected as part of a Radian Corporation project for a client. The site is a former petroleum refinery, and the hydrocarbons are primarily gasoline and diesel.

\section{4 V18/023864}

Evaluation of Abiotic Fate Mechanisms in Soil Slurry Bioreactor Treatment

Glaser, J.A.; McCauley, P.T.; Dosani, M.A.; Platt, J.S.; Krishnan, E.R.

U.S. Environmental Protection Agency, Risk Reduction Engineering Laboratory, Cincinnati, $\mathrm{OH}$; International Technology Corporation, Cincinnati, $\mathrm{OH}$

EPA/600/R-95/012; CONF-9504110; Proceedings of the 21st Annual Risk Reduction Engineering Laboratory (RREL) Research Symposium, Cincinnati, OH, April 4-6, 1995. U.S. Environmental Protection Agency, Cincinnati, OH, 398 pp.; (pp. 61-63) (April 1995)

Biological treatment of contaminated soil slurries may offer a viable technology for soil bioremediation. Slurry bioreactor treatment of soils, however, has not sufficiently progressed to be a durable, reliable, and cost-effective treatment option. Critical to the evaluation of slurry bioreactors is a better description of pollutant mass transfer during the treatment phase. Losses attributable to abiotic means are generally overlooked in field application of the technology. Discussions with EPA regional personnel and inspection of active soil slury bioreactor operations have identified operational problems such as foaming which could result in possible abiotic loss. Field biosiurry operations have adopted various approaches to reduce foaming: (1) the addition of defoaming agents, (2) the reduction of rotational speed of the agitator, and (3) the reduction of gas flow through the bioreactor system. The foaming phenomena is viewed as a nuisance rather than a potential beneficial removal mechanism. In the case where the pollutants have a specific gravity less than water, once desorbed from the slurried soil, they would rise to the surface as in a flotation process. Our hypothesis was that foam formation could be related to this pollutant release process. If this analysis has merit, it is possible that the operational strategy used in the field is counterproductive since a separated contaminant phase is re-entrained with a partially cleaned soil material.

\section{5}

\section{V18/021066}

Evaluation of Air Treatment Technologies for Destroying SVE Emissions at McClellan Air Force Base

Hodge, S.; Danko, J.; Krishnan, R.

U.S. Air Force, McClellan Air Force Base, CA; CH2M Hill Inc., Corvallis, OR

CONF-940499 (Vol. 1); Proceedings of the 1994 Federal

Environmental Restoration III and Waste Minimization II Conference and Exhibition, New Orleans, LA, April 27-29, 1994. Hazardous Materials Control Resources Institute, Rockville, MD, Vol. 1, 783 pp.; (pp. 337-343) (1994)

A soil vapor extraction (SVE) system was installed and operated at a former spent fuels and solvents disposal site at McClelian Air Force Base. The SVE offgases have been treated with three trearment technologies: catalytic oxidation with and without a caustic scrubber, and a regeneratable resin adsorption system. The main objective for operating the different emission control systems was to compare overall costs, destruction performance, and residue management associated with each system. Based on this comparison, McClellan will select the most optimal system for implementation at other SVE sites across the base. Preliminary findings indicate that catalytic oxidation is extremely effective at destroying all VOCs present; however, the generation of $\mathrm{HCl}$ and other residues may affect the overall effectiveness of this technology. The regeneratable resin adsorption system began testing in September 1993 and continued through February 1994. Preliminary findings show the difficulty of adsorbing and desorbing a complex suite of VOCs on the polymeric resins. Critical comparative data generated by February 1994 should be of significant value to all facilities faced with the requirement of treating SVE offgas.

\section{6}

\section{$\mathrm{V} 18 / 024150$}

Evaluation of Airborne Imaging Spectrometry Data for Identifying Different Soil Properties

Preissler, $\mathrm{H}$.

University of Munich, Department of General and Applied Geology, Munich, Germany

CONF-960613 (Vol. 3); Technology, Measurement \& Analysis, Proceedings of the Second International Airborne Remote Sensing Conference and Exhibition, San Francisco, CA, June 24-27, 1996, Vol. 3, 870 pp;; (pp. III-408 - III-415) (1996)

The aim of this study is the assessment of soil parameters from remote sensing data sets which are important as input parameters for environmental information systems (e.g., modelling of hydrological cycles, evaluation of areas with erosional hazards). The soil parameters extracted from laboratory reflectance spectra are 
correlated with the soil properties and implemented in a spectral soil data base. The existence of a spectral soil data base is of central importance for further applications of spectral evaluation routines such as mixed signature analysis. The main emphasis has been focused on the extraction of soil properties from laboratory spectra such as the soil color, the content of organic material, the mineral composition and the soil texture. This study compares the information content of spectral data sets of different remote sensing data sources, such as the information derived from the laboratory measurements, the spectral reflectance of the ground truth campaign and the extracted signatures of the airborne multispectral data sets of the TMS scanner. Through the help of a spectral soil data base the spectral characteristics of the signatures can be linked with the physical and chemical properties of the soils and areas with different soil properties can be identified.

\section{7}

V18/024147

Evaluation of Headspace Method for Volatile

Constituents in Soils and Sediments

Looney, B.B.; Eddy, C.A.; Sims, W.R.

Westinghouse Savannah River Company, Aiken, SC

CONF-930167; State of the Art and Research Needs, Proceedings of a National Symposium on Measuring and Interpreting VOCs in Soils, Las Vegas, NV, January 12-14, 1993 (1997)

Detection and delineation of volatile organic contaminants (VOCs) in sediments and soils underlying a hazardous waste site is often a complex problem. The number and quality of analyses used in characterization studies can be compromised by the difficulties and costs associated with quantitative analysis of volatile analytes. A headspace analysis method was developed to facilitate the accurate and rapid delineation of the vertical and horizontal distribution of VOCs in the subsurface, and to reduce the sample handling, laboratory preparation, and analytical complexity associated with most existent sampling and analysis schemes. The headspace method consists of the following four steps: (1) subsample the core immediately after retrieval using a small tube/plunger system; (2) place the subsample into a $22.5 \mathrm{~mL}$ headspace vial; (3) add $5 \mathrm{~mL}$ of suspending solution and cap with a teflon lined septum; and (4) analyze an aliquot of the headspace using a gas chromatograph.

2638

V18/022112

Evaluation of Soil Lead Contamination at Former Firing Ranges on Governors Island, New York

Mehan, D.G.; Martin, B.A.; Gavini, B.G.

Daniel, Mann, Johnson \& Mendenhall, Arlington, VA; U.S. Coast Guard, Governors Island, NY

CONF-951139 (Vol. 1); Superfund 16: Proceedings of a Hazardous Waste Conference and Exhibition, Washington, DC, November 6-8, 1995. E.J. Krause and Associates, Bethesda, MD, Vol. 1, 828 pp.; (pp. 201-207) (1994)

Hundreds of former firing ranges used to discharge small caliber arms are located at military bases slated for closure throughout the United States. Each of these firing ranges poses unique assessment, remediation, and closure challenges. The former firing ranges are typically impacted with bullets that cause surficial soil contamination with the heavy metals lead, copper, and zinc and may pose a risk to adjacent populations through ingestion or inhalation contact. This paper discusses some of the issues and challenges associated with sampling, analysis, and remediation of two U.S. Coast Guard former firing ranges located on Governors Island, New York. The collection of representative and homogeneous soil samples is difficult because of the random distribution of bullets at former firing range sites. Lead concentrations in the soil at Govemors Island varied from 10 milligrams per kilogram (mg/kg) to over $50,000 \mathrm{mg} / \mathrm{kg}$. Impacts to groundwater are typically minimal because these metals are not highly mobile in the surficial soils where they accumulate and soil $\mathrm{pH}$ concentrations are not acidic enough to induce downward mobility. The evaluation and selection of appropriate remedial alternative(s) and clean-up concentrations should consider the historical and future use of the military base. For instance, Govemors Island, has been occupied by various military agencies for over 500 years and has been the site of military action during the Revolutionary War and War of 1812. Due to the Islands military history, clean-up to natural or background concentrations may be difficult. Decisions on base closure and future land use at Fort Jay should dictate the selection of the appropriate remedial solutions for the former firing ranges. Remedial options evaluated include simple control measures (e.g. fencing, impervious cover), soil stabilization, and soil removal.

\section{9}

V18/021767

\section{Evaluation of Vapor Extraction of Vadose Zone Contamination}

Crotwell, A.T.; Waehner, M.J.; Lyon, B.F.; MacInnis, J.M.; Travis, C.C.

Oak Ridge National Laboratory, Health and Safety Research Division, Oak Ridge, TN; Oak Ridge Institute for Science and Education, Oak Ridge, TN

ORNL/TM-12117; 50 pp. (May 1992)

An in-depth analysis of vapor extraction for remediation of soils contaminated with volatile organic compounds (VOCs) was conducted at 13 sites. The effectiveness of vapor extraction systems (VES) was evaluated on the basis of soil concentrations of VOC's and soil-gas concentrations of VOC's. The range of effectiveness was found to be $64 \%-99 \%$ effective in removing organic contaminants from soil. At nine of the 13 sites studied in this report, vapor extraction was found to be effective in reducing VOC concentrations by less than $90 \%$. Vapor extraction is ongoing at two of these sites. At a third, the ineffectiveness of the vapor extraction is attributed to the presence of "hot spots" of contamination. At the fourth site, where performance was found to be relatively poor, the presence of geological tar deposits at the site is thought to be a major factor in the ineffectiveness.

\section{0}

\section{V18/021717}

Evaluation of a Remediation Process for Lead Contaminated Soil by Toxicity Bioassays: Plants and Earthworms

Chana, L.W.; Smith, K. U.S. Environmental Protection Agency, Cincinnati, $\mathrm{OH}$ CONF-9511137; Global Environmental Protection: Science, Politics, and Common Sense, Proceedings of the Second Society of 
Environmental Toxicology and Chemistry (SETAC) World Congress and 16th Annual Meeting, Vancouver, British Columbia, Canada, November 5-9, 1995. Society of Environmental Toxicology and Chemistry, Pensacola, FL, 378 pp.; (pp. 235-236) (1995)

Soil from a site contaminated with heavy metals (predominantly lead) was treated using the TERRAMET lead extraction process. Earthworm acute toxicity and plant seed germination/root elongation ( $S G / R E$ ) bioassays were used to evaluate the toxicity of the soil before treatment (BT), after treatment (AT), and after treatment followed by rinsing with water, intended to simulate exposure to rainfall (RT). The resuits showed $B T$ and $R T$ were not toxic to earthworms in a 14-day exposure while AT showed significant toxicity. The LC50 values for Eisenia and Lumbricus were 44.04 and 28.83 (as \% AT soil/test soil mixture), respectively. The phytotoxicity data indicated that all 3 test soils significantly inhibited lettuce $S G / R E$ in a dose-related manner, with $A T$ being the most phytotoxic. In oats, $\mathrm{RT}$ had no effect on $\mathrm{SG} / \mathrm{RE}$ and $\mathrm{AT}$ was more toxic than BT. For the two local-site grass seeds tested (blue grama and sideoat grama), the AT soil was the most phytotoxic followed by $\mathrm{BT}$ and $\mathrm{RT}$. The results suggest that the soil after this remediation process exerts significant toxicity on both plant and earthworm, but after a rain-simulating rinse, the toxicity is the same as, or less than, the toxicity before treatment. Further studies are in progress to confirm the assumption that the high salt concentrations generated by acidification during the leaching process, followed by neutralization are responsible for the increased toxicity of unrinsed soil in both plant and earthworm.

\section{1}

V18/023018

Evaluation of a Transportable Hot-Gas Decontamination System for the Decontamination of Explosives-Contaminated Debris and Piping

Roy F. Weston, Inc., West Chester, PA

Report; 310 pp. (September 1996)

Since 1978, the United States Army Environmental Center (USAEC) has been conducting laboratory investigations and pilot-scale studies of the hot-gas decontamination (HGD) process. Results from these investigations and pilot-scale studies verified the effectiveness of the HGD technology for treating chemical agents and explosives. Post-test recommendations indicated that equipment designed specifically for the HGD concept would improve system efficiencies and process optimization goals. The equipment design was delivered to USAEC's test site at the Alabama Army Ammunition Plant (ALAAP) located in Alpine, Alabama, for demonstration and validation testing in August 1995. The HGD system demonstration and validation testing was conducted between December 1995 and March 1996. This Procurement Fabrication Guidance document provides a complete description of the transportable HGD system equipment that was successfully validated at ALAAP. A complete set of as-built drawings and equipment specifications is provided. The information contained in this document should allow the user to specify and purchase a transportable HGD system similar to the equipment supplied to USAEC by WESTON.

\section{2 \\ V18/022776}

Expedited Soil Remediation Employing Soil Vapor
Extraction and Bioventing at Castle Air Force Base

Hoge, J.

Jacobs Engineering Group Inc., Sacramento, CA CONF-960804 (Vol. 2); Spectrum '96: Nuclear and Hazardous Waste Management, Proceedings of an International Topical Meeting, Seattle, WA, August 18-23, 1996. American Nuclear Society, La Grange Park, IL, Vol. 2, 873 pp.; (pp. 1294-1301) (1996)

Soil vapor extraction (SVE) involves in-situ removal and treatment of volatile organic compounds (VOCs) from the vadose zone. An SVE system includes vent wells screened in the areas of highest contamination, a piping network connecting the vent wells to a SVE treatment unit, blower(s), and a treatment unit. Typical treatment units include granular activated carbon, catalytic oxidation (catox), thermal oxidation and internal combustion (IC) engines. The type of treatment unit selected is a function of the characteristics of the incoming vapor stream. The blower(s) apply vacuum to selected vent wells, resulting in propagation of a pressure gradient some distance from the wells. This is known as the radius of influence. The zone of remediation within this radius of influence is the distance from the well where sufficient flow velocity exists such that timely clean up of VOCs from the vadose zone can occur. Bioventing is most effective in removing petroleum hydrocarbons with less than 10 carbon chains ( $\mathrm{ClO}+$ ). Bioventing involves passive or active injection of air into the subsurface, thus promoting the natural biodegradation of residual petroleum hydrocarbons. Passive injection involves opening vent wells to the atmosphere. Active injection is performed by connecting blowers to vent wells, or the existing piping manifold, and injecting air. Bioventing is most effective in promoting natural biodegradation of residual hydrocarbons in compounds with more than $\mathrm{C10}+$ carbon chains. Factors effecting bioventing performance include: (1) microorganisms (capable of producing enzymes that can degrade the contamination); (2) energy source (carbon); (3) electron acceptor (oxygen); (5) soil moisture; (6) pH; (7) nutrients; (8) soil temperature; and (9) absence of compounds toxic to microorganisms.

2643 V18/024860

Extraction and Analysis of Pollutant Organics from Contaminated Solids Using Off-Line Supercritical Fluid Extraction (SFE) and On-Line SFE-Infrared Spectroscopy: Task 2 - Semiannual Report, April 1-September 30, 1996

North Dakota University, Energy and Environmental Research Center, Grand Forks, ND

DOE/MC/31388-5497; 10 pp. (1996)

This activity will result in a commercialized version of a field-portable instrument for performing supercritical fluid extraction (SFE) with on-line Fourier transform infrared (FT-IR) detection. The Energy \& Environmental Research Center (EERC) has developed an SFE field-portable method for quantitatively extracting organic pollutants (e.g., polycyclic aromatic hydrocarbons [PAHs], polychlorinated biphenyls [PCBs], total petroleum hydrocarbons [TPHS]) from soils and sludges under U.S. Environmental Protection Agency (EPA) funding. FT-IR is a detector that can yield quantitative and compound-class 
information for organic pollutants and is excellent for survey uses, since virtually all organic compound classes can be monitored.

\section{4}

V18/023642

Factors Influencing the Development of a Biostimulant for the Insitu Anaerobic Dechlorination of Polychlorinated Biphenyls in Fox River, Wisconsin, Sediments

Hollifield, M.B.; Park, J.K.; Boyle, W.C.; Fritschel, P.R.

Radian Corporation, Milwaukee, WI; University of Wisconsin, Department of Civil and Environmental Engineering, Madison, WI

CONF-9406413; Dredging, Remediation, and Containment of Contaminated Sediments, K.R. Demars, G.N. Richardson, R.N. Yong and R.C. Chaney (eds.), Proceedings of a Symposium, Montreal, Quebec, Canada, June 23-24, 1994, 343 pp.; (pp. 155-169) (1995)

Polychlorinated biphenyl (PCB) contaminated sediments were collected from the Fox River, Wisconsin, and analyzed for the possible occurrence of reductive dechlorination. Evidence of in-situ dechlorination was observed. However, the extent of this in-situ dechlorination was less than that typically reported in the literature, suggesting that stimulation of further dechlorination was possible. The use of nutrients and surfactants was explored for stimulating additional dechlorination. The nutrient amendment reported here was found to be inhibitory. Surfactants had varying effect, but none significantly improved dechlorination over control treatments. The most significant factors were observed to be the initial extent of dechlorination and PCB concentration. Additional dechlorination was most likely to be observed in sediments with higher PCB concentration and less initial dechlorination. All sediments converged on a common dechlorination level regardless of the initial state of the sediments.

\section{$2645 \quad$ V18/023179}

Fast GC-MS-Analysis of Contaminated Soil: Routine Field Screening in Hamburg

Matz, G.; Schroeder, W.

Technical University of Hamburg-Harburg, Department of Electrical Measurement, Hamburg, Germany

CONF-9210194; Proceedings of an International Symposium on Environmental Contamination in Central and Eastem Europe, Budapest, Hungary, October 12-16, 1992, 968 pp.; (pp. 214-216) (1992)

After a five year period of development, fast analytical on-site methods for organic soil contaminants based on a mobile gas chromatography/mass spectrometry (GC-MS) system, have become a standard component in Hamburg's routine residual analytics. With a focus on high sample throughput for volatile and semivolatile organics, the application of fast high performance analytics to field screening within 5 minutes per sample has led to new site remediation strategies. For the analysis of volatiles a fast soil headspace technique with quantification limits in the low $\mathrm{ppb}$ range is employed. Semivolatiles are ultrasonically extracted and analysed rendering limits of detection of some ppm. Quality assurance and quality control ( $Q A / Q C$ ) objectives are met by duplicate analysis of spiked soil on a daily basis, the use of surrogates (deuterated aromatic compounds) and employing one-way sample preparation equipment to prevent memory effects and contamination of the machine. The results obtained on hazardous waste sites, partially verified by laboratory methods are preserited.

\section{6}

V18/021978

Fate of $\mathbf{N}$ and $\mathbf{P}$ Sources in Subsurfaces During Insitu Bioremediation

Amery, J.H.A.; Bajpai, R.K.; Zappi, M.E.

University of Missouri, Chemical Engineering Department, Columbia, MO; U.S. Army Corps of Engineers, Waterways Experiment Station, Vicksburg, MS

CONF-9509139; Emerging Technologies in Hazardous Waste Management VII, D.W. Tedder (ed.), Proceedings of the Seventh American Chemical Society Industrial and Engineering Chemistry Division Special Symposium, Atlanta, GA, September 17-20, 1995. American Chemical Society, Washington, DC, 1291 pp.; (p. 162) (1995)

Limitations of macronutrients and electron acceptors are considered primary reasons why a number of otherwise easily biodegradable chemicals persist in nature even in presence of microbial flora capable of metabolizing them. In this research, interactions of a number of macronutrients (nitrogen and phosphorus sources) with several different soils have been investigated. Both sorptive as well as biotic and abiotic transformations have been studied. The experimental results and their interpretations will be discussed in this presentation. Quantification of these interactions is expected to lead to a more methodical selection of the appropriate macronutrients and their doses for in-situ Bioremediation. (Complete text)

2647

V18/023653

Fate of Toxic Pollutants in Contaminated Sediments Yong, R.N.

McGill University, Montreal, Quebec, Canada

CONF-9406413; Dredging, Remediation, and Containment of Contaminated Sediments, K.R. Demars, G.N. Richardson, R.N. Yong and R.C. Chaney (eds.), Proceedings of a Symposium, Montreal, Quebec, Canada, June 23-24, 1994, 343 pp.; (pp. 13-38) (1995)

Sediments function as sinks for various kinds of contaminants (pollutants and nonpollutants) discharged into the receiving waters. Toxic poliutants in the sediments constitute a significant concem inasmuch as they can infect the waters above the sediment if they are released from the sediments. Hence the persistence and fate of these toxic pollutants need to be determined. At least two sets of interests can be identified in the contamination of sediments as a whole: (1) assessment of the storage capacity (for contaminants) of the sediments, and the potential for mobilization or release of contaminants into the aqueous environment, particularly into the overlying water, and (2) development of a strategy for removal of the contaminants from the sediments that would be most appropriate (i.e., compatible with the manner in which the contaminants are retained in the sediment) and cost-effective. Both sets of interests require a knowledge of the distribution of the contaminants, i.e., characterization of the contaminants contained in the sediment, and the manner in which these are held within the 
sediment, i.e., bonded to the various sediment solid fractions (constituents).

2648

V18/024646

Feasibility Studies of Bioremediation of Hydrocarbon-Contaminated Soils

Elektorowicz, M.; Yong, R.N.

Concordia University, Department of Civil Engineering, Montreal, Quebec, Canada; McGill University, Geotechnical Research Centre, Montreal, Quebec, Canada

Bioremediation of Pollutants in Soil and Water, B.S. Schepart (ed.), Proceedings of a Symposium, Fort Worth, TX, October 14-15, 1993. American Society for Testing and Materials (ASTM), Philadelphia, PA, 265 pp.; (pp. 35-47) (May 1995)

Insitu and exsitu bioremediation of contaminated soil should be a priori tested during feasibility studies. Three cases of feasibility studies are presented in this paper. Each one concerns a different type of soil contaminated by various hydrocarbons. Different techniques of bioremediation have been chosen in every case. The natural clayey soil and clayey fill soil were provided for the exsitu treatment but insitu treatment was applied to sandy soil. The clayey soil was pretreated before subjection to bioremediation. The final results of feasibility studies for all cases show a limited possibility of bio-treatment. The bioremediation needs supplementary optimization of technological parameters before its application on site.

\section{9}

V18/022668

Feasibility of Insitu Electrical Corona for Soil Detoxification

Heath, W.O.; Caley, S.M.; Peurrung, L.M.; Lerner, B.D.; Moss, RW.

Pacific Northwest Laboratory, Richland, WA

CONF-941124; Insitu Remediation: Scientific Basis for Current and Future Technologies, G.W. Gee and N.R. Wing (eds.), Proceedings of the 33rd Hanford Symposium on Health and the Environment, Pasco, WA, November 7-11, 1994. Battelle Press, Columbus, $\mathrm{OH}_{2}$ Part 2, 605 pp.; (pp. 799-818) (1994)

The Insitu Corona Project, which is part of the US Department of Energy's Office of Technology Development In Situ Remediation Integrated Program, is developing a new technology that uses electric fields to oxidize organic compounds in situ by means of a two-step process: (1) relatively low voltage heats the soil in the vadose zone; steam formed from intrinsic soil moisture and any volatile and semivolatile soil contaminants are removed through a central soil-vapor extraction vent; (2) higher voltages delivered through the same electrode array create corona directly on soil particles in narrow bands along spreading interfaces between moist and dry soil. Ions, electrons, and secondary oxidants formed in the corona oxidize any residual organic contaminants. Results from this study indicate that insitu corona is feasible on a bench scale, providing remarkably uniform soil treatment at levels that exceed regulatory objectives. Projected voltage and power requirements for treating large soil volumes appear achievable with readily available, relatively inexpensive equipment. Compared to other insitu technologies, insitu corona may prove uniquely applicable to: sites with complex stratigraphies that include low-permeability soils contaminated with nonvolatile or bound contaminants; difficult organic contaminants, such as polyaromatic hydrocarbons and polychlorinated biphenyls, that are not removable by other means; situations where the need for added chemicals or long treatment times precludes use of other insitu techniques. Above all, at a total cost of $\$ 60$ to $\$ 80$ per ton of soil treated, insitu corona appears promising as a cost-effective alternative to above-surface treatment.

2650 V18/023638

Feasibility of Using Bioventing to Remediate Fuel Oil Contaminated Soils

Gan, D.R.; Wright, C.C.

CONF-951023 (Vol. 8); WEFTEC '95, Proceedings of the 68th Annual Conference and Exposition of the Water Environment Federation, Miami Beach, FL, October 21-25, 1995. Water Environment Federation, Alexandria, VA, Vol. 8, 498 pp.; (p. 123) (1995)

A pilot study was conducted to evaluate the feasibility of using, bioventing to remediate soils contaminated with heavy fuel oil at a site in northem Wisconsin. The test site consisted of poorly graded sands of varying grain size with occasional intervals of sand and gravel. Groundwater occurred at a depth of $21 \mathrm{~m}$ (70 feet). The study was implemented using one test well and three soil gas monitoring points. Each monitoring point included a nest of three monitoring probes at different depths. A portable soil vapor extraction vacuum blower installed at the test well was used to pull fresh air into the soils. The blower was run continuously for 4 weeks, except when oxygen (O2) and carbon dioxide (CO2) concentrations at the monitoring points were periodically monitored. In situ respiration tests indicated that the subsurface $\mathrm{O} 2$ concentrations decreased with time, following first-order disappearance behavior. The pilot study demonstrated that in situ bioventing enhanced the in situ bioactivity and degraded residual fuel oil in the unsaturated soils. Estimated biodegradation rates for heavy fuel oil in unsaturated soils are within the range of 20 to 90 $\mathrm{mg} / \mathrm{kg}$-day. (Complete text)

2651 V18/023641

Field Demonstrations of Sediment Treatment Technologies by the US EPA's Assessment and Remediation of Contaminated Sediments (ARCS) Program

Garbaciak, S., Jr.; Miller, J.A.

U.S. Environmental Protection Agency, Great Lakes National Program Office, Chicago, IL; U.S. Army Corps of Engineers, Chicago, IL

CONF-9406413; Dredging, Remediation, and Containment of Contaminated Sediments, K.R. Demars, G.N. Richardson, R.N. Yong and R.C. Chaney (eds.), Proceedings of a Symposium, Montreal, Quebec, Canada, June 23-24, 1994, 343 pp.; (pp. 145-154) (1995)

The Great Lakes National Program Office (GLNPO) of the US Environmental Protection Agency (U.S. Environmental Protection Agency) has established the Assessment and Remediation of Contaminated Sediments (ARCS) Program in response to the Water Quality Act of 1987. The ARCS Program was charged with assessing 
and demonstrating remedial options for contaminated sediment problems in the Great Lakes. A set of technologies was identified, through a literature survey, for laboratory and field testing with sediment samples collected from five Great Lakes Areas of Concern. Laboratory tests were conducted using nine processes, and pilot-scale (field-based) demonstrations of bioremediation, sediment washing, solvent extraction, and low-temperature thermal desorption were conducted at five sites. Analyses were performed on feed materials and all process residues showing polychlorinated biphenyl (PCB), polynuclear aromatic hydrocarbon $(\mathrm{PAH})$, and heavy metals removal efficiencies ranging from greater than $6 \%$ to $99 \%$. This paper presents the results of the five pilot-scale demonstrations conducted by the ARCS Program.

2652

V18/023748

Field Evaluation of Five Landfill Liner Insulations

Benson, C.H.; Olson, M.A.; Bergstrom, W.R.

University of Wisconsin, Department of Civil and Environmental Engineering, Madison, WI; Abletech, Inc., Ann Arbor, MI; Engineering Geo-Techniques, Midland, MI

CONF-950978; Municipal and Industrial Waste, Proceedings of the 18th International Madison Waste Conference, Madison, WI, September 20-21, 1995. University of Wisconsin, Madison, WI, 461 pp.; (pp. 309-318) (1995)

Five methods for thermally insulating the side slope of a landfill liner were evaluated in a field test. The insulations consisted of leachate collection sand, leachate collection sand and chipped tires, polyurea foam, polystyrene boards, and encapsulated fiber glass geoinsulation panels. Results of the study show that tire chips are an effective means to insulate landfill liners, whereas sand alone is inadequate. Of the three geoinsulations tested, the encapsulated fiber glass and extruded polystyrene worked best. The polyurea foam performed poorly, although its performance would have been better had it been thicker.

2653

V18/022007

Field Evaluation of Pneumatic Fracturing Enhanced Bioremediation

Venkatraman, S.N.; Boland, T.M.; Schuring, J.R.; Kosson, D.S.

Rutgers University, Department of Chemical and Biochemical Engineering, Piscataway, NJ; New Jersey Institute of Technology, Department of Civil and Environmental Engineering, Newark, NJ

CONF-9509139; Emerging Technologies in Hazardous Waste Management VII, D.W. Tedder (ed.), Proceedings of the Seventh American Chemical Society Industrial and Engineering Chemistry Division Special Symposium, Atlanta, GA, September 17-20, 1995. American Chemical Society, Washington, DC, 1291 pp.; (pp. 1165-1168) (1995)

Insitu bioremediation has been shown to be one of the most efficient and cost-effective technologies for the treatment of soils contaminated with benzene, toluene, and the xylenes (BTX). Application of bioremediation to clean up large contaminated sites is often limited by the rate of transport of substrate and electron acceptors (oxygen, nitrate, etc.) to the microorganisms, especially in soil formations with moderate to low permeability. For insitu bioremediation to be successful in a timely manner, the microbial population must be stimulated by injecting nutrients and an oxygen source to the microbes. In all but the most permeable formations, it is extremely difficult to supply microorganisms with sufficient nutrients to make bioremediation technically and economically feasible.

\section{4}

V18/020693

Field Experiments Regarding Microbiological Decontamination of PAH-Polluted Soil (a Former Gas Works Site) at Solingen-Ohligs: Final Report

Steilen, N.; Heinkele, T.; Reineke, W.

MB Geosphere Limited, Ismaning, Germany; Technische University, Lehrstuhl fuer Bodenschutz und Rekultivierung, Cottbus, Germany; Wuppertal University, Lehrstuhl Chemische Mikrobiologie, Gesamthochschule, Wuppertal, Germany; Landesumweltamt Nordrhein-Westfalen, Essen, Germany

ETDE-DE-339; 157 pp. (1996)

Former gas works and coking plant sites, being highly polluted, normally require decontamination. The hazardous substances in these sites making decontamination indispensable for the protection of man and the environment are, especially, polycyclic aromatic hydrocarbons (PAHS). Current decontamination methods are, apart from scrubbing techniques, thermal techniques and some recently developed ones that have so far been little tested or used on an industrial scale (vacuum distillation, water vapour desorption, gas phase extraction, ozonization), especially microbiological techniques. However, these mostly have been successfully used up to now in silos to degrade mineral oil hydrocarbons. As industrial-scale results for the PAH group of substances in terms of microbiological degradability are scarce so far, the field tests described in the report were carried out with the aim to make an exemplary assessment of the state of the art in this sector. A site was selected for the experiments which is by all means comparable to other sites in North-Rhine-Westphalia for its marginal conditions (type of soil, level of pollution), in order to warrant the transferability of results. Yet the results described, which were marginally successful, must not be generalized because soil composition and biological availability vary greatly from one case to another. They show that PAH decontamination of coking plant and gas works sites using microbiological methods will not be state of the art as long as more detailed scientific results, especially regarding degradation budgets, adsorption and desorption effects during the humification or biological fixation of PAHs in soil and suitable toxicity tests are not available. Further, the experiments revealed that the preliminary studies to be carried out in order to assess the biological remediation capability of soil must be more demanding than the ones normally performed by companies. This report makes appropriate recommendations. (This document is in German).

2655 V18/022651

Field Measurement Approach to the Quantification of Depleted Uranium in Soil

Riel, G.K.; Olenik, C.J.; Nelson, M.E.

U.S. Navy, Naval Surface Warfare Center, Silver Spring, 
MD; U.S. Navy, Naval Academy, Annapolis, MD

CONF-9607135; Proceedings of the 41st Annual Meeting of the Health Physics Society, Seattle, WA, July 21-25, 1996; Health Physics 70(6):65c (June 1996)

Samples of Depleted Uranium (DU) contaminated soil were measured in a field study to determine the effectiveness of a soil cleaning technology. Even though most samples would be analyzed later by a shielded Canberra germanium detector, they were initially analyzed in the field by averaging the count rate of four $5 \times 5 \mathrm{~cm} \mathrm{NaI}$ detectors surrounding a 4-L Marinelli beaker. The samples were not dried, and DU chunks were visible in some of them. Consequently, the seif absorption varied greatly from sample to sample. Two equations were solved to find the unknown concentration and self absorption because Canberra's ACCUSPEC software reported both Th-234 and Pa-234. Performing the field measurement using the counts associated with the $1001 \mathrm{KeV}$ photopeak, found in the isomeric transition decay of $\mathrm{Pa}-234$, minimized the need for self-absorption correction. The ratio of the field measurement in counts per minute to the laboratory measurement in Becquerels per gram was 335 [+-] 17\%. This field measurement approach was found to be effective in providing rapid, approximate sample analysis to be followed by a more precise analysis in the laboratory.

2656

V18/023181

\section{Field Screening Methods for TNT and RDX in Soil}

Jenkins, T.F.; Walsh, M.E.

U.S. Amy, Cold Regions Research and Engineering Laboratory, Hanover, NH

CONF-9210194; Proceedings of an International Symposium on Environmental Contamination in Central and Eastem Europe, Budapest, Hungary, October 12-16, 1992, 968 pp.; (pp. 222-224) (1992)

Simple field-screening methods have been developed for detecting 2,4,6-TNT and RDX in munitions-contaminated soil. A $20 \mathrm{~g}$ portion of soil is extracted manually by shaking with $100 \mathrm{~mL}$ of acetone for 3 minutes. After the soil settles, the supernatant is filtered and divided into two aliquots. One aliquot is reacted with potassium hydroxide and sodium sulfite and forms the red-colored Janowsky complex when $2,4,6$-TNT is present. The second aliquot of the extract is passed through a strong anion exchange resin to remove nitrate and nitrite. The extract is then acidified and RDX is reduced with zinc to nitrous acid, which is reacted with a Griess reagent (NitriVer 3 powder pillow) to produce a highly colored azo dye. The presence of TNT and RDX can be detected visually, and concentrations can be estimated from their absorbances at 540 and $507 \mathrm{~nm}$, respectively. Detection limits are about $1 \mathrm{mu}$ g/g for 2,4,6-TNT and RDX. Concentration estimates from field analyses correlate well with laboratory analyses. These procedures are used by the U.S. Army for site characterization at a number of Army installations. Draft EPA SW846 methods, based upon these results, are available.

\section{7}

\section{V18/022669}

Field Studies on the Thermally Induced Desiccation Risk of Cohesive Soil Liners Below Geomembranes in Landfill Covers

Vielhaber, B.; Melchior, S.; Berger, K.; Miehlich, G.
University of Hamburg, Institute fuer Bodenkunde, Hamburg, Germany

CONF-941124; Insitu Remediation: Scientific Basis for Current and Future Technologies, G.W. Gee and N.R. Wing (eds.), Proceedings of the 33rd Hanford Symposium on Health and the Environment, Pasco, WA, November 7-11, 1994. Battelle Press, Columbus, OH, Part 1, 704 pp.; (pp. 663-674) (1994)

Composite liners (geomembranes above compacted, cohesive soil liners) are used in landfill covers. They are subjected to a number of risks that might reduce their efficiency. Desiccation and shrinkage of the compacted soil liner below the geomembrane due to thermally induced water transport is one of the major threats. This study presents an in-situ experiment to evaluate the desiccation risk. Three test fields have been installed within the compacted soil liner of a landfill cover. Temperature conditions within two test fields are modified and controlled. First results show that water movement in the soil liners is primarily caused by variations in both the temperature and the temperature gradient. Under anisothermal conditions, with the temperature at the top of the composite liner constantly higher than at the bottom, the enhanced downward water movement decreases the matric potential within the liner. However, critical values that cause shrinkage have not yet been reached. Slight desiccation has been measured under isothermal conditions. The authors assume this was caused by variations of capillary forces due to changes in absolute temperature. A third test field serves as a control plot, with no manipulation of the temperature regime. The experiment is to be continued through the summer of 1994 .

2658

$$
\text { V18/023304 }
$$

Field Trials of the Site Characterization and Analysis Penetrometer System at the Savannah River Site (SRS): Final Report

Koester, J.P.; Lee, L.T., Jr.; Olsen, R.S.; Douglas, D.H.; Comes, G.D.; Cooper, S.S.; Powell, J.F.

U.S. Army Corps of Engineers, Waterways Experiment Station, Vicksburg, MS

GL-93-16; 95 pp. (July 1993)

The purpose of these field investigations was to demonstrate and evaluate the effectiveness and versatility of the Site Characterization and Analysis Penetrometer System (SCAPS) for geotechnical and environmental site characterization activities. Specific objectives of this study were to: demonstrate SCAPS capabilities to penetrate to depths of at least $150 \mathrm{ft}(45.7 \mathrm{~m})$ at the SRS Integrated Demonstration Site, demonstrate and evaluate the SCAPS capabilities to classify and delineate the soil layers encountered, and evaluate the performance of SCAPS resistivity and fiber optic sensors to detect known solvent and hydrocarbon contamination in soils.

2659

$\mathrm{V} 18 / 021016$

Flameless Thermal Oxidation: Innovative Technology Summary Report

U.S. Department of Energy, Office of Environmental Management, Washington, DC

Report; 20 pp. (September 1995)

The Flameless Thermal Oxidizer (FTO) is a commercial technology 
offered by Thermatrix, Inc. The FTO has been demonstrated to be an effective destructive technology for process and waste stream off-gas treatment of volatile organic compounds (VOCs), and in the treatment of VOC and chlorinated volatile organic compounds (CVOCs) off-gases generated during site remediation using either baseline or innovative in situ environmental technologies. The FTO process efficiently converts VOCs and CVOCs to carbon dioxide, water, and hydrogen chloride. When FTO is coupled with a baseline technology, such as soil vapor extraction (SVE), an efficient in situ soil remediation system is produced.

\section{0}

\section{V18/022242}

Fluidized Bed Desorption System for Recycling Mercury from Contaminated Soil

Harriss, C.; Baum, D.L., Jr.; Read, W.L.

Philip Environmental Services Corporation, Columbia, IL

CONF-951139 (Vol. 2); Superfund 16: Proceedings of a Hazardous Waste Conference and Exhibition, Washington, DC, November 6-8, 1995. E.J. Krause and Associates, Bethesda, MD, Vol. 2, 817 pp.; (pp. 939-949) (1994)

The land disposal restrictions effective for wastes containing mercury have created a need for technologies that can meet the best demonstrated available technologies (BDAT) treatment standards. In the past, technologies for mercury were in short supply. In addition to the already existing short supply, the natural gas industry has begun to remediate the numerous metering sites that have been contaminated with mercury from manometers installed along their pipelines. To meet the need for a mercury technology, Philip Environmental Services Corporation (Philip) evaluated and tested two different technologies capable of recovering mercury from contaminated soil. Philip initially performed some tests using gravitational methods followed by pilot-scale testing using a fluidized bed desorber. As a result of the testing, Philip constructed a full-scale fluidized bed system which can recover mercury from contaminated soil and debris. The name of Philip's technology is the Solvating Vapor Pressure Process (SVPP). The main purpose of this paper is to discuss the results of the SVPP pilot testing and describe the process.

\section{$2661 \quad$ V18/024309}

Framework for Assessing Risk Reduction Due to DNAPL Mass Removal from Low Permeability Soils

Freeze, R.A.; McWhorter, D.B.

R. Allan Freeze Engineering, Inc., White Rock, British Columbia, Canada; Colorado State University, Fort Collins, CO; Oak Ridge National Laboratory, Oak Ridge, TN

ORNL/TM-13305; Insitu Remediation of DNAPL Compounds in Low Permeability Media Fate/Transport, Insitu Control Technologies, and Risk Reduction, 318 pp.; (pp. 2.1-2.30) (August 1996)

Many emerging remediation technologies are designed to remove contaminant mass from source zones at dense nonaqueous phase liquid (DNAPL) sites in response to regulatory requirements. There is often concem in the regulated community as to whether mass removal actually reduces risk, or whether the small risk reductions achieved warrant the large costs incurred. This paper sets out a framework for quantifying the degree to which risk is reduced as mass is removed from shallow, saturated, low-permeability, dual-porosity, DNAPL source zones. Risk is defined in terms of meeting an alternate concentration level (ACL) at a compliance well in an aquifer underlying the source zone. The ACL is back-calculated from a carcinogenic health-risk characterization at a downstream water-supply well. Source-zone mass-removal efficiencies are heavily dependent on the distribution of mass between media (fractures, matrix) and phases (dissolved, sorbed, free product). Due to the uncertainties in currently-available technology performance data, the scope of the paper is limited to developing a framework for generic technologies rather than making risk-reduction calculations for specific technologies. Despite the qualitative nature of the exercise, results imply that very high mass-removal efficiencies are required to achieve significant long-term risk reduction with technology applications of finite duration.

\section{$2662 \quad \mathrm{~V} 18 / 022691$}

Framework for Successful SCAPS Deployment

Kram, M.; How, D.; Mellor, S.; Dean, M.; Soule, R.; Steffen, G.

U.S. Navy, Naval Facilities Engineering Service Center, Port Hueneme, CA; Ogden Professional Services Corporation, Camarillo, CA; U.S. Navy, Naval Public Works Center, San Diego, CA; U.S. Navy, Naval Public Works Center, Jacksonville, FL

CONF-960393 (Part 1); Contaminated Soils and Groundwater: Analysis, Fate, Environmental and Public Health Effects, and Remediation, Proceedings of the Sixth Annual West Coast Conference, Newport Beach, CA, March 11-14, 1996. Association for the Environmental Health of Soils, Amherst, MA, Part 1, 257 pp.; (p. 34) (1996)

The Site Characterization and Analysis Penetrometer System (SCAPS) is capable of rapidly detecting subsurface petroleum contamination and characterizing site geology. SCAPS uses laser induced fluorescence to obtain real-time screening of fuel type and concentration. SCAPS data is used to reduce site characterization and cleanup costs when compared to conventional drilling, sampling, and analytical methods. This paper provides a brief description of SCAPS, items which require consideration for successful implementation, a few special cases, and considerations for SCAPS data applications in remedial activities.

\section{3}

\section{V18/023914}

Frost Effects on Soil Liner Systems: Results of a Research Project

Erickson, A.E.; Chamberiain, E.J.; Benson, C.H. CH2M Hill Inc., Milwaukee, WI; U.S. Army, Cold Regions Research and Engineering Laboratory, Hanover, NH; University of Wisconsin, Department of Civil and Environmental Engineering, Madison, WI

CONF-950177; Waste Tech '95, Proceedings of a Conference, New Orleans, LA, January 23-25, 1995. Environmental Industry News, Washington, DC, 530 pp.; (pp. 81-104) (1995)

A research study was completed on the impact of frost action 
(freeze-thaw) on compacted clay liners, sand-bentonite liners, and geosynthetic clay liners (GCLs) under field and laboratory conditions. The goal of the research discussed in this paper was to improve understanding of the effect of freeze-thaw on these parts of liner systems so that design and construction could be improved. The U.S. Army Corps Cold Regions Research Engineering Laboratory (CRREL), CH2M Hill, Inc., and a team of industrial partners joined together in a cooperative effort to fund and complete this study under the U.S. Army Corps Construction Productivity Advancement Research (CPAR) program. In 1992 and 1993, five large-scale compacted-soil test pads, and nine GCL test pans were constructed at WMX, Inc.'s Parkview Landfill in Milwaukee, Wisconsin. Two of the large-scale test pads were constructed of a low-plasticity clay, two were of a medium-plasticity clay, and one was a sand-bentonite mixture manufactured in a mobile mixer onsite. Three different GCL products were used in the GCL test pans. All of these materials were tested in the field for at least one winter; in the CRREL laboratory in Hanover, New Hampshire; and at the University of Wisconsin-Madison. Results of these tests indicate that the hydraulic conductivity of compacted clay increases significantly in the field after one winter of freezing. In laboratory testing, the use of thin-walled shelby tubes changes the clay structure and masks the effect of freeze-thaw. These tests indicated that the detrimental effects of freeze-thaw were reversed by increasing confining pressure. The hydraulic conductivity of the sand-bentonite test pad was found to be below $1 \times 10(\mathrm{E}-8) \mathrm{cm} / \mathrm{s}$ after two winter seasons. The GCLs showed no increase in hydraulic conductivity from freeze-thaw action. However, the field test results raised questions that need to be resolved.

\section{$2664 \quad$ V18/024664}

Full-Scale Bioremediation of No. 6 Fuel Oil-Contaminated Soil: 6 Months of Active and 3 Years of Passive Treatment, Chapter 8

Fogel, S.

Bioremediation Consulting, Inc., Newton, MA

Bioremediation: Field Experience, P.E. Flathman, D.E. Jerger and J.H. Exner (eds.), Lewis Publishers, Boca Raton, FL, 560 pp.; (pp. 161-175) (1994)

Bioremediation is a technology that can result in the destruction of a wide range of organic contaminants, including petroleum hydrocarbons (PHCs), under proper environmental conditions. For remediation of PHC-contaminated soil, the rate and extent of treatment that can be achieved depend upon several factors, such as the starting concentration of the PHCs, the types of PHC constituents, available inorganic mineral nutrient concentrations, treatment, temperature, etc. The primary sources of information on the biodegradation potential of PHCs in soil have been laboratory investigations using well-mixed soil samples under controlled environmental conditions. While laboratory data is useful for short term evaluations, e.g., less than a year, there are, for a number of practical reasons, limits to conducting longer term laboratory evaluations. Field remediations offer an opportunity to gain insight into the fate of contaminants in soil over a period of years. In addition, insight can be gained into the question of the extent of contaminant biodegradation under conditions where active field operation has been discontinued. This paper presents a case study for bioremediation of No. 6 fuel oil-contaminated soil. The project involved six months of active treatment in the field, followed by three years of passive treatment. Soil contamination resulted from a single spill of the fuel oil from a storage tank into a $60,000 \mathrm{sq} \mathrm{ft}(5,600 \mathrm{ha})$ bermed area. Since surface soil was relatively permeable and an impermeable layer was located at 8 in. $(20 \mathrm{~cm})$, the fuel oil spread uniformly into the surface soil, resulting in a relatively uniform distribution of PHCs as determined by analysis of composite samples collected throughout the site. Additional soil homogenization, during the 180-day period of active biological treatment, subsequently allowed the analysis of one composite sample collected from the site to be representative for the entire site. This chapter is from the book entitled Bioremediation: Field Experience.

\section{5}

\section{V18/023782}

\section{Full-Scale Soil Washing/TERRAMET [R] Soil Leaching}

Fristad, W.E.; Klein, E.S.

CONF-9504134; HAZMACON' 95, T. Bursztynsky and M.L. Loss (eds.), Proceedings of the Twelfth Hazardous Materials Management Annual Conference and Exhibition, San Jose, CA, April 4-6, 1995. Association of Bay Area Governments, Oakland, CA, 790 pp.; (pp. 139-146) (1995)

COGNIS TERRAMET $[R]$ soil leaching and Bescorp soil washing systems have been successfully combined to remediate an ammunition test burn area at the Twin Cities Army Ammunition Plant (TCAAP), New Brighton, MN. This cleanup is the first in the country to combine these two technologies, and this approach offers a permanent remedial solution. In Fall 1993, 1,600 tons of soil were remediated with an additional $10,000+$ tons treated in 1994. The cleaned soil remained on-site, and the heavy metal contaminants were removed, recovered, and recycled. Eight heavy metals were removed from the contaminated soil achieving the very stringent cleanup criteria of less than $175 \mathrm{ppm}$ for residual lead and achieving background concentrations for seven other heavy metals (antimony, cadmium, chromium, copper, mercury, nickel, and silver). Initial contaminant levels were measured as high as 86,000 $\mathrm{ppm}$. In addition, both live and spent ordnance had to be removed in the soil treatment plant to meet the cleanup criteria. By combining the two systems, COGNIS and Bescorp were able to assemble a process which effectively treats all the soil fractions so that all soil material can be returned on-site, no wastewater is generated, and the heavy metals are recovered and recycled. No hazardous waste requiring landfill disposal was generated during the entire operation. At TCAAP the Bescorp soil washing system separated the feed soil into three fractions: oversize, sand, and fines. The oversize fraction was clean and discharged from the plant for redeposition on-site after removal of the live and spent ammunition. The sand fraction contained sand-size fragments of lead and copper and was subjected to density separation techniques to remove the majority of these metal fragments. Both the fines and density-pretreated sand streams were then leached in two parallel leaching circuits. The COGNIS TERRAMET heavy metal extraction process leached and recovered heavy metals, and particularly lead and copper, from contaminated soil with a proprietary aqueous leaching solution. The leachant was specifically matched with the substrate and the level and type of heavy metal contaminants. The metal recovery process delivered the metals in a 
compact form which was easily recycled and reused at a local secondary lead smelter. Only by combining both the metal fragment removal and leaching did the soil meet the stringent cleanup criteria.

2666

V18/022752

Geochemical and Petrographic Studies and the Relationships to Durability and Leach Resistance of Vitrified Products from the Insitu Vitrification Process

Timmons, D.M.; Thompson, L.E.

Geosafe Corporation, Issaquah, WA; Geosafe Corporation, Richland, WA

CONF-960804 (Vol. 2); Spectrum '96: Nuclear and Hazardous Waste Management, Proceedings of an Intemational Topical Meeting, Seattle, WA, August 18-23, 1996. American Nuclear Society, La Grange Park, IL, Vol. 2, 873 pp.; (pp. 1026-1029) (1996)

Soil and sludge contaminated with hazardous and radioactive materials from sites in the United States and Australia were vitrified using in situ vitrification. Some of the resulting products were subjected to detailed geochemical, leach and durability testing using a variety of analytical techniques. The leach resistance and durability performance was compared to that of vitrified high level waste with borosilicate composition. Particular attention was given to crystallization behavior, the effects of crystallization on residual melt chemistry and how crystallization influences the behavior of contaminant ions. The results of this work show that the vitrified material studied has superior chemical durability and leach resistance relative to typical borosilicate waste glasses. Crystallization behavior was variable depending upon melt chemistry and cooling history. Crystallization was not observed to adversely affect chemical durability or leach resistance.

2667

V18/022407

Geosafe Insitu Vitrification (ISV) Technology: Parsons

Chemical Superfund Site - U.S. EPA SITE

Demonstration Program

Geosafe Corporation, Richland, WA

Videotape [VHS Format]; 17 mins. (December 1994)

This videotape presents the Insitu Vitrification (ISV) technology being developed by GeoSafe. It provides a brief overview of the EPA's SITE program including the technology research program, innovative technology demonstrations and related publications. It describes the preliminary development of ISV by Pacific Northwest Laboratory and the subsequent technology transfer and licensing to GeoSafe Corp. The technology was demonstrated at the former Parsons Chemical site in Grand Ledge, MI, a superfund site contaminated by pesticide and herbicide manufacturing, among other chemicals. The purpose of the demonstration was to determine the effectiveness of treatment and to perform a cost-benefit analysis. All technical aspects of the demonstration are featured including the electrode array configuration, soil temperature obtained, rate of processing, off-gas treatment, subsidence, and volume reduction. The economics are discussed in terms of power and fuel consumption, operating time and manpower requirements. Results of final waste form testing are presented, including the TCLP test and treatment of the scrubber water. Finally, costs per ton for a full-scale operation are discussed. This videotape runs approximately 17 minutes.

2668

V18/023913

Geosynthetic Clay Liner Applications in Waste Disposal Facilities

McGrath, L.T.; Creamer, P.D.

RMT, Inc., Madison, WI

CONF-950177; Waste Tech '95, Proceedings of a Conference, New Orleans, LA, January 23-25, 1995. Environmental Industry News, Washington, DC, 530 pp.; (pp. 70-80) (1995)

Geosynthetic Clay Liners (GCLs) are becoming a popular alternative to compacted clay barrier layers, and represent the state of the art in waste disposal facility design. They possess many of the same qualities of compacted clay barrier layers while occupying only a small fraction of the airspace. This is a very attractive feature to waste disposal facility owners and operators. There are many manufacturers of GCLs in the marketplace, providing numerous products that can be used in a wide variety of applications. Designing for and constructing with a GCL can be a challenging task; stability issues must be evaluated, selecting the appropriate product should be considered, comprehensive specifications are needed to ensure proper product selection and installation, and steps must be taken during installation to prevent damage to the GCL. Perhaps most importantly, state regulatory agencies must be convinced that GCLs will provide long-term protection equivalent to a clay barrier layer. This paper will discuss design considerations, specification guidelines, installation criteria, construction quality assurance guidelines and regulatory issues pertaining to $G C L$. The paper will also present three brief case histories of relevant $G C L$ applications in waste disposal facility design and construction. The purpose of the paper is to demonstrate that GCLs are a viable aiternative to compacted clay barrier layers and to provide useful information in designing, specifying and installing them in waste disposal facilities.

2669

V18/021819

German Washing Process Pulls Out Contaminants in a Fine Slurry

Goldberg, E.

Lockwood Greene Engineers, Inc., New York, NY

Soil and Groundwater Cleanup (August/September 1995); 3 pp. (August-September 1995)

The Harbauer soil washing process has been practiced on a commercial scale in Europe for the past nine years. It is being used in three plants in Germany and has cleaned thousands of tons of soils contaminated with organics, metals and cyanides. Now available in the US through Lockwood Greene Engineers, Inc., New York, New York, the soil washing system is a physical separation process which concentrates the contaminated soil to about 5 percent of its original volume. This is accomplished with equipment commonly used in the mining and mineral processing industries. The Harbauer system uses staged mechanical agitation which separates clean fractions from the contaminated soils. The volume reduction concentrates the contaminants, which are lodged on the fine particle fraction of the soil, which is produced as a 
concentrated paste slurry. This concentrate is subsequently treated to remove or recover the contaminant. The technology has been proven on a commercial scale and has processed soils containing petroleum products, BTEX, PCBs, phenol, halogenated hydrocarbons, cyanides and heavy metals. The system is based on a modular design in which each module is pre-piped and pre-wired for quick connection and assembly.

\section{0}

\section{V18/025378}

Grass-Enhanced Bioremediation for Clay Soils Contaminated with Polynuclear Aromatic Hydrocarbons, Chapter 13

Qiu, X.; Shah, S.I.; Kendall, E.W.; Sorensen, D.L.; Sims, R.C.; Engelke, M.C.

Union Carbide Corporation, Central Research and Engineering Technology, South Charleston, WV; Union Carbide Corporation, Department of Environmental Protection, Seadrift Plant, North Seadrift, TX; Utah State University, Department of Civil and Environmental Engineering, Logan, UT; Texas Agricultural Experiment Station, Research and Extension Center, Dallas, TX

Bioremediation Through Rhizosphere Technology, T.A. Anderson and J.R Coats (eds.), American Chemical Society, Washington, DC, 249 pp.; (pp. 142-157) (1994)

In situ biotreatment of polynuclear aromatic hydrocarbons (PAH) contaminated clay soils is a challenge. A grass-enhanced bioremediation system was conceived as a relatively passive but potentially effective remediation method. Our laboratory studies to date have shown that a statistically significant increase in $\mathrm{PAH}$ removal is possible through the use of a grass-enhanced system. $A$ field demonstration for grass-enhanced bioremediation for PAH contaminated soil is being conducted for a 2-yr period at a Union Carbide Plant. The objective is to evaluate, at pilot-scale level, the ability of a fibrous root system to facilitate the bioremediation of PAH in clay soils typical in the Gulf Coast area. The performance of the process is being evaluated by comparison of the $\mathrm{PAH}$ concentration reductions in soil planted with 'Prairie' Buffalograss to that in soil in the absence of grass. This pilot study will determine degradation kinetics of PAH compounds, formation of toxic metabolites, and the influence of soil characteristics and microbial populations in the field. Soil gas and solid phase of the top soil zone as well as the groundwater in the upmost aquifer are being monitored. A parallel experiment is conducted to assess the performance of twelve warm-season grass species with various genetic origins. Randomized, complete block experiments were designed to appraise the effect of individual grass species. The visual differences in grass germination, establishment, survival, density, height, and root depths are being observed.

V18/021709

Green Remediation: Using Plants to Clean the Soil Comis, D.

U.S. Department of Agriculture, Agricultural Research Service, Greenbelt, MD

Journal of Soil and Water Conservation 51(3):184-187 (May-June 1996)
A day is foreseen when plants with an appetite for toxic heavy materials will be used to clean contaminated soils at smelter and mining sites, landfills, nuclear waste dumps, farmland, or at any urban or rural site contaminated with lead, cadmium, zinc, nickel, or radioactive isotopes such as uranium or cobalt. The plants would take up the toxic metals or isotopes through their roots and transport them to stems or leaves where they could be easily removed by harvesting. A U.S. Department of Agriculture agronomist, Chaney, says the cost of using plants to clean polluted soil "could be less than one-tenth the price tag for either digging up and trucking the soil to a hazardous waste landfill or making it into concrete." The cost could be further offset by recovering heavy metals from the plants and selling them. The metal-scavenging plants, called hyperaccumultors, would be grown and harvested like hay, Chaney says. Burning the hay allows recovery and recycling of the metals. The ash is similar to commercial ore and could be sold as "Bio-Ore". Chaney calls the process "green remediation." He says that without intervention, heavy metals stay in soil for centuries.

\section{$2672 \quad \mathrm{~V} 18 / 022251$}

Guidance for Characterizing Explosives Contaminated Soils: Sampling and Selecting Onsite Analytical Methods

Crockett, A.B.; Craig, H.D.; Jenkins, T.F.; Sisk, W.E.

Idaho National Engineering Laboratory, Idaho Falls, ID; U.S. Environmental Protection Agency, Portland, OR: U.S. Army, Cold Regions Research and Engineering Laboratory, Hanover, NH; U.S. Army Environmental Center, Aberdeen Proving Ground, MD

INEL-96/00128; CONF-9608125; Proceedings of the Twelth Annual Waste Testing and Quality Assurance Symposium. Washington, DC, August 23-26, 1996; (8 pp.) (1996)

A large number of defense-related sites are contaminated with elevated levels of secondary explosives. Levels of contamination range from barely detectable to levels above $10 \%$ that need special handling due to the detonation potential. Characterization of explosives-contaminated sites is particularly difficult due to the very heterogeneous distribution of contamination in the environment and within samples. To improve site characterization, several options exist including collecting more samples, providing on-site analytical data to help direct the investigation, composting samples, improving homogenization of samples, and extracting larger samples. Onsite analytical methods are essential to more economical and improved characterization. Onsite methods might suffer in terms of precision and accuracy, but this is more than offset by the increased number of samples that can be run. While verification using a standard analytical procedure should be part of any quality assurance program, reducing the number of samples analyzed by the more expensive methods can result in significantly reduced costs. Often 70 to $90 \%$ of the soil samples analyzed during an explosives site investigation do not contain detectable levels of contamination. Two basic types of on-site analytical methods are in wide use for explosives in soil, colorimetric and immunoassay. Colorimetric methods generally detect broad classes of compounds such as nitroaromatics or nitramines, while immunoassay methods are more compound specific. Since TNT or RDX is usually present in explosive-contaminated soils, the use of procedures designed to detect only these or similar compounds can be very effective. 
Selection of an on-site analytical method involves evaluation of many factors including the specific objectives of the study, compounds of interest and other explosives present at the site, number of samples to be run, sample analysis rate, interferences/cross-reactivity of the method, skill required, analytical costs per sample, and the need for and availability of support facilities/services. Other factors to be considered are the precision and accuracy of the on-site analytical method, but it should be remembered that the analytical error is generally small compared to field error and that the precision and accuracy of a method are dependent on the site (compounds present and relative concentration) and the specific objectives. Modifications to on-site methods may improve method performance including extracting a larger soil sample to improve the representativeness of the analytical sample, ensuring that the shaking/extraction phase of all methods lasts at least three minutes, and evaluating the rate of extraction for heavy soils by conducting a simple kinetic study. With appropriate use, on-site analytical methods are valuable tools for characterization of soils at hazardous waste sites and monitoring soil remediation operations. This paper summarizes an Issue Paper prepared for the EPA's Federal Facility Forum through the EPA's Technology Support Center for Monitoring and Site Characterization, Characterization Research Division, Las Vegas.

2673 V18/022097

Hazardous Lead-Contaminated Soil Treatment: Lead Recovery and Recycling of 150,000 Tons of Soil at the Longue Pointe Site

Holbein, B.E.; Hall, D.W.; MacDonald, M.W.; Hulley, I.M.

Tallon, Inc., Princeton, NJ; Tallon Metal Technologies, Inc., Ville St. Laurent, Quebec, Canada

CONF-951139 (Vol. 2); Superfund 16: Proceedings of a Hazardous Waste Conference and Exhibition, Washington, DC, November 6-8, 1995. E.J. Krause and Associates, Bethesda, MD, Vol. 2, 817 pp.; (pp. 744-749) (1994)

Heavy metal contamination is present at approximately $50 \%$ of the Superfund sites on the EPA's National Priority List and of these, approximately $50 \%$ include lead contamination. The Longue Pointe site is in Montreal, Canada and involves the treatment of approximately 115,000 tonnes of soil (dry) containing hazardous quantities of $\mathrm{Pb}$ (2000 to $30,000 \mathrm{ppm})$, making this the largest soil treatment project of its kind in North America. The site had become contaminated through both automotive battery recycling operations which contributed substantial coarse $\mathrm{Pb}$ contamination and a secondary lead smelter which contributed extensive fine lead fly ash contamination. The soil is also a high clay matrix ( $50 \%$ clay of size less than $5 \mathrm{mu} \mathrm{m}$ ) and approximately $80 \%$ of the lead resides in this fine soil fraction. Conventional soil washing/volume reduction was thus shown to have very limited utility. WE are currently operating an 800 tons per day treatment plant on the site which provides recovery of coarse lead by advanced soil washing and gravity separation techniques and extraction and recovery of fine lead by hydrometallurgical techniques. Recovered lead products are recycled in the base metal industry whereas treated soil with residual concentrations of greater than $500 \mathrm{ppm}$ or greater than $900 \mathrm{ppm}$ $\mathrm{Pb}$ (area dependent) is reused as backfill on the site. The site is bordered by residential areas and is enjoying continued use for military activities. The project has demonstrated the merits of full treatment and reuse of treated soil. A similar approach can provide a more environmentally sound and cost-effective approach to the remediation of Superfund or other sites containing $\mathrm{Pb}$ or other heavy metals, thereby overcoming some of the limitations imposed by previously-used approaches involving isolation/restriction or soil disposal.

\section{4}

$\mathrm{V} 18 / 023331$

Hazardous Waste Site Soil Remediation: Theory and Application of Innovative Technologies

\section{Wilson, D.J.}

Hazardous Waste Site Soil Remediation: Theory and Application of Innovative Technologies, A.N. Clarke (ed.), Marcel Dekker, New York, NY (January 1994)

This guide introduces recent innovative technologies for remediating contaminated soils and aquifers, for environmental managers and regulators, and for engineers who are not necessarily experts in remediation technologies. The ten chapters address contaminant transport and behavior in the subsurface; problems with the remediation of diffusion-limited fractured-rock systems; chemical stabilization of contaminated soils; soil vapor stripping; thermally enhanced vapor stripping; thermal desorption; enhanced biodegradation for on-site remediation of contaminated soils and groundwater; saturated zone remediation of VOCS through sparging; in situ verification; and soil surfactant flushing/washing.

\section{5}

V18/020972

Heap Leach Process for Remediation of Plutonium and Americium Contaminated Soils

Turney, W.R.J.R.; Kitten, J.J.; Schake, B.S.; Mason, C.F.V.; Lu, N.P.

Los Alamos National Laboratory, Los Alamos, NM

CONF-960212; Waste Management '96: Working Towards a Cleaner Environment, Proceedings of a Conference on $\mathrm{HLW}$, LLW, Mixed Wastes and Environmental Restoration, Tucson, AZ, February 25-29, 1996; (12 pp.) (1996)

As an extension of previous successful studies for remediation of uranium-contaminated soil using adaptation of the heap leach process, results documenting the removal of plutonium and americium from soils are reported. In addition, results of leaching schemes from soils co-contaminated, not only with plutonium and americium but also with uranium, are reported. The first soils tested that contained plutonium and americium as contaminants were obtained from the Rocky Flats Plant site in Colorado, whereas soils that contained uranium, in addition to plutonium and americium, were obtained from the site of the former plutonium processing facilities at Los Alamos National Laboratory (which were active from 1945 to 1978). Heap leach has proved to be a relatively fast, low-tech, economical solution for the remediation of plutoniumand americium-contaminated soils at laboratory scale. Using different leach reagents, more than two thirds of plutonium and/or americium present in the soil samples were successfully removed using the heap leach process. Uranium was also removed. Leach solutions used in experiments consisted of various compositions of citrate, bicarbonate, and/or dithionite. Comparative studies of the different reagents are reported and the results from Rocky Flats and LANL are compared. The laboratory experiments show promise for 
remediation of soil by a simultaneous leach of multiple radionuclides.

2676 V18/021034

Heterogeneity and Vapor Extraction Performance

Chesnut, D.A.

Lawrence Livermore National Laboratory, Physical Sciences Division, Livermore, CA

CONF-9209226 (Vol. 1); Emerging Technologies in Hazardous Waste Management IV, D.W. Tedder and F.G. Pohland (eds.), Proceedings of the Fourth American Chemical Society Industrial and Engineering Chemistry Division Special Symposium, Atlanta, GA, September 21-23, 1992. American Chemical Society, Washington, DC, Vol. 1, 381 pp.; (pp. 8-32) (1992)

Soil venting or vapor extraction, the "pump and treat" method of aquifer remediation, and petroleum production by primary or secondary recovery all involve the flow of fluids of varying composition in porous geologic media. Properties of these media which govern fluid flow and contaminant transport, such as porosity, permeability, mineralogy, saturations, and solute concentration, vary from point to point, often by orders of magnitude. As this spatial heterogeneity increases, the performance of the remediation or petroleum production process deteriorates markedly, requiring the extraction of larger and larger total quantities of fluid to recover the desired amount of "product" (contaminant, oil, etc.). A simple model is presented for quantifying the effects of heterogeneity on vapor extraction. It was originally developed to determine the effect of heterogeneity on waterflooding for secondary oil recovery and subsequently extended to estimate the travel time distribution for radionuclides dissolved in water moving through fractured porous rock. Heterogeneity is quantified by a single parameter, sigma, which determines the shape of a breakthrough curve for the transport of a tracer or other distinguishable fluid front as it moves through the medium. The resulting extraction model is simple enough to use in Monte Cario and similar sampling procedures to estimate the uncertainty in cost or duration of the remediation project.

\section{$2677 \quad$ V18/024107}

High Gradient Magnetic Separation (HGMS)

Los Alamos National Laboratory, Los Alamos, NM

LALP-94-264; 1 p. (1994)

Large volumes of contaminated soil and fluid exist in and are being generated by the DOE Defense Complex. Chemical treatment or direct disposal of these wastes can be prohibitively expensive. One of the Los Alamos responses to this problem is the development of high gradient magnetic separation (HGMS). The technology can be used to extract slightly magnetic radioactive particles from host materials such as water, soil, or air. All uranium and plutonium compounds are slightly magnetic while most host materials are "nonmagnetic." The process operates by passing contaminated fluid or slurry through a magnetized volume. The magnetized volume contains a magnetic matrix material such as steel wool that extracts the slightly magnetic contamination particles from the slurry. Los Alamos and Lockheed Environmental are currently developing the soil decontamination aspect of this technology through a cooperative research and development agreement (CRADA).
Commercialization of the fluid waste treatment aspects of HGMS may still be possible with an alternate partner.

2678

V18/022394

Hot Air Injection for Removal of Dense, Non-Aqueous-Phase Liquid Contaminants from Low-Permeability Soils

Payne, F.C.

Envirogen, Inc., MWR Division, Lawrenceville, NJ; Oak Ridge National Laboratory, Oak Ridge, TN

ORNL/TM-13305; 14 pp. (August 1996)

The performance of soil vapor extraction systems for the recovery of volatile and semi-volatile organic compounds is potentially enhanced by the injection of heated air to increase soil temperatures. The soil temperature increase is expected to improve soil vapor extraction (SVE) performance by increasing target compound vapor pressures and by increasing soil permeability through drying. The vapor pressure increase due to temperature rise relieves the vapor pressure limit on the feasibility of soil vapor extraction. However, the system still requires an air flow through the soil system to deliver heat and to recover mobilized contaminants. Although the soil permeability can be increased through drying, very low permeability soils and low permeability soils adjacent to high permeability air flow pathways will be treated slowly, if at all. All thermal enhancement methods face this limitation. Heated air injection offers advantages relative to other thermal techniques, including low capital and operation costs. Heated air injection is at a disadvantage relative to other thermal techniques due to the low heat capacity of air. To be effective, heated air injection requires that higher air flows be established than for steam injection or radio frequency heating. Heated air injection is not economically feasible for the stratified soil system developed as a standard test for this document. This is due to the inability to restrict heated air flow to the clay stratum when a low-resistance air flow pathway is available in the adjoining sand. However, the technology should be especially attractive, both technically and economically, for low-volatile contaminant recovery from relatively homogeneous soil formations.

\section{9}

\section{$\mathrm{V} 18 / 022689$}

Hot Air Vapor Extraction System for Remediation of Petroleum Contaminated Sites

Pal, D.; Karr, L.; Fann, S.; Mathews, A.P.; Price, P.A.; Linginemi, S.

U.S. Navy, Naval Facilities Engineering Service Center, Port Hueneme, CA; Kansas State University, Manhattan, KS; Sound Remedial Technologies, Duvall, WA; Environmental Modeling, Las Vegas, NV

CONF-960393 (Part 1); Contaminated Soils and Groundwater: Analysis, Fate, Environmental and Public Health Effects, and Remediation, Proceedings of the Sixth Annual West Coast Conference, Newport Beach, CA, March 11-14, 1996. Association for the Environmental Health of Soils, Amherst, MA, Part 1, 257 pp.; (p. 2) (1996)

This paper describes the results of a demonstration of a technology entitled Hot Air Vapor Extraction (HAVE) at the Hydrocarbon 
National Test Site (HNTS), Port Hueneme, Califomia. The demonstration of the HAVE technology at HNTS was conducted over a 3-month period between August 21, 1995 and November 22, 1995 and the lessons leamed from the demonstration are discussed in details to guide the Department of Defense (DoD) decision makers in analyzing the applicability of this technology to their contaminated sites. This technology demonstration was conducted under the Department of Defense Strategic Environmental Research and Development Program (SERDP) as part of the National Environmental Technology Demonstration Program (NETDP). The primary objectives of the demonstration were to: (1) validate the efficacy of the HAVE technology to treat a wide range of hydrocarbons contaminated soils, (2) gather data to estimate treatment costs, and (3) develop engineering guidance needed to apply this remediation technology DoD-wide. Test runs were made on 5 different treatment cells containing various fuel hydrocarbons, ranging from gasoline to heavier petroleum fractions such as lubricating oil. Computer modeling was conducted to analyze the test results and also to optimize the HAVE system design. An economic analysis was conducted for various remediation project sizes ranging from 750 to 9,000 cubic yards; the per cubic yard treatment costs were found to vary from $\$ 64.05$ down to $\$ 36.54$ respectively. (Complete text).

\section{$2680 \quad$ V18/023887}

Hydraulic Fractures as Anaerobic and Aerobic Biological Treatment Zones

Davis-Hoover, W.J.; Roulier, M.H.; Bryndzia, L.T.; Herrmann, J.G.; Vane, L.M.; Murdoch, L.C.; Vesper, S.J.

U.S. Environmental Protection Agency, Risk Reduction Engineering Laboratory, Cincinnati, $\mathrm{OH}$; University of Cincinnati, Cincinnati, $\mathrm{OH}$

EPA/600/R-95/012; CONF-9504110; Proceedings of the 21st Annual Risk Reduction Engineering Laboratory (RREL) Research Symposium, Cincinnati, OH, April 4-6, 1995. U.S. Environmental Protection Agency, Cincinnati, OH, 398 pp.; (pp. 323-324) (April 1995)

Hydraulic fractures were initially developed to be used in bedrock to enhance oil recovery. We have modified the procedure for use in the environmental field in shallower subsurface soils to increase the permeability of the soils to liquids, gases, and solids. This has allowed us to significantly enhance in situ methods of soil cleaning (pump and treat, steam injection, solvent extraction) and aerobic bioremediation. We are now concentrating on enhancing movement of contaminants between hydraulic fractures and into hydraulic fractures using electrokinetics and destruction of contaminants within the hydraulic fractures. Bioremediation, very specific to the unusual conditions that electrokinetics presents to the subsurface soil, is being developed. This work is being done as a result of the Remediation Technologies Development Forum (RTDF) and in conjunction with researchers at Monsanto, Dupont, General Electric, and DOE. Hydraulic fracturing allows for the insertion of a pancake-shaped lens of sand. The sand lens increases the soil permeability of the area allowing a 10 fold increase in the area of influence of the well allowing for a 10 fold increase in vapor extraction, and a 10 fold increase in liquid addition (such as solubilized nutrients and hydrogen peroxide), which leads to a 100 fold increase in aerobic bioremediation. The process allows for other solid additions to contaminated subsurface soils such as solid slow-releasing oxygen which increases aerobic bioremediation. The Lasagna technology uses 2 outer hydraulic fractures as two dimensional electrodes in the electrokinetic process moving contaminants into 3 inner hydraulic fractures designed to be zones of biodegradation. Several experiments that the members of the research consortium have performed have indicated that the process of electrokinetics modifies the $\mathrm{pH}$ of the soil to a spectrum of 2 to 10 and increases the temperature significantly. Thus as a result of this we decided to naturally select for thermophilic organisms that will degrade contaminants at these high and low pHs. We have been successful in obtaining thermophilic organisms that will degrade contaminants at high and low pHs. These are being tested in lasagna microcosms. The next step is to test them in the field. (Complete text)

2681 V18/023886

Hydraulic Fractures as Subsurface Electrodes: Early Work on the Lasagna Process

Murdoch, L.C.; Chen, J.L.; Cluxton, P.; Kemper, M.; Anno, J.; Smith, D.

University of Cincinnati, Center for Geoenvironmental Science and Technology, Cincinnati, $\mathrm{OH}$

EPA/600/R-95/012; CONF-9504110; Proceedings of the 21st Annual Risk Reduction Engineering Laboratory (RREL) Research Symposium, Cincinnati, OH, April 4-6, 1995. U.S. Environmental Protection Agency, Cincinnati, OH, 398 pp.; (pp. 318-322) (April 1995) .

Fine-grained sediments present the greatest obstacle to in situ remediation at many contaminated sites. Electrokinetics is an effective method of inducing the movement of water, ions, and colloids through fine-grained sediments, but it has a number of drawbacks and potential problems. Recent investigations have shown that it may be possible to address some of the shortcomings of electrokinetics by degrading contaminants in situ. Hydraulic fracturing is a method of improving the performance of electrodes and of creating in situ degradation zones. To assess the usefulness of hydraulic fractures in creating in situ electrodes two roughly circular, horizontal hydraulic fractures filled with electrically conductive graphite were created. A potential difference was maintained between the fractures, and specially-designed monitoring instrumentation was used to measure subsurface physical properties. Theoretical analyses were also performed to predict the effects of the fractures. The field observations indicated that graphite-filled hydraulic fractures behave as broad sheet-like electrodes capable of providing useful electrical potential gradients distributed over a reasonably large soil volume. Preliminary measurements of fluid flows suggest that the observed potential gradients induce electroosmotic migration of water through the region between the fractures.

2682 V18/024308

Hydraulic Fracturing to Enhance the Remediation of DNAPL in Low Permeability Soils

Murdoch, L.C.; Slack, B.

University of Cincinnati, Cincinnati, OH; FRX Inc., Cincinnati, OH; Oak Ridge National Laboratory, Oak Ridge, 
TN

ORNL/TM-13305; Insitu Remediation of DNAPL Compounds in Low Permeability Media Fate/Transport, Insitu Control Technologies, and Risk Reduction, 318 pp.; (pp. 9.1-9.19) (August 1996)

Meager rates of fluid flow are a major obstacle to in situ remediation of low permeability soils. This paper describes methods designed to avoid that obstacie by creating fractures and filling them with sand to increase well discharge and change paths of fluid flow in soil. Gently dipping fractures $10 \mathrm{~m}$ in maximum dimension and 1 to 2 $\mathrm{cm}$ thick can be created in some contaminated soils. Hydraulic fractures can also be used to create electrically conductive layers or to deliver granules of chemically or biologically active compounds that will degrade contaminants in place. Benefits of applying hydraulic fractures to DNAPL recovery include rates of fluid recovery, enhancing upward gradients to improve hydrodynamic stabilization, forming flat-lying reactive curtains to intersect compounds moving downward, or improving the performance of electrokinetics intended to recover compounds dissolved in water.

2683

V18/025456

\section{Hydrocarbon Remediation Using Bioventing and Soil} Vapor Extraction

Moore, B.J.; Armstrong, J.E.; Hardisty, P.E.; Dupont, R.R.

Komex International Limited, Calgary, Alberta, Canada; Utah State University, Logan, UT; Department of the Environment, Environmental Protection Service, Ottawa, Ontario, Canada

CONF-951086; Proceedings of the Fifth Annual Symposium on Groundwater and Soil Remediation, Toronto, Ontario, Canada, October 2-6, 1995. Environment Canada - Environmental Protection Service, Hull, Quebec, Canada, 566 pp.; (pp. 427-437) (1995)

Soil vapor extraction (SVE) and bioventing, two technologies frequently used to remediate vadose zone contamination by volatile contaminants, are described. Four aspect of an SVE and bioventing research project, started in 1992 at a natural gas processing plant in Alberta, are reviewed in this paper: (1) characterization of the subsurface air flow to assess the role of oxygen recharge, (2) study of the effects of temperature changes during a typical Canadian winter on biodegradation rates, (3) examination of the use of biodegradation data derived from in-situ respiration data, and (4) assessment of the degree of clean-up achievable through SVE and bioventing. The methodology used and results obtained in each of the four areas are summarized.

\section{$2684 \quad$ V18/023477}

Impact of Soil Properties on the Rate of Degradation of Chlorinated Hydrocarbons

Walsh, K.P.; McLaughlan, R.G.; Anderson, B.N.; Henkler, R.D.

University of Technology, Sydney, Australia; Royal Melbourne Institute of Technology, Melbourne, Australia; ICI Paints, Slough, United Kingdom

CONF-960730 (Vol. 3); Technologies Critical to a Changing World, Volume III: Emerging Energy Technologies, Clean Technologies,
Remediation and Emission Control Fuels, and Petrochemicals, Proceedings of the Fifth World Congress of Chemical Engineering, San Diego, CA, July 14-18, 1996. American Institute of Chemical Engineers, New York, NY, Vol. 3, 1118 pp.; (pp. 772-776) (1996)

Soils from two geologically and geochemically different sites were evaluated for their potential to degrade chlorinated hydrocarbons. The chlorinated hydrocarbons included trichloroethene, tetrachloroethene, carbon tetrachloride and chloroform. Laboratory microcosm studies were used to determine the degradation rates under anaerobic conditions. Soils were distinguished on the basis of physical properties such as grain size and on chemical properties such as organic carbon content. There appeared to be little direct correlation between observed degradation rates and soil organic carbon content for soils containing less than $0.1 \%$ organic carbon. It was found that grain size distribution appeared to have some effect on degradation rates observed in soils with low organic carbon content $(<0.1 \%)$. Soils with much higher organic carbon concentrations were observed to mineralize the chlorinated hydrocarbons at rates four to five orders of magnitude greater than that found in the lower organic carbon soils.

2685

V18/024314

Insitu Chemical Degradation of DNAPLs in Contaminated Soils and Sediments

Gates, D.D.; Korte, N.E.; Siegrist, R.L.

Oak Ridge National Laboratory, Oak Ridge, TN

ORNL/TM-13305; Insitu Remediation of DNAPL Compounds in

Low Permeability Media Fate/Transport, Insitu Control

Technologies, and Risk Reduction, 318 pp.; (pp. 4.1-4.25) (August 1996)

An emerging approach to in situ treatment of organic contaminants is chemical degradation. The specific processes discussed in this chapter are in situ chemical oxidation using either hydrogen peroxide $(\mathrm{H} 2 \mathrm{O} 2)$ or potassium permanganate $(\mathrm{KMnO})$ and in situ dechlorination of halogenated hydrocarbons using zero-valence base metals such as iron. These technologies are primarily chemical treatment processes, where the treatment goal is to manipulate the chemistry of the subsurface environment in such a manner that the contaminants of interest are destroyed and/or rendered non-toxic. Chemical properties that can be altered include $\mathrm{pH}$, ionic strength, oxidation and reduction potential, and chemical equilibria. In situ contaminant destruction processes alter or destroy contaminants in place and are typically applied to compounds that can be either converted to innocuous species such as $\mathrm{CO} 2$ and water, or can be degraded to species that are non-toxic or amenable to other in situ processes (i.e., bioremediation). With in situ chemical oxidation, the delivery and distribution of chemical reagents are critical to process effectiveness. In contrast, published approaches for the use of zero valence base metals suggest passive approaches in which the metals are used in a permeable reaction wall installed in situ in the saturated zone. Both types of processes are receiving increasing attention and are being applied both in technology demonstration and as final solutions to subsurface contaminant problems. 
Proportional Counter

Bush, S.P.; Hamby, D.M.

University of Michigan, Ann Arbor, MI

CONF-9607135; Proceedings of the 41st Annual Meeting of the Health Physics Society, Seattle, WA, July 21-25, 1996; Health Physics 70(6):39b (June 1996)

A current method of site characterization involves techniques to gather field samples, package, and transport them to laboratories to be analyzed. A detector is proposed to quantify contamination in the field to eliminate some problems associated with laboratory analysis. The detector is a wall-less gas flow proportional counter that uses $\mathrm{P}-10$ as its fill gas. Proportional counters rely on gas multiplication, which requires large values of the electrical field. The gas multiplication factor for cylindrical geometry was applied to find the optimal voltage, anode wire radius, and cathode inner radius. Energy resolution and detection efficiency calibrations were characterized. Field investigation results will verify usability and accuracy in quantifying radioactivity in soil. This detector is intended to eliminate some sample preparation and analysis. It will provide real time results of concentrations of radioactive contaminants in soil, thus speeding up site characterization and reducing cost. It also allows in-field determination of whether clean-up goals have been achieved and can be used to monitor clean areas for unintentional radioactive spills.

2687

\section{$\mathrm{V} 18 / 022775$}

Insitu Immobilization of Lead from Aqueous Solutions and Contaminated Soils by Phosphate Rocks

Chen, K.; Peurrung, L.M.; Wright, J.V.; Conca, J.L.

Pacific Northwest National Laboratory, Richland, WA; Washington State University Tri-Cities, Richland, WA

CONF-960804 (Vol. 2); Spectrum '96: Nuclear and Hazardous Waste Management, Proceedings of an International Topical Meeting, Seattle, WA, August 18-23, 1996. American Nuclear Society, La Grange Park, IL, Vol. 2, 873 pp.; (pp. 1286-1293) (1996)

This study investigated and demonstrated that dissolved lead $(\mathrm{Pb})$ from aqueous solutions and contaminated soils can be effectively immobilized under a wide range of $\mathrm{pH}$ conditions using a natural phosphate rock (PR) from North Carolina, USA. As little as $2 \% \mathrm{PR}$ added can significantly reduce the $\mathrm{Pb}$ concentrations in the leachates of a contaminated soil to below the Toxicity Characteristic Leaching Procedure (TCLP) maximum allowable level or drinking water standard, depending on leaching solution $\mathrm{pH}$. Lead immobilization occurs primarily when PR dissolves, and pyromorphite-type minerals precipitate under acidic conditions, or hydrocerussite precipitates under alkaline conditions. The pyromorphite-type minerals are highly leach-resistant under different $\mathrm{pH}$ conditions. These results, along with the ready availability and low cost of PR, imply that this technology could be a cost-effective option in the remediation of metal-contaminated soils, wastes, and groundwater. Current and developing emplacement methods will put this technology into practice.
Willis, C.; Williams, $M$.

Black and Veatch Waste Science, Inc., Kansas City, MO

CONF-951139 (Vol. 2); Superfund 16: Proceedings of a Hazardous Waste Conference and Exhibition, Washington, DC, November 6-8, 1995. E.J. Krause and Associates, Bethesda, MD, Vol. 2, 817 pp.; (pp. 892-898) (1995)

This paper provides a progress report on the performance of an in situ soil flushing system during remediation of a chromium contaminated site. The soil flushing system was designed to remove chromium contaminated pore water from deep, unsaturated soils beneath a former wood treating facility in California. The paper also provides an overview of project history and the findings of a pilot study conducted in 1991 and describes the full-scale system in operation at the site since June 1992. The full-scale system involves gravity-fed injection of treated effluent into the soil and extraction of contaminated groundwater for onsite treatment by electrochemical precipitation. The focus of this paper is an evaluation of site remediation progress based on 3 years of full-scale system monitoring data. The evaluation includes a review and interpretation of analytical results of water samples collected from suction lysimeters, monitoring tubes, and monitoring wells at the soil flushing site. Discussions presented also consider injection and extraction flow rates, pore water and groundwater quality, zone of soil flushing influence, and capture of soil flushing effluent at the site.

2689

V18/022723

Insitu Stabilization Wall for Containment and Hot Spot Retrieval

Loomis, G.G.

Idaho National Engineering Laboratory, Idaho Falls, ID CONF-960804 (Vol. 1); Spectrum '96: Nuclear and Hazardous Waste Management, Proceedings of an International Topical Meeting, Seattle, WA, August 18-23, 1996. American Nuclear Society, La Grange Park, Il, Vol. 1, 887 pp.; (pp. 367-374) (1996)

This paper presents the results of a fuil scale field demonstration of an in situ stabilization technology applicable to buried transuranic waste. The technology involves creating a jet grouted wall around selected regions or hot spots within a buried waste site. The resulting wall provides a barrier against further horizontal migration of the contaminants and allows vertical digging of material inside the wall, thus minimizing waste during a hot spot removal action. The demonstration involved creating a "Un" shaped wall in the interior of a full sized, simulated waste pit. The wall simulated the main features of a four sided wall. The demonstration also involved a destructive examination and a stability test for a hot spot retrieval scenario.

2690

V18/021939

Insitu Vitrification

Geosafe Corporation, Richland, WA

EPA/540/MR-94/520; 2 pp. (August 1994)

In Situ Vitrification (ISV) is designed to treat soils, sludges, sediments, and mine tailings contaminated with organic and inorganic compounds. The process uses electrical current to heat (melt) and vitrify the soil in place. Organic contaminants are 
decomposed by the extreme heat into simple gases, which then rise through and escape from the molten soil. Inorganic contaminants are trapped within the molten soil, which cools and solidifies into a glassy monolith.

2691

$\mathrm{V} 18 / 021990$

Insitu Fixation of Lead in Soil: A Case Study

Keefe, M.; Robinson, W.W.

Environmental Solutions, Inc., Richmond, VA

CONF-9509139; Emerging Technologies in Hazardous Waste Management VII, D.W. Tedder (ed.), Proceedings of the Seventh

American Chemical Society Industrial and Engineering Chemistry Division Special Symposium, Atlanta, GA, September 17-20, 1995. American Chemical Society, Washington, DC, 1291 pp.; (p. 37) (1995)

Excavation and treatment of lead contaminated soil is routine today. Much less typical is the case where the soil is remediated and placed back into immediate use through the application of insitue techniques. A case study will be presented that will highlight the problem and the unique problem solving approach that allowed the site owner to promptly return his property to productive use. (Complete text)

\section{2}

V18/022005

Insitu Land Treatment Demonstration Employing Alternative Bioremediation Supplements on Historically Impacted Soils

Wilson, M.B.; Portier, R.J.

Louisiana State University, Department of Civil and Environmental Engineering, Hazardous Substance Research Center S\&SW, Baton Rouge, LA; Louisiana State University, Institute of Environmental Studies, Baton Rouge, LA

CONF-9509139; Emerging Technologies in Hazardous Waste Management VII, D.W. Tedder (ed.), Proceedings of the Seventh American Chemical Society Industrial and Engineering Chemistry Division Special Symposium, Atlanta, GA, September 17-20, 1995. American Chemical Society, Washington, DC, 1291 pp.; (pp. 1142-1145) (1995)

Bioremediation must transform constituents to non-toxic or less toxic forms to be considered successful. The transformation products of mutagenic parent compounds may have mutagenic or toxic characteristics but these may decrease with time. Toxicity bioassays are utilized to evaluate toxicity reduction of waste constituents in the environment. Assays using microorganisms are often used due to their speed, simplicity, ease in handling, cost effectiveness, and use of statistically significant number of test organisms that is required to detect the effects of potentially toxic materials. One of the accepted tests used is the Microtox [TM] assay. This is a standardized, instrument based general toxicity test based on the measured reduction in light output produced by marine luminescent bacteria in response to a water soluble sample. This test is recommended because it considers the physiological effect of the toxicant on the test organism and correlates favorably with other bioassays. The Ames assay [TM] can be used but the information obtained from this test tells mutagenic potential of the compounds. There is a relationship between mutagenicity and toxicity but it is not ciearly defined. The toxicity of metals is an area of concern and there is no quick bioassay accepted by the EPA for testing. The MetPLATE and/or MetPAD test is one potentially useful procedure is being examined. These are fundamentally the same assay using a mutant strain of $E$. coli in which an enzymatic reaction has a colored product or if bioavailable metals are present in the sample.

V18/023302

Insitu Vitrification (ISV) Organic-Surrogate Vapor Emissions During a 1-Ton Pilot Melt: Draft Report

Dietz, R.N.; Wieser, R.F.; Fajer, R.W.; Mancini, J.D.; Senum, G.I.

Brookhaven National Laboratory, Tracer Technology Center, Environmental Chemistry Division, Upton, NY

BNL-63981; 45 pp. (September 1996)

Pilot tests of a commercial soil vitrification process of entombing Animal/Chemical and Glass Hole area wastes were evaluated by incorporating perfluorocarbon tracers (PFTs) into aqueous and organic "wastes" within bottles of the type buried in typical Brookhaven-type holes. The objective was to add sufficient known PFT quantities of two or more types in the aqueous and organic phases while, at the same time, surrounding the test pit with known emission rate PFT sources, one type in the soil and another type in the air, such that monitoring of the air above ground and below ground would allow computation of the fugitive emission rates from the process as it occurred. Hood off-gas PFT concentrations were also to be monitored in order to verify the fraction present; claims have been made that greater than $99 \%$ of pit organics are destroyed during the melt. The output was to be the percentage escape (i.e., not captured by the hood) of pit aqueous and organic phases as the vitrification process proceeded.

\section{4}

V18/025373

Influence of Plant Species on Insitu Rhizosphere Degradation, Chapter 5

Shann, J.R.; Boyle, J.J.

University of Cincinnati, Department of Biological Sciences, Cincinnati, $\mathrm{OH}$

Bioremediation Through Rhizosphere Technology, T.A. Anderson and J.R. Coats (eds.), American Chemical Society, Washington, DC, 249 pp.; (pp. 70-81) (1994)

The degree of xenobiotic degradation in rhizosphere soil appears related to the species of plant involved. Species of plants are known to vary in their morphology, primary and secondary metabolism, and in their ecological interactions with other organisms. Current investigations examine differences in the rate and quality of root exudates, the adsorption characteristics of root cell walls, and the uptake of xenobiotics by plants. These factors vary with plant species and are correlated to changes in rhizosphere degradation. It is suggested that root exudation may influence degradation by directly altering the microbial community. Cell wall adsorption and plant uptake may limit microbial degradation by controlling the bioavailability of xenobiotics within the rhizosphere ecosystem. This document is a chapter from the book Bioremediation through Rhizosphere Technology. 


\section{5}

V18/022084

Initial Characterization of Uranium Concentration in Indoor Dust

Rutz, E.E.; Valentine, J.D.; Eckart, R.E.

University of Cincinnati, Cincinnati, $\mathrm{OH}$

CONF-941148 (Vol. 2); DDER-'94: Decommissioning,

Decontamination, and Environmental Restoration at Contaminated

Nuclear Sites, M.G. White (ed.), Proceedings of an Embedded

Topical Symposium of the American Nuclear Society Winter

Meeting, Washington, DC, November 13-18, 1994. American

Nuclear Society, Inc., La Grange Park, IL, Vol. 2, 241 pp.; (pp.

332-334) (1994)

The University of Cincinnati has provided support for the Uranium in Soils Integrated Demonstration program by collection and measurement of uranium in indoor dust and outdoor soil samples.

Samples of indoor dust were collected from three residences. These samples were analyzed using kinetic phosphorimetry analysis to determine the amount of uranium in the dust. The concentration of uranium in indoor dust was compared to the concentration of uranium in the soil surrounding each residence. The results of this work show that the uranium content of indoor dust is approximately $15 \%$ of the uranium content of the outdoor soil. These results can be used to estimate the potential health impact of uranium or other contaminants in soil, and subsequently, determine the cleanup levels for such contaminants in soils.

\section{6}

\section{V18/021123}

Initial Field Test of High-Energy Corona Process for Treating a Contaminated Soil-Offgas Stream

Shah, R.R.; Garcia, R.E.; Jeffs, J.T.; Virden, J.W.; Heath, W.O.

Pacific Northwest Laboratory, Richland, WA

PNL-9224; 65 pp. (April 1995)

In May 1993, the Pacific Northwest Laboratory's High Energy Corona (HEC) process was demonstrated on a pilot scale at the Savannah River Site for treating a soil offgas stream contaminated with 670 plus or minus 55 ppmv perchloroethylene (PCE), 100 plus or minus $9.0 \mathrm{ppmv}$ trichloroethylene (TCE), and trace concentrations of trichloroethane. The process was tested at treatment rates from 1.4 to $42 \mathrm{cfm}$, corresponding to residence times of 15.7 to $0.8 \mathrm{~s}$. All systems functioned correctly, enabling the field demonstration to be completed ahead of schedule. In the field, TCE destruction was greater than $99 \%$ for all cases except 0.8 $s$ and PCE destruction ranged between $73 \%$ to greater than $99 \%$. On a carbon mass basis, all organic byproducts represented less than $4.2 \%$ of the total inlet carbon in TCE and PCE at the shortest residence time of $0.8 \mathrm{~s}$. Prior to the field-test a prototype HEC reactor was characterized in the laboratory under expected conditions over reactor residence times between 0.8 to $3.1 \mathrm{~s}$. For an inlet mixture of PCE and TCE, TCE destruction remained at or near $99 \%$ whereas PCE destruction ranged from $65 \%$ to $69 \%$. Thus, destruction efficiencies measured in the field generally exceeded those measured in the laboratory. The power requirements were also $14 \%$ to $34 \%$ lower in the field than in the laboratory. Based on field performance data, coupled with engineering scaleup assumptions, the annual costs for HEC would be projected to be between four and six times lower than for catalytic oxidation at offgas treatment rates between 300 and $500 \mathrm{~cm}$, respectively at PCE and TCE combined concentrations at $3000 \mathrm{ppmv}$. Compared to commonly quoted costs for treatment using activated carbon $(\$ 15$ to $\$ 30 / \mathrm{hb}$ of contaminant), HEC would be projected to be between 10 and 50 times less expensive, within the range of stream flowrates and contaminant concentrations used in the preliminary cost analysis.

\section{7} V18/023911

Innovative Applications of Co-Extruded Geomembranes Thiel, R.S.; Cadwallader, M.W.

EMCON Associates, Sacramento, CA; Gundle Lining Systems, Inc., Houston, TX

CONF-950177; Waste Tech '95, Proceedings of a Conference, New Orleans, LA, January 23-25, 1995. Environmental Industry News, Washington, DC, 530 pp.; (13 pp.) (1995)

This paper describes the use of polyethylene geomembranes with co-extruded layers providing certain functions beyond the normal functions of $\mathrm{HDPE}$ geomembranes. These added functions were found in standard landfill and pond liner applications to solve some of the concerns associated currently with traditional polyethylene geomembrane installation and performance.

\section{8}

V18/022681

Innovative Insitu Mixing Technology and Its Applications in the Waste Remediation Industry

Toor, I.A.; Lanter, $R$.

Texilla Environmental, Inc., Addison, TX; ITEX

Environmental Services, Inc., Addison, TX

CONF-941124; Insitu Remediation: Scientific Basis for Current and Future Technologies, G.W. Gee and N.R. Wing (eds.), Proceedings of the 33rd Hanford Symposium on Health and the Environment. Pasco, WA, November 7-11, 1994. Battelle Press, Columbus, OH, Part 2, 605 pp.; (pp. 1089-1095) (1994)

An innovative in-situ remediation technology has been developed for solidification and stabilization of hazardous wastes. The system incorporates a specially designed rotary mixing head attached to the boom of a long-reach backhoe or other dirt-moving equipment. A variety of mixing-head configurations are available to treat various types of wastes, ranging from oil sludge to very dry contaminated soils containing significant amounts of large aggregates and gravel. The system has been successfully applied in the field to remediate hazardous petroleum sludge, mine tailings, and steel mill process sediments containing heavy metals (e.g., chromium, arsenic, cadmium, and lead). A very elaborate quality assurance/quality control program was implemented to ensure minimum variation in additive concentration and thorough mixing. The mixing effectiveness and reagent injection capabilities of this unit have resulted in the in-situ treatment of listed hazardous wastes to below delisting thresholds at depths in excess of $15 \mathrm{ft}$. Applications of this unit are currently being reviewed for incorporating and mixing nutrients in a bioremediation process. The new technology provides a very economical means for treatment, with excellent product quality. 
Innovative Treatment for TCE-Contaminated Saturated Clay Soils

West, O.R.; Cameron, P.A.; Smuin, D.R.; Korte, N.E.; Lucero, A.J.

Oak Ridge National Laboratory, Environmental Sciences Division, Oak Ridge, IN; Oak Ridge National Laboratory, Chemical Technology Division, Oak Ridge, TN

CONF-9509139; Emerging Technologies in Hazardous Waste Management VII, D.W. Tedder (ed.), Proceedings of the Seventh American Chemical Society Industrial and Engineering Chemistry Division Special Symposium, Atlanta, GA, September 17-20, 1995. American Chemical Society, Washington, DC, 1291 pp.; (pp. 340-343) (1995)

Mixed region vapor stripping (MRVS) is an in situ technology for removing volatile organic compounds (VOCs) from low-permeability soils. Its effectiveness in unsaturated silty clays has been demonstrated in laboratory tests, field demonstrations, and the full-scale clean-up of soil underlying a former land treatment facility. In saturated soils with high clay content, MRVS efficiency can be severely limited by reduced soil air porosity, and/or the formation of large soil clumps. Under these conditions, amending the contaminated soil with calcium oxide is an effective means for achieving optimum conditions for MRVS. The hydration of calcium oxide upon contact with wet soil reduces the amount of free moisture, thereby increasing soil air porosity and the friability of the soil. Heat released by the exothermic hydration reaction can also enhance vapor stripping of the VOCs. This paper describes the evaluation of MRVS coupled with calcium oxide conditioning for removing trichloroethylene (TCE) for a site underlain by saturated clay soils. VOC removals during MRVS with and without calcium oxide conditioning were simulated using a previously developed model. The results of the modeling were compared with laboratory MRVS tests on undisturbed soil cores taken from the study site.

\section{0}

\section{V18/020943}

Innovative Vitrification for Soil Remediation [February 1996]

Jetta, N.W.; Patten, J.S.; Hnat, J.G.

Vortec Corporation, Collegeville, PA

CONF-960212; Waste Management '96: Working Towards a Cleaner Environment, Proceedings of a Conference on $\mathrm{HLW}$, LLW, Mixed Wastes and Environmental Restoration, Tucson, $A Z$, February 25-29, 1996; (12 pp.) (1996)

Vortec has successfully completed the detail design of a high throughput glass melter for the DOE "Innovative Fossil Fuel Fired Vitrification Technology for Soil Remediation" demonstration program. The principal objective of the program is to demonstrate the ability of the Vortec Cyclone Melting System (CMS [TM]) to remediate DOE contaminated soils, mixed wastes and other waste forms containing RCRA hazardous materials, low levels of radionuclides, and TSCA (PCB) containing wastes. The demonstration program will verify the ability of this vitrification process to produce a chemically stable glass final waste form which passes both TCLP and PCT quality control requirements, while meeting all federal and state emission control regulations. The demonstration system is designed to process 36-72 ton/day of as-received drummed or buik wastes. Construction will begin in mid
1996 with the testing to be accomplished in the first quarter of 1997. The demonstration testing will be conducted at the DOE Gaseous Diffusion Plant in Paducah, KY. This paper presents a description of the program, equipment, and testing accomplished to date.

\section{1}

V18/023632

Insitu Gamma Spectrometry Intercomparison Exercise in Salzburg, Austria: Nuclide Specific Exposure Rate Measurements

Steger, F.; Lovranich, E.; Urbanich, E.; Streit, S.

Oesterreichisches Forschungszentrum Seibersdorf $\mathrm{GmbH}$, Institute fuer Strahlenschutz, Seibersdorf, Austria; Austrian Radiation Protection Association, Seibersdorf, Austria; International Radiation Protection Association, Washington, DC

CONF-960409 (Vol. 2); IRPA9, K.E. Duftschmid (ed.), Proceedings of the 1996 International Radiation Protection Association (IRPA) Ninth World Congress on Radiation Protection, Vienna, Austria, April 14-19, 1996. Berger, Horn, Austria, 817 pp.; (pp. 721-723) (1996)

Insitu gamma spectrometry has become a useful method to assess the nuclide concentration of artificial and natural gamma-emitters in the soil. With such measurements the activity levels in the soil can be calculated and also nuclide-specific exposure rates; consequently, it is possible to decide which radionuclide contributes the main part of the exposure rate in a given radiation field. For quality assurance of the measurements periodic intercomparison exercises are essential. To meet this requirement exercises were organised in different European countries since 1989. The last exercise in September 1994 was organised in Salzburg, Austria. The participation of 24 measurement teams from all over Europe emphasizes the importance of the intercomparison. Salzburg was selected because the Province of Salzburg, Austria was among the most heavily contaminated regions outside the former USSR by the Chemobyl fallout. Two different typical sites were selected for the measurements. Site 1 was inside the urban area of Salzburg on intensively used agricultural land which had not been disturbed since the fallout. This site is representative of intensively used agricultural regions in the Province of Salzburg. Site 2 was in the mountainous region of the Tauem at an elevated altitude of approximately $1700 \mathrm{~m}$. This site represents the soil and contamination conditions of the Alpine region. Both sites differ significantly in terms of different soil distribution and contents of natural and artificial radionuclides. The main origin of the specific exposure rates in these regions depends from this facts. Results are presented.

2702

V18/020640

Insitu RF/Microwave Remediation of Soil Benchtop Experiment Overview and Results

Regan, A.H.; Palomares, M.E.; Polston, C.; Rees, D.E.; Roybal, W.T.

Los Alamos National Laboratory, Los Alamos, NM

LA-UR-96-1686; CONF-9607121; Proceedings of the 31st Annual Microwave Symposium, Boston, MA, July 1996; (3 pp.) (1996) 
The authors have developed an in-situ process that combines $\mathrm{RF} /$ microwave energy application with soil vapor extraction to help mobilize and efficiently remove soil contaminants. They have conducted a number of benchtop experiments involving $\mathrm{RF} / \mathrm{microwave}$ energy deposition and vapor extraction on controlled contaminated soil samples with successful removal of the DNAPL contaminants. This paper will describe the experiments performed and present results.

\section{3}

V18/020677

\section{Insitu RF/Microwave Remediation of Soil Experiment Overview}

Regan, A.H.; Roybal, W.T.; Ortega, R.; Palomares, M.E.; Rees, D.E.; Tischler, D.

Los Alamos National Laboratory, Los Alamos, NM LA-UR-96-1315; CONF-960804 (Vol. 1); Spectrum '96: Nuclear and Hazardous Waste Management, Proceedings of an International Topical Meeting, Seattle, WA, August 18-23, 1996. American Nuclear Society, La Grange Park, IL, Vol. 1, 887 pp.; (pp. 331-336) (1996)

Contaminant plumes are significant waste problems that require remediation in both the government and private sectors. The authors have developed an in-situ process that uses RF/microwave stimulation to remove pollutants from contaminated soils. This process is more efficient than existing technologies, creates less secondary pollution, and is applicable to situations that are not amenable to treatment by existing technologies. Currently the most commonly used process is soil vapor extraction. However, even when it is successful, this technology is energy inefficient. The objective is to combine RF/microwave energy application with soil vapor extraction to help mobilize and efficiently remove the soil contaminants, specifically demonstrating the viability of $\mathrm{RF} / \mathrm{microwave}$ induced, in-situ, soil remediation of light and dense non-aqueous phase liquids (LNAPL, DNAPL) contaminants. The authors have conducted a number of benchtop experiments involving RF/microwave energy deposition and vapor extraction on controlled contaminated soil samples with successful removal of the contaminants. This paper will describe the experimental hardware utilized, the experiments performed, the chemical analysis performed pre- and post-energy application, and results. In the experiments, two different halogenated liquids were used to contaminate the soil: carbon tetrachloride and 1,1,1-trichloroethane. V18/024142

Insitu Radio Frequency Heating to Enhance Vacuum Extraction of Chlorinated Volatile Organics from Clay Bearing Sediments

Jarosch, T.R.; Looney, B.B.; Kasevich, R.S.; Faust, D.L.; Beleski, R.J.

Westinghouse Savannah River Company, Savannah River Technology Center, Aiken, SC; KAI Technologies, Inc., Woburn, MA; Eyring Corporation, Provo, UT;

Westinghouse Science and Technology Center, Pittsburgh, PA

CONF-9309146; Emerging Technologies in Hazardous Waste Management V, Proceedings of the Fifth American Chemical
Society Industrial and Engineering Chemistry Division Special Symposium, Atlanta, GA, September 27-29, 1993. American Chemical Society, Washington, DC, 903 pp.; (3 pp.) (1993)

A demonstration of in-situ radio frequency heating to enhance vacuum extraction of chlorinated volatile organics (primarily trichloroethylene and perchloroethylene) from shallow clay lenses was performed at the Savannah River Site (SRS) as part of the DOE Office of Technology Development's Integrated Demonstration. Data from previous characterization and remediation studies performed at the site show that residual solvents are preferentially retained in these clay rich zones. Conventional vacuum extraction techniques are mass transfer limited due to the low permeability of the clays (kaolinite). By heating the clays to temperatures at or above 100 degrees $C$, release of the residual solvents will be enhanced as a result of the higher vapor pressures, equilibrium shifts in adsorption, a potential increase in the permeability of the clays as water is removed, and the added effect of stream stripping from water vapor generated in-situ.

2705

V18/022677

Insitu Remediation of Soil Contaminated with Low Concentrations of Radionuclides

Entry, J.A.; Vance, N.C.; Hamilton, M.A.; Zabowski, D.

Auburn University, Department of Agronomy and Soils, Aubum, AL; U.S. Forest Service, Corvallis, OR; Idaho National Engineering Laboratory, Idaho Falls, ID; University of Washington, College of Forest Resources, Seattle, WA

CONF-941124; Insitu Remediation: Scientific Basis for Current and Future Technologies, G.W. Gee and N.R. Wing (eds.), Proceedings of the 33rd Hanford Symposium on Health and the Environment, Pasco, WA, November 7-11, 1994. Battelle Press, Columbus, OH, Part 2, 605 pp.; (pp. 1055-1066) (1994)

Since plants are known to take up and accumulate Cs-37 and Sr-90, removal of these radionuclides from contaminated soils by plants would provide a reliable and economical method of remediation. One approach is to use fast-growing, perennial plants combined with specific mycorrhizal fungi to maximize plant accumulation and removal of Cs-137 and Sr-90 from contaminated soils. The objective is to find a series of plants that can quickly accumulate and remove radionuclides from soils. Specific mycorrhizal fungi inocuiated onto plants should enhance the uptake of Cs-137 and Sr-90. Laboratory studies indicate that certain plants may be able to remove radionuclides, especially $\mathrm{Cs}-137$ and $\mathrm{Sr}-90$, from soil over a period of less than $10 \mathrm{yr}$. In addition, one could change the physical and chemical properties of the soil to enhance the availability of Cs-137 and Sr-90 to plants while decreasing the mobility of these radionuclides in soil. The above-ground portion of perennial plants would be harvested. High-temperature combustion would be used to oxidize plant material, concentrating $\mathrm{Cs}-137$ and $\mathrm{Sr}-90$ in ash for disposal. One of the many strengths of this method is its applicability to any terrestrial environment. Transportation of radionuciides from the site could be minimized through plant management, selection of plants that are less palatable to grazing animals, and fencing. Environmental conditions will change with each site; however, radionuclide accumulation could be accomplished by plants that are adapted to a wide spectrum of environmental conditions. There is no other practical and economic method to remove these radionuclides from the vast areas of land that have 
been contaminated by nuclear testing and nuclear reactor accidents.

2706

V18/022680

Insitu Vitrification: Large-Scale Results and Planned Applications for Site Remediation

McElroy, J.L.; Hansen, J.E.; Thompson, L.E.; Timmerman, C.L.

Geosafe Corporation, Richland, WA

CONF-941 124; Insitu Remediation: Scientific Basis for Current and Future Technologies, G.W. Gee and N.R. Wing (eds.), Proceedings of the 33rd Hanford Symposium on Health and the Environment, Pasco, WA, November 7-11, 1994. Battelle Press, Columbus, OH, Part 2, 605 pp.; (pp. 677-689) (1994)

Geosafe Corporation began commercial application of in-situ vitrification (ISV) during 1993. The first application is at the Parsons Chemical/ETM Enterprises Superfund Site (Parsons Site) in Grand Ledge, Michigan, which contained 4,800 tons of pesticideand mercury-contaminated soil. The effectiveness of the cleanup and overall performance of the ISV system will be presented. Projects in the US that will follow the Parsons project include: (1) soils associated with a former transformer service facility, which are contaminated with polychlorinated biphenyls; (2) a chemical packaging plant contaminated with dioxin, pesticides, and other chemicals; and (3) a contaminated landfill. The status and expected results of these projects is discussed. In Australia, ISV has been selected for in-place treatment of burial pits at the Maralinga Nuclear Weapons Test Site, which contains test debris and plutonium and uranium contamination. In Japan, a 3-yr engineering-scale testing program has been completed, in which the application of ISV for vitrifying a low-level-waste burial vault has been evaluated. This paper provides technical information showing that ISV can successfully remediate various contaminated sites if adequate site characterization and preparation are provided and small-scale ISV testing is utilized to understand the technical obstacles that must be dealt with in the field. The paper identifies the benefits of ISV for hazardous, radioactive and mixed-waste site remediation and criteria pertinent to such applications.

2707

V18/023407

Instrumental Basis Utilizing a Sodium Iodide Detector for Radioactive Soil Evaluations for Site Remediation

Davis, A.I.

Bechtel Hanford, Inc., Richland, WA

BHI-00885; 27 pp. (July 1996)

This document provides the design rational for using a 5.08 by 5.08 $\mathrm{cm}$ ( 2 by 2 in.) sodium iodide detector to aid in boundary mapping of the radioactive contaminated soils at the Hanford Site. The detector can provide adequate response to a homogeneously contaminated soil volume of at least 1.22 to $1.52 \mathrm{~m}$ in diameter and up to $45.7 \mathrm{~cm}$ deep. The gamma activity basis is described by a soil column in a right circular cylinder that is uniformly isotopic. The detection techniques and characteristics are used to define contaminated areas requiring excavation by locating regions where gamma activities exceed cleanup standards. To determine the areas and boundary of contamination, the boundary and adjacent surfaces will be mapped using the detector operated in a windowed gross-gamma mode.

2708

V18/025372

Intact Rhizosphere Microbial Communities Used to Study Microbial Biodegradation in Agricultural and Natural Soils, Chapter 5

Knaebel, D.B.; Vestal, J.R.

University of Idaho, Department of Bacteriology and Biochemistry, Moscow, ID; University of Cincinnati, Department of Biological Sciences, Cincinnati, OH

Bioremediation Through Rhizosphere Technology, T.A. Anderson and J.R. Coats (eds.), American Chemical Society, Washington, DC, 249 pp.; (pp. 56-69) (1994)

The rhizosphere has been shown to have a higher and more active microbial biomass than surrounding bulk soil. In agricultural and natural soils that harbor plants, this zone may affect the fate of organic chemicals in the soil. In this study corn and soybeans were grown in an agricultural soil and a woodlot soil; the experimental chambers were designed to contain the soil and roots, but exclude the above-ground plant biomass. Controis contained soils without plants. The biodegradation of several chemicals (anionic, cationic, and nonionic surfactants) was measured. The rhizosphere generally increased initial rates of mineralization, but the total amounts mineralized were not significantly different from controls. This implies that rhizosphere microbial communities metabolize foreign chemicals at greater rates than those in the bulk soil. Since the total amounts mineralized were the same as the controls, however, biodegradation of these chemicals in soils may be limited by other soil-chemical interactions.

2709

V18/023921

Integrated Bioremediation Route for Heavy Metal Contaminated Land Based on the Sulphur Cycle

Eccles, H.; Holroyd, C.P.; Humphreys, P.N.

British Nuclear Fuels pic, Preston, United Kingdom; British Nuclear Fuels plc, Warrington, Cheshire, United Kingdom

CONF-961018; Extraction and Processing for the Treatment and Minimization of Wastes, V. Ramachandran and C.C. Nesbitt (eds.), Proceedings of the Second International Symposium, Scottsdale, AZ, October 27-30, 1996. The Minerals, Metals, \& Materials Society, Warrendale, PA, 856 pp.; (pp. 833-844) (1996)

BNFL, an internationally acclaimed company noted for its nuclear fuel cycle services and waste management technologies, collaborated with Viridian BioProcessing Ltd, a small company acknowledged for developing environmental biological processes, and an intemationally recognised professor of biological sciences, to develop a unique bioremediation process for treating toxic, heavy metal contaminated land. This paper describes the process, with particular reference to the problem and scope of land contamination with toxic, heavy metals and the current available technologies. The process technologies are based on using indigenous, soil micro-organisms which can be stimulated to produce acid or sulphide ions to mobilise or precipitate the heavy metals respectively. Laboratory studies have indicated metal removal efficiencies of greater than $90 \%$ can be achieved, whilst recovery efficiencies from the metal loaded leachate are even higher at 
approximately $95 \%$.

2710

V18/023831

Integrated Cleanup of an ECRA Site Using Innovative Pneumatic Fracturing Extraction/Hot Gas Injection

Liskowitz, J.J.; Schuring, J.R.

Accutech Remedial Systems, Inc., Keyport, NJ; New Jersey Institute of Technology, Newark, NJ

CONF-9306269; HazMat '93 International, Proceedings of the Eleventh Annual Environmental Management and Technology Conference and Exhibition, Atlantic City, NJ, June 9-11, 1993. Advanstar Expositions, Glen Ellyn, II, 731 pp.; (pp. 383-387) (1993)

Soil Vapor Extraction (SVE) is a widely utilized process for the in-situ removal of volatile organic compounds from contaminated soils. The remedial effectiveness of the SVE technology is principally a function of: (1) the ability to circulate and extract sufficient volumes of air from the formation, and (2) the pathway of that air relative to the location of contaminants within the subsurface matrix. When applied in high permeability geologic formations such as sand and gravel, the mass removal rates and remedial efficiency for SVE and are very high. However, when the technology is applied at sites with low permeability geology such as silts, clay and fractured rock, very low air extraction volumes, very small vacuum radii of influences and slow contaminant mass removal cause the process to be severely limited in its effectiveness. An innovative process called Pneumatic Fracturing Extraction [SM], (PFE) [SM] was recently successfully demonstrated under the U.S. EPA Superfund Innovative Technology Evaluation (SITE) program at an NJDEPE Environmental Cleanup Responsibility Act (ECRA) site located in Somerville, New Jersey. The patented process, which is derived from the technique used to enhance oil deposit yields known as hydraulic fracturing, can be described as the injection of air into a formation to create fractures or subsurface pathways. Compressed air is injected into an isolated zone of a borehole at a flowrate which exceeds the formation permeability and at a pressure which exceeds the natural geologic stresses. The effect of Pneumatic Fracturing on sedimentary rock formations is graphically represented in Figure 1. As the media fails, the air and newly created fracture pathways propagate outward from the injection point. Once a network of fractures is created in the subsurface, the flow of liquids and/or vapors through the formation is greatly enhanced.

2711 V18/023889

Integrated Pneumatic Fracturing and Bioremediation for the Insitu Treatment of Contaminated Soil

Venkatraman, S.N.; Kosson, D.S.; Boland, T.M.; Schuring, J.R.; Frank, U.

Rutgers University, Department of Chemical and Biochemical Engineering, Piscataway, NJ; New Jersey Institute of Technology, Department of Civil and Environmental Engineering, Newark, NJ; U.S. Environmental Protection Agency, Releases Control, Edison, NJ

EPA/600/R-95/012; CONF-9504110; Proceedings of the 21st Annual Risk Reduction Engineering Laboratory (RREL) Research Symposium, Cincinnati, OH, April 4-6, 1995. U.S. Environmental
Protection Agency, Cincinnati, OH, 398 pp.; (pp. 329-332) (April 1995)

Insitu bioremediation is often limited by the rate of transport of nutrients and electron acceptors (e.g., oxygen, nitrate) to the microorganisms, particularly in soil formations with moderate to low permeability. An investigation was conducted to integrate the process of pneumatic fracturing with bioremediation to overcome these rate limitations. Pneumatic fracturing is an innovative technology which utilizes high pressure air to create artificial fractures in the contaminated geologic formations, resulting in enhanced air flow and transport rates in the subsurface. Following the fracturing, the pneumatic fracturing system can be used to inject electron acceptors and other biological supplements directly into the formations to stimulate biodegradation. A project to investigate the coupling of pneumatic fracturing and bioremediation was sponsored by the U.S. Environmental Protection Agency under the Superfund Innovative Technology Evaluation (SITE) Emerging

Technologies Program and an industrial sponsor. A field demonstration of the integrated technologies was carried out at a gasoline refinery site in Pennsylvania. The integrated technology was clearly shown to be an efficient process for removal of aromatic hydrocarbons such as benzene, toluene, and xylenes, especially in overconsolidated soils.

2712

V18/023892

Integrated Pneumatic Fracturing/Bioremediation for the Insitu Treatment of Contaminated Soil

Frank, U.; Schuring, J.R.

U.S. Environmental Protection Agency, Risk Reduction Engineering Laboratory, Edison, NJ; New Jersey Institute of Technology, Hazardous Substance Management Research Center, Newark, NJ

EPA/600/R-95/012; CONF-9504110; Proceedings of the 21st Annual Risk Reduction Engineering Laboratory (RREL) Research Symposium, Cincinnati, OH, April 4-6, 1995. U.S. Environmental Protection Agency, Cincinnati, OH, 398 pp.; (p. 379) (April 1995)

The objective of this project is to demonstrate that for low permeability soils, treatment by pneumatic fracturing to increase permeability will enhance bioremediation. For in-situ bioremediation to be successful in a timely manner, the microbial population must be stimulated by injecting nutrients and an oxygen source to the microbes. Normally, formations with low permeability make it extremely difficult to supply microbes with the necessary subsistence making bioremediation technically and economically infeasible. This project involves pneumatic fracturing of contaminated soils followed by biodegradation using indigenous or cultivated microbes. The soils under investigation are contaminated with benzene, toluene, and the xylenes (BTX) in concentrations ranging from $120-1500 \mathrm{mg} / \mathrm{kg}$ soil. The end point target of the remediation is a $95 \%$ reduction in the BTX concentration in the top five feet of the soil bed. The pneumatic fracturing process involves the injection of high pressure air at controlled flow rates and pressures in the zone of contaminated soil. In fine-grained, low permeability soils such as clay, this process creates conductive channels in the formation. The vapor movement in the formation becomes convection and diffusion-controlled instead of just diffusion-controlled. This increases the permeability and the exposed surface area of the soil, facilitating the treatment and 
removal of contaminants. Pneumatic fracturing is also used to enhance stacked aerobic, denitrifying and methanogenic microbial processes in staggered spatial distribution for maximum effectiveness. Aerobic processes will dominate at the fracture interfaces, and to a limited distance, into the soil away from the fracture. Depletion of oxygen during aerobic biodegradation will allow the formation of a denitrifying zone a short distance away from the fracture. Depletion of nitrate by denitrifying biodegradation processes allows the formation of methanogenic populations at greater distances from the fractures. During methanogenic processes, methane will be generated and diffuse out with the fracture sweep air. Resuits of pilot-scale testing will be presented. (Complete text).

\section{3}

V18/023862

Integrated System for Treating Soil Contaminated with Wood Treating Wastes

Acheson, C.M.; Brenner, R.C.; Khodadoust, A.P.; Wilson, G.W.; Miller, K.M.; Suidan, M.T.

U.S. Environmental Protection Agency, Risk Reduction Engineering Laboratory, Cincinnati, OH; University of Cincinnati, Department of Civil and Environmental Engineering, Cincinnati, $\mathrm{OH}$

EPA/600/R-95/012; CONF-9504110; Proceedings of the 21st Annual Risk Reduction Engineering Laboratory (RREL) Research Symposium, Cincinnati, OH, April 4-6, 1995. U.S. Environmental Protection Agency, Cincinnati, OH, 398 pp.; (pp. 45-48) (April 1995)

Approximately $20 \%$ of the hazardous waste sites undergoing bioremediation are contaminated with wood treating wastes, primarily compounds such as pentachlorophenol (PCP), creosote, polycyclic aromatic hydrocarbons (PAHs), and other hydrocarbons. A process that combines soil washing with sequential anaerobic and aerobic biotreatment is being integrated to remediate soil contaminated with these wood treating wastes. By extracting the target compound from the soil, soil washing facilitates degradation by mobilizing the target compound and expanding the range of feasible remediation technologies. Additional flexibility is possible since soil washing can be conducted in an in-situ or exsitu format. In this process, the wash solution is initially bioremediated in an anaerobic environment. Mineralization of the target compound is completed aerobically. Based on preliminary results, the integrated process could meet the target cleanup level for PCP in approximately $45 \%$ of the bioremediation sites. Process development began by independently evaluating soil washing and target compound degradation. PCP contaminated soils were the initial focus, but this work is currently being extended to include soils contaminated with both PCP and PAHs. In addition, based on promising results from the soil washing and degradation evaluations, these individual unit operations are being integrated to form a complete process to remediate soils contaminated with wood treating wastes. This complete process incorporates soil washing, soil wash solution recycling, and biodegradation of the target compounds.
Lesley, M.P.; Rangan, C.R.

State of Delaware, Department of Natural Resources and Environmental Control, Underground Storage Tank Branch, New Castle, DE

CONF-960393 (Part 2); Contaminated Soils and Groundwater: Analysis, Fate, Environmental and Public Health Effects, and Remediation, Proceedings of the Sixth Annual West Coast Conference, Newport Beach, CA, March 11-14, 1996. Association for the Environmental Health of Soils, Amherst, MA, Part 2, 226 pp.; (p. 24) (1996)

A prototype integrated soil vacuum extraction/biofiltration system has been designed and installed at a gasoline contaminated leaking underground storage tank (LUST) site in southern Delaware. The prototype system remediates contaminated moisture entrained in the air stream, employs automatic water level controls in the filters, and achieves maximum vapor extraction and VOC destruction efficiency with an optimum power input. In addition, the valving and piping layout allows the direction of air flow through the filters to be reversed at a given time interval, which minimizes biofouling, thereby increasing efficiency by minimizing the need for frequent cleaning. This integrated system achieves constant VOC destruction rates of $40 \%$ to $70 \%$ while maintaining optimal VOC removal rates from the subsurface. The modular design allows for easy mobilization, setup and demobilization at state-lead LUST sites throughout Delaware.

2715

V18/023475

Interactions Between Soil Fractions and Polynuclear Aromatic Hydrocarbon (PAH) Compounds in Thermal Desorption of Contaminated Soils

Mehrotra, A.K.; Svrcek, W.Y.; Maguire, V.

University of Calgary, Alberta, Canada; Amoco Canada Petroleum Company, Limited, Calgary, Canada

CONF-960730 (Vol. 3); Technologies Critical to a Changing World, Volume III: Emerging Energy Technologies, Clean Technologies, Remediation and Emission Control Fuels, and Petrochemicals, Proceedings of the Fifth World Congress of Chemical Engineering, San Diego, CA, July 14-18, 1996. American Institute of Chemical Engineers, New York, NY, Vol. 3, 1118 pp.; (pp. 570-575) (1996)

Results are reported for the interactions between three fractions of a soil, namely fulvic acid (FA), humic acid (HA), and humic/inorganic fractions, and three polynuclear aromatic hydrocarbons (PAHs). Prepared PAH+soil fraction mixtures, with 0.8-7.0 mass\% $\mathrm{PAH}$, were tested using a differential scanning calorimeter (DSC) over a temperature range of 20-390 degrees C. The DSC resuits for the PAH+HA mixtures showed distinctly different characteristics than the other two soil fractions, where the endothermic peak for the vaporization of the PAH was absent. With the aid of flash caiculations, the absence of the vaporization peak is interpreted to be due to the liquid-phase miscibility of the PAHs and the HA fraction. The miscible behavior of $\mathrm{HA}+\mathrm{PAHS}$ implies that the temperature necessary for complete removal of a PAH would be higher than its boiling point temperature.

V18/022494

International Applications Status of Insitu Vitrification 
on Mixed TRU and LLW Buried Wastes

Thompson, L.E.; McElroy, J.L.; Timmerman, C.L.

Geosafe Corporation, Richland, WA

CONF-950877; Mixed Waste, A.A. Moghissi, B.R. Love and R.K. Blauvelt (eds.), Proceedings of the Third Biennial Symposium, Baltimore, MD, August 7-10, 1995, 545 pp.; (pp. 5.1.1-5.1.9)

(1995)

In Situ Vitrification (ISV) is an electric thermal treatment process for contaminated soils. Electrodes are inserted into the ground and soils are heated to a molten state. Upon cooling, a vitrified product is formed that is highly durable, consisting of a mixture of glass and crystalline phases. In addition to Geosafe's full-scale commercial ISV operations that are on-going on the U.S. on hazardous waste sites, Geosafe is proceeding with the evaluation of the ISV process for international applications on mixed transuranic (TRU) and low level waste (LLW) buried waste sites in Australia and on other nuclear applications in Japan. This paper provides an overview of the ISV process and the full-scale U.S. commercial operations followed by a discussion of Australian and Japanese applications. Small- and intermediate-scale ISV test results will be summarized and application plans described.

2717

V18/023037

Investigation and Remediation of Oil Hazardous Substance Contamination: An Approach for Electric Power Companies

Staker, R.D.

CONF-951208; Power-Gen America '95, Book II: Environmental Issues, Proceedings of a Power Generation Conference, Anaheim CA, December 5-7, 1995. PennWell Conferences and Exhibitions, Houston, TX, 436 pp.; (pp. 69-73) (1995)

Oil, other petroleum hydrocarbons and hazardous substances are present at most electric power company sites. Sites include power generating plants, service centers, substations, and landfills owned or used by electric power companies. Substances present at many of these types of sites include petroleum lubricants and fiels, solvents, acids, caustics, mercury, lead based paint, asbestos and other materials that are detrimental to human health and the environment. If there are spills, leaks, or improper disposal of these substances which contaminate a site, state and federal environmental regulation require investigation and remediation or cleanup of soil, water, concrete or other materials contaminated with the substances. Certain procedures should be followed during the investigation and cleanup. Failure to do so could result in additional effort and cost to reperform the investigations to satisfy regulators and could result in significant fines. This paper discusses an approach electric power companies can use to investigate and remediate contaminated sites.

\section{8}

\section{V18/020637}

Investigation of Possibilities of Electrokinetic Method for Soils and Waters Decontamination

D'yakov, A.A.; Rostovtsev, V.Y.; Mikhajlovskaya, L.N.; Makhov, V.A.

Gosudarstvennyj Komitet po Ispol'zovaniyu Atomnoj Ehnergii SSSR, Fiziko-Ehnergeticheskij Institut, Obninsk,
Russian Federation

INIS-RU-417; CONF-9310457 (Vol. 2); Radioecological Problems in Nuclear Energetics and in Industry Conversion, Proceedings of Mendeleev's 15th Meeting on General and Applied Chemistry, Obninsk, Russian Federation, October 1993, Vol. 2, 202 pp.; (pp. 47-48) (1993)

Short communication. No abstract available. (This document is in Russian).

2719 $\mathrm{V} 18 / 024318$

Investigation of Remediation of Soil Contaminated with Diesel Fuel Using Air Venting

Fotinich, A.; Joo, Y.; Dhir, V.K.

University of California, Mechanical and Aerospace Engineering Department, Los Angeles, CA

CONF-961105 (Vol. 4); Proceedings of an American Society of Mechanical Engineers (ASME) Heat Transfer Division 1996 Intemational Mechanical Engineering Congress and Exhibition: Natural Convection Within a Horizontal Circular Cylinder Heated from Below and Cooled from Above, Numerical Methods for Coupled Fluid-Thermal-Structural Interaction, Thermal Analysis in Waste Processing and Disposal, Heat Transfer in Fire and Combustion Systems, D.W. Pepper, R.W. Douglass and J.C. Heinrich (eds.), Atlanta, GA, November 17-22, 1996. ASME, New York, NY, Vol. 4, 443 pp.; (pp. 113-119) (1996)

Soil venting is an effective and widely used method to remediate hydrocarbon contaminated soils. A non-isothermal model, proposed by Lingineni and Dhir (1992) to predict evaporation rates of organic contaminants in an unsaturated non-sorbing soil, was incorporated into a computer code capable of numerically analyzing multi-component diesel fuel. The program accounts for 14 major components of diesel fuel as well as for temperature variation due to evaporation of the contaminant, preheating of the venting air, and heat loss. Experiments to verify the model performance were conducted in a one-dimensional column. Temperature readings from thermocouples located in the test section were recorded during the experiment and the composition of hydrocarbons in the effluent air was also monitored. The effluent gas samples were extracted at the selected times and analyzed with the help of a gas chromatograph. The experimental temperature readings and vapor composition in the extracted samples are in general agreement with the predictions from the computer program. The results show that the diesel components are removed according to their volatility with the higher volatility components being removed first. It is also found that preheating of the venting air can significantly increase the removal rates of the components.

2720

V18/024652

Investigation of Soil Venting-Based Remediation at a UST Site in the Appalachian Piedmont

Widdowson, M.A.; Ray, R.P.; Reeves, H.W.; Aelion, C.M.; Holbrooks, K.D.

Virginia Polytechnic Institute and State University, Department of Civil Engineering, Blacksburg, VA; University of South Carolina, Department of Civil Engineering, Columbia, SC; University of South Carolina, Department of 
Geological Science, Columbia, SC; University of South Carolina, Department of Environmental Health Sciences, Columbia, SC

Bioremediation of Pollutants in Soil and Water, B.S. Schepart (ed.), Proceedings of a Symposium, Fort Worth, TX, October 14-15, 1993. American Society for Testing and Materials (ASTM), Philadelphia, PA, 265 pp.; (pp. 135-148) (May 1995)

The feasibility and effectiveness of soil vapor extraction (SVE)-based remediation technologies is being addressed at a petroleum-contaminated site in the Piedmont region of South Carolina through a multi-disciplinary research program. The program objective is to gain better understanding of mechanisms governing remediation of contaminated soil by SVE-based techniques. Baseline data collection of physical, chemical, and microbial properties is augmented by mathematical modeling of the processes. A pilot-scale remediation system has been designed to allow evaluation of SVE-based systems within Piedmont materials. System off-gas and soil vapor will be monitored to delineate which physical and microbial treatment processes contribute to in situ VOC removal.

\section{1}

V18/025458

Investigations of Enzymatic Alterations of 2,4-Dichlorophenol Using 13C-Nuclear Magnetic Resonance in Combination with Site-Specific 13C-Labeling: Understanding the Environmental Fate of this Pollutant

Nanny, M.A.; Bortiatynski, J.M.; Tien, M.; Hatcher, P.G. Pennsylvania State University, University Park, PA CONF-9504283; Proceedings of a Department of Defense Tri-Service Workshop on Bioavailability of Organic Contaminants in Soils and Sediments, Monterey, CA, April 9-12, 1995; Environmental Toxicology and Chemistry 15(11):1857-1864 (November 1996)

The biodegradation of 13C-labeled 2,4-dichlorophenol (DCP labeled at the $C-2$ and $C-6$ positions) in the presence and absence of natural organic matter (NOM) by the white-rot fungus Phanerochaete chrysosporium, was examined using $13 \mathrm{C}$-nuclear magnetic resonance (NMR). Using this method permitted the chemistry occurring at or near the labeled site to be followed. The formation of alkyl ethers and alkene ethers was observed. No aromatic by-products were detected, indicating that aromatic compounds are quickly degraded. Examining the reaction with time shows the exponential removal of 2,4-DCP and the consequential formation of labeled by-products, whose concentration reaches a maximum just before all 2,4-DCP is consumed. After this, the by-products degrade exponentially. The presence of NOM causes 2,4-DCP to be removed from the aqueous phase more quickly than in its absence and also causes the by-products to reach their maximum concentration much earlier. Degradation of the by-products occurs at a much greater rate in the presence of NOM. One hypothesis for this behavior is that the NOM interacts with 2,4-DCP and its by-products, allowing them to be incorporated into the fungal biomass. 13C-nuclear magnetic resonance spectra of the fungal biomass after $\mathrm{NaOH}$ extraction show the presence of alkanes and a small amount of 2,4-DCP.

\section{2}

V18/023865

Iron Enhanced Abiotic Degradation of Chlorinated Hydrocarbons

Chen, C.T.

\section{U.S. Environmental Protection Agency, Edison, NJ}

EPA/600/R-95/012; CONF-9504110; Proceedings of the 21st Annual Risk Reduction Engineering Laboratory (RREL) Research Symposium, Cincinnati, OH, April 4-6, 1995. U.S. Environmental Protection Agency, Cincinnati, OH, 398 pp.; (pp. 74-78) (April 1995)

Since the 1970 s, several researchers have investigated the ability of certain zero-valent metals or alloys to enhance the degradation of halogenated organic compounds in contaminated water. Iron, zinc, aluminum, brass, copper, and stainless steel have been studied at various times with varying degrees of success. Gillham and O'Hannesin have recently made a literature review and conducted tests on 14 halogenated aliphatic compounds using zero-valent iron as an enhancing agent. The results showed that rapid dehalogenation occurred on all of the compounds tested except dichloromethane. Based on these tests results, EnviroMetal Technologies, Inc. proposed to remediate groundwater contaminated with chlorinated organic compounds using this technology. The EPA Superfund Innovative Technology Evaluation (SITE) program has accepted this technology for demonstration. This demonstration project will include two processes, above ground reactor and in situ permeable wall. The demonstration on the above ground reactor is being conducted at a site in Wayne, New Jersey. The main contaminants at this site are tetrachloroethene (PCE) and trichloroethene (TCE). The in situ permeable wall process will be conducted at a site in 4 upstate New York. This site is a shallow sand aquifer containing TCE, dichloroethenes, and 1,1,1-trichloroethane. Before the site demonstrations, laboratory experiments were conducted on the contaminated groundwater to evaluate the efficiency of the process under simulated site conditions. These experiments and the above-ground reactor demonstration are described in this paper.

2723 V18/025471

Iron-Phosphate-Based Chemically Bonded Phosphate Ceramics for Mixed Waste Stabilization

Wagh, A.S.; Jeong, S.Y.; Singh, D.

Argonne National Laboratory, Argonne, $I L$

ANL/ET/CP-91088; CONF-970335; Waste Management '97: Working Towards a Cleaner Environment, Proceedings of a Conference on HLW, LLW, Mixed Wastes and Environmental Restoration, Tucson, AZ, March 2-6, 1997; (10 pp.) (1997)

In an effort to develop chemically bonded phosphate ceramics for mixed waste stabilization, a collaborative project to develop iron-phosphate based ceramics has been initiated between Argonne National Laboratory and the V. G. Khlopin Radium Institute in St. Petersburg, Russia. The starter powders are oxides of iron that are generated as inexpensive byproduct materials in the iron and steel industry. They contain iron oxides as a mixture of magnetite (Fe3O4) and haematite (Fe2O3). In this initial phase of this project, both of these compounds were investigated independently. Each was reacted with phosphoric acid solution to form iron phosphate ceramics. In the case of magnetite, the reaction was 
rapid. Adding ash as the waste component containing hazardous contaminants resulted in a dense and hard ceramic rich in glassy phase. On the other hand, the reaction of phosphoric acid solution with a mixture of haematite and ash waste contaminated with cesium and americium was too slow. Samples had to be molded under pressure. They were cured for 2-3 weeks and then hardened by heating at 350 degrees $C$ for $3 \mathrm{~h}$. The resulting ceramics in both cases were subjected to physical tests for measurement of density, open porosity, compression strength, phase analyses using X-ray diffraction and differential thermal analysis, and leaching tests using toxicity characteristic leaching procedure (TCLP) and ANS 16.1 with 7 days of leaching. Using the preliminary information obtained from these tests, these materials were evaluated for stabilization of Department of Energy's mixed waste streams.

\section{4}

\section{V18/020971}

\section{Isotopic Analysis of Uranium in Contaminated Soils by} Gamma Ray Spectroscopy

\section{McHugh, J.A.}

Hilbert Associates, Inc., Saratoga Springs, NY

CONF-960212; Waste Management '96: Working Towards a Cleaner Environment, Proceedings of a Conference on HLW, LLW, Mixed Wastes and Environmental Restoration, Tucson, AZ, February 25-29, 1996; (13 pp.) (1996)

The total uranium radioactivity concentration $(\mathrm{Bq} / \mathrm{g})$ of soils contaminated with enriched uranium can be determined by gamma ray spectroscopy, as opposed to alpha spectroscopy. The gamma spectroscopy method saves considerable time and reduces expenses associated with site characterization and remedial activities. Uranium 234 is the dominant contributor to the radioactivity of enriched uranium (e.g. the U-234 represents greater than $90 \%$ of the total uranium radioactivity for uranium at 6 weight percent U-235). Since U-234 is an alpha emitter with no practical gamma yield, alpha spectroscopy is the usual method of choice for the analysis and characterization of soils contaminated with enriched uranium. However, gamma spectroscopy can be used to determine the U-234 concentration (or the total uranium concentration) by using the fact that the U-234/U-235 ratio is nearly invariant for a particular uranium contaminant source. This fact, coupled with accurate U-235 and U-238 measurements by gamma ray spectroscopy, provides a method that meets the site specific remedial investigation sensitivity, accuracy and sample analysis tum-around time requirements. The gamma spectroscopy method is nondestructive, fast, and reliable. A sample turn-around time of 10 minutes can be achieved for a U-234 minimum detectable concentration (MDC) of $0.12 \mathrm{~Bq} / \mathrm{g}$ ( $3.4 \mathrm{pCi} / \mathrm{g})$ at a $95 \%$ confidence level. A range of uranium contamination levels and contaminant enrichments were encountered in this study: uranium concentrations of 0.03 to $20 \mathrm{~Bq} / \mathrm{g}$ ( 1 to $540 \mathrm{pCi} / \mathrm{g}$ ), and enrichment levels to 6 weight percent $U-235$. The accuracy and success of the method is dependent on the use of uranium calibration standards (as opposed to multinuclide gamma standards), and applying all appropriate gamma emission interference corrections. The methodology was validated by comparing 45 soil gamma spectroscopy analysis results with the alpha spectroscopy results performed on the same set of samples.

\section{Kinetics of Metal Leaching from Heavy Metal Contaminated Soils}

Van Benschoten, J.E.; Ganguly, C.; Matsumoto, M.R.

State University of New York at Buffalo, Buffalo, NY; University of Califomia, College of Engineering, Riverside, CA

EPA/600/R-95/012; CONF-9504110; Proceedings of the 21st Annual Risk Reduction Engineering Laboratory (RREL) Research Symposium, Cincinnati, OH, April 4-6, 1995. U.S. Environmental Protection Agency, Cincinnati, OH, 398 pp.; (pp. 338-343) (April 1995)

The evaluation of the rate and extent of heavy metal leaching from contaminated real waste site soils is an important aspect in the design of soil washing processes. Although the technology of soil washing is well established in Europe, until recently it had been demonstrated only on a pilot scale in the United States. In January 1992, the first full scale soil washing system in the United States started operation at the King of Prussia Technical Corporation Superfund site at Winslow Township, New Jersey. Of the 498 Records of Decision published in 1991, only 18 specified soil washing as the primary remediation technology. Currently, models that may yield design information are not available and the soil washing technology is at an empirical level of development. The goal of this project was to develop a deterministic model to describe the kinetics of metal leaching from contaminated soils. Specific objectives of the project were to: (1) experimentally measure leaching kinetics under acidic conditions from real waste site soils, (2) determine through numerical simulation the fate and interactions of the various contaminant phases during the washing process, and (3) identify the rate controlling steps and gain insight into design and operational aspects of the washing process. The focus of the study was on $\mathrm{Pb}$ contaminates soils. The model that was developed matched experimental leaching data well, but some improvements remain to be made.

\section{6 \\ V18/025279}

Kwajalein Bioremediation Demonstration: Final Technical Report

Walker, J.F., Jr.; Walker, A.B.

Oak Ridge National Laboratory, Oak Ridge, TN

ORNL/TM-12871; 205 pp. (December 1994)

The U.S. Army Kwajalein Atoll (USAKA) Base, located in the Republic of the Marshall Islands (RMI) in the east-central Pacific Ocean, has significant petroleum hydrocarbon contamination resulting from years of military activities. Because of its remoteness, the lack of on-site sophisticated remediation or waste disposal facilities, the amenability of petroleum hydrocarbons to biodegradation, and the year-round temperature favorable for microbial activity, USAKA requested, through the Hazardous Waste Remedial Actions Program (HAZWRAP), that a project be conducted to evaluate the feasibility of using bioremediation for environmental restoration of contaminated sites within the atoll. The project was conducted in four distinct phases: (1) initial site characterization and on-site biotreatability studies, (2) selection of the demonstration area and collection of soil columns, (3) laboratory column biotreatability studies, and (4) an on-site bioremediation demonstration. The results of phases (1) and (3) 
have been detailed in previous reports. This report summarizes the results of phases (1) and (3) and presents phases (2) and (4) in detail. A short documentary video that highlights the approach, the field activities on Kwajalein Island, and the results is available.

2727

V18/022649

LRAD Soil Surface Contamination Monitor Test and Demonstration at the Savannah River Site

Sigg, R.A.; Hochel, R.C.

Westinghouse Savannah River Company, Aiken, SC

WSRC-RP-95-911; 18 pp. (September 1995)

The Savannah River Site (SRS) Solid Waste Management (SWM) organization requested Savannah River Technology Center (SRTC)/Analytical Development Section (ADS) assistance in evaluating a Long Range Alpha Detector (LRAD) as a soil surface contamination monitor. Solid Waste Management also contracted TMA NcClean to bring the equipment to SRS and to operate it during the demonstration. For the demonstration, we measured LRAD signals above different surface materials including asphalt, concrete, clay soil, sandy soil, gravel, and a plywood sheet. This report describes the tests conducted at SRTC in the period August 22, 1995 through August 24, 1995. In order to put the data that were acquired in these tests in perspective, the physical principals on which LRAD is based are discussed.

\section{8}

\section{V18/020638}

Laboratory Analysis of Soil Hydraulic Properties of TA-49 Soil Samples: Volume I - Report Summary

Los Alamos National Laboratory, Los Alamos, NM; Daniel B. Stephens \& Associates, Inc., Albuquerque, NM

LA-SUB-96-77 (Vol. 1); 62 pp. (April 1995)

The Hydrologic Testing Laboratory at Daniel B. Stephens Associates, Inc. (DBS A) has completed laboratory tests on TA-49 soil samples as specified by Mr. Daniel A. James. The specifications and results are compiled into tables. Raw laboratory data and graphical plots of data (where appropriate) are contained in Appendices $A$ through $\mathrm{K}$. Appendix $\mathrm{L}$ lists the methods used in these analyses. Methods used to calculate thermal properties are covered in detail in Appendix K. Typically, soil thermal conductivities are determined using empirical fitting parameters (five in this case), Some assumptions are also made in the equations used to reduce the raw data. In addition to the requested thermal property measurements, calculated values are also presented as the best available internal check on data quality. For both thermal conductivities and specific heats, calculated and measured values are consistent and the functions often cross. Interestingly, measured thermal conductivities tend to be higher than calculated thermal conductivities around typically encountered in situ moisture contents (plus or minus 5 percent). While an explanation of the difference is not ventured sensitivity testing of any problem requiring nonisothermal modeling across this range is in order.

2729

V18/024761

Laboratory Biotreatability Studies, Chapter 4

Skladany, G.J.; Baker, K.H.

Envirogen, Inc., Lawrenceville, NJ; Environmental
Microbiology Associates, Inc., Harrisburg, PA

Bioremediation, K.H. Baker and D.S. Herson (eds.), McGraw-Hill, Inc., New York, NY, 404 pp.; (pp. 97-172) (1994)

This is a chapter from the book titled, Bioremediation. The biotreatability laboratory serves a variety of purposes when dealing with pollution prevention and hazardous waste-site remediation projects. Both fundamental and complex questions regarding the suitability of using large-scale biological processes are frequently asked by those directly responsible for the project, as well as supporting hazardous waste professional and regulatory personnel. These questions include: (1) Are the contaminants biodegradable? (2) Are indigenous microorganisms suitable for the task? (3) How fast will the chemicals by destroyed? (4) What final contaminant concentrations are attainable? (5) Are any hazardous by-products produced? (6) What are the optimal growth conditions for the appropriate microorganisms? and (7) What bioreactor design (above ground or in situ) is optimal for the application? In many cases, biotreatability studies can be used to provide answers to these and other questions.

\section{0}

\section{V18/025594}

Laboratory-Scale Study of Supercritical Fluid Extraction for Large Scale Soil Remediation

Silver, W.; Bhat, N.; Rahme, Z.; Secker, L.; Gray, D.; Zytner, $\mathrm{R}$.

Guelph University, Ontario, Canada; Department of the Environment, Environmental Protection Service, Ottawa, Ontario, Canada

CONF-951086; Proceedings of the Fifth Annual Symposium on Groundwater and Soil Remediation, Toronto, Ontario, Canada, October 2-6, 1995. Environment Canada - Environmental Protection Service, Hull, Quebec, Canada, 566 pp.; (pp. 479-481) (1995)

The use of supercritical fluid extraction for analytical chemistry applications demonstrates that it is technically feasible to remove organic contaminants from a variety of solid matrices, assuming favorable thermodynamic and kinetic parameters. Results of laboratory scale measurements of these parameters utilizing packed columns of soil contaminated with naphthalene are discussed. The effect of supercritical fluid extraction treatment on the microbial population of the soil was also measured. The reduction in population for loamy sand was 10 per cent, for silt loam it was 75 per cent, however, survivors included both spore-forming and non-spore-forming species.

\section{$2731 \quad$ V18/025384}

Land Remediation Using Gentle Technologies

Holmes, R.G.G.; Eccles, H.; Smart, N.G.; Dam, A.S.

British Nuclear Fuels plc, Seascale, Cumbria, United Kingdom; BNFL, Inc., Fairfax, VA

CONF-970335; Waste Management '97: Working Towards a Cleaner Environment, Proceedings of a Conference on HLW, LLW, Mixed Wastes and Environmental Restoration, Tucson, AZ, March 2-6, 1997; (2 pp.) (1997)

Restoration of contaminated land, either contaminated with toxic or hazardous materials, heavy metals or radionuclides, or indeed 
both remains a significant challenge. There are a number of technologies available that though successful in restoring land often utilize extreme conditions that may denature the soils e.g., high temperatures. British Nuclear Fuels plc in conjunction with a number of collaborators have attempted to develop or utilize technologies that avoid denaturing the land thereby avoiding additional concerns about the fate of the remediated soil. Two example technologies are presented to illustrate this approach, there are supercritical fluid extraction and bioremediation. At present these technologies are rapidly approaching deployment and the results of the projects to date are discussed.

\section{2 \\ V18/022239}

Landfarming of Phthalate Ester-Contaminated Soil: Two Years of Bioremediation Results

Kunze, C.M.; Yu, J.; Wilson, S.; Rezin, J.L.; Adronico, A.

Biorem Technologies, Inc., Waterloo, Ontario, Canada; O'Sullivan Corporation, Winchester, VA; Roy F. Weston, Inc., Wilmington, $\mathrm{MA}$

CONF-951139 (Vol. 2); Superfund 16: Proceedings of a Hazardous Waste Conference and Exhibition, Washington, DC, November 6-8, 1995. E.J. Krause and Associates, Bethesda, MD, Vol. 2, 817 pp.; (pp. 1063-1069) (1994)

Biorem Technologies Inc. collaborated with Regalite Plastics Corporation over 2 years to clean up approximately 600 cubic yards of soil contaminated with di-2-ethylhexyl phthalate ester (DEHP) and \#2 fuel oil using a landfarming bioremediation process. The contaminated soils consisted of sandy backfill material which had been excavated during the removal of two underground storage tanks (USTs). In 1994, the initial average DEHP concentration was 4,551 ppm while the TPH concentration was 7,252 ppm. In 1995, the initial DEHP concentration was $1067 \mathrm{ppm}$ while TPH was $3,733 \mathrm{ppm}$. Prior to the implementation of the project, Biorem Technologies completed a laboratory biofeasibility study to demonstrate that a bacterial culture isolated from the site had the capacity to efficiently degrade DEHP in the soil. It was determined during this study that nitrogen and phosphorus nutrient amendments were needed to promote the bioremediation process.

\section{3 \\ V18/022724}

\section{Landfill Covers for Dry Environments}

Dwyer, S.F.

Sandia National Laboratories, Albuquerque, NM

CONF-960804 (Vol. 1); Spectrum '96: Nuclear and Hazardous Waste Management, Proceedings of an International Topical Meeting, Seattle, WA, August 18-23, 1996. American Nuclear Society, La Grange Park, IL, Vol. 1, 887 pp.; (pp. 411-417) (1996)

A. large-scale landfill cover field test is currently underway at Sandia National Laboratories in Albuquerque, New Mexico. It is intended to compare and document the performance of alternative landfill cover technologies of various costs and complexities for interim stabilization and/or final closure of landfills in arid and semi-arid environments. Test plots of traditional designs recommended by the US Environmental Protection Agency for both RCRA Subtitle ' $C$ ' and ' $D$ ' regulated facilities have been constructed side-by-side with the altemative covers and will serve as baselines for comparison to these alternative covers. The alternative covers were designed specifically for dry environments. The covers will be tested under both ambient and stressed conditions. All covers have been instrumented to measure water balance variables and soil temperature. An on-site weather station records all pertinent climatological data. A key to acceptance of an altemative environmental technology is seeking regulatory acceptance and eventual permitting. The lack of acceptance by regulatory agencies is a significant barrier to development and implementation of innovative cover technologies. Much of the effort on this demonstration has been toward gaining regulatory and public acceptance.

\section{4}

\section{V18/022205}

Lasagna [TM] Soil Remediation

Science Applications International Corporation, Gaithersburg, MD

DOE/EM-0308; 19 pp. (April 1996)

Lasagna [TM] is an integrated, in-situ remediation technology being developed which remediates soils and soil pore water contaminated with soluble organic compounds. Lasagna [TM] is especially suited to sites with low permeability soils where electroosmosis can move water faster and more uniformly than hydraulic methods, with very low power consumption. The process uses electrokinetics to move contaminants in soil pore water into treatment zones where the contaminants can be captured and decomposed. Initial focus is on trichloroethylene (TCE), a major contaminant at many DOE and industrial sites. Both vertical and horizontal configurations have been conceptualized, but fieldwork to date is more advanced for the vertical configuration. Major features of the technology are electrodes energized by direct current, which causes water and soluble contaminants to move into or through the treatment layers and also heats the soil; treatment zones containing reagents that decompose the soluble organic contaminants or adsorb contaminants for immobilization or subsequent removal and disposal; and a water management system that recycles the water that accumulates at the cathode (high $\mathrm{pH}$ ) back to the anode (low $\mathrm{pH}$ ) for acid-base neutralization. Alternatively, electrode polarity can be reversed periodically to reverse electroosmotic flow and neutralize $\mathrm{pH}$.

\section{$2735 \quad$ V18/022049}

Laser-Induced Fluorescence Analysis of PAC-Doped Model Oils on Alumina, Sand and Soil Surfaces

Roch, T.; Loehmannsroeben, H.G.; Meyer, T.

Institut fuer Physikalische und Theoretische Chemie, Braunschweig, Germany

CONF-9506232; Environmental Monitoring and Hazardous Waste Site Remediation, T. Vo-Dinh and R. Niessner (eds.), Proceedings of a Conference of the Society of Photo-Optical Instrumentation Engineers, Munich, Germany, June 19-23, 1995. International Society for Optical Engineering, Bellingham, WA, 613 pp.; (pp. 453-467) (1995)

From the fluorescence analysis of PAC-doped model oils on alumina, quartz sand and soil surfaces IIF intensity/concentration-relationships (calibration curves) were obtained. It was found that LIF measurements directly from soil 
surfaces allow the in-situ analysis of PAC contaminations in environmentally relevant concentration ranges. However, the LIF signals measured cannot directly be related to photophysical parameters of the PAC in solution. Also reported are results of preliminary investigations of the long-term behavior and the depth profile of perylene or fluoranthene LIF signals from surfaces reflecting mass transport and sorption processes.

\section{6}

V18/025600

Lead-Phase Determination and Demonstration of Contaminated Soil Remediation Mechanism by Scanning Electron Microscopy and Characteristic X-Ray Imaging

Vander Wood, T.B.

MVA, Inc., Norcross, GA

CONF-960877; Microscopy and Microanalysis 1996, G.W. Bailey, J.M. Corbett, RV.W. Dimlich, J.R. Michael and N.J. Zaluzec (eds.), Proceedings of a Conference, Minneapolis, $M \mathbb{N}$, August 11-15, 1996. San Francisco Press, Inc., San Francisco, CA, 1107 pp.; (pp. 514-515) (1996)

In the present study, samples of a lead contaminated soil before and after treatment with a proposed remediation technology were examined by scanning electron microscopy/energy dispersive $x$-ray spectrometry (SEM/EDS). The technique included the use of characteristic $\mathrm{X}$-rays to produces $\mathrm{X}$-ray images of elemental distributions within the samples. In this soil, lead occurred primarily as lead metal and lead oxide. No noticeable phosphate formation had taken place and there was no evidence for lead dissolution and reprecipitation as rims or rinds on other particles. This soil was then mixed with a treatment whose principal active component was phosphoric acid, with a resulting dramatic decrease in lead occurring in leaching solutions. Microscopic examination of the treated soil showed extensive formation of lead phosphate rims on the lead metal and lead oxide grains, suggesting incongruent alteration of the lead rich particles. No evidence for congruent alteration (e.g., lead phosphate rich rims on non-lead bearing grains) was observed. Selected area electron diffraction of the rim of a representative treated grain identified the lead rich phase as pyromorphite. The occurrence of incongruent alteration rims on lead-rich grains indicates that the principal mechanism of remediation is encapsulation rather than complete reaction of a soluble form.

\section{7 \\ V18/021989}

\section{Leaded Soil Extraction Using Hydrogen Peroxide and pH} Control

Reimers, R.S.; Murray, N.K.; Baldwin, P.N., Jr.

Tulane University, New Orleans, LA; ICFL, Inc., Las Vegas, NV

CONF-9509139; Emerging Technologies in Hazardous Waste Management VI, D.W. Tedder (ed.), Proceedings of the Seventh American Chemical Society Industrial and Engineering Chemistry Division Special Symposium, Atlanta, GA, September 17-20, 1995. American Chemical Society, Washington, DC, 1291 pp.; (p. 35) (1995)

The mobility of a metal from a soil is controlled by a number of factors. Among them are cation ion capacity, porosity, anion exclusion potential, and $\mathrm{pH}$. When attempting to fix or stabilize a metal these conditions as well as the redox conditions in part determined by the characteristics mentioned must be taken into consideration to achieve low effective diffusivities of the metal in the final treated product. Similarly, when there is a desire to extract a metal from a soil through some chemical technique, these same factors must be noted. In this work, a commercially contaminated soil containing lead is used to study the effects of $\mathrm{pH}$ and low levels of peroxide on the mobility of the lead from the soil. The total iron oxide content of the soil, the cation exchange as well as the total organic content are held as initial constants to the study.

2738

V18/023787

Life-Cycle Cost Comparison of VOC Emission Control Technologies

Ungun, Z.G.; Chaganti, S.; McMillan, J.C.; Campbell, C.

ICF Kaiser Engineers, Inc., Oakland, CA

CONF-9504134; HAZMACON '95, T. Bursztynsky and M.L. Loss

(eds.), Proceedings of the Twelfth Hazardous Materials

Management Annual Conference and Exhibition, San Jose, CA, April 4-6, 1995. Association of Bay Area Governments, Oakland, CA, 790 pp.; (pp. 257-270) (1995)

Site chemical data were used for conducting life-cycle cost analysis of VOC emission control technologies for the design of a 6000 cubic feet per minute (cfm) soil vapor extraction system. The nominal 10-year life-cycle costs were prepared as part of the feasibility study and preliminary design activities for the system to aid in selecting an emissions control technology. The site being remediated was a former industrial plant located in California. Chemicals of concern at the site are mainly perchloroethylene (PCE) and trichloroethylene (TCE). PCE concentrations detected the vadose zone soils are as high as 40,000 milligrams per kilogram (mg/kg) and TCE concentrations are as high as $2,600 \mathrm{mg} / \mathrm{kg}$. Concentrations detected in the soil vapors ranged from less than 1 micrograms per liter (mu $\mathrm{g} / \mathrm{L}$ ) to $38,000 \mathrm{mu} \mathrm{g} / \mathrm{L}$ for $\mathrm{PCE}$ and from less than $1 \mathrm{mu} g / \mathrm{L}$ to $44,000 \mathrm{mu} g / \mathrm{L}$ for TCE. A feasibility study was conducted as well as a long term pilot test at the site to select the remedial alternative for the site which would meet the Remedial Action Objectives. These studies indicated that SVE was the most cost-effective remedial alternative for the site. Various emission control technologies were evaluated as part of these studies and life-cycle costs were used as a tool in their selection. This paper presents the technologies considered and the methodology used to assemble with life-cycle cost estimates for technology evaluation. The cost components considered, assumptions and the methodology used to include the effect of decreasing concentrations in the subsurface with time are described.

\section{9}

V18/025405

Magnetically Stabilized Fluidized Bed - New Technology for Remediation of Contaminated Soils, Sludges, and Liquid Wastes

Clement, L.; Jovanovic, G.

Oregon State University, Department of Chemical Engineering, Corvallis, OR

CONF-970335; Waste Management '97: Working Towards a Cleaner Environment, Proceedings of a Conference on HLW, 
LLW, Mixed Wastes and Environmental Restoration, Tucson, $A Z$, March 2-6, 1997; (11 pp.) (1997)

Oregon State University WERC-Task-Force has developed a unique and innovative engineering approach toward cleaning up liquids, sludges, and contaminated soil type wastes. The extensive contamination by heavy metals, hydrocarbons, chlorinated biphenyls, and in some cases radionuclides has presented a great challenge for developing effective engineering methods for remediation of soil, sludges, and contaminated liquids. Existing technologies often fall short of productive remediation due to stringent requirements and high expectations while trying to comply with free release CERCLA regulations. This work presents an effort to enhance our engineering options in dealing with a variety of clean-up situations and requirements. As a result, the use of a magnetically stabilized fluidized bed (MSFB) is envisioned to remove particularly targeted or an array of contaminants from liquids and sludges containing mixtures of different above mentioned contaminants. MSFB incorporates high mass transfer and high conversion rate characteristics of packed beds, in addition to excellent characteristics of fluidized beds like: low pressure drop, and the ability to process solids. A magnetically stabilized fluidized bed is the addition of a magnetic field to the traditional fluidized bed. Fluidized particles contain a ferromagnetic material which can be magnetized while in the magnetic field. Magnetized ferromagnetic particles create inter-particle magnetic forces which act to control the dynamic behavior of fluid and solids for the purpose of increasing or controlling the intensity of multiphase contact. Magnetic field strength, fluid velocity, particle composition, percentage of solids in the sludge, and fluid viscosity are all adaptable operating parameters. The MSFB has been shown to have robust operating characteristics and to have enhanced mass transfer capabilities up to $75 \%$ while efficiently remediating sludges of $20-30 \%$ solids. The MSFB technology is based on the custom made fluidizing particles containing ferromagnetic material and additional active substances like adsorbents and catalysts. Ferromagnetic particles act as platforms for a multitude of active substances that can be tailored toward a variety of specific applications/tasks. For example, our research indicates that the use of OSU-Sorb-2R particles can be successfully implemented for simultaneous adsorption and catalytic decomposition of hydrocarbons in sludges.

\section{0}

V18/023020

Manufactured Gas Plant (MGP) Site Remediation: Available Technologies and a Review of Institute of Gas Technology's Innovative Approaches

Srivastava, V.J.

Institute of Gas Technology, Des Plaines, II

CONF-960144; Hazardous Waste and Environmental Management in the Gas Industry, Proceedings of a Conference, Albuquerque, NM, January 23-24, 1996, 117 pp.; (11 pp.) (1996)

Manufactured Gas Plants (MGPs) produced large quantities of tars and other by-products during the period of their operation for low to medium quality gas. This paper lists several waste specific remediation technologies which are applicable to MGP sites and discusses in some detail the two innovative and low-cost MGP site remediation technologies developed at the Institute of $\mathrm{Gas}$ Technology (IGT), namely the MGP-REM Process and the Foam Assisted Chemical Enhanced (FACE) Process.
Means and Method for Hydraulically Isolating Unsaturated Zones in Soil

Ankeny, M.D.; Burkhard, M.E.

Daniel B. Stephens \& Associates, Inc., Albuquerque, NM

U.S. Patent 05421672; 10 pp. (June 6, 1995)

This patent describes a method and apparatus for hydraulically isolating a volume in porous unsaturated material, such as soil. Air is forced through a permeable layer of material adjacent to the volume to be hydraulically isolated. The air flow through the permeable layer creates a water potential gradient. This causes water to migrate from more saturated areas which in turn would allow hydraulic isolation of any unsaturated area. This ability to isolate movement of moisture through the ground has applications to improve such things as barrier systems for the long-term underground passive storage of waste materials, to contain environmentally hazardous spills in the ground, or to hydraulically isolate any given unsaturated volume in the ground.

2742 V18/024655

Mechanisms of Heavy Metal Uptake in a Mixed Microbial Ecosystem

Ibeanusi, V.M.; Archibold, E.A.

Spelman College, Center for Scientific Applications of Mathematics (CSAM), Atlanta, GA; Morehouse College, Atlanta, GA

Bioremediation of Pollutants in Soil and Water, B.S. Schepart (ed.), Proceedings of a Symposium, Fort Worth, TX, October 14-15, 1993. American Society for Testing and Materials (ASTM), Philadelphia, PA, 265 pp.; (pp. 191-203) (May 1995)

The potential use of a mixed microbial ecosystem for the bioremediation, and removal of heavy metals from contaminated water and soil was investigated. The study included the development of metal-tolerant microbial strains for increased metal recovery, and the investigation of the uptake dynamics of ( $\mathrm{CrVI}), \mathrm{Pb}$, and Se. The results indicated that the microbial growth dynamics towards a stable mat structure resulted in a typical two microbial phase pattem: (1) a mixed bacterial bloom, during which the metal ions were enzymatically detoxified, and mobilized towards the pond surface, and (2) a cyanobacterial phase, a period marked by the stabilization of the metal species in the floating microbial mat. Investigation of the bioremediation processes suggested that reduction by microbial sulfate reactions, precipitation of metal ions, adsorption at bacterial membrane sites, reduction by change of oxidation states, and chelation played major roles in describing the strategies of bacterial response to the heavy metals investigated.

2743

V18/023335

Metal Speciation and Contamination in Soil

Allen, H.E.; Huang, C.P.; Bailey, G.W.

Metal Speciation and Contamination in Soil, Lewis Publishers, Inc., Chelsea, MI, 358 pp. (February 1995)

No abstract available. 
2744

V18/020833

Method for Mobilization of Hazardous Metal Ions in Soils

Dugan, P.R; Pfister, R.M.

Lockheed Idaho Technologies Company, Idaho Falls, ID

U.S. Patent 05427247; 9 pp. (June 27, 1995)

This invention relates to a method for the mobilization of metal ions in soils and on other surfaces and more particularly to a method using reducing agents in conjunction with indigenous microorganisms to mobilize hazardous metals bound to soils and other contaminated solid surfaces. This microbial process removes heavy metals such as bismuth, cadmium, lead, thorium, uranium and other transuranics from soils and sediments, utilizing indigenous, or isolates of indigenous, microorganisms and reducing agents, such as cysteine or sodium thioglycollate, or complexing agents such as the amino acid glycine, to effect the mobilization or release of the metals from the soil particles.

V18/022683

Method for Predicting the Extent of Petroleum Hydrocarbon Biodegradation in Contaminated Soils

Huesemann, M.H.

Pacific Northwest Laboratory, Engineering Technology Center, Richland, WA

CONF-941124; Insitu Remediation: Scientific Basis for Current and Future Technologies, G.W. Gee and N.R. Wing (eds.), Proceedings of the 33rd Hanford Symposium on Health and the Environment, Pasco, WA, November 7-11, 1994. Battelle Press, Columbus, OH, Part 1, 704 pp.; (pp. 195-207) (1994)

A series of solid-and slurry-phase soil bioremediation experiments involving different crude oils and refined petroleum products were performed to investigate the factors which affect the maximum extent of total petroleum hydrocarbon (TPH) biodegradation. The authors used a comprehensive petroleum hydrocarbon characterization procedure involving group-type separation analyses, boiling-point distributions, and hydrocarbon typing by field ionization mass spectroscopy. Initial and final concentrations of specified hydrocarbon classes were determined in each of seven different bioremediation treatments. Generally, they found that the degree of TPH biodegradation was affected mainly by the type of hydrocarbons in the contaminant matrix. In contrast, the influence of experimental variables such as soil type, fertilizer concentrations, microbial plate counts, and treatment type (siurry versus landfarming) on the overall extent of TPH biodegradation was insignificant. Based on these findings, a predictive algorithm was developed to estimate the extent of TPH biodegradation from the average reduction of 86 individual hydrocarbon classes and their respective initial concentrations. Model predictions for gravimetric TPH removals were in close agreement with analytical results from two independent laboratories.

V18/023631

Method for the Determination of Vertical Distribution Profiles of Radioactive Contamination In Soils

Roed, J.; Togawa, O.
Risoe National Laboratory, Environmental Science and Technology Department, Roskilde, Denmark; Japan Atomic Energy Research Institute, Tokai Research Establishment, Department of Environmental Safety Research, Ibaraki, Japan; Austrian Radiation Protection Association, Seibersdorf, Austria; International Radiation Protection Association, Washington, DC

CONF-960409 (Vol. 2); IRPA9, K.E. Duftschmid (ed.), Proceedings of the 1996 International Radiation Protection Association (IRPA) Ninth World Congress on Radiation Protection, Vienna, Austria, April 14-19, 1996. Berger, Horn, Austria, 817 pp.; (pp. 666-668) (1996)

A method for precise determinations of vertical profiles of radioactive contamination in soils is described. A polyethylene tube is driven into the ground and the tube, together with a soil core, withdrawn. The tube and the core are frozen and the whole sectioned with a diamond saw. The technique produces precision engineered parallel-sided circular discs. Discs of less than $1 \mathrm{~cm}$ in thickness can be produced if desired, thus permitting a well resolved soil profile. The individual sections are dried, weighed and analyzed. The method was used in the city of Gaevle in Sweden and showed that more than eight years after contamination by fallout from Chernobyl, the cesium concentration in undisturbed soil (sandy loam) peaked at a point several centimeters below the ground surface. Trace amounts of cesium were found to have migrated to a depth of at least $15 \mathrm{~cm}$. The data obtained are suitable for testing models designed to represent downward migration of cesium fallout in soils and for calculating dose rates over undisturbed soils contaminated with cesium.

2747

V18/020823

Methods and Apparatus to Confine Earth Currents for Recovery of Subsurface Volatiles and Semi-Volatiles

Bridges, J.E.; Sresty, G.C.

IIT Research Institute, Chicago, IL

U.S. Patent 05420402; 24 pp. (May 30, 1995)

Improved methods and apparatus are disclosed for confining ohmic heating currents to a subsurface formation in the use of in situ ohmic heating for recovery of volatile and semi-volatile materials, such as hazardous waste, hydrocarbon-like materials, and valuable minerals having thermally responsive properties. Spacing between emplaced electrodes and the number of electrodes employed are controlled to cause coupling between electrodes for more uniform and higher temperature heating. Electrode designs are disclosed which suppress spurious earth currents which would heat other formations not of interest. Suppression of electrode end currents is accomplished by the use of distinct rings of insulation, control of the applied potential along the electrode, and injection or withdrawal of fluids at distinct locations along the electrode.

2748 V18/020685

Microbe Complex of Soddy Podzolic Soils Contaminated by Radionuclides

Zimenka, T.G.; Charnyatsova, I.B.; Mokhava, S.V. Akadehmiya Navuk Belarusi, Institute Mikrabiyalogii, Minsk, Belarus 
Vestsi Akademii Navuk Belarusi, Seryya Biyalgichnykh Navuk 2:69-72 (March-April 1995)

Features of the formation of various microbe communities on the soddy podzolic soils via radioactive contamination density (from 1 up to $40 \mathrm{Ci} / \mathrm{sq} \mathrm{km}$ ) were investigated. The bioaccumulation of Cs-137 by separate soil microbes was determined. New hybrid communities of mushrooms with high concentrations of melanin are growing in contaminated soils. Results of this research advance the potential use of some microbes as biosorbents. (This document is in Byelorussian).

\section{V18/022706}

Microbial Response to Remediation and Other Perturbations of Subsurface Environments

Brockman, F.J.; Fredrickson, J.K.; Li, S.W.; Sun, W.; Kief, T.L.

Pacific Northwest Laboratory, Richland, WA; Washington State University, Pullman, WA; New Mexico Institute of Mining and Technology, Socorro, NM

CONF-941124; Insitu Remediation: Scientific Basis for Current and Future Technologies, G.W. Gee and N.R. Wing (eds.), Proceedings of the 33rd Hanford Symposium on Health and the Environment, Pasco, WA, November 7-11, 1994. Battelle Press, Columbus, OH, Part 1, 704 pp.; (pp. 151-165) (1994)

Microbial biomass and activity in subsurface environments is determined by the concentration and flux of a variety of electron acceptors, electron donors, and other nutrients. Perturbations associated with sampling and laboratory handling, and intentional perturbations such as those induced during bioremediation, result in changes in the structure and physiological status of the microbial community. The objective of the research is to characterize these changes for the purpose of (1) ensuring that microbial measurements approximate the in-situ condition as closely as possible, and (2) documenting the progress of in-situ bioremediation. Manipulative experiments were performed in the laboratory to assess the impact of disturbance, increased moisture, and increased $\mathrm{O} 2$ on vadose-zone sediments. DNA probes and enrichments for microbial functional groups were used to assess microbial response in sediments during bioremediation of a trichloroethylene (TCE)-contaminated zone 30 to $43 \mathrm{~m}$ below the surface at the Savannah River Site. Microbial populations able to degrade trichloroethylene (TCE) under methane-, propane-, and ammonia-oxidizing enrichment conditions commonly increased a minimum of 10 - to greater than 1,000-fold in sediments sampled following injection of air, methane, nitrous oxide, and triethyl phosphate, compared to sediments sampled following injection of air only. Results obtained with the soluble methane monooxygenase gene probe showed that cultural enrichment methods commonly underestimate methane-oxidizing populations by several orders of magnitude.

\section{$2750 \quad$ V18/021075}

Microwave Assisted Pyrolysis of Waste Polyaromatic Hydrocarbons

Dauerman, L.

New Jersey Institute of Technology, Department of Chemical Engineering, Newark, NJ
CONF-9509204; Proceedings of a Conference on Microwave and High Frequency Heating, Cambridge, United Kingdom, September 17-21, 1995; (pp. D1.1-D1.4) (1995)

Polyaromatic hydrocarbons are highly carcinogenic ubiquitous industrial wastes. Concentrations of these wastes are diminished by microwave-assisted pyrolysis. Prior to exposure to microwave radiation, the wastes are covered with a non-combustible material consisting of loose, discrete particles like sand. Susceptors may be added to the waste prior to radiation. Volatiles from the process can be absorbed in a susceptor like granulated activated charcoal. When saturated, this granulated activated charcoal can be added to the said wastes in a subsequent treatment. In situ processing can be carried out by pneumaticaily splitting the underlying rock bed and filling the fissures with graphite, a susceptor, to impede downward diffusion of the contaminants. Other experiments using hydrogen peroxide will be discussed.

\section{1 \\ V18/021311}

\section{Military Munitions Working Group: 1994 Annual} Report

Western Governors' Association, Denver, CO; Federal Advisory Committee to Develop Onsite Innovative Technologies, Washington, DC

Report; 60 pp. (December 1994)

The Munitions Working Group met four times during 1994. The primary focus of the Working Group meetings has been on developing demonstration plans for the four candidate DOIT demonstration sites that were identified in the January 31, 1994, DOIT Committee recommendations. The four initial candidate sites were: Yuma Proving Ground, Black Hills Amy Depot, Fort Ord, and Jefferson Proving Ground. The Working Group added a fifth site, Kaho 'olawe Island, at its September meeting. The Working Group's effort to develop demonstration plans included conducting DOIT orientation briefings of the site command organizations, local and regional stakeholders and others within the service structure of the sites. The briefings were conducted to determine the level of interest and commitment of the site command and stakeholder community in the demonstration project, and to educate the site command and community about the DOIT process. The briefings were also designed to identify the specific "value-added" enhancements or process changes that could be tested at DOIT demonstrations.

2752

$\mathrm{V} 18 / 025586$

Mineral Hydrocarbons of the Soil Found in a Remediation Procedure: A Model of Standardization Procedures for Analytical Calculations

Wanior, G.; Stempel, R.; Rosenberger, T.; Baumgarten, D.; Schmid, T.; Hempe, W.

Trischler und Partner GmbH, Geotechnik, Umweltschutz, Darmstadt, Germany; Hessische Landesanstalt fuer Umwelt, Wiesbaden, Germany; Chemisch Analytisches Laboratory (CAL), Darmstadt, Germany

Umweltwissenschaften und Schadstoff-Forschung 8(6):335-341 (December 1996)

Various analyses and evaluative procedures are used to provide 
evidence of success using remediation procedures. Because of the lack of standardized procedures for soil assessment, a precise auditing of remediation quality has not been possible. This article describes the problems of determining mineral hydrocarbon concentrations on soil and also describes the remediation of oil damage, which occurred on the site of a former waste oil redestillation facility. This procedure has been proven in practice and serves as a model for remediation characterization. (This document is in German).

2753

V18/021010

Minimum Additive Waste Stabilization (MAWS) Phase I: Soil Washing Final Report

Argonne National Laboratory, Argonne, IL; GTS Duratek, Inc., Columbia, $\mathrm{MD}$

ANL-95/46; 45 pp. (August 1995)

As a result of the U.S. Department of Energy's environmental restoration and technology development activities, GTS Duratek, Inc., and its subcontractors have demonstrated an integrated thermal waste treatment system at Femald, $\mathrm{OH}$, as part of the Minimum Additive Waste Stabilization (MAWS) Program. Specifically, MAWS integrates soil washing, vitrification of mixed waste streams, and ion exchange to recycle and remediate process water to achieve, through a synergistic effect, a reduction in waste volume, increased waste loading, and production of a durable, leach-resistant, stable waste form suitable for disposal. This report summarizes the results of the demonstration/testing of the soil washing component of the MAWS system installed at Fernald (Plant 9). The soil washing system was designed to (1) process contaminated soil at a rate of 0.25 cubic yards per hour; (2) reduce overall waste volume and provide consistent-quality silica sand and contaminant concentrates as raw material for vitrification; and (3) release clean soil with uranium levels below $35 \mathrm{pCi} / \mathrm{g}$. Volume reductions expected ranged from 50-80 percent; the actual volume reduction achieved during the demonstration reached 66.5 percent. The activity level of clean soil was reduced to as low as $6 \mathrm{pCi} / \mathrm{g}$ from an initial average soil activity level of $17.6 \mathrm{pCi} / \mathrm{g}$ (the highest initial level of soil provided for testing was $41 \mathrm{pCi} / \mathrm{g}$ ). Although the throughput of the soil washing system was inconsistent throughout the testing period, the system was online for sufficient periods to conclude that a rate equivalent to 0.25 cubic yards per hour was achieved.

\section{4 \\ V18/024311}

Mixed Region Reactors for Insitu Treatment of DNAPL Contaminated Low Permeability Media

West, O.R.; Siegrist, R.L.

Oak Ridge National Laboratory, Oak Ridge, IN

ORNL/TM-13305; Insitu Remediation of DNAPL Compounds in Low Permeability Media Fate/Transport, Insitu Control Technologies, and Risk Reduction, 318 pp.; (pp. 16.1-16.13) (August 1996)

Fine-textured soils and sediments contaminated by dense non-aqueous phase liquids (DNAPLs) present a significant environmental restoration chailenge. An emerging approach to rapid in situ treatment within low permeability media involves the use of soil mixing to create mixed region reactors wherein biological or physical/chemical treatment processes can be employed. In cohesive soils, mixing breaks up the original soil structure and produces soil aggregates or clods separated by interaggregate void spaces. These void spaces create preferential flow paths for more efficient extraction of contaminants from the soil matrix or more rapid diffusion of treatment agents into the soil aggregates. This enhancement technology has been most successfully used with vapor stripping. However, other technologies can also be coupled with soil mixing including chemical degradation, biodegradation and solidification. The application of this technology to DNAPL-contaminated low permeability media appears promising but requires further experiments and models that can simulate the movement of DNAPLs in mixed regions.

\section{5} V18/021803

Modeling Advective Contaminant Transport During Soil Vapor Extraction

Falta, R.W.; Pruess, K.; Chesnut, D.A.

Clemson University, Department of Earth Sciences, Clemson, SC; Lawrence Berkeley National Laboratory, Earth Sciences Division, Berkeley, CA; Lawrence Livermore National Laboratory, Earth Sciences Department, Livermore, $\mathrm{CA}$

Groundwater 31(6):1011-1020 (November-December 1993)

A general semianalytical method for modeling the advective transport of a volatile organic compound (VOC) to a soil vapor extraction well has been developed. Assuming that the VOC is not present in the form of a nonaqueous phase liquid (NAPL), this technique is applicable to cases in which the VOC is partitioned in the unsaturated zone between the gas, aqueous, and solid phases. The VOC may have a one-, two-, or three-dimensional initial distribution. The method may be applied to problems having a oneor two-dimensional steady-state gas flow field in which the gas streamfunction and gas travel time distribution are known. Examples are included to show the application of the method to radial and two-dimensional cylindrical gas flow fields with different VOC distributions and characteristics.

2756 V18/023662

Modeling Air Emissions from Contaminated Sediment Dredged Materials

Valsaraj, K.T.; Thibodeaux, L.J.; Reible, D.D.

Louisiana State University, Department of Chemical Engineering, Baton Rouge, LA; University of Sydney, New South Wales, Australia

CONF-9406413; Dredging, Remediation, and Containment of Contarminated Sediments, K.R. Demars, G.N. Richardson, R.N. Yong and R.C. Chaney (eds.), Proceedings of a Symposium, Montreal, Quebec, Canada, June 23-24, 1994, 343 pp.; (pp. 227-238) (1995)

Volatilization rates for hydrophobic organic compounds from a confined disposal facility (CDF) containing contaminated dredged material are presently unknown. The primary purpose of this study is to indicate the availability of theoretical models for the evaluation of volatile emission from a CDF. Four emission locales are identified and modeled: the sediment relocation (dredging) locale, the exposed sediment locale, the ponded sediment locale, and 
the vegetation-covered sediment locale. Rate expressions are derived to estimate the volatile organic chemical (VOC) emission from each locale. Emission rates (in mass of total VOCs per unit time) are primarily dependent on the chemical concentration at the source, the surface area of the source, and the degree to which the dredged material is in direct contact with air. The relative magnitude of these three parameters provides a basis upon which a tentative ranking of emission rates from the different locales can be given. Exposed sediment results in the greatest estimated emissions of volatiles followed by water with high levels of suspended sediments, such as might occur during dredging or during placement in a CDF. Expected to be lower in volatile emissions are dredged materials covered by a quiescent water column or vegetation.

\section{$2757 \quad$ V18/022755}

Modeling Column Extraction of Lead Contaminated Soils and Identification of Solid Lead Phases

Heil, D.M.; Echer, C.; Samani, Z.A.; Hanson, A.T.; Hu, S.; Gomez, C.

New Mexico State University, Las Cruces, NM; Lawrence Berkeley National Laboratory, Berkeley, CA

CONF-960804 (Vol. 2); Spectrum '96: Nuclear and Hazardous Waste Management, Proceedings of an Intemational Topical Meeting, Seattle, WA, August 18-23, 1996. American Nuclear Society, La Grange Park, II, Vol. 2, 873 pp.; (pp. 1046-1052) (1996)

Chelate extraction using ethylenediaminetetraacetic acid (EDTA) and other chelates has been demonstrated to be an effective method of removal of $\mathrm{Pb}$ from many contaminated soils. Batch shaker extractions require a small investment of time and labor compared to column extractions. Also, column leaching of $\mathrm{Pb}$ from alkaline soils with EDTA has been problematic due to extremely low soil permeability. The first purpose of this study was to model the column extraction of $\mathrm{Pb}$ by EDTA based on batch extraction results. The second purpose of this study was to determine the effect of the addition of $\mathrm{KOH}$ and $\mathrm{Ca}(\mathrm{Cl}) 2$ to K2H2EDTA extraction solution on $\mathrm{Pb}$ removal and hydraulic conductivity. A $\mathrm{Pb}$-contaminated soil was sampled from an abandoned lead-acid battery recycling facility. Both batch shaker extractions and column leaching experiments were completed using 5 different EDTA extract solutions. Addition of $\mathrm{Ca}(\mathrm{Cl}) 2$ only to K2H2EDTA did not change the amount of $\mathrm{Pb}$ removed by batch extraction. Lead solubility was observed to decrease as $\mathrm{pH}$ was increased by the addition of $\mathrm{KOH}$. The amount of time required to leach $6.0 \mathrm{~L}$ of extraction solution through the soil columns varied from 2 to 33 days. The addition of $\mathrm{Ca}(\mathrm{Cl}) 2$ and/or $\mathrm{KOH}$ resulted in increased soil hydraulic conductivity. However, $\mathrm{Pb}$ removal was diminished with the addition of $\mathrm{Ca}(\mathrm{Cl}) 2$ and $\mathrm{KOH}$ because of decreased $\mathrm{Pb}$ solubility and also a shorter residence time of the extract solution in the column. The hydraulic conductivity was related to residual calcium carbonate content, suggesting that dissolution of $\mathrm{CaCO} 3$ and subsequent production of $\mathrm{CO} 2$ gas in soil pores was partially responsible for the observed reductions in soil permeability. Several different solid phases of $\mathrm{Pb}$ were identified by Analytical Electron Microscopy (AEM). This observation is consistent with the experimentally observed dependence of $\mathrm{Pb}$ solubility on residual soil $\mathrm{Pb}$ concentration and also the kinetics of dissolution of $\mathrm{Pb}$ from the soil.
2758

V18/023720

Modeling and Analysis of Transport and Biodegradation in Laboratory Chambers with Plants

Narayanan, M.; Davis, L.C.; Erickson, L.E.; Hoffman, R.M.; Russell, N.K.; Hammaker, R.M.; Fateley, W.G.

Kansas State University, Departments of Biochemistry, Chemical Engineering, and Chemistry, Manhattan, KS

CONF-960730 (Vol. 3); Technologies Critical to a Changing World, Volume III: Emerging Energy Technologies, Clean Technologies, Remediation and Emission Control Fuels, and Petrochemicals, Proceedings of the Fifth World Congress of Chemical Engineering, San Diego, CA, July 14-18, 1996. American Institute of Chemical Engineers, New York, NY, Vol. 3, 1118 pp.; (pp. 694-705) (1996)

The fate of several volatile organic compounds including phenol, toluene, 1,1,1-trichloroethane, trichloroethylene, and chloroform have been investigated in sandy soil with alfalfa plants growing in the soil. A mathematical model has been developed to follow the fate of water, contaminant, root exudates produced by the plants, oxygen, and microbial growth. Concentrations of the contaminants have been measured in the gas phase, plant biomass, and groundwater. Headspace analysis of the gas in the enclosed chamber showed that small quantities of the chlorinated compounds migrated into the gas phase above the alfalfa plants. Research is in progress to investigate the transport of volatile contaminants through plants. The concentrations of the volatile contaminants which evolved with the transpired water are diluted significantly as they enter the gas phase because of the small amount of water that is soluble in air at ambient temperatures. Vegetated bioremediation systems have been employed at several field sites in the U.S. and in several other countries. The model can be used to design fields of vegetation which function as solar driven pump-and-treat processes; these systems are very inexpensive.

2759

V18/023186

Modelling and Optimization of an Hydrogeological System to Prevent Groundwater Pollution from a Leaky Landfill

Dassargues, A.

University of Liege, Laboratory of Engineering Geology, Liege, Belgium

CONF-9210194; Proceedings of an International Symposium on Environmental Contamination in Central and Eastern Europe, Budapest, Hungary, October 12-16, 1992, 968 pp.; (pp. 250-252) (1992)

Numerical simulations of the groundwater flow and contamination in a confined sandstone aquifer underlying a leaky landfill, have turned out very helpful in the choice of the prevention means to be taken. The geometry of a buried impervious wall and the scheme of the associated pumping system are optimized using a finite element code. The results of this study are illustrated, commented upon, and analyzed with an eye to the further applications of this method to other cases. This consistent way to make use of all the available data provides undoubtedly a very good tool to advise the decision-makers facing this kind of environmental problem. 
2760

V18/021094

Monitoring Radio-Frequency Heating of Contaminated Soils Using Electrical Resistance Tomography

Ramirez, A.L.; Daily, W.D.

Lawrence Livermore National Laboratory, Livermore, CA

UCRL-ID-115373; 23 pp. (September 1993)

Electrical resistance tomography (ERT) was used to monitor a radio-frequency heating process used for the in situ remediation of volatile organic compounds from subsurface water and soil at the Savannah River Site, near Aiken, South Carolina. A dipole antenna located in a horizontal well in the unsaturated zone was used to heat a contaminated clay layer. The heat-induced changes were tomographically imaged by their effects on the formation electrical resistivity. The resistivity changes observed appear to be related to heating and vaporization of the pore water, formation of steam condensate, and infiltration of rainwater through the heated zones and adjacent areas. There is a clear asymmetry downward in the resistivity decreases associated with the heating process. The resistivity decreases observed in the vicinity of the heating well are believed to be caused by the heating and downward migration of warm water originally located within a radius of a few feet around the heating well; the magnitude of the change is between $10-20 \%$. The decreasing resistivity implies an increasing rate of radio wave attenuation as heating progressed; therefore, the rate of energy deposition around the heating well increased while the penetration distance of the radio waves decreased. Saturation changes in the clay near the antenna during heating were estimated to be $50-55 \%$ based on the observed resistivity decreases. Resistivity changes observed at distances greater than 3 meters to one side of the antenna appear to be related to rainwater infiltration. We propose that gaps in near surface clay layers allow rainwater to migrate downward and reach the top of clay rich zone penetrated by the antenna borehole. The water may then accumulate along the top of the clay.

\section{1}

\section{V18/021095}

Monitoring Six-Phase Ohmic Heating of Contaminated Soils Using Electrical Resistance Tomography

Ramirez, A.L.; Daily, W.D.

Lawrence Livermore National Laboratory, Livermore, CA

UCRL-ID-118418; 23 pp. (September 1994)

Electrical resistance tomography (ERT) was used to monitor six-phase ohmic heating used for the insitu remediation of volatile organic compounds from subsurface water and soil at the Savannah River Site, near Aiken, South Carolina. The changes in electric conductivity caused by six-phase ohmic-heating in a clay layer located in the vadose zone were monitored during a period of approximately 2 months, before, during and after heating. From an array of electrodes located in 4 boreholes, we collected electrical resistivity data between five pairs of adjacent holes pairs. This data was used to calculate tomograph which showed the electrical conductivity changes along five vertical planes. The difference tomographs show the combined effects of moisture redistribution and heating caused by six-phase heating and vapor extraction. The tomographs show that most of the clay layer increased in electrical conductivity during the first 3 weeks of the 4 week long heating phase. At this time, the electrical conductivities near the center of the heating array were twice as large as the pre-heat conductivities. Then the electrical conductivity started to decrease for portions of the clay layer closest to the vapor extraction well. We propose that the conductivity decreases are due to the removal of moisture by the heating and vacuum extraction. Parts of the clay layer near the extraction well reached electrical conductivities as low as $40 \%$ of the pre-heating values. We propose that these regions of lower than ambient electrical conductivities are indicators of regions where the vapor removal by vacuum extraction was most effective. At the end of the heating phase, our estimates suggest that the clay saturation may have dropped to as low as $10 \%$ based on the observed conductivity changes.

2762

V18/023802

Monitoring of a Controlled LNAPL Spill Using Ground-Penetrating Radar

Campbell, D.L.; Lucius, J.E.; Ellefsen, K.J.; Deszcz-Pan, M.

U.S. Geological Survey, Denver, CO

CONF-960477; SAGEEP '96, R.S. Bell and M.H. Cramer (eds.), Proceedings of the Ninth Annual Symposium on the Application of Geophysics to Engineering and Environmental Problems, Denver, CO, April 15-May 1, 1996. Environmental and Engineering Geophysical Society, Wheat Ridge, CO, 1353 pp.; (pp. 511-518) (1996)

Using ground penetrating radar (GPR), we monitored a controlled low-density non-aqueous phase liquid (LNAPL) gasoline spill at a test facility at Oregon Graduate Institute (OGI), near Portland, OR. The results were different from some reported for uncontrolled gasoline spills, in which the gasoline apparently blurs the contrast in dielectric permittivity that usually exists at the top of the saturated zone (SZ), so that GPR reflections from the SZ are subdued. Instead, at $\mathrm{OGI}$ we saw a SZ reflection almost everywhere, but this reflection was brighter (higher amplitude) under the spill. The bright spots grew and spread as the spill progressed. We explain this effect by noting that sand grains above the SZ were quite moist, so that values of relative dielectric permittivity (RDP) were relatively high there. As the spilled gasoline displaced this interstitial moisture, RDP values dropped, leading to a GPR high velocity layer and concomitant bright spots.

\section{3}

\section{V18/021955}

\section{Mower Detector to Judge Soil Sorting}

Bramlitt, E.T.; Johnson, N.R.

Thermo Nuclear Services, Inc., Albuquerque, NM

CONF-951209; Proceedings of the 17th Annual U.S. Deparment of Energy Low-Level Radioactive Waste Management Conference, D. Lake (ed.), Phoenix, AZ, December 12-14, 1995, 480 pp.; (1 p.) (1995)

Thermo Nuclear Services (TNS) has developed a mower detector as an inexpensive and fast means for deciding potential value of soil sorting for cleanup. It is a shielded detector box on wheels pushed over the ground (as a person mows grass) at $30 \mathrm{ft} / \mathrm{min}$ with gamma-ray counts recorded every $0.25 \mathrm{sec}$. It mirror images detection by the TNS transportable sorter system which conveys soil at $30 \mathrm{ft} / \mathrm{min}$ and toggles a gate to send soil on separate paths based on counts. The mower detector shows if contamination is 
variable and suitable for sorting, and by unique calibration sources, it indicates detection sensitivity. The mower detector has been used to characterize some soil at Department of Energy sites in New Jersey and South Carolina.

\section{4}

V18/023550

Natural Analogs of the Long-Term Performance of Engineered Covers

Waugh, W.J.; Petersen, K.L.; Link, S.O.; Bjornstad, B.N.; Gee, G.W.

Environmental Sciences Laboratory, Grand Junction, CO; Pacific Northwest Laboratory, Richland, WA

CONF-941124; Insitu Remediation: Scientific Basis for Current and Future Technologies, G.W. Gee and N.R. Wing (eds.), Proceedings of the 33rd Hanford Symposium on Health and the Environment, Pasco, WA, November 7-11, 1994. Battelle Press, Columbus, OH, Part 1, 704 pp.; (pp. 379-409) (1994)

The unprecedented legislative demand that in-situ waste-disposal facilities effectively persist indefinitely requires a performance assessment approach that exceeds standard engineering practices and incorporates possible long-term changes in site hydrology, geology, and ecology. Even in relatively arid regions, over time, buried waste will be vulnerable to transport via rainwater percolation, gas diffusion, erosion, and intrusion by plant roots, burrowing animals, and humans. Standard models and field tests of engineered covers designed to impede these pathways implicitly and erroneously assume that initial conditions of many key determinants will persist indefinitely. Evidence from natural, archaeological, and engineered analogs, is needed to: (1) identify and understand emergent system attributes that cannot be captured with computer models or short-term experiments, and (2) develop modeling and field tests that reasonably bound possible future changes in waste-site environments. Analogs of local responses to future global climate change exist as proxy ecological and archaeological records of similar paleoclimates. Future pedogenic influences can be inferred from measurements of key soil properties in natural and archaeological soil profiles analogous to engineered covers. Many cover designs depend on water extraction by plants. Influences of vegetation change can be inferred by measuring water extraction parameters in plant communities representing successional chronosequences. Habitats similar to those created on waste sites provide evidence of the potential for biological intrusion. Recent and ancient manmade structures provide evidence of the future stability of waste-site covers and of features that may be discourage human intrusion.

2765

V18/021820

\section{New Recipe Combines Technologies}

Soil and Groundwater Cleanup (May 1995); 4 pp. (May 1995)

The Lasagna process merges several well known technologies into a treatment system to provide in situ treatment of contaminated clayey soils at any depth. The process, developed jointiy by Monsanto and EPA's Remediation Technology Development Fonum, merges three basic well known technologies. The first is an electrokinetic technology to force contaminants out of the microscopic pores in the clayey and silty regions of the soil so they cannot continue to leach into groundwater. The second component is the introduction of in situ sorption or degradation zones in the soil so that the contaminants do not have to be brought to the surface for treatment after they were forced out of the clay. The third component is to treat contaminants within the newly created treatment zones by introducing appropriate materials such as sorbents, catalytic agents, microbes, oxidants or buffers.

2766

V18/025598

New Soil Remediation Technology: The HTM's Process Shiralian, M.

Department of the Environment, Environmental Protection Service, Ottawa, Ontario, Canada

CONF-951086; Proceedings of the Fifth Annual Symposium on Groundwater and Soil Remediation, Toronto, Ontario, Canada, October 2-6, 1995. Environment Canada - Environmental Protection Service, Hull, Quebec, Canada, 566 pp.; (pp. 535-537) (1995)

A new proprietary technology that offers on-site treatment of soils contaminated by hydrocarbons and heavy metals is described. The technology is portable, and it does not involve incineration, microbial or slurry processes. It consists of two steps. In step 1 the soil is loaded in the feed hopper, transported to a mixer where oxidants are added, passes through a mill where it is subjected to intense accelerational fields, as well as intense aeration combined with violent self impacting. In step 2 the micronized particles are picked up in a violent air stream which strips off the organics from the solid particles. The air-bome organics are then oxidized before passing through a wet scrubber and vented filters. The oxidation process can be enhanced by the injection of strong oxidants such as hydrogen peroxide. The processed soil is then further separated from the gas phase and exited via an enclosed plenum containing spray nozzles for remoisturization. Several pilot and field trials have demonstrated that contaminant removal efficiency over 99 per cent can be easily achieved. Treatment cost was in the range of $\$ 20$ to $\$ 28$ per metric ton.

2767

V18/021714

Nitrogen Fixation, Denitrification and $\mathrm{CO} 2$ Flux Under Conditions of Combined Gamma-Irradiation and Heavy Metals Contamination in Soil

Egorova, E.I.

Radiatsionnaya Biologiya Radioehkologiya 36(2):219-226

(March-April 1996)

The effects of $\mathrm{Zn}, \mathrm{Cd}$, and gamma radiation on nitrogen fixation, denitrification, and $\mathrm{CO} 2$ flux in soddy-podzolic soils were determined in a model experiment. (This document is in Russian).

2768 V18/022639

Nonaqueous-Phase-Liquids-Contaminated Soil/Groundwater Remediation Using Foams

Peters, R.W.; Enzien, M.V.; Bouillard, J.X.; Frank, J.R.; Srivastava, V.J.; Hayes, T.D.

Argonne National Laboratory, Energy Systems Division, Argonne, II; Institute of Gas Technology, Chicago, IL; Gas Research Institute, Chicago, IL 
CONF-941124; Insitu Remediation: Scientific Basis for Current and Future Technologies, G.W. Gee and N.R. Wing (eds.), Proceedings of the 33rd Hanford Symposium on Health and the Environment, Pasco, WA, November 7-11, 1994. Battelle Press, Columbus, OH, Part 2, 605 pp.; (pp. 1067-1087) (1994)

This paper describes a new remediation technology that uses foams to treat dense, nonaqueous-phase liquids (DNAPL) in the subsurface. This project is a joint effort involving Argonne National Laboratory and the US Department of Energy Office of Technology Development (under the Insitu Remediation Integrated Program) and the Gas Research Institute (in collaboration with the Institute of Gas Technology and the Illinois Institute of Technology). Foams are used to release and mobilize NAPL contaminants in the subsurface, thereby making the contaminants bioavailable. Foam is a dispersion of gas bubbles, separated by thin liquid films containing surfactants. Foams are currently used by the oil industry to improve crude oil recovery, resulting in 20 to $50 \%$ higher recoveries of oil for some applications. Foams can be designed with different phases (e.g., three-phase foams containing an aqueous foam with an organic pollutant or oil phase), wettabilities, surfactant concentrations, mobilities, and stabilities. Foams can carry different gases, chemicals, bacteria. Foams can also be coupled to and enhance in-situ bioremediation since surfactant concentrations are well below toxicity levels. Furthermore, foams can be designed to enhance bioremediation by carrying nutrients, bacteria, or specific gases.

2769 V18/024101

Nonthermal Plasma Treatment of Hazardous/Toxic Pollutants

Los Alamos National Laboratory, Los Alamos, NM

LALP-94-237; 1 p. (1994)

Operating at ambient temperature and pressure, nonthermal plasmas (NTPs) generate highly reactive free radicals that efficientiy decompose hazardous organic compounds in air streams, flue-gas streams, and other off-gases. NTP processors consist of a power supply and plasma cell. A. contaminated air stream containing chlorinated solvent vapors passes through the system, yielding carbon dioxide, water, and hydrochloric acid. Los Alamos has demonstrated removal efficiencies from $95 \%$ to greater than $99.999 \%$ for volatile organic compound solvents, such as trichloroethylene (TCE) and 1,1,1-trichloroethane (TCA); tetrachloroethene (PCE), carbon tetrachloride ( $\mathrm{CCl} 4)$, benzene, toluene, ethylbenzene and xylenes (BTEX), and polychlorinated biphenyls (PCB) surrogates; and chlorofluorocarbons.

2770 V18/023038

Numerical Modelling of Unsaturated Flow in Multilayer Soil Covers

Aubertin, M.; Aachib, M.; Chapuis, R.P.; Bussiere, B.; Crespo, J.R.

Ecole Polytechnique, Montreal, Quebec, Canada

Hydrogeologie 1:3-13 (1996)

When dealing with the closure of waste disposal sites, multilayer soil cover systems with various types of soils are often used to secure the area and to control fluid motion. The hydraulic conditions in the cover, which usually involve different grain size materials and unsaturated flows, are quite difficult to evaluate because of the non-linearity of the constitutive laws involved. This paper presents the results of a numerical study of unsaturated flow conditions in systems that comprise 2 (silt over sand) and 3 (sand -silt -sand) distinct layers and a simulation of the flow conditions using a commercially available finite-element code (SEEP/W). Five and two different cases were modelled with the 2 and 3 layers systems, respectively. The results demonstrate the importance of using materials with very different hydraulic properties. The laboratory and field work are briefly described. (This document is in French).

2771 V18/023480

Numerical and Experimental Study of Two-Phase Flow and Heat Transfer in a Porous Formation with Localized Heating from Below

Easterday, O.T.; Wang, C.Y.; Cheng, P.

University of Hawaii, Department of Mechanical Engineering, Honolulu, HI; Hong Kong University of Science and Technology, Department of Mechanical Engineering, Honolulu, HI

CONF-951135; Proceedings of an American Society of Mechanical Engineers (ASME) Heat Transfer and Fluids Engineering Divisions 1995 International Mechanical Engineering Congress and Exhibition: Fluid Mechanics and Heat Transfer in Sprays - Heat, Mass and Momentum Transfer in Environmental Flows Measurement Techniques in Mutiphase Flow - Muliphase Transport in Porous Media, J.W. Hoyt, T.J. O'Hem and C. Presser (eds.), San Francisco, CA, November 12-17, 1995. ASME, New York, NY, 761 pp.; (pp. 723-732) (1995)

Understanding and predicting two-phase flow and heat transfer in porous media is of fundamental interest for a number of engineering applications. Examples include thermal technologies for remediation of contaminated subsurfaces, the extraction of geothermal energy from vapor-dominated reservoirs, and the assessment of high-level nuclear waste repositories. A numerical and experimental study is reported for two-phase flow and heat transfer in a horizontal porous formation with water through flow and partial heating from below. Based on a newly developed two-phase mixture model, numerical results of the temperature distribution, liquid saturation, liquid and vapor phase velocity fields are presented for three representative cases with varying inlet velocities. It is found that the resulting two-phase structure and flow patterns are strongly dependent upon the water inlet velocity and the bottom heat flux. The former parameter measures the flow along the horizontal direction, while the latter creates a relative motion between the phases in the vertical direction. Experiments are also performed to measure temperature distributions and to visualize the two-phase flow patterns. Qualitative agreement between experiments and numerical predictions is achieved. Overall, this combined experimental and numerical study has provided new insight into conjugate single- and two-phase flow and heat transfer in porous media, although future research is required if accurate modeling of these complex problems is to be accomplished.

2772

V18/022746

On the Problem of Deactivation of Land Areas Contaminated with Radionuclides 
Blagoev, V.V.; Galkin, A.P.; Blagoev, R.V.; Galkina, L.A.; Tsygankova, V.A.; Vasiliev, A.N.; Dulnev, P.G.

Institute of Bioorganic Chemistry \& Petrochemistry, Kiev, Ukraine; Agroecokhim Company, Kiev, Ukraine

CONF-960804 (Vol. 2); Spectrum '96: Nuclear and Hazardous Waste Management, Proceedings of an Intemational Topical Meeting, Seattle, WA, August 18-23, 1996. American Nuclear Society, La Grange Park, IL, Vol. 2, 873 pp.; (pp. 963-966) (1996)

This paper describes a complex of technologies for land reclamation in areas of nuclear accidents, short-term chemical remediation of such dusting areas as well as long-term combined chemical and biological remediation. Short-term stabilization is based on application of chemical compositions containing side-products of hydrolysis of cellulose and calcium chloride. Long-term remediation is achieved by growing plants that establish ground cover very quickly. These combined techniques prevent an expansion of radionuclides into environment. Methods of remediation include removal of the surface layer of soil following displacement or burial. Effective remediation is provided by available techniques and affordable chemicals.

\section{3}

\section{V18/021055}

Onsite Remediation of Pesticide Contaminated Soils by Using Thermal Treatment

Wells, S.K.; Hodges, H.I.

Separation Systems Consultants, Inc., Houston, TX CONF-940499 (Vol. 1); Proceedings of the 1994 Federal Environmental Restoration III and Waste Minimization II Conference and Exhibition, New Orleans, LA, April 27-29, 1994. Hazardous Materials Control Resources Institute, Rockville, MD, Vol. 1, 783 pp.; (pp. 11-16) (1994)

SSCI used the EnviroSpec thermal treatment process to successfully remediate pesticide contaminated soils at a former federal facility on the U.S.-Mexico border. This work was done as part of a contract for remediation of two facilities in the Lower Rio Grande Valley. Remediation was carried out by three different methods. Five percent of contaminated soils were transported offsite to a commercial incineration facility. Ten percent of contaminated soils were transported offsite to a commercial Class One landfill. The remaining 85 percent of contaminated soils was treated onsite using a mobile thermal treatment unit, which resulted in significant cost savings compared to the other two methods. This paper details remediation work at the two sites, the process used to determine which of the three different remediation strategies would be used for each area of contamination, and compares the costs associated with each of the methods. Information is also presented on sampling and assessment work to delineate contaminated areas and verify successful cleanup, determination of action levels for the various pesticides encountered, and the types of technical and other problems that were overcome as part of the remediation program.

\section{4 \\ V18/020689}

Ontario's Approach to Sediment Assessment and Remediation

Jaagumagi, R.; Persaud, D.; Bedard, D.

Ontario Ministry of Environment and Energy, Toronto,
Ontario, Canada

CONF-9511137; Global Environmental Protection: Science, Politics, and Common Sense, Proceedings of the Second Society of Environmental Toxicology and Chemistry (SETAC) World Congress and 16th Annual Meeting, Vancouver, British Columbia, Canada, November 5-9, 1995. Society of Environmental Toxicology and Chemistry, Pensacola, FL, 378 pp.; (p. 227) (1995)

Contaminated sediment is a major environmental concern in many areas of Ontario, especially the Great Lakes. Persistent toxic substances that have accumulated in freshwater sediments from industrial, municipal and non-point sources are a threat to the survival of benthic organisms and their consumers. In order to deal effectively with sediment quality problems, environmental managers need to know what amount of risk is associated with a given level of contamination. Guidelines for the evaluation of sediment help to provide a basis for determining when sediments are considered clean, what levels of contamination are acceptable in the short-term, and when contamination is severe enough to warrant significant remedial action. The Provincial Sediment Quality Guidelines (PSQGs) are a set of numerical guidelines using a three tiered approach, that were developed for the protection of aquatic biological resources, especially those organisms directly impacted by contaminated sediment. The Guidelines also protect against biomagnification of contaminants through the food chain from sediment contaminant sources, and forms the primary basis for decision-making relative to sediment assessment and remediation options. The procedure used in determining the need for remedial action will be provided and also includes physical site-specific characterization and information on biological effects. The biological assessment can include effects on individuals and communities, both in the field and the laboratory. Concurrent with environmental data gathering, efforts should be made to obtain information on contaminant input to the area. Finally, consideration of remedial action in an area of contaminated sediment requires the development of a clean-up goal. The goal should be reasonably achievable and compatible with existing land uses. (Complete text)

\section{5}

V18/022037

Open-Path and Extractive FT-IR Environmental Monitoring Above and Below the Ground

Fateley, W.G.; Hammaker, R.M.; Chaffin, C.T.; Marshall, T.L.

Kansas State University, Department of Chemistry, Manhattan, KS; AeroSurvey, Inc., Manhattan, KS

CONF-9506232; Environmental Monitoring and Hazardous Waste Site Remediation, T. Vo-Dinh and R. Niessner (eds.), Proceedings of a Conference of the Society of Photo-Optical Instrumentation Engineers, Munich, Germany, June 19-23, 1995. International Society for Optical Engineering, Bellingham, WA, 613 pp.; (pp. 2-13) (1995)

To demonstrate the versatility of Fourier transform infrared (FT-IR) spectrometry, two site investigations are discussed. The first is the monitoring of emissions from active volcanoes. The second is the analysis of soil gases from a site that is currently under remediation for groundwater and soil contamination. The 
monitoring performed at the volcanoes used open-path FT-IR methods and the monitoring at the remediation site used extractive FT-IR methods. Descriptions of the sampling systems employed and the emissions monitored at these sites will be used to demonstrate the advantages and limitations of environmental monitoring using FT-IR spectrometry.

2776

V18/022753

Optimization of Site Characterization and Remediation Methods Using 3-D Geoscience Modeling and Visualization Techniques

Hedegaard, R.F.; Ho, J.N.; Eisert, J.

Jacobs Engineering Group Inc., Martinez, CA; Jacobs Engineering Group Inc., Sacramento, CA

CONF-960804 (Vol. 2); Spectrum '96: Nuclear and Hazardous Waste Management, Proceedings of an International Topical Meeting, Seattle, WA, August 18-23, 1996. American Nuclear Society, La Grange Park, IL, Vol. 2, 873 pp.; (pp. 1030-1037) (1996)

Three-dimensional (3-D) geoscience volume modeling can be used to improve the efficiency of the environmental investigation and remediation process. At several unsaturated zone spill sites at two Superfund (CERCLA) sites (Military Installations) in California, all aspects of subsurface contamination have been characterized using an integrated computerized approach. With the aid of software such as LYNX GMS [TM], Wavefront's Data Visualizer [TM], and Gstools (public domain), we have created a central platform from which to map a contaminant plume, visualize the same plume three-dimensionally, and calculate volumes of contaminated soil or groundwater above important health risk thresholds. The developed methodology allows rapid data inspection for decisions such that the characterization process and remedial action design are optimized. By using the 3-D geoscience modeling and visualization techniques, the technical staff are able to evaluate the completeness and spatial variability of the data and conduct 3-D geostatistical predictions of contaminant and lithologic distributions. The geometry of each plume is estimated using 3-D variography on raw analyte values and indicator thresholds for the kriged model. Three-dimensional lithologic interpretation is based on either 'linked' parallel cross-sections or on kriged grid estimations derived from borehole data coded with permeability indicator thresholds. Investigative borings, as well as soil vapor extraction/injection wells, are sighted and excavation costs are estimated using these results. The principal advantages of the technique are the efficiency and rapidity with which meaningiul results are obtained and the enhanced visualization capability which is a desirable medium to communicate with both the technical staff as well as non-technical audiences.

\section{$2777 \quad$ V18/020777}

Optimization of Surfactant-Aided Remediation of Industrially Contaminated Soils

Joshi, M.M.; Lee, S.G.

University of Akron, Department of Chemical Engineering, Akron, $\mathrm{OH}$

Energy Sources 18(3):291-301 (April-May 1996)

Soil matrices contaminated with polycyclic aromatic hydrocarbons
(PAHs) abound at the sites of coke-oven gas plants, refineries, and many other major chemical industries. The removal of PAHs from soil using pure water, via soil washing (exsitu) or soil flushing (in situ), is quite ineffective due to their low solubility and hydrophobicity. However, addition of suitable surfactant(s) has been shown to increase the removal efficiency several fold. For the present work, the removal of PAHs occurring in industrialiy contaminated soil was studied. The objective was to use a nonionic surfactant solution for in situ soil flushing and to evaluate the optimal range of process parameters that can significantly increase the removal efficiency. The process parameters chosen were surfactant concentration, ratio of washing solution volume to soil weight, and temperature of washing solution. These parameters were found to have a significant effect on PAH removal from the contaminated soil and an optimal range was determined for each parameter under given washing conditions.

2778

V18/023788

Optimizing Soil Vapor Extraction System Design and Operations

Farr, J.M.; McMillan, J.C.; Shibberu, D.

ICF Kaiser Engineers, Inc., Oakland, CA; ICF Kaiser Engineers, Inc., Rancho Cordova, CA

CONF-9504134; HAZMACON '95, T. Bursztynsky and M.L. Loss (eds.), Proceedings of the Twelfth Hazardous Materials Management Annual Conference and Exhibition, San Jose, CA, April 4-6, 1995. Association of Bay Area Govemments, Oakland, CA, 790 pp.; (pp. 287-295) (1995)

Within the constraints of regulatory requirements and site cleanup time schedules, mass removal rates of volatile organic compounds (VOCs) per cost unit is maximized through model-aided design and operations planning for soil-vapor extraction (SVE) systems. The specific objective is to maximize the net marginal mass removal rate per incremental remedial cost. The costs associated with SVE systems relate to: (1) the number of vadose-zone vents (air extraction, inlet, or injection), (2) the configuration and materials used in constructing the vents, (3) the capacity of manifolds, air blowers, and treatment systems, and (4) the operational air-extraction rates and VOC mass removal rates. Decision variables within all four categories (covering capital and O\&M costs) are active during system design, while only the fourth category (O\&M) is active during operations optimization for existing SVE systems. Because all the decision variables are generally related to the air-extraction rate(s), this variable is used as a surrogate for remedial cost in the simplified analysis presented here. Knowledge of the subsurface response in terms of achievable mass removal rates as a function of operational air-extraction rates is thus critical to optimization efforts. This paper describes how field testing and transport modeling are used to characterize the subsurface response and optimize SVE system designs and operations accordingly. Field testing is required because mass removal rates depend on poorly understood distributions of subsurface VOCs and air-flow patterns and complex field-scale interphase mass transfer processes. SVE systems are frequently operated at sufficiently high air-extraction rates to induce rate-limited interphase mass transfer of VOCs, which must be considered when optimizing SVE designs and operations. The application of our methods at a major field site in Califomia is presented to illustrate how the analysis of observed subsurface 
air-flow and mass transport behavior is used to maximize VOC mass removal versus costs.

2779

V18/023873

Overview of Technical Resource Document for Solvent Contaminants and Remedial Options at Superfund Sites

Frank, U.; Sullivan, D.; Wilkowski, K. U.S. Environmental Protection Agency, Edison, NJ

EPA/600/R-95/012; CONF-9504110; Proceedings of the 21st Annual Risk Reduction Engineering Laboratory (RREL) Research Symposium, Cincinnati, OH, April 4-6, 1995. U.S. Environmental Protection Agency, Cincinnati, OH, 398 pp.; (pp. 172-176) (April 1995)

Solvent contamination is a persistent problem found at numerous Superfund sites. Solvents at Superfund sites are usually halogenated or nonhalogenated organic liquids whose source can be traced to many manufacturing, industrial, and commercial processes and uses. Almost half of all Superfund sites listed in the record of decision (ROD) summary database contain solvents as a contaminant. The Environmental Protection Agency's (EPA) Office of Research and Development developed a technical resource document to assist project managers in making remedial action decisions. The publication discusses the properties of solvents and the remedial technologies available to reach estabilished cleanup levels. This paper describes the contents of the technical resource document and summarizes the characteristics of many of the remedial technologies.

\section{0}

V18/023656

\section{Oxidation of Pyrite in Marine Clays and Zinc} Adsorption by Clays

Ohtsubo, $\mathrm{M}$.

Kyushu University, Department of Agricultural Engineering, Fukuoka, Japan

CONF-9406413; Dredging, Remediation, and Containment of Contaminated Sediments, K.R. Demars, G.N. Richardson, R.N. Yong and R.C. Chaney (eds.), Proceedings of a Symposium, Montreal, Quebec, Canada, June 23-24, 1994, 343 pp.; (pp. 50-57) (1995)

The oxidation of pyrite in marine clays exposed to a subaerial environment was confirmed and was determined to be well correlated with decreased adsorption of zinc by the clays. The production of sulfuric acid and iron oxide by this oxidation and the accompanying decrease in $\mathrm{pH}$ was demonstrated based on an investigation of the chemistry of the marine clay profile and laboratory incubation tests for remolded clay samples. Both $\mathrm{pH}$ decrease and the production of iron oxides reduced the zinc adsorption capability of the clays. This suggests that the zinc adsorbed by the marine clays would be released into the pore water due to exposure of the sediment surface to the atmosphere.

2781 V18/022444

\section{Passive Soil Vapor Extraction: A Cost Effectiveness} Study

Cummings, M.; Booth, S.R.
Los Alamos National Laboratory, Los Alamos, NM Remediation 16(3):69-79 (Summer 1996)

An analysis of the cost effectiveness of passive soil vapor extraction (PSVE) is presented. PSVE, or "barometric pumping," is an approach to the remediation of volatile organic compounds (VOCs) that seeks to harness and enhance the naturally occurring processes of wind and atmospheric pressure changes to facilitate the release of gas-phase contaminants from the subsurface. The technology background and current status are discussed, niches for the potential applicability of PSVE are identified, and a cost comparison with the conventional treatment method of active soil vapor extraction (ASVE) is examined.

\section{$2782 \quad$ V18/023474}

Pentachlorophenol Mineralization in an Immobilized Soil Bioreactor

Karamanev, D.; Chavarie, C.; Samson, R.

Ecole Polytechnique, Montreal, Quebec, Canada

CONF-960730 (Vol. 3); Technologies Critical to a Changing World, Volume III: Emerging Energy Technologies, Clean Technologies, Remediation and Emission Control Fuels, and Petrochemicals, Proceedings of the Fith World Congress of Chemical Engineering, San Diego, CA, July 14-18, 1996. American Institute of Chemical Engineers, New York, NY, Vol. 3, 1118 pp.; (pp. 731-736) (1996)

The biological degradation of pentachlorophenol (PCP) was conducted in a new type of reactor-the immobilized soil bioreactor. In this bioreactor soil particles having natural microbial activity in degrading the target pollutant are entrapped into a solid membrane with a large pore size distribution. The resulting "immobilized soil" system can be easily supplied with dissolved mineral salts, oxygen and target pollutant, and as a result an active microbial consortium will be quickly established. This consortium is later used for treatment of aqueous solutions of the pollutant, for instance, contaminated groundwater. We have studied the process of PCP biodegradation in both batch and continuous regime. Our results showed that the volumetric effectiveness of the process of PCP mineralization in the immobilized soil bioreactor is between 7 and 4000 times higher than results reported in the literature. It has been found that both chlorine and carbon atoms of PCP are at least $99 \%$ mineralized.

2783

V18/023637

Performance Evaluation Report for Soil Vapor

Extraction System Operations at the Carbon

Tetrachloride Site - February 1992-June 1996 [Rev. 1]

Rohay, V.J.

Bechtel Hanford, Inc., Richland, WA

BHI-00720 (Rev. 1); 86 pp. (September 1996)

The purpose of this report is to review carbon tetrachloride soil vapor extraction data to provide a summary of the operating data and effectiveness of vapor extraction operations in addressing unsaturated zone contamination based on the existing design. The report covers the operating period from February 25, 1992 through June 30,1995 . The scope of the report includes the history of active vapor extraction operations; the efficiency of operations over time; the volume of air processed per system; the change in 
carbon tetrachloride concentrations with time; and the mass removed per site.

2784

V18/021411

Performance of Horizontal Versus Vertical Vapor Extraction Wells

Birdsell, K.H.; Rosenberg, N.D.; Edlund, K.M.

Los Alamos National Laboratory, Los Alamos, NM

LA-12783-MS; 33 pp. (June 1994)

Vapor extraction wells used for site remediation of volatile organic chemicais in the vadose zone are typically vertical wells. Over the past few years, there has been an increased interest in horizontal wells for environmental remediation. Despite the interest and potential benefits of horizontal wells, there has been little study of the relative performance of horizontal and vertical vapor extraction wells. This study uses numerical simulations to investigate the relative performance of horizontal versus vertical vapor extraction wells under a variety of conditions. The most significant conclusion that can be drawn from this study is that in a homogeneous medium, a single, horizontal vapor extraction well outperforms a single, vertical vapor extraction well (with surface capping) only for long, linear plumes. Guidelines are presented regarding the use of horizontal wells.

\section{5}

V18/024028

Phosphate-Accelerated Bioremediation

TIE Quarterly 5(2):1,3 (Fall 1996/Winter 1997)

In bioremediation processes that are phosphorus-limited (where the amount of phosphorus determines biomass growth and reaction rates), controlled addition of the nutrient is the key to effective process control and to reducing the time needed to destroy contaminants. Savannah River Site (SRS) scientists, in partnership with Oak Ridge National Laboratory, developed a new, improved process to control the addition of vapor-phase phosphorus to bioremediation systems, bioreactors, and other biotechnology applications. Called the PHOSter systems, the technology offers significant advantages over existing technology, such as: (1) improved control, (2) simpler design and operation, (3) increased flexibility for site-specific customization, (4) improved use of the phosphorus feedstock, and (5) great ability to document performance.

\section{6}

V18/025588

Photocatalytic Remediation of Contaminated Solids

Chiarenzelli, J.R.; Scrudato, R.J.

State University of New York, Research Center, Oswego, NY; Department of the Environment, Environmental Protection Service, Ottawa, Ontario, Canada

CONF-951086; Proceedings of the Fifth Annual Symposium on Groundwater and Soil Remediation, Toronto, Ontario, Canada, October 2-6, 1995. Environment Canada - Environmental Protection Service, Hull, Quebec, Canada, 566 pp.; (pp. 463-465) (1995)

Results of various experiments to utilize photocatalysis to photodegrade polychlorinated biphenyls (PCBs) and pesticide-contaminated sediments and soils in slurry suspensions are discussed. The mechanism of the reaction (i.e., simultaneously bringing together the catalyst, contaminant, and light through mixing of the material) is explained. Potential advantages of the method (on-site treatment, simultaneous degradation of multiple contaminants, low energy requirements, no emission of toxic effluents, reusable inert catalyst, no landfilling or future liability, etc.,) are reviewed. A pilot-scale test is planned for the near future to provide performance data needed for eventual commercialization.

2787

V18/021787

Phylogeny and Ecology of Methylotrophic Bacteria Hanson, R.S.; Bratina, B.J.; Brusseau, G.A.

University of Minnesota, Department of Microbiology, Navarre, MN; University of Minnesota, Gray Freshwater Biological Institute, Navarre, MN

Phylogeny and Ecology of Methylotrophic Bacteria - Microbial Growth on C-1 Compounds, J.C. Murrell and D.P. Kelly (eds.), Intercept Limited., Andover, United Kingdom, 450 pp.; (pp. 285-302) (1993)

Methylotrophic bacteria are a diverse group of microbes that utilize one-carbon compounds more reduced than carbon dioxide. In addition, these bacteria assimilate carbon at the oxidation level of formaldehyde. Methanotrophs are a subset of methylotrophs that are able to use methane as a carbon and energy source. In 1970 , Whittenbury et al. described the properties of more than 100 new isolates of methanotrophic bacteria. These isolates were classified into five groups on the basis of morphology, fine structure of intracytoplasmic membranes and types of resting stages formed. The proposed groups were named Methylosinus, Methylomonas, Methylobacter and Methylococcus. Subsequent studies led to the separation of methanotrophs into three groups. Group I included those bacteria that utilized the ribulose-monophosphate pathway (RUMP) for formaldehyde assimilation while bacteria included in Group II are those bacteria that employed the serine pathway for formaldehyde assimilation. Another group, Group X, was added to accommodate Methylococcus capsulatus, a methanotrophic bacterium that contained enzymes of the RuMP pathway, to a lesser extent enzymes of the serine pathway and enzymes of the Calvin Cycle for $\mathrm{CO} 2$ fixation.

2788

V18/021773

Physical Barriers Stop Plumes in Their Tracks

Initiatives in Environmental Technology Investment 3(August 1996):1-3 (August 1996)

Contaminants leaking from hundreds of U.S. Department of Energy storage tanks, landfills, and trenches are polluting groundwater and. threatening the health of people and wildlife. DOE's Office of Science and Technology is exploring use of physical barriers as a way to quickly and effectively prevent the spread of radioactive and hazardous waste plumes. By blocking the advance of piumes, DOE hopes to control the contaminants until positive remediation is feasible. In 1996, DOE plans to demonstrate two types of physical barriers - cryogenic, or frozen, soil and viscous liquid. 
Physical and Biological Remediation of Oil-Polluted River Bed and Hillside Sediments Resulting from a Ruptured Oil Pipeline in Northwestern Italy

Bonfa, I.; Gambera, M.; McIntosh, R.S.

Groundwater Technology, Inc., Cantu, Italy; Groundwater Technology, Inc., Norwood, MA

CONF-9306269; HazMat '93 International, Proceedings of the Eleventh Annual Environmental Management and Technology Conference and Exhibition, Atlantic City, NJ, June 9-11, 1993. Advanstar Expositions, Glen Ellyn, IL, 731 pp.; (pp. 79-89) (1993)

A few years ago, the rupture of an underground pipeline caused the spill of a large volume of fuel-oil on a hill slope, located next to the Rio Barca, a mountain stream. The Rio Barca is a torrential watercourse, situated on the southern border of the Province of Alessandria, Piemonte region, in the north of Italy. Approximately 500 meters of the stream was affected by the loss from the pipeline rupture to where the stream joins the main river, Rio Lemme. The spill occurred during a time when the Rio Barca was almost totally dry, therefore allowing the fuel-oil to saturate the sandy-silty-gravelly sediments, which form the bed of watercourse. Several tens of thousands of liters of oil was spilled into the Rio Barca. As a follow up to the fuel loss, Groundwater Technology was asked to establish the feasibility of conducting an in situ remediation. In order to define the full extension of the contaminated area as well as the relative hydrocarbon concentration, a water and soil sampling program was conducted both for the stream bed and the hill slope where the accident took place. Based on characterization results, a two-step remediation strategy was developed the remove the hydrocarbons in the stream. The residual hydrocarbon contamination in the hillside soils were addressed in a separate plan. Step 1 was mechanical liberation and recovery of the free-phase hydrocarbon trapped in the sediments; Step 2 involved in-situ treatment via the Enhanced Natural Bioremediation (END [TM]) program. This paper provides a case study of the operation and results.

2790

V18/020692

\section{Phytoremediation of Soil Contaminated with Low Concentrations of Radionuclides}

Entry, J.A.; Vance, N.C.; Hamilton, M.A.; Zabowski, D.; Watrud, L.S.; Adriano, D.C.

Auburn University, Department of Agronomy and Soils, Auburn, AL

Water, Air and Soil Pollution 88(1-2):167-176 (March 1996)

Ecosystems throughout the world have been contaminated with radionuclides by above-ground nuclear testing, nuclear reactor accidents and nuclear power generation. Radioisotopes with characteristics of nuclear fission, such as $\mathrm{Cs}-137$ and Sr-90, that are released into the environment can become more concentrated as they move up the food chain often becoming human health hazards. Natural environmental processes will redistribute long lived radionuclides that are released into the environment among soil, plants and wildlife. Numerous studies have shown that Cs-137 and Sr-90 are not removed from the top 0.4 meters of soil even under high rainfall, and migration rate from the top few centimeters of soil is slow. The top 0.4 meters of the soil is where plant roots actively accumulate elements. Since plants are known to take up and accumulate Cs-137 and SI-90, removal of these radionuclides from contaminated soils by plants could provide a reliable and economical method of remediation. One approach is to use fast growing plants inoculated with mycorrhizal fungi combined with soil organic amendments to maximize the plant accumulation and removal of radionuclides from contaminated soils, followed by harvest of above-ground portion of the plants. High temperature combustion would be used to oxidize plant material concentrating Cs-137 and Sr-90 in ash for disposal. When areas of land that have been contaminated with radionuclides are large, using energy intensive engineering solutions to mediate huge volumes of soil is not feasible or economical. Plants are proposed as a viable and cost effective method to remove radionuclides from the soils that have been contaminated by nuclear testing and nuclear reactor accidents.

2791 V18/023466

Phytoremediation of TNT: C. roseus Hairy Roots as a Model System

Lauritzen, J.R.; Hughes, J.B.; Shanks, J.V.

Rice University, Houston, TX

CONF-960730 (Vol. 3); Technologies Critical to a Changing World, Volume III: Emerging Energy Technologies, Clean Technologies, Remediation and Emission Control Fuels, and Petrochemicals, Proceedings of the Fifth World Congress of Chemical Engineering, San Diego, CA, July 14-18, 1996. American Institute of Chemical Engineers, New York, NY, Vol. 3, 1118 pp.; (pp. 795-800) (1996)

Widespread contamination by 2,4,6-trinitrotoluene (TNT) of Soil exists at former munitions production and handling facilities. Phytoremediation may be an effective alternative to existing methods of TNT remediation: incineration is highly expensive and recalcitrant reduction products are formed in composting. Recently, the intrinsic ability of plants to transform TNT has been demonstrated using hairy root cultures of Catharanthus roseus as a model system. Kinetic studies were performed at concentrations of 30 and $50 \mathrm{mg} / \mathrm{L}$ TNT in growth medium. The pseudo-first order rate constants for disappearance ranged from 0.0103 to 0.0161 ( $L / g$-day); TNT disappears completely within seven to ten days of exposure. The fate of the TNT molecule in plants is also currently under study, mass balance studies were performed with 1-C-14 TNT. After a seven day exposure period, $72 \%$ of the label was associated with the roots and $30 \%$ was associated with the medium. However, high performance liquid chromatography (HPLC) analysis shows that less than $5 \%$ (wt\%) of the TNT added is recoverable from both the plants and the media in the form of reduction products.

2792

V18/025335

Pilot Treatment Project for the Remediation of Uranium-Contaminated Soil at a Former Nuclear Weapons Development Site at the Los Alamos National Laboratory

Turney, W.R.J.R.; Lu, N.P.; Mason, C.F.V.; Duff, M.C.; Dry, D.E.

Los Alamos National Laboratory, Los Alamos, NM

CONF-970335; Waste Management '97: Working Towards a Cleaner Environment, Proceedings of a Conference on $\mathrm{HLW}$, LLW, Mixed Wastes and Environmental Restoration, Tucson, AZ, March 2-6, 1997; (10 pp.) (1997) 
An environmental pilot treatment study for the remediation of uranium-contaminated soil by use of a two-step, zero-discharge, $100 \%$ recycle system was conducted at a former weapons research site. In the first step, following excavation, the soil was sorted by use of the ThemoNuclean Services segmented gate system (SGS) into two different streams: one stream with radioactivity greater than $30 \mathrm{pCi} / \mathrm{g}$, the other stream with radioactivity less than 30 pCi/g. Following the sorting, the soil with radioactivities less than $30 \mathrm{pCi} / \mathrm{g}$ was returned to the excavation site as it met regulatory soil release guidelines. The portion of soil with radioactivities greater than $30 \mathrm{pCi} / \mathrm{g}$ was chemically treated in a second step containerized vat leach process by use of sodium-bicarbonate leach solution. The results of the second step are reported here.

\section{3}

V18/022237

Pilot-Scale Field Study on the Anaerobic Biotreatment of Soil Impacted with Highly Chlorinated Benzenes

Ramanand, K.; Foulke, B.; Deinicki, W.A.; Ying, A.C.; Baek, N.H.; Coats, M.L.; Duffy, J.J.

Trea Tek-CRA Company, Niagara Falls, NY; Occidental Chemical Corporation, Grand Island, NY

CONF-951139 (Vol. 2); Superfund 16: Pioceedings of a Hazardous Waste Conference and Exhibition, Washington, DC, November 6-8, 1995. E.J. Krause and Associates, Bethesda, MD, Vol. 2, 817 pp.; (pp. 1098-1104) (1994)

An on-site pilot-scale demonstration of anaerobic biodegradation of highly chlorinated benzenes was successfully performed at a chemical manufacturing industrial facility in Niagara Falls, New York. The field investigation was conducted in $6 \mathrm{cu}$ yd capacity soil boxes. Approximately $4 \mathrm{cu}$ yd of soil impacted with chlorinated compounds was placed in each soil box. Chlorinated benzenes with 3 or more chlorines accounted for about 85 percent of the total chemistry in the soil. The soil box amended with water, nutrients, and acclimated soil microbial inoculum exhibited greater than $78 \%$ reduction in the levels of highly chlorinated compounds after one year of field study. The total concentrations of hexa-, penta-, tetra-, and trichlorobenzenes decreased from $920 \mathrm{mg} / \mathrm{kg}$ to less than $190 \mathrm{mg} / \mathrm{kg}$, while the total concentrations of di-, and monochlorobenzene increased from $8 \mathrm{mg} / \mathrm{kg}$ to greater than 400 $\mathrm{mg} / \mathrm{kg}$ during one year of field operation. The control soil that did not receive any external nutrient or microbial amendments maintained the same percentage of the highly chlorinated benzenes after one year and di-, and monochiorobenzene never exceeded more than $4 \mathrm{mg} / \mathrm{kg}$ at any given time period. The anaerobic activity was further confirmed by monitored parameters such as nutrient consumption (butyrate, nitrogen, organic matter), sulfate depletion, and methane production.

\section{4}

\section{V18/021775}

\section{Plants Boost Microbial Remediation}

McCleary, $\mathrm{H}$.

Bioremediation Report 2(1):3-4 (January 1993)

Over the past few years plant-laden "artificial wetlands" have shown great promise in remediating waste. Scientists have even been experimenting with plants as "hyperaccumulators" of heavy metals such as zinc and lead. But efforts to recruit plants for work on dry land are just getting underway. Investigators at Oak Ridge National Laboratory have discovered that soil contaminated with trichloroethylene remediated more quickly if plant roots have grown in the soil. The work provides strong evidence that vegetation may actively promote microbial restoration of chemically contaminated surface and near-surface soils.

\section{5}

V18/024307

Pneumatic Fracturing of Low Permeability Media Schuring, J.R.

New Jersey Institute of Technology, Newark, NJ; Oak Ridge National Laboratory, Oak Ridge, TN

ORNL/TM-13305; Insitu Remediation of DNAPL Compounds in Low Permeability Media Fate/Transport, Insitu Control Technologies, and Risk Reduction, 318 pp.; (pp. 12.1-12.19) (August 1996)

Pneumatic fracturing of soils to enhance the removal and treatment of dense nonaqueous phase liquids is described. The process involves gas injection at a pressure exceeding the natural stresses and at a flow rate exceeding the permeability of the formation. The paper outlines geologic considerations, advantages and disadvantages, general technology considerations, low permeability media considerations, commercial availability, efficiency, and costs. Five case histories of remediation using pneumatic fracturing are briefly summarized.

\section{$2796 \quad \mathrm{~V} 18 / 022771$}

Polymer Gel as a Barrier for Ground Oil Spill Containment

Wilkins, E.

University of New Mexico, Department of Chemical and Nuclear Engineering, Albuquerque, NM

CONF-960804 (Vol. 2); Spectrum '96: Nuclear and Hazardous Waste Management, Proceedings of an International Topical Meeting, Seattle, WA, August 18-23, 1996. American Nuclear Society, La Grange Park, IL, Vol. 2, 873 pp.; (pp. 1263-1269) (1996)

The specific problem that is of concern here is to stop or at least significantly retard the migration of oil spill and other waste fluids into groundwater. Stopping or slowing migration of contaminants will allow remediation of the source of the contaminants, or at least provide more time for the required remediation technology to be developed and applied. The solution proposed is to employ a polymer gel barrier that is highly impermeable to the contaminants of interest. The barrier will be formed by injection into the ground of ungelled polymer, which will then gel in controlled fashion in situ. The importance and innovation of this proposed technique lies in 'ungelled'. The material to be injected via drill holes will have a viscosity and density close to water, hence the pump power and costs will be very low compared with other methods. Several promising polymer gels have been identified and tested for the purpose of forming effective barriers. The permeability of our gel barrier is very low, in the order of $10(\mathrm{E}-8)$ to $10(\mathrm{E}-9) \mathrm{cm} / \mathrm{sec}$, which is much lower than $10(\mathrm{E}-7) \mathrm{cm} / \mathrm{sec}$ - the criterion for an ideal barrier. Further, gelation time, which is an important factor in constructing a gel barrier, can be easily controlled by varying the $\mathrm{pH}$ 
of the ungelled polymer-crosslinking agent mixture.

2797

V18/025374

Potential Use of Mycorrhizal Fungi as Bioremediation Agents, Chapter 8

Donnelly, P.K.; Fletcher, J.S.

University of Oklahoma, Department of Botany and Microbiology, Norman, OK

Bioremediation Through Rhizosphere Technology, T.A. Anderson and J.R. Coats (eds.), American Chemical Society, Washington, DC, 249 pp.; (pp. 93-99) (1994)

Currently the most common practice of cleaning contaminated soil is to remove the soil from the site and transfer it to a permanent storage cell, or to an incinerator for combustion of organics. The use of microorganisms as bioremediation agents is gaining popularity based primarily on degradation studies conducted under laboratory conditions. Unfortunately these microorganisms are often not active degraders when moved from the laboratory to the field, presumably because they cannot compete with the native organisms. This paper proposes the use of ectomycorrhizal fungi as bioremediation agents with special attention focused on both the fungus and the host plant. The host plant will give the fungus a selective advantage for surviving at a contaminated site. Several of these fungi are known to metabolize various chlorinated aromatic compounds, such as 2,4-dichlorophenoxyacetic acid (2,4-D), atrazine, and polychlorinated biphenyls (PCBs). This group of fungi may play an important role in the bioremediation of hazardous compounds in soil. This chapter summarizes the work to date using mycorrhizal fungi in bioremediation studies.

2798 V18/022208

Practical Application of Remediating Soil Impacted by Salt from Produced Water

Cresswell, G.A.; Williams, O.W.

U.S. Department of Energy, Washington, DC; Amoco Production Company, Houston, TX; Conoco, Inc., Stamford, CT; Mobil Exploration \& Producing US Inc., Houston, TX

CONF-9509296; Environmental Issues and Solutions in Petroleum Exploration, Production, and Refining, K.L. Sublette (ed.), Proceedings of the Second International Petroleum Environmental Conference, New Orleans, LA, September 25-27, 1995, 1078 pp.; (pp. 667-674) (1995)

In many geographical areas where crude oil is produced, saltwater is a natural by-product of the oil production stream. The dissolved solids of this produced saltwater varies significantly with geography. Often the higher salinity values are associated with produced water at secondary crude oil recovery waterfloods and on occasion with depletion-drive and water drive primary crude oil recovery. Secondary recovery methods, waterfloods, typically follow many years of primary crude oil production thereby extending the producing life another 20 to 40 years. Many of the major fields producing today have been on stream for more than 50 years. The historical actions associated with these operations, high salt concentrations of the water and the cumulative volumes of saltwater handled all combine to increase the environmental risk of adversely impacting surface. This paper shares some of the experiences one company has encountered in an effort to assess and reduce the economic and environmental risks associated with sait impacted soils at waterfloods. The focus of this paper is on the practical aspects of identifying soil areas impacted before the nationwide improvements in environmental requirements in the mid 1970 s and improving the productivity of surface soils. It summarizes how successful remediation approaches have been aligned with soil characteristics and intended surface uses. Remediation approaches have included calcium/sodium exchange, fresh water flushing, and organic additives. Also presented are the precautions used to make sure potential adverse impacts from the salt are not passed from the soil to other media.

2799

V18/020690

Pre- and Post-Dredged Sediment Monitoring for Open Water Disposal and Sediment Remediation Programs

Thompson, T.; Kendall, D.

Science Applications International Corporation, Bothell, WA; U.S. Army Corps of Engineers, Seattle, WA

CONF-9511137; Global Environmental Protection: Science, Politics, and Common Sense, Proceedings of the Second Society of Environmental Toxicology and Chemistry (SETAC) World Congress and 16 th Annual Meeting, Vancouver, British Columbia, Canada, November 5-9, 1995. Society of Environmental Toxicology and Chemistry, Pensacola, FL, 378 pp.; (p. 230) (1995)

Clean dredged sediments are rapidly becoming an important commodity for use in sediment remediation programs, specifically thin or thick layer placement over contaminated sediments in Washington, dredged sediments are characterized according to procedures defined by the Puget Sound Dredged Sediment Disposal Analyses (PSDDA) program. Under PSDDA, sediments are chemically analyzed and compared to analytical screening levels (SL). If SLs are exceeded, sediments are tested biologically using a suite of acute and chronic sediment bioassays. Sediments deemed to be suitable for open water disposal may then be disposed al one of the state-operated disposal sites, or may be reconsidered for use in the growing number of near-shore remediation projects. Recently, four significant projects have used clean dredged sediment for capping contaminated bottom sediments, including the heavily creosote-contaminated sediments at the Eagle Harbor Superfund Site. Post-disposal PSDDA monitoring at the disposal sites in or near urban embayments involves the use of Sediment Vertical Profiling System, on and off-site sediment chemistry and bioassay monitoring, and off-site benthic infaunal community and infaunal chemical analyses. Monitoring results have demonstrated that dredged sediments remain within the perimeter of the disposal site, and have not caused any significant off site adverse affects. In at least one embayment, Elliott Bay, post-disposal site sediments are cleaner than pre-disposal native sediments. Cap-monitoring utilizes the same tools, but may include other tools, such as precision bathymetry or subbottom profiling. This paper will show how these monitoring tools are used in a regulatory environment, and discuss the relative success of PSDDA in contributing to meeting the mandates of the Clean Water Act for dredged sediment disposal, while assisting environmental restoration in Washington. (Complete text) 
2800

V18/024857

Proceedings of a Conference on Phytoremediation, Arlington, VA, May 8-10, 1996

CONF-960592; Proceedings of a Conference on Phytoremediation, Arlington, VA, May 8-10, 1996. Intemational Business

Communications, Southborough, MA, 388 pp. (1996)

Sessions of this conference covered the following topics: (1) The Role of Phytoremediation in Hazardous Waste Management, (2) Phytoremediation of Explosives: Fundamentals to Field, (3) Inorganic Contaminants, (4) Mechanisms of Metal Accumulation and Resistance, (5) Phytoremediation of Organic Contaminants. Much of the material in the proceedings volume is in the form of viewgraphs or short communications. Individual papers within the scope of this data base have been indexed separately.

\section{1}

V18/020838

Process and System for the Onsite Remediation of Lead-Contaminated Soil and Waste Battery Casings

Bitler, J.A.; Baranski, J.P.

Exide Corporation, Reading, PA

U.S. Patent 05439498; 13 pp. (August 8, 1995)

A mobile system for the remediation of a mixture of lead-contaminated soil and waste lead-acid battery casings inciudes a plasma arc furnace unit having a plasma arc torch which operates at a sufficiently elevated temperature to (i) convert the battery casings in the mixture into a combustible gas, (ii) volatilize lead contaminants which are present in the mixture and entrain the volatilized lead contaminants as a vapor in the combustible gas, and (iii) vitrify the soil, whereby lead contaminants that were present in the mixture are substantially removed therefrom. An intemal combustion engine-driven generator supplies the plasma arc furnace with electrical power. In this regard, the internal combustion engine-driven generator receives the combustible gas from the plasma arc funace as a fuel source in order to drive the generator. A lead-filtration unit is preferably interposed between the generator and the plasma arc furnace so as to receive the combustible gas generated by the plasma arc furnace and remove the entrained lead contaminants therefrom. A supply of secondary fuel gas (e.g., liquified petroleum gas, natural gas or the like) may optionally be supplied to the internal combustion engine-driven generator as a supplemental fuel together with the combustible gas generated by the plasma arc furnace. The various nit operations may be mounted for mobility (e.g., on truck beds, rail cars or the like) to permit transportation to a landfill in need of remediation.

2802

\section{V18/020834}

Process for Removing Hazardous, Toxic, and Radioactive Wastes from Soils, Sediments, and Debris

Cash, A.B.

U.S. Patent 05434332; 19 pp. (July 18, 1995)

This patent describes a process for reducing the levels of contaminants in soils, sediments and debris comprised of an immersion of the contaminated media in a solvent, and the full drainage of the solvent from the soils, sediments and debris. The contaminants can be organic chemicals, metals, or radioactive materials. The process eliminates the effect of channeling, and allows contaminant levels to be brought to very low levels throughout the soils, sediments, and debris being processed. This invention provides a novel low-cost method of leaching that assures total treatment of the contaminated solids.

\section{3}

\section{V18/020829}

Process for the Electroreclamation of Soil Material

Pool, W.

U.S. Patent 05433829; 16 pp. (July 18, 1995)

This invention relates to a process for electroreclamation of soil material. A pluraiity of electrodes is brought into current-conducting connection with the soil material to be reclaimed. One or more of the electrodes are brought into current-conducting connection with the positive or negative pole of a source of $D C$ voltage, and the remaining electrodes are brought into contact with the other pole of the source of DC voltage. There are thus formed one or more anodes and one or more cathodes. An electric current is passed through the soil material to be reclaimed between the differently charged electrodes. According to the invention, the physico-chemical parameters of the medium of both the regions adjoining the anode(s) and the regions adjoining the cathode(s) are controlled.

\section{4}

V18/021695

Protein Patterns as Endpoints in Environmental Remediation

Bradley, B.; Brown, D.

University of Maryland, Department of Biological Sciences, College Park, MD

CONF-9511137; Global Environmental Protection: Science, Politics, and Common Sense, Proceedings of the Second Society of Environmental Toxicology and Chemistry (SETAC) World Congress and 16th Annual Meeting, Vancouver, British Columbia, Canada, November 5-9, 1995. Society of Environmental Toxicology and Chemistry, Pensacola, FL, 378 pp.; (p. 233) (1995)

Biological endpoints can complement chemical analyses in monitoring environmental remediation. In some cases the levels of chemical detection are so low that the costs of clean-up to no detection would be prohibitive. In addition, chemical tests do not indicate the availability of the contaminants to the biota. On the other hand many if not most biological tests lack specificity. The authors have investigated a protein expression assay to establish an endpoint for clean-up of sulfur mustard (SM) and breakdown products. Earthworms (Lumbricus terrestris) were exposed to SM, a breakdown product thiodiethanol (TDE), and ethylene glycol, the solvent for the two chemicals. Tissue from the lining of the coelomic cavity was taken from each of 6 worms in each treatment class. Soluble proteins were extracted and separated on one and two-dimensional gels. The 1-D gels showed no difference visually but the patterns from control and solvent control worms on 2-D gels differed from those of worms exposed to TDE and SM. The 1-D gel data were digitized and analyzed by pattem recognition using artificial neural networks. The protein patterns under the two treatments and the two controls were determined in one set of data and successfully recognized in a second. This indicated that what was 
determined was useful in recognizing patterns induced by SM and TDE. Thus a possible endpoint for remediation would be the protein pattem at no effect levels of chemicals of interest.

2805 V18/022503

Protocol for Assessing the Biotreatability of Hydrocarbon Contaminated Exploration and Production Site Soils

Tezak, J.; Miller, J.A.; Lawrence, A.W.; Keffer, R.E.; Weightman, R.L.; Hayes, T.D.

Remediation Technologies, Inc., Concord, MA; Gas Research Institute, Chicago, IL

CONF-950333; SPE-29770; Government and Industry Working Together to Find Cost Effective Approaches to Protecting the Environment, Proceedings of the Society of Petroleum Engineers (SPE)/U.S. Environmental Protection Agency (EPA) Exploration Production Environmental Conference, Houston, TX, March 27-29, 1995. SPE, Richardson, TX, 797 pp.; (pp. 757-766) (1995)

It is estimated that there are over 260,000 natural gas production wells in the continental United States. At many of these locations, production or reserve pits exist which may require remediation depending on several conditions such as: the manner in which they were initially closed; whether or not they were lined; and the local climate, soil type, and depth to groundwater. This paper includes the treatability results obtained from subjecting a number of E\&P pit soils to the treatability protocol. The factors influencing the amenability of these soils to bioremediation as determined from the test results are discussed.

2806

\section{V18/024128}

Quantitative Evaluation of Spectral Gamma-Ray Borehole Data to Map Gamma-Emitting Contaminants

Los Alamos National Laboratory, Los Alamos, NM

LALP-95-20; 1 p. (1995)

Passive spectral gamma-ray (SGR) borehole logging is a mature technology that can detect and identify the artificial gamma-emitting nuclides found in the ground at some nuclear waste sites, as well as natural gamma-emitters found in most rocks and soils. Because the results are not normally quantitative, Los Alamos has modified and adapted existing data-processing techniques developed for uranium exploration and other applications to the problem of assessing environmental contamination.

2807

V18/022659

Quantitative Soil Vapor: An Innovative Tool for Site Characterization and Remediation

Preslo, L.M.; Comstock, C.

CONF-960393 (Part 2); Contaminated Soils and Groundwater: Analysis, Fate, Environmental and Public Health Effects, and Remediation, Proceedings of the Sixth Annual West Coast Conference, Newport Beach, CA, March 11-14, 1996. Association for the Environmental Health of Soils, Amherst, MA, Part 2, 226 pp.; (p. 2) (1996)

This paper discusses comparisons of concentrations of volatile organic compounds (VOCs) in soil vapor with those in collected soil samples at several sites. Hundreds of soil/soil vapor sample pairs have been analyzed. The data from these pairs has shown that quantitative soil vapor sampling is a better tool than traditionally collected soils for estimating VOCs in the vadose zone. These comparisons have shown that soil vapor provided a better VOC estimate than soil samples in more than $90 \%$ of the comparisons in various soil types. The paper discusses the comparisons, the quality assurance/quality control (QA/QC) data required for quantitative soil vapor work, various ways to analyze the data, and sensitivity analyses performed on the data. In addition, they focus on using the vapor data as a tool to: locate non-aqueous phase liquids (NAPL) in the vadose zone; better conceptualize the VOC distribution in the vadose zone; better design remedial systems, specifically soil vapor extraction systems; better negotiate realistic cleanup levels and corresponding realistic remedial management strategies. A case study illustrating these issues, including cleanup levels in terms of vapor VOC concentrations is presented. (Complete Text)

2808

V18/021704

Radio Frequency Enhanced Soil Vapor Extraction for Insitu Remediation

Pearce, J.A.; Daniel, D.E.; Boerigter, J.; Zuluga, A.

University of Texas, Austin, TX

CONF-9505249 (Vol. 49); Ceramic Transactions: Microwaves Theory and Application in Materials Processing III, Proceedings of the 97th American Ceramic Society (ACS) Annual Meeting and Exposition, Cincinnati, $\mathrm{OH}$, May 1-4, 1995. ACS, Westerville, $\mathrm{OH}$, Vol. 49, 666 pp.; (pp. 91-98) (1995)

Traditional forms of soil vapor extraction seek to volatilize and remove organic contaminants by percolation of environmental air through the contaminated soil volume. As a practical matter this is effective for contaminants with vapor pressures in excess of about 1 torr at soil temperatures below about 20 degrees $C$. The list of potentially susceptible contaminants can be expanded by heating the soil to increase the vapor pressure. Steam heat may be used, but its effect is limited to established vapor passageways. Radio frequency (RF) heating has many advantages because of its ability to heat volumetrically. However, the RF absorption of soil types, and thus the observed heating rate, varies widely depending on soil constituents and moisture content. We present measurements of soil RF absorption and contaminant removal rates as projected from measurements of soil water removal in a measured $\mathrm{RF}$ electric field at $27 \mathrm{MHz}$. Heat transfer effects in the small laboratory fixture are estimated from additional experiments and applied to estimate the temperatures which might be achieved in a large volume field test at the same electric field. Though the uncertainty is high, the desired temperature range (in excess of 150 degrees $\mathrm{C}$ ) is achievable in most soil types.

\section{$2809 \quad$ V18/024310}

\section{Radio Frequency Heating for Insitu Remediation of} DNAPL

Kasevich, R.S.

KAI Technologies, Inc., Woburn, MA; Oak Ridge National Laboratory, Oak Ridge, TN

ORNL/TM-13305; Insitu Remediation of DNAPL Compounds in Low Permeability Media Fate/Transport, Insitu Control 
Technologies, and Risk Reduction, 318 pp.; (pp. 6.1-6.21) (August 1996)

Insitu radio frequency (RF) heating technology for treating soils contaminated with dense nonaqueous phase liquids (DNAPLs) is described. RF imparts heat to non-conducting materials through the application of carefully controlled RF transmissions, improving contaminant flow characteristics and facilitating separation and removal from subsurface soils. The paper outlines advantages and limitations of $R F$ remediation, process operations, general technology considerations, low permeability media considerations, commercial availability, and costs. Two case histories of RF remediation are briefly summarized.

\section{$2810 \quad$ V18/021089}

Rate of TCE Degradation by Indigenous Methanotrophic Bacteria at the Savannah River Site

Andrews, G.F.; Hansen, S.G.; Downs, W.C.

Idaho National Engineering Laboratory, Biotechnology and Environmental Science Group, Idaho Falls, ID

CONF-930482; Proceedings of the Second International Insitu and Onsite Bioreclamation Symposium, San Diego, CA, April 5-8, 1993; (1 p.) [presented, but not published] (1993)

The differential soil bioreactor is a laboratory scale device that can simulate events in real time in a finite element of the subsurface during an in situ bioremediation operation. It is applied to measuring the inherent kinetics of trichloroethylene (TCE) degradation by methanotrophic bacteria under the geochemical and hydrological conditions in the unsaturated zone of the subsurface at the Savannah River Site. Results show the importance of supplying large amounts of methane initially in order to grow a substantial concentration of methanotrophic bacteria from indigenous population. The dissolved methane concentration must then be maintained at the order of 10 $\mathrm{ppb}$ in order to maintain cell viability while not causing competitive inhibition of TCE degradation by the methane mono-oxygenase enzyme. Under these conditions, degradation rates of $70 \mathrm{mg}$ TCE/day cubic meters of ground were maintained, with $\mathrm{TCE} /$ methane consumption ratios up to $10 \mathrm{gm} / \mathrm{gm}$, at a (dissolved) TCE concentration of $1 \mathrm{ppm}$. (Complete text).

\section{1}

\section{V18/023747}

\section{Rational Design Approach for Landfill Liner Protective} Soil Cover

Ruetten, M.G.; Bandi, S.R.; Reddy, K.R.

STS Consultants Limited, Green Bay, WI; Rust Environment \& Infrastructure, Livonia, MI; University of Illinois, Chicago, II

CONF-950978; Municipal and Industrial Waste, Proceedings of the 18th International Madison Waste Conference, Madison, WI, September 20-21, 1995. University of Wisconsin, Madison, WI, 461 pp.; (pp. 302-308) (1995)

This paper presents a rational approach for designing protective soil cover for landfill geomembrane liners in order to prevent damage to the liners. The present practice involves using a combination of geotextile and soil layer as protective cover. The geotextile is placed directly over the geomembrane and then a protective soil is placed on the geotextile. The protective soil layer generally consists of a free-draining granular soil which also serves as a drainage layer for the leachate collection and removal system. The degree of protection offered to the geomembrane depends on the type of geotextile, and the composition and thickness of the protective soil used.

2812

V18/022008

Recent Developments in Lead Based Cleanup Criteria at Hazardous Waste Sites

Ahlert, W.K.; Williams, B.C.

Lawler, Matusky and Skelly Engineers, Pearl River, NY CONF-9509139; Emerging Technologies in Hazardous Waste Management VII, D.W. Tedder (ed.), Proceedings of the Seventh American Chemical Society Industrial and Engineering Chemistry Division Special Symposium, Atlanta, GA, September 17-20, 1995. American Chemical Society, Washington, DC, 1291 pp.; (p. 1223) (1995)

In 1994 the U.S. Environmental Protection Agency (EPA) issued two guidance documents to address soil lead contamination. The Office of Solid Waste \& Emergency Response (OSWER) released the Revised Interim Soil Lead Guidance that recommends a risk-based screening level for lead in soil for residential use and the use of the Integrated Exposure Uptake Biokinetics (IEUBK) Model to evaluate potential risks to humans from environmental exposure to lead at hazardous waste sites in residential setuings. The other guidance was released by the Office of Prevention. Pesticides, and Toxic Substances (OPPTS) and promotes activities that would reduce lead-based paint (LBP) hazards, including lead contaminated soils in residential areas. Both of these guidance documents identify $400 \mathrm{ppm}$ as the level in soil below which no further action is necessary. However, the OPPTS guidance identifies concentrations between $400-5000 \mathrm{ppm}$ as the levels in soil which necessitate only interim controls (e.g., the placement of ground cover to prevent direct exposure). In the past, the final record of decision (ROD) issued by the EPA for most Superfund sites, where the primary contaminant of concern was lead, used the OSWER guidance to determine the final lead cleanup level for the site. Over 300 sites with lead in soil have been placed on the national priorities list (NPL). In many cases the RODs issued by EPA required the removal of lead contaminated soils that contained levels of lead between $400-5000 \mathrm{ppm}$. Even though the OPPTS guidance is applicable to residential areas where soils have been contaminated with lead as a result of LBP, if applied to hazardous waste sites many remedial actions required by EPA in the past would not be necessary under this guidance. This shows an inconsistency in how these two guidance documents are applied in developing response actions and shows a difference in policies towards soil lead contamination by offices within EPA. This paper will discuss recent changes in federal and state policies regarding the cleanup of hazardous waste sites where lead in soil is the principal problem and how this may affect future remedial investigations and the development of appropriate cleanup criteria.

Reclaiming Contaminated Land: Insitu/Exsitu Remediation of Creosote- and Petroleum Hydrocarbon-Contaminated Sites, Chapter 6 
Ellis, B.

Celtic Technologies Limited, CBT Centre, Cardiff, United Kingdom

Bioremediation: Field Experience, P.E. Fiathman, D.E. Jerger and J.H. Exner (eds.), Lewis Publishers, Boca Raton, FL, 560 pp.; (pp. 107-143) (1994)

Contamination of soil and groundwater by oil (or petroleum) hydrocarbons (PHCs), pesticides, and other contaminants is a widespread problem brought about by accidental spillage of chemicals on land used for chemical production, refining processes, and pesticide manufacture, for example. Excavation and replacement of contaminated soil is expensive and involves transferring the soil to another location if indeed, such a location (i.e. landfill or toxic tip) is available rather than completely resolving the problem. Several workers have reviewed the possible altematives for treating contaminated soil on site. These alternatives include air stripping, encapsulation, chemical treatment, soil washing, and bioremediation. The planning and design of remedial action can involve extremely complex and interactive processes requiring a broad range of scientific and engineering expertise. This is particularly the case when treatment involves the use of microbiological techniques. This chapter presents case histories to illustrate how bioremediation was used successfully to remediate a creosote-contaminated site in Sweden and $a$ an oil refinery site in Germany. The projects demonstrated that organic contaminants such as creosote oils, phenols, and polycyclic aromatic hydrocarbons can be treated on a commercial scale by both in situ and exsitu biological treatment. An integrated technical approach was crucial for the treatment programs. This included understanding the type and extent of contamination, geological and hydrogeological conditions, soil chemistry and nutrition for microbial growth, and the physical rate-limiting factors goveming the kinetics of degradation.

2814

\section{V18/023835}

Recycling of Contaminated Soils by the AMREC Cold-Mix, Asphalt-Emulsion Process

Camougis, $\mathrm{G}$.

American Reclamation Corporation, Ashland, MA CONF-9306269; HazMat '93 Intemational, Proceedings of the Eleventh Annual Environmental Management and Technology Conference and Exhibition, Atlantic City, NJ, June 9-11, 1993. Advanstar Expositions, Glen Ellyn, IL, 731 pp.; (pp. 628-638) (1993)

This paper describes the management of contaminated soils by recycling with a cold-mix, asphalt-emulsion process developed by the American Reclamation Corporation (AmRec). This is a soil recycling/reuse process in which soils contaminated with petroleum products and other contaminants can be processed into asphalt products with beneficial uses. Most of the discussion will center on soils contaminated with petroleum products. However, the recycling of soils with other contaminants (e.g., heavy metals) will also be discussed. AmRec has produced approximately 500,000 tons of asphalt products with recycled materials. These products have been used beneficially in roadways, access roads, parking areas, and landfills throughout the northeast.
Reduction of Polycyclic Aromatic Hydrocarbons (PAHs) from Petroleum-Contaminated Soil Using Thermal Desorption Technology

Silkebakken, D.M.; Davis, H.A.; Ghosh, S.B.; Beardsley, G.P.

Parsons Engineering Science, Inc., Atlanta, GA; U.S. Air Force Base Conversion Agency, Rantoul, IL

CONF-951139 (Vol. 2); Superfund 16: Proceedings of a Hazardous Waste Conference and Exhibition, Washington, DC, November 6-8, 1995. E.J. Krause and Associates, Bethesda, MD, Vol. 2, 817 pp.; (pp. 956-965) (1994)

The remediation of petroleum-contaminated soil typically requires the selection of a treatment option that addresses the removal of both volatile and semivolatile organic compounds. Volatile organic compounds (VOCs), primarily BTEX (benzene, toluene, ethylbenzene, and xylenes) compounds, can be readily removed from the soil by a variety of well-established technologies. The semivolatile organic compounds, especially the polycyclic aromatic hydrocarbons (PAHs) that are characteristic of petroleum-contaminated soil, are not as amenable to conventional treatment. Low temperature thermal volatilization (LTTV) can be a viable treatment technology depending on the initial contaminant concentrations present and applicable cleanup objectives that must be attained. A two-phase treatability study was conducted at 14 former underground storage tank (UST) sites to evaluate the applicability and effectiveness of LTTV for remediation of approximately 31,000 tons of PAH-contaminated soil. The PAHs of primary concern included benzo(a)anthracene, chrysene, benzo(a)pyrene, benzo(b)fluoranthene, benzo(k)fluoranthene, indeno(1,2,3-cd)pyrene. During Phase I, LTTV operational parameters were varied by trial-and-error and changes in soil treatment effectiveness were monitored. Phase II of the treatability study incorporated the appropriate treatment regime established during Phase I to efficiently remediate the remaining contaminated soil. A single direct-fired LTTV unit was selected for the treatability study. The unit was operated at average temperatures between 600 and 800 degrees Fahrenheit while maintaining a soil feed capacity of 80 to 120 tons per hour. Approximately 80 percent of the soil treated using LTTV technology met applicable regulatory cleanup objectives for all individual PAHs after one residence time in the unit. The remaining 20 percent required multiple treatments to achieve acceptable contaminant reduction, thus increasing the effective residence time. The influent soil had an average moisture content of approximately 16 percent and combined $\mathrm{PAH}$ concentrations of less than $10 \mathrm{mg} / \mathrm{kg}$ (most less than $1 \mathrm{mg} / \mathrm{kg}$ ). Performance data support the viability of this treatment altemative for remediation of PAH-contaminated soil.

\section{6}

V18/024319

Regulatory Perspectives on the Use of Remediation by Natural Attenuation for Petroleum Fuel Releases from Underground Storage Tanks

Daugherty, S.J.

Orange County Health Care Agency, Santa Ana, CA

CONF-9611118; HazMat West '96, Proceedings of an International 
Environmental Management and Technology Conference and Exhibition, November 5-7, 1996. Advanstar Expositions, Duluth, MN, 544 pp.; (pp. 463-481) (1996)

This paper presents a comprehensive general explanation of remediation of hydrocarbon fuels in the subsoil and groundwater by natural attenuation. Attention is focused on the aromatic hydrocarbons benzene, toluene, ethylbenzene, and xylene (BTEX) and the oxygenated fuel additive methyl tertiary butyl ether (MTBE), as these are the most important and the most prevalent groundwater contaminants from fuel. The draft American Society for Testing and Materials (ASTM) Risk-Based Corrective Action (RBCA) Standard Guide for Remediation by Natural Attenuation at Petroleum Release Sites, hereafter referred to as the draft ASTM RNA Guide, is described as it appeared in April of this year. Endorsement of the ASTM RNA Guide by U.S. Environmental Protection Agency may be forthcoming as EPA's involvement with RNA has been similar to their participation in the development of the ASTM RBCA Guide. An integration of ASTM RBCA and the ASTM RNA Guide, adapted for local use, may help resolve the complex and difficult underground storage tank (UST) fuel release problem. The combination of scientific observation by sampling and analysis of appropriate chemicals, combined with reasonable efforts to predict the movement and fate of contaminants based on scientific principles, certainly presents us with the best means of defensible site evaluation.

\section{$2817 \quad \mathrm{~V} 18 / 023640$}

Regulatory Strategies for Remediation of Contaminated Sediments

Zar, H.

U.S. Environmental Protection Agency, Chicago, IL CONF-9406413; Dredging, Remediation, and Containment of Contaminated Sediments, K.R. Demars, G.N. Richardson, R.N. Yong and R.C. Chaney (eds.), Proceedings of a Symposium, Montreal, Quebec, Canada, June 23-24, 1994, 343 pp.; (pp. 319-328) (1995)

A number of federal and state laws may be used to obtain remediation of contaminated sediments in the US. Until recently, the most prominent approaches at the federal level were the use of Superfund authorities for sites on the National priority List and navigational dredging activity by the Corps of Engineers. However, with the increasing concern about contaminated sediments, regional offices of the US Environmental Protection Agency (EPA) and state agencies have begun to use a greater variety of regulatory approaches, both individually and in combination. These efforts have been particularly evident in the Great Lakes and are now being extended nationwide, as embodied in the EPA's Contaminated Sediment Management Strategy. This paper will describe some of the regulatory approaches being applied, case examples in the Great Lakes area, and the expected directions of these efforts, as embodied in the national strategy.

\section{8}

V18/022780

Remedial Experiences in the Application of Full-Scale Soil Washing

Groenendijk, E.; Corden, F.L.; Mann, M.J.

Alternative Remedial Technologies, Inc., Tampa, FL
CONF-960804 (Vol. 2); Spectrum '96: Nuclear and Hazardous Waste Management, Proceedings of an Intemational Topical Meeting, Seattle, WA, August 18-23, 1996. American Nuclear Society, La Grange Park, IL, Vol. 2, 873 pp.; (pp. 1318-1321) (1996)

This paper will discuss the experience and lessons learned on the evaluation, design and operational aspects of full-scale soil washing. Although soil washing is becoming more accepted as a treatment technology in the U.S., limited experience in its full-scale application still appears to be a barrier to more widespread implementation. The purpose of this paper is to overcome this barrier by demonstrating actual field experience in the development and use of full-scale soil washing. Three case studies involving full-scale soil washing are presented here.

2819

V18/023920

Remediation Processes for Heavy Metals Contaminated Soils

Torma, G.A.; Hsu, P.C.; Torma, A.E.

AMROT International, Rio Rancho, NM; Metallurgical Engineering, Mining and Waste Management, Arvada, CO

CONF-961018; Extraction and Processing for the Treatment and Minimization of Wastes, V. Ramachandran and C.C. Nesbitt (eds.), Proceedings of the Second International Symposium, Scottsdale, AZ, October 27-30, 1996. The Minerals, Metals, \& Materials Society, Warrendale, PA, 856 pp.; (pp. 289-304) (1996)

This paper provides information on selected technologies available for remėdiation of metal contaminated soils and industrial effluent solutions. Because some of the historical sites are contaminated with organics (solvents, gasolines and oils), an effort has been made to introduce the most frequently used cost-effective cleanup methods, such as "bioventing" and "composting." The microorganisms involved in these processes are capable of degrading organic soil contaminants to environmentally harmless compounds: water and carbon dioxide. Heavy metals and radionuclides contaminated mining and industrial sites can be remediated by using adapted heat and dump leaching technologies, which can be chemical in nature or bio-assisted. The importance of volume reduction by physical separation is discussed. A special attention is devoted to the remediation of soils by leaching (soil washing) to remove heavy metal contaminants, such as chromium, lead, nickel and cadmium. Furthermore, the applicability of biosorption technology in the remediation of heavy metals and radionuclides contaminated industrial waste waters and acidic mining effluent solutions was indicated.

\section{0}

\section{V18/023489}

Remediation Technologies for Contaminated Bed Sediment: A Brief Review

Thibodeaux, L.J.; Reible, D.D.; Valsaraj, K.T.

Louisiana State University, Department of Chemical Engineering, Baton Rouge, LA

CONF-960730 (Vol. 3); Technologies Critical to a Changing World, Volume III: Emerging Energy Technologies, Clean Technologies, Remediation and Emission Control Fuels, and Petrochemicals, Proceedings of the Fifth World Congress of Chemical Engineering, 
San Diego, CA, July 14-18, 1996. American Institute of Chemical Engineers, New York, NY, Vol. 3, 1118 pp.; (pp. 722-727) (1996)

An overview of the remediation of contaminated bed sediments, including interim controls, is provided. Technologies for insitu and exsitu management are very briefly described. Insitu management practices include natural recovery, in-place capping, immobilization and chemical treatment, and biological treatment. Exsitu management techniques described are treatment, pretreatment and solids-water separation, physical separation, chemical separation, thermal desorption, immobilization, thermal and chemical destruction, biological treatment, and containment.

\section{1}

\section{$\mathrm{V} 18 / 022655$}

Remediation Technologies for Petroleum Contaminated Soils: Methods for Treatment and Decontamination

Lindmark, P.; Larsson, L.B.

Statens Geotekniska Institute, Linkoeping, Sweden; Swedish Environmental Protection Agency, Solna, Sweden

SNV-4445; 183 pp. (September 1995)

The experience with different treatment methods for contaminated soil and groundwater is very limited in Sweden. Most of the techniques have been developed and implemented in the USA, Germany and the Netherlands. This report describes treatment options for petroleum contaminated areas and gives a basis for evaluation and selection of appropriate remediation methods. Proposed criteria for evaluation are: contaminant properties, soil type, environmental goals, land use, time, cost, etc. It is stressed that each new situation must be studied thoroughly before treatment decisions are made. The report consists of two parts: a general overview and a closer description of the different methods. Flow charts and tables are presented to facilitate screening out appropriate methods for a specific case. Possibilities for combining methods are also indicated. For three different methods detailed information is given under the headings: Introduction, Technical Description, Application, Results, Capacity and Cost, Case Histories, Status and Availability, and References. (This document is in Swedish).

\section{2}

V18/020774

Remediation and Reuse of Chromium Contaminated Soils Through Cold Top Exsitu Vitrification

Meegoda, J.N.; Librizzi, B.; McKenna, G.F.; Kamolpornwijit, W.; Cohen, D.; Vaccari, D.A.; Ezeldin, S.; Walden, L.; Noval, B.A.; Mueller, R.T.; Santora, S.

New Jersey Institute of Technology, Newark, NJ; Stevens Institute of Technology, Hoboken, NJ; Energy Products Enrichment, Inc., Norristown, PA; New Jersey Department of Environmental Protection, Trenton, NJ

CONF-9507204; Hazardous and Industrial Wastes, A.K. Sengupta (ed.), Proceedings of the 27th Mid-Atlantic Industrial Waste Conference, Bethlehem, PA, July 9-12, 1995. Technomic Publishing Company, Lancaster, PA, 973 pp.; (pp. 470-479) (1995)

Ten chromium contaminated soil samples were obtained from sites in Hudson County, New Jersey, to investigate the feasibility of vitrification and if they could be used as construction materials.
Each soil contained between 1,000 ppm to $2.5 \%$ chromium with more than $20 \%$ as $\mathrm{Cr}-6+$. All ten soils had high concentrations of iron but were deficient of silica and aluminum. The soil also had very high $\mathrm{pH}$ values and in-situ water contents. Sand was added to augment the silica deficiency. To prevent the detrimental effect of high $\mathrm{pH}$ to vitrification, graphite was added to each soil. Five soil samples were vitrified in a commercial laboratory and slow-cooled to room temperature. The vitrified product was free of $\mathrm{Cr}-6+$ and had low digestible chromium contents. Vitrification seems to produce a stronger and more durable aggregate with high specific gravity to be used as a construction material. This paper describes research in progress.

\section{3}

\section{V18/025457}

Remediation of Contaminated Soils and Groundwater Using a Transportable, Multiphase Bioslurping Treatment System

Dedhar, S.; Cracknell, J.

Jacques Whitford Environment Limited, Markham, Ontario, Canada; Department of the Environment, Environmental Protection Service, Ottawa, Ontario, Canada

CONF-951086; Proceedings of the Fith Annual Symposium on Groundwater and Soil Remediation, Toronto, Ontario, Canada, October 2-6, 1995. Environment Canada - Environmental Protection Service, Hull, Quebec, Canada, 566 pp.; (pp. 267-278) (1995)

A new transportable in-situ remediation system, combining enhanced bioremediation and total fluids vacuum recoven technology with air and water injection developed by Jaeques Whitford Environmental Limited is described. The unit u as designed based on a pilot scale testing program conducted at a former retail fueling operation in downtown Toronto. The unit is capable of rapid remediation of a wide variety of contaminant types at sites with variable subsurface conditions. All processes are automatically controlled using a programmable logic controller and system monitoring. Diagnostics and downloading of data are done by remote telemetry using a high speed modem. Principal fearures of the unit, operational issues, and treatment cost comparisons are discussed.

\section{4}

\section{V18/024621}

Remediation of Contaminated Soils, Chapter 13

Boulder, J.R.

Eastem Research Group, Inc., Lexington, MA

Soil, Vadose Zone, and Groundwater Contamination Assessment, Prevention, and Remediation, Lewis Publishers, Boca Raton, FL, 947 pp.; (pp. 731-760) (1995)

This is a chapter in the book titled: Practical Handbook of Soil, Vadose Zone, and Groundwater Contamination by J. Russell Boulding. Remediation of Contaminated Soils is part of the section on Prevention and Remediation. Soil remediation techniques are applied to the vadose zone ranging from the soil rooting zone to the capillary fringe, and to situations where the saturated zone is engineered to become unsaturated (e.g., when groundwater is pumped to create an unsaturated zone). A table provides information on the suitability of different treatment technologies 
for contaminated soils and sludges. Remediation techniques for contaminated soils can be broadly classified as follows: (1) physical and chemical treatment, (2) biological treatment, (3) fixation or encapsulation, and (4) thermal destruction. Tables provide the following additional summary information on specific techniques in these five categories: (1) ways in which technique can be used (in situ, prepared bed or in-tank). These categories are discussed; (2) the function of the treatment method (detoxification, separation, volume reduction, immobilization); (3) types of wastes that are amenable to treatment using the technique; (4) possible residuals or transformation products; and (5) possible limitations to the technique.

\section{5}

\section{V18/020970}

\section{Remediation of $\mathrm{Hg}$ Contaminated Soil}

Sobolev, I.A.; Barinov, A.S.; Prozorov, L.B.; Kuptsov, V.M. Scientific and Industrial Association - Radon, Engineering Department of the Moscow Government, Moscow, Russian Federation

CONF-960212; Waste Management '96: Working Towards a Cleaner Environment, Proceedings of a Conference on $\mathrm{HLW}$, LLW, Mixed Wastes and Environmental Restoration, Tucson, AZ, February 25-29, 1996; (24 pp.) (1996)

The position of mercury contamination was determined and content of mercury in solid and pore waters was estimated on the artificial range in Sergiev Posad branch of Mos NPO "Radon". The range contains $82.6 \mathrm{~g}$ of mercury in solid and $172.3 \mathrm{mg}$ of mercury in pore water. Desorption of the mercury by the $\mathrm{H}+$ ions in laboratory experiments was studied. Special laboratory research with electrokinetic cell demonstrated that mercury in the hole water had cation form. Electroosmosis and electromigration provided transport of desorbed ions between electrodes. The construction of a metal collector with cationexchangable membranes gave the possibility to accumulate up to concentration $1 \mathrm{~mol} / \mathrm{h}$. The metal collector was tested during 1 month (current $1 \mathrm{~A}$, potential approximately $30 \mathrm{~V}$ ). In natural condition approximately $100 \mathrm{mg}$ mercury was collected. A desorption solution must be introduced in order to receive practical results.

2826

\section{$\mathrm{V} 18 / 023659$}

Remediation of Lead-Contaminated Soil with EDTA: Batch and Column Studies

Heil, D.M.; Samani, Z.A.; Hanson, A.T.; Hu, S.; Rudd, B. New Mexico State University, Las Cruces, NM

CONF-9605266; Proceedings of the 1996 Hazardous Substance Research Center/Waste-Management Education and Research Consortium Joint Conference on Environment, L.E. Erickson, S.C. Grant, D.L. Tillison and J.P. McDonald (eds.), Albuquerque, NM, May 21-23, 1996. Great Plains-Rocky Mountain Hazardous Substance Research Center, Kansas State University, Manhattan, KS, 706 pp.; (pp. 2-10) (1996)

Chelate extraction using ethylenediaminetetraacetic acid (EDTA) and other chelates has been demonstrated to be an effective method of removal of $\mathrm{Pb}$ from many contaminated soils. However, column leaching of $\mathrm{Pb}$ from alkaline soils with EDTA has been problematic due to extremely low soil permeability. The purpose of this study was to determine the effect of the addition of $\mathrm{KOH}$ and $\mathrm{CaCl} 2$ to K2H2-EDTA extraction solution on $\mathrm{Pb}$ removal and hydraulic conductivity. A Pb-contaminated soil was sampled from an abandoned lead-acid battery recycling facility. Both batch shaker extractions and column leaching experiments were completed using five different EDTA extract solutions. Addition of $\mathrm{CaCl} 2$ only to K2H2-EDTA did not change the amount of $\mathrm{Pb}$ removed by batch extraction, and $\mathrm{Pb}$ solubility was only slightly decreased by the addition of both $\mathrm{CaCl} 2$ and $\mathrm{KOH}$. Lead solubility was observed to decrease as $\mathrm{pH}$ was increased by the addition of $\mathrm{KOH}$. The amount of time required to leach $6.0 \mathrm{I}$ of extraction solution through the soil columns varied from 2 to 33 days. The addition of $\mathrm{CaCl} 2$ and/or $\mathrm{KOH}$ resulted in increased soil hydraulic conductivity. However, $\mathrm{Pb}$ removal was diminished with the addition of $\mathrm{CaCl} 2$ and $\mathrm{KOH}$ because of decreased $\mathrm{Pb}$ solubility and also a shorter residence time of the extract solution in the column. The hydraulic conductivity was related to residual calcium carbonate content, suggesting that dissolution of $\mathrm{CaCO} 3$ and subsequent production of $\mathrm{CO} 2$ gas in soil pores was partially responsible for the observed reductions in soil permeability.

\section{$2827 \quad$ V18/020775}

Remediation of Metal/Organic Contaminated Soils by Combined Acid Extraction and Surfactant Washing

Van Benschoten, J.E.; Ryan, M.E.; Huang, C.; Healy, T.C.; Brandl, P.J.

State University of New York at Buffalo, Buffalo, NY CONF-9507204; Hazardous and Industrial Wastes, A.K. Sengupta (ed.), Proceedings of the 27th Mid-Atlantic Industrial Waste Conference, Bethlehem, PA, July 9-12, 1995. Technomic Publishing Company, Lancaster, PA, 973 pp.; (pp. 551-560) (1995)

The specific objectives of this research are to: (1) determine the solubilization of two polycyclic aromatic compounds (PAHs) (naphthalene and pyrene) using several surfactants at low pH conditions; (2) determine the losses of candidate surfactants due to precipitation or adsorption to a test soil as a function of $\mathrm{pH}$; and (3) evaluate the performance of surfactants under acidic conditions for removal of lead and PAH compounds from a contaminated soil. In this paper, experimental results related to the first two objectives are presented.

\section{$2828 \quad$ V18/025585}

Remediation of PCB-Contaminated Soil

Miyamura, A.; Taniguchi, S.; Ebihara, A.

Ebara Corporation, Tokyo, Japan

Ebara Jiho (Ebara Times) 173:23-32 (October 20, 1996)

Results of an experiment (by Ebara Corporation) intended for the remediation of PCB-contaminated soil by the base catalyzed decomposition $(B C D)$ process are discussed in this report. For the purpose of meeting Japan's environmental quality standards for PCB-contaminated soil, a bench-scale decomposition experiment was conducted for a PCB-contaminated soil specimen. In another effort, a pilot-scale experiment was carried out, in which soil specimens contaminated with low and intermediate leveis of PCBs were augmented with various quantities of $\mathrm{NaHCO} 3$ and subjected to 
continual decomposition at various reaction temperatures. The soil treated in the bench-scale experiment satisfied the above standards. The effects of decomposition conducted under various conditions of reaction temperature, reaction time, and $\mathrm{NaHCO}_{3}$ augmentation were compared to determine optimum values. $\mathrm{PCBs}$ were dechlorinated in the soil reactor for the formation of monochlorides, dichlorides, etc., and the results of the pilot-scale continual decomposition experiment were similar to those of the bench-scale experiment. (This document is in Japanese).

\section{9}

\section{V18/025615}

Remediation of Radioactive Contaminants in Soils [Latest Citations from the Energy Science and Technology Database]

NERAC, Inc., Tolland, CT

Bibliography (June 1997)

This bibliography contains citations for articles on the remediation of radionuclides in contaminated soils. Included are discussions of specific sites, remedial investigations, site characterizations, remediation plans, and monitoring. Remediation techniques covered include ion exchange, ultrafiltration, physical and chemical absorption or adsorption, and stabilization.

\section{0}

\section{V18/024129}

\section{Remediation of Radioactively Contaminated Soils}

Los Alamos National Laboratory, Los Alamos, NM

LALP-95-45; 1 p. (1995)

Los Alamos scientists have discovered an efficient and effective way to remove uranium, plutonium, and americium from contaminated soils. Using a variety of leach agents and a sprinkler system, these metals are dissolved and removed from the soil. For uranium, sodium bicarbonate (baking soda) removes radioactive material from soil at uranium-contaminated sites. When uranium-contaminated soil reaches the remediation sites, any physically separable uranium is removed before the soil is transported to leach areas. Each leach area consists of multiple impermeable, slightly sloped ( $3 \%$ grade) leach pads. Uranium-contaminated soil heaped on these pads is sprayed with sodium bicarbonate solution. The solution leaches the uranium from the soil. A trough at the base of the pads carries the uranium-bearing solution to a processing facility, where the uranium is chemically/physically separated. After this remediation process, the soil is environmentally safe and will support plant life.

\section{1}

V18/023636

Remediation of Soil-Bound Polynuclear Aromatic Hydrocarbons Using Nonionic Surfactants

Yeom, I.; Ghosh, M.M.; Cox, C.

University of Tennessee, Knoxville, TN

CONF-951023 (Vol. 8); WEFTEC '95, Proceedings of the 68th

Annual Conference and Exposition of the Water Environment

Federation, Miami Beach, FL, October 21-25, 1995. Water

Environment Federation, Alexandria, VA, Vol. 8, 498 pp.; (p. 424) (1995)

The solubilization and biodegradation of soil-bound polyaromatic hydrocarbons (PAHs) from a manufactured gas plant (MGP) site soil was investigated using surfactants. Three nonionic polyoxyethylene (POE) surfactants, Triton $X-100$, Tween 80 , and Brij 35, were used. The fate of four PAHs, phenanthrene, anthracene, pyrene, and benzo(a)pyrene were monitored during the remediation process. The measured concentrations of solubilized PAHs agreed well with those estimated using the micelle-water partitioning coefficient, $\mathrm{Km}$, and Raoult's law. The solubilization of soil-bound PAHs by surfactants is a slow, nonequilibrium process. Diffusion of PAH molecules within the weathered soil-tar matrix is proposed as the rate-limiting step in solubilizing PAHs from such soils. A radial diffusion model is used to describe solubilization of PAHs by surfactant washing. The model predicts experimental results fairly well at low surfactant dosages while at high dosages it somewhat overestimates the extent of solubilization.

Biodegradation studies were performed using a natural consortium of microorganisms enriched from PAH-contaminated soils. Surfactants enhanced biodegradation of PAHs except for Tween 80 . However, biodegradation of surfactants themselves appear to attenuate the beneficial effects of surfactant-mediated bioremediation.

2832

V18/022215

Remediation of Uranium-Contaminated Soil Using the Segmented Gate System and Containerized Vat Leaching Techniques: A Cost Effectiveness Study

Cummings, M.; Booth, S.R.

Los Alamos National Laboratory, Los Alamos, NM

LA-UR-26-2663; 10 pp. (1996)

Because it is difficult to characterize heterogeneously contaminated soils in detail and to excavate such soils precisely using heavy equipment, it is common for large quantities of uncontaminated soil to be removed during excavation of contaminated sites. Until now, volume reduction of radioactively contaminated soil depended upon manual screening and analysis of samples, a costly and impractical approach, particularly with large volumes of heterogeneously contaminated soil. The baseline approach for the remediation of soils containing radioactive waste is excavation, pretreatment, containerization, and disposal at a federally permitted landfill. However, disposal of low-level radioactive waste is expensive and storage capacity is limited. ThermoNuclean's Segmented Gate System (SGS) removes only the radioactively contaminated soil, in turn greatly reducing the volume of soils that requires disposal. After processing using the SGS, the fraction of contaminated soil is processed using the containerized vat leaching (CVL) system developed at LANL. Uranium is leached out of the soil in solution. The uranium is recovered with an ion exchange resin, leaving only a small volume of liquid low-level waste requiring disposal. The reclaimed soil can be returned to its original location after treatment with CVL.

2833

V18/025312

Remediation of Uranium-Contaminated Soil Using the Segmented Gate System and Containerized Vat Leaching Techniques: A Cost Effectiveness Study

Cummings, M.; Booth, S.R.

Los Alamos National Laboratory, Technology and Safety Division, Energy and Environmental Analysis Group, Los 
Alamos, NM

CONF-970335; Waste Management '97: Working Towards a Cleaner Environment, Proceedings of a Conference on $\mathrm{HLW}$, LLW, Mixed Wastes and Environmental Restoration, Tucson, AZ, March 2-6, 1997; (10 pp.) (1997)

An innovative, two-stage process for the remediation of uranium-contaminated soils was successfully demonstrated at Los Alamos National Laboratory (LANL) Technical Area 33 (TA-33). The first step in the treatment process reduced the volume of the contaminated soil using the Thermo Nuclean (a division of the Thermo NUtech company) Segmented Gate System (SGS). This technique applies the use of radiation detectors to separate clean soil from contaminated soil as it moves along a conveyor belt. Contaminated soil is diverted to a separate storage bin to await further processing, while uncontaminated soil is returned to its original location. From the $\mathbf{2 1 8}$ cubic yards of soil excavated from the test site at TA-33, only 7 cubic yards were found to contain uranium contamination above the criterion release limit, yielding an initial waste volume reduction of $97 \%$. The second step in the remediation was removal of the uranium from the 7 cubic yards of remaining soil using the containerized vat leaching (CVL) process developed at LANL. By applying the combined SGS/CVL processes, the total volume of radioactive waste at TA-33 was reduced from 218 cubic yards of contaminated soil to approximately 30 gallons of leachate solution and resins. In addition, the recovered commercial-grade uranium may be resold to recover some of the costs of operation. The current price of uranium is $\$ 14.80 / \mathrm{b}$. A cost effectiveness analysis was performed comparing the above two-stage treatment process to conventional excavation, containerization, and intermment (dig and haul). Results showed that while the cost of remediating the small volume of soil at TA-33 was slightly more expensive using the baseline treatment method, significant cost savings can be realized using SGS/CVL when treating greater volumes of soil, assuming that the contaminated soil must be shipped to a permitted facility such as Utah's Envirocare.

\section{4}

V18/024130

Remediation of Uranium-Contaminated Soils

Los Alamos National Laboratory, Los Alamos, NM

LALP-95-45; 1 p. (1995)

Scientists have discovered an efficient and effective way to use sodium bicarbonate (baking soda) to remove radioactive material from soil at uranium-contaminated sites. When uranium-contaminated soil reaches the remediation sites, any physically separable uranium is removed before the soil is transported to leach areas. Each leach area consists of multiple impermeable, slightly sloped ( $3 \%$ grade) leach pads.

Uranium-contaminated soil heaped on these pads is sprayed with sodium bicarbonate solution. The solution leaches the uranium from the soil. A trough at the base of the pads carries the uranium-bearing solution to a processing facility, where the uranium is chemically/physically separated. After this remediation process, the "cleaned soil" is environmentally safe and will support plant life.

\section{5}

\section{V18/023919}

Removal of $\mathrm{As}, \mathrm{Cd}$, and $\mathrm{Pb}$ from Contaminated Smelter Soils by Incineration
White, C.V.; Hager, J.P.

Colorado School of Mines, Department of Metallurgical and Materials Engineering, Golden, $\mathrm{CO}$

CONF-961018; Extraction and Processing for the Treatment and Minimization of Wastes, V. Ramachandran and C.C. Nesbitt (eds.), Proceedings of the Second International Symposium, Scottsdale, AZ, October 27-30, 1996. The Minerals, Metals, \& Materials Society, Warrendale, PA, 856 pp.; (pp. 115-129) (1996)

An experimental study was undertaken to investigate the feasibility of utilizing vapor transport for the treatment of heavy metal contaminated smelter soils. The focus of this project was to develop process chemistries that would make incineration a viable process for the treatment of these soils. The experimentation concentrated on the elimination of arsenic, cadmium, and lead, and was performed in a laboratory scale rotary kiln setup. Three soil samples from non-ferrous smelter sites, which contained various concentrations of contaminants, were utilized in the experimentation. Three chemistries were investigated for the volatilization of the heavy metals: Chloriding volatilization, ferric chloride vapor complex formation, and the use of oxygen potential control. The samples were analyzed for residual heavy metals so that the extractions could be determined. However, the ultimate test was the leachability of the residuai arsenic, cadmium, and lead, as determined by the TCLP test. The results firmly establish that incineration is a feasible process for the treatment of metal contaminated soils. It was found that no one process chemistry is suitable for all different soil samples. A two-step process consisting of a reducing step followed by a hydro-chlorination step was required to make Soil Sample-B pass the TCLP tests for all three heavy metals. Soil Sample-A passed the TCLP tests for arsenic, cadmium, and lead using a hydro-chlorination process at a minimum temperature of 700 degrees $C$. In addition to passing the TCLP test for Soil Sample-A and Soil Sample-B, 70 to 80 percent removal of the impurities was accomplished. This demonstrates that the leachability of the impurities was decreased primarily due to the removal of a large fraction of the contaminants. Soil Sample-C possessed very high levels of cadmium and lead and only moderate extractions of the impurities were generated from this soil. The arsenic TCLP test was passed at 500 degrees $C$ using a process gas containing ferric chloride and at temperatures of 700 degrees $\mathrm{C}$ and above using chlorination or hydro-chlorination.

\section{6 \\ V18/023643}

Removal of Contaminated Sediments: Equipment and Recent Field Studies

Herbich, J.B.

Texas A\&M University, College Station, TX; Consulting and Research Services, Inc., College Station, TX; Consulting and Research Services, Inc., Wailuku, HI

CONF-9406413; Dredging, Remediation, and Containment of Contaminated Sediments, K.R. Demars, G.N. Richardson, R.N. Yong and R.C. Chaney (eds.), Proceedings of a Symposium, Montreal, Quebec, Canada, June 23-24, 1994, 343 pp.; (pp. 77-111) (1995)

The problem of contaminated marine sediments has emerged as an environmental issue of national importance. Harbor areas in particular have been found to contain high levels of contaminants in bottom sediments due to wastes from municipal, industrial, and 
riverine sources. This paper briefly examines the extent and significance of marine sediment contamination in the US, and reviews the state of the art of contaminated sediment cleanup and recent field studies or demonstrations.

\section{$2837 \quad$ V18/024106}

\section{Removal of Uranium from Soil}

Los Alamos National Laboratory, Los Alamos, NM

LALP-94-265; 1 p. (1994)

Millions of cubic yards of soil that are contaminated with uranium need to be cleaned up in an economical, safe, and effective manner. A new technology for doing this is an adaptation of a proven mining method called heap leaching. We have modified this method to remove uranium from soil. The process is being simulated in the laboratory by using leaching columns. At field scale, uranium-contaminated soil will be excavated and heaped up on an impermeable pad. The leaching solution will be applied on top of the heap with a drip irrigation system. The solution flows downward, by gravity, through the heap, leaching out the uranium. The leachate emerging from the bottom of the heap will be collected and the uranium will be recovered. The regenerated leaching solution will be recycled to the top of the heap in a closed loop operation. The leaching reagent for uranium is an aqueous solution of sodium bicarbonate, known to the general public as baking soda.

2838

\section{V18/023866}

Research on the Low-Temperature Decontamination of Soil

Hetland, M.D.; Rindt, J.R.

University of North Dakota, Energy and Environmental Research Center, Grand Forks, ND

EPA/600/R-95/012; CONF-9504110; Proceedings of the 21st Annual Risk Reduction Engineering Laboratory (RREL) Research Symposium, Cincinnati, OH, April 4-6, 1995. U.S. Environmental Protection Agency, Cincinnati, OH, 398 pp.; (pp. 89-93) (April 1995)

Decontamination of organically contaminated soil requires at least two processes: (1) separation of the contaminants from the soil, and (2) destruction or stabilization and recovery of the organic contaminants. Techniques used to convert the organic contaminants must produce environmentally acceptable products. A process is seen as more favorable if the inorganic portion remaining after destruction of the organic contaminants retains a "natural" state, since ideally the residual should be returned to the original ecological system. Low-temperature plasma (LTP) processing has the potential to offer decontamination equivalent to incineration with decreased production of harmful by-products and without changing the morphology of the inorganic matrix. Low-temperature plasmas (LTP) are formed by electric discharge (rather than thermal means) at conditions that do not result in thermal equilibrium. It is possible with an LTP system for typical plasma reactions to occur at nearly ambient bulk temperatures. The purpose of this project is to perform the appropriate engineering evaluations needed to scale up an LTP soil decontamination process developed at the Energy \& Environmental Research Center (EERC). The LTP process under development uses oxygen plasma, resulting in oxidation of the contaminant species. Previous research at the EERC proved that the technique successfully separates organic contaminants from soil. The success of this previous research indicated that the use of LTP as a decontamination technique should be investigated further, with possible scaleup to real-world application.

2839

V18/021810

Researchers Study Munitions-Contaminated Soil

Comfort, S.D.; McDonald, J.P.

University of Nebraska, Department of Agronomy, Lincoln, NE

HazTech Transfer (July 1995):4-5 (July 1995)

Past practices of disposing of munitions waste at numerous locations around the country have resulted in large volumes of soil contaminated with TNT and other munitions residues. One such facility, the Nebraska Ordnance Plant (NOP), offers researchers at the University of Nebraska a unique opportunity to study phenomena critical to cleanup of these soils. An interdisciplinary team of researchers is studying TNT transport and fate in contaminated soil. Soil columns and long-term equilibration experiments are being conducted to obtain information that will be used to develop a computer model to predict TNT transport and fate in soil under various scenarios.

2840

V18/024317

ResonantSonic [R] Drilling Method Produces Core Samples and Monitoring Wells at Competitive Costs Hazardous Waste Consultant 13(4):1.1-1.3 (July-August 1995) Water Development Corporation (Woodland, California) recently teamed with the U.S. Department of Energy (DOE) to develop a drilling method for the environmental industry that does not require the addition of any drilling fluid. Originally patented for use in the mining industry, ResonantSonic [R] drilling uses a combination of mechanically generated vibrations and rotation to drill boreholes and collect subsurface materials, particularly undisturbed, continuous core samples. The technology was demonstrated between 1991 and 1994 at three DOE sites: Hanford (Richland, Washington), Sandia National Laboratory (Albuquerque, New Mexico), and Pantex (Amarillo, Texas).

\section{$2841 \quad$ V18/022003}

Results of Lasagna Process Field Experiment at the Paducah Gaseous Diffusion Plant

Athmer, C.J.; Ho, S.V.

Monsanto Company, Environmental Sciences Center, St. Louis, MO

CONF-9509139; Emerging Technologies in Hazardous Waste Management VII, D.W. Tedder (ed.), Proceedings of the Seventh American Chemical Society Industrial and Engineering Chemistry Division Special Symposium, Atlanta, GA, September 17-20, 1995. American Chemical Society, Washington, DC, 1291 pp.; (p. 871) (1995)

The Lasagna process is being developed to remediate clayey soils in-situ. Lasagna is a combination of electrokinetics and in-situ 
treatment taking place in installed treatment zones. The zones are formed in either horizontal or vertical orientation using modified existing geoengineering processes. A Lasagna field experiment combining electroosmosis with carbon adsorption in the vertical orientation has been conducted at a TCE contaminated DOE site in Paducah, KY. Carbon adsorption was chosen for this first field test so that a material balance could confirm the movement of TCE from the clay to the treatment zones. The results of this experiment are presented in this paper. (Complete text)

\section{2 \\ V18/023893}

Results of a SITE Demonstration of the COGNIS Terramet [R] Lead Extraction Process to Remove Heavy Metals from Soil

Banerjee, P.; Royer, M.D.

PRC Environmental Management, Inc., Rolling Meadows, IL; U.S. Environmental Protection Agency, Risk Reduction Engineering Laboratory, Edison, NJ

EPA/600/R-95/012; CONF-9504110; Proceedings of the 21st Annual Risk Reduction Engineering Laboratory (RREL) Research Symposium, Cincinnati, OH, April 4-6, 1995. U.S. Environmental Protection Agency, Cincinnati, OH, 398 pp.; (p. 380) (April 1995)

The COGNIS, Inc. Terramet [R] process is a chemical process that extracts and recovers lead and other metals from contaminated soil, dust, sludge, or sediment. The process begins by removing and washing oversize material and then separating the remaining soil into sands and fines fractions. The sands fraction is further treated by density separation methods to isolate particulate metals as a concentrate. The sands and fines fractions are then separately leached in the Terramet $[R]$ portion of the process by a proprietary leachant to bring fine metallic particles and ionic metals into solution. Leached metals are recovered through proprietary reductive electrochemical cells, producing a metal concentrate and regenerating the leachant for recycling. Clean soil exiting the system can be retumed to the site. The recovered metals are recyclable. No wastewater streams are generated during process operations. The COGNIS, Inc. Terramet $[R]$ process was selected to remediate approximately 10,000 tons of heavy-metal (predominantly lead) contaminated soil at the Twin Cities Army Ammunition Plant (TCAAP), New Brighton, Minnesota. EPA's Superfund Innovative Technology Evaluation (SITE) program is currently evaluating the COGNIS, Inc. Terramet $[R]$ process. The evaluation included a 4-day sampling effort during the TCAAP remediation. The SITE sampling effort focussed primarily on determining the effectiveness of the leaching processes for removing lead from both the sands and the fines fractions of the soil. Other results that will be reported as part of the evaluation include overall effectiveness of lead removal, efficiency of lead recovery cells, and costs. (Complete text)

\section{3}

\section{V18/023881}

Review of Mathematical Modeling for Evaluation of SVE Applications

Jordan, D.L.; Mercer, J.W.

GeoTrans, Inc., Sterling, VA

EPA/600/R-95/012; CONF-9504110; Proceedings of the 21st Annual Risk Reduction Engineering Laboratory (RREL) Research
Symposium, Cincinnati, OH, April 4-6, 1995. U.S. Environmental Protection Agency, Cincinnati, OH, 398 pp.; (pp. 265-271) (April 1995)

Soil vapor extraction (SVE), a demonstrated technology, enhances the removal of volatile chemicals from the subsurface through application of a vacuum at an extraction well to induce air flow through the subsurface toward the well. The work reported here included a review of models that can be applied to SVE applications. This paper provides a brief discussion of the review process and provides a table that summarizes capabilities, advantages, limitations, and availability of models included in the review.

2844

V18/024111

Rock Melting: An "Aseptic" Drilling Technology

Los Alamos National Laboratory, Los Alamos, NM

LALP-94-242; 1 p. (1994)

Rock melting represents a true "aseptic" drilling method that offers several advantages over conventional drilling systems. Unlike mechanical drilling, rock melting does not produce tailings or require the use of lubricants and casings. As a result, manmade materials and contaminants (such as kerosenes, detergents, plastics, and metals) are not introduced during the drilling operation. Moreover, this technology minimizes the remobilization of in situ waste products. The field-tested compactor-penetrator tool prototype Los Alamos developed is particularly adapted to penetrating soils and various sorted-unconsolidated and porous-consolidated rocks encountered at many waste sites.

\section{5}

V18/025370

\section{Role of Microorganisms in Soil Bioremediation,} Chapter 1

Bollag, J.M.; Mertz, T.; Otjen, L.

Pennsylvania State University, Laboratory of Soil

Biochemistry, Center for Bioremediation and Detoxification, University Park, PA

Bioremediation Through Rhizosphere Technology, T.A. Anderson and J.R. Coats (eds.), American Chemical Society, Washington, DC, 249 pp.; (pp. 1-10) (1994)

It has long been recognized that microorganisms have distinct and unique roles in the detoxification of polluted soil environments and, in recent years, this process has been termed bioremediation or bioreclamation. The role of microorganisms and their limitations for bioremediation must be better understood so they can be more efficiently utilized. Application of the principles of microbial ecology will improve methodology. The enhancement of microbial degradation as a means of bringing about the in situ clean-up of contaminated soils has spurred much research. The rhizosphere, in particular, is an area of increased microbial activity that may enhance transformation and degradation of pollutants. The most common methods to stimulate degradation rates include supplying inorganic nutrients and oxygen, but the addition of degradative microbial inocula or enzymes as well as the use of plants (phytoremediation) should also be considered. This document is a chapter from the book Bioremediation through Rhizosphere Technology. 


\section{6}

$\mathrm{V} 18 / 022216$

SAGEEP '96: Proceedings of the Ninth Annual Symposium on the Application of Geophysics to Engineering and Environmental Problems, Denver, CO, April 15-May 1, 1996

Bell, R.S.; Cramer, M.H.

CONF-960477; SAGEEP '96, R.S. Bell and M.H. Cramer (eds.), Proceedings of the Ninth Annual Symposium on the Application of Geophysics to Engineering and Environmental Problems, Denver, CO, April 15-May 1, 1996. Environmental and Engineering Geophysical Society, Wheat Ridge, CO, 1353 pp. (1996)

This document contains the Proceedings of the Symposium on the Application of Geophysics to Engineering and Environmental Problems which was held on April 28-May 2, 1996 in Keystone, Colorado, USA. Topics covered in the presentations include: Innovations in Electrical and Electromagnetic Methods, Near Surface Seismic Applications, Environmental Aspects of Abandoned and Inactive Mines, Hydrogeology, The Search for Buried Objects, Ground Penetrating Radar (GPR) Applications, Geotechnical Applications, Computer Applications and Advancements, Borehole and Tomographic Studies, Site Assessments, and Environmental Geophysics in Finland. Poster presentations also covered a variety of topics including electromagnetic mapping of karstic aquifers, mapping of mine subsidence, geophysical surveys of abandoned reactor sites, and several other applications of geophysics. Papers within the scope of this database have been indexed separately.

\section{7}

V18/021723

\section{SELPhOx Process for Remediation of Contaminated} Soil

Ekhtera, M.R.; Mensinger, M.C.; Rehmat, A.; Deville, B. University of Illinois, Chicago, II; Institute of Gas Technology, Des Plaines, II; U.S. Environmental Protection Agency, National Research Laboratory, Cincinnati, $\mathrm{OH}$

CONF-960376 (Part 1); Proceedings of the 211th American Chemical Society (ACS) National Meeting, New Orleans, LA, March 24-28, 1996. ACS, Washington, DC, Part 1, 1172 pp.; (p. 963, Paper I EC 218) (1996)

The SELPhOx process is being developed as a highly flexible means of remediating and destroying both high and low concentrations of light aliphatic to heavy aromatic contaminants from solid and soil matrices. The process employs two distinct technologies: extraction of organic contaminants with supercritical carbon dioxide and wet air oxidation (WAO) destruction of the extracted contaminants. A separation step links the two process stages. IGT has conducted supercritical extraction tests over wide ranges of temperature, pressure, and $\mathrm{CO} 2$ /contaminant ratios with soils from a wood treatment plant and two manufacturing gas plant sites. The addition of methanol as an extraction modifier was also explored. At comparable $\mathrm{CO} 2$-to-contaminant ratios and extraction conditions of 48 degrees $C$ and $137 \mathrm{~atm}$, the total PAHs removed from the three soils ranged from 76.9 to 97.9 percent with $\mathrm{CO} 2$ alone and from 88.4 to 98.6 percent with methanol added. Results of these tests are presented. (Complete text)
SITE Demonstration of Bioremediation of Cyanide at the Summitville Colorado Site

Thompson, L.C.; Fischer, R.; Beckman, S.W.

Pintail Systems, Inc., Aurora, CO; Dames \& Moore, Denver, $\mathrm{CO}$; Science Applications International Corporation, Hackensack, NJ

EPA/600/R-95/012; CONF-9504110; Proceedings of the 21st Annual Risk Reduction Engineering Laboratory (RREL) Research Symposium, Cincinnati, OH, April 4-6, 1995. U.S. Environmental Protection Agency, Cincinnati, OH, 398 pp.; (pp. 134-139) (April 1995)

The Summitville Mine in southern Colorado is located in the San Juan mountains at an average site altitude of 11,500 feet. There are multiple sources of contamination at the site due to historic and Summitville Consolidated Mining Corporation, Inc. (SCMCI) mining operations. Emergency response operations at the site have prevented releases of severely contaminated solution, and studies are underway to define a permanent solution to detoxification or neutralization of the various mine waste units. This report addresses demonstration of an innovative bioremediation technology for treatment of cyanide and soluble leachable metals in the heap and heap solutions. The heap leach pad (HLP) pad consists of approximately 10 million tons of cyanide-leached ore and 90 to 150 million gallons of process solution. Dames \& Moore and Pintail Systems, Inc. (PSI) jointly submitted a proposal suggesting application of biotreatment processes for treatment of the spent ore and process solutions in the HLP. The primary objectives of the Dames \& Moore/Pintail Systems proposal were to: (1) Demonstrate the feasibility of spent ore and process solution cyanide bio-detox; (2) Develop site-specific biotreatment processes for spent ore and process solution cyanide detox; (3) Provide treatment data for use in the RU/FS and Record of Decision (ROD) for the Spent Ore and Entrained Solutions operable units at the Summitville Mine; and (4) Immobilize potentially leachable metals including zinc, copper, manganese, iron and arsenic within the heap to improve water quality. Tests and demonstrations outlined in the proposal were conducted in PSI's Aurora, Colorado lab and pilot plant and at the mine site. Spent ore treatability testing included waste characterization, bacteria isolation and bioaugmentation, parallel column treatment tests, data evaluation and reporting.

2849

V18/023868

SITE Demonstration of Terra-Kleen Response Group's Mobile Solvent Extraction Process

Meckes, M.C.; Engle, S.W.; Kosco, B.

U.S. Environmental Protection Agency, Cincinnati, OH; PRC Environmental Management, Inc., Cincinnati, $\mathrm{OH}$

EPA/600/R-95/012; CONF-9504110; Proceedings of the 21st Annual Risk Reduction Engineering Laboratory (RREL) Research Symposium, Cincinnati, OH, April 4-6, 1995. U.S. Environmental Protection Agency, Cincinnati, OH, 398 pp.; (pp. 125-128) (April 1995)

Terra-Kleen Response Group's (TKRG) solvent extraction process was effective in removing polychlorinated biphenyls (PCB) and Oil and Grease from dry sandy soils. The extraction process was operated for 11 cycles to achieve a predetermined remediation goal of less than $2.0 \mathrm{mg} / \mathrm{kg} \mathrm{PCB}$ in soil. Oil and Grease concentrations in 
the contaminated soils were also reduced to less than $330 \mathrm{mg} / \mathrm{kg}$. All five batches treated met the remediation goal demonstrating that treatment of solids was consistent. Vacuum extraction combined with biological treatment was able to reduce the concentration of residual solvent in treated solids to less than 0.5 percent. Further reduction of residual solvent concentrations in solids may have been possible if treatment would have been allowed to continue.

\section{0}

\section{V18/023871}

\section{SITE Demonstration of the SVVS Technology}

de Percin, P.R.

U.S. Environmental Protection Agency, Risk Reduction Engineering Laboratory, Cincinnati, $\mathrm{OH}$

EPA/600/R-95/012; CONF-9504110; Proceedings of the 21st Annual Risk Reduction Engineering Laboratory (RREL) Research Symposium, Cincinnati, OH, April 4-6, 1995. U.S. Environmental Protection Agency, Cincinnati, OH, 398 pp.; (pp. 149-152) (April 1995)

The Subsurface Volatilization and Ventilation System (SVVS) is an integrated technology used for attacking all phases of volatile organic compound (VOC) contamination in soil and groundwater. The SVVS technology promotes in-situ remediation of soil and groundwater contaminated with organic compounds through the injection of air into the saturated and unsaturated zones and extraction of vapors from the vadose zone. Through this process, volatile and semivolatile organic compounds are stripped from the soil and groundwater. The subsurface circulation of air also increases dissolved oxygen concentrations in the saturated zone, capillary fringe, and vadose zone, thereby promoting aerobic microbiological processes. The contaminated air extracted from the wells can be treated at the surface before being discharged to the environment. The SVVS process was evaluated under the Superfund Innovative Technologies Evaluation (SITE) program at the Electro-Voice, Inc., (EV) facility in Buchanan, Michigan. The soils were contaminated with aromatic hydrocarbons and halogenated and non-halogenated volatile and semivolatile organic compounds (SVOC) through discharge into a dry well. Baseline data indicated that approximately $1,000 \mathrm{~kg}$ of VOC and SVOC contamination was present in the dry well area soils, principally in a subsurface sludge layer. The resuits from the demonstration indicate the SVVS technology provided a site average of $80.6 \%$ reduction of volatile organics in the vadose zone.

\section{1}

\section{V18/022962}

\section{SITE Technology Capsule: UTRI Radio Frequency Heating Technology}

\section{U.S. Environmental Protection Agency, Cincinnati, $\mathrm{OH}$}

EPA/540/R-94/527a; 10 pp. (March 1995)

Radio Frequency heating (RFH) technologies use electromagnetic energy in the radio frequency (RF) band to heat soil in situ, thereby potentially enhancing the performance of standard soil vapor extraction (SVE) technologies. Contaminants are removed from in situ soils and transferred to collection or treatment facilities. The Illinois Institute of Technology Research Institute (ITR) RFH process was evaluated under the U.S. Environmental Protection Agency's (EPA) Superfund Innovative Technology Evaluation (SITE) Program at a site containing various organic contaminants in a heterogeneous soil matrix. Due to changes in the original design and operational problems experienced during the demonstration, the treatment area was evaluated as two separate zones: the "revised" design treatment zone and the "heated" zone. The revised design treatment zone reflects both changes made to the design of the RFH system and operational problems associated with shallow groundwater at the test site. The heated zone consists of the area that achieved the target temperature of 150 degrees $C$.

Concentration changes were calculated from paired pre- and post-demonstration soil samples; these concentration changes were evaluated for statistical significance. Conclusions have been drawn based only on data that were statistically significant at greater than or equal to the 90 percent confidence level.

\section{2}

V18/025327

Safety of Various Waste Disposal Options for Soil from the Clean-Up of Federal Facilities

Schaffer, S.A.; McLaughlin, T.; Numark, N.; Boyd, M.

Sanford Cohen \& Associates, Inc., Sykesville, MD; U.S. Environmental Protection Agency, Washington, DC

CONF-970335; Waste Management '97: Working Towards a Cleaner Environment, Proceedings of a Conference on $\mathrm{HLW}$, LLW, Mixed Wastes and Environmental Restoration, Tucson, AZ, March 2-6, 1997; (6 pp.) (1997)

Contaminated soil from the clean-up of U.S. federal facilities represents a unique waste disposal problem because its very large volume and relatively low concentrations of hazardous contaminants when compared to other waste streams. Disposal of this soil in a typical low-level waste facility could be extremely expensive and wasteful because of the large volume and low contamination characteristics of the soil. In addition, low-level waste disposal may not protect against the hazardous of the non-radioactive hazardous substances. A study was conducted to determine the safety of disposing contaminated soil in the following four different types of land disposal systems: (1) Municipal Landfill (RCRA Subtitle D); (2) Hazardous Waste Landfill (RCRA Subtitle C); (3) Uranium Mill Tailings Facility; and (4) Low-Level Waste Facility. The results of the risk assessment showed that the more water soluble radionuclides (I-129 and TC-99) represented the far greater risk. The overall risk from each disposal option was below 3E-04 suggesting that any of the four land disposal systems could provide an acceptable level of protection.

2853

V18/022209

Salt Associated with Oil and Gas Activities: Remediation and Related Issues

Deuel, L.E., Jr.

U.S. Department of Energy, Washington, DC

CONF-9509296; Environmental Issues and Solutions in Petroleum Exploration, Production, and Refining, KL. Sublette (ed.), Proceedings of the Second International Petroleum Environmental Conference, New Orleans, LA, September 25-27, 1995, 1078 pp.; (pp. 605-617) (1995)

Salt, or brine, are generic terms for the chemical compound sodium chloride. Ancient cultures and civilizations actually used salt as money for barter and trade for goods and services. Presently, salt in 
the oil patch can still be equated with money, but in terms of capital outlay rather than barter and trade. Hazardous wastes, heavy metals, hydrocarbons, and other substances, are perceived by the public as a greater environmental threat than salt and thus receive greater corporate attention. However, in terms of actual damage to the environment and capital outlay necessary for remediation, all other constituents pale in comparison to salt. The primary source of salt associated with oil and gas activities is produced water, with produced solids, drilling muds, and cuttings a very distant second. Produced waters contain salt concentrations ranging from trace levels to 2.6 pounds per gallon of water. The average for production provinces in the continental United States is about 0.7 pounds per gallon. Salt wasting of land is considered complete and irreparable at a salt concentration in soil of 7,500 ppm. Salt damaged soils are classed as either saline, saline/sodic, or sodic. The only way to reclaim a saline soil is to flush it with fresh water. There is no miracle product or magic elixir that can do this job. A saline/sodic soil contains both excess salt and excess exchangeable (adsorbed) sodium. Remediation of a saline/sodic soil requires the addition of amendments to address the exchangeable sodium, prior to the addition of fresh water to flush the excess salt. Sodic soils are the most difficult to remediate because of their dispersed nature, and the innate difficulty of placing amendments in contact with the soil particles necessary for the exchange processes to occur.

2854 V18/021817

\section{Sampling Liner Finds the Way}

Keller, C.

Soil and Groundwater Cleanup (May 1995); 3 pp. (May 1995)

Use of the Seamist system is growing rapidly as its workings, advantages and full range of applications are discovered. The methods of installation are becoming much more varied than the simple reel canister method. The major limitation is the requirement for an open hole. But given an open hole in any direction, the system supports the installation of a wide variety of measurement and remedial tools. The air driven everting liner can tow logging tools, cameras, sampling tubing, absorbers or other tools into pipes, tanks and boreholes to collect data - with minimum hazard to workers, and without contamination or loss of the instruments.

2855

V18/025618

Scale-Up and Economic Analysis for the Design of Supercritical Fluid Extraction Equipment for Remediation of Soil

Montero, G.A.; Giorgio, T.D.; Schnelle, K.B., Jr.

Vanderbilt University, Nashville, TN

Environmental Progress 15(2):112-121 (Summer 1996)

The magnitude of the contaminated site clean-up in the United States indicates the need for more effective, less costly remediation technologies. Supercritical Fluid Extraction (SFE) using carbon dioxide $\mathrm{CO} 2$ as a supercritical fluid is a possible altemative technology for remediation of soil contaminated with volatile organic compounds. The feasibility of this process is mainly dependent on two factors: the extent and extraction rate of heavy molecular weight organic compounds from soil by supercritical carbon dioxide (SC-CO2). This paper presents results of a bench-scale study for remediation of soils contaminated with naphthalene and 1,2,4 trimethyl benzene as a function of the $\mathrm{CO} 2$ flow rate and supercritical fluid density. These data are used to perform a basic economic analysis of the process by using these two organics selected as model soil contaminants. An additional aim of this study was to develop scale-up methodology from laboratory SFE devices to industrially useful equipment. Furthermore, this study included the collection and analysis of the experimental data to support the application of the supercritical fluid extraction technology and to provide the conceptual design and operational processes required for the construction of a pilot plant unit.

2856

V18/021454

\section{Scientists Put the Chill in Drill to Clean Up Waste}

Wooldridge, $\mathrm{M}$.

Lawrence Berkeley National Laboratory, Berkeley, CA

LBL Currents 22(20):1 (May 20, 1994)

Researchers in the Earth Sciences Division have put a cool twist on the underground drilling used to clean up toxic waste sites. They have invented a drill that blasts super-cold nitrogen gas as it bores, creating frozen holes that won't collapse even in the sandiest of soils. Nitrogen is injected down the drill's center pipe and exits through nozzles near the spinning drill bit. At -196 deg C. the gas freezes difficult soils rich in sand, gravel or ash long enough for workers to insert stabilizing metal casings into the holes before the ground thaws.

2857

V18/023743

\section{Seasonal Effects on Bioremediation at a Fixed Site Soil} Center

Solsrud, T.T.; Green, R.B.; Hater, G.R.

Ridgeview Recycling and Disposal Facility, Whitelaw, WI; Waste Management Inc. Biosites, Cincinnati, $\mathrm{OH}$

CONF-950978; Municipal and Industrial Waste, Proceedings of the 18th Intemational Madison Waste Conference, Madison, WI, September 20-21, 1995. University of Wisconsin, Madison. WI, 461 pp.; (pp. 102-109) (1995)

Temperature influences the bioremediation rate of petroleum hydrocarbon contaminated soil. The measurement of oxygen utilization and carbon dioxide production is a commonly used method of estimating aerobic microbiological activity in soils. In this study, oxygen, carbon dioxide and temperature was monitored at multiple depths during winter and summer operation of two aerated soil piles. Each pile contains up to 40,000 tons of petroleum contaminated soil. This remediation technique known as vacuum heap, consists of an aerated pile inoculated with petroleum degrading bacterial cultures and a nutrient source. Results of the study suggest that carbon dioxide production and oxygen utilization are sensitive to changes in soil temperature. Although soil microbial activity, as measured by oxygen use and carbon dioxide production, slowed at very low temperatures, it did not cease completely. Additionally, petroleum hydrocarbon levels during winter and summer operation were reduced to such levels that the remediated soil could be beneficially reused, thus demonstrating the feasibility of year round treatment of petroleum contaminated soil using this technique. 


\section{8}

V18/020968

Selective Chelation of Lead in Soil with a Water Soluble Polymer

Rampley, C.G.; Ogden, K.L.; Sauer, N.N.

University of Arizona, Department of Chemical and Environmental Engineering, Tucson, AZ; Los Alamos National Laboratory, Chemical Science and Technology Division, Los Alamos, NM

CONF-960212; Waste Management ' 96 : Working Towards a Cleaner Environment, Proceedings of a Conference on $\mathrm{HLW}$, LLW, Mixed Wastes and Environmental Restoration, Tucson, AZ, February 25-29, 1996; (11 pp.) (1996)

A proprietary chelating polymer has been synthesized with a high affinity for lead. Batch experiments show the chelator's ability to reduce lead contaminated levels to below EPA requirements in a single washing step. In order to effectively investigate the process feasibility of soil remediation of lead contaminated soil with this polymer, soil transport characteristics must be known. Column experiments using radiolabeled chelator yield information pursuant to vital parameters needed for feasibility studies. Preliminary data suggests that the chelator has a low affinity for quart.

V18/023615

Simulation of Bioventing for Soil and Groundwater Remediation

McClure, P.D.; Sleep, B.E.

University of Toronto, Department of Civil Engineering, Toronto, Ontario, Canada

Journal of Environmental Engineering 122(11):1003-1012 (November 1996)

A three-dimensional finite difference model for simulation of bioventing is presented. The model incorporates three-phase (gas-water-organic) flow with equilibrium interphase mass transfer and dispersive transport of organic compounds, oxygen, and carbon dioxide. Growth of microorganisms, substrate and oxygen consumption, and carbon dioxide production due to microbial activity are included. Biodegradation limitations due to both substrate and oxygen availability are modeled using the dual Monod formulation. The model is applied to predict the fate of a spill of toluene in the vadose zone under natural conditions and with various configurations of air injection and vapor extraction wells. Configurations of wells are determined that maximize biodegradation and minimize both the amount of toluene withdrawn in extraction wells and the amount lost to the atmosphere.

\section{0}

\section{V18/020912}

\section{Site Experience - Bioventing Technology Forum}

Stone, D.A.

U.S. Air Force, Environmental Management, Hill Air Force Base, Utah

Fostering the Needed Partnerships: Doing the Necessary Science to Support Technology Development, Commercialization, Deployment, E.L. Helminski (ed.), Proceedings of the Seventh Annual Western Governors' Association/Weapons Complex
Monitor Applied Research and Cleanup Technology Colloquium, Phoenix, AZ, April 29-May 2, 1996. Exchange/Monitor Publications and Forums, Lake Bluff, IL, 500 pp.; (7 pp.) (1996)

This paper consists of viewgraphs for a presentation given at the Western Govemors' Association / Weapons Complex Research and Technology Colioquium. The presentation described three tech transfer forums (called site demonstration projects) sponsored by HWGT WG: Bioventing, SCAPS-LIF, and SVE Off-gas Treatment. the purpose was to test DOIT process enhancements to improve stakeholder involvement, enhance state-to-state coordination, improve information dissemination and to streamline commercialization. Planning, agenda, attendance, conclusions, and benefits from the forums are discussed.

\section{1}

V18/022211

Skim and Burial Plough: A New Implement for Reclamation of Radioactively Contaminated Land

Roed, J.; Andersson, K.G.; Prip, H.

Risoe National Laboratory, Roskilde, Denmark

Journal of Environmental Radioactivity 33(2):117-128 (1996)

Radionuclides accidentally released to the atmosphere in severe nuclear accidents can give rise to widespread radioactive contamination of land. If no remedial action is taken, the contamination may constitute a long-term external radiation hazard. Similarly, agricultural and dairy produce from the contaminated land may be a source of internal radiation. A newly developed agricultural implement named the 'skim and burial' plough has been built and tested and shown to be an effective countermeasure against both of these potential hazards but without the disadvantages of some other land reclamation methods. The new plough skims off a shallow layer of the contaminated top soil and buries it at a depth of about $45 \mathrm{~cm}$ without inverting the $5-45$ $\mathrm{cm}$ horizon. The results are that radiation levels at the soil surface are greatly reduced, the contamination becomes much less available for plant uptake and in most cases there is little or no effect on soil quality. The efficacy of the new plough has been demonstrated under particularly severe field conditions.

2862

V18/022004

Soil Aeration to Achieve Co-Metabolic Biodegradation of Chlorinated Solvents in the Presence of Inducer Compounds

Eisenbeis, J.J.; Bourquin, A.W.

Camp Dresser \& McKee, Inc., Denver, CO

CONF-9509139; Emerging Technologies in Hazardous Waste Management VI, D.W. Tedder (ed.), Proceedings of the Seventh American Chemical Society Índustrial and Engineering Chemistry Division Special Symposium, Atlanta, GA, September 17-20, 1995. American Chemical Society, Washington, DC, 1291 pp.; (pp. 918-920) (1995)

A chemical distribution facility in Denver has been found to have soil and groundwater contaminated with a wide variety of organic compounds, primarily toluene and chlorinated solvents, and their breakdown products. Since toluene and chlorobenzenes (both present at the site) have been shown to be inducers for an aerobic enzyme pathway that can degrade TCE, 1,2-DCE and vinyl 
chloride, field and laboratory studies are on-going to determine if co-metabolic aerobic biodegradation of these and other compounds is occurring in soils that have been aerated with soil vapor extraction (SVE).

\section{3}

\section{V18/023741}

Soil Flushing Study for Petroleum Hydrocarbon Removal

Dedek, K.S.; O'Connell, T.P.; Dell, L.R.

Dell Engineering, Inc., Holland, MI

CONF-950978; Municipal and Industrial Waste, Proceedings of the 18th International Madison Waste Conference, Madison, WI, September 20-21, 1995. University of Wisconsin, Madison, WI, 461 pp.; (p. 69) (1995)

A 5-week soil column treatability study was conducted to evaluate the feasibility of a closed-loop groundwater recovery and reinjection system to enhance soil flushing and biodegradation of petroleum contaminants. The site soil and groundwater are impacted with BTEX and PAH contaminants due to the release of No. 2 and No. 6 fuel oil from a UST. Nutrients and two nonionic surfactants, Tergitol NP-10 and Tween 80, were evaluated for the potential of enhancing soil flushing and biodegradation. The amendments were added to unimpacted oxygenated site groundwater which was continuously pumped to the top of the soil columns and allowed to percolate vertically downward through the columns to simulate unsaturated flow through the soil. Total heterotrophic microbial plate counts conducted at the end of the 5-week study were highest in soil amended with Tergitol NP-10 and nutrients $(1.9 \times 10[E+8]$ CFU/dry gram soil) compared to $6.2 \times 10(E+6) C F U / d r y$ gram soil in the initial soil sample. Initial concentrations of total BTEX (270 $\mathrm{mu} \mathrm{g} / \mathrm{kg}$ and naphthalene $(8,500 \mathrm{mu} \mathrm{g} / \mathrm{kg})$ were reduced to below detectable limits in all of the soil columns. Total PAH removal rates were $52 \%$ and $51 \%$ in unamended and nutrient-amended soils, respectively, from an initial total soil PAH concentration of approximately $70 \mathrm{mg} / \mathrm{kg}$. Amendment with nutrients and Tergitol NP-10 resulted in a $48 \%$ reduction in total soil PAFs compared to $39 \%$ in a microbially-inhibited Tergitol NP-10 + nutrient-amended soil. The Tween $80+$ nutrient-amendment resulted in only a $34 \%$ reduction in the total soil PAHs. TPH concentrations measured in the effluent groundwater were highest in the Tergitol NP-10 + nutrient-amended soil $(37.6 \mathrm{mg} / \mathrm{l})$ after 1 week. However, after 5 weeks, the effluent TPH concentration had leveled off to $6.5 \mathrm{mg} / \mathrm{l}$ compared to $29.4 \mathrm{mg} /$ in the microbially-inhibited Tergitol NP-10 + nutrient-amended soil. Negative biological effects of Tergitol NP-10 (e.g., increased BOD resulting in reduced oxygen levels) appear to have offset early enhancement of petroleum hydrocarbon removal since the surfactant amendment did not increase overall contaminant removal. It was concluded that a closed-loop groundwater recovery and reinjection system with oxygen amendment only would be an effective option for petroleum contaminant removal from the site soils. (Complete text)

\section{4}

\section{V18/022501}

Soil Gas Surveys: A Cost-Effective Site Assessment Technique

Barker, G.W.; Brown, D.R.; Corgan, J.M.; Fisher, J.B.; Raterman, K.T.; Trent, G.L.
Pacific Northwest Laboratory, Richland, WA; Amoco Production Company, Tulsa, OK

CONF-950333; SPE-29768; Government and Industry Working Together to Find Cost Effective Approaches to Protecting the Environment, Proceedings of the Society of Petroleum Engineers (SPE)/U.S. Environmental Protection Agency (EPA) Exploration Production Environmental Conference, Houston, TX, March 27-29, 1995. SPE, Richardson, TX, 797 pp.; (pp. 661-670) (1995)

Accurate delineation of the extent of subsurface hydrocarbon contamination in soils and groundwater is important when initiating a monitoring plan or considering remediation options at E\&P sites. Traditional site-assessment techniques used to delineate subsurface hydrocarbon contaminants (e.g., soil boreholes, excavation, monitor well installation, etc.) can be expensive, time-consuming, and disruptive to local land use or production operations. Soil gas surveys can provide a rapid, cost-effective, nonobtrusive altemative to traditional site-assessment techniques.

2865

V18/021822

\section{Soil Mixing Key to Bioremediation}

de Serres, F.

National Institute of Environmental Health Sciences, Research Triangle Park, NC

Soil and Groundwater Cleanup (November 1995); 2 pp. (November 1995)

Mixing nutrients into contaminated soils speeds the bioremediation process by stimulating naturally occurring organisms to degrade the contaminants. One way to accomplish such mixing in a controlled manner is to excavate the soil, and windrow it on top of a poly liner. With such an arrangement, the soil can be readily sampled, treated and tested. H\&H EcoSystems, Inc., Bonneville, Wa, has developed a machine, the Turbo-Rator, that can straddle a windrow as wide as 4.25 meters at the base, and move along the windrow, mixing, aerating and nourishing the soil to the full depth of the windrow. The machine is fitted with a series of fan knife blades that create a vortex that not only mixes soil, nutrients, chemicals, air water and microbes to maximize microbial activity, but also supercharges the mixture with fresh air, and purges it of accumulated $\mathrm{CO} 2$.

\section{$2866 \quad$ V18/024109}

Soil Monitors for Alpha Contamination

Los Alamos National Laboratory, Los Alamos, NM

LALP-94-234; 1 p. (1994)

Industry's role in finding and cleaning up radioactively contaminated soil continues to grow. Not only do nuclear facilities within DOE and DoD have such contamination, some residential communities have huge amounts of uranium mill tailings under them. Los Alamos has developed and fielded a simple, rugged, and reliable monitor that can help scientists identify which areas require remediation and which should be left alone. These new monitors use long-range alpha detector (LRAD) technology, in which the monitor detects ions generated by the passage of alpha particles through the air rather than the alpha particles themselves. Soil with only natural background activity gives a signal in the LRAD soil surface monitor that is twenty times higher than the intrinsic detector background. 
With a $5 \%$ to $10 \%$ signal precision, LRAD soil surface monitors can easily distinguish areas with natural background radiation levels from areas with radioactive contamination. This detector can monitor as many as 30 locations a day without disturbing the soil or generating waste byproducts.

\section{7}

V18/021712

Soil Remediation at Natural Gas Mercury Meter Stations in Montana and Northwestern Wyoming

Larango, G.J.

Olympus Environmental, Inc., Billings, MT

CONF-9607116; Proceedings of an American Association of Petroleum Geologists (AAPG) Rocky Mountain Section Meeting, Billings, MT, July 28-31, 1996; AAPG Bulletin 80(6):974a (June 1996)

The Montana Power Company initiated voluntary soil assessment and remediation at natural gas meter stations reported to have contained a mercury manometer at some time during facility operation. Remedial sites were selected according to criteria developed from data collected during a Phase I Assessment of approximately 400 facilities. The Montana Power Company and the Montana Department of Environmental Quality agreed upon a soil cleanup action level of 23 parts per million total mercury. Remedial field work included an initial assessment with a mercury vapor analyzer to determine the areal extent of impact at each site, excavation of soil until laboratory analyses of confirmation samples met the cleanup action level, and disposal of the excavated soil. The mercury meters were typically housed in small sheds measuring less than 10 feet by 10 feet. Generally, the spilled mercury was confined to areas beneath or adjacent to the meters; but in some cases, mercury was detected in other areas inside and outside the sheds. Approximately 355 cubic yards of soil at 103 sites were excavated primarily by hand and occasionally with a backhoe, and placed in one-yard soil bags for disposal. Composite soil samples were collected from each soil bag and analyzed by the Toxicity Characteristic Leaching Procedure for mercury to characterize the material as hazardous or non-hazardous. Bags characterized as non-hazardous were transported to an industrial landfill in Montana, while bags characterized as hazardous were transported to a facility in Tennessee where the mercury was recovered through a recycling process.

V18/021828

\section{Soil Treatment Session (Panel)}

Vijayan, S.

CONF-951209; Proceedings of the 17th Annual U.S. Department of Energy Low-Level Radioactive Waste Management Conference, D. Lake (ed.), Phoenix, AZ, December 12-14, 1995, 480 pp.; (1 p.) (1995)

This documents a panel discussion covering waste volume reduction, soil decontamination by chemical methods, cleanup target, technology selection and economics, and disposal considerations and costs.
Radioactive Contaminants: Final Report - September 1992-October 1995

Atomic Energy of Canada Limited, Chalk River Laboratories, Chalk River, Ontario, Canada

DOE/MC/28245-5291; 215 pp. (July 1996)

A research and development project to remove uranium and related radioactive contaminants from soil by an ultrasonically-aided chemical leaching process began in 1993. The project, to cover a period of about thirty months, was designed to include bench-scale and pilot-scale studies to remove primarily uranium from the Incinerator Area soil, at Fernald, Ohio, as well as strontium-90, cobalt-60 and cesium-137 from a Chalk River soil, at the Chalk River Laboratories, Ontario. The project goal was to develop, design and cost estimate a process to remove radionuclides from the soils to a residual level of $35 \mathrm{pCi} / \mathrm{g}$ of soil or less. Additional goals were to provide a dischargeable water effluent as a result of soil leaching and a concentrate that could be recovered for reuse or solidified as a waste for disposal. In addition, a supplementary goal was to test the effectiveness of in-situ soil treatment through a field study using the Chalk River soil.

2870

V18/023789

Soil Vapor Extraction System Design Scale-Up Considerations

Battey, R.F.

Earth Technology Corporation, Berkeley, CA

CONF-9504134; HAZMACON '95, T. Bursztynsky and M.L. Loss

(eds.), Proceedings of the Twelfth Hazardous Materials

Management Annual Conference and Exhibition, San Jose, CA, April 4-6, 1995. Association of Bay Area Governments, Oakland, CA, 790 pp.; (pp. 296-306) (1995)

Tried and true design considerations for soil vapor recovery systems need to be re-examined when designing a 10,000 standard cubic feet per minute ( $\mathrm{scfm}$ ) system compared to the more typical 100-1,000 scfm system. Soil vapor extraction (SVE) systems have typically been applied at many sites on a fairly small scale, involving air flows of several hundred to a thousand cubic feet per minute. Much larger systems are rarely encountered and call for some unique design considerations. This paper will describe the technology options, equipment availability, and other design considerations for an in situ SVE system being designed for a former aircraft maintenance facility in Southern Califormia.

\section{Soil Vapor Extraction with Dewatering}

Thomson, N.R.

University of Waterloo, Waterloo, Ontario, Canada; Oak Ridge National Laboratory, Oak Ridge, TN

ORNL/TM-13305; Insitu Remediation of DNAPL Compounds in Low Permeability Media Fate/Transport, Insitu Control

Technologies, and Risk Reduction, 318 pp.; (pp. 14.1-14.17)

(August 1996)

The physical treatment technology of soil vapor extraction (SVE) is reliable, safe, robust, and able to remove significant amounts of mass at a relatively low cost. SVE combined with a pump-and-treat 
system to create a dewatered zone has the opportunity to remove more mass with the added cost of treating the extracted groundwater. Various limiting processes result in a significant reduction in the overall mass removal rates from a SVE system in porous media. Only pilot scale, limited duration SVE tests conducted in low permeability media have been reported in the literature. It is expected that the presence of a fracture network in low permeability media will add another complexity to the limiting conditions surrounding the SVE technology.

2872

$$
\mathrm{V} 18 / 025381
$$

\section{Soil Washing Technologies in Europe}

Rose, K.W.; Runge, H.; Schmidt, D.

DETEC GmbH, Alzenau, Germany; NUKEM Nuclear Technologies, Columbia, SC

CONF-970335; Waste Management 97: Working Towards a Cleaner Environment, Proceedings of a Conference on HLW, LLW, Mixed Wastes and Environmental Restoration, Tucson, AZ, March 2-6, 1997; (6 pp.) (1997)

Cleaning of radioactive contaminated ground is a very recent development in Westem Europe. Technology development and projects performed are mainly reported from Germany. Namely, soil washing was applied in several projects. NUKEM has demonstrated that the volume of contaminated ground which otherwise must be disposed as radioactive waste can be reduced by about two orders of magnitude if treated in combined sieving and washing processes.

2873

\section{V18/025848}

\section{Soil Washing Technologies in Europe}

Runge, H.; Schmidt, D.

DETEC GmbH, Alzenau, Germany; NUKEM Nuclear Technologies, Columbia, SC

CONF-961103; Decommissioning, Decontamination, and Reutilization Worldwide Experience: DD\&R, What Does It Mean, M.G. White, R.G. Thomas and R.F. Ranellone (eds.), Proceedings of an Embedded Topical Symposium of an American Nuclear Society Winter Meeting, Washington, DC, November 10-14, 1996. American Nuclear Society, Inc., La Grange Park, IL, 328 pp.; (pp. 245-248) (1996)

Cleaning of radioactive contaminated ground is a very recent development in Western Europe. Technology development and projects performed are mainly reported from Germany. Namely, soil washing was applied in several projects. NUKEM has demonstrated that the volume of contaminated ground which otherwise must be disposed as radioactive waste can be reduced by about two orders of magnitude if treated in combined sieving and washing processes.

2874

V18/021977

Soil Washing and Leaching: Heavy Metal Removal at Several Sites

Fristad, W.E.; Elliott, D.K.

COGNIS, Inc., Santa Rosa, CA

CONF-9509139; Emerging Technologies in Hazardous Waste
Management VII, D.W. Tedder (ed.), Proceedings of the Seventh American Chemical Society Industrial and Engineering Chemistry Division Special Symposium, Atlanta, GA, September 17-20, 1995. American Chemical Society, Washington, DC, 1291 pp.; (pp. 31-34) (1995)

We define soil washing to be the use of physical techniques to separate and surface clean soil particles. Soil leaching is considered to be the use of chemical techniques to dissolve, displace, and recover heavy metal contaminants which are adsorbed onto the surface of soil particles. The combination of physical and chemical techniques allows metal contaminants of most any type to be addressed both in laboratory-scale treatability studies as well as in a full-scale treatment plant. This presentation will give an overview of the combined soil washing and leaching approach and present data from three different treatability studies and one full-scale project. The goal is to show how a standard set of physical and chemical steps were modified to successfully treat three out of four sites, all of which were contaminated by different means: battery breaking, steel making, ammunition manufacturing, and grenade testing.

2875 V18/022002

Soil Washing as a "Tailor Made" Solution for Treatment of Lead Paint Manufacturing Contaminated Soils

Groenendijk, E.; Pruijn, M.F.

Alternative Remedial Technologies, Inc., Tampa, FL; Heidemij Realisatie, Waalwijk, Netherlands

CONF-9509139; Emerging Technologies in Hazardous Waste Management VII, D.W. Tedder (ed.), Proceedings of the Seventh American Chemical Society Industrial and Engineering Chemistry Division Special Symposium, Atlanta, GA, September 17-20, 1995. American Chemical Society, Washington, DC, 1291 pp.; (pp. 960-963) (1995)

Soil washing is a water based soil treatment process that relies on traditional physical separation and chemical extraction technologies to remove a wide range of contaminants such as: metals, radionuclides, PNA's, PCBs, pesticides and hydrocarbons from the soil matrix. Soil washing is not a fixed process, but a highly flexible arrangement of standard unit operations. Based on the nature of the soil and contaminant characteristics, the selected soil washing units are configured into a treatment process which is effective for the specific project. For treatment of lead contaminated soils at a lead paint manufacturing site, a "tailor made" soil washing treatment process was developed and demonstrated at production scale.

2876 V18/023664

Soil-Bentonite Design Mix for Slurry Cutoff Walls Used as Containment Barriers

Rad, N.S.; Bachus, R.C.; Jacobson, B.D.

GeoSyntec Consultants, Atlanta, GA

CONF-9406413; Dredging, Remediation, and Containment of Contaminated Sediments, K.R. Demars, G.N. Richardson, R.N. Yong and R.C. Chaney (eds.), Proceedings of a Symposium, Montreal, Quebec, Canada, June 23-24, 1994, 343 pp.; (pp. 239-251) (1995)

In recent years, soil-bentonite slurry cutoff walls have been 
increasingly used as containment barriers around contaminated soils to impede or, in some cases, nearly eliminate the off-site migration of contaminated groundwater or other potentially hazardous liquids. The paper presents the procedures used and the results obtained during an extensive laboratory testing program performed to select varying soil-bentonite slurry mix components for a soil-bentonite slurry cutoff wall constructed around an old landfill at a former oil refinery. The landfill is underlain to varying depths by a coarse granular soils that has been exposed to oil-products. Compatibility of three commercially available bentonite products with the free oil-products and the oil-contaminated groundwater found at some locations in the landfill was initially investigated. Based on the test results, one of the bentonite products was selected for use in the soil-bentonite siurry testing program. A clayey soil from a bonow source, potable water from the site, and subsurface soils from the proposed soil-bentonite slurry wall alignment were used to form different soil-bentonite slurry mixes. Slump tests were performed to evaluate the workability of the mixes. Based on the test results, a single mix was selected for further study, including permeability/compatibility testing. The resuits of the compatibility testing program are presented and discussed in the paper. A specific design mix methodology for evaluating the chemical compatibility of soil-bentonite slurry mixes with permeants is proposed.

2877

V18/022229

Solid-Phase Bioremediation of Diesel

Fuel-Contaminated Soil Utilizing Indigenous

Microorganisms

Cagnetta, P.J.; Laubacher, R.C.

R.E. Wright Environmental, Inc., Middletown, PA; BP Oil

Company, Cleveland, $\mathrm{OH}$

CONF-951139 (Vol. 2); Superfund 16: Proceedings of a Hazardous Waste Conference and Exhibition, Washington, DC, November 6-8, 1995. E.J. Krause and Associates, Bethesda, MD, Vol. 2, 817 pp.; (pp. 1223-1229) (1994)

In the spring of 1993, R.E. Wright Environmental, Inc. (REWEI) was retained by BP Oil Company (BP) to evaluate the use of bioremediation technology to remediate approximately $3000 \mathrm{cu}$ yd of soil impacted with diesel fuel. The impacted soil resulted from the release of several hundred gallons of diesel fuel from a ruptured valve on an aboveground pipeline within a terminal. The overland flow of the diesel fuel resulted in a significant area of soil being impacted by the fuel. Immediate response activities limited vertical migration of the fuel through the excavation and stockpiling of the surface-impacted soil. The nature of the contaminant-an unweathered, refined petroleum product comprised primarily of alkanes of a medium chain length-and the biodegradable nature of the diesel fuel made bioremediation a cost-effective and technically feasible remedial option. The objective of the project was to reduce the concentrations of the petroleum hydrocarbons to below the Pennsylvania Department of Environmental Protection (DEP) soil cleanup levels in order to reuse the soil on-site as fill. Basic agronomic principles were applied throughout all phases of the project in order to successfully biodegrade the hydrocarbon.

V18/024665

Solid-Phase Bioremediation of Petroleum Hydrocarbon-Contaminated Soil: Laboratory
Treatability Study Through Site Closure, Chapter 9

Jerger, D.E.; Woodhull, P.M.; Flathman, P.E.; Exner, J.H.

OHM Remediation Services Corporation, Findlay, OH; JHE Technology Systems, Alamo, CA

Bioremediation: Field Experience, P.E. Flathman, D.E. Jerger and J.H. Exner (eds.), Lewis Publishers, Boca Raton, FL, 560 pp.; (pp. 177-193) (1994)

Solid-phase bioremediation (or land treatment) is a process which employs the physical, chemical, and biological properties of soil to degrade, transform, and/or immobilize waste constituents. Land treatment provides a system for effective waste detoxification that prevents the contamination of surface and groundwaters and is an accepted altemative for the remediation of environments contaminated with fuel oils, certain mineral and crude oils, and petroleum refinery wastes. This technology has been used for many years in the treatment of petroleum residuals, often at costs lower than other destructive technologies. This chapter reports on the treatment of approximately $58,200 \mathrm{cu}$ yd of petroleum hydrocarbon-contaminated soil from a Califomia mining site. Laboratory treatability studies and full-scale field remediation are included in the discussion. Treatment resulted in site closure approval from the regulatory agencies. This chapter is from the book entitled Bioremediation: Field Experience.

\section{9}

V18/022091

Solidification Treatment of Thiophene and BTEX Contaminated Soils

Zarlinski, S.J.; Kingham, N.W.; Blevins, J.

Kiber Environmental Services, Inc., Atlanta, GA; U.S. Environmental Protection Agency, San Francisco, CA

CONF-951139 (Vol. 2); Superfund 16: Proceedings of a Hazardous Waste Conference and Exhibition, Washington, DC, November 6-8, 1995. E.J. Krause and Associates, Bethesda, MD, Vol. 2, 817 pp.; (pp. 899-908) (1995)

A treatability study was performed to evaluate the effectiveness of in situ solidification treatment of materials contaminated with high concentrations of benzene, toluene, ethylbenzene, and xylenes (BTEX), as well as thiophene and other organic compounds. The contaminated materials were extremely acidic ( $\mathrm{pH}$ less than 1 ) and had high organic and sulfur contents of greater than 70 percent and 10 percent, respectively. A total of 150 mixtures were screened to evaluate the effectiveness of 15 reagents. Based on the preliminary screening results, six mixtures were selected as being the most effective at treating contaminated materials. Comprehensive evaluations of the candidate mixtures included: (1) quantitative glovebox volatilization studies; (2) chemical characterization of the treated materials; (3) strength characterizations at multiple cure times of up to 60 days; (4) emissions monitoring of the treated materials at cure times of 7 and 14 days; and (5) the evaluation of oxidation reagents for treatment of the thiophene contamination. The treatability study demonstrated that solidification treatment is an effective alternative for remediation of the thiophene and BTEX contaminated materials. 
Los Alamos National Laboratory, Los Alamos, NM

LALP-94-276; 1 p. (1994)

New water-soluble chelating polymèrs are being used for the selective recovery of both toxic and hazardous metals from contaminated soils and industrial process wastes. Wastes or contaminated soils are washed with aqueous solutions of the polymeric extractant. The solid residue is allowed to settle, and the solution containing the metal-loaded polymer is filtered and concentrated using a well known commercial process called ultrafiltration. The polymer can readily be generated and the extracted metal can be recovered or solidified for disposal. Valuable metals are produced in concentrated solutions for potential recycle. A pilot scale unit for lead-contaminated soils from a superfund site will be completed by December 1994.

\section{$2881 \quad$ V18/025463}

Sorption of Cesium and Strontium on Savannah River Soils Impregnated with Colloidal Silica

Hakem, N.; Al Mahamid, I.; Apps, J.; Moridis, G.J. Lawrence Berkeley National Laboratory, Earth Sciences Division, Berkeley, CA

LBNL-39498; CONF-970208; Proceedings of an International Containment Technology Conference and Exhibition, St. Petersburg, FL, February 9-12, 1997; (10 pp.) (January 1997)

Colloidal silica (CS) is being considered as an injectable low viscosity fluid for creation of impermeable barrier containment of low level radioactive waste at the Savannah River Site (SRS), South Carolina. The sorption behavior of cesium and strontium on Savannah River Site Soils impregnated with Colloidal Silica was studied using a batch experimental method. The samples were prepared by addition of CS and an aqueous solution of $\mathrm{CaCl} 2$ to the soil materials. Sorption studies were conducted after the gelation of the CS samples had occurred. The variation of the sorption ratio as a function of cesium or strontium concentration was examined. The Freundlich isotherm was used to fit the data and very good results were obtained.

2882

\section{V18/023910}

Stability Concerns Related to Use of GCLs in Liner Systems

Stewart, W.; Carey, P.J.

CONF-950177; Waste Tech '95, Proceedings of a Conference, New Orleans, LA, January 23-25, 1995. Environmental Industry News, Washington, DC, 530 pp.; (25 pp.) (1995)

The use of manufactured bentonite mats (GCLs) as the soil portion of composite liner systems has seen rapid growth in recent years. For landfills, surface impoundments and waste piles, GCLs have been utilized in the formation of the primary composite liner and/or secondary composite liner, depending on the site-specific design requirements. The GCLs offer an economical altemative to all or a portion of the soil component of a composite liner and, due to the very low permeability of the bentonite, are very effective at reducing leakage. There are some important factors that must be considered when using GCLs. For example, the bentonite portion of the GCL represents a potential plane of weakness, especially if it becomes saturated, that can have an overriding impact on the stability of a lined site. The shear strength parameters applicable to GCLs have been fairly well documented in recent literature. Shear strength of the GCL tends to vary significantly depending on the degree of wetting assumed, the rate of shiear strain, and the composition of the GCL. This paper presents a rational basis for selecting GCL shear strength for a variety of water content conditions. It also contains discussions relative to the selection of shear strength for shear reinforced GCLs based on adjustment from the typical short-term test values to the long-term design condition.

2883 V18/023915

Stability of Soil Layers on Compound Geosynthetic Slopes

Corcoran, G.T.; McKelvey, J.A.

Roy F. Weston, Inc., West Chester, PA

CONF-950177; Waste Tech '95, Proceedings of a Conference, New Orleans, LA, January 23-25, 1995. Environmental Industry News, Washington, DC, 530 pp.; (pp. 242-256) (1995)

Geosynthetic materials can greatly reduce the stability of soil covers on landfill closure side slopes, primarily due to the low interface friction angles associated with many of these materials. Generally, if a uniform thickness of cover soil is placed on a geosynthetic-lined slope, a tensile force will develop within the geosynthetics if the angle of slope exceeds the minimum interface friction angle between the various geosynthetic materials. This tensile force may easily be determined using limit equilibrium approaches such as two-wedge or infinite slope analyses as presented in recent papers. The two-wedge method was developed for a constant slope inclination with a horizontal base at the toe of the slope. Analyzing a compound slope, a slope with two distinct slope angles, using the infinite slope approach will result in the prediction of excessive tensile loads on the geosynthetics. Conversely, using the available two-wedge equations may overestimate the resisting force associated with the buttressing wedge at the base of the upper slope. This would underestimate the tensile loads on the geosynthetics as the buttressing wedge associated with the buttressing wedge at the base of the upper slope. This would underestimate the tensile loads on the geosynthetics as the buttressing wedge associated with a compound slope offers less resisting force than a horizontal base at the toe of the slope. This paper will develop a design equation for geosynthetic tension, incorporating the effects of compound slopes. Evaluation techniques to model equipment loadings used to place the cover soil will also be presented. A design example incorporating the analysis approaches will be provided to help the reader gain an appreciation of the presented material.

\section{4}

\section{V18/025354}

Stabilization of Contaminated Soil and Wastewater with Chemically Bonded Phosphate Ceramics

Wagh, A.S.; Jeong, S.Y.; Singh, D.; Strain, R.; No, H.; Wescott, J.B.

Argonne National Laboratory, Argonne, IL

CONF-970335; Waste Management '97: Working Towards a Cleaner Environment, Proceedings of a Conference on HLW, LLW, Mixed Wastes and Environmental Restoration, Tucson, AZ, March 2-6, 1997; (6 pp.) (1997) 
Argonne National Laboratory has developed chemically Bonded phosphate ceramic (CBPC) technology to stabilize the U.S. Department of Energy's problem mixed waste streams, for which no other stabilization technology is suitable. In this technology, solid waste is mixed with $\mathrm{MgO}$ and reacted with aqueous solutions of phosphoric acid or acid phosphates at room temperature to form a slurry that sets in approximately 2 hours to a hard and dense ceramic waste form. Initial studies involved stabilizing the surrogate waste streams and then testing the waste forms for leaching of contaminants. After achieving satisfactory performance of the waste forms, actual waste streams were incorporated at bench scale. These tests produced waste forms that were then tested with the Toxicity Characteristic Leaching Procedure (TCLP). This presentation deals with stabilization of soil contaminated with $\mathrm{Cd}$, $\mathrm{Cr}, \mathrm{Pb}, \mathrm{Ag}, \mathrm{Ba}$, and $\mathrm{Hg}$, and of low-level radioactive wastewater. The TCLP results showed excellent immobilization of all the RCRA metals, and radioactive contaminant levels were below the detection limit of $0.2 \mathrm{pCi} / \mathrm{mL}$. Long-term leaching studies using the ANS 16.1 procedure showed that the retention of contaminants is excellent and comparable to or better than most of other stabilization processes.

\section{5}

\section{V18/023493}

\section{Stabilization of Pentachlorophenol by Solidification in} Portland Cement

Franca, V.V.; Buechler, P.M.

Sao Paulo University, Chemical Engineering Department, Sao Paulo, Brazil

CONF-960730 (Vol. 3); Technologies Critical to a Changing World, Volume III: Emerging Energy Technologies, Clean Technologies, Remediation and Emission Control Fuels, and Petrochemicals, Proceedings of the Fifth World Congress of Chemical Engineering, San Diego, CA, July 14-18, 1996. American Institute of Chemical Engineers, New York, NY, Vol. 3, 1118 pp.; (pp. 718-721) (1996)

Leaching tests were performed to investigate the feasibility of solidifying pentachlorophenol (PCP) in Portland cement. The PCP in the leachate was measured with a gas chromatograph. Test results indicate that the percentage extraction is low for PCP in cement, and lower when organo-clay is mixed with cement. The compressive strength of the block is reduced by the clay, but will be above the minimum required for safe storage. The stabilization of PCP by solidification in Portland cement and organo-clay is both environmentally and economically viable, particularly if the organo-clay is derived from fatty acids.

\section{6}

\section{V18/023651}

\section{State of the Art: Confined Disposal Facility (CDF)} Contaminant Pathway Control

Richardson, G.N.; Petrovski, D.M.; Chaney, R.C.; Demars, K.R.

G.N. Richardson and Associates, Raleigh, NC; U.S. Environmental Protection Agency, CERCLA Division,

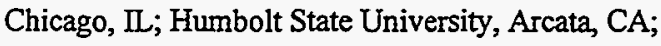
University of Connecticut, Storrs, CT

CONF-9406413; Dredging, Remediation, and Containment of Contaminated Sediments, K.R. Demars, G.N. Richardson, R.N. Yong and R.C. Chaney (eds.), Proceedings of a Symposium, Montreal,
Quebec, Canada, June 23-24, 1994, 343 pp.; (pp. 195-219) (1995)

Within the US, about 400 million cubic yards ( 520 million cubic meters) of sediments are dredged annually. Sediment is the material that settles to the bottom of a body of water and includes soil particles consisting of clays, silts, and sands; organic matter; shells; and residuals from industrial discharges, which can include organics and heavy metals. Contaminants from sediments contained within a confined disposal facility (CDF) can be discharged to the environment via six potential pathways. These pathways include three waterborne pathways, the direct uptake of the contaminants by plants or animals, and airborne emission of contaminants. Conventional CDF design focuses on retention of sediment particles with perimeter dikes. Depending upon the nature of the site, the contaminants of concern, method of dredging, physical properties of the dredged material, operational aspects, and many other factors, including socio-political factors, supplemental environmental design criteria may be required for the CDF. This paper reviews design altematives to control contaminant loss from the CDF basin through the six identified contaminant pathways. These alternatives include the use of both additional design components and operational constraints. The need for a specific pathway control measure is shown to depend on both site and sediment-specific evaluation criteria.

V18/022930

Stimulation of Indigenous Microbes to Bioremediate Oil-Contaminated Soils

Stewart J.R.; Williams, D.L.; Kriel, K.D.; Stewart, G.A.; Hulse, R.C.

University of Texas, Tyler, TX; MAP Productions, Inc., Tyler, TX

CONF-941065; Proceedings of the 44th Annual Convention of the Gulf Coast Association of Geological Societies and the 41st Annual Convention of the Gulf Coast Section of the Society of Economic and Paleontologists and Mineralogists, R.P. Major (ed.), Austin, TX, October 5-7, 1994, 847 pp.; Transactions of the Gulf Coast Association of Geological Societies 44:772 (1994)

The purpose of our study was to determine the effectiveness of bioremediation of two oil-contaminated soils by stimulating indigenous oil-degrading microbes. The soil treatment consisted of tilling, liming, and fertilizing, and bioremediation was monitored by changes in the microbial populations (MPs) and by changes in total petroleum hydrocarbons (TPHs) in the soils. Location one was a 12 $x 12 \mathrm{ft}$ plot that had been repeatedly contaminated with pressure pump oil for 8 years. After treatment, the MP increased 400 -fold in 3 weeks and remained unchanged for 6 more weeks. The initial TPH was $18,500 \mathrm{ppm}$, and it was declined steadily to $3,000 \mathrm{ppm}$ by 7 weeks. Location two was a rectangular plot approximately $20 \times 500$ $\mathrm{ft}$ on a hillside where about $50 \mathrm{bbl}$ of crude oil had been spilled. MPs and TPHs were made at the three sites: site 1 , top of hill where spill occurred; site 2, midway uphill; and site 3 , about 22 ft below site 1 . The initial MPs at the three sites increased a thousandfold in 10 weeks after treatment. Initial TPHs at the three sites ranged from 15,000 to $20,000 \mathrm{ppm}$ and remained unchanged for 26 weeks. At week 30, the TPHs of sites I and 2 were less than 10,000 ppm; site 3 required an extra treatment and 12 more weeks before the TPH was below $10,000 \mathrm{ppm}$. At locations one and two, the decreases in TPH were inversely proportional to the increases in MPs. 
Bioremediation by stimulating indigenous microbes was effective, and, in terms of materials and labor, efficient.

\section{8}

\section{V18/022214}

Strategic Plan for the Northeast Waste Management Enterprise

Brookhaven National Laboratory, Upton, NY; Long Island Research Institute, Nesconset, NY

BNL-52441; LIRI-94-004; 28 pp. (November 1994)

The Northeast Waste Management Enterprise (NEWME) is a new form of partnership whose goal is to increase the economic, commercial, and environmental effectiveness of solid waste management (SWM) through implementation of new technologies. Of particular interest to NEWME are technologies that are applicable to the Northeast's waste management problems and technologies applicable to the Department of Energy's waste management and environmental cleanup programs. These include land reclamation using bioremediation, pyrolysis, waste stabilization/ash utilization, and landfill containment. The next step, which has already begun, is to evaluate specific technologies within these focus areas. A concurrent economic analysis will take place along with each program, which, together with technical evaluations, will form the basis for decisions relating to the ultimate commercialization of the technology. The financial plan for NEWME anticipates an evolution over time in which the Federal Government provides most of the funding in the early design phase, with some industrial participation. As the program progresses through demonstration and early commercialization, the program becomes more expensive, and a larger fraction of the costs is borne by the private sector. NEWME itself will participate financially in each commercialization vehicle in order to form the basis for the eventual self-sufficiency of the program.

\section{9}

\section{V18/023649}

Strategies for Management of Contaminated Sediments Palermo, M.R.; Miller, J.A.

U.S. Army Corps of Engineers, Waterways Experiment Station, Vicksburg, MS; U.S. Army Corps of Engineers, Chicago, IL

CONF-9406413; Dredging, Remediation, and Containment of Contaminated Sediments, K.R. Demars, G.N. Richardson, R.N. Yong and R.C. Chaney (eds.), Proceedings of a Symposium, Montreal, Quebec, Canada, June 23-24, 1994, 343 pp.; (pp. 289-296) (1995)

In 1985, the US Army Corps of Engineers (USACE) developed a Management Strategy for evaluation of dredged material alternatives which focused on contaminant testing and controls. The Environmental Protection Agency (EPA) later initiated development of a similar management strategy focusing on environmental considerations of disposal altematives. A USACE/EPA work group was subsequently formed for the purpose of developing a joint Technical Framework endorsed by both agencies. In 1992, the USACE and EPA published the Technical Framework as a guidance document for their agencies' personnel to follow in identifying environmentally acceptable altematives for the management of dredged material. The USACE and EPA are also cooperating in developing strategies for managing sediment remediation projects. This paper provides a summary of the strategies that can be used in management of contaminated sediments, a description of the more detailed guidance documents available, and plans for future developments.

$2890^{\circ}$

V18/022230

Successful Bioremediation: The Importance of the Biofeasibility Study

Chaparian, $\mathrm{M}$.

Blue Planet Technologies, Inc., Madison Heights, MI

CONF-951139 (Vol. 2); Superfund 16: Proceedings of a Hazardous Waste Conference and Exhibition, Washington, DC, November 6-8, 1995. E.J. Krause and Associates, Bethesda, MD, Vol. 2, 817 pp.; (pp. 1209-1212) (1994)

Bioremediation is an innovative technology rapidly amassing an impressive track record, in terms of both performance and cost. It offers several advantages over outdated practices such as landfilling and incineration in that it can permanently remove hazardous contaminants from the environment instead of merely transferring them. It is also very versatile, and can be used in combination with a number of other treatment technologies including soil vapor extraction and air sparging. However, in order to realize the tremendous potential benefits of bioremediation, a careful preliminary assessment of site conditions and analysis of site samples (soil or groundwater) must be conducted. This is in large part due to the uniqueness of each site with regard to its chemical and physical characteristics, such as temperature, $\mathrm{pH}$, nutrients available to microbes, and bioavailability of the contaminants. This data, collected and interpreted prior to implementing bioremediation, may be the most important information influencing the success of the cleanup. The bioremediation feasibility study (biofeasibility study) is the vehicle through which this data is collected and analyzed. The laboratory conducting this study must have the expertise in applying the principles of microbiology, biochemistry, analytical chemistry, and microbial ecology to the specific conditions at or problems presented by the site and the specific contaminants to be destroyed. The biofeasibility study should include, at a minimum, an analysis of the contaminants and their concentrations, the concentration of naturally occurring microbes in the site sample, and a quantitative, direct measure of the microbial capacity to degrade the contaminants. Beyond this minimal study, the biofeasibility study should be designed to provide such significant information as the biodegradation kinetics, end-point, and range of conditions. The significance of these parameters is discussed, as well as the cost effectiveness of the biofeasibility study.

2891

V18/022671

Surface Barriers: Problems, Solutions, and Future Needs

Daniel, D.E.

University of Texas, Department of Civil Engineering, Austin, TX

CONF-941124; Insitu Remediation: Scientific Basis for Current and Future Technologies, G.W. Gee and N.R. Wing (eds.), Proceedings of the 33rd Hanford Symposium on Health and the Environment, Pasco, WA, November 7-11, 1994. Battelle Press, Columbus, OH, Part 1, 704 pp.; (pp. 441-487) (1994) 
The problem of designing a surface barrier for a remediation project can be an enormously challenging task. There is a widely held misconception that surface barrier technology is well developed and works as expected. In fact, the technology is largely unproved and experimental, particularly in terms of long-term performance. The most difficult problem with surface barriers is to provide a long-term barrier to infiltration of water. The materials that have traditionally been considered for the hydraulic barrier within surface barrier systems are low-permeability compacted soil, geomembranes, and the geosynthetic clay liner (GCL). Data are presented to suggest that low-permeability compacted soil is often a poor choice of materials. Unless the compacted soil liner is buried under a very thick layer of protective soil or covered by a geomembrane, the low-permeability, clay-rich, compacted soil is likely to desiccate and lose its low hydraulic conductivity. Differential settlement of a compacted soil liner from uneven compression of underlying waste or other causes is almost certain to produce cracks within the soil liner. Geomembranes do not suffer as much from these problems, but their design life is, at best, a few centuries, The GCL, which contains a thin layer of bentonite, is much better able to resist damage from freezing/thawing, desiccation, and differential settlement than compacted soil liners. The technology of the GCL, which is particularly well suited for arid sites, is reviewed in some detail in this paper because of its technical attributes in surface-barrier applications. Published case histories of the performance of surface barriers are summarized.

\section{2}

V18/022663

Surfactant-Enhanced Insitu Remediation: Current and Future Techniques

Clarke, A.N.; Oma, K.H.; Megehee, M.M.; Mutch, R.D., Jr.; Wilson, D.J.

Eckenfelder, Inc., Nashville, TN

CONF-941124; Insitu Remediation: Scientific Basis for Current and Future Technologies, G.W. Gee and N.R. Wing (eds.), Proceedings of the 33rd Hanford Symposium on Health and the Environment, Pasco, WA, November 7-11, 1994. Battelle Press, Columbus, OH, Part 2, 605 pp.; (pp. 965-987) (1994)

The ability of surfactants to increase the solubilization of hydrophobic compounds is well documented. Eckenfelder Inc. has developed a technique by which the surfactant solution spent in the remediation of contaminated soil can be recycled and reused. This technique results in a significantly reduced volume of contaminants to be disposed of as well as substantial cost savings. While the exsitu or washing technique is frequently more suitable to the use of surfactant-enhanced soil remediation, there are definite roles for the use of the in-situ application. This paper describes the recycling technology (including the scientific basis) which was developed to permit the reuse of the surfactant solution as well as provide samples of its efficacy. The authors will also present two scenarios in which the in-situ approach would be viable. The first scenario involves an impermeable layer such as bedrock or clay located beneath the aquifer. The second involves a man-made, bowl-like intragradient configuration whereby the surfactant solution is contained and pumped to the surface for treatment and reuse. The latter scenario can be especially desirable in areas where the groundwater is deep and the contamination has not yet reached the aquifer. Another advantage of in-situ surfactant-enhanced remediation is its potential (in some cases) to separate mixed wastes, i.e., remove nonradioactive organic compounds while minimally affecting the radioactive inorganic contaminants.

2893

V18/021962

Surfactant-Like Compounds Enhance the

Bioavailability of Organic Contaminants: Treatability Results for a Field Demonstration

Gillespie, M.T.; Strong-Gunderson, J.M.; Palumbo, A.V.

Oak Ridge National Laboratory, Environmental Sciences Division, Oak Ridge, TN

CONF-9509139; Emerging Technologies in Hazardous Waste Management VII, D.W. Tedder (ed.), Proceedings of the Seventh American Chemical Society Industrial and Engineering Chemistry Division Special Symposium, Atlanta, GA, September 17-20, 1995. American Chemical Society, Washington, DC, 1291 pp.; (p. 632) (1995)

Methods to enhance rates of TCE degradation were investigated during laboratory treatability studies in support of a field demonstration. Organic contaminants such as TCE are sorbed to the soil and thus are difficult to degrade, i.e. not bioavailable for degradation by microorganisms, especially in soils with a high clay content. In these types of environments, the bioavailability can be enhanced by the addition of surfactant-like compounds, which increase the solubility of TCE, thereby making it more available for microbial degradation. Several commercially available nutrients with surfactant-like properties were assayed for their effect on enhancing TCE bioavailability and rates of degradation.

2894

$$
\text { V18/023785 }
$$

TESVE Model for Design of Soil Vapor Extraction Systems with Thermal Enhancement

Ghuman, A.S.

Lowney Associates, Mountain View, CA

CONF-9504134; HAZMACON '95, T. Bursztynsky and M.L. Loss (eds.), Proceedings of the Twelfth Hazardous Materials Management Annual Conference and Exhibition, San Jose, CA, April 4-6, 1995. Association of Bay Area Governments, Oakland, CA, 790 pp.; (pp. 235-243) (1995)

Soil vapor extraction (SVE) is a popular and effective technology for removal of volatile organic compounds (VOCs), from the subsurface soils. The performance of SVE systems is based on three key parameters: the rate of mass removal, the time required to achieve cleanup goals, and the cost of cleanup. These performance parameters depend on physical and chemical factors such as the rate and pattern of air flow through the affected soils, contaminant type, and the degree of partitioning between the vapor-, liquid-, dissolved-, and adsorbed- phase. The effectiveness of SVE can be enhanced by raising the soil temperature. This is done using various methods including electrical heating, and hot air volatilization. TESVE (Thermally-Enhanced Soil Vapor Extraction), a multi-component, non-isothermal, three dimensional software model, is a powerful tool in evaluating the feasibility of SVE, optimizing system design, predicting system performance, and, ultimately reducing cleanup costs. The TESVE model was run for a SVE site at McClellan Air Force Base, California. Four SVE design 
scenarios were modeled for removal of trichloroethylene (TCE) from the subsurface soil. Two scenarios used hot air injection/extraction, one considered ambient air injection/extraction, and one usëd high flow vapor extraction with no injection. The model predicted pressure distribution, velocity vectors, temperature profile, mass removal rate, and concentration degradation rate. These data were used to establish the optimal design for installation and operation of the SVE. Preliminary results indicated that by optimizing the system design, the United States Air Force (USAF) would achieve a savings of approximately $\$ 500,000$ and 4 years of system operation over the conventional SVE design being proposed.

\section{$2895 \quad$ V18/022495}

Technical Basis for Establishing Environmentally Acceptable Endpoints in Contaminated Soils

Nakles, D.V.; Linz, D.G.

Remediation Technologies, Inc., Pittsburgh, PA; Gas Research Institute, Chicago, IL

CONF-950333; SPE-29689; Government and Industry Working Together to Find Cost Effective Approaches to Protecting the Environment, Proceedings of the Society of Petroleum Engineers (SPE)/U.S. Environmental Protection Agency (EPA) Exploration Production Environmental Conference, Houston, TX, March 27-29, 1995. SPE, Richardson, TX, 797 pp.; (pp. 9-17) (1995)

There is a growing body of evidence that soils that contain residual concentrations of contaminants above ground or pristine conditions may not pose unacceptable risk to the environment and human health. The initial results of a research program sponsored by the Gas Research Institute support this contention. The GRI research program has reviewed the existing soil literature: (1) to obtain a better understanding of the physical and chemical interactions that their rate of release into the environment and to living organisms; and (2) to examine and/or develop correlations between soil treatment and the resulting toxicity and mobility of contaminants in the soil matrix. This paper presents a sample of the supporting data which have been found regarding the persistence of contaminants in soil with time; the effects of aging of contaminants on their availability to microorganisms, the extractability of contaminants from the soil and the release of contaminants from the soil into the environment; the effects of sorption of contaminants on soil on their effective toxicity; and the results of biological treatment on the concentration, toxicity, and mobility of PAHs in soil. The implications of these findings on the determination of environmentally acceptable endpoints in contaminated soils and the management of contaminated sites are also discussed.

\section{6}

\section{V18/023494}

Technologies Critical to a Changing World - Emerging Energy Technologies, Clean Technologies, Remediation and Emission Control, Fuels and Petrochemical: Proceedings of the Fifth World Congress of Chemical Engineering, Vol. 3, San Diego, CA, July 14-18, 1996 CONF-960730 (Vol. 3); Technologies Critical to a Changing World, Volume III: Emerging Energy Technologies, Clean Technologies, Remediation and Emission Control Fuels, and Petrochemicals,
Proceedings of the Fith World Congress of Chemical Engineering, San Diego, CA, July 14-18, 1996. American Institute of Chemical Engineers, New York, NY, Vol. 3, 1118 pp. (1996)

Volume 3 of the proceedings from the 5 th World Congress of Chemical Engineering covers four major topic areas: Emerging Energy Technologies, Clean Technologies, Remediation and Emission Control, and Fuels and Petrochemicals. Among subtopics included are: Environmental Technologies; Emerging Separation Technologies; Environmental Catalysis; Separations Processes for Environmental Treatment; Environmental Catalysis/Reaction Engineering; Transport Processes Applied to Environmental Remediation and Emission Control; and Biological Processes Applied to Environmental Remediation and Emission Control. Papers within the scope of this database have been indexed separately.

\section{7}

V18/023195

Ten Years of Soil Cleanup in The Netherlands Soczo, E.R.; Meeder, T.A.; Versluijs, C.W.

National Institute of Public Health and Environmental Protection, Laboratory for Waste Materials and Emissions, Bilthoven, Netherlands

CONF-9210194; Proceedings of an International Symposium on Environmental Contamination in Central and Eastern Europe, Budapest, Hungary, October 12-16, 1992, 968 pp.; (pp. 291-294) (1992)

In the early 1980 s the Netheriands, like many other countries, was faced with the problem of contaminated soil. In 1981, the estimated number of sites under suspicion was 4,000 . However, since then it has become clear that this number will be exceeded many times. To date, about 4,000 contaminated sites have been investigated and about 1,000 sites have been cleaned up under the jurisdiction of the Interim Soil Cleanup Act (IBS). The total expenditure for the investigation and the cleanup, financed by the government, is approximately 1.5 billion Dutch guilders (about 750 million US dollars). The supplementary cleanup circuit spent approximately 0.5 billion Dutch guilders on site cleanup. This paper discusses cleanup policy, management of the cleanup process, soil treatment techniques, and research developments.

\section{8}

\section{V18/023655}

Testing of a Cement-Bentonite Mix for a Low-Permeability Plastic Barrier

Deschenes, J.H.; Massiera, M.; Tournier, J.P.

Geoconseil Inc., Montreal, Quebec, Canada; Universite de Moncton, Department of Civil Engineering, New Brunswick, Canada; Societe d'Energie de la Baie James, Montreal, Quebec, Canada

CONF-9406413; Dredging, Remediation, and Containment of Contaminated Sediments, K.R. Demars, G.N. Richardson, R.N. Yong and R.C. Chaney (eds.), Proceedings of a Symposium, Montreal, Quebec, Canada, June 23-24, 1994, 343 pp.; (pp. 252-270) (1995)

A laboratory investigation was carried out to determine the physical properties of a suitable mix of cement-bentonite for a low-permeability cutoff wall implemented in 1991 under the north dyke at the LG-1 hydroelectric site, which is part of the James Bay 
Development Project in Northern Quebec. The project specifications required the mix to have a hydraulic conductivity of less than $10(\mathrm{E}-8) \mathrm{m} / \mathrm{s}$ and be able to sustain a plastic deformation of $6 \%$ without fissuring, as measured in a triaxial compression test with a lateral pressure of $100 \mathrm{kPa}$ on a specimen cured for 90 days. A two-phase laboratory study was carried out. Phase 1 involved the determination of the mix design, while the second phase consisted of the laboratory control of the manufactured mixture. During phase 1 , laboratory samples were prepared with different proportions of cement, bentonite, sand, and water. The permeability, triaxial compression, and unconfined compression tests were performed after curing periods ranging from 8 to 120 days. Once the appropriate mix was selected, it was tested to check if it met the specifications. During phase 2, or during actual production or construction, density and viscosity measurements of the cement-bentonite slurry were made routinely at the plant and at the discharge of the slurry pipe. Cylindrical specimens were molded using slurry from the discharge of the pipe and from the trench. Permeability, triaxial compression, and unconfined compression tests were performed on the specimens after curing periods ranging from 3 to 103 days.

\section{V18/023560}

Thermal Enhanced Vapor Extraction Systems: Design, Application, Performance Prediction, Including Contaminant Behavior

Phelan, J.M.; Webb, S.W.

Sandia National Laboratories, Environmental Restoration Technologies, Albuquerque, NM; Sandia National Laboratories, Geohydrology Department, Albuquerque, NM

CONF-941124; Insitu Remediation: Scientific Basis for Current and Future Technologies, G.W. Gee and N.R. Wing (eds.), Proceedings of the 33rd Hanford Symposium on Health and the Environment, Pasco, WA, November 7-11, 1994. Battelle Press, Columbus, OH, Part 2, 605 pp.; (pp. 737-762) (1994)

Soil-heating technologies have been demonstrated as a method to accelerate contaminant removal from subsurface soils. $A^{*}$ comprehensive field demonstration of powerline and radiofrequency soil heating, vacuum vapor extraction, off-gas treatment and process monitoring is being implemented at an organic, waste-disposai cell at the Sandia National Laboratories Chemical Waste Landfill. The goal of this effort is to: (1) expand understanding of the interactions of subsurface water, contaminant, and heat and vacuum extraction through model predictions and field data collection; (2) design and implement a vapor treatment system and vapor monitoring system capable of handling contaminant-laden steam. To date, model predictions have shown a dramatic improvement in contaminant removal rates that is proportional to the vapor pressure of the compound. Optimized treatment temperatures will be based on steam distillation principles, pure component vapor pressures, or adjusted pure component vapor pressure due to mixture with other codisposed materials. Simulations of the in-situ heating and vapor extraction have been performed with the TOUGH2-volatile organic carbon (VOC) code, which models the behavior of water (liquid and vapor), air, and a single-component VOC (nonaqueous phase liquids [NAPL] and vapor phase). As the soil is heated, in-situ water and NAPL vaporize and are generally transported to the vapor extraction borehole. Proper design of the vapor extraction system will contain the contaminant with the heated zone. The effects of buried metal objects on soil heating is dependent on the distribution relative to electrode placements. The off-gas treatment and vapor sampling and analysis systems must be modified to handle the large volume of water removed from the soil and can be engineered to accommodate this with standard industrial hardware. System designs and pretest analysis have been completed, with field demonstration anticipated between October and December 1994. The demonstration location is a disposal cell that received a wide variety of organic wastes that range from low-boiling acetone to high-boiling vacuum pump oils. Approximately $1000 \mathrm{~m} 3$ of soil will be treated for up to 90 days to a final treatment temperature of 200 degrees $C$.

2900 V18/022241

Thermal Treatment of Competing Technologies for Remediation of MGP (Manufactured Gas Plant) Sites

McGowan, T.F.; Greer, B.A.; Lawless, M.

RMT/Four Nines, Inc., Atlanta, GA; ENSCI Environmental, Blacksburg, VA

CONF-951139 (Vol. 2); Superfund 16: Proceedings of a Hazardous Waste Conference and Exhibition, Washington, DC, November 6-8, 1995. E.J. Krause and Associates, Bethesda, MD, Vol. 2, 817 pp.; (pp. 910-918) (1994)

More than 1,500 MGP (manufactured gas plant) sites exist throughout the U.S. Many are contaminated with coal tar from coal-fueled gas works which produced "town gas" from the mid-1800s through the 1950s. Virtually all old U.S. cities have such sites. Most are in downtown areas, as they were installed for central distribution of manufactured gas. While a few sites are CERCLA/Superfund, most are not. However, the contaminants and methods used for remediation are similar to those used for Superfund cleanups of coal tar contamination from wood-treating and coke oven facilities. Clean-up of sites is triggered by property transfers and re-development as well as releases to the environment - in particular, via groundwater migration. This paper describes recent experience with high capacity/low cost thermal desorption process for this waste. It also reviews competing non-thermal technology, such as. bio-treatment, capping, recycling, and dig and haul. Cost data is provided for all technologies, and a case study for thermal treatment is also presented.

2901

V18/024305

Thermal Treatment of Low Permeability Soils Using Electrical Resistance Heating

Udell, K.S.

University of California, Berkeley, CA; Oak Ridge National Laboratory, Oak Ridge, TN

ORNL/TM-13305; Insitu Remediation of DNAPL Compounds in Low Permeability Media Fate/Transport, Insitu Control

Technologies, and Risk Reduction, 318 pp.; (pp. 15.1-15.18) (August 1996)

The acceleration of recovery rates of second phase liquid contaminants from the subsurface during gas or water pumping operations is realized by increasing the soil and groundwater temperature. Electrical heating with $\mathrm{AC}$ current is one method of 
increasing the soil and groundwater temperature and has particular applicability to low permeability soils. Several mechanisms have been identified that account for the enhanced removal of the contaminants during electrical heating. These are vaporization of liquid contaminants with low boiling points, temperature-enhanced evaporation rates of semi-volatile components, and removal of residual contaminants by the boiling of residual water. Field scale studies of electrical heating and fluid extraction show the effectiveness of this technique and its applicability to contaminants found both above and below the water table and within low permeability soils.

2902

V18/022206

Thermally Unstable Complexants/Phosphate Mineralization of Actinides

Nash, $K$.

Pacific Northwest National Laboratory, Richland, WA; Argonne National Laboratory, Argonne, II

PNNL-SA-27105; CONF-960158; Efficient Separation and Processing Crosscutting Program, Proceedings of the 1996 Techniçal Exchange Meeting, Gaithersburg, MD, January 16-19, 1996, 52 pp.; (pp. 35-38) (1996)

Insitu immobilization is an approach to isolation of radionuclides from the hydrosphere that is receiving increasing attention. Rather than removing the actinides from contaminated soils, this approach transforms the actinides into intrinsically insoluble mineral phases resistant to leaching by groundwater. The principal advantages of this concept are the low cost and low risk of operator exposure and/or dispersion of the radionuclides to the wider environment. The challenge of this approach is to accomplish the immobilization without causing collateral damage to the environment (the cure shouldn't be worse than the disease) and verification of system performance.

2903

V18/025371

Toxicant Degradation in the Rhizosphere, Chapter 2

Walton, B.T.; Guthrie, E.A.; Hoylman, A.M.

Oak Ridge National Laboratory, Environmental Sciences Division, Oak Ridge, TN; University of North Carolina, Department of Environmental Sciences and Engineering, School of Public Health, Chapel Hill, NC; University of Tennessee, Graduate Program in Ecology, Knoxville, TN

Bioremediation Through Rhizosphere Technology, T.A. Anderson and J.R. Coats (eds.), American Chemical Society, Washington, DC, 249 pp.; (pp. 11-26) (1994)

The thizosphere provides a complex and dynamic microenvironment where bacteria and fungi, in association with roots, form unique communities that have considerable potential for detoxification of hazardous organic compounds. Detoxification may result from degradation, mineralization, or polymerization of the toxicant in the rhizosphere. These detoxification processes are influenced not only by the rhizosphere microbiota, but also by unique properties of the host plant, soil properties, and environmental conditions. Understanding the interactions among plants, thizosphere microbial communities, and organic toxicants will facilitate the successful use of vegetation to remediate chemically contaminated soils. This document is a chapter from the book Bioremediation through Rhizosphere Technology.

2904

V18/025459

Toxicological Risk Assessment as a Decision-Making Tool for the Remediation of Contaminated Soil near the Lachine Canal

Morin, D.; Desbiens, R.

D'Aragon, Desbiens, Halde Associates Ltd., Montreal, Quebec, Canada; Department of the Environment, Environmental Protection Service, Ottawa, Ontario, Canada

CONF-951086; Proceedings of the Fifth Annual Symposium on Groundwater and Soil Remediation, Toronto, Ontario, Canada, October 2-6, 1995. Environment Canada - Environmental Protection Service, Hull, Quebec, Canada, 566 pp.; (pp. 303-309)

A case history of contaminated soil and groundwater remediation near the Lachine Canal in Montreal is described. The case was of particular significance because site-specific criteria chiefly based on risk assessment were used in planning the project. This method is more complex and controversial than methods based on pre-established criteria, but has the advantage of addressing site specific conditions. The methodology involves several steps: data collection and analysis, exposure assessment, toxicity assessment, risk characterization, and risk management. The specific application on the Lachine Canal project demonstrated the benefits of the specificity of approach to a given site and the significant cost reduction that may result from adopting this approach.

2905

V18/025530

Tracer Verification and Monitoring of Containment Systems

Lowry, W.E.; Dunn, S.D.; Williams, C.V.

Science and Engineering Associates, Inc., Santa Fe, NM; Sandia National Laboratories, Albuquerque, NM

CONF-960804 (Vol. 2); Spectrum '96: Nuclear and Hazardous Waste Management, Proceedings of an International Topical Meeting, Seattle, WA, August 18-23, 1996. American Nuclear Society, La Grange Park, Il, Vol. 2, 873 pp.; (pp. 1342-1349) (1996)

Insitu barrier emplacement techniques and materials for the containment of high-risk contaminants in soils are currently being developed by the Department of Energy (DOE). Because of their relatively high cost, the barriers are intended to be used in cases where the risk is too great to remove the contaminants, the contaminants are too difficult to remove with current technologies, or the potential for movement of the contaminants to the water table is so high that immediate action needs to be taken to reduce health risks. Consequently, barriers are primarily intended for use in high-risk sites where few viable alternatives exist to stop the movement of contaminants in the near term. Assessing the integrity of the barrier once it is emplaced, and during its anticipated life, is a very difficult but necessary requirement. Existing surface-based and borehole geophysical techniques do not provide the degree of resolution required to assure the formation of an integral insitu barrier. Science and Engineering Associates, Inc., 
(SEA) and Sandia National Laboratories (SNL) are developing a quantitative subsurface barrier assessment system using gaseous tracers. Called SEAtrace [TM], this system integrates an autonomous, multipoint soil vapor sampling and analysis system with a global optimization modeling methodology to pinpoint leak sources and sizes in real time. SEAtrace [TM] is applicable to impermeable barrier emplacements above the water table, providing a conservative assessment of barrier integrity after emplacement, as well as a long term integrity monitoring function. The SEAtrace [TM] system is being developed under funding by the DOE-EM Subsurface Contaminant Focus Area.

\section{6}

\section{V18/021969}

\section{Transformation of Carbon Tetrachloride by Biogenic Fe} (II)

Gorby, Y.A.; Workman, D.J.; Amonette, J.E.; Fruchter, J.S.

Pacific Northwest Laboratory, Richland, WA

CONF-9509139; Emerging Technologies in Hazardous Waste Management VII, D.W. Tedder (ed.), Proceedings of the Seventh American Chemical Society Industrial and Engineering Chemistry Division Special Symposium, Atlanta, GA, September 17-20, 1995. American Chemical Society, Washington, DC, 1291 pp.; (p. 593) (1995)

The dissimilatory Fe(II)-reducing bacterium Shewanella alga, strain $\mathrm{BrY}$ reduced structural $\mathrm{Fe}$ (III) in layered silicates and $\mathrm{Fe}(\mathrm{III})$ in a variety of synthetic and natural crystalline Fe(III)-oxides. Reduction of Fe(III) in each compound supported growth of bacteria and provided Fe(II) that either remained bound in the clay lattice of the layered silicates or was adsorbed to the surfaces of the crystalline oxides. Bound and sorbed Fe(II) chemically degraded carbon tetrachloride under anoxic conditions, whereas soluble Fe(II) did not. Similar results were obtained using Hanford subsurface or Columbia River sediments that contained microbially-reduced Fe(II). Microbial reduction of $\mathrm{Fe}$ (III) to reactive $\mathrm{Fe}$ (II) provides potential for in situ degradation of carbon tetrachloride under anoxic conditions. (Complete text)

\section{7}

\section{V18/023340}

Transport and Remediation of Subsurface Contaminants: Colloidal, Interfacial, and Surfactant Phenomena

Sabatini, D.A.

University of Oklahoma, Norman, OK

Transport and Remediation of Subsurface Contaminants: Colloidal, Interfacial, and Surfactant Phenomena, R.C. Knox (ed.), American Chemical Society, Washington, DC (March 1992)

This book contains 19 papers from a symposium in Norman, Oklahoma, June 1991 that discuss the natural migration and remediation of contaminants just below the surface of the soil. Covering colloids, organic and inorganic compounds and surfactants, they include perspectives from chemistry, chemical engineering and materials and environmental sciences. from Contaminated Soils
Mathur, S.P.; Ceci, V.M.; Phelan, J.M.; Misra, M.; Mehta, R.K.

U.S. Department of Energy, Germantown, MD; BDM Federal, Inc., Gaithersburg, MD; Sandia National Laboratories, Albuquerque, NM; University of Nevada, Reno, NV

CONF-960804 (Vol. 2); Spectrum '96: Nuclear and Hazardous Waste Management, Proceedings of an International Topical Meeting, Seattle, WA, August 18-23, 1996. American Nuclear Society, La Grange Park, IL, Vol. 2, 873 pp.; (pp. 1379-1386) (1996)

Treatability studies for the physical separation of heavy metals from contaminated soils have been conducted on soils from five (5) Department of Energy Sites. Using uranium or plutonium contaminated soils, six (6) technologies were evaluated at the University of Nevada at Reno by Mackay School of Mines personnel for their effectiveness in reducing the volume of contaminated soil by separating soils into clean and dirty fractions. Test results show that depending upon the soil characteristics (clay or sand rich) and the type of contamination present (particulate or adsorbed) these technologies can be effective in reducing the amount of soil that must be further treated or disposed at a certified Land Disposal Facility.

2909

V18/020676

Treatability Studies to Improve Site Remediation Wilson, J.J.

Golder Associates Limited, Calgary, Alberta, Canada

CONF-951038; Environmental Conference '95: Proceedings of the Eighth Annual Calgary Environmental Trade Show and Conference, Calgary, Alberta, Canada, October 31-November 1, 1995, 203 pp.; (pp. 161-173) (November 1995)

The approaches used in technology selection and treatability testing to support site bioremediation plans are described. It is suggested that inappropriate technologies without prior testing could create more problems than originally existed. Inexpensive testing can avoid these problems. The following treatability tests are recommended to be performed prior to the use of any remediation technology: respirometry tests, bioslurry tests, soil plan tests, abiotic losses tests, and other specialized testing. Characteristic features of these tests, as well as their costs and scheduling parameters, are summarized. Depending on the complexity of the site, proper remedial design can require a collaborative effort of geologists, hydrologists, agronomists, chemists, biologists, and engineers.

V18/022226

Treatment Alternatives for Lead Impacted Media: Case Studies

Carey, M.J.; Nagelski, S.D.

National Environmental Technologies, Inc., Charlotte, NC

CONF-951139 (Vol. 2); Superfund 16: Proceedings of a Hazardous Waste Conference and Exhibition, Washington, DC, November 6-8, 1995. E.J. Krause and Associates, Bethesda, MD, Vol. 2, 817 pp.; (pp. 1289-1295) (1994) 
Lead impacted media resulting from past waste management practices was detected at a lead casting facility, two mirror manufacturing plants, and a municipal landfill. Leachable lead concentrations prior to treatment ranged from 10 milligrams per liter $(\mathrm{mg} / \mathrm{L})$ in a mirror waste pile to $900(\mathrm{mg} / \mathrm{L})$ at a lead casting facility. Cement stabilization and the application of the MAECTITE [R] chemical treatment process solution were evaluated as treatment alternatives for each facility based on the cost of treatment and disposal, and time limitations. Cement stabilization was used at two of the facilities and the application of the MAECTITE [R] chemical treatment process solution was used at the other two facilities. The evaluation of treatment alternatives began by characterizing the waste at each facility and performing treatability studies to determine the minimum ratio of cement-to-waste or the minimum concentration of MAECTITE [R] solution needed to render the lead impacted waste non-hazardous. Cement stabilized wastes were recycled for reuse as fill for the construction of a parking lot at one facility and as the sub-base of a new road at another facility. The use of the MAECTITE [R] chemical process solution permitted on-site treatment and off-site disposal of non-hazardous waste at a RCRA Subtitle $D$ landfill. Following treatment by either cement stabilization or MAECTITE [R] chemical treatment process, leachable lead concentrations were reduced below federal regulatory levels according to the Resource Conservation and Recovery Act (RCRA) maximum allowable concentration limit of $5 \mathrm{mg} / \mathrm{L}$ lead (D008) by the toxicity characteristic leaching procedure (TCLP).

\section{1}

\section{V18/023794}

Treatment Train Approach to Insitu Bioremediation Leavitt, M.E.

International Technology Corporation, Knoxville, TN CONF-9504134; HAZMACON' '95, T. Bursztynsky and M.L. Loss (eds.), Proceedings of the Twelfth Hazardous Materials Management Annual Conference and Exhibition, San Jose, CA, April 4-6, 1995. Association of Bay Area Governments, Oakland, CA, 790 pp.; (pp. 354-357) (1995)

Bioremediation technology has developed into a viable and often cost-effective altemative for environmental restoration. However, there has been a propensity for the "overselling" of bioremediation to the extent that users can be disappointed in bioremediation's limitations. IT's approach to bioremediation often utilizes additional treatment technologies so that a swift, effective system is used to achieve treatment goals. This paper will present a case history describing a site remedy that utilized soil vapor extraction, in situ aquifer bioremediation, and air stripping to address gasoline/diesel contamination in saturated and unsaturated soil at a service station.

\section{2}

V18/022662

Treatment of Plutonium Contaminated Soil/Sediment from the Mound Site Using the ACT*DE*CON [SM] Process

Negri, M.C.; Swift, N.A.; North, J.P.

Argonne National Laboratory, Argonne, II; Selentec, Atlanta, GA; Rust Remedial Services, Inc., Anderson, SC ANL/ES/CP-90891; 140 pp. (1996)
The removal and/or treatment of contaminated soil is a major problem facing the US DOE. The EG\&G Mound Applied Technologies site in Miamisburg, Ohio, has an estimated 1.5 million cubic feet of soils from past disposal and waste burial practices awaiting remediation from plutonium contamination. This amount includes sediment from the Miami Erie Canal that was contaminated in 1969 following a pipe-rupture accident. Conventional soil washing techniques that use particle separation would generate too large a waste volume to be economically feasible. Therefore, innovative technologies are needed for the cleanup. The $A C T^{*} D^{*} C O N[S M]$ process was developed by SELENTEC for washing soils to selectively dissolve and remove heavy metals and radionuclides. $\mathrm{ACT}{ }^{*} \mathrm{DE} * \mathrm{CON}[\mathrm{SM}]$ chemically dissolves and removes heavy metals and radionuclides from soils and sediments into an aqueous medium. The $A C T * D E * C O N$ [SM] process uses oxidative carbonate/chelant chemistry to dissolve the contaminant from the sediment and hold the contaminant in solution. The objective of recent work was to document the conditions necessary to achieve the Mound-site and regulatory-cleanup goals using the $A C T * D E * C O N[S M]$ technology.

\section{3}

\section{V18/021988}

Treatment of Soils Artificially Contaminated by Heavy Metals Using Chelating Agents as Washing Solutions Yang, G.C.C.; Chen, T.C.

National Sun Yat-Sen University, Institute of Environmental Engineering, Kaohsiung, Taiwan

CONF-9509139; Emerging Technologies in Hazardous Waste Management VII, D.W. Tedder (ed.), Proceedings of the Seventh American Chemical Society Industrial and Engineering Chemistry Division Special Symposium, Atlanta, GA, September 17-20, 1995. American Chemical Society, Washington, DC, 1291 pp.; (pp. 38-41) (1995)

Soils contaminated by heavy metals are commonplace around the world. The rapid development of various technologies and changing of industrial products frequently carry with them the increased generation of hazardous wastes. Oftentime, heavy metals are associated with these toxic wastes. These wastes, if improperly disposed of, can pose great hazards to public health and the environment. In this study, batch-type washing with various chelant solutions was employed for the treatment of soils artificially contaminated by heavy metals. The effectiveness of each chelant solution for washing such soils was then evaluated. The effect of $\mathrm{pH}$ on washing effectiveness was determined as well.

\section{Two-Stage Bioremediation of TNT Contaminated Soils} Funk, S.B.; Crawford, D.L.; Roberts, D.J.; Crawford, R.L. University of Idaho, Department of Microbiology, Molecular Biology, and Biochemistry, Moscow, ID; University of Houston, Department of Environmental and Civil Engineering, Houston, TX; University of Idaho, Center for Hazardous Waste Remediation Research, Moscow, ID Bioremediation of Pollutants in Soil and Water, B.S. Schepart (ed.), Proceedings of a Symposium, Fort Worth, TX, October 14-15, 1993. American Society for Testing and Materials (ASTM), 
Philadelphia, PA, 265 pp.; (pp. 177-189) (May 1995)

Bioremediation appears to be a feasible approach for cleaning soils contaminated with 2,4,6-trinitrotoluene (INT) and related explosives. Development of an effective, inexpensive biological remediation method for cleaning these soils would result in major economic savings to owners of munitions-contaminated sites. Here we report on the development of an anaerobic microbial bioremediation process. Munitions-contaminated soil was obtained from a munitions depot site near Umatilla, Oregon. A method was developed in which the contaminated soil was mixed with phosphate buffer in the presence of a starch-rich carbon source. A strictly anaerobic bacterial consortium became established and degraded the munitions compounds. Temperature and $\mathrm{pH}$ strongly affect the rate of solubilization of TNT from the contaminated soil, as well as the biological activity within the soil slurries.

2915

V18/023562

UFA [TM] Technology for Characterization of Insitu Barrier Materials

Conca, J.L.; Wright, J.

Washington State University Tri-Cities, Richland, WA; Pacific Northwest Laboratory, Richland, WA

CONF-941124; Insitu Remediation: Scientific Basis for Current and Future Technologies, G.W. Gee and N.R. Wing (eds.), Proceedings of the 33rd Hanford Symposium on Health and the Environment, Pasco, WA, November 7-11, 1994. Battelle Press, Columbus, $\mathrm{OH}$, Part 2, 605 pp.; (pp. 1179-1193) (1994)

Site characterization, choice of remedial strategies for site restoration, and performance assessment of chosen strategies all require knowledge of the transport properties for subsurface materials. Examples of such properties are hydraulic conductivity, diffusion coefficient, retardation or sorption properties, and in-situ recharge. Unsaturated conditions in the vadose zone are especially difficuit to investigate because of the extreme variability in the transport properties of geologic materials as a function of water content. A new technique, the unsaturated flow apparatus (UFA [TM]) method, was developed to rapidly attain hydraulic steady state in all porous/fractured media, including multicomponent/multiphase systems. The larger driving forces obtainable with centrifugation techniques are combined with precision fluid flow through a rotating seal. Hydraulic steady state is achieved in a period of hours to days, instead of months to years, depending on the target water content and intrinsic permeability of the material. Barrier materials, such as bentonite slurries, chemical barriers, cements, and asphalt concretes, can be rapidly run in the UFA prior to emplacement in order to fine-tune formulations and to identify any site-specific or substrate-specific problems that could not otherwise be identified without actual testing under field conditions.

\section{6}

V18/022779

\section{Uranium Extraction from Soil}

Dworjanyn, L.O.

Westinghouse Savannah River Company, Aiken, SC CONF-960804 (Vol. 2); Spectrum '96: Nuclear and Hazardous Waste Management, Proceedings of an International Topical

Meeting, Seattle, WA, August 18-23, 1996. American Nuclear Society, La Grange Park, IL, Vol. 2, 873 pp.; (pp. 1311-1317) (1996)

Numerous areas within the DOE Complex are contaminated with organics, inorganics and radionuclides. Steed's Pond at Savannah River Site is contaminated with uranium and nickel at up to 5000 $\mathrm{ppm}$ (mg/kg soil). The Ohio Fernald Site is contaminated extensively with uranium at 500 to $1000 \mathrm{ppm}$. The Fernald Site was selected by DOE for demonstrating advaneed technologies for removing uranium from soil. Various DOE labs were commissioned to perform an Integrated Demonstration for uranium contaminated soils cleanup. This effort included extensive soil characterization as well as new decontamination technology such as extended leaching, chelating agents, biphase separation, paramagnetic separation and heap leaching. This work was aimed at determining the best uranium extraction possible using attrition scrubbing, commercial soil processing equipment, and environmentally compatible leachants.

\section{7}

\section{V18/021975}

Uranium Stabilization by Microbial Reduction and Photodegradation: X-Ray Spectroscopic Studies

Dodge, C.J.; Francis, A.J.; Clayton, C.R.

Brookhaven National Laboratory, Department of Applied Science, Upton, NY; State University of New York, Stony Brook, NY

CONF-9509139; Emerging Technologies in Hazardous Waste Management VII, D.W. Tedder (ed.), Proceedings of the Seventh American Chemical Society Industrial and Engineering Chemistry Division Special Symposium, Atlanta, GA, September 17-20, 1995. American Chemical Society, Washington, DC, 1291 pp.: (p 25) (1995)

$X$-ray absorption near edge structure (XANES) at the National Synchrotron Light Source (NSLS) and X-ray photoelectron spectroscopy (XPS) were used to determine the speciation of uranium in contaminated soils and wastes. XPS (surface technique) and XANES (bulk analysis) showed that an anaerobic bacterium Clostridium sp. reduced soluble U(VI) to insoluble U(IV) in culture medium and in uranium waste. Photodegradation of U(VI)-citrate resulted in formation of a precipitate. Characterization of the resulting solid by XPS, XANES, and X-ray diffraction (XRD) showed the formation of insoluble and stable uranium trioxide (UO32H2O). X-ray spectroscopic techniques have been used to confirm the application of two patented treatment processes developed at Brookhaven National Laboratory to immobilize and stabilize uranium in contaminated soils and wastes. (Complete text)

\section{V18/022785}

Uranium-Contaminated Soil Pilot Treatment Study Turney, W.R.J.R.; Mason, C.F.V.; Michelotti, R.A.; Hickmott, D.D.; Hoard, D.J.; Fluk, L.; Johnson, N.R.; Thomson, B.M.

Los Alamos National Laboratory, Los Alamos, NM; ICF Kaiser Engineers, Inc., Los Alamos, NM; Thermo Nutech, Albuquerque, NM; University of New Mexico, Albuquerque, NM

CONF-960804 (Vol. 2); Spectrum '96: Nuclear and Hazardous 
Waste Management, Proceedings of an International Topical Meeting, Seattle, WA, August 18-23, 1996. American Nuclear Society, La Grange Park, IL, Vol. 2, 873 pp.; (pp. 1371-1378) (1996)

This paper describes a pilot treatment study that utilizes procedures to assay, sort and extract uranium from large volumes of uranium-contaminated soil. The Segmented Gate System (SGS), developed by ThermoNutech, formerly TMA Eberline) is used on-site to assay and sort uranium-contaminated soil from non-contaminated soil. This pretreatment process is followed by a containerized vat leach (CVL) system developed by Los Alamos National Laboratory (LANL) that will leach uranium from the uranium-contaminated portion of the sorted soil. Results from the pilot treatment study will be used to assess the capabilities of removing radioactive contamination from large volumes of soil, to remediate sites, and reduce the volume of radioactive waste. The results will also be used to assess the cost effectiveness of this approach for future work at similar sites.

\section{9 \\ V18/021780}

Use of 16S rRNA Analysis to Investigate Phylogeny of Methylotrophic Bacteria

Bratina, B.J.; Brusseau, G.A.; Hanson, R.S. •

University of Minnesota, Gray Freshwater Biological Institute, Department of Microbiology, Navarre, $M N$

International Joumal of Systematic Bacteriology 42(4):645-648 (October 1992)

Small-subunit rRNAs from 24 gram-negative methylotrophic bacteria have been sequenced. A phylogenetic tree was constructed on the basis of sequence similarities by using a weighted least-mean-square difference method. The methylotrophs were separated into coherent clusters in which bacteria in each group shared physiological characteristics.

2920 V18/023790

Use of 3D-Numerical Models for SVE Design

Chaganti, S.; Shibberu, D.

ICF Kaiser Engineers, Inc., Oakland, CA; ICF Kaiser Engineers, Inc., Rancho Cordova, $\mathrm{CA}$

CONF-9504134; HAZMACON '95, T. Bursztynsky and M.L. Loss (eds.), Proceedings of the Tweltth Hazardous Materials Management Annual Conference and Exhibition, San Jose, CA, April 4-6, 1995. Association of Bay Area Governments, Oakland, CA, 790 pp,; (pp. 307-319) (1995)

The design of soil-vapor extraction (SVE) systems for remediation has generally been based on the use of analytical solutions, which are limited by restrictive assumptions. These solutions are generally one-dimensional, and applicable only for radial flow to a single well. Many SVE remediation efforts are concerned with relatively thin vadose zones, where groundwater occurs at shallow depths. In such cases, the restrictive assumptions involved with analytical solutions are sometimes acceptable, unlike cases where multi-vent SVE systems are required. For the case of a large vent field, the pressure/flow distribution in the vent field can best be adequately determined through numerical modeling. In addition, thick, multi-layered vadose zones, with heterogeneously distributed recent contaminants generally precludes the use of simplified analytical or numerical techniques. With the development of sophisticated PC-based numerical models for fluid flow and transport, it has become practical to use 3D numerical models to aid in the design of SVE systems. This paper discusses numerical flow and mass transport modeling performed for the design of a large, complex soil vapor extraction system in California. The main objectives of the modeling effort can be summarized as follows: (1) Simulate the pressure and flow distributions for each proposed vent layout design. This information is need to evaluate relative effectiveness; (2) Provide estimates of mass removal rates and cleanup times; (3) Simulate various operating modes/chronologies to assure compliance with design requirements; and (4) Aid in the placement of optimum vent locations and screen intervals.

2921

V18/023836

Use of Air-Based Technologies as Interim Remedial Measures in RCRA: A Case Study

Skoularikis, N.D.; Loureiro, J.J.

Loureiro Engineering Associates, Plainville, CT

CONF-9306269; HazMat '93 International, Proceedings of the Eleventh Annual Environmental Management and Technology Conference and Exhibition, Atlantic City, NJ, June 9-11, 1993. Advanstar Expositions, Glen Ellyn, IL, 731 pp.; (pp. 662-672) (1993)

Recently there has been a strong movement towards the use of innovative cost-effective technologies for the removal of volatile organic compounds (VOCs) from contaminated media. Soil vapor extraction (SVE) and air sparging are two air-based technologies which have found extensive application as interim remedial measures at RCRA Corrective Action Programs. Interim measures are implemented, often voluntarily by RCRA facilities, to avoid further spreading of the contamination, and control the release or the source of the contaminants at an early stage if possible. Recent innovative variations to the SVE include the dual vacuum extraction process intended to remove and treat both contaminated water and vapor, and steam enhanced extraction in which the injected steam enhances volatilization of the contaminants. This paper presents a case study involving the use of a network of SVE wells and vapor monitoring probes strategically placed at and around identified hot spots.

2922 V18/023647

Use of Bathymetry for Sediment Characterization at Indiana Harbor

Petrovski, D.M.

U.S. Environmental Protection Agency, Chicago, IL CONF-9406413; Dredging, Remediation, and Containment of Contaminated Sediments, K.R. Demars, G.N. Richardson, R.N. Yong and R.C. Chaney (eds.), Proceedings of a Symposium, Montreal, Quebec, Canada, June 23-24, 1994, 343 pp.; (pp. 40-49) (1995)

In 1992, US EPA, Region 5, sampled sediments within the Federal Navigation Project at Indiana Harbor, IN. Lack of a disposal site has precluded dredging since 1972, resulting in the accumulation of over $750,000 \mathrm{cu} \mathrm{m}$ of highly contaminated sediment. The Federal Project covers approximately $1.08 \mathrm{sq} \mathrm{km}$ of both enhanced and 
secondary sediment accumulation. The purpose of the sampling effort was to characterize these sediments under Subtitle $C$ of the Resource Conservation and Recovery Act (RCRA). Several approaches common to regulatory characterization were considered and rejected in favor of a bathymetry based procedure. Bathymetric surveys were used to identify 14 areas of thick sediment accumulation. Such areas are indicative of reduced water velocities which favor the accumulation of finer-grained sediment having a strong tendency to be associated with higher contaminant concentrations. Samples obtained from these locations should contain contaminant concentrations that exceed the mean concentrations for the project sediments. Consequently, a regulatory decision based upon these samples should be conservative. Bathymetry may provide a mechanism to reduce the number of samples necessary to characterize large sediment volumes, while maintaining an acceptable level of confidence in any derived regulatory decision.

\section{$2923 \quad$ V18/020879}

Use of Cryogenic Fluids for Environmental Drilling in Unconsolidated Formations

Simon, R.D.; Cooper, G.A.

University of California, Department of Materials Science and Mineral Engineering, Berkeley, $\mathrm{CA}$

CONF-940113 (Vol. 56); Drilling Technology, J.P. Vizniak (ed.), Proceedings of the Energy-Sources Technology Conference and Exhibition, New Orleans, LA, January 23-26, 1994. American Society of Mechanical Engineers, New York, NY, Vol. 56, 280 pp; (7 pp.) (1994)

A novel method is being developed to drill and support horizontal boreholes in loose, unconsolidated formations such as sands or gravels. It consists of drilling using supercooled air as the flushing medium in order to freeze the surrounding soil. The method is suited to drilling near surface holes for environmental monitoring and remediation because no additional polluting substances are introduced into the hole and there is little permanent alteration of the surrounding soil. In addition, subsurface pollutants adjacent to the borehole will be frozen in place, preventing them from spreading along the borehole or returning to the surface and endangering workers. Laboratory drilling tests have demonstrated that sands with as little as $2.5 \%$ water content ( $11 \%$ saturation), subjected to pressures simulating 60 meters $(2000 \mathrm{ft}$ ) of overburden may be drilled without collapse, and that the freezing is sufficiently rapid to allow penetration rates up to $9 \mathrm{~m} / \mathrm{hr}$ ( $30 \mathrm{ft} / \mathrm{hr}$ ) under some conditions. Observed borehole collapse pressures agree with those predicted from measured strengths of frozen sand samples.

Preliminary work suggests that conventional air drilling equipment may be used with minimal modifications.

\section{$2924 \quad$ V18/023034}

Use of Engineered Lightweight Fill for Landfill Cover Remediation

Poe, D.E.; Gardner, R.B.; Xiaoyu, F.

CONF-950177; Waste Tech '95, Proceedings of a Conference, New Orleans, LA, January 23-25, 1995. Environmental Industry News, Washington, DC, 530 pp.; (pp. 212-226) (1995)

In 1991, SCS was retained to provide design and construction engineering services to retrofit a landfill gas migration control system and regrade/repair an existing low-permeability soil final cover system for a 10-acre closed landfill located in west-central Florida. The final cover system modifications consisted of regrading the top of the landfill to re-establish positive drainage across and off of the top of the landfill. While active, the landfill had received municipal solid waste (MSW), commercial solid waste, and various industrial wastes and sludges. The landfill was closed in the early 1980's. At the time of filling, the subject landfill was operated as a trench fill. A series of 40-foot deep trenches were excavated across the fill area, and the MSW was placed and compacted into the trenches. The soil excavated during construction of the trenches was used to construct berms along the sides of the individual trenches. No constructed bottom liner or leachate collection system was incorporated into the design. This report presents the results of a conceptual evaluation of utilizing expanded polystyrene blocks or Geofoam as the lightweight fill component for an alternative cover remediation.

2925

V18/020686

Use of Field Screening in PCB Remediation: A Case Study

Venkateswar, R.; Anderer, B.S.; Saraf, S.; Desai, A. TRC Environmental Corporation, Downers Grove, IL CONF-950209 (Vol. 1); VIP-47, Proceedings of the Fourth International Symposium on Field Screening Methods for Hazardous Wastes and Toxic Chemicals, Las Vegas, NV, February 22-24, 1995. Air and Waste Management Association, Pittsburgh, PA, Vol. 1, 733 pp.; (pp. 292-300) (1995)

Field Screening methods serve as a vital tool in delineating the extent of on-site contamination. Rapid tum-around time allows for a more detailed contaminant characterization, thereby reducing the volume of soils to be treated and/or sent out to the landfills for disposal. The use of a field gas chromatograph (GC) equipped with an electron capture detector (ECD) for remediating a PCB contaminated site has shown to be cost effective and reproducible.

2926

$\mathrm{V} 18 / 022656$

Use of Health Risk Assessment Methodologies in Conjunction with Vadose Zone Modeling to Determine Shut-Off Levels for a Vapor Extraction System Smith, W.M.; Pelletier, J.W.; Mosley, W.; Veenstra, R.B. Kleinfelder, Inc., Diamond Bar, CA; Radian Corporation, El Segundo, CA; Environmental Science \& Engineering, Inc., Williamston, MI

CONF-960393 (Part 1); Contaminated Soils and Groundwater: Analysis, Fate, Environmental and Public Health Effects, and Remediation, Proceedings of the Sixth Annual West Coast Conference, Newport Beach, CA, March 11-14, 1996. Association for the Environmental Health of Soils, Amherst, MA, Part 1, 257 pp.; (p. 25) (1996)

A solvent recovery and distribution facility was requested to install and operate a vapor extraction system to remove the organic constituents which had been spilled into the soils over 40 years of operation. The facility was required to continue vapor extraction until health-protective levels could be reached and maintained 
off-site. The purpose of this study was to determine the health-protective levels of contaminants in the subsurface which must be achieved prior to cessation of vapor extraction activities. This was accomplished through the determination of on-site concentrations, predicted by vadose zone modeling, that must be maintained so that they do not result in concentrations of these chemicals migrating off site which exceed health-protective levels. These health-protective levels were generated considering both a worst case and a realistic case scenario for exposure.

2927

V18/022001

Use of Hydraulic Fracturing to Enhance Soil Vapor Extraction: A Case Study

Baker, J.E.; Wells, S.L.

Golder Applied Technologies, Atlanta, GA

CONF-9509139; Emerging Technologies in Hazardous Waste Management VII, D.W. Tedder (ed.), Proceedings of the Seventh American Chemical Society Industrial and Engineering Chemistry Division Special Symposium, Atlanta, GA, September 17-20, 1995. American Chemical Society, Washington, DC, 1291 pp.; (p. 559) (1995)

Many environmental remediation activities can be cost effectively implemented through the use of soil vapor extraction. While this approach has been shown to work well in relatively high permeability soils, it is much less effective in low permeability silts and clays. The low permeability nature of these soils makes the flow of air required to remove volatile organic vapors difficult, if not impossible. Hydraulic soil fracturing, a modification of petroleum engineering technology to the environmental field, is a viable technique for overcoming this difficulty. The process involves injecting, under pressure, a high viscosity fluid which serves as the carrier for a sand propant. Enzymes which are mixed with the fluid cause the fracturing fluid to revert to a low permeability, allowing it to be pumped out, leaving a series of high permeability sand lenses. Several such lenses are injected at the site of each well, allowing efficient injection and/or extraction of vapors from the soil mass. The details of the fracture design and the results of the remedial action are presented. (Complete text)

\section{8 \\ V18/024301}

Use of Sorbents for Decreasing the Cs-137 Active Concentration in Soils Near the Chernobyl Zone

Gorodetskij, D.V.; Arkhipov, A.N.

Nauchno-Proizvodstvennoe Ob'edinenie Pripyat, Chernobyl, Ukraine; Ministerstvo Ukrainy po Delam Zashchity Naseleniya ot Posledstvij Avarii na Chernobyl'skoj AEhS, Kiev, Ukraine

INIS-UA-026/A; CONF-960002; Chemobyl 96: Results of 10 Years Work on ChNPP Accident Mitigation, Proceedings of the Fifth International Scientific-Technical Conference, N.P. Arkhipov (ed.), Zelenyj Mys, Ukraine, 1996, 526 pp.; (p. 240) (1996)

Short communication. No abstract available. (This document is in Russian).
Performance-Based Screening Method for Petroleum Hydrocarbons

Slavin, P.J.; Crandall, K.; Dawson, L.A.; Kottenstette, R.; Wade, $M$.

GRAM, Inc., Albuquerque, NM; Brown and Root Environmental, Albuquerque, NM; Sandia National Laboratories, Albuquerque, NM; INTERA, Inc., Albuquerque, NM

CONF-960804 (Vol. 2); Spectrum '96: Nuclear and Hazardous Waste Management, Proceedings of an International Topical Meeting, Seattle, WA, August 18-23, 1996. American Nuclear Society, La Grange Park, IL, Vol. 2, 873 pp.; (pp. 1214-1219) (1996)

Thermal desorption/gas chromatography (TD/GC) can be used on a wide variety of contaminants. Typical applications include fuel-contaminated and PCB-contaminated soils. TD/GC proved to be an extremely useful screening technique for detecting the non-hazardous mineral oil found in soil at the HERMES site, one of two technical areas under RCRA investigation at Sandia National Laboratories/New Mexico. It was used to screen soil samples on site for total petroleum hydrocarbon (TPH) content during a RCRA Facility Investigation (RFD). It proved to be a rapid, cost-effective tool for detecting non-aromatic mineral oil in soil. The on-site TD/GC results correlated well with those generated at an off-site laboratory. The method detected TPH at concentrations as low as $10 \mathrm{mg} / \mathrm{kg}$, one-tenth of the New Mexico State action level of 100 $\mathrm{mg} / \mathrm{kg}$, and half the minimum concentration of $20 \mathrm{mg} / \mathrm{kg}$ detected by EPA Method 418.1. Thus the method is capable of detecting TPH at concentrations well below those needed for site characterization purposes.

2930

\section{V18/023456}

Uses of Biotechnology in Waste Treatment

Holmes, R.G.G.; Benson, J.

British Nuclear Fuels plc, Springfields, Preston, United Kingdom; Electric Power Research Institute, Palo Alto, CA; Paul Williams and Associates, Medina, $\mathrm{OH}$

EPRI-TR-106929; CONF-960783; Proceedings of the 1996 Electric Power Research Institute (EPRD) International Low Level Waste Conference, New Orleans, LA, July 22-24, 1996, 715 pp.; (pp. 375-385) (October 1996)

British Nuclear Fuels Ltd. (BNFL) has invested in a biotechnology program to address waste treatment problems. The use of biotechnology to destroy organic pollutants is well known and has been successfully employed both in-situ and exsitu. The BNFL approach has been to concentrate on the interaction of microbial systems with inorganic materials. This study has resulted in two major programs of work that show every indication of being suitable for large scale application. The first program of work investigated using, to decontaminate concrete surfaces, the phenomena of concrete degradation by sulphur oxidizing bacteria. Laboratory tests proved encouraging and have resulted in a Co-operative Research and Development Agreement (CRADA), between BNFL and Lockheed Martin Idaho Technologies Company for the INEL site. The CRADA will lead to a demonstration of the technology. The second major area of investigation is the development of an integrated bioremediation process for the removal and recovery of 
toxic heavy metais from contaminated land. The two stage process, which can be employed in an in-situ or exsitu mode, involves the use of indigenous micro-organisms to generate sulphuric acid and environmental consortia to generate hydrogen sulphide. This project has reached the point of field trials. Results from both programs will be presented and their applications at nuclear sites detailed.

\section{1}

V18/021720

Using Cyclodextrin for Insitu Remediation of Petroleum Contamination

Brusseau, M.L.; McCray, J.; Wang, X.

University of Arizona, Tucson, AZ

CONF-960376 (Part 1); Proceedings of the 211th American Chemical Society (ACS) National Meeting, New Orleans, LA, March 24-28, 1996. ACS, Washington, DC, Part 1, 1172 pp.; (p. 787, Paper ENVR 103) (1996)

The potential of agents such as surfactants and cosolvents to influence the solubility, sorption, and transport of organic compounds in porous media has fomented research on their use for enhancing contaminant removal (e.g., enhanced pump and treat). However, the application of these agents for in-situ remediation may, in some cases, be constrained by various factors such as reactivity with soil and potential toxicity. As an altemative, microbially produced cyclodextrins are not limited by these disadvantages because they have many unique properties. In this work we examine the potential of selected cyclodextrins to enhance the removal of low-polarity organic compounds from contaminated soil and aquifer materials. (Complete text)

\section{2 \\ V18/023740}

Using a Groundwater Flow Model to Evaluate and Enhance Operation of a Vapor Extraction System

Regan, J.M.; Quinn, K.J.; Bandt, K.E.; Leibrock, M.J.

Montgomery Watson Americas, Inc., Madison, WI; Waste Management, Inc.-Midwest, Westchester, IL

CONF-950978; Municipal and Industrial Waste, Proceedings of the 18th International Madison Waste Conference, Madison, WI, September 20-21, 1995. University of Wisconsin, Madison, WI, 461 pp.; (pp. 1-13) (1995)

The vapor extraction system at a former waste disposal site was modeled in order to determine gas flow paths under the current operating condition and to evaluate a method for enhancing system operations. The model was a three-dimensional finite-difference numerical model that simulates the movement of a fluid through porous media. The model initially was developed for groundwater flow, thus requiring appropriate conversions from hydraulic to pneumatic properties. The model was calibrated using pilot-study and full-scale operational data. Initial calibration results using pilot-study data indicated that there was a sufficient source of methane gas generation within the disposal area to supply a steady-state flow to one pilot test well (i.e., the vacuum did not extend beyond the clay cover area). Recalibration to data from operation of the full system showed that methane gas generation was occurring only in one area of the site, and that recharge of atmospheric air from outside the disposal area was the primary source of gas flow. This was consistent with the oxygen and methane gas readings from the extraction wells. The model offers the visualization of gas flow paths under different operating scenarios, therefore allowing the adjustment of extraction rates to eliminate stagnation zones and target the highest air velocities to the zones of highest VOC concentrations.

2933

V18/022688

Utilization of Thin-Layer Chromatography for Confirmational Sampling During Remedial Excavation

Burton, P.J.

Woodward-Clyde Consultants, Anchorage, AK

CONF-960393 (Part 3); Contaminated Soils and Groundwater: Analysis, Fate, Environmental and Public Health Effects, and Remediation, Proceedings of the Sixth Annual West Coast Conference, Newport Beach, CA, March 11-14, 1996. Association for the Environmental Health of Soils, Amherst, MA, Part 3, 366 pp.; (p. 11) (1996)

Thin-layer chromatography (TLC) is a simple, efficient, inexpensive, and accurate method of chemical analysis. This method is applicable to field testing for confirming the limits of excavation during excavation of petroleum, oil, and/or lubricant (POL) contamination. Traditionally, excavation at contaminated sites suffers from a time delay due to the need to obtain laboratory confirmation of the limits of excavation. All suspected contaminated material is removed for stockpiling or remediation. The remaining soils need to be sampled to confirm that no contaminated material remains in the excavation. The site scientist collects samples and sends them out for analysis at a certified laboratory. The laboratory requires, even for a rush order, several days to analyze the samples. This time delay interferes with the efficiency of the operation. The excavations either have to be left open (which is a safety hazard) or reopened if additional material must be excavated. TLC samples can be collected and analyzed in several hours allowing for a short tumaround time for analytical results. The TLC method can be easily performed by a technician. Results of a case study from a subarctic Alaskan site will is reported. Simple operational TLC procedures are shared. The equipment required for TLC analysis is outlined and correlation data between TLC and laboratory analysis is presented.

\section{4 \\ V18/022212}

VETEM: A Very Early Time Electromagnetic System Year 2

Pellerin, L.; Pfeifer, M.C.; Labson, V.F.

Lawrence Berkeley National Laboratory, Berkeley, CA

CONF-960477; SAGEEP '96, R.S. Bell and M.H. Cramer (eds.), Proceedings of the Ninth Annual Symposium on the Application of Geophysics to Engineering and Environmental Problems, Denver, CO, April 15-May 1, 1996. Environmental and Engineering Geophysical Society, Wheat Ridge, CO, 1353 pp.; (pp. 91-100) (1996)

In electrically conductive conditions common in environmental characterization studies the minimum depth of investigation for traditional electromagnetic (EM) sounding techniques is roughly 5 meters, while ground penetrating radar (GPR) systems often 
investigate no more than the top meter or so when clay minerals are present in the soil. Hence, in many cases, there is a gap in our detection capability between the lower limit of GPR and the upper limit of traditional electromagnetics (EM). Bridging this gap is essential to the characterization of buried waste, contaminant plumes, and other environmental and hydrogeological targets located in the shallow subsurface. The Very Early Time Electromagnetic (VETEM) system is designed to ascertain the conductivity and dielectric properties of the shallow subsurface in conductive terrain. Hence, the one-dimensional (1-D) and three-dimensional (3-D) numerical modeling algorithms, developed in the first year of the project, contain the full solution to the EM problem including both displacement and conduction currents.

\section{5}

\section{V18/022654}

Validation of a General 3-D Numerical Model for Simulating Organic Pollutants Migration and Application to Site Remediation

Le Thiez, P.A.; Pottecher, G.; Recherche, A.; Come, J.M. Institut Francais du Petrole, Rueil-Malmaison, France CONF-960623 (Vol. 1); Proceedings of the Third International Conference on Health, Safety and Environment in Oil and Gas Exploration and Production, New Orleans, LA, June 9-12, 1996. Society of Petroleum Engineers (SPE), Inc., Richardson, TX, Vol. 1, 941 pp.; (pp. 723-733) (1996)

This paper presents a general numerical model able to simulate both organic pollutants migration (3-phase compositional flows, mass transfer, transport) in soils and aquifers and decontamination techniques such as pumping, skimming, venting, hot venting, steam injection, surfactant injection and biodegradation. To validate the simulator, a 3-D experiment in a large pilot ( $25 \mathrm{~m} \mathrm{x} 12 \mathrm{~m} \mathrm{x} 4 \mathrm{~m}$ ) was carried out. A total of 0.475 cubic meters of diesel oil was injected into the pilot, and numerous in-situ measurements were performed to determine pollutants location and concentrations within the vadose and saturated zones. Prior to the pilot test, a predictive simulation computed the extent of the contaminated zone and the oil saturations. Numerical results showed good agreement between experiment and simulation. To demonstrate the simulator abilities to improve remediation operations, a soil vapor extraction (venting) of weathered gasoline in the vadose zone under a service station was simulated. Fourteen wells were drilled on the site and extraction took nine months. The simulation closely matches the field data. Further simulations show the possibility of venting optimization for this site.

\section{6}

V18/022213

\section{Very Early Time Electromagnetic (VETEM) System: First Field Test Results}

Wright, D.L.; Grover, T.P.; Labson, V.F.; Pellerin, L. U.S. Geological Survey, Denver, CO; Lawrence Berkeley National Laboratory, Berkeley, CA

CONF-960477; SAGEEP '96, R.S. Bell and M.H. Cramer (eds.), Proceedings of the Ninth Annual Symposium on the Application of Geophysics to Engineering and Environmental Problems, Denver, CO, April 15-May 1, 1996. Environmental and Engineering Geophysical Society, Wheat Ridge, CO, 1353 pp.; (pp. 81-90) (1996)
The very early time electromagnetic (VETEM) system is a time-domain, surface-deployed system that has potential applications to direct detection of non-aqueous phase liquids as well as to the detection of buried objects. It is designed to operate in environments that are too conductive for ground penetrating radar (GPR) to be effective, and too shallow for standard electromagnetic systems. The VETEM system is a faster profiling complement to the frequency-domain high frequency sounder (HFS). First field tests of the VETEM were made at the Geophysics Performance Evaluation Range at Rabbit Valley west of Grand Junction, Colorado in June and July, 1995. A number of well defined targets of various types are buried there. The VETEM system was next used as part of the Electromagnetics Integrated Demonstration (EMID) at the Cold Test Pit at the Idaho National Engineering Laboratory (INEL) in November, 1995. The Cold Test Pit has a number of subareas with buried objects of various types. For the EMID tests, VETEM was run over three gridded areas: the Primary Grid (PG), the Large Object Pit (LOP), and the Calibration Cell (CC). In this paper we display recorded lines from the LOP that show VETEM is responding to electrical properties of the near surface and to buried objects.

\section{$2937 \quad$ V18/024866}

Volatilisation from Soil and Exposure Assessment Markey, B.; Anderssen, B.

Environment Protection Authority, Chatswood, New South Wales, Australia; Commonwealth Scientific and Industrial Research Organization, Division of Mathematics and Statistics, Canberra, Australia

Proceedings of the Third National Workshop on the Health Risk Assessment and Management of Contaminated Sites (Contaminated Sites Monograph Series No. 5, 1996), A. Langley, B. Markey and H. Hill (eds.), Sydney, Australia, May 1995. South Australian Health Commission, Rundle Mall, South Australia, 470 pp.; (pp. 441-468) (1996)

In Australio, there are no nationally-endorsed contaminated land Human Health Investigation Levels (HILs) for volatile organic compounds (VOCs). To derive HIILs for the VOCs will require, at least, a mathematical description of the movement of the volatiles through soil into buildings where exposure may occur via inhalation. Building type will need to be considered because this may influence vapor transport mechanisms. In order to augment the current qualitative understanding of these complex processes, this paper specifically examines the mathematical description of diffusion-dominated volatilization. This paper focuses on the important behavior Assessment Model (BAM) of Jury, Spencer and Farmer, since, as they show, it has an explicit solution which is easily exploited computationally to simulate representative scenarios. The advantage of the explicit solution, which allows representative scenarios to be rapidly assessed, is illustrated with MATHEMATICA, a high level mathematics language available on personal computers. It is shown how shortcomings in the BAM model can be overcome by extending it to accommodate general initial conditions and non-homogeneous surface-boundary conditions. An explicit solution to this extension, which includes the published BAM solution as a special case, is then presented. The paper concludes with a discussion, from a regulatory viewpoint, of the future needs for the modelling of volatilization processes in 
contaminated soils.

\section{8}

\section{V18/022074}

\section{Volatility Studies in a Rotating Hearth Furnace}

Yeast, T.F.; Eschenbach, R.C.; Pierce, G.D.; Amdt, M.B.; Ginsburg, J.

Retech, Inc., Ukiah, CA; Lockheed Environmental Systems and Technologies Company, Idaho Falls, ID; S.M. Stoller Corporation, Idaho Falls, ID

CONF-941148 (Vol. 2); DDER-'94: Decommissioning, Decontamination, and Environmental Restoration at Contaminated Nuclear Sites, M.G. White (ed.), Proceedings of an Embedded Topical Symposium of the American Nuclear Society Winter Meeting, Washington, DC, November 13-18, 1994. American Nuclear Society, Inc., La Grange Park, IL, Vol. 2, 241 pp.; (pp. 433-441) (1994)

The Plasma Arc Centrifugal Treatment (PACT) system will be used for treating radioactive and mixed wastes. Because the centerline temperature of plasmas is quite high, concern has been expressed that this might cause excessive volatilization of heavy metals, especially in the presence of chlorine. This paper reports data from tests run with feeds spiked with cerium oxide as a plutonium surrogate, or spiked with low levels of plutonium (about 2 nanocuries per gram). In the PACT process, waste material is fed into a sealed centrifuge where it is heated by a transferred-arc plasma torch. Organic material is evaporated and destroyed aimost immediately upon entering the primary chamber. Inorganic material is reduced to a molten phase that is uniformly heated and mixed by the motion of the centrifuge and the effect of the plasma arc. Material can be added during the process to control slag quality. The off-gas treatment system removed particulates, harmful gases and volatilized metals. Off-gas monitoring ensures that applicable environmental regulations are met. Four tests were run in a lab-size rotating hearth furnace designated the PACT-1 (inside diameter of the centrifuge was 1 foot, $0.3 \mathrm{~m}$ ). A closed loop gas system was used which recycled or stored all the gas for the duration of each test, eliminating gas discharge until after verification of suitability for discharge. The first two tests were conducted at the Retech plant in Ukiah, California. Test I used soil spiked with cerium oxide as a surrogate for plutonium. Test 2 used soil plus metal and $30 \%$ PVC, spiked with the same amount of cerium oxide. The second pair of tests was conducted in the laboratories of Argonne-West at the Idaho National Engineering Laboratory. The soil, or soil plus metal and PVC respectively, was spiked with plutonium to a level of 2 nanocuries per gram. Less than $0.1 \%$ of the cerium or plutonium charged was found in the off-gas cleanup system or the storage tank. This was true both for the test with mainly soil, and for the test with soil plus PVC and metal.

\section{9}

\section{V18/025376}

\section{Volatilization and Mineralization of Naphthalene in} Soil - Grass Microcosms, Chapter 11

Watkins, J.W.; Sorensen, D.L.; Sims, R.C.

Utah State University, Department of Civil and Environmental Engineering, Logan, UT

Bioremediation Through Rhizosphere Technology, T.A. Anderson and J.R. Coats (eds.), American Chemical Society, Washington, DC,

249 pp.; (pp. 123-131) (1994)

The potential for vegetation-enhanced biodegradation of naphthalene in artificially contaminated soil was studied in laboratory microcosms. Microcosms containing soil without plants and soil supporting two-month old Bell Rhodesgrass were treated with naphthalene and spiked with (7-Carbon-14)naphthalene. Compressed air was continuously passed through each microcosm, through a trap to collect volatile organics, and through a trap for $\mathrm{CO} 2$. The microcosms were incubated under artificial lighting with a $16 \mathrm{~h}$ photoperiod for 25 days. After incubation, soil was solvent extracted and combusted to recover bound radiolabel. Volatilization losses during operation and analysis prevented reaching a mass balance of the radiolabel. Naphthalene volatilization was enhanced by vegetation but mineralization was decreased in vegetated microcosms in comparison to those without vegetation.

V18/023909

Waste Tech '95: Proceedings of a Conference, New Orleans, LA, January 23-25, 1995

CONF-950177; Waste Tech '95, Proceedings of a Conference, New Orleans, LA, January 23-25, 1995. Environmental Industry News, Washington, DC, 530 pp. (1995)

This document contains reports which were presented at the Waste Tech 95 meeting on Landfill Technology. Topics include: monitoring; remedial action; tracer techniques; coverings; landfill design; liners; biodegradation; leachates; landfill closure; and pollution. Nine individual reports have been indexed separately for the RAPIC database.

\section{$2941 \quad \mathrm{~V} 18 / 023549$}

Water Removal from a Dry Barrier Cover System

Stormont, J.C.; Ankeny, M.D.; Tansey, M.K.

Sandia National Laboratories, Albuquerque, NM; Daniel B. Stephens \& Associates, Inc., Albuquerque, NM

CONF-941124; Insitu Remediation: Scientific Basis for Current and Future Technologies, G.W. Gee and N.R. Wing (eds.), Proceedings of the 33rd Hanford Symposium on Health and the Environment, Pasco, WA, November 7-11, 1994. Battelle Press, Columbus, OH, Part 1, 704 pp.; (pp. 325-345) (1994)

A dry barrier is a layer of soil that is dried by air flow. Incorporating a dry barrier within a landfill cover system adds an additional component to the water balance of the cover, increasing the available storage within. As covers typically include multiple, laterally continuous layers with contrasts in material properties, air flow is channeled through relatively coarse, air-permeable layers within the cover. Systems can be active, using blowers and fans, or passive, exploiting atmospheric phenomena. We performed a numerical analysis of a three-layer landfill cover design (topsoil, sand, and gravel) to investigate the mechanisms of water movement induced by air flow. The simulations were conducted using the TOUGH2 numerical code. Initial conditions were established by simulating drainage from conditions of near saturation throughout the entire cover to an equilibrium distribution of soil water content at ambient, static, air-pressure conditions. A series of simulations were then conducted with the influent airstream at various horizontal and vertical air-pressure gradients and relative humidities. Pressure gradients readily established with commercially available 
equipment resulted in virtually complete removal of water from the gravel layer within 6 months for hectare-sized landfills. Although there was very little drying in the fine layer due to advective air flow, the removal of water by evaporation near the fine/coarse layer interface reduced the local water content and hydraulic head. Water therefore moved toward the fine/coarse-layer interface, becoming available for evaporation. This is important because it suggests that the fine-layer water content may be moderated by air flow in the coarse layer.

2942 V18/022665

White Rot Fungus Bioremediation: Mother Nature's Pollution Solution [R]

Keene, M.A.

Intech One-Eighty Corporation, North Logan, UT

CONF-960393 (Part 3); Contaminated Soils and Groundwater: Analysis, Fate, Environmental and Public Health Effects, and Remediation, Proceedings of the Sixth Annual West Coast Conference, Newport Beach, CA, March 11-14, 1996. Association for the Environmental Health of Soils, Amherst, MA, Part 3, 366 pp.; (p. 19) (1996)

The white rot fungi (WRF) bioremediation system developed by Intech One-Eight Corporation (NTECH), which has evolved from both the decade of basic research work cited here and additional applied research efforts, may be easily and sharply differentiated from conventional bioremediation processes relying on the enzymatic activities of bacteria. The technology is an on-site, exsitu bioremediation process employing selected strains of WRF to degrade a wide spectrum of environmentally persistent organic compounds which may contaminate soils, sludges and sediments. Successful demonstrations of cost-effective soil decontamination using WRF technology, ranging in size up to 10,000 tons, have now been performed by licensed affiliates. The use of any WRF organisms or their enzymes for the bioremediation of most organic compounds is covered worldwide by issued and pending patents.

\section{3}

V18/023792

\section{Wood Preservatives - Contaminated Soil Treatment}

Palepu, S.D.; TerKonda, P.K.; Kapila, S.

University of Missouri, Department of Civil Engineering, Rolla, MO; University of Missouri, Center for Environmental Science \& Technology, Rolla, MO

CONF-9504134; HAZMACON '95, T. Bursztynsky and M.L. Loss (eds.), Proceedings of the Twelfth Hazardous Materials Management Annual Conference and Exhibition, San Jose, $C A$, April 4-6, 1995. Association of Bay Area Governments, Oakland, CA, 790 pp.; (pp. 333-343) (1995)

The objective of this study was to evaluate the effects of non-ionic surfactant on biodegradation of PAHs in a slurry-phase bioreactor. Experiments on slurry-phase biodegradation were carried out in absence and in presence of a non-ionic surfactant TMN-10 at various concentrations. Studies were carried out with indigenous or "acclimatized microbial population." PAHs with $2-4$ benzene rings were selected as the model compounds. Slurry-phase biodegradation using indigenous microbes was shown to be effective with and without the surfactant. The results obtained showed that presence of surfactant lead to an increased release of PAHs into the solution phase, which in turn resulted in higher biotransformation efficiency. Two- and three-ring compounds were degraded in the bioreactor about $96-99$ percent in 15 days in presence of the surfactant compared to 30 days required when the surfactant was not used. 



\section{GROUNDWATER REMEDIATION}


2944

V18/022647

Intrinsic Bioremediation of Petroleum Hydrocarbons in Groundwater at the Phoenix Pipeline Terminal, Arizona

Neaville, C.C.; Salanitro, J.P.; Wiedemeier, T.H.

Shell Development Company, Westhollow Technology Center, Houston, TX; Parsons Engineering Science, Inc., Denver, $\mathrm{CO}$

CONF-960393 (Part 3); Contaminated Soils and Groundwater: Analysis, Fate, Environmental and Public Health Effects, and Remediation, Proceedings of the Sixth Annual West Coast Conference, Newport Beach, CA, March 11-14, 1996. Association for the Environmental Health of Soils, Amherst, MA, Part 3, 366 pp.; (p. 31) (1996)

The intrinsic bioremediation of benzene, toluene, ethylbenzene, and xylenes (BTEX) dissolved in groundwater was evaluated at the Phoenix Pipeline Terminal (PPT) in Phoenix, Arizona. Three lines of evidence were used to document the occurrence of intrinsic bioremediation at the PPT site, inciuding: (1) documented loss of contaminants at the field scale; (2) geochemical evidence; and (3) direct microbial evidence. Data collected from 1988 to 1994 indicate that the extent of the dissolved BTEX plume has not increased, and that contaminant concentrations have generally decreased during this period. Comparison of BTEX electron acceptor and biodegradation byproduct isopleth maps suggests that biodegradation of BTEX is occurring at the site via aerobic respiration and the anaerobic processes of denitrification, iron reduction, and sulfate reduction. Direct evidence of the existence of a viable microbial population capable of consuming BTEX compounds was provided through enumeration of the total microbial population and the population of BTEX-degrading organisms. First-order biodegradation rates for the BTEX compounds were computed from field data. Calculated rates suggest that biodegradation accounts for the destruction of approximately $0.9 \%$ of the dissolved BTEX mass per day.

\section{5}

V18/023513

Numerical Analysis of the In-Well Vapor-Stripping System Demonstration at Edwards Air Force Base

White, M.D.; Gilmore, T.J.

Pacific Northwest National Laboratory, Richland, WA

PNNL-1 1348; 145 pp. (October 1996)

In-well vapor stripping is a remediation technology designed to remove dissolved volatile organic compounds from groundwater. The in-well vapor-stripping system comprises an engineered and a hydrologic component that operates in unison to form an in situ recirculation pattern. The engineered system is driven with compressed air, utilizing an air-lift pumping scheme that volatilizes dissolved organic compounds. The volatile vapors are removed from the gas stream above the ground surface and pumped water is infiltrated into the hydrologic system below the ground surface. This technology was demonstrated at Edwards Air Force Base (AFB), near Mojave, California, by collaborating researchers from Pacific Northwest National Laboratory and Stanford University as part of the interim cleanup activities at the base. Preliminary results on the performance of the demonstration system have been reported and indicate a significant reduction in the concentration of contaminant, dissolved trichloroethylene (TCE), around the demonstration well.

2946 V18/021637

Bioventing and Natural Attenuation: The Combination of Insitu Treatment Technologies Provides Effective Site Remediation

Brown, K.L.; Malloy, J.; Sekerka, P.; Sibbett, B.; Thomas, M.; Tyner, L.; Zhong, J.; Caron, D.R.

International Technology Corporation, San Bernardino, CA

CONF-951124; HazMat West '95, Proceedings of the Eleventh Annual Environmental Management and Technology Conference and Exhibition, Long Beach, CA, November 7-9, 1995. Advanstar Expositions, Duluth, MN, 597 pp.; (pp. 57-75) (1995)

IT Corporation (IT) is evaluating the combination of free product removal, bioventing, and natural attenuation for remediation of jet fuel-impacted soil and groundwater at George Air Force Base, California. Remedial activities are focused on a 155-acre benzene and 27-acre free product plume which have resulted from a leaking liquid fuels distribution system. Insitu remedial options are favored at this site due to the reduced yield of the aquifer, low groundwater velocity, large areal extent of contamination, reduced risk of exposure, and ongoing site operations. Following the completion of a long-term monitoring investigation including bioventing pilot operations, natural attenuation, monitoring, and free product recovery, remedial designs will be formalized.

2947

V18/022095

Steam Injection Vacuum Extraction Technology Demonstration, Naval Air Station, Lemoore, California

Gopinath, A.; Gemar, D.W.

OHM Remediation Services Corporation, Pleasanton, CA

CONF-951139 (Vol. 2); Superfund 16: Proceedings of a Hazardous Waste Conference and Exhibition, Washington, DC, November 6-8, 1995. E.J. Krause and Associates, Bethesda, MD, Vol. 2, 817 pp.; (pp. 816-825) (1994)

A leaking underground pipeline released jetfuel (JP5) into the soils and groundwater beneath Site 17 at NAS, Lemoore in Califomia's central San Joaquin Valley. To evaluate innovative technologies, the Naval Facilities Engineering Service Center (Port Hueneme, CA) awarded OHM a contract for design, construction and operation of a Steam Injection Vacuum Extraction (SIVE) system for remediation of contaminated soil and groundwater and recovery of JP5. Two steam injection wells, five extraction wells, and fourteen temperature monitoring wells were installed. Facies analyses during drilling revealed three hydrostratigraphic units; basal clay aquitard, perched sandy aquifer and silty vadose zone. Groundwater was encountered in sixteen feet below ground surface. JP5 was encountered in all three hydrostratigraphic units and a capillary fringe of JP5 was present floating in the sandy aquifer. The SIVE system was based upon the direct volatilization and steam stripping of volatile organic compounds and recovery of JP5 from the subsurface. The major process equipment included eight pneumatic total liquid downhole pumps, air compressor, steam boiler, two heat exchangers, vacuum blower, two oil/water 
separators, and vapor and aqueous phase carbon adsorbers. Steam generated from the boiler was injected into the subsurface soil via the injection wells. The increased pressure gradient elevated temperature in the soils, and displacement of groundwater caused by the advancement of the steam front drove the contaminant to the extraction wells. The JP5 contaminant (vapor and liquid phases) was extracted to the aboveground system for treatment prior to discharge. The average vapor and liquid flow rate from the extraction wells was $260 \mathrm{scfm}$ and $9 \mathrm{gpm}$, respectively. A total of 95,973 gallons of free product were recovered, from the $1,217,532$ gallons of groundwater extracted during the 90 day SIVE demonstration.

\section{$2948 \quad$ V18/022788}

Design of Groundwater Remediation Control Systems at Lawrence Livermore National Laboratory

Hernandez, M.

Lawrence Livermore National Laboratory, Livermore, CA CONF-960804 (Vol. 2); Spectrum '96: Nuclear and Hazardous Waste Management, Proceedings of an International Topical Meeting, Seattle, WA, August 18-23, 1996. American Nuclear Society, La Grange Park, II, Vol. 2, 873 pp.; (pp. 1400-1405) (1996)

Lawrence Livermore National Laboratory (LLNL) is operated for the Department of Energy by the University of Califomia. In 1987, the LLNL Livermore site was placed on the National Priorities List based on the presence of volatile organic components (VOCs) in groundwater. By late 1999, LLNL will have completed the build-up phase of its remediation program with plans calling for nine treatment facilities. At least three more facilities will be operating at Site 300, LLNL's high explosive test area. Control systems for all treatment facilities are required to be highly reliable, robust, and verifiable. The systems must also allow for adaptable process configurations to provide for occasional process changes due to component failures, well field management, and remediation experiments and special measurements. They must be designed to maximize the efficiency of maintenance support over their lifetime. The facility control systems are being integrated into the established Environmental Restoration Division networking and database systems. LLNL engineers have combined object oriented modeling and design methods, rigorous validation and verification procedures, human factors engineering, and application of standard instrumentation and software to produce systems that meet these requirements and that can be efficiently duplicated at all LLNL treatment facilities. Significant savings in implementation, testing, and maintenance costs are expected using the methods described.

V18/021619

Groundwater Cleanup Using Hydrostratigraphic Analysis

Blake, R.G.

Science and Technology Review (January-February 1996):6-15 (January-February 1996)

The Lawrence Livermore National Laboratory's groundwater cleanup program has made dramatic strides in removing contaminants underneath the Laboratory and nearby areas. Individual contaminant plumes are effectively targeted for hydraulic capture and cleanup by a Livermore team of researchers. Their use of hydrostratigraphic analysis integrates chemical hydraulic, geologic, and geophysical data, which results in a three-dimensional model of the subsurface area. The resulting hydrostratigraphic framework developed at Livermore is proving to be a highly useful management tool to plan, budget, implement, and monitor the groundwater cleanup effort. Researchers expect to transfer their knowledge to other remediation sites. Dollar savings so far have been in optimally placing extraction wells, thereby maximizing contaminant removal and saving time.

\section{0}

V18/020672

TCE Remediation Using Insitu, Resting-State Bioaugmentation

Duba, A.G.; Jackson, K.J.; Jovanovich, M.C.; Knapp, R.B.; Taylor, R.T.

Lawrence Livermore National Laboratory, Livermore, CA

Environmental Science \& Technology 30(6):1982-1989 (June 1996)

A field test has demonstrated that an in situ biofilter using resting-state cells effectively remediated groundwater with about $425 \mathrm{ppb}$ of trichloroethene (TCE) as the sole contaminant species. About $5.4 \mathrm{~kg}$ (dry weight equivalent) of a strain of methanotrophic bacteria (Methylosinus trichosporium OB3b) was suspended in 1800 $\mathrm{L}$ of groundwater $[5.4 \times 10(E+9)$ cells $/ \mathrm{mL}]$ and injected into an aquifer through a single well at a depth of $27 \mathrm{~m}$, several meters below the water table. The injected groundwater was devoid of TCE and growth substrates but was amended with a phosphate solution $(10 \mathrm{mM})$ to buffer the $\mathrm{pH}$ and phenol red $(20[\mathrm{mu}] \mathrm{m})$ to act as a tracer. Approximately $50 \%$ of the injected bacteria attached to the sediments, forming an in-situ, fixed-bed bioreactor of unknoun geometry. Contaminated groundwater was subsequenty withdraun through the biofilter region by extracting at $3.8 \mathrm{Lmin}$ for $30 \mathrm{~h}$ and then at $2.0 \mathrm{~L} / \mathrm{min}$ for the remaining 39 days of the field experiment. TCE concentrations in the extracted groundwater decreased from 425 to less than $10 \mathrm{ppb}$ during the first $50 \mathrm{~h}$ of withdrawal, which is equivalent to a $98 \%$ reduction. TCE concentration extracted through the biofilter gradually increased to background values at 40 days when the experiment was terminated.

V18/023786

\section{2-Phase Groundwater and Soil Vapor Extraction Site Test at McClellan AFB}

Koerner, C.; Kingsley, G.B.; Lawrence, J.; Wong, K.

Radian Corporation, Sacramento, CA; U.S. Air Force, McClellan Air Force Base, CA

CONF-9504134; HAZMACON '95, T. Bursztynsky and M.L. Loss (eds.), Proceedings of the Twelfth Hazardous Materials Management Annual Conference and Exhibition, San Jose, CA, April 4-6, 1995. Association of Bay Area Governments, Oakland, CA, 790 pp.; (pp. 244-256) (1995)

The innovative 2-phase extraction technique is a method recently patented by Xerox Corporation for simultaneously extracting contaminated groundwater and soil vapor from the subsurface. The 2-phase technique is primarily applicable to those sites with semipermeable soils containing volatile organic compound (VOC) 
contamination in both soils and groundwater. This technique has several distinct advantages over either conventional soil vapor extraction or groundwater extraction, because it can: (1) cut the dollar per-contaminant-pound cleanup costs by an order of magnitude; (2) simplify the extraction and treatment of both contaminated water and vapor; and (3) shorten remediation times. The U.S. EPA and the Air Force elected to conduct an EPA Site test of the 2-phase Extraction technology at McClellan AFB. The purpose of the test was to demonstrate its effectiveness and to compare the cost and efficiency of 2-phase extraction to the existing McClellan groundwater pump-and-treat system. This paper describes the test results and demonstrates that the 2-phase extraction and treatment technology offers a cost-effective alternative for the remediation of many potential sites with soil and groundwater contamination. Preliminary McClellan results indicate: (1) the groundwater flow rate is twice that of the pump-and-treat system; (2) the mass of contaminants from a single well removed increased from $130 \mathrm{lbs} /$ year to more than $5,000 \mathrm{lbs} /$ year, over 30 times more than the pump-and-treat rate, with potential for even higher removal rates: 5,000 to 8,000 pounds of contaminants per year; and (3) up to $95 \%$ of the contamination was extracted in the vapor phase, where it could be treated more easily and efficientiy.

2952 V18/023770

Design Considerations for Multilevel Monitoring Wells McGlochlin, L.M.

Earth Technology, Inc., Colton, CA

CONF-9504134; HAZMACON' '95, T. Bursztynsky and M.L. Loss (eds.), Proceedings of the Twelfth Hazardous Materials Management Annual Conference and Exhibition, San Jose, CA, April 4-6, 1995. Association of Bay Area Governments, Oakland, CA, 790 pp.; (pp. 3-13) (1995)

Much has been written about the advantages of multilevel (multiport) monitoring wells over clustered or nested monitoring wells; however, there is little published information that provides helpful hints and "dos and don'ts" for planning successful multilevel well projects. This paper discusses the differences in both design and construction techniques between conventional monitoring wells and multilevel wells, with emphasis on avoiding some of the pitfalls that can occur with deep multilevel monitoring wells. Numerous methods and procedures are discussed, ranging from using downhole video logs for accurate packer placement to selecting the appropriate size sand for the bentonite/sand mix annular seal. The author refers to a project at Norton AFB in San Bernardino, Califomia, where EARTH TECH, while under contract to the United States Air Force, recently installed eight multilevel wells, each with a Waterloo Multilevel Groundwater Monitoring System. The systems were installed to depths of 400 to 700 feet to characterize the vertical and lateral extent of a plume of trichloroethene (TCE). The off-base portion of the TCE plume at Norton AFB has gained national attention because it threatens 26 municipal wells that provide a major percentage of the domestic water supply for the City of Riverside. Because of the contamination, which resulted from the spillage of TCE during aircraft maintenance activities from 1942 to 1966, Norton AFB has been named a National Priorities List (NPL) site. According to manufacturer, Solinst Canada Ltd, this is the largest group of deep Waterloo Multilevel systems over installed in the United States and the first used for a remedial investigation of groundwater contamination on an Air Force installation. Not including those systems installed by EARTH TECH, only 13 Waterloo Multilevel systems had been previously installed in the United States and Canada to depths greater than 400 feet.

2953 V18/022782

Cure Electrocoagulation Demonstration at Rocky Flats Environmental Technology Site

Bridges, J.L.; Dalrymple, C.; Jones, J.; Ball, T.; Gatchett, A.M.

PRC Environmental Management, Inc., Denver, CO; General Environmental Corporation, Denver, CO; U.S.

Environmental Protection Agency, National Risk Management Research Laboratory, Cincinnati, $\mathrm{OH}$ CONF-960804 (Vol. 2); Spectrum '96: Nuclear and Hazardous Waste Management, Proceedings of an International Topical Meeting, Seattle, WA, August 18-23, 1996. American Nuclear Society, La Grange Park, II, Vol. 2, 873 pp.; (pp. 1350-1357) (1996)

A demonstration of an innovative technology for remediating radionuclide contamination in water took place at the Rocky Flats Environmental Technology Site (RFETS) in Golden, Colorado, during the summer of 1995 . The demonstration was part of the U.S. Environmental Protection Agency (EPA) Superfund Innovative Technology Evaluation (SITE) program and was conducted by EPA, the U.S. Department of Energy (DOE), and General Environmental Corporation (GEC). The SITE program encourages the development and demonstration of innovative treatment and monitoring technologies. The purpose of this demonstration was to evaluate the ability of GEC's innovative CURE technology to remove uranium, plutonium, and americium from water taken from the $A$ and $B$ solar evaporation ponds at RFETS. The CURE electrocoagulation process uses an anode and cathode in a patented geometry to remove contaminants, including radionuclides, from wastewater in a continuous flow process. Electrocoagulation has been recognized as a method of removing a variety of contaminants from wastewaters. With the CURE process, GEC has refined the technology and adapted it to hazardous waste cleanup. Bench scale treatability testing conducted in April 1995 indicated 99 percent removal efficiencies were possible for uranium, plutonium-239/240, and americium-241. During the field scale demonstration in August and September 1995, samples were collected from four demonstration runs at RFETS. A removal efficiency of approximately 50 percent was achieved for uranium and nearly 99 percent for plutonium and americium.

$2954 \quad$ V18/022878

Implementation of a Fully Automated Process Purge-and-Trap Gas Chromatograph at an Environmental Remediation Site

Blair, D.S.; Morrison, D.J.

Sandia National Laboratories, Albuquerque, NM

SAND97-0422C; CONF-970113; Field Screening Methods for

Hazardous Wastes and Toxic Chemicals, Proceedings of a Conference, Las Vegas, NV, January 29-31, 1997; 17 pp. (1997) 
The AQUASCAN, a commercially available, fully automated purge-and-trap gas chromatograph from Sentex Systems Inc. (Ridgefield, N.J.), was implemented and evaluated as an in-field, automated monitoring system of contaminated groundwater at an active DOE remediation site in Pinellas, FL. Though the AQUASCAN is designed as a stand alone process analytical unit, implementation at this site required additional hardware. The hardware included a sample dilution system and a method for delivering standard solution to the gas chromatograph for automated calibration. As a result of the evaluation the system was determined to be a reliable and accurate instrument. The AQUASCAN reported concentration values for methylene chloride, trichloroethylene, and toluene in the Pinellas groundwater within $20 \%$ of reference laboratory values.

\section{5}

V18/022198

Separation Technologies for the Treatment of Idaho National Engineering Laboratory Wastes

Todd, T.; Herbst, S.

Pacific Northwest National Laboratory, Richland, WA

PNNL-SA-27105; CONF-960158; Efficient Separation and Processing Crosscutting Program, Proceedings of the 1996 Technical Exchange Meeting, Gaithersburg, MD, January 16-19, 1996, 52 pp.; (pp. 7-9) (1996)

The Idaho National Engineering Laboratory (INEL) is collaborating with several DOE and international organizations to develop and evaluate technologies for the treatment of acidic high-level radioactive wastes. The focus of the treatment of high-level radioactive wastes is on the removal of cesium and strontium from wastes typically 1 to 3 molar in acidity; technologies to treat groundwater contaminated with radionuclides and/or toxic metals; technologies to remove toxic metals from hazardous or mixed waste streams, for neutral $\mathrm{pH}$ to 3 molar acidic waste streams.

2956

V18/021624

Insitu Wastewater Treatment and Groundwater Remediation at a Sugar Beet Processing Facility

Olson, J.L.; Fuller-Pratt, P.R.; Mielke, R.A.

Maxim Technologies, Inc., Billings, MT; Western Sugar

Company, Denver, $\mathrm{CO}$

CONF-9607116; Proceedings of an American Association of Petroleum Geologists (AAPG) Rocky Mountain Section Meeting, Billings, MT, July 28-31, 1996; AAPG Bulletin 80(6):977c (June 1996)

Groundwater monitoring data collected at the Western Sugar Company sugar beet processing plant, in Billings, Montana identified groundwater mounding and groundwater nitrogen concentration increases associated with lime slurry discharge to an on-site storage pile. The nitrogen impacts (primarily ammonia) likely originated through decomposition of organic matter in the slurry. Initially, Western Sugar considered constructing an expensive anaerobic and nitrification-denitrification wastewater treatment system. However, further investigation of the lime pile revealed that it was already serving as an efficient filter and anaerobic reactor. Comparisons of slurry application with other land application systems suggested that groundwater nitrogen impacts could be minimized through groundwater capture, re-application, and improved slury management. The resultant system required little capital and maintenance cost. The immediate effect was to substantially decrease the groundwater mound. Subsequent monitoring has demonstrated a gradual decline in nitrogen concentrations under the lime pile and a considerable concentration decrease downgradient of the groundwater recovery system.

2957 $\mathrm{V} 18 / 022620$

Use of Micropores for Fine Bubble Creation in the Removal of PCE in Groundwater

Kerfoot, W.B.; McCulloch, W.; Connors, J.

$\mathrm{K}-\mathrm{V}$ Associates, Inc., Falmouth, MA; McCulloch Environmental Equipment Sales, Vacaville, CA; Nevada Division of Environmental Protection, Carson City, NV

CONF-960393 (Part 2); Contaminated Soils and Groundwater: Analysis, Fate, Environmental and Public Health Effects, and Remediation, Proceedings of the Sixth Annual West Coast Conference, Newport Beach, CA, March 11-14, 1996. Association for the Environmental Health of Soils, Amherst, MA, Part 2, 226 pp.; (p. 23) (1996)

The use of microporous Spargepoint $[R]$ to create fine bubbles, which easily penetrate sandy formations to allow fluid flow, has unexpected benefits when used with multiple gas systems. Microfine bubbles accelerate the transfer rate of tetrachloroethene (PCE) from aqueous to gaseous state. The bubble rise transfers the PCE to the vadose zone. The ten-fold difference in surface-to-volume ratio of Spargepoint $[R]$ microbubbles compared to bubbles from well screens results in a three-fold improvement in transfer rates. To block the gaseous state from reverting to surface dissolved state in the vadose (unsaturated) zone, a microprocessor system shuttles an oxidizing gas through the vadose zone to chemically degrade the transported PCE. Destruction of the PCE and vacuum extraction of gaseous byproducts eliminates reflux of the contaminant under rainfall conditions in the unsaturated zone. Use of a 50 CFM sparge system at the Crossroads Mall site in Carson City, Nevada resulted in extremely rapid removal of PCE.

\section{8}

V18/022609

Remediation of Chromate-Contaminated Groundwater Using Zero-Valent Iron: Field Test at USCG Support Center, Elizabeth City, North Carolina

Puls, R.W.; Paul, C.J.; Powell, R.M.

National Risk Management Research Laboratory, Subsurface Protection and Remediation Division, Ada, OK

EPA/600/A-96/075; 19 pp. (1996)

A field test was conducted near an old hard-chrome plating facility on the U.S. Coast Guard (USCG) Support Center near Elizabeth City, North Carolina to evaluate the in situ remediation of groundwater contaminated by hexavalent chromium using a passive permeable reactive barrier composed of a zero-valent iron-sand-aquifer material mixture. The remedial effectiveness of this innovative in situ technology was monitored over a one year period. 
Full-Scale Testing and Early Production Results from Horizontal Air Sparging and Soil Vapor Extraction Wells Remediating Jet Fuel in Soil and Groundwater at JFK International Airport, New York

Roth, R.J.; Bianco, P.; Kirshner, M.; Pressly, N.C.

Terra Vac Corporation, Mid-Atlantic Division, Windsor, NJ; Port Authority of New York and New Jersey, New York, NY; Pressly Associates, Inc., Brookhaven, NY

CONF-9611118; HazMat West '96, Proceedings of an International Environmental Management and Technology Conference and Exhibition, November 5-7, 1996. Advanstar Expositions, Duluth, MN, 544 pp.; (pp. 363-377) (1996)

Jet fuel contaminated soil and groundwater contaminated at the International Arrivals Building (IAB) of the JFK International Airport in Jamaica, New York, are being remediated using soil vapor extraction (SVE) and air sparging (AS). The areal extent of the contaminated soil is estimated to be 70 acres and the volume of contaminated groundwater is estimated to be 2.3 million gallons. The remediation uses approximately 13,000 feet of horizontal SVE (HSVE) wells and 7,000 feet of horizontal AS (HAS) wells. The design of the HSVE and HAS wells was based on a pilot study followed by a full-scale test. In addition to the horizontal wells, 28 vertical AS wells and 15 vertical SVE wells are used. Three areas are being remediated, thus, three separate treatment systems have been installed. The SVE and AS wells are operated continuously while groundwater will be intermittently extracted at each HAS well, treated by liquid phase activated carbon and discharged into stormwater collection sewerage. Vapors extracted by the SVE wells are treated by vapor phase activated carbon and discharged into ambient air. The duration of the remediation is anticipated to be between two and three years before soil and groundwater are remediated to New York State cleanup criteria for the site. Based on the monitoring data for the first two months of operation, approximately $14,600 \mathrm{lbs}$. of vapor phase volatile organic compounds (VOCs) have been extracted. Analyses show that the majority of the VOCs are branched alkanes, branched alkenes, cyclohexane and methylated cyclohexanes.

2960

V18/023622

Remediation of Chromate-Contaminated Groundwater Using Zero-Valent Iron: Field Test at U.S. Coast Guard (USCG) Support Center, Elizabeth City, North Carolina

Puls, R.W.; Paul, C.J.; Powell, R.M.

U.S. Environmental Protection Agency, Robert S. Kerr Environmental Research Laboratory, Ada, OK; ManTech Environmental Research Services Corporation, Ada, OK

CONF-9605266; Proceedings of the 1996 Hazardous Substance Research Center/Waste-Management Education and Research Consortium Joint Conference on Environment, L.E. Erickson, S.C. Grant, D.L. Tillison and J.P. McDonald (eds.), Albuquerque, NM, May 21-23, 1996. Great Plains-Rocky Mountain Hazardous Substance Research Center, Kansas State University, Manhattan, KS, 706 pp.; (pp. 69-77) (1996)

A field test was conducted near an old hard-chrome plating facility on the U.S. Coast Guard (USCG) Support Center near Elizabeth City, North Carolina to evaiuate the in situ remediation of groundwater contaminated by hexavalent chromium using a passive permeable reactive barrier composed of a zero-valent iron-sand-aquifer material mixture. The remedial effectiveness of this innovative in situ technology was monitored over a one-year period. The success of this small-scale test has prompted a full-scale implementation of the technology at the site for late Spring 1996.

\section{1}

V18/020684

Success in Horizontal Barrier Developments

Pettit, P.J.; Ridenour, D.E.; Harris, D.; Jalovec, J.

Brown and Root Environmental, Houston, TX; Fernald Environmental Restoration Management Corporation, Cincinnati, OH; U.S. Department of Energy, Fernald Environmental Management Project, Fernald, $\mathrm{OH}$

FEMP-2491; CONF-960212; Waste Management '96: Working Towards a Cleaner Environment, Proceedings of a Conference on HLW, LLW, Mixed Wastes and Environmental Restoration, Tucson, AZ, February 25-29, 1996; (5 pp.) (1996)

A successful proof of concept demonstration has been conducted of operational methods and tooling for the in situ construction of underground horizontal barriers for the control and containment of groundwater and contamination. The method involves jet grouting with specially adapted tools guided between twin, parallel wells for the placement of a grout beneath a waste site. The objective of the work is to develop reliable methods of constructing extensive, competent horizontal barriers underneath waste sites without excavating or penetrating the waste during the process.

2962 V18/025445

Butz Landfill Groundwater Remediation, Monroe County, Pennsylvania: Designer's Operating Criteria U.S. Department of the Interior, Bureau of Reclamation, Water Treatment Engineering and Research Group, Denver, CO

Report; 50 pp. (June 1997)

This report documents the overall design philosophy of the groundwater remediation project and provides standard operating procedures for the treatment plant operator(s). The groundwater remediation treatment system is designed and constructed to intercept, convey, and treat groundwater with VOC concentrations greater than $200 \mathrm{ug} / \mathrm{L}$. The system will isolate the contaminated plume, which moves through the fracture zones from the northwest, in the vicinity of the Butz Landfill, reduce the risk of further contamination of groundwater, and return contamination concentrations to original background levels.

2963

V18/022102

Accelerated Clean-Up Action: A Practical Approach to Remediation

Bosque, A.; Mateo, J.M.; Agrelot, J.C.

U.S. Environmental Protection Agency, San Juan, Puerto

Rico; Johnson and Johnson Pharmaceutical Partners, Gurabo, Puerto Rico; Soil Tech Corporation, San Juan, Puerto Rico

CONF-951139 (Vol. 1); Superfund 16: Proceedings of a Hazardous Waste Conference and Exhibition, Washington, DC, November 6-8, 
1995. E.J. Krause and Associates, Bethesda, MD, Vol. 1, 828 pp.; (pp. 638-652) (1994)

Hazardous substances have been articles of commerce which, when properly used and converted, provide some of the materials that are an everyday part of our standard of living. When improperly handled, they pose a threat or danger to the human health or the environment. Unfortunately, when releases occur, either by accident or by negligence, it is imperative not just an immediate surface clean-up response but an accelerated clean-up action of the impacted media. This paper presents the initial results of an accelerated clean-up action program at Jansen Pharmaceuticals, Inc. (Janssen) a wholly owned subsidiary of Johnson \& Johnson Company a non-National Priority List (NPL) site in Gurabo, Puerto Rico. Also, it shows how responsible parties together with regulatory agencies can join efforts in the development and implementation of a practical approach to remediation.

\section{4}

\section{V18/024001}

Demonstration of Eastman Christensen Horizontal Drilling System Integrated Demonstration Site, Savannah River Site

Westinghouse Savannah River Company, Aiken, SC WSRC-TR-92-577; 155 pp. (December 1992)

An innovative horizontal drilling system was used to install two horizontal wells as part of an integrated demonstration project at the Savannah River Site (SRS), Aiken, South Carolina. The SRS is located in south-central South Carolina in the upper Coastal Plain physiographic province. The demonstration site is located near the $\mathrm{A} / \mathrm{M}$ Area, and is currently known as the Integrated Demonstration Site. The drilling system was designed by Eastman Christensen Environmental Services and consisted of a downhole motor with directional control capabilities, electronic borehole surveying equipment, and an adjustable drill rig mast for drilling at angles less than vertical. One well was installed in the vadose zone, and the other was instailed in the watertable aquifer. Several modifications of the drilling program were made during installation of the vadose zone well; these modifications were applied to installation of the watertable aquifer well, speeding its completion. The report describes problems encountered during the instaliation of the wells and makes recommendations for improved use of the technique.

\section{$2965 \quad$ V18/023980}

Design and Management of System Components for Insitu Methanotrophic Bioremediation of Chlorinated Hydrocarbons

Lombard, K.H.; Borthen, J.W.; Hazen, T.C.

Bechtel Savannah River, Inc., Aiken, SC; ECOVA Corporation, Redmond, WA; Westinghouse Savannah River Company, Aiken, SC

WSRC-MS-92-454; 16 pp. (1992)

The successful operation of an in situ bioremediation system is inherent within its design. Well-organized system components enable ease of maintenance, limited down time, and relatively rapid data acquisition. The design effort in this project focused on injection of a low-pressure air/methane mixture into a horizontal well below the water table, a methane-blending system that provided control of the injected mixture, redundant safety interlocks, vapor-phase extraction from a second horizontal well, and an off-gas treatment system that provided efficient thermal catalytic oxidation of the extracted contaminant vapors. The control instrumentation provided sufficient redundancies to allow the system to remain in operation in the event of a component failure, and equally important, the safe shut down of the system should any designed safety parameters be exceeded (i.e., high methane concentration). Final design approval took into consideration the reliability of the equipment and the components specified. Product knowledge and proper application limited the risk of a component or system failure while providing a safe, efficient, and cost-effective remediation system. Microprocessor data acquisition and system control were integrated with an autodialer to provide 24 hour emergency response and operation without on-site supervision. This integrated system also insured accurate data analysis and minimum downtime. Since operations commenced, the system has operated a total of 7,760 hours out of the possible 8,837 hours available. This equates to an operating efficiency of $87.8 \%$.

\section{6}

V18/023732

\section{Dual-Phase Liquid and Vapor Treatment System}

Rogers, J.; Weems, J.

Pantex Plant, Environmental Restoration, Amarillo, TX

CONF-960741; DOE Pollution Prevention in the 21st Century, Proceedings of the Twelfth Annual DOE Pollution Conference, Chicago, IL, July 9-11, 1996; (6 pp.) (1996)

As a result of more than 50 years of operation at Pantex Plant, high explosives such as TNT, RDX, and HMX and contaminants such as TCE, DCE, and hexavalent chromium have been found in a perched aquifer under the plant. A fine-grained aquitard separates the perched aquifer from the Ogallala Aquifer, a primary source of drinking water. An accelerated program was initiated to delineate the contaminant extent; findings showed that while no contamination exists in either the Ogallala or the perched aquifers, contamination has reached the southeastem plant boundary. The U.S. Department of Energy, Mason \& Hanger, and Battelle Memorial Institute (subcontractor) developed one of the most flexible and sophisticated multimedia treatability demonstrations in the state of Texas.

2967

V18/023548

Deploying Insitu Bioremediation at the Hanford Site Truex, M.J.; Johnson, C.D.; Newcomer, D.R.; Doremus, L.A.; Hooker, B.S.; Peyton, B.M.; Skeen, R.S.; Chilakapati, A.

Pacific Northwest Laboratory, Richland, WA

CONF-941 124; Insitu Remediation: Scientific Basis for Current and Future Technologies, G.W. Gee and N.R. Wing (eds.), Proceedings of the 33rd Hanford Symposium on Health and the Environment, Pasco, WA, November 7-11, 1994. Battelle Press, Columbus, OH, Part 1, 704 pp.; (pp. 209-231) (1994)

An innovative in-situ bioremediation technology was developed by Pacific Northwest Laboratory (PNL) to destroy nitrate and carbon tetrachloride ( $\mathrm{CCl} 4)$ in the Hanford groundwater. The goal of this in-situ treatment process is to stimulate native microorganisms to 
degrade nitrate and $\mathrm{CCl} 4$. Nutrient solutions are distributed in the contaminated aquifer to create a biological treatment zone. This technology is being demonstrated at the U.S. Department of Energy's Hanford Site to provide the design, operating, and cost information needed to assess its effectiveness in contaminated groundwater. The process design and field operations for demonstration of this technology are influenced by the physical, chemical, and microbiological properties observed at the site. A description of the technology is presented, including the well network design, nutrient injection equipment, and means for controlling the hydraulics and microbial reactions of the treatment process.

\section{8}

V18/022764

Development of a Sitewide Groundwater Remediation Strategy at the Hanford Site, Washington

Goswami, D.

Washington State Department of Ecology, Kennewick, WA CONF-960804 (Vol. 2); Spectrum '96: Nuclear and Hazardous Waste Management, Proceedings of an International Topical Meeting, Seattle, WA, August 18-23, 1996. American Nuclear Society, La Grange Park, IL, Vol. 2, 873 pp.; (pp. 1166-1172) (1996)

Over $440 \mathrm{sq}$ kilometers ( $170 \mathrm{sq}$ miles) of groundwater beneath the Hanford Site are contaminated by hazardous and radioactive waste, out of which almost half is over state and federal drinking water standards. These plumes are often mixed with radionuclides, inorganics, and organics. In addition to the complicated nature of these plumes, remediation is further obscured by limited application of available technologies and hydrogeologic information. This paper briefly describes the processes used by the Washington State Department of Ecology (Ecology), U.S. Environmental Protection Agency (EPA), and U.S. Department of Energy (USDOE) in developing a sitewide groundwater remediation strategy for Hanford and its outcome. The final remediation strategy alternatives remain a product of risk assessment, technical feasibility, site use scenarios, and cost consideration. In order to develop a strategy for the final cleanup, several issues such as aquifer restoration, natural attenuation, potential contamination of groundwater from the tank farms and from the existing contamination source in the vadose zone must be looked at in detail $i$ conjunction with public and stakeholder's values.

\section{9}

\section{V18/022628}

Clinoptilolite as an Insitu Permeable Barrier to Strontium Migration in Groundwater

Cantrell, K.J.; Martin, P.F.; Szecsody, J.E.

Pacific Northwest Laboratory, Richland, WA

CONF-941124; Insitu Remediation: Scientific Basis for Current and Future Technologies, G.W. Gee and N.R. Wing (eds.), Proceedings of the 33rd Hanford Symposium on Health and the Environment, Pasco, WA, November 7-11, 1994. Battelle Press, Columbus, OH, Part 2, 605 pp.; (pp. 839-850) (1994)

Batch adsorption experiments were conducted with three zeolites (clinoptilolite, chabazite, and A-51) to determine their potential applicability as in-situ permeable barriers to groundwater strontium migration in the 100-N Area of the Hanford Site. Each of the zeolites was an effective adsorbent for strontium, even in competition with calcium at concentrations typical of Hanford groundwater, and the authors determined that clinoptilolite would be the most cost-effective. The strontium adsorption data for calcium-saturated clinoptilolite were fitted to a Langmuir isotherm, which is linear at solution concentrations of less than 10[E-5] $\mathrm{mol} / \mathrm{L}$. In this region, the adsorption coefficient (Kd) was $956 \mathrm{I} / \mathrm{kg}$. Because strontium concentrations in Hanford groundwater are typically $3 \times 10[\mathrm{E}-6] \mathrm{mol} / \mathrm{L}$, assuming linear adsorption $(\mathrm{Kd}=956$ $\mathrm{L} / \mathrm{kg}$ ) for modeling purposes is appropriate. These data were used to design an effective barrier and were incorporated into a transport model to assess its performance. Calculations indicated that a barrier $1.3 \mathrm{~m}$ thick would prevent strontium-90 migration to the Columbia River at 100-N Area for over $50 \mathrm{yr}$. Because of radioactive decay and adsorption, the maximum breakthrough of strontium-90, approximately $5 \%$ of the initial input, would occur at $100 \mathrm{yr}$. Preliminary experimental work was conducted to determine the adsorption kinetics of strontium on clinoptilolite. A comparison of the adsorption rate of strontium with its residence time (within the barrier) indicates that adsorption kinetics are sufficiently fast that the barrier performance will not be significantly affected.

\section{0}

\section{V18/022601}

Ion Exchange Removal of Strontium from Simulated and Actual N-Springs Well Water at the Hanford 100-N Area

Brown, G.N.; Carson, K.J.; DesChane, J.R.; Elovich, R.J.; Kafka, T.M.; White, L.R.

Pacific Northwest National Laboratory, Richland, WA; Minnesota Mining and Manufacturing Company, St. Paul, $\mathrm{MN}$

PNNL-11198; 41 pp. (June 1996)

Experimental ion exchange studies are being conducted by the Pacific Northwest National Laboratory (PNNL) under the Efficient Separations and Processing (ESP) Crosscutting Program to evaluate newly emerging materials and technologies for removing cesium, strontium, technetium, and transuranic elements from simulated and actual wastes at Hanford. Previous work focused on applications to treat high-level alkaline tank wastes, but many of the technologies can also be applied in process and groundwater remediation. Ultimately, each process must be evaluated in terms of life-cycle costs, removal efficiency, process chemical consumption and recycle, stability of materials exposed to chemicals and radiation, compatibility with other process streams, secondary waste generation, process and maintenance costs, and final material disposal. This report assesses the performance of the $3 \mathrm{M}$-designed Process Absorber Development Unit (PADU) and the AlliedSignal-produced sodium nonatitanate (NaTi) material on trace quantities of strontium from simulated and actual Hanford N-Springs groundwater. The experimental objective was to determine the strontium-loading breakthrough profile of a proprietary 3M-engineered material in either disk or cartridge forms.

2971

V18/025386

Bench- and Pilot-Scale Testing of Ion-Exchange Media for Removal of Radionuclides from Hanford 200 Area Groundwater 
Dada, A.; Erb, D.B.; Shealy, S.E.

Bechtel Hanford, Inc., Richland, WA; IT Hanford, Inc., Richland, WA; International Technology Corporation, Knoxville, TN

CONF-970335; Waste Management '97: Working Towards a Cleaner Environment, Proceedings of a Conference on $\mathrm{HLW}$, LLW, Mixed Wastes and Environmental Restoration, Tucson, AZ, March 2-6, 1997; (17 pp.) (1997)

Bench-scale and large-scale pilot treatability testing was conducted in support of remedial design activities in the Hanford Site 200 Area. This testing provided data needed to develop pump and treat systems for the BP-5 Reverse Well groundwater plume in the 200 Area. The treatability testing included bench-scale batch equilibrium (isotherm) and mini-column tests on a number of ion exchange resins and other adsorption media and testing of selected media in the large-scale (100 liters/minute feed) pilot treatment facilities. The mini-column and pilot tests were conducted in the field with groundwater from the BP-5 Reverse well plume. The B-5 Reverse Well plume contains plutonium, strontium, and cesium and a series of batch equilibrium tests were conducted to evaluate several adsorbents and ion exchange materiais for removal of these contaminants. Bone Char was effective on plutonium while clinoptilolite, a natural zeolite ion exchange material, was very effective on cesium and strontium. Based on the batch test results, the pilot system included adsorbers packed with bone char and clinoptilolite. After the batch tests mini-column tests on clinoptilolite were conducted. These tests demonstrated that, while the clinoptilolite has a good loading capacity for both strontium and cesium, $\mathrm{Sr} 90$ bleeds through the column fairly rapidly. In addition a second series of batch equilibrium tests were conducted to screen additional ion exchange media for strontium removal. The second round of batch equilibrium tests were conducted to screen additional ion exchange media for strontium removal. The second round of batch equilibrium tests identified a synthetic zeolite that had better performance for strontium than did the clinoptilolite and also a synthetic resin that was effective on plutonium. The synthetic zeolite was also tested in a mini-column system and gave slightly lower effluent $\mathrm{Sr} 90$ than the clinoptilolite. The mini-column and pilot-scale testing also showed that kinetics were limiting strontium removal and that contact times of 40 to 54 minutes will be required for achieving the $8 \mathrm{pCi} /$ iter criteria for $\mathrm{Sr} 90$. These tests were conducted concurrent with operation of the pilot system. The pilot-scale testing demonstrated that plutonium and cesium treatment criteria were met for a run length of 3700 bed volumes. Strontium in the effluent rapidly broke through to $1200 \mathrm{pCi} /$ iter, $32 \%$ of inlet concentration but did not increase for 3700 bed volumes. One of the mini-column systems, operating with longer contact time with the clinoptilolite, gave better performance, $86 \%$ strontium removal for 3500 bed volumes.

2972

V18/025571

200-UP-1 Groundwater Pump-and-Treat - Phase 1: Annual Report - FY 1996

Myers, D.A.; Denslow, C.W.; Erb, D.B.; Gustafson, F.W.; Green, J.W., Jr.; McMahon, W.J.

Bechtel Hanford, Inc., Richland, WA

BHI-00951; 63 pp. (November 1996)
A groundwater pump-and-treat system is being operated in the 200-UP-1 Groundwater Operable Unit under the authority of the Hanford Federal Facility Agreement and Consent Order. The purposes of the pump-and-treat system are to contain and treat elevated concentrations of uranium and technetium- 99 in the groundwater in the 200-UP-1 Groundwater Operable Unit and to provide data for evaluation of the aquifer response as a result of the pump-and-treat operations. The 200-UP-1 pump-and-treat site is located on the north side of the 216-U-17 Crib in the 200 West Area of the Hanford Site, located in Richland, Washington. This report summarizes and evaluates treatment, hydrologic, and hydrochemistry data collected for the annual reporting period of 200-UP-1 Phase I pump-and-treat operations (9/25/95 through 9/30/96). Section 2.0 discusses the treatment system performance, Section 3.0 discusses the hydraulic and contaminant response of the aquifer, and Section 4.0 provides recommendations for modifications to the current well configuration and the treatment system.

2973

V18/023627

\section{0-ZP-1 Operable Unit Borehole Summary Report for FY 1995 and FY 1996}

Darrach, M.E.

Bechtel Hanford, Inc., Richland, WA

BHL-00927; 313 pp. (October 1996)

This document details the well construction, sampling, analyses, and geologic character of the Ringold Formation fluvial unit $\mathrm{E}$ gravels as encountered in 16 boreholes in the 200-ZP-1 Operable Unit. These boreholes were drilled by Water Development Hanford Corporation during fiscal years 1995 and 1996. Two of the sixteen boreholes were abandoned; the remaining 14 boreholes were completed as functioning production and compliance wells. The borehole logs and well summary sheets included as Appendices $A$ and $B$ of this document, respectively, depict and describe the vadose zone stratigraphic units encountered during the course of drilling. Appendix $\mathrm{C}$ contains the results of sieve analyses conducted on samples obtained via resonant sonic coring and standard split-spoon methods. The sieve analyses were the driver behind the majority of the well designs. Also, for completeness, Appendices D and E contain the well design calculations and the well development process.

2974

V18/023803

3-D Electrical Resistivity Tomography for Environmental Monitoring

LaBrecque, D.J.; Morelli, G.

University of Arizona, Laboratory for Advanced Subsurface Imaging, Tucson, $A Z$

CONF-960477; SAGEEP '96, R.S. Bell and M.H. Cramer (eds.), Proceedings of the Ninth Annual Symposium on the Application of Geophysics to Engineering and Environmental Problems, Denver, CO, April 15-May 1, 1996. Environmental and Engineering Geophysical Society, Wheat Ridge, CO, 1353 pp.; (pp. 723-732) (1996)

Electrical Resistance Tomography (ERT) images the electrical properties of the subsurface using crosshole resistivity 
measurements. Interpretation of ERT data requires

multi-dimensional inverse modeling. We discuss a 3-D Occam's

inversion routine. The routine uses a finite-element forward

solution and a conjugate gradient based inverse routine. The algorithm finds the smoothest possible model that fits the data to a given a-priori chi squared level. In general, the 3-D algorithm takes 10 to 20 iterations to converge to a final solution. However, the 3-D algorithm requires only a single forward solution per iteration and does not require direct solution of a large system of equations. Instead, it requires only the multiplication of a vector times the sensitivity matrix or its transpose. This is accomplished without creating or storing the full sensitivity matrix. A field example is shown in which ERT was used to monitor the injection of air from a vertical well at a shallow petroleum remediation site in California. Data was interpreted using both 3-D and 2-D methods. Air injection caused large changes in resistivity. At early times these were confined to an area near the injection point. Later the changes were along a dipping, tabular region. At the latest times there is evidence of mixing of brackish water at the depth of the injection point with fresh water in a shallower aquifer on the site. This mixing would have decreased the resistivity and thus the apparent the size and magnitude of the zone of influence of sparging.

\section{5}

\section{V18/025570}

AFCEE Remediation Matrix - Hierarchy of Preferred Alternatives

U.S. Air Force Center for Environmental Excellence, Brooks Air Force Base, TX

Report; 1 p. (March 21, 1994)

Short communication. No abstract available.

2976

V18/023630

Abating Coal Tar Seepage into Surface Water Bodies Using Sheet Piles with Sealed Interlocks

Collingwood, B.I.; Boscardin, M.D.; Murdock, R.F.

GEI Consultants, Inc., Winchester, MA

CONF-9406413; Dredging, Remediation, and Containment of Contaminated Sediments, K.R. Demars, G.N. Richardson, R.N. Yong and R.C. Chaney (eds.), Proceedings of a Symposium, Montreal, Quebec, Canada, June 23-24, 1994, 343 pp.; (pp. 220-226) (1995)

A former coal tar processing facility processed crude coal tar supplied from manufactured gas plants in the area.

Coal-tar-contaminated groundwater from the site was observed seeping through an existing timber bulkhead along a tidal river and producing a multicolored sheen on the surface of the river. As part of a short-term measure to abate the seepage into the river, 64-m long anchored sheet pile wall with sheet pile wing walls at each end was constructed inland of the of the timber bulkhead. The sheet piles extended to low-permeability soils at depth and the interlocks of the sheet piles were provided with polyurethane rubber seals. Based on postconstruction observations for leakage and sheens related to leakage, the steel sheet piles with polyurethane rubber interlock seals appeared to provide a successful seal and abate coal-tar-contaminated groundwater seepage into the river. The tie rod penetration sealing proved to be a more problematic detail, but through several postconstruction grouting episodes, an effective seal was produced.
Accelerated Subsurface Investigations Using the Cone-Sipper [TM]

TIE Quarterly 5(2):8,4 (Fall 1996/Winter 1997)

Site Characterization is an essential part of every environmental cleanup project involving soil or groundwater contamination. The process of sampling soil gas and groundwater and characterizing subsurface conditions has always been slow and costly. Conventional drilling methods were used to collect samples until the early 1980 s. Then, the cone penetrometer was first used as an environmental tool. It provided substantial improvement, but left room for much more. The Cone-Sipper (TM) sequentially collects samples of groundwater and soil gas at multiple depths and does not require withdrawal and reinsertion between samples. It can be decontaminated in place. Based on initial testing and use at the Savannah River Site the Cone-Sipper (TM) can significantly reduce the time and costs associated with acquiring samples.

2978 V18/025443

Advanced Fuel Hydrocarbon Remediation National Test Location - Groundwater Circulation Well Environmental Cleanup Systems

Heath, J.; Lory, E.

U.S. Navy, Naval Facilities Engineering Service Center, Port Hueneme, CA

NFESC-TDS-2014-ENV-REV; 4 pp. (March 1997)

When a contaminant is treated in place on the original site it is termed in situ remediation. Bioremediation refers to cleanup effected by living organisms such as bacteria and fungi. Certain species of bacteria are able to consume pollutants as a food source, thus detoxifying these compounds. In situ bioremediation is being considered as a viable and practical solution for reducing petroleum contamination levels in groundwater.

2979

V18/025434

Advanced Fuel Hydrocarbon Remediation National Test Location - Insitu Air Sparging System (Revised)

Health, J.; Lory, E.

U.S. Navy, Naval Facilities Engineering Service Center, Port Hueneme, CA

NFESC-TDS-2029-ENV-REV; 6 pp. (March 1997)

Air sparging is the process of injecting clean air directly into an aquifer for remediation of contaminated groundwater. For removing contaminants, air sparging relies on two basic mechanisms working either alone or in tandem: biodegradation and volatilization. The objective of air sparging is to force air through contaminated aquifer materials to provide oxygen for bioremediation and/or to strip contaminants out of the aquifer.

2980

V18/023888

Advances in TCE-Degrading Thermophilic, Mesophilic, and Alkaline-Resistant Organisms

Vesper, S.J.; Davis-Hoover, W.J.; Roulier, M.H.; Murdoch, L.C.; Vane, L.M.; Herrmann, J.G. 
University of Cincinnati, Cincinnati, OH; U.S. Environmental Protection Agency, Cincinnati, $\mathrm{OH}$ EPA/600/R-95/012; CONF-9504110; Proceedings of the 21st Annual Risk Reduction Engineering Laboratory (RREL) Research Symposium, Cincinnati, OH, April 4-6, 1995. U.S. Environmental Protection Agency, Cincinnati, OH, 398 pp.; (pp. 325-328) (April 1995)

Trichloroethylene (TCE) is a chlorinated organic solvent that has been widely used a number of industries. The methylotrophic bacteria have been shown to co-metabolize TCE. These organisms have been utilized as degraders of TCE in aquifers which suggests that the use of methylotrophs is a practical solution for TCE contamination. Electroosmosis is a relatively old technique used to dewater soils. Electroosmosis uses a direct-current electric field to induce a motion of a liquid and dissolved ions that transports the contaminants in the electric field. This technique creates highly acidic and basic zones in the soil and can also raise the temperature of the soil substantially. This paper reports a laboratory-scale screening program to identify methylotrophs that appear to be able to survive and degrade TCE in this environment. Tests were conducted both in serum bottles and in a model electroosmosis microcosm.

2981

V18/022670

Air Sparging for Subsurface Remediation of Dense Nonaqueous Phase Liquids

McCray, J.E.; Falta, R.W.

Clemson University, Clemson, SC

CONF-950828; Heat Transfer - Portland 1995, M.S. El-Genk (ed.), Proceedings of the 1995 National Heat Transfer Conference, Albuquerque, NM, August 5-9, 1995. American Institute of Chemical Engineers, New York, NY, 378 pp.; (pp. 50-57) (1995)

Multiphase numerical simulations indicate that air sparging may be an efficient remediation technology for subsurface DNAPLs. Measurement of the sparging-induced pressure increase below the water table, which may be performed in the field, is recommended as the best method for determining the radius of influence. The authors use numerical simulations to support this recommendation, and to illustrate the transient and steady-state aquifer behavior during sparging.

\section{V18/024313}

Air Sparging in Low Permeability Soils

Marley, M.C.

Envirogen, Inc., Canton, MA; Oak Ridge National Laboratory, Oak Ridge, TN

ORNL/TM-13305; Insitu Remediation of DNAPL Compounds in Low Permeability Media Fate/Transport, Insitu Control

Technologies, and Risk Reduction, 318 pp.; (pp. 8.1-8.19) (August 1996)

Sparging technology is rapidly growing as a preferred, low cost remediation technique of choice at sites across the United States. The technology is considered to be commercially available and relatively mature. However, the maturity is based on the number of applications of the technology as opposed to the degree of understanding of the mechanisms governing the sparging process.
Few well documented case studies exist on the long term operation of the technology. Sparging has generally been applied using modified monitoring well designs in uniform, coarse grained soils. The applicability of sparging for the remediation of dense nonaqueous phase liquids (DNAPLs) in low permeability media has not been significantly explored. Models for projecting the performance of sparging systems in either soils condition are generally simplistic but can be used to provide general insight into the effects of significant changes in soil and fluid properties. The most promising sparging approaches for the remediation of DNAPLs in low permeability media are variations or enhancements to the core technology. Recirculatory sparging systems, sparging/biosparging trenches or curtains and heating or induced fracturing techniques appear to be the most promising technology variants for this type of soil.

2983

V18/025375

Alfalfa Plants and Associated Microorganisms Promote Biodegradation Rather Than Volatilization of Organic Substances from Groundwater, Chapter 10

Davis, L.C.; Muralidharan, N.; Visser, V.P.; Chaffin, C.T.; Fateley, W.G.; Erickson, L.E.; Hammaker, R.M.

Kansas State University, Departments of Biochemistry, Chemical Engineering, and Chemistry, Manhattan, KS

Bioremediation Through Rhizosphere Technology, T.A. Anderson and J.R. Coats (eds.), American Chemical Society, Washington, DC, 249 pp.; (pp. 112-122) (1994)

Bacteria have the capacity for bioremediation of both volatile and non-volatile organic compounds. Plants support a rhizosphere microflora, enhance soil microbial populations, and may also be able themselves to metabolize some hazardous organic compounds. Plants move large amounts of water by transpiration, and for volatile compounds intersystem transfer by transpiration might occur when plants are exposed to such materials. These possibilities were tested experimentally. A tank with a channel width of $10 \mathrm{~cm}$ and a depth of $35 \mathrm{~cm}$ was used for plant growth. Alfalfa plants were supplied with a subsoil water source saturated $(500 \mathrm{ppm})$ with toluene or containing $500 \mathrm{ppm}$ phenol. Sampling wells were used to monitor the depth of the water table and concentrations of toluene and phenol in the groundwater. The toluene concentration in the groundwater remained constant or decreased slightly during passage of water through the tank although there was an average net input of greater than $300 \mathrm{mg}$ toluene per day to the system. Measurements showed that only a small to nil fraction of the input toluene arrived in the gas phase. With phenol the concentration decreased in the aqueous phase and was undetectable in the gas phase. The observed mass balance suggests that effective degradation of toluene and phenol occurs in the system and that potential intersystem transport of volatiles by transpiration is not a problem. This chapter summarizes the work to date using mycorrhizal fungi in bioremediation studies.

\section{$2984 \quad$ V18/023894}

Alternative Treatment Technology Information Center Computer Database System

Sullivan, D.

U.S. Environmental Protection Agency, Risk Reduction 
Engineering Laboratory, Edison, NJ

EPA/600/R-95/012; CONF-9504110; Proceedings of the 21st Annual Risk Reduction Engineering Laboratory (RREL) Research Symposium, Cincinnati, OH, April 4-6, 1995. U.S. Environmental Protection Agency, Cincinnati, OH, 398 pp.; (p. 383) (April 1995)

The Altemative Treatment Technology Information Center (ATTIC) computer database system was developed pursuant to the 1986 Superfund law amendments. It provides up-to-date information on innovative treatment technologies to clean up hazardous waste sites. ATTIC v2.0 provides access to several independent databases as well as a mechanism for retrieving full-text documents of key literature. It can be accessed with a personal computer and modem 24 hours a day, and there are no user fees. ATTIC provides "one-stop shopping" for information on alternative treatment options by accessing several databases: (1) treatment technology database - this contains abstracts from the literature on all types of treatment technologies, including biological, chemical, physical, and thermal methods. The best literature as viewed by experts is highlighted; (2) treatability study database - this provides performance information on technologies to remove contaminants from wastewaters and soils. It is derived from treatability studies. This database is available through ATTIC or separately as a disk that can be mailed to you; (3) underground storage tank database - this presents information on underground storage tank corrective actions, surface spills, emergency response, and remedial actions; and (4) oil/chemical spill database - this provides abstracts on treatment and disposal of spilled oil and chemicals. In addition to these separate databases, ATTIC allows immediate access to other disk-based systems such as the Vendor Information System for Innovative Treatment Technologies (VISITT) and the Bioremediation in the Field Search System (BFSS). The user may download these programs to their own PC via a high-speed modem. Also via modem, users are able to download entire documents through the ATTIC system. Currently, about fifty publications are available, including Superfund Innovative Technology Evaluation (SITE) program documents. (Complete text).

\section{5}

\section{V18/024767}

\section{Anoxic/Anaerobic Bioremediation, Chapter 9}

Liss, S.N.; Baker, K.H.

Ryerson Polytechnic University, School of Chemical Engineering, Toronto, Ontario, Canada; Environmental Microbiology Associates, Inc., Harrisburg, PA

Bioremediation, K.H. Baker and D.S. Herson (eds.), McGraw-Hill, Inc., New York, NY, 404 pp.; (pp. 297-342) (1994)

This is a chapter from the book titled, Bioremediation. Biological methods for the reclamation of contaminated soils and aquifers and for the treatment of oil spills have been based largely on aerobic processes. The prevalence of aerobic technologies is related to the historical observations that the initial steps in the biodegradation of hydrocarbons by microorganisms, including bacteria and fungi, involves oxidation of the substrates by oxygenases and by the recognition of oxygen as a limiting factor in many natural environments. Notwithstanding the growing evidence that anoxic/anaerobic biodegradation of aromatic and nonaromatic hydrocarbons by microorganisms also occurs, the rates of degradation have been considered to be low and of minor ecological significance. The conditions for optimal activities of such consortia are complex and difficult to elucidate. As a result, anoxic/anaerobic bioremediation has received little attention in the past. Recently, however, anoxic/anaerobic-based bioremediation has been shown to have considerable potential for remediation of soils and subsurface environments. Anoxic/anaerobic bioremediation may be particularly desirable in the latter case because many of these sites are already anoxic/anaerobic and the effectiveness and cost of oxygen delivery may be formidable.

2986

V18/024098

Apparatus and Method for Phosphate-Accelerated Bioremediation

Looney, B.B.; Phelps, T.J.; Hazen, T.C.; Pfiffner, S.M.; Lombard, K.H.; Borthen, J.W.

Westinghouse Savannah River Company, Aiken, SC U.S. Patent A8186065; 35 pp. (1994)

The present invention relates to in situ bioremediation of contaminated soil and groundwater. In particular, the invention relates to an apparatus and method for adding vapor-phase nutrients to a contaminated subsurface region to stimulate the growth of contaminant-degrading microorganisms. The apparatus includes a housing adapted for containing a quantity of a volatile liquid nutrient, a conduit in fluid communication with the interior of the housing, and means for contacting a gas flowing through the conduit with the nutrient so that a portion thereof is vaporized and transferred to the gas. The resulting gas-nutrient mixture is delivered to the contaminated site via a system of injection and extraction wells configured to the site.

\section{7}

V18/023867

Application of Ambersorb 563 Adsorbent Technology for Treatment of Chlorinated Organics in Groundwater

Frye, R.W.; Martino, J.F.; Turner, R.E.; Isacoff, E.G.; Plantz, D.A.

Roy F. Weston, Inc., West Chester, PA; Rohm and Haas Company, Research Laboratories, Spring House, PA

EPA/600/R-95/012; CONF-9504110; Proceedings of the 21st Annual Risk Reduction Engineering Laboratory (RREL) Research Symposium, Cincinnati, OH, April 4-6, 1995. U.S. Environmental Protection Agency, Cincinnati, OH, 398 pp.; (pp. 108-112) (April 1995)

Roy F. Weston, Inc. (WESTON [R]), in conjunction with Rohm and Haas Company (Rohm and Haas), conducted a field pilot study to demonstrate the technical feasibility and cost-effectiveness of Ambersorb [R] 563 (A-563) carbonaceous adsorbent for the remediation of groundwater contaminated with volatile organic compounds (VOCs). The project was conducted under the Emerging Technology Program of the EPA Superfund Innovative Technology Evaluation (SITE) program. Ambersorb adsorbents are a family of patented, synthetic, tailorable carbonaceous adsorbents that were developed by Rohm and Haas in the 1970's for the treatment of contaminated water. In specific applications, Ambersorb adsorbent technology may offer a cost-effective altemative to air stripping or granular activated carbon (GAC), 
which are typically used in pump and treat systems for remediating groundwater contaminated with organic compounds. Ambersorb adsorbents have been found to be effective in the removal of low levels of VOCs and other synthetic organic compounds from contaminated water. Previous applications using Ambersorb adsorbents have demonstrated several key performance benefits over GAC. Ambersorb 563 adsorbent can be regenerated onsite using steam, solvents, or other techniques, permitting the recovery of a concentrated organic stream which can be disposed of or reclaimed. Ambersorb 563 adsorbent has a significantly greater adsorption capacity than GAC for chlorinated hydrocarbons when the contaminants are present at low concentrations. Ambersorb 563 adsorbent systems can operate at higher flow rates than GAC systems, while maintaining effluent water quality below drinking water standards.

2988

\section{V18/021801}

Application of Microbial Biomass and Activity Measures to Assess Insitu Bioremediation of Chlorinated Solvents

Phelps, T.J.; Pfiffner, S.M.; Mackowski, R.; Ringelberg, D.B.; White, D.C.; Palumbo, A.V.

Oak Ridge National Laboratory, Environmental Sciences Division, Oak Ridge, TN

CONF-930482 (Vol. 2-1); Proceedings of the Second International Insitu and Onsite Bioreclamation Symposium, San Diego, CA, April 5-8, 1993; Bioremediation Series 2(1) - Bioremediation of Chlorinated and Polycyclic Aromatic Hydrocarbon Compounds, R.E. Hinchee, A. Leeson, L. Semprini and S.K. Ong (eds.), Lewis Publishers, Boca Raton, FL, 560 pp.; (pp. 404-408) (1994)

The evaluation of in-situ bioremediation of trichloroethylene (TCE) and chlorinated solvents at the Savannah River Site has included the application of microbial biomass and activity measures to assess the effects of treatment regimens. Groundwater samples have been analyzed biweekly for the abundance of microorganisms, abundance of physiologic groups implicated in TCE degradation, activities of the resident subsurface microorganisms, nitrogen transformations (urease activity and ammonia uptake), and assessment of toxicant degrading capabilities. Prior to the treatment period approximately $15 \%$ of the groundwater analyses revealed more than 0.1 methanotrophs/ml. Within two months of methane injection $38 \%$ of the groundwater analyses indicated more than 0.1 methanotrophs/ml whereas $13 \%$ exhibited methanotrophic populations greater than $10 / \mathrm{ml}$. Methylotrophic populations also increased two orders of magnitude; $60 \%$ of the samples exhibited approximately $10 / \mathrm{ml}$ prior to treatment and $67 \%$ exhibited greater than 10(3) methylotrophs/ml within 2 months of treatment initiation. Lipid analyses have revealed increased biomass and increased polyhydroxy-butyrate/phospholipid ratios characteristic of chlorocarbon degrading conditions in response to the subsurface treatment. Approximately $65 \%$ of the groundwater samples exhibited the ability to mineralize [14C]TCE to $14 \mathrm{CO} 2$ within 30 days after enrichment with methane. Numerous samples have also exhibited the ability to mineralize tetrachloroethylene.

Measurements of urease activity have not indicated any significant changes during the treatment, but ammonia uptake appears to have increased in some of the wells in response to the bioremediation activities. Analysis of changes in microbial biomass and activity has been useful in demonstrating the effects of bioremediation treatments on subsurface microbial communities.

2989

V18/023031

Application of a Multiphase Compositional Model for Design of DNAPL Remediation Strategies

Sudicky, E.A.; Forsyth, P.A.; Unger, A.J.A.

University of Waterloo, Waterloo, Ontario, Canada

CONF-960527; Global Exploration and Geotechnology, Proceedings of an Annual Convention of the American Association of Petroleum Geologists, Inc., and the Society for Sedimentary Geology, San Diego, CA, May 19-22, 1996, 231 pp.; AAPG Bulletin 80(5):135c (1996)

Many industries produce and store hazardous chemicals, which, when released into the subsurface, form a dense non-aqueous phase (DNAPL) which sinks below the water table. Since DNAPLs are slightly soluble in water, it may take hundreds of years to dissolved the non-aqueous phase source of contamination. During this time, an enormous plume of contaminated groundwater may develop. Consequently, it is highly desirable to remove the DNAPL source as quickly as possible. This paper focuses on simulating remediation strategies for removing the non-aqueous phase contaminant. It must be recognized that in any real situation, there exists substantial uncertainty in many of the model parameters. For example, detailed permeability data are not usually available, and experimental data for three phase relative permeability and capillary pressure are also typically lacking. In this situation, the goal of simulation is to determine a robust remediation strategy. A robust remediation process will be effective in removing the DNAPL contaminant for a wide range of hydrogeologic parameters, and thus will be a good candidate for a remediation strategy for a real site, where such parameters are highly uncertain. A three-dimensional multiphase model is used to simulate a variety of strategies involving vacuum extraction, air sparging, pump and treat, and combinations of these processes. The effect of placement of injector/producers, use of horizontal injectors, and pressures at the vacuum extractor are studied.

2990

V18/022006

Application of the UTCHEM Simulator to DNAPL Site Characterization

Butler, G.W. .

INTERA, Inc., Austin, TX

CONF-9509139; Emerging Technologies in Hazardous Waste Management VII, D.W. Tedder (ed.), Proceedings of the Seventh American Chemical Society Industrial and Engineering Chemistry Division Special Symposium, Atlanta, GA, September 17-20, 1995. American Chemical Society, Washington, DC, 1291 pp.; (pp. 1161-1164) (1995)

Dense, non-aqueous phase liquids (DNAPLs) such as trichloroethene (TCE) present considerable characterization and remediation problems when they enter the subsurface due to their high densities, low solubilities and low viscosities. In order for any DNAPL remediation method to be effective, it is essential that the DNAPL zones be properly characterized. The characterization of DNAPL contamination in aquifers involves the location of DNAPL zones and the estimation of the amounts of DNAPL within the zones. 
The requirements of DNAPL site characterization techniques have pointed to the need for improved field methods for rapid and effective detection of DNAPL zones. Numerical simulation using UTCHEM has been used to evaluate two innovative DNAPL characterization methods involving the use of surfactants and partitioning tracers to characterize a suspected TCE DNAPL zone beneath the U.S. Air Force Plant 4 in Fort Worth, Texas.

UTCHEM is a three-dimensional, multi-phase, multi-component, finite-difference simulator originally designed to model enhanced oil recovery. The simulations were performed using a cross-sectional model of the alluvial aquifer in an area that is believed to be contain residual TCE at the base of the aquifer. Characterization simulations compare standard groundwater sampling, an interwell NAPL Solubilization Test (NST), and an interwell NAPL Partitioning Tracer Test(NPTT).

\section{1}

$$
\text { V18/026080 }
$$

Applied Bioremediation of Petroleum Hydrocarbons CONF-950483 (Vol. 3-6); Proceedings of the Third International Insitu and Onsite Bioreclamation Symposium, San Diego, CA, April 24-27, 1995; Bioremediation Series 3(6) - Applied Bioremediation of Petroleum Hydrocarbons, R.E. Hinchee, J.A. Kittel and H.J. Reisinger (eds.), Battelle Press, Columbus, OH, 534 pp. (1995)

This volume is part of a ten volume set of papers derived from the Third International Insitu and Onsite Bioreclamation Symposium, which was held in San Diego, California, in April 1995. The purpose of the conference was to provide a multidisciplinary forum for exchange of state-of-the-art information on bioremediation. The papers that appear in the set of volumes were accepted after peer review. The articles in this volume focus on petroleum hydrocarbon bioremediation, with an emphasis on pilot-scale and field-scale applications. Individual papers within the scope of this data base have been indexed separately.

2992

\section{V18/022045}

Areas of Long-Lasting Anthropopression: Assessment and Monitoring of Pollution Potential to Soil and Groundwater

Twardowska, I.

Polish Academy of Sciences, Institute of Environmental Engineering, Zabrze, Poland

CONF-9506232; Environmental Monitoring and Hazardous Waste Site Remediation, T. Vo-Dinh and R. Niessner (eds.), Proceedings of a Conference of the Society of Photo-Optical Instrumentation Engineers, Munich, Germany, June 19-23, 1995. Intemational Society for Optical Engineering, Bellingham, WA, 613 pp.; (pp. 253-264) (1995)

Correct identification and assessment of the prevailing source, scope and extent of pollution potential is essential for providing efficient preventive remedial actions and management of already occurring contamination on a least-cost basis. In this paper, an identification/assessment procedure for areas with several sources of long-lasting nonpoint contamination is illustrated by example of the Wroclaw waterworks area in Poland which is impacted by emissions from a ferro-chrome smelter and power plant, as well as by various sources of polycyclic aromatic hydrocarbons. Investigations and studies comprised: (i) analysis of physicochemical composition of emitted particulates and deposited wastes, their time-dependent transformations and leachability of contaminants as a function of time; (ii) direct multilevel sampling of dump and vadose zone profiles and examination of pore solutions and matrices; (iii) groundwater survey in the saturation zone; (iv) investigation of infiltration and contaminant migration from radioisotope data; (v) survey of surface water quality; (vi) numerical simulation and direct measurements of particulate emission from various sources; (vii) analysis and comparison of data on point and nonpoint emission/imission of contaminants with the extent and scope of contamination. In another example, current investigations on the vadose zone screening and monitoring in the area of a high environmental risk in the vicinity of Sendzimir Steelworks near Cracow, Poland, are presented.

\section{3}

\section{V18/020917}

Assessment of TCE-Degradative Potential in a Contaminated Aquifer by Gene Probe Analysis Sun, W.; Ogram, A.V.; Payne, W.; Brockman, F.J. Washington State University, Pullman, WA; Southwest Missouri State University, Springfield, MO; Pacific Northwest Laboratory, Richland, WA

CONF-9305258; Proceedings of the 93rd General Meeting of the American Society for Microbiology, Atlanta, GA, May 16-20, 1993; (1 p.) (1993)

The response of selected catabolic genotypes to methane and air injection of samples taken from a trichloroethylene (TCE) contaminated aquifer was assessed by hybridization of total DNA extracts with mRNA gene probes constructed from six boreholes at depths ranging from 10 feet to 140 feet in 10 foot increments was hybridized with probes constructed from cloned haloalkane dehalogenase, soluble methane monooxygenase, methane dehydrogenase, toluene monooxygenase, and toluene dioxygenase genes. Sequences homologous to the two methanotroph-specific probes were detected in all bore holes, although the highest concentrations did not correlate with increased TCE degradation. Sequences homologous to toluene monooxygenase were present in all bore holes and toluene dioxygenase was detected in 4 out of 5 boreholes, and no correlation with methane treatment was observed. This work is part of the Savannah River Integrated Demonstration Project being conducted by the Department of Energy. (Complete Text)

2994

\section{V18/023878}

Base Catalyzed Decomposition: New Hydrogen Donors and Reaction Activators/Catalysts

Kawahara, F.K.; Michalakos, P.M.

U.S. Environmental Protection Agency, Risk Reduction Engineering Laboratory, Cincinnati, $\mathrm{OH}$

EPA/600/R-95/012; CONF-9504110; Proceedings of the 21st Annual Risk Reduction Engineering Laboratory (RREL) Research Symposium, Cincinnati, OH, April 4-6, 1995. U.S. Environmental Protection Agency, Cincinnati, OH, 398 pp.; (pp. 207-210) (April 1995)

A significant challenge today is the need to develop a fast and complete detoxification process suitable for the destruction of 
polychlorinated biphenyl (PCBs) and other chlorinated organic compounds lying as waste in soils, sediments, water, air and concentrates in waste dumps. The Risk Reduction Engineering Laboratory has confirmed that a chemical reaction conducted under basic conditions can completely remove covalently bound chlorine from a variety of organic compounds, including PCBs. This reaction is referred to as Base Catalyzed Decomposition (BCD). The present investigation was undertaken to study the products and the yield of biphenyl from the dechlorination of $\mathrm{PCBs}$ resulting from the $\mathrm{BCD}$ reaction. Objectives of the study included: (1) determining the conditions under which PCBs could be completely dechlorinated at 340 degrees or lower in two hours or less; (2) studying the donor-transfer mechanism; and (3) looking for an effective, inexpensive catalyst that could accelerate the reaction rate. All the objectives were met. A number of new hydrogen donors were used in the BCD reaction; one reaction mechanism pathway was discovered; and a new, inexpensive catalyst was found effective in dechlorinating PCBs.

\section{5}

\section{V18/023860}

Bio-Polymer Slurry Trench Method for Installation of Insitu Air Sparging System

Linneman, D.M.

Geo-Con, Inc., Mulberty, FL

CONF-960154; PETRO-SAFE '96, Proceedings of a Conference Held as Part of the Energy Week ' 96 Conference and Exhibition, Houston, TX, January 29-February 2, 1996. PennWell Conferences and Exhibitions, Houston, TX, 291 pp.; (pp. 151-155) (1996)

An investigation was conducted at a site in Greenville County, South Carolina which detected contaminants in the groundwater. It was then decided that remedial action was required. The contaminants and their location in the groundwater led to the selection of an in-situ air sparging system to be installed at approximately thirty-four feet deep. Due to design depth requirements and other site conditions, the bio-polymer slurry trench (B-P drain) method was utilized in the air sparging system installation. The two trenches were installed using a biodegradable slurry in lieu of the bentonite slurry commonly utilized in the more traditional slurry trench technique. The slurry temporarily supported the trench walls while the air sparging components were submerged and set at the proper elevations. Once backfilled with stone, the slurry in both trenches was broken by introducing a breaker solution which reduced the slurry to sugar water. The trenching, air sparging piping installation, and backfilling operations were completed in about six weeks.

\section{6 \\ V18/025580}

Bioaugmentation for Site Remediation

CONF-950483 (Vol. 3-3); Proceedings of the Third International Insitu and Onsite Bioreclamation Symposium, San Diego, CA, April 24-27, 1995; Bioremediation Series 3(3) - Bioaugmentation for Site Remediation, R.E. Hinchee, J. Fredrickson and B.C. Alleman (eds.), Battelle Press, Columbus, OH, 261 pp. (1995)

This volume is part of a ten volume set of papers derived from the Third International Insitu and Onsite Bioreclamation Symposium, which was held in San Diego, California, in April 1995. The purpose of the conference was to provide a multidisciplinary forum for exchange of state-of-the-art information on bioremediation. The papers that appear in this set of volumes were accepted after peer review. This volume deals with bioaugmentation, the introduction of nonindigenous microorganisms for bioremediation. Individual papers within the scope of this data base have been indexed separately.

2997 V18/021797

Biodegradation of Chlorinated Aliphatic Hydrocarbon Mixtures in a Single-Pass Packed-Bed Reactor Lackey, L.W.; Phelps, T.J.; Bienkowski, P.R.; White, D.C. University of Tennessee, Center for Environmental Biotechnology, Knoxville, TN; University of Tennessee, Department of Chemical Engineering, Knoxville, TN; University of Tennessee, Department of Microbiology, Knoxville, TN; Oak Ridge National Laboratory, Environmental Sciences Division, Oak Ridge, TN Applied Biochemistry and Biotechnology 39/40:702-712 (1993)

Aliphatic chlorinated compounds, such as trichloroethylene (TCE) and tetrachloroethylene (PCE), are major contaminants of groundwater. A single-pass packed-bed bioreactor was utilized to study the biodegradation of organic waste mixtures consisting of PCE, TCE, and other short-chain chlorinated organics. The bioreactor consisted of two 1960 -mL glass columns joined in a series. One column was packed with sand containing a microbial consortia enriched from a contaminated site. The other column provided a reservoir for oxygen and a carbon source of methane/propane that was recirculated through the reactor. Sampling was accomplished by both direct headspace and liquid effluent concentration analyses. The reactor was operated in a single-pass mode. Greater than $99 \%$ degradation of trichloroethylene, approaching drinking water standards, was observed when the bioreactor residence time ranged from 1.9 to 3.2 d. Typically, when the reactor was pulse-fed with methane, propane, and air, $1 \mathrm{~mol}$ of TCE was degraded $/ 110 \mathrm{~mol}$ of substrate utilized. Perturbation studies were performed to characterize reactor behavior. The system's degradation behavior was affected by providing different carbon sources, a pulse feeding regime, supplementing microbial biomass, and by altering flow rates.

\section{8 \\ V18/021813}

Biodegradation of Chlorinated Aliphatics and Aromatic Compounds in Total-Recycle Expanded-Bed Biofilm Reactors

Korde, V.M.; Phelps, T.J.; Bienkowski, P.R.; White, D.C. University of Tennessee, Center for Environmental Biotechnology, Knoxville, TN; University of Tennessee, Department of Chemical Engineering, Knoxville, TN; Oak Ridge National Laboratory, Environmental Sciences Division, Oak Ridge, TN

Applied Biochemistry and Biotechnology 39/40:631-641 (1993)

Groundwater contamination by chlorinated aliphatic compounds is a major cause for concem because of their toxicity. This study examined the biodegradation of trichloroethylene and aromatic compounds by microbial consortia enriched from contaminated subsurface sediments. The consortia were capable of utilizing methane and propane as sources of carbon and energy. Two 
continuously recycled expanded-bed bioreactors were inoculated with (1) the subsurface consortium, and (2) P. fluorescence, P. putida (strains pRB1401 and pWWO), and M. trichosporium OB3b. An uninoculated reactor containing $0.2 \%$ sodium azide and $0.5 \%$ formalin served as the control. Methane ( $5 \% \mathrm{v} / \mathrm{v})$ and propane $(3 \%$ $v / v)$ were maintained by batch feeding through the course of the experiment. Greater than $97 \%$ degradation of trichloroethylene was observed over a period of $12 \mathrm{~d}$. More than $99 \%$ of benzene, toluene, and xylene were degraded within the first $7 \mathrm{~d}$. Dissolved oxygen levels were measured and found to be in the range $4.9-6.5 \mathrm{mg} / \mathrm{L}$ throughout the experiments.

\section{9}

V18/021964

Biodegradation of Petroleum Constituents by Indigenous Bacteria Isolated from Petroleum Reservoirs

Azadpour, A.

Dynamac Corporation, Ada, OK

CONF-9509139; Emerging Technologies in Hazardous Waste Management VII, D.W. Tedder (ed.), Proceedings of the Seventh American Chemical Society Industrial and Engineering Chemistry Division Special Symposium, Atlanta, GA, September 17-20, 1995. American Chemical Society, Washington, DC, 1291 pp.; (pp. 639-642) (1995)

The National Academy of Sciences estimates that the annual release of petroleum into the environment is between 1.7 and 8.8 million metric tones. The majority of which finds its way into the earth's water where it persists for a long periods of times. Biodegradation of petroleum by the indigenous population of microorganisms represents one of the primary ways to eliminate environmental pollutants. However, bioremedial efforts become specially complicated when dealing with subsurface media because oil alone is not sufficient to support microbial growth since it is deficient in both a source of nitrogen and a source of phosphorus. This deficiency probably accounts for the lack of microbial activity. It has been shown, for example, that the addition of a nitrogen and a phosphorus source to microorganisms isolated from production water resulted in good microbial growth using oil as the carbon and energy source.

3000 V18/024692

\section{Bioengineering of Soils and Ground Waters, Chapter 5}

Troy, M.A.

OHM Remediation Services Corporation, Princeton, NJ

Bioremediation, K.H. Baker and D.S. Herson (eds.), McGraw-Hill, Inc., New York, NY, 404 pp.; (pp. 173-201) (1994)

This is a chapter from the book titled, Bioremediation. The term bioengineering implies the alliance of a biological system and an engineered system for the remediation of undesirable chemical contamination. In most instances, it denotes the use of engineering techniques to optimize and/or maximize an already ongoing biological process. In this chapter, both the in situ and exsitu bioengineering of soils and ground waters will be discussed. In situ treatment refers to the performance of in-place remediation of the contamination. The advantages of in situ bioengineered treatment are that it does not require excavation of the contaminated material and movement to another locale, it can allow above-ground site activities to occur while treatment is going on, and it minimizes exposure to the contaminants. Exsitu treatment refers to the extraction and/or excavation of the contaminated material for treatment aboveground in an engineered treatment system. The objectives of the bioengineered remediation treatment process are analogous to those of conventional biological treatment operations. With conventional biological treatment systems, a treatment vessel is "engineered" to provide optimal conditions for the microorganisms to grow. As a result of their growth, the microorganisms will metabolize the compound(s) of interest, usually resulting in the production of innocuous end products. An example of this concept would be a wastewater treatment facility. For this process, the conditions in a treatment vessel are optimized ( $\mathrm{pH}$ adjusted, aerated, provisions to control flow rates to provide adequate contact time) to promote biodegradation of the organic materials in the wastewater. For a bioengineered treatment system, instead of utilizing a manufactured container to accommodate the treatment process, the soil environment could be "bioengineered" to create an in-place treatment vessel and to provide optimal growth conditions from the indigenous microorganisms present. The effective application of this type of biological treatment can result in the complete breakdown of the contaminant(s) to innocuous end products in many instances. The successful implementation of bioengineered remediation techniques will involve a multidisciplinary approach requiring input from individuals with expertise in microbiology, chemistry, geology, soil science, environmental engineering, and chemical engineering. In order to use bioengineering successfully for the remediation of environmental contamination problems, the first step is to obtain a thorough understanding of the matrix characteristics of the media to be treated and the properties (physical, chemical, microbiological) of the contaminant(s).

3001

V18/023885

\section{Biofiltration for Control of Volatile Organic} Compounds (VOCs)

Bishop, D.F.; Govind, R.

U.S. Environmental Protection Agency, Risk Reduction Engineering Laboratory, Cincinnati, $\mathrm{OH}$; University of Cincinnati, Department of Chemical Engineering, Cincinnati, $\mathrm{OH}$

EPA/600/R-95/012; CONF-9504110; Proceedings of the 21st Annual Risk Reduction Engineering Laboratory (RREL) Research Symposium, Cincinnati, OH, April 4-6, 1995. U.S. Environmental Protection Agency, Cincinnati, OH, 398 pp.; (pp. 298-304) (April 1995)

Air biofiltration is a promising technology for control of air emissions of biodegradable volatile organic compounds (VOCs). In conjunction with vacuum extraction of soils or air stripping of groundwater, it can be used to mineralize VOCs removed from contaminated soil or groundwater. The literature describes three major biological systems for treating contaminated air: bioscrubbers, biotrickling filters and biofilters. Biofilters and biotrickling filters use microbial populations in biofilms immobilized on support media to degrade or transform contaminants in air. Filter media can be classified as: bioactive fine or irregular particulates, such as soil, peat, compost or mixtures of these materials; pelletized, which are randomly packed in a bed; and structured, such as monoliths with 
defined or variable passage size and geometry. The media can be made of sorbing and nonadsorbing materials. Laboratory studies reported in this paper evaluated peat and compost biofilters, pelletized (activated carbon, ceramic, and encapsulated biomass) biofilters, and structural geometry (ceramic and carbon coated ceramic passages) biofilters. Removal efficiencies ase reported for several volatile organic compounds, including toluene, methylene chloride, trichloroethylene, and iso-pentane.

3002

V18/024289

Biological Degradation of Dense Nonaqueous Phase Liquids (DNAPLs)

Ensley, B.; Strong-Gunderson, J.M.; Palumbo, A.V. Oak Ridge National Laboratory, Oak Ridge, TN

ORNLTM-13305; Insitu Remediation of DNAPL Compounds in Low Permeability Media Fate/Transport, Insitu Control Technologies, and Risk Reduction, 318 pp.; (pp. 3.1-3.16) (August 1996)

In situ bioremediation is a very attractive, safe and efficient method of not only removing, but eliminating hazardous compounds from the environment. However, the quickest and most efficient method of restoring a hazardous waste site would be to link several remediation processes. In situ biodegradation can involve the addition of nutrients, oxygen, electron donors, electron acceptors, organisms or all the above. These amendments can be introduced and coupled to a variety of other technologies such as permeability enhancements, chemical treatments and/or physical processes. In addition to in situ technologies, bioremediation in bioreactors is an efficient tool facilitating mineralization of contaminants. Overall, biodegradation has a significant potential to increase the rate of site restoration and decrease overall costs.

\section{3}

V18/023464

Biological Fluidized Bed Reactor (FBR): Emissionless Groundwater Treatment

Hines, R.D., Jr.; Laubacher, R.C.; Kunce, L.K.

Envirex Inc., Waukesha, WI; BP Oil Company, Cleveland, $\mathrm{OH}$

CONF-960730 (Vol. 3); Technologies Critical to a Changing World, Volume III: Emerging Energy Technologies, Clean Technologies, Remediation and Emission Control Fuels, and Petrochemicals, Proceedings of the Fifth World Congress of Chemical Engineering, San Diego, CA, July 14-18, 1996. American Institute of Chemical Engineers, New York, NY, Vol. 3, 1118 pp.; (pp. 789-794) (1996)

Groundwater treatment costs in the 1990's have gone up significantly due to the air regulations that allow minimal or no VOC emissions. Treatment for air stripper off-gas has typically been vapor-phase carbon or catalytic oxidation. A more cost-effective altemative for groundwater treatment using a biological Granular Activated Carbon (GAC) Fluidized Bed Reactor (FBR) has been implemented successfully in remediating groundwater at two British Petroleum (BP) Distribution terminals. In the FBR system, GAC is the support media for biological growth, as well as a mechanism for organic adsorption. The FBR system predissolves self-generated pure oxygen to promote the aerobic degradation of dissolved hydrocarbons as they pass through the biofilm attached to the GAC. The use of predissolved pure oxygen prevents the air stripping action of conventional biological systems. Any hydrocarbons not rapidly broken down are adsorbed and subsequently degraded. The result is a high quality effluent without release of VOC air emissions.

\section{$3004 \quad$ V18/026083}

Biological Unit Processes for Hazardous Waste Treatment

CONF-950483 (Vol. 3-9); Proceedings of the Third International Insitu and Onsite Bioreclamation Symposium, San Diego, CA, April 24-27, 1995; Bioremediation Series 3(9) - Biological Unit Processes for Hazardous Waste Treatment, R.E. Hinchee, G.D. Sayles and R.S. Skeen (eds.), Battelle Press, Columbus, OH, 358 pp. (1995)

This volume is part of a ten volume set of papers derived from the Third International Insitu and Onsite Bioreclamation Symposium, which was held in San Diego, California, in April 1995. The purpose of the conference was to provide a multidisciplinary forum for exchange of state-of-the-art information on bioremediation. The papers that appear in the set of volumes were accepted after peer review. Papers within this volume discuss applications of exsitu biological processing to soils, slurries, groundwater, and air. Individual papers within the scope of this data base have been indexed separately.

\section{5}

V18/024691

\section{Bioremediation}

Bioremediation, K.H. Baker and D.S. Herson (eds.), McGraw-Hill, Inc., New York, NY, 404 pp. (1994)

Bioremediation involves a multidisciplinary approach encompassing many aspects of science, from macro-geological formations whose development may be plotted in eons to ephemeral microbiological events that may be virtually instantaneous. Because of this broad range, and because of the relative newness of the field, information vital to bioremediation is scattered throughout the corpus of scientific endeavor. The purpose of this book, therefore, is twofold. First, it is intended as an introduction to the field, with fundamental information regarding both the background and the practice of bioremediation for the graduate student or professional coming to it from a grounding in a particular branch of science. Second, and perhaps even more important, this book should serve as an entry to the literature in the field; the chapter references are as significant as the chapter contents themselves. In soliciting contributors, we have sought the participation of scientists who are all involved in the practical implementation of bioremediation. They are not academics only, but people with field experience.

\section{$3006 \quad$ V18/025293}

Bioremediation from an Ecological Perspective

Tiedje, J.M.

Michigan State University, Center for Microbial Ecology, East Lansing, MI

Insitu Bioremediation: When Does It Work?, National Academy Press, Washington, DC, 207 pp.; (pp. 110-120) (1993)

The ecological approach to bioremediation is distinctly different from the traditional engineering approach: it focuses on such 
principles as microbial natural selection rather than on mass balances of pollutants. Questions derived from certain basic ecological principles, including specificity and diversity, can serve as key guides in determining the feasibility of bioremediation at a particular site. Similarly, certain kinds of evidence in the biological record, such as numbers of organisms, are strongly indicative of successful bioremediation. A shift in paradigm - emphasizing the ecological principles governing biodegradation instead of contaminant mass balances - would greatly advance the understanding of bioremediation.

\section{7}

\section{V18/024695}

Bioremediation in Freshwater and Marine Systems, Chapter 8

Wubah, D.A.; Hale, D.D.; Rogers, J.E.

Towson State University, Department of Biology, Towson, MD; Technology Applications, Inc., Athens, GA; U.S. Environmental Protection Agency, Environmental Research Laboratory, Athens, GA

Bioremediation, K.H. Baker and D.S. Herson (eds.), McGraw-Hill, Inc., New York, NY, 404 pp.; (pp. 281-295) (1994)

This is a chapter from the book titled, Bioremediation. A major challenge in today's world is to maximize the benefits that accrue from the industrial, agricultural, and domestic use of xenobiotic chemicals while minimizing any adverse effects on natural ecosystems. Some of the means to achieve this goal are (1) waste minimization, (2) proper management of waste disposal, and (3) cleanup of sites already contaminated. Contaminated sites can include surface and subsurface soil, groundwater, and freshwater and marine sediments with their associated water. In this chapter the use of biological techniques for remediating contaminated aquatic environments will be discussed. Often the cleanup or remediation of such sites must employ techniques from a number of disciplines, including biology, chemistry, geology, hydrology, and engineering. The use of indigenous microorganisms to clean waste sites also has made bioremediation a more cost-effective technology.

Bioremediation in aquatic environments often requires treatment of both surface waters and sediments.

\section{$3008 \quad \mathrm{~V} 18 / 026078$}

\section{Bioremediation of Chlorinated Solvents}

CONF-950483 (Vol. 3-4); Proceedings of the Third International Insitu and Onsite Bioreclamation Symposium, San Diego, CA, April 24-27, 1995; Bioremediation Series 3(4) - Bioremediation of Chlorinated Solvents, R.E. Hinchee, A. Leeson and L. Semprini (eds.), Battelle Press, Columbus, OH, 338 pp. (1995)

This volume is part of a ten volume set of papers derived from the Third International Insitu and Onsite Bioreclamation Symposium, which was held in San Diego, California, in April 1995. The purpose of the conference was to provide a multidisciplinary forum for exchange of state-of-the-art information on bioremediation. The papers that appear in the set of volumes were accepted after peer review. This volume deals with the use of aerobic and anaerobic biological degradation to dehalogenate sites contaminated with pesticides and chlorinated solvents such as trichloroethylene, tetrachloroethylene, carbon tetrachloride, pentachlorophenol, and chlorinated benzenes. Individual papers within the scope of this data base have been indexed separately.

3009

V18/021967

Bioremediation of Chlorinated Solvents Through Public-Private Partnerships

Ellis, D.E.; Gannon, D.J.; Heitkamp, M.A.; Klecka, G.M.; Maiers, D.T.; Pardieck, D.L.; Salvo, J.J.; Sayles, G.D.; Vogel, C.M.

DuPont Specialty Chemicals, Wilmington, DE; Monsanto Company, St. Louis, MO; Dow Chemical Company, Midland, MI; Ciba-Geigy Corporation, Greensboro, NC; General Electric Company, Schenectady, NY; U.S. Environmental Protection Agency, Cincinnati, OH; U.S. Air Force, Tyndall Air Force Base, FL; Idaho National Engineering Laboratory, Idaho Falls, ID

CONF-9509139; Emerging Technologies in Hazardous Waste Management VII, D.W. Tedder (ed.), Proceedings of the Seventh American Chemical Society Industrial and Engineering Chemistry Division Special Symposium, Atlanta, GA, September 17-20, 1995. American Chemical Society, Washington, DC, 1291 pp.; (pp. 470-472) (1995)

The Remediation Technology Development Forum (RTDF) was formed on the initiative of EPA and several industrial companies to provide an arena for the public and private sectors to work jointly towards the development of better, faster and cheaper remediation technologies. Recognizing the potentials of bioremediation for site clean-up, six companies - Ciba, Dow, DuPont, General Electric, Monsanto, and Zeneca - and three federal agencies - the U.S. Department of Energy (DOE), the U.S. Environmental Protection Agency (EPA), and the U.S. Department of Defense (DOD) have created an RTDF consortium to demonstrate bioremediation technologies at actual contaminated sites. Chlorinated solvents, one of the country's most widespread and troublesome contaminants (and a major problem for both industry and government) were selected for the demonstration. The three in-situ processes being tested - cometabolic bioventing, intrinsic bioremediation, and accelerated anaerobic biodegradation, provide remediation routes for both the vadose source zone and for impacted groundwater. The program objectives are: (1) to demonstrate that these processes are effective and reliable, and offer substantial savings over traditional 'dig and burn' approaches for contaminated soil and over 'pump and treat' systems for contaminated groundwater, and (2) to achieve public and regulatory acceptance of these technologies.

3010

V18/024679

Bioremediation of Ethylene Glycol-Contaminated Groundwater at the Naval Air Warfare Center in Lakehurst, New Jersey, Chapter 23

Flathman, P.E.; Bottomley, L.S.

OHM Remediation Services Corporation, Findlay, OH; U.S. Navy, Naval Air Warfare Center, Aircraft Division, Lakehurst, NJ

Bioremediation: Field Experience, P.E. Flathman, D.E. Jerger and J.H. Exner (eds.), Lewis Publishers, Boca Raton, FL, 560 pp.; (pp. 491-503) (1994)

Biological techniques were used to remediate ethylene 
glycol-contaminated groundwater following the loss of an estimated $4000 \mathrm{gal}(15,000 \mathrm{~L})$ of cooling water from a lined surface storage lagoon at the Naval Air Warfare Center (NAWC) in Lakehurst, NJ, which until recently was known as the Naval Air Engineering Center. The cooling water at the site was estimated to contain 25 percent $(v / v)$ ethylene glycol. The problem developed on January 5 , 1982, when a break occurred in the lined lagoon. A subsequent investigative program confirmed soil contamination around the lagoon and identified a $180-\mathrm{ft}(55-\mathrm{m})$ long by $45-\mathrm{ft}(14-\mathrm{m})$ wide contaminant plume extending to the east. The cooling water had moved through $30 \mathrm{ft}(9 \mathrm{~m})$ of porous sandy soil to contaminate groundwater. At the start of the project, average ethylene glycol concentration in groundwater was $1440 \mathrm{ppm}(\mathrm{n}=20, \mathrm{~s}=132 \mathrm{ppm})$. Approximately 85 to 93 percent of the ethylene glycol was removed from groundwater within the first 26 days of biological treatment. By the completion of the project, ethylene glycol was reduced to below the analytical limit of detection ( $L O D=50 \mathrm{ppm}$ ) in all production wells at the site. This chapter is from the book entitled Bioremediation: Field Experience.

\section{1 \\ V18/026084}

\section{Bioremediation of Inorganics}

CONF-950483 (Vol. 3-10); Proceedings of the Third International Insitu and Onsite Bioreclamation Symposium, San Diego, CA, April 24-27, 1995; Bioremediation Series 3(10) - Bioremediation of Inorganics, R.E. Hinchee, J.L. Means and D.R. Burris (eds.), Battelle Press, Columbus, OH, 174 pp. (1995)

This volume is part of a ten volume set of papers derived from the Third International Insitu and Onsite Bioreclamation Symposium, which was held in San Diego, California, in April 1995. The purpose of the conference was to provide a multidisciplinary forum for exchange of state-of-the-art information on bioremediation. The papers that appear in the set of volumes were accepted after peer review. The papers in this volume discuss bioremediation of inorganics, including metals, nitrates, and cyanide. Both insitu and exsitu processes in soil and water media are included. Individual papers within the scope of this data base have been indexed separately.

\section{2 \\ V18/024643}

Bioremediation of Pollutants in Soil and Water: Proceedings of a Symposium, Fort Worth, TX, October 14-15, 1993

Bioremediation of Pollutants in Soil and Water, B.S. Schepart (ed.), Proceedings of a Symposium, Fort Worth, TX, October 14-15, 1993. American Society for Testing and Materials (ASTM), Philadelphia, PA, 265 pp. (May 1995)

This symposium was organized as a series of five sessions: (1) Feasibility and Applicability; (2) Bioremediation of PAHs; (3) In situ Bioremediation; (4) Bioremediation of Hazardous Chemicals; and (5) Enhancement of Bioremediation. Section One deals with the economics of bioremediation technology and compares them with other technologies. Data demonstrates that associated costs are significantly lower compared with other technologies, with competition playing a large role in cleanup costs. The role of screening strategies in lab- and pilot-scale for evaluating bioremediation as a treatment option supports the philosophy for upfront planning prior to full-scale levels. Section Two addresses the significant problems associated with sites contaminated with polynuclear aromatic hydrocarbons ( $\mathrm{PAHs}$ ), compounds that are relatively recalcitrant and comprise a number of carcinogens. The goal for their successful bioremediation is to ensure PAH-degrading organisms are present and can target all constituents of interest. Compared with other petroleum products, cleanup costs are higher. This technology is clearly demonstrated at bench-, pilot-, and full-scale levels. Section Three provides data concerning in situ bioremediation applications. Successful applications are found to be dictated by the contaminant and its concentration, cleanup goals, physical restraints depending on geology/hydrogeology, cost, and time. Rhizosphere communities, where plants and microbes act symbiotically, are shown to play a significant role in bioremediation of agrochemicals. Sections Four and Five address bioremediation of hazardous chemicals and advanced applications of bioremediation. Recent advances in biological treatment of compounds demonstrate aerobic/anaerobic combinations are required for their bioreduction. Further discussions were generated during a poster presentation on their topics. In addition, data demonstrates a role for biological treatment of lead and organic wastes. The presentations of beach cleanup following the Exxon-Valdez spill in Alaska, and fixed-based facilities for cleanup of contaminated soil, demonstrate the significance of bioremediation as a cost effective technology now and in the future.

3013 V18/026081

\section{Bioremediation of Recalcitrant Organics}

CONF-950483 (Vol. 3-7); Proceedings of the Third International Insitu and Onsite Bioreclamation Symposium, San Diego, CA, April 24-27, 1995; Bioremediation Series 3(7) - Bioremediation of Recalcitrant Organics, R.E. Hinchee, R.E. Hoeppel and D.B. Anderson (eds.), Battelle Press, Columbus, OH, 368 pp. (1995)

This volume is part of a ten volume set of papers derived from the Third International Insitu and Onsite Bioreclamation Symposium, which was held in San Diego, California, in April 1995. The purpose of the conference was to provide a multidisciplinary forum for exchange of state-of-the-art information on bioremediation. The papers that appear in the set of volumes were accepted after peer review. There are as yet no commercial technologies commonly used to remediate most recalcitrant compounds. The articles in this volume address field and laboratory experience with recalcitrant compounds. Individual papers within the scope of this data base have been indexed separately.

3014 V18/023628

Bioremediation of Uranium-Bearing Wastewater: Biochemical and Chemical Factors Influencing Bioprocess Application

Macaskie, L.E.; Yong, P.; Doyle, T.C.; Roig, M.G.; Diaz, M.; Manzano, T.

University of Birmingham, School of Biological Sciences, Edgbaston, United Kingdom; University of Oxford, Department of Biochemistry, Oxford, United Kingdom; Universidad de Salamanca, Department de Quimica Fisica, Salamanca, Spain

Biotechnology and Bioengineering 53(1):100-109 (January 5, 1997) 
A biotechnological process for the removal of heavy metals from aqueous solutions utilizes an enzymaticaliy liberated phosphate ligand which precipitates with heavy metals $(M)$ as cell-bound MHPO4. The enzyme, a phosphatase, obeys Michaelis-Menten kinetics in resting and immobilized cells; an integrated form of the Michaelis-Menten equation was used to calculate the apparent $\mathrm{Km}$ (Km app) as operating in immobilized cells in flow-through columns by a ratio method based on the use of two enzyme loadings (Eol, E02) or two input substrate concentrations (So1, So2). The calculated $\mathrm{Km}$ app ( $4.08 \mathrm{mM}$ ) was substituted into an equation to describe the removal of metals by immobilized cells. In operation the activity of the bioreactor was in accordance with that predicted mathematically, within $10 \%$. The initial tests were done at neutral $\mathrm{pH}$, whereas the pH of industrial wastewaters is often low; an increase in the $\mathrm{Km}$ app at low $\mathrm{pH}$ was found in previous studies. Immobilized cells were challenged with acidic mine drainage wastewaters, where the limiting factors were chemical and not biochemical. Bioreactors initially lost activity in this water, but recovered to remove uranyl ion with more than $70 \%$ efficiency under steady-state conditions in the presence of competing cations and anions. Possible reasons for the bioreactor recovery are chemical crystallization factors.

\section{5}

V18/022254

\section{Bioremediation of Wastewater Containing RDX}

Ogden, K.L.

University of Arizona, Department of Chemical and Environmental Engineering, Tucson, $A Z$

\section{LA-SUB-96-113; 16 pp. (October 1994)}

A free suspension model of the biodegradation of RDX by a consortium has been developed as a part of an overall model that will describe the waste treatment for explosives in a continuous process. The free suspension model uses experimentally determined parameters to predict the concentrations of the bacteria cells, the substrate (yeast extract), RDX, and the mononitroso intermediate. The model correctly predicts the experimentally observed trends; however, the values predicted for the cell concentrations are consistently lower than those observed experimentally. This can be resolved by better characterizing the growth parameters of the consortium. The degradation of RDX was found to be first order in RDX concentration and assumed to be first order in cell concentration, $\mathrm{X}$, i.e., $\mathrm{d}(\mathrm{RDX}) / \mathrm{dt}=\mathrm{k} 1(\mathrm{X})(\mathrm{RDX})$. The degradation rate constant, kl, was found to be 0.043 (L/(g cells hr). Similarly, the degradation rate constant of the mononitroso intermediate was found to be $0.066 \mathrm{~L} /(\mathrm{g}$ cells hr).

\section{6}

\section{V18/024659}

\section{Bioremediation: Field Experience}

Bioremediation: Field Experience, P.E. Flathman, D.E. Jerger and J.H. Exner (eds.), Lewis Publishers, Boca Raton, FL, 560 pp. (1994)

This book is intended to present a series of examples of successful field bioremediation that will lead to more rapid acceptance of the process. Individual sections cover the following topics: (1) environmental regulations, (2) factors for selection of bioremediation, (3) shoreline treatment following a crude oil spill, (4) land treatment of soils, (5) treatment of surface impoundment sludges, (6) aqueous waste treatment, (7) hydrological modeling for optimization of in situ treatment, (8) hydrogen peroxide and nitrate for enhanced in situ treatment, (9) in situ treatment of subsurface soil and groundwater, (10) treatment of subsurface soil and groundwater, and (11) vapor-phase treatment of volatile organic compounds. Individual chapters within the scope of this database have been indexed separately.

\section{$3017 \quad \mathrm{~V} 18 / 022626$}

Blast Created Trenches for Groundwater Remediation

McKown, A.F.; Smith, L.P.; Loney, J.E.

CONF-950247 (Vol. 2); Proceedings of the 21st Annual Conference on Explosives and Blasting Techniques, Nashville, TN, February 5-9, 1995. International Society of Explosives Engineers, Cleveland, OH, Vol. 2, 345 pp.; (pp. 305-322) (1995)

Recovery of contaminated groundwater migrating through bedrock can be very difficult due to the low transmissivity of many bedrock fracture systems. To overcome these difficulties, a system of controlled trench blasting has been used on several projects to assist in cutting off and collecting groundwater plumes in bedrock. By using a combination of trench blasting and presplitting techniques, linear fracture zones are created in appropriate locations to significantly increase flow into recovery wells and control plume migration. The basics of rock fracturing using explosives will be briefly discussed, along with blasting impacts on utilities and structures in the area, and mitigation measures. Then three case histories are described which illustrate the techniques used to create the blasted trench and the effectiveness in varying rock conditions.

3018 V18/023880

By-Products from Supercritical Water Oxidation: Pathways, Kinetics, and Mechanisms

Savage, P.E.; Gopalan, S.

University of Michigan, Chemical Engineering Department, Ann Arbor, MI

EPA/600/R-95/012; CONF-9504110; Proceedings of the 21st Annual Risk Reduction Engineering Laboratory (RREL) Research Symposium, Cincinnati, OH, April 4-6, 1995. U.S. Environmental Protection Agency, Cincinnati, OH, 398 pp.; (pp. 254-257) (April 1995) :

Supercritical water oxidation (SCWO) is an emerging technology for the ultimate destruction of organic wastes. Organic compounds and oxygen can be intimately mixed in a single homogeneous aqueous phase at supercritical conditions $(\mathrm{Tc}=374$ degrees $\mathrm{C}, \mathrm{Pc}=218$ $\mathrm{atm}$ ). Thus, the rapid oxidation reactions are unhindered by interphase transport limitations that could occur at subcritical conditions where multiple phases exist. The research reported in this paper focused on the oxidation of phenolic compounds. All oxidation experiments were performed in a reactor that nominally operated isothermally, isobarically, and in plug flow. Aqueous solutions of oxygen and phenol were prepared separately and used as reactor feed streams. Dimerization of phenol is the primary pathway for phenol consumption between 380 and 480 degrees C. A successful strategy for treatment of phenolic wastes by SCWO must ensure the destruction of these dimers and the formation of $\mathrm{CO} 2$ in high selectivities. A quantitative reaction model shows that long residence times and high reaction temperatures favor the destruction of dimers and the formation of $\mathrm{CO}$ and $\mathrm{CO}$. Results 
show that identifying and quantifying reaction intermediates and developing accurate quantitative reaction models is of vital importance for any rational SCWO process design.

3019

V18/021997

\section{CROW [TM] Process Field Demonstration Status}

Fahy, L.J.; Johnson, L.A., Jr.; Thingvold, D.A.; Leuschner, A.P.

Westem Research Institute, Laramie, WY; Bell Lumber and Pole Company, New Brighton, MN; Remediation Technologies, Inc., Concord, MA

CONF-9509139; Emerging Technologies in Hazardous Waste Management VII, D.W. Tedder (ed.), Proceedings of the Seventh American Chemical Society Industrial and Engineering Chemistry Division Special Symposium, Atlanta, GA, September 17-20, 1995. American Chemical Society, Washington, DC, 1291 pp.; (pp. 349-351) (1995)

The contained recovery of oily wastes (CROW [TM]) process removes organic contaminants from an aquifer by adaptation of secondary and heavy oil recovery technology. The organic contaminants are mobilized by controlled in situ heating and are displaced to extraction wells by hot-water or steam injection. This recovery of the mobile organic material produces an immobile residual saturation of organic liquids and greatly enhances conditions for microbial degradation. The CROW technology was successfully tested in the laboratory as part of the U.S. Environmental Protection Agency (EPA) SITE Program's Emerging Technology Program. Additional development of the process included a 30-day, two-well pilot test at an active wood treatment facility which is owned and operated by Bell Lumber and Pole Company (Bell Pole) in New Brighton, Minnesota. The pilot test consisted of injecting hot, potable water into the aquifer where mobile, organic liquids, having a specific gravity similar to water, were present.

3020 V18/023875

Case Studies of the High Voltage Electron Beam Technology for Wastewater Treatment

Cooper, W.J.; Waite, T.D.; Kurucz, C.N.; Nickelsen, M.G.; Kajdi, D.C.; Gensel, F.; Stinson, M.K.

High Voltage Environmental Applications, Inc., Miami, FL; High Voltage Environmental Applications, Inc., Deutschland $\mathrm{GmbH}$, Eichenbarleben, Germany; U.S. Environmental Protection Agency, Risk Reduction Engineering Laboratory, Edison, NJ

EPA/600/R-95/012; CONF-9504110; Proceedings of the 21st Annual Risk Reduction Engineering Laboratory (RREL) Research * Symposium, Cincinnati, OH, April 4-6, 1995. U.S. Environmental Protection Agency, Cincinnati, OH, 398 pp.; (pp. 181-185) (April 1995)

The development of innovative technologies for the remediation of contaminated sites is continually being considered as a treatment option for several reasons. From an economic standpoint, the treatment costs of conventional technologies continues to increase and from an environmental impact view, treatment technologies are sought that destroy contaminants without creating additional disposal problems. The high energy electron beam process has been shown to be effective in destroying many organic compounds associated with contaminated sites. The experiments to date have been conducted at both bench and full scale. A mobile unit has been developed to provide on-site treatability and feasibility studies and small-scale cleanups. This paper describes the reaction chemistry and discusses case studies conducted at full scale using the mobile treatment process.

3021

V18/023454

Catalytic Oxidation of Volatile Organic Compounds Using Ceramic Membrane Reactors

Pina, M.P.; Menendez, M.; Santamaria, J.

University of Zaragoza, Department of Chemical and Environmental Engineering, Zaragoza, Spain

CONF-960730 (Vol. 3); Technologies Critical to a Changing World, Volume III: Emerging Energy Technologies, Clean Technologies, Remediation and Emission Control Fuels, and Petrochemicals, Proceedings of the Fifth World Congress of Chemical Engineering, San Diego, CA, July 14-18, 1996. American Institute of Chemical Engineers, New York, NY, Vol. 3, 1118 pp.; (pp. 266-269) (1996)

$\mathrm{Pt} / g a m m a-A 12 \mathrm{O} 3$ ceramic membranes have been prepared for their use as combustors of Volatile Organic Compounds (VOCs) in diluted streams. The membranes operate in the Knudsen regime, which gives a highly efficient contact between the feedstream and the catalytic material on the membrane. This has led to essentially complete combustion of VOCs at temperatures below 190 degrees C.

3022

V18/021448

Characterization of Methanotrophic Bacterial

Communities Present in a Trichloroethylene Contaminated Subsurface Groundwater Site

Bowman, J.P.; Jimenez, L.E.; Rosario, I.; Hazen, T.C.; Sayler, G.S.

University of Tennessee, Center for Environmental Biotechnology, Knoxville, TN; Westinghouse Savannah River Company, Savannah River Laboratory, Aiken, SC

Applied Environmental Microbiology 59(8):2380-2387 (1993)

Groundwater, contaminated with trichloroethylene (TCE) (40-658

$\mathrm{ppb}$ ) and tetrachloroethylene (PCE) (2-270 ppb), was collected from 13 monitoring wells at Area M on the U.S. Department of Energy, Savannah River Site near Aiken, South Carolina. Direct bacterial accounts of Area $M$ groundwater ranged from $3.2 \mathrm{x}$ $10(E+4)$ to $1.0 \times 10(E+6)$ cells $/ \mathrm{ml}$ while heterotrophic viable bacterial counts ranged from $1.0 \times 10(\mathrm{E}+3)$ to $1.3 \times 10(\mathrm{E}+5)$ $\mathrm{CFU} / \mathrm{ml}$. Filtered groundwater samples were enriched with $50 \%$ methane leading to the isolation of 25 methanotrophic isolates. These isolates were characterized using microscopy, phenotypic tests, phospholipid fatty acid analysis (PLFA), and anaiyzed for soluble methane monooxygenase activity using the naphthalene oxidation assay, gene probe analysis, and TCE degradation. The PLFA profiles of all the isolates were dominated by 18:1 [omega]8c(60-80\%); a signature lipid for group II methanotrophs. Subsequent phenotypic testing showed the majority of the strains were of the genus Methylosinus while one isolate was of Methylocystis. A majority of the methanotroph isolates exhibited soluble MMO activity. This was presumptively indicated 
by the naphthalene oxidation assay and confirmed by hybridization with a gene probe encoding the soluble methane monooxygenase mmoB gene and by cell free extract assays. TCE was degraded at varying rates by the majority of the $S \mathrm{MMO}$-producing isolates while PCE was not degraded. Of the 13 wells sampled, 9 were found to have methanotrophs which were capable of rapid TCE degradation by virtue of soluble methane monooxygenase activity.

\section{$3023 \quad \mathrm{~V} 18 / 022445$}

Chlorinated Solvent Reductions Induced by an Aquifer Sparge Fence

Payne, F.C.; Rogers, D.T.; Buehlman, M.D.

Envirogen, Inc., MWR Division, Lawrenceville, NJ; Clayton Environmental Consultants, Inc., Novi, MI; Amsted Industries, Inc., Chicago, IL

Proceedings of the First International Symposium on Insitu Air Sparging for Site Remediation, Las Vegas, NV, October 23-25, 1996; (15 pp.) (1996)

Aquifer sparging was selected as the remedial method for removal of chlorinated solvents from groundwater at a site in southeast lower Michigan. An aquifer sparge fence was selected as the first phase of remediation, to prevent contaminants in groundwater from migrating beyond the site property boundary, until a full-scale aquifer sparge system could be designed and approved by regulators. While an aquifer sparge fence may be the final remedial action for some sites, the owner of the subject site prefers to achieve site-wide closure at the earliest possible time. Therefore, a full-scale aquifer sparge/SVE system has been installed and will begin operation during November 1996. The purpose of this paper is to provide a detailed review of contaminant reduction and hydraulic effects using an aquifer sparge fence for those sites which select a sparge fence as a final remedial action.

\section{4}

\section{V18/022622}

Column Study of Geochemical Factors Affecting Reductive Dechlorination of Chlorinated Solvents by Zero-Valent Iron

Johnson, T.L.; Tratnyek, P.G.

Oregon Graduate Institute of Science and Technology, Department of Environmental Science and Engineering, Portland, OR

CONF-941124; Insitu Remediation: Scientific Basis for Current and Future Technologies, G.W. Gee and N.R. Wing (eds.), Proceedings of the 33rd Hanford Symposium on Health and the Environment, Pasco, WA, November 7-11, 1994. Battelle Press, Columbus, OH, Part 2, 605 pp.; (pp. 931-947) (1994)

Laboratory and field studies have shown that fillings of metal that are predominantly $\mathrm{Fe}[\mathrm{E}+0]$ can rapidly dehalogenate a variety of chlorinated solvents, and several technologies have recently been proposed to use this reaction in remediation of contaminated groundwater. This report describes results from a laboratory column designed to model the spatial distribution of chemical conditions when iron is applied as part of an in-situ permeable reactive barrier. The column contains a zone of granular iron located between up-gradient and down-gradient zones of sand, and has received deionized water with varying concentrations of $\mathrm{CCl} 4$ for over 6 months. Aerobic corrosion results in complete consumption of dissolved oxygen and precipitation of ferric hydroxides at the interface where water enters the iron-bearing zone. Within the iron-bearing zone, corrosion continues due to oxidation of the iron by water and carbon tetrachloride, resulting in increased $\mathrm{pH}$ and concentration of dissolved iron in the pore water. At the down-gradient interface, $\mathrm{pH}$ decreased as the result of precipitation of iron-bearing minerals. Carbon tetrachloride (up to $1.6 \mathrm{mM}$ ) was fully dehalogenated by the first sample port within the iron-bearing zone. The chloroform produced was further dechlorinated to dichloromethane, but at a slower rate. First-order disappearance kinetics for chloroform applied across the zone of iron, and $k[0 b s]$ has changed little over several months. No evidence has been found so far for unusual reactivity of the chlorinated solvents at either the up-gradient or down-gradient interfaces.

\section{5}

\section{V18/023610}

Commonly Asked Questions Regarding the Use of Natural Attenuation for Petroleum-Contaminated Sites at Federal Facilities

\section{U.S. Environmental Protection Agency, Washington, DC}

Report; 29 pp. (October 1996)

This brochure answers commonly asked questions regarding the use of natural attenuation for petroleum-contaminated sites. It includes a definition of natural attenuation, a discussion of the circumstances under which it may be effective, and the advantages and limitations.

3026

\section{$\mathrm{V} 18 / 024644$}

Comparative Cost Analysis: Conventional Treatment - Technologies and Bioremediation

Davis, K.L.; Smith, H.R.; Day, S.M.

University of Tennessee, International Waste Management Systems, Knoxville, TN; University of Tennessee, Waste Management Research and Education Institute, Knoxville, TN

Bioremediation of Pollutants in Soil and Water, B.S. Schepart (ed.), Proceedings of a Symposium, Fort Worth, TX, October 14-15, 1993. American Society for Testing and Materials (ASTM), Philadelphia, PA, 265 pp.; (pp. 5-17) (May 1995)

The refinement of an effective institutional framework for regulating the cleanup of hazardous wastes is greatly enhanced through the collection of reliable information on cleanup costs. This information is critical in order to develop environmental policy that is sensitive to the economic tradeoffs between environmental restoration and the allocation of funds to social programs and future economic growth. Unfortunately, a dearth of cost data is evident for biologically-based waste treatment methodologies, which recently have gained widespread acceptance as effective means of remediating wastes under appropriate environmental conditions. Costs of remediating petroleum underground storage tank sites in Tennessee were studied in order to compare resources allocated to the cleanup of sites which used soil bioremediation versus other "conventional" types of soil remediation. An analysis of various site characteristics was undertaken in order to gain an understanding of cost variations between biological and non-biological cleanup methodologies. 
3027

V18/024138

Comparison of Innovative Depth Discrete Sampling

Technologies for Sediments and Groundwater for Environmental Characterization

Eddy, C.A.; Looney, B.B.; Kaback, D.S.

Westinghouse Savannah River Company, Environmental Sciences Division, Aiken, SC

CONF-920466; Waste Management and Environmental Restoration, Proceedings of an Engineering and Technology Conference, San Juan, Puerto Rico, April 9-11, 1992; (pp. 124-133) (1992)

The Savannah River Site is the location of an Integrated Demonstration Project designed to evaluate innovative remediation technologies for environmental restoration at sites contaminated with volatile organic solvents. The purpose of the demonstration is to use directionally drilled horizontal wells to deliver gases and extract contaminants from the subsurface. The first phase of the Integrated Demonstration used in-situ air stripping to remediate soils and sediments. As part of site characterization, an effort was made to demonstrate and evaluate new technologies for robust, rapid, and cost-effective environmental characterization. The purpose of this paper is to discuss two depth discrete sampling techniques that can be used to improve remedial investigations.

V18/023751

Comparison of Low Flow Pumping and Bailing for VOC Groundwater Sampling at Landfills

Svavarsson, G.; Connelly, J.; Kuehling, $\mathrm{H}$.

Wisconsin Department of Natural Resources, Bureau of Solid and Hazardous Waste Management, Madison, WI

CONF-950978; Municipal and Industrial Waste, Proceedings of the 18th International Madison Waste Conference, Madison, WI, September 20-21, 1995. University of Wisconsin, Madison, WI, 461 pp.; (pp. 360-377) (1995)

The state of Washington has more than 10,000 groundwater monitoring wells that will continue to be sampled into the future. Most samplers in this state use a bailer to purge and sample these wells. The EPA has questioned the use of a bailer for volatile organic compound (VOC) sampling because of the potential to increase sample aeration and cause significantly more turbidity than using a low flow pumping method. A total of nine monitoring wells that had a history of VOC contamination were sampled at three landfills. The wells were sampled using both a low flow pump and bailer in the summer of 1994 and again in the following winter. Generally, only small differences were found between the VOC results collected using the low flow pumping and the bailing techniques. In addition, the method resulting in higher recovery of organic compounds differed, depending on the particular well, season, and compound.

3029

V18/023902

Comparison of Onsite VOC Analysis for Water and Soil, to Fixed Laboratory Analysis at Low PPB Detection Limits

Cozad, D.B.; Caron, D.R.
International Technology Corporation, San Bernardino, CA; U.S. Air Force, George Air Force Base, CA

CONF-951124; HazMat West '95, Proceedings of the Eleventh Annual Environmental Management and Technology Conference and Exhibition, Long Beach, CA, November 7-9, 1995. Advanstar Expositions, Duluth, MN, 597 pp.; (pp. 277-290) (1995)

The use of a field gas chromatograph (GC) to determine the concentration of BTEX and halogenated compounds in groundwater is demonstrated and compared to laboratory analysis. Innovative empirical calibration, in the sample matrix, increases the reliability and accuracy of the headspace analysis with a field GC. Close correlation of results with fixed laboratory analysis demonstrate the accuracy of this technique for field screening. Thermal augmentation of the sample increases the headspace concentration and reduces the detection limits to the 1-10 parts per billion (ppb) range for water samples. The procedures for utilizing these methods to analyze soil are presented. The use of sonication and bag headspace extraction increases the accuracy of the method for soil analysis. In addition, the performance of these analyses in a time critical, production oriented, site investigation with excellent results, is well documented. The briefcase-size, field $G C$ and auxiliary equipment can provide accurate screening at U.S. Environmental Protection Agency Quality Level 2+ in real time, at a very low cost. This method allows the acceleration of site investigation and well/boring placement, with demonstrated quality.

\section{0}

\section{V18/023805}

\section{Complex Electrical Resistance Tomography of a} Subsurface PCE Plume

Ramirez, A.L.; Daily, W.D.; LaBrecque, D.J.

Lawrence Livermore National Laboratory, Livermore, CA; University of Arizona, Tucson, AZ

CONF-960477; SAGEEP '96, R.S. Bell and M.H. Cramer (eds.), Proceedings of the Ninth Annual Symposium on the Application of Geophysics to Engineering and Environmental Problems, Denver, CO, April 15-May 1, 1996. Environmental and Engineering Geophysical Society, Wheat Ridge, CO, 1353 pp.; (pp. 753-762) (1996)

A controlled experiment was conducted to evaluate the performance of complex electrical resistivity tomography (CERT) for detecting and delineating free product dense non aqueous phase liquid (DNAPL) in the subsurface. One hundred ninety liters of tetrachloroethylene (PCE) were released at a rate of 2 liters per hour from a point $0.5 \mathrm{~m}$ below ground surface. The spill was conducted within a double walled tank where saturated layers of sand, bentonite and a sand/bentonite mixture were installed. Complex electrical resistance measurements were performed from 4 vertical electrode arrays, each with 10 electrodes spaced between 3 $\mathrm{m}$ and $0.5 \mathrm{~m}$ depth. Data were taken before the release, several times during, and then after the PCE was released. Magnitude and phase were measured at 1 and $64 \mathrm{~Hz}$. Data from before the release were compared with those during the release for the purpose of imaging the changes in conductivity resulting from the plume. Conductivity difference tomographs showed a decrease in electrical conductivity as the DNAPL penetrated the soil. A pancake-shaped anomaly developed on the top of a bentonite layer at $2 \mathrm{~m}$ depth. The anomaly grew in magnitude and extent during the release, and 
borehole television surveys data confirmed the anomaly to be free-product PCE whose downward migration was stopped by the low permeability clay. The tomographs clearly delineated the plume as a resistive anomaly. Images showing phase changes caused by the spill are also presented. The phase changes at $64 \mathrm{~Hz}$ suggest that the DNAPL spill increased the induced polarization (IP) effect of the clay layers.

\section{1}

$\mathrm{V} 18 / 022301$

Conceptual Air Sparging Decision Tool in Support of the Development of an Air Sparging Optimization Decision Tool - Final

Parsons Engineering Science, Inc., Cleveland, $\mathrm{OH}$ DOE/ID/12735-2; 196 pp. (September 1995)

This document describes a conceptual decision tool (hereinafter, Tool) for determining applicability of and for optimizing air sparging systems. The Tool was developed by a multi-disciplinary team of internationally recognized experts in air sparging technology, lead by a group of project and task managers at Parsons Engineering Science, Inc. (Parsons ES). The team included Mr. Douglas Downey and Dr. Robert Hinchee of Parsons ES, Dr. Paul Johnson of Arizona State University, Dr. Richard Johnson of Oregon Graduate Institute, and Mr. Michael Marley of Envirogen, Inc. User Community Panel Review was coordinated by Dr. Robert Siegrist of Colorado School of Mines (also of Oak Ridge National Laboratory) and Dr. Thomas Brouns of Battelie/Pacific Northwest Laboratory. The Tool is intended to provide guidance to field practitioners and environmental managers for evaluating the applicability and optimization of air sparging as remedial action technique.

3032

V18/022623

Contaminated Soils and Groundwater - Analysis, Fate, Environmental and Public Health Effects, and Remediation: Proceedings of the Sixth West Coast Conference, Pt. 2, Newport Beach, CA, March 11-14, 1996

CONF-960393 (Part 2); Contaminated Soils and Groundwater: Analysis, Fate, Environmental and Public Health Effects, and Remediation, Proceedings of the Sixth Annual West Coast Conference, Newport Beach, CA, March 11-14, 1996. Association for the Environmental Health of Soils, Amherst, MA, Part 2, 226 pp. (1996)

This conference was held March 11-14, 1996 in Newport Beach, California. The purpose of this conference was to provide a multidisciplinary forum for exchange of state-of-the-art information on contaminated soils and groundwater. Attention is focused on the following areas: analysis; fate; environmental and public health effects; and remediation. This volume focuses on remediation. Papers within the scope of this database have been indexed separately.

3033

\section{V18/022627}

Contaminated Soils and Groundwater - Analysis, Fate, Environmental and Public Health Effects, and Remediation: Proceedings of the Sixth West Coast Conference, Pt. 3, Newport Beach, CA, March 11-14,
1996

CONF-960393 (Part 3); Contaminated Soils and Groundwater: Analysis, Fate, Environmental and Public Health Effects, and Remediation, Proceedings of the Sixth Annual West Coast Conference, Newport Beach, CA, March 11-14, 1996. Association for the Environmental Health of Soils, Amherst, MA, Part 3, 366 pp. (1996)

This conference was held March 11-14, 1996 in Newport Beach, Califomia. The purpose of this conference was to provide a multidisciplinary forum for exchange of state-of-the-art information on contaminated soils and groundwater. Attention is focused on the following areas: analysis; fate; environmental and public health effects; and remediation. This volume includes the following: innovative technologies; analysis and fate; and bioremediation/natural attenuation. Papers within the scope of this database have been indexed separately.

3034

V18/022637

Contaminated Soils and Groundwater - Analysis, Fate, Environmental and Public Health Effects, and Remediation: Proceedings of the Sixth West Coast Conference, Pt. 1, Newport Beach, CA, March 11-14, 1996

CONF-960393 (Part 1); Contaminated Soils and Groundwater: Analysis, Fate, Environmental and Public Health Effects, and Remediation, Proceedings of the Sixth Annual West Coast Conference, Newport Beach, CA, March 11-14, 1996. Association for the Environmental Health of Soils, Amherst, MA, Part 1, 257 pp. (1996)

This conference was held March 11-14, 1996 in Newport Beach, California. The purpose of the conference was to provide a multidisciplinary forum for exchange of state-of-the-art information on contaminated soils and groundwater. Attention is focused in the following areas: analysis; fate; environmental and public health effects; and remediation. This volume includes papers on California leaking underground storage tanks (LUFT) work, regulations, risk assessment, and Navy work. The majority of the papers focus on petroleum related problems.

3035

V18/023616

\section{Control Technologies at Remediation Sites}

Hunter, L.L.; Engleman, V.S.; Priebe, S.J.

Environmental Protection 5(1):40-45 (January 1994)

What are the most economic and technically feasible ways to recover or destroy volatile organic compounds from soil and groundwater remediation projects. This screening model may help you decide. A comparative study of control technologies at three separate sites is described.

3036

V18/022613

\section{Controlled Field Test of Surfactant-Enhanced Aquifer} Remediation

Fountain, J.C.; Middleton, T.M.; Beikirch, M.G.; Taylor, C.; Hodge, D.S.; Starr, R.C.

State University of New York at Buffalo, Department of Geology, Buffalo, NY; Idaho National Engineering 
Laboratory, Idaho Falls, ID

Groundwater 34(5):910-916 (September-October 1996)

The presence of dense nonaqueous phase liquids is one of the principal problems associated with current groundwater remediation efforts. Standard pump-and-treat methods are ineffective largely because of the low aqueous solubilities of DNAPL components. Surfactants can increase DNAPL solubility and hence have the potential for increasing the rate of DNAPL dissolution in pump-and-treat systems. To test the effectiveness of surfactants under field conditions, a controlled field test at Canadian Forces Base Borden was undertaken. Results indicate surfactant-enhanced aquifer remediation can rapidly remove the majority of DNAPL using simple modifications of a pump-and-treat system. As in all pump-and-treat systems, the efficiency is a function of the hydraulic conductivity. The persistence of high DNAPL concentrations at specific elevations within the aquifer throughout the test indicates that little vertical movement of DNAPL occurred as a result of the introduction of the surfactant. Since the test was stopped when small amounts of DNAPL still remained, the limit of removal was not investigated.

3037

V18/022638

Coordinating Bifurcated Remediation of Soil and Groundwater at Sites Containing Multiple Operable Units

Laney, D.F.

Dames \& Moore, Santa Ana, CA

CONF-960393 (Part 2); Contaminated Soils and Groundwater: Analysis, Fate, Environmental and Public Health Effects, and Remediation, Proceedings of the Sixth Annual West Coast Conference, Newport Beach, CA, March 11-14, 1996. Association for the Environmental Health of Soils, Amherst, MA, Part 2, 226 pp.; (p. 14) (1996)

On larger and/or more complex sites, remediation of soil and groundwater is sometimes bifurcated. This presents some unique advantages with respect to expedited cleanup of one medium, however, it requires skillful planning and significant forethought to ensure that initial remediation efforts do not preclude some long-term options, and/or unduly influence the subsequent selection of a technology for the other operable units and/or media. this paper examines how the decision to bifurcate should be approached, the various methods of bifurcation, the advantages and disadvantages of bifurcation, and the best methods to build flexibility into the design of initial remediation systems so as to allow for consideration of a fuller range of options for remediation of other operable units and/or media at a later time. Pollutants of concern include: metals; petroleum hydrocarbons; and chlorinated solvents.

\section{8}

V18/023471

Cost Effective Insitu Remediation of Chlorinated Volatile Organic Compounds (VOCs) Using Permeable Iron Reactive Walls

Vogan, J.L.; Krug, T.A.; Major, D.W.

EnviroMetal Technologies, Inc., Guelph, Ontario, Canada; Beak Consultants Limited, Guelph, Ontario, Canada
CONF-9606300; HazMat International '96, Proceedings of the 14th Annual Environmental Management and Technology International Conference, Atlantic City, NJ, June 18-20, 1996. Advanstar Expositions, Duluth, MN, 527 pp.; (pp. 221-227) (1996)

In situ chemical treatment walls can provide a cost effective alternative to pump and treat techniques for control of dissolved phase plumes containing chlorinated volatile organic compounds (CVOCs). The passive technique involves the installation of a permeable treatment wall containing a reactive metal in the ground to intersect the dissolved phase plume. The groundwater containing dissolved chemicals flows through the permeable treatment wall, and the metal generates conditions which will rapidly degrade chemicals. The technique can be used to degrade chlorinated solvents such as trichloroethane (TCE), perchloroethene (PCE), and vinyl chloride (VC). Because this technique does not require active operation and maintenance it offers the potential to control dissolved phase plumes at a much lower long term cost than conventional pump and treat techniques. In situ systems using permeable iron treatment sections have been installed at several sites in the United States for the remediation of dissolved chlorinated solvents.

3039

V18/022614

Cost-Effective Sampling of Groundwater Monitoring Wells [Rev. 1]

Ridley, M.; Johnson, V.; Tuckfield, R.; Anderson, R. Lawrence Livermore National Laboratory, Livermore, CA; Savannah River Technology Center, Aiken, SC

UCRL-JC-1 18909 (Rev. 1); CONF-960804 (Vol. 2); Spectrum '96: Nuclear and Hazardous Waste Management, Proceedings of an International Topical Meeting, Seattle, WA, August 18-23, 1996. American Nuclear Society, La Grange Park, IL, Vol. 2, 873 pp.; (pp. 1015-1020) (November 1995)

Cost-Effective Sampling is a systematic methodology for estimating the lowest-frequency sampling schedule for a given groundwater monitoring location which will still provide needed information for regulatory and remedial decision-making. Increases in frequency dictated by remedial actions are left to the judgment of personnel reviewing the recommendations. To become more applicable throughout the life cycle of a groundwater cleanup project or for compliance monitoring, several improvements are envisioned, including: chemical signature analysis to identify minimum suites of contaminants for a well, a simple flow and transport model so that sampling of downgradient wells is increased before movement of contamination, and a sampling cost estimation capability. By blending qualitative and quantitative approaches, it is hoped to create a defensible system while retaining interpretation ease and relevance to decision making.

3040

V18/023469

Countermeasures Against Contaminated Soil and Groundwater (Investigations and Remediations)

Nakamura, T.; Inoue, $H$.; Hsueh, Y.

Hitachi Metals, Limited, Tokyo, Japan; Hitachi Plant Engineering and Construction Company Limited, Tokyo, Japan; Hitachi Limited, Tokyo, Japan

Hitachi Hyoron 78(7):49-54 (July 1, 1996) 
This paper discusses contaminated soil and groundwater and measures to deal with them. Soil contamination is a cumulative process, and its impact on groundwater lingers on even after the original source of pollutants is gone. At the beginning of the investigation and analysis of a site, its history and available data on groundwater and geology have to be gathered so that the extent of pollution can be established. Next, drilling is done to investigate pollution, geology, and groundwater at levels deep in the ground. In dealing with heavy metal contamination, cut-off and

insolubilization are measures that have been employed with success. Use of washing and heating for separation and recovery of heavy metals are still in the stage of research and development. In use as measures for organochlorine compounds are removal by excavation, soil gas extraction, and pumping of groundwater. In an example of Hitachi Group efforts to deal with tetrachloroethylene, the soil was remediated by vacuum extraction, groundwater was remediated by pumping, and the contaminant was separated and recovered by low-temperature heating. (This document is in Japanese).

\section{1}

V18/022778

\section{Creation of a Subsurface Permeable Treatment Barrier Using Insitu Redox Manipulation}

Fruchter, J.S.; Cole, C.R.; Williams, M.D.; Yabusaki, S.B.; Vermeul, V.R.; Teel, S.S.; Amonette, J.E.; Szecsody, J.E.; Humphrey, M.D.; Istok, J.D.

Pacific Northwest Laboratory, Richland, WA; Oregon State University, Corvallis, OR

CONF-960804 (Vol. 2); Spectrum '96: Nuclear and Hazardous Waste Management, Proceedings of an International Topical Meeting, Seattle, WA, August 18-23, 1996. American Nuclear Society, La Grange Park, IL, Vol. 2, 873 pp.; (pp. 1306-1310) (1996)

Subsurface contaminants at Department of Energy (DOE) sites occur in both the vadose and groundwater saturated zones. Many of the groundwater plumes are already dispersed over large areas (square miles) and are located hundreds of feet below the ground. This type of dispersed, inaccessible contamination, which is more difficult than other types of contamination to treat using excavation or pump-and-treat methods, may only be treated successfully by the in situ manipulation of natural processes to change the mobility or form of the contaminants.

\section{2}

\section{V18/025299}

\section{Current Practice of Bioremediation}

Insitu Bioremediation: When Does It Work?, National Academy Press, Washington, DC, 207 pp.; (pp. 47-62) (1993)

Increasingly, in situ bioremediation is being heralded as a promising "new" alternative groundwater cleanup technology. In fact, however, bioremediation is not new. It has been used commercially for more than 20 years. The first commercial in situ bioremediation system was installed in 1972 to clean up a Sun Oil pipeline spill in Ambler, Pennsylvania. Since 1972, bioremediation has become well developed as a means of cleaning up spills of gasoline, diesel, and other easily degraded petroleum products. In general, in situ bioremediation has not developed to the point where it can be used on a commercial scale to treat compounds other than easily degraded petroleum products. However, although in situ bioremediation of petroleum-based fuels is the only common use of the technology now, in the future bioremediation will likely be used to treat a broad range of contaminants. Recently, research has intensified on bioremediation of less easily degraded compounds, such as chlorinated solvents, pesticides, and polychlorinated biphenyls (PCBs). Bioremediation of many such recalcitrant compounds has been successfully field tested. This chapter describes the state of the practice of in situ bioremediation as used today. Although the current uses of bioremediation apply primarily to petroleum-based fuels, the principles of practice outlined here extend to a much broader range of uses for the technology in the future.

\section{$3043 \quad$ V18/024144}

DOE/SRS Integrated Demonstration: Insitu Bioremediation of Soil and Groundwater

Hazen, T.C.; Dougherty, J.M.; Enzien, M.V.; Franck, M.M.; Fliermans, C.B.; Eddy, C.A.; Lombard, K.H.

Westinghouse Savannah River Company, Savannah River Technology Center, Aiken, SC

CONF-9211153; Proceedings of the Third Technical Information Exchange (TIE) Workshop, Pleasanton, CA, November 17-19, 1992; (1 p.) (1992)

The Savannah River Integrated Demonstration focuses on "Clean-up of Soils and Groundwater Contaminated with Chlorinated VOCs." The principal-remediation technology being tested during 1992 is in situ bioremediation. Severai laboratories including our own have demonstrated the ability of methanotrophic bacteria to completely degrade or mineralize chlorinated solvents, and these bacteria were naturally found in soil and aquifer material. Groundwater was monitored biweekly from 13 wells for a variety of chemical and microbiological parameters. Groundwater from wells in affected areas showed increases in methanotrophs of more than 1 order of magnitude every 2 weeks for several weeks after $1 \%$ methane in air injected was started. Simultaneous with the increase in methanotrophs was a decrease in water and soil gas concentrations of trichloroethylene and tetrachloroethylene. All of the wells in the zone of effect showed significant decreases in contaminants in less than 1 month. Four of five vadose zone piezometers (each with 3 sampling depths) declined from concentrations as high as $10,000 \mathrm{ppm}$ ( $\mathrm{vol} / \mathrm{vol}$ ) to less than $5 \mathrm{ppm}$ in less than 6 weeks. The fifth cluster also declined by more than $90 \%$. A variety of other microbial parameters increased with methane injection indicating the extent and type of stimulation that had occurred. (Complete text).

\section{$3044 \quad$ V18/024640}

Decisions on Rehabilitation Methods: After Things Go Wrong, Chapter 8

Smith, S.A.

Smith Consulting Services, $\mathrm{Ada}, \mathrm{OH}$

Monitoring and Remediation Wells: Problem Prevention, Maintenance, and Rehabilitation, Lewis Publishers, Boca Raton, FL, 203 pp.; (pp. 119-138) (1995)

Rehabilitation choices depend on the problem. Treatments per se are only used for biofouling and encrustation, where something is 
removed or suppressed. Preventing or rectifying sandpumping and corrosion require some reconstruction strategy to keep the abrasives out and limit deterioration of the screen and casing, as well as the pump. Sand- or silt-pumping additionally can be addressed through redevelopment. In well rehabilitation, these are essentially preventive activities (materials selection, design, and development) applied reactively. This chapter covers issues, recommendations, and techniques for well rehabilitation. Topics covered include site management, safety, contracting, and waste handling. Major sections cover factors that affect the decision to rehabilitate, cost estimating for rehabilitation, and choosing rehabilitation methods. This chapter is from the book entitled Monitoring and Remediation Wells: Problem Prevention, Maintenance, and Rehabilitation.

\section{5}

\section{V18/023729}

Dedicated Groundwater Sampling Pumps: Reduced Monitoring Costs and Increased Effectiveness

Sheneman, R.S.

Princeton Plasma Physics Laboratory, Princeton, NJ

CONF-960741; DOE Pollution Prevention in the 21st Century, Proceedings of the Twelfth Annual DOE Pollution Conference, Chicago, IL, July 9-11, 1996; (9 pp.) (1996)

With the increasing complexity of environmental restoration activities, and the current and anticipated budgetary constraints for the Environmental Restoration (EM-40) program, it is critically important that site characterization, remediation, and monitoring programs incorporate waste minimization measures to control costs while increasing effectiveness. A project at the Princeton Plasma Physics Laboratory, funded through the Waste Minimization Program, is underway to install dedicated groundwater sampling pumps in monitoring wells at the site. Traditional groundwater sampling practices involve the pumping or "purging" of between three and five well volumes prior to sample collection. Where groundwater is contaminated, it must be collected, stored, transported, and treated at considerable cost. Significant recent research, including U.S. Department of Energy (DOE)-funded research, indicates that more representative groundwater samples can be obtained by using dedicated low-flow sampling pumps and the "micropurge" or "millipurge" sampling technique. This technique generates significantly less purge water than that generated by traditional methods. Adoption of this sampling method not only reduces the volume of wastewater that must be collected and treated, but also improves the quality of groundwater samples collected, reduces the associated analytical costs, and increases the efficiency and safety of sampling and monitoring activities. Benefits from this project cross-cut program boundaries and are shared by EM-30, EM-40, and Energy Research. Other DOE facilities where long-term groundwater monitoring is anticipated are strongly encouraged to adopt this strategy to reduce overall characterization and monitoring costs, while improving data quality and program effectiveness.

\section{6}

\section{V18/024027}

\section{Degradation of Metal - Nitrilotriacetate Complexes by} Chelatobacter Heintzii

Bolton, H., Jr.; Girvin, D.C.; Plymale, A.E.; Harvey, S.D.; Workman, D.J.
Pacific Northwest Laboratory, Richland, WA

Environmental Science \& Technology 30(3):931-938 (1996)

Nitrilotriacetic acid (NTA) is a synthetic chelating agent that can form strong water-soluble complexes with a wide range of radionuclide and metal ions and has been used to decontaminate nuclear reactors and in the processing of nuclear materials. The co-disposal of NTA or other synthetic chelating agents with radionuclides may result in increased dispersal of NTA or other synthetic chelating agents with radionuclides in soil and subsurface environments. Understanding the influence of aqueous geochemistry on NTA degradation is essential to predict the mobility and fate of inorganic contaminant-NTA complexes in the subsurface. Chelatobacter heintzii (ATCC 29600) was shown to degrade Carbon-14 labeled NTA to $14 \mathrm{CO} 2$ with first-order kinetics at concentrations ranging from 0.05 to $5.23 \mathrm{mu} \mathrm{M}(0.01-1 \mathrm{mu} g$ of NTA per $\mathrm{mL}$ ). The degradation of various metal-NTA complexes was investigated under conditions in which the NTA was predominantly present as the metal-NTA complex. The order of the rates of degradation was HNTA(2-) greater than CoNTA(1-) = FeOHNTA $(1-)=$ ZnNTA(1-) greater than AlOHNTA(1-) greater than CuNTA(1-) greater than NiNTA(1-), which is not related to the order of metal-NTA stability constants. The metal concentration used was not inhibitory to glucose mineralization, suggesting that toxicity of the chelated metal was not responsible for the differences in the rates of NTA degradation. After degradation of CoNTA(1-) and NiNTA(1-), greater than $3 \%$ of the $\mathrm{Co}$ or $\mathrm{Ni}$ was associated with $\mathrm{C}$. heintzii cells. This indicates that, after degradation of the metal-NTA complex, metal ions will be predominantly present in the aqueous phase. The degradability of the various metal-NTA complexes was not related to their thermodynamic stability constants, but was related to the lability of the various metal-NTA complexes or the relative rates of formation of HNTA(2-).

\section{$3047 \quad$ V18/021768}

Degradation of Polychlorinated Biphenyls (PCBs) Using Palladized Iron

West, O.R.; Liang, L.; Holden, W.L.; Korte, N.E.; Fernando, Q.; Clausen, J.L.

Oak Ridge National Laboratory, Environmental Sciences Division, Oak Ridge, TN

ORNL/TM-13217; 50 pp. (June 1996)

This study was directed towards the development of a cost-effective technology for removing/degrading polychlorinated biphenyls (PCBs) from 001-Outfall surface water at the Paducah Gaseous Diffusion Plant (PGDP). Both batch and column experiments showed that palladized iron $(\mathrm{Pd} / \mathrm{Fe})$ can be used as a reactive material to treat PCB-contaminated aqueous solutions at room temperature. The reductive degradation rates with bimetallic substrate are several orders of magnitude higher than those observed for biodegradation processes. Furthermore, in contrast to high-temperature processes where dioxins and furans are potentially produced, the major by-product of dechlorination by paliadized iron is biphenyl, which is substantially less toxic than the parent compounds. 
Delineation of Creosote-Based DNAPLs Using CPT-Deployed Laser Induced Fluorescence

Ruggery, D.A., Jr.; Misquitta, N.J; Coll, F.R.

Beazer East, Inc., Pittsburgh, PA; Key Environmental, Inc., Pittsburgh, PA

CONF-960393 (Part 3); Contaminated Soils and Groundwater: Analysis, Fate, Environmental and Public Health Effects, and Remediation, Proceedings of the Sixth Annual West Coast Conference, Newport Beach, CA, March 11-14, 1996. Association for the Environmental Health of Soils, Amherst, MA, Part 3, 366 pp.; (p. 22) (1996)

This paper presents a case study of the first commercial use of cone penetrometer testing (CPT)/deployed laser induced fiuorescence

(LIF) to address specific objectives at a creosote DNAPL site. The objectives of the investigation using CPT/LIF were to: quickly and cost effectively delineate the horizontal and vertical extent of creosote DNAPL in soil/groundwater; delineate/differentiate creosote DNAPL constituents within the extent of DNAPL; delineate dissolved-phase versus free phase DNAPL compounds in the subsurface. The complexity of investigation and the extent of creosote DNAPL magnifies the time and cost of the application of conventional investigative techniques. The application of CPT/LIF at the site allowed a comparison between CPT/LIF and more conventional investigative techniques. A diesel-like fuel phase and a creosote-like phase were detected in two major areas of the site using CPT/LIF. As a result of the CPT/LIF program, three monitoring wells were installed to monitor the areas determined to be impacted by creosote. Good lithologic and chemical correlations were observed between the CPT/LIF data and sampling results. CPT/LIF, however, did not discriminate between free-phase and dissolved phase constituents.

\section{$3049 \quad$ V18/023996}

Demonstration of Innovative Monitoring Technologies at the Savannah River Integrated Demonstration Site

Rossabi, J.; Jenkins, R.A.; Wise, M.B.; Guerin, M.R.; Kearl, P.M.; Ballard, S.; Elbring, G.J.; Frye, G.C.; Milanovich, F.P.; Daley, P.F.; Ramirez, A.L.; Daily, W.D.; Kaplan, E.; Neilsen, B.; Evans, J.; Olsen, K.B.

Westinghouse Savannah River Company, Aiken, SC; Oak Ridge National Laboratory, Oak Ridge, TN; Sandia National Laboratories, Albuquerque, NM; Lawrence Livermore National Laboratory, Livermore, CA; Brookhaven National Laboratory, Upton, NY

WSRC-TR-93-671; 95 pp. (1993)

This report summarizes the results of field demonstrations of technologies that address the measurement of both physical and chemical parameters related to subsurface characterization and monitoring as well as in situ sampling methods. Several different platforms were targeted for the deployment of these sensors including placement directly in the subsurface, in wells, and at the surface. The following categories of instruments have been demonstrated as part of this program: (1) instruments that monitor physical parameters by measuring surrogate parameters, (2) instruments that capture liquid or vapor samples from the subsurface with minimal invasiveness, and (3) instruments that analyze chemical concentration. Many of the technologies are licensed to private industry and are mature enough to begin technology transfer and to initiate progress toward regulatory acceptance.

3050

V18/022629

Demonstration of Insitu Bioremediation of $\mathrm{CCl} 4$ at the Hanford Site

Hooker, B.S.; Skeen, R.S.; Truex, M.J.; Peyton, B.M.

Pacific Northwest Laboratory, Richland, WA

CONF-941124; Insitu Remediation: Scientific Basis for Current and Future Technologies, G.W. Gee and N.R. Wing (eds.), Proceedings of the 33rd Hanford Symposium on Health and the Environment, Pasco, WA, November 7-11, 1994. Battelle Press, Columbus, OH, Part 1, 704 pp.; (pp. 281-292) (1994)

The US Department of Energy's Volatile Organic Compound Arid Integrated Demonstration Program is developing an in-situ bioremediation technology to meet the need for a cost-effective method to clean groundwater contaminated with chlorinated solvents, nitrates, or other organic and inorganic contaminants. Currently, a field demonstration of the technology is being conducted at the Hanford Site in southeastern Washington state. The goal of this demonstration is to stimulate native denitrifying microorganisms to destroy carbon tetrachloride and nitrate. Contaminants are destroyed by mixing an electron donor (acetate) and an electron acceptor (nitrate) into the aquifer, using a matrix of recirculation wells. This work also evaluates the effectiveness of applying scale-up techniques developed in the petrochemical industry to bioremediation. The scale-up process is based on combining fluid mixing and transport predictions with numerical descriptions for biological transport and reaction kinetics. This paper focuses on the necessity of this design approach to select nutrient feeding strategies that limit biofouling while actively destroying contaminants.

3051

V18/023455

Design Study for a Medium-Scale Field Demonstration of the Viscous Barrier Technology

Moridis, G.J.; Yen, P.; Persoff, P.; Finsterie, S.; Williams, P.; Myer, L.; Pruess, K.

Lawrence Berkeley National Laboratory, Berkeley, CA; Bechtel Corporation, San Francisco, CA

LBNL-38916; 104 pp. (September 1996)

This report is the design study for a medium-scale field demonstration of Lawrence Berkeley National Laboratory's new subsurface containment technology for waste isolation using a new generation of barsier liquids. The test site is located in central California in a quarry owned by the Los Banos Gravel Company in Los Banos, Califomia, in heterogeneous unsaturated deposits of sand, silt, and gravel typical of many of the DOE cleanup sites and particularly analogous to the Hanford site. The goals of the field demonstration are: (a) to demonstrate the ability to create a continuous subsurface barrier isolating a medium-scale volume $(30 \mathrm{ft}$ long by $30 \mathrm{ft}$ wide by $20 \mathrm{ft}$ deep (i.e., $1 / 10$ th to $1 / 8$ th the size of a buried tank at the Hanford Reservation) in the subsurface, and (b) to demonstrate the continuity, performance, and integrity of the barrier. 


\section{2}

V18/022777

Design and Construction of a Large Scale Groundwater Remediation System

Leach, J.D.; Loftin, D.C.; Watkin, G.W.; Lanning, T.E. Jacobs Engineering Group Inc., Martinez, CA; Jacobs Engineering Group Inc., Sacramento, CA; U.S. Air Force, Atwater, CA

CONF-960804 (Vol. 2); Spectrum '96: Nuclear and Hazardous Waste Management, Proceedings of an International Topical Meeting, Seattle, WA, August 18-23, 1996. American Nuclear Society, La Grange Park, IL, Vol. 2, 873 pp.; (pp. 1302-1305) (1996)

This paper presents a case study of the implementation of a large scale groundwater extraction, treatment and injection system for a trichloroethene (TCE) contamination plume at an Air Force Base in the western United States. The project was initiated to comply with CERCLA. The paper addresses site conditions; Record of Decision (ROD) requirements; design considerations; and challenges associated with budgetary, regulatory and public involvement constraints. The paper explores the reasons groundwater clean up is generally expensive, time consuming and challenging. Background information, system design concepts and evolution, and commentary on challenges encountered along the way are included. The resulting story provides insight into the overall process, time-frame, and costs that are all required to successfully implement a final remedial action once a contamination problem has been identified.

\section{3}

V18/024295

Design, Installation and Operational Methods of Implementing Horizontal Wells for Insitu Groundwater and Soil Remediation

Larson, R.B.

Levine-Fricke, Tampa, FL

CONF-9611118; HazMat West '96, Proceedings of an International Environmental Management and Technology Conference and Exhibition, November 5-7, 1996. Advanstar Expositions, Duluth, MN, 544 pp.; (pp. 355-362) (1996)

The design and installation of horizontal wells is the primary factor in the efficiency of the remedial actions. Often, inadequacies in the design and installation of remediation systems are not identified until remedial actions have commenced, at which time, required modifications of operational methods can be costly. The parameters required for designing a horizontal well remediation system include spatial variations in contaminant concentrations and lithology, achievable injection and/or extraction rates, area of influence from injection and/or extraction processes, and limitations of instaliation methods. As with vertical wells, there are several different methods for the installation of horizontal wells. This paper will summarize four installation methods for horizontal wells, including four sites where horizontal wells have been utilized for in-situ groundwater and soil remediation.

\section{4}

\section{V18/022044}

Detection of Mercury Compounds Using

\section{Invertase-Glucose Oxidase-Based Biosensor}

Amine, A.; Cremisini, C.; Palleschi, G.

Faculte des Sciences et Techniques, Department Biologie, Mohammadia, Morócco; Energie Nucleare e delle Energie Alternative (ENEA), Rome, Italy; Universita di Napoli-Federico II, Naples, Italy

CONF-9506232; Environmental Monitoring and Hazardous Waste Site Remediation, T. Vo-Dinh and R. Niessner (eds.), Proceedings of a Conference of the Society of Photo-Optical Instrumentation Engineers, Munich, Germany, June 19-23, 1995. International Society for Optical Engineering, Bellingham, WA, 613 pp.; (pp. 209-220) (1995)

Mercury compounds have been determined with an electrochemical biosensor based on invertase inhibition. When invertase is in presence of mercury its activity decreases; this causes a decrease of glucose production which is monitored by the glucose sensor and correlated to the concentration of mercury in solution. Parameters as $\mathrm{pH}$, enzyme concentration, substrate concentration, and reaction and incubation time were optimized. Mercury compounds determination using soluble or immobilized invertase were reported. Results showed that the inhibition was competitive and reversible. Mercury compounds can be detected directly in aqueous solution in the range $2-10 \mathrm{ppb}$.

\section{5}

V18/023617

Determination of Kinetic Coefficients for the Reduction and Removal of Uranium from Water by the Desulfovibrio Desulfuricans Bacteria

Tucker, M.D.; Barton, L.L.; Thomson, B.M.

Sandia National Laboratories, Albuquerque, NM

CONF-951023 (Vol. 8); WEFTEC '95, Proceedings of the 68th Annual Conference and Exposition of the Water Environment Federation, Miami Beach, FL, October 21-25, 1995. Water Environment Federation, Alexandria, VA, Vol. 8, 498 pp.; (p. 304) (1995)

Uranium contamination of groundwater and surface water from abandoned uranium mill tailings piles is a serious concern in many areas of the western United States. U(VI) is soluble in water and, as a result, is relatively mobile in the environment. U(IV), however, is generally insoluble in water and, therefore, is not subject to aqueous transport. In recent years, researchers have discovered that certain microorganisms, such as the sulfate-reducing bacteria Desufiovibrio desulfricans, can mediate the reduction of U(VI) to U(IV) by anaerobic respiration. Although the ability of this microorganism to reduce U(VI) has been studied in some detail by previous researchers, the kinetics of the reaction have not been characterized. The purpose of this research was to perform kinetic studies on Desulfiovibrio desulfricans during simultaneous reduction of sulfate and uranium and to determine the mineral phase of uranium after it has been reduced. The studies were conducted in a laboratory-scale chemostat under substrate-limited growth conditions with pynvate as the substrate. The maximum rate of substrate utilization $(k)$ was determined to be 4.70 per day while the half-velocity constant (Ks) was $140 \mathrm{mg}$ CODA. The yield coefficient $(Y)$ was determined to be $0.17 \mathrm{mg}$ cells $/ \mathrm{mg}$ COD while the endogenous decay coefficient (kd) was found to be 0.072 per day. After reduction, U(IV) precipitated from solution in the uraninite (UO2) phase as predicted by 
thermodynamics. Uranium removal efficiency as high as $90 \%$ was achieved in the chemostat. (Complete text)

\section{6}

V18/024297

Development of Risk-Based Cleanup Levels for Petroleum-Related Contaminants in Soil and Groundwater

Lau, V.; Hoffman-Kiefer, A.

CONF-961149; SETAC 17: Partnerships for the Environment Science, Education, and Policy, Proceedings of the 17th Annual Meeting of the Society of Environmental Toxicology and Chemistry, Washington, DC, November 17-21, 1996. Society of Environmental Toxicology and Chemistry, Pensacola, FL, 378 pp.; (p. 153) (1995)

The US Environmental Protection Agency's (EPA) Office of Underground Storage Tanks (USTs) has provided final guidance for cleanup of USTs based on individual state-approved programs. This allows cleanup levels to fluctuate by several orders of magnitude from state to state depending on the local soil, climate, geology, and demographics of the region. A recent study conducted by the Lawrence Livermore National Laboratory in Califomia indicates that releases of petroleum-related contaminants from leaking USTs rarely pose an actual human health concern. The study recommends that the American Society for Testing and Materials (ASTM) Risk-Based Corrective Actions (RBCA) framework be applied on UST contaminated sites to provide a systematic, consistent approach that can be adopted on a state level, but permits local implementation. The authors have adopted the RBCA approach to estimate cleanup levels for key petroleum-related constituents including total petroleum hydrocarbon (TPH); benzene, toluene, ethylbenzene, and total xylene (BTEX); and polycyclic aromatic hydrocarbons (PAHs). A tier 2 analysis using Jury et al.'s Behavior Assessment Model (BAM) was used to provide an upper bound risk-based cleanup levels for these compounds based on a sophisticated mass-balance equations. It is their contention that risk-based cleanup levels are significantly higher than guidance levels previously approved by state agencies.

3057

V18/022744

Development of Technologies for Groundwater Cleanup by Natural Sorbents

Borisov, V.N.; Bezdenezhnykh, V.S.; Vasiliev, A.P.; Laptev, N.N.; Petrov, P.V.

Institute of Technical Physics, Snezhinsk, Russian Federation

CONF-960804 (Vol. 2); Spectrum '96: Nuclear and Hazardous Waste Management, Proceedings of an International Topical Meeting, Seattle, WA, August 18-23, 1996. American Nuclear Society, La Grange Park, IL, Vol. 2, 873 pp.; (pp. 951-955) (1996)

The results of investigating effectiveness of cleanup of model aqueous solutions from radionuclides and heavy metals for some of the Ural natural minerals under static conditions are represented. The mathematical model of the cleaning water processes are being developed which will enable to change-over to design pilot and then industrial facilities.
3058

V18/024079

Development of an Integrated, Insitu Remediation Technology: Task 5, Cost Analysis - Topical Report, September 26, 1994-May 25, 1996

Quinton, G.; Schultz, D.S.; Landis, R.C.; Griffith, R.; Shoemaker, S.H.

DuPont Company, Wilmington, DE; Monsanto Company, St. Louis, MO

DOE/MC/31185-5389; 30 pp. (1997)

Contamination in low permeability soils poses a significant technical challenge to in situ remediation efforts. Poor accessibility to the contaminants and difficulty in delivery of treatment reagents have rendered existing in situ treatments such as bioremediation, vapor extraction, and pump and treat rather ineffective when applied to low permeability soils present at many contaminated sites. The Lasagna [TM] technology is an integrated in situ treatment in which established geotechnical methods are used to install degradation zones directly in the contaminated soil, and electro-osmosis is utilized to move the contaminants back and forth through those zones until the treatment is completed. This topical report presents the results of an engineering evaluation and cost analysis of the vertically configured treatment process completed by the DuPont Company. The cost evaluation was prepared by developing a cost optimization model of the overall treatment process. This model considers various input parameters such as soil properties, depth of contamination, cost for emplacing electrodes and treatment zones, required purge water volume, time constraints to achieve cleanup, and cost of power. Several example cases were run using the cost model to provide representative cost ranges for applying the technology to clean up trichloroethene contamination in clay. These costs are estimated to range from $\$ 40$ to $\$ 95$ per cubic yard of soil for a 1-acre site, with cost depending on depth of contamination (cost range valid from 15 to $45 \mathrm{ft}$ ), method of electrode/treatment zone emplacement (cost range valid for Lasagna [TM] Phase I emplacement and optimized emplacement techniques), and time available to complete remediation (cost range valid for one- and three-year timeframe).

\section{V18/024078}

Development of an Integrated, Insitu Remediation Technology: Task 9-II, TCE Degradation Using Non-Biological Methods - Topical Report, September 26, 1994-May 25, 1996

Orth, R.G.; McKenzie, D.E.

Monsanto Company, St. Louis, MO

DOE/MC/31185-5393; 25 pp. (1997)

Contamination in low permeability soils poses a significant technical challenge to in situ remediation efforts. Poor accessibility to the contaminants and difficulty in delivery of treatment reagents have rendered existing in situ treatments such as bioremediation, vapor extraction, and pump and treat rather ineffective when applied to low permeability soils present at many contaminated sites. The technology is an integrated in situ treatment in which established geotechnical methods are used to install degradation zones directly in the contaminated soil, and electro-osmosis is utilized to move the contaminants back and forth through those 
zones until the treatment is completed. The use of zero valence iron for reductive dechlorination of aliphatic chlorinated hydrocarbons is currently under investigation by a number of research groups as a potential method of in situ treatment of contaminated groundwater. The reactor appears to involve the transfer of electrons to chloro-aliphatic compounds by the oxidation of zero valence iron to ferrous iron $[\mathrm{Fe}(2+)]$. Our studies have indicated that this reaction is consistent with those of corrosion, and as such, can be influenced or increased by the presence of small amounts of metals ( $5 \%$ by weight) such as copper, tin, silver, gold and palladium coated on the iron surface.

Incomplete coverage of the iron surface with a more electropositive metal results in an open galvanic cell, which increases the oxidation of iron and facilitates and increases the concurrent reduction of trichloroethylene and other chlorinated aliphatic compounds to the corresponding alkenes and alkanes. Our results show that plating more electropositive metals onto certain iron surfaces results in approximately a factor of ten increase in the dechlorination rate of small organochlorine compounds such as TCE.

\section{0}

V18/024082

Development of an Integrated, Insitu Remediation Technology: Task 9-I, TCE Degradation Using Non-Biological Methods - Topical Report, September 26, 1994-May 25, 1996

Shapiro, A.P.; Sivavec, T.M.; Baghel, S.S.

Monsanto Company, St. Louis, MO; General Electric Company, Corporate Research and Development Center, Schenectady, NY

DOE/MC/31185-5392; 30 pp. (1997)

Contamination in low permeability soils poses a significant technical challenge to in-situ remediation efforts. Poor accessibility to the contaminants and difficulty in delivery of treatment reagents have rendered existing in-situ treatments such as bioremediation, vapor extraction, pump and treat rather ineffective when applied to low permeability soils present at many contaminated sites. This technology is an integrated in-situ treatment in which established geotechnical methods are used to install degradation zones directly in the contaminated soil and electroosmosis is utilized to move the contaminants back and forth through those zones until the treatment is completed. The present Draft Topical Report for Task No. 9 summarizes laboratory investigations into TCE degradation using nonbiological methods. These studies were conducted by the General Electric Company. The report concentrates on zero valent iron as the reducing agent and presents data on TCE and daughter product degradation rates in batch experiments, column studies, and electroosmostic cells. It is shown that zero valent iron effectively degrades TCE in electroosmotic experiments. Daughter product degradation and gas generation are shown to be important factors in designing field scale treatment zones for the Lasagna [TM] process.

\section{1}

\section{V18/023623}

Direct Push Technology in Air Sparging Pilot Studies for Groundwater Remediation

Joiner, D.P.; O'Keefe, T.L.; Smith, M.D.

Baker Environmental, Inc., Corapolis, PA
Iron and Steel Engineer (December 1996):53-58 (December 1996)

The application of direct push technology for the installation of well points for an air sparging pilot study conducted at the US Naval Base in Norfolk is discussed. Since system design parameters are empirically based, the implementation of air sparging generally requires a pilot study to determine site-specific design parameters. To perform the air sparging pilot study more cost-effectively, the use of direct push technology was tested. Direct push technology was used for the installation of test wells and monitoring points for the pilot study. Because site conditions necessitated the installation of air sparging points to depths of $40 \mathrm{ft}$, the technical and economic benefits of the direct push method were compared with conventional drilling methods. The use of the direct push method provided significant cost savings and demonstrated that direct push technology can be used successfully in pilot study applications. Recommendations are made on the use of direct push technology in similar pilot study applications.

3062 V18/023998

Direct Sampling Ion Trap Mass Spectrometer for the Rapid Analysis of Volatile Organic Compounds in Groundwater Samples

Eddy-Dilek, C.A.; Rossabi, J.; Keenan, M.A.

Westinghouse Savannah River Company, Aiken, SC

WSRC-TR-93-563; 16 pp. (1993)

Analytical results of volatile organic compounds (VOC) concentrations in groundwater samples from $\mathrm{A} / \mathrm{M}$ Area obtained using a direct sampling ion trap mass spectrometer (DSITMS) and a gas chromatograph (GC) with an electron capture detector (ECD) were comparable. Replicate water samples were collected at the Integrated Demonstration Site during four bi-weekly sampling periods and analyzed by both instruments. The calibration curves prepared for both the DSITMS and GC-ECD are essentially linear over the concentration range analyzed. The advantage of the DSITMS over the GC-ECD method is the rapid sample analysis time of the DSITMS. In order to validate the technology for use in the sample minimization efforts at SRS, duplicate groundwater samples from selected compliance wells were analyzed by DSITMS and GC-ECD. The DSITMS is appropriate to use for field screening water samples before offsite analysis. These analytical results will be compared with results from offsite labs contracted to perform contract lab program (CLP) analyses of regulatory samples when these analyses are available.

\section{3}

V18/021821

Don't Give up on Pump and Treat

Marquis, S.A., Jr.

Soil and Groundwater Cleanup (August/September 1995); 5 pp. (September 1995)

A computer modeling study was undertaken by McLaren/Hart Environmental Engineering, Irvine, $\mathrm{CA}$ to evaluate the effectiveness of pump and treat, in situ bioremediation, and pump and treat combined with in situ bioremediation to clean up a chemical plume. The study also examined how injection and extraction well locations and injected dissolved oxygen concentrations affect remediation, and sought to identify the 
factors that limit the applicability and influence the success of the three technologies. To ensure that direct comparisons could be made of the effectiveness of the three methods, the number of wells, injection or pumping rates and hydrologic input parameters were the same for each scenario. The scenarios were ranked in terms of plume control and cleanup effectiveness, based on modeling results and estimated cost for one year using a numerical point system. Although the best approach for groundwater cleanup is highly site-specific and depends on the hydrogeologic, microbiological and time and budgetary constraints, the modeling results suggest that scenarios that included pump and treat were superior to the other scenarios in containing the migration of the plume.

\section{4}

V18/023917

Effect of Natural Variability on Statistical Analysis of Groundwater Quality: A Case Study of a Coastal Plain Landfill

Hogue, S.S.; McMillan, T.B.; Nesbitt, S.R.

City of Newport News, Newport News, VA; Malcolm Pirnie, Inc., Newport News, VA

CONF-950177; Waste Tech '95, Proceedings of a Conference, New Orleans, LA, January 23-25, 1995. Environmental Industry News, Washington, DC, 530 pp.; (pp. 385-431) (1995)

A case study is presented describing regulatory conflicts which arise when strict compliance criteria are applied to groundwater systems that demonstrate natural variability in water quality. Many older landfills with monitoring plans approved under pre-existing regulations were designed to use qualitative assessment in attributing differences in water quality to natural variability or contamination. In the transition to new RCRA Subtitle $D$ regulations many of these landfills were required to apply quantitative statistical analyses to water quality data with results often indicating statistically significant variation between up and downgradient wells. The current regulatory framework triggers assessment monitoring for each sampling event whenever variability in leachate indicator parameters between up and downgradient well locations is statistically significant, regardless of the cause of the statistical variation. Consequently, many landfills have been required to initiate costly Assessment Monitoring programs. An evaluation of groundwater quality data is presented for a 220 -acre coastal plain landfill performed in response to a statistically significant change in groundwater quality due to natural variability. Historical groundwater quality data pre-dating landfill operations are presented and analyzed. Although specific conductivity, $\mathrm{pH}$ and boron were found to vary significantly over relatively short distances at the landfill site, these statistically significant variations were found to be due to low groundwater flow rate and variable composition of coastal plain sediments within which the monitoring wells were screened. Intra-well comparisons as well as altemative statistical and laboratory methods were used to demonstrate the condition results from natural variability.

\section{$3065 \quad \mathrm{~V} 18 / 02262$}

Effect of Pneumatic Fracturing When Applied to Groundwater Aquifers

Keffer, E.B., III; Liskowitz, J.J.; Fitzgerald, C.D.
Accutech Remedial Systems, Inc., Keyport, NJ

CONF-960393 (Part 2); Contaminated Soils and Groundwater: Analysis, Fate, Environmental and Public Health Effects, and

Remediation, Proceedings of the Sixth Annual West Coast Conference, Newport Beach, CA, March 11-14, 1996. Association for the Environmental Health of Soils, Amherst, MA, Part 2, 226 pp.; (p. 24) (1996)

Pneumatic Fracturing, an innovative in-situ treatment technology, was originally developed as a process to enhance remediation of the vadose zone. Recent application to saturated zones has provided evidence that the process can also effectively enhance remediation of saturated zones. The characteristics that are changed include an aquifer's transmissivity, hydraulic conductivity and relative storage function. Additional data and observations indicate that Pneumatic Fracturing also lessens the effects of heterogeneities making them more isotropic. The combined effect of these changes is that an area of an aquifer that has been pneumatically fractured can be dewatered quicker and more effectively. This result can then be integrated with soil vapor extraction or other remedial technologies to provide effective site remediation. When Pneumatic Fracturing has been applied to saturated zones containing significant volumes of free product, the magnitude of the change in product recovery rates has been observed to be several orders of magnitude. This paper provides a brief history of the Pneumatic Fracturing technology. Slug test and pump test data collected during pre-fracture and post-fracture tests is presented which supports the change in an aquifer's transmissivity, hydraulic conductivity. Further information is provided supporting the theory that Pneumatic Fracturing effects the heterogeneity of an aquifer. An explanation based upon the cubic law of flow in fractured media is provided for some of the non-empirical assumptions. Finally, a discussion of possible Pneumatic Fracturing applications is presented.

3066 V18/022772

Effect of Subsurface Electrical Heating and Steam Injection on the Indigenous Microbial Community

Krauter, P.; MacQueen, D.H.; Bishop, D.

Lawrence Livermore National Laboratory, Livermore, CA

CONF-960804 (Vol. 2); Spectrum '96: Nuclear and Hazardous Waste Management, Proceedings of an Intemational Topical Meeting, Seattle, WA, August 18-23, 1996. American Nuclear Society, La Grange Park, IL, Vol. 2, 873 pp.; (pp. 1270-1274) (1996)

Electrical heating coupled with steam injection and vacuum extraction is a remediation technique successfully demonstrated at Lawrence Livermore National Laboratory (LLNL). This thermal technique rapidly processed about 3,600 gallons of gasoline located in groundwater and sediments 100 feet below the surface. Sediments, containing residual gasoline, located beyond the perimeter of the treatment area are potentially suitable for a bioremediation strategy. Since the potential for contaminant bioremediation in steam treated subsurface environments has not been explored, the thermal remediation treatment of the gasoline spill at LLNL provided an opportunity to study microbial community changes in the subsurface environment. Many terrestrial microorganisms die, or become metabolically inactive, if heated for a sufficient time at temperatures of 62-100 degrees $C$; thus thermal remediation 
techniques are expected to significantly alter the microbial community structure. We studied changes in community structure and population abundance before and after steam treatment. A 90-98\% decline in total microorganism populations in hot (up to 94 degrees $C$ ) subsurface sediments occurred, and the microbial diversity of culturable microorganisms obtained from sediment cores before and after thermal treatment shifted from gram-negative to gram-positive types. Surviving thermotolerant microorganisms were found to possess elevated concentrations of saturated fatty acids in their lipid membranes. We also observed that some thermotolerant microorganisms were capable of degrading gasoline compounds.

\section{7 \\ V18/022502}

\section{Effectiveness of Chemically Enhanced Mobilization of} Hydrocarbons

Kan, A.T.; Hunter, M.A.; Fu, G.; McRae, T.A.; Tomson, M.B.

Rice University, Department of Environmental Science and Engineering, Houston, TX

CONF-950333; SPE-29769; Government and Industry Working Together to Find Cost Effective Approaches to Protecting the Environment, Proceedings of the Society of Petroleum Engineers (SPE)/U.S. Environmental Protection Agency (EPA) Exploration Production Environmental Conference, Houston, TX, March 27-29, 1995. SPE, Richardson, TX, 797 pp.; (pp. 757-766) (1995)

Hydrocarbon spills and leaks are a major source of groundwater pollution for urban and industrial regions of the United States. Clean-up is most often attempted using pump-and-treat methods with numerous wells and a central treatment facility. Such procedures are notoriously inefficient when hydrocarbons are trapped in oil ganglia, capillaries, or irreversibly sorbed. The residual hydrocarbons cannot be displaced under reasonable hydraulic gradients. Therefore, it is important to develop a more efficient method of removing such a pollutant source. Miscible solvents and surfactants are often proposed as the chemical enhancer for pump and treat. Several researchers have applied the surfactant flush in both the laboratory soil columns and field test plots. The efficiency of surfactants usually diminished within 20 pore volumes and a significant fraction of contaminant was not mobilized. There may exist some thermodynamic or kinetic limitations in surfactant flush. Research has shown that surfactant often adsorbed to soil and altered the adsorption/desorption properties of soil. These processes may be reversed by controlling the $\mathrm{pH}$ and ionic strength. Miscible solvent has been shown to be very effective in laboratory tests. There are strong reasons to believe that a combination of several enhancement regimes will have substantial performance advantages. Just as with bioremediation, different chemical enhancement methods will probably be better suited to particular combinations of contaminant types and aquifer characteristics. This paper will discuss the effectiveness of chemical enhancement treatments and possible limitations.

\section{8 \\ V18/021622}

Effects of Closure Cap and Liner on Contaminant Release Rates from Grouted Wastes

Yu, A.D.; Fowler, J.R.; Bignell, D.T.

Westinghouse Savannah River Company, Aiken, SC
WSRC-MS-96-0042; CONF-960482; High Performance

Computing, Proceedings of a Society of Computer Simulation (SCS) Muiticonference, New Orleans, LA, April 8-11, 1996; (8 pp.)

(1996)

This paper describes a groundwater modeling study of waste disposal concepts using grouted waste forms. The focus of the study is on the effects of clay caps and concrete vaults on contaminant migration. The authors modeled three waste disposal scenarios: (1) Grouted waste was solidified in an earthen trench and covered with soil with no vault and no cap; (2) grouted waste was solidified in an earthen trench then the entire waste disposal facility was closed under a clay cap; and (3) grouted waste was solidified in a concrete vault and protected by the same closure as in 2 . Because of the huge contrast in hydraulic conductivities and highly non-linear multi-phase flow characteristics, these waste disposal concepts presented a difficult problem for numerical simulation. Advanced fluid flow and contaminant transport codes were used to solve the problem. Among the codes tested, ECLIPSE out-performed other codes in speed, accuracy (smaller material balance errors) and capability in handling sophisticated scenarios. The authors used nitrate as a tracer for the simulation. Nitrate does not adsorb in the solid phase and does not decay. As a result, predicted release rate based on nitrate is conservative. They also assumed that the facility is intact for 10,000 years. In other words, properties of the materials used for this study do not change with time. Predicted peak flux for the no vault and no closure case was $5.8 \times 10(\mathrm{E}-4)$ per year at 12 years. If a clay cap was installed, predicted peak flux was $8.5 \times 10$ (E-5) per year at 110 years. If the grout was disposed in a concrete vault and covered by a clay cap, predicted peak flux became $4.4 \times 10$ (E-6) per year at 8,000 years. Both concrete liner and clay cap can reduce the rate of contaminant release to the water table and delay the peak time.

3069 V18/022646

Efficacy Monitoring of Insitu Fuel Bioremediation

Mueller, J.G.; Borchert, S.M.; Heard, C.

SBP Technologies, Inc., Gulf Breeze, FL

CONF-960393 (Part 1); Contaminated Soils and Groundwater:

Analysis, Fate, Environmental and Public Health Effects, and

Remediation, Proceedings of the Sixth Annual West Coast Conference, Newport Beach, CA, March 11-14, 1996. Association for the Environmental Health of Soils, Amherst, MA, Part 1, 257 pp.; (p. 13) (1996)

The wide-scale, multiple-purpose use of fossil fuels throughout the industrialized world has resulted in the inadvertent contamination of myriad environments. Given the scope and magnitude of these environmental contamination problems, bioremediation often represents the only practical and economically feasible solution. This is especially true when depth of contamination, magnitude of the problem, and nature of contaminated material preclude other remedial actions, short of the no-response altemative. From this perspective, the effective, safe and scientifically valid use of in situ bioremediation technologies requires cost-efficient and effective implementation strategies in combination with unequivocal approaches for monitoring efficacy of performance. Accordingly, with support from the SERDP program, the authors are field-testing advanced in situ bioremediation strategies and new approaches in efficacy monitoring that employ techniques in stable carbon and 
nitrogen isotope biogeochemistry. One field demonstration has been initiated at the Navel Exchange (NEX) site in Port Hueneme, CA (US Navy's National Test Site). The objectives are: (1) to use stable isotopes as a biogeochemical monitoring tool for in situ bioremediation of refined petroleum (i.e., BTEX) and (2) to use vertical groundwater circulation technology to effect in situ chemical containment and enhanced in situ bioremediation.

\section{$3070 \quad \mathrm{~V} 18 / 022232$}

Efficacy of Monitoring Insitu Bioremediation of Fossil Fuel: Using the Mesocosm System

Borchert, S.M.; Mueller, J.G.; Coffin, R.B.; Trust, B.; Kelly, C.; Schultz, W.W.; Cifuentes, L.; Checkai, R.T.; Gervasoni, T.R.

SBP Technologies, Inc., Aberdeen Proving Ground, MD; SBP Technologies, Inc., Gulf Breeze, FL; U.S. Environmental Protection Agency, Environmental Research Laboratory, Gulf Breeze, FL; U.S. Navy, Naval Research Laboratory, Washington, DC; Texas A\&M University, College Station, TX; U.S. Army, Aberdeen Proving Ground, MD

CONF-951 139 (Vol. 2); Superfund 16: Proceedings of a Hazardous Waste Conference and Exhibition, Washington, DC, November 6-8, 1995. E.J. Krause and Associates, Bethesda, MD, Vol. 2, 817 pp.; (pp. 1165-1169) (1994)

With in situ bioremediation applications being recommended frequently out of practical and economic necessity (i.e., depth of contamination or nature of contaminated material precludes all other remedial actions short of the no-response alternative), cost-efficient and effective implementation strategies needed to be developed and/or refined. At the same time, unequivocal approaches for demonstrating in situ bioremediation of target contaminants need to be established. Toward this end, we have developed and refined innovative in situ soil and groundwater bioremediation strategies on a pilot and full-scale, including monitoring approaches using stable carbon isotope biogeochemistry to assess progress during in situ bioremediation of fossil fuels (more specifically PAHs and BTEX).

\section{1}

\section{V18/021077}

Electrodialysis-Ion Exchange for the Separation of Dissolved Salts

Baroch, C.J.; Grant, P.J.

Wastren, Inc., Westminster, $\mathrm{CO}$; Wastren, Inc., Hummelstown, PA

DOE/MC/321 12-96/C0632; CONF-9510108 (Vol. 1); Environmental Technology Through Industry Partnership, V.P. Kothari (ed.), Proceedings of a Conference, Morgantown, WV, October 3-5, 1995, Vol. 1, 312 pp.; (pp. 87-97) (October 1995)

The Department of Energy generates and stores a significant quantity of low level, high level, and mixed wastes. As some of the DOE facilities are decontaminated and decommissioned, additional and possibly different forms of wastes will be generated. A significant portion of these wastes are aqueous streams containing acids, bases, and salts, or are wet solids containing inorganic salts. Some of these wastes are quite dilute solutions, whereas others contain large quantities of nitrates either in the form of dissolved salts or acids. Many of the wastes are also contaminated with heavy metals, radioactive products, or organics. Some of these wastes are in storage because satisfactory treatment and disposal processes have not been developed. There is considerable interest in developing processes that remove or destroy the nitrate wastes. Electrodialysis-Ion Exchange (EDIX) is a possible process that should be more cost effective in treating aqueous waste streams. This report describes the EDIX process.

3072

V18/021625

Electrokinetic Remediation II: Amphoteric Metals and Enhancement with a Weak Acid

Wilson, D.J.; Rodriguez-Maroto, J.M.; Gomez-Lahoz, C.

Vanderbilt University, Nashville, TN; Universidad de Malaga, Malaga, Spain

Separation Science and Technology 30(16):3111-3128 (September 1995)

A one-dimensional model is developed for the electrokinetic treatment of aquifers contaminated with an ionic salt.

Electrokinetic removal of amphoteric metals such as zinc and lead is simulated. The use of a weak acid (acetic acid) to neutralize a portion of the $\mathrm{OH}$-generated electrolytically in the cathode compartment is explored in connection with the electrokinetic removal of nonamphoteric metals such as copper and cadmium.

3073 V18/022195

Electrokinetic Remediation of Soils, Sludges and Groundwater

Clarke, R.L.; Kimmel, S.; Lageman, R.; Smedley, S.

Geokinetics, Orinda, CA; Fluor Daniel, Inc., Irvine, CA; Geokinetics, Reisen, Netherlands; SRI International, Menlo Park, CA

CONF-960426; Proceedings of the 58th Annual Meeting of the American Power Conference, A.E. McBride (ed.), Chicago, IL, April 9-11, 1996. American Power Conference, Chicago, Il, Vol. 58-I, 767 pp.; (pp. 347-352) (1996)

Electrokinetic remediation techniques are now rapidly emerging as a favorable and commercially applicable ground and groundwater remediation technology. Unfortunately, through common use the term, electrokinetic remediation embodies many different approaches. The approach discussed here is based on using the Pool Process to manage and maintain optimal soil and electrolyte conditions. Geokinetics has applied this process commercially for several years, and it has been proven to be highly effective in managing, maintaining and/or modifying soil chemistry. Although the early focus was exclusiveiy on the recovery of ionic species, the versatility of the Pool Process is such that a variety of agents can be added to soil and electromigrated into place to considerably extend the range of treatment options. The purpose of this paper is to introduce Geokinetics Intemational, Inc.; outline the important milestones in the development of the technology; outline the Pool Process; show how this is combined with EIX electrolyte management to recover ionic contamination; and outline other applications of the Pool Process in which the authors are conducting advanced research and field testing. 
3074

V18/023783

\section{Electrokinetic Treatment of Hazardous Wastes in Soil and Groundwater}

Loo, W.W.

Environment and Technology Services, San Francisco, CA

CONF-9504134; HAZMACON '95, T. Bursztynsky and M.L. Loss (eds.), Proceedings of the Twelfth Hazardous Materials

Management Annual Conference and Exhibition, San Jose, CA, April 4-6, 1995. Association of Bay Area Govemments, Oakland, CA, 790 pp.; (pp. 147-158) (1995)

Electrokinetic (EK) treatment processes are recognized by the U.S. Department of Defense, U.S. Department of Energy, and the U.S. Environmental Protection Agency as the most potentially cost effective treatment of hazardous wastes. Recently, EK has attracted the attention of Dupont, General Electric, and Monsanto for various aspects of hazardous waste treatment. Electrolysis and electro-osmosis are known electrokinetic processes. Electrolysis is one of the principal industrial processes used in the production of aluminum, chlorine, metal plating, welding, corrosion protection, etc. Electro-osmosis is a very well established process used to dewater and stabilize the clayey foundations of buildings and structures. These processes are very effective in the treatment of hazardous metals and organic compounds in soil, sludge, and water. Electrolysis can be applied in both permeable and impermeable media. It can be used as a neutralization process for $\mathrm{pH}$ control. It can also be used for the isolation or capture of metallic ions, or positively charged ions, at and near the cathode electrode and negatively charged ions at or near the anode electrode. Electrolysis will also oxidize petroleum hydrocarbons and benzene-based organic chemicals such as PCBs, pesticides, and PAHs. Electro-osmosis can be used in the treatment of hazardous chemicals in silty and clayey material. The electro-osmotic process causes an imbalance of charge bonds in clayey material that results in clay compaction and chemical desorption. The compaction and desorption processes will reduce the cleanup time and are particularly successful in the desorption of organic chemicals and metals from clayey materials. This accelerates and improves the performance of typically inefficient pump and treat projects. Electrokinetic processes can be applied both above ground (exsitu) or in the subsurface (in situ). The following is a list of hazardous chemicals that can be effectively treated by the electrokinetic processes: (1) Chemical oxidation petroleum hydrocarbons such as gasoline, BTEX, diesel, fuel oil, and so on; (2) Chemical oxidation of benzene-based organic chemicals such as PAHs, pesticides, and PCBs, (3) Isolation, capture, and precipitation/stabilization of hazardous metals; and (4) Isolation/capture of common hazardous anions like nitrate and nitrite and capture/disinfection of pathogenic bacteria.

3075 V18/025548

Electrosorption of Chromium Ions on Carbon Aerogel Electrodes as a Means of Remediating Groundwater

Farmer, J.C.; Bahowick, S.M.; Harrar, J.E.; Fix, D.V.; Martinelli, R.E.; Vu, A.K.; Carroll, K.L.

Lawrence Livermore National Laboratory, Livermore, CA

CONF-9603236; Proceedings of a Symposium on Production and Use of Carbon-Based Materials for Environmental Cleanup, New
Orleans, LA, March 24-28, 1996; Energy and Fuels 11(2):337-347 (March-April 1997)

An electrically regenerated separation process has been developed for removing unwanted ions from aqueous waste streams as a minimally polluting, energy-efficient, and potentially cost-effective alternative to ion exchange, reverse osmosis, electrodialysis, and evaporation. Groundwater containing various anions and cations is passed through a stack of carbon aerogel electrodes, each having a very high specific surface area and exceptionally low electrical resistivity. After polarization of the stack, impurity ions are removed from the electrolyte by the imposed electric field and adsorbed on the electrode surfaces. Field tests have shown that hexavalent chromium can be selectively removed from contaminated groundwater with a $530 \mathrm{ppm}$ total dissolved solids (TDS) background. The concentration of $\mathrm{Cr}(\mathrm{VI})$ can be lowered from 35 to $2 \mathrm{ppb}$, well below the acceptable level for the regulatory surface water discharge limit of $11 \mathrm{ppb}$. The mechanism for $\mathrm{Cr}(\mathrm{VI})$ separation involves chemisorption on the carbon aerogel anode, a process that can be reversed by cathodic polarization. $\mathrm{Cr}(\mathrm{VI})$ removal is not based upon simple double-layer charging.

\section{6}

\section{V18/024139}

Emerging Technologies for Abatement of Atmospheric Chlorinated Volatile Organic Compound Emissions

Haselow, J.S.; Rossabi, J.; Jarosch, T.R.

Savannah River Laboratory, Environmental Sciences Section, Aiken, SC

CONF-920466; Waste Management and Environmental

Restoration, Proceedings of an Engineering and Technology

Conference, San Juan, Puerto Rico, April 9-11, 1992; (pp.

205-213) (1992)

Chlorinated volatile organic compounds (CVOCs) are the most pervasive subsurface contaminants within the Department of Energy Complex. Current remediation technologies for CVOCs ultimately produce a gas-phase stream containing CVOCs, either via vacuum soil venting from the unsaturated zone or groundwater recovery from the saturated zone and subsequent airstripping. Many states, including South Carolina, have permitted the direct discharge of the gaseous CVOCs to the atmosphere, where these compounds are decomposed through ultraviolet photolysis. However, the 1990 Clean Air Act Amendments will require that these emissions be abated through the best available technologies. Because of the ubiquity of subsurface CVOC contamination, a modest improvement can provide tremendous benefits over the currently utilized technologies of incineration, catalytic oxidation, and carbon adsorption. This need has motivated the development of diverse technologies for abatement of CVOC emission which may be classified as: free radical decomposition, carbon regeneration, biodestruction, membrane separation, and thermal catalytic oxidation technologies. The Savannah River Technology Center is systematically evaluating several technologies from each of these classes under the Integrated Demonstration Program that is funded by the DOE, Office of Technology Development. A review of the strengths and weaknesses of existing and emerging technologies is provided, as well as a discussion of the program for evaluating the emerging technologies. 
3077

V18/025295

Engineering Challenges of Implementing Insitu Bioremediation

Alvarez-Cohen, $\mathrm{L}$.

University of California, Berkeley, CA

Insitu Bioremediation: When Does It Work?, National Academy

Press, Washington, DC, 207 pp;; (pp. 136-152) (1993)

The use of in situ bioremediation to destroy groundwater contaminants essentially requires the creation and management of a subsurface bioreactor. Physical and chemical conditions within the subsurface environment can be manipulated to optimize microbial growth by using hydrodynamic or gas-phase controls. Requisite factors for successful application of in situ bioremediation include adequate aquifer permeability; a suitable microbial population; sufficient hydrodynamic control for plume containment and delivery of required electron donors, electron acceptors, and/or nutrients; and a complete monitoring system. Evaluating the progress of in situ bioremediation and proving that the microbes are responsible for contaminant degradation can be challenging because of the inaccessibility of the subsurface bioreactor, aquifer heterogeneities, and the wide range of potential contaminant fates. However, overlapping lines of evidence from a range of field-monitoring techniques may provide suitable indication of successful in situ bioremediation.

3078

V18/022643

Enhanced Intrinsic Bioremediation of Hydrocarbons with Oxygen Release Compound (ORC [R])

Koenigsberg, S.; Johnson, J.; Odencrantz, J.; Norris, R.D.

Regenesis Bioremediation Products, San Juan Capistrano, CA; GRAM, Inc., Albuquerque, NM; Tri-S Environmental Corporation, Newport Beach, CA; Eckenfelder, Inc., Nashville, TN

CONF-960393 (Part 3); Contaminated Soils and Groundwater: Analysis, Fate, Environmental and Public Health Effects, and Remediation, Proceedings of the Sixth Annual West Coast Conference, Newport Beach, CA, March 11-14, 1996. Association for the Environmental Health of Soils, Amherst, MA, Part 3, 366 pp.; (p. 25) (1996)

$O R C[R]$ is a unique formulation of magnesium peroxide that releases oxygen at a slow and controlled rate when hydrated. The compound is insoluble and simply releases oxygen while being converted to ordinary magnesium hydroxide which is also insoluble. The rate control feature is a function of the synthesis of the molecular matrix and not achieved by a coating process. ORC $[R]$ is packaged in exchangeable filter socks and is contacted with contaminated groundwater via an array of wells or trenches. A linear array of filter socks generates an oxygenated zone, that can last four months to a year as a function of contaminant flux, and supports the remediating microbial consortia. The objective of this oxygen barrier is plume cut-off, however, any significant reduction of contaminant mass mediated by the oxygen barrier will serve to pull the control point back towards the source; this may play an important role in the implementation of risk reduction strategies. The results presented here support the use of oxygen barrier systems to help manage plume migration and for the control of

point source contamination. The most extensively studied oxygen barrier to date, installed at a BTEX contaminated site in Belen, NM, produced a readily observable oxygen barrier and demonstrated an acceptable level of contaminant control during the course of the experiment.

\section{9 \\ V18/024625 \\ Enhancement of Biodegradation, Chapter 5}

Riser-Roberts, E.

Bioremediation of Petroleum Contaminated Sites, C.K. Smoley, Chelsea, MI, 464 pp.; (pp. 67-116) (1992)

This is a chapter in the book titled: Bioremediation of Petroleum Contaminated Sites by Eve Riser-Roberts. Enhancement of Biodegradation is covered in the following areas: Optimization of Soil Biodegradation, Optimization of Groundwater Biodegradation, and, Optimization of Freshwater, Estaurine, and Marine Biodegradation. An in-depth evaluation of the potential for microorganisms to remove anthropogenic organic compounds from a contaminated environment indicates that use of properly selected populations of microbes, and the maintenance of environmental conditions most conducive to their metabolism, can be an important means of optimizing biological treatment of organic wastes. Most bacteria in the subsurface are firmly attached to soil particles. As a result, nutrients must be brought to the microbes by advection or diffusion through the mobile phases, i.e., water and soil gas. In the simplest and perhaps most common case, the organic compound to be consumed for energy and cell synthesis is brought into aqueous solution by infiltrating water. At the same time. oxygen, the electron acceptor used to oxidize the carbon source is brought by diffusion through the soil gas. In the unsaturated zone. volatile organic compounds can also move readily as vapors in the soil gas. Below the water table all transport must be through liquid phases, and as a result, the prospects for aerobic metabolism are severely limited by the very low solubility of oxygen in water. In the final analysis, the rate of biological activity is controlled by: (1) the stoichiometry of the metabolic process; $(2)$ the concentration of the required nutrients in the mobile phases; (3) the advective flow of the mobile phases or the steepness of concentration gradients within the phases; (4) opportunity for colonization in the subsurface by metabolically capable organisms; and (5) toxicity exhibited by the waste or a co-occurring material.

V18/023561

Enhancing the Design of Insitu Chemical Barriers with Multicomponent Reactive Transport Modeling

Sevougian, S.D.; Steefel, C.I.; Yabusaki, S.B.

Pacific Northwest Laboratory, Richland, WA

CONF-941124; Insitu Remediation: Scientific Basis for Current and Future Technologies, G.W. Gee and N.R. Wing (eds.), Proceedings of the 33rd Hanford Symposium on Health and the Environment, Pasco, WA, November 7-11, 1994. Battelle Press, Columbus, OH, Part 2, 605 pp.; (pp. 883-911) (1994)

This paper addresses the need for systematic control of field-scale performance in the emplacement and operation of insitu chemical treatment barriers. In particular, it addresses the issue of how the local coupling of reaction kinetics and material heterogeneities in the laboratory can be accurately upscaled to the field. The authors 
have recently developed modeling analysis tools that can explicitly account for all relevant chemical reactions that accompany the transport of reagents and contaminants through a chemically and ${ }^{\circ}$ physically heterogeneous subsurface rock or soil matrix. These tools are incorporated in an enhanced design methodology for insitu chemical treatment technologies. The new methodology is demonstrated in the ongoing design of a field experiment for the In Situ Redox Manipulation (ISRM) project at the U.S. Department of Energy Hanford Site. The ISRM design approach, which systematically integrates bench-scale and site-characterization information, provides an ideal test for the new reactive transport techniques. The need for the enhanced chemistry capability is demonstrated by an example that shows how intra-aqueous redox kinetics can affect the transport of reactive solutes. Simulations are carried out on massively parallel computer architectures to resolve the influence of multiscale heterogeneities on multicomponent, multidimensional reactive transport. The technology will soon be available to design larger-scale remediation schemes.

\section{1}

\section{V18/025581}

Environmental Biomineralization and Microbial Remediation

Tazaki, $\mathrm{K}$.

Kanazawa University, Graduate School of Natural Science and Engineering, Ishikawa, Japan

Shigen To Sozai 112(12):1-9 (October 25, 1996)

The function of bacteria is to concentrate elements with high toxicity from the surrounding environment, detoxify them, and fix them to the deposit. This process is called biomineralization, and it plays a very important role in purification of the earth's environment. In this paper experiments in environmental pollution and biomineralization using bacteria are introduced. Examples of purifying polluted soil and water around uranium mines by bacteria and algae are provided. The corrosion of concrete due to thiobacillus thioreductant and thiobacillus thiooxidans is mentioned. Experimental results with respect to the water-purifying ability of charcoal, activated carbon, special materials (e.g., zeolites), and the use of plants in remediation are described. An example of preparing bio-minerals by the bacteria in active sludge is also cited. (This document is in Japanese).

\section{2}

\section{V18/024000}

Environmental Diagnostic Analysis of Groundwater Bacteria and Their Involvement in Utilization of Aromatic Compounds

Wear, J.E., Jr.

Westinghouse Savannah River Company, Aiken, SC

WSRC-TR-93-083; Thesis (Ph.D.); 187 pp. (May 1993)

The objective of this study was to examine the hypothesis that select functional groups of bacteria from pristine sites have an innate ability to degrade synthetic aromatics that often contaminate groundwater environments, due to exposure to naturally occurring recaicitrant aromatics in their environment. Groundwater was pumped at monthly intervals from twelve wells at four different sites. Two of these sites could be considered pristine. The other two sites were contaminated, one with trichloroethylene, the other with polyaromatic hydrocarbons and possible sulfur compounds. The bacteria in shallower wells tended to have both the greatest direct counts and heterotrophic viable counts. Acridine orange direct count differences between any of the wells were less than one order of magnitude. In contrast, viable counts had several orders of magnitude difference between wells. This illustrates that there are great variations in physiological states and metabolic needs of bacteria in these different aquifers. All but one of the wells studied demonstrated higher counts on low nutrient media than high nutrient media, suggesting the oligotrophic nature of these groundwater environments. This study demonstrates that subsurface microbial communities are capable of utilizing lignin and humic acid breakdown products. Utilizers of these compounds were found to be present in most of the wells tested. Even the deepest aquifer tested had utilizers present for all six of the aromatics tested. Highest counts for the aromatics tested were observed with the naturally occurring breakdown products of either lignin or humic acid. Carboxylic acids were found to be an important sole carbon source for groundwater bacteria possibly explained by the fact that they are produced by the oxidative cleavage of aromatic ring structures. The carbohydrate sole carbon sources that demonstrated the greatest densities were ones commonly associated with humics. This study indicates that utilization of naturally occurring aromatic compounds in the subsurface is an important nutritional source for groundwater bacteria. In addition, it suggests that adaptation to naturally occurring recalcitrant substrates is the origin of degradative pathways for xenobiotic compounds with analogous structure. This work has important implications for in situ bioremediation as a method of environmental cleanup.

3083

V18/024132

\section{Environmental Monitoring Sensors and Methods Development Program}

Los Alamos National Laboratory, Los Alamos, NM

LALP-95-39; 1 p. (1995)

Los Alamos has an arrangement of engineered barriers and a monitoring zone below those barriers to prevent, detect, locate, and remedy an leak from a containment system before it gets into the vadose zone or the groundwater. The monitoring zone consists of three engineered material layers and a series of tunnels that provide access to the area under the containment; such an arrangement enables scientists to insert or retrieve sensors, instrumentation, and chemical absorbers, using SEAMIST [TM] equipment. In the monitoring zone, scientists can detect vapor or moisture; this system can detect, locate, characterize, and even remedy a leak before it becomes a hazard to the environment. This program also tests various commercially available sensors and instrumentation for applications in environmental monitoring. Tests include those to determine applicability, lifetime use, sensitivity and range, and the ability to withstand hazardous and radioactive constituents expected in the real world.

\section{$3084 \quad \mathrm{~V} 18 / 021785$}

Envirowall [TM]: An Innovative Approach for Environmental Restoration, Using Permeable Walls

Fostering the Needed Partnerships: Doing the Necessary Science to Support Technology Development, Commercialization, Deployment, E.L. Helminski (ed.), Proceedings of the Seventh 
Annual Western Govemors' Association/Weapons Complex Monitor Applied Research and Cleanup Technology Colloquium, Phoenix, AZ, April 29-May 2, 1996. Exchange/Monitor Publications and Forums, Lake Bluff, IL, 500 pp.; (3 pp.) (1996)

Emerging technologies for in-situ environmental restoration are rapidly moving from development and demonstration phases and into commercialization. These technologies continue to face the unavoidable challenge of controlling site hydrologic conditions to capture and force contaminated groundwater into a treatment system without requiring the impacted water to be pumped to the surface is an innovative idea that is now a practical tool with the growing development of funnel and gate permeable wall technology. The EnviroWall [TM] System takes this concept even further. Permeable reaction wall technology provides a completely passive system that does not impact the natural groundwater flow pattem while treating contamination in-situ with reaction media. Both of these in-situ treatment technologies are on the cutting edge of environmental restoration activities. The EnviroWall[TM] System has been demonstrated for the U.S. Department of Energy, at their Savannah River Site, Aiken, SC. The System has worked to expectation and is now a practical technology.

3085

\section{V18/025300}

\section{Evaluating Insitu Bioremediation}

Insitu Bioremediation: When Does It Work?, National Academy Press, Washington, DC, 207 pp.; (pp. 63-90) (1993)

Showing that a bioremediation project is working requires evidence not only that contaminant concentrations have decreased but also that microbes caused the decrease. Although other processes may contribute to site cleanup during a bioremediation, the microbes should be critical in meeting cleanup goals. Without evidence of microbial involvement, there is no way to verify that the contaminant did not simply volatilize, migrate off-site, sorb to subsurface solids, or change form via abiotic chemical reactions. This chapter discusses a strategy for evaluating the effectiveness of in situ bioremediation projects, based on showing that microbes were responsible for declining contaminant concentrations. Regulators and buyers of bioremediation services can use the strategy to evaluate the soundness of a proposed or ongoing in situ bioremediation system. Researchers can apply the strategy to evaluate the results of field tests.

\section{$3086 \quad$ V18/022634}

Evaluation of Actinide Biosorption by Microorganisms Happel, A.M.

Lawrence Livermore National Laboratory, Livermore, CA UCRL-ID-124223; 20 pp. (June 1996)

Conventional methods for removing metals from aqueous solutions include chemical precipitation, chemical oxidation or reduction, ion exchange, reverse osmosis, electrochemical treatment and evaporation. The removal of radionuclides from aqueous waste streams has largely relied on ion exchange methods which can be prohibitively costly given increasingly stringent regulatory effluent limits. The use of microbial cells as biosorbants for heavy metals offers a potential altemative to existing methods for decontamination or recovery of heavy metals from a variety of industrial waste streams and contaminated groundwaters. The toxicity and the extreme and variable conditions present in many radionuclide containing waste streams may preclude the use of living microorganisms and favor the use of non-living biomass for the removal of actinides from these waste streams. In the work presented here, we have examined the biosorption of uranium by non-living, non-metabolizing microbial biomass thus avoiding the problems associated with living systems. We are investigating biosorption with the long term goal of developing microbial technologies for the remediation of actinides.

3087

V18/023750

Evaluation of Field Sampling Methods for Groundwater Metals Analysis

Sorsa, K.; Thompson, S.; Osten, $\mathrm{M}$.

RMT, Inc., Madison, WI; Land Reclamation Company, Sanifill, WI

CONF-950978; Municipal and Industrial Waste, Proceedings of the 18 th International Madison Waste Conference, Madison, WI, September 20-21, 1995. University of Wisconsin, Madison, WI, 461 pp.; (pp. 342-357) (1995)

At a site in southeast Wisconsin, a sampling study was designed to compare groundwater sampling and handling methods. The purpose of this study was to determine if statistically significant differences in observed metals concentrations were exhibited between samples collected by bailing with field-filtering $(0.45-\mathrm{mu} \mathrm{m}$ and $1.0 \mathrm{mu} \mathrm{m}$ filters) and low-flow pumping methods, and to determine whether historical sampling/filtration methods were appropriate at this site. The findings of this study documented that using bailers with filtration and low-flow pumping with no filtration yielded samples with lower solids and metals content than those collected by bailers without filtration. There was no statistically significant difference in the metals concentrations of samples that were filtered with 1.0 $\mathrm{mu} \mathrm{m}$ filters versus those with 0.45 - mu $\mathrm{m}$ filters. There was also no statistically significant difference in the metals concentrations of samples that were bailed and filtered ( 1.0 - or 0.45 - mu $\mathrm{m}$ filter) versus samples that were collected with the low-flow pumps and not filtered. It was concluded that historical metals results of groundwater obtained by using bailers and then filtered are equivalent to the results from low-flow pumping without filtration.

3088

V18/021638

Evaluation of Selected Trade-Offs Between Groundwater Remediation and Waste Minimization for the Petroleum Refining Industry

Andrews, C.D.; McTernan, W.F.; Willett, K.K.

Discovery Energy, Inc., Tulsa, OK; Oklahoma State University, Stillwater, OK

Journal of Energy Engineering 122(2):41-60 (August 1996)

An investigation comparing environmental remediation altematives and attendant costs for a hypothetical refinery site located in the Arkansas River alluvium was completed. Transport from the surface to and through the groundwater for three spill sizes was simulated. These cases represented a base case and two possible levels of waste minimization. Remediation costs were calculated for five alternative remediation options, for three possible regulatory levels and alternative site locations, for four levels of technology 
improvement, and for eight different years. The study considered whether it is better from environmental and economic perspectives to initiate significant efforts and expenditures that are necessary to minimize the amount and type of waste produced and disposed of during refinery operations or if, given expected improvements in technology, it is better to wait until remediation technologies improve, allowing greater environmental compliance at lower costs. The present work used deterministic modeis to track a light nonaqueous phase liquid (LNAPL) spill through the unsaturated zone to the top of the water table. Benzene leaching from LNAPL to the groundwater was further routed through the alluvial aquifer. Contaminant plumes were simulated over 50 years of transport, and remediation costs assigned for each of the five treatment options for each of these years. The results of these efforts show that active remediation is most cost effective after a set point or geochemical quasi-equilibrium is reached, where long-term improvements in technology greatly tilt the recommended option toward remediation. Finally, the impacts associated with increasingly rigorous regulatory levels present potentially significant penalties for the remediation option, but their likelihood of occurrence is difficult to define.

3089

V18/020612

Evaluation of Ultraviolet Oxidation (UV/OX) Methods for the Remediation of Explosives Contaminated Groundwater: Final Report

Marks, P.J. ; Wujcik, W.J. ; Young, C.T. ; Hammell, J.O.

Roy F. Weston, Inc., West Chester, PA

SFIM-AEC-ET-CR-95068; 588 pp. (June 1995)

The primary objective of this task was to evaluate the technical-and cost effectiveness of advanced oxidation processes (AOP), specifically UV/Oxidation (UV/OX) in remediating groundwaters containing 2,4,6-trinitrotoluene (TNT) and other nitroaromatics by performing a pilot-scale demonstration. In addition to evaluating the effectiveness of UV/OX methods, USAEC wanted to identify the cost parameters associated with each of the commercially available processes for the treatment of explosives and assess the adequacy of bench-scale testing data for predicting full-scale equipment requirements. All four of the UV/OX processes evaluated achieved the treatment criteria for $\mathrm{mT}$ and $\mathrm{mB}$ on one or more days of the demonstration. There was considerable variation in the consistency with which the processes met these criteria.

\section{0}

V18/022300

Existing Air Sparging Model and Literature Review for the Development of an Air Sparging Optimization Decision Tool

Parsons Engineering Science, Inc., Cleveland, $\mathrm{OH}$ DOE/ID/12735-1; 135 pp. (August 1995)

The objectives of this Report are two-fold: (1) to provide overviews of the state-of-the-art and state-of-the-practice with respect to air sparging technology, air sparging models and related or augmentation technologies (e.g., soil vapor extraction); and (2) to provide the basis for the development of the conceptual Decision Tool. The Project Team conducted an exhaustive review of available literature. The complete listing of the documents, numbering several hundred and reviewed as a part of this task, is included in Appendix A. Even with the large amount of material written regarding the development and application of air sparging there still are significant gaps in the technical community's understanding of the remediation technology. The results of the literature review are provided in Section 2. In Section 3, an overview of seventeen conceptual, theoretical, mathematical and empirical models is presented. Detailed descriptions of each of the models reviewed are provided in Appendix B. Included in Appendix $D$ is a copy of the questionnaire used to compile information about the models. The remaining sections of the document reflect the analysis and synthesis of the information gleaned during the literature and model reviews. The results of these efforts provide the basis for development of the decision tree and conceptual decision tool for determining applicability and optimization of air sparging. The preliminary decision tree and accompanying information provided in Section 6 describe a three-tiered approach for determining air sparging applicability: comparison with established scenarios; calculation of conceptual design parameters; and the conducting of pilot-scale studies to confirm applicability. The final two sections of this document provide listings of the key success factors which will be used for evaluating the utility of the Decision Tool and descriptions of potential applications for Decision Tool use.

\section{1}

\section{V18/022240}

Fast-Track Aquifer Characterization and Bioremediation of Groundwater

Owen, S.B.; Erskine, J.A.; Adkisson, C.

Black and Veatch Waste Science, Inc., Concord. CA: East Bay Municipal Utility District, Oakland, CA

CONF-951139 (Vol. 2); Superfund 16: Proceedings of a Hazardous Waste Conference and Exhibition, Washington. DC. November 6-8, 1995. E.J. Krause and Associates, Bethesda, MD. Vol. 2. 817 pp.; (pp. 1084-1087) (1994)

A short duration step-drawdown pumping test has been used to characterize a highly permeable aquifer contaminated with petroleum hydrocarbons in support of an in situ, closed loop extraction and reinjection bioremediation system for groundwater. The short-term pumping test produces a manageable quantity of contaminated groundwater while yielding a range of values for transmissivity and specific yield parameters. This range of aquifer coefficients is used in an analytical model to estimate a range of groundwater extraction rates that provide a suitable radius of influence for the extraction and reinjection system. A multi-enzyme complex catalyzed bioremediation process has been used to aerobically degrade petroleum hydrocarbons. Enzymes, amino acids, and biosurfactants are supplied to the extracted groundwater to significantly speed up the degradation by naturally occurring bacteria. During the process, amino acids promote the rapid growth of the microbial population while enzymes and bacteria attach to hydrocarbons forming a transformation state complex that degrades to fatty acids, carbon dioxide, and water. This paper presents a case study of a fast-track bioremediation using pumping test data, analytical modeling, and an enzyme technology.

3092 V18/023609

Federal Facilities and Federal Groundwater Law 
Eklund, E.N.

U.S. Air Force Institute of Technology, Wright-Patterson Air Force Base, $\mathrm{OH}$

AFIT-96-089; 76 pp. (September 30, 1996)

The Federal government is the nation's largest property holder, owning roughly one third of the United States. There are literally hundreds of thousands of Federal facilities located on Federal property, and undemeath it lie vast quantities of groundwater. Unfortunately, Federal facilities have been, and continue to be, substantial contributors to groundwater pollution. For example, in Colorado at the Rocky Mountain Arsenal, the Army polluted nearly thirty square miles of the shallow water table aquifer with nerve gas and chemical manufacturing waste. In Ohio, over one-half million pounds of radioactive materials were released from the Fernald weapons plant into both the atmosphere and the states's largest drinking water aquifer. Similarly, in Califomia, between 1983 and 1986, twenty-eight different Federal facilities caused toxic groundwater contamination. The military is by far the greatest contributor to pollution at Federal facilities: years of weapons testing have contaminated thousands of acres of test ranges with exploded and unexploded ordnance, some of which contains uranium; solvents used to clean aircraft, vehicles and weapons systems have leached into the soil and groundwater; and fuels and lubricating products have routinely overflowed onto, and been absorbed into, the underlying soil and groundwater. The problem of groundwater contamination is not unique to Federal facilities or Federal lands however, as contaminated groundwater is present in each of the fifty states. Although there are a number of Federal statutes that deal, in part, with the regulation and protection of groundwater, there is no comprehensive Federal statute aimed specifically at groundwater protection.

3093

V18/024004

Fiber Optic Sensors for Environmental Applications: A Brief Review

Rossabi, J.

Westinghouse Savannah River Company, Aiken, SC

WSRC-RP-92-471; 20 pp. (April 1992)

Understanding the flow and transport of contaminants in the subsurface is vital to a complete knowledge of groundwater quality. This understanding is achieved by measurement of the appropriate chemical and physical subsurface parameters. The ideal measurement would accurately assess a parameter without affecting the parameter or its environment. Fiber optic spectroscopy offers some of the most promising techniques for accurate, non-invasive measurements of environmental parameters. Fiber optic sensors for subsurface applications are currently being developed by several Department of Energy laboratories. Some of these sensors have been successfully deployed in the field and are attaining the goals of accurate, non-invasive, real time measurements in the subsurface.

3094

\section{V18/021092}

Fiber-Optic Sensors for Characterizing Soil and Groundwater Contamination

Milanovich, F.P.; Yow, J.L., Jr.

Lawrence Livermore National Laboratory, Livermore, CA
UCRL-LR-112400-92-2/93-1; Environmental Restoration/Waste Management - Applied Technology, Semiannual Report for July 1992-June 1993 - Volume 1, Number 2 and Volume 2, Number 1; (pp. 33-37) (1993)

The ER/WM-AT Program is developing and field-testing a fiber-optic sensor technology for monitoring chlorinated organic solvents such as trichloroethylene (TCE) and chloroform. The fiber-optic chemical sensor for groundwater and vadose-zone monitoring uses a colorimetric detection technique and it is accurate and sensitive enough for environmental monitoring of trichloroethylene and chloroform. The sensor's design permits it to be placed into the subsurface solely with hydraulically driven penetrations (cone penetrometry). By assisting in optimizing the siting of monitoring wells, this sensor will significantly reduce remediation costs. The objectives of the work presented here were to deliver the sensor, using cone penetrometry, to multiple locations; to expose the sensor to a range of TCE concentrations; and to observe the effect of pumping, as in a vadose zone grab sample operation, on the measurement process.

3095 V18/021983

Field Experiment, Anaerobic Biodegradation of Highly Chlorinated Aromatics

Duffy, J.J.; Baek, N.H.; Coats, M.L.

Occidental Chemical Corporation, Grand Island, NY; Trea Tek-CRA Company, Niagara Falls, NY

CONF-9509139; Emerging Technologies in Hazardous Waste Management VII, D.W. Tedder (ed.), Proceedings of the Seventh American Chemical Society Industrial and Engineering Chemistry Division Special Symposium, Atlanta, GA, September 17-20, 1995. American Chemical Society, Washington, DC, 1291 pp.; (pp. 1148-1151) (1995)

Chlorinated compounds have been manufactured and used extensively across the country. A large number of locations have been found to contain residual levels of this type of compound in soils, sediments, and groundwaters. Of particular interest for this experiment is complex chlorinated compound mixtures, containing chlorinated benzenes and toluenes of various chlorine content. The objective of the current study is to perform a field experiment to evaluate the effectiveness of the anaerobic biodegradation of chlorinated benzenes and toluenes. A laboratory study to compare to the field experiment is being conducted concurrently. Previous experimental work on substrates with similar contaminants had shown poor response of the higher chlorinated materials to aerobic degradation. Anaerobic dehalogenation had been observed in soils in small scale laboratory studies.

\section{$3096 \quad$ V18/023395}

Field Test of a Waste Containment Technology Using a New Generation of Injectable Barrier Liquids

Moridis, G.J.; Apps, J.; Persoff, P.; Myer, L.; Muller, S.J.; Pruess, K.; Yen, P.

Lawrence Berkeley National Laboratory, Berkeley, CA; Bechtel Corporation, San Francisco, CA

LBNL-38817; CONF-960804; Spectrum '96: Nuclear and Hazardous Waste Management, Proceedings of an International Conference, 
Seattle, WA, August 18-23, 1996; (16 pp.) (August 1996)

A first stage field injection of a new generation of barrier liquids was successfully completed. Two types of barrier liquids, colloidal silica (CS) and polysiloxane (PSX), were injected into heterogeneous unsaturated deposits of sand, silt, and gravel typical of many of the arid DOE cleanup sites and particularly analogous to the conditions of the Hanford Site. Successful injection by commercially available chemical grouting equipment and the tube-a-manchette technique was demonstrated. Excavation of the grout bulbs permitted visual evaluation of the soil permeation by the grout, as well as sample collection. Both grouts effectively permeated all of the formation. The PSX visually appeared to perform better, producing a more uniform and symmetric permeation regardless of heterogeneity, filling large as well as small pores and providing more structural strength than the CS. Numerical simulation of the injection tests incorporated a stochastic field to represent site heterogeneity and was able to replicate the general test behavior. Tiltmeters were used successfully to monitor surface displacements during grout injection.

3097

$\mathrm{V} 18 / 022970$

Field-Scale Demonstration of Air Sparging to

Remediate Tritiated Fluids

Russell, C.E.; Gillespie, D.R.; Hokett, S.L.; Donithan, J.D.

U.S. Department of Energy, Nevada Operations Office, Las Vegas, NV; Nevada University, Water Resources Center, Las Vegas, NV

\section{DOENV/11508-09; 36 pp. (September 1996)}

Two pilot field-scale studies were conducted during the period of May 24 to July 22, 1996, to evaluate the potential of air sparging to remediate tritiated fluids. Previous analytical solutions to the rate of tritium removal were evaluated and compared to the experimental results. The analytical solution of $\mathrm{Craig}$ and Gordon that describes isotopic fractionation of an evaporating body of water appears to most accurately describe the process, versus the more limited isotopic exchange equation of Slattery and Ingraham and the mass transfer equation of Wilson and Fordham, which are accurate only at moderate to high humidities and do not describe the tritium enrichment process that would occur at low humidities. The results of the two experiments demonstrated that air sparging of tritium is a viable process in the field. Tritium removal rates of 60 percent were reported during the first experiment and 66 percent for the second experiment. Comparison to previous laboratory work revealed that rates could have been improved by starting with higher concentrations, utilizing smaller bubbles, and longer bubble path lengths. Risks associated with the pilot study were greater the closer one worked to the experiment with a maximum increase in the Lifetime Excess Total Risk per Unit Uptake of $2.4 \times 10(\mathrm{E}-5)$. Conduct of this experiment at locations with much higher activities of tritium would significantly increase the associated risk.

\section{8}

V18/023995

Final Report of Offgas Treatment Technologies for Abatement of Atmospheric Emissions of Chlorinated Volatile Organic Compounds

Jarosch, T.R.

Westinghouse Savannah River Company, Aiken, SC
WSRC-RP-94-927; 49 pp. (November 1994)

This report summarizes the results of the program for offgas treatment of atmospheric emissions of chlorinated volatile organic compounds (CVOCs), in particular trichloroethylene (TCE) and perchloroethylene (PCE). This program was part of the Department of Energy (DOE) Office of Technology Development's (OTDs) VOCs in Non-Arid Soils Integrated Demonstration (VNID). The Savannah River Technology Center field tested and evaluated several technologies from each of the following classes: free radical oxidation, thermal oxidation, separation/recovery, and biodestruction. The tests were conducted with a soil vapor extraction system connected to a vertical well screened in the vadose zone at a site contaminated primarily with TCE and PCE. The technologies tested proved or exhibited strong potential as viable methods for treating offgas streams containing chlorinated organics under typical field conditions.

3099

V18/022039

Flow-Field-Flow-Fractionation as a New Tool for Fractionating Aquatic Colloids

Fruhstorfer, P.; Niessner, R.

Technical University of Munich, Institute of Hydrochemistry, Munich, Germany

CONF-9506232; Environmental Monitoring and Hazardous Waste Site Remediation, T. Vo-Dinh and R. Niessner (eds.), Proceedings of a Conference of the Society of Photo-Optical Instrumentation Engineers, Munich, Germany, June 19-23, 1995. International Society for Optical Engineering, Bellingham, WA, 613 pp.; (pp. 98-106) (1995)

The Flow-Field-Flow-Fractionation (Flow-FFF) is a sensitive and gentle technique for the size measurement and separation of macromolecular and particulate matter. Its theoretical fractionation power extends across a broad size spectrum ranging from about 1 nanometer to several micrometers. In a first step the optimal working conditions for applications on environmental aquatic colloids have been evaluated. Subsequently a calibration procedure using certified polystyrene latex microspheres of different sizes was carried out. The influence of electrolytes on the fractionation process was tested with several experiments carried out in groundwater. To control the fractionation process, most of the eluates were collected and examined by scanning electron microscopy (SEM). The results show that excellent fractionation results are obtained for particles with diameters between $30 \mathrm{~nm}$ and $500 \mathrm{~nm}$. For bigger particles the fractionation becomes increasingly inexact (e.g. broad elution peaks), thus the resolution is deteriorated. Based on these results the size distribution of a commercial humic acid before and after coagulation was determined.

3100 V18/024005

Fluorescent Antibody Application in Bioremediation Procedures at the Savannah River Site

Brigmon, R.L.; Richardson, B.S.; Franck, M.M.

Westinghouse Savannah River Company, Aiken, SC

WSRC-MS-96-0773; 15 pp. (January 30, 1997)

Direct Fluorescent Antibodies (DFA) and Most Probable Number (MPN) techniques are currently being employed at the Savannah 
River Site (SRS) to monitor methanotrophic bacteria for the bioremediation of trichloroethylene (TCE) in field studies. Direct Fluorescent Antibodies were developed against various methanotrophic bacteria isolated from SRS as well as methanotrophic bacteria acquired from the American Type Culture Collection (ATCC). DFA's are anticipated to be more efficient for monitoring methanotroph activity than MPN's because of shorter processing time, lower cost, and the direct nature of the assay. The DFA method is a direct technique, in that samples are processed immediately and can be enumerated within an hour. The MPN method is indirect, since samples must be cultured for 6-8 weeks before measuring methane consumption and carbon dioxide production. Indirect methods are not highly selective and have limited application. The greatest advantage of a faster assay, is that bioremediation procedures utilizing methanotrophic bacteria could be amended. These amendments would be based on environmental monitoring with results in real time (1 hour). The elimination of the MPN technique and the use of DFA's will save significantly in both materials and labor. The data obtained from DFA's and MPN's were statistically compared to each other and to total bacterial counts (AODC). The statistical analysis used was Analysis of Variance (ANOVA). Using this analysis groundwater samples were found to be not significantly different, but soil were significantly different. These methods were employed on soil samples from the Southem Sector and groundwater samples from the TCE-contaminated Sanitary Landfill at SRS. Acridine Orange Direct Counts were compared to show relative differences between total bacterial and methanotroph population.

\section{1}

\section{V18/022630}

Formation of a Barrier to Groundwater Contaminants by the Injection of Zero-Valent Iron Colloids: Suspension Properties

Kaplan, D.I.; Cantrell, K.J.; Wietsma, T.W. Pacific Northwest Laboratory, Richland, WA

CONF-941124; Insitu Remediation: Scientific Basis for Current and Future Technologies, G.W. Gee and N.R. Wing (eds.), Proceedings of the 33rd Hanford Symposium on Health and the Environment, Pasco, WA, November 7-11, 1994. Battelle Press, Columbus, OH, Part 2, 605 pp.; (pp. 821-837) (1994)

Zero-valent iron (FE) (metallic iron) is a strong chemical reductant that is capable of degrading several halogenated-hydrocarbon compounds (e.g., trichloroethene and tetrachloroethene) and chemically reducing several highly mobile oxidized oxyanions and oxycations to their immobile forms. A series of studies was undertaken to develop methods of injecting micrometer-sized Fe colloids into the subsurface environment to form a chemical barrier to these highly mobile contaminants. Forming a barrier by means of this technique may have the distinct advantage over traditional trench-and-fill technologies: it may be safer, more cost-effective, and may be used at greater depths. Several commercially available Fe colloids were evaluated. One type was selected for further study based on its small size ( 1 to 2 [micro]m) and the presence of an organic coating. This organic coating was weathered away within 7 days by Hanford groundwater $(\mathrm{CaCO} 3$ system, $\mathrm{pH} 8.1)$ and exposed the chemically active Fe-colloid surface. Through the use of surfactants in a low ionic strength solution, the length of time that these extremely dense $(7.8 \mathrm{~g} \mathrm{~cm}[\mathrm{E}-3])$ colloids remained in suspension increased as much as $250 \%$. The efficiency of quartz-sand columns to remove surfactant-coated Fe colloids appeared to be at least partially controlled by injection rate; the filter coefficient values at injection rates of 6,124 , and $248 \mathrm{ml}$ $\min [E-1]$ were $0.30,0.05$, and $0.02 \mathrm{~cm}[E-1]$, respectively. Studies are underway to develop further understanding of this relationship and to determine the interactive effect of influent colloid concentration and injection flow rate on colloid placement in aquifer sediments for barrier formation.

3102

V18/021344

Forum on Groundwater Remediation

Farvolden, R.N.; Apgar, M.A.

National Ground Water Association, Department of Natural Resources and Environmental Control, Dublin, $\mathrm{OH}$

Groundwater 32(3):354-355 (1994)

Mounting concern about the effectiveness and efficiency of Superfund-directed remediation of soil and groundwater led the National Ground Water Association (NGWA)to convene a Forum on Groundwater Remediation. The purpose of the Forum was to provide an opportunity to people knowledgeable and active in the field of groundwater remediation to describe the current state of the program. The Forum was cosponsored by the American Bar Association (Business Law Section), the Chemical Manufacturers Association, Clean Sites, the Colorado State Department of Public Health, the Environmental Protection Agency (Technology Innovation Office), and the University of Westem Michigan (Institute of Water Sciences).

3103

V18/023768

Friendly Forests

Miller, J.A.

Dowell Schlumberger, Sugar Land, TX

CONF-960623 (Vol. 1); Proceedings of the Third International Conference on Health, Safety and Environment in Oil and Gas Exploration and Production, New Orleans, LA, June 9-12, 1996. Society of Petroleum Engineers (SPE), Inc., Richardson, TX, Vol. 1, 941 pp.; (pp. 717-722) (1996)

Removal of releases of petroleum hydrocarbons and chlorinated hydrocarbons from soil and groundwater has been a nationwide effort since the mid-1980s. Successes have been rare. Mechanical removal systems have been found to require an inordinate amount of time. Bioremediation has used existing, added, or altered microorganisms to metabolize or biodegrade hydrocarbons. Problems with delivering the microorganisms directly to the hydrocarbon and specific site factors have combined to thwart or slow bioremediation. Phytoremediation uses plants to biodegrade shallow soil contamination in the rhizosphere. Trees are used to extract groundwater from aquifers and simulate a pumping system for contaminated groundwater plume control. Simultaneously, the trees create a rhizosphere biodegradation zone and extract hydrocarbons through uptake in the transpiration stream.

Phytoremediation is proposed for environmental cleanup of historical contamination as a method that will occur in place, at a reasonable cost, and require little maintenance. The initiative of one major service company at a Louisiana site is described. The 
effort commenced in June 1995 with the planting of 92 hybrid poplar trees for the purposes of: (1) controlling groundwater movement, (2) uptaking constituents from soil and groundwater, and (3) enhancing bioremediation of soil and groundwater in the rhizosphere. Results to date are reported.

\section{4}

V18/021981

Full-Scale Demonstration of Insitu Bioremediation of Trichloroethylene: Laboratory and Modeling Studies

Goltz, M.N.; Carrothers, T.J.; Hopkins, G.D.; Jenal-Wanner, U.; Kawakami, B.T; McCarty, P.L.

Stanford University, Department of Civil Engineering, Stanford, CA; Western Region Hazardous Substance Research Center, Stanford, CA

CONF-9509139; Emerging Technologies in Hazardous Waste Management VII, D.W. Tedder (ed.), Proceedings of the Seventh American Chemical Society Industrial and Engineering Chemistry Division Special Symposium, Atlanta, GA, September 17-20, 1995. American Chemical Society, Washington, DC, 1291 pp.; (pp. 144-147) (1995)

A full-scale study of in situ bioremediation is being planned for implementation at a trichloroethylene (TCE) contaminated site at Edwards Air Force Base. The bioremediation system that is being proposed has been developed over 9 years of research and testing in the laboratory and at a pilot field site located at Moffett Federal Airfield in Mountain View, California. Studies conducted at the Moffett site have demonstrated that trichloroethylene can be effectively biodegraded cometabolically through the introduction into the subsurface of a primary substrate (such as phenol or toluene) and an oxygen source (such as hydrogen peroxide) to support the growth and energy requirements of a native population of microorganisms.

Full-Scale Field Demonstration on the Use of Hydrogen Peroxide for Insitu Bioremediation of an Aviation Gasoline-Contaminated Aquifer, Chapter 16

Wilson, J.R.; Armstrong, J.M.; Rafai, H.S.

U.S. Environmental Protection Agency, Robert S. Kerr Environmental Research Laboratory, Ada, OK

Bioremediation: Field Experience, P.E. Flathman, D.E. Jerger and J.H. Exner (eds.), Lewis Publishers, Boca Raton, FL, 560 pp.; (pp. 333-359) (1994)

The U.S. Environmental Protection Agency (EPA) and the U.S. Coast Guard conducted a joint full-scale evaluation of in situ biological treatment of petroleum hydrocarbons (PHCs) following spillage of aviation gasoline at a Coast Guard Air Station in Traverse City, MI. At the Coast Guard site, soil core samples were collected and analyzed to quantify aviation gasoline contamination in the aquifer. Hydraulic modeling was used to design an infiltration system that flooded all of the fuel-contaminated subsurface soil. The spill area was pretreated with groundwater, which was amended with $380 \mathrm{mg} / \mathrm{L}$ ammonium chloride, $190 \mathrm{mg} / \mathrm{L}$ disodium phosphate, and $190 \mathrm{mg} / \mathrm{L}$ potassium phosphate. During treatment, hydrogen peroxide concentrations in the aquifer were gradually raised to a maximum value of 750 to $1000 \mathrm{mg} / \mathrm{L}$. After 17 months of field operation and at distances up to $110 \mathrm{ft}(33.5 \mathrm{~m})$ from infiltration wells, the groundwater concentration of benzene in the most contaminated depth interval at the site was reduced to less than 1 ug/L. Remaining alkylbenzenes were also reduced to below federal drinking water standards. These alkylbenzenes included ethylbenzene, toluene, and o-, m-, and p-xylene. This chapter is from the book entitled Bioremediation: Field Experience.

\section{$3106 \quad$ V18/023884}

Full-Scale Insitu Bioremediation of Trichloroethylene in Groundwater: Preliminary Modeling Studies

Goltz, M.N.; Kawakami, B.T.; McCarty, P.L.

Stanford University, Department of Civil Engineering, Stanford, CA

EPA/600/R-95/012; CONF-9504110; Proceedings of the 21st Annual Risk Reduction Engineering Laboratory (RREL) Research Symposium, Cincinnati, OH, April 4-6, 1995. U.S. Environmental Protection Agency, Cincinnati, OH, 398 pp.; (pp. 283-287) (April 1995)

A full-scale study of in-situ bioremediation is being planned for implementation at Edwards Air Force Base. The bioremediation system that is being proposed has been developed over 8 years of research and testing in the laboratory and at a pilot field site located at Moffett Naval Air Station in Mountain View, Califomia. Studies conducted at the Moffett field site have demonstrated that trichloroethylene (TCE), the contaminant found at Edwards, can be effectively biodegraded cometabolically through the introduction into the subsurface of a primary substrate (such as phenol or toluene) and an oxygen source (such as hydrogen peroxide) to support the growth and energy requirements of a native population of microorganisms. The full-scale remediation would be accomplished by using injection and extraction wells to introduce the primary substrate, toluene, and oxygen into the aquifer and mix them with the TCE to create a bioremediation zone. This paper reports the results of computer modeling that was done to assess the remediation system. Based on reasonable parameter values and the results of prior work at the experimental field site, the studies show that the planned operation of the in situ aerobic cometabolic bioremediation system can be expected to result in observable decreases in TCE mass and concentration at the Edwards site.

\section{$\mathrm{V} 18 / 025301$}

\section{Future Prospects for Bioremediation}

Insitu Bioremediation: When Does It Work?, National Academy Press, Washington, DC, 207 pp.; (pp. 91-96) (1993)

In preparing this report the National Council's Committee on In Situ Bioremediation sought to communicate the scientific and technological bases for bioremediation. As the report has explained, the principle underlying bioremediation is that microorganisms (mainly bacteria) can be used to destroy hazardous contaminants or transform them into less harmful forms. Microorganisms are capable of performing almost any detoxification reaction. Nevertheless, the commercial practice of bioremediation today focuses primarily on cleaning up petroleum hydrocarbons. The full potential of bioremediation to treat a wide range of compounds cannot be realized as long as its use is clouded by controversy over what it does and how well it works. By providing guidance on how to 
evaluate bioremediation, the committee hopes this report will eliminate the mystery that shrouds this highly multidisciplinary technology and pave the way for further technological advances. This chapter summarizes new research advances that the committee foresees as expanding the future capabilities of bioremediation. It recommends steps that will improve the ability to evaluate bioremediation technologies objectively, whether the technologies are new or established.

3108

V18/023229

\section{GRUNDFOS Groundwater Sampling Pump}

Heegaard, J.

GRUNDFOS A/S, Bjerringbro, Denmark

CONF-9210194; Proceedings of an International Symposium on Environmental Contamination in Central and Eastem Europe, Budapest, Hungary, October 12-16, 1992, 968 pp.; (pp. 550-552) (1992)

One major criterion of the "ideal" groundwater sampling device is that it be able to purge a monitoring well of stagnant water at a relatively high rate of flow (e.g., more than 10 liters per minute) and be able to sample groundwater at a low flow rate (e.g., $0.1-1$ liter per minute) so as not to impact the integrity of the sample. Sampling devices for two-inch diameter wells generally have been able to deliver water at low flow rates, but have been relatively ineffective during the purging phase because their maximum flow rates are generally less than four to six liters per minute.

GRUNDFOS has developed a new small diameter pump for purging and sampling groundwater from small diameter (2-inch) monitoring wells. Blasland, Bouck \& Lee, in conjunction with the University of Waterloo Centre for Ground Water Research, ran a series of tests on the pump under controlled (laboratory) conditions to evaluate the ability of the pump to deliver "representative" groundwater samples. The performance of the pump was also evaluated under field operating conditions to examine its effectiveness for purging as well as sampling monitoring wells and its long term reliability. The GRUNDFOS MP1 sampling pump offers the ability to deliver "representative" samples of water from two-inch monitoring wells throughout a broad range of depths. It also offers the flexibility of being able to purge water at flow rates in excess of 30 liters per minute during the process of preparing the well for sampling within a reasonable length of time.

3109

V18/022910

Geochemical Effects on the Behavior of LLW Radionuclides in Soil/Groundwater Environments

Krupka, K.M.; Serne, R.J.

Pacific Northwest National Laboratory, Richland, WA

CONF-951209; Proceedings of the 17th Annual U.S. Department of Energy Low-Level Radioactive Waste Management Conference, D. Lake (ed.), Phoenix, AZ, December 12-14, 1995, 480 pp.; (10 pp.) (1995)

Assessing the migration potential of radionuclides leached from low-level radioactive waste (LLW) and decommissioning sites necessitates information on the effects of sorption and precipitation on the concentrations of dissolved radionuclides. Such as assessment requires that the geochemical processes of aqueous speciation, complexation, oxidation/reduction, and ion exchange be taken into account. The Pacific Northwest National Laboratory (PNNL) is providing technical support to the U.S. Nuclear Regulatory Commission (NRC) for defining the solubility and sorption behavior of radionuclides in soil/groundwater environments associated with engineered cementitious LLW disposal systems and decommissioning sites. Geochemical modeling is being used to predict solubility limits for radionuclides under geochemical conditions associated with these environments. The solubility limits are being used as maximum concentration limits in performance assessment calculations describing the release of contaminants from waste sources. Available data were compiled regarding the sorption potential of radionuclides onto "fresh" cement/concrete where the expected $\mathrm{pH}$ of the cement pore waters will equal to or exceed 10 . Based on information gleaned from the literature, a list of preferred minimum distribution coefficients (Kd's) was developed for these radionuclides. The $\mathrm{Kd}$ values are specific to the chemical environments associated with the evolution of the compositions of cement/concrete pore waters.

3110

V18/023801

Geophysical Characterization of a Fractured-Bedrock Aquifer and Blast-Fractured Contaminant-Recovery Trench

Lane, J.W., Jr.; Haeni, F.P.; Soloyanis, S.; Placzek, G.; Williams, J.H.; Johnson, C.D.; Buursink, M.L.; Joesten, P.K.; Knutson, K.D.

U.S. Geological Survey, Rolla, MO; MITRE Corporation, McLean, VA

CONF-960477; SAGEEP '96, R.S. Bell and M.H. Cramer (eds.), Proceedings of the Ninth Annual Symposium on the Application of Geophysics to Engineering and Environmental Problems, Denver, CO, April 15-May 1, 1996. Environmental and Engineering Geophysical Society, Wheat Ridge, CO, 1353 pp.; (pp. 429-442) (1996)

Borehole- and surface-geophysical methods were used to characterize the hydrogeology and the effects of blast fracturing an in-situ recovery trench in a contaminated fractured-bedrock aquifer. The recovery trench is located at the former fire-training area of Loring Air Force Base in Aroostook County, Maine.

Borehole-geophysical methods, used in six wells at the site, included video, acoustic televiewer, heat-pulse flowmeter under nonpumping and low-rate pumping conditions, natural gamma, electromagnetic induction, fluid temperature and conductivity, caliper, deviation, and borehole radar. Borehole radar was used in a single-hole reflection configuration with directional and non-directional $60-\mathrm{MHz}$ (megahertz) antennas and in a cross-hole tomography configuration with 22-MHz antennas. One surface-geophysical method, azimuthal square-array direct-current resistivity, also was used. Geophysical surveys were conducted before and after blast fracturing the recovery trench. Integrated interpretation of the geophysical data collected before blasting indicates that most transmissive fractures are steeply dipping and are oriented northeast and southwest. Analysis of azimuthal square-array-resistivity data indicates that the secondary porosity of the fractured-bedrock aquifer is about 1 percent. The borehole-geophysical data and cross-hole radar tomography data indicate that more fractures are present in the upper 20 to $25 \mathrm{~m}$ (meters) of bedrock than in 
bedrock below this depth. Interpretation of the geophysical data collected after blast fracturing the recovery trench indicates that the blast created an intensely fractured zone about $3 \mathrm{~m}$ wide, $26 \mathrm{~m}$ deep, along the $50-\mathrm{m}$ length of the recovery trench. Blast-induced porosity in the recovery trench is estimated from the borehole-radar data to be 13.5 plus/minus 5 percent at the midpoint of the trench, decreasing to 7.3 plus/minus 6 percent at the northwestern end. Post-blast effects on the hydrology of the area adjacent to the recovery trench include: (1) a decline in static water levels, (2) order-of-magnitude increases in upward flow in two wells, (3) reversal of flow directions in two wells, (4) order-of-magnitude increases in the estimated transmissivity of three wells, and (5) an estimated increase in aquifer secondary porosity to 2 percent near the trench. The increase in secondary porosity is estimated on the basis of azimuthal square-array resistivity data collected over the recovery trench and cross-hole tomography collected parallel to but outside the trench. These effects are consistent with increased porosity and permeability in the blast-fractured recovery trench and with increased fracture transmissivity near the recovery trench. The increased fracture transmissivity resulted from an apparent hydraulic cleaning that occurred when water was ejected out of wells near the trench during the blast.

\section{1 \\ V18/023990}

Groundwater Model Testing: Systematic Evaluation and Testing of Code Functionality and Performance

van der Heijde, P.K.M.; Kanzer, D.A.

Colorado School of Mines, International Ground Water

Modeling Center, Golden, CO; U.S. Environmental

Protection Agency, National Risk Management Research

Laboratory, Ada, OK

EPA/600/SR-97/007; 6 pp. (February 1997)

Effective use of groundwater simulation codes as management decision tools requires the establishment of their functionality, performance characteristics, and applicability to the problems at hand. This is accomplished through systematic code-testing protocol and code selection strategy. The protocol contains two main elements: functionality analysis and performance evaluation. Functionality analysis is the description and measurement of the capabilities of a simulation code; performance evaluation concerns the appraisal of a code's operational characteristics (e.g., computational accuracy and efficiency, sensitivity for problem design and parameter selection, and reproducibility). Testing of groundwater simulation codes may take the form of: (1) benchmarking with known, independently derived analytical solutions; (2) intracomparison using different code functions inciting the same system responses; (3) intercomparison with comparable simulation codes; or (4) comparison with field or laboratory experiments. The results of the various tests are analyzed using standardized statistical and graphical techniques to identify performance strengths and weaknesses of code and testing procedures. The protocol is demonstrated and evaluated using a three-dimensional finite difference flow and solute transport simulation code, FTWORK.

\section{2 \\ V18/023916}

Groundwater Extraction System to Control VOCs in a Bedrock Aquifer
Wessley, D.J.; Weber, R.H.; Otzelberger, D.G.

Montgomery Watson Americas, Inc., Madison, WI; Montgomery Watson Americas, Inc., Milwaukee, WI; Waste Management of Wisconsin, Inc., Menomonee Falls, WI

CONF-950177; Waste Tech '95, Proceedings of a Conference, New Orleans, LA, January 23-25, 1995. Environmental Industry News, Washington, DC, 530 pp.; (pp. 369-384) (1995)

Groundwater quality in the bedrock aquifer at a solid waste landfill has been evaluated since 1984 . Since that time, several volatile organic compounds (VOCs) have been detected in various bedrock monitoring wells at the site. Continued detection of VOCS in the bedrock aquifer led to an investigation and design of a remediation system to address the contaminated aquifer. This paper discusses the site background, geology, hydrogeology, and landfill characteristics; the methods and results of the landfill monitoring and investigations performed; and the groundwater extraction system which was designed and constructed to control further off-site migration of contaminants in the bedrock aquifer.

3113 V18/021621

Groundwater Model for Management and Remediation of a Highly Polluted Aquifer (Organo-Chlorine Compounds) in an Urban Area, Using Radioactive Tracers I-131 for Hydrodynamic Parameters and Dispersivity Measurements

Bersano Begey, M.; Cargnelutti, M.; Pirastru, E.

United Nations Educational, Scientific and Cultural Organization (UNESCO), Paris, France; International Atomic Energy Agency, Vienna, Austria; Hydrodata S.p.A., Turin, Italy; Energie Nucleare e delle Energie Alternative (ENEA), Centro Ricerche di Saluggia, Vercelli, Italy

STIPUB-970; CONF-950343 (Vol. 2); Isotopes in Water Resources Management, Proceedings of a Symposium, Vienna, Austria, March 20-24, 1995. IAEA, Vienna, Austria, Vol. 2, 530 pp.; (pp.

229-248) (1996)

The paper presents the methodology and results of a flow and transport model for organo-chlorine compounds, mainly trichloroethylene (TCE). The monitoring data showed that the source of the pollution was in the industrial part of the town, where a chemical plant is located. The breakdown responsible for the pollution was identified as industrial sewage pipeline damage. TCE mass lost in the aquifer from 1988 to 1992 was accurately evaluated as $252.3 \mathrm{~kg}$. A numerical model was developed with the following aims: (1) to simulate the plume evolution (up to the year 2020) with and without remediation; (2) to define which public wells would be reached by the contaminant plume and to calculated the concentration versus time curves in these wells; (3) to define the maximum extension of the contaminated area in order to drill new wells as altemative sources of supply for the polluted area; and (4) to define wellhead protection areas and the location of monitoring wells around public wells. Aquifer parameters were mainly evaluated using the radioactive tracer $1-131$, by means of dilution point tests (single well method) and multiwell tests. 


\section{by Design}

Hasbrouck, R.

Lawrence Livermore National Laboratory, Livermore, CA Science and Technology Review (May 1996):12-23 (May 1996)

Computer modeling is proving useful as cleanup of contaminated groundwater proceeds at the Livermore site. Modeling is an extremely effective tool for deciding where and how groundwater remediation efforts should be directed. Evaluation processes that used to take days or weeks can now be done in minutes and often with a higher degree of accuracy. Lawrence Livermore National Laboratories has developed several software tools that can be applied to simulate groundwater flow and transport in a large number of possible well field configurations. Maplt, for example, can read a variety of one-, two-, and three-dimensional data sources and allows rapid production of input files for the various simulation codes. The time needed to regrid and execute new three-dimensional conceptualizations has been reduced from months to hours. In the past a different code preparation program was required for each groundwater simulation code. Another tool is PLANET, an easy to use program that replaces laborious, manual operation of modeling codes to evaluate altemative remediation scenarios. These new modeling methods enable quick evaluation of millions of prospective engineering designs and optimization of remediation pumping strategies. These methods use artificial neural network (ANN) technology to process a much smaller set of simulations, repeatedly, for any and all configurations.

3115

V18/021620

Groundwater Monitoring and Remediation

Hodson, C.O.; Kilbourne, A.

Pollution Engineering 28(7):48 (July 1996)

Groundwater samples are literally an effective measure of groundwater. Samples taken from groundwater reserves are analyzed in laboratories to obtain information on what pollutants, if any, are found in the source. Groundwater modeling is a computer-based method of tracking and calculating pollutant flow and migration. An emerging facet is the inclusion of risk assessment. Remediation of contaminated groundwaters is a burgeoning industry, with several remediation methods available. Air sparging is the injection of air into the contaminated groundwater, allowing release of the contaminants by aeration. Bioremediation is the process of using microorganisms or contaminant-specific organisms to render the contaminants innocuous.

3116

V18/023901

Groundwater Protection with Site-Specific Risk-Based Soil Concentrations: A Case Study with Chromium

Linton, J.; Henry, L.; Flickinger, M.; Davis, A.

Brown and Caldwell, Tampa, FL; Atlantic Richfield Company, Los Angeles, CA; Geomega, Boulder, CO

CONF-951 124; HazMat West '95, Proceedings of the Eleventh Annual Environmental Management and Technology Conference and Exhibition, Long Beach, CA, November 7-9, 1995. Advanstar Expositions, Duluth, MN, 597 pp.; (pp. 267-276) (1995)

Establishing soil concentrations that are protective of groundwater is a critical area of scientific uncertainty in site investigation and remediation. For chromium concentrations in soil at a Florida Superfund site, U.S. Environmental Protection Agency Region 9 initially suggested an acceptable concentration of $40 \mathrm{mg} / \mathrm{kg}$ total chromium to prevent leaching of chromium into the Biscayne aquifer. Site-specific partition coefficient tests conducted using sand and carbonate soil from the site and reconstituted groundwater, demonstrated that concentrations between $800-1,000 \mathrm{mg} / \mathrm{kg}$ of total chromium in soil was protective of groundwater to drinking water standards. This paper presents the mechanisms of metal mobility, methods for site-specific partition coefficient tests, and the importance of factoring non-linear behavior into the calculations. A simple method for differentiating between linear and nonlinear partitioning is presented.

\section{$3117 \quad \mathrm{~V} 18 / 025560$}

Groundwater Pumping and Advanced Oxidation Treatment: A Complementary Pair of Technologies for Remediating Soluble, Non-Degradable Contaminants

Martin, P.; McGlone, J.

Groundwater Technology Canada Limited, Mississauga, Ontario, Canada; Department of the Environment, Environmental Protection Service, Ottawa, Ontario, Canada

CONF-951086; Proceedings of the Fifth Annual Symposium on Groundwater and Soil Remediation, Toronto, Ontario, Canada, October 2-6, 1995. Environment Canada - Environmental Protection Service, Hull, Quebec, Canada, 566 pp.; (pp. 541-543) (1995)

Factors influencing the choice of remediation technologies, such as chemical/physical properties, stratigraphy, clean-up goals/time-frame, and economics are discussed. Experience has shown that most sites have mixtures of contaminants, requiring combinations of remedial technologies to be used. Soil vapor extraction with air sparging are very effective when the site is relatively homogenous, permeable, and the contaminants are strippable and aerobically degradable. However, soluble, non-degradable compounds do not respond to conventional air stripping, activated carbon adsorption or bioreactors. In these situations groundwater pumping and advanced oxidation treatment may be the most cost-effective treatment method to apply. This case study demonstrates a successful remediation project using a combination of "pump and treat" and advanced oxidation technologies. A comparison of the results with results obtained using competitive technologies is also given.

\section{8 \\ V18/020609}

Groundwater Remediation by Means of UV-Activated Oxidation: Neutralization of a Pollutant Mixture in the Site of Operation of a Chemical Factory

Roetlich, H.; Trageser, M.; Offman, R; Roemer, R. Gruenbeck Wasseraufbereitung GmbH, HoechstaedtDonau, Germany; VitaTec UV-Systeme, Freigericht, Germany; Lahmeyer International $\mathrm{GmbH}$, Munich, Germany WLB Wasser Luft und Boden 40(1-2):59-61 (January-February 1996)

A UV method (UV/H2O[E+2]) was successfully used to 
decontaminate groundwater polluted by a complex mixture of substances in a site where a chemical factory is in operation. So far, the results of a bench-scale experiment and a test run had been available. Since March 1995, the groundwater, which is contaminated with BTX, PAHs, lightly halogenated hydrocarbons, $\mathrm{PCP}$, phenols and tensides has been continuously treated by means of a UV plant. This treatment has confirmed the results of the laboratory test and the six-month test run: the pollutants are destroyed and the limiting values imposed by the authorities are complied with without problems. (This document is in German).

\section{9}

\section{V18/020673}

\section{Groundwater Remediation with Granular Collection} System

Frieseke, R.W.; Christensen, E.R.

Giles Engineering Associates, Inc., Waukesha, WI; University of Wisconsin, Milwaukee, WI

Journal of Environmental Engineering 122(6):546-549 (June 1996)

The purpose of this study is to evaluate the use of a granular groundwater collection system to increase groundwater recovery well yieid and radial influence during remediation of gasoline-contaminated groundwater. The field study was conducted at a site in Kenosha, Wisconsin. Two identical recovery wells were designed and installed within the granular groundwater collection system (RW No. 1) and the native silty fine sand soils (RW No. 2), respectively, in order to allow a direct comparison of recovery well yields and radial influence. The comparison was based on laboratory grain size and permeability tests, and in-situ yield and pump tests. The results show that RW No. 1 can produce $2.2-4.5$ times the quantity of groundwater of RW No. 2, and that the radial influence (groundwater drawdown) created by extracting from RW No. 1 was three to four times the drawdown from RW No. 2. There was a significant improvement in groundwater quality since the implementation of the remediation system. The achieved increase in the recovery well yield and radial influence should reduce the time and cost to complete a groundwater remediation project.

\section{0 \\ V18/021627}

\section{Groundwater Restoration of Insitu Uranium Mines}

NUEXCO: Monthly Report to the Nuclear Industry 39:21-25 (May 1994)

Insitu leaching is a relatively new uranium production technology that is expected to account for a growing share of future output. Depending upon the leaching solution used, the process may have considerable impact on the groundwater. Since restoration of groundwater quality is required in most countries and since this restoration is by far the most costly aspect of reclamation of an insitu mine, it is necessary to utilize a process that lends itself both to the efficiency of the leaching process and the restoration process. This article examines a number of techniques that may be used in the restoration efforts. These inciude: (1) groundwater sweep, (2) reverse osmosis, (3) chemical restoration, and (4) electrodialysis. The article also discusses disposal of the excess fluids used in the restoration process.
Los Alamos National Laboratory, Los Alamos, NM LALP-95-19; 1 p. (1995)

Establishing an engineering basis from which to make decisions for many environmental problems requires an understanding of contaminant transport in the subsurface and the ability to model the processes and technical solutions involved. In many cases, the tools, skills, and knowledge presently available are not adequate for effective decision making. Los Alamos has developed computer codes that simulate the flow of air, water, and heat, as well as the transport of contaminants in both saturated and partially saturated porous and fractured media. Los Alamos has expertise and experience in using these codes to address a variety of environmental problems.

3122

\section{$\mathrm{V} 18 / 023322$}

Groundwater and Subsurface Remediation: Research Strategies for Insitu Technologies

Groundwater and Subsurface Remediation: Research Strategies for Insitu Technologies, H. Kobus and B. Barczewski (eds.), Springer Verlag, New York, NY, 340 pp. (June 1996)

No abstract available.

3123 V18/020918

Heterogeneity and Contaminant Transport Modeling for the Savannah River Integrated Demonstration Site Chesnut, D.A.

Lawrence Livermore National Laboratory, Earth Sciences Department, Livermore, CA

UCRL-JC-1 12037; CONF-930589; Proceedings of the Fourth International Conference on Contaminated Soil, Berlin, Germany, May 3-7, 1993; (pp. 191-198) (1993)

The effectiveness of remediating aquifers and vadose zone sediments is frequently controlled by spatial heterogeneities. A continuing and long-recognized problem in selecting, planning, implementing, and operating remediation projects is the development of methods for quantitatively describing heterogeneity and predicting its effects on process performance. The Savannah River Integrated Demonstration Project has produced a wealth of data upon which to try a variety of modeling approaches, from conceptualization through calculation. Several approaches will be described briefly. The similarity to and differences from modeling oil recovery processes in the petroleum industry are illustrated by the extension to contaminant extraction processes of an analytic model originally developed for waterflooding petroleum reservoirs. The resulting equations incorporate the effects of heterogeneity through a single parameter. Fitting this model to the Savannah River In Situ Air Stripping test data suggests that the injection of air into a horizontal well below the water table may have improved performance by changing the flow pattem in the vadose zone. This change increased the capture volume, and consequently the contaminant mass inventory, of the horizontal injection well completed in the vadose zone. The apparent increases (compared to extraction only from the horizontal well) are from 10,200 to 21,000 pounds for TCE and from 3,600 pounds to 59,800 pounds for PCE. The predominance of PCE in this calculated increase suggests that redistribution of flow paths in the vadose zone, rather 
than insitu stripping, may provide most of the improvement. Although this preliminary conclusion remains to be reinforced by more sophisticated modeling currently in progress, there appears to be a definite improvement, which is attributable to air injection, over conventional remediation methods.

3124

V18/024288

High-Vacuum System Accelerates Remediation of Low-Permeability Soils and Aquifers

Hazardous Waste Consultant 13(4):1.3-1.6 (July-August 1995)

Although conventional pump-and-treat and soil vapor extraction systems have met with some success in remediating contaminated, high-permeability soils and aquifers, these technologies have generally performed poorly at sites with low-permeability strata. The low permeability of the vadose and/or saturated zones does not allow adequate migration of contaminants to remediate such sites in a reasonable time frame, if remediation to targeted cleanup levels is possible at all. Instead of tuming to costly and complex exsitu techniques, remediators may now have another option. Xerox Corporation has developed and patented a high-vacuum technique that draws both soil vapor and groundwater from low-permeability sites. The technique is applicable primarily at sites where both soil and groundwater are contaminated with volatile organic compounds.

3125

V18/023991

Hydrogeologic Characterization of Fractured Rock Formations: A Guide for Groundwater Remediators

Cohen, A.J.B.; Karasaki, K.; Benson, S.; Bodvarsson, G.; Freifeld, B.; Benito, P.; Cook, P.; Clyde, J.; Grossenbacher, K.; Peterson, J.; Solbau, R.; Thapa, B.; Vasco, D.; Zawislanski, $\mathrm{P}$.

Lawrence Berkeley National Laboratory, Berkeley, CA; U.S. Environmental Protection Agency, Cincinnati, $\mathrm{OH}$; National Risk Management Research Laboratory, Ada, OK

EPA/600/S-96/001; 6 pp. (May 1996)

A field site was developed in the foothills of the Sierra Nevada, California, to develop and test a multidisciplinary approach to the characterization of groundwater flow and transport in fractured rocks. Nine boreholes were drilled into the granitic bedrock, and a wide variety of instruments and methodologies were tested. Fracture properties were measured on outcrops and in boreholes using acoustic televiewer, digital borehole color scanner, and by down-hole camera logs. Conventional geophysical logs were collected. In addition, thermal-pulse and impeller flowmeter logging, fluid replacement and conductivity logging, packer-injection profiling tests, and ordinary open-hole pumping tests were conducted. Transmissive fractures were identified by integrating results from hydrologic and geophysical measurements, and the hydrogeologic structure of the formation was hypothesized. Cross-hole seismic surveys yielded tomograms of interborehole rock properties. Visualization software was used in combination with geophysical logs to interpolate interborehole properties, and a detailed 3-D model of the subsurface was constructed. Other referenced work at the site includes cross-hole hydrologic tomography, tracer tests, fracture-specific morphology studies, and development of an automated data acquisition system used to collect data and monitor and control test parameters during borehole testing. A novel aspect of the project report is its guidebook format. A description of each tool and methodology, the strengths and shortcoming of each, how they compare with one another, and suggestions of how best to analyze and integrate data are presented.

3126

V18/023463

Identification of Biological Processes in a Mixed Hydrocarbon Plume at a Paint Manufacturing Facility

McLaughlan, R.G.; Walsh, K.P.; Henkler, R.D.; Anderson, B.N.

University of Technology, Sydney, Australia; ICI Paints, Slough, United Kingdom; Royal Melbourne Institute of Technology, Melbourne, Australia

CONF-960730 (Vol. 3); Technologies Critical to a Changing World, Volume III: Emerging Energy Technologies, Clean Technologies, Remediation and Emission Control Fuels, and Petrochemicals, Proceedings of the Fifth World Congress of Chemical Engineering, San Diego, CA, July 14-18, 1996. American Institute of Chemical Engineers, New York, NY, Vol. 3, 1118 pp.; (pp. 767-771) (1996)

In situ biodegradation is increasingly being used as a cost effective remedial strategy for contaminated sites. However, for the remediation to be successful, it is necessary to understand the fundamental geochemical and microbiological processes occurring at a particular site. At a paint manufacturing facility, a mixed hydrocarbon plume containing both benzene, ethylbenzene, tolvene, and xylene (BTEX) and paraffinic hydrocarbons (Stoddard solvent) has contaminated the aquifer. The microbial processes occurring in the plume were investigated to better define the capacity of the aquifer to degrade hydrocarbons. Microbial oxidation of hydrocarbons is known to be coupled with the reduction of redox active species including oxygen, nitrate, ferric iron and sulfate as well as the production of methane. Water quality data, redox parameters and contaminant information were collected from the site to identify candidate biological processes occurring. The results show that as the contaminant concentration increases, the redox decreases indicating the generation of a more reduced environment. The decreasing redox correlates with increased concentrations of ammonia, ferrous iron and sulfide. The data indicates that there have been a range of different electron acceptor systems operating at the site. This has been correlated with a theoretical amount of benzene consumed. The chemistry from the wells at the site show that at least $47 \mathrm{mg} / \mathrm{L}$ of benzene is capable of being mineralized within the aquifer by microbial based transformations given the current contaminant loading and flow rate.

\section{$3127 \quad \mathrm{~V} 18 / 023305$}

Impacts of Physical and Chemical Heterogeneity on Co-Contaminant Transport in a Sandy Porous Medium

Tompson, A.F.B.; Schafer-Perini, A.L.; Smith, R.W.

Lawrence Livermore National Laboratory, Livermore, CA; Idaho National Engineering Laboratory, Idaho Falls, ID

UCRL-JC-120685; 30 pp. (March 1995)

This paper presents a simplified numerical study of the transport of a uranyl-citric acid mixture through a nonuniform and reactive sandy porous medium. The approach seeks to identify the more 
important impacts of medium heterogeneity, as embodied in spatially variable physical and chemical properties, on the migration and dilution rates of a model co-contaminant mixture, as well as on the overall partitioning among the aqueous and solid species formed from complexation and sorption reactions. Solid phase reactions are considered to occur on hydro-ferric oxide (goethite) coatings on the sand and are controlled by the abundance of the oxide as a function of the specific sand surface area and larger-scale patterns of oxide deposition. The simulations involve calculation of fluid flow and chemical migration within highly resolved, two-and three-dimensional regions with synthetic material properties that approximate observed conditions in a sandy coastal aquifer. Transport computations are based upon a random walk particle model, modified to treat multicomponent complexation and sorption reactions. The results illustrate the importance of multicomponent interactions on the overall migration behavior of a co-contaminant mixture, specific impacts of heterogeneity in, and correlation between, physical and chemical properties, as well as differences that arise between behavior in two- and three-dimensional systems.

\section{8}

V18/022499

Implementation and Operation of an Active Permeable-Barrier Trench System for the Containment of Groundwater Contamination

Ratliff, $M$.

\section{Halliburton Energy Services, Houston, TX} CONF-950333; SPE-29758; Government and Industry Working Together to Find Cost Effective Approaches to Protecting the Environment, Proceedings of the Society of Petroleum Engineers (SPE)/U.S. Environmental Protection Agency (EPA) Exploration Production Environmental Conference, Houston, TX, March 27-29, 1995. SPE, Richardson, TX, 797 pp.; (pp. 655-659) (1995)

This paper is a case study of the implementation and operation of an active permeable barrier-trench system beneath an oilfield service facility in eastem New Mexico. The system was designed to prevent the migration of petroleum hydrocarbon contaminants into the groundwater. Gasoline-range contaminants were discovered during the removal of underground fuel storage tanks at the site. The active permeable barrier trench system was installed in 1992 and consists of two trenches, which are 128 and $132 \mathrm{ft}$ long and approximately $15 \mathrm{ft}$ deep. Trenches extend approximately $3 \mathrm{ft}$ below the surface of the water table and were installed in three phases. Each trench was lined with a water-permeable geotextile fabric barrier, which was used to keep silt from permeating into the trench, but still allowed water to freely flow through the fabric. Each trench was then filled with 8 vertical feet of 2 -in. gravel to increase porosity and permeability within the furrow. The remaining $6 \mathrm{ft}$ of trench was filled with soil and the entire area was capped with asphalt. Each trench was fitted with an air transmission system, at a depth of $14 \mathrm{ft}$ below grade, to bubble air into the passing groundwater. Air was supplied by a blower at the surface to strip volatile contaminants from the water column and increase the dissolved oxygen content of the groundwater to promote microbial activity. Nutrient feed pipes were set in the trenches at a depth of $12 \mathrm{ft}$ below grade. The feed pipes were used to inject nutrients into the groundwater to promote microbial growth and increase hydrocarbon degradation. Vapor extraction lines were installed at a depth of $8 \mathrm{ft}$ below grade to remove any volatilized hydrocarbons. The vapor extraction system was connected to a passive ventilation system at the surface. The system has been in operation for approximately 2 years with good results.

3129

\section{$\mathrm{V} 18 / 022636$}

Implementation of a Funnel-and-Gate Remediation System [March 1996]

O'Brien, K.; Keyes, G.; Sherman, N.

Geraghty \& Miller, Inc., Richmond, CA; Louisiana-Pacific Corporation, Samoa, CA

CONF-960393 (Part 2); Contaminated Soils and Groundwater: Analysis, Fate, Environmental and Public Health Effects, and Remediation, Proceedings of the Sixth Annual West Coast Conference, Newport Beach, CA, March 11-14, 1996. Association for the Environmental Health of Soils, Amherst, MA, Part 2, 226 pp.; (p. 16) (1996)

Funnel-and-gate systems are gaining attention, not necessarily because they speed up the remediation process, but because their use recognizes the limitations of groundwater cleanup programs and factors these limitations into minimizing the lifetime costs of implementing remedial actions. The term funnel-and-gate refers to the installation of low-permeability barriers downgradient of impacted groundwater which are arranged so as to direct the flow of the groundwater through treatment gates. The flow through the treatment gates is driven by natural groundiwater gradients, eliminating extraction pumps and above-ground treatment systems. The treatment gates are designed specifically to treat the contamination in the groundwater that will flow through the gates. Funnel-and-gate systems attempt to eliminate or at least minimize mechanical systems, thereby reducing the long-term operation and maintenance costs that so often drive up the lifetime costs of remedial projects. Long-term operation and maintenance costs are reduced because the site does not need a continuous input of energy or manpower. In addition, groundwater monitoring and system compliance issues can be streamlined for even greater cost savings. Since it is a developing technology, there are few commercial applications where funnel-and-gate systems have been proven. Pollutants of concem include: petroleum hydrocarbons; chlorinated solvents; and halogenated volatile organic compounds. This paper describes the implementation of a funnel-and-gate system at a studmill in Mendocino County, California.

\section{0}

\section{V18/021634}

Implementation of a Funnel-and-Gate Remediation System [November 1995]

O'Brien, K.; Keyes, G.; Sherman, N.

Geraghty \& Miller, Inc., Richmond, CA; Louisiana-Pacific Corporation, Samoa, CA

CONF-951124; HazMat West '95, Proceedings of the Eleventh Annual Environmental Management and Technology Conference and Exhibition, Long Beach, CA, November 7-9, 1995. Advanstar Expositions, Duluth, MN, 597 pp.; (pp. 399-408) (1995)

Funnel-and-gate systems are gaining attention, not necessarily because they speed up the remediation process, but because their use recognizes the limitations of groundwater cleanup programs and 
factors the limitations into minimizing the lifetime costs of implementing remedial actions. The term funnel-and-gate refers to the installation of low-permeability barriers downgradient of impacted groundwater which are arranged so as to direct the flow of the groundwater through treatment gates. The flow through the treatment gates is driven by natural groundwater gradients, eliminating extraction pumps and above-ground treatment systems. The treatment gates are designed specifically to treat the contamination in the groundwater that will flow through the gates. Funnel-and-gate systems attempt to eliminate or at least minimize mechanical systems, thereby reducing the long-term operation and maintenance costs that so often drive up the lifetime costs of remedial projects. Long-term operation and maintenance costs are reduced because the site does not need a continuous input of energy or manpower. In addition, groundwater monitoring and system compliance issues can be streamlined for even greater cost savings. Since it is a developing technology, there are few commercial applications where funnel and gate systems have been proven.

\section{1}

V18/023904

Insitu Air Sparging: Mass Transfer Mechanisms and Modifications to Accommodate Hydrogeologic Heterogeneity

Anderson, K.S.; Suthersan, S.S.

GeoEngineers, Inc., Seattle, WA; Geraghty \& Miller, Inc., Langhorne, PA

CONF-951124; HazMat West '95, Proceedings of the Eleventh Annual Environmental Management and Technology Conference and Exhibition, Long Beach, CA, November 7-9, 1995. Advanstar Expositions, Duluth, MN, 597 pp.; (pp. 409-420) (1995)

Application of air sparging in coarse-grained homogeneous environments is relatively straight forward. For these types of sites contaminant mass transfer variables such as advection and dispersion can be enhanced to increase mass transfer and removal rates. However, for most sites the hydrogeology is not homogeneous, and also may not have the ideal hydraulic conductivity that is conducive to conventional air sparging. For both homogeneous and heterogeneous sites, an understanding of variables such as advection, dispersion, and retardation that affect contaminant mass transfer rates is critical. Without correct application of technology, complete design test data, and understanding of mass transfer mechanisms, heterogeneity and fine-grained soils can result in several undesirable conditions such as: (I) lateral spreading and uncontrolled migration of vapor-phase contaminants in the saturated and unsaturated zone, (2) lateral spreading of the dissolved-phase contaminant plume, (3) ineffective areal coverage of the air sparging system, (4) reduction of aquifer permeability in the target zone, and (5) unacceptable contaminant mass transfer and removal rates. To accommodate heterogeneous and/or fine-grained hydrogeologic conditions, modifications of conventional in situ air sparging can be made. Examples of these modifications include (1) trench sparging, (2) sparging curtains, (3) pneumatic fracturing and air sparging, (4) trenching for vapor collection, and (5) in-well sparging. With each of these modified air sparging methods, mass transfer mechanisms and subsequent rates of removal will vary.
Insitu BTEX Biotransformation Under Enhanced Nitrate- and Sulfate-Reducing Conditions

Reinhard, M.; Shang, S.; Kitanidis, P.K.; Orwin, E.; Hopkins, G.D.; Lebron, C.A.

Stanford University, Western Region Hazardous Substance Research Center, Stanford, CA; U.S. Navy, Naval Facilities Engineering Service Center, Port Hueneme, CA

Environmental Science \& Technology 31(1):28-36 (1997)

In situ anaerobic biotransformation of BTEX (benzene, toluene, ethylbenzene, 0-xylene, and $\mathrm{m}$-xylene) was investigated under enhanced nitrate- and sulfate-reducing conditions. Controlled amounts of BTEX compounds added to slugs of treated groundwater were released into a gasoline-contaminated aquifer at Seal Beach, CA. In a series of studies, the slugs, $470-1700 \mathrm{~L}$ in volume, were released into the aquifer through a multi-port injection/extraction well and were subsequently withdrawn over a 2-3-month period. To evaluate unamended in situ conditions, the injectate was treated with granular activated carbon (GAC) and augmented with bromide as a tracer. To evaluate nitrate- and sulfate-reducing conditions, the injectate was also deionized and augmented with $200-300 \mathrm{ug} / \mathrm{L}$ BTEX, nitrate or sulfate, and background electrolytes. Under unamended conditions, transformation appeared to be limited to the slow removal of toluene and $m, p-x y l e n e$ (i.e., sum of $m+p-x y l e n e$ ). Under nitrate-reducing conditions, toluene, ethylbenzene, and $m$-xylene were transformed without a lag phase in less than 10 days, and 0 -xylene was transformed in 72 days. Under sulfate-reducing conditions, toluene, $m$-xylene and $o-x y l e n e$ were completely transformed in less than $\mathbf{5 0}$ days, and ethylbenzene was removed in 60 days. Benzene appeared to be removed under sulfate-reducing conditions, but the trend was pronounced only at some levels. $A$ two-dimensional model is presented for the evaluation of reactive solute behavior in such slug tests. For compounds that are transformed without a lag phase, zero-order kinetics appears to be more applicable than first-order kinetics.

3133

V18/023896

Insitu Biological Treatment of Chlorinated Solvents in Soil and Groundwater

Henry, S.M.; Padilla, K.K.

Kennedy/Jenks Consultants, Irvine, CA

CONF-951124; HazMat West '95, Proceedings of the Eleventh Annual Environmental Management and Technology Conference and Exhibition, Long Beach, CA, November 7-9, 1995. Advanstar Expositions, Duluth, MN, 597 pp.; (pp. 39-55) (1995)

Laboratory research has demonstrated conclusively that under the right conditions, both aerobic and anaerobic bacteria can degrade chloroethenes completely to harmless by-products. More importantly, field demonstrations and pilot studies have demonstrated that in situ remediation of chloroethenes is not only feasible, but, when properiy engineered, can be a cost-effective remediation approach. In situ remediation of chlorinated solvents has received broad support from both public and private sectors. The EPA, the Department of Energy (DOE), and the Department of Defense (DOD) have provided millions of dollars in research funding for the development of in situ bioremediation technologies for chlorinated solvents. Technologies have been evaluated as a part of the EPA Superfund Innovative Technology Evaluation (SITE) 
program. Industry has also invested millions of dollars for research and technology development.

\section{$3134 \quad$ V18/022498}

Insitu Bioremediation of a Former Natural Gas Dehydrator Site Using Bioventing/Biosparging

Sharmory, B.D.; Lawrence, A.W.; Miller, D.L.; Miller, J.A.; Weightman, R.L.; Raetz, R.M.; Hayes, T.D.

Remediation Technologies, Inc., Concord, MA; Global Remediation Technologies, Inc., Traverse City, MI; Gas Research Institute, Chicago, IL

CONF-950333; SPE-29753; Government and Industry Working Together to Find Cost Effective Approaches to Protecting the Environment, Proceedings of the Society of Petroleum Engineers (SPE)/U.S. Environmental Protection Agency (EPA) Exploration Production Environmental Conference, Houston, TX, March 27-29, 1995. SPE, Richardson, TX, 797 pp.; (pp. 587-599) (1995)

The Gas Research Institute (GRI) is conducting a research program on site remediation and residuals management for natural gas exploration and production (E\&P) activities. Biological processes are considered to be a key component of the GRI remedial strategy since most of the chemicals-of-interest in soils and groundwater at E\&P sites have been reported to be biodegradable. A bioventing/biosparging field demonstration was conducted over a ten month period at a former glycol dehydrator site, located near Traverse City, MI. The results of this study suggest that bioventing/biosparging is a feasible technology for in situ remediation of soil and groundwater at gas industry glycol dehydrator sites and that pulsed operating mode may have an advantage over the other modes.

\section{5 \\ V18/025294}

Insitu Bioremediation: The State of the Practice Brown, R.A.; Mahaffey, W.; Norris, R.D. Groundwater Technology, Inc., Trenton, NJ; ECOVA Corporation, Redmond, WA; Eckenfelder, Inc., Nashville, TN

Insitu Bioremediation: When Does It Work?, National Academy Press, Washington, DC, 207 pp.; (pp. 121-135) (1993)

Since the pioneering work by Dick Raymond during the 1970 s and early 1980s, in situ bioremediation has been widely used to clean up aquifers contaminated with petroleum hydrocarbons. A need for better performance led to development of the use of hydrogen peroxide and direct injection of air into the aquifer as sources of oxygen, which was a critical problem in bioremediation. Bioremediation has developed in two branches. The first has been engineering techniques and mathematical models for applying bioremediation to readily degradable contaminants. The second branch has focused on ways to address more recalcitrant contaminants such as chlorinated solvents, polychlorinated biphenyls, and pesticides. Work on these more challenging problems has met with some success in the laboratory, but the techniques have yet to be commercialized, largely because of failure to establish and maintain critical control parameters in the subsurface. Continued improvements in the technology will result from efforts in site delineation, engineering controls, use of nonindigenous microorganisms, and field methods for evaluating the microbiological processes.

\section{6}

V18/025290

Insitu Bioremediation: When Does It Work?

Insitu Bioremediation: When Does It Work?, National Academy Press, Washington, DC, 207 pp. (1993)

This report by the Committee on In Situ Bioremediation of the National Research Council attempts to communicate the scientific and technical bases for in situ bioremediation with the goal of eliminating the mystery that surrounds this highly multidisciplinary technology. The report presents guidelines for evaluating in situ bioremediation projects to determine if they will or are meeting regulatory guidelines. The committee was formed in 1992 with the specific task of developing such guidelines. Its membership represents the span of groups involved in bioremediation, including buyers of bioremediation services, bioremediation contractors, environmental regulators, and academic researchers. The report contains four main chapters that discuss basic principles of bioremediation, current implementation practices, methods of evaluating the performance of field projects, and the future prospects for bioremediation. The report also contains seven background papers written by committee members that represent the range of perspectives from which bioremediation may be viewed. Individual chapters and papers within the scope of this data base have been indexed separately.

\section{7}

\section{V18/021093}

\section{Insitu Microbial Filter for Groundwater Remediation}

Knapp, R.B.; Duba, A.G.; Jackson, K.J.; Jovanovich, M.C.; Taylor, R.T.

Lawrence Livermore National Laboratory, Livermore, CA UCRL-LR-112400-92-2/93-1; Environmental Restoration/Waste Management - Applied Technology, Semiannual Repon for July 1992-June 1993 - Volume 1, Number 2 and Volume 2. Number 1; (pp. 18-22) (1993)

In situ microbial filters offer a simple solution to the problems encountered in other bioremediation methods. They can be engineered for specific field applications and might cost only half as much as current pump-and-treat processes. In situ microbial filters are a significant departure from current in situ bioremediation practice. The concept has two main components: (1) treatment of only the contaminant source region and selected portions of the plume and (2) injection of resting bacterial cells into the subsurface, without nutrients. The main advantages of the approach are its simplicity and the ability to engineer field applications to specific sites. It eliminates the problems caused by nutrient injection because injection occurs for only a short time. Treatment of the pollutant source regions eliminates continued release of contamination; treatment of selected regions of the plume simplifies remediation by reducing the characterization effort while preventing further spread of the plume. Engineering control is achieved by designing a biofilter whose length and bacterial density are matched to the expected contaminant flux. The actual geometry of the biofilter depends on the injection pattern, but in general, a thin region is formed that extends across the expanding contaminant plume. The microbial filter concept can be generalized, even though the current 
focus is on intercepting chlorinated ethene plumes. It is possible to bioremediate many classes of contaminants, especially when suites of microbial species are considered.

\section{8}

$$
\text { V18/022233 }
$$

Insitu Sparging: Managing Subsurface Transport and Mass Transfer

Clayton, W.S.; Nelson, C.H.

Groundwater Technology, Inc., Golden, CO

CONF-951139 (Vol. 2); Superfund 16: Proceedings of a Hazardous Waste Conference and Exhibition, Washington, DC, November 6-8, 1995. E.J. Krause and Associates, Bethesda, MD, Vol. 2, 817 pp.; (pp. 1135-1144) (1994)

Mass transfer during in situ sparging (ISS) is generally diffusion-limited, since not all of the contaminated media is directly contacted by the sparged gas. The distance over which diffusion must occur (diffusion path length) and the air-water interfacial area are directly related to the geometry of air-filled pores and the air saturation developed. During ISS, the pore-scale and the air saturation developed. During ISS, the pore-scale distribution of air fingers is a primary factor controlling these properties. Furthermore, the physical and chemical properties of the sparged gas, the contaminants, and the subsurface strongly influence mass transfer. Numerical modelling of nonsteady-state mass transfer during ISS indicates that the rate of mass transfer is increased for higher air saturations and smaller soil pore sizes. Organic carbon in soils can result in extreme disequilibrium between soil and groundwater. This may account for the observed "rebound" of dissolved contaminant concentrations after shutdown of sparging systems. Ozone is a strong oxidizer which has been applied to groundwater via ozone sparging. Numerical modeling and site data for ozone sparging show that the process is sensitive to the ozone reaction rates and the air flow dynamics. Transfer of ozone to groundwater can be maximized by increased ozone injection concentrations and increased air saturations.

\section{$3139 \quad \mathrm{~V} 18 / 021808$}

Insitu Permeable Sensor to Monitor Groundwater Flow Ballard, $\mathbf{S}$.

Sandia National Laboratories, Albuquerque, NM

Sensors (December 1992):20-26 (December 1992)

Groundwater flow is perhaps the most important mechanism for the dispersal of many types of toxic waste once they have been released into the subsurface. Accurate information about the groundwater flow field is therefore crucial to the characterization of waste sites, inspection of waste-remediation activities, and monitoring of the post-closure performance of remediated waste sites. A new groundwater flow sensing technology now under development at Sandia National Laboratories should find widespread applications in all these areas. The instrument uses a thermal perturbation technique to directly measure the 3-D groundwater flow velocity vector in permeable geologic formations. This paper describes the technology development and field testing to date.

3140

V18/025448

Insitu Remediation of Hydrocarbon Contaminated
Groundwater in Low Hydraulic Conductivity Media Using Trench and Gate Technology

Bowles, M.; Rathgeber, J.; Bentley, L.; Barker, J.

Calgary University, Department of Geology and Geophysics, Calgary, Alberta, Canada; Komex International Limited, Calgary, Alberta, Canada; Waterloo Center for Groundwater Research, Department of the Environment, Waterloo, Ontario, Canada; Environmental Protection Service, Ottawa, Ontario, Canada

CONF-951086; Proceedings of the Fifth Annual Symposium on Groundwater and Soil Remediation, Toronto, Ontario, Canada, October 2-6, 1995. Environment Canada - Environmental Protection Service, Hull, Quebec, Canada, 566 pp.; (pp. 35-47) (1995)

A modified version of the funnel and gate technology used for the remediation of high hydraulic conductivity media (i.e., sand and gravel) was assessed for use with low hydraulic conductivity media, such as hydrocarbon-contaminated groundwater hosted by fine-grained glacial deposits (e.g., silt and clay tills). A pilot-scale system, termed "trench and gate" was designed for installation at the Amoco-operated East Garrington Gas Plant in Alberta. The theoretical background, site history, hydrogeologic setting, contaminant sources and concentrations, design considerations and construction techniques, and advantages of the trench and gate system are described. Preliminary findings suggest that while the trench and gate system may be useful in certain applications, it is not cost-effective for treating very wide or deep contaminant plumes.

\section{$3141 \quad \mathrm{~V} 18 / 023745$}

Insitu Treatment of Landfill Leachate and Wastes Using Bioventing Technology [September 1995]

Barr, K.D.; O'Flanagan, B.D.; Newman, W.A.; Julik, J.K.; Wetzstein, D.W.

Delta Environmental Consultants, Inc., St. Paul, MN; Minnesota Pollution Control Agency, St. Paul, MN

CONF-950978; Municipal and Industrial Waste, Proceedings of the 18th International Madison Waste Conference, Madison, WI, September 20-21, 1995. University of Wisconsin, Madison, WI, 461 pp.; (pp. 248-259) (1995)

The effectiveness of in-situ, aerobic biodegradation of landfill leachate has been tested by applying bioventing at a closed municipal solid waste landfill in Minnesota. A pilot test was conducted with air injection into a field of six bioventing wells for a six month period, creating an aerobic biotreatment zone for leachate as it migrates to groundwater. Results show that an effective aerobic treatment zone can be established and maintained with organic compounds actively biodegraded and dissolved inorganic compounds, such as metals, oxidized and immobilized. Groundwater contaminants also showed decreasing concentrations during the pilot test. This approach may, ultimately, obviate the need for groundwater removal and treatment. 


\section{Riser-Roberts, E.}

Bioremediation of Petroleum Contaminated Sites, C.K. Smoley, Cheisea, MI, 464 pp.; (pp. 35-57) (1992)

This is a chapter in the book titled: Bioremediation of Petroleum Contaminated Sites by Eve Riser-Roberts. Microorganisms are the principal agents responsible for the recycling of carbon in nature. In many ecosystems there is already an adequate indigenous hydrocarbonoclastic microbial community capable of extensive oil biodegradation, provided that environmental conditions are favorable for oil-degrading metabolic activity. This has been shown for many soil and marine and fresh-water environments. It is suggested by some researchers that all soils, except those that are very acidic, contain the organisms capable of degrading oil products, that microbial seeding is not necessary, and that the problem is actually one of supplying the necessary nutrients at the site. The ability to utilize hydrocarbons is widely distributed among diverse microbial populations. Many species of bacteria, cyanobacteria, filamentous fungi, and yeasts coexist in natural ecosystems and may act independently or in combination to metabolize aromatic hydrocarbons. In general, population levels of hydrocarbon utilizers and their proportions within the microbial community appear to be a sensitive index of environmental exposure to hydrocarbons. In unpolluted ecosystems, hydrocarbon utilizers generally constitute less than $0.1 \%$ of the microbial community; in oil-polluted ecosystems, they can constitute up to $100 \%$ of the viable microorganisms. This difference seems to reflect quantitatively the degree or extent of exposure of an ecosystem to hydrocarbon contaminants. Extensive degradation of petroleum pollutants generally is accomplished by mixed microbial populations, rather than single microbial species. There are advantages to relying on indigenous microorganisms rather than adding microorganisms to degrade wastes. Through countless generations of evolution, natural populations have developed that are ideally suited for survival and proliferation in that environment. This is particularly true of uncontrolled hazardous waste sites where microorganisms have been exposed to the wastes for years or even decades.

\section{3}

\section{V18/023999}

\section{Industry Survey for Horizontal Wells: Final Report}

Wilson, D.D.; Kaback, D.S.

Westinghouse Savannah River Company, Aiken, SC WSRC-TR-93-511; 65 pp. (July 1993)

An international survey of horizontal wells was performed during May and June of 1993. The purpose of the survey was to provide the environmental industry with an inventory of horizontal environmental wells and information pertaining to the extent of the use of horizontal environmental wells, the variety of horizontal environmental well applications, the types of geologic and hydrogeologic conditions within which horizontal environmental wells have been installed, and the companies that perform horizontal environmental well installations. Other information, such as the cost of horizontal environmental well installations and the results of tests performed on the welis, is not complete but is provided as general information with the caveat that the information should not be used to compare drilling companies. The inventory was compiled through a telephone/telefacsimile survey. The strategy used consisted of contacting drilling companies and drilling equipment suppliers and acquiring a list of locations that horizontal environmental wells have been installed. Once the locations had been determined, personnel familiar with the drilling projects were contacted and information was gathered concerning the objectives of the project, the directional drilling methods used, description of the drilling and well installation method, the current status of the wells, results of tests performed on the wells, and the approximate cost of the wells. The result of the survey is a catalogue of horizontal environmental wells that are categorized by the objective or use of the wells, the vertical depth of the wells, and the drilling company contracted to install the wells.

\section{4}

\section{V18/025292}

Industry's Perspective on Intrinsic Bioremediation

Salanitro, J.P.

Shell Development Company, Houston, TX

Insitu Bioremediation: When Does It Work?, National Academy Press, Washington, DC, 207 pp.; (pp. 104-109) (1993)

Laboratory and field evidence is now sufficient to demonstrate that soil microorganisms in aquifers are responsible for a significant portion of the attenuation of aromatic compounds - benzene, toluene, ethylbenzene, and xylenes (BTEX) - from fuel spills to the subsurface environment. Most subsoils contain indigenous microbes that can biodegrade low levels of BTEX (ppb to low ppm), given enough dissolved oxygen in the groundwater. With adequate site characterization, analysis, and monitoring, this type of intrinsic bioremediation can shrink plumes and control the migration of hydrocarbons. In situ biodegradation processes, properly monitored, should be considered practical, cost-effective altematives for managing low-risk, hydrocarbon-contaminated groundwaters that are unlikely to affect drinking water wells.

\section{5}

\section{V18/024025}

Influence of Humic Substances on Co $(+2)$ Sorption by a Subsurface Mineral Separate and Its Mineralogic Components

Zachara, J.M.; Resch, C.T.; Smith, S.C.

Pacific Northwest Laboratory, Richland, WA

Geochimica et Cosmochimica Acta 58(2):553-566 (1994)

The sorption of $\mathrm{Co}(2+)[10(\mathrm{E}-6) \mathrm{mol} / \mathrm{L}]$ was measured on subsurface mineral materials in the absence and presence of a sorbed leonardite humic acid (LHA) to: (1) evaluate the sorptive role of mineral-bound humic substances, and (2) establish approaches to model metal ion binding in composite materials. The subsurface materials were a less than $2.0 \mathrm{mu} \mathrm{m}$ size fraction of an ultisol saprolite $(\mathrm{CP})$ and this same material treated with dithionite-citrate-bicarbonate (DCB) to remove Fe-oxides (DCP). Comparable experiments (with and without LHA) were also performed with mineral sorbents representing dominant phases in the CP separate (gibbsite, Al-goethite, and kaolinite) to evaluate their potential contributions to Co sorption. The mineral-bound LHA ranged in concentration between 0.1-0.4 mg-C/m2, representing approximately $0.7 \%$ of the subsurface isolate by mass. The sorption-desorption of LHA on the mineral surfaces, and its affinity for $\mathrm{Co}$ as an aqueous phase complexant were also determined. Batch measurements were employed (sorbents at 20-90 
$\mathrm{m} 2 / \mathrm{L}$; LHA-DOC at approximately $11 \mathrm{mg}-\mathrm{C} / \mathrm{L}$ ) over a range in $\mathrm{pH}$ and ionic strength (I) at $I=0.01$ and 0.1 in NaClO4.

3146

V18/021777

Influence of Nitrogen and Phosphorus on the Insitu Bioremediation of Trichloroethylene

Palumbo, A.V.; Scarborough, S.P.; Pfiffner, S.M.; Phelps, T.J.

Oak Ridge National Laboratory, Environmental Sciences Division, Oak Ridge, TN

CONF-940526; Proceedings of the 16th Symposium on Biotechnology for Fuels and Chemicals, Gatlinburg, TN, May 9-13, 1994; (20 pp.) (1994)

The U.S. Department of Energy, Office of Technology Development, has supported a field-scale in-situ demonstration of trichloroethylene (TCE) bioremediation at the Westinghouse Savannah River Site (WSRS). Several methods were used to examine the influence of nitrogen and phosphorus species on TCE degradation during methane $(\mathrm{CH} 4)$ injection into contaminated sediments. Laboratory experiments using WSRS groundwater revealed that the rate of acetate incorporation into microbial lipids was stimulated when triethyl-phosphate (TEP) or nitrous oxide (N2O) was added. The trend was: $\mathrm{CH} 4+\mathrm{N} 2 \mathrm{O}$ more than $\mathrm{CH} 4+$ TEP more than $\mathrm{CH} 4+\mathrm{N} 2 \mathrm{O}+\mathrm{TEP}$ more than $\mathrm{CH} 4$ alone. The degree of 14C-TCE mineralization in groundwater incubated for 30 days in the laboratory with added methane and nutrients increased in the order: $\mathrm{OP}=\mathrm{TEP}$ more than NH3 $+\mathrm{TEP}=\mathrm{NH} 3$ more than $\mathrm{N} 2 \mathrm{O}$ (OP, orthophosphate; $\mathrm{NH} 3$, ammonia). Monitoring of WSRS groundwater revealed significant differences among sampling wells over time in nutrient concentrations, nitrogen uptake, and urease activity during operations of the bioremediation demonstration. In the field addition of TEP $+\mathrm{N} 2 \mathrm{O}$ to the pulsed injection of $\mathrm{CH} 4$ resulted in dramatic stimulation of TCE degrading potentials observed in groundwater enrichments. The potential to mineralize 14C-TCE in groundwater enriched with nutrients in the laboratory increased from less than $50 \%$ of the samples taken during injection of methane in the field to greater than $90 \%$ of the samples taken during the injection of $\mathrm{CH} 4+\mathrm{TEP}+\mathrm{N} 2 \mathrm{O}$ treatment. These results demonstrated the dramatic impacts of nitrogen and phosphorus supplements during the in situ bioremediation of chlorinated solvents.

\section{7}

V18/025528

Injectability and Durability of Urethane as a Permeation Grout for Subsurface Containment of Waste

Gabr, M.A.; Freshwater, J.S.; Cook, E.E.

West Virginia University, Morgantown, WV

CONF-960804 (Vol. I); Spectrum '96: Nuclear and Hazardous Waste Management, Proceedings of an International Topical Meeting, Seattle, WA, August 18-23, 1996. American Nuclear Society, La Grange Park, IL, Vol. 1, 887 pp.; (pp. 383-390) (1996)

A laboratory testing program was conducted to investigate the feasibility of using urethane as grout for the formation of in situ waste barriers. Injectability, reduction in hydraulic conductivity, and the size of the formed barrier were investigated. Results indicated that the performance of the urethane barrier was affected by the acid and base test chemicals. The hydraulic conductivity of the urethane-grouted sand using deionized water was measured to be on the order of $5 \times 10(\mathrm{E}-8)$ centimeters/s. A hydraulic conductivity value in the range of $1 \times 10(E-4)$ centimeters/s to $1 \times 10(E-6)$ centimeters/s was measured using acid and base solutions. Accordingly, a permanent-specific permeability test should be conducted to judge the suitability of the urethane grout as a barrier material depending on the intended application.

\section{$3148 \quad V 18 / 022640$}

\section{Innovative Approaches to Remediation for VOC Sites} Using Recirculating Wells

Dawson, G.W.

CONF-960393 (Part 3); Contaminated Soils and Groundwater: Analysis, Fate, Environmental and Public Health Effects, and Remediation, Proceedings of the Sixth Annual West Coast Conference, Newport Beach, CA, March 11-14, 1996. Association for the Environmental Health of Soils, Amherst, MA, Part 3, 366 pp.; (p. 28) (1996)

In-well air stripping with approaches such as the patented NoVOCs system offer both cost and operational advantages over pump and treat, and in situ air sparging technologies. With in-well stripping, the water is treated in the well and discharged without being brought to the surface. Discharged water is circulated through the saturated zone acting as a carrier to continually flush contaminants from the aquifer matrix and transport them to the well for treatment. With pumping rates up to four times those of comparable extraction wells, latge radii of influence can be maintained and remediation is achieved faster and more efficiently. In-well stripping is applicable to any strippable contaminant including chlorinated solvents (i.e., trichloroethene [TCE] and tetrachloroethene [PCE]) and hydrocarbons such as the aromatic components in petroleum fuels. Growing costs associated with water discharge, NPDES permits, water rights and, in some areas, salt water intrusion have provided economic incentives to retrofit existing pump and treat systems with NoVOCs units. A large number of wells are amenable to retrofitting depending on their diameter, location and length of screens, and back fill. Even with the new initiatives for intrinsic remediation for petroleum fuel releases, there is a role for the NoVOCs technology. Free product removal wells based on the NoVOCs design eliminate the need to treat and permit water discharges produced when generating a cone of depression for collecting the floating fuel. Additionally, the stripping action and introduction of dissolved oxygen reduce soluble hydrocarbon concentrations to risk levels that can be easily addressed through intrinsic bioremediation.

3149

V18/023618

Innovative Funnel and Gate Approach to Groundwater Remediation

Johnson, D.O.; Wilkey, M.L.; Willis, J.M.; Breaux, L.; McKinsey, T.

Argonne National Laboratory, Energy Systems Division, Argonne, IL; Barrier Member Containment Corporation, Belle Chasse, LA

ANL/ES/CP-91223; CONF-9609162; Proceedings of the Third 
International Symposium and Exhibition on Environmental Contamination in Central and Eastern Europe, Warsaw, Poland, September 10-13, 1996, 200 pp.; (6 pp.) (1996)

The US Department of Energy, office of Science and Technology (EM-50) sponsored a demonstration project of the Barrier Member Containment Corporation's patented EnviroWall (TM) system at the Savannah River site. With this system, contaminated groundwater can be funneled into a treatment system without pumping the contaminated water to the surface. The EnviroWall (TM) barrier and pass-through system, an innovative product of six years of research and development, provides a means to enhance groundwater flow on the upgradient side of an impermeable wall and direct it to an in situ treatment system. The EnviroWall (TM) system is adaptable to most site conditions. Remedial applications range form plume containment to more robust designs that incorporate groundwater manipulation coupled with in situ treatment. Several key innovations of the EnviroWall (TM) system include the following: a method for guide box instaliation; a means for using interlocking seals at vertical seams; a down-hole video camera for inspecting seams and panels, instaliation of horizontaland vertical-collection systems; installation of vertical monitoring wells and instrumentation on each side of the barrier; site-specific backfill design; and a pass-through system for funneling groundwater into a treatment system.

3150

V18/022612

Innovative Groundwater Remediation Solutions for the Mercury Aircraft Site

Forbes, T.H.; Frappa, R.H.; McManus, A.M.C.

Malcolm Pirnie, Inc., Buffalo, NY

CONF-9505206; Proceedings of the 50th Industrial Waste

Conference, R.F. Wukasch (ed.), West Lafayette, IN, May 8-10,

1995. Ann Arbor Press, Inc., Chelsea, MI, 861 pp.; (pp. 97-106)

(1996)

Complex hydrogeologic conditions and groundwater contaminated with high concentrations of chlorinated solvents are common remediation problems at many industrial sites in New York State. This paper presents the results of an innovative remedial alternative implemented as an Interim Remedial Measure at the Mercury Aircraft site. The densely fractured bedrock conditions at this site precluded the cost-effective use of traditional individual pumping wells and/or in-situ groundwater treatment to mitigate the spread of contaminated groundwater. In addition, the high concentrations of VOCs presented a concern with respect to New York State air emissions limits for conventional exsitu treatment technologies. The remedial alternatives evaluated and the specifics of implementation of the selected alternative are presented along with performance results. In 1985, an estimated 300 to 500 gallon trichloroethene (TCE) spill occurred from a vapor degreasing process at Mercury Aircraft's manufacturing building. Much of the TCE was recovered during spill response cleanup operations; however, some TCE migrated through a seam in the floor of the vapor degreasing area and entered a leaky storm sewer beneath the facility.

3151

V18/023922

Innovative Use of Activated Carbon for the Removal of
Heavy Metals from Groundwater Sources

Lewis, T., III

Lewis Environmental Services, Inc., Pittsburgh, PA

CONF-961018; Extraction and Processing for the Treatment and Minimization of Wastes, V. Ramachandran and C.C. Nesbitt (eds.), Proceedings of the Second International Symposium, Scottsdale, AZ, October 27-30, 1996. The Minerals, Metals, \& Materials Society, Warrendale, PA, 856 pp.; (pp. 845-853) (1996)

This report discusses the evaluation of ENVIRO-CLEAN PROCESS, a technology developed by Lewis Environmental Services, Inc., for the recovery of metals such as chromium, mercury, copper, cadmium, lead, and zinc from surface and groundwater streams. This new heavy metal removal process (patent-pending) utilizes granular activated carbon with a proprietary conditioning pretreatment to enhance heavy metal adsorption combined with electrolytic metal recovery to produce a saleable metallic product. The process generates no sludge or hazardous waste and the effluent meets EPA limits. A $50 \mathrm{gpm}$ system was installed for recovering hexavalent chromium from a groundwater stream at a site located in Fresno, California. The effluent from the activated carbon system was reinjected into the groundwater table with the hexavalent chromium concentration less than $10 \mathrm{ppb}$. The system simultaneously removed trichloroethylene (TCE) to concentration levels less than $0.5 \mathrm{ppb}$. The activated carbon is regenerated off-site and the chromium electrolytically recovered. The full scale system has treated over 5 million gallons of groundwater since installation.

3152

V18/025593

Insitu Aeration: Air Sparging, Bioventing, and Related Remediation Process

Hinchee, R.E.; Miller, R.N.; Johnson, P.C.

Battelle Memorial Institute, Columbus, OH; U.S. Air Force Center for Environmental Excellence, Brooks Air Force Base, TX; Arizona State University, Tempe, AZ

CONF-950483 (Vol. 3-2); Proceedings of the Third International Insitu and Onsite Bioreclamation Symposium, San Diego, CA, April 24-27, 1995; Bioremediation Series 3(2) - Insitu Aeration: Air Sparging, Bioventing, and Related Remediation Processes, R.E. Hinchee, R.N. Miller and P.C. Johnson (eds.), Battelle Press, Columbus, OH, 630 pp. (1995)

This volume is part of a ten volume set of papers derived from the Third International Insitu and Onsite Bioreclamation Symposium, which was held in San Diego, California, in April 1995. The purpose of the conference was to provide a multidisciplinary forum for exchange of state-of-the-art information on bioremediation. The papers that appear in the set of volumes were accepted after peer review. This volume deals with the use of air sparging, bioventing, and other aeration processes to remediate hydrocarbon-contaminated soils and groundwater. Individual papers within the scope of this data base have been indexed separately.

3153

V18/024677

Insitu Bioremediation of Petroleum

Hydrocarbon-Contaminated Soil and Groundwater in a Low-Permeability Aquifer, Chapter 12

Norris, R.D.; Down, K.D. 
Eckenfelder, Inc., Nashville, TN; W.W. Irwin, Inc, Long

Beach, CA

Bioremediation: Field Experience, P.E. Flathman, D.E. Jerger and J.H. Exner (eds.), Lewis Publishers; Boca Raton, FL, 560 pp.; (pp. 457-474) (1994)

It is well understood that bioremediation is easier to implement in sandy or gravely soils than in silts and, particularly, in clayey soils. There have been frequent attempts to derive rules of thumb regarding a specific hydraulic conductivity below which in situ bioremediation is impractical. Such approaches can be oversimplistic. The importance of hydraulic conductivity is a function of the contaminant mass to be biodegraded. The greater the contaminant mass, the greater the impact of hydraulic conductivity. In evaluating the feasibility of utilizing bioremediation, the time and cost for implementation at a specific site can be approximated by using hydraulic conductivity or pump test data, estimates of the mass and extent of contamination, and appropriate nutrient and terminal electron acceptor concentrations in the injection water. This estimate can be used to compare bioremediation to other options, most of which will also be less attractive in low-permeability soils. This chapter describes a bioremediation project that was completed in a petroleum hydrocarbon-contaminated aquifer, the permeability of which would have excluded it from consideration for bioremediation according to some rules of thumb. Remediation was completed in 10 months, despite the low permeability, because the mass of contaminant was modest. This chapter is from the book entitled Bioremediation: Field Experience.

\section{4}

V18/024675

Insitu Bioremediation: Site Characterization, System Design, and Full-Scale Field Remediation of Petroleum Hydrocarbon- and Trichloroethylene-Contaminated Groundwater, Chapter 19

Kinsella, J.V.; Nelson, M.J.K.

SCS Engineers, Inc., Bellevue, WA; EMCON Northwest, Inc., Bothell, WA

Bioremediation: Field Experience, P.E. Flathman, D.E. Jerger and J.H. Exner (eds.), Lewis Publishers, Boca Raton, FL, 560 pp.; (pp. 413-428) (1994)

In situ biological treatment of groundwater contaminated with organic compounds is an accepted remedial method that may provide an altemative or adjunct to conventional solutions. The method uses naturally occurring microorganisms that are adapted to site conditions for removal of groundwater contaminants. Successful application of the process requires and understanding of the physical, chemical, and biological parameters of the subsurface environment. This understanding is obtained during the site characterization phase and is used to design the treatability and pilot-scale tests. Laboratory treatability studies provide an evaluation of the biodegradability of the contaminants. Pilot-scale testing gathers information on the performance of the injection/recovery system and determines the degree of dilution. This chapter describes the above aspects of treatment design and implementation and presents the results of a pilot-scale demonstrations of remediation of petroleum hydrocarbon and trichloroethylene-contaminated aquifers. This chapter is from the book entitled Bioremediation: Field Experience.

3155

V18/021718

Insitu Clay Modification for Environmental Remediation

Boyd, S.A.

Michigan State University, East Lansing, MI

CONF-960376 (Part 1); Proceedings of the 211th American Chemical Society (ACS) National Meeting, New Orleans, LA, March 24-28, 1996. ACS, Washington, DC, Part 1, 1172 pp.; (p. 181, Paper ANYL 187) (1996)

Organoclays are formed by replacing native inorganic exchange cations of 2:1 layer silicates with organic cations such as quaternary ammonium compounds (QACs). These modified clays are effective sorbents for removing common organic contaminants from water. An in-situ subsurface remediation approach based on the conversion of soil clays to organoclays is being developed. This approach involves injections of QAC solutions to create sorptive zones that can intercept and immobilize contaminant plumes. Aspects of this technology will be discussed including binding of QACs to soil clays, hydraulic properties of modified subsoils, sorption of contaminants by modified clays, toxicity of QACs to soil microorganisms, and bioavailability of sorbed contaminants to pollutant degrading bacteria. (Complete text)

3156

\section{V18/022684}

\section{Insitu Hydrocarbon Delineation Using Laser-Induced} Fluorescence

Taer, A.D.; Hastings, R.W.; Brown, A.Y.; Frend, R.

Loral Environmental Systems, Houston, TX; Shell Development Company, Houston, TX; Brown and Caldwell, Irvine, $\mathrm{CA}$

CONF-960393 (Part 3); Contaminated Soils and Groundwater: Analysis, Fate, Environmental and Public Health Effects, and Remediation, Proceedings of the Sixth Annual West Coast Conference, Newport Beach, CA, March 11-14, 1996. Association for the Environmental Health of Soils, Amherst, MA, Part 3, 366 pp.; (p. 15) (1996)

An investigation of hydrocarbons in soils was conducted at an active Shell Oil Company petroleum products terminal, located in Carson, California. An investigation approach involving Laser-Induced Fluorescence (LIF) and Cone Penetrometer Testing (CPT) technologies was implemented to provide real-time, in-situ characterization of site stratigraphy, hydrocarbon distribution and, importantly, hydrocarbon product differentiation. The area of investigation is located along a property boundary, where a plume of separate phase hydrocarbons has been actively recovered for several years. CPT/LIF technology was selected for the investigation since previous delineation efforts using hydrocarbon fingerprinting methods proved inconclusive. Additionally, the CPT/LIF technology had the potential to provide a cost effective solution to accomplish project objectives. Based on the information obtained during this investigation, it was determined that the plume of separate phase hydrocarbons along the northern property boundary is from a source distinctiy different than any identified hydrocarbons known to be from on-site sources. In addition, the 
plume was determined to not be connected with any other known on-site hydrocarbon plumes. The results of this CPT/LIF investigation were consistent with the known hydrogeologic conditions. This evaluation determined that CPT/LIF technology was very effective in addressing project objectives and resulted in a significant cost savings.

\section{7 \\ V18/023626}

Insitu Instrumentation for Evaluating Air Injection Remediation Technologies

Baldwin, C.K.; Hall, B.L.; Dupont, R.R.

Utah State University, Utah Water Research Laboratory, Logan, UT

CONF-9605266; Proceedings of the 1996 Hazardous Substance Research Center/Waste-Management Education and Research Consortium Joint Conference on Environment, L.E. Erickson, S.C. Grant, D.L. Tillison and J.P. McDonald (eds.), Albuquerque, NM, May 21-23, 1996. Great Plains-Rocky Mountain Hazardous Substance Research Center, Kansas State University, Manhattan, KS, 706 pp.; (pp. 408-423) (1996)

An instrumentation system consisting of driven well-points, instrumentation bundles, and discrete sampling has been developed for monitoring subsurface conditions during the operation of air injection remediation systems. The driven well points provide intimate contact reducing the impact on the remediation process. The instrumentation bundles afford continuous monitoring of subsurface conditions. The saturated zone bundle provides information on dissolved oxygen, temperature, and groundwater displacement for use in defining the volume of influence of air injection systems in the saturated zone. The vadose zone bundle provides data on changes in oxygen concentrations and temperature. Both bundles allow discrete sampling for laboratory analysis. Criteria for sensor evaluation and laboratory testing protocols used for sensor evaluation are discussed. Also included are descriptions of the bundle housing and well-point layout at a field site.

3158 V18/022625

Insitu Redox Manipulation Field Experiment: Design Analysis

Williams, M.D.; Yabusaki, S.B.; Cole, C.R.; Vermeul, V.R. Pacific Northwest Laboratory, Richland, WA

CONF-941124; Insitu Remediation: Scientific Basis for Current and Future Technologies, G.W. Gee and N.R. Wing (eds.), Proceedings of the 33rd Hanford Symposium on Health and the Environment, Pasco, WA, November 7-11, 1994. Battelle Press, Columbus, OH, Part 2, 605 pp.; (pp. 1131-1153) (1994)

Groundwater contaminants are often dispersed in plumes over large areas deep below the surface, making them inaccessible to conventional types of remediation. Manipulation of subsurface oxidation-reduction (redox) conditions can provide a means to treat such contaminants, since many of them can be destroyed or immobilized by changes in the redox potential. The authors are investigating the feasibility of altering the subsurface redox potential through field experiments. Chemical and microbiological mechanisms for altering the subsurface redox potential are being studied in the laboratory, but the complex interactions between reducing agents, groundwater chemistry, and aquifer solids, coupled with the natural variability of the subsurface, require that field experiments also be performed. In the first field experiment planned, a single well will be used to inject a chemical reagent and a nonreactive tracer into a small volume of an aquifer to induce reduction of solid-phase ferric iron. After allowing time for the reagent to react, any unreacted reagent, nonreactive tracer, and aqueous reaction products will be withdrawn through the same injection well. The withdrawn water will be analyzed, and sediment samples will be collected before and after the experiment to assess the success of the redox manipulation.

\section{9}

\section{V18/022666}

Insitu Remediation - Scientific Basis for Current and Future Technologies: Proceedings of the 33rd Hanford Symposium on Health and the Environment, Part 2, Pasco, WA, November 7-11, 1994

Gee, G.W.; Wing, N.R.

Pacific Northwest Laboratory, Richland, WA; Westinghouse Hanford Company, Richland, WA

CONF-941 124; Insitu Remediation: Scientific Basis for Current and Future Technologies, G.W. Gee and N.R. Wing (eds.), Proceedings of the 33rd Hanford Symposium on Health and the Environment, Pasco, WA, November 7-11, 1994. Battelle Press, Columbus, OH, Part 2, 605 pp. (1994)

The Thirty-Third Hanford Symposium on Health and the Environment was held during the golden anniversary year of the establishment of the Hanford Site. The symposium reflects the changing mission at Hanford, from production and reprocessing of nuclear materials to environmental cleanup. Most of the papers presented are a direct resuit of DOE-sponsored projects designed to improve technology for cleanup. The symposium was relatively narrow in scope, dealing with issues primarily related to disposal or treatment of nuclear wastes. Insitu remediation options are considered including bioremediation, thermal treatment, chemical treatment, as well as surface and subsurface barriers. The symposium focused on the developing technologies of insitu remediation and their scientific basis. It also addressed the influence of heterogeneities on the application of these technologies. Topics included in Part 1 are: Subsurface barriers, Bioremediation, and Surface Barriers. Part 2 contains Thermal treatment, Insitu chemical treatment, and Heterogeneity issues. All papers have been indexed separately in the database.

3160 V18/022705

Insitu Remediation - Scientific Basis for Current and Future Technologies: Proceedings of the 33rd Hanford Symposium on Health and the Environment, Pt. 1, Pasco, WA, November 7-11, 1994

Gee, G.W.; Wing, N.R.

Pacific Northwest Laboratory, Richland, WA; Westinghouse Hanford Company, Richland, WA

CONF-941124; Insitu Remediation: Scientific Basis for Current and Future Technologies, G.W. Gee and N.R. Wing (eds.), Proceedings of the 33rd Hanford Symposium on Health and the Environment, Pasco, WA, November 7-11, 1994. Battelle Press, Columbus, OH, 
Part 1, 704 pp.; (1994)

The Thirty-Third Hanford Symposium on Health and the Environment was held during the golden anniversary year of the establishment of the Hanford Site. The symposium reflects the changing mission at Hanford, from production and reprocessing of nuclear materials to environmental cleanup. Most of the papers presented are a direct result of DOE-sponsored projects designed to improve technology for cleanup. The symposium was relatively narrow in scope, dealing with issues primarily related to disposal or treatment of nuclear wastes. Insitu remediation options are considered including bioremediation, thermal treatment, chemical treatment, as well as surface and subsurface barriers. The symposium focused on the developing technologies of insitu remediation and their scientific basis. It also addressed the influence of heterogeneities on the application of these technologies. Topics included in Part 1 are: Subsurface barriers, Bioremediation, and Surface Barriers. Part 2 contains Thermal treatment, Insitu chemical treatment, and Heterogeneity issues. All papers have been indexed separately in the database.

\section{1}

V18/022618

\section{Insitu Remediation by 2-PHASE [TM]: A 2-Year Success Story}

Huber, S.M.; Siegfried, J.E.

Radian Corporation, Rochester, NY

CONF-960393 (Part 3); Contaminated Soils and Groundwater: Analysis, Fate, Environmental and Public Health Effects, and Remediation, Proceedings of the Sixth Annual West Coast Conference, Newport Beach, CA, March 11-14, 1996. Association for the Environmental Health of Soils, Amherst, MA, Part 3, 366 pp.; (p. 38) (1996)

As part of Xerox Corporation's worldwide commitment to assess and remediate the environment of their facilities, 2-PHASE [TM] Extraction was used to remove subsurface volatile organic constituents (VOCs) at one their manufacturing plants in Ontario. The 2-PHASE Extraction system, developed by Xerox as an alternative to conventional pump-and-treat technology, uses a high-vacuum source applied to an extraction tube within a recovery well to increase groundwater removal rates in low-permeability geologic settings. 2-PHASE [TM] Extraction removes both subsurface liquids and vapors, thus improving contaminant removal rates, and simplifies post-extraction groundwater treatment because as much as $95 \%$ of the VOCs in the water phase are transferred to the vapor phase. Site investigations at the Ontario facility indicated that chemical releases from underground storage tanks and solvent spray booths had resulted in two distinct areas of localized soil and groundwater contamination. Contamination occurred inside the plant building under the floor slab of a manufacturing area at the location of a former solvent spray booth and underground storage tanks. Contamination also occurred outside the bujlding at the location of two former underground 7,000 gallon solvent storage tanks. Contaminants present were primarily 1,1,1-trichloroethane (1,1,1-TCA), tetrachloroethene (PCE), trichloroethene (TCE), and their associated degradation products (trans-1,2-dichlorethene, 1,1-dichloroethene and 1,1-dichloroethane). Mineral spirits were also present.
3162

\section{V18/022632}

Insitu Remediation of Contaminated Groundwater Using the MAG*SEP [SM] Technology

Dunn, M.J.

Bradtec-US, Inc., Atlanta, GA

CONF-941124; Insitu Remediation: Scientific Basis for Current and Future Technologies, G.W. Gee and N.R. Wing (eds.), Proceedings of the 33rd Hanford Symposium on Health and the Environment, Pasco, WA, November 7-11, 1994. Battelle Press, Columbus, OH, Part 2, 605 pp.; (pp. 1041-1053) (1994)

Argonne National Laboratory is leading a project for demonstration of in-situ remediation of contaminated groundwater utilizing MAG*SEP [SM] technology developed by Bradtec. This technology is being considered for eventual application at sites involving groundwater contaminated with heavy metals and/or radionuclides, such as the Savannah River Site (SRS) and Berkeley Pit. The MAG*SEP [SM] technology uses specially coated magnetic particles to selectively adsorb contaminants from groundwater. Particles are mixed with groundwater, contaminants are adsorbed onto the particles, and the particles are removed by magnetic filtration. The technology can recover low levels of radioactive and/or inorganic hazardous contamination (in the ppm range), leaving nonradioactive/nonhazardous species essentially unaffected. The first phase of this project has involved the optimization of MAG*SEP [SM] process chemistry for a selected site at SRS. To date this work has identified a candidate adsorber material (the amino form of iminodicarboxylic acid) for selective removal of lead, cadmium, and mercury from this site's groundwater. Decontamination factors of 170,270 , and 235 , respectively, for each contaminant have been achieved. Further process chemistry optimization work for this adsorber material is planned. The project will eventually lead to an in-situ demonstration of the MAG*SEP [SM] technology, integrated with the EnviroWall [TM] barrier technology developed by Barrier Member Containment Corporation (BMC).

3163

\section{V18/023808}

\section{Integrated Geophysical Investigation of an Inactive Wood Treatment Facility}

Kar, J.; Miller, P.T.

C.C. Johnson \& Malhotra, P.C., Silver Spring, MD; Roy F. Weston, Inc., Edison, $\mathrm{NJ}$

CONF-960477; SAGEEP '96, R.S. Bell and M.H. Cramer (eds.), Proceedings of the Ninth Annual Symposium on the Application of Geophysics to Engineering and Environmental Problems, Denver, CO, April 15-May 1, 1996. Environmental and Engineering Geophysical Society, Wheat Ridge, CO, 1353 pp.; (pp. 1189-1198) (1996)

Five geophysical methods were used to characterize the subsurface at an inactive wood treatment facility. Seismic refraction, electromagnetic conductivity (EM-31 and EM-34), very low frequency (VLF), and spontaneous potential (SP) methods were used to locate potential water-bearing zones and to help understand the driving mechanisms for the movement of groundwater and chemical constituents below the site. The investigation was successful in delineating areas where gravity drainage, groundwater seepage, and 
preferential groundwater movement was occurring. Typically, these areas were characterized by lower bedrock elevations, decreased bedrock velocities, increased electrical conductivity values, and anomalous VLF and SP deflections. The data were incorporated into the generation of site models, the determination of critical geologic information, and the placement of seven proposed monitoring wells.

\section{4}

\section{V18/024676}

Integrated System Approach for Insitu Bioremediation of Petroleum Hydrocarbon-Contaminated Soil and Groundwater, Chapter 20

Nelson, C.H.; Hicks, R.J.; Andrews, S.D.

Groundwater Technology, Inc., Englewood, CO; Groundwater Technology, Inc., Concord, CA

Bioremediation: Field Experience, P.E. Flathman, D.E. Jerger and J.H. Exner (eds.), Lewis Publishers, Boca Raton, FL, 560 pp.; (pp. 429-456) (1994)

The purpose of this chapter is to describe and discuss a case history in which in situ bioremediation was used to remediate both soils and groundwater contaminated with primarily nonvolatile petroleum hydrocarbons. The remediation system was installed at a truck maintenance facility owned by Public Service Company (PSC) of Colorado, a public utility company located in Denver. This chapter describes the remediation system that was used to treat both vadose and saturated zone contamination. It should be noted that the goal of the project was to remediate the site in a cost- and time-effective manner using state-of-the-art bioremediation techniques as they existed in 1988 to 1989 . Therefore, some of the analyses and procedures were not as rigorous as might be afforded under more research-oriented, regulatory-driven, or current conditions. This chapter is from the book entitled Bioremediation: Field Experience.

\section{5}

V18/022635

Integrated Technologies for Expedited Soil and Groundwater Remediation

Lewis, R.; Wellman, D.

Woodward-Clyde Consultants, Santa Ana, CA

CONF-960393 (Part 2); Contaminated Soils and Groundwater: Analysis, Fate, Environmental and Public Health Effects, and Remediation, Proceedings of the Sixth Annual West Coast Conference, Newport Beach, CA, March 11-14, 1996. Association for the Environmental Health of Soils, Amherst, MA, Part 2, 226 pp.; (p. 22) (1996)

A fast-track and economic approach was necessary to meet the needs of a property transfer agreement and to minimize impact to future usage of a site in the Los Angeles Basin. Woodward-Clyde responded by implementing site investigation, remedial action plan preparation for soil and groundwater, and selection and installation of remedial alternatives in an aggressive schedule of overlapped tasks. Assessment of soil and groundwater was conducted at the site, followed by design and construction of remediation systems. This phase of activity was completed within 2 years. Soil and groundwater were found to be impacted by chlorinated solvents and petroleum hydrocarbons. A vapor extraction system $(2,000 \mathrm{scfm}$ capacity) was installed for soil remediation, and an innovative air sparging system was installed for cost effective groundwater cleanup. A bioventing system was also applied in selected areas. The vapor extraction wellfield consists of 26 extraction and monitoring well points, with multiple screened casings. The air sparging . wellfield consists of 32 sparging wells with a designed maximum flow of $400 \mathrm{scfm}$. The systems began operation in 1993, and have resulted in the estimated removal of approximately 30,000 pounds of contaminants, or about $90 \%$ of the estimated mass in place. The combined vapor extraction/air sparging system is expected to reduce the time for on-site groundwater remediation from $1 / 3$ to $1 / 6$ the time when compared to the conventional pump and treat method for groundwater remediation.

\section{6}

V18/023033

Integrated Use of Air Sparging, Soil Vapor Extraction and Pump and Treat Technologies to Remediate Chlorinated Hydrocarbon Contaminated Water-Bearing Units at a High Density Polyethylene (HDPE) Facility

Sturdivant, R., Jr.; Schramm, W.H.; Bains, F.E.

C-K Associates, Baton Rouge, LA; Louisiana Department of Environmental Quality, Baton Rouge, LA; Paxon Polymer Company, Baton Rouge, LA

CONF-9610180; Proceedings of an American Association of Petroleum Geologists (AAPG) Gulf Coast Association of Geological Societies Meeting, San Antonio, TX, October 2-4, 1996; AAPG Bulletin 80(9):1515c (September 1996)

Disposal practices prior to RCRA caused the release of chlorinated hydrocarbons (CHCs) into the shallow groundwater under a temporary pond at the facility. This impact was discovered through a due diligence survey and properly reported to the Louisiana Department of Environmental Quality (LDEQ). Through a phased investigation the company, in cooperation with $\mathrm{LDEQ}$, has determined that the upper three water bearing units have been affected by multiple contaminants forming a DNAPL plume. Remedial actions were proposed to the Agency and implemented with approval during 1994-95. The remedial system includes soil vapor extraction and air sparging for the uppermost zone and pump and treat for contaminated water removal in the second zone. Throughout 1995, the systems efficiency was evaluated and continuous adjustments were made to improve the recovery. A balanced approach to minimize downward movement of contaminants and achieve optimum recovery included: startup of system components, manipulation of recovery rates and installation of additional equipment. Data assimilated over the past year of operation suggests the effective recovery of CHCs. Monitoring of the impacted zones shows a downward trend in contamination levels, however it is evident that control of the impacted zones is incomplete. Proposed aiterations to the system include additional recovery wells, pump tests, and continued evaluations to improve the system. Further efforts will be required by the Agency to address the remaining contaminants. This paper will address the implementation of the Corrective Action Program and present the current state of operations and proposed augmentations to improve the system.

V18/021968

Interfacial Phenomena Affecting Contaminant Remediation with Zero-Valent Iron Metal 
Tratnyek, P.G.; Johnson, T.L.; Schattauer, A.

Oregon Graduate Institute of Science and Technology, Department of Environmental Science and Engineering, Portland, OR

CONF-9509139; Emerging Technologies in Hazardous Waste Management VII, D.W. Tedder (ed.), Proceedings of the Seventh American Chemical Society Industrial and Engineering Chemistry Division Special Symposium, Atlanta, GA, September 17-20, 1995. American Chemical Society, Washington, DC, 1291 pp.; (pp. 589-592) (1995)

Over the last several years, a great deal of interest has developed in the groundwater remediation community over the prospects of new treatment strategies based on contaminant degradation by granular iron metal. These developments have created a need for process-level insight into the chemistry of these systems in order to explain, predict, and/or enhance their performance. To this end, we have been investigating various aspects of the reduction of organic substances at the iron-water interface. Recent results have demonstrated the importance of corrosion, precipitation, and mass transport in determining the reactivity of granular iron. The purposes of this paper are to discuss the importance of oxygen (or anoxia) in these systems, and to explore the various ways in which all of these processes reflect interfacial phenomena.

\section{$3168 \quad \mathrm{~V} 18 / 026077$}

\section{Intrinsic Bioremediation}

CONF-950483 (Vol. 3-1); Proceedings of the Third International Insitu and Onsite Bioreclamation Symposium, San Diego, CA, April 24-27, 1995; Bioremediation Series 3(1) - Intrinsic Bioremediation, R.E. Hinchee, J.T. Wilson and D.C. Downey (eds.), Battelle Press, Columbus, OH, 266 pp. (1995)

This volume is part of a ten volume set of papers derived from the Third International Insitu and Onsite Bioreclamation Symposium, which was held in San Diego, California, in April 1995. The purpose of the conference was to provide a multidisciplinary forum for exchange of state-of-the-art information on bioremediation. The papers that appear in the set of volumes were accepted after peer review. This volume deals with intrinsic remediation. Intrinsic remediation can be defined as the combined effect of natural destructive and nondestructive processes to reduce a contaminant's mobility, mass, and associated risks. The primary emphasis of this document is destructive attenuation processes, specifically aerobic and anaerobic biodegradation. Individual papers within the scope of this data base have been indexed separately.

3169 V18/022645

Intrinsic Remediation of Fuel Hydrocarbons in Low-Temperature Groundwater Environments

Herrington, R.T.; Wiedemeier, T.H.

Parsons Engineering Science, Inc., Denver, $\mathrm{CO}$

CONF-960393 (Part 3); Contaminated Soils and Groundwater: Analysis, Fate, Environmental and Public Health Effects, and Remediation, Proceedings of the Sixth Annual West Coast Conference, Newport Beach, CA, March 11-14, 1996. Association for the Environmental Health of Soils, Amherst, MA, Part 3, 366 pp.; (p. 19) (1996)
Geochemical trends and biodegradation rates observed at five petroleum-contaminated sites in Alaska and northem Michigan suggest that both aerobic and anaerobic biodegradation are removing petroleum hydrocarbons dissolved in low-temperature groundwater. Based on site-specific groundwater geochemistry and expressed assimilative capacity estimates, anaerobic biodegradation dominates the removal of contaminants at these sites, mainly through sulfate reduction or methanogenesis. Despite the cold groundwater environments of Alaska (typically below $10 \mathrm{C}$ ) and northem Michigan (typically below $15 \mathrm{C}$ ), estimated biodegradation rates for benzene, toluene, ethylbenzene, and xylenes (BTEX) approach or exceed $1 \%$ per day. The importance of these results is that they broaden the demonstrated applicability of intrinsic remediation from sites in warmer, temperate climates to include those in colder regions.

3170

V18/023333

Introduction to Environmental Hydrogeology: With Emphasis on Evaluation and Remediation of Hydrocarbon Contamination in Groundwater and Soil Introduction to Environmental Hydrogeology With Emphasis on Evaluation and Remediation of Hydrocarbon Contamination in Groundwater and Soil, Society for Sedimentary Geology, San Diego, CA (June 1993)

No abstract available.

\section{1 \\ V18/024865}

Investigation and Remediation of Contaminated Soil and Groundwater: A Review and Evaluation of Standard Operating Procedures

Barber, C.

Commonweaith Scientific and Industrial Research Organization, Division of Water Resources, Centre for Groundwater Studies, Perth, Western Australia

Proceedings of the Third National Workshop on the Health Risk Assessment and Management of Contaminated Sites (Contaminated Sites Monograph Series No. 5, 1996), A. Langley, B. Markey and H. Hill (eds.), Sydney, Australia, May 1995. South Australian Health Commission, Rundle Mall, South Australia, 470 pp.; (pp. 479-439) (1996)

Standard operating procedures (SOPs) in Australia for investigation and monitoring of groundwater at contaminated sites are reviewed and assessed, and areas have been identified where further refinement and development of procedures are likely or necessary. There are particular problems with investigation and monitoring of volatile organic contaminants (VOC) in groundwater. These VOCs are the most prevalent groundwater contaminants in the US, and have become much more important in Australia in the last five years. A case study of contamination of a sand aquifer by a petrol leak from an underground storage tank near Perth WA is used to illustrate some problems of investigations using current SOPs, but more specifically in assessing monitoring data requirements for risk-based evaluations of the need to remediate contaminated soil and groundwater. It is concluded that more detailed monitoring data will often be required for proper assessment of risk. It is clear that these requirements can be met with development of more efficient sampling techniques, and as our understanding of the behavior of 
aquifer systems improves.

3172

V18/023465

Iron Mediated Reductive Transformations of Chlorinated Organic Compounds in Aqueous Systems

Farrell, J.

University of Arizona, Department of Chemical and Environmental Engineering, Tucson, AZ

CONF-960730 (Vol. 3); Technologies Critical to a Changing World, Volume III: Emerging Energy Technologies, Clean Technologies, Remediation and Emission Control Fuels, and Petrochemicals, Proceedings of the Fifth World Congress of Chemical Engineering, San Diego, CA, July 14-18, 1996. American Institute of Chemical Engineers, New York, NY, Vol. 3, 1118 pp.; (pp. 585-590) (1996)

Recent laboratory and field studies indicate that metallic iron may be used for in-situ remediation of groundwater contaminated by chlorinated organic compounds. This research investigated the effects of iron surface passivation, $\mathrm{pH}$, and bimetal addition on trichloroethylene (TCE) dehalogenation rates in columns packed with iron filings. In unbuffered water, TCE reaction rates showed a continual decline with increasing elapsed time of operation. The high reactivity of the iron surfaces with water leads to unfavorable $\mathrm{pH}$ changes and contributes to the buildup of passivating iron oxyhydroxide precipitates. Carbonate buffering increased TCE reaction rates by up to a factor of 12 compared to unbuffered water. Plating $0.05 \%(w / w)$ palladium or $0.20 \%(w / w)$ copper on the iron particles increased reaction rates by more than a factor of ten in unbuffered water. In buffered water, palladium treatment was equally effective at increasing TCE reaction rates, whereas, the effect of copper was significantly diminished.

3173

V18/023620

Kinetic Coefficients for Simultaneous Reduction of Sulfate and Uranium by Desulfovibrio Desulfuricans

Tucker, M.D.; Barton, L.L.; Thomson, B.M.

New Mexico University, Department of Civil Engineering, Albuquerque, NM; New Mexico University, Laboratory of Microbial Chemistry, Albuquerque, NM

Applied Microbiology and Biotechnology 46(1):74-77 (1996)

Previously it was demonstrated that bacteria are capable of transforming soluble uranyl ion, U(VI), to insoluble uraninite, U(IV); however, the rate for this transformation has not been determined. We report the kinetic coefficients for Desulfovibrio desulfuricans DSM 1924 grown in a continuous-flow chemostat where pyruvate was the electron donor and sulfate was the electron acceptor. The medium was supplemented with $1 \mathrm{mM}$ uranyl nitrate, and the chemostat flow rate ranged from $1.12 \mathrm{ml} / \mathrm{h}$ to $4.75 \mathrm{ml} / \mathrm{h}$ with incubation at $28 \mathrm{C}$. The maximum rate of pyruvate utilization (k) was determined to be 4.7 per days, while the half-velocity constant (Ks) was $127 \mathrm{mg} / \mathrm{l}$. The yield coefficient $(\mathrm{Y})$ of cells per mole of pynuate oxidized was calculated to be $0.021 \mathrm{~g}$, while the endogenous decay coefficient $(\mathrm{kd})$ ) was determined to be 0.072 per day. More than $90 \%$ of U(VI) was transformed to U(VI) in the chemostat under the conditions employed.
Laboratory and Field Evaluation of Enhanced Insitu Bioremediation of Trichloroethylene, cis- and trans-Dichloroethylene, and Vinyl Chloride by Methanotrophic Bacteria, Chapter 18

Semprini, L.; Hopkins, G.D.; Grbic-Galic, D.; McCarty, P.L.; Roberts, P.V.

Oregon State University, Department of Civil Engineering, Corvallis, OR; Stanford University, Department of Civil Engineering, Stanford, CA

Bioremediation: Field Experience, P.E. Flathman, D.E. Jerger and J.H. Exner (eds.), Lewis Publishers, Boca Raton, FL, 560 pp.; (pp. 383-412) (1994)

A pilot-scale field study was performed that assessed, under field conditions, the capacity of native microorganisms (i.e., bacteria indigenous to the groundwater zone) to degrade halogenated aliphatic compounds (HACs) when proper conditions were provided to enhance bacterial growth. Specifically, the growth of methanotrophic bacteria was stimulated in a natural hydrogeologic setting by providing ample supplies of dissolved methane and oxygen. Then, the transformation by these organisms of representative HACs, including trichloroethylene (TCE), cis-1,2-dichloroethene (c-DCE), trans-1,2-dichloroethene (t-DCE), and vinyl chloride (VC), was assessed by means of controlled addition, frequent sampling, quantitative analysis, and mass balance comparisons. To provide guidance for the field work, as well as a firm foundation for interpretation, and to improve basic understanding of key microbial and physical processes, laboratory experiments were also performed. A numerical model that incorporates the basic processes of importance, including advection, dispersion, sorption, and cometabolic transformation, provided a means of comparing laboratory results with field results. This chapter summarizes the results of the field study and the associated laboratory and modeling studies. This chapter is from the book entitled Bioremediation: Field Experience.

3175 V18/024642

Learning and Going Forward, Chapter 10

Smith, S.A.

Smith Consulting Services, Ada, $\mathrm{OH}$

Monitoring and Remediation Wells: Problem Prevention, Maintenance, and Rehabilitation, Lewis Publishers, Boca Raton, FL, 203 pp.; (pp. 153-164) (1995)

This chapter contains an assemblage of case histories relevant to monitoring well and remediation well rehabilitation taken from environmental, geotechnical, and water supply situations. The case histories are illustrative of possible problems and how they were handled. Among the problems discussed are iron biofouling of water supply wells and pump failure due to encrustation and biofouling. A final section presents a list of needs in well rehabilitation and some recommendations concerning education, communication, and other human factors. This chapter is from the book entitled Monitoring and Remediation Wells: Problem Prevention, Maintenance, and Rehabilitation.

MAPIT: A New Software Tool to Assist in the 
Transition from Conceptual Model to Numerical Simulation Models

Canales, T.W.; Grant, C.W.

Lawrence Livermore National Laboratory, Livermore, CA

CONF-960804 (Vol. 1); Spectrum '96: Nuclear and Hazardous Waste Management, Proceedings of an International Topical Meeting, Seattle, WA, August 18-23, 1996. American Nuclear Society, La Gtange Park, IL, Vol. 1, 887 pp.; (pp. 671-675) (1996)

MAPIT is a new software tool developed at Lawrence Livermore National Laboratory to assist groundwater remediation professionals in generating numerical simulation models from a variety of physical and chemical data sources and the corresponding 1-, 2-, and 3-dimensional conceptual models that emerge from analysis of such data.

\section{7}

\section{V18/022178}

Magnetic-Seeding Filtration

DePaoli, D.W.

Oak Ridge National Laboratory, Oak Ridge, TN

PNNL-SA-27105; CONF-960158; Efficient Separation and Processing Crosscutting Program, Proceedings of the 1996 Technical Exchange Meeting, Gaithersburg, MD, January 16-19, 1996, 52 pp.; (pp. 85-87) (1996)

This task will investigate the capabilities of magnetic-seeding filtration for the enhanced removal of magnetic and nonmagnetic particulates from liquids. This technology applies to a wide range of liquid wastes, including groundwater, process waters, and tank supernatant. Magnetic-seeding filtration can be used in several aspects of treatment, such as (1) removal of solids, particularly those in the colloidal-size range that are difficult to remove by conventional means; (2) removal of contaminants by precipitation processes; and (3) removal of contaminants by sorption processes.

\section{8}

V18/025368

\section{Manipulation of Groundwater Colloids for Environmental Restoration}

Manipulation of Groundwater Colloids for Environmental Restoration, J.F. McCarthy and F.J. Wobber (eds.), Lewis Publishers, Boca Raton, FL, 371 pp. (1993)

This meeting was part of a series of research conferences on colloids in subsurface environments initiated in 1984 by the U.S. Department of Energy's Environmental Science Division. The purpose of the meeting was to evaluate the question: Can a fundamental understanding of processes controlling the mobilization and deposition of groundwater colloids be applied to the development of strategies to manipulate colloid mobility for mitigation or remediation of waste sites? The scope of the meeting included consideration of both organic and inorganic colloids and organic, heavy metal, and radionuclide contaminants, as well as mixed waste. Technical sessions included: (1) Mobilizing and Depositing Colloids, (2) Biocolloid Mobility, (3) Manipulating Colloids to Change Aquifer Permeability, and (4) Introducing Modified Colloids, Surfactants and Emulsions.
Mass Balance of Reaction Products from Irradiated TCE Vapor

Matthews, S.M.; Wang, F.T.; Mill, T.; Su, M.; Yao, C.C.D. Lawrence Livermore National Laboratory, Livermore, CA; SRI International, Menlo Park, CA

CONF-940604; Proceedings of the 1994 Institute of Electrical and Electronic Engineers (IEEE) International Conference on Plasma Science, Santa Fe, NM, June 6-8, 1994. IEEE Service Center, Piscataway, NJ, 252 pp.; (p. 7) (1996)

Trichloroethylene (TCE) vapor, at a concentration of $3000 \mathrm{ppmv}$ in synthetic air, was sealed in Tedlar bags and irradiated with a 3.7 $\mathrm{MeV}$ electron beam. Bags of dry vapor and vapor at $90 \%$ relative humidity were irradiated. Doses up to 11 megarads (11 MR) were applied. Each bag was chemically analyzed for reaction products and a mass balance of chlorine and carbon was obtained within the 11 MR dose range. The results of these radiolysis experiments and chemical analysis show that, given the proper treatment, the TCE concentration is reduced to below detection limit and the reaction products of the organic carbon and chlorine are carbon monoxide (CO), carbon dioxide (CO2), chlorine gas (CL2) and hydrochloric acid $(\mathrm{HCl})$. No detectable amounts of dichloroacetyl chloride (DCAC) or phosgene (PG) remained in the sample after proper treatment. DCAC and PG were found only as intermediary oxidation products of the TCE. High energy ionizing radiation, as electron beams and bremsstrahlung, is a new treatment technology for destroying toxic compounds and hazardous wastes. A demonstration of complete destruction of organic products, using this treatment at standard temperature and pressure, is expected to help implement the use of this technology. (Complete Text)

3180

V18/023742

Measurement of the Radius of Influence of Insitu Sparging System in a Large Scale Sand Model

Wirtanen, D.A.; Tinker, J.R., Jr.

Ayres Associates, Inc., Eau Claire, WI; University of Wisconsin, Eau Claire, WI

CONF-950978; Municipal and Industrial Waste, Proceedings of the 18th International Madison Waste Conference, Madison, WI, September 20-21, 1995. University of Wisconsin, Madison, WI, 461 pp.; (p. 71) (1995)

Air sparging is one method of remediating petroleum contaminated aquifers. In previous applications of this technology, scientists, engineers, and hydrogeologists have relied on indirect measurements to determine design parameters, including radius of influence of an air sparging well. In this study, the radius of influence of an air sparging system was measured in a large scale sand model. The model demonstrated that the radius of influence can be measured when there is not an unsaturated zone present. Under experimental conditions, the radius of influence ranged from 1.73 feet to 2.55 feet. The depth to the top of the sparge well screen was 4.1 feet. A poorly sorted medium sand and a well sorted medium sand were used in the experiment. (Complete text)

3181

V18/021090

Methanotrophic Treatment of Contaminated Well Water Using a Pilot Scale Bioreactor 
Berry, C.J.; Hazen, T.C.; Franck, M.M.; Rossabi, J.

Westinghouse Savannah River Company, Savannah River Technology Center, Aiken, SC

CONF-930482; Proceedings of the Second International Insitu and Onsite Bioreclamation Symposium, San Diego, CA, April 5-8, 1993; (1 p.) [presented, but not published] (April 1993)

An aerobic trickle-type methanotrophic bioreactor system was tested for its ability to degrade trichloroethylene (TCE) in well water. The system is one of three such systems built and tested by Battelle Columbus for the Air Force. It consists of two columns filled with 6-feet of ceramic 0.125 in diameter packing material. The liquid flow rate through the system varied from 0.25 to 1.5 $\mathrm{gpm}$. Residence times within the system were 54 minutes at a 0.5 gpm flow rate. Gas Flows ranged from 0-130 SLPH. Inlet Methane concentrations were kept below $4 \% \mathrm{vol} / \mathrm{vol}$. A biofilm consisting of a natural consortia of organisms was developed from TBG-4D, a well located at the TNX area of the Savannah River Site, in Aiken, SC. Trace minerals in a Nitrate/Phosphate buffered media were added to the system along with Methane as a carbon source. The efficacy of the biofilm was tested with a variety of different operating parameters; including TCE concentration, flow rate, nutrient loading, $\mathrm{pH}$, dissolved oxygen content, and different methane addition schemes. The operational results of the system are compared to those obtained at Battelle Columbus. Uninoculated test runs with a $0.5 \%$ Formalin and $0.2 \%$ Sodium Azide solution were done to model absorption and volatilization within the reactor. During testing inlet TCE concentrations varied from $1100 \mathrm{mu} / \mathrm{g} / \mathrm{l}$ to $200 \mathrm{mu}$ g/l. A mass balance of the system was done using $\mathrm{Gas}$ Chromatography and Mass Spectrophotometry. Tracer tests using a fiber optic flow cell connected to a Diode Array Spectrophotometer were done. These tests gave residence time distributions and residence times within the bioreactor during operation.

Microbiological analysis of the bioreactor included acridine orange direct counts, 1\% PTYG plate counts, FA staining for Nitrogen utilizers, MPN counts of methanotrophs, and Biology analysis. (Complete text).

\section{2}

\section{V18/020841}

Method and Apparatus for Tritiated Water Separation Nelson, D.A.; Duncan, J.B.; Jensen, G.A.

Battelle Memorial Institute, Richland, WA

U.S. Patent 05451322; 16 pp. (September 19, 1995)

The present invention is a membrane method and apparatus for separating isotopic water constituents from light water. The method involves providing a supported membrane of an aromatic polyphosphazene and pressurizing the water on one side of the membrane thereby forcing the light water through the supported membrane while isotopic water constituents are retained or vice versa. The apparatus of the present invention includes an aromatic polyphosphazene placed on a porous support and means for pressurizing water through the membrane while certain isotopic water constituents are retained.

Method for Aquifer and Piezometric Surface Mapping With a Cone Penetrometer
Aggarwal, P.K.; Burton, J.C.; Meyer, W.T.; Stefano, J.E.

Argonne National Laboratory, Environmental Research Division, Argonne, IL

CONF-940499 (Vol. 2); Proceedings of the 1994 Federal Environmental Restoration III and Waste Minimization II Conference and Exhibition, New Orleans, LA, April 27-29, 1994. Hazardous Materials Control Resources Institute, Rockville, MD, Vol. 2, 858 pp.; (pp. 1384-1393) (1994)

The electronic cone penetrometer (ECPT) is increasingly being used for environmental characterization of hazardous waste sites, especially to delineate subsurface lithology and to obtain samples of groundwater. A potentially powerful use of the ECPT is the mapping of subsurface hydrostratigraphic features and aquifer piezometric surface(s) by using measurements of pore pressure. Most published studies on the use of the ECPT have been limited to shallow sand-clay sequences and indicate only limited success in hydrogeologic characterization. In this paper, we discuss a method for delineating the depth and thicknesses of unsaturated and saturated zones on the basis of the nature and rate of pore pressure dissipation. We have used this method to depths of $110 \mathrm{ft}$ at several sites underlaid by clay-sand or weathered shale-limestone sequences. The equilibrium pore pressures in the saturated zone should ideally indicate the depth of the water table or aquifer piezometric surface; however, our data indicate that an apparent equilibrium value for pore pressures may be obtained that may be lower or higher than the true value, depending on the composition and grain size of the material in the aquifer, the depth of the dissipation test within the saturated zone, and the history of use of the porous filter in the cone penetrometer assembly. Consequently, the data on dissipation must be carefully calibrated and tested with measurements in a monitoring well before the data are used to determine piezometric surfaces.

\section{4 \\ V18/024095}

Method of Degrading Pollutants in Soil

Hazen, T.C.; Lopez De Victoria, G.

U.S. Patent 5326703; 23 pp. (July 5, 1994)

A method and systems for enhancing the motility of microorganisms by placing an effective amount of chlorinated hydrocarbons, preferably chlorinated alkenes, and most preferably trichloroethylene (TCE) in spaced relation to the microbes so that the surprisingly strong, monomodal, chemotactic response of the chlorinated hydrocarbon on subsurface microbes can draw the microbes away from or towards and into a substance, as desired. In remediation of groundwater pollution, for example, TCE can be injected into the plume to increase the population of microbes at the plume whereby the plume can be more quickly degraded. A TCE-degrading microbe, such as Welchia alkenophilia, can be used to degrade the TCE following the degradation of the original pollutant.

\section{5}

\section{V18/020836}

Methods and Apparatus for Decontamination of Subsoil Husten, P.F.

U.S. Patent 05449249; 16 pp. (September 12, 1995)

This patent describes an apparatus for the decontamination of a 
subsoil formations, particularly highly volatile halogenated hydrocarbons, by causing contaminants to be flushed out and separated from the groundwater at the surface. Extraction is by a stripping process. In order to also be able to remove contaminants having higher specific gravities and contaminants with a low solubility in water, it is proposed to vibrate the water saturated soil/rock zone by means of an acoustic transmitter. The acoustic transmitter consists of two plate-like elements as membranes between which there is a coil. The process utilizes boreholes for removal of groundwater. The acoustic pulses increase the permeability in the ground in the immediate vicinity of the borehole which is drilled in the area of highest contaminant concentration.

\section{6}

V18/024624

\section{Microbial Degradation and Transformation of Petroleum Constituents and Related Elements, Chapter 4}

Riser-Roberts, E.

Bioremediation of Petroleum Contaminated Sites, C.K. Smoley, Chelsea, MI, 464 pp.; (pp. 59-65) (1992)

This is a chapter in the book titled: Bioremediation of Petroleum Contaminated Sites by Eve Riser-Roberts. There are three processes by which microorganisms can break down hydrocarbons: fermentation, aerobic respiration, and anaerobic respiration. In fermentation, the carbon and energy source is broken down by a series of enzyme-mediated reactions that do not involve an electron transport chain. In aerobic respiration, the carbon and energy source is broken down by a series of enzyme-mediated reactions in which oxygen serves as an external electron acceptor. In anaerobic respiration, the carbon and energy source is broken down by a series of enzyme-mediated reactions in which nitrates, sulfates, carbon dioxide, and other oxidized compounds (excluding oxygen), serve as external electron acceptors. These three processes of obtaining energy form the basis for the various biological wastewater treatment processes. The different ways these processes are used by the organisms and the relationship between the processes and redox potential are summarized in a table. The differences between heterotrophic and autotrophic metabolism are also described.

\section{7}

V18/026082

\section{Microbial Processes for Bioremediation}

CONF-950483 (Vol. 3-8); Proceedings of the Third Intemational Insitu and Onsite Bioreclamation Symposium, San Diego, CA, April 24-27, 1995; Bioremediation Series 3(8) - Microbial Processes for Bioremediation, R.E. Hinchee, C.M. Vogel and F.J. Brockman (eds.), Battelle Press, Columbus, OH, 361 pp. (1995)

This volume is part of a ten volume set of papers derived from the Third International Insitu and Onsite Bioreclamation Symposium, which was held in San Diego, California, in April 1995. The purpose of the conference was to provide a multidisciplinary forum for exchange of state-of-the-art information on bioremediation. The papers that appear in the set of volumes were accepted after peer review. The articles in this volume report on field and laboratory research on bioremediation of a wide range of compounds, with emphasis on microbial processes. Individual papers within the scope of this data base have been indexed separately.

\section{8}

V18/023629

Microbial Reduction of Uranium Using Cellulosic Substrates

Thombre, M.S.; Thomson, B.M.; Barton, L.L.

University of New Mexico, Albuquerque, NM

CONF-9605266; Proceedings of the 1996 Hazardous Substance Research Center/Waste-Management Education and Research Consortium Joint Conference on Environment, L.E. Erickson, S.C. Grant, D.L. Tillison and J.P. McDonald (eds.), Albuquerque, NM, May 21-23, 1996. Great Plains-Rocky Mountain Hazardous Substance Research Center, Kansas State University, Manhattan, KS, 706 pp.; (pp. 59-68) (1996)

Previous work at the University of New Mexico and elsewhere has shown that sulfate-reducing bacteria are capable of reducing uranium from the soluble +6 oxidation state to the insoluble +4 oxidation state. This chemistry forms the basis of a proposed groundwater remediation strategy in which microbial reduction would be used to immobilize soluble uranium. One such system would consist of a subsurface permeable barrier which would stimulate microbial growth resulting in the reduction of sulfate and nitrate and immobilization of metals while permitting the unhindered flow of groundwater through it. This research investigated some of the engineering considerations associated with a microbial reducing barrier such as identifying an appropriate biological substrate, estimating the rate of substrate utilization, and identifying the final fate of the contaminants concentrated in the barrier matrix. The performance of batch reactors and column systems that treated simulated plume water was evaluated using cellulose, wheat straw, alfalfa hay, sawdust, and soluble starch as substrates. The concentrations of sulfate, nitrate, and $\mathrm{U}(\mathrm{VI})$ were monitored over time. Precipitates from each system were collected, and the precipitated U(TV) was determined to be crystalline UO2s by x-ray diffraction. The results of this study support the proposed use of cellulosic substrates as candidate barrier materials.

3189

V18/023318

Microcosm Test to Determine the Potential Leachability at Crude Oil Site in a Tidal Environment

Owen, T.J.; Chang, S.B.R.

Thomas J, Owen and Associates, Fountain Valley, CA

CONF-960393 (Part 3); Contaminated Soils and Groundwater: Analysis, Fate, Environmental and Public Health Effects, and Remediation, Proceedings of the Sixth Annual West Coast Conference, Newiport Beach, CA, March 11-14, 1996. Association for the Environmental Health of Soils, Amherst, MA, Part 3, 366 pp.; (35 pp.) (1996)

A risk-based corrective action (RBCA) was conducted in 1993, at a crude oil site in Redondo Beach, California. During free-product and impacted soil removal operations, weathered crude oil was observed to readily desorb into the groundwater when disturbed by excavation operations. After remedial actions, crude oil impacted soil remained at depths in excess of forty to sixty feet, below ground surface (bgs). A site-specific leachability test was developed to quantify the fate of phase-separated petroleum hydrocarbons proposed to be abandoned on-site with no-further action. This physical contaminant transport test model was designed to justify the 
hypothesis that the residual saturation of crude oil would not leach out of the sandy soil in the saturated zone near the primary interface of the ocean water and fresh groundwater under the site.

\section{0}

V18/024133

Mining and Mineral Processing by Polymer Filtration

Los Alamos National Laboratory, Los Alamos, NM

LALP-95-202; 1 p. (1995)

A number of metal mines and processing plants generate waste defined as toxic under the Environmental Protection Agency's Toxics Release Inventory. Metals of concem include copper, lead, chromium, cadmium, manganese, nickel, silver, and zinc. To address this problem, Los Alamos has developed a technology known as polymer filtration, which couples water-soluble polymers with ultrafiltration. Scientists use a homogeneous solution in which the polymer binds with metal ions; this process is many times faster than conventional ion-exchange resins. After the polymer binds to the metal ions, the polymer-metal association is filtered and concentrated using a method known as ultrafiltration. The resultant metal an be recovered and the water meets all reguiatory requirements. The Los Alamos process can address the acid mine drainage problem by using these water-soluble polymers.

\section{1}

$$
\text { V18/025596 }
$$

\section{Mixed Oxidant (MIOX) Remediation Technology}

\section{Dobbs, B.}

Los Alamos Technical Associates, Inc., Albuquerque, NM; Department of the Environment, Environmental Protection Service, Ottawa, Ontario, Canada

CONF-951086; Proceedings of the Fifth Annual Symposium on Groundwater and Soil Remediation, Toronto, Ontario, Canada, October 2-6, 1995. Environment Canada - Environmental Protection Service, Hull, Quebec, Canada, 566 pp.; (pp. 551-552) (1995)

A remediation technology - MIOX - in which mixed oxidants are generated by passing dilute salt water through an electrolytic cell, is described. The flow in the electrolytic cell is split: one stream contains a low concentration of $\mathrm{NaOH}$, while the other contains free available chlorine and oxidants that are used for water treatment. No hazardous materials are used or generated. The technology is more cost-effective than chlorination and eliminates corrosion problems and the need for chlorine feed-rate adjustments. Several areas of water treatment and remediation efforts using the MIOX technology were described.

\section{2}

\section{V18/025296}

\section{Modeling Insitu Bioremediation}

Bedient, P.B.; Rifai, H.S.

Rice University, Houston, TX

Insitu Bioremediation: When Does It Work?, National Academy

Press, Washington, DC, 207 pp.; (pp. 153-159) (1993)

The problem of quantifying biodegradation of subsurface pollutants can be addressed by using models that combine physical, chemical, and biological processes. Developing such models is difficult, however, for reasons that include the lack of field data on biodegradation and lack of numerical schemes that accurately simulate the relevant processes. This paper reviews modeling efforts, including BIOPLUME II.

3193

V18/024670

Modeling of Hydrogeologic Field Data for Design and Optimization of Insitu Bioremediation of Contaminated Aquifers, Chapter 14

Norris, R.D.; Falotico, R.J.

Eckenfelder, Inc., Nashville, TN; Groundwater Technology, Inc., Trenton, NJ

Bioremediation: Field Experience, P.E. Flathman, D.E. Jerger and J.H. Exner (eds.), Lewis Publishers, Boca Raton, FL, 560 pp.; (pp. 287-307) (1994)

This chapter discusses site characterization and design requirements for in situ bioremediation and presents a simple, analytical hydrogeological flow modeling technique. The modeling technique can be used to evaluate the potential of bioremediation, to design a treatment system, and to make adjustments to an on-line system based solely on approximating the dynamics of groundwater flow at a site under natural and operating conditions. The cost of hydrogeological modeling is minimal compared to the benefits realized from improvements in system design and potentially shorter remediation times. For complex and/or large sites, other models can be applied after using an analytical model for screening purposes. Several models that incorporate adsorption, reactivity, etc., such as those developed at Rice University, are more thorough but require more data and are significantly more costly to implement. Intermediate approaches may also be considered, such as that recently discussed by Borden. Case studies are presented that demonstrate the use of the modeling technique. This chapter is from the book entitled Bioremediation: Field Experience.

\section{4}

\section{V18/023861}

Modeling the Effectiveness of Hydraulic and Impermeable Barriers for Improving Contaminant Extraction or Surfactant Injection

Gupta, H.S.; Knox, R.C.

Woodward-Clyde Consultants, Santa Ana, CA; University of Oklahoma, School of Civil Engineering and Environmental Science, Norman, OK

CONF-960154; PETRO-SAFE '96, Proceedings of a Conference Held as Part of the Energy Week ' 96 Conference and Exhibition, Houston, TX, January 29-February 2, 1996. PennWell Conferences and Exhibitions, Houston, TX, 291 pp.; (pp. 156-166) (1996)

Current approaches to remediation of dense non-aqueous phase liquids (DNAPLs) generally involve pump and treat systems that are hydraulically inefficient. These pumping systems produce large volumes of lightly contaminated water that must be treated at the surface. Barriers have historically been applied as a containment measure against groundwater pollution. Innovative applications of pumping systems and barrier systems could enhance DNAPL extraction. Ultimately, innovative pumping and barrier systems could be coupled with injection of chemical extractants to significantly enhance DNAPL removal. This numerical modeling study assesses the effectiveness of hydraulic and impermeable 
barriers for improving the hydraulic efficiency of pump and treat systems which could involve injection of chemicals into the subsurface for remediation purposes. The United States Geological Survey (USGS) Method of Characteristics (MOC) numerical code was utilized to model the innovative applications of barrier technology and pumping systems. A previously studied field site was chosen to calibrate and apply the numerical model. Transport of trichloroethylene (TCE) was governed by a nonlinear Freundlich adsorption isotherm. Three types of impermeable barriers (liner upgradient, peripheral upgradient, partially enclosing) and two types of hydraulic barriers (single upgradient driver well, driver-deflector well) were studied for their ability to target contamination zones and maximize recovery of injected chemicals (surfactants) and TCE. A dual type impermeable-hydraulic barrier was also studied for its ability to enhance the delivery of surfactants. Sensitivity analyses were performed relative to barrier location, barrier length, and driver-feflector well injection rates. Results of this study show use of a dual (hydraulic and permeable) barrier system to be most efficient in terms of reducing the volume of fresh groundwater migrating through the contaminated zone and controlling migration of injected chemicals.

\section{5}

\section{V18/025554}

Modelling Bioventing for Remediation of Organic Contamination of Ground water

McClure, P.D.; Sleep, B.E.

University of Toronto, Department of Civil Engineering, Toronto, Ontario, Canada; Department of the Environment, Environmental Protection Service, Ottawa, Ontario, Canada

CONF-951086; Proceedings of the Fifth Annual Symposium on Groundwater and Soil Remediation, Toronto, Ontario, Canada, October 2-6, 1995. Environment Canada - Environmental Protection Service, Hull, Quebec, Canada, 566 pp.; (pp. 515-516) (1995)

A model for design and analysis of bioventing systems has been developed, and the substrate and oxygen limitations of biodegradation were modeled using the dual Monod kinetic formulation. The model was applied to several different bioventing configurations to demonstrate the effectiveness of each approach in enhancing contaminant removal by biodegradation. The remediation scenarios examined suggest that simple bioventing configurations may be effective in removing hydrocarbons, particularly from the unsaturated zone. Well location and appropriate gas flow rates appear to be critical factors in determining the effectiveness of bioventing operations. Oxygen transfer rates to the saturated zone were observed to remain low under all bioventing configurations, suggesting the need for using groundwater pumping, or biosparging in conjunction with bioventing, to prevent dissolved plume migration in the saturated zone.

V18/023187

Modelling Dense Non-Aqueous Phase Liquids Contamination in Aquifers Using 3D Geoscientific Information Systems

Fisher, T.R.

Radian Corporation, Geographic Information Systems and
Services, Austin, TX

CONF-9210194; Proceedings of an International Symposium on Environmental Contamination in Central and Eastem Europe, Budapest, Hungary, October 12-16, 1992, 968 pp.; (pp. 270-271) (1992)

Numerous instances of subsurface contamination and groundwater pollution result from improper storage, use and handling of organic compounds. These compounds may be present as multiple phases in a contaminated aquifer, making them extremely difficult to model and analyze. The problems of modelling and analysis are partly overcome through use of three-dimensional (3D) geoscientific information systems (GSISs). Such computer graphics-based software applications provide continuous volumetric data structures which afford solutions for efficient visualization, modelling, and interpretation of multiple geologic or other attributes in their true 3D spatial relationships. Properly used, these systems can provide help in developing information about organic compounds where adequate sampling densities cannot be obtained. They also provide a means of developing geologic frameworks within which subsurface processes can be analyzed. Additionally, they may be used to supply parameters to sophisticated $3 \mathrm{D}$ groundwater and contaminant transport models.

\section{7 \\ V18/023804}

Monitoring Air Sparging in Complex Aquifers

LaBrecque, D.J.; Morelli, G.; Lundegard, P.D.

University of Arizona, Laboratory for Advanced Subsurface Imaging, Tucson, AZ; Unocal Corporation, Corporate Environmental Remediation and Technology, Brea, CA

CONF-960477; SAGEEP '96, R.S. Bell and M.H. Cramer (eds.), Proceedings of the Ninth Annual Symposium on the Application of Geophysics to Engineering and Environmental Problems, Denver, CO, April 15-May 1, 1996. Environmental and Engineering Geophysical Society, Wheat Ridge, CO, 1353 pp.; (pp. 733-742) (1996)

The success of air sparging depends on the size and geometry of the region of air flow. The purpose of this study was to use Electrical Resistance Tomograph (ERT) surveys to observe changes in saturation, and thus air flow in a complex aquifer. This paper describes the results of ERT surveys to monitor air flow in a heterogeneous aquifer in glacial till in Washington State. Most of the air flow was confined a single, thin layer. Within this layer, the flow was not uniform but moved preferentially in one direction. Some flow also occurred in a shallower layer but there is little evidence of leakage into the upper part of the aquifer. After sparging there was a great deal of air trapped within the layers.

3198

V18/021779

\section{Monitoring Probe for Groundwater Flow}

Looney, B.B.; Ballard, S.

U.S. Department of Energy, Washington, DC

U.S. Patent 05339694; 7 pp. (August 23, 1994)

This patent describes a monitoring probe for detecting groundwater migration. The monitor features a cylinder made of a permeable membrane carrying an array of electrical conductivity sensors on its outer surface. The cylinder is filled with a fluid that has a 
conductivity different than the groundwater. The probe is placed in the ground at an area of interest to be monitored. The fluid, typically saitwater, diffuses through the permeable membrane into the groundwater. The flow of groundwater passing around the permeable membrane walls of the cylinder carries the conductive fluid in the same general direction and distorts the conductivity field measured by the sensors. The degree of distortion from top to bottom and around the probe is precisely related to the vertical and horizontal flow rates, respectively. The electrical conductivities measured by the sensors about the outer surface of the probe are analyzed to determine the rate and direction of the groundwater flow.

3199

\section{V18/023891}

Monitoring and Control of Pseudomonas Sp. Strain KC for Insitu Bioaugmentation of Carbon Tetrachloride Contaminates Sites

Criddle, C.S.; Dybas, M.J.; Tatara, G.M.; Wiggert, D.C.; Witt, M.E.; Tiedje, J.M.; Bezborodnikov, S.; Lubman, D.; Fogler, $\mathrm{S}$.

Michigan State University, East Lansing, MI; University of Michigan, Ann Arbor, MI

EPA/600/R-95/012; CONF-9504110; Proceedings of the 21st Annual Risk Reduction Engineering Laboratory (RREL) Research Symposium, Cincinnati, OH, April 4-6, 1995. U.S. Environmental Protection Agency, Cincinnati, OH, 398 pp.; (pp. 349-353) (April 1995)

Pseudomonas sp. strain KC converts carbon tetrachloride (CT) to carbon dioxide, formate, and non-volatile product(s) without the production of chloroform under denitrifying conditions. Most other organisms that transform CT under such conditions do so slowly and/or produce chloroform, making strain $\mathrm{KC}$ an attractive candidate for bioaugmentation applications. For strain $\mathrm{KC}$, the mechanism of CT transformation involves secretion of a low molecular weight factor under iron-limiting conditions. The secreted factor fortuitously transforms CT and is activated for transformation by live whole cells. To determine whether the capabilities of strain $\mathrm{KC}$ can be applied for in-situ remediation of CT contamination, the Michigan Department of Natural Resources is supporting a field experiment in a CT-contaminated aquifer at Schoolcraf, MI. The present report describes laboratory work funded by the Great Lakes and Mid-Atlantic Hazardous Substance Research Center in support of the field project. These laboratory efforts have focused on: (1) isolation and identification of the secreted factor; (2) development and testing of a laboratory-scale model aquifer and numerical simulator to describe establishment and maintenance of a CT-transforming zone; (3) development and testing of a gene probe for detection and monitoring of strain $\mathrm{KC}$; (4) identification of characteristic biochemical markers for strain $\mathrm{KC}$; and (5) identification of key transport and retention mechanisms for strain $\mathrm{KC}$.
3200
V18/024639

Monitoring and Remediation Wells: Problem Prevention, Maintenance, and Rehabilitation

Smith, S.A.

Smith Consulting Services, Ada, $\mathrm{OH}$
Monitoring and Remediation Wells: Problem Prevention, Maintenance, and Rehabilitation, Lewis Publishers, Boca Raton, FL, 203 pp. (1995)

There is a growing problem of performance degradation of wells and associated systems on sites where groundwater quality is monitored or remediation is performed. It is getting to the point where people are beginning to doubt the validity of pump-and-treat as a method. In a lot of cases, the problem is not the concept, but the execution and the tough operating conditions these system face. This book is intended to be a guide in keeping monitoring and pumping well systems operating to their best capacity. It is written for those people who have to wrestle with such problems: site managers, their consultants and regulators, and contractors who may perform well and pump restoration services. Problems experienced with monitoring and remediation wells are nothing new or unique. What site managers are experiencing has long before been a headache to a greater or lesser degree for operators of water supply, dewatering, recharge, and hydraulic-relief wells. Many of the same solutions apply in principle, but in a much more limited way in practice. This book is intended to address the need for and methods of environmental well maintenance and restoration. It is a guidebook to the causes of well deterioration, methods of well maintenance, and well restoration and rehabilitation methods. Chapters from this book that are within the scope of this database have been indexed separately.

3201 V18/026079

\section{Monitoring and Verification of Bioremediation}

CONF-950483 (Vol. 3-5); Proceedings of the Third Intemational Insitu and Onsite Bioreclamation Symposium, San Diego, CA, April 24-27, 1995; Bioremediation Series 3(5) - Monitoring and Verification of Bioremediation, R.E. Hinchee, G.S. Douglas and S.K. Ong (eds.), Battelle Press, Columbus, OH, 273 pp. (1995)

This volume is part of a ten volume set of papers derived from the Third International Insitu and Onsite Bioreclamation Symposium, which was held in San Diego, California, in April 1995. The purpose of the conference was to provide a multidisciplinary forum for exchange of state-of-the-art information on bioremediation. The papers that appear in the set of volumes were accepted after peer review. This volume deals with monitoring and verifying bioremediation processes and includes papers on a broad range of methods. Individual papers within the scope of this data base have been indexed separately.

3202

V18/021071

Monitoring of Insitu Trichlorethylene (TCE) and Per-Chloroethylene (PCE) Bioremediation at the Savannah River Integrated Demonstration Site

Brockman, F.J.; Payne, W.; Workman, D.J.; Soong, A.; Sun, W.; Ogram, A.V.

Pacific Northwest Laboratory, Richland, WA; Washington State University, Pullman, WA

CONF-9405149; Proceedings of the 94th Annual Meeting of the American Society for Microbiology, Las Vegas, NV, May 23-27, 1994; (Paper No. N-76) (1994)

The field site was manipulated with injection of air (control experiment), $1 \%$ methane (in air), pulsing of air only and $4 \%$ 
methane, and pulsing of $4 \%$ methane supplemented with gaseous forms of nitrogen and phosphorus. Following each injection regime, sediment samples from the contaminated region (100-140 feet below ground surface) were analyzed. During methane injection, methylotrophs increased more than 3 orders of magnitude (to greater than $24,000 / \mathrm{g}$ in $100 \%$ of the samples), methanotrophs increased more than 4 orders of magnitude (to greater than or equal to $1000 / \mathrm{g}$ in $43 \%$ of the samples), and ammonia oxidizer populations increased more than 4 orders of magnitude (to greater than $24,000 / \mathrm{g}$ in $20 \%$ of the samples). Following injection of nitrogen and phosphorus to the site, both TCE and PCE were removed in $60-80 \%$ of the methylotrophic and methanotrophic enrichments with $0.001 \mathrm{~g}$ of sediment. PCE removal from iron-reducer, sulfate-reducer, and methanogenic enrichments (with $0.1 \mathrm{~g}$ of sediment) did not occur before methane injection, but was observed in $10-30 \%$ of the samples following methane injection. Methane monooxygenase, methanol dehydrogenase, toluene dioxygenase, and toluene monooxygenase gene probes showed that these genes increased $2-4$ orders of magnitude in many of the samples during methane injection. Increases in populations of TCE-degrading microorganisms corresponded with contaminant removal in groundwater and in the vadose zone, strongly suggesting that microorganisms were responsible for much of the TCE and PCE removal. This research was supported by the U.S. Department of Energy (DOE).(Complete Text)

\section{3}

V18/022047

\section{Near-Infrared Fluorescence Sensor Technology}

Evans, L., III; Casay, G.A.; Dai, D.; Patonay, G.

Georgia State University, Department of Chemistry, Atlanta, $\mathrm{GA}$

CONF-9506232; Environmental Monitoring and Hazardous Waste Site Remediation, T. Vo-Dinh and R. Niessner (eds.), Proceedings of a Conference of the Society of Photo-Optical Instrumentation Engineers, Munich, Germany, June 19-23, 1995. International Society for Optical Engineering, Bellingham, WA, 613 pp.; (pp. 316-323) (1995)

Fluorescence spectroscopy has been used extensively to solve environmental problems (including biological, water quality, separation, etc.) Despite its numerous applications, long wavelength, near-infrared (NIR) fluorescence has been the subject of very few studies. This wavelength region is advantageous, if we wish to minimize the effect of background interference. Lowering the background interference is especially advantageous in environmental monitoring applications where very little or no preseparation is necessary to achieve selective measurements. The application of NIR absorbing fluorophores which usually have high molar absorptivities and good quantum yields can be especially advantageous when laser diodes are employed as the excitation source. This paper will focus on several general practical analytical applications of NIR fluorescence spectroscopy for solving environmental related analytical problems, including but not limited to: use of NIR fluorophores as labels (in conjunction with immunosensor technology) and the use of NIR chromophores as direct probes ( $\mathrm{pH}$, metal ions, etc.). Additionally the use of laser diodes and semiconductor detectors (silicon photodiodes and avalanche photodiodes) as light sources and detectors will be discussed.
3204

V18/023806

New Approach to Insitu Determination of the Hydraulic Conductivity

Efferso, F.; Sorensen, K.I.

Aarhus University, Department of Earth Sciences, Aarhus, Denmark

CONF-960477; SAGEEP '96, R.S. Bell and M.H. Cramer (eds.), Proceedings of the Ninth Annual Symposium on the Application of Geophysics to Engineering and Environmental Problems, Denver, CO, April 15-May 1, 1996. Environmental and Engineering Geophysical Society, Wheat Ridge, CO, 1353 pp.; (pp. 1107-1114) (1996)

Increasing demands for detailed groundwater and transport models for planning of water extraction and prevention of groundwater pollution have accentiated an integrated application of hydraulic and geophysical data. This integration requires that relations between hydraulic and geophysical properties becomes better known, but also that detailed methods become accessible. In this context, a new method (Injection Method) for detailed in situ determination of apparent hydraulic conductivity has been developed as an altemative to pumping tests and piezometer tests. The measurements are carried out in connection with down drilling of a hollow stem auger, where a transducer mounted inside the drilling stem measures the rise in hydraulic head outside the drilling stem due to injection of a controlled water flow. By measuring the hydraulic head in situ, the method is expected to provide close estimates of the apparent hydraulic conductivity.

3205 V18/021987

New Device for Real Time Monitoring of Microbial Population Dynamics During Insitu and Exsitu Bioremediation

Woodward, R.E.; Malone, R.W.

Sierra Environmental Services, Inc., Houston, TX; BioTech International, Inc., Sugarland, TX

CONF-9509139; Emerging Technologies in Hazardous Waste Management VII, D.W. Tedder (ed.), Proceedings of the Seventh American Chemical Society Industrial and Engineering Chemistry Division Special Symposium, Atlanta, GA, September 17-20, 1995. American Chemical Society, Washington, DC, 1291 pp.; (pp. 291-294) (1995)

Monitoring of microbial population dynamics is an important operating parameter for successful bioremediation projects. The traditional method of plate counts or most probable number (MPN) requires 2 to 7 days for development and therefore provides a historical measurement of little real-time population density and is linear in the population range from $10(E+4)$ to $10(E+8) C F U / m L$. This paper summarizes the use of this enzyme based, real-time measurement of microbial population dynamics for the management of four bioremediation projects: (1) differentiation of assimilation from nitrification during the metabolism of ammonia in an industrial waste stream, (2) treatability assessment and management of activated sludge processes during the treatment of a hazardous, petrochemical waste, (3) measurement of intrinsic microbial activity in soil cores at a spill site, and (4) non-invasive monitoring of microbial populations during in situ bioremediation of 
two aquifers.

3206

V18/022741

New Technology for Removal of Heavy Metals from Water Field Experiment with Treatment of Groundwater Containing $\mathrm{As}, \mathrm{Cr}$, and $\mathrm{Ni}$

Christensen, T.C.; Nielsen, P.B.

Kruger A/S, Soborg, Denmark

CONF-960804 (Vol. 2); Spectrum '96: Nuclear and Hazardous Waste Management, Proceedings of an International Topical Meeting, Seattle, WA, August 18-23, 1996. American Nuclear Society, La Grange Park, IL, Vol. 2, 873 pp.; (pp. 915-921) (1996)

Together with A/S De Smithske (Desmi) in Norresundby, Denmark, Kruger has developed a fluidised-bed technology for removal of iron, manganese and dissolved heavy metals from water without the production of aqueous sludge. The process has been documented on a fuil scale and/or pilot scale for $\mathrm{Fe}, \mathrm{Mn}, \mathrm{Cr}, \mathrm{As}, \mathrm{Ni}, \mathrm{Zn}$ and $\mathrm{Cd}$. In April/May 1996, tests will be conducted on Se and Mo treatment. Based on the present process knowledge of and results from precipitation and adsorption tests described in the literature it can be concluded that many other metals than the ones already tested can be treated to a high degree.

3207

V18/022423

Nickel and Chromium in Groundwater Samples as Influenced by Well Construction and Sampling Methods

Oakley, D.; Korte, N.E.

Lockheed Martin Energy Systems, Inc., Hazardous Waste Remedial Actions Program, Oak Ridge, TN; Oak Ridge National Laboratory, Environmental Sciences Division, Grand Junction, $\mathrm{CO}$

Groundwater Monitoring and Remediation 16(1):93-99 (Winter 1996)

An investigation of elevated concentrations of nickel and chromium in certain groundwater samples collected at Williams Air Force Base (AFB) indicated that type 304 stainless steel well materials are the source. Chloride in the groundwater has apparently caused crevice corrosion of the stainless steel well screens installed during site characterization. An evaluation of site geochemistry suggested that chromium released from the well screen would precipitate, while nickel would remain dissolved. Thus, low-flow purging and sampling significantly reduces the chromium found in the groundwater samples because such sampling minimizes the collection of artificially entrained particulates. In contrast to chromium, nickel concentrations did not decrease during low-flow purging and sampling, indicating that it is dissolved. Nickel and chromium concentrations are both low following high-volume purging when turbidity levels are stabilized below 10 nephelometric turbidity units prior to sampling. In the latter case, chromium concentration is low because particulate collection is minimized, and nickel concentration is low because of increased dilution. Based on these results, it is recommended that elevated levels of nickel and chromium in groundwater samples collected from stainiess steel monitoring wells be carefully elevated, because well materials may be the source. In addition, although low-volume purging is increasingly becoming the sampling method of choice, high-volume purging may be a useful means of determining whether the well materials influence nickel and chromium concentrations.

3208

V18/024673

Nitrate-Mediated Biodegradation of BTEX in JP-4-Contaminated Soil and Groundwater: A Field Pilot-Scale Demonstration Project, Chapter 17

Down, W.C.; Hutchins, S.R.; Wilson, J.T.; Douglass, R.H.; Hendrix, D.J.

Idaho National Engineering Laboratory, Idaho Falls, ID; U.S. Environmental Protection Agency, Robert S. Kerr

Environmental Research Laboratory, Ada, OK; Global Environmental Engineering, Inc., Traverse City, MI; Solar Universal Technologies, Inc., Cleveland, $\mathrm{OH}$

Bioremediation: Field Experience, P.E. Flathman, D.E. Jerger and J.H. Exner (eds.), Lewis Publishers, Boca Raton, FL, 560 pp.; (pp. 361-379) (1994)

The success of bioremediation efforts is often limited by the inability to provide sufficient oxygen to the contaminated intervals, due to the low solubility of oxygen. Nitrate can be used as a replacement for oxygen as an electron acceptor in a metabolic process under anaerobic conditions; this results in anaerobic biodegradation of organic compounds through nitrate reduction and denitrification. Because nitrate is less expensive and more soluble than oxygen, it may be more economical to restore fuel-contaminated aquifers using nitrate rather than oxygen. Several investigators have observed biodegradation of aromatic fuel hydrocarbons under denitrifying conditions. The process is not well understood, and there have been few definitive field studies of its viability in the biorestoration of fuel-contaminated aquifers. A field demonstration project of nitrate-mediated bioremediation of a fuel-contaminated aquifer was conducted at a U.S. Coast Guard facility in Traverse City, Michigan. Leaks from underground storage tanks containing JP-4 jet fuel contaminated groundwater at the facility. The focus of the field demonstration project was a $30 \times 30$ ft $(9 \times 9 \mathrm{~m})$ infiltration area located within the larger area contaminated by the JP-4 plume. An infiltration gallery was constructed as part of a closed-loop system designed to perfuse the study area with groundwater supplemented with nitrate and nutrients. A series of recirculation wells was installed downgradient to intercept contaminants, nutrients, and nitrate and to provide hydraulic recirculation back through the infiltration gallery. In addition, four interdiction wells were installed to provide a net discharge from the site and prevent escape of nitrate or contaminants to regional flow in the aquifer. Hydraulic computer simulations were used in the design of the system to estimate the infiltration rate necessary to raise the piezometric surface above the contaminated zone, the withdrawal rates necessary to retain the contaminants and nutrients on-site, and the nutrient contact time important to biological treatment. A tracer study was conducted to confirm estimated breakthrough times and to provide other useful information necessary to allow an evaluation of the performance of the in situ bioreactor. The effects of recirculation, wasting, and biodegradation on the decrease in solution concentration of BTEX compounds within the treatment zone were examined. This chapter is from the book entitled Bioremediation: Field Experience. 
Non-Aqueous Phase Liquids (NAPLs) in Subsurface Environment - Assessment and Remediation: Proceedings of the Specialty Conference Held in Conjunction with the ASCE National Convention, November 12-14, 1996, Washington, DC

Non-Aqueous Phase Liquids (NAPLs) in Subsurface Environment: Assessment and Remediation, L.N. Reddi and U.P. Singh (eds.), Proceedings of a Specialty Conference Held in Conjuction with the American Society of Civil Engineers (ASCE) National Convention, November 12-14, 1996, Washington, DC, ASCE, New York, NY (October 1996)

No abstract available.

\section{0}

\section{V18/022048}

Non-Invasive Monitoring of Inorganic Species in Water Ahmad, S.R.; Iles, A.

Cranfield University, School of Electrical Engineering and Science, Swindon, Wiltshire, United Kingdom

CONF-9506232; Environmental Monitoring and Hazardous Waste Site Remediation, T. Vo-Dinh and R. Niessner (eds.), Proceedings of a Conference of the Society of Photo-Optical Instrumentation Engineers, Munich, Germany, June 19-23, 1995. International Society for Optical Engineering, Bellingham, WA, 613 pp.; (pp. 436-447) (1995)

Results of the UV absorption properties of nitrate in waters and the effects of potential inorganic and organic species on these properties are presented. The attenuation of the water Raman and Rayleigh back-scattered light of appropriate wavelengths by nitrate distributed along the probed water column is correlated with nitrate concentration. An analysis of the results in terms of an extended source in the water column and integrated absorption (over a certain depth) is presented. The feasibility of using a differential absorption and scattering technique utilizing water Raman and Rayleigh back scattered signals without any optical contact with cell walls is examined, so that the problem of cell fouling in conventional absorption measurements is avoided.

\section{1}

\section{V18/023625}

Numerical Simulation of Air Sparging for Remediation of NAPL Contamination

McCray, J.E.; Falta, R.W.

Clemson University, Clemson, SC

Groundwater 35(1):99-1 10 (January-February 1997)

A numerical simulation study of air sparging for the removal of nonaqueous phase liquids (NAPLs) from the subsurface is presented. These simulations were performed using the T2VOC integrated finite-difference, multiphase-flow, contaminant transport code. The code is used to model two-dimensional air sparging experiments from Ji et al. (1993) which include both homogeneous and heterogeneous permeability distributions. The model predicts the experimental gas plume shape and behavior very well. Field-scale simulations using a radially symmetric, cylindrical mesh are then used to model hypothetical DNAPL and LNAPL spills and air sparging remediation performance in various hydrogeologic settings. Both homogeneous and heterogeneous systems are considered. The results of the study indicate that the sparging-induced gas pressure increase, or positive pressure, measured at steady state below the water table, closely corresponds to both the subsurface gas distribution and the effective zone of contaminant reduction. Because this positive pressure is easily measured in the field with a simple monitoring device, it can be used to realistically define the sparging radius of influence.

3212

V18/022619

\section{Numerical Simulation of Surfactant-Enhanced} Remediation Using UTCHEM

Freeze, G.A.; Fountain, J.C.; Pope, G.A.; Jackson, R.E. INTERA, Inc., Albuquerque, NM; State University of New York at Buffalo, Buffalo, NY; University of Texas, Austin, TX; INTERA, Inc., Austin, TX

CONF-950828; Heat Transfer - Portland 1995, M.S. El-Genk (ed.), Proceedings of the 1995 National Heat Transfer Conference, Albuquerque, NM, August 5-9, 1995. American Institute of Chemical Engineers, New York, NY, 378 pp.; (pp. 68-73) (1995)

The UTCHEM multiphase compositional simulator was used to model the migration and surfactant-enhanced remediation of perchloroethylene (PCE) in a test cell at Canadian Forces Base Borden, Ontario. A line of five injection wells was installed on one side of the test cell and a line of five withdrawal wells was installed on the opposite side of the cell. The injection and withdrawal wells penetrated the entire depth of the sand aquifer. A total of 231 liters of PCE was injected into a shallow well in the center of the test cell. Prior to surfactant flushing, 47 liters of free-phase PCE, which flowed into the injection and withdrawal wells over a two week period, was removed using a small-diameter plastic tube and a peristaltic pump. One to two months of water flooding (pump-and-treat), using the injection-withdrawal well system, flushed an additional 12 liters of PCE. Following the water flooding, an aqueous surfactant solution of $1 \%$ nonyl phenol ethoxylate and $1 \%$ phosphate ester of the nonyl phenol ethoxylate was circulated through the test cell via the injection-withdrawal wells. Between November 11, 1990 and May 29, 1991, a total of 130,000 liters of surfactant solution were recirculated through the test cell, during which time 62 liters of PCE were recovered. This paper describes preliminary scoping simulations of the surfactant flushing process at the Borden test site to demonstrate the capability of UTCHEM to model surfactant-enhanced remediation of a non-aqueous-phase liquid (NAPL). A discussion of efforts to simulate PCE migration is also presented.

3213

V18/020611

Optimal Groundwater Remediation Design Using Multiple Control Technologies

Marryott, R.A.

Environ Corporation, Princeton, NJ

Groundwater 34(3):425-433 (May-June 1996)

Combined optimization-simulation models for designing groundwater remediation systems generally focus on design strategies that use only one remedial technology, typically pumping. In practice, many field remediation programs use pumping along with one or more additional groundwater control technologies, such as drains, trenches, slurry walls, and low 
permeability caps. Simulated annealing provides a flexible optimization framework that can incorporate a number of different remedial technologies into the design process. Using simulated annealing, additional remedial technologies can be added to or subtracted from the optimization at any time. This flexibility can provide for remedial design evaluations that are more consistent with current field implementations. The use of simulated annealing is demonstrated by a series of hypothetical remediation design problems that incorporate four different remedial technologies. The computed optimal design solution depends on the relative costs of the remedial tools as specified by the cost function and on the effects that each tool has on the system behavior. A sensitivity analysis can reveal which costs are critical to the outcome of the optimization.

\section{4 \\ V18/024671}

Oxygen Sources for Insitu Bioremediation, Chapter 15

Brown, R.A.; Crosbie, J.R.

Groundwater Technology, Inc., Trenton, NJ; Groundwater Technology, Inc., Chads Ford, PA

Bioremediation: Field Experience, P.E. Flathman, D.E. Jerger and J.H. Exner (eds.), Lewis Publishers, Boca Raton, FL, 560 pp.; (pp. 311-331) (1994)

Oxygen transport is a critical part of bioremediation. First, oxygen availability has a significant impact on bacterial levels and on the rates of biodegradation. Second, the oxygen system is one of the highest cost elements of the biological treatment system. There are, however, a number of ways of providing oxygen, including aeration, air sparging, chemical carriers, and soil venting. The effectiveness of each system varies with the degree of contamination and the characteristics of the site. Selecting an oxygen supply system is, therefor, an important part of the design of biological treatment systems. By understanding the level of contamination, closure goals, and site characteristics, a cost-effective and efficient system for oxygenation can be implemented. In general, air systems are more cost-effective than are chemical systems. With high levels of contamination, soil venting and/or air sparging are the most cost-effective. With low levels of contamination aerated water and venting/sparging can also be cost-effective. This chapter describes the various methods for oxygenation and their relative advantages and disadvantages and presents case histories illustrating field applications. This chapter is from the book entitled Bioremediation: Field Experience.

3215 V18/021636

Ozone-Electron Beam Treatment for Groundwater Remediation

Gehringer, P.; Eschweiler, H.; Fiedler, H.

Austrian Research Centre, Seibersdorf, Austria

CONF-940908; Dedicated to the Dissemination and Advancement of the Technology of Industrial Radiation Processing, Proceedings of the Ninth International Meeting on Radiation Processing, Istanbul, Turkey, September 11-16, 1994; Radiation Physics and Chemistry 46(4-6):1075-1078 (October-December 1995)

Dose rate effects and low penetration are major disadvantages of electron beam irradiation. Addition of ozone before or during irradiation may eliminate dose rate effects as shown for the remediation of groundwater contaminated with trace amounts of chlorinated solvents such as trichloroethylene (TCE) and perchloroethylene (PCE). Besides the elimination of dose rate effects, the necessary radiation dose for pollutant decomposition is considerably lowered by the presence of ozone during irradiation. As a consequence the economy of the combined ozone/irradiation process becomes better than that of irradiation alone. Irradiation of turbulent water flows enables cleanup of water layers thicker than the maximum penetration of the electrons used. This effect is improved by the presence of ozone during irradiation, too.

3216 V18/021085

Ozone/Electron Beam Process for Water Treatment: Design, Limitations, and Economic Considerations

Gehringer, P.; Eschweiler, H.

Chemische Verfahrenstechnik, Verfahrens-und Umwelttechnik, Seibersdorf, Austria

OEFZS-4767; CONF-960252; Proceedings of the Second International Symposium on Environmental Applications of Advanced Oxidation Technologies, San Francisco, CA, February 28-March 1, 1996; 11 pp. (January 1996)

Electron beam irradiation of water is the easiest way to generate $\mathrm{OH}$ free radicals but the efficiency of the irradiation process as advanced oxidation process (AOP) is deteriorated by reducing species formed simultaneously with the $\mathrm{OH}$ free radicals. Addition of ozone to the water before or during irradiation improves the efficiency essentially by converting the reducing species into $\mathrm{OH}$ free radicals and turning by that the irradiation process into a full $A O P$. The main reaction pathways of the primary species formed by the action of ionizing radiation on water in a natural groundwater with and without the presence of ozone are reviewed. Based on these data an explanation of both the dose rate effect and the ozone effect is attempted. New data is presented which illustrates the effect of alkalinity on the way in which ozone is introduced into the water, and the impact of both water matrix and chemical structure of the pollutants to the efficacy of the ozone/electron beam process.

3217 V18/024849

Performance Assessment of the In-Well Vapor-Stripping System

Gilmore, T.J.; Pinto, M.J.; White, M.D.; Ballard, S.; Gorelick, S.M.; Taban, O.; Spane, F.A., Jr.

Pacific Northwest National Laboratory, Richland, WA; Stanford University, Department of Geological and Environmental Sciences, Stanford, CA; Earth Technology Corporation, Long Beach, CA

PNNL-1 1414; 93 pp. (October 1996)

In-well vapor stripping is a remediation technology designed to preferentially extract volatile organic compounds dissolved in groundwater by converting them to a vapor phase and then treating the vapor. This vapor-stripping system is distinctly different from the more traditional in situ air-sparging concept. In situ sparging takes place in the aquifer formation; in-well vapor stripping takes place within the well casing. The system was field demonstrated at Edwards Air Force Base, Califomia; the first-time demonstration of 
this technology in the United States. Installation and testing were completed in late 1995 , and the demonstration was operated nearly continuously for 6 months (191 days) between January 16 and July 25,1996 . Post demonstration hydrochemical sampling continued until September 1996. The demonstration was conducted by collaborating researchers from Pacific Northwest National Laboratory and Stanford University as part of an interim cleanup action at the base. Edwards Air Force Base and its environmental subcontractor, Earth Technology Corporation, as well as EG\&G Environmental, holders of the commercial rights to the technology, were also significant contributors to the demonstration.

\section{8}

\section{V18/022194}

\section{Performance Monitoring for Plume Remediation and} Containment Action

Unkefer, P.J.; Herrick, J.

Los Alamos National Laboratory, Los Alamos, NM

LA-UR-96-3177; 5 pp. (1996)

This is the final report of a one year, Laboratory Directed Research and Development project at the Los Alamos National Laboratory. Bioremediation is a promising altemative to conventional cleanup technologies because of its relative speed, safety, and cost. However, current methods for measuring and evaluating the performance of bioremediation are inadequate. The development of the basic understanding and methods for assessing bioremediation research sites was a focus of this project. It sought to develop an improved understanding of the pathways and genes employed by bacteria in the catabolism of pollutants in actual field situations.

3219

V18/023316

Perimeter-Based Groundwater Protection Strategy for Waste Management Units at a Petroleum Refinery

Wenzlau, R.K.

Pacific Environmental Group, Inc., San Jose, CA

CONF-960393 (Part 1); Contaminated Soils and Groundwater: Analysis, Fate, Environmental and Public Health Effects, and Remediation, Proceedings of the Sixth Annual West Coast Conference, Newport Beach, CA, March 11-14, 1996. Association for the Environmental Health of Soils, Amherst, MA, Part 1, 257 pp.; (18 pp.) (1996)

This article presents a groundwater management strategy and its application to regulatory compliance for the Shell Oil Company Martinez Manufacturing Complex, a refinery located within northem California. The purpose of the strategy is to protect the beneficial uses of groundwater which are present beyond the facility boundary while recognizing the occurrence of limited degradation of groundwater upgradient of the perimeter. The strategy applies perimeter-based groundwater monitoring and control of two general sources of groundwater quality degradation: historic spill and leak sites and inactive waste management units. To regulate the groundwater contaminant plumes originating from historic spill and leak sites, the California Regional Water Quality Control Board (Regional Board) has issued Site Cleanup Requirements (SCR). To satisfy the SCR, Shell developed in 1989 a Basin Boundary Control Plan as the first implementation of the groundwater strategy. To regulate groundwater quality impacts from solid waste management units, the Regional Board issues Waste Discharge Requirements (WDR). In 1995 the Regional Board issued revised WDR that established consistency between waste management unit regulation and the facility groundwater management strategy. The Regional Board made two findings that allowed this consistency. The first finding was that the Points of Compliance for all 23 solid waste management units are at the down-gradient perimeter of the facility. The second finding was that all waste management units were within corrective action, regardless of whether a known release of waste constituents occurred from a given waste unit. Therefore the SCR and the WDR are both consistent with the facility groundwater strategy. This strategy satisfies federal and state regulation, is cost effective, and is focused on maintaining beneficial uses of groundwater beyond the facility through monitoring for contaminant and remediating contaminants when concentrations exceed applicable limits.

3220

V18/022783

Permeable Reactive Wall Composed of Clinoptilolite for Containment of Sr-90 in Hanford Groundwater

Cantrell, K.J.

Pacific Northwest National Laboratory, Richland, WA

CONF-960804 (Vol. 2); Spectrum '96: Nuclear and Hazardous Waste Management, Proceedings of an International Topical Meeting, Seattle, WA, August 18-23, 1996. American Nuclear Society, La Grange Park, IL, Vol. 2, 873 pp.; (pp. 1358-1365) (1996)

Large volumes of water containing strontium-90 (90Sr) and other radionuclides were disposed of in the past in two liquid waste disposal facilities (trenches) at the Hanford $100 \mathrm{~N}$ Area. As a result of these past disposal practices, $90 \mathrm{Sr}$ has migrated in the groundwater towards the Columbia River. One potential altemative for treatment of this groundwater is the use of a permeable treatment wall containing an adsorbent. Because of their high adsorption affinity for strontium, zeolites appear to be promising candidates for use as a material to construct an in situ permeable treatment zone. Supporting bench scale work included batch adsorption experiments conducted with three zeolites (clinoptilolite, chabazite and $A-51$ ) to determine their potential applicability as materiais for an in situ permeable barrier to strontium migration in groundwater. Each of the zeolites tested were found to be effective adsorbents for strontium, even in competition with calcium at concentrations typical of Hanford groundwater. It was determined that clinoptilolite would be the most cost-effective zeolite for a barrier at the Hanford site. Equilibrium Sr adsorption data for Ca saturated clinoptilolite were fit to a Langmuir isotherm. Adsorption kinetics of $\mathrm{Sr}$ onto clinoptilolite were also determined. These data were used to develop a kinetic model. The kinetic model parameters were incorporated into a transport modeling code (RAFT). This model was used to design an effective barrier and to assess its performance. Modeling results indicated that a barrier $1.0 \mathrm{~m}$ thick would effectively reduce Sr-90 migration to the Columbia River at the 100-N Area of the Hanford Site. With this design, it was determined that a maximum of $0.10 \%$ of the Sr-90 would pass through the barrier at 235 years. To be effective the permeable reactive wall must be more permeable than the surrounding aquifer material. Hydraulic conductivity measurements were performed on three commercially available particle size ranges and a custom particle 
size range which could also be produced by the supplier at low cost. These results will be discussed in relation to the permeability of Hanford aquifer material and the permeabilities of other potential application sites.

\section{1}

\section{V18/024108}

Permeable-Reactive Barrier Wall Systems with Gel Enhancements

Los Alamos National Laboratory, Los Alamos, NM

LALP-94-248; 1 p. (1994)

Controlling low-level groundwater plumes is a widespread problem for government and industry. Los Alamos has developed an alternative to conventional activities (such as pump and treat), which take too long, are too disruptive, and cost too much. The Los Alamos method consists of an instrumented suite of field-scale test cells and simple barrier systems. This project integrates water-permeable barriers that chemically capture or degrade contaminants without significantly altering the natural water flow regime. Specifically, we are integrating gel barrier materials; chemical extraction with simple, readily available materials; chemical tracer approaches; and reservoir characterization. By integrating these processes, Los Alamos believes it can provide containment while in situ treatment is being defined. This integrated process will provide the necessary information to effectively apply in situ remediation and enhanced closure systems, as well as to conduct long-term monitoring.

\section{2}

\section{V18/022386}

Photocatalytic Oxidation and Reduction Chemistry and a New Process for Treatment of Pink Water and Related Contaminated Water

Blake, D.M.; Wolfrum, E.; Boulter, J.; Prairie, M.R.; Showalter, S.; Rodacy, P.; Leslie, P.; Stange, B.

National Renewable Energy Laboratory, Golden, CO; Sandia National Laboratories, Albuquerque, NM

NREL/TP-430-21580; 115 pp. (October 1996)

This project was carried out at the National Renewable Energy Laboratory (NREL), Sandia National Laboratory (SNL), and by a group at the University of Idaho (UI) working under subcontract to NREL. Project staff met with engineering and environmental compliance staff at Longhom and Iowa Army Ammunition Plants to become familiar with current pink water treatment technology and requirements. The initial focus was on photocatalytic oxidation and reduction chemistry that could use sunlight as the photon source. This work demonstrated the technical feasibility of the photocatalytic processes; however, the process removed the hazardous components of pink water at such low efficiency that it would be expensive to operate lamps in a treatment system. Technical success in removing trinitrotoluene (TNT) from water by photocatalytic reduction chemistry led us to test that as a pretreatment step for a biological treatment process. The photocatalytic reduction of TNT did render the simulated pink water more amenable to mineralization by Phanerochaete chrysosporium. This result led us to explore other chemistry for removal of TNT and related explosives from water.
3223

V18/021956

Photochemical Oxidation: A Solution for the Mixed Waste Dilemma

Prellberg, J.W.; Thornton, L.M.; Cheuvront, D.A.

Vulcan Peroxidation Systems, Inc., Tucson, AZ

CONF-951209; Proceedings of the 17th Annual U.S. Department

of Energy Low-Level Radioactive Waste Management Conference, D. Lake (ed.), Phoenix, AZ, December 12-14, 1995, 480 pp.; (7 pp.) (1995)

Numerous technologies are available to remove organic contamination from water to wastewater. A variety of techniques also exist that are used to neutralize radioactive waste. However, few technologies can satisfactorily address the treatment of mixed organic/radioactive waste without creating unacceptable secondary waste products or resulting in extremely high treatment costs. An innovative solution to the mixed waste problem is on-site photochemical oxidation. Liquid-phase photochemical oxidation has a long-standing history of successful application to the destruction of organic compounds. By using photochemical oxidation, the organic contaminants are destroyed on-site leaving the water, with radionuclides, that can be reused or disposed of as appropriate. This technology offers advantages that include zero air emissions, no solid or liquid waste formation, and relatively low treatment cost. Discussion of the photochemical process will be described, and several case histories from recent design testing, including cost analyses for the resulting full-scale installations, will be presented as examples.

3224

V18/023397

Physical Barriers Formed from Gelling Liquids: 1 Numerical Design of Laboratory and Field Experiments

Finsterle, S.; Moridis, G.J.; Pruess, K.; Persoff, P.

Lawrence Berkeley National Laboratory, Berkeley, CA

LBL-35113; 51 pp. (January 1994)

The emplacement of liquids under controlled viscosity conditions is investigated by means of numerical simulations. Design calculations are performed for a laboratory experiment on a decimeter scale, and a field experiment on a meter scale. The purpose of the laboratory experiment is to study the behavior of multiple grout plumes when injected in a porous medium. The calculations for the field trial aim at designing a grout injection test from a vertical well in order to create a grout plume of a significant extent in the subsurface.

3225

V18/021961

Phytoremediation of Explosives Contaminated Ground Waters by Plant Enzyme Systems in Constructed Wetlands

Jackson, R.P., Jr.

U.S. Army Environmental Center, Aberdeen Proving Ground, MD

CONF-9509139; Emerging Technologies in Hazardous Waste Management VII, D.W. Tedder (ed.), Proceedings of the Seventh American Chemical Society Industrial and Engineering Chemistry Division Special Symposium, Atlanta, GA, September 17-20, 1995. 
American Chemical Society, Washington, DC, 1291 pp.; (p. 609) (1995)

A plant enzyme system has successfully degraded the explosives TNT, RDX, and HMX to environmentally acceptable products during laboratory studies. The process has been further studied in the field in batch systems. The field results have been consistent with the laboratory findings. An artificial wetlands will be constructed to remediate explosives contaminated groundwater at an Army ammunition plant. An overview of the phytoremediation program will be presented. (Complete text)

\section{$3226 \quad$ V18/021626}

Phytoremediation: Using Green Plants to Clean Up Contaminated Soil, Groundwater, and Wastewater Negri, M.C.; Hinchman, R.R.; Gatliff, E.G.

Argonne National Laboratory, Argonne, IL; Applied Natural Sciences, Inc., Hamilton, $\mathrm{OH}$

ANL/ES/CP-89941; CONF-960804 (Vol. 2); Spectrum '96: Nuclear and Hazardous Waste Management, Proceedings of an International Topical Meeting, Seattle, WA, August 18-23, 1996. American Nuclear Society, La Grange Park, IL, Vol. 2, 873 pp.; (pp. 1220-1225) (1996)

Phytoremediation, an emerging cleanup technology for contaminated soils, groundwater, and wastewater that is both low-tech and low-cost, is defined as the engineered use of green plants (including grasses, forbs, and woody species) to remove, contain, or render harmless such environmental contaminants as heavy metals, trace elements, organic compounds, and radioactive compounds in soil or water. The authors research includes a successful field demonstration of a plant bioreactor for processing the salty wastewater from petroleum wells. The demonstration is currently under way at a natural gas well site in Oklahoma, in cooperation with Devon Energy Corporation. A greenhouse experiment on zinc uptake in hybrid poplar (Populus sp.) was initiated in 1995. These experiments are being conducted to confirm and extend field data indicating high levels of zinc $(4,200$ $\mathrm{ppm}$ ) in leaves of hybrid poplar growing as a cleanup system at a site with zinc contamination in the root zone of some of the trees. Analyses of soil water from experimental pots that had received several doses of zinc indicated that the zinc was totally sequestered by the plants in about 4 hours during a single pass through the root system. The data also showed concentrations of sequestered metal of greater than $38,000 \mathrm{ppm} \mathrm{Zn}$ in the dry root tissue. These levels of sequestered zinc exceed the levels found in either roots or tops of many of the known "hyperaccumulator" species. Because the roots sequester most of the contaminant taken up in most plants, a major objective of this program is to determine the feasibility of root harvesting as a method to maximize the removal of contaminants from soils. Available techniques and equipment for harvesting plant roots, including young tree roots, are being evaluated and modified as necessary for use with phytoremediation plants.

\section{7}

V18/021986

Practical Application of New and Emerging Technologies in the Treatment of Contaminated Soils and Groundwater

Davies, R.N.
GeoSyntec Consultants, Atlanta, GA

CONF-9509139; Emerging Technologies in Hazardous Waste Management VII, D.W. Tedder (ed.), Proceedings of the Seventh American Chemical Society Industrial and Engineering Chemistry Division Special Symposium, Atlanta, GA, September 17-20, 1995. American Chemical Society, Washington, DC, 1291 pp.; (p. 559) (1995)

Over the past several years various new or emerging technologies have been developed for the remediation of contaminated soils and groundwater. Numerous technologies have been tested at laboratory and bench scale, but a lesser number have a proven track record of success at full scale. The paper will present a synopsis of some emerging technologies that are starting to be offered by contractors. Successes and acceptance by regulatory agencies will be addressed. The paper will also present alternative contracting strategies that have been developed in an attempt to encourage innovation and competitive pricing while maintaining equitable risk sharing between the various contracting parties. (Complete text)

3228 V18/024708

Practical Handbook of Soil, Vadose Zone, and Groundwater Contamination: Assessment, Prevention, and Remediation

Boulding, J.R.

Eastern Research Group, Inc., Lexington, MA

Practical Handbook of Soil, Vadose Zone, and Groundwater Contamination: Assessment, Prevention, and Remediation, Lewis Publishers, Boca Raton, FL, 947 pp. (1995)

This book focuses on technical aspects of soil and groundwater contamination, assessment and management. It provides a single, convenient, reference source to be used by environmental managers and professionals for answers to questions pertaining to contaminated groundwater or soils. The book is divided into three sections. Part One contains four chapters covering Basic Concepts of geology, hydrology, geochemistry, microbiology and environmental transport as they relate to soil and groundwater contamination. Part Two contains six chapters on Assessment and Monitoring that provide up-to-date and comprehensive information on methods for characterizing contaminated sites and analyzing site data. The four chapters in Part Three, Prevention and Remediation, provide systematic and practical information for identifying and implementing methods for preventing or minimizing contamination and, cleaning up sites that are already contaminated. Three of these chapters are indexed separately in the RAPIC database. V18/022201

Precipitation and Separation of Salts from Aqueous Saline Solutions

Bader, M.S.H.

U.S. Department of Energy, Washington, DC; Amoco Production Company, Houston, TX; Conoco, Inc., Stamford, CT; Oklahoma State University, Stillwater, OK

CONF-9509296; Environmental Issues and Solutions in Petroleum Exploration, Production, and Refining, K.L. Sublette (ed.), Proceedings of the Second International Petroleum Environmental Conference, New Orleans, LA, September 25-27, 1995, 1078 pp.; 


\section{(pp. 631-650) (1995)}

Experimental databases for the precipitation and separation of chloride, sulfate, and nitrate in possible cation forms from aqueous solutions were generated using isopropylamine and other miscible organic solvents as precipitation agents. The measurements were carried out to demonstrate: (1) the precipitation of a single salt from an aqueous solution; (2) the coprecipitation of double or triple salts from an aqueous solution; (3) the viability of the precipitation process with actual saline waters. It was found that the precipitation process has a significant potential in the fields of saline water conversion as well as the recovery of radioactive materials and metals from aqueous solutions. A rigorous thermodynamic framework based on the excess Henry's constant approach was developed to model the precipitation measurements. Wohl's expansion was used to express the excess Gibbs free energy function. The precipitation measurements were sufficiently predicted by the framework. The framework provides an insight into the basic fundamentals underlying the precipitation process.

\section{0}

V18/023997

Preliminary Technology Report for the Insitu Bioremediation Demonstration (Methane

Biostimulation) of the Savannah River Integrated Demonstration Project, DOE/OTD

Hazen, T.C.

Westinghouse Savannah River Company, Aiken, SC

WSRC-TR-93-670; 40 pp. (January 1995)

This project was designed to demonstrate in situ bioremediation of groundwater and sediment contaminated with chlorinated solvents. Indigenous microorganisms were stimulated to degrade trichloroethylene (TCE), tetrachloroethylene (PCE), and their daughter products in situ by addition of nutrients to the contaminated aquifer and adjacent vadose zone. The principal carbon and energy source nutrient used in this demonstration was methane (natural gas). In situ biodegradation is a highly attractive technology for remediation because contaminants are destroyed, not simply moved to another location or immobilized, thus decreasing cleanup costs, risks, and time, while increasing efficiency, safety, and public and regulatory acceptability. This report describes the preliminary results of the demonstration and provides conclusions only for those measures that the Bioremediation Technical Support Group (BTSG) expert panel felt were so overwhelmingly convincing that they do not require further analyses. Though this report is necessarily superficial, it provides a basis for further evaluating the technology, and for practitioners to immediately apply some parts of the technology. It is the first of seven technology reports that will be issued regarding this demonstration. The others will deal with nucleic acid probe analyses, community structure analyses, biodegradation analyses, site preparation and field engineering, modeling, and the final summary.

\section{1}

V18/022901

Presumptive Response Strategy and Exsitu Treatment Technologies for Contaminated Groundwater at CERCLA Sites, Final Guidance

U.S. Environmental Protection Agency, Washington, DC
EPA/540/R-96/023; OSWER Directive 9283.1-12; 75 pp. (October 1996)

In implementing the Superfund and other remediation programs, cleanup of contaminated groundwater has proven to be more difficult than anticipated. This guidance is intended to emphasize the importance of using site-specific remedial objectives as the focus of the remedy selection process for contaminated groundwater. By providing presumptive technologies, this guidance attempts to streamline selection of these technologies and shift the time and resources employed in remedy selection to other, more fundamental aspects of the groundwater remedy. This guidance also describes a presumptive response strategy which facilitates selection of both short and long-term remediation objectives during remedy selection, and allows the effectiveness of the remedy to be improved during implementation.

\section{2}

V18/025298

\section{Principles of Bioremediation}

Insitu Bioremediation: When Does It Work?, National Academy Press, Washington, DC, 207 pp.; (pp. 16-46) (1993)

The key players in bioremediation are bacteria - microscopic organisms that live virtually everywhere. Microorganisms are ideally suited to the task of contaminant destruction because they possess enzymes that allow them to use environmental contaminants as food and because they are so small that they are able to contact contaminants easily. In situ bioremediation can be regarded as an extension of the purpose that microorganisms have served in nature for billions of years: the breakdown of complex human, animal, and plant wastes so that life can continue from one generation to the next. Without the activity of microorganisms. the earth would literally be buried in wastes, and the nutrients necessary for the continuation of life would be locked up in the detritus. Whether microorganisms will be successful in destroying marmade contaminants in the subsurface depends on three factors: the type of organisms, the type of contaminant, and the geological and chemical conditions at the contaminated site. This chapter explains how these three factors influence the outcome of a subsurface bioremediation project. It reviews how microorganisms destroy contaminants and what types of organisms play a role in in situ bioremediation. Then, it evaluates which contaminants are most susceptible to bioremediation in the subsurface and describes the types of sites where bioremediation is most likely to succeed.

3233

V18/024291

Processes Affecting Soil and Groundwater Contamination by DNAPL in Low-Permeability Media

McWhorter, D.B.

Colorado State University, Fort Collins, CO; Oak Ridge National Laboratory, Oak Ridge, TN

ORNL/TM-13305; Insitu Remediation of DNAPL Compounds in Low Permeability Media Fate/Transport, Insitu Control Technologies, and Risk Reduction, 318 pp.; (pp. 1.1-1.24) (August 1996)

This paper is one of a set of focus papers intended to document the current knowledge relevant to the contamination and remediation of soils and groundwater by dense, nonaqueous phase liquids (DNAPL). The emphasis is on low permeability media such as 
fractured clay and till and unconsolidated, stratified formations. Basic concepts pertaining to immiscible-fluid mixtures are described and used to discuss such aspects as DNAPL transport, dissolved-phase transport, and equilibrium mass distributions. Several implications for remediation are presented.

\section{4 \\ V18/024290}

Pump and Treat in Low Permeability Media

Mackay, D.M.

University of Waterloo, Waterloo, Ontario, Canada; Oak Ridge National Laboratory, Oak Ridge, TN

ORNLTM-13305; Insitu Remediation of DNAPL Compounds in

Low Permeability Media Fate/Transport, Insitu Control

Technologies, and Risk Reduction, 318 pp.; (pp. 7.1-7.11) (August 1996)

Pump and Treat (P\&T) is a commonly applied technology whose primary promise for the low permeability environments of interest to these technology reviews is almost certainly containment of the problem. Conventional P\&T would be expected to offer little promise of complete restoration in such environments, unless very long time frames (decades or centuries) are considered. A variety of approaches have been proposed to enhance the efficiency of P\&T; some appear to offer little promise in low or mixed permeability environments, while others may offer more promise (e.g. hydro- or pneumatic-fracturing, which are described elsewhere in this document, and application of vacuum to the extraction well(s), which is a proprietary technology whose promise is currently difficult to assess objectively). Understanding the potential advantages and means of optimizing these enhancement approaches requires more understanding of the basic processes limiting P\&T performance in low or mixed permeability media. These efforts are probably also necessary to understand the advantages and means of optimizing many of the very different remedial technologies that may be applicable to low or mixed permeability environments. Finally, since a reasonably certain capability of P\&T is containment (i.e. prevention of further migration of contaminants), P\&T may generally be required as a sort of safety net around sites at which the alternative technologies are being tested or applied.

\section{5}

\section{V18/024293}

Pump-and-Treat Groundwater Remediation: A Guide for Decision Makers and Practitioners

\section{Eastern Research Group, Inc., Lexington, MA}

EPA/625/R-95/005; 92 pp. (July 1996)

This guide uses the term pump-and-treat in a broad sense to include any system where withdrawal from or injection into groundwater is part of a remediation strategy. This guide provides an introduction to pump-and-treat groundwater remediation by addressing several questions. When is pump-and-treat an appropriate remediation approach? What is involved in 'smart' application of the pump-and-treat approach? What are tailing and rebound, and how can they be anticipated? What are the recommended methods for meeting the challenges of effective hydraulic containment? How can the design and operation of a pump-and-treat system be optimized and its performance measured? Finally, when should variations and alternatives to conventional pump-and-treat methods be used?

\section{6}

V18/024103

Radioactive Waste Management System Integration

Los Alamos National Laboratory, Los Alamos, NM

LALP-94-236; 1 p. (1994)

Los Alamos can effectively characterize and remediate an environment contaminated with radioactive waste. Our experience in radioactive materials subsystems inciudes: (1) in-situ characterization, including rock/water interaction, interaction with waste, remote sampling and handling, and in situ analysis; (2) process characterization, including radioactive material dissolution, immobilization-sorption, low-level detection, and isotopic analysis;

(3) risk-assessment, for which all work can be performed within the regulatory framework, under quality assurance program parameters and regulations, up to and including meeting Quality Assurance Standards for Nuclear Facilities (NQA-1) standards for nuclear facilities. This system engineering approach defines critical components and requirements of the system and is incorporated into a risk assessment model to drive the characterization, remediation, or siting of a facility.

\section{7}

\section{V18/021943}

Rapid Dechlorination of Polychlorinated Biphenyls on the Surface of a Pd/Fe Bimetallic System

Grittini, C.; Malcomson, M.; Fernando, Q.; Korte, N.E.

University of Arizona, Department of Chemistry, Tucson, AZ; Oak Ridge National Laboratory, Environmental Sciences Division, Grand Junction, $\mathrm{CO}$

Environmental Science \& Technology 29(11):2898-2900 (1995)

Polychlorinated biphenyls (PCBs) are a group of synthetic aromatic compounds with the general formula $\mathrm{C} 12 \mathrm{Hl} 0-\mathrm{xClx}$ that have been widely used because of their excellent dielectric properties and their resistance to heat and chemical degradation. PCBs have been introduced into the environment via improper disposal and accidental leaks from transformers, heat exchangers, and hydraulic systems. PCBs in the environment are transported primarily by particulate matter containing the adsorbed compounds and as a consequence are dispersed worldwide. The uptake of PCB-contaminated sediments by biota at the water-sediment interface can introduce PCBs into the food chain and may cause serious health problems in humans. It is of utmost importance, therefore, to seek effective methods to remove PCBs from the environment. We report here a simple method for the rapid and complete dechlorination of a methanol-water solution containing all the congeners of PCBs present in the commercially available mixtures Arochlor and Arochlor 1254. The dechlorination reaction occurs at ambient temperatures on the surface of palladized iron, a $\mathrm{Pd} / \mathrm{Fe}$ bimetallic system that has been found to rapidly dechlorinate one- and two-carbon chlorinated compounds. The reaction products are biphenyl and chloride ions.

\section{8 \\ V18/024040}

Rapid Screening for Bacteria Capable of Degrading Toxic Organic Compounds

Gorden, R.W.; Hazen, T.C.; Fliermans, C.B. 
Illinois Natural History Survey, Champaign, IL; Westinghouse Savannah River Company, Aiken, SC Journal of Microbiological Methods 18:339-347 (1993)

Routine procedures for isolating and characterizing microorganisms capable of degrading toxic chemicals are time consuming and labor intensive. The objective of this paper is to describe a new method for screening aerobic bacterial isolates and consortia that will rapidly determine metabolic capacity for various toxic chemicals and assess the use of various substrates as inducers in the degradation process. This method uses the Biolog $[R]$ multiwell plate technology - a four-step method that includes inoculation followed by incubation of a uniform suspension of cells into a microtiter plate to test more than 40 bacterial isolates and mixtures against 30 toxic chemicals. Several bacteria and consortia have been shown to degrade toxic chemicals at concentrations of $10-500 \mathrm{ppm}$. These results indicate that Biolog [R] GN and MT plates are useful tools for screening bacterial isolates and consortia for their ability to survive, metabolize, and potentially degrade selected organic chemicals.

\section{V18/023453}

\section{Recovery of Metal Contaminants Using Membrane} Separation Techniques

Gopal, V.; April, G.C.

University of Alabama, Chemical Engineering Department, Tuscaloosa, AL

CONF-960730 (Vol. 3); Technologies Critical to a Changing World, Volume III: Emerging Energy Technologies, Clean Technologies, Remediation and Emission Control Fuels, and Petrochemicals, Proceedings of the Fifth World Congress of Chemical Engineering, San Diego, CA, July 14-18, 1996. American Institute of Chemical Engineers, New York, NY, Vol. 3, 1118 pp.; (pp. 143-148) (1996)

The presence of metallic contaminants (in the form of cations) in waste water streams has long been a source of concern to the process industries. Conventional methods of removal of metallic components from waste water result in products which have little or no further use. This study proposes a method (electro-membrane process) for the selective recovery of cations from industrial effluents. The recovered metals can then be converted into a useful form leading to resource conservation and improved process economics. This method uses a combination of electrochemical reduction and ion-exchange techniques. Preliminary studies for validating this process are made with lead ions in acidic solutions. An attempt is made to selectively recover $\mathrm{Pb}(2+)$ ions from solution.

\section{$3240 \quad \mathrm{~V} 18 / 022769$}

Reduced Cost Cleanup of Groundwater Using Pump and Treat and Two New Insitu Technologies

Younker, L.W.; Copeland, A.B.

Lawrence Livermore National Laboratory, Livermore, CA

CONF-960804 (Vol. 2); Spectrum '96: Nuclear and Hazardous Waste Management, Proceedings of an International Topical Meeting, Seattle, WA, August 18-23, 1996. American Nuclear Society, La Grange Park, IL, Vol. 2, 873 pp.; (pp. 1226-1233) (1996)
A project is being conducted at Lawrence Livermore National Laboratory (LLNL) to demonstrate the application of a combination of technologies designed to reduce the total cost of cleaning up VOCs in groundwater to the point of formal closure of remedial activity. Essential elements of this project include: a solid functional understanding of site hydrogeology and contaminant distribution; an effective pump and treat system for boundary plume control and distal plume cleanup; and field experience with critical elements of new in situ methods to be used for rapid contaminant source area remediation. The new methods are in situ hydrous pyrolysis/oxidation achieved by injecting steam and oxygen into the contaminated source region and in situ microbial filters which use a resting-state bioaugmentation technique to remove contaminants at the periphery of the treated source area. The project includes a strategy for developing both appropriate future application sites as well as commercial practitioners of the application of these remediation technologies.

3241

\section{V18/023870}

Reductive Photo-Dechlorination (RPD) Process for Safe Conversion of Hazardous Chlorocarbon Waste Streams

Lavid, M.; Gulati, S.K.; Teytelboym, M.

ENERGIA, Inc., Princeton, NJ

EPA/600/R-95/012; CONF-9504110; Proceedings of the 21st Annual Risk Reduction Engineering Laboratory (RREL) Research Symposium, Cincinnati, OH, April 4-6, 1995. U.S. Environmental Protection Agency, Cincinnati, OH, 398 pp.; (pp. 140-144) (April 1995)

A novel technology designated Reductive Photo-Dechlorination (RPD) has been developed and successfully tested for environmentally safe treatment of waste streams containing hazardous chlorinated hydrocarbons. This RPD process employs ultraviolet (UV) light in a reducing atmosphere and at moderate temperatures to efficiently convert chlorocarbon contaminants into valuable hydrocarbons such as methane, ethane, ethylene, acetylene and hydrogen chloride. The UV light promotes carbon-chloride bond cleavage and long-chain radical reactions with the hydrogenous bath gas leading to the thermodynamically and kinetically favored hydrocarbon products at a conversion of $+99 \%$. The pilot-scale prototype consists of five main units: (1) Input/Mixer; (2) Photo-thermal Reactor; (3) Scrubber; (4) Separator/Storage; and (5) Recycling. Chlorinated waste streams can be introduced in one of three ways: liquid, vapor or adsorbates (to activated carbon). In the Photo-thermal Reactor a separated vapor is irradiated and heated. The UV light breaks the $\mathrm{C}-\mathrm{Cl}$ bond, and the temperature sustains long-chain radical reactions. RPD treatment was successfully tested with a representative chlorocarbon 1,1,1-trichloroethane (TCA) in a photothermal annular flow reactor.

3242

V18/024641

Rehabilitation Methods: Technical Descriptions, Chapter 9

Smith, S.A.

Smith Consulting Services, Ada, OH

Monitoring and Remediation Wells: Problem Prevention, Maintenance, and Rehabilitation, Lewis Publishers, Boca Raton, FL, 203 pp.; (pp. 139-152) (1995) 
This chapter gives an overview of various methods of well rehabilitation under the following categories: physical treatment, chemical treatment, and blended treatments. Physical treatments discussed include conventional redevelopment and a variety of additional methods such as cold $\mathrm{CO} 2$ fracking and sonic/vibratory disruption. Chemical treatments covered include acidizing, use of sequestering agents, and use of antibacterial agents. Blended treatments make use of two or more physical and chemical treatments. The chapter also provides example procedures for a rehabilitation effort and discusses post treatment after rehabilitation. This chapter is from the book entitled Monitoring and Remediation Wells: Problem Prevention, Maintenance, and Rehabilitation.

\section{3}

V18/023619

Remedial Action Selection Using Groundwater Modeling

Haddad, B.I.; Parish, G.B.; Hauge, L. Graef, Anhalt, Schloemer \& Associates, Milwaukee, WI CONF-951023 (Vol. 8); WEFTEC '95, Proceedings of the 68th Annual Conference and Exposition of the Water Environment Federation, Miami Beach, FL, October 21-25, 1995. Water Environment Federation, Alexandria, VA, Vol. 8, 498 pp.; (p. 125) (1995)

An environmental investigation uncovered petroleum contamination at a gasoline station in southem Wisconsin. The site was located in part of the ancestral Rock River valley in Rock County, Wisconsin where the valley is filled with sands and gravels. Groundwater pump tests were conducted for determination of aquifer properties needed to plan a remediation system; the results were indicative of a very high hydraulic conductivity. The site hydrogeology was modeled using the U.S. Geological Survey's groundwater model, Modflow. The calibrated model was used to determine the number, pumping rate, and configuration of recovery wells to remediate the site. The most effective configuration was three wells pumping at 303 liters per minute ( $(1 / \mathrm{min})(80$ gallons per minute [gpm]), producing a total pumping rate of $908 \mathrm{l} / \mathrm{m}(240$ $\mathrm{gpm}$ ). Treating $908 \mathrm{l} / \mathrm{min}$ ( $240 \mathrm{gpm}$ ) or 1,308,240 liters per day ( 345,600 gallons per day) constituted a significant volume to be treated and discharged. It was estimated that pumping for the two year remediation would cost $\$ 375,000$ while the air sparging would cost $\$ 200,000$. The recommended remedial system consisted of eight air sparging wells and four vapor recovery laterals. The Wisconsin Department of Natural Resources (WDNR) approved the remedial action plan in March, 1993. After 11 months of effective operation the concentrations of removed VOCs had decreased by 94 percent and groundwater sampling indicated no detectable concentrations of gasoline contaminants. Groundwater modeling was an effective technique to determine the economic feasibility of a groundwater remedial alternative. (Complete text)

Remediation by 2-PHASE [TM] Extraction: A 2-year Success Story

Koerner, C.; Dee, P.E.; Baxter, J.; Huber, S.M.

Radian Corporation, Herndon, VA; Radian Corporation, Rochester, NY; Xerox Corporation, Webster, NY
CONF-960527; Global Exploration and Geotechnology, Proceedings of an Annual Convention of the American Association of Petroleum Geologists, Inc., and the Society for Sedimentary Geology, San Diego, CA, May 19-22, 1996, 231 pp.; AAPG Bulletin 80(5):76c (1996)

Radian has used the Xerox 2-PHASE [TM] extraction technology at several facilities worldwide to remove VOCs and petroleum hydrocarbons from subsurface soils and groundwater. The use of high vacuum with 2-PHASE [TM] causes greater forces to be applied to the subsurface than do other dual-phase methods. 2-PHASE [TM] improves dewatering, increases vacuum and groundwater radii of influence, deepens vadose zone development, enhances vapor stripping of soil contamination, improves vapor flow, and expedites remediation timeframes. This paper describes the successful 2-year application of 2-PHASE [TM] to remediate soil and groundwater contamination. Contamination occurred under a floor slab near a former solvent spray booth and several underground storage tanks. Contaminants were primarily chlorinated VOCs and mineral spirits ranging to $330 \mathrm{mg} / \mathrm{kg}$ in soil and $1,070 \mathrm{mg} / \mathrm{L}$ in groundwater. The 2-PHASE [TM] system was installed in October 1993; business constraints necessitated the completion of remediation within two years. The system was modified and expanded to optimize the removal effectiveness and extend the area of influence. Subsurface soil data obtained 8 and 11 months into the remediation program were used with soil gas data to predict future soil concentrations. VOC concentrations in the soil and groundwater were reduced by over 95 percent, and remediation goals were met within 18 months following start of in situ 2-PHASE [TM] remediation. The system has been decommissioned following agency and landowner approval.

\section{5 \\ V18/024622}

Remediation of Contaminated Groundwater, Chapter 14

Boulding, J.R.

Eastern Research Group, Inc., Lexington, MA

Soil, Vadose Zone, and Groundwater Contamination Assessment, Prevention, and Remediation, Lewis Publishers, Boca Raton, FL, 947 pp.; (pp. 761-804) (1995)

This is a chapter in the book titled: Practical Handbook of Soil, Vadose Zone, and Groundwater Contamination by J. Russell Boulding. Remediation of Contaminated Groundwater is part of the section on Prevention and Remediation. This chapter provides an overview of aquifer restoration technologies utilizing techniques derived from interrelated disciplines of hydrology, geochemistry, civil engineering, construction, biology, and agronomy. Many of the technologies have been developed by demonstration and research in conjunction with remedial activities in the Superfund program. There are three general response actions and process options for a groundwater remediation program from a management viewpoint. The components of an active restoration response include the removal and treatment of contaminated groundwater, the discharge of the treated water, and institutional controls. The containment response option includes the monitoring and containment of the contaminated groundwater as well as institutional controls. The natural attenuation response includes institutional controls and monitoring. This chapter, which focuses on the technical aspect of remediation, briefly discusses the 
extraction and treatment components of active restoration and containment. The major emphasis of the chapter is on groundwater pumping systems and in situ biological treatment for organic contaminants that are found at almost all hazardous waste sites.

\section{6}

\section{V18/025559}

\section{Remediation of DNAPL Contamination by Steam Flushing}

She, Y.; Sleep, B.E.

University of Toronto, Department of Civil Engineering, Toronto, Ontario, Canada; Department of the Environment, Environmental Protection Service, Ottawa, Ontario, Canada CONF-951086; Proceedings of the Fifth Annual Symposium on Groundwater and Soil Remediation, Toronto, Ontario, Canada, October 2-6, 1995. Environment Canada - Environmental Protection Service, Hull, Quebec, Canada, 566 pp.; (pp. 513-514) (1995)

The removal of dense nonaqueous phase liquids (DNAPL) constitutes a major challenge in remediating contaminated groundwater systems. Steam flushing and increasing subsurface temperatures to decrease interfacial tension have been among the techniques used in the past. In this study several factors that are important in multidimensional groundwater systems have been examined to determine whether channeling due to soil heterogeneities, viscous fingering, and gravity separation may lead to reduced NAPL recovery rates in many soils. Laboratory studies included measurements of the temperature dependence of solubility, viscosity, interfacial tension, capillary pressure and residual saturation. Steam injection experiments were conducted in cells instrumented with thermocouples, pressure transducers and time domain reflectometry probes. A 3-D, three-phase finite difference numerical model was constructed. Results show that complete removal of contaminants is possible. Distillation is the primary removal mechanism, since changes in viscosity, solubility, interfacial tension, capillary pressure and residual saturation are small over the temperature range typical of steam flushing. Gravity segregation is a problem that requires careful control. Channeling due to heterogeneities was found to be moderate.

\section{7}

V18/021623

Remediation of DNAPL Groundwater Contamination at a Former Landfill

Clark, K.B.; Bucher, B.; Stringer, C. Maxim Technologies, Inc., Helena/Missoula, MT CONF-9607116; Proceedings of an American Association of Petroleum Geologists (AAPG) Rocky Mountain Section Meeting, Billings, MT, July 28-31, 1996; AAPG Bulletin 80(6):981-982d (June 1996)

A landfill in western Montana was used for disposal of laboratory waste for a period of five years in the early 1980s. Wastes included chloroform and other chlorinated hydrocarbons which are heavier than water and only slightly soluble in water. These dense non-aqueous phase liquids (DNAPLs) migrated to the water table and eventually created a contaminant plume about three-quarters of a mile long in a residential and commercial area dependent on the aquifer for its water supply. Remediation efforts to date have consisted of excavation of contaminated soil, treatment of soil on-site, and pumping and treatment of groundwater. An extensive drilling program was undertaken to delineate the extent of groundwater and soil contamination. 75,000 cubic yards of contaminated soil and overburden were excavated and the contaminated soils were treated through volatilization of hydrocarbons. Groundwater pumping in the source area, combined with air stripping has further reduced contaminant concentrations. Replacement water supplies are being installed while remediation continues. A groundwater model has been developed which is being used to predict the effect of remedies. A decision on the final remedy for this site will be made in 1996.

3248

V18/022611

Remediation of Polycyclic Aromatic Hydrocarbons [Latest Citations from Pollution Abstracts]

NERAC, Inc., Tolland, CT

Bibliography (December 1996)

The bibliography contains citations on remediation of polycyclic aromatic hydrocarbons in contaminated soil or water. The relevant chemical or biological processes are discussed. Both in-sin and exsitu processes are included. The relationship between the chemical structure of polycyclic aromatic hydrocarbons and the rate of decomposition, selection of the most effective microorganisms, and factors which can accelerate or inhibit degradation are discussed.

3249

V18/024678

Remediation of Soil and Groundwater Contaminated with Petroleum Hydrocarbons Using the PetroClean [R] Bioremediation System, Chapter 22

Lieberman, M.T.; Schmitt, E.K.; Caplan, J.A.

ESE Biosciences, Inc., Raleigh, NC

Bioremediation: Field Experience, P.E. Flathman, D.E. Jerger and J.H. Exner (eds.), Lewis Publishers, Boca Raton, FL, 560 pp.; (pp. 477-490) (1994)

Bioremediation has many applications, including groundwater pump-and-treat, process wastestream treatment, wastewater treatment, exsitu biological landfarming, and in situ treatment of soil and groundwater. ESE Biosciences, Inc., a subsidiary of Environmental Science and Engineering, Inc., has successfully implemented these technologies at many sites nationwide. This chapter will discuss two recent bioremediation projects completed at sites with widely differing characteristics. Each project was conducted in three phases: Phase 1 involved site assessment and contaminant delineations; Phase 2 involved performing a laboratory pilot-scale biofeasibility evaluation for obtaining design information; and Phase 3 involved installation and operation of the full-scale treatment system. Each site was treated using ESE Biosciences' patented submerged, fixed-film PetroClean [R] bioreactor, engineered to operate in conjunction with a groundwater recovery well network and soil recharge infiltration system, as part of the total PetroClean [R] Bioremediation System. This chapter is from the book entitled Bioremediation: Field Experience.

3250

$\mathrm{V} 18 / 021630$

Remediation of Water and Hydrocarbon Phase Trapping 
Problems in Low Permeability Gas Reservoirs

Bennion, B.D.; Thomas, F.B.; Bietz, R.F.; Bennion, D.W.

Petroleum Society of CIM, Calgary, Alberta, Canada; Hycal Energy Research Laboratories Limited, Calgary, Alberta, Canada

CONF-9606128; Creating Value: Advances in Resource Development, Proceedings of an Oil Conference in Conjunction with the National Petroleum Show, Calgary, Alberta, Canada, June 9-14, 1996, Petroleum Society of Canada, Calgary, Alberta, Canada; (pp. 1-14) (1996)

The mechanism of how phase traps are induced by direct displacement, counter-current imbibition or depletion effects, are described. Diagnostic techniques to determine whether a reservoir is likely to suffer an aqueous phase trapping problem, and techniques for minimizing aqueous and hydrocarbon phase trapping are reviewed. Methods to remove existing phase traps, such as increased drawdown, alteration of interfacial tension, alteration of pore geometry, dry gas injection, and formation heat treatment are outlined. Laboratory techniques that would assist in selecting the optimum process for use in a given situation are also included.

\section{1 \\ V18/021039}

Remediation of a TCE Ground Spill Using an Electron Accelerator

Matthews, S.M.

Lawrence Livermore National Laboratory, Livermore, CA

CONF-9406143; Proceedings of the First Intemational Conference on Advanced Oxidation Technologies for Water and Air Remediation, London, Ontario, Canada, June 25-30, 1994; (pp. 8-9) (1994)

Radiolytic decomposition of TCE and VOCs dissolved in groundwater and in the vapor phase has been experimentally demonstrated in the laboratory and at a Superfund Site using radiation provided by an electron accelerator of several $\mathrm{MeV}$ energy. Either high energy bremsstrahlung or electron beam radiation may be used to produce this decomposition. An initial TCE concentration of several hundred $\mathrm{ppb}$ in groundwater was reduced to $1 \mathrm{ppb}$ with an applied bremsstrahlung dose of less than $100 \mathrm{kRads}$. Bremsstrahlung has also been demonstrated to decompose VOC mixtures of TCE, $\mathrm{PCE}, \mathrm{CHCl} 3$ and $\mathrm{CCl} 4$ in groundwater with the initial VOC concentration spiked to $400 \mathrm{ppm}$. The mass of chlorine from these decomposed VOCs was found to equal the increase in chloride ions found in the treated water. TCE vapor at a concentration of $200 \mathrm{ppmv}$ in effluent from a vacuum extraction well at Site-300 (a Superfund Site) was reduced to below 1 ppmv by exposure to a bremsstrahlung dose of less than $500 \mathrm{kRads}$.

3252

V18/020824

Remotely Monitored and Controlled Self-Flushing Secondary Containment System

Lewis, M.E.

U.S. Patent 05421671; 9 pp. (June 6, 1995)

This patent describes a remotely monitored and controlled secondary containment system for underground storage tanks. Contamination of the soil and groundwater in populated communities by gasoline and other petroleum products leaking from corroded underground iron or steel storage tanks has risen to an alarming level. This invention provides an efficient, and economically built and easily installed means for cleanup and for in-place decontamination of leaked or spilled hazardous liquids from the tank environment and for the repair of the leaking tank, without excavating the tank.

3253

V18/021061

Removal of Benzene in a Simulated Low-Level Mixed Waste

Cooper, W.J.; Nickelsen, M.G.; Lin, K.; Kurucz, C.N.; Waite, T.D.; Bibler, J.P.; Dougal, R.

Florida International University, Drinking Water Research Center, Miami, FL; University of Miami, Coral Gables, FL; Westinghouse Savannah River Company, Aiken, SC; University of South Carolina, Columbia, SC

CONF-940499 (Vol. 1); Proceedings of the 1994 Federal Environmental Restoration III and Waste Minimization II Conference and Exhibition, New Orleans, LA, April 27-29, 1994. Hazardous Materials Control Resources Institute, Rockville, MD, Vol. 1, 783 pp.; (pp. 224-227) (1994)

The treatment of mixed wastes presents numerous problems for the generator as well as for anyone interested in site remediation largely due to its classification as both a radiological and hazardous waste. The goal of this project was to develop a treatment process that could be used to destroy the hazardous organic compounds in a continuous stream of low-level mixed waste. Once the toxic organic compound(s) is destroyed, the waste would be classified only as a radiological waste and could be treated using known technology. Electron beam irradiation has proven to be an effective technology for removing hazardous organic compounds in aqueous streams. The removal resuits from the action of highly reactive chemical species $(\mathrm{OH}+$, e- sub aq, $\mathrm{H}+$ ) generated when high energy electrons penetrate water. Since e-sub aq and $\mathrm{H}+$ are reducing radicals and $\mathrm{OH}+$ is an oxidizing radical, the process is effective against a wide range of individual organic compounds as well as mixtures of compounds commonly found in low-level mixed waste. Pilot scale (100 gpm) studies, on simulated low-level mixed waste, were conducted at the Electron Beam Research Facility (EBRF) located in the Central District Wastewater Treatment Plant in Miami, Florida. The electron beam system used for these studies utilizes a $1.5 \mathrm{MeV}, 50 \mathrm{~mA}$ continuous beam accelerator. This paper will present a brief overview of the technology, and selected results from the simulated low-level mixed waste experiments.

3254 V18/021959

Removal of Explosives Using Standard and Innovative Adsorption Technologies

Fleming, B.C.; Christiansen, K.; Cerar, R.J.

U.S. Army Corps of Engineers, Waterways Experiment Station, Vicksburg, MS; U.S. Army Corps of Engineers, Omaha, NB; U.S. Army Environmental Center, Aberdeen Proving Ground, MD

CONF-9509139; Emerging Technologies in Hazardous Waste Management VII, D.W. Tedder (ed.), Proceedings of the Seventh American Chemical Society Industrial and Engineering Chemistry 
Division Special Symposium, Atlanta, GA, September 17-20, 1995. American Chemical Society, Washington, DC, 1291 pp.; (pp. 602-605) (1995)

The Comhusker Army Ammunition Plant (CAAP) is located in Grand Island, Nebraska, and occupies 11,936 acres in Hall County. The CAAP is classified as a load, assembly, and pack facility (LAP) and was constructed in 1942 for the purpose of manufacturing bombs for World War II. An Installation Assessment Study (IAS) identified 58 sources of contamination by explosive compounds. The U.S. Army Engineer District and U.S. Army Environmental Center requested that the USAE Waterways Experiment Station (WES) perform bench-scale evaluations of adsorption and ultraviolet/chemical oxidation (UVChO) technologies for remediation of explosives-contaminated groundwater at the CAAP site. The main objective of the study was to determine the most effective adsorption process for removal of RDX, TNB, TNT, and $\mathrm{HMX}$ from CAAP waters. The efficiency of adsorption processes for removal of RDX, TNB, TNT, and HMX was to be compared to the efficiency of UVChO Processes. The U.S. Environmental Protection Agency (U.S. Environmental Protection Agency) drinking water standard for RDX, TNB, and TNT is a $2 \mathrm{mu} g / \mathrm{l}$ and for HMX is $400 \mathrm{mu} g /$. RDX, TNB, and TNT concentrations in the CAAP waters were well above the drinking water standards but $\mathrm{HMX}$ concentrations were below the standard for that compound.

3255 V18/023736

Removal of Uranium, Arsenic, and Nitrate by Continuously Regenerated Ion Exchange Process

Chang, D.; Awad, J.; Panahi, Z.

CH2M Hill Inc., Santa Ana, CA; Public Utilities Department, Riverside, CA

CONF-951108; Proceedings of the 1995 Water Quality Technology Conference, November 12-16, 1995. American Water Works Association, New Orleans, LA, 2625 pp.; (pp. 1199-1211) (1995)

Groundwater is the major source of water supply for the City of Riverside (the City). Groundwater from some of the local wells contains high levels of uranium, arsenic, and nitrate. The City is evaluating treatment technologies that can remove these contaminants, in order to be prepared to select appropriate treatment technologies when groundwater treatment is required. Treatment technologies identified by the U.S. Environmental Protection Agency as best available technology (BAT) for uranium and arsenic removal are coagulation/filtration, lime softening, ion exchange, and reverse osmosis. Among these technologies, ion exchange is the most cost-effective and suitable for wellhead treatment applications. Ion exchange is also effective for nitrate removal. An ion exchange pilot study was conducted for the removal of uranium, arsenic and nitrate from groundwater. This paper presents a summary of the test results, conceptual design criteria, and preliminary cost estimate for a full-scale facility.

3256 V18/023830

Research and Development of a Commercial Supercritical Water Oxidation Process

McBrayer, R.; Li, L.; Gloyna, E.F.

Eco Waste Technologies, Austin, TX; University of Texas,
Center for Energy Studies, Austin, TX

CONF-9306269; HazMat ' 93 International, Proceedings of the Eleventh Annual Environmental Management and Technology Conference and Exhibition, Atlantic City, NJ, June 9-11, 1993. Advanstar Expositions, Glen Ellyn, IL, 731 pp.; (pp. 90-111) (1993)

This paper describes a joint research and development effort between the University of Texas at Austin (UT) and Eco Waste Technologies (EWT). The objective was to develop a commercial supercritical water oxidation (SCWO) process. SCWO technology relies on the unique properties of supercritical water to create an excellent reaction medium. The SCWO treatment system is capable of operating as a totally enclosed wastewater treatment facility, providing complete destruction, and meeting regulatory effiuent requirements. As such, this technology is an environmentally attractive option. Because of favorable treatability, safety and economic considerations, a growing number of private and governmental entities have been involved in research and development leading to the commercialization of SCWO waste treatment processes. The cooperative R\&D program began in 1990 . UT provided research support in the general areas of reaction kinetics and mechanisms, solids separation, salt formation and solubility, mass and heat transfer, transformation product identification, catalysis, corrosion, and additive impacts. EWT focused on the development and testing of a 40-gph SCWO pilot-plant. The objectives were to scale-up the SCWO process. Major design considerations for commercial applications included materials of construction, reactor design, heat recovery, control strategy, safety requirements, and process integration. This R\&D effort has resulted in the design of a commercial SCWO processing facility for Texaco Chemical Company located in Austin, Texas. The facility will become operational in early 1994.

3257 V18/024299

Research to Compare New Remediation Technologies Groundwater Notes 9(2):8-9 (July 1996)

A comparison study into new technologies for remediating groundwater contamination was conducted to determine how the technologies work when the contamination involves both petrochemical and chlorinated solvents. A series of tests were performed involving the remediation of an artificially-created groundwater plume at Canadian Forces Base Borden and an existing contaminant plume at a United States Department of Defense site. The two distinct remedial technologies tested were anaerobic degradation of contaminants by microorganisms, and aerobic removal of contaminants by providing oxygen for the microbes. Anaerobic degradation involved the addition of a semi-passive nutrient (benzoic acid) to promote the growth of the microorganisms, which in turn break down the perchloroethylene and the carbon tetrachloride that have been added to contaminate the water. Aerobic technology involves the use of compressed oxygen bubbled into the subsurface to re-aerate the groundwater after a biotic anaerobic treatment.

3258

V18/022641

Respiration Testing for Bioventing and Biosparging Remediation of Petroleum Contaminated Soil and Groundwater 
Gray, A.L.; Brown, A.; Moore, B.J.; Payne, R.E.

Komex-H2O Science, Huntington Beach, CA ; Komex-H2O Science, Calgary, Alberta, Canada; Mobil Oil Corporation, Fairfax, VA

CONF-960393 (Part 3); Contaminated Soils and Groundwater: Analysis, Fate, Environmental and Public Health Effects, and Remediation, Proceedings of the Sixth Annual West Coast Conference, Newport Beach, CA, March 11-14, 1996. Association for the Environmental Health of Soils, Amherst, MA, Part 3, 366 pp.; (p. 22) (1996)

Respiration tests were performed to measure the effect of subsurface aeration on the biodegradation rates of petroleum hydrocarbon contamination in vadose zone soils (bioventing) and groundwater (biosparging). The aerobic biodegradation of petroleum contamination is typically limited by the absence of oxygen in the soil and groundwater. Therefore, the goal of these bioremediation technologies is to increase the oxygen concentration in the subsurface and thereby enhance the natural aerobic biodegradation of the organic contamination. One case study for biosparging bioremediation testing is presented. At this site atmospheric air was injected into the groundwater to increase the dissolved oxygen concentration in the groundwater surrounding a well, and to aerate the smear zone above the groundwater table. The results of this test have demonstrated that biosparging enhances the biodegradation of petroleum hydrocarbons, but the results as they apply to remediation are not known. Two case studies for bioventing respiration testing are presented. At both sites atmospheric air was injected directly into the vadose zone to aerate the soil. These tests have demonstrated the effectiveness and applicability of bioventing for the remediation of petroleum contaminated soils.

\section{V18/023468}

Review of Insitu Air Sparging for the Remediation of VOC-Contaminated Saturated Soils and Groundwater

Reddy, K.R.; Kosgi, S.; Zhou, J.

University of Illinois, Chicago, IL

Hazardous Waste and Hazardous Materials 12(2):97-118 (1995)

Insitu air sparging is a developing remediation technique that has significant potential for use in VOC-contaminated saturated soils and groundwater. This technique consists of injecting air below the contaminated area to partition the dissolved, sorbed and free phase VOCs into the gas phase and to enhance the aerobic biodegradation of the VOCs. Because of the buoyancy effect, the VOCs in the gas phase are transported by air to the vadose zone where they are removed and subsequently treated by a soil vapor extraction system. Currently, the design, operation, and monitoring of air sparging systems is based mainly on an empirical approach with limited field experience. Extreme care must be exercised in designing and implementing the air sparging system so that the contaminants are removed efficiently and without adverse effects on the subsurface environment, particularly the spread of the contaminants to the clean areas. The current state of knowledge is inadequate for the design of effective air sparging systems which also prevent the spreading of contaminants into the clean areas. This paper first outlines the fundamentals of air sparging and then presents an overview of previous air sparging field and laboratory investigations. The paper then details a critical assessment of modeling studies which predict contaminant transport during the air sparging process. Finally, the paper outlines an ongoing comprehensive research program that involves developing the most efficient and economical air sparging systems. This research program, which is being conducted at the University of Illinois at Chicago (UIC), includes performing laboratory aquifer simulation tests to characterize the basic mechanisms of air sparging, developing a contaminant transport model to optimize the different design variables in a typical air sparging system, and conducting a field demonstration of the optimal air sparging system.

3260

V18/020773

Review of Limitations of Pump-and-Treat Simulation Models for Groundwater Remediation

Lennon, G.P.

Lehigh University, Department of Civil and Environmental Engineering, Bethlehem, PA

CONF-9507204; Hazardous and Industrial Wastes, A.K. Sengupta (ed.), Proceedings of the 27th Mid-Atlantic Industrial Waste Conference, Bethlehem, PA, July 9-12, 1995. Technomic Publishing Company, Lancaster, PA, 973 pp.; (pp. 681-688) (1995)

Simulation models have proven to be useful tools in understanding and predicting groundwater flow and contaminant transport, including sites undergoing pump-and-treat (P\&T) remediation. Powerful flow codes can handle complex flow behavior such as flow in fractured rock, heterogeneity, complex boundary conditions and density variations. Inverse algorithms provide efficient methods to evaluate aquifer parameters. Contaminant transport codes can simulate phenomena such as desorption from soil using a wide range of algorithms tailored to site-specific conditions. Coupled codes have been developed that simultaneously solve for flow, contaminant transport, and geochemical reactions. Some problems can stem from misuse when applying models, such as overkill, improper conceptualization, improper model selection, improper boundary conditions, application of a generic model to a specific site, inappropriate prediction, misinterpretation, misuse of the numerical approximation, and undetected coding error. Although there are many facets to modeling, this paper focuses on the simulation of key factors that affect the design of remediation systems, with a special emphasis on predicting clean-up times. These key factors include presence of pure non-aqueous phase liquids (NAPLs), slow desorption from soil, slow diffusion from low permeability zones, and areas of near stagnant flow.

3261

V18/023735

Review of Pollution Prevention Opportunity Assessment for Geologic Subsurface Investigations

Goddard, C.M.R.; Alexander, H.J.

Lockheed Martin Energy Systems, Inc., Oak Ridge, TN; Business Environment, Inc., Knoxville, TN

CONF-960741; DOE Pollution Prevention in the 21st Century, Proceedings of the Twelfth Annual DOE Pollution Conference, Chicago, IL, July 9-11, 1996; (9 pp.) (1996)

A Pollution Prevention Opportunity Assessment (PPOA) resulted in the identification and evaluation of pollution prevention options 
for equipment decontamination, soil boring, well installation, and well sampling activities associated with geologic subsurface investigations. The options were evaluated for technical and economic feasibility, and a subset of options was then recommended for implementation. Some of the options consisted of modifications to procedures and did not require significant economic investment, while other options required the purchase of new equipment and related materials. Twenty-two options were generated, developed, and evaluated in accordance with procedures in a U.S. Department of Energy document entitled Model Pollution Prevention Opportunity Assessment Guidance. A key document appended to the PPOA was entitled Management of Waste Generated from Field Investigation and Sampling Activities. Pollution Prevention Opportunity Assessment activities were carried out through a Level II evaluation effort.

\section{2}

V18/021972

\section{Review of Sparging Technology}

Marley, M.C.; Droste, E.X.

Envirogen, Inc., Lawrenceville, NJ

CONF-9509139; Emerging Technologies in Hazardous Waste Management VII, D.W. Tedder (ed.), Proceedings of the Seventh American Chemical Society Industrial and Engineering Chemistry Division Special Symposium, Atlanta, GA, September 17-20, 1995. American Chemical Society, Washington, DC, 1291 pp.; (pp. 1121-1124) (1995)

Sparging is a remediation technology primarily applied to the removal of volatile organic contaminants (VOC's) or to enhance biodegradation of organic compounds in saturated soils and groundwater. Conceptually, sparging is simple: clean air is injected into the aquifer beneath the water table to induce mass transfer of volatile contaminants to the vapor phase and mass transfer of oxygen to the aqueous phase. Sparging usually is used in conjunction with soil vapor extraction (SVE) to control the migration of sparged contaminants in the vadose zone. A data base of 59 sites has been assembled and evaluated which provided insight on sparging system design, operation, and evaluation. Data from 53 pilot-scale sites and 19 full-scale sites were input to the data base. Long-term water quality from 12 sites indicated significant reductions of dissolved phase VOC's resulting from sparging. While a few sites achieved closure, sparging was still in progress at the remaining sites. Long-term water quality data following sparging system shut-down was limited.

\section{3}

\section{V18/021629}

Risk Analysis for the Uncertainty in the Remediation Time of a Contaminated Aquifer

Sykes, J.F.; Harvey, D.J.M.; Wilger, C.

Canadian Society for Civil Engineering, Montreal, Quebec, Canada; University of Waterloo, Department of Civil Engineering, Waterloo, Ontario, Canada; Union Carbide Corporation, South Charleston, WV

CONF-9605216; Proceedings of the 1996 Canadian Society for Civil Engineering Annual Conference, Structural Specialty Conference, Transportation Conference, and Environmental Engineering Speciaity Conference, D.W. Smith (ed.), Edmonton, Alberta, Canada, May 29-June 1, 1996. Canadian Society for Civil
Engineering, Montreal, Quebec, Canada; (pp. 151-163) (1996)

The effects of parameter uncertainty on the time to remediate a contaminated aquifer at a site with multiple contaminants, was studied. Regulatory agencies often require an estimation of the time required for remediation of an aquifer. The estimated time is also used in benefit-cost-risk studies to determine the net present worth of a remedial option as a function of operation and maintenance costs. In this study, groundwater flow and solute transport were simulated using a numerical model. The time required to remediate an aquifer to water quality standards was determined using the Latin Hypercube sampling technique which considered both the hydraulic and transport properties. A fundamental equation, defining three dimensional transient groundwater flow in a heterogeneous, saturated, anisotropic porous media, was developed. It was concluded that the uncertainty in time for the remediation of an aquifer could be calculated as a function of both uncertain flow and uncertain contaminant transport parameters.

\section{4}

\section{V18/025442}

\section{Risk-Based Approàch to Petroleum Hydrocarbon} Remediation

Miller, R.N.; Haas, P.; Faile, M.; Taffinder, S.

U.S. Air Force Center for Environmental Excellence, Brooks Air Force Base, TX

Report; 7 pp. (1994)

The risk-based approach utilizes tools developed under the Intrinsic Remediation (natural attenuation), Bioslurper, and Bioventing Initiatives of the Air Force Center for Environmental Excellence Technology Transfer Division (AFCEE/ERT). The objective is to construct a risk-based, cost-effective approach to the cleanup of petroleum-contaminated sites. The AFCEE Remediation Matrix identifies natural attenuation as the first remediation alternative for soil and groundwater contaminated with petroleum hydrocarbons. The intrinsic remediation (natural attenuation) alternative requires a scientifically defensible risk assessment based on contaminant sources, pathways, and receptors. For fuel-contaminated sites, the first step is to determine contaminants of interest. For the groundwater pathway (usually considered most important by regulators), this will normally be the most soluble, mobile, and toxic compounds, namely benzene, toluene, ethylbenzene, and $o, m, p$, xylene.

\section{5}

$$
\text { V18/022867 }
$$

Role of Organic Complexants and Microparticulates in the Facilitated Transport of Radionuclides

Schilk, A.J.; Robertson, D.E.; Abel, K.H.; Cooper, E.L.; Killey, R.W.D.; Hartwig, P.G.; Thomas, C.W.; Pratt, S.L.; Vilks, P.; Mattie, J.F.; Haas, M.K.; Lepel, E.A.; Matzner, R.; King, K.

Pacific Northwest National Laboratory, Richland, WA; Atomic Energy of Canada Limited, Chalk River Laboratories, Chalk River, Ontario, Canada; Whiteshell Laboratories, Pinawa, Manitoba, Canada; Los Alamos National Laboratory, Los Alamos, NM

NUREG/CR-6429; PNL-10897; 95 pp. (December 1996)

This progress report describes the results of ongoing radiological and 
geochemical investigations of the mechanisms of radionuclide transport in groundwater at two low-level waste (LLW) disposal sites within the waste management area of Chalk River Laboratories (CRL), Ontario, Canada. These sites, the Chemical Pit liquid disposal facility and the Waste Management Area C solid LLW disposal site, have provided valuable 30 - to 40 -year-old field locations for characterizing the migration of radionuclides and evaluating a number of recent site performance objectives for LLW disposal facilities. These studies focused on identifying the physico-chemical species of mobile radionuclides in groundwater at these field locations and characterizing their behavior in the sub-surface environment. Field and laboratory studies have shown that the mobile radionuclide species, including Fe-55, Co-60, Ru-106, Sb-125, Pu-239, and Pu-240, are generally anionic in nature and being sequestered by naturally occurring and/or man-made complexing materials, such as fulvic and humic substances. Ion chromatographic separations of contaminated groundwater have identified a number of individual mobile chemical species of Co-60 and Ru-106, indicating the presence of a complex mixture of these sequestered radionuclides being transported in the groundwater. These studies have shown, through the use of multiple state-of-the-art characterization methodologies, the consistent relationship between migrating radionuclides and naturally occurring humic and fulvic materials in CRL groundwater. Their ubiquitous presence in sampled waters, substantial capacity for the complexation of cationic radionuclides under the existing geochemical conditions, the general lack of attraction for most mineral surfaces in the aquifer medium suggest that these species are primarily responsible for the facilitated transport of radionuclides in this region. As the CRL site serves as a viable model for $L L W$ disposal sites in humid environments, the results of this investigation have far-reaching implications in the fields of facility design, maintenance, and remediation. On-going field and laboratory studies are continuing to provide information on the degree of retardation of the mobile organo-radionuclide species as well as corresponding cationic forms by site soils. These measurements will allow more accurate and reliable modeling assessments of radionuclide transport in groundwater at CRL and similar humid sites. Work is also continuing on characterization of the movement of $14 \mathrm{C}$ through the sub-surface environment, its release to the atmosphere as a gaseous species, and its uptake by vegetation growing in the immediate vicinity of the contaminated groundwater plume (by both root and foliative pathways).

3266

V18/024026

Role of Sorbed Humic Substances on the Distribution of Organic and Inorganic Contaminants in Groundwater

Murphy, E.M.; Zachara, J.M.

Pacific Northwest Laboratory, Interfacial Geochemistry Group, Richland, WA

Geoderma 67:103-124 (1995)

Mineral bound humic substances modify inorganic surfaces in subsurface sediments, changing the nature and number of complexation sites for contaminants. Because of adsorptive enrichment, the reactive surface area or site concentration contributed by mineral-bound humic substances can exceed that of dissolved or colloidal humic substances by two orders of magnitude. Mineral-bound humic materials may, therefore, provide a major sink for the removal of contaminants in groundwater. The reactivity of the humic substance is primarily determined by the structural and bulk chemical properties of the humic substance and the aqueous solution chemistry. Organic and inorganic contaminants sorb readily to mineral-bound humic substances. The sorption of hydrophobic organic compounds increases as ionic strength decreases, is enhanced by divalent cations, and displays non-linear isotherms and competitive adsorption behavior. Collectively, these results suggest that hydrophobic adsorption, rather than phase partitioning, is the primary sorption mechanism for neutral organic molecules on these particle coatings. Mineral-bound humic substances augment, rather than change, the intrinsic complexation properties of mineral surfaces for metal cations. The degree of sorption enhancement promoted by mineral-bound organic material varies strongly with $\mathrm{pH}$ and depends on the magnitude of the stability constants between the metal cation and the humic substance, the strength and magnitude of adsorption of the humic substance by the mineral surface, and the extent of aqueous complex formation between the non-sorbed humic substance and metal. The simplest sorption model for humate-modified surfaces is the linear additivity model (LAM). Sorption data for certain hydrophobic organic compounds and metal cations appear to conform to this model.

\section{V18/023874}

SITE Demonstration of the Dynaphore/Forager Sponge Technology to Remove Dissolved Metals from Contaminated Groundwater

Esposito, C.R.; Vaccaro, G.

U.S. Environmental Protection Agency, Risk Reduction Engineering Laboratory, Edison, NJ; Science Applications International Corporation, Hackensack, NJ

EPA/600/R-95/012; CONF-9504110; Proceedings of the 21st Annual Risk Reduction Engineering Laboratory (RREL) Research Symposium, Cincinnati, OH, April 4-6, 1995. U.S. Environmental Protection Agency, Cincinnati, OH, 398 pp.; (pp. 177-180) (April 1995)

A Superfund Innovative Technology Evaluation (SITE) demonstration was conducted of the Dynaphore/Forager Sponge technology during the week of April 3, 1994 at the N.L. Industries Superfund Site in Pedricktown, New Jersey. The Forager Sponge is an open-celled cellulose sponge incorporating an amine-containing chelating polymer that selectively absorbs dissolved heavy metals in both cationic and anionic states. This technology is a volume reduction technology in which heavy metal contaminants from an aqueous medium are concentrated into a smaller volume for facilitated disposal. The developer states that the technology can be used to remove heavy metals from a wide variety of aqueous media, such as groundwater, surface waters and process waters. The sponge matrix can be directly disposed, or regenerated with chemical solutions. For this demonstration the sponge was set up as a mobile pump-and-treat system which treated groundwater contaminated with heavy metals. The demonstration focused on the system's ability to remove lead, cadmium, chromium and copper from the contaminated groundwater over a continuous 72-hour test. The removal of heavy metals proceeded in the presence of significantly higher concentrations of innocuous cations such as calcium, magnesium, sodium, potassium, and aluminum. 
3268 V18/023876

SITE Demonstration of the ZenoGem [TM] Technology to Treat High Strength Wastewaters

Sullivan, D.; Merdinger, M.; Kosco, W.; Tonelli, F.A. U.S. Environmental Protection Agency, Edison, NJ; Foster Wheeler Environmental Corporation, Livingston, NJ; PRC Environmental Management, Inc., Cincinnati, $\mathrm{OH}$; Zenon Environmental Systems, Burlington, Ontario, Canada EPA/600/R-95/012; CONF-9504110; Proceedings of the 21st Annual Risk Reduction Engineering Laboratory (RREL) Research Symposium, Cincinnati, OH, April 4-6, 1995. U.S. Environmental Protection Agency, Cincinnati, OH, 398 pp.; (pp. 186-193) (April 1995)

High strength organic wastewaters are encountered at hazardous waste sites in the form of leachate and in some cases groundwater. The ZenoGem [TM] Process is designed to remove biodegradable materials, including most organic contaminants, from wastewater to produce a high quality effiuent. This technology was accepted into EPA's Superfund Innovative Technology Evaluation (SITE) program in summer 1992; this paper summarizes the technology demonstration performed at the Nascolite Superfund site in 1994, where the groundwater is contaminated with volatile organic compounds. The results of an 89 day test run conclusively demonstrated the efficient removal of contaminants.

3269

V18/022196

Selective Sorption of Technetium from Groundwater Brown, G.N.

Pacific Northwest Laboratory, Richland, WA; Oak Ridge National Laboratory, Oak Ridge, TN

PNNL-SA-27105; CONF-960158; Efficient Separation and Processing Crosscutting Program, Proceedings of the 1996 Technical Exchange Meeting, Gaithersburg, MD, January 16-19, 1996, 52 pp.; (pp. 39-42) (1996)

The purpose of this project is to develop an anion exchange resin that will selectively remove the radionuclide technetium, in the form of the pertechnetate anion $\mathrm{TCO} 4(1-)$, from groundwater, leaving behind other interfering anions. A resin bed of this material will be used either as part of a coupled treatment recirculation system for the in-situ remediation of groundwater contaminated with technetium or in a once-through treatment scheme.

3270

V18/023467

Selective and Regenerable Metal-Sorbing Vesicles for Metal Ion Recovery

Stanish, I.; Shamsai, B.; Monbouquette, H.G.

University of California, Chemical Engineering Department, Los Angeles, CA

CONF-960730 (Vol. 3); Technologies Critical to a Changing World, Volume III: Emerging Energy Technologies, Clean Technologies, Remediation and Emission Control Fuels, and Petrochemicals, Proceedings of the Fifth World Congress of Chemical Engineering, San Diego, CA, July 14-18, 1996. American Institute of Chemical Engineers, New York, NY, Vol. 3, 1118 pp.; (pp. 131-135) (1996)
Phospholipid vesicles or liposomes mimic closely biological cell membranes, and unilamellar lipid vesicles harboring a lipophilic ionophore in the capsule wall and encapsulating a strong water-soluble metal chelating agent rapidly take up and concentrate metal cations. This capability has been exploited in the design of metal-sorbing vesicles (MSVs) for the selective removal of heavy metal cations such as $\mathrm{Cu}(2+)$ and $\mathrm{Pb}(2+)$ from dilute aqueous solution. MSVs present exposed membrane surface areas of $3000-30,000 \mathrm{sq} m / \mathrm{L}$ at vesicle concentrations of $1-10 \% \mathrm{w} / \mathrm{v}$, exhibit high surface area to encapsulated volume ratios of 50 or more sq $\mathrm{m} / \mathrm{mL}$, and have exceedingly-small membrane wall thicknesses of $3-5 \mathrm{~nm}$. These attributes give rise to very rapid metal ion extraction rates and high concentration factors. MSVs have been polymerized for enhanced stability, and schemes for their use in continuous metal ion recovery processes have been developed.

\section{$3271 \quad$ V18/022199}

Separation of Tritiated Water from Water Using Composite Membranes

Duncan, J.; Nelson, D.A.

Pacific Northwest National Laboratory, Richland, WA

PNNL-SA-27105; CONF-960158; Efficient Separation and Processing Crosscutting Program, Proceedings of the 1996 Technical Exchange Meeting, Gaithersburg, MD, January 16-19, 1996, 52 pp.; (pp. 15-18) (1996)

Polymeric composite membranes are being developed to remove tritium from contaminated water at DOE sites. Industrial membrane systems are being developed that have proven to be energy efficient, and membrane technologies such as reverse-osmosis have been well developed for desalination and other industrial/municipal applications. Aromatic polyphosphazene membranes are being investigated because they have excellent radiological, thermal, and chemical stability. The FY 1996 effort is directed toward delineating a potential mechanism, providing a statistical approach to data acquisition, refining a mass balance, and designing a staged array module.

3272

V18/022197

Sequestering Agents for the Removal of Actinides from Waste Streams

Raymond, K.; White, D.; Whisenhunt, D.

Pacific Northwest National Laboratory, Richland, WA; University of California, Berkeley, CA; Lawrence Livermore National Laboratory, Livermore, CA

PNNL-SA-27105; CONF-960158; Efficient Separation and Processing Crosscutting Program, Proceedings of the 1996 Technical Exchange Meeting, Gaithersburg, MD, January 16-19, 1996, 52 pp.; (pp. 53-56) (1996)

The ultimate goal of this project is to develop new separation technologies to remove radioactive metal ions from contaminated DOE sites. To this end we are studying both the fundamental chemistry and the extractant properties of some chelators that are either found in nature or are closely related to natural materials. The work is a collaboration between Lawrence Berkeley National Laboratory, University of Califomia, Berkeley, and the Glenn T. Seaborg Institute for Transactinium Science at Lawrence Livermore 
National Laboratory.

\section{3}

V18/022223

Site Specific Evaluation of Remedial Alternatives for DNAPL Contaminated Groundwater

Zamojski, L.D.; Connare, K.M.

Acres International Corporation, Amherst, NY; New Jersey Department of Environmental Protection, Trenton, NJ

CONF-951139 (Vol. 2); Superfund 16: Proceedings of a Hazardous Waste Conference and Exhibition, Washington, DC, November 6-8, 1995. E.J. Krause and Associates, Bethesda, MD, Vol. 2, 817 pp.; (pp. 1368-1372) (1994)

The groundwater in the shallow aquifer at this Superfund site has been identified as being contaminated with volatile organic compounds, specifically tetrachloroethylene (PCE) and trichloroethylene (TCE) and some metals. In the Record of Decision (ROD), the pump and treat technology with reinjection of the treated groundwater was selected as the preferred remedial action. Based upon review of analytical data, past activities and further investigation of the site, it appeared likely that dense non aqueous phase liquid (DNAPL) was present at the site. As a result of the investigated presence of a DNAPL at this site and the desire to effect a successful remedial program, an evaluation of remedial alternatives for DNAPL and contaminated groundwater was undertaken. The evaluation included other technological enhancements in addition to the pump and treat altemative. This paper presents a summary of this evaluation. The technologies available for the remediation of contaminated groundwater fall into the following four general categories: (1) Containment; (2) In Situ Methods; (3) Ex Situ Methods; and (4) Excavation/Treatment. A brief description of site conditions, together with an evaluation of the alternatives is presented. A summary of the evaluations and recommendations for a modified remedial program is given. Based on site conditions, a surfactant flushing system was proposed.

\section{4}

\section{V18/023769}

\section{Solidifiers for Oil Spill Response}

Dahl, W.A.; Lessard, R.R.; Cardello, E.A.; Fritz, D.E.; Norman, F.S.; Twyman, J.D.; Clayton, E.W.; Knight, B.L.; Crane, R.D.; Johnson, S.J.; Martin, B.R.

Exxon Research and Engineering Company, Florham Park, NJ; Amoco Corporation; Aramco Services Company; Arco Exploration and Production Technology, Plano, TX; Marathon Oil Company; Mobil Oil Corporation, New York, NY; Texaco Inc.

CONF-960623 (Vol. 1); Proceedings of the Third International Conference on Health, Safety and Environment in Oil and Gas Exploration and Production, New Orleans, LA, June 9-12, 1996. Society of Petroleum Engineers (SPE), Inc., Richardson, TX, Vol. 1,941 pp.; (pp. 803-810) (1996)

Solidifiers are an existing technology that have the potential to be applied to marine spills especially for protecting shorelines. This paper summarizes the results of a research program conducted by Exxon under the auspices of the Petroleum Research Forum (PERF) to determine the applicability of the use of solidifiers for responding to oil spills. The program included laboratory evaluation of commercially available solidifiers, field evaluation to extend existing application techniques to solidifiers and identification of recovery, removal and disposal options.

3275

\section{V18/021082}

Soluble Methane Monooxygenase Activity in Methylomonas methanica 68-1 Isolated from a Trichloroethylene-Contaminated Aquifer

Koh, S.C.; Bowman, J.P.; Sayler, G.S.

University of Tennessee, Department of Microbiology, Knoxville, TN

CONF-930482 (Vol. 2-1); Proceedings of the Second International Insitu and Onsite Bioreclamation Symposium, San Diego, CA, April 5-8, 1993; Bioremediation Series 2(1) - Bioremediation of Chlorinated and Polycyclic Aromatic Hydrocarbon Compounds, R.E. Hinchee, A. Leeson, L. Semprini and S.K. Ong (eds.), Lewis Publishers, Boca Raton, FL, 560 pp.; (pp. 327-332) (March 1994)

It has been postulated that certain habitats, in particular groundwater, lacking readily available copper but with abundant methane and oxygen, may provide a suitable niche for methanotrophs producing soluble methane monoxygenase. Soluble methane monooxygenase (sMMO), which occurs in a select variety of methanotrophs, has an extremely broad substrate specificity. Most recent research has focused on SMMO degradation of chlorinated aliphatic compounds, in particular trichloroethylene. In situ bioremediation efforts involving methane/air injection into subsurface sediments and groundwaters are focused on stimulating growth of methanotrophs that produce this enzyme.

3276 V18/021791

Soluble Methane Monooxygenase Production and Trichloroethylene Degradation by a Type I Methanotroph, Methylomonas methanica 68-1

Koh, S.C.; Bowman, J.P.; Sayler, G.S.

University of Tennessee, Center for Environmental Biotechnology, Knoxville, TN; University of Tennessee, Department of Microbiology, Knoxville, TN

Applied and Environmental Microbiology 59(4):960-967 (April 1993)

A methanotroph (strain 68-1), originally isolated from a trichloroethylene (TCE)-contaminated aquifer, was identified as the type I methanotroph Methylomonas methanica on the basis of intracytoplasmic membrane ultrastructure, phospholipid fatty acid profile, and 16S rRNA signature probe hybridization. Strain 68-1 was found to oxidize naphthalene and TCE via a soluble methane monooxygenase (SMMO) and thus becomes the first type I methanotroph known to be able to produce this enzyme. The specific whole-cell sMMO activity of 68-1, as measured by the naphthalene oxidation assay and by TCE biodegradation, was comparatively higher than sMMO activity levels in Methylosinus trichosporium $\mathrm{OB} 3 \mathrm{~b}$ grown in the same copper-free conditions. The maximal naphthalene oxidation rates of Methylomonas methanica 68-1 and Methylosinus trichosporium OB3b were $551+/-27$ and $321+/-16 \mathrm{nmol} h(-1) \mathrm{mg}$ of protein-1, respectively. The maximal TCE degradation rates of Methylomonas methanica 68-1 and Methylosinus trichosporium $O B 3 b$ were $2,325+/-260$ and $995+1-$ 
$160 \mathrm{nmol} \mathrm{h}(-1) \mathrm{mg}$ of protein-1, respectively. The substrate affinity of 68-1 sMMO to naphthalene $(\mathrm{Km}, 70+/-\mathrm{muM})$ and TCE $(\mathrm{Km}, 225+1-13 \mathrm{muM})$, however, was comparatively lower than that of the SMMO of OB3b, which had affinities of $40+1-3$ and $126+/-8$ muM, respectively. Genomic DNA slot and Southern blot analyses with an SMMO gene probe from Methylosinus trichosporium OB3b showed that the sMMO genes of 68-1 have little genetic homology to those of $O B 3 b$. This result may indicate that evolutionary diversification of the sMMOs.

\section{7 \\ V18/023749}

Some Conceptual and Statistical Issues in Analysis of Groundwater Monitoring Data

Gibbons, R.D.

University of Illinois, Chicago, IL

CONF-950978; Municipal and Industrial Waste, Proceedings of the 18th International Madison Waste Conference, Madison, WI, September 20-21, 1995. University of Wisconsin, Madison, WI, 461 pp.; (pp. 320-341) (1995)

Statistical issues in analysis of groundwater monitoring data are detailed, particularly detection of releases from waste disposal facilities into groundwater flowing beneath a landfill. The probability that new geochemical measurements from each of $k$ monitoring welis are consistent with background levels based on a sample of $n$ historical measurements is discussed. Future comparisons (i.e., $\mathrm{k}$ monitoring wells each sampled for $\mathrm{q}$ chemical constituents) and analytical limitations on data censoring (i.e., samples for which the analyte cannot be quantified) result in complex statistical decisions. Current regulations require all $\mathrm{kx} \mathrm{q}$ comparisons be within background limits at each semi-annual monitoring event. Parametric and nonparametric solutions to this problem are described.

3278

V18/024292

Steam Injection for Insitu Remediation of DNAPLs in Low Permeability Media

Sleep, B.E.

University of Toronto, Toronto, Ontario, Canada; Oak Ridge National Laboratory, Oak Ridge, TN

ORNL/TM-13305; Insitu Remediation of DNAPL Compounds in Low Permeability Media Fate/Transport, Insitu Control Technologies, and Risk Reduction, 318 pp.; (pp. 13.1-13.13) (August 1996)

The potential for remediation of dense, nonaqueous phase liquid (DNAPL) contamination by steam injection is investigated, including the advantages and disadvantages of the technology. The primary advantage is the significant enhancement of removal rates through steam distillation. The disadvantages are related to the lack of field experience with the technology and difficulties related to stearm override and channeling in heterogeneous soils. The problems related to steam injection in low permeability fractured clay are examined, and removal times and costs are postulated for a hypothetical DNAPL contamination scenario. It is concluded that steam injection has significant potential for remediation of DNAPL in fractured clay soils, but there is significant uncertainty in predictions of the performance of steam injection in these soils.
3279

V18/021827

Stochastic Indicators for Waste Site Characterization

Christakos, G.; Hristopulos, D.T.

University of North Carolina, Department of Environmental Sciences and Engineering, Chapel Hill, NC

Water Resources Research 32(8):2563-2578 (August 1996)

Site characterization is an important prerequisite of risk assessment and remediation strategies. Evaluation of the health effects of groundwater and soil contamination depends on the adequate analysis of spatial heterogeneity, exceedance levels, and uncertainties. In this work we formulate and calculate stochastic indicators that provide a rigorous characterization of exposure levels in sites with heterogeneous contaminant distributions and offer valuable information for a cost-effective cleanup analysis. These site indicators are general and can be used for different types and distributions of groundwater and soil contaminants. Important properties of the stochastic indicators are examined which can evaluate the potential for contamination at large scales, and improve understanding of threatened and damaged ecosystems. Analytically tractable formulas are derived that allow the practical estimation of site indicators on the basis of experimental data. Scale and modeling effects on contaminant level analysis are examined in terms of the stochastic indicators. Site cleanup costs depend directly on inferred characteristics of the stochastic indicators, which thus can play an important role in waste site management. Applications are discussed that offer insight regarding certain aspects of stochastic site characterization. Analytical methods of site characterization are compared to numerical simulations. It is shown that the latter can provide a practical altemative to the former, but they could lead to inaccurate results if they are not interpreted carefully.

\section{$3280 \quad \mathrm{~V} 18 / 023612$}

Streamline Simulation of Surfactant Enhanced Aquifer Remediation - Master's Thesis

Tunison, D.I.

U.S. Navy, Naval Postgraduate School, Monterey, CA

AD-A-313459/0; 108 pp. (December 1996)

Nonaqueous Phase Liquids (NAPLs) are a recognized source of groundwater contamination. Surfactant Enhanced Aquifer Remediation (SEAR) shows promise in increasing the efficiency and effectiveness over traditional pump and treat NAPL remediation processes. Laboratory results are not always consistent with the effects observed in field applications because of the complex interactions that occur in the subsurface. Mathematical modeling is required to enable accurate prediction and understanding of SEAR.

\section{1 \\ V18/021639}

Streamlined Simulation of Surfactant Enhanced Aquifer Remediation

Tunison, D.I.

U.S. Navy, Naval Postgraduate School, Monterey, CA

Thesis (M.S.); 108 pp. (December 1996)

Nonaqueous Phase Liquids (NAPLs) are a recognized source of 
groundwater contamination. Surfactant Enhanced Aquifer Remediation (SEAR) shows promise of increasing the efficiency and effectiveness over traditional pump-and-treat NAPL remediation processes. Laboratory results are not always consistent with the effects observed in field applications because of the complex interactions that occur in the subsurface. Mathematical modeling is required to enable accurate prediction and understanding of SEAR.

3282

V18/024848

Study of Electrokinetic Effects to Quantify Groundwater Flow

Brown, S.R.; Haupt, R.W.

Sandia National Laboratories, Albuquerque, NM; Massachusetts Institute of Technology, Lincoln Laboratory, Lexington, MA

SAND94-2607; 27 pp. (April 1997)

An experimental study of electrokinetic effects (streaming potential) in earth materials was undertaken. The objective was to evaluate the measurement of electrokinetic effects as a method of monitoring and predicting the movement of groundwater, contaminant plumes, and other fluids in the subsurface. The laboratory experiments verified that the electrokinetic effects in earth materials are prominent, repeatable, and can be described well to first order by a pair of coupled differential equations.

3283

V18/024694

\section{Subsurface Aerobic Bioremediation, Chapter 7}

Litchfield, C.D.

George Mason University, Biology Department, Fairfax, VA

Bioremediation, K.H. Baker and D.S. Herson (eds.), McGraw-Hill, Inc., New York, NY, 404 pp.; (pp. 261-280) (1994)

This is a chapter from the book titled, Bioremediation. In general, the subsurface environment can be divided into three zones: the vadose zone, the capillary fringe, and the saturated zone. There are slightly different modifications of bioremediation depending on which region is to be treated, although one can usualiy combine the capillary zone and the saturated zone in designing the bioremedial response. Before bioremediation is initiated, it is important to determine whether light nonaqueous-phase liquids (LNAPLs) or dense nonaqueous-phase liquids (DNAPLs) are present.

Bioremediation of groundwater can be accomplished by treating the groundwater in place (in situ bioremediation) or by treating extracted groundwater (often called pump and treat). In some instances, it may be useful to combine in situ biotreatment with an above-ground treatment system. Conditions which make this the selected design include more soluble contaminants, high concentrations of the constituents in the groundwater, an extremely stringent cleanup goal, restrictions by the regulatory agencies against recycling contaminated groundwater back into the aquifer, and the comparative ease of manipulating the microbial population, redox conditions, temperature, and $\mathrm{pH}$ of the system to shorten the time for the remediation. All these factors, of course, must be weighed against the increased costs from the construction of an above-ground bioreactor and the operation and maintenance costs associated with such a unit. This chapter describes laboratory studies and in situ remediation efforts in groundwater aquifers, vadose zones, harbors, and lagoons and includes examples of the combined treatment-train approach described above.

V18/022617

Subsurface Stormflow Modeling with Sensitivity Analysis Using a Latin-Hypercube Sampling Technique

Gwo, J.P.; Toran, L.E.; Morris, M.D.; Wilson, G.V.

Oak Ridge National Laboratory, Oak Ridge, TN; Desert Research Institute, Water Resources Center, Las Vegas, NV

Groundwater 34(5):811-818 (September-October 1996)

During storm events, the shallow disposal facilities at Oak Ridge National Laboratory become inundated, and subsurface stormflow may intermittently extract radionuclides from the surrounding soils and the wastes themselves. It is estimated that $90 \%$ of the rain water infiltrating the soil horizons becomes subsurface stormflow, yet stormflow is a poorly understood process. The objectives of this research are to model stormflow: (1) to identify important parameters for waste site monitoring and data collections; (2) to evaluate remediation designs; and (3) to investigate the effect of local heterogeneities on stormflow paths. Numerical models of a proposed waste disposal site were developed, and a Latin-hypercube simulation technique was used to study the uncertainty of model parameters. Sensitivity analyses of model parameters suggested that hydraulic conductivity was the most influential parameter.

However, local heterogeneities may alter flow patterns and result in complex recharge and discharge processes. Hydraulic conductivity, therefore, may not be used as the only reference for subsurface flow monitoring and engineering designs. Neither of two engineering designs, capping and French drains, was found to be effective in hydrologically isolating downslope waste trenches. However, combinations of both designs may prove more effective than either one alone.

3285

V18/021809

Suggested Modifications to Groundwater Sampling Procedures Based on Observations from the Colloidal Borescope

Kearl, P.M.; Korte, N.E.; Cronk, T.A.

Oak Ridge National Laboratory, Grand Junction, CO

Groundwater Monitoring and Remediation 12(2):155-161 (Spring 1992)

Observations of colloidal movement under natural conditions and during pumping were conducted at several field sites. Results indicate that several modifications to present sampling protocols may improve the representativeness and cost effectiveness of obtaining groundwater samples for assessing the total mobile contaminant load. These modifications include the installation of dedicated sampling devices, limited purging of the well prior to sampling, sampling at a flow rate of $100 \mathrm{~mL} / \mathrm{min}$, and no filtering of samples. This sampling approach can result in significant cost savings while providing the best possible water samples.

3286

V18/020610

Summary of Field Operations, Well TRN-1

Fritts, J.E.; Thomas, E.; McCord, J.P. 
GRAM, Inc., Albuquerque, NM; INTERA, Inc., Albuquerque, NM

SAND96-0163; 66 pp. (March 1996)

TRN-1 was drilled near the SE comer of Kirtland Air Force Base to a depth of 510 feet. This well is in the Site-Wide Hydrogeologic Characterization task field program, which is part of Sandia's Environmental Restoration Project. After drilling, the borehole was logged, plugged to a depth of $352 \mathrm{ft}$, and completed as a monitoring well. Sand pack interval is from 305 to $352 \mathrm{ft}$ and the screen interval is from 320 to $340 \mathrm{ft}$. During field operations, important subsurface geologic and hydrologic data were obtained (drill cuttings, geophysical logs of alluvial cover). Identification of the Abo formation in the subsurface will be useful. The subsurface hydrologic data will help define the local hydrostratigraphic framework within the bedrock. Future aquifer testing will be conducted for transmissivity, etc.

3287

V18/02263I

Summary of Insitu Bioremediation Demonstration (Methane Biostimulation) via Horizontal Wells at the Savannah River Site Integrated Demonstration Project

Hazen, T.C.; Looney, B.B.; Fliermans, C.B.; Eddy-Dilek, C.A.; Lombard, K.H.; Enzien, M.V.; Dougherty, J.M.; Wear, J.E., Jr.

Westinghouse Savannah River Company, Savannah River Technology Center, Aiken, SC; Bechtel Savannah River, Inc., Aiken, SC; Argonne National Laboratory, Argonne, IL; U.S. Environmental Protection Agency, Irving, TX; Catawba State College, Salisbury, North Carolina

CONF-941124; Insitu Remediation: Scientific Basis for Current and Future Technologies, G.W. Gee and N.R. Wing (eds.), Proceedings of the 33rd Hanford Symposium on Health and the Environment, Pasco, WA, November 7-11, 1994. Battelle Press, Columbus, OH, Part 1, 704 pp.; (pp. 137-150) (1994)

The Savannah River Site (SRS) Integrated Demonstration focuses on Clean-up of Soils and Groundwater Contaminated with Chlorinated VOC. Several laboratories, including SRS, had demonstrated the ability of methanotrophic bacteria (found in soil and aquifer material) to completely degrade or mineralize chlorinated solvents. The test consisted of injecting methane mixed with air into the contaminated aquifer via a horizontal well and extracting it from the vadose zone via a parallel horizontal well. Groundwater was monitored biweekly from 13 wells for a variety of chemical and microbiological parameters. The water from wells in affected areas showed increases in methanotrophs of more than 1 order of magnitude every 2 weeks for several weeks after $1 \%$ methane in air injection started. Simultaneous with the increase in methanotrophs was a decrease in water and soil gas concentrations of trichloroethylene (TCE) and tetrachloroethylene (PCE). In two wells, the TCE/PCE concentration in the water declined by more than $90 \%$, to below $2 \mathrm{ppb}$. All of the wells in the zone of effect showed significant decreases in contaminants in less than 1 month. In four of five vadose-zone piezometers (each with three sampling depths) concentrations declined from as high as $10,000 \mathrm{ppm}$ (vol/vol) to less than $5 \mathrm{ppm}$ in less than 6 weeks. The fifth cluster also declined by more than $95 \%$. A variety of other microbial parameters increased with methane injection, indicating the extent and type of stimulation that had occurred.

\section{8}

V18/021635

Supercritical Fluids in Environmental Remediation and Pollution Prevention

Akgerman, A.

Texas A\&M University, College Station, TX

CONF-960376 (Part 1); Proceedings of the 21 1th American Chemical Society (ACS) National Meeting, New Orleans, LA, March 24-28, 1996. ACS, Washington, DC, Part 1, 1172 pp.; (p. 963, Paper I EC 217) (1996)

During the last decade uses of supercritical fluids in environmental applications have increased due to their unique properties. Technologies have already been developed for extraction of organic compounds from aqueous and solid environmental matrices, and research on extraction of metals is in progress. In most applications supercritical carbon dioxide is the solvent of choice because it is environmentally benign, safe, and abundant and is low in cost. A more recent research focus is on use of supercritical fluids as solvents and reaction media. Especially as the reaction media supercritical fluids offer properties that may significantly affect reaction selectivities. They may be used to eliminate side reactions, exceed thermodynamic yield limitations, or control polymer chain lengths and molecular weight distributions. Fundamental aspects of these applications with specific examples are presented. (Complete text)

3289

V18/020682

Supercritical Technology: Applications for

Environmental Remediation [Latest Citations from the Energy Science and Technology Database]

NERAC, Inc., Tolland, CT

Bibliography (June 1996)

The bibliography contains 50-250 citations concerning environmental hazardous materials clean-up using supercritical fluid technologies. Citations are included for papers which discuss applications of supercritical extraction to contaminated soils, groundwater, waste water, and sludges. Articles address the use of supercritical carbon dioxide and water for remediation of chlorinated organics, heavy metals, explosives, and other hazardous substances. The bibliography includes a subject term index and title list.

3290 $\mathrm{V} 18 / 021976$

Supercritical Water Oxidation of Organics: Status Report

Baldwin, P.N., Jr.; Nakashima, T.

ADTECHS Corporation, Herndon, VA

CONF-9509139; Emerging Technologies in Hazardous Waste Management VII, D.W. Tedder (ed.), Proceedings of the Seventh American Chemical Society Industrial and Engineering Chemistry Division Special Symposium, Atlanta, GA, September 17-20, 1995. American Chemical Society, Washington, DC, 1291 pp.; (pp. 28-29) (1995)

Supercritical fluid research has been going on for a number of years. 
In fact the initial work on supercritical fluids is attributed to a French scientist in the early 1820 's. One of the first successful commercial uses involved the supercritical properties of carbon dioxide and its ability to extract organics from solid matrices. This usefulness has been applied to the food as well as the hazardous waste treatment industries. Water, the most important solvent found in nature, has very interesting properties when it is utilized near its supercritical region. Above the critical temperature of 374 degrees $C$ and critical pressure of 221 bar water exhibits very dramatic properties in the presence of inorganic and organic materials.

3291

V18/021632

Surfactant Enhanced Remediation of Subsurface Petroleum Contamination: Results of a Field Test

Sabatini, D.A.; Knox, R.C.; Shiau, B.J.

University of Oklahoma, Norman, OK

CONF-960376 (Part 1); Proceedings of the 211th American Chemical Society (ACS) National Meeting, New Orleans, LA, March 24-28, 1996. ACS, Washington, DC, Part 1, 1172 pp.; (p. 788, Paper ENVR 106) (1996)

Pump-and-treat remediation of petroleum contaminated groundwater is frequently limited by the presence of residual saturation. Surfactant enhanced subsurface remediation is one approach for overcoming this limitation. A field test of surfactant enhanced solubilization was conducted at a U.S. Coast Guard site in Traverse City, Michigan. The contaminants of interest were jet fuel and tetrachloroethylene (PCE). Micellar solubilization was evaluated at this site using 60 mmole Dowfax 8390. Excellent surfactant recovery was realized in the field test using a vertical circulation well system The regulatory permit was based on $95 \%$ surfactant recovery with the actual results exceeding this level. During the test the contaminant mass removal increased by a factor of seven relative to water alone. (Complete text)

3292

V18/021633

Surfactant Selections for Subsurface Remediation of Petroleum Wastes

Shiau, B.J.; Wu, B.; Karapanagioti, H.K.; Carter, T.

University of Oklahoma, Norman, OK

CONF-960376 (Part 1); Proceedings of the 211th American Chemical Society (ACS) National Meeting, New Orleans, LA, March 24-28, 1996. ACS, Washington, DC, Part 1, 1172 pp.; (p. 788, Paper ENVR 108) (1996)

Laboratory batch and column studies were conducted by using different surfactant/cosurfactant mixtures for petroleum wastes (i.e., jet fuels and VOCs) obtained from a field site. Solubility enhancements were three to four orders of magnitude relative to water alone via solubilization. Middle phase microemulsions (microemulsification) outperformed solubilization by an additional one to two orders of magnitude under similar conditions. Empirical equations from the enhanced oil recovery literature were used to predict the optimal formulations for the middle phase microemulsion. High performance surfactants (alkyl diphenyloxide disulfonates) were less susceptible to losses (precipitation and sorption) than other ionic and nonionic surfactants while effectively solubilizing petroleum wastes. However, the high performance surfactants alone appeared to be too hydrophilic to form the middle phase microemulsion. Scaleup of these results for two ongoing field tests of petroleum contamination will also be presented. (Complete text)

3293

V18/023613

Surfactant-Enhanced Aquifer Remediation

Fountain, J.C.

CONF-951023 (Vol. 8); WEFTEC '95, Proceedings of the 68th Annual Conference and Exposition of the Water Environment Federation, Miami Beach, FL, October 21-25, 1995. Water Environment Federation, Alexandria, VA, Vol. 8, 498 pp.; (p. 226) (1995)

Surfactants can be used to rapidly remove NAPL from contaminated aquifers. They are effective for virtually any organic contaminant. Use in LNAPL contaminated sites requires adequate hydraulic conductivity and control of flow using either hydraulic or physical methods. The presence of DNAPL requires consideration of vertical mobility; a competent confining layer (aquitard) is required if additional aquifers are present at greater depths. Surfactant processes, whether based upon mobilization or solubilization, can be effective at mass removal, but cannot be expected to provide restoration to drinking water standards. The fraction of mass removal and the cost of remediation using surfactants are dependent upon a sites hydrogeology. Both minimization of cost and maximization of NAPL removal requires detailed characterization of a site's contaminant distribution and hydrogeology. Assessment of the feasibility of surfactant-enhanced remediation is dependent upon a detailed site characterization. (Complete text)

\section{4}

V18/020828

System for Sparging Groundwater Contaminants Pennington, L.H.

U.S. Patent 05425598; 7 pp. (June 20, 1995)

This patent describes an apparatus and method for sparging groundwater by developing density driven convection and promoting the physical removal and biodegradation of contaminants. The method includes providing a well casing having two fluid permeable sidewalls separated by a fluid impermeable sidewall, and inserting the well casing into a generally vertical borehole so that the fluid permeable sidewalls are positioned below the water table. An injector tube is provided in the well casing so that a lower end thereof is located at the lower end of the well casing and below the level of groundwater collected in the well casing. Gas under pressure is forced out the lower end of the injector tube and into the groundwater collected in the well casing to cause the gas to carry water upwardly within the well casing and out the well casing through the uppermost fluid permeable sidewall. This causes water to be drawn into the lowermost fluid permeable sidewall, producing a vertically oriented circulation of groundwater into the lower end of the well casing and out the uppermost permeable sidewall. 
Iron

O'Hannesin, S.F.; Gillham, R.W.; Vogan, J.L.

University of Waterloo, Waterloo Centre for Groundwater Research, Waterloo, Ontario, Canada; EnviroMetal Technologies, Inc., Guelph, Ontario, Canada

CONF-9509139; Emerging Technologies in Hazardous Waste Management VII, D.W. Tedder (ed.), Proceedings of the Seventh American Chemical Society Industrial and Engineering Chemistry Division Special Symposium, Atlanta, GA, September 17-20, 1995. American Chemical Society, Washington, DC, 1291 pp.; (pp. 55-58) (1995)

Studies at the Waterloo Centre for Groundwater Research at the University of Waterloo indicated that various zero-valent metals are effective in enhancing the rate of degradation of a wide range of chlorinated compounds. Granular iron was selected as the main material for testing due to its effectiveness, availability and relatively low cost. Of 14 halogenated methanes, ethanes, and ethenes tested with iron, 13 clearly showed enhanced degradation with normalized half lives ranging from 5 to 15 orders of magnitude lower than values reported in the literature for natural abiotic degradation rates.

3296

$\mathrm{V} 18 / 025486$

Technical Protocol for Implementing Intrinsic Remediation with Long-Term Monitoring for Natural Attenuation of Fuel Contamination Dissolved in Groundwater: Volume 1

Wiedemeier, T.H.; Wilson, J.T.; Kampbell, D.H.; Miller, R.N.; Hansen, J.E.

Parsons Engineering Science, Inc., Denver, CO

Report; 323 pp. (June 1995)

The intent of this document is to present a technical protocol for data collection and analysis in support of intrinsic remediation with long term monitoring (LTM) for restoration of groundwater contaminated with fuel hydrocarbons. Specifically, this protocol is designed to evaluate the fate in groundwater of fuel hydrocarbons that have regulatory standards. Intrinsic remediation is an innovative remedial approach that relies on natural attenuation to remediate contaminants in the subsurface. In many cases, the use of this protocol will allow the proponent of intrinsic remediation to show that natural degradation processes will reduce the concentrations of these contaminants to below regulatory standards before potential receptor exposure pathways are completed. The evaluation should include consideration of existing exposure pathways, as well as exposure pathways arising from potential future use of the groundwater.

3297

V18/025487

Technical Protocol for Implementing Intrinsic Remediation with Long-Term Monitoring for Natural Attenuation of Fuel Contamination Dissolved in Groundwater: Volume 2

Wiedemeier, T.H.; Wilson, J.T.; Kampbell, D.H.; Miller, R.N.; Hansen, J.E.

Parsons Engineering Science, Inc., Denver, CO
Report; 343 pp. (June 1995)

This report presents the results of an engineering evaluation/cost analysis (EE/CA) conducted to evaluate the use of intrinsic remediation (natural attenuation) with long-term monitoring (LTM) for remediation of fuel-hydrocarbon contamination dissolved in groundwater at underground storage tank (UST) Site 870, Hill Air Force Base (AFB), Utah. The main emphasis of the work described was to evaluate the potential for intrinsic degradation mechanisms to reduce dissolved-phase benzene, toluene, ethylbenzene, and xylene (BTEX) concentrations in groundwater to levels that are protective of human health and the environment.

V18/023339

Technologies for Environmental Cleanup: Soil and Groundwater

Avogadro, A.; Ragaini, R.C.

Technologies for Environmental Cleanup: Soil and Groundwater, KJuwer Academic Publishers, Dordrecht, Netherlands (March 1993)

No abstract available.

V18/024003

Technology Status Report: Off-Gas Treatment Technologies for Chlorinated Volatile Organic Compound Air Emission

Rossabi, J.; Haselow, J.S.

Westinghouse Savannah River Company, Aiken, SC WSRC-RP-92-473; 15 pp. (April 15, 1992)

The purpose of this document is to review technologies for treatment of air streams that contain chlorinated volatile organic compounds (CVOCs) and to describe a Department of Energy Office of Technology Development program that is planned to demonstrate innovative technologies for the abatement of CVOC emissions. This report describes the first phase of testing of off-gas treatment technologies. At least one more phase of testing is planned. Guidance for the preparation of this document was provided by a predecisional draft outline issued by the Department of Energy's Office of Technology Development. The report is intended to evaluate the technical and regulatory aspects, public acceptance, and estimated costs of technologies selected for development and testing. These technologies are compared to currently practiced or baseline methods for treatment of CVOC-laden airstreams. A brief overview is provided rather than detailed cost and data comparisons because many of these technologies have not yet been field tested. A description of other promising technologies for the treatment of CVOC emissions is also included.

3300

$\mathrm{V} 18 / 022812$

Technology Transfer Environmental Investigations

Bradford, M.; Chodorowski, T.

Jacobs Engineering Group Inc., Houston, TX; Pace Consultants, Houston, TX

CONF-960804 (Vol. 3); Spectrum '96: Nuclear and Hazardous Waste Management, Proceedings of an International Topical Meeting, Seattle, WA, August 18-23, 1996. American Nuclear 
Society, La Grange Park, IL, Vol. 3, 841 pp.; (pp. 1799-1801) (1996)

The Pace Consultants conducted a number of environmental investigations at chemical complexes in Mexico. The purposes of the audits was to determine compliance with the Mexican environmental regulations, to develop a list of action items to improve the performance of the facilities, and to estimate the cost of the action items. An additional goal of the investigations was to transfer environmental technology from the U.S. to Mexico. The initial work was actually conducted under a technology transfer tax incentive. Initial surveys found very little soil and groundwater contamination at the sites. To confirm these results, areas of potential contamination were investigated in more detail. Technology on common use in the US, a geoprobe combined with the use of field analytical screening was used to better evaluate the sites. This large sampling program was able to confirm the previous results - very little soil and groundwater contamination is present.

3301

V18/025297

Testing Bioremediation in the Field

Wilson, J.T.

U.S. Environmental Protection Agency, Robert S. Kerr

Environmental Research Laboratory, Ada, OK

Insitu Bioremediation: When Does It Work?, National Academy

Press, Washington, DC, 207 pp.; (pp. 160-184) (1993)

An operational definition for success of in situ bioremediation at field scale includes meeting regulatory goals for groundwater quality in a timely fashion at a predictable cost. Current practice for site characterization does not adequately define the amount of contamination subject to bioremediation. As a result, laboratory estimates of the requirements for electron acceptors and mineral nutrients and of the time required for remediation have much uncertainty. Another aspect of success is the capacity to continue to meet regulatory goals for groundwater quality after the active phase of remediation is complete. In contrast to laboratory studies, the extent of remediation achieved at field scale is influenced by dilution of compounds of regulatory concern in circulated water and by partitioning of the regulated compounds between water and residual nonaqueous-phase oily material. The extent of weathering of residual oily-phase material and the hydrologic environment of the residual have a strong influence on the potential for groundwater contamination after active remediation ceases.

\section{2}

V18/021618

Theoretical Relationships Between Reactivity and Permeability for Monomineralic Porous Media

Smith, R.W.; Schafer-Perini, A.L.; Tompson, A.F.B. Idaho National Engineering Laboratory, Idaho Falls, ID; Lawrence Livermore National Laboratory, Livermore, CA

CONF-951155; Scientific Basis for Nuclear Waste Management, W.M. Murphy and D.A. Knecht (eds.), Proceedings of a Materials Research Society Fall Meeting and Symposium, Boston, MA, November 27-December 1, 1995. Materials Research Society, Pittsburgh, PA, Vol. 412, 957 pp.; (pp. 693-700) (1996)

The release of contaminants to the subsurface has lead to potential or actual contamination of groundwater resources. The remediation of these piumes requires improved capability for the prediction of contaminant fate and transport. Key to improving predictive capabilities is an increased understanding of natural chemical (or reactive) heterogeneity in subsurface media and how chemical and physical heterogeneity are related. Although the effects of physical heterogeneity on transport has received significant attention, similar investigations of chemical heterogeneity, and the correlation of chemical and physical heterogeneity are in their infancy. Theoretical considerations for unconsolidated porous media composed of sand-sized grains of a single reactive phase suggest that chemical reactivity and permeability are inversely related. This correlation is consistent with measured permeability, porosity, and surface area data for unconsolidated sands. The correlation arises because both reactivity and permeability are functions of the surface area of the porous media. This relationship suggests that for a heterogeneous porous media, significant contaminant transport will occur in zones of minimal reactivity.

3303

V18/022040

Time-Resolved Fluorescence Spectroscopy for Application to PAH Contaminated Areas and Hydrogeological Research

Kotzick, R.; Haaszio, S.; Niessner, R.

Technical University of Munich, Institute of Hydrochemistry, Munich, Germany

CONF-9506232; Environmental Monitoring and Hazardous Waste Site Remediation, T. Vo-Dinh and R. Niessner (eds.), Proceedings of a Conference of the Society of Photo-Optical Instrumentation Engineers, Munich, Germany, June 19-23, 1995. International Society for Optical Engineering, Bellingham, WA, 613 pp.; (pp. 107-114) (1995)

A mobile fiber-optical sensor system for the on-line and in situ detection of aquatic fluorophores has been developed. By the use of time-resolved laser-induced fluorescence spectroscopy the determination of contaminants i.e. polycyclic aromatic hydrocarbons (PAH) or fluorescence tracers in various environments is possible. In both cases attempts to detect these substances in water by means of fluorescence spectroscopy are complicated by the low concentrations and the overlapping and featureless fluorescence spectra in combination with background fluorescence caused by further compounds e.g. humic material. By collecting the fluorescence decay time as an additional independent dimension, the analytical information is significantly increased, and to a certain extent the determination of the desired analyte in complex natural matrices is possible. At a first application, the detection of pyrene (PYR) in real samples from a contaminated former coking plant site has been realized. The system is also best suitable for hydrogeological research. Here applications spread from the investigation of the fluorescence tracer migration in an artificial aquifer system to the determination of hydrogeological parameters at a domestic waste disposal site.

$3304 \quad$ V18/021807

Treatment of Hazardous Organic Wastes Using Silent Discharge Plasmas

Rosocha, L.A.; Anderson, G.K.; Bechtold, L.A.; Coogan, J.J.; Heck, H.G.; Kang, M.; McCulla, W.H.; Tennant, R.A.; 
Wantuck, P.J.

Los Alamos National Laboratory, Chemical and Laser Sciences Division, Los Alamos, NM

NATO ASI Series G34, Part B:1; Non-Thermal Plasma Techniques for Pollution Control, B.M. Penetrante and S.E. Schultheis (eds.), Springer-Verlag, Berlin, Germany (1993)

Non-equilibrium plasmas have been applied to the chemical processing of gaseous media for over a century. Two major applications are chemical synthesis, exemplified by ozone generation and the removal of undesirable compounds from flue gases, exemplified by the electrostatic precipitator developed by Lodge. During the past two decades, interest in applying non-equilibrium plasmas to the removal of hazardous chemicals from gaseous media has been growing, in particular from heightened concerns over the pollution of our environment and a growing body of environmental regulations. These more-recent applications have involved efforts to destroy toxic chemical agents, to remove harmful greenhouse gases, such as sulfurous and nitrous oxides - SOx and NOx, and to treat other environmentally-hazardous hydrocarbon and halocarbon compounds.

\section{5}

V18/023746

Treatment of Landfill Leachate-Impacted Groundwater Using Cascade Aeration and Constructed Wetlands

Loer, J.; O'Flanagan, B.D.; Fellows, W.; Wetzstein, D.W.; Julik, J.K.

Delta Environmental Consultants, Inc., St. Paul, MN; Minnesota Pollution Control Agency, St. Paul, MN

CONF-950978; Municipal and Industrial Waste, Proceedings of the 18th International Madison Waste Conference, Madison, WI, September 20-21, 1995. University of Wisconsin, Madison, WI, 461 pp.; (pp. 260-275) (1995)

At an unlined municipal solid waste landfill, heavy metal and toxic organic compounds present in leachate have impacted groundwater, necessitating extraction and treatment of the contaminated groundwater. A remedial design relying on a natural systems engineering approach will take advantage of existing contours (gravity flow) and surroundings (wetlands), and will limit energy inputs and eliminate chemical inputs. Impacted groundwater will be extracted, and aerated via a cascade constructed of polypropylene sheets fabricated into "step" sections and set into a side slope of the landfill. Volatilization of organics and oxidation of iron and heavy metals to insoluble compounds will occur during cascading and will continue within a sedimentation basin where settling of iron precipitates will induce co-settling of heavy metal precipitates. Following the sedimentation basin, a constructed wetland containing both aerobic zones and anaerobic zones will provide additional treatment of remaining solids and heavy metals, before surface discharge. Use of a natural systems approach significantly reduces operating costs compared to a mechanical-aeration, chemical-precipitation system, and is more aesthetically pleasing and suited to the remote locale. The system is under construction and seasonal operation will begin in spring 1996.

\section{6}

V18/021960

Treatment of Low-Level Explosives and Solvents Contaminated Groundwater Using Advanced Oxidation

\section{Processes}

Zappi, M.E.; Toro, E.; Kodukula, P.S.; Gilbertson, R.M.

U.S. Army Corps of Engineers, Waterways Experiment Station, Vicksburg, MS; Woodward-Clyde Consultants, Overland Park, KS; U.S. Army Corps of Engineers, Kansas City, MO

CONF-9509139; Emerging Technologies in Hazardous Waste Management VII, D.W. Tedder (ed.), Proceedings of the Seventh American Chemical Society Industrial and Engineering Chemistry Division Special Symposium, Atlanta, GA, September 17-20, 1995. American Chemical Society, Washington, DC, 1291 pp.; (pp. 606-608) (1995)

The U.S. Department of Defense (DoD) has literally thousands of sites contaminated from past military activities associated with national defense that require environmental remediation. Many of these sites are contaminated with explosives compounds such as 2,4,6-trinitrotoluene (TNT),

hexahydro-1,3,5-trinitro-1,3,5-triazine (RDX), and octahydro-1,3,5,7-tetranitro-1,3,5,7-tetrazocine (HMX). Activities that resulted in the contamination of the environment include explosives manufacturing, weapons load-and-packing (LAP), and open burning of obsolete weapons. These facilities often have other forms of contamination including chlorinated solvents, lead, and mercury from weapons manufacturing and processing. This study focused on the evaluation of advanced oxidation processes (AOPs) as an innovative treatment alternative for an organics contaminated groundwater at a former DoD facility in Nebraska. The two primary contaminants present in the groundwater are trichloroethene (TCE) and RDX present at levels up to $0.7 \mathrm{ug} / 1$ and $0.02 \mathrm{ug} / \mathrm{l}$, respectively. The target treatment objective for both contaminants is $0.002 \mathrm{ug} /$. Traditional technology for treating groundwaters containing contaminants of this type is activated carbon. Although activated carbon is a viable process, adsorption results in the generation of spent carbon requiring further treatment and/or disposal. Four candidate AOPs were evaluated as potential treatment options for the site groundwater during this study. The results indicated that TCE could be removed to within target treatment goals by all candidate AOPs within 10 minutes of treatment.

\section{7}

V18/021957

Trichloroethylene Degradation by Subsurface Microbial Communities

Pfiffner, S.M.; Beauchamp, J.J.; Phelps, T.J.; Palumbo, A.V. Oak Ridge National Laboratory, Environmental Sciences Division, Oak Ridge, TN

CONF-9509139; Emerging Technologies in Hazardous Waste Management VI, D.W. Tedder (ed.), Proceedings of the Seventh American Chemical Society Industrial and Engineering Chemistry Division Special Symposium, Atlanta, GA, September 17-20, 1995. American Chemical Society, Washington, DC, 1291 pp.; (pp. 336-338) (1995)

The in situ bioremediation demonstration at the U.S. Department of Energy/Office of Technology Development, Westinghouse Savannah River Site (WSRS), involved an area of subsurface and groundwater contaminated with trichloroethylene (TCE) and tetrachloroethylene (PCE) from an abandoned process sewer line. A 
series of increasingly more aggressive treatments were delivered into a lower horizontal well coupled with vacuum extraction from a vadose zone horizontal well to stimulate trichloroethylene-degrading microorganisms. A control phase (phase 1) without treatment was followed by air injection (phase 2), injection of $1 \%$ methane in air (phase 3), $4 \%$ methane in air (phase 4), pulsed methane and air injection (phase 5), and continuous addition of triethyl phosphate and nitrous oxide in air with pulsed additions of methane and air (phase 6). Microbial monitoring was utilized to demonstrate the effectiveness of bioremediation and to optimize the treatment regimes and continued for a few months after termination of all treatments.

\section{8}

\section{V18/023036}

Tritium Transport from a Solid Radioactive Waste Burial Ground Whose Heterogeneous Conductivity Field is Based on Site Lithologic Data

Hamm, L.L.; Flach, G.P.; Harris, M.K. Westinghouse Savannah River Company, Aiken, SC CONF-960527; Global Exploration and Geotechnology, Proceedings of an Annual Convention of the American Association of Petroleum Geologists, Inc., and the Society for Sedimentary Geology, San Diego, CA, May 19-22, 1996, 231 pp.; AAPG Bulletin 80(5):60a (1996)

Variability in hydraulic conductivity can dominate regional scale groundwater (GW) flow patterns and dispersive transport. An approach for generating heterogeneous conductivity fields from sediment lithologic descriptions is employed. The approach involves creating a fine-scale representation of mud (silt+clay) fraction using "stratified" interpolation that is translated into horizontal and vertical conductivities using direct correlations. The fine scale conductivity fields are then scaled-up to a coarser grid for use in GW modeling. The approach is demonstrated using a 3-D model for tritium migration from a Savannah River Site solid radioactive waste burial ground. The site area contains a significant number of core logs for defining lithology, has complex vertical heterogeneity in the upper aquifer units, numerous monitoring wells for hydraulic heads, and several tritium sources (ideal tracer) for assessing the model's accuracy. This study demonstrates that detailed lithologic information can be successfully incorporated directly into the model. A more defensible method of addressing aquifer heterogeneities (than the traditional layered approach) is achieved because the model more closely reflects the actual lithologic data. For the burial ground field-observed preferential pathways for tritium transport occur without the need to resort to the artificial creation of locally high conductivity zones. A comparison to measurements is presented for tritium breakthrough at the down-gradient seepage face of Fourmile Branch Creek.

\section{9}

\section{V18/021628}

Two-Dimensional Hydraulics of Recirculating Groundwater Remediation Wells in Unconfined Aquifers

Stallard, W.M.; Wu, K.C.; Shi, N.; Corapcioglu, M.Y. W. M. Stallard, Sacramento, CA; Texas A\&M University, Department of Civil Engineering, College Station, TX

Journal of Environmental Engineering 122(8):692-699 (August
1996)

A technique for remediating and protecting groundwater and drinking-water wells from contamination is presented. A groundwater remediation well design is proposed in which groundwater is drawn into the well bottom, treated in the well casing, and retumed clean to the aquifer at the well top. The hydraulics of groundwater circulation around imperfectly penetrating wells were examined experimentally in pilot-scale tanks and mathematically with numerical models in a two-dimensional domain. Ambient groundwater velocities of from 1 to $3 \mathrm{~m} /$ day, which are typical for coarse sand and gravel aquifers, were simulated in combination with in-well vertical velocities of from 2 to 16 $\mathrm{m} /$ day. Under some of these flow conditions, contaminants were intercepted and drawn into the wells for treatment. Hydraulic problems identified with the experimental apparatus and simulated by the computer models included blow through of contaminant at the well intake by high ambient groundwater velocities and submergence by the well hydraulics of surface contaminant plumes without interception. Both types of problems were corrected by adjusting intemal well velocities. Important design parameters include ambient groundwater velocity and well pumping rate.

\section{$3310 \quad \mathrm{~V} 18 / 023877$}

Two-Phase Ozonation of Chlorinated Organics

Bhattacharyya, D.; Freshour, A.; West, D.

University of Kentucky, Department of Chemical Engineering, Lexington, $\mathrm{KY}$

EPA/600/R-95/012; CONF-9504110; Proceedings of the 2Ist Annual Risk Reduction Engineering Laboraton (RREL) Research Symposium, Cincinnati, OH, April 4-6, 1995. U.S. Environmental Protection Agency, Cincinnati, OH, 398 pp.; (pp. 194-198) (April 1995)

In the last few years the amount of research being conducted in the field of single-phase ozonation has grown extensively. However, traditional aqueous-phase ozonation systems are limized by a lack of selective oxidation potential, low ozone solubility in water, and slow intermediate decomposition rates. Furthermore, ozone may decompose before it can be utilized for pollutant destruction since ozone can be highly unstable in aqueous solutions. Naturally occurring compounds such as $\mathrm{NaHCO} 3$ also affect ozone reactions by inhibiting the formation of $\mathrm{OH}$ free radicals. To compensate for these factors, excess ozone is typically supplied to a reactor. Since ozone generation requires considerable electric power consumption (16-24 kWh/kg of O3), attempts to enhance the ozone utilization rate and stability should lead to more efficient application of this process to hazardous waste treatment. To improve the process, ozonation may be more efficiently carried out in a two-phase system consisting of an inert solvent (saturated with 03 ) contacted with an aqueous phase containing pollutants. From practical considerations, the non-aqueous phase must meet the following criteria: (1) non-toxic; (2) very low vapor pressure, (3) high density (for ease of separation), (4) complete insolubility in water, (5) reusability, (6) selective pollutant extractability, (7) high oxidant solubility, and (8) extended $\mathrm{O} 3$ stability. Previously published studies have indicated that a number of fluorinated hydrocarbon compounds fit these criteria. For this project, FC40 (a product of $3 \mathrm{M} \mathrm{Co}$.) was chosen due to its low vapor pressure ( $3 \mathrm{~mm} \mathrm{Hg}$ ) and high specific gravity (1.9). The primary advantages of the FC40 solvent are that 
it is nontoxic, reusable, has an ozone solubility 10 times that of water, and that $85 \%$ of the ozone remains in the solvent even after 2 hours. This novel two-phase process has been utilized to study the rapid destruction of pentachlorophenol (PCP), 1,3 dichlorobenzene (DCB), trichloroethylene (TCE), and organic mixtures.

\section{$3311 \quad$ V18/023812}

Use of Capacitive Deionization with Carbon Aerogel Electrodes to Remove Inorganic Contaminants from Water

Farmer, J.C.; Fix, D.V.; Mack, G.V.; Pekala, R.W.; Poco, J.F. Lawrence Livermore National Laboratory, Livermore, CA EPRI-TR-105569; CONF-950718; Proceedings of the 1995 Electric Power Research Institute (EPRI) International Low-Level Waste Conference, Orlando, FL, July 10-12, 1995, 600 pp.; (pp. 39.1-39.10) (November 1995)

The capacitive deionization of water with a stack of carbon aerogel electrodes has been successfully demonstrated for the first time. Unlike ion exchange, one of the more conventional deionization processes, no chemicals were required for regeneration of the system. Electricity was used instead. Water with various anions and cations was pumped through the electrochemical cell. After polarization, ions were electrostatically removed from the water and held in the electric double layers formed at electrode surfaces. The water leaving the cell was purified, as desired.

\section{$3312 \quad$ V18/023744}

Use of Constructed Mixed Microbial Mats for Landfill Leachate Treatment

Goodroad, L.; Bender, J.; Phillips, P.; Gould, J.; Hater, G.R.; Burrow, $\mathbf{B}$.

Rust Federal Services, Inc., Clemson Technical Center, Anderson, SC; M.A.T.S. Inc., Atlanta, GA; Waste Management Inc. Biosites, Cincinnati, OH; WMI Outer Loop Recycling and Disposal Facility, Louisville, KY

CONF-950978; Municipal and Industrial Waste, Proceedings of the 18th International Madison Waste Conference, Madison, WI, September 20-21, 1995. University of Wisconsin, Madison, WI, 461 pp.; (pp. 235-247) (1995)

BIOMAT [TM] (Mats) is a system of constructed microbial mats which are natural heterotrophic and autotrophic communities dominated by cyanobacteria (blue-green algae). Mats constructed with specific microbial components have been developed for various bioremediation applications: removal of metals, organic degradation, removal of radionuclides, treatment of mixed contaminants, biological treatment ponds, and soil remediation. Based on the potential applications of the constructed microbial mat system, a pilot scale leachate treatment system has been constructed at the Waste Management, Inc. Outer Loop RDF near Louisville, $\mathrm{KY}$ in conjunction with M.A.T.S., Inc. The system consists of two lined lagoons with various constructed mat configurations. Changes in leachate chemistry including: $\mathrm{pH}$, dissolved oxygen, color, nitrate/nitrite and ammonium concentration were monitored on influent and effluent leachate streams and within the pilot system to determine operational characteristics of the constructed microbial mat system. The
M.A.T.S., Inc. treatment system is expected to reduce capital costs for leachate treatment plants, decrease leachate treatment operating costs, and create a "green" self-contained image for landfills.

3313

V18/022687

Use of High Vacuum Soil Vapor Extraction to Improve Contaminant Recovery from Groundwater Zones of Low Transmissivity

Brown, A.; Farrow, J.R.C.; Burgess, W.; Payne, R.E.

Komex-H2O Science, Huntington Beach, CA ; University

College, Department of Geological Sciences, London, United Kingdom; Mobil Oil Corporation, Fairfax, VA

CONF-960393 (Part 2); Contaminated Soils and Groundwater: Analysis, Fate, Environmental and Public Health Effects, and Remediation, Proceedings of the Sixth Annual West Coast Conference, Newport Beach, CA, March 11-14, 1996. Association for the Environmental Health of Soils, Amherst, MA, Part 2, 226 pp.; (p. 17) (1996)

This study examines the potential for enhancing hydrocarbon contaminant mass recovery from groundwater using high vacuum soil vapor extraction (SVE). The effectiveness of this form of remediation is compared with the effectiveness of conventional pump-and-treat. This study focuses on the performance of a high vacuum SVE system at two groundwater monitoring wells (MW-17 and $M W-65 b$ ) at a site in Santa Barbara, Califomia, USA. The site is a highly characterized site with vadose zone and groundwater petroleum hydrocarbon contamination (gasoline). The groundwater wells are located beyond a defined area of vadose zone soil contamination. Groundwater hydrocarbon contamination [light non-aqueous phase liquid (LNAPL) and dissolved phase] is present at each of the wells. the groundwater wells have been part of a low-flow, pump-and-treat, groundwater treatment system (GWTS) since August, 1986. The low transmissivity of the aquifer sediments prevents flow rates above approximately $0.02 \mathrm{gpm}(0.01 \mathrm{l} / \mathrm{min})$ per well.

\section{$3314 \quad \mathrm{~V} 18 / 022642$}

Use of Insitu Dual Vacuum Extraction [TM] for Remediation of Soil and Groundwater

Dodson, M.E.; Trowbridge, B.E.; Ott, D.

Terra Vac Corporation, Northwest Division, Seattle, WA; Terra Vac Corporation, Newport Beach, CA; Terra Vac Corporation, Northeast Division, Westford, MA

CONF-941 124; Insitu Remediation: Scientific Basis for Current and Future Technologies, G.W. Gee and N.R. Wing (eds.), Proceedings of the 33rd Hanford Symposium on Health and the Environment, Pasco, WA, November 7-11, 1994. Battelle Press, Columbus, OH, Part 2, 605 pp.; (pp. 1249-1262) (1994)

Dual Vacuum Extraction [TM] provides a rapid and cost-effective method of remediating soil and groundwater contaminated with volatile organic compounds. The system involves the removal of both water and vapors through the same borehole by use of entrainment. This technology provides for the remediation of the vadose zone, capillary fringe, smear zone, and existing water table. The effectiveness of this technology is shown in a case study. A 
release from an underground storage tank was responsible for a hydrocarbon plume spreading over approximately 50,000 square feet. The release produced vadose-zone contamination in the silty and sandy clays from 10 to $30 \mathrm{ft}$ below ground surface (bgs) with total petroleum hydrocarbon (TPH) concentrations up to 1,400 $\mathrm{mg} / \mathrm{kg}$. In addition, a layer of free-floating liquid hydrocarbon was present on a shallow aquifer located at $25 \mathrm{ft}$ bgs in thicknesses ranging from 0.5 to $3.0 \mathrm{ft}$. An in-situ dual-extraction system was installed to remediate the soils and groundwater to levels as required by the Los Angeles Regional Water Quality Control Board (RWQCB). The system operated $24 \mathrm{hr}$ a day, with an operating efficiency of over $99 \%$. After 196 days (28 weeks), over $17,000 \mathrm{lb}$ of hydrocarbons had been extracted from the soils. Seven confirmatory soil borings in the area of highest initial hydrocarbon concentrations indicated that TPH and benzene, toluene, ethylbenzene, xylene (BTEX) concentrations had decreased over $99 \%$ from initial soil concentrations.

\section{5}

V18/021438

Use of Laboratory Soil Columns to Optimize Insitu Biotransformation of Tetrachloroethene

Morrissey, C.M.; Herbes, S.E.; West, O.M.; Palumbo, A.V.; Phelps, T.J.; Hazen, T.C.

Oak Ridge National Laboratory, Environmental Sciences Division, Oak Ridge, TN

Applied Biotechnology for Site Remediation, R.E. Hinchee (ed.), CRC Press, Inc., Lewis Publishers, Boca Raton, FL, 504 pp.; (pp. 326-331) (March 1996)

Tetrachloroethene (perchloroethylene, PCE) is a major groundwater contaminant at many U.S. Department of Energy (DOE) sites, often at concentrations of several milligrams per liter. At the Savannah River Integrated Demonstration (SRID) site, PCE, together with trichloroethene (TCE), has been detected in both soil and groundwater. Biological degradation of the combination of PCE and TCE may prove difficult in the subsurface gas injection scheme at the SRID. The injection of methane into the subsurface at SRID will provide aerobic, methanotrophic conditions that are favorable for TCE degradation. However, PCE is degraded by a reductive dechlorination process under anaerobic conditions but has proven recalcitrant under aerobic, methanotrophic conditions. The research reported herein includes three main objectives: (1) to evaluate the potential for anaerobic dechlorination of $\mathrm{PCE}$ at high $\mathrm{mg} / \mathrm{L}$ concentrations; (2) to evaluate the potential for PCE removal by coupling anaerobic PCE dechlorination with aerobic, methanotrophic degradation of the anaerobic products; and (3) to simulate the subsurface environment of the SRID gas injection test site in the laboratory and evaluate the fate of PCE in this laboratory simulation. To accomplish these objectives, two types of experiments were conducted: (1) saturated sand column experiments inoculated with either anaerobic digester sludge or soil from local waste disposal sites; and (2) soil column experiments packed with soil from the SRID site and purged with either $3 \% \mathrm{CH} 4$ in air or N2. This technical note describes the experimental methods used in and the results obtained from these ongoing experiments.

3316

V18/022633

Use of Micro-Organisms for the Remediation of Solutions Contaminated with Actinide Elements, Other
Radionuclides, and Organic Contaminants Generated by Nuclear Fuel Cycle Activities

Macaskie, L.E.; Lloyd, J.R.; Thomas, R.A.P.; Tolley, M.R. Birmingham University, School of Biological Sciences, Birmingham, United Kingdom

CONF-9601114; Proceedings of a BNES Conference on Chemistry of the Nuclear Fuel Cycle, Manchester, United Kingdom, January 11-12, 1996; Nuclear Energy 35(4):257-271 (August 1996)

Many heavy elements, including actinides, form insoluble precipitates with ligands such as inorganic phosphate (abbreviated $\mathrm{Pi}$. This can be generated biochemically, e.g. using the activity of a phosphatase enzyme of a Citrobacter sp., which forms HPO4(2-) in juxtaposition to nucleation sites on the cell surface; insoluble metal phosphate promotes the formation of large crystals of, for example, HUO2PO44H20, to loads of several times the weight of the biomass. For use the biomass is immobilized within a flow-through column. The metals can be removed efficiently from dilute solution since the continuous production of a high localized concentration of $\mathrm{Pi}$ allows the solubility product of the metal phosphate to be exceeded, even in the presence of competing chelating ligands (e.g. citrate). Application of this approach to the removal of uranium, americium, plutonium and neptunium from acid mine drainage waters $(\mathrm{U})$ and laboratory test solutions ( $\mathrm{Am}, \mathrm{Pu}$, $\mathrm{Np}$ ) is described. The phosphate "donor" molecule (phosphatase substrate) is an organophosphate, usually glycerol 2-phosphate. Tributyl phosphate has also been cleaved enzymatically to support the removal of uranium from solution by a new mixed culture. Some metal species such as technetium (VII), TcO4(1-), do not form insoluble phosphates. Here, the reductase activity of other microorganisms can be hamessed to the bioreduction of Tc(VII) to insoluble species which are precipitated onto the biomass. Special problems can occur in plant decontamination, where soluble metal-ligand complexes may be generated.

\section{7}

\section{V18/020613}

Use of Natural Sedimentary Zeolites for Metal Ion Recovery from Hydrometallurgical Solutions and for the Environmental Remediation of Acid Mine Drainage

Carland, R.M.; Aplan, F.F.

Kentucky-Tennessee Clay Company, Mayfield, KY; Pennsylvania State University, Mineral Processing Section, University Park, PA

CONF-9510120 (Vol. 4); Precious Metals Processing and Mineral Waste and the Environment, Proceedings of the 19th International Mineral Processing Congress, San Francisco, CA, October 22-27, 1995. Society for Mining, Metallurgy, and Exploration, Inc., Littleton, CO, Vol. 4, 210 pp.; (pp. 95-100) (1995)

Six natural zeolites were evaluated for their ability to selectively remove heavy metal cations from solution. Ion selectivity was found to be $\mathrm{Pb}(\mathrm{E}+2)$ greater than $\mathrm{Zn}(\mathrm{E}+2)$ greater than $\mathrm{Ni}(\mathrm{E}+2)$ and $\mathrm{Cu}(\mathrm{E} \div 2)$ greater than $\mathrm{Co}(\mathrm{E}+2)$ from their respective solutions. The presence of $\mathrm{K}(\mathrm{E}+), \mathrm{Ca}(\mathrm{E}+2)$ and $\mathrm{Mg}(\mathrm{E}+2)$ in the actual waters to be used may seriousiy interfere with the ion exchange and elution of cations from zeolites. Zeolites were found not to be effective in removing precious metals from their cyanide solutions. 


\section{8}

V18/023225

Use of Rapid, Specific Immunoassay-Based Field Tests for Assessing Soil and Water Contamination

Carter, K.R.

EnSys Environmental Products, Inc., Research Triangle Park, NC

CONF-9210194; Proceedings of an International Symposium on Environmental Contamination in Central and Eastern Europe, Budapest, Hungary, October 12-16, 1992, 968 pp.; (pp. 527-529) (1992)

The application of field analytical methods to site assessments can enhance the quality of the site assessment and result in substantial savings of time and expense relative to the conventional practice of collecting samples and submitting them for laboratory analysis. With the appropriate method and adequate quality assurance/quality control this can be accomplished without an accompanying decrease in the quality of the data necessary to support the decision-making process based on the site assessment results. Field analytical testing can be used to substantial advantage for the "real-time" delineation of soil contamination and the extent of contaminant plume migration. The recent development of several low-cost, rapid, analyte-specific field analytical tests based on immunoassay technology has provided on-site tools for the cost-effective assessment of soil and water contamination. Extensive application of immunoassay-based field analytical methods for pentachlorophenol, polychlorinated biphenyls, petroleum hydrocarbons, and polyaromatic hydrocarbons have shown them to be accurate, rugged, and reliable.

\section{9 \\ V18/023771}

Use of Soil Gas Monitoring to Locate Contaminant Sources

Cohen, W.L.; Izzo, V.J.

Califomia Regional Water Quality Control Board, Central Valley Region, Sacramento, CA

CONF-9504134; HAZMACON '95, T. Bursztynsky and M.L. Loss (eds.), Proceedings of the Twelfth Hazardous Materials Management Annual Conference and Exhibition, San Jose, CA, April 4-6, 1995. Association of Bay Area Governments, Oakland, CA, 790 pp.; (pp. 32-41) (1995)

Volatile organic compounds (VOCs) are used in many industrial and commercial activities. In the past, before much was known about the harm these chemicals could do to the environment, disposal practices were not designed to prevent the release of VOCs to the environment. These practices have resulted in contamination of soil and groundwater in many locations. In Califomia's Central Valley, numerous drinking water supply wells were found to be contaminated with VOCs through sampling required by a 1984 state law. Many wells were shut down and investigations were begun to locate the sources of the contamination. Soil gas monitoring has proven to be an effective tool to locate sources of VOCs in soil because they generally do not adhere to soil particles, so may not be measured in bulk soil samples. However, VOCs in vapor form in the soil can be measured and often correlated to groundwater contamination plumes.
3320

V18/023470

Use of Zero-Valent Iron and Ultrasonic Energy for Insitu Groundwater Remediation

Afiouni, G.F.; Clausen, C.A.; Geiger, C.L.; Reinhart, D.; Ruiz, N.E.

University of Central Florida, Oriando, FL

CONF-960807; Proceedings of the 212th American Chemical Society (ACS) National Meeting, Orlando, FL, August 25-30, 1996. ACS, Washington, DC; National Meeting - American Chemical Society, Division of Environmental Chemistry 36(2):42-44 (1996)

Contamination in groundwater in general and drinking water in particular has become a major concern in the twentieth century. EPA strictly regulates the amount of acceptable contamination to extremely low levels for chemical industries. Old techniques, such as pump-and-treat, have proven to have some limitations in decreasing the concentrations to acceptable levels, thus forcing research groups to look into other alternatives for groundwater remediation. A new technique is to implement an in situ treatment of groundwater that depends mainly on the natural water flow through a treatment wall. This active wall would consist of zero-valent-iron, with high surface area to mass ratio to accelerate the kinetics of the dehalogenation of chlorinated organic molecules, mainly trichloroethylene (TCE), into environmentally acceptable hydrocarbons that can be consumed by microorganisms underground. In addition, ultrasonic chemistry is co-applied in order to replenish the oxidized metal surface area, i.e., to help in maintaining wall activity which theoretically should increase the wall lifetime. Data from both batch and column reactions show the feasibility of such a procedure. Kinetic data are presented

3321

V18/022624

Use of Zero-Valent Metals in Insitu Remediation of Contaminated Groundwater

Gillham, R.W.; Blowes, D.W.; O'Hannesin, S.F.; Ptacek, C.J.

University of Waterloo, Waterloo, Ontario, Canada; National Water Research Institute, Canada Centre for Inland Waters, Burlington, Ontario, Canada

CONF-941124; Insitu Remediation: Scientific Basis for Current and Future Technologies, G.W. Gee and N.R. Wing (eds.), Proceedings of the 33rd Hanford Symposium on Health and the Environment, Pasco, WA, November 7-11, 1994. Battelle Press, Columbus, OH, Part 2, 605 pp.; (pp. 913-930) (1994)

Technologies based on the ability of metals to release electrons are being developed as possible methods for in-situ remediation of contaminated groundwater. Laboratory tests have indicated considerable potential for removal of electroactive metals and for degradation of a wide range of halogenated aliphatic organic compounds. A laboratory column $15 \mathrm{~cm}$ in length was packed with 50 mass \% each of iron fillings and quartz sand. After passage of 150 pore volumes of a solution containing $18 \mathrm{mg} / \mathrm{L}$ chromium, the concentration in the effluent remained below detection $(0.05$ $\mathrm{mg} / \mathrm{L}$ ). Under the highly reducing conditions in the column, the hexavalent chromium was precipitated as a highly insoluble chromium hydroxide/ferric hydroxide precipitate. It is postulated that the process could be effective for removal of other electroactive chemicals. In both batch and column tests, the 
addition of elemental iron was shown to be highly effective in enhancing degradation rates of chlorinated aliphatic compounds. The process appears to be reductive dechlorination, with iron serving as the source of electrons for the reduction process. Of 14 chlorinated methanes, ethanes, and ethenes that were tested, all (with the exception of dichloromethane) showed measurable rates of degradation. Normalizing the experimental results in $1 \mathrm{~m} 2$ of iron surface per $\mathrm{ml}$ of solution gave $t$ [sub 50] values ranging from 0.013 to $20 \mathrm{hr}$. The normalized rates were 5 to 15 orders of magnitude greater than rates reported for natural abiotic degradation. Field studies are in progress to evaluate the use of metals as a fully passive in-situ method for groundwater remediation.

\section{2}

V18/023030

Using an Integrated Approach for Quantifying VOC Source Areas for Site Remediation

Kearl, P.M.; Korte, N.E.; Zutman, J.L.; Stites, M.E.

Oak Ridge National Laboratory, Grand Junction, $\mathrm{CO}$; AlliedSignal, Inc., Kansas City, MO

Waste Management 15(8):599-607 (1995)

Locating and quantifying free-phase volatile organic compounds (VOCs) in the subsurface represent two of the more difficult challenges facing hazardous waste site remediation programs. Successful remediation programs require reliable data on the size and extent of potential VOC contamination sources. Improving subsurface quantification of VOCs requires a large number of reliable low-cost samples. Satisfying this objective relies on improved sampling techniques, field analysis of samples, and a modified quality assurance program. This paper describes an integrated approach using conventional split-spoon samplers, microcore sampling, hexane extractions, and a field gas chromatograph with an autosampler as part of a technical demonstration for innovative remediation technologies. Using this approach, it was possible to delineate a subsurface source of free-phase VOCs at a cost of $\$ 15$ per sample. The distribution of dense nonaqueous phase liquid determined by this sampling approach agreed with the conceptual model for the site.

\section{3}

V18/021786

Utilization of Differential Volume Reactor Systems for Fate Analysis of Trichloroethylene in Subsurface Environments

Lackey, L.W.; Webb, O.F.; Phelps, T.J.; Bienkowski, P.R.; White, D.C.

University of Tennessee, Center for Environmental Biotechnology, Knoxville, TN; University of Tennessee, Department of Chemical Engineering, Knoxville, TN; University of Tennessee, Department of Microbiology, Knoxville, TN; Oak Ridge National Laboratory, Environmental Sciences Division, Oak Ridge, TN

Report; 35 pp. (1992)

Trichloroethylene (TCE) and other organic solvents constitute one of the major sources of groundwater contamination. The biotic and abiotic fate of these contaminants in the subsurface is of utmost importance for understanding in-situ biodegradation. In this study a
1.9L packed-bed sand-column and a differential volume soil reactor were used to simulate the subsurface environment for transport and degradation of TCE and other chlorinated and aromatic organics. The differential volume reactor (DVR) system was equipped with on-line detection devices for chlorinated organics. The differential volume reactor (DVR) system was equipped with on-line detection devices for chlorinated organics. From abiotic experiments the DVR system was characterized as to axial dispersion and aqueous/soil mass transfer using perturbation experiments while varying flow rate, pressure drop and soil characteristics. The experimentally derived dispersion and mass transfer coefficients were used to solve the convection-dispersion equation. The coefficients derived from the DVR system were used in modeling the larger $1.9 \mathrm{~L}$ packed-bed sand column.

\section{4}

V18/023317

Vadose Zone Water Infiltration Study at a Former Shell Agricultural Chemicals Distribution Center

Farmayan, W.F.; Chiang, C.Y.; McAllister, P.M.; Maner, P.M.; Caico, C.A.; Otermat, A.L.; Ward, C.J.

Shell Development Company, Houston, TX

CONF-960393 (Part 3); Contaminated Soils and Groundwater: Analysis, Fate, Environmental and Public Health Effects, and Remediation, Proceedings of the Sixth Annual West Coast Conference, Newport Beach, CA, March 11-14, 1996. Association for the Environmental Health of Soils, Amherst, MA, Part 3, 366 pp.; (11 pp.) (1996)

An overview is provided of an ongoing water infiltration field study being conducted at an agricultural chemicals retail facility located in the central coast region of Califomia. The main objectives of the study are to identify and understand the infiltration rejated field conditions leading to observed contamination patterns at the site, and to use this understanding to develop strategies for controlling infiltration of vadose zone contaminants to groundwater. Results to date have been quite encouraging and suggest that "infiltration control and monitor" is a practical alternative to excavation in many field situations.

3325

V18/023800

Very Low Frequency (VLF) Geophysics: A Case Study on Locating Bedrock Wells in Water Bearing Fracture Zones for Use in Contaminant Migration Interception Covel, C.L.; Kaymen, D.T.; Phillips, T.M.; Harrison, J.C.

New England Geoscience and Geophysics, Inc., Grantham, NH; GEI Consultants, Inc., Concord, NH; GEI Consultants, Inc., Winchester, MA; Polaroid Corporation, Waltham, MA CONF-960477; SAGEEP '96, R.S. Bell and M.H. Cramer (eds.), Proceedings of the Ninth Annual Symposium on the Application of Geophysics to Engineering and Environmental Problems, Denver, CO, April 15-May 1, 1996. Environmental and Engineering Geophysical Society, Wheat Ridge, CO, 1353 pp.; (pp. 61-80) (1996)

A Very Low Frequency (VLF) geophysical investigation was performed during June 1995 at an industrial facility in Waltham, MA. The VLF survey was used to locate groundwater monitoring wells in water bearing bedrock fracture zones at the site to 
determine contaminate migration pathways and improve ongoing remediation of the groundwater. The bedrock at the site consisted of Granodiorite and Gabbro-diorite, and brittle fracture analysis indicated bedrock was permeable and highly fractured. Historical releases of chemicals have reportedly occurred at the site. Previous investigations indicated contaminated groundwater exists in the bedrock at the site. The objective of using VLF geophysics was to increase the likelihood that water bearing fractures in the bedrock were intercepted during drilling, and that the most conductive zones were intercepted. The VLF geophysical survey consisted of six days of field work by two geophysicists, covering 5,290 meters of geophysical survey line, and nine days of data interpretation, to select the proper drill targets. Three separate VLF stations were used to collect the data. The data were collected and interpreted using the ABEM WADI [TM] instrument and SECTOR [TM] software.

3326

VI8/023766

WEFTEC '95: Proceedings of the 68th Annual Conference and Exposition of the Water Environment Federation, Vol. 8, Miami Beach, FL, October 21-25, 1995

CONF-951023 (Vol. 8); WEFTEC '95, Proceedings of the 68th Annual Conference and Exposition of the Water Environment Federation, Miami Beach, FL, October 21-25, 1995. Water Environment Federation, Alexandria, VA, Vol. 8, 498 pp. (1995)

The papers appearing in this publication comprise the Proceedings of the 68th annual conference of the Water Environment Federation. This volume contains only the abstract for each paper presented. The papers were organized into 80 sessions which covered topics such as municipal wastewater treatment, hazardous and industrial wastes, groundwater, surface water quality and ecology, residuals and biosolids, collection systems, management issues, and, a variety of research topics. Individual abstracts considered to be within the scope of the RAPIC database are indexed separately.

3327

V18/025470

Zeta Potential Control in Decontamination with Inorganic Membranes and Inorganic Adsorbents

Andalaft, E.; Vega, R.; Correa, M.; Araya, R.; Loyola, P.

Comision Chilena de Energia Nuclear, Santiago, Chile; International Atomic Energy Agency, Vienna, Austria

IAEA-TECDOC-929; Treatment Technologies for Low and Intermediate Level Waste from Nuclear Applications, Final Report of a Co-Ordinated Research Programme 1991-1996, 207 pp.; (pp. 15-32) (February 1997)

The application of some advanced separation processes such as microfiltration, ultrafiltration, electroosmosis, and electrodialysis for treating nuclear waste from different aqueous streams is under examination at the Chilean Commission for Nuclear Energy. The application of these techniques can be extended to regular industrial wastes when economically advisable. This report deals mainly with electrodialysis, electroosmosis, and adsorption with inorganic materials. Special attention is paid to zeta potential control as a driving factor for electroosmosis. For radioactive contaminants that are present in the form of cations, anions, non-ionic solutions, colloids and suspended matter, appropriate combinations of the processes may considerably increase the efficiency of processes used. As an example, colloids and suspended particles may be retained in porous ceramic membranes by nanofiltration, ultrafiltration or microfiltration depending on the particle size of the particles. The control of zeta potential by acting in the solid phase or else on the liquid phase has been studied. A mathematical model to predict electrodialysis data has been developed, and the use of a home-made inorganic adsorbent illustrated. The effect of gamma irradiation on the membranes has also been studied. Properties such as salt retention, water flux and pore size diameter determined on both organic and inorganic membranes before and after irradiation indicate deterioration of the organic membrane. 


\section{ENVIRONMENTAL MEASUREMENTS, ANALYSIS, AND DECISION-MAKING}




\section{8}

V18/022462

Slashing Costs and Chopping Schedules: Restructuring the CERCLA Process for a DOE Superfund Site

Lamarre, A.L.

Lawrence Livermore National Laboratory, Livermore, CA

CONF-950868; ER '95: Committed to Results, Proceedings of a

U.S. Department of Energy Environmental Remediation

Conference, Denver, CO, August 13-18, 1995; (5 pp.) (1995)

Regulatory document preparation for hazardous waste sites has proved to be costly and time consuming when complying with the Comprehensive Environmental Response, Compensation, and Liability Act (CERCLA) of 1980. At Lawrence Livermore National Laboratory (LLNL) in Livermore, California, we are developing a methodology that we expect will save millions of dollars and shorten the time to initiation of cleanup while meeting the intent of CERCLA to remediate contaminated sites and protect human health and the environment.

3329

V18/021189

Screening Radionuclides for Ecological Risk Assessment at the INEL

VanHom, R.L.; Hampton, N.L.; Morris, R.

Idaho National Engineering Laboratory, Idaho Falls, ID

CONF-9511137; Global Environmental Protection: Science, Politics, and Common Sense, Proceedings of the Second Society of Environmental Toxicology and Chemistry (SETAC) World Congress and 16th Annual Meeting, Vancouver, British Columbia, Canada, November 5-9, 1995. Society of Environmental Toxicology and Chemistry, Pensacola, FL, 378 pp.; (p. 178) (1995)

The Idaho National Engineering Laboratory (NEL) is a DOE facility as defined in Section 101 (9) of CERCLA, 42 U.S.C. 9601(9) and was listed by U.S. EPA on the National Priorities List on November 21, 1989. Since the establishment of the INEL site in 1949, materials (hazardous substances) have been produced, disposed of, and released at the INEL. The list of hazardous materials includes approximately 160 radionuclides. The INEL developed a method to screen these radionuclides based on the discussion presented in the International Atomic Energy Agency (IAEA) technical report entitled "Effects of Ionizing Radiation on Plants and Animais at Levels implied by Current Radiation Protection Standards" (IAEA 1992). This report reviewed the available information on the effects of ionizing radiation on natural organisms determined the radiation dose and /or dose rates above which there have been shown to be deleterious effects on populations of different types of terrestrial plants and animals. The finding presented in this technical report were the basis of the development of a methodology that was used to screen radionuclides for ecological risk assessment purposes at the INEL. This paper will include a discussion of the IAEA results including the basis for the reference values used for radionuclides and the equations (for both internal and external dose) used to determine exposure. Also, this paper will discuss in detail the use of these equations and present the results of a screening performed at a waste area group at the INEL. (Complete text)
3330

V18/025488

CERCLA-Based Decision Support System for Environmental Remediation Strategy Selection

Grelk, B.J.

U.S. Air Force Institute of Technology, Wright-Patterson Air Force Base, $\mathrm{OH}$

AFIT/GOR/97M-10; 245 pp. (March 1997)

The Idaho National Environmental Engineering Laboratory (INEEL), operating in conjunction with the Department of Energy (DOE), faces the complex decision of selecting an environmental remediation strategy for the Subsurface Disposal Area (SDA) of the Radioactive Waste Management Complex (RWMC). This research uses value-focused thinking and multiattribute preference theory techniques to produce a decision analysis model to aid the decisionmakers as they select a remediation strategy. A deterministic analysis using expert opinion and the best available engineering data demonstrates the model's capabilities. The model ranks 27 specific remediation strategies based on how well they meet CERCLA's five balancing criteria: implementability, short-term effectiveness, long-term effectiveness, reduction of toxicity, mobility, or volume through treatment, and cost. The model allows for sensitivity analysis to display the effects of changes in engineering opinion, the values of the data, and model parameters. Overall, the model provides decision tools that can help the decisionmakers at INEEL make a better informed and better documented decision when choosing a remediation strategy. Furthermore, the model can be easily manipulated and applied by decision makers at other DOE sites.

3331

V18/021258

Characterization of Aquifer Relationships by Using Geochemical Techniques for Plume Delineation

Aggarwal, P.K.; Burton, J.C.; Rose, C.M.

Argonne National Laboratory, Environmental Research Division, Argonne, IL

CONF-940499 (Vol. 2); Proceedings of the 1994 Federal Environmental Restoration III and Waste Minimization II Conference and Exhibition, New Orleans, LA, April 27-29, 1994. Hazardous Materials Control Resources Institute, Rockville, MD, Vol. 2, 858 pp.; (pp. 1311-1316) (1994)

Conventional approaches to characterize aquifers at hazardous waste sites rely heavily on the installation of monitoring wells, hydraulic testing, and sampling and analysis of groundwater for contaminant concentrations. The use of geochemical techniques to determine relationships among aquifers in environmental investigations is limited, in part, because of a generally held view that these techniques may not be useful for shallow aquifers. In this paper, to identify multiple aquifers, to establish the lateral extent of aquitards, and to determine hydraulic interconnections among aquifers at two hazardous waste sites, we discuss the use of: (1) Major ion compositions; (2) Stable isotope ratios of oxygen, hydrogen, and carbon; and (3) The abundance of tritium. Our experience with these and ongoing investigations at several other sites demonstrates that carefully conducted geochemical sampling and analysis of limited samples of groundwater provide an effective tool for hydrogeologic characterization in a variety of geologic 
settings.

3332

V18/021518

Bases for Secondary Standards for Residual Radionuclides in Soil and Some Recommendations for Cost-Effective Operational Implementation

Anspaugh, L.R.; Daniels, J.I.

Lawrence Livermore National Laboratory, Livermore, CA Health Physics 70(5):722-731 (May 1996)

The future use of land contaminated with radionuclides depends upon scientifically defensible bases for setting limits for radionuclides in soil. The purpose of this work is to develop such bases for establishing "posting criteria" to protect nonradiological workers at the Nevada Test Site and to provide a rationale for cost-effective measurements to readily determine the boundary conditions. The analysis begins with a mandated limit on total effective dose equivalent ( $1 \mathrm{mSv}$ per year) via all pathways. The possible pathways of exposure are external gamma exposure, inhalation of resuspended material, and incidental soil ingestion. These pathways are evaluated for each radionuclide of interest on the Nevada Test Site, and the results are used to define for each radionuclide the deposition-density limits for each pathway of exposure. The minimum deposition-density limits are noted to occur via the external gamma-exposure pathway for most radionuclides; exceptions are incidental soil ingestion for Sr-90/Y-90 and inhalation for Pu-238, Pu-239, 240, and Am-241. The limiting values of deposition density or average concentration in soil are then determined appropriately by combining all pathways. Procedures are developed for dealing with mixtures of many radionuclides and to apply the principles developed so that even a simple measurement of extemal garnma-exposure rate may be used to define the boundary conditions in the field, provided that the relative abundance of the radionuclide mixture is known and that the defining level of exposure rate is sufficiently above background.

3333

V18/021555

Field Tests of Passive Alpha Detectors at the Nevada Test Site for Screening of Radiologically Contaminated Soils

Meyer, K.E.; Gammage, R.B.; Dudney, C.S.

Oak Ridge National Laboratory, Health Sciences Research Division, Oak Ridge, TN

CONF-950209 (Vol. 2); VIP-47, Proceedings of the Fourth International Symposium on Field Screening Methods for Hazardous Wastes and Toxic Chemicals, Las Vegas, NV, February 22-24, 1995. Air and Waste Management Association, Pittsburgh, PA, Vol. 2, 701 pp.; (pp. 1182-1189) (1995)

Two types of passive alpha detectors developed for indoor radon measurements have been field tested for applications to screening of alpha-emitting contaminants (e.g., $\mathrm{Pu}, \mathrm{Am}, \mathrm{U}, \mathrm{Th}$ ) in soils. Electric Ionization Chambers (EICs) measure air ionization due to alpha emission from the soil surface, while Alpha Track Detectors (ATDs) register alpha particles as microscopic damage pits. The detectors are inexpensive, rugged, simple to use, and respond reproducibly and linearly over three orders of magnitude of contamination levels. It was found that aipha emission rates per unit of soil activity varied widely with soil composition. Procedures were developed for establishing site-specific calibrations for each type of detector. Both types of detectors were deployed directly on the surface of soils contaminated with Pu-239 and Am-241 at the Nevada Test Site. Deployment times of 5 minutes to 5 days were necessary in order to reliably detect contamination levels of 100 $\mathrm{nCi} / \mathrm{g}(\mathrm{Pu}+\mathrm{Am})$ down to background (approximately $22 \mathrm{pCi} / \mathrm{g}$ total alpha). The advantages of the EIC detectors were found to be their immediate on-site readout capability, while the primary advantages of the ATD detectors were their insensitivity to beta/gamma radiations and radon and their ability to identify hot particles. Techniques were developed to discriminate against environmental radon and background alpha/beta/gamma radiations. ATDs in the form of long narrow strips, deployed in stake-driven holes, were used to obtain contamination depth profiles quickly and reproducibly.

3334

V18/024029

\section{Site Prioritization Using Preliminary Risk Assessment} Techniques

Knowlton, B.

Sandia National Laboratories, Albuquerque, NM

TIE Quarterly 5(2):3 (Fall 1996/Winter 1997)

Sandia National Laboratories/New Mexico has completed preliminary risk assessments for nearly all the sites within its Environmental Restoration (ER) Project to support the prioritization of the ER sites. The primary purpose of these risk assessments was to provide a quantitative basis for ranking the potential for adverse human health effects on the basis of the available data at each site. Secondary goals of this risk evaluation project were: (1) to provide input on the logical course of action for each site (e.g., No Further Action [NFA], continued characterization to reduce uncertainties, or voluntary corrective measures with risk-based target cleanup goals); (2) preliminary evaluation to determine if a site would require a risk assessment to defend closure options and how rigorous that risk evaluation should be (e.g., compliance with conservative action levels versus a reasonable maximum exposure risk evaluation or a probabilistic analysis that quantifies uncertainty); and (3) prioritization of characterization needs (e.g., concentrate data collection activities to reduce uncertainties on the distribution of a given contaminant or to focus on hydrologic characterization data if a groundwater exposure pathway was possible).

3335

V18/021197

Successful Effort to Involve Stakeholders in the Selection of a Site for a Corrective Action Management Unit

Conway, R.; Merkhofer, M.W.; Oms, E.

Sandia National Laboratories, Albuquerque, NM; Applied Decision Analysis, Inc., Menlo Park, CA; U.S. Department of Energy, Kirtland Area Office, Albuquerque, NM

SAND95-2639C; CONF-960804 (Vol. 2); Spectrum '96: Nuclear and Hazardous Waste Management Proceedings of an International Topical Meeting, Seattle, WA, August 18-23, 1996. American Nuclear Society, La Grange Park, IL, Vol. 2, 873 pp.; (pp. 
1695-1699) (1995)

As part of the effort to clean up hazardous waste sites, Sandia National Laboratories in New Mexico (SNL/NM) adopted a novel approach to involving stakeholders in a key decision associated with its Environmental Restoration (ER) Project. The decision was where to locate a Corrective Action Management Unit (CAMU), an area designed to consolidate, store, and treat wastes generated from cleanup activities. The decision-making approach was a variation of a technique known as multiattribute utility analysis (MUA). Although MUA has rarely been undertaken during normal Project activities, it proved to be a surprisingly effective means for involving stakeholders in the decision process, generating consensus over a selected site, and enhancing public trust and understanding of Project activities. Requirements and criteria for selecting CAMU sites are provided by the U.S. Environmental Protection Agency's (EPA's) CAMU Final Rule (EPA 1993). Recognizing the lack of experience with the Rule and the importance of community understanding and support, the ER Project sought an approach that would allow stakeholders to participate in the site-selection process.

3336 V18/022992

Documenting Use of "Acceptable Knowledge" for Environmental Restoration Waste Characterization

Krueger, J.W.; Glenn, R.; Winch, M.J.

Los Alamos National Laboratory, Los Alamos, NM

CONF-951006; Proceedings of an American Nuclear Society (ANS) Winter Meeting, San Francisco, CA, October 29-November 1, 1995. ANS, La Grange Park, IL, 522 pp.; Transactions of the American Nuclear Society 73:103-104 (1995)

During 1994, the first year that the Los Alamos National Laboratory (LANL) environmental restoration (ER) project began generating significant quantities of waste, a team was established from the LANL ER, waste management, and regulatory compliance organizations to work on issues concerning relative responsibilities of these programs. The two primary goals were (a) to establish clear paths of communication between the organizations and (b) to develop sampling and characterization strategies for waste that would optimize the use of analytical data and other site information for both site characterization and waste characterization purposes. This paper describes in some detail the development and implementation of a new policy and system of documentation for the use of acceptable knowledge for waste characterization.

\section{7}

\section{V18/020907}

Emissions of Contaminated Fugitive Dust Under Extreme (Non-Tornado) Wind Conditions

Pehrson, J.R.; Chiou, J.D.

Fluor Daniel, Inc., Irvine, CA; Brown and Root

Environmental, Pittsburgh, PA

CONF-960443; Best of D\&D - Creative, Comprehensive and Cost Effective, Proceedings of an American Nuclear Society Topical Meeting on Decontamination and Decommissioning, Chicago, IL, April 14-17, 1996. American Nuclear Society, La Grange, IL, 314 pp.; (pp. 147-154) (1996)

A review was conducted of existing fugitive dust emission models to identify those with several input parameters that could be adjusted for site-specific conditions. The dependence of the reviewed emission models on soil particle size; moisture content; sand, silt and clay content; resistance to abrasion; threshold friction velocity; size of the eroding area; ambient relative humidity; and wind speed were considered. The model with the most parameters that could be adjusted to site-specific conditions was selected to calculate daily fugitive dust emissions under extreme wind conditions. Fugitive dust emissions were calculated from the open portion of the on-site disposal cell during construction, using the selected wind erosion model. The dust was assumed to contain low levels of radionuclides and a dispersion model was used to determine the maximum daily exposure of a receptor to the contaminated, airborne dust. Remedial activities at the Femald Environmental Management Project (FEMP) site may result in the release of pollutants to the air. Therefore, quantification of these potential releases need to be completed. This paper presents the methodology and modeling used to determine site-specific resuspension and dispersion of contaminated soil/material from open area sources. In this particular study, the source was considered to be the working portion of the on-site disposal cell.

\section{8}

V18/021746

\section{Geostatistics and Cost-Effective Environmental Remediation}

Rautman, C.A.

Sandia National Laboratories, Albuquerque, NM

SAND94-3100C; CONF-9609131; Proceedings of the 5th International Geostatistics Congress, Wollongong, Australia, September 22-27, 1996; (10 pp.) (April 12, 1996)

Numerous sites within the U.S. Department of Energy (DOE) complex have been contaminated with various radioactive and hazardous materials by defense-related activities during the post-World War Il era. The perception is that characterization and remediation of these contaminated sites will be too costly using currently available technology. Consequently, the DOE Office of Technology Development has funded development of a number of alternative processes for characterizing and remediating these sites. The former Feed Materials Processing Center near Fernald, Ohio (USA), was selected for demonstrating several innovative technologies. Contamination at the Fernald site consists principally of particulate uranium and derivative compounds in surficial soil. A field characterization demonstration program was conducted during the summer of 1994 specifically to demonstrate the relative economic performance of seven proposed advanced-characterization tools for measuring uranium activity of in-situ soils. These innovative measurement technologies are principally radiation detectors of varied designs. A risk-based economic decision model has been used to evaluate the performance of alternative characterization tools. The decision model computes the dollar value of an objective function for each of the different characterization approaches. The methodology not only can assist site operators to choose among engineering altematives for site characterization and/or remediation, but also can provide an objective and quantitative base for decisions with respect to the completeness of site characterization.

3339 V18/022920

Integrating Citizen Advisory Boards in Public 


\section{Participation: Lessons from the Field}

Snyder, S.

Bechtel Corporation, Berkeley, CA

CONF-951006; Proceedings of an American Nuclear Society (ANS)

Winter Meeting, San Francisco, CA, October 29-November 1, 1995. ANS, La Grange Park, IL, 522 pp.; Transactions of the American Nuclear Society 73:46-47 (1995)

Citizen advisory boards have been used successfully, particularly by the chemical industry, as programs for public participation. Now the U.S. Department of Energy (DOE) has responded to a growing demand for more direct citizen involvement in environmental restoration decision making. The experience of the site-specific advisory board at the department's Fernald Environmental Management Project near Cincinnati provides lessons that contribute to the development of a model for the most efficient use of citizen advisory boards.

\section{$3340 \quad \mathrm{~V} 18 / 021560$}

Use of Passive Alpha Detectors to Screen for Uranium Contamination in a Field at Fernald, Ohio

Dudney, C.S.; Meyer, K.E.; Gammage, R.B.; Wheeler, R.V.; Salaskey, M.; Kotrappa, P.

Oak Ridge National Laboratory, Oak Ridge, TN; Landauer, Inc., Glenwood, IL; Rad Elec, Inc., Frederick, MD

CONF-950209 (Vol. 2); VIP-47, Proceedings of the Fourth International Symposium on Field Screening Methods for Hazardous Wastes and Toxic Chemicals, Las Vegas, NV, February 22-24, 1995. Air and Waste Management Association, Pittsburgh, PA, Vol. 2, 701 pp.; (pp. 1190-1196) (1995)

This paper reports the results from a field test of newly developed techniques for inexpensive, in situ screening of soil for alpha contamination. Passive alpha detectors that are commercially available for the detection indoor airbome alpha activity (i.e., Rn-222) have been modified so they can be applied to the detection of alpha contamination on surfaces or in soils. Results reported here are from an intercomparison involving several different techniques during the summer of 1994. All measurements were made in a field near the formerly used uranium processing facility at Fernald, Ohio. The results for two types of passive alpha detectors show that the quality of calibration is improved if soils samples are milled to increase homogeneity within the soil matrices. The field evaluation of passive alpha detectors revealed that using short-exposure, screening protocols resulted in a lower limit of detection comparable to the mean uranium concentration occurring at the site, causing much scatter in the data. The bias seen in the screening results probably results from moisture and other artifacts adversely affecting the measurements. The total cost per measurement for either type of passive alpha detector is probably less than $\$ 25$ and should provide a cost-effective means for site managers to develop the information needed to find areas with remaining alpha contamination so resources can be allocated efficiently.

Evaluation of Contaminated Groundwater Cleanup Objectives

Arquiett, C.; Gerke, M.; Datskou, I.C.
Oak Ridge National Laboratory, Center for Risk

Management, Oak Ridge, TN

CONF-951 147; Proceedings of an International Clean Water Conference, La Jolla, CA, November 28-30, 1995; Water, Air and Soil Pollution 90(1/2):83-92 (July 1996)

The US Department of Energy's (DOE's) Environmental

Restoration Program will be responsible for remediating the approximately 230 contaminated groundwater sites across the DOE Complex. A major concern for remediation is choosing the appropriate cleanup objective. The cleanup objective chosen will influence the risk to the nearby public during and after remediation; risk to remedial and non-involved workers during remediation; and the cost of remediation. This paper discusses the trends shown in analyses currently being performed at Oak Ridge National Laboratory's (ORNL) Center for Risk Management (CRM). To evaluate these trends, CRM is developing a database of contaminated sites. This paper examines several contaminated groundwater sites selected for assessment from CRM's data base. The sites in this sample represent potential types of contaminated groundwater sites commonly found at an installation within DOE. The baseline risk from these sites to various receptors is presented. Residual risk and risk during remediation is reported for different cleanup objectives. The cost associated with remediating to each of these objectives is also estimated for each of the representative sites. Finally, the general trends of impacts as a function of cleanup objective will be summarized. The sites examined include the Savannah River site, where there was substantial ground pollution from radionuclides, oil, coal stockpiles, and other forms of groundwater contamination. The effects of various types of groundwater contamination on various types of future user is described.

3342

$\mathrm{V} 18 / 021320$

Environmental Data Management Implementation Handbook for the Environmental Restoration Program [Rev. 1]

Hook, L.A.; Brandt, C.C.; Ball, T.S.; Fischer, K.N.; James, T.L.

Lockheed Martin Energy Systems, Inc., Oak Ridge, TN ES/ER/TM-88/R1; 65 pp. (April 1996)

The purpose of this handbook is to assist environmental restoration (ER) projects in the preparation of a data management implementation plan (DMIP). The DMIP identifies and documents and ER project's requirements and responsibilities for the management, quality assurance, use, and archival of its environmental data. It is important that a project complete its DMIP in the early planning phase to ensure that the necessary and appropriate data management systems and personnel are in place before the project begins acquiring data. All ER projects that collect or use environmental data at the Oak Ridge National Laboratory, the Oak Ridge Y-12 Plant, the Oak Ridge K-25 Site, the Paducah Gaseous Diffusion Plant, the Portsmouth Gaseous Diffusion Plant, and surrounding onsite and offsite areas must prepare a DMIP. Project types that often collect environmental data include surveillance and maintenance, decontamination and decommissioning, remedial design/remedial action, and remedial investigation/feasibility studies. Even if a project does little 
environmental data management, a DMIP is required to document this fact.

Re-Engineering the Environmental Restoration Records Management and Document Control Program: A Case Study

Lawson, R.A.; Glenn, A.M.

Lockheed Martin Energy Systems, Inc., Oak Ridge, TN

CONF-960466; Inforum '96: Partnerships in Information, Knowledge - The Competitive Edge, Proceedings of the 1996 Technical Information Meeting, Oak Ridge, TN, April 24-25, 1996. U.S. Department of Energy, Office of Scientific and Technical Information, Oak Ridge, TN; (9 pp.) (1996)

The Lockheed Martin Energy Systems, Inc. Environmental Restoration (ER) Program investigates the release of hazardous substances to the environment associated with past waste management and operational activities at three major U.S. Department of Energy Oak Ridge Operations (DOE-OR) (Oak Ridge National Laboratory, Oak Ridge Y-12 Plant, and Oak Ridge K-25 Site). In April of 1993, DOE chartered ER Information Resource Management (IRM) to consolidate all DOE-OR ER records activities and effectively and efficiently manage the records associated with ER operations. The development and implementation of a single records and information system supporting all DOE-ORO ER records activities was a challenging task due to the multi-faceted aspects of ER operations, as well as a lack of clear record guidance. Although the ER Records Program had been in existence for five years prior to April 1993, the requirements for a consolidated records management program had not been clearly defined nor understood. As a result, ER record activities were not consolidated or consistent. In response to this challenge, the ER and Information Management Services (IMS) organizations combined efforts to generate a strategy for developing, implementing and managing a model ER Program records management and document control system. Goals were identified and prioritized. These included issuance of the Environmental Restoration Information Resource Management Program Plan, development of a work flow process, acquisition of necessary space, development or revision of procedures, and training on those procedures. Resources necessary to accomplish these goals were then identified. The completion of these future improvements will ensure the capture and maintenance of $E R$ records and will provide the platform for a comprehensive electronic information management system.

\section{4}

V18/022961

Technical Specification for Transferring Biota Data to the Oak Ridge Environmental Information System (OREIS)

Lockheed Martin Energy Systems, Inc., Oak Ridge, TN ES/ER/TM-195; 85 pp. (March 1997)

In June 1995, a team was formed to develop, document, and implement technical specifications for transmitting biological measurements data and $\mathrm{QC}$ (Quality Control) data to the Oak Ridge Environmental Information System (OREIS). This document describes the requirements, responsibilities, criteria, and format for transmitting biological measurements data and QC data to OREIS.

3345

V18/020991

Toxicological Benchmarks for Screening Potential Contaminants of Concern for Effects on Aquatic Biota: 1996 Revision [Rev. 2]

Suter, G.W., II; Tsao, C.L.

Lockheed Martin Energy Systems, Inc., Health Sciences

Research Division, Oak Ridge, TN

ES/ER/TM-96/R2; 145 pp. (June 1996)

The purpose of this report is to present and analyze alternate toxicological benchmarks for screening chemicals for aquatic ecological effects. The alternative benchmarks are based on different conceptual approaches to estimating concentrations causing significant effects. For the upper screening benchmark, there are the acute National Ambient Water Quality Criteria (NAWQC) and the Secondary Acute Values (SAV). The SAV concentrations are values estimated with $80 \%$ confidence not to exceed the unknown acute NAWQC for those chemicals with no NAWQC. The alternative chronic benchmarks are the chronic NAWQC, the Secondary Chronic Value (SCV), the lowest chronic values for fish and daphnids, the lowest EC20 for fish and daphnids from chronic toxicity tests, the estimated EC20 for a sensitive species, and the concentration estimated to cause a $20 \%$ reduction in the recruit abundance of largemouth bass. It is recommended that ambient chemical concentrations be compared to all of these benchmarks. To the extent that toxicity data are available, this report presents the altemative benchmarks for chemicals that have been detected $o$ the Oak ridge Reservation. It also presents the data used to calculate the benchmarks and the sources of the data. It compares the benchmarks and discusses their relative conservatism and utility. Publication of this document meets a milestone for the Environmental Restoration (ER) Risk Assessment Program. This report supercedes a prior aquatic benchmarks report. Since the prior edition of this report, both the U.S. Environmental Protection Agency Office of Solid Waste and Emergency Response and EPA Region IV have developed sets of screening benchmarks for water. This report includes those values and updates the other benchmarks that were presented in the last edition.

3346

V18/021193

Decision Tool for Selecting Trench Cap Designs

Paige, G.B.; Stone, J.J.; Hakonson, T.E.; Lane, L.J.

U.S. Department of Agriculture, Agriculture Research Service, Tucson, AZ; Colorado State University, Center for Ecological Risk Assessment and Management, Fort Collins, $\mathrm{CO}$

CONF-951209; Proceedings of the 17th Annual U.S. Department of Energy Low-Level Radioactive Waste Management Conference, D. Lake (ed.), Phoenix, AZ, December 12-14, 1995, 480 pp.; (13 pp.) (1995)

A computer based prototype decision support system (PDSS) is being developed to assist the risk manager in selecting an appropriate trench cap design for waste disposal sites. The selection of the "best" design among feasible altematives requires consideration of multiple and often conflicting objectives. The 
methodology used in the selection process consists of: selecting and parameterizing decision variables using data, simulation models, or expert opinion; selecting feasible trench cap design altematives; ordering the decision variables and ranking the design alternatives. The decision model is based on multi-objective decision theory and uses a unique approach to order the decision variables and rank the design altematives. Trench cap designs are evaluated based on federal regulations, hydrologic performance, cover stability and cost. Four trench cap designs, which were monitored for a four year period at Hill Air Force Base in Utah, are used to demonstrate the application of the PDSS and evaluate the results of the decision model. The results of the PDSS, using both data and simulations, illustrate the relative advantages of each of the cap designs and which cap is the "best" alternative for a given set of criteria and a particular importance order of those decision criteria.

\section{7}

V18/021769

RAMS (Risk Analysis - Modular System) Methodology

Stenner, R.D.; Strenge, D.L.; Buck, J.W.; Smith, D.E.; White, M.K.; Bagaasen, L.M.; Gelston, G.M.; Harper, B.L.; Hoopes, B.L.; Middleton, K.R.; Farris, W.T.

Pacific Northwest National Laboratory, Richland, WA

PNNL-1 1330; 99 pp. (October 1996)

The Risk Analysis - Modular System (RAMS) was developed to serve as a broad scope risk analysis tool for the Risk Assessment of the Hanford Mission (RAHM) studies. The RAHM element provides risk analysis support for Hanford Strategic Analysis and Mission Planning activities. The RAHM also provides risk analysis support for the Hanford 10-year Plan development activities. The RAMS tool draws from a collection of specifically designed databases and modular risk analysis methodologies and models.

\section{8}

\section{V18/022936}

SCOPE - Safety-Controls Optimization by Performance Evaluation: A Systematic Approach for Safety-Related Decisions at the Hanford Tank Waste Remediation System - Phase 1: Final Report

Bergeron, K.D.; Williams, D.C.; Slezak, S.E.; Young, M.L.; Leach, C.E.; Plys, M.G.; Malinovic, B.; Grigsby, J.M.

Sandia National Laboratories, Albuquerque, NM; Westinghouse Hanford Company, Richland, WA; Fauske and Associates, Inc., Burr Ridge, IL; G\&P Consulting, Inc., Richland, WA

\section{SAND96-2927; 150 pp. (December 1996)}

The Department of Energy's Hanford Tank Waste Remediation system poses a significant challenge for hazard management because of the uncertainty that surrounds many of the variables that must be considered in decisions on safety and control strategies. As a result, site managers must often operate under excessively conservative and expensive assumptions. This report describes a systematic approach to quantifying the uncertainties surrounding the critical parameters in control decision (e.g., condition of the tanks, kinds of wastes, types of possible accidents) through the use of expert elicitation methods. The results of the elicitations would then be used to build a decision support system and accident analysis model that would allow managers to see how different control strategies would affect the cost and safety of a facility configuration.

3349

V18/020870

"Should Cost" Estimating: A New Philosophy

Williamson, R.D.

CONF-941246; Proceedings of the Second Annual EM Cost Management Conference, San Francisco, CA, December 5-9, 1994; (6 pp.) (1994)

EG\&G Rocky Flats (EG\&G/RF), the Maintenance and Operating (M\&O) contractor at the Department of Energy (DOE) Rocky Flats Environmental Technology Site (RFETS), has advanced the philosophy of cost estimating. This innovative new philosophy is called "Should Cost" Estimating and will help achieve the DOE goal of reducing project costs to a level that is comparable with industry.

3350

V18/024044

\section{3-D Digital Imaging}

Nichols, R.L.; Looney, B.B.; Huddleston, J.E.

Westinghouse Savannah River Company, Aiken, SC

Environmental Science \& Technology 26(4):642-649 (1992)

Before sites contaminated below ground can be cleaned up, the location, depth, and concentration of the pollutant mass must be characterized. The interpretation of data collected during characterization activities at such sites requires the synthesis of diverse and sometimes voluminous data sets. The information collected typically includes chemical, geologic, and hydrologic measurements at scattered positions. After collection, the fundamentally interrelated data often are processed and presented with minimal coordination. As a result, understanding and communicating information about the site can be difficult. Three-dimensional digital imaging (TDDI), however, makes it possible to obtain and handle these disparate data in a coordinated, systematic fashion. The process of 3-D digital imaging is demonstrated by an example that uses data from the Savannah River Site in South Carolina.

\section{$3351 \quad$ V18/023188}

3D Geographic Information Systems in Waste Site Assessment and Management

Janssen, L.A.

Radian Corporation, Oak Ridge, TN

CONF-9210194; Proceedings of an International Symposium on Environmental Contamination in Central and Eastern Europe, Budapest, Hungary, October 12-16, 1992, 968 pp.; (p. 272) (1992)

A common mistake in waste site investigation is going to the field with no tools to manage and record information. With no background information to assess the current magnitude of problems, where do you start? 3D Geographic Information Systems (GIS) combined with management planning software is the answer to efficient display of potential waste site problems with a uniform approach to an economic resolution. To date, information has been assembled on waste sites in canned packages with little value or interface ability to the big picture which is remediation of the site or no action. Three dimensional looks at the site and the extent of its impact at present or in the future is the management tool that 
affords the most accuracy and the most efficient technical direction.

\section{2}

\section{V18/023182}

Advanced X-Ray Fluorescence Analysis for Hazardous Site Screening and Remediation

Leland, D.; Little, S.

Spectrace Instruments, Mountain View, CA; TN Technologies, Round Rock, TX

CONF-9210194; Proceedings of an International Symposium on Environmental Contamination in Central and Eastern Europe, Budapest, Hungary, October 12-16, 1992, 968 pp.; (pp. 233-236) (1992)

The process of screening and remediating a hazardous site requires the analysis of hundreds of soil samples. If these analyses can be performed rapidly on-site, the screening and remediation operations can be adjusted while they are in progress. When the distribution of contamination is not uniform, such flexibility can result in significant savings compared to the costs of pursuing a predetermined program. X-ray fluorescence (XRF) has suffered in past years from a variety of shortcomings including relatively delicate and bulky apparatus and rather severe analytical interferences from common soil forming elements. A number of recent advances in XRF technology have removed these difficulties. Two new instruments complement each other: a truly portable unit utilizing radioisotopes for excitation and a high resolution, non-cryogenic Hgl2 X-ray detector; and a rugged, compact lab system with direct $\mathrm{X}$-ray tube excitation and a Peltier-cooled $\mathrm{Si}(\mathrm{Li})$ $\mathrm{X}$-ray detector. The portable unit provides excellent screening capabilities and the lab system, which may also be carried in a mobile laboratory, provides the ultimate performance for checking low levels of contaminants. Both instruments feature fundamental parameters; a calibration technology based upon theoretical considerations. This powerful capability provides satisfactory accuracy on completely unknown samples, eliminating the burden of obtaining site-specific standards. Screening and remediation strategies that take full advantage of this capability are discussed. The analytical performance of both instruments is also discussed.

3353 V18/022825

Air Sparging Decision Tool: A Practical Guide for Determining Applicability and Refining Conceptual Designs

Beabes, L.A.; Karkalik, E.J.; Schaad, D.E.; Volpi, R.W.; A.T.

Parsons Engineering Science, Inc., Cleveland, OH; Westem Environmental Technology Office, Butte, MT

CONF-960804 (Vol. 3); Spectrum '96: Nuclear and Hazardous Waste Management, Proceedings of an International Topical Meeting, Seattle, WA, August 18-23, 1996. American Nuclear Society, La Grange Park, IL, Vol. 3, 841 pp.; (pp. 1886-1893) (1996)

This document provides an overview of the Air Sparging Decision Tool (Tool) which has been developed for determining the applicability of and for refining air sparging system designs and operations. The Tool was developed by a multi-disciplinary team of internationally recognized experts in air sparging technology, led by a group of project and task managers at Parsons Engineering Science, Inc. (Parsons ES) and MSE, Inc. (MSE). The objectives of the Tool are to provide guidance to field-based users and environmental managers for evaluating the applicability of air sparging technology to a wide range of sites. The Tool is not intended to model site-specific hydrogeologic conditions or to provide detailed design of air sparging systems. The Tool quickly and cost-effectively assists the user in screening for applicability of the technology at a proposed site through application of progressively detailed dialogs. This is accomplished in three (3) distinct steps or tiers. The three tiers are the Scenario Approach, Conceptual Design Approach, and Pilot Scale Testing Approach. To assist the user in applying the Tool, the following are provided: (1) a complete, cross-referenced decision tree; (2) site conceptual models; (3) a comprehensive tutorial; (4) a detailed User's Manual; (5) Help screens; (6) several on-line reference documents; and (7) a complete bibliography.

\section{4}

V18/025441

Analyzing Remediation Technologies for Department of Energy Sites Contaminated with DNAPL Pollutants

Papatyi, A.F.

U.S. Air Force Institute of Technology, Wright-Patterson Air Force Base, $\mathrm{OH}$

AFIT/GOR/ENS/97M-17; $150 \mathrm{pp.} \mathrm{(March} \mathrm{1997)}$

The Department of Energy (DOE) is in the process of conducting a Remedial Investigation/Feasibility Study for a site contaminated with Dense Non-Aqueous Phase Liquid (DNAPL) pollutants at their Paducah, Kentucky facility. This thesis focuses on acquinng insight into a number of remediation technology trains that are candidates for the Paducah site. This insight is used to recommend and justify. the screening of candidate technology trains. The research males use of two decision analysis models (one is deterministic, the other is probabilistic) built to provide a quantitative assessment of the candidate technology trains. Dominance considerations and multi-attribute utility theory are utilized to make the quantitative assessments and to gain insight into each candidate technology train. The results of the analysis provide the DOE with a rational justification for screening 55 of the 58 candidate technology trains from further consideration.

\section{5}

V18/022357

Annual Report of Operations for the Oak Ridge Environmental Information System (OREIS) [Rev. 2]

Lockheed Martin Energy Systems, Inc., Environmental Restoration Division, Oak Ridge, TN

ES/ER/TM-108/R2; 30 pp. (November 1996)

The Annual Report of Operations for the Oak Ridge Environmental Information System (OREIS) reports quantitative and textual summaries of OREIS activities for FY 1996. The report provides annual highlights and summaries of user services, systems support, data base contents, configuration management, and $Q A$ activities. $A$ list of current OREIS documents and procedures and a copy of the OREIS data model as of September 1996 also are provided. 
3356

V18/022558

Application of Probability Distribution Functions in the ASTM RBCA Framework for Use in California

Dooher, B.P.; Rice, D.W.; Kastenberg, W.E.; Graves, K.

University of California, Los Angeles, CA; Lawrence

Livermore National Laboratory, Livermore, CA; University of California, Berkeley, CA; Regional Water Quality Control Board, Oakland, CA.

CONF-960393 (Part 1); Contaminated Soils and Groundwater: Analysis, Fate, Environmental and Public Health Effects, and Remediation, Proceedings of the Sixth Annual West Coast Conference, Newport Beach, CA, March 11-14, 1996. Association for the Environmental Health of Soils, Amherst, MA, Part 1, 257 pp.; (p. 26) (1996)

Currently, Environmental Protection Agency and other conventional methodologies of risk assessment, such as the American Society for Testing and Materials risk-based corrective action (ASTM/RBCA) format, make use of deterministic, or point numbers in making estimates of risk. The goal of risk assessment is to provide a systematic tool to evaluate hazards and exposures to assist in the management of society's activities. To properly do this, there must be an attempt by the regulator or the responsible party to use information as effectively as possible. The use of historical data and probability distribution functions is a suggested initial approach to dealing with leaking underground fuel tanks (LUFT) sites in California, taking into account geophysical, societal, and health based parameters particular to the State. These parameters may be based on results of the California leaking underground storage tank Historical Case Analysis (CailUFT HCA), from California Census information, or from other sources, where appropriate. Because of the limitations involved with the use of point sources in the ASTM/RBCA format, probability distribution functions can be used to give regulatory personnel and risk managers more understanding of the actual range of risks involved. Such information will allow the risk manager a higher comfort level in dealing with risks, and will, by detailing the residual risks involved, allow for the potential consequences of decisions to be better known. The above methodology effectively allows the risk manager to choose a level of health risk appropriate for the site, allows for a general prioritizing in regards to other sites, and removes some of the restrictions in applying remedial action necessitated by maximum contaminant levels (MCLs) or deterministic risk estimates.

\section{$3357 \quad$ V18/020977}

Application of Risk-Based Corrective Action Techniques for Environmental Restoration Projects at Department of Energy (DOE) Remediation Sites

Kuykendall, T.A.

Parsons Engineering Science, Inc., Denver, $C O$

CONF-960212; Waste Management '96: Working Towards a Cleaner Environment, Proceedings of a Conference on HLW, LLW, Mixed Wastes and Environmental Restoration, Tucson, AZ, February 25-29, 1996; (11 pp.) (1996)

The nuclear technology community has struggled for years with the concept of "how clean is clean?", and how to approach the

decontamination, decommissioning, cleanup, and release to the public of radiologically contaminated facilities and lands formerly used to support the national defense mission. Astronomical cost estimates for remediation efforts have refocused the evaluation of these programs to consider the issue of "how clean is clean enough?" Compliance to established performance-based environmental standards presents an undue burden on the national cleanup budget, since it is not practical or necessary that properties be restored to the same standard (dependent upon projected future use). An alternative to compliance with predetermined regulatory standards is the implementation and utilization of a site-specific risk-based corrective action (RBCA) process. The concept of utilization of a risk-based approach to establishment of remediation goals has been developed primarily for RCRA sites contaminated with petrochemical contamination (e.g., ASTM Emergency Standard ES 38-94). Parsons has been instrumental in assisting a number of DOE sites in developing a basis for utilization of an analogous approach for cleanup of radiological contamination. In the event of soils and groundwater cleanup, this approach can result in progressive remediation efforts that maintain realistic health and environmental protection goals. This process can be a functional element of DOE programs involving a streamlined approach for environmental restoration (SAFER). Risk-based decision making is used to help determine the appropriate type and level of corrective action. Based on the principles of protection of human health and the environment commensurate with actual risks (rather than strict compliance with assigned performance-based goals), and expedites corrective action in a cost-effective manner. The basis for the Parsons approach to RBCA programs integrates the framework established by ASTM, including the provisional standards for cleanup developed by the Voluntary Cleanup Task Group.

\section{$3358 \quad$ V18/021517}

Application of the Maximum Entropy Method for Assessments of Residual Radioactivity at Contaminated Sites

Reginatto, M.; Shebeil, P.; Miller, K.M. CONF-9510773; IEEE Nuclear Science Symposium and Medical Imaging Conference, San Francisco, October 23-28, 1995; IEEE Transactions on Nuciear Science 43(3-Pt2):1837-1868 (June 1996)

An important requirement in surveying for residual radioactivity is the detection of localized areas of elevated contamination, sometimes referred to as hot spots. In the present work the authors have developed a computer code that searches for distributions of surface activity (possibly many) that are consistent with a series of in situ measurements on a grid indicating the possible presence of hot spots. The algorithm makes use of a maximum entropy deconvolution of the data, followed by further analysis. The algorithm is quite general and could be modified for use in other types of measurements. Properties of the algorithm are demonstrated using data from actual field measurements.

\section{V18/021388}

Applying Systems Engineering to Environmental Management

Wilcynski, J.M.

U.S. Department of Energy, Idaho Operations Office, Idaho 


\section{Falls, ID}

Fostering the Needed Partnerships: Doing the Necessary Science to Support Technology Development; Commercialization, Deployment, E.L. Helminski (ed.), Proceedings of the Seventh Annual Western Governors' Association/Weapons Complex Monitor Applied Research and Cleanup Technology Colloquium, Phoenix, AZ, April 29-May 2, 1996. Exchange/Monitor Publications and Forums, Lake Bluff, IL, 500 pp.; (10 pp.) (April 1996)

The viewgraphs from this presentation highlight a systems engineering approach to environmental management. Included are the OST Process/Product Model, OST Management Structure, EM Integration through System Engineering, Mixed Waste Systems Engineering Process, and the INEL Plan with Private Sector Characterization and Treatment.

\section{$3360 \quad$ V18/024152}

Assessment of Sensors for Oil Spill Applications

Fingas, M.F.; Brown, C.E.; Fruhwirth, M.

Environmental Technology Centre, Emergencies Science Division, Ottawa, Ontario, Canada

CONF-960613 (Vol. 3); Technology, Measurement \& Analysis, Proceedings of the Second International Airborne Remote Sensing Conference and Exhibition, San Francisco, CA, June 24-27, 1996, Vol. 3, 870 pp.; (pp. III-689 - III-698) (1996)

Remote-sensors for operational application to oil spills are assessed. The capability of sensors to detect oil and to discriminate oil from background targets is the most important assessment criterion. $\mathrm{A}$ common sensor is an infrared camera or an IRUV system. This sensor class can detect oil under a variety of conditions, discriminate oil from some backgrounds and has the lowest cost of any sensor. The inherent weaknesses include the inability to discriminate oil on beaches, among weeds or debris and under certain lighting conditions oil is not detected. Furthermore, water-in-oil emulsions sometimes are not detected in the infrared. The laser fluorosensor is recommended because of its unique capability to identify oil on backgrounds that include water, soil, ice, and snow. It is the only sensor that can positively discriminate oil on most backgrounds. Radar, although low in priority for purchase, offers the only potential for large area searches and foul weather remote sensing. Radar is costly and requires a dedicated aircraft. Radar is prone to many interferences. False targets can be as high as $95 \%$. Equipment that measures relative slick thickness is still under development. Passive microwave has been studied for several years, but many commercial instruments lack sufficient spatial resolution to be practical, operational instruments. A laser-acoustical instrument, which provides the only technology to measure absolute oil thickness, is under development. Equipment operating in the visible spectrum, such as cameras and scanners is useful for documentation or providing a basis for the overlay of other data. It is not useful beyond this because oil shows no spectral characteristics in the visible region. All sensors require real-time displays and printers to yield useful results. More emphasis on this aspect is required because data is required promptly and in usable forms for oil spills.
Automated Technologies for Quantifying Residual Radioactive Materials

Coomer, B.; Gray, M.

Thermo Analytical, Inc., Oak Ridge, TN

CONF-941148 (Vol. 2); DDER-94: Decommissioning, Decontamination, and Environmental Restoration at Contaminated Nuclear Sites, M.G. White (ed.), Proceedings of an Embedded Topical Symposium of the American Nuclear Society Winter Meeting, Washington, DC, November 13-18, 1994. American Nuclear Society, Inc., La Grange Park, IL, Vol. 2, 241 pp.; (pp. 350-356) (1994)

One of the many challenges facing us today involves the collection of data and the subsequent compilation and analysis of that data as they pertain to the decision-making process when remediating or verifying contaminated areas. Current methods of data collection for the purpose of generating data to prove or verify that a remedial are is "clean" or below criteria are, at best, efforts to provide statistically defensible data. As new technologies and automation are applied to the instruments we currently use for data collection, we are able to achieve 100 percent verification of residual radioactive contamination in some cases.

3362

$\mathrm{V} 18 / 022262$

BLT-MS (Breach, Leach, and Transport - Multiple Species) Data Input Guide: A Computer Model for Simulating Release of Contaminants from a Subsurface Low-Level Waste Disposal Facility

Sullivan, T.M.; MacKinnon, R.J.; Kinsey, R.R.; Aronson, A.; Divadeenam, $M$.

Brookhaven National Laboratory, Upton, NY; Ecodynamics Research Associates, Inc., Albuquerque, NM

NUREG/CR-6492; BNL-NUREG-52509; 175 pp. (November 1996)

The BLT-MS computer code has been developed, implemented, and tested. BLT-MS is a two-dimensional finite element computer code capable of simulating the time evolution of concentration resulting from the time-dependent release and transport of aqueous phase species in a subsurface soil system. BLT-MS contains models to simulate the processes (water flow, container degradation, waste form performance, transport, and radioactive production and decay) most relevant to estimating the release and transport of contaminants from a subsurface disposal system. Water flow is simulated through tabular input or auxiliary files. Container degradation considers localized failure due to pitting corrosion and general failure due to uniform surface degradation processes. Waste form performance considers release to be limited by one of four mechanisms: rinse with partitioning, diffusion, uniform surface degradation, or solubility. Radioactive production and decay in the waste form are simulated. Transport considers the processes of advection, dispersion, diffusion, radioactive production and decay, reversibly linear sorption, and sources (waste forms releases). To improve the usefulness of BLT-MS, a pre-processor, BLTMSIN, which assists in the creation of input files, and a post-processor, BLTPLOT, which provides a visual display of the data, have been developed. This document reviews the models implemented in BLT-MS and serves as a guide to creating input files for BLT-MS. Project summaries for the following projects are included in this month's report: CP-5 Large Scale Technology Demonstration; 
Femald Plant-I Large Scale Technology Demonstration; Hanford C-Reactor Large Scale Technology Demonstration; U.S. Army Corps of Engineers; Chemical Decontamination of TRU-Contaminated Components; PHOENIX: A Computer-Based Decisionmaking Tool for D\&D of Nuclear Facilities; Florida International University Support; International Union of Operating Engineers; Airborne and Ground-Based Laser Induced Fluorescence (LIF); Portable X-ray, K-edge Heavy Metal Detector; Advanced Worker Protection Systems (AWPS); Characterization of Radioactive Contamination Inside Pipes with the Pipe Explorer System; Coherent Laser Vision System (CLVS); Portable Sensor for Hazardous Waste; Protective Clothing Based on Permselective Membrane and Carbon Adsorption; Rapid Surface Sampling and Archive Record (RSSAR) System; Three Dimensional Integrated Characterization and Archiving System (3D-ICAS); ROBOCON: Operator Interface for Robotic Applications; Diagnostics and Data Fusion of Robotic Sensors; Gas Phase Decontamination Process Demonstration; Concrete Decontamination by Electro-Hydraulic Scabbling; Electrokinetic Decontamination of Concrete; Laser Ablation of Contaminants from Concrete and Metal Surfaces; Remote-Operated Vehicle Dry Ice Pellet Decontamination System; Removal of Contaminants from Equipment and Debris and Waste Minimization Using the TechXtract [TM] Technology; Depleted Uranium Recycling Products; Electromagnetic Mixed Waste Processing System for Asbestos Decontamination; In Situ Version of Asbestos; Mobile Work System for Decontamination and Decommissioning; Decontamination and Dismantlement (D\&D) of Robotics; Decontamination and Dismantlement of Efficient Separations Treatment; Reuse of Concrete From Contaminated Structures; Demonstrations of Light Aided Technologies for Hanford D\&D Projects; Advanced Technologies for Decontamination and Conversion of Scrap Metal; Asbestos Pipe-Insulation Removal System; and Reconfigurable In-Tank Mobile Robot.

\section{3}

V18/022062

Balancing Health Effects and Economics in the Management of Radioactive Materials

Sandquist, G.M.; Slaughter, D.M.; Rogers, V.C.

University of Utah, Salt Lake City, UT; Rogers and Associates Engineering Corporation, Salt Lake City, UT

CONF-941148 (Vol. 2); DDER-'94: Decommissioning, Decontamination, and Environmental Restoration at Contaminated Nuclear Sites, M.G. White (ed.), Proceedings of an Embedded Topical Symposium of the American Nuclear Society Winter Meeting, Washington, DC, November 13-18, 1994. American Nuclear Society, Inc., La Grange Park, IL, Vol. 2, 241 pp.; (pp. 524-529) (1994)

The economic impact of performing the radioactive waste management actions proposed for remediation of the various contaminated sites and sources may prove unacceptable to U.S. public as the actual magnitude of these costs become apparent that begin to significantly impact upon the economy. Total regulatory driven radiological expenditures, approaching several percent of the GDP, when added to the economic demands implicit in health care reform, increasing entitlement expenditures and other "high priority" financial obligations will probably limit the anticipated level of radiological remediation and restoration now proposed.
3364

V18/023994

Basis of Estimate Software Tool (BEST): A Practical Solution to Part of the Cost and Schedule Integration Puzzle

Murphy, L.; Bain, P.

Kaiser-Hill Company, Golden, CO; Tenera Federal Projects, Golden, $\mathrm{CO}$

RFP-5083; CONF-970335; Waste Management '97: Working

Towards a Cleaner Environment, Proceedings of a Conference on HLW, LLW, Mixed Wastes and Environmental Restoration, Tucson, AZ, March 2-6, 1997; (6 pp.) (1997)

The Basis of Estimate Software Tool (BEST) was developed at the Rocky Flats Environmental Technology Site (Rocky Flats) to bridge the gap that exists in conventional project control systems between scheduled activities, their allocated or assigned resources, and the set of assumptions (basis of estimate) that correlate resources and activities. Having a documented and auditable basis of estimate (BOE) is necessary for budget validation, work scope analysis, change control, and a number of related management control functions. The uniqueness of BEST is demonstrated by the manner in which it responds to the diverse needs of the heavily regulated environmental workplace - containing many features not found in conventional off-the-shelf software products. However, even companies dealing in relatively unregulated work places will find many attractive features in BEST. This product will be of particular interest to current Government contractors and contractors preparing proposals that may require subsequent validation.

3365

V18/021190

Benefits of Integrating Cost-Benefit Analysis and Risk Assessment

Fisher, K.; Clarke-Whistler, K.

Beak Consultants Limited, Brampton, Ontario, Canada

CONF-951 1137; Global Environmental Protection: Science, Politics, and Common Sense, Proceedings of the Second Society of Environmental Toxicology and Chemistry (SETAC) World Congress and 16th Annual Meeting, Vancouver, British Columbia, Canada, November 5-9, 1995. Society of Environmental Toxicology and Chemistry, Pensacola, FL, 378 pp.; (p. 167) (1995)

It has increasingly been recognized that knowledge of risks in the absence of benefits and costs cannot dictate appropriate public policy choices. Recent evidence of this recognition includes the proposed EPA Risk Assessment and Cost-Benefit Analysis Act of 1995, a number of legislative changes in Canada and the U.S., and the increasing demand for field studies combining measures of impacts, risks, costs and benefits. Failure to consider relative environmental and human health risks, benefits, and costs in making public policy decisions has resulted in allocating scarce resources away from areas offering the highest levels of risk reduction and improvements in health and safety. The authors discuss the implications of not taking costs and benefits into account in addressing environmental risks, drawing on examples from both Canada and the U.S. The authors also present the results of their recent field work demonstrating the advantages of 
considering costs and benefits in making public policy and site remediation decisions, including a study on the benefits and costs of prevention, remediation and monitoring techniques applied to groundwater contamination; the bênefits and costs of banning the use of chlorine; and the benefits and costs of Canada's concept of disposing of high-level nuclear waste. The authors conclude that a properly conducted Cost-Benefit Analysis can provide critical input to a Risk Assessment and can ensure that risk management decisions are efficient, cost-effective and maximize improvement to environmental and human health. (Complete text)

\section{6}

\section{V18/021048}

Biomarker, P450 RGS, for Detecting and Monitoring Organic Compounds in Environmental Samples

Anderson, J.W.; Richter, K.; Tukey, R.

Columbia Aquatic Sciences, Carlsbad, CA; NRaD, San Diego, CA; University of Califomia, Department of Pharmacology, La Jolla, CA

CONF-940499 (Vol. 1); Proceedings of the 1994 Federal

Environmental Restoration III and Waste Minimization II

Conference and Exhibition, New Orleans, LA, April 27-29, 1994.

Hazardous Materials Control Resources Institute, Rockville, MD, Vol. 1, 783 pp.; (pp. 669-671) (1994)

Sampling the environment to determine the extent and degree of contamination from organic pollutants is generally expensive and time consuming. Organizations which have the capability of applying a rapid and sensitive survey tool can provide cost savings to the client and gain a competitive advantage. To efficiently select the most appropriate sites for detailed chemical characterization, rapid assessment tools are gaining wider acceptance. A bacterial test (Microtox) and an immunoassay kit (ELISA) are presently being used, but they are generally only able to detect 10 s or 100 s of ppm concentrations or organics. CAS recently transferred the technology from University scientists to make use of a genetically-engineered cell line in testing environmental samples. When samples containing toxic and carcinogenic organic compounds (dioxins, coplaner PCBs and polyaromatic hydrocarbons) are applied to small cell cultures, a series of molecular interactions results in the production of an enzyme which can be rapidly quantified by luminescence. After this $\mathrm{P} 450$ Reporter Gene System (RGS) reaction is stopped (18 hrs.), the cells are lysed and the cytoplasm is measured for protein content (for normalization) and luminescence. Induction of the enzyme infers that organics are present in the samples at levels that are potentially toxic, carcinogenic, or mutagenic to organisms, and the magnitude of response is a function of the potency of the toxicant. Very small volumes of solvent extracts ( $2 \mathrm{mu} / \mathrm{l})$ of tissue, water, aquatic sediments or soils, prepared using standard analytical methods, can be directly applied to the assay system. Test results show significant $P 450$ RGS induction from a typical $40-$ gr. sediment sample would be (in ngr./gr. or ppb): 0.001 for Dioxin, 1 for a range and 300 for a mixture of PAHs. Pesticides (including DDTs) and non-coplanar PCBs do not induce this system. The detection limits would be at least an order of magnitude lower for pollutants in water, since 1-1 volumes are extracted. Testing with extracts of marine sediments, tissues, and water has demonstrated the usefulness of the approach for identifying contaminated sites. CAS believes this rapid, inexpensive, and sensitive screening tool can save clients substantial costs, while assuring adequate environmental protection.

V18/024873

Breaking Through the Barriers to Cleanup Innovation: Report of the Planning Committee for the Regional Forum on Military Base Cleanup Technology

Proceedings of a Regional Forum on Military Base Cleanup Technology, Milbrae, CA, September 26-27, 1996; (16 pp.) (September 26-27, 1996)

On September 27, 1996, a two-day conference entitled "Regional Forum on Military Base Cleanup Technology" was held in Milbrae, Califormia. The goal of this event was to develop a model to elicit regional input from individuals representing diverse interests on military base technology needs and concerns and to communicate that information to the Department of Defense. The forum was a by-product of the Western Governors' Association Federal Advisory Committee to Develop Onsite Innovative Technologies (DOIT) initiative. The Forum sought to bring together people from a variety of backgrounds within U.S. EPA Regions 9 and 10 to explore their common interests in providing military base cleanup through the development and use of innovative technologies. The event was aimed at generating a regional perspective to assist federal technology programs in prioritizing their efforts to develop and field technologies which result in better, faster, cheaper, and safer cleanups. Primarily, the Forum's organizers wanted to give the people working on and affected by military base cleanups an opportunity to act regionally to influence national policy. Participants at the Forum concluded that the most significant factor impeding the development and use of innovative cleanup technologies is the barrier to effective communications, an.obstacle this project was conceived to address.

3368

V18/023310

\section{Budget Estimates Fiscal Year 1998}

U.S. Nuclear Regulatory Commission, Washington, DC NUREG-1 100 (Vol. 13); 136 pp. (February 1997)

The U.S. Nuclear Regulatory Commission's (NRC) FY 1998 appropriations legislation and its accompanying analysis are given. All dollar amounts in this document represent budget authority enacted for 1996, estimated for 1997, and requested for 1998. The document contains summaries for budget authority by function and by program, a summary of staffing by program,and an explanation of resource changes by program. The detailed justifications for direct program activities are presented. Note that the funds related to the reimbursable program are not financed by NRC's appropriated funds, but solely through reimbursable agreements with other Federal agencies and non-Federal entities. The following programs are included: Reactor Program, Nuclear Materials and Nuclear Waste Program, Management and Support Program, and, Inspector General Program.

V18/024123

CAP-LANL: A Graphic User Interface to CAP-88 Dose Modeling Surface

Los Alamos National Laboratory, Los Alamos, NM

LALP-95-277; 1 p. (1995) 
The Environmental Protection Agency requires that organizations use CAP-88 dose modeling software to calculate annual doses from airborne activity. CAP-88 requires a mainframe computer so that it can calculate multiple parameters that describe specific environmental and human conditions. To make CAP-88 more accessible, Los Alamos converted the original CAP-88 mainframe programs to run on a personal computer (PC). Scientists then designed a graphic user interface, CAP-LANL and a graphical display of output, that enables users to easily change parameters they have identified as being most important. It also is capable of distributive computing or file sharing among other PCs, UNIX, or PC-based operating systems.

\section{$3370 \quad \mathrm{~V} 18 / 023208$}

CLEANTEC DATA: A Concept for Sourcing and Disseminating Industrial Environment Information

Pembleton, $\mathrm{P}$.

United Nations Industrial Development Organization, Industrial and Technological Information Bank, Vienna, Austria

CONF-9210194; Proceedings of an International Symposium on Environmental Contamination in Central and Eastern Europe, Budapest, Hungary, October 12-16, 1992, 968 pp.; (pp. 377-380) (1992)

The paper outlines the United Nations Industrial Development Organization's (UNIDO) energy and environment information program, which is a sub-system of the Industrial and Technological Information Bank (INTIB). It gives a brief introduction to the latter's services. CLEANTEC DATA, the concept under which the sub-system functions, is explained and the UNIDO approach to information sourcing, preparation of dissemination packages, and the problems of developing countries in accessing relevant information are covered. The need to 'know-who' or 'know-where' to look for information is considered as important as the 'know-how' part of the equation. For this reason the utilization of existing sources of knowledge plays a large role in the program. The tools used by and the products already derived from the CLEANTEC DATA program are explained. The second section of the paper points out some of the problems of developing countries in respect to industrial environment information and presents an action program which will be the focus of this program's work in the near future.

V18/022557

California Leaking Underground Fuel Tank (LUFT) Historical Case Analyses: Data Collection, Data Input and Data Quality Control

Rempel, R.; Temko, H.; McGee, K.

State Water Resources Control Board, Sacramento, CA

CONF-960393 (Part 1); Contaminated Soils and Groundwater: Analysis, Fate, Environmental and Public Health Effects, and Remediation, Proceedings of the Sixth Annual West Coast Conference, Newport Beach, CA, March 11-14, 1996. Association for the Environmental Health of Soils, Amherst, MA, Part 1, 257 pp.; (p. 22) (1996)

By 1994, more than 27,000 leaking underground fuel tank (LUFT) cases had been identified in the State of California, with about 21,000 active cases. Since 1985, regulatory oversight agencies have accumulated literally mountains of paperwork containing both spatial and time-series hydrogeologic, chemical, and other data reported at LUFT sites. Prior to November 1994, there had been no systematic attempt to assemble these data into a computerized format suitable for statistical evaluation. In November of 1994, the State Water Resources Control Board (SWRCB) began collection of LUFT data throughout Califomia to create such a database in support of the Lawrence Livermore National Laboratories (LLNL) California Leaking Underground Fuel Tank (LUFT) Historical Case Analyses. The purpose of these efforts was to evaluate the distribution of measured soil and groundwater impacts caused by gasoline, diesel, and waste oil, and to identify the controlling factors which influence the magnitude and extent of fuel hydrocarbon plumes in groundwater. From the eligible pool, the SWRCB selected a representative (or targeted) subset of 1,831 sites for its own data collection efforts. Pertinent data were collected by two SWRCB teams who traveled to various regulatory agencies throughout the State and obtained the most complete, up-to-date information available in the files for each site.

\section{$3372 \quad V 18 / 022559$}

California Leaking Underground Fuel Tank (LUFT) Historical Case Analyses

Michaelson, J.C.; Cullen, S.J.; Everett, L.G.; Rice, D.W.; MacQueen, D.H.; Grose, R.D.; Marino, M.A.; Dooher, B.P.; Kastenberg, W.E.

University of California, Santa Barbara, CA; Lawrence Livermore National Laboratory, Livermore, CA; University of California, Davis, CA; University of California, Los Angeles, CA; University of California, Berkeley, CA CONF-960393 (Part 1); Contaminated Soils and Groundwater: Analysis, Fate, Environmental and Public Health Effects, and Remediation, Proceedings of the Sixth Annual West Coast Conference, Newport Beach, CA, March 11-14, 1996. Association for the Environmental Health of Soils, Amherst, MA, Part 1, 257 pp.; (p. 33) (1996)

The primary goal of this study is to support revision of the leaking underground fuel tank (LUFI) corrective action process. Califomia LUFT case historical data have been collected by state regulatory agencies for about ten years. Analysis of these data can provide information about the fate and transport of fuel hydrocarbons (FHCs) released into Califomia's diverse hydrogeologic settings. The LUFT case data can also provide a basis for continuous evaluation of both the past and future impact LUFT releases may have on human health, the environment, and groundwater resources. Several key questions that can be addressed by an analysis of the Califomia LUFT case historical data are: Do FHC plumes behave in predictable ways? What factors influence the length and mass of FHC plumes? To what extent are FHC plumes impacting California's groundwater resources? The answers to these questions will help identify riskand resource-management approaches that balance the cost of performing remediation against the anticipated benefits. The historical LUFT case analysis was divided into three phases, i.e., exploratory, primary, and secondary analysis phases. This document reports the resuits of the exploratory and primary analysis phases. 
3373

V18/022425

\section{Characterizing Waste Sites Onsite}

Korte, N.E.

Oak Ridge National Laboratory, Environmental Sciences

Division, Grand Junction, CO

Geotimes 40(5):18-20 (May 1995)

Not long ago, characterizing a hazarcous waste site meant deploying a team, guided by a geologist, to prepare lithologic logs and to collect, package, and ship samples to a laboratory. Onsite decisions and field skills were minimal. Today, we know that regulatory-mandated methods for handling soil samples are time-consuming, expensive, and may be inadequate for maintaining sample integrity. The result is an increasing reliance on field analyses with benefits in cost and time. Analytical chemistry has joined geology as a required field skill, and the acquisition of large amounts of field data requires frequent and sophisticated on-site decisions. To rely solely on locations marked on a map is no longer efficient. Instead, geologists may select their next sampling location based on data gathered only minutes before. Such quick decisions can be supported by entering the data into an on-site computer and using a geographic information system. As a result, investigations that required years to complete can be finished in weeks or months; and the skill and experience of the field personnel are the most important elements of a successful site characterization.

\section{4}

V18/024113

Chlorinated and Aromatic Hydrocarbon Thin Film Chemical Sensors

Los Alamos National Laboratory, Los Alamos, NM

LALP-94-251; 1 p. (1994)

Sensor and/or analytical methods used to conduct field monitoring and near-real-time monitoring of organics (such as chlorinated hydrocarbons) play a crucial role in performing air quality measurements, real-time monitoring, plume/site remediation, industrial waste stream characterization, and detection of storage tank leaks. Using molecular self-assembly techniques, we are developing compact, inexpensive, and robust surface-acoustic-wave-based (SAW) chemical sensors that can conduct remote, real-time sensing of specific chlorinated hydrocarbons in air, groundwater, and possibly soil. These unique sensors are small enough to fit on the tape-lead gear of an audio cassette and can be integrated onto a silicon chip. Because of such compactness, these sensors can easily fit in areas difficult to access with conventional sensor systems. Moreover, scientists can custom tailor these sensors to meet specific needs.

\section{$3375 \quad \mathrm{~V} 18 / 023776$}

Common Laboratory Errors Found During Audits

Pacheco, S.J.; Kassakhian, G.H.

Tetra Tech, Inc., San Bernardino, CA

CONF-9504134; HAZMACON' '95, T. Bursztynsky and M.L. Loss (eds.), Proceedings of the Twelfth Hazardous Materials Management Annual Conference and Exhibition, San Jose, CA, April 4-6, 1995. Association of Bay Area Governments, Oakland, CA, 790 pp.; (pp. 71-76) (1995)
Routine audits of various analytical laboratories yield common errors. Tetra Tech, Inc., routinely provides oversight to their subcontractor analytical laboratories by performing an on site audit. During these audits, typical discrepancies are noted by the auditing team that can have negative impacts on analytical data acquired by the laboratory. The technical areas have common discrepancies that can be avoided with the establishment by the laboratory of an enabled internal quality assurance/quality control program.

\section{6}

V18/022759

Comparison of Dose Versus Risk at Environmental Restoration Sites

Holm-Hansen, T.; Pastor, R.S.

PRC Environmental Management, Inc., Aiken, SC CONF-960804 (Vol. 2); Spectrum '96: Nuclear and Hazardous Waste Management, Proceedings of an International Topical Meeting, Seattle, WA, August 18-23, 1996. American Nuclear Society, La Grange Park, IL, Vol. 2, 873 pp.; (pp. 1131-1138) (1996)

This paper compares current U.S. Environmental Protection Agency methods for completing risk assessments at radionuclide-contaminated sites with the Intemational Council for Radiation Protection dose-based method. The two methods produce inconsistent results that could complicate cleanup decisions. Important issues include uncertainties associated with the use of carcinogenic slope factors and methods to account for institutional controls and decay of the source term for decision-making purposes. Overall, risk management at sites contaminated with radionuclides should be driven by a dose-based approach through adoption of the proposed 15 millirem cleanup standard found in Title 40 Code of Federal Regulations, Part 191.

\section{$3377 \quad$ V18/022911}

\section{Comparison of RESRAD with Hand Calculations}

Rittmann, P.D.

Westinghouse Hanford Company, Richland, WA

CONF-951209; Proceedings of the 17th Annual U.S. Department of Enérgy Low-Level Radioactive Waste Management Conference, D. Lake (ed.), Phoenix, AZ, December 12-14, 1995, 480 pp.; (11 pp.) (1995)

This report is a continuation of an earlier comparison (Benchmarking of Computer Codes and Approaches for Modeling Exposure Scenarios, DOE/LLW-188) done with two other computer programs, GENII and PATHRAE. The dose calculations by the two programs were compared with each other and with hand calculations. These hand calculations have now been compared with RESRAD Version 5.41 to examine the use of standard models and parameters in this computer program. The hand calculations disclosed a significant computational error in RESRAD. The Pu-241 ingestion doses are five orders of magnitude too small. In addition, the external doses from some nuclides differ greatly from expected values. Both of these deficiencies have been corrected in later versions of RESRAD.

V18/022847

Compendium of Cost Data for Environmental 
Remediation Technologies

DuTeaux, S.B.

Los Alamos National Laboratory, Los Alamos, NM

LA-UR-96-2205; 130 pp. (August 1996)

This Compendium provides a representative sample of cost information for environmental remediation technologies used in the treatment of hazardous, radioactive, and mixed waste. Data were gathered from a variety of sources and summarized herein to provide actual cost summaries or engineering cost estimates, site characteristics, and comments detailing remedial projects. By using this collection of data, managers and decision makers can access a current compilation of different scenarios to compare costs and performance of remedial actions closely resembling the scale and characteristics of projects under construction. This Compendium includes synopses of site characteristics, contaminants, and remedial strategies. Detailed information can be obtained from the cited references. The reader is cautioned that all cost data included are site specific and site experiences are highly variable. To be inciuded as an entry, the data must have been from actual commercial or pilot-scale remedial actions, completed or in progress. As such, neither hypothetical cost scenarios nor cost comparisons were used as the basis for the numbers entered herein.

\section{9}

\section{V18/020830}

Computer Control System for Portable Self-Contained Groundwater Testing Assembly

Vollweiler, T.J.; Vollweiler, A.R.

U.S. Patent 05432709; 16 pp. (July 11, 1995)

This invention relates to a portable assembly for testing for environmental contamination in groundwater. A portable groundwater sampling apparatus has a submersible pump or other water sampling apparatus attached through a hose to a hydraulically driven spool mounted on a boom attached to the bed of a truck or trailer. The hydraulically operated boom enables the operator to place the pump over the well and lower the pump into the well from the spool. A second spool also mounted on the boom operates a cable attached to a discrete liquid sampler or appliance of operator's choice for lowering into the well to take water samples or collect data. A decontamination apparatus is also attached to the boom and washes the hose and cable to remove contaminants therefrom. The contaminated wash fluid is removed to a holding tank for later disposal at a safe site. Hydraulically driven level-wind mechanisms are attached to each spool. One or more computers are used on site to track the pumping and purging, as well as monitor sensors measuring fluid characteristics, such as, temperature of the water, conductivity and flow.

\section{0 \\ V18/021396}

Consolidation and Defined Needs of the Landfill Stabilization and Contaminated Plumes Focus Areas

Brown, J.P.

U.S. Department of Energy, Savannah River Operations Office, Aiken, SC

Fostering the Needed Partnerships: Doing the Necessary Science to Support Technology Development, Commercialization, Deployment, E.L. Helminski (ed.), Proceedings of the Seventh
Annual Westem Governors' Association/Weapons Complex Monitor Applied Research and Cleanup Technology Colloquium, Phoenix, AZ, April 29-May 2, 1996. Exchange/Monitor Publications and Forums, Lake Bluff, IL, 500 pp.; (20 pp.) (April 1996)

This presentation describes the consolidation and realignment of the Contaminant Plumes Focus Area and the Landfill Stabilization Focus Area into the Subsurface Contaminants Focus Area. Viewgraphs provide highlights of the following areas: Consolidation objectives and assumptions, Problem description, Mission redefinition, Strategic goals, Deployment sectors, Organizational concept, Realignment initiatives, and Transition plan summary. The prioritization and strategic investment process includes: Inventory of site problems and needs, a Problem model filter, Formulation of needs statements, Prioritizing needs, Applying strategic investment criteria, and Basis for investment.

3381

V18/024104

Contaminant Analysis Automation (CAA)

Los Alamos National Laboratory, Los Alamos, NM

LALP-94-247; 1 p. (1994)

Currently characterization of waste sites is extremely expensive, costing the Department of Energy billions of dollars each year. In addition to the enormous costs, there is a lack of necessary facilities and trained personnel. The Contaminant Analysis Automation (CAA) Program is a team of national laboratories, industry, and universities dedicated to developing technologies necessary to automate the sampling and analysis processes of waste remediation. CAA's goal is to develop automated laboratories that can run continuously, thereby reducing the time required to analyze environmental samples. Automation will greatly increase the precision of each analysis and improve turnaround time as well. Researchers in this program are presently designing several unique analysis systems known as standard analysis methods (SAM), which industry can use for specific application. Using a building block known as standard laboratory module (SLM), each SAM will automate a specific chemical method, which includes sample preparation, the analysis, and the data interpretation.

\section{$3382 \quad$ V18/023832}

Cost-Effective Approaches to Field Screening at ECRA Sites

Comell, F.W.; Fallon, J.R.

Environmental Liability Management, Inc., Princeton, NJ

CONF-9306269; HazMat '93 International, Proceedings of the Eleventh Annual Environmental Management and Technology Conference and Exhibition, Atlantic City, NJ, June 9-11, 1993. Advanstar Expositions, Glen Ellyn, IL, 731 pp.; (pp. 388-400) (1993)

Field screening methods offer a means of rapidly identifying and delineating areas of potential environmental concern. As more products undergo development and commercialization, wider use in site investigations is expected. The sampling plan is probably the most important component of the site characterization process. $A$ well designed sampling program wiil characterize the site without over sampling the site. A poor sample design will introduce 
tremendous uncertainties into a site evaluation and may be excessively costly. If sample locations and/or depths are not properly selected, contamination that is present at a site may not be detected during the initial investigation phase. The soil sample collection method can significantly affect the results of analysis. The most accurate sampling procedures involve collection of a discrete, relatively undisturbed soil sample, which can be prepared prior to analysis. Other methods include in situ sampling methods, such as soil gas sampling and fiber optic sampling. Soil gas sampling is a widely used screening tool that involves extracting air from the soil pore space and analyzing the air sample. Fiber optic sampling involves placing fiber optic probes into the ground, and using spectrometric methods (which direct and collect light through the optical fibers) to analyze the soil (or water).

\section{$3383 \quad \mathrm{~V} 18 / 021308$}

Criteria for Establishing De Minimis Levels of Radionuclides and Hazardous Chemicals in the Environment

Kocher, D.C.

Oak Ridge National Laboratory, Environmental Restoration Division, Oak Ridge, TN

ES/ER/TM-187; 15 pp. (June 1996)

This paper develops proposed criteria for establishing de minimis levels of radionuclides and hazardous chemicals in the environment. The proposed criteria are intended to provide upper bounds on risks that are trivial (negligible). Thus, action to reduce risks at these levels or below generally would not be warranted, regardless of cost-benefit or any other considerations. Furthermore, reduction of risks is not necessarily required whenever risks exceed the upper bounds on de minimis levels. Rather, the proper interpretation in this case is that the feasibility of risk reduction generally must be considered, but action to reduce risk would be required only if it is practicable (i.e., if the risks are above levels judged as low as reasonably achievable). This paper does not develop specific recommendation on numerical values for de minimus levels of various contaminants in environmental media other than water (e.g., surface soil). Rather, a proposal is discussed suggesting that models for converting the de minimus criteria to levels in environmental media should incorporate reasonably likely, but somewhat conservative, assumptions about exposure pathways, rather than very unlikely, worst-case assumptions. Given the other conservative assumptions about the duration and location of exposures that normally are included in health risk assessments, this approach should still provide estimates of de minimus levels in the environment that are unlikely to correspond to risks exceeding the proposed criteria.

\section{4}

$\mathrm{V} 18 / 023189$

Data Modelling and Management for Support of Environmental Site Investigation and Remediation

Nunke, M.P.

Radian Corporation, Austin, TX

CONF-9210194; Proceedings of an Intemational Symposium on Environmental Contamination in Central and Eastern Europe, Budapest, Hungary, October 12-16, 1992, 968 pp.; (pp. 273-275) (1992)
Site investigation and remediation efforts generate massive volumes of data. These data form the basis for conclusions concerning the nature and extent of contamination and evaluation of remediation alternatives, and provide a historical record to measure the success of the remediation effort. Data complexity and quantity make a coherent plan for data management imperative. Data management is complicated by activities driven by the associated dynamic regulatory and legal environment and the support of changes in the underlying science. Additional complexity is introduced by analytical results which really are not a single data point, but include supporting data providing measurements of the many sources of error found in sampling and analysis. Database implementation must support a broad variety of applications, for example, health risk assessment, quality assurance and control, groundwater modelling, computerized mapping, geographic information systems (GIS), and three-dimensional geoscientific information systems (3D-GSIS). Object-oriented analysis is used to analyze and model site data and the processes by which they are collected and used. This provides an excellent way to abstract data complexities and accommodate dynamics within the database. The resulting object-oriented view can be mapped to relationship database management systems to develop the actual site database.

\section{5}

\section{V18/020735}

\section{Decision Making Software for Site Remediation}

Kulik, C.; Aroeste, $\mathrm{H}$.

CONF-950952; Coal - Energy and the Environment, Proceedings of the Twelfth Annual International Pittsburgh Coal Conference, Pittsburgh, PA, September 11-15, 1995, 1248 pp.; (p. 760) (1995)

Choosing the appropriate technologies to remediate a contaminated site can be a problem. AccOn Services, a joint venture of Accord Services, Inc. and ANCON International are developing a computer program capable of determining whether the Simplified Clean Soil Process being commercially demonstrated in 1995 is the appropriate technology for remediating a particular site. GIST (Guided Inquiry System Technique) has been used for acquiring and processing information in an easily comprehensible framework at NASA, EPRI and elsewhere. This program has been adapted to the field of environmental remediation.

\section{6}

V18/021432

Defining Mixed Waste: Efforts to Establish Radioactive Release Criteria

Greene, R.T.

International Technology Corporation, Knoxville, TN

CONF-950877; Mixed Waste, A.A. Moghissi, B.R. Love and R.K. Blauvelt (eds.), Proceedings of the Third Biennial Symposium, Baltimore, MD, August 7-10, 1995, 545 pp.; (pp. 3.2.1-3.2.4)

Complicated regulatory issues and limited disposal options exist for wastes classified as mixed wastes. Definitions of mixed waste acknowledge that the wastes contain hazardous constituents as well as radioactive components. However, current regulations fail to define a de minimis quantity or concentration of radioactive material below which the waste is considered nonradioactive. This regulatory deficiency results in hazardous wastes that contain low 
levels of radioactive material being classified as mixed wastes. Without a federally-established de minimis level, waste generators have adopted a variety of criteria for determining the radiological status of their waste materials. Use of these de facto limits has resulted in shipments of slightly contaminated materials (i.e., mixed wastes) to facilities not authorized to receive them. For example, the U.S. Department of Energy (DOE) recognized this inconsistent approach to waste classification, and in response issued a moratorium on shipments of all Resource Conservation and Recovery Act-Hazardous and Toxic Substance Control Act-regulated waste to unlicensed commercial disposal facilities in May of 1991. The moratorium applied to all wastes that originated in radiologically controlled areas of DOE sites. The question "When is a hazardous waste a mixed waste?" is still under considerable debate. This paper will describe the efforts of one company to establish exemptions for low-level radioactive materials. Past attempts by the U.S. Nuclear Regulatory Commission to establish regulatory exemptions will be reviewed.

\section{7}

V18/022248

Department of Defense and the Environment: A Phase I Study of the Installation Restoration Program

Shaklee, $\mathrm{T}$.

Oklahoma State University, Department of Political Science, Stillwater, OK

CONF-951 139 (Vol. 2); Superfund 16: Proceedings of a Hazardous Waste Conference and Exhibition, Washington, DC, November 6-8, 1995. E.J. Krause and Associates, Bethesda, MD, Vol. 2, 817 pp.; (pp. 122-128) (1994)

The Department of Defense (DOD), like a number of entities responsible for environmental contamination and remediation, is dealing with an area about which relatively little is known. In addition to the scientific complexity of the hazardous waste problem, are the complexities of the legal system which has been established, the difficulties inherent in policy implementation, the structure of the service agencies within DOD and the "corporate culture" of the Department itself. To combine the complex legal and technical problems associated with remediating hazardous waste sites with such a large and complex organization as DOD is to invite massive problems. The purpose of this study is to examine the Installation Restoration Program (IRP) to determine implementation obstacles (both internal and external) that DOD faces in making hazardous waste remediation policy work for the Department.

\section{$3388 \quad$ V18/023826}

Determination of Ultra-Trace Amounts of Radium, Thorium, and Uranium in Waste Water by High-Resolution ICP-MS After Coprecipitation with the Iron (III) Hydroxide

Sushida, K.; Nakamura, $K$.

Toray Research Center, Inc., Inorganic Analysis Laboratory, Otsu, Shiga, Japan

CONF-960113; Proceedings of the 1996 Winter Conference on Plasma Spectrochemistry, Fort Lauderdale, FL, January 8-13, 1996, 378 pp.; (p. 309) (1996)
Inductively coupled plasma mass spectrometry with a quadrupole mass analyzer (ICP-MS) is now regarded as a powerful technique to determine almost every element in the periodic table with ppt $(\mathrm{pg} / \mathrm{mi})$ level. So far, this technique has been used to measure long half-life radionuclides in our "polluted" environment. For example, Pu-239 and Pu-240 in the top-soil were measured precisely and relatively easily in the range of 0.2 to $2.6 \mathrm{mBq} / \mathrm{g}$ by using ICP-MS. Conventional radiometric methods which have very high sensitivity for short half-life radionuclides need, however, complex chemical pretreatment for isolation and concentration of focused isotopes, and are time consuming. Higher sensitivity and lower detection limits are still needed for monitoring low concentration of long half-life radionuclides in the environmental samples. Recently, high resolution ICP-MS (HR-ICP-MS) with a double focusing mass spectrometer was developed and applied without delay to the determination of ultratrace elements in a variety of samples at high resolution (M/(delta)M approximately 10000) and high sensitivity (ppq $=\mathrm{fg} / \mathrm{ml}$ level). In this study, HR-ICP-MS was applied to the determination of ultra-trace amounts of $R \mathrm{a}, \mathrm{Th}$, and $U$ in waste water samples including high concentrations of alkaline, alkaline earth and transition metal elements.

3389

V18/021187

Development of Methodology for Evaluating Risks to Ecological Receptors from Contaminant Exposure

Hlohowskyj, I.; Cheng, J.J.; Euskirchen, E.; Yu, C.; Chen, S.Y.

Argonne National Laboratory, Environmental Assessment Division, Argonne, IL

CONF-9511137; Global Environmental Protection: Science, Politics, and Common Sense, Proceedings of the Second Society of Environmental Toxicology and Chemistry (SETAC) World Congress and 16th Annual Meeting, Vancouver, British Columbia, Canada, November 5-9, 1995. Society of Environmental Toxicology and Chemistry, Pensacola, FL, 378 pp.; (p. 166) (1995)

Argonne National Laboratory is developing a PC-based computer code for estimating risks from contaminant exposure to ecological receptors. The code is based on and is consistent with the methodologies of the RESRAD-CHEM computer code for human health risk assessment. The code will use food web uptake models, which were developed for several contaminated sites, to estimate contaminant dose to ecological receptors. Fate and transport models will be used to estimate contaminant concentrations in groundwater, surface water, sediment, air, and vegetation from an initial contaminated soil source. A database of 151 organic and inorganic chemicals containing information such as Kow and soil-to-plant transfer factors will be included to permit selection of the site-specific contaminants of concern. Five ecological receptors including two bird and three mammal species will be considered, and the user will be able to select or suppress individual food chain pathways to reflect site-specific ecological conditions. The code will use the species-specific life history information and environmental media contaminant concentrations to calculate an applied daily dose (ADD). The ADD can be used to calculate an ecological effects quotient and estimate risk to the ecological receptor. Default values will be provided for many of the input parameters, including life history parameters, if site-specific data are unavailable. Sensitivity 
analyses for the input parameters can be performed. The code will generate a text report that includes the predicted environmental media concentrations and ADD estimates, and calculation results can be graphically displayed. The code will be user friendly, with a menu driven interface and on-line help. Monte Carlo analyses and additional species uptake models are under development. (Complete text)

3390

V18/020736

Development of a Decision Support System for the

Department of Energy's Selection of Waste Site Remediation Technologies

Ralston, B.E.; Jackson, J.A.; Kloeber, J.M.; Deckro, R.F.

U.S. Air Force Institute of Technology, Wright-Patterson Air Force Base, $\mathrm{OH}$

AFIT-CMSATR/96-02; 134 pp. (March 1996)

The Department of Energy is faced with the complex decision of selecting technologies for waste site remediation. This research focused on developing a decision support system to aid the decision maker in selecting the best strategy of remediation technologies. Specifically, the research outlined the use of multiple attribute utility theory using exponential attribute utility functions with a simple additive objective function. A decision analysis model was developed which incorporates life-cycle cost data, risk information, and user input, to analyze the technology choices. The best available data was used to demonstrate the capabilities of the model. The model provides the decision maker with information on utility, cost, and time. Cumulative and frequency distributions illustrate the dominance of technology choices and the variance in the results. Cost and time plots allow the decision maker to see the trade-offs inherent in the utility functions. The model also allows for sensitivity analysis in the form of rainbow and tomado diagrams to display the affects of changes in the values of the input variables.

\section{$3391 \quad$ V18/023828}

Direct Analysis of Soil Samples Using DC ARC CW Spectroscopy

Mahan, C.

Los Alamos National Laboratory, Inorganic Trace Analysis, Los Alamos, NM

CONF-960113; Proceedings of the 1996 Winter Conference on Plasma Spectrochemistry, Fort Lauderdale, FL, January 8-13, 1996, 378 pp.; (p. 247) (1996)

Direct analysis of materials remains an important frontier in analytical chemistry. Recent improvements in solid state multichannel detectors and the need for rapid direct analysis methods has led to a renewed interest in the dc arc emission technique. The charge injection device (CID) detector represents relatively new technology, and it is this device that has the potential to improve analytical performance over the traditional $\mathrm{dc}$ arc spectroscopic technique. Many of the traditional dc arc analytical problems are minimized as a result of the signal processing capabilities of the CID. Optimum signal integration for each element on the burned sample precludes the need for internal standardization. In addition, both trace and matrix elements can be analyzed in the same bum due to the non-destructive readout feature of the $\mathrm{CD}$. The limited linear dynamic range remains a problem but can be alleviated by choosing lines with different sensitivities at different concentration ranges (i.e., line switching). A soil method has been developed that provides rapid quantitative information for several environmentally important elements. Most element detection limits are below the soil action levels determined for the area surrounding Los Alamos county and are therefore adequate for most environmental remediation applications. The performance of this instrument will be compared with the traditional spectrochemical methods of ICP-OES and EDXRF.

3392

V18/024054

Direct Sampling MS for Environmental Screening

Wise, M.B.; Guerin, M.R.

Oak Ridge National Laboratory, Oak Ridge, TN

Analytical Chemistry 69(1):26A-32A (January 1, 1997)

Decades of improper storage and disposal of hazardous materials by government and industry have resulted in approximately 40,000 contaminated sites that will require cleanup by state and federal agencies. Almost 1,300 of these sites are classified as especially serious threats and are listed on the Superfund National Priorities List (NPL) for accelerate remediation; by 2020 , it is estimated that the number of NPL sites will exceed 3,000. Given that an average of 10 years is required to clean up a Superfund site, remediation of known hazardous sites will continue well into the next century. Cost projections for environmental restoration range from nearly $\$ 200$ billion to more than $\$ 2$ trillion. This paper discusses screening methods and direct sampling mass spectrometry (MS) for more cost-effective and efficient environmental characterization. Direct sampling MS refers to the introduction of analytes from a sample directly into a mass spectrometer using a simple interface with minimal sample preparation and no prior chromatographic separation. The method results in real-time response and high sample throughput. It is applicable to most types of environmental samples for volatile and semivolatile organics.

3393 V18/022411

\section{EM-Wide Waste Management Unit Cost Study}

MACTEC, Ashtabula, OH

Report; 17 pp. (1995)

This report evaluates current DOE literature, vendor literature, completed projects, and current projects to calculate and identify explicit unit cost factors on a global (macroscopic) scale that could be applied to LLW management activities as a proposed performance indicator. This study was undertaken to determine whether currently available data exists in sufficient quality and quantity to support the development of unit cost factors for activities associated with managing different types of waste. This required that DOE and vendor literature, completed projects and current projects be evaluated to calculate and identify explicit unit cost factors on a global scale for different waste types in general, and for LLW in particular. Unfortunately, findings indicate that while data does exist to support the development of such factors, it is currently not of sufficient quality and quantity to support the calculation of factors in a narrow enough range to be useful. It is our recommendation that $\mathrm{DOE}$ request more detailed, site-specific information on the Total Affected Volume (TAV) for each site as 
waste operations continue.

\section{4}

V18/025481

EMMI (Includes Water Methods and Guidance CD) (Environmental Monitoring Methods Index), Version 2.0 (Single User) (on Diskette)

U.S. Environmental Protection Agency, Office of Science and Technology, Washington, DC

Report; (4 diskettes) (July 1995)

The EPA's Environmental Monitoring Methods Index (EMMI) software assists users in comparing and evaluating analytical methods applicable to environmental pollutants of interest. EMMI combines rapid search capabilities with a user-friendly interface. EMMI allows the user access to an extensive list of analytes and analytical methods. It provides CAS numbers, regulatory lists, and regulatory limits. The database also contains method abstracts that include sample collection, storage, preservation, preparation, extraction, and analysis information. EMMI also contains information on contact points within offices and organizations responsible for publishing the analytical methods or regulatory information contained in EMMI. A powerful search engine provides searching by method number, analyte name or keywords in the text. All text, tables, diagrams, flowcharts and figures are included. The user can electronically jump from the Table of Contents to documents of interest and lookup chemicals on the Analyte List and electronically jump to recommended methods.

\section{5 \\ V18/023576}

EPA Superfund Site Assessment and Remediation: Irregular Report

U.S. Environmental Protection Agency, Office of Emergency and Remedial Response, Washington, DC

Report; 10 pp. (1997)

The subscription provides issued by the Superfund program on site assessment and remediation. This topic covers site assessment-general; the National Priorities Listing Process; risk assessment; risk management; remedial action-general; remedial investigation and feasibility studies; remedial design and remedial action; guidance on records of decision; public participation-general; community relations; state and local involvement; and Technical Assistance Grants.

\section{6}

V18/024867

Ecological Risk Assessment Methodologies

Chek, W.L.

Environment Protection Authority, Victoria, Australia

Proceedings of the Third National Workshop on the Health Risk Assessment and Management of Contaminated Sites (Contaminated Sites Monograph Series No. 5, 1996), A. Langley, B. Markey and H. Hill (eds.), Sydney, Australia, May 1995. South Australian Health Commission, Rundle Mall, South Australia, 470 pp.; (pp. 365-384) (1996)

Methodologies for ecological risk assessment proposed by the United States Environmental Protection Agency, Canada and the Netherlands are reviewed and discussed in this paper. Based on the findings of this review, a framework for environmental risk assessment of contaminated sites in Australia is proposed. This framework integrates human health risk assessment and ecological risk assessment. It consists of five basic components (problem identification, receptor identification, exposure assessment, hazard assessment, and risk characterisation) within a three-tier approach.

\section{7}

V18/024121

Ecological Risk Assessment at Los Alamos

Los Alamos National Laboratory, Los Alamos, NM

LALP-96-27; 1 p. (1996)

At Los Alamos scientists are developing an approach to ecological risk assessment based on the framework developed by the Environmental Protection Agency. This approach consists of three factors: (1) The action taken is defensible from a scientific standpoint; (2) the action taken is integrated with ongoing human risk assessment and land management decisions; and (3) the action allows for flexibility among alternatives in achieving an acceptable level of ecological risk. The Los Alamos approach uses the Ecological Exposure Unit (EEU) concept, in which EEUs are defined on the basis of ecological considerations and may contain several contaminated sites. By performing a risk assessment simultaneously on all the sites within an EEU, scientists can develop an approach that results in the minimum remediation required to mitigate risk, thereby saving time and money.

Effect of Soil Matrix on Elemental Analysis Using Laser-Induced Breakdown Spectroscopy (LIBS)

Moy, M.M.; Cremers, D.A.; Junk, C.P.

Los Alamos National Laboratory, Los Alamos, NM

CONF-960113; Proceedings of the 1996 Winter Conference on Plasma Spectrochemistry, Fort Lauderdale, FL, January 8-13, 1996, 378 pp.; (p. 131) (1996)

Laser-induced breakdown spectroscopy (LIBS) has been demonstrated for chemical analysis of various solid materials. Nd-YAG laser pulses focused on the solid surface results in the generation of a laser plasma which vaporizes and ionizes a small amount of the solid material. Emissions from neutral and ionized atoms in the laser plasma are spectroscopically analyzed and the composition of the sample is determined from the elemental emission intensities generated by the plasma. LIBS has also been shown to provide a rapid quantitative elemental analysis of gases, liquids, and aerosols as well. Quantitative analysis of significantly more complex samples such as glasses and soils by LIBS depends on the ability to calibrate the method and to account for differences between the calibration standards and the real-world samples due to matrix effects. In this work, the effect of the chemical form of chromium and lead on LIBS measurements has been investigated. Analytical figures of merit include: detection limits, accuracy, and precision. Addition of these elements as liquid and solid compounds to matrices of soil and soil simulants have been used to evaluate matrix effects and to generate calibration curves. Univariant and multi-variant techniques were used to develop calibration curves and to study interelement correlation of spectral intensities. The experimental apparatus used was similar to those typically used for laboratory-based LIBS measurements. In this work, we focused 150 
$\mathrm{mJ} /$ pulse Nd-YAG laser pulses on soil and soil simulants at normal incidence using a repetition rate of $10 \mathrm{~Hz}$. The plasma light was collected by a fiber optic cable and directed onto the entrance slit of a $1 \mathrm{~m}$-focal-length spectrograph. The emission spectra were recorded by a gated, intensified photodiode array. V18/022891

Effects of Ionizing Radiation on Terrestrial Plants and Animals: A Workshop Report

Barnthouse, L.W.

Oak Ridge National Laboratory, Oak Ridge, TN

ORNL/TM-13141; 22 pp. (December 1995)

The U.S. Department of Energy (DOE) Air, Water, and Radiation Division (EH-412) is preparing to issue protective radiological standards for aquatic and terrestrial organisms. To support this effort, DOE sponsored a workshop to evaluate the adequacy of current approaches to radiological protection. Workshop participants reviewed and discussed a 1992 Intemational Atomic Energy Agency (LAEA) report on radiological protection of biota for its adequacy and completeness in answering the following questions: Can DOE use these data and conclusions for promulgating radiological standards for the protection of terrestrial organisms? Are the conclusions given in this report still valid or have they been superseded by more recent data? The consensus of the workshop participants was that the dose limits for animals and plants recommended by the IAEA are adequately supported by the available scientific information. Participants agreed, however, that better guidance on application of those dose limits is needed. Participants further agreed with the IAEA that dose limits designed to protect humans generally protect biota as well, except when: (1) human access is restricted without restricting access by biota, (2) unique exposure pathways exist, (3) rare or endangered species are present, or (4) other stresses are significant. To deal with these exceptions, site-specific exposures should be considered in developing secondary standards. Existing exposure models were found to be sufficient in principle for developing secondary standards. Workshop participants concluded, however, that: (1) site-specific transfer coefficients are needed for some important species and exposure routes and (2) improved methods of dosimetry for reference biota are needed to eliminate unnecessary conservatism and provide a practical approach for implementing the standards.

3400 V18/022552

\section{Electronic Management of Environmental Data}

Smith, R.A.

Black and Veatch Special Projects Corporation, Tacoma, WA

CONF-960393 (Part 3); Contaminated Soils and Groundwater: Analysis, Fate, Environmental and Public Health Effects, and Remediation, Proceedings of the Sixth Annual West Coast Conference, Newport Beach, CA, March 11-14, 1996. Association for the Environmental Health of Soils, Amherst, MA, Part 3, 366 pp.; (p. 48) (1996)

When attempting to reach conclusions during contaminated site characterization and remediation projects, the effort to analyze, correlate, and model large data sets can be staggering. Therefore, efficient organization and manipulation of data (data management) is essential. The use of a relational database system, integrated with data analysis tools, to manage environmental data electronically reduces project costs for contaminated site projects. Other benefits over manual methods include increased accuracy, reduced rework, and expanded data analysis capabilities. This paper relates the benefits of using an electronic data management system (EDMS) for contaminated sites and offers criteria important in establishing or purchasing a new system. Examples of development and use are included.

3401

V18/021524

Engineering Parameters for Environmental Remediation Technologies: Final Report

Kikkeri, S.R.; Ness, E.R.

Woodward-Clyde Federal Services, Gaithersburg, MD; U.S. Coast Guard Research and Development Center, Groton, CT

CG-D-15-96; 124 pp. (June 1996)

This document identifies engineering parameters and establishes ranges of values for 33 environmental remediation technologies. The main purpose is to provide U.S. Coast Guard (USCG) civil engineering personnel with summarized information regarding matrix characteristics and design parameters that are applicable to each of the technologies. This information is intended to guide USCG personnel when making decisions regarding the selection of appropriate remediation technologies.

3402

V18/022497

Environmental Compliance Management System

Cason, A.; Larrinaga, L.

Dow Chemical Company, Midland, MI; Dow Environmental Inc., Midland, $\mathrm{MI}$

CONF-950333; SPE-29699; Government and Industry Working Together to Find Cost Effective Approaches to Prolecting the Environment, Proceedings of the Society of Petroleum Engineers (SPE)/U.S. Environmental Protection Agency (EPA) Exploration Production Environmental Conference, Houston, TX, March 27-29, 1995. SPE, Richardson, TX, 797 pp.; (pp. 109-112) (1995)

A cross-functional team of environmental regulatory experts, plant managers, and plant engineers have been working since 1991 on the development, implementation and maintenance of the

Environmental Compliance Management System. The Environmental Compliance Management System is a practical and accurate method of determining the applicability of the state and federal regulations and of establishing standard and straightforward procedures to meet these requirements. The Environmental Compliance Management System allows individual manufacturing facilities to avoid the additional manpower that would be required to read, digest and decide on the applicability and plan of action to meet the requirements of all the environmental regulations.

3403 $\mathrm{V} 18 / 020862$

Environmental Cost Handbook: A Guide for Developing, Using, and Supporting Communities

EER Systems, El Segundo, CA 
Report; 130 pp. (December 14, 1995)

This Environmental Cost Handbook was developed by the USAF Space and Missile Systems Center Financial Management Cost (SMC/FMC) Organization in response to growing environmental regulations and increased need to have visibility into system environmental costs. Cost estimating and analysis is a vital part of the environmental decision making process for DoD weapon system acquisition. Many new regulations are imposing challenges to the acquisition of new systems. Critical decisions regarding environmental issues must be made in each phase of acquisition. The timeliness, accuracy and consistency of environmental cost data will influence the quality of those decisions. This scope of this handbook includes any acquisition life cycle environmental activity where cost estimating or analysis may be involved. It is envisioned that this handbook will be provided to students as they receive environmental cost training at SMC. The material contained in the handbook is patterned after the most rigorous of acquisition requirements, an ACAT I Major Defense Acquisition Program (MDAP). The purpose of the handbook is to help ensure that program decisions are based upon sound cost data and to avoid any delays in program planning and execution due to environmental cost matters.

\section{$3404 \quad$ V18/022737}

Environmental Data Collection Process

Bottrell, D.W.; Harrington, P.A.

U.S. Department of Energy, Washington, DC; MAC Technical Services Company, Germantown, MD

CONF-960804 (Vol. 1); Spectrum '96: Nuclear and Hazardous Waste Management, Proceedings of an International Topical Meeting, Seattle, WA, August 18-23, 1996. American Nuclear Society, La Grange Park, IL, Vol. 1, 887 pp.; (pp. 830-835) (1996)

Environmental restoration and waste management decisions rely on defensible environmental data. The major elements of the environmental data collection process lay out the steps to address what data need to be collected and how data are assessed for usability in decision making. These data collection process elements are planning, sampling, analysis, data verification and validation, and data quality assessment. This paper describes the elements, along with some of the tools currently used to implement them, and how the elements relate to each other.

\section{$3405 \quad$ V18/022143}

Environmental Impact Assessment Models: 1995 Scientific Report of the Belgian Nuclear Research Centre

Zeevaert, $T$.

Centre d'Etude de l'Energie Nucleaire, Mol, Belgium

INIS-mf-14878; 138 pp. (pp. 92-93) (1996)

The objectives of the research activities in the field of the environmental impact assessment models at the Belgian Nuclear Research Centre SCK-CEN are: (1) to optimize radiological assessment models by validation and intercomparison and (2) to support the policy of radioactive waste management authorities in the field of radiation protection. In particular, research has been performed in the field of methodologies for the assessment of the impact of land disposal of radioactive waste in Belgium and on the assessment of the radiological consequences of important nuclear accidents or residual site contamination. The main achievements for 1995 are given.

3406

V18/023197

Environmental Implementation Programming: A Realistic Possibility in Present Central and Eastern European Circumstances?

Mansfeld, L.C.B.H.

Ministry of Environment, Den Haag, Netherlands

CONF-9210194; Proceedings of an International Symposium on Environmental Contamination in Central and Eastem Europe, Budapest, Hungary, October 12-16, 1992, 968 pp.; (pp. 301-303) (1992)

In this article, one of the important implementation techniques is dealt with: Implementation Programming. This management tool can be applied inside and outside the environmental field. Implementation programming is of particular use when an environmental policy-product that connects to complex, persisting problems is required in large quantities. This paper basically deals with the criteria an Environmental Implementation Program has to meet to be effective. Requirements learned from Dutch practice are put forward. The present situation in Central and Eastem Europe seems to be very well suited for the application of implementation programming in an original way.

3407

V18/023327

\section{Environmental Remediation Contracting}

Environmental Remediation Contracting, Wiley Law Publishers, New York, NY (October 1992)

This book contains practical, step-by-step guidance on remediation contract opportunities under federal and state laws, permit requirements, contract management, allocation of liabilities, coverage under CGL and other insurance policies. Sample contract terms and clauses, names and addresses of environmental offices, waste exchangers and others are featured in this comprehensive source.

\section{8}

V $18 / 023342$

Environmental Remediation Contracting - 1994 Supplement

Erickson, R.L.

Environmental Remediation Contracting, 1994 Supplement, Wiley Law Publishers, New York, NY (January 1994)

This book contains practical, step-by-step guidance on remediation contract opportunities under federal and state laws, permit requirements, contract management, allocation of liabilities, coverage under CGL and other insurance policies. Sample contract terms and clauses, names and addresses of environmental offices, waste exchangers and others are featured in this comprehensive source.

V18/023343

Environmental Remediation Contracting - 1995 Cumulative Supplement 


\section{Erickson, R.L.}

Environmental Remediation Contracting, 1995 Cumulative Supplement, Wiley Law Publishers, New York, NY (November 1994)

This book contains practical, step-by-step guidance on remediation contract opportunities under federal and state laws, permit requirements, contract management, allocation of liabilities, coverage under CGL and other insurance policies. Sample contract terms and clauses, names and addresses of environmental offices, waste exchangers and others are featured in this comprehensive source.

\section{0}

\section{V18/023325}

\section{Environmental Remediation Contracting - 1996}

Cumulative Supplement

Erickson, R.L.

Environmental Remediation Contracting, 1996 Cumulative Supplement, Wiley Law Publishers, New York, NY (1996)

This book contains practical, step-by-step guidance on remediation contract opportunities under federal and state laws, permit requirements, contract management, allocation of liabilities, coverage under CGL and other insurance polices. Sample contract terms and clauses, names and addresses of environmental offices, waste exchanges and others are featured in this comprehensive source.

V18/023507

\section{Environmental Remediation Cost and Risk Estimating} Software Summary

Youngblood, A.; Booth, S.R.

Los Alamos National Laboratory, Los Alamos, NM

LA-UR-92-1932; 30 pp. (June 1992)

This report describes the various cost estimating models currently available or under development for potential use in DOE environmental remediation efforts. Some models have received, or are receiving funding from the U.S. Government. As part of the Environmental Technology Cost Savings Analysis Project (ETCAP) at Los Alamos, a review of these models was conducted to identify which might be applicable to our effort. The results of that review are presented in this report.

\section{2 \\ V18/023328}

Environmental Reports and Remediation Plans: Forensic and Legal Review, 1996

Environmental Reports and Remediation Plans: Forensic and Legal Review, 1996, Wiley Law Publications, New York, NY (April 1996)

This book discusses: introduction to environmental reporting; legal considerations mandating environmental investigation; types of environmental reports; legal application of environmental reports; forensic review of environmental reports; geologic characterization; groundwater investigations; laboratory analysis and data presentation; federal guidelines and considerations; and potential liability and damages for remediation work.
Environmental Response Training Program: Schedule of Courses - September 1, 1996-September 30, 1997

U.S. Environmental Protection Agency, Office of Emergency and Remedial Response, Washington, DC

EPA/540/R-96/022; OSWER-9285.9-31A; 80 pp. (August 1996)

As part of EPA's comprehensive program for protecting the public and the environment from hazardous materials, the Emergency Response Division of OERR has developed the Environmental Response Training Program (ERTP). The courses of this program are designed for personnel who respond to emergencies or who investigate and clean up abandoned hazardous waste sites. Training is provided in safety and health as well as in the various technical operations needed to identify, evaluate and control hazardous substances that have been released.

3414

V18/024118

\section{Environmental Technology Cost-Savings Analysis Project (ETCAP)}

Los Alamos National Laboratory, Los Alamos, NM

LALP-95-47; 1 p. (1995)

The Environmental Cost-Savings Analysis Project (ETCAP) analyzes the potential cost savings that can accrue from successfully implementing innovative environmental technologies. This Los Alamos service involves comparing the life-cycle costs of a technology or system to that of a competing conventional or "baseline" system under comparable performance conditions. The analysis results can help managers rank new technologies in terms of cost effectiveness, allocate scarce research and development funding, and recommend which new technologies should undergo implementation for environmental activities.

3415

V18/021186

Environmental and Energy Applications of Neural Networks: Proceedings of the 1995 Workshop, Richland, WA, March 30-31, 1995

Hashem, S.; Keller, P.E.; Kouzes, R.T.; Kangas, L.J.

Pacific Northwest Laboratory, Richland, WA

PNL-SA-26375; CONF-9503142; Proceedings of a Workshop on Environmental and Energy Applications of Neural Networks, Richland, WA, March 30-31, 1995, 193 pp. (1995)

These proceedings contain edited versions of the technical presentations of the Workshop on Environmental and Energy Applications of Neural Networks, held on March 30-31, 1995, in Richland, Washington. The purpose of the workshop was to provide a forum for discussing environmental, energy, and biomedical applications of neural networks. Panels were held to discuss various research and development issues relating to real-world applications in each of the three areas. The applications covered in the workshop were: Environmental applications - modeling and predicting soil, air and water pollution, environmental sensing, spectroscopy, hazardous waste handling and cleanup; Energy applications - process monitoring and optimization of power systems, modeling and control of power plants, environmental monitoring for power systems, power load forecasting, fault location and diagnosis of power systems; and Biomedical applications - medical image and signal analysis, medical diagnosis, 
analysis of environmental health effects, and modeling biological systems. Selected papers are indexed separately for inclusion in the Energy Science and Technology Database.

\section{$3416 \quad \mathrm{~V} 18 / 022075$}

Estimation of Remediation-Related Contamination and Projected D\&D Worker and Public Exposure Doses

Thomas, R.G.

Consultant, Bigfork, MT

CONF-941 148 (Vol. 2); DDER-'94: Decommissioning, Decontamination, and Environmental Restoration at Contaminated Nuclear Sites, M.G. White (ed.), Proceedings of an Embedded Topical Symposium of the American Nuclear Society Winter Meeting, Washington, DC, November 13-18, 1994. American Nuclear Society, Inc., La Grange Park, Il, Vol. 2, 241 pp.; (pp. 445-455) (1994)

Interest in reconstruction of the radiation exposure doses that might possibly have been received by workers and members of the population continues to gain momentum in the process of decontamination, decommissioning, and environmental restoration (DD\&ER). The reasons for this increased enthusiasm for dose reconstruction are not so much attributed to realistic cause-effect phenomena, but more to a public apprehension based upon the current desire to live in a no-risk society. The apprehension is real, as it is kindled by socio-economic conditions, job security, and our ever expanding litigiousness. Regardless of the reason, it is an exciting field of science, it deals with the environment which is important to every individual, and it ultimately leads to a more acceptable living condition for the populous involved. The following general topics will be discussed in this presentation: (1) Contamination: Where and What Is It? (2) Factors Important in Dose Reconstruction; (3) Realistic Dose Estimation Based on Background Radiation; (4) Dose to the Public and Regulations; (5) Modeling Requirements for DD\&ER and Dose Reconstruction; (6) Stumbling Blocks in the DD\&ER Process. Regardless of the ultimate degree of cleanliness desired, the steps outlined are needed to establish the extent of the cleanup and restoration that is to be funded. The examples to be used show in actual practice how this has been handled in the recent past, at one or more sites, under present regulatory restrictions.

\section{7 \\ V18/022971}

\section{Estimation of Whole-Fish Contaminant Concentrations from Fish Fillet Data}

Bevelhimer, M.S.; Beauchamp, J.J.; Sample, B.E.; Southworth, G.R.

Lockheed Martin Energy Systems, Inc., Oak Ridge, TN; Oak Ridge National Laboratory, Risk Assessment Program, Oak Ridge, TN

$$
\text { ES/ER/TM-202; } 16 \text { pp. (February 1997) }
$$

The purpose of this technical memorandum is to present the results of an investigation of the relationship between fillet and whole-fish contaminant concentrations and develop equations for the estimation of whole-fish concentrations for several analytes. Fish were collected from several sites in Tennessee and Ohio and analyzed for contaminants; analyses were conducted on fillet portions as well as the remaining carcasses of 31 bass and 10 catfish. The report provides contaminant-specific equations to describe the relationship between fillet and whole-body contaminant concentrations.

\section{$3418 \quad \mathrm{~V} 18 / 022416$}

Evaluation of Commercial Environmental Cost Databases: Final Letter Report for Task 9 - March 15, 1995 Through June 15, 1995

Stanton, J.

ARINC, Annapolis, MD; U.S. Department of Energy, Office of Infrastructure Acquisition, Washington, DC

Report; 15 pp. (1995)

The purpose of this task was to evaluate the commercially available cost databases and determine their suitability for development of cost-estimating relationships (CERs) or other tools for use in environmental cost-estimating. The scope of the task was to describe the cost databases, evaluate the databases based upon pre-established criteria, and summarize the results. Three databases were evaluated in detail. Additionally, a limited review was performed on the PEI Associates, Inc., and the Savannah River Site data that were provided as additional information at the mid-term review. This final letter report summarizes the work that was accomplished under Task 9 of Contract DE-AC01-92PR 10003 for the Department of Energy (DOE) Office of Infrastructure Acquisition (FM-50). The period of performance was March 15 . 1995 , through June 15,1995 . This report summarizes the evaluation of various cost databases for use in environmental cost estimating.

Evaluation of Radiochemical Data Usability

Paar, J.G.; Porterfield, D.R.

University of Tennessee, Knoxville, TN; Oak Ridge National Laboratory, Oak Ridge, TN; Los Alamos National

Laboratory, Chemical Science and Technology Division, Los Alamos, NM

ES/ER/MS-5; 75 pp. (April 1997)

Environmental remedial decisions require the acquisition of data of known and sufficient quality for intended use. Data verification and validation (V\&V) are two of the tools that ensure a level of quality assurance in data usability. When applied to radiochemistry, no national standard currently covers V\&V concepts adequately, and the need for a document of this type was recognized by most of the Department of Energy Complex. This document was developed through intersite cooperation and provides a reasonable approach for the evaluation of radioanalytical data for purposes of environmental remediation but can also be applied to data intended for non-remedial purposes. This document is intended to provide a framework onto which implementing procedures can be written. It is a stand-alone document for the purposes of data evaluation; however, sufficient laboratory deliverables must exist to enable the $V \& V$ tools to be used. It is recommended that if $V \& V$ procedures are written based on this document, that corresponding specifications for analytical laboratory deliverables are also written. 


\section{0}

V18/021519

Evaluation of Three Representative Multimedia Models Used to Support Cleanup Decision-Making at Hazardous, Mixed, and Radioactive Waste Sites Moskowitz, P.D.; Pardi, R; Fthenakis, V.M.; Holtzman, S. Brookhaven National Laboratory, Upton, NY Risk Analysis 16(2):279-287 (April 1996)

The decision process involved in cleaning sites contaminated with hazardous, mixed, and radioactive materials is often supported by results obtained from computer models. These results provide limits within which a decision-maker can judge the importance of individual transport and fate processes, and the likely outcome of alternative cleanup strategies. Thie transport of hazardous materials may occur predominately through one particular pathway but, more often, actual or potential transport must be evaluated across several pathways and media. Multimedia models are designed to simulate the transport of contaminants from a source to a receptor through more than one environmental pathway. Three such multimedia models are reviewed here: MEPAS, MMSOILS, and PRESTO-EPA-CPG. The reviews are based on documentation provided with the software, on published reviews, on personal interviews with the model developers, and on model summaries extracted from computer databases and expert systems. The three models are reviewed within the context of specific media components: air, surface water, groundwater, and food chain. Additional sections evaluate the way that these three models calculate human exposure and dose and how they report uncertainty. Special emphasis is placed on how each model handles radionuclide transport within specific media. For the purpose of simulating the transport, fate and effects of radioactive contaminants through more than one pathway, both MEPAS and PRESTO-EPA-CPG are adequate for screening studies; MMSOILS only handles nonradioactive substances and must be modified before it can be used in these same applications. Of the three modeis, MEPAS is the most versatile, especially if the user needs to model the transport, fate, and effects of hazardous and radioactive contaminants.

3421 V18/024073

Evaluation of an Evanescent Fiber Optic Chemical Sensor for Monitoring Aqueous Volatile Organic Compounds

Blair, D.S.

Sandia National Laboratories, Environmental Characterizations and Monitoring Systems Department, Albuquerque, NM

SAND97-0782; 40 pp. (April 1997)

Linear chemometric algorithms were used to model the quantitative response of an evanescent fiber optic chemical sensor in aqueous mixtures with concentrations between 20 and $300 \mathrm{ppm}$. Four data sets were examined with two different experimental arrangements. Two data sets contained trichloroethene, 1,1,2, trichloroethane, and toluene. Partial Least Squares (PLS) and Principal Component Regression (PCR) algorithms performed comparably on these calibration sets with cross-validated root mean squared errors of prediction (RMSEP) for trichloroethene, 1,1,1 trichloroethane, and toluene of approximately 26,29 and 22 ppm, respectively. The third data set contained trichloroethene, 1,1,2 trichloroethane, toluene, and chloroform and the fourth contained these four analytes as well as tetrachloroethene. Again, both chemometric algorithms performed comparably on a given data set with RMSEP for trichloroethene, 1,2,2 trichloroethane, toluene, and chloroform of approximately $6,6,9$, and $16 \mathrm{ppm}$ from the first set, and 7,11, 13 , and $31 \mathrm{ppm}$ from the second set with tetrachloroethene RMSEP of $31 \mathrm{ppm}$. The decrease in the quantitative performance of the sensor for modeling toluene and chloroform upon addition of tetrachloroethene to the sample solutions is due to increased cladding absorption features in the spectral response matrix. These features overlap with the analyte absorption features of toluene and chloroform. These results suggest one of the limitations with this type of sensing format.

\section{2} V18/024046

Evaluation of an Insitu, On-Line Purging System for the Cone Penetrometer

Doskey, P.V.; Aldstadt, J.H.; Kuo, K.M.; Costanza, M.S.

Argonne National Laboratory, Environmental Research Division, Argonne, IL

Air and Waste Management Association 46(11):1081-1085 (November 1996)

Materials that will be used to construct an in situ, on-line purging system for the cone penetrometer were evaluated. Transfer efficiencies for volatile organic compounds (VOCs) through stainless steel, nickel, aluminum, and Teflon [R] tubings were determined using a gas-phase mixture of VOCs containing trichloromethane, tetrachloromethane, 1,1,1-trichloroethane, tetrachloroethene, hexane, benzene, toluene, and 1,2-dimethylbenzene. The water content of the gas stream had an insignificant effect on the quantitative transfer of VOCs through Teflon $[R]$ tubing but was critical to efficiently transfer the compounds through metal tubing, particularly nickel. Transfer efficiencies for all eight analytes in moist gas streams through stainless steel were greater than $95 \%$. Toluene, tetrachloroethene, and 1,2-dimethylbenzene were transferred with $93 \%, 81 \%$, and $80 \%$ efficiency, respectively, when they were drawn through Teflon [R] PFA (perfiuoroalkoxy) tubing. In general, the retention of the VOCs by Teflon $[R]$ increases with decreasing aqueous solubility of the analyte. The efficiencies at which VOCs were purged from aqueous standards in Teflon [R] PFA, Type 304 stainless steel, and glass vessels were similar. Stainless steel was superior to nickel, aluminum, and the Teflon [R] polymers as a material for an in situ, on-line purging system for the cone penetrometer.

\section{3}

V18/022038

Evaluation of the Performance of Laser Sources and Fiber Optic Probes for Insitu Raman Measurements

Angel, S.M.; Cooney, T.F.; Skinner, H.T.

University of South Carolina, Department of Chemistry and Biochemistry, Columbia, SC

CONF-9506232; Environmental Monitoring and Hazardous Waste Site Remediation, T. Vo-Dinh and R. Niessner (eds.), Proceedings of a Conference of the Society of Photo-Optical Instrumentation Engineers, Munich, Germany, June 19-23, 1995. International 
Society for Optical Engineering, Bellingham, WA, 613 pp.; (pp. 40-51) (1995)

Systematic and reproducible methods of evaluating fiber-optic probes and laser sources for Raman spectroscopy have been developed. We have investigated the performance of two different types of extemal cavity diode laser sources for Raman spectroscopy. These lasers were evaluated in terms of long-term wavelength drift and power stability. Experimental methods and computer-generated models were developed to evaluate fiber-optic Raman probe performance under a variety of conditions and for a variety of sample types. Performance parameters investigated include probe sensitivity, sampling volume, and discrimination against fiber-optic silica background. Sample types studied include clear liquids and solids, highly scattering solids and slurries, and highly adsorbing liquids and solids.

\section{$3424 \quad \mathrm{~V} 18 / 022101$}

Expediting Site Closures Using a Risk-Based Corrective Action Approach

Sims, J.T.; Douthit, T

Land Tech Remedial, Inc., Frederick, MD; Land Tech Remedial, Inc., Farmingdale, NY

CONF-951139 (Vol. 1); Superfund 16: Proceedings of a Hazardous Waste Conference and Exhibition, Washington, DC, November 6-8, 1995. E.J. Krause and Associates, Bethesda, MD, Vol. 1, 828 pp.; (pp. 653-658) (1994)

As more states and federal agencies adopt risk-based corrective action criteria, determining the risk of exposure of hazardous chemicals to health and the environment becomes the means for establishing the priority for action at impacted sites and the necessity for remediation. Currently, this procedure involves an often costly, multi-phase process including determining the location and extent of a contaminant plume, the rate at which contaminants are moving through soil and groundwater, and whether or not natural degradation is occurring. The comprehensive acquisition of data commencing at the start of the corrective action process correlates directly to cost-effectively closing sites impacted by contaminants. This is supported by the number of states allowing for the use of, and in many cases, requiring accelerated site characterization. A number of new tools have been developed to speed and improve sample and data acquisition as well as the analysis of data on-site. These tools allow on-site personnel to make informed decisions as to the progress of the investigation and effectively direct subsequent efforts.

\section{5}

V18/025502

Fast and Accurate Radon Measurement Tool for Remedial Actions in Buildings

Soavi, R.

Silena S.p.A., Cernusco S/N, Milan, Italy

CONF-930607; Proceedings of the First Intemational Workshop on Indoor Radon Remedial Action: The Scientific Basis and Practical Implications, Rimini, Italy, June 27-July 2, 1993; Radiation Protection Dosimetry 56(1-4):251-254 (1994)

Continuous monitoring of radon concentration is an effective and fast method for assessing radon sources in buildings. For this purpose, fast response and absence of residual contribution from previous measurements is of primary importance to cut intervention time and cost in a remedial action. An instrument is described based on a scintillation cell. The instrument has the ability to characterize both high and low activity environments in rapid sequence, even with a switch off/on operation in between, with almost no influence on the measurement accuracy. A discussion of the computations and results from measurements is given.

\section{6}

\section{V18/022826}

Fernald's Dilemma: Do We Recycle the Radioactively Contaminated Metals, or Do We Bury Them?

Yuracko, K.L.; Hadley, S.W.; Perlack, R.D.; Gresalfi, M.J.; Yerace, P.

Oak Ridge National Laboratory, Oak Ridge, TN; Oak Ridge National Laboratory, Germantown, MD; U.S. Department of Energy, Fernald Environmental Management Project, Fernald, $\mathrm{OH}$

CONF-960804 (Vol. 3); Spectrum '96: Nuclear and Hazardous Waste Management, Proceedings of an International Topical Meeting, Seattle, WA, August 18-23, 1996. American Nuclear Society, La Grange Park, IL, Vol. 3, 841 pp.; (pp. 1894-1900) (1996)

During the past five years, a number of U.S. Department of Energy (DOE) funded efforts have demonstrated the technical efficacy of converting various forms of radioactive scrap metal (RSM) into usable products. From the development of large accelerator shielding blocks, to the construction of low level waste containers, technology has been applied to this fabrication process in a safe and stakeholder supported manner. The potential health and safety risks to both workers and the public have been addressed. The question remains; can products be fabricated from RSM in a cost efficient and market competitive manner? This paper presents a methodology for use within DOE to evaluate the costs and benefits of recycling and reusing some RSM, rather than disposing of this RSM in an approved burial site. This life cycle decision methodology, developed by both the Oak Ridge National Laboratory (ORNL) and DOE Fernald is the focus of the following analysis.

\section{7}

\section{V18/020745}

Field Assessment Screening Team (FAST) Technology Process and Economics [July 1995]

Nickelson, M.D.; Long, D.D.

Lockheed Martin Energy Systems, Inc., Oak Ridge, TN

CONF-9507204; Hazardous and Industrial Wastes, A.K. Sengupta (ed.), Proceedings of the 27th Mid-Atlantic Industrial Waste Conference, Bethlehem, PA, July 9-12, 1995. Technomic Publishing Company, Lancaster, PA, 973 pp.; (pp. 664-668) (1995)

The Field Assessment Screening Team (FAST) is a concept of site characterization innovative technologies that have been integrated (1) to expedite the characterization process for hazardous and/or radioactive waste sites, (2) to optimize characterization quality, (3) to reduce field time, and (4) to effect characterization cost reductions in the $60 \%$ to $80 \%$ range. The FAST system has the following advantages: (1) reduces environmental site 
characterization field time, (2) reduces site characterization sampling costs, (3) reduces site characterization analytical costs, (4) reduces waste generation during field activities, (5) improves field worker safety during environmental site characterizations, and (6) allows for rapid technology transfer.

\section{$3428 \quad V 18 / 021191$}

Field Assessment Screening Team (FAST) Technology Process and Economics [February 1995]

Nickelson, M.D.; Long, D.D.

Lockheed Martin Energy Systems, Inc., Oak Ridge, TN CONF-950209 (Vol. 1); VIP-47, Proceedings of the Fourth International Symposium on Field Screening Methods for Hazardous Wastes and Toxic Chemicals, Las Vegas, NV, February 22-24, 1995. Air and Waste Management Association, Pittsburgh, PA, Vol. 1, 733 pp.; (pp. 79-82) (1995)

The Field Assessment Screening Team (FAST) is a concept of innovative site characterization technologies that have been integrated (1) to expedite the characterization process for hazardous and/or radioactive waste sites, (2) to optimize characterization quality, (3) reduce field time, and (4) to effect characterization cost reductions in the 60 to $80 \%$ range. The FAST technology is an integrated system of state-of-the-art components that collectively produce a process that ensures a lower cost, high-quality, real-time decision-making environmental field screening. The components of the integrated system are as follows: (1) intrusive sampling based on (but not limited to) "push" technology for surface, subsurface, and groundwater media sampling; (2) a field mobile laboratory equipped to complement expected site contaminants; (3) computer-assisted design/geographic information system (CAD/GIS) data management with interactive three-dimensional graphics presentation capability; (4) a global positioning system to determine sample coordinates; and (5) a telecommunication linkup for data transmittal and receiving. Using the integrated components, the technology is designed to determine the horizontal and vertical extent of site soil and/or groundwater contamination with one mobilization of the field investigative team. The system allows the user to make informed field decisions concerning site investigation plans on a real-time basis, thus assuring minimum field time, minimum cost, and optimum data collection.

\section{9}

\section{V18/022418}

Field Comparison of Micropurging vs. Traditional Groundwater Sampling

Kearl, P.M.; Korte, N.E.; Stites, M.E.; Baker, J.L.

Oak Ridge National Laboratory, Oak Ridge, TN; Oak Ridge National Laboratory, Environmental Sciences Division, Grand Junction, CO; AlliedSignal, Inc., Kansas City, MO

Groundwater Monitoring and Remediation 14(4):8 (1994)

Micropurge sampling of groundwater wells has been suggested as a possible replacement to traditional purge and sample methods. To compare methods, duplicate groundwater samples were collected at two field sites using traditional and micropurge methods. Samples were analyzed for selected organic and inorganic constituents, and the results were compared statistically. Analysis of the data using the nonparametric sign test indicates that within a 95 percent confidence interval, there was no significant difference between the two methods for the site contaminants and the majority of analytes. These analytical results were supported by visual observations with the colloidal borescope, which demonstrated impacts on the flow system in the well when using traditional sampling methods. Under selected circumstances, the results suggest replacing traditional sampling with micropurging based on reliability, cost, and waste minimization.

\section{0}

\section{V18/021941}

Field Testing Plan for Unsaturated Zone Monitoring and Field Studies

Young, M.H.; Wieregna, P.J.; Warrick, A.W.; Hofmann, Musil, S.A.; Scanlon, B.R.; Nicholson, T.J.

University of Texas, Austin, TX; University of Arizona, Tucson, $A Z$

\section{NUREG/CR-6462; 55 pp. (October 1996)}

The University of Arizona, in cooperation with the Bureau of Economic Geology at The University of Texas at Austin, and Stephens and Associates in Albuquerque, New Mexico has developed a field testing plan for evaluating subsurface monitoring systems. The U.S. Nuclear Regulatory Commission has requested development of these testing plans for low-level radioactive waste disposal sites ( $L L W$ ) and for monitoring at decommissioned facilities designated under the "Site Decommissioning Management Plan" (SDMP). The tests are conducted on a $50 \mathrm{~m}$ by $50 \mathrm{~m}$ plot on the University of Arizona's Maricopa Agricultural Center. Within the $50 \mathrm{~m}$ by $50 \mathrm{~m}$ plot one finds: (1) an instrumental buried trench, (2) monitoring islands similar to those proposed for the Ward Valley, California LLW Facility, (3) deep borehole monitoring sites, (4) gaseous transport monitoring, and (5) locations for testing non-invasive geophysical measurement techniques. The various subplot areas are instrumented with commercially available instruments such as neutron probes, time domain reflectometry probes, tensiometers, psychrometers, heat dissipation sensors, thermocouples, solution samplers, and cross-hole geophysics electrodes. Measurement depths vary from ground surface to $15 \mathrm{~m}$. The data from the controlled flow and transport experiments, conducted over the plot, will be used to develop an integrated approach to long-term monitoring of the vadose zone at waste disposal sites. The data will also be used to test field-scale flow and transport models. This report describes in detail the design of the experiment and the methodology proposed for evaluating the data.

3431 V18/023819

Field-Based Laser-Induced Breakdown Spectroscopy (LIBS) Instrumentation

\author{
Cremers, D.A.; Ferris, M.J.; Blacic, J.D.; Pettit, D.R.
}

Los Alamos National Laboratory, Los Alamos, NM

CONF-960113; Proceedings of the 1996 Winter Conference on Plasma Spectrochemistry, Fort Lauderdale, FL, January 8-13, 1996, 378 pp.; (p. 121) (1996)

Laser-Induced Breakdown Spectroscopy (LIBS) has many advantages for field-based elemental analysis of materials compared 
to conventional analysis methods. These inciude: (1) simplicity; (2) absence of sample preparation; (3) multi-element analysis capability, (4) in-situ analysis because only optical access to the sample is required, (5) good detection sensitivity for many elements, and (6) compact instrumentation. Because of these advantages, IIBS is being considered for real-world analysis problems not feasible using conventional elemental anaiysis techniques. At Los Alamos National Laboratory, prototype instruments have been developed to analyze airborne toxic materials, contaminants on surfaces (e.g., lead in paint), metals in soils, and surfaces at standoff distances. These instruments are all based on laser plasmas formed by Nd:YAG lasers operating at 1064 $\mathrm{nm}$. For air monitoring, a LIBS instrument has been designed specifically to monitor airbome concentrations of Be particles. To determine contaminant on surfaces, a portable LIBS instrument has been developed that fits completely within a small suitcase. The LIBS-based soil analyzer is contained within a large plastic shipping container and can provide a rapid anaiysis of soils. The soil samples, ranging in mass from 4-20 grams are inserted into the instrument for analysis. A field-transportable remote LIBS analyzer has been developed to monitor contaminants in soils, to distinguish between different steel alloys, and to monitor dusts on surfaces. The instrument consists of a sampling head containing the laser and a large suitcase containing the analysis instrumentation. This device is currently undergoing testing for use in nonproliferation monitoring activities. Some analysis results obtained using this instrument will be described.

\section{2 \\ V18/021516}

Framework for Ecological Risk Assessment: General Guidance

Canadian Council of Ministers of the Environment, Winnipeg, Manitoba, Canada

Report; 32 pp. (March 1996)

A framework for ecological risk assessment (ERA) for contaminated sites was developed as part of the Canadian Council of Ministers of the Environment (CCME)-initiated National Contaminated Sites Remediation Program. This document is intended as a general guide for utilizing the ERA framework. The program was developed by CCME to remediate high-risk contaminated sites that threaten the environment or human health. The framework for ERA was developed in order to promote consistency in the assessment and remediation of these sites. It serves as the basis for making remediation decisions and to derive environmental quality criteria. A three-step approach to ERA is recommended: (1) screening assessment, (2) preliminary quantitative ERA, and (3) detailed quantitative ERA. The primary purpose of the ERA assessment is to obtain toxicity information for the contaminants concerned and to evaluate the target chemicals.

\section{3}

V18/023773

Future of Petroleum Hydrocarbon Analyses in California

DeMartino, L.; Morales, E.

National Environmental Testing, Santa Rosa, CA; Sierra

Environmental Services, Inc., Martinez, CA
CONF-9504134; HAZMACON '95, T. Bursztynsky and M.L. Loss (eds.), Proceedings of the Twelfth Hazardous Materials Management Annual Conference and Exhibition, San Jose, CA, April 4-6, 1995. Association of Bay Area Governments, Oakland, CA, 790 pp.; (pp. 42-50) (1995)

The shortcomings of the current methodologies for Petroleum Hydrocarbon identification and quantification, as described in the LUFT Field Manual and the Tri-Regional Board Staff Recommendations for Preliminary Evaluation and Investigation of Underground Tank Sites, are becoming increasingly evident. The lack of specificity within these methods allow for individual laboratory interpretation which results in a wide variability in data. These methods do not address the occurrence of organic material not related to petroleum hydrocarbons being present in the groundwater or soil. Nor do they answer the questions, "Is the response on the instrument actually a petroleum hydrocarbon?", and "is the material present in the groundwater or soil negatively impacting the environment?" This paper presents case studies which demonstrate the amount of additional consulting time and costs associated with the interpretation of laboratory generated by these ineffective, non-specific analytical methods. In addition, this paper includes technical approaches that have been proposed to the State sponsored Petroleum Hydrocarbon Committee for consideration in their evaluation of new and existing methodology for use in UST investigations. The proposed technical approaches include the following: mandatory submission of petroleum hydrocarbon chromatograms generated during preliminary investigations; uniform extraction techniques with proper clean-up procedures to account for selected non-petroleum interferences; the use of high resolution gas chromatography for better overall fuel identification with attention to indicator compounds such as pristane and phytane; and simplified toxicity screening for non-petroleum waste characterization. Now exists an urgent need to replace existing LUFT methodology with a technicaily stronger suite of analyses geared towards absolute identification and consistent quantification of petroleum wastes. The California SWRCB and RWQCBs need to adopt definitive analytic procedures to allow UST owners and operators to conduct cost effective investigations. The proposed technical approaches as described in this paper will serve to minimize wasted time and money in clarifying petroleum hydrocarbon results and enhance UST investigations.

3434

V $18 / 024127$

Gravity Gradiometers for Environmental Waste Inspection

Los Alamos National Laboratory, Los Alamos, NM

LALP-95-35; 1 p. (1995)

Los Alamos has developed a process to measure and map changes in gravitational fields by using sensitive gravity gradiometers with superconducting quantum interference device (SQUID) sensors. This process detects localized variations in the gravitational field caused by sizable bodies of materials in which the density of the constituents vary or are different from their surroundings. This process does not introduce radiation or any other from of energy into the region of interest. Applications for this technology include the passive measurements of density variations and subterranean structures. 


\section{5}

V18/022436

Guidance Manual on Sampling, Analysis, and Data Management for Contaminated Sites: Volume 1

Canadian Council of Ministers of the Environment, Winnipeg, Manitoba, Canada

Report; 79 pp. (1993)

This two-volume set is one of a series of technical support documents to assist in the assessment and remediation of contaminated sites across Canada. It provides a consistent approach to sampling, analysis, and data management of contaminated sites on a national basis. It stresses the significance of quality assurance, focusing on the specific analytes identified in CCME's 1991 report, Interim Environmental Quality Criteria for Contaminated Sites. Volume 1 is the main report and covers the sampling, analyzing, and data management of the four environmental matrices: soils, sediments, surface waters, and groundwater. Volume 2, the analytical method summaries, identifies the information needed for the selection of methods, and the major analytical instrumentation required.

\section{6}

V18/023346

Guidance Manual on Sampling, Analysis, and Data Management for Contaminated Sites: Volume 2

Canadian Council of Ministers of the Environment, Winnipeg, Manitoba, Canada

Report; 171 pp. (1993)

This two-volume set is one of a series of technical support documents to assist in the assessment and remediation of contaminated sites across Canada. It provides a consistent approach to sampling, analysis, and data management of contaminated sites on a national basis. It stresses the significance of quality assurance, focusing on the specific analytes identified in CCME's 1991 report, Interim Environmental Quality Criteria for Contaminated Sites. Volume 1 is the main report and covers the sampling, analyzing, and data management of the four environmental matrices, soils, sediments, surface waters, and groundwater. Volume 2, the analytical method summaries, identifies the information needed for the selection of methods, and the major analytical instrumentation required.

3437

\section{V18/023392}

Guidance for Evaluation of Federal Agency Demonstrations that Remedial Actions Are Operating Properly and Successfully Under CERCLA Section 120(h)(3)

U.S. Environmental Protection Agency, Office of Solid Waste and Emergency Response, Washington, DC

Report; 19 pp. (August 1996)

This guidance is intended to provide direction to Environmental Protection Agency (EPA) Regional Federal Facility programs concerning the implementation of Comprehensive Environmental Response, Compensation, and Liability Act (CERCLA) section 120(h)(3). It addresses the approach EPA should use in evaluating a federal agency's demonstration that a remedial action is 'operating properly and successfully' as a precondition to the deed transfer of federally-owned property, as required in section $120(h)(3)$.

3438

V18/021059

Guidance for Generating Legally Defensible Data

Rosecrance, A.; Kibler, L.

Core Laboratories, Analytical Chemistry Division, Houston, TX

CONF-940499 (Vol. 1); Proceedings of the 1994 Federal Environmental Restoration III and Waste Minimization II Conference and Exhibition, New Orleans, LA, April 27-29, 1994. Hazardous Materials Control Resources Institute, Rockville, MD, Vol. 1, 783 pp.; (pp. 460-469) (1994)

The current emphasis on enforcement to achieve compliance with environmental regulations places increased demands on environmental professionals to generate legally defensible data. Since any environmental data may potentially be used in civil or criminal litigation, it must be suitable for use as admissible evidence. Although data cannot be guaranteed to be legally defensible because the proof of defensibility can only be determined in actual legal proceedings, there are steps that can be taken to enhance or increase the chances of admissibility. In order for data to be defensible and of known and documented quality, all sampling and analysis activities must meet applicable technical standards and be fully documented. Recordkeeping must be stressed throughout all sampling and analysis activities; failure to keep proper records is a common allegation in enforcement actions and a cause for lack of data defensibility. Though there is extensive reference documentation on the requirements for technical data quality, there is limited guidance available on data defensibility procedures. This paper provides guidance to assist field samplers, laboratory personnel, and project managers in planning for and generating legally defensible data. An example checklist that can be used in the planning and verification stages of the data generation process is provided.
3439
V18/021436

Guide for Developing Data Quality Objectives for Ecological Risk Assessment at DOE Oak Ridge Operations Facilities [Rev. 1]

Barnthouse, L.W.; Suter, G.W., II

Oak Ridge National Laboratory, Environmental Restoration Risk Assessment Program, Oak Ridge, IN

ES/ER/TM-185/R1; 15 pp. (June 1996)

For the past several years the United States Environmental Protection Agency (EPA) has been attempting to streamline and increase the efficiency of field data collection programs, especially Comprehensive Environmental Response, Compensation, and Liability Act (CERCLA) Remedial Investigation (RD) Programs, by encouraging project managers to develop Data Quality Objectives (DQOs) prior to initiation of sampling. The Agency has been aggressively promoting DQOs as a planning tool for RI/Feasibility Studies (FS) activities at CERLCA sites. The Oak Ridge Reservation Environmental Restoration Program has been actively involved in the DQO process since 1992, when the Clinch River RI Program was chosen as a pilot site for application of EPA's draft DQO guidance. Although DQO experts from EPA conducted the process, 
difficulties were immediately encountered in applying the guidance to data collection programs intended to support ecological risk assessments. The DQO process, as defined by EPA, is "...a strategic planning approach based on the Scientific Method that is used to prepare for a data collection activity. It provides a systematic procedure for defining the criteria that a data collection design should satisfy, including when to collect samples, where to collect samples, the tolerable level of decision errors for study, and how many samples to collect." It is important to note that DQOs are developed through a process that ties data collection to specific problems and decisions. The process involves identification and participation of stakeholders and issues, not simple application of statistical formulas. This technical memorandum provides guidance for the DQO process.

\section{$3440 \quad \mathrm{~V} 18 / 021409$}

Handbook on the Use of Technology Development Files Marshall, R.W., Jr.

Idaho National Engineering Laboratory, Idaho Falls, ID DOE/DD-10449; 35 pp. (October 1993)

This handbook describes the purpose and use of Technology Development Files (TDFs) for work funded by Environmental Restoration and Waste Management's (EM-50) Office of Technology Development (OTD). The TDF has multiple uses. Its primary purpose is to document and communicate base level technical information, as it is generated, to those persons who need the information. Second, it stores this information in an easily retrievable manner for future use by program and project personnel. As planned, this system will also permit distribution nationaily to other interested US DOE people supporting OTD's development effort. This document describes the type of information that should be contained within a TDF and the process for preparing and maintaining TDFs. Examples of TDFs and Engineering Design Files, the predecessor to TDFs, are provided.

\section{1 \\ V18/020741}

Identification and Radiological Characterization of Contaminated Sites: Criteria and Methods

Laraia, $M$.

International Atomic Energy Agency, Waste Management Section, Vienna, Austria

IAEA-TECDOC-865; CONF-9310459 (Vol. 1); Planning for Environmental Restoration of Radioactively Contaminated Sites in Central and Eastem Europe, Volume 1: Identification and Characterization of Contaminated Soils, Proceedings of a Workshop on Environmental Restoration in Central and Eastem Europe, Budapest, Hungary, October 4-8, 1993. International Atomic Energy Agency, Vienna, Austria, Vol. 1, 356 pp.; (pp. 19-30) (February 1996)

The purpose of a site characterization program centers on the need to obtain specific radiological data concerning areas that have become radioactively contaminated as the result of accidents, uranium mining and milling, or other nuclear activities. A site characterization requires a logical and planned approach in order to obtain the data necessary for planning an environmental restoration program. The data is used to determine effective and appropriate techniques and sequencing to support the environmental restoration effort. This data is also needed for planning radioactive waste disposal, accurate scheduling assessment, and estimating the cost of an environmental restoration program. The first step in any characterization effort is the development of a plan. The basis for this plan is provided by definition of the final restoration objective(s). The characterization plan may require preliminary investigations to support existing information. Based on the objectives of the plan, data acquisition instruments and protocols are selected that best obtain required data in the most cost-effective manner. Radiological information is obtained by a combination of in situ measurements and laboratory sample analysis.

3442

V18/023221

Identifying Data Needs and Developing Data Quality Objectives

Rottero, T.E.

Theta Technologies, Inc., Oak Ridge, TN

CONF-9210194; Proceedings of an International Symposium on Environmental Contamination in Central and Eastem Europe, Budapest, Hungary, October 12-16, 1992, 968 pp;; (pp. 487-489) (1992)

This paper presents an overview of data needs identification and the development of data quality objectives (DQOs) for site specific environmental restoration activities. Restoration activities are conducted in phases which include: Phase 1 - an investigation, Phase 2 - selection of remedy and feasibility study, Phase 3 - remedy design, Phase 4 - remedial activity. Identifying data needs, developing quality objectives, and collecting viable data is an intricate part of each restoration phase. DQOs applicable to all data collection activities and are established prior to any collection activity. The degree of data quality is directly related to the intended use of the data. All investigation activities should be conducted and documented in a manner that ensures that sufficient data of a known quality are collected to support decisions concerning restoration. This paper is intended to present an overview of the processes used to identify data needs and deveiop DQOs as well as address the need for viable data. Although the variability of site characteristics makes it impossible to apply a generic set of DQOs to all restoration activities, the process for identifying data needs and developing the DQOs for individual sites will be the same.

\section{$3443 \quad \mathrm{~V} 18 / 021362$}

Impact of Standards for Recycling Radioactive Scrap Metal

Large, D.E.

Scientific Ecology Group, Inc., Oak Ridge, TN

CONF-940798; Proceedings of the Workshop on Radioactively Contaminated Scrap Metal, University of Tennessee, Energy, Environment and Resources Center, Knoxville, TN, July 12-14, 1994; (3 pp.) (July 12, 1994)

Of great focus during these years and bringing to point now is the lack of applicable standards for release of recycled radioactive scrap metal. However, many tons of surface contaminated metal have been successfully decontaminated to existing requirements and 
released for reuse in commerce. In the U.S. we do not yet have approved standards for unrestricted commercial use of decontaminated volumetrically contaminated scrap metal. European countries, such as Spain, permit the reuse of scrap metal which has been volumetrically contaminated but decontaminated to a prescribed becquerel level.

\section{$3444 \quad$ V18/024876}

Insitu Permeable Flow Sensor: A Groundwater Flow Velocity Meter

Ballard, S.

Sandia National Laboratories, Geophysics Department, Albuquerque, NM

Groundwater 34(2):231-240 (March-April 1996)

A new technology called the In Situ Permeable Flow Sensor has been developed at Sandia National Laboratories. These sensors use a thermal perturbation technique to directly measure the direction and magnitude of the full three-dimensional groundwater flow velocity vector in unconsolidated, saturated, porous media. The velocity measured is an average value characteristic of an approximately 1 cubic meter volume of the subsurface. The sensors are permanently buried in direct contact with the formation at the point where the velocity measurement is to be made. While this deployment strategy means that the approximately $\$ 2500$ instruments are not recovered, borehole effects which can negatively influence the quality of the measurement are avoided. The sensors can be connected to a data acquisition system which can be monitored remotely, via modem and telephone connection, for extended periods of time. The technology is able to measure flow velocities in the range of $5 \times 10(E-6)$ to $1 \times 10(E-3) \mathrm{cm} / \mathrm{s}$, depending on the thermal properties of the medium in which it is buried.

3445

V18/024112

Insitu RCRA Metals Analysis: Field Analysis for Contamination in Soils

Los Alamos National Laboratory, Los Alamos, NM

LALP-94-250; 1 p. (1994)

Soil analysis for metals taken from hazardous waste sites, such as the Solid Waste Management Units, are primarily analyzed in the laboratory. Sample acquisition and handling prior to laboratory analysis is a prime consideration for accurate and dependable analyses. High analysis costs presently restrict sampling to a limited number of locations. Choosing a representative sample is a difficult but critical task with limited sampling. The use of an instrument based on laser-induced breakdown spectroscopy (LIBS) technology will be a cost-effective solution to the sampling problem. Using LIBS, it will be possible to determine rapidly both the concentration and location of elemental species in a waste site.

3446

V18/021395

Increasing the Efficiency of Deploying Technologies to Address DOE Cleanup: Moving Toward Performance Based Contracts

Warren, S.W.

U.S. Department of Energy, Office of Environmental Restoration, Washington, DC
Fostering the Needed Partnerships: Doing the Necessary Science to Support Technology Development, Commercialization, Deployment, E.L. Helminski (ed.), Proceedings of the Seventh Annual Western Governors' Association/Weapons Complex Monitor Applied Research and Cleanup Technology Colloquium, Phoenix, AZ, April 29-May 2, 1996. Exchange/Monitor Publications and Forums, Lake Bluff, IL, 500 pp.; $(20$ pp.) (April 1996)

This presentation focuses on the need to reduce costs of site remediation and reduce technology selection bias. Performance based remediation contracts are examined as a method for achieving desired results and benefits. Issues and areas of concern which must be resolved include: identifying future land use in order to establish risk levels, identifying cleanup objectives, defining performance specifications, allowing the market to drive technology altematives and selecting the most advantageous and cost-effective alternative.

3447

V18/021980

Increasing the Value of the Program Dollar: Conducting Sampling and Analysis Activities with Efficiency

Steele, S.M.

Science Applications International Corporation, Idaho Falls, ID

CONF-9509139; Emerging Technologies in Hazardous Waste Management VII, D.W. Tedder (ed.), Proceedings of the Seventh American Chemical Society Industrial and Engineering Chemistry. Division Special Symposium, Atlanta, GA, September 17-20. 1995. American Chemical Society, Washington, DC, 1291 pp.; (pp 78-81) (1995)

Conducting sampling and analysis activities is essential for the purposes of assessing the status of remedial actions, performing scientific research, or establishing regulatory compliance. A key element of any of these types of assessments is the generation of physical and chemical data of sufficient quality. An effective sampling and analysis program forms the basis upon which credible data can be generated. However essential to the assessment, generating quality data from sampling and anaiysis activities is costly. Cost is often a limiting factor in the amount of assessment or research that can be accomplished. Program managers and researchers must use every avenue possible to get the most out of available funds, while keeping quality at a satisfactory level. In order to maximize the retum on programmatic funding, adequate program planning must be performed. Steps must be taken to identify: (1) the program's objectives; (2) the methods that can be used to satisfy these objectives; (3) the mechanisms to employ these methods; and (4) the mechanisms to collect and manage the resulting data. The importance of adequately planning each phase of the process, and how this can lead to a heightened efficiency in the overall performance of the program, is discussed in the following text.

3448 V18/023824

Influence of $\mathrm{Na}$ and $\mathrm{Ca}$ on $\mathrm{REE}+$ Intensities in the Analysis of Geological and Related Samples by ICP-MS

Brenner, I.B.; Goldbart, Z.

Geological Survey, Geochemistry Division, Jerusalem, Israel; NRCN, Beersheva, Israel 
CONF-960113; Proceedings of the 1996 Winter Conference on Plasma Spectrochemistry, Fort Lauderdale, FL, January 8-13, 1996, 378 pp.; (p. 274) (1996)

Both enhancement and suppression of ion counts were observed when solutions containing up to 1000 and $500 \mathrm{mg} / \mathrm{l} \mathrm{Na}$ and $\mathrm{Ca}$, respectively, were analyzed by ICP-MS. Signal suppressions are considered to be due to physical interference effects in the sample introduction system while enhancements could be due to EIE effects in the plasma. The optimum nebulizer gas flow rates (at which maximum signal intensity was obtained) were generally mass dependent, higher gas flows required for higher mass ions from about $0.45 \mathrm{~V} / \mathrm{min}$ for $\mathrm{Be}-9$ to 0.55 for $\mathrm{Ce}-140$. The temporal variation of up to 10 percent for a period of $100 \mathrm{~min}$ was compensated with the use of $\mathrm{Tb}-159$ as an internal standard. Using a matrix match calibration procedure, the data for a wide range of SRMs, decomposed using alkali fusions and mixed acid digestion, compared favorably with the recommended values. In spite of the high dilution factors due to total salt constraints, the determination limits of ICP-MS were superior to those of ICP-AES by about two orders of magnitude. REE chondrite and shale distributions were used to distinguish REE mineralization processes from normal sedimentary and igneous rocks.

\section{9 \\ V18/022140}

Integrated Environmental Site Characterization Involving Geochemistry, Geophysics, and Geology: A Shortcut to Remediation

Viellenave, J.H.; Slatten, M.; Church, G.; Anderson, M. TEG Rocky Mountain, Golden, CO; Northeast Research Institute LLC, Lakewood, CO; Maverick Geophysical Services, Golden, CO; Jacobs Engineering Group Inc., Golden, $\mathrm{CO}$

CONF-960477; SAGEEP '96, R.S. Bell and M.H. Cramer (eds.), Proceedings of the Ninth Annual Symposium on the Application of Geophysics to Engineering and Environmental Problems, Denver, CO, April 15-May 1, 1996. Environmental and Engineering Geophysical Society, Wheat Ridge, CO, 1353 pp.; (pp. 865-876) (1996)

Environmental site characterization processes have evolved from simple drill-and-sample routines into more sophisticated evaluations of increasingly complex problems involving a variety of contaminants. Strategic integration of several geoscience tools into a more holistic approach benefits the site owner/operator by developing a synoptic perspective of the site at the earliest possible time, allowing for more selective and focused use of the expensive and invasive technologies. The ultimate effect is a better site characterization, including attention to difficult potentially responsible party (PRP) issues, lower liability, fewer risks of bypassing potentially hazardous contaminant accumulations, and a result that is more targeted to environmental and human health risks. An integrated site investigation system requires good geology and hydrology, but is properly augmented by use of modern and sophisticated geochemical and geophysical tools. Establishing characterization objectives is critical in deciding what geoscience tool(s) to deploy in any given situation. For each tool, critical criteria are identified that will enable the user to best decide which to use for what purposes.
V18/024115

Integrated Spectroscopic System for Environmental Contamination

Los Alamos National Laboratory, Los Alamos, NM

LALP-94-255; 1 p. (1994)

Soil, sludge, and groundwater remediation methods are costly and inefficient. Although current analytical approaches can examine various chemical forms or species in the environment, these methods cannot address speciation over a broad spatial range. Metals are of particular concem because they can exist in multiple oxidation states. Without identifying each form of a contaminant before remediation begins, selecting the appropriate remediation strategy is done by trial and error. The Integrated Spectroscopic System for Environmental Contaminant Speciation (ISSECS) can improve the economics of remediation by providing accurate speciation data early in the process. ISSECS is a laboratory-based solution that uses a unique combination of four analytical techniques. Developed to address tough environmental analyses, such as soils contaminated with uranium or plutonium, ISSECS also can improve speciation of common industrial pollutants, including selenium, mercury, lead, and cyanide.

\section{1}

\section{V18/020627}

International Co-Operation on Environmental Restoration: The Role of the IAEA

Laraia, $\mathrm{M}$.

International Atomic Energy Agency, Waste Management Section, Vienna, Austria

IAEA-TECDOC-865; CONF-9310459 (Vol. 1); Planning for Environmental Restoration of Radioactively Contaminated Sites in Central and Eastem Europe, Volume 1: Identification and Characterization of Contaminated Soils, Proceedings of a Workshop on Environmental Restoration in Central and Eastern Europe, Budapest, Hungary, October 4-8, 1993. International Atomic Energy Agency, Vienna, Austria, Vol. 1,356 pp.; (pp. 7-18) (February 1996)

Radioactive waste management is a prominent International Atomic Energy Agency (IAEA) activity and has to be dynamic in nature to keep pace with the changing needs of Member States. Meeting these needs is a challenge considering the diverse nature of waste management activities that are planned or under way in our Member States. The main objective of the waste management program is to ensure the safe management and disposal of radioactive waste in accordance with the IAEA's mandate to promote the safety and peaceful use of atomic energy. Although this project is called the Technical Cooperation Regional Project on Environmental Restoration in Central and Eastern Europe (CEE), the need for environmental restoration is not confined to this region alone. There are sites all over the world that are in an unacceptable state due to bad practices in the handling of radioactive waste, nuclear accidents, or weapons testing activities. The wastes come from a wide range of activities and the nature and character of the radioactive materials may differ among countries. 


\section{Contamination}

Los Alamos National Laboratory, Los Alamos, NM

LALP-95-16; 1 p. (1995)

Los Alamos is developing monitors capable of disclosing low levels of contamination in real time in the field. These monitors are based on long-range alpha detector technology. The monitors are sensitive and fast yet rugged and inexpensive. The flexibility of this technology permits monitoring of soil, sand, concrete, metal, liquids, and objects with random shapes for alpha emitters such as uranium or plutonium. Contamination can be on land, in rivers and lakes, and within buildings.

\section{$3453 \quad \mathrm{~V} 18 / 023823$}

Isotope Ratio Analysis Utilizing Glow Discharge Fourier Transform Ion Cyclotron Resonance Mass Spectrometry (GD-FTICR-MS)

Goodner, K.L.; Eyler, J.R.; Watson, C.H.; Barshick, C.M.; Smith, D.H.

Oak Ridge National Laboratory, Chemical and Analytical Sciences Division, Oak Ridge, TN

CONF-960113; Proceedings of the 1996 Winter Conference on Plasma Spectrochemistry, Fort Lauderdale, FL, January 8-13, 1996, 378 pp.; (p. 243) (1996)

The ability to measure isotope ratios accurately and with good precision is important in such diverse areas as geology and medicine, yet is often difficult to achieve. There has been relatively little work utilizing glow discharge ionization for the determination of isotopic ratios. The authors have analyzed the usefulness of coupling a glow discharge with FTICR-MS for ultra-high resolution isotope ratio analysis. Other studies have shown that the relative standard deviation increased from 0.25 to 1.7 by increasing mass resolution from approximately 35,000 to greater than 100,000 . This is partially attributed to differences in the powder absorbed by the isotopes. This source of error might be improved by using multiple excitation pulses or tailored pulses.

\section{4}

V18/025503

Key Role of Local Elected Officials

Edwards, K.; Koh, B.

Village of Newburgh Heights, OH; B. Koh Associates, Inc., Owings Mills, $\mathrm{MD}$

CONF-960804 (Vol. 2); Spectrum '96: Nuclear and Hazardous Waste Management, Proceedings of an International Topical Meeting, Seattle, WA, August 18-23, 1996. American Nuclear Society, La Grange Park, IL, Vol. 2, 873 pp.; (pp. 1678-1682) (1996)

Many factions have a stake in the cleanup of radioactively contaminated properties. Often, the interests of these groups conflict, and the ensuing controversy leads to long delays in the decommissioning. The authors were deeply involved in one such project. Their experience revealed that local elected officials are in the best position to take a leadership role among the parties. Elected officials can use the authority of their office to represent the affected constituents and get action from regulators, legislators and the parties responsible for the cleanup.

\section{$3455 \quad$ V18/023822}

Laser Ablation Microprobe-Inductively Coupled Plasma-Mass Spectrometry (LAM-ICP-MS) of Geological Materials

Longerich, H.P.; Jackson, S.E.; Forsythe, L.; Horn, I.

Memorial University of Newfoundland, Department of Earth Sciences and Centre for Earth Resources Research, St. John's, Newfoundland, Canada

CONF-960113; Proceedings of the 1996 Winter Conference on Plasma Spectrochemistry, Fort Lauderdale, FL, January 8-13, 1996, 378 pp; (p. 144) (1996)

Using our recently installed enhanced sensitivity inductively coupled plasma-mass spectrometer with our in-house constructed laser ablation microprobe (LAM) sample introduction system, we will demonstrate the current capability and recent applications of the system for the microanalysis of geological materials. With this system we can obtain cost effective in situ microanalysis of solid geological samples at concentrations and resolutions which were not previously possible. A Nd:YAG laser, with the output frequency quadrupled to produce $266 \mathrm{~nm}$ in the ultraviolet, is used exclusively in preference to the infrared fundamental at $1064 \mathrm{~nm}$ or the frequency doubled visible green at $512 \mathrm{n}$. The ultraviolet produces smaller pit diameters due to its shorter wavelength, and in the ultraviolet the absorbance of many materials increases, producing well formed pits in contrast to the "catastrophic" pits produced in phases which are transparent at $1064 \mathrm{~nm}$.

\section{6}

V18/023821

Laser Induced Breakdown Spectroscopy of Geological Materials

Koskelo, A.; Gamble, T.; Lippert, T.

Los Alamos National Laboratory, Los Alamos, NM

CONF-960113; Proceedings of the 1996 Winter Conference on Plasma Spectrochemistry, Fort Lauderdale, FL, January 8-13, 1996, 378 pp.; (p. 130) (1996)

The authors have been developing laser-induced breakdown spectroscopy (LIBS) as a tool for rapid field analysis of soils and mine tailings for heavy metals, including RCRA regulated metals. The goal of the work is production of a cost-effective, field-portable instrument that meets the needs for field screening of hazardous waste sites. Laser-induced breakdown spectroscopy is primarily an atomic emission technique. In the method, a short pulse of laser light is focused onto the surface of a material. Absorption of the light initially heats the material to $10,000 \mathrm{~K}$ or greater. The high temperature vaporizes, atomizes, and electronically excites some of the material in a single laser pulse. The authors have measured the figures of merit of LIBS instrumentation using parameters appropriate for fieldable equipment. Materials examined include NIST standard soil samples, local Los Alamos soil, and samples from mine tailing waste sites in Butte, Montana. Detection limits range from about $10 \mathrm{ppm}$ for lead to $400 \mathrm{ppm}$ for arsenic in the Los Alamos soil. Detection limits were determined using three standard deviations of 100 shot data on untreated materials and slopes of curves using standard addition. These results were obtained in thirty second measurements using samples that had been dried and pressed. The dominate source of 
noise which limits the detection limit is typically sample inhomogeneity.

3457

V18/023858

Legal and Strategic Considerations in Risk-Based Closures

Worrell, D.G.

Brown McCarroll \& Oaks Hartline, L.L.P., Austin, Texas CONF-960154; PETRO-SAFE '96, Proceedings of a Conference Held as Part of the Energy Week ' 96 Conference and Exhibition, Houston, TX, January 29-February 2, 1996. PennWell Conferences and Exhibitions, Houston, TX, 291 pp.; (pp. 125-130) (1996)

The Texas Natural Resource Conservation Commission (TNRCC) Risk Reduction Rules represent a major step forward in implementing risk-based closures. Although certain issues such as deed recordation and off-site contamination remain stumbling blocks for implementation of certain closure standards under these Rules, these Rules provide a more realistic, site-specific, flexible manner to close or remediate contaminated facilities or sites. Further, the revisions to the Rules that are being developed by TNRCC staff may result in even more realistic closure scenarios based on potential exposure and risk.

\section{8 \\ V18/021194}

Licenses Expedite Remedial Actions

Ram, N.

Groundwater Technology, Inc., Norwood, MA

Environmental Protection 5(4):30-33 (April 1994)

Massachusetts is the first state to establish Licensed State Professional for rendering opinions on remedial actions at most hazardous waste sites. This shifts the routine supervision of clean-up sites from state regulators to licensed individuals in the private sector. The state hopes to accelerate its environmental cleanups.

\section{9}

\section{V18/023825}

Los Alamos National Laboratory Center for Direct Chemical Analysis of Materials

Koskelo, A.; Figg, D.; Mahan, C.; Wayne, D.; Thomton, D.

Los Alamos National Laboratory, Chemical Science and Technology Division, Los Alamos, NM

CONF-960113; Proceedings of the 1996 Winter Conference on Plasma Spectrochemistry, Fort Lauderdale, FL, January 8-13, 1996, 378 pp.; (p. 288) (1996)

The Center for Direct Chemical Analysis at Los Alamos National Laboratory is undertaking a major effort to develop, improve, and implement direct analysis techniques for radionuclide, organic, and inorganic constituents. The Center consists of a multidisciplinary team of researchers who possess expertise in the quantitative and qualitative characterization of solid materials using a variety of analytical technologies. Materials include soils and sludges, building materials, foods, chemicals, and atmospheric gases. Direct chemical analysis techniques measure the analytes directly in the solid material with minimal sample pretreatment, whereas conventional techniques, such as atomic absorption and emission spectrochemistry, require that the solid materials be rendered in aqueous solution using concentrated acids prior to measurement. Direct chemical analysis completely bypasses the digestion process, thereby increasing the sample throughput and saving both time and money. Direct chemical analysis is unique in that it alone can conduct certain specialized but highly useful types of analysis, such as depth-profiling and the chemical structural characterization of surfaces. In addition, some direct analytical techniques eliminate the sampling step and permit rapid analysis of samples at the point of origin. Direct analysis in situ would further reduce costs and potential hazards related to sample collection and transport to the analytical laboratory.

3460

V18/020742

Mathematical Model, Algorithm, and Package of Programs for Simulation and Prompt Estimation of the Atmospheric Dispersion of Radioactive Pollutants

Nikolaev, V.I.; Yatsko, S.N.

Academy of Sciences, Institute of Radioecological Problems, Minsk, Belarus

Journal of Engineering Physics and Thermophysics 68(3):385-394 (December 1995)

A mathematical model and a package of programs are presented for simulating the atmospheric turbulent diffusion of contaminating impurities from land based and other sources. Test calculations and investigations of the effect of various factors are carried out.

3461

V18/023906

Mating Dance in Cleanup Recoveries: How to Court Responsible Parties and in What Court to Do It

Meyer, G.A.

Parker, Milliken, Clark, O'Hara \& Samuelian, Los Angeles, $\mathrm{CA}$

CONF-951124; HazMat West '95, Proceedings of the Eleventh Annual Environmental Management and Technology Conference and Exhibition, Long Beach, CA, November 7-9, 1995. Advanstar Expositions, Duluth, MN, 597 pp.; (pp. 535-546) (1995)

This article discusses the legalities which pertain specifically to hazardous waste cleanup. Topics of discussion include the following: threshold decisions: litigate or negotiate; forum issues-Federal or state court; claims in state court; and different types of damages and recovery. CERCLA is not the only grounds for recovery in environmental contamination cases. Common law and RCRA are also attractive.

\section{$3462 \quad$ V18/023457}

Maximizing Environmental Return on Investment (ROI): A Systems Approach to Environmental Restoration (ER) Project Selection

Sharp, G.L.; Redus, K.S.

Scientific Ecology Group, Inc., Oak Ridge, TN; MACTEC, Oak Ridge, TN

CONF-961103; Decommissioning, Decontamination, and Reutilization Worldwide Experience: DD\&R, What Does It Mean, M.G. White, R.G. Thomas and R.F. Ranellone (eds.), Proceedings of an Embedded Topical Symposium of an American Nuclear Society 
Winter Meeting, Washington, DC, November 10-14, 1996. American Nuclear Society, Inc., La Grange Park, IL, 328 pp.; Transactions of the American Nuclear Society 75:66-67 (1996)

This paper presents a systems approach and model for identifying, evaluating, selecting, and scheduling defensible environmental restoration (ER) project options (POs). The approach integrates risk, cost, and other important considerations into a common framework and process. The output provides data needed to select projects that maximize environmental return on investment (ROI). Although this model was initially constructed to provide a basis for selecting optimum facility deactivation project combinations for the Oak Ridge National Laboratory ER program, the approach is equally useful for selecting among technology alternatives within large and complex projects.

\section{$3463 \quad$ V18/023334}

Means Environmental Remediation Estimating Methods Rast, R.R.

Means Environmental Remediation Estimating Methods, Robert S. Means Company, New York, NY (April 1997)

No abstract available.

3464 V18/022492

Meeting Sampling and Analytical Needs of the Department of Energy

Goheen, S.C.; Fadeff, S.K.; Riley, R.G.; Thomas, B.L.; McCulloch, M.; Sklarew, D.S.; Thompson, C.J.; Mong, G.M.; Carter, M.H.

Pacific Northwest Laboratory, Richland, WA; U.S.

Department of Energy, Gaithersburg, MD

CONF-950877; Mixed Waste, A.A. Moghissi, B.R. Love and R.K. Blauvelt (eds.), Proceedings of the Third Biennial Symposium, Baltimore, MD, August 7-10, 1995, 545 pp.; (pp. 2.1.1-2.1.8) (1995)

Despite the availability of a large number of sampling and analytical methods for analyzing complex waste, the U.S. Department of Energy (DOE) has recognized the need to generate new sampling and analytical methods that apply to some of its activities. The DOE encourages the use of the U.S. Environmental Protection Agency, American Society for Testing and Materials, and other standard methods when they meet data quality objectives. However, when they do not, alternative methods are necessary. The DOE has produced several new methods that address waste minimization, cost, matrix effects, and radiation exposure concerns. These methods are being distributed through DOE Methods for Evaluating Environmental and Waste Management Samples (DOE Methods). This manuscript provides a few examples of methods available in DOE Methods. Six sampling, seven organic, four inorganic, and seven radiochemistry methods are summarized. These represent only a fraction of the total number of methods in DOE Methods as of April 1995. Their key features are provided. In addition, the origin of many of the methods and other characteristics of DOE Methods is described.

\section{5}

V18/023818

Mercury Speciation with an IC/ICPMS System: A

\section{Marriage of Convenience}

Buckley, B.; Heintz, M.; Fang, W.; Johnson, W.

Rutgers University, EOHSI-Busch Campus, Piscataway, NJ

CONF-960113; Proceedings of the 1996 Winter Conference on Plasma Spectrochemistry, Fort Lauderdale, FL, January 8-13, 1996, 378 pp.; (p. 97) (1996)

Mercury is found in both elemental and organomercury forms in the environment. In particular, the biologically mediated conversion of inorganic mercury to methylmercury is widely observed in many environmental media. Because of the different toxicological properties and bioavailability of the many species, it is important to know the chemical form of any mercury contaminant. Speciation is regularly accomplished with ion chromatographic (IC) or high performance liquid chromatographic (HPLC) separation, and mass spectrometric detection. Detection limits on the order of single ppb can be easily achieved with this method. In this lab speciation has been performed by coupling an inductively coupled plasma/mass spectrometer (ICP/MS) (VG PQS by Fisons) with an ion chromatograph (Dionex DX300). The separation of the mercury compounds was accomplished using a column which has both HPLC and ion exchange characteristics. In this presentation improvements of the ICP/MS detection system are discussed, in particular the fabrication of a direct injection nebulizer (DIN) is reported.

\section{$3466 \quad \mathrm{~V} 18 / 021269$}

Method for Cs-137 Separation from the Decontamination Solutions

Toropov, I.G.; Efremenkov, V.M.; Toropova, V.V.; Satsukevich, V.M.; Davidov, Y.P.

Academy of Sciences, Institute of Radioecological Problems, Minsk, Belarus; Academy of Sciences, Institute of Power Engineering Problems, Minsk, Belarus

CONF-950917 (Vol. 1); ICEM '95, Proceedings of the Fifth International Conference on Radioactive Waste Management and Environmental Remediation, Vol. 1: Cross-Cutting Issues and Management of High-Level Waste and Spent Fuel, S. Slate, F. Feizollahi and J. Creer (eds.), Berlin, Germany, September 3-7, 1995. American Society of Mechanical Engineers, New York, NY, 902 pp.; (pp. 349-351) (1995)

Results of investigations are presented on separation of radiocesium from decontamination solutions containing reducing agents (thiocarbamide). The scientific basis for solving this task is from data on radionuclide state and sorption behavior in solutions of complicated composition. Based on that data, and using a combination of sorption and ultrafiltration methods, it was assumed possible to concentrate the radionuclide in a small volume and to purify the main part of the solution. Ferrocyanide based sorbent is proposed for radiocesium removal from the solution. Use of this sorbent is justified since its high selectivity and effectiveness for radiocesium sorption from solutions of different composition is well known. When the sorbent is synthesized directly in the treating solution, two components as a minimum should be added to it; namely, $\mathrm{K} 4 \mathrm{Fe}(\mathrm{CN}) 6$ and metal ions of Ni-II, $\mathrm{Co}-\mathrm{II}, \mathrm{Cu}-\mathrm{II}$, etc. The results of this work show the possibility of radiocesium separation from decontamination solutions containing $60-100 \mathrm{~g} / 1$ of salts, using sorption and membrane separation methods. Using known 
peculiarities of Fe-III's physico-chemical behavior in solution, in the presence of cyanide ions and thiocarbamide, it is possible to avoid addition to the solution's metal salts $(\mathrm{Ni}, \mathrm{Cu}$, etc.). Utilization of the proposed method for spent decontamination solution treatment allows for a reduction of cesium concentration in solution by $2-4$ orders of magnitude, without the addition of relatively expensive metal salts.

3467

V18/022329

Miniature GC for Insitu Monitoring of VOC's Within a Cone Penetrometer: Final Report - July 1994-May 1996

U.S. Department of Energy, Morgantown Energy

Technology Center, Morgantown, WV; Microsensor

Systems, Inc., Bowling Green, KY

DOE/MC/31187-5259; 65 pp. (May 31, 1996)

The "Cone-GC" was developed in response to a need for down hole, in-situ characterization of volatile organics within the soil profile, in the vadose zone, or a water headspace. A design based on the use of a miniature gas chromatograph was selected since it was believed that such an instrument would be adaptable to a broad range of analytes and could be used in complex, real-world situations where the environmental contaminants to be monitored may exist in complex mixtures with other vapors. The Cone-GC is versatile and will also fit within many other soil probes, hole liners, and minimally intrusive emplacement systems where small size in addition to high performance are required. The Cone-GC was designed to allow environmental specialists for the first time to obtain immediate, in-situ chemical measurements in a soil probe and to make real-time, on-site decisions that will greatly reduce the time (and cost) of site characterization and remediation. It will no longer be necessary to collect samples (using long sampling lines that may become contaminated), send them to an off-site laboratory for analysis, and then wait hours or days for results.

3468

V18/023193

Modeling Environmental Remediation Costs from Hydrocarbon Releases

Gancarz, D.H.

Radian Corporation, Austin, TX

CONF-9210194; Proceedings of an International Symposium on Environmental Contamination in Central and Eastern Europe, Budapest, Hungary, October 12-16, 1992, 968 pp;; (pp. 275-277) (1992)

A computer model and database were developed to estimate environmental remediation costs from hydrocarbon releases at retail gasoline stations and bulk storage facilities. Uses of the model include estimating clean-up costs for property transfer negotiations or budgetary purposes, identifying sites requiring additional field investigations, prioritizing environmental remediation actions, and developing optimum strategies for upgrading or closing facilities. The model, the Clean-up Cost Model (CCM), uses a Monte Carlo sampling approach to probabilistically describe the likelihood of potential product release volumes and soil and groundwater remediation costs at petroleum storage and distribution facilities. It simulates various processes and operations at these facilities that can result in an uncontrolled release of product and then applies a built-in expert system to select and cost soil and groundwater remedies consistent with the nature of the release, site conditions, and applicable environmental regulations. This paper describes one application of the methodology to a group of 39 facilities and the usefulness of an approach that provides probabilistic information about clean-up costs.

\section{9}

\section{V18/022676}

Modeling Equilibrium and Kinetic Major Ion Chemistry with $\mathrm{CO} 2$ Production/Transport Coupled to Unsaturated Water Flow

Suarez, D.L.; Simunek, J.

U.S. Department of Agriculture, Agricultural Research Service, Salinity Laboratory, Riverside, CA

CONF-941124; Insitu Remediation: Scientific Basis for Current and Future Technologies, G.W. Gee and N.R. Wing (eds.), Proceedings of the 33rd Hanford Symposium on Health and the Environment, Pasco, WA, November 7-11, 1994. Battelle Press, Columbus, OH, Part 2, 605 pp.; (pp. 1215-1246) (1994)

Modeling the aqueous-phase composition in the unsaturated zone requires prediction of the gas-phase composition as well as water flow and chemical reactions. The authors discuss and demonstrate the use of two finite-element codes developed for variably saturated media at near earth-surface temperature. The SOILCO2 code was designed for predicting the $\mathrm{CO} 2$ concentration in the unsaturated zone, while the UNSATCHEM-2D code was designed for predicting major ion composition in the unsaturated zone. The SOILCO2 code couples $\mathrm{CO} 2$ production and transport with a variably saturated water flow model. The UNSATCHEM-2D code couples a variably saturated water flow model to $\mathrm{CO} 2$ production and transport, solute transport, and major-ion chemistry submodels. Since the solution chemistry in the unsaturated zone is significantly influenced by variations in water content, and in temperature and $\mathrm{CO}_{2}$ concentrations in the soil gas, all these variables are calculated by the models. The $\mathrm{CO} 2$ transport submodel includes both liquid and gas-phase transport.

3470

V18/021195

Modelling of Radionuclide Interception and Loss

Processes in Vegetation and of Transfer in

Semi-Natural Ecosystems: Second Report of the VAMP

Terrestrial Working Group - Part of the IAEA/CEC

Co-Ordinated Research Programme on the Validation of Environmental Model Predictions (VAMP)

International Atomic Energy Agency, Vienna, Austria

IAEA-TECDOC-857; 84 pp. (January 1996)

Following the Chernobyl accident and on the recommendation of the International Nuclear Safety Advisory Group (INSAG) in its Summary Report on the Post-Accident Review Meeting on the Chernobyl Accident, the LAEA established a Co-ordinated Research Programme on "The Validation of Models for the Transfer of Radionuclides in Terrestrial, Urban and Aquatic Environments and the Acquisition of Data for that Purpose." The programme seeks to use the information on the environmental behavior of radionuclides which became available as a result of the measurement programmes instituted in the countries of the former USSR and in many European countries after April 1986 for the purpose of testing the reliability of assessment models. Such models find application in 
assessing the radiological impact of all parts of the nuclear fuel cycle. They are used at the planning and design stage to predict the radiological impact of planned nuclear facilities, in assessing the possible consequences of accidents involving releases of radioactive material to the environment and in establishing criteria for the implementation of countermeasures. In the operational phase they are used together with the results of environmental monitoring to demonstrate compliance with regulatory requirements regarding release limitations.

\section{1}

V18/020916

Multisorbent Arrayed Sampler for Collection and Concentration of Vadose Zone VOCs

Jenkins, R.A.

\section{Oak Ridge National Laboratory, Oak Ridge, TN}

CONF-940145 (Vol. 2); Outreach to Industry: Partnerships for the Future - Technology Profiles, Proceedings of the Technical Information Exchange Meeting with Industry on Environmental Restoration Needs in the Northwest United States, Seattle, WA, January 25-27, 1994, Vol. 2; (2 pp.) (1994)

There is a need for sub-surface sampling in the vadose zone for a broad range of volatile organic compounds (VOCs) at contaminated sites, either during site characterization or remediation. Many chemical sensors can provide monitoring of target constituents or classes of constituents. However, other species may be present, either as co-contaminants or as by-products of remediation activities. These species may not be amenable to monitoring by specific chemical sensors. Conventional approaches to the acquisition of a soil gas sample at depths of more than a few feet involve the implantation of a tube, and withdrawal of a soil gas sample to the surface. There are a number of potential problems with such an approach. First, in geologic strata with low porosity, the volume of gas which needs to be pulled to the surface may be greater than that which can be replenished by diffusion through the surrounding soil. Extraction of a large sample can disturb the sub-surface equilibrium, and gas can be withdrawn which is not representative of that present in the soil. Secondly, there can be significant losses of organic vapors through permeable tubing, such as Teflon, especially when the lengths of tubing involved is considerable. Even in non-porous tubing, organic vapors may adsorb on or react with tubing surfaces, or dissolve in water vapor condensed on the walls of the tubing.

\section{2}

V18/024126

\section{Multispectral Borehole Logging to Map Subsurface Contaminants}

Los Alamos National Laboratory, Los Alamos, NM

LALP-95-21; 1 p. (1995)

Neutron-induced spectral gamma-ray (multispectral) borehole logging measures gamma-ray energy spectra during and after irradiation of the borehole environment by energetic neutrons. Neutrons interact with matter in a variety of ways to produce gamma rays with energy distributions that enable specific elements and isotopes to be positively identified. Analysis of the induced gamma-ray energy spectra is done with a high-resolution intrinsic germanium detector and ultra-high-speed multi-channel analyzer. This technology is capable of identifying many elements, including

non-radioactive isotopes, and is nuclide-specific.

V18/022438

National Classification System for Contaminated Sites

Canadian Council of Ministers of the Environment, Winnipeg, Manitoba, Canada

Report; 54 pp. (1992)

This classification system was developed to promote consistency in the assessment of sites under CCME's National Contaminated Sites Remediation Program, but is applicable to contaminated sites generally. It is based on an extensive review of existing provincial, territorial, and international methods for classifying contaminated sites, and rates the sites according to their adverse impact on human health or the environment. Its purpose is to provide an evaluative framework for identifying sites into general categories of concern, thereby indicating the necessity of further action. It is not designed to provide a general or quantitative risk assessment, but to take the first step in general evaluation and priority setting.

3474

V18/023458

National Corrective Action Prioritization System (NCAPS): RCRA Information Brief

U.S. Department of Energy, Office of Environment, Safety, and Health, RCRA/CERCLA Division, Washington, DC

DOE/EH-413-070/1296; 6 pp. (December 1996)

The Environmental Protection Agency (EPA) created the National Corrective Action Prioritization System (NCAPS) as a tool to: (1) evaluate the overall environmental significance of releases of hazardous wastes and hazardous constituents at treatment, storage, and disposal (TSD) facilities regulated under the Resource, Conservation, and Recovery Act (RCRA) and (2) determine the relative priority for performing corrective action activities at TSD facilities. The NCAPS establishes national criteria for ranking facilities as high, medium, or low priority for comective action in order to focus limited resources on those facilities, and/or areas within a facility, which pose the greatest hazard to human health and the environment. This information brief describes the NCAPS ranking system, which considers the environmental setting of the facility, potential receptors, actual and potential releases of hazardous wastes or constituents, and the toxicity of constituents of concern in ranking facilities. It also provides a summary of the results of NCAPS scores for DOE facilities. According to the Resource, Conservation, and Recovery Information System, 18 DOE facilities have received NCAPS rankings.

V18/023199

National Recording of Environmental Incidents in Scotland

Forbes, G.I.

Ruchill Hospital, Environmental Health, Glasgow, Scotland, United Kingdom

CONF-9210194; Proceedings of an International Symposium on Environmental Contamination in Central and Eastern Europe, Budapest, Hungary, October 12-16, 1992, 968 pp.; (pp. 310-312) (1992) 
One of the main problems in determining the environmental status of a territory is the common failure to accurately record the occurrence of environmental incidents. All too often control of pollution is the responsibility of various independent central and local government departments without overall cooperation and recording of incidents. If an official recording mechanism is not in place no determination of the number of environmental incidents that occur in a given period of time can be determined, no relation of connected incidents can be made, no lessons can be learned and passed on to all those working in the pollution control field, and no assessment of improved environmental standards can be achieved. In Scotland for the past three years a central system for recording environmental health incidents has been in place and many benefits from this administrative arrangement are already evident. The implementation, management benefits and results obtained from the program are given and suggestions are made as to how this program could be extended internationally.

\section{6}

V18/024122

Neighborhood Environmental Watch Network (NEWNET)

Los Alamos National Laboratory, Los Alamos, NM

LALP-95-38; 1 p. (1995)

The Neighborhood Environmental Watch Network (NEWNET) is a hardware and data system that brings industry and the public together to address environmental concems. It helps the public become more involved in observing the environment and understanding the impact of agents on the environment; it also provides researchers with important data needed to better understand the environment. NEWNET implementation consists of installing environmental monitoring stations with instrumentation to monitor environmental parameters of interest; a station computer takes periodic measurements and displays the results locally. Interested citizens have free access to the station and can observe the results any time. Data are available through internet to industry and the public.

\section{$3477 \quad \mathrm{~V} 18 / 022109$}

\section{New Direction for Prioritizing Federal Agency Cleanups}

McCrillis, L.; O'Connor, L.; Chantry, W., Jr.; Rummel, E.

U.S. Environmental Protection Agency, Federal Facilities

Restoration and Reuse Office, Washington, DC;

DynCorp/Environmental, Energy and National Security

Programs, Alexandria, VA

CONF-951139 (Vol. 1); Superfund 16: Proceedings of a Hazardous Waste Conference and Exhibition, Washington, DC, November 6-8, 1995. E.J. Krause and Associates, Bethesda, MD, Vol. 1, 828 pp.; (pp. 304-310) (1994)

Departments and agencies of the federal government manage a vast array of activities at 27,000 facilities. Due to the nature of such activities, federal facilities could be contaminated with hazardous substances. It is estimated that the federal government ultimately will be responsible for or have a significant role in the cleanup of up to 500,000 sites. Although federal facilities comprise only a small percentage of the community regulated under the Comprehensive Environmental Response, Compensation and Liability Act
(CERCLA), federal facilities owned or operated by the Department of Energy (DOE) and the Department of Defense (DOD) are usually larger and more complex than their private industrial counterparts. Federal facilities routinely have a larger number of sites on their facilities with varying degrees of risk. CERCLA Section 120(a) requires that federal facilities comply with CERCLA requirements to the same extent as private facilities. Executive Order 12580 delegates the President's authority for cleaning up federal facilities to the federal agency. For federal facility National Priorities List (NPL) sites, there is a need to maximize the dollars spent on activities with the highest priority. CERCLA Section 120(e)(2) mandates that cleanups be conducted under an interagency agreement (IAG) between the Environmental Protection Agency (EPA) and the relevant federal agency. States are often a party to these agreements as well. CERCLA further requires that schedules of cleanup be published. Contamination at federally owned and operated facilities poses a significant challenge for the nation logistically, economically, and in resource allocation. At present, the approaches for allocating resources for environmental restoration of federal facilities, for incorporating stakeholder concerns in the allocation, and for obtaining funding from Congress vary greatly from one agency to another. The federal government recognizes the need to evaluate the current resource allocation system for funding remediation projects and to establish a broader-based publicly supported priority-setting method. This paper outlines a possible new direction and summarizes the conclusions reached in a handful of forums created to address the issue of priority setting.

3478 V18/023621

New Insitu Procedures for Measuring Trace Metals in Pore Waters

Zhang, H.; Davison, W.; Grime, G.W.

Lancaster University, Division of Environmental Science, Lancaster, United Kingdom; University of Oxford, Oxford, United Kingdom

CONF-9406413; Dredging, Remediation, and Containment of Contaminated Sediments, K.R. Demars, G.N. Richardson, R.N. Yong and R.C. Chaney (eds.), Proceedings of a Symposium, Montreal, Quebec, Canada, June 23-24, 1994, 343 pp.; (pp. 170-181) (1995)

The most mobile and biological and chemically active fractions of trace metals in sediments are the dissolved components present in pore waters. Measuring metals in pore waters is complicated by the requirement for anoxic handling procedures. Due to the dynamic nature of sediment, steep concentration gradients extending over as little as $1 \mathrm{~mm}$ may develop at the sediment-water interface. New procedures for measuring metals in pore waters using polyacrylamide gels as in-situ probes are described. The gel can be used to establish a diffusive equilibration in a thin-film (DET). Because the film is typically less than $1 \mathrm{~mm}$ thick, equilibration is achieved within five minutes and insertion of the gel assembly causes minimal disturbance of sediment. An alternative procedure is to use a diffusive gradient in a thin-film (DGT), whereby a monolayer of chelating resin is incorporated at one side of the gel. Such a technique provides a kinetic measurement of labile species in solution. If the supply of metal from solid phase sediment to pore waters is fast enough, DGT provides a quantitative estimate of labile metal concentration. Alternatively, it measures directly the rate of 
supply of metal from solid phase to pore waters. As both DET and DGT are simple procedures capable of submillimeter spatial resolution, they provide previously unobtainable information on trace metal concentrations and fluxes. Furthermore, DGT has the potential to be used as a long-term monitor, providing mean concentrations of metals in sediment pore waters over periods of days, weeks, or even months.

V18/024114

Novel Detector for the Field Measurements of Chlorinated Hydrocarbons

Los Alamos National Laboratory, Los Alamos, NM

LALP-94-253; I p. (1994)

In the past, field characterization of hazardous waste sites has been hampered by the lack of hand-held detectors that can detect a wide variety of halogenated hydrocarbon species (HHCs) in air, water, or soil gas. Using a novel combination of a proven oxidation mechanism and a proven detection mechanism, scientists at Los Alamos National Laboratory have recently developed a detector capable of measuring HHCs in the matrices listed above. Proof of principle experiments have been performed on a wide range of compounds including trichloroethene, trichloroethane, carbon tetrachloride, fluorobenzene, and bromoform. Initial field trials have been conducted at SM-30 where pore gas samples collected in Tedlar bags were screened in conjunction with mass spectrometry analysis.

\section{0}

V18/022294

Oak Ridge Environmental Information System (OREIS) Functional System Design Document [Rev. 1]

Lockheed Martin Energy Systems, Inc., Environmental Restoration Division, Oak Ridge, TN

ES/ER/TM-66/R1; 30 pp. (October 1996)

This document provides a functional description of the Oak Ridge Environmental Information System (OREIS). It updates the system requirements as defined in previous versions of this document. Documentation of OREIS development and modifications is based on the Automated Data Processing System Development Methodology, a Lockheed Martin Energy Systems, Inc., procedure developed to assist in developing scientific and technical computer systems. This document focuses on the functional design of the user interface only because most of the OREIS functions are provided by commercial applications software. The data model and data dictionary are summarized briefly; however, the OREIS Data Dictionary (available through the web) provides the complete data dictionary and detailed descriptions of the requirements for the data base structure. The OREIS system will provide the following functions: (1) view manager, (2) data analysis, (3) spatial analysis/map generation (ARC/INFO and ArcView), (4) a help and information system using web pages, (5) a data query tool using web pages, and (6) risk assessment modules.

\section{$3481 \quad$ V18/021971}

Object-Oriented Database Design for the Contaminant Analysis Automation Project

Smutniak, F.S.
Los Alamos National Laboratory, Measurement Technologies Group, Engineering Sciences and Applications Division, Los Alamos, NM

CONF-9509139; Emerging Technologies in Hazardous Waste Management VII, D.W. Tedder (ed.), Proceedings of the Seventh American Chemical Society Industrial and Engineering Chemistry Division Special Symposium, Atlanta, GA, September 17-20, 1995. American Chemical Society, Washington, DC, 1291 pp.; (p. 582) (1995)

The Contaminant Analysis Automation project's automated soil analysis laboratory uses an Object-Oriented database for storage of runtime and archive information. Data which is generated by the processing of a sample, and is relevant for verification of the specifics of that process, is retained in the database. The database also contains intermediate results which are generated by one step of the process and used for decision making by later steps. The description of this database reveals design considerations of the objects used to model the behavior of the chemical laboratory and its components. (Complete text)

\section{$3482 \quad \mathrm{~V} 18 / 023047$}

On Environmental Interventions and Management Strategies

Clemens, B.

University of Tennessee, Energy, Environment, and Resources Center, Knoxville, IN

Thesis (Ph.D.); 107 pp. (February 1997)

This dissertation investigates the relationship between the form of environmental initiatives and the response strategies of regulated organizations. The first chapter introduces the study and sets the stage for the balance of the piece. The second chapter reviews the literature, develops the theoretical basis, and defines the hypotheses to be tested. The third chapter describes the methodology for testing the hypotheses. Data analysis is described in the fourth chapter, and the conclusions are in the fifth and last chapter. The most noteworthy finding was that the level of cooperation between firms was the strongest indicator of a firm's strategies to address environmental intervention.

3483

V18/023345

Oversight Hearing on Environmental Remediation at DOE Facilities: Hearing Before the Subcommittee on Energy and Power of the Committee on Commerce, House of Representatives, One Hundred Fourth Congress, First Session, October 31, 1995

Oversight Hearing on Environmental Remediation at DOE Facilities - Hearing Before the Subcommittee on Energy and Power of the Committee on Commerce, House of Representatives, One Hundred Fourth Congress, First Session, October 31, 1995, Government Printing Office, Washington, DC, 87 pp. (1995)

No abstract available.

\section{4} V18/022070

Pennsylvania Public Education Program on the Need for Establishing a Low-Level Radioactive Waste Disposal Site (PELLRAD) 
Ryan, D.F.; Jester, W.A.; Bonner, J.J.; Shields, M.

Pennsylvania State University, University Park, PA

CONF-941148 (Vol. 2); DDER-'94: Decommissioning, Decontamination, and Environmental Restoration at Contaminated Nuclear Sites, M.G. White (ed.), Proceedings of an Embedded Topical Symposium of the American Nuclear Society Winter Meeting, Washington, DC, November 13-18, 1994. American Nuclear Society, Inc., La Grange Park, IL, Vol. 2, 241 pp.; (pp. 393-397) (1994)

PELLRAD (Public Education on Low Level Radiation) is a public service program of the Pennsylvania State University. Its mission is to provide timely information and educational programs on all issues related to low-level radioactive waste management and disposal for the citizens of the Appalachian States Low-Level Radioactive Waste Compact. The goal of the PELLRAD staff is to provide citizens, especially key decision makers, with accurate information that will enable them to make informed decisions related to the siting and operation of the federally-mandated disposal facility. All information and programs are provided to the citizens of Delaware, Maryland, Pennsylvania, and West Virginia (compact states) at no charge.

\section{5 \\ V18/020631}

Planning and Preparation for Environmental Restoration of Radioactively Contaminated Sites in Russia: Status, Problems, and Outlook

Nechaev, A.F.; Projaev, V.V.

St. Petersburg State Institute of Technology, St. Petersburg, Russia

IAEA-TECDOC-865; CONF-9404316 (Vol. 2); Planning for Environmental Restoration of Radioactively Contaminated Sites in Central and Easterm Europe, Volume 2: Planning for Environmental Restoration of Contaminated Sites, Proceedings of a Workshop on Environmental Restoration in Central and Eastern Europe, Piestany, Slovakia, April 11-15, 1994. International Atomic Energy Agency, Vienna, Austria, Vol. 2, 248 pp.; (pp. 153-182) (March 1996)

Recent developments in the Russian Federation's political situation has heightened attention (both on official and everyday levels) to the problems of radiation protection and rehabilitation of contaminated sites. Because of a number of objective reasons, the Russian government, Navy and industry have only recently become active and open in initiatives to identify, remediate and prevent radioactive contaminations. Although remediation and preventative 'actions have been taken before now, there still exists vast opportunities for further urgent and goal-oriented actions in this vital field. This paper describes key principles of the regulatory framework, hierarchy of organizational structure and the present status of Federal and regional restoration programs with emphasis on actual problems of planning systems.

\section{6}

V18/020630

Planning for Environmental Restoration of Contaminated Sites: Criteria and Methods

Laraia, M.

International Atomic Energy Agency, Waste Management

\section{Section, Vienna, Austria}

IAEA-TECDOC-865; CONF-9404316 (Vol. 2); Planning for Environmental Restoration of Radioactively Contaminated Sites in Central and Eastern Europe, Volume 2: Planning for Environmental Restoration of Contaminated Sites, Proceedings of a Workshop on Environmental Restoration in Central and Eastern Europe, Piestany, Slovakia, April 11-15, 1994. Intemational Atomic Energy Agency, Vienna, Austria, Vol. 2, 248 pp.; (pp. 7-23) (March 1996)

If decontamination of contaminated areas is required, the organization managing the operation should review and update relevant parts of any preliminary plan, and assemble the human and other resources needed to implement the cleanup and disposal operations. Characterization of the contamination and knowledge of the extent and types of areas affected permits planners to determine boundaries and define zones needing special attention or special equipment. The final management plan must tie together all elements linked to the cleanup of the area. Therefore, the plant will include subplans on items such as contamination characterization, details of the cleanup methods and equipment selected for various zones, logistics and supply, health physics support, transportation, packaging and disposal. Although the safety and radiation protection aspects of the plant are paramount in the implementation, the cleanup work must be done in an efficient and cost effective manner because of the potential for extremely high costs of an operation of this magnitude. Most of the information contained in this paper is based - with modifications and adaptation - on the IAEA Technical Report Series No. 327, "Planning for Cleanup of Large Areas Contaminated as a Result of a Nuclear Accident, 1991."

\section{7}

\section{V18/020628}

\section{Planning for Environmental Restoration of} Radioactively Contaminated Sites in Central and Eastern Europe - Planning for Environmental Restoration of Contaminated Sites: Proceedings of a Workshop on Environmental Restoration in Central and Eastern Europe, Vol. 2, Piestany, Slovakia, April 11-15, 1994

LAEA-TECDOC-865; CONF-9404316 (Vol. 2); Planning for Environmental Restoration of Radioactively Contaminated Sites in Central and Eastern Europe, Volume 2: Planning for Environmental Restoration of Contaminated Sites, Proceedings of a Workshop on Environmental Restoration in Central and Eastem Europe, Piestany, Slovakia, April 11-15, 1994. International Atomic Energy Agency, Vienna, Austria, Vol. 2, 248 pp. (March 1996)

The radioactive contaminant materials resulting from diverse activities in relation to the nuclear fuel cycle, defense related operations, and various industries along with medical and research facilities represent perhaps the most severe and immense pollution left from a past era. The political changes in central and eastem Europe (CEE) not only brought some disclosure of the radioactively contaminated sites, but also resulted in a political condition in which this region has become receptive to cooperation from a range of outside countries. It is under these circumstances that the International Atomic Energy Agency (IAEA) decided to launch a Technical Cooperation (TC) Project on Environmental Restoration in Central and Eastern Europe. The project was initiated in the 
latter part of 1992 and ended in 1994. The countries that were involved and represented in this forum are: Belarus, Bulgaria, Croatia, Czech Republic, Estonia, Hungary, Kazakhstan, Poland, Romania, Russian Federation, Slovakia, Slovenia and the Ukraine. Several experts from countries outside the region participated and offered their co-operation throughout the project.

\section{8}

\section{$\mathrm{V} 18 / 020629$}

Planning for the Environmental Restoration of Radioactively Contaminated Sites in the United Kingdom

Fellingham, L.R.

\section{AEA Technology, Harwell Laboratory, Engineering Services} Division, Didcot, Oxfordshire, United Kingdom

LAEA-TECDOC-865; CONF-9404316 (Vol. 2); Planning for Environmental Restoration of Radioactively Contaminated Sites in Central and Eastern Europe, Volume 2: Planning for Environmental Restoration of Contaminated Sites, Proceedings of a Workshop on Environmental Restoration in Central and Eastern Europe, Piestany, Slovakia, April 11-15, 1994. International Atomic Energy Agency, Vienna, Austria, Vol. 2, 248 pp.; (pp. 237-246) (March 1996)

The general approach to investigating and remediating radioactive contamination of sites in the United Kingdom has involved a multi-stage programme. The stages of such a programme are: (1) review of the existing site history and characteristics, (2) radiological investigations, (3) modelling of contaminants' spread, (4) identification of remediation options, (5) risk assessment and cost-benefit analysis, (6) interactions with regulatory authorities, (7) selection and design of preferred cleanup option, (8) implementation of preferred option, (9) monitoring of achievement of cleanup standards and, (10) closeout of works. This paper describes also in detail the regulatory framework and interactions among involved parties. Specific information is given on cleanup criteria in the UK and criteria for the selection of appropriate cleanup technologies. Disposal of radioactive wastes is a key element in planning and managing environmental restoration activities: provisions for waste disposal in the UK are also described in this paper.

\section{9}

V18/021812

\section{Portable Acoustic Wave Sensor Systems for On-Line Monitoring of Volatile Organics}

Frye, G.C.; Martin, S.J.; Cernosek, R.W.; Pfeifer, K.B. Sandia National Laboratories, Albuquerque, NM International Joumal of Environmentally Conscious Manufacturing 1(1):37-45 (1992)

Real-time, on-line monitoring of exhaust stacks, process streams, and work-place environments can play a critical role in providing safe, environmentally sound operation of processes using volatile organic species. The ability to guarantee worker safety and to document environmental impact can be crucial to removing roadblocks preventing the implementation of alternative processes for environmentally conscious manufacturing (ECM). To meet these requirements, monitoring systems are needed that are inexpensive yet still powerful enough to be effective. We have demonstrated that two independent responses, wave velocity and wave attenuation, can be obtained from surface acoustic wave (SAW) devices coated with viscoelastic polymers. This patented dual output technique enables identification and concentration determined of an isolated species with a single sensor. To demonstrate the utility of these dual output sensors for real-time industrial monitoring, a portable acoustic wave sensor (PAWS) system has been developed. Tests of this system show rapid, reversible detection of gas phase species, rapid reestablishment of sensor baseline using a carbon-based scrubber, and discrimination of species based on a comparison of the attenuation and velocity responses. On-line monitoring of spray cleaning processes has been effective in quantifying how emissions can be decreased based on substituting solvents, optimizing worker protocols, and utilizing new spray nozzle configurations.

\section{0 \\ V18/023184}

Potential Applications of Remote Sensing Technology in Monitoring Bioremediation Efforts at Toxic and Hazardous Waste Sites

Smith, A.

U.S. Army, Cold Regions Research and Engineering Laboratory, Hanover, NH

CONF-9210194; Proceedings of an International Symposium on Environmental Contamination in Central and Eastem Europe. Budapest, Hungary, October 12-16, 1992, 968 pp.; (pp. 242-244) (1992)

There is currently a great deal of interest in utilizing bioremediation technologies at toxic and hazardous waste sites. The two general approaches are: (1) microbiological - in which contaminant-specific organisms are introduced to the site; and (2) ecological - in which physical and chemical factors are adjusted to enhance narurall! occurring microbial communities. Although the two strategies differ in their methods and limitations for specific sites, both require continued monitoring, not only of physical parameters to maintain optimum microbial activity, but also of site recovery processes. Environmental conditions in cold regions pose particular problems for the use of bioremediation. High microbial activity is extremely difficult to maintain for a large portion of the year. In addition, sites may not be easily accessible. Cold Regions Research and Engineering Laboratory (CRREL) researchers are currently addressing these problems in Alaska. The development and integration of remote sensing technologies for use in monitoring these sites has several potential advantages. For example, data for temperature and moisture (critical factors affecting microbial growth) can be obtained through various remote sensors. Digital data are then available not only for use in monitoring a specific site, but also for development of predictive models which may have applications at other contaminated sites.

\section{Preliminary Remediation Goals for Ecological} Endpoints [Rev. 1]

Efroymson, R.A.; Suter, G.W., II; Sample, B.E.; Jones, D.S. U.S. Department of Energy, Oak Ridge Operations Office, Oak Ridge, TN; Lockheed Martin Energy Systems, Inc., Oak Ridge, TN 
ES/ER/TM-162/R1; 35 pp. (July 1996)

This technical memorandum was prepared to present preliminary remediation goals (PRGs) for ecological risk assessments and decision making at Comprehensive Environmental Response, Compensation, and Liability Act (CERCLA) sites. Preliminary remediation goals (PRGs) are useful for risk assessment and decision making at Comprehensive Environmental Response,

Compensation, and Liability Act (CERCLA) sites. PRGs are upper concentration limits for specific chemicals in specific environmental media that are anticipated to protect human health or the environment. They can be used for multiple remedial investigations at multiple facilities. In addition to media and chemicals of potential concem, the development of PRGs generally requires some knowledge or anticipation of future land use. In Preliminary Remediation Goals for Use at the U.S. Department of Energy Oak Ridge Operations Office (Energy Systems 1995), PRGs intended to protect human health were developed with guidance from Risk Assessment Guidance for Superfund: Volume I - Human Health Evaluation Manual, Part B (RAGS) (EPA 1991). However, no guidance was given for PRGs based on ecological risk. The numbers that appear in this volume have, for the most part, been extracted from toxicological benchmarks documents for Oak Ridge National Laboratory (ORNL) and have previously been developed by ORNL. The sources of the quantities, and many of the uncertainties associated with their derivation, are described in this technical memorandum.

\section{2}

V18/023798

Private Party Cost Recovery and Injunctive Relief Actions in Property Contamination Cases - Claims and Defenses

Dennis, P.W.; Kim, J.S.; McHenry, T.J.P.

McClintock, Weston, Benshoff, Rochefort, Rubalcava, \& MacCuish, Los Angeles, CA

CONF-9504134; HAZMACON '95, T. Bursztynsky and M.L. Loss (eds.), Proceedings of the Twelfth Hazardous Materials Management Annual Conference and Exhibition, San Jose, CA, April 4-6, 1995. Association of Bay Area Governments, Oakland, CA, 790 pp.; (pp. 394-404) (1995)

Property owners in California are increasingly faced with the prospect of investigating and, if necessary, remediating contamination on real property that may have been caused or contributed to by prior owners, tenants, or neighbors. This article explores some of the legal remedies available to such property owners as well as some of the practical considerations associated with bringing such claims in California state and federal courts. Such suits, commonly referred to as private party cost recovery actions, are now a regular feature on the civil litigation dockets of California courts and have resulted in a number of recent judicial opinions, some of which are covered in this article. In addition to covering the basic elements of the most commonly alleged causes of action, this article also explores the available remedies, the statutes of limitation, and some common defenses, as well as jurisdiction and venue considerations. We do not cover claims against insurance carriers to recover cleanup costs under insurance contracts. The article is organized by first reviewing the few, but important, statutorily-created private rights of action. These statutory provisions were enacted, in part, out of the legislature's stated perception of the failure of traditional common law claims to provide practical remedies. In addition, statutorily-created private rights of action were viewed by federal and state legislators as an important compliment to the broad authority being granted to public agencies in the same statutes to oversee the cleanup of contaminated sites. However, given the sparse language in these private remedy statutory provisions, it is clear that the legislators did not anticipate the significant door they had opened into the courts. Even a cursory review of the decisions reported in any of the published annotated codes under CERCLA Section 107, 42 USC Section 9607 , illustrates the large numbers of opinions, most issued in the past 10 years.

\section{3}

V18/022731

Probabilistic Approach to Cost and Duration Uncertainties in Environmental Decisions

Boak, D.M.; Painton, L.

Sandia National Laboratories, Albuquerque, NM

CONF-960804 (Vol. 1); Spectrum '96: Nuclear and Hazardous Waste Management, Proceedings of an International Topical Meeting, Seattle, WA, August 18-23, 1996. American Nuclear Society, La Grange Park, IL, Vol. 1, 887 pp.; (pp. 700-708) (1996)

Sandia National Laboratories has developed a method for analyzing life-cycle costs during probabilistic cost forecasting and utility theory to determine the most cost-effective alternatives for safe interim storage of radioactive materials. The method explicitly incorporates uncertainties in cost and storage duration by: (1) treating uncertain component costs as random variables represented by probability distributions, (2) treating uncertain durations as chance nodes in a decision tree, and (3) using stochastic simulation tools to generate life-cycie cost forecasts for each storage alternative. The method applies utility functions to the forecasted costs to incorporate the decision maker's risk preferences, making it possible to compare alternatives on the basis of both cost and cost utility. Finally the method is used to help identify key contributors to the uncertainty in forecasted costs to focus efforts aimed at reducing cost uncertainties. Where significant cost and duration uncertainties exist, and where programmatic decisions must be made despite these uncertainties, probabilistic forecasting techniques can yield important insights into decision alternatives, especially when used as part of a larger decision analysis framework and when properly balanced with deterministic analyses. Although the method is built around an interim storage example, it is potentially applicable to many other environmental decision problems.

\section{$3494 \quad$ V18/021192}

Probabilistic Environmental Decision Support Framework for Managing Risk and Resources Gallegos, D.P.; Webb, E.K.; Davis, P.A.; Conrad, S.H. Sandia National Laboratories, Albuquerque, NM SAND96-0395C; CONF-960647; Proceedings of the Third International Conference on Probabilistic Safety Assessment and Management, Crete, Greece, June 24-28, 1996; (6 pp.) (1996)

The ability to make cost effective, timely decisions associated with waste management and environmental remediation problems has been the subject of considerable debate in recent years. On one 
hand, environmental decision makers do not have unlimited resources that they can apply to come to resolution on outstanding and uncertain technical issues. On the other hand, because of the possible impending consequences associated with these types of systems, avoiding making a decision is usually not an altemative either. Therefore, a structured, quantitative process is necessary that will facilitate technically defensible decision making in light of both uncertainty and resource constraints. An environmental decision support framework has been developed to provide a logical structure that defines a cost-effective, traceable, and defensible path to closure on decision regarding compliance and resource allocation. The methodology has been applied effectively to waste disposal problems and is being adapted and implemented in subsurface environmental remediation problems.

\section{5 \\ V18/022077}

Problems Associated with Measurement and Analysis of Potassium in the Environment

Wood, R.P.; Ijaz, T.; Rutz, E.E.

Trinity Engineering Associates, Inc., Cincinnati, $\mathrm{OH}$

CONF-941148 (Vol. 2); DDER-'94: Decommissioning, Decontamination, and Environmental Restoration at Contaminated Nuclear Sites, M.G. White (ed.), Proceedings of an Embedded Topical Symposium of the American Nuclear Society Winter Meeting, Washington, DC, November 13-18, 1994. American Nuclear Society, Inc., La Grange Park, Il, Vol. 2, 241 pp.; (pp. 484-488) (1994)

$\mathrm{K}-40$ and total $\mathrm{K}$ concentrations were measured for environmental samples collected from a Superfund site and from two "background" areas near the site. The total $\mathrm{K}$ concentration was then used to predict the $K-40$ concentration based on the naturally occurring isotopic mix. The ratio of the measured $\mathrm{K}-40$ concentration in a particular sample to the predicted value of the concentration was formulated. Ideally, the ratio would be normally distributed around unity. The site soil concentration data, however, showed measured $\mathrm{K}-40$ concentrations significantly above the predicted values (ratio greater than 1), with the magnitude of the ratio apparently correlated with the total potassium concentration. When the ratio was plotted against total potassium concentration on a log-log plot, a linear relationship could be seen. Similar behavior was observed in samples from all the environmental media, from both onsite and offsite sources. The relationship exhibited by the samples was indicative of a bias in the measurement of $\mathrm{K}-40$, total potassium, or both. To estimate the source of this bias, the measurement and analysis methods were reviewed. The total potassium concentration in the samples was measured using inductively coupled plasma-atomic emission spectroscopy (ICP-AES), a technique which can have problems when analyzing for potassium. If magnesium is also present in significant concentrations, secondary emission from the magnesium can interfere with the potassium spectrum. For the site under investigation, magnesium was generally present in greater concentrations than potassium. The interference problem can be accounted for during calibration of the ICP-AES, however, the procedures utilized for calibration did not include the proper calibration samples required for this accounting. The review of the measurement procedures used for determination of $\mathrm{K}-40$ concentration revealed a potential source of bias which could be contributed to the unexpectedly high measured $\mathrm{K}$ concentrations.

\section{6 \\ V18/023816}

Proceedings of the $\mathbf{1 9 9 6}$ Winter Conference on Plasma Spectrochemistry, Fort Lauderdale, FL, January 8-13, 1996

CONF-960113; Proceedings of the 1996 Winter Conference on Plasma Spectrochemistry, Fort Lauderdale, FL, January 8-13, 1996, 378 pp. (1995)

The Winter Conference on Plasma Spectrochemistry is sponsored biennially by the ICP Information Newsletter. Technical sessions feature lectures and posters describing application, fundamental, and instrumentation developments with popular electrical plasma sources. Inductively coupled plasma, direct current plasma, and microwave induced plasma are featured, and glow discharge sources are included. Laser assisted plasma spectrochemistry also has become significant. New spectrometric instrumentation, novel sample introduction systems, plasma system automation, and new diagnostic characteristics and theoretical treatments have been highlighted. Individual papers within the scope of the RAPIC database are indexed separately.

3497

V18/024864

Proceedings of the Third National Workshop on the Health Risk Assessment and Management of Contaminated Sites (Contaminated Sites Monograph Series No. 5, 1996), Sydney, Australia, May 1995

Proceedings of the Third National Workshop on the Health Risk Assessment and Management of Contaminated Sites (Contaminated Sites Monograph Series No. 5, 1996), A. Langley, B. Markey and H. Hill (eds.), Sydney, Australia, May 1995. South Australian Health Commission, Rundle Mall, South Australia, 470 pp. (1996)

This workshop was held in Sydney in May 1995, and the proceedings of the workshop are presented in this volume. The 1995 workshop was attend by representatives of Australian State, Territory, and Commonwealth health and environment departments and health and environment representatives from New Zealand. Papers included in this proceedings cover several topics including: the toxicity of several metals, exposure scenarios and exposure factors, uncertainty analysis, carcinogenic risk assessment guidelines, bioavailability, and bioassays. Papers within the scope of this data base have been indexed separately.

3498

V18/021052

Professional Judgment in the Data Quality Objectives Process: A Bayesian Approach to Screening Assessment Black, P.K.; Neptune, M.D.; Ryti, R.T.; Hickmott, D.D. Neptune and Company, Inc., Los Alamos, NM; Los Alamos National Laboratory, Los Alamos, NM

CONF-940499 (Vol. 2); Proceedings of the 1994 Federal Environmental Restoration III and Waste Minimization II Conference and Exhibition, New Orleans, LA, April 27-29, 1994. Hazardous Materials Control Resources Institute, Rockville, MD, Vol. 2, 858 pp.; (pp. 1157-1166) (1994)

The Data Quality Objectives (DQO) process provides a logical planning structure for specifying the optimal sample allocation for defensible decision making, depending on acceptable levels of 
decision uncertainty and anticipated sampling and measurement errors. These planning inputs must be established prior to designing the data collection activity. Application of the DQO process has traditionally been performed under the framework of Classical statistical theory; elicited decision errors have been interpreted as Classical Type I and Type II errors; mean and variance constraints have been incorporated based on historical information; and, Classical statistical testing methods have been used to determine optimal sample sizes. However, decision errors are usually stated, for dichotomous hypotheses, in terms of the probability of making a false positive or false negative decision; these probabilities, at best, relate loosely to probabilities of Classical Type I and Type II errors. Statements of Classical error types are couched in the language of the probability of rejection of hypotheses as opposed to the probability that a hypothesis is correct. Also, historical or archival data are often insufficient to adequately support prior judgments of means and variances. In many circumstances, however, expert knowledge and opinion is not only available, but is substantial. Finally, a paradigm that provides solutions for other than dichotomous decision problems offers greater diversity for solving real worid problems. The example presented in this paper provides an example of how expert opinion can be characterized so that it is available through the DQO process. Expert judgment is modeled formally, through a Bayesian statistical model, to provide a rational, defensible basis for decision making. Formal statistical modeis of expert judgment are developed through an elicitation session, in which the decision makers and technical experts provide information at a cognitively appropriate level. The required design inputs fulfill the needs of the prior distribution for the parameter of interest, the associated loss function, and the cost of sampling function. The likelihood function is established similarly in both this approach and in the Classical counterpart. Once the elicitation process is complete, and costs associated with sampling have been established, this approach provides the needed information, through application of Bayesian statistical decision theory, for determining the need for sampling and the optimal number of samples. The optimal sample size is generated by balancing the expected losses, due to incorrect decisions, at each possible sample size against the cost of taking that many samples. The optimal sample size is achieved when the value of information gained from taking one more sample is outweighed by the cost of taking that sample. The Bayesian approach is applied to a site example to determine the presence of trinitrotoluene (TNT) in soil at concentrations greater than a prescribed regulatory action level. A feature of this problem that makes the approach used more appealing vis-a-vis a Classical statistical analysis is that one of the hypotheses under consideration corresponds to a boundary condition on the parameter space.

\section{9}

\section{V18/022345}

Program Management Plan for the Management Control Information System (MCIS) - Phase II

Lockheed Martin Energy Systems, Inc., Oak Ridge, TN; Software Control International, Oak Ridge, TN

ES/ER/TM-192; 45 pp. (January 1997)

The objective of MCIS Phase II is to build a client-server system to improve upon existing Comprehensive Environmental Restoration Management Information System (CERMIS). Current CERMIS functionality will be incorporated, and user-centered requirements analysis will result in new capabilities. Project objectives are to: (1) provide consistent and accurate data, (2) complete the definition of the Environmental Restoration (ER) Division's business processes, (3) streamline ER operations, (4) enhance communications among sites, and (5) satisfy all documented requirements.

3500

V18/023196

Program for Providing Engineering Technical Assistance to Site Remediation Managers

Blaney, B.L.

U.S. Environmental Protection Agency, Risk Reduction Engineering Laboratory, Cincinnati, $\mathrm{OH}$

CONF-9210194; Proceedings of an International Symposium on Environmental Contamination in Central and Eastem Europe, Budapest, Hungary, October 12-16, 1992, 968 pp.; (pp. 297-300)

The Office of Research and Development (ORD) of the U.S. Environmental Protection Agency (U.S. Environmental Protection Agency) provides technical support to U.S. Environmental Protection Agency Regional Offices which are responsible for overseeing and/or implementing the remediation of contaminated sites. As a result, ORD has developed a number of effective mechanisms for providing timely, practical and high quality technical support on such site remediation projects and has produced a variety of technology transfer documents on the topic. This paper describes these activities, with particular emphasis on the program of the U.S. Environmental Protection Agency ORD Risk Reduction Engineering Laboratory's program to deal with engineering remediation problems.

3501

V18/022440

Protocol for the Derivation of Environmental and Human Health Soil Quality Guidelines

Canadian Council of Ministers of the Environment, Winnipeg, Manitoba, Canada

Report; 169 pp. (1996)

To promote consistency and provide guidance in assessing contaminated sites, CCME released an interim set of numerical environmental quality guidelines in September 1991. These interim criteria were established to meet a defined need, and were based on existing soil and water criteria in various jurisdictions. However, a number of the interim criteria were not scientifically defensible; this protocol has been developed so that revised environmental quality will be so. It considers the effects of contaminated soil exposure on human and ecological receptors for given land uses. The document is divided into four basic parts. Information on complementary scientific tools developed under the National Contaminated Sites Remediation program is provided in Part A. The processes for deriving environmental and human health soil quality guidelines are described in Parts B and C. Part D concludes by providing guidance on derivation of the final soil quality guideline. Methods and models employed in the ecological sections of the document, and check mechanisms for indirect exposure from soil contaminants for the human health guidelines, are provided in appendices. 
Providing a Corporate Direction: The OST "Corporate Technology Board"

Wagoner, $\mathrm{J}$.

U.S. Department of Energy, Richland Operations Office, Richland, WA

Fostering the Needed Partnerships: Doing the Necessary Science to Support Technology Development, Commercialization, Deployment, E.L. Helminski (ed.), Proceedings of the Seventh Annual Western Governors' Association/Weapons Complex Monitor Applied Research and Cleanup Technology Colloquium, Phoenix, AZ, April 29-May 2, 1996. Exchange/Monitor Publications and Forums, Lake Bluff, IL, 500 pp.; (20 pp.) (April 1996)

The viewgraphs for this presentation highlight the role of the OST in providing corporate direction for EM activities throughout the DOE complex. Primary objectives are met through involving the OST Board of Directors, the Focus Areas Cross Cut Programs and the Site/Site Technology Coordination Groups (STCGs). The Tank Focus Area is featured to provide examples of the organizational structure. Accomplishing OST objectives at Hanford is discussed in terms of innovative technology development, demonstration and deploymènt.

3503

\section{V18/022918}

Public Participation: Picking the Players

McNeill, L.; Jernigan, G.

Westinghouse Savannah River Company, Aiken, SC CONF-951006; Proceedings of an American Nuclear Society (ANS) Winter Meeting, San Francisco, CA, October 29-November 1, 1995. ANS, La Grange Park, IL, 522 pp.; Transactions of the American Nuclear Society 73:45 (1995)

When citizens become involved in the public policy decision-making process, who picks the players? Are there any criteria for determining which members of the public should sit at the table? These are few questions frequently asked by new participants and observers of the public involvement process. If the question of how many members of the public to involve is answered in the context of the moral and business drivers, it becomes more an issue of quality than quantity. If only three members of the community are interested enough in an environmental impact to attend a meeting, assuming that the meeting was adequately publicized and the issue was explained sufficiently, then the interested public has participated. It is not the duty of companies or govemment agencies to try to create interest in a issue where none exists inherently.

\section{$3504 \quad$ V18/023907}

Pursuing Other Deep Pockets: California's Underground Storage Tank Cleanup Fund and Insurance Policies

Almanza, P.R.

Parker, Milliken, Clark, O'Hara \& Samuelian, Los Angeles, CA

CONF-951124; HazMat West '95, Proceedings of the Eleventh Annual Environmental Management and Technology Conference and Exhibition, Long Beach, CA, November 7-9, 1995. Advanstar Expositions, Duluth, MN, 597 pp.; (pp. 547-560) (1995)

When faced with a potentially very expensive environmental cleanup, most companies and individuals try to do the only sensible thing, which is to find out if anyone else will pay the bill. This presentation will outline two avenues that may provide a substantial financial contribution to environmental cleanups: (a) California's Underground Storage Tank Cleanup Fund and (b) insurance policies. The Underground Storage Tank Cleanup Fund was established in 1989 to help eligible owners and operators of petroleum underground storage tanks (USTs) to: (a) get reimbursed for costs of unauthorized releases of petroleum from USTs (b) get reimbursed for damages awarded to third parties as a result of unauthorized releases of petroleum from USTs; and (c) meet federal and state requirements that the UST owner and/or operator be able to pay for cleanup costs and damages to third parties caused by unauthorized releases of petroleum.

3505

V18/022295

Quality Assurance Plan for the Oak Ridge Environmental Information System (OREIS) [Rev. 2]

Lockheed Martin Energy Systems, Inc., Environmental Restoration Division, Oak Ridge, TN

ES/ER/TM-74/R2; 35 pp. (October 1996)

This QA plan for the Oak Ridge Environmental Information System (OREIS QA Plan) supplements the Lockheed Martin Energy Systems, Inc. (Energy Systems), Environment Restoration (ER) Quality Program Plan (QPP). The ER QPP was developed in compliance with DOE Order 5700.6C, Quality Assurance, and is based on the Energy Systems Quality Program Plan (Y-QD-16, Rev. 1), and other applicable standards and procedures of Energ. Systems. The OREIS QA. Plan adheres to the applicable NQA-1 requirements identified in the ER QPP. It is responsive to the American National Standards Institute/American Society of Mechanical Engineers Nuciear Quality Assurance-1 (ANSVASME NQA-1). By DOE order, the consensus standard NQA-1, Quality Assurance Program Requirements for Nuclear Facilities, and the guidelines established by NQA-2, Quality Assurance Requirements of Computer Software for Nuclear Facility Applications, apply to all work of Energy Systems. The application of QAMS-005/80 does not apply to the OREIS program.

3506 V18/020633

Quality Assurance Programs Developed and Implemented by the U.S. Department of Energy's Analytical Services Program for Environmental Restoration and Waste Management Activities

Lillian, D.; Bottrell, D.W.

U.S. Department of Energy, Germantown, MD; Pacific Northwest Laboratory, Richland, WA

PNL-10076; CONF-9303220; Measurement Quality Assurance for Ionizing Radiation: Proceedings of a Workshop, J.A. Heath and K.L. Swinth (eds.), Gaithersburg, MD, March 16-18, 1993, 468 pp.; (pp. 61-66) (1993)

The U.S. Department of Energy's (DOE) Office of Environmental Restoration and Waste Management (EM) has been tasked with 
addressing environmental contamination and waste problems facing the Department. A key element of any environmental restoration or waste management program is environmental data. An effective and efficient sampling and analysis program is required to generate credible environmental data. The bases for DOE's EM Analytical Services Program (ASP) are contained in the charter and commitments in Secretary of Energy Notice SEN-13-89, EM program policies and requirements, and commitments to Congress and the Office of Inspector General (IG). The Congressional commitment by DOE to develop and implement an ASP was in response to concerns raised by the Chairman of the Congressional Environment, Energy, and Natural Resources Subcommittee, and the Chairman of the Congressional Oversight and Investigations Subcommittee of the Committee on Energy and Commerce, regarding the production of analytical data. The development and implementation of an ASP also satisfies the IG's audit report recommendations on environmental analytical support, including development and implementation of a national strategy for acquisition of quality sampling and analytical services. These recommendations were endorsed in Departmental positions, which further emphasise the importance of the ASP to EM's programs. In September 1990, EM formed the Laboratory Management Division (LMD) in the Office of Technology Development to provide the programmatic direction needed to establish and operate an EM-wide ASP program. In January 1992, LMD issued the "Analytical Services Program Five-Year Plan." This document described LMD's strategy to ensure the production of timely, costeffective, and credible environmental data. This presentation describes the overall LMD Analytical Services Program and, specifically, the various quality assurance $(\mathrm{Q})$ ) programs.

\section{7}

V18/022550

Quantum Improvement in Efficient Use of Sampling and Analysis Resources for Environmental Compliance

McClellan, Y.; Royer, R.; Morris, R.

Sandia National Laboratories, Albuquerque, NM

CONF-9511137; Global Environmental Protection: Science, Politics, and Common Sense, Proceedings of the Second Society of Environmental Toxicology and Chemistry (SETAC) World Congress and 16th Annual Meeting, Vancouver, British Columbia, Canada, November 5-9, 1995. Society of Environmental Toxicology and Chemistry, Pensacola, FL, 378 pp.; (p. 298) (1995)

DOE Orders, CERCLA, RCRA, and NEPA activities often result in multiple sample collection and analysis. The current budget constraints should drive sampling, analysis, and reporting activities to fulfill multiple regulatory requirements. The most efficient use of sampling and analysis data should allow fewer sampling and analysis activities to accomplish the same goals. The redundancy should be avoided by standardizing the sampling and analysis to make data useful for more than one program. In addition, site programs (e.g., environmental restoration, water sampling, and air sampling) should make data available through documentation and promulgation of an electronic database. (Complete text)

V18/023394

RAAS1.1 - Remedial Action Assessment System
Bryant, J.L.; White, M.K.

Pacific Northwest Laboratory, Richland, WA

ESTSC-001116IB48601; (8 3.5 Diskettes for RAAS and 23.5

Diskettes for Acrobat Adobe Reader) (September 1, 1996)

RAAS1.1 is a software-based system designed to assist remediation professionals at each stage of the environmental analysis process. RAASI.1 provides a template for environmental restoration analysis and provides the user with key results at each step in the analysis. RAAS1.1 assists the user to develop a coherent and consistent site description, estimate baseline and residual risk to public health from the contaminated site, identify applicable environmental restoration technologies, and formulate feasible remedial response alternatives. In addition, the RAAS1.1 methodology allows the user to then assess and compare those remedial response alternatives across EPA criteria, including: compliance with objectives; short-term and long-term effectiveness; extent of treatment; and implementation ability of the technologies. The analytic methodology is segmented and presented in a standardized, concise, easy-to-use format that can be viewed on the personal computer screen, saved and further manipulated, or printed for later use. Each screen and analytic step is accessed via a user-friendly personal computer graphical interface.

Intuitively-designed buttons, menus, and lists help the user focus in on the particular information and analysis component of interest; the corresponding results are presented in a format that facilitates their use in decision-making.

3509

V18/020927

RADLEG - Development of a Sophisticated Computer-Based Data System for Evaluation of the Radiation Legacy of the Former USSR and Setting Priorities on Remediation and Prevention Policy

Egorov, N.; Iskra, A.; Laverov, N.; Lebedev, O.; Novikov, V. Ministry of Russian Federation for Atomic Energy, Moscow, Russian Federation

CONF-960212; Waste Management '96: Working Towards a Cleaner Environment, Proceedings of a Conference on $\mathrm{HLW}$, LLW, Mixed Wastes and Environmental Restoration, Tucson, AZ, February 25-29, 1996; (8 pp.) (1996)

The objective of the Project is to create a public accessible database linked to geographical information system (GIS) that will describe available information on the radiation legacy of the former Soviet Union. This system will be developed so as to aid policy makers in two principle areas: (1) Identify and set priorities on radiation safety problems and (2) Provide guidance for the development of technically, economically, publicly, and institutionally sound policies to reduce the impact of radioactively contaminated sites. Over the past 50 years, vast quantities of radioactive waste (RW) and numerous radioactively contaminated sites resulting from the production of nuclear weapons and civilian use of nuclear energy have accumulated in several countries. Although there are studies and cooperative efforts on aspects of this overall issue, there has been no systematic, comprehensive and interdisciplinary effort to exchange information and coordinate activities to achieve technically sound and cost effective management, and cleanup of the $\mathrm{RW}$. The aim of this project is to provide usable information that can aid in making decisions for radiation hazard management. 
It will also aid in conducting risk estimate studies, analyzing the transboundary and transjurisdictional aspects of waste and spent fuel transportation, determining future land uses, and evaluating radionuclide material flows through the environment. In accordance with the funding directives of the ISTC, this project has been separated into two phases, the first phase will last one year and is being carried out now. Phase 1 consists of: (1) the development of the methodology necessary for a systems approach to the creation of the database and GIS technology; (2) collection and analysis "first order" data - determination of the computer application methodologies; and (3) development of a simple operational prototype data system linked to 2 or 3 GIS examples. Phase 2 will consist of: (1) an evaluation of the completeness of data collected during Phase 1 ; (2) collection and analysis of additional, "second order" data including socio-institutional, geographic, demographic, and climatic characteristics necessary to develop a public accessible data base and GIS; (3) development of the map blocks as GIS components; and (4) creation of a public accessible data system including data base and GIS on radiation legacy of the former USSR.

\section{0}

V18/022297

\section{RCRA Corrective Action Determination of No Further} Action

U.S. Department of Energy, Office of Environmental Policy and Assistance, Washington, DC

EH-413-063/0696; 4 pp. (June 1996)

On July 27, 1990, the U.S. Environmental Protection Agency (EPA) proposed a regulatory framework (55 FR 30798) for responding to releases of hazardous waste and hazardous constituents from solid waste management units (SWMUs) at facilities seeking permits or permitted under the Resource Conservation and Recovery Act (RCRA). The proposed rule, "Corrective Action for Solid Waste Management Units at Hazardous Waste Facilities," would create a new Subpart $S$ under the 40 CFR 264 regulations, and outlines requirements for conducting RCRA Facility Investigations, evaluating potential remedies, and selecting and implementing remedies (i.e., corrective measures) at RCRA facilities. EPA anticipates instances where releases or suspected releases of hazardous wastes or constituents from SWMUs identified in a RCRA Facility Assessment, and subsequently addressed as part of required RCRA Facility Investigations, will be found to be non-existent or non-threatening to human health or the environment. Such releases may require no further action. For such situations, EPA proposed a mechanism for making a determination that no further corrective action is needed. This mechanism is known as a Determination of No Further Action (DNFA) (55 FR30875). This Information Brief describes what a DNFA is and discusses the mechanism for making a DNFA. This is one of a series of Information Briefs on RCRA corrective action.

\section{$3511 \quad$ V18/025455}

\section{REMTEC Site Remediation Treatment Technology}

Database

Brendon, D.

Department of the Environment, Environmental Protection Service, Ottawa, Ontario, Canada

CONF-951086; Proceedings of the Fifth Annual Symposium on
Groundwater and Soil Remediation, Toronto, Ontario, Canada, October 2-6, 1995. Environment Canada - Environmental Protection Service, Hull, Quebec, Canada, 566 pp.; (pp. 399-403) (1995)

The Site Remediation Technology Database, REMTEC, a relational database of technologies for the treatment of sediment, soil, groundwater, and off-gas, jointly developed by Environment Canada and the Ontario Ministry of Energy and Environment, is described. REMTEC will provide the user with a number of search options ranging from keyword searching to problem solving approaches. The user will also be able to print the information in a variety of useful report formats.

3512

V18/022069

RESRAD-BUILD: A Computer Model for Assessing Human Health Risks Resulting from Building Decontamination Activities

Yu, C.; LePoire, D.J.; Jones, L.G.; Chen, S.Y.; Loureiro, C.O. Argonne National Laboratory, Argonne, Il; University of Minas Gerais, School of Engineering, Belo Horizonte, Brazil CONF-941148 (Vol. 2); DDER-'94: Decommissioning, Decontamination, and Environmental Restoration at Contaminated Nuclear Sites, M.G. White (ed.), Proceedings of an Embedded Topical Symposium of the American Nuclear Society Winter Meeting, Washington, DC, November 13-18, 1994. American Nuclear Society, Inc., La Grange Park, II, Vol. 2, 241 pp.; (pp. 461-467) (1994)

The RESRAD-BUILD computer code is a pathway analysis model designed to evaluate the potential radiological dose incurred by an individual who works or lives in a building contaminated with radioactive material. A single run of the RESRAD-BUILD code can model a building with up to three compartments, 10 distinct source geometries, and 10 receptor locations. A shielding material can be specified between each source-receptor pair for external gamma dose calculations. Exposure pathways considered in RESRAD-BUILD include external exposure directly from the source; extemal exposure to materials deposited on the floor; external exposure due to air submersion; inhalation of airborne radioactive particulates; inhalation of aerosol indoor radon progeny; and inadvertent ingestion of radioactive material, either directly from the sources or from materials deposited on the surfaces of the building compartments. RESRAD-BUILD runs on IBM-compatible computers.

3513

V18/024881

RESRAD-BUILD: External Exposure Model for Various Geometries of Contaminated Materials

LePoire, D.J.; Kamboj, S.; Yu, C.

Argonne National Laboratory, Argonne, IL

CONF-9607135; Proceedings of the 41st Annual Meeting of the Health Physics Society, Seattle, WA, July 21-25, 1996; Health Physics 70(6):32a (June 1996)

A computational model for external exposure was developed for the U.S. Department of Energy's residual radioactive materials guideline computer code (RESRAD) on the basis of dose coefficients from Federal Guidance Report No. 12 and the point-kemel method. This 
model includes the effects of different materials and exposure distances, as well as source geometry (cover thickness, source depth, area, and shape). A material factor is calculated on the basis of the point-kemel method using material-specific photon cross-section data and buildup factors. This present model was incorporated into RESRAD-RECYCLE (a RESRAD family code used for computing radiological impacts of metal recycling) and is being incorporated into RESRAD-BUILD (a DOE recommended code for computing impacts of building decontamination). The model was compared with calculations performed with the Monte Carlo N-Particle Code (MCNP) and the Microshield code for three different source geometries, three different radionuclides U-234, U-238, and Co-60 (representing low, medium, and high energy, respectively) and five different source materials (iron, copper, aluminum, water, and soil). The comparison shows that results of this model are in very good agreement with MCNP calculations (within $5 \%$ for $\mathrm{Co}-60$ and within $30 \%$ for U-238 and U-234 for all materials and source geometries). Significant differences (greater than $100 \%$ ) were observed with Microshield for thin U-234 sources.

\section{4}

V18/024880

\section{RESRAD-BULD: Use of the RESRAD-BULLD Code to Calculate Building Surface Contamination Limits}

Faillace, E.R.; LePoire, D.J.; Yu, C.

Argonne National Laboratory, Argonne, Il

CONF-9607135; Proceedings of the 41st Annual Meeting of the Health Physics Society, Seattle, WA, July 21-25, 1996; Health Physics 70(6):33 (June 1996)

Surface contamination limits in buildings were calculated for Ra-226, Th-230, Th-232, and natural uranium on the basis of 1 mSv per year (100 mrem per year) dose limit. The RESRAD-BUILD computer code was used to calculate these limits for two scenarios: building occupancy and building renovation. RESRAD-BUILD is a pathway analysis model designed to evaluate the potential radiological dose incurred by individuals working or living inside a building contaminated with radioactive material. Six exposure pathways are considered in the RESRAD-BUILD code: (1) external exposure directly from the source; (2) external exposure from materials deposited on the floor; (3) external exposure due to air submersion; (4) inhalation of airbome radioactive particles; (5) inhalation of aerosol indoor radon progeny; and (6) inadvertent ingestion of radioactive material, either directly from the sources or from materials deposited on the surfaces. The code models point, line, area, and volume sources and calculates the effects of radiation shielding, building ventilation, and ingrowth of radioactive decay products. A sensitivity analysis was performed to determine how variations in input parameters would affect the surface contamination limits. In most cases considered, inhalation of airbome radioactive particles was the primary exposure pathway. However, the direct extemal exposure contribution from surfaces contaminated with Ra-226 was in some cases the dominant pathway for building occupancy depending on the room size, ventilation rates, and surface release fractions. The surface contamination limits are most restrictive for Th-232, followed by Th-230, natural uranium, and Ra-226. The results are compared with the surface contamination limits in the Nuclear Regulatory Commission's Regulatory Guide 1.86, which are most restrictive for Ra-226 and Th-230, followed by Th-232, and are least restrictive for natural uranium.

3515 $\mathrm{V} 18 / 021403$

Radiation Dose Assessments to Support Evaluations of Radiological Control Levels for Recycling or Reuse of Materials and Equipment

Hill, R.L.; Aaberg, R.L.; Baker, D.A.; Kennedy, W.E., Jr. Pacific Northwest Laboratory, Richland, WA

PNL-8724; 130 pp. (July 1995)

Pacific Northwest Laboratory (PNL) is providing Environmental Protection Support and Assistance to the U.S. Department of Energy (DOE), Office of Environmental Guidance, Air, Water, and Radiation Division (DOE/EH-232). As part of this effort, PNL is collecting data and conducting technical evaluations to support DOE analyses of the feasibility of developing radiological control levels for recycling or reuse of metals, concrete, or equipment containing residual radioactive contamination from DOE operations. The radiological control levels will be risk-based, as developed through a radiation exposure scenario and pathway analysis. The analysis will include evaluation of relevant radionuclides, potential mechanisms of exposure, and both health and non-health-related impacts. The main objective of this report is to develop a methodology for establishing control levels for recycle or reuse. This report provides the results of the radiation exposure scenario and pathway analyses for 42 key radionuclides generated during DOE operations that may be contained in metals or equipment considered for either recycling or reuse. The scenarios and information developed by the International Atomic Energy Agency (IAEA) in Safety Series No. 111-P-1.1. Application of Exemption Principles to the Recycle and Reuse of Materials from Nuclear Facilities, are used as the initial basis for this study. The analyses were performed for both selected worker populations at metal smeiters and for the public downwind of a smelter facility. Doses to the public downwind were estimated using the U.S. Environmental Protection Agency's (EPA) CAP88-PC computer code with generic data on atmospheric dispersion and population density. Potential non-health-related effects of residual activity on electronics and on film were also analyzed. As additional relevant data are collected, this initial generic assessment may need to be revised. Thus, this report is intended to serve as an intermediate product that will help to focus future technical support efforts for the DOE.

\section{$3516 \quad \mathrm{~V} 18 / 022900$}

Radioactive Waste Management Glossary International Atomic Energy Agency, Vienna, Austria Report; 55 pp. (December 1993)

The purpose of this Glossary is to provide a source of words which are commonly used or have special meanings in the field of radioactive waste management. However, it should be noted that some terms are used and defined differently in other areas of technology and even in other IAEA publications. To keep the Glossary to a manageable size, words whose meaning in the waste management literature is unchanged from that found in a standard dictionary are generally omitted. Technical terms whose meaning is unchanged from that of a specific discipline, such as engineering or geology, have also been omitted. 


\section{7}

V18/025504

Radioecological Risk Perception by the Students: Preliminary Assessments

Nechaev, A.F.; Projaev, V.V.; Minin, A.V.

St. Petersburg State Institute of Technology, St. Petersburg, Russian Federation

CONF-960804 (Vol. 2); Spectrum '96: Nuclear and Hazardous Waste Management, Proceedings of an Intemational Topical Meeting, Seattle, WA, August 18-23, 1996. American Nuclear Society, La Grange Park, IL, Vol. 2, 873 pp.; (pp. 1614-1617) (1996)

This paper summarizes the background work and gives some results of a study carried out in two universities in St. Petersburg in 1995. The aim of the study was to evaluate the levels of radioecological risk perception and acceptance in a student audience. The investigation was a part of the initiative project on development of human resources for radioactive waste management and environmental restoration of radioactively contaminated sites.

\section{8}

\section{V18/022046}

\section{Raman Spectroscopy: What do we Need for Field} Measurement?

Vickers, T.J.; Mann, C.K.

Florida State University, Department of Chemistry, Tallahassee, FL

CONF-9506232; Environmental Monitoring and Hazardous Waste Site Remediation, T. Vo-Dinh and R. Niessner (eds.), Proceedings of a Conference of the Society of Photo-Optical Instrumentation Engineers, Munich, Germany, June 19-23, 1995. Intemational Society for Optical Engineering, Bellingham, WA, 613 pp.; (pp. 310-315) (1995)

Success in field measurements requires both appropriate instrumentation and appropriate data acquisition and treatment strategies. Recent advantages in instrumentation have improved the utility of Raman spectroscopy for field measurements. This presentation will focus on data acquisition and treatment strategies. We have built into our measurement systems both hardware and software to provide automated wavenumber and intensity calibration and correction. Field measurements demand better wavenumber accuracy than is generally appreciated. In our approach, wavenumber calibration is based on atomic line spectra. Intensity axis calibration requires correction for pixel-to-pixel and wavelength-dependent sensitivity variations of the detector and wavelength- and time-dependent throughput variations of the probe and spectrograph optics. The data needed for these corrections are obtained by measurement with a calibrated white light source and with a standard sample. This presentation will describe reference materials and how the calibration and corrections are effected.

\section{9}

V18/023183

Rapid Assessment of the Extent of Environmental Contamination Using Borehole Techniques and Portable Instrumentation

Kaelin, L.P.; Fekete, A.; Mickunas, D.; Wynnyk, R.; Humphrey, A.; Prince, G.
Roy F. Weston, Inc., Edison, NJ; U.S. Environmental Protection Agency, Edison, NJ

CONF-9210194; Proceedings of an International Symposium on Environmental Contamination in Central and Eastern Europe, Budapest, Hungary, October 12-16, 1992, 968 pp.; (pp. 240-242) (1992)

The United States Environmental Protection Agency Environmental Response Team (U.S. EPA/ERT) has used borehole techniques to collect the volatile organic vapors from the soil vadose zone at hazardous wastes sites across the U.S. and abroad. These vadose zone vapor samples are called soil gas samples. Soil gas analysis can indicate the presence of volatile organic compounds (VOCs) in the soil column or underlying groundwater aquifers. Soil gases are sampled using a manually driven slam bar and collected in inert Teflon $[R]$ gas sampling bags using a vacuum box of simple design. The gas sample bags are analyzed on site using commercially available field-portable instruments. The instrumentation used can be analyte or non-analyte specific but must be able to operate on intemal power and instrument supplies for four hours or more to be useful for on-site field applications. The U.S. EPAVERT has developed field procedures to collect and analyze soil gas samples for rapidly determining the extent of contamination at hazardous waste sites.

\section{0}

V18/022732

Rapid Data Access: Key to Integrated Use of Environmental Characterization and Monitoring Information

Canales, T.W.; Ottesen, P.

Lawrence Livermore National Laboratory, Livermore, CA

CONF-960804 (Vol. 1); Spectrum '96: Nuclear and Hazardous Waste Management, Proceedings of an International Topical Meeting, Seattle, WA, August 18-23, 1996. American Nuclear Society, La Grange Park, IL, Vol. 1, 887 pp.; (pp. 714-717) (1996)

Environmental investigations result in large quantities of data. The value of these data lies in their interpretation and use by project staff, management, and the regulatory community. Traditional modes of data access can be frustrating and time-consuming. Software tools that join networking technology of the World Wide Web (WWW) with database access have decreased labor-intensive overhead in site characterization and monitoring, thus increasing the efficiency of the groundwater restoration project at Lawrence Livermore National Laboratory (LLNL). DOE and project personnel have dynamic access to statistical processing, database retrieval, and cost estimating tools. By adding mouse-sensitive site maps and post-processing capabilities, we have extended the utility of standard web browsers, such as Netscape or Mosaic. Users can retrieve chemical compound concentrations, groundwater elevations, descriptive information about monitoring locations, or analytical services' cost estimations. Data may be viewed as time-series graphs, contour maps, chemical concentration histograms, or simply displayed as text. Platform independence and easy retrieval make more comprehensive review of data possible. Cost-savings are realized; efficiency is increased; planning and decision-making are facilitated.

3521

V18/023220 


\section{Real-Time Monitoring of Hazardous Chemical Waste}

Koutsandreas, J.D.

Florida State University, Center for Biomedical and Toxicological Research, Taliahassee, FL

CONF-9210194; Proceedings of an International Symposium on Environmental Contamination in Central and Eastern Europe, Budapest, Hungary, October 12-16, 1992, 968 pp.; (pp. 484-487) (1992)

The requirement for immediate information during surveillance of hazardous waste sites is becoming more demanding every day. Laboratory analyses of field samples continues to tax the laboratories beyond their capacities. These demands will increase asymptotically as the Department of Defense and other federal facilities continue with environmental restoration and/or remediation programs. The Eastem European communities and the former Soviet Union are also facing cleanup problems similar to those in the United States. Field analysis techniques produce accurate, real-time data at low cost per sample during waste site characterization. More efficient non-intrusive sampling strategies are necessary for characterizing the hazardous waste facilities and optimizing the numbers of monitoring wells. Technologies most appropriate for meeting these requirements include fiber optic chemical sensors. Sippican, Inc. has developed a commercially available field instrument employing a fiber optic sensor. Called CHEMSENSOR $[R]$, the unit is field-portable and capable of making in-situ, real-time measurements of chemical contaminants.

\section{2}

\section{V18/023393}

Recent Advances in Optimal Project Selection Using Risk Management and Cost Minimization

Redus, K.S.; Sharp, G.L.

MACTEC, Oak Ridge, TN; Scientific Ecology Group, Inc., Oak Ridge, TN

CONF-961103; Decommissioning, Decontamination, and Reutilization Worldwide Experience: DD\&R, What Does It Mean, M.G. White, R.G. Thomas and R.F. Ranellone (eds.), Proceedings of an Embedded Topical Symposium of an American Nuciear Society Winter Meeting, Washington, DC, November 10-14, 1996. American Nuclear Society, Inc., La Grange Park, IL, 328 pp.; Transactions of the American Nuclear Society 75:67-69 (1996)

Program managers need to choose the optimal number of projects (or specific technology solutions to a single project) to address the challenge: What projects should be funded that demonstrate success given limited dollars? This paper presents recent advances and new results in optimal project selection. A portfolio of an environmental restoration (ER) project, a decontamination and decommissioning (D\&D) project, or a surveillance and maintenance (S\&M) project is selected that minimizes life cycle cost (LCC) given: (a) annual budget constraints, (b) human health and environmental risk (HH\&E) reduction requirements, and (c) risk management issues associated with schedule delays, regulatory compliance, radiological worker safety, use of best-management practices, use of best-demonstrated available technologies, and stakeholder acceptance.
Regulator's Perspective on Insitu Bioremediation Shauver, J.M.

Michigan Department of Natural Resources, Lansing, MI Insitu Bioremediation: When Does It Work?, National Academy Press, Washington, DC, 207 pp.; (pp. 99-103) (1993)

Bioremediation, like any technology applied to clean up a contaminated site, must first be approved by government regulators who ultimately must agree that the technology has a reasonable chance to reduce the contaminant(s) at the site to acceptable levels. This paper describes the information that regulators need to make their decision. Basically, this information comprises descriptions of the site, the specific cleanup process, and the overall approach to site cleanup. The paper aiso answers the questions of who, what, when, where, and how in the context of bioremediation on the basis of the authors 24 years of experience as a regulator.

\section{4}

\section{V18/022988}

\section{Regulatory Overview of Site Remediation in Manitoba}

Yee, E.J.

Manitoba Environment, Winnipeg, Manitoba, Canada CONF-9610147; Sustainability: The Evolution of Waste Management to Pollution Prevention and Resource Recovery, Proceedings of the 18th Canadian Waste Management Conference, Winnipeg, Manitoba, Canada, October 7-10, 1996. Canadian Environmental Industry Association, Winnipeg, Manitoba, Canada, 600 pp.; (9 pp.) (October 1996)

An overview of the regulations regarding the assessment and management of contaminated soils in Manitoba is given. The issue of contaminated site liability is discussed. The Geographic Information System (GIS) evaluation process is described. Vulnerability maps of Manitoba were compiled in the GIS. These maps contain important data to assess where groundwater and surface water is most susceptible to contamination. The maps include the soil landscapes of Manitoba, the aquifers that are most important for municipal water supplies, the provincial ecological reserves, and provincial and federal parks. The vulnerability map of Manitoba was compiled based on a numerical model that simulated pollution migration into groundwater and surface water, and receptor exposure probability.

\section{5}

\section{V18/024357}

Remediation of Hazardous Waste Sites for Protection of Wildlife: Development of Remedial Goal Options

Sample, B.E.

Oak Ridge National Laboratory, Environmental Sciences Division, Oak Ridge, TN

CONF-961149; SETAC 17: Partnerships for the Environment Science, Education, and Policy, Proceedings of the 17th Annual Meeting of the Society of Environmental Toxicology and Chemistry, Washington, DC, November 17-21, 1996. Society of Environmental Toxicology and Chemistry, Pensacola, FL, 378 pp.; (p. 158) (1995)

The final step in an ecological risk assessment of hazardous waste sites is to suggest remedial goal options (RGOs). RGOs feed into the Feasibility Study as suggested clean-up targets, that if met, should 
reduce or eliminate ecological risks. Because wildlife are exposed through multiple media, development of RGOs for their protection has been problematic. This paper presents an approach for the development of RGOs for protection of individual wildlife and populations. Individual-level RGOs were calculated based on soil concentration and soil-to-biota contaminant uptake factors. Soil concentrations were manipulated and exposure estimates iteratively recalculated to generate exposure estimates equivalent to the lowest observed adverse effect level (LOAEL). The RGO is equivalent to this soil concentration. If a contaminant presented risks to more than one species, the final RGO was set to the lowest RGO calculated. If the final $R G O$ was less than background, the $R G O$ was set to the background concentration. To recommend sites for remediation to reduce population-level risk to an acceptable level, Monte Carlo simulations of exposure were recalculated, with exposures at the most contaminated sites set to either zero (for organics) or to background (for inorganics). This approach focuses on the most contaminated sites with the goal of reducing population-level risk to an acceptable level. As a consequence, some sites, where point estimates of exposure indicate risks may be present, will not be recommended for remediation. While these sites may present a hazard to individuals that use these sites extensively, remediation is not required to prevent risks at the population-level.

\section{6}

V18/024148

Remote Oil Spill Sensing System (ROSSS)

Fornaca, S.; Agravante, H.H.; Eberhard, C.; Hauss, B.I.; Lee, P.S.; Mussetto, M.S.; Pearlman, J.S.; Stark, B.H.; Talmadge, S.; Valles, A.; Wagner, T.

TRW, Inc., Redondo Beach, CA

CONF-960613 (Vol. 1); Technology, Measurement \& Analysis, Proceedings of the Second International Airborne Remote Sensing Conference and Exhibition, San Francisco, CA, June 24-27, 1996, Vol. 1, 702 pp.; (pp. I491-I496) (1996)

To provide tactical information during an oil spill, TRW developed Remote Oil Spill Sensing System (ROSSS). It is an integrated system of airborne sensors for rapid in-situ surveillance and a ground system that provides data analysis and display support at the spill cleanup command center. It provides knowledge of precise location of oil spill and produces timely updates, which are critical for effective spill containment and cleanup operations. It is capable of distinguishing where the bulk of spill exists, which is the key to directing cleanup efforts for maximum efficiency. Using a passive microwave radiometric imager as the primary sensor, it provides data acquisition capabilities in both day and night and through haze, fog, and light rain. The high-speed air-to-ground telemetry link permits timely delivery of surveyed data from the spill site to the ground system to aid in the planning and assessment of cleanup strategies. ROSSS has been in service since November 1992, ready to respond in any oil spill emergencies along the U.S. West Coast.

\section{7}

V18/024151

Remote Sensing for Chemical Monitoring

Jago, R.A.; Curran, P.J.

University of Southampton, Department of Geography, Southhampton, United Kingdom

CONF-960613 (Vol. 3); Technology, Measurement \& Analysis,
Proceedings of the Second International Airborne Remote Sensing Conference and Exhibition, San Francisco, CA, June 24-27, 1996, Vol. 3, 870 pp.; (pp. III549-III558) (1996)

Imaging spectrometry offers the potential of estimating the biochemical content of vegetation canopies, which is likely to provide a more powerful discriminant of land contamination than remotely sensed estimates of vegetation cover. A red edge/chlorophyll concentration/land contamination relationship provides a novel link between reflectance and the biochemical results of contamination. Canopy reflectance data were collected using a field spectrometer in conjunction with substantial ground-based measurements of chlorophyll concentration and leaf area index (LAI) across a contaminated site. There was a strong red edge/chlorophyll concentration/land contamination relationship across the study site and the correlation between red edge position and chlorophyll concentration was $r=0.86$. Spectral mixture modelling demonstrated the effects of variable canopy cover and land contamination on the position of the red edge and provided an understanding of a double-peaked maxima present in derivative spectra. Strong red edge/chlorophyll concentration/land contamination relationships at this study site highlighted the potential use of the CASI to estimate depleted canopy chlorophyll concentration and evaluate further the utility of imaging spectrometers for the remote sensing of contaminated land.

3528

V18/023882

Representative Sampling and Analysis of Heterogeneous Soils

Leitzinger, A.; Evans, J.; Hayes, S.; Partymiller, K.; Swanson, G.

U.S. Environmental Protection Agency, Cincinnati, $\mathrm{OH}$; Science Applications International Corporation, Idaho Falls, ID; Science Applications International Corporation, Cincinnati, OH; PRC Environmental Management, Inc., Georgetown, KY; S-Cubed, San Diego, CA

EPA/600/R-95/012; CONF-9504110; Proceedings of the 21st Annual Risk Reduction Engineering Laboratory (RREL) Research Symposium, Cincinnati, OH, April 4-6, 1995. U.S. Environmental Protection Agency, Cincinnati, OH, 398 pp.; (pp. 272-277) (April 1995)

Sampling and analysis presents specific problems with heterogeneous soils. These problems have been carefully evaluated in several projects for the Risk Reduction Engineering Laboratory (RREL), specifically Superfund Innovative Technology Evaluation (SITE) demonstrations. Of particular concern is the inability of standard analytical methods to account for heterogeneous samples. While a typical analytical method may normally accommodate only 2 grams (g) of sample (and therefore requires that "oversized material" be removed from a sample before analysis, potentially biasing analytical results), a representative sample aliquot from a heterogenous site may require a sample size that is orders of magnitude greater than this. The inability to analyze representative samples may be the result of various factors, including the presence of oversized material (such as rocks or other debris); highly concentrated contaminants (such as lead chunks or tar balls), which may preclude taking large laboratory samples that would overwhelm instrument capabilities; or volatile contaminants which cannot be mixed to create a more homogeneous aliquot because of the 
volatility of the contaminant being investigated. This paper contains several case studies that present the problems associated with sampling and analyzing heterogeneous soils; approaches to specific problems encountered in each of the projects discussed; and the relative success of these approaches.

3529

V18/021520

Review of Orders and Regulations Requiring Environmental Protection

Kelly, E.J.; Cunningham, R.D.; Michael, D.

Los Alamos National Laboratory, Los Alamos, NM; Science Applications International Corporation, Washington, DC; Neptune and Company, Inc., Los Alamos, NM

LA-UR-96-3040; 62 pp. (1996)

With the increased awareness of and interest in potential ecological risks associated with past, current, and future Department of Energy (DOE) activities, DOE's Defense Programs (DP) Office of Technical and Environmental Support sponsored a study to (1) evaluate the effectiveness of the current compliance-driven environmental protection and assessment efforts relative to ecological concerns; (2) explore the need for a more focused, integrated approach to address ecological impacts; and (3) identify the requirements for an integrated approach. The study explored four questions: (a) Which federal regulations and DOE orders either explicitly require ecological assessments or implicitly require them through environmental protection language; (b) What currently is being done at selected DOE facilities to implement these regulations and orders; (c) What are private sector industries doing in terms of ecological risk assessments and how do industry approaches and issues compare with those of DOE; and (d) What, if anything, in addition to current efforts is needed to ensure the protection of ecological resources associated with DOE facilities, to support defensible decision making, and to improve efficiency. The results of this study are presented in a report titled "Integrated, Comprehensive Ecological Impact Assessments in Support of Department of Energy Decision Making". This report is a companion document to that report. This report provides a more detailed discussion of the document reviews of the relevant environmental protection regulations and current and pending DOE orders. The main goal of the document reviews was to understand existing requirements for ecological data collection and impact assessments.

Risk Assessment Methods and Cleanup Level Determination for Human Health Threats Posed by Hazardous Environmental Contaminants

DeAngeles, A.J.; Meadows, S.D.; Turnblom, S.M. PRC Environmental Management, Inc., Seattle, WA CONF-9210194; Proceedings of an International Symposium on Environmental Contamination in Central and Eastem Europe, Budapest, Hungary, October 12-16, 1992, 968 pp.; (pp. 424-425) (1992)

Risk assessment, as conducted in the U.S.A. under the Comprehensive Environmental Response, Compensation and Liability Act (CERCLA) program consists of four basic steps: (1) contaminant identification, (2) exposure assessment, (3) toxicity assessment, and (4) risk characterization. Contaminants are identified by comparing contaminant concentration with background levels and risk-based concentrations. Exposure assessment includes identification of potential receptors, a discussion of land use scenarios, and estimations of the type and magnitude of human exposures. Toxicity assessment weighs available evidence regarding the potential for a substance to cause an adverse health effect. Risk characterization integrates the exposure and toxicity assessments into quantitative and qualitative expressions of risk. Risks can be assessed for metal and chemical contaminants, and radionuclides. Risk management involves the use of risk assessment results to develop remedial actions for the site cleanup. Cleanup levels for hazardous contaminants are calculated using information provided in the risk assessment. However, preliminary cleanup levels can be determined before the risk assessment is performed by using a target risk such as 1 in 1 million for carcinogenic compounds. Any potential risks posed to human health by the remedial actions themselves can also be assessed through risk assessment methods and procedures.

3531

V18/021031

Risk Assessment as a Decision Making Tool for Environmental Restoration and Waste Management

Nazarali, A.M.; Young, J.K.; Pelton, M.A.

Jacobs Engineering Group Inc., Kennewick, WA; BDM Federal, Inc., Richland, WA; Advanced Sciences, Inc., Richland, WA

CONF-960212; Waste Management '96: Working Towards a Cleaner Environment, Proceedings of a Conference on $\mathrm{HLW}$, LLW, Mixed Wastes and Environmental Restoration, Tucson, AZ, February 25-29, 1996; (17 pp.) (1996)

This paper presents a human health risk assessment methodology for a large site that includes multiple facilities with solid and liquid waste disposal sites, which contribute contamination through several media such as air, groundwater, soil, and surface water. Risk-based decision making is evaluated for agricultural, residential, industrial, and recreational land uses. Also evaluated are risk-based decision making as it pertains to Native American land uses. The methodology includes a risk presentation that is useful for communicating with interested groups and valuable for decision makers. The human health risk is presented in isopleths overlaid on the region of analysis. This region of analysis may be the region within the site boundary or the region outside of the site boundary as far as necessary. The risk assessment methodology is applied as a decision making tool. Decisions on whether to undertake a remedial action are evaluated based on parameters such as the extent of remediation and restoration achieved compared to target risk, the amount of risk reduction at varying cost levels, and the risk from various land uses before and after remediation. Several examples of the human heath risk contours are presented. The high-risk areas within an isopleth are traced back to the media, source, and the constituents that cause the high risk. Comparisons of various altematives versus cost are presented. Finally, the feasibility of a single or multipurpose land-use strategy is evaluated based on human health risk and ecological risk for several remedial alternatives. 


\section{Risk Averse: DOE is Wasting Time, Money in Cleanup Effort - GAO}

Newman, $P$.

Energy Daily 22(168):3 (September 1, 1994)

According to an August 1994 GAO report, internal strife, poor decisionmaking and conflicting stakeholder interests have plagued the cleanup effort and prevented DOE from taking advantage of what its own technology program calls the best hope for ensuring a substantive waste reduction. This article details the problems affecting radioactive waste cleanup at DOE facilities and lists the five technology priorities which have been established.

\section{V18/020942}

Risk Based Comparison of Remedial Action Alternatives Including Worker Risk

Unione, A.; Marty, R; Rieke, T.

Jason Associates Corporation, Idaho Falls, ID

CONF-960212; Waste Management '96: Working Towards a Cleaner Environment, Proceedings of a Conference on $\mathrm{HLW}$, LLW, Mixed Wastes and Environmental Restoration, Tucson, AZ, Febraary 25-29, 1996; (35 pp.) (1996)

Current budget planning strategy within the Department of Energy emphasizes risk reduction potential as a basis for prioritizing expenditures within the complex. To implement such a strategy, a consistent methodology must be available for estimating health risk to workers as a result of project activity. This report provides a comprehensive methodology for considering worker risk in the evaluation of project risk reduction potential. An example comparison of alternative projects to remediate surface impoundments containing radionuclides and hazardous chemicals at the Oak Ridge National Laboratory is used to illustrate the methodology. Results of this example evaluation clearly indicate that the choice of a preferred environmental management altemative can be affected by considering worker risk. In particular, the result of "net valuing" potentially achievable reductions in long term environmental risk against incurred worker risk tends to support a conclusion that less complex remediation altematives have a higher net risk reduction value.

\section{4}

\section{V18/023216}

\section{Risk Based Decision Analysis Applied to Uranium Mine} Decommissioning

Goldsworthy, M.H.; Been, K.; Ernst, P.

Golder Associates GmbH, Celle, Germany

CONF-9210194; Proceedings of an International Symposium on Environmental Contamination in Central and Eastern Europe, Budapest, Hungary, October 12-16, 1992, 968 pp.; (pp. 434-436) (1992)

One of the major problems facing Central and Eastern Europe is how to allocate the limited financial resources available for environmental clean-up so as to maximize the overall benefit to society. It is clear in this context that the cost of an acceptable clean-up at any given site must also be minimized but still achieve acceptable results. Probabilistic methods, or risk based decision analyses, provide a rational approach to ensuring that the best possible decisions are made to protect the environment and human health in the face of uncertainties about future events, about what lies under the ground, and about contaminant transportation processes. A risk based approach to decommissioning of uranium mine facilities is outlined. The analysis consists of determining all the alternative treatments for each facility to be decommissioned, ranging from "do nothing" to "complete isolation" solutions. The consequences of each treatment are assessed probabilistically in terms of environmental impact, human health, and cost. This allows the possible consequences and the confidence level in the predicted performance to be determined as a function of the money spent at each facility. The final step is a combined analysis for all facilities for any given expenditure to show which combination of treatments results in the greatest benefit to society.

\section{5}

\section{V18/024340}

\section{Risk Based Treatment Selection and Optimization of} Contaminated Site Remediation

Heitzer, A.; Scholz, R.W.

Swiss Federal Institute of Technology, Zurich, Switzerland

CONF-961149; SETAC 17: Partnerships for the Environment Science, Education, and Policy, Proceedings of the 17th Annual Meeting of the Society of Environmental Toxicology and Chemistry, Washington, DC, November 17-21, 1996. Society of Environmental Toxicology and Chemistry, Pensacola, FL, 378 pp.; (p. 43) (1995)

During the past few years numerous remediation technologies for the cleanup of contaminated sites have been developed. Because of the associated uncertainties concerning treatment reliability it is important to develop strategies to characterize their risks to achieve the cleanup requirements. For this purpose it is necessary to integrate existing knowledge on treatment efficacy and efficiency into the planning process for the management of contaminated sites. Based on field-scale experience and data for the remediation of soils contaminated with petroleum hydrocarbons, two treatment technologies, biological land treatment and physico-chemical soil washing, were analyzed with respect to their general performance risks to achieve given cleanup standards. For a specific contamination scenario, efficient application ranges were identified using the method of linear optimization in combination with sensitivity analysis. Various constraints including cleanup standards, available financial budget, amount of contamination and others were taken into account. While land treatment was found to be most efficient at higher cleanup standards and less contaminated soils, soil washing exhibited better efficiency at lower cleanup standards and higher contaminated soils. These results compare favorably with practical experiences and indicate the utility of this approach to support decision making and planning processes for the general management of contaminated sites. In addition, the method allows for the simultaneous integration of various aspects such as risk based characteristics of treatment technologies, cleanup standards and more general ecological and economical remedial action objectives.

3536 V18/022362

Risk Characterization for Ecological Risk Assessment of Contaminated Sites

Lockheed Martin Energy Systems, Inc., Environmental 
Restoration Risk Assessment Program, Oak Ridge, TN

ES/ER/TM-200; 35 pp. (October 1996)

Risk characterization combines information concerning exposure to chemicals with information concerning effects of chemicals to estimate risks. Risk characterization for ecological risk assessments (ERAs) is performed by weight of evidence. That is, rather than simply model risks, ecological risk assessors examine all available data from chemical analyses, toxicity tests, biological surveys, and biomarkers to estimate the likelihood that significant effects are occurring or will occur and describe the nature, magnitude, and extent of effects on the designated assessment endpoints. This document describes the approach for estimating risks based on individual lines of evidence and then combining them through a process of weighing the evidence. The lines of evidence are integrated independently so that the implications of each are explicitly presented. This makes the logic of the assessment clear and allows independent weighing of the evidence by risk managers and stakeholders. For each line of evidence, it is necessary to evaluate the relationship of the measurement endpoint to the assessment endpoint, the quality of the data, and the relationship of the exposure metrics in the exposure-response data to the exposure metrics for the site. The general approach was described in the strategy for ERA on the Oak Ridge Reservation. This document expands the guidance by providing more specific information on how ecological risk characterization should be performed.

\section{7 \\ V18/022921}

\section{Risk Communication Basics}

Corrado, P.G.

Lawrence Livermore National Laboratory, Livermore, CA CONF-951006; Proceedings of an American Nuclear Society (ANS) Winter Meeting, San Francisco, CA, October 29-November 1, 1995. ANS, La Grange Park, IL, 522 pp.; Transactions of the American Nuciear Society 73:47-48 (1995)

Risk communication is a dialogue with laypeople about potential harm. It is part of an environmental program where risk assessment identifies and defines hazards; risk management controls hazards; and risk communication explains hazards. In low-trust, high-concern situations, $50 \%$ of your credibility comes from perceived empathy and caring, demonstrated in the first 30 seconds you come in contact with someone. There is no second chance for a first impression. These and other principles contained in this paper provide you with a basic level of understanding of risk communication. The principles identified are time-tested caveats and will assist you in effectively communicating technical information.

\section{8}

\section{V18/022564}

\section{Risk Control and the Minimum Significant Risk}

Seiler, F.A.; Alvarez, J.L.

International Technology Corporation, Albuquerque, NM; Auxier and Associates, Inc., Parker, $\mathrm{CO}$

CONF-9607135; Proceedings of the 41st Annual Meeting of the Health Physics Society, Seattle, WA, July 21-25, 1996; Health Physics 70(6):6b (June 1996)

Risk management implies that the risk manager can, by his actions, exercise at least a modicum of control over the risk in question. In the terminology of control theory, a management action is a control signal imposed as feedback on the system to bring about a desired change in the state of the system. In the terminology of risk management, an action is taken to bring a predicted risk to lower values. Even if it is assumed that the management action taken is $100 \%$ effective and that the projected risk reduction is infinitely well known, there is a lower limit to the desired effects that can be achieved. It is based on the fact that all risks, such as the incidence of cancer, exhibit a degree of variability due to a number of extraneous factors such as age at exposure, sex, location, and some lifestyle parameters such as smoking or the consumption of alcohol. If the control signal is much smaller than the variability of the risk, the signal is lost in the noise and control is lost. This defines a minimum controllable risk based on the variability of the risk over the population considered. This quantity is the counterpart of the minimum significant risk which is defined by the uncertainties of the risk model. Both the minimum controllable risk and the minimum significant risk are evaluated for radiation carcinogenesis and are shown to be of the same order of magnitude. For a realistic management action, the assumptions of perfectly effective action and perfect model prediction made above have to be dropped, resulting in an effective minimum controllable risk which is determined by both risk limits. Any action below that effective limit is futile. Finally, some implications of the effective minimum controllable risk on the use of the as low as reasonably achievable (ALARA) principle and on the evaluation of remedial action goals are presented.

\section{9}

\section{V18/025660}

Risk Implications of Approaches to Setting Soil Remediation Goals at Hazardous Waste Contaminated Sites

Labieniec, P.A.

North Dakota University, Energy and Environmental Research Center, Grand Forks, ND

ORISE-9752304; 142 pp. (August 1994)

An integrated exposure and carcinogenic risk assessment model for organic contamination in soil, SoilRisk, was developed and used for evaluating the risk implications of both site-specific and uniform-concentration approaches to setting soil remediation goals at hazardous-waste-contaminated sites. SoilRisk was applied to evaluate the uncertainty in the risk estimate due to uncertainty in site conditions at a representative site. It was also used to evaluate the variability in risk across a region of sites that can occur due to differences in site characteristics that affect contaminant transport and fate when a uniform concentration approach is used. In evaluating regional variability, Ross County, Ohio and the State of Ohio were used as examples. All analyses performed considered four contaminants [benzene, trichloroethylene (TCE), chlordane, and benzo[a]pyrene (BAP)] and four exposure scenarios (commercial, recreational and on- and offsite residential). Regardless of whether uncertainty in risk at a single site or variability in risk across sites was evaluated, the exposure scenario specified and the properties of the target contaminant had more influence than variance in site parameters on the resulting variance and magnitude of the risk estimate. In general, variance in risk was found to be greater for the relatively less degradable and more mobile of the chemicals studied 
(TCE and chlordane) than for benzene which is highly degradable and BAP which is very immobile in the subsurface.

3540

V $18 / 023215$

Risk Management Under Uncertainty to Foster Cleanup Effort

Bogardi, I.; Stansbury, J.

University of Nebraska, Lincoln, NE; Woodward-Clyde Consultants, Omaha, NE

CONF-9210194; Proceedings of an International Symposium on Environmental Contamination in Central and Eastern Europe, Budapest, Hungary, October 12-16, 1992, 968 pp.; (pp. 426-428) (1992)

A risk management methodology is presented with an application example to help in selecting cost-effective environmental cleanup alternatives. Ecological and health risk and cost assessments are often associated with very large uncertainties stemming from such factors as contaminant transport modelling and loss function assessment. If risk-cost analysis is conducted without considering these uncertainties, inappropriate management policies may result. On the other hand, considering these uncertainties may cause difficulties in decision making if they make management alternatives effectively indistinguishable. Carcinogenic and noncarcinogenic risk to humans, and toxicological risk to ecological species are estimated for each cleanup alternative. The final evaluation measure is computed as a fuzzy number allowing the options with their associated uncertainties to be compared and ranked.

3541

V18/021640

Risk Variability Due to Uniform Soil Remediation Goals

Labieniec, P.A.; Dzombak, D.A.; Siegrist, R.L.

Carnegie Mellon University, Department of Civil and Environmental Engineering, Pittsburgh, PA; Colorado School of Mines, Environmental Science and Engineering Division, Golden, CO

Joumal of Environmental Engineering 122(7):612-621 (July 1996)

If a single contaminant concentration in soil were to be used as the remediation goal at all potential remediation sites in a region, risk would be expected to vary across sites due to differences in site characteristics that affect transport and fate. A methodology is developed to evaluate such variability. It is applied to Ross County, Ohio, a region for which compiled, detailed hydrogeologic information is available. Four carcinogenic contaminants (benzene, trichloroethylene, chlordane, and benzo[a]pyrene) and exposure scenarios (on-site commercial, on-site recreational, and on-site and off-site residential) are evaluated. Results vary, but generally indicate that for contaminants that are highly degradable such as benzene or immobile in the subsurface such as benzo[a]pyrene, specifying a uniform soil remediation goal would result in relatively small degree of regional risk variability. However, for highly mobile and persistent contaminants like trichloroethylene, a uniform goal would result in a large degree of regional risk variability. Application of the methodology to a larger, less well-characterized region is analyzed.
3542

V18/021427

Risk-Based Approach to Site-Wide Management of Land Use, Cleanup Goals, and Disposal Options at Multi-Unit Mixed-Waste Facilities

Stoker, C.; Ornelas, J.P.; Pehrson, J.R.; Booras, J.S.

Fluor Daniel Environmental Services Operating Company, Irvine, $\mathrm{CA}$

CONF-950877; Mixed Waste, A.A. Moghissi, B.R. Love and R.K. Blauveit (eds.), Proceedings of the Third Biennial Symposium, Baltimore, MD, August 7-10, 1995, 545 pp.; (pp. 10.1.1-10.1.6) (1995)

There is currently no standard procedure for evaluating the impact to site-wide risk of operable-unit decisions on land use, cleanup goals, and disposal options. If addressed solely from an operable-unit standpoint, these issues have significant negative impact on the overall site-wide protectiveness of post-remedial site conditions, potentially delaying the remedial process and increasing cleanup costs. To monitor these impacts throughout the remedial process, the authors conduct a Site-Wide Risk Evaluation (SWRE) at key decision points in multi-unit remedial programs. The SWRE is used first to verify the validity of initial scoping assumptions, and later to assess the potential human health impact of multi-unit remedial alternatives. This paper discusses key issues in side-wide risk assessment, including potential problems with the current remedial process at multi-unit sites. The use of the SWRE to prevent such problems is presented.

\section{$3543 \quad$ V18/020922}

Risk-Based Decision Making in the DOE: Challenges and Status

Henry, C.J.; Godin, M.

U.S. Department of Energy, Office of Environmental Management, Office of Integrated Risk Management, Washington, DC

CONF-960212; Waste Management '96: Working Towards a Cleaner Environment, Proceedings of a Conference on HLW, LLW, Mixed Wastes and Environmental Restoration, Tucson, $A Z$, February 25-29, 1996; (9 pp.) (1996)

The primary responsibility of the Environmental Management program is to address the most immediate, urgent risks to human health and the environment from the nuclear weapons complex, while managing long-term contamination and safety threats. Environmental Management cannot meet this responsibility unless it integrates the best risk management practices into its decision making processes. In response to direction and guidance from Congress, the National Academy of Sciences, and other organizations, the Environmental Management program has implemented a risk-based approach to decision making, successfully using a qualitative evaluation process to inform decisions in the fiscal year 1996 and 1997 budget cycles. Risk information will be used even more rigorously and more in-depth for the fiscal year 1998 budget development cycle and beyond. The process of using risk information to establish priorities will improve as the Department improves data quality, incorporates peer review, defines the future of its sites, and keeps its stakeholders fully informed and involved. 
3544

V18/024355

Risk-Based Environmental Remediation: Sensitivity of Expected Value of Sample Information to Model Structure Assumptions

Dakins, M.E.; Toll, J.E.; Small, M.J.

University of Idaho, Idaho Falls, ID; Parametrix, Inc., Kirkland, WA; Carnegie Mellon University, Pittsburgh, PA

CONF-961149; SETAC 17: Partnerships for the Environment Science, Education, and Policy, Proceedings of the 17th Annual Meeting of the Society of Environmental Toxicology and Chemistry, Washington, DC, November 17-21, 1996. Society of Environmental Toxicology and Chemistry, Pensacola, FL, 378 pp; (p. 159) (1995)

A methodology for analyzing environmental remediation decisions is explored further, using the case of polychlorinated biphenyl (PCB) remediation for New Bedford Harbor sediments. The analysis probabilistically forecasts outcomes from future data collection, predicts how the new data may affect current uncertainty in a decision model, and estimates the expected value of sample information (EVSI). The EVSI forecasts the ability of future data to improve the cost effectiveness of remediation and provides a measure of whether the data should be collected. The decision model, which integrates models of PCB fate and transport, bioaccumulation, remediation costs, and resource damage estimates, has been presented elsewhere; as has the Bayesian Monte Carlo technique for updating uncertainty estimates, based either on new data, or on an analysis of uncertainty about the future results of prospective data gathering. This paper presents new methods and results for analyzing EVSI sensitivity to changes in model structure and to other characteristics of the analysis. The sensitivity analysis includes changing assumptions about uncertainties in the decision model, changing the forecast of future information (likelihood function) from symmetric to asymmetric, varying the number of simulations in the Monte Carlo analysis, and altering the structure of the loss function (the measure of the value of alternative remediation decisions). Results of this study will be used to develop specific recommendations for investigators and environmental managers interested in applying decision analysis to environmental remediation problems.

\section{5 \\ V18/021360}

Risky Business: Assessing Cleanup Plans for Waste Sites

Blaylock, B.

Oak Ridge National Laboratory, Oak Ridge, TN

Oak Ridge National Laboratory Review 28(1):23-34 (1995)

The U.S. Department of Energy's many production and research sites contain radioactive and hazardous wastes. These waste sites pose potential risks to the health and safety of remediation and waste management workers and the public. The risks, however, vary from site to site. Some sites undoubtedly present larger risks than others and should be cleaned up first. However, before the cleanup begins, DOE is required by law to prepare an environmental impact statement on any actions that may significantly affect the environment-even actions that would clean it up. The impact statement must also consider the health and safety risks to workers and the public from the cleanup and management of the resulting wastes. In other words, attempts to reduce potential or existing health risks by cleaning up a waste site could produce other risks, altering the benefit-to-risk ratio. Clearly, it is a difficult task to weigh the relative risks of leaving wastes at their sites or removing, treating, and disposing of them to restore DOE sites to their original environmental condition. ORNL has taken the lead role in assessing the current risks of DOE waste sites to the public, workers, and ecological systems and in predicting the risks of environmental restoration and management of the wastes produced in the cleanup process. This article describes ORNL's work in computer modeling and human health risk assessment.

\section{6 \\ V18/024069}

Road Transportable Analytical Laboratory (RTAL) System: Final Report - Volume 1

Finger, S.M.; De Avila, J.C.; Keith, V.F. Engineering Computer Optecnomics, Inc., Annapolis, $\mathrm{MD}$ DOE/MC/29109-5312 (Vol. 1); 40 pp. (August 1996)

Remediation of Department of Energy (DOE) sites requires extensive sampling to determine the extent of the contamination, to monitor clean-up and remediation progress, and for post-closure monitoring of facilities. The DOE would benefit greatly if it had reliable, road transportable, fully independent laboratory systems that could perform on-site a full range of analyses meeting high levels of quality assurance and control. Such systems would accelerate and thereby reduce the cost of clean-up and remediation efforts by: (1) providing critical analytical data more rapidly, and (2) eliminating the handling, shipping, and manpower associated with sample shipments. The goals of the Road Transportable Analytical Laboratory (RTAL) project are the development and demonstration of a system to meet the unique needs of the DOE for rapid and accurate analysis of a wide variety of contaminants. The laboratory is designed to provide the field and laboratory analytical equipment necessary to detect and quantify radionuclides, organics, heavy metal, and other inorganic parameters. The laboratory system consists of a set of individual laboratory modules deployable independently or as an interconnected group to meet site-specific needs. A prototype RTAL system was constructed for demonstration at the Fernald Environmental Management Project, where it was deployed and its performance evaluated.

\section{7}

\section{V18/024070}

Road Transportable Analytical Laboratory (RTAL) System: Final Report - Volume 2, B

Finger, S.M.; De Avila, J.C.; Keith, V.F.

Engineering Computer Optecnomics, Inc., Annapolis, MD DOE/MC/29109-5312 (Vol. 2); 185 pp. (August 1996)

Remediation of Department of Energy (DOE) sites requires extensive sampling to determine the extent of the contamination, to monitor clean-up and remediation progress, and for post-closure monitoring of facilities. The DOE would benefit greatly if it had reliable, road transportable, fully independent laboratory systems that could perform on-site a full range of analyses meeting high 
levels of quality assurance and control. Such systems would accelerate and thereby reduce the cost of clean-up and remediation efforts by: (1) providing critical analytical data more rapidly, and (2) eliminating the handling, shipping, and manpower associated with sample shipments. The goals of the Road Transportable Analytical Laboratory (RTAL) project are the development and demonstration of a system to meet the unique needs of the DOE for rapid and accurate analysis of a wide variety of contaminants. The laboratory is designed to provide the field and laboratory analytical equipment necessary to detect and quantify radionuclides, organics, heavy metal, and other inorganic parameters. The laboratory system consists of a set of individual laboratory modules deployable independently or as an interconnected group to meet site-specific needs. A prototype RTAL system was constructed for demonstration at the Fernald Environmental Management Project, where it was deployed and its performance evaluated. Appendices A and B contain RTAL analytical data reports for aqueous volatile organic analysis (VOA) and semivolatile organic analysis (SVOA), respectively.

\section{8}

\section{V18/024071}

Road Transportable Analytical Laboratory (RTAL) System: Final Report - Volume 3, Appendices C Through J

Finger, S.M.; De Avila, J.C.; Keith, V.F. Engineering Computer Optecnomics, Inc., Annapolis, MD DOE/MC/29109-5312 (Vol. 3); 225 pp. (August 1996)

Remediation of Department of Energy (DOE) sites requires extensive sampling to determine the extent of the contamination, to monitor clean-up and remediation progress, and for post-closure monitoring of facilities. The DOE would benefit greatly if it had reliable, road transportable, fully independent laboratory systems that could perform on-site a full range of analyses meeting high levels of quality assurance and control. Such systems would accelerate and thereby reduce the cost of clean-up and remediation efforts by: (1) providing critical analytical data more rapidly, and (2) eliminating the handling, shipping, and manpower associated with sample shipments. The goals of the Road Transportable Analytical Laboratory (RTAL) project are the development and demonstration of a system to meet the unique needs of the DOE for rapid and accurate analysis of a wide variety of contaminants. The laboratory is designed to provide the field and laboratory analytical equipment necessary to detect and quantify radionuclides, organics, heavy metal, and other inorganic parameters. The laboratory system consists of a set of individual laboratory modules deployable independently or as an interconnected group to meet site-specific needs. A prototype RTAL system was constructed for demonstration at the Femald Environmental Management Project, where it was deployed and its performance evaluated. Appendices $C$ and $D$ contain analytical data reports for soil sample TCLP volatile organic analysis (VOA) and semivolatile organic analysis (SVOA), respectively. Appendix $E$ contains the analytical data report for aqueous sample RCRA metals, and Appendix F contains the analytical data report for soil sample uranium. Appendices $G, H, I$, and $\mathrm{J}$ are analytical performance summaries for VOA samples, SVOA samples, RCRA metal samples, and uranium samples, respectively.

\section{$3549 \quad$ V18/022142}

Role of Natural Processes and Risk in Environmental Remediation Decisions

Breckenridge, R.P.; Maiers, D.T.; Wichlacz, P.L.

Idaho National Engineering Laboratory, Idaho Falls, ID

INEL-96/00274; CONF-961119; Eco-Informa 96: Global Networks

for Environmental Information, Proceedings of a Conference, Lake

Buena Vista, FL, November 4-7, 1996. Environmental Research

Institute of Michigan, Ann Arbor, MI, Vols. 10 and 11, 1103 pp.; (pp. 173-178) (1996)

Much attention is currently given to risk-based approaches to managing natural resources and hazardous waste. In order to apply a risk-based approach, input from the various stakeholders needs to be obtained eariy and updated throughout the effort. Applying a risk-based approach allows decision makers to evaluate options based upon sound scientific data. This paper discusses two examples of how risk-based approaches have been used to evaluate remediation options for management of natural resources and hazardous material problems in the Intermountain West. These examples demonstrate that without stakeholder involvement and using a risk-based approach, time and effort would have been wasted and decisions made to correct perceived rather than actual problems. The paper also describes the role that natural attenuation plays in making both risk and remedial action decisions.

3550 $\mathrm{V} 18 / 023185$

SYNLOG: A Computer Model for Selection of Detection Methods in the Development of a Hydrocarbon Probe

Brummer, C.H.; Olie, J.J.

\section{Delft Geotechnics, Delfh, Netherlands}

CONF-9210194; Proceedings of an International Symposium on Environmental Contamination in Central and Eastem Europe, Budapest, Hungary, October 12-16, 1992, 968 pp.; (pp. 247-250)

In order to develop a hydrocarbon probe, a model has been developed for selecting detection techniques to be built into a sounding device. This sounding device is intended to detect floating and DNAPL layers in the soil, caused by spills at the surface. The methods for detection are based on techniques stemming from petrophysical exploration and chemical analysis. The basis of the computer model is a complete description of the subsurface. The subsurface is divided into solid phase and pore space, which consists fluid phases. The fluid phase includes gas, groundwater and/or pure product from a floating or DNAPL layer where a spill has occurred. Each phase will contribute to a measurement signal depending on phase composition and its interaction with the detection method employed. Each method will result in some more and less distinct features for detecting floating and DNAPL layers. The model is used to validate eight different methods, based on measurement of gamma radiation, neutron radiation and fluorescence. By comparison of the methods, the most distinct responses can be generated. The most promising techniques are measurement of fluorescence and induced gamma radiation. 
3551

$\mathrm{V} 18 / 023178$

Screening for Environmental Contamination via Field-Portable Gas Chromatographs

Kaelin, L.P.; Wynnyk, R.; Mickunas, D.; Humphrey, A.; Pritchett, T.

Roy F. Weston, Inc., Edison, NJ; U.S. Environmental Protection Agency, Edison, NJ

CONF-9210194; Proceedings of an International Symposium on Environmental Contamination in Central and Eastern Europe, Budapest, Hungary, October 12-16, 1992, 968 pp.; (pp. 211-213) (1992)

Field-portable gas chromatographs (FPGC) are rugged field-deployable instruments that can generate qualitative and quantitative data on volatile organics in a variety of sample matrices. FPGCs are able to operate on internal carrier gases and batteries at remote site locations. FPGCs should be considered whenever the rapid generation of on-site data will result in greater protection of the environment and public health or where financial constraints limit the use of more traditional methods of sampling and analysis.

\section{$3552 \quad \mathrm{~V} 18 / 021268$}

Sensitivity Studies on Uranium Mobilisation Using the Biogeochemical Transport Code Drink

Johnstone, T.; Humphreys, P.N.; Trivedi, D.; Hoffmann, A.

British Nuclear Fuels plc, Environmental Services, Risley, United Kingdom

CONF-950917 (Vol. 2); ICEM '95, Proceedings of the Fifth International Conference on Radioactive Waste Management and Environmental Remediation, Vol. 2: Management of Low-Level Waste and Remediation of Contaminated Sites and Facilities, $S$. Slate, R. Baker and G. Benda (eds.), Berlin, Germany, September 3-7, 1995. American Society of Mechanical Engineers, New York, NY, 913 pp.; (pp. 1521-1524) (1995)

Solid low level radioactive wastes (LLW) may contain significant amounts of cellulosic materials which are susceptible to microbial degradation. The sensitivity of uranium mobilization from LLW to cellulose degradation rates and the solubility of any uranium oxide (UO2) precipitated, was investigated in a generic study using the biogeochemical transport code DRNK. Three arbitrary degradation rates were employed, corresponding to cellulose half lives of $6.6,66$ and 660 years. At all degradation rates reducing conditions were generated due to microbial consumption of the available oxygen. At the shortest half life, oxidizing conditions were re-established due to the majority of cellulose being degraded. Under reducing conditions uranium mobilization was controlled by the solubility of $\mathrm{UO} 2$ precipitate whereas under oxidizing conditions it was strongly Kd dependent. These simulations emphasise the importance of representative values for degradation rates and solid phase solubilities when assessing uranium migration.

3553

V18/023459

Simplified Method for Quantitative Assessment of the Relative Health and Safety Risk of Environmental Management Activities
Eide, S.A.; Smith, T.H.; Peatross, R.G.; Stepan, I.E.

Idaho National Engineering and Environmental Laboratory, Idaho Falls, ID

INEL-95/0645; 205 pp. (September 1996)

This report presents a simplified method to assess the health and safety risk of Environmental Management activities of the US Department of Energy (DOE). The method applies to all types of Environmental Management activities inciuding waste management, environmental restoration, and decontamination and decommissioning. The method is particularly useful for planning or tradeoff studies involving muitiple conceptual options because it combines rapid evaluation with a quantitative approach. The method is also potentially applicable to risk assessments of activities other than DOE Environmental Management activities if rapid quantitative results are desired.

$3554 \quad$ V18/024686

Site Characterization for Bioremediation, Chapter 6 Cookson, J.T., Jr.

International Network for Environmental Training, Inc., Potomac, MD

Bioremediation Engineering: Design and Application, G.F. Nalven (ed.), McGraw-Hill, Inc., New York, NY, 539 pp.; (pp. 205-240) (1995)

This is a chapter in the book titled Bioremediation Engineering: Design and Application. Any treatment process must be well managed for success. A well-managed process requires process control, and this is achieved only when site evaluations have been properly performed. Site characterization requires an intense investigation, particularly for in situ treatment. Bioremediation is a scientific intense technology that relies on the application of many disciplines. The integration of each discipline is an important part of a project's initial planning phase. The project manager orchestrates the necessary inputs from each of these disciplines. This requires the knowledge to place limits on the extensiveness of each while assuring adequate data for successful design and operation. Site characterizations must define the potential biological systems, the site characteristics that impact on biological reactions, and provide information for process control. Site characterization must provide adequate data for designing a facility that provides control of the degradation process. This includes the delivery of necessary chemicals and nutrients at appropriate rates throughout the treatment zone. First, one must determine the appropriateness of bioremediation. The applicability of bioremediation is established after considering the following: (1) the nature of the contaminants, (2) the concentration and distribution of contaminants, (3) the site's microbial activity, (4) the site's hydraulic characteristics, (5) the site's redox potential, (6) the soil and water characteristics, and (7) availability of nutrients. Site assessments must address these questions and provide data to optimize the desired biochemical transformations.

3555

V18/023201

Site Remediation: Source Control Curriculum Development for Central and Eastern Europe

Grasso, D.; Hoag, G. 
University of Connecticut, Environmental Research Institute, Department of Civil Engineering, Storrs, CT

CONF-9210194; Proceedings of an International Symposium on Environmental Contamination in Central and Eastem Europe, Budapest, Hungary, October 12-16, 1992, 968 pp.; (pp. 317-319) (1992)

The United States Environmental Protection Agency (U.S. Environmental Protection Agency) has funded a major curriculum development project at the University of Connecticut (UCONN) entailing the design and structuring of a graduate level instructor's guide on site remediation specifically addressing source control issues. Topics covered include: regulatory frameworks, critical issues in technology selection, review of basic engineering principles, groundwater issues, conventional technologies applicable to hazardous waste, soil vapor extraction, soil washing, solidification/stabilization, chemical destruction/extraction, bioremediation, thermal processes, and risk analysis. Each module covers fundamental principles, feasibility issues, design protocols, and costs. Technology modules are reviewed by the U.S. Environmental Protection Agency, an environmental engineering consulting firm (ENVIRON Corp.), and an Association of Environmental Engineering Professors task force. The course has been test taught at four U.S. universities and will be ready for dissemination to interested universities in August 1992. This paper highlights major aspects of the UCONN/U.S. Environmental Protection Agency project in light of their applicability to Central and Eastem Europe environmental remediation projects.

V18/020744

Site Restoration: Estimation of Attributable Costs from Plutonium-Dispersal Accidents

Chanin, D.I.; Murfin, W.B.

Sandia National Laboratories, Albuquerque, NM; Technadyne Engineering Consultants, Inc., Albuquerque, NM

\section{SAND96-0957; 240 pp. (May 1996)}

A nuclear weapons accident is an extremely unlikely event due to the extensive care taken in operations. However, under some hypothetical accident conditions, plutonium might be dispersed to the environment. This would result in costs being incurred by the government to remediate the site and compensate for losses. This study is a multi-disciplinary evaluation of the potential scope of the post-accident response that includes technical factors, current and proposed legal requirements and constraints, as well as social/political factors that could influence decision making. The study provides parameters that can be used to assess economic costs for accidents postulated to occur in urban areas, Midwest farmiand, Western rangeland, and forest. Per-area remediation costs have been estimated, using industry-standard methods, for both expedited and extended remediation. Expedited remediation costs have been evaluated for highways, airports, and urban areas. Extended remediation costs have been evaluated for all land uses except highways and airports. The inclusion of cost estimates in risk assessments, together with the conventional estimation of doses and health effects, allows a fuller understanding of the post-accident environment. The insights obtained can be used to minimize economic risks by evaluation of operational and design alternatives, and through development of improved capabilities for accident response.

3557

V18/023306

Software Development Quality Assurance Plan for the Management Control Information System (MCIS) Phase II

Software Control International, Oak Ridge, TN; Lockheed Martin Energy Systems, Inc., Oak Ridge, TN

ES/ER/TM-193; 45 pp. (April 1997)

The purpose of this software development quality assurance plan (QAP) is to establish and define the quality assurance (QA) requirements for the Management Control Information System (MCIS) Phase II. MCIS is a project management and decision support system providing a repository for all official project data, change control for the official data, access to appropriate external data, summarization of detailed data to selected levels, cost estimating, performance measurement calculations and comparisons, official reports for the U.S. Department of Energy (DOE), and project management reports for data analysis. The project data represents costs, schedules, performance, estimates, financial commitments, prime contractor costs, and financial planning. MCIS accesses the Lockheed Martin Energy Systems, Inc. (LMES), Cost Accounting System for actual cost and related data; LMES' Automated Estimating System and the Cost Account Planning procedure for project cost estimates; Open Plan for the project work breakdown structure, schedule, and milestone data, and various DOE systems for financial and budget data. MCIS supports Task Work Agreements, including Incentive Task Orders, and it supports the Baseline, Prioritization, and Funding Profile. This plan is used to ensure that specific standards, procedures, and other management controls are developed and followed to satisfy the Environmental Management and Enrichment Facilities (EMEF) QA program. This plan applies to all organizations involved in the development and implementation of MCIS. The overall purpose of this plan is to help managers at all levels to: (1) minimize system life cycle costs, (2) develop a system that performs correctly, and (3) deploy a system that satisfies user requirements.

3558

V18/021282

Software Perspective of Environmental Data Quality Banerjee, B.

Argonne National Laboratory, Argonne, II CONF-950601; Proceedings of an American Nuclear Society (ANS) Annual Meeting, I.O. Macke (ed.), Philadelphia, PA, June 25-29, 1995. ANS, La Grange Park, IL; Transactions of the American Nuclear Society 72:34 (1995)

Because of the large number of complex data in environmental projects, particularly large decontamination and decommissioning projects, data quality has a profound impact on the success and cost of the mission. In every phase of the project life cycle, including regulatory intervention and legal proceedings, maintaining the quality of data and presenting it in a timely and meaningful manner are critical. In this paper, a systemic view of data quality management from the software engineering perspective is presented. An evaluation methodology evolves from this view. This methodology complements the principles of data quality objective. 
When graded adequately, the evaluation methodology establishes a paradigm for data quality assurance for new and renewed projects. This paper also demonstrates that incorporating software engineering good practices in the data management process leads to continuous improvement of data quality.

\section{9}

V18/023176

Soil and Vegetation Pollution Study - Quality Control of Analytical Data

Hudnik, V.; Hodnik, A.; Lobnik, F.; Kozak-Legisa, S.

Institute of Chemistry, Hajdrihova, Slovenia; University of Ljubljana, Jamnikarjeva, Slovenia

CONF-9210194; Proceedings of an International Symposium on Environmental Contamination in Central and Eastern Europe, Budapest, Hungary, October 12-16, 1992, 968 pp.; (pp. 60-62) (1992)

The principles of the analytical methodology used in the study of soil and vegetation pollution in the Celje region are presented. The sampling program, sample handling, and validation of analytical methods applied for determination of $\mathrm{Cd}, \mathrm{Pb}$ and $\mathrm{Zn}$ in soil and vegetation samples are described and discussed.

\section{0}

V18/023781

Spatially Predictive Three-Dimensional Model of Subsurface VOCs

Chau, L.L.; Brandabur, T.M.; Preslo, L.M.

ICF Kaiser Engineers, Inc., Oakland, CA; Consultant, San Francisco, CA; Earth Technology Corporation, Berkeley, CA CONF-9504134; HAZMACON' 95, T. Bursztynsky and M.L. Loss (eds.), Proceedings of the Twelfth Hazardous Materials Management Annual Conference and Exhibition, San Jose, CA, April 4-6, 1995. Association of Bay Area Governments, Oakland, CA, 790 pp.; (pp. 126-136) (1995)

As regulators rely more heavily on a cost-effective, risk-based approach to site regulation, the use of spatial geostatistical modeling and transport simulations are becoming indispensable. In Califomia, it is anticipated that models will play an increasingly important role, such as in the establishment of Groundwater "Non-Attainment Areas" per the Ground Water Basin Plan Amendments of August 17, 1994. For example, under this policy, in order for a site to be considered for candidacy as a Groundwater "Non-Attainment Area", the responsible party must present to the regulators a clear picture of the subsurface contaminant distribution. Three-dimensional (3-D) contaminant characterization with model results presented in computer graphics can unambiguously communicate the required information to regulators in a vastly improved manner over conventional contour plots. This discussion outlines the procedures in synthesizing a visual model through the use of a 3-D spatially predictive method. The model's engineering objectives of volume and mass estimates as well as uncertainty anaiysis are not discussed in detail.

\section{$3561 \quad V 18 / 021273$}

Stabilization of Vitrified Wastes: Task 4 - Topical Report, October 1994-September 1995

Hurley, J.P.
University of North Dakota, Energy and Environmental Research Center, Grand Forks, ND

DOE/MC/31388-5141; 106 pp. (September 1995)

The goal of this task was to work with private industry to refine existing vitrification processes to produce a more stable vitrified product. The initial objectives were to demonstrate a waste vitrification procedure for enhanced stabilization of waste materials and to develop a test protocol to understand the long-term leaching behavior of the stabilized waste form. The testing protocol was expected to be based on a leaching procedure called the synthetic groundwater leaching procedure (SGLP). This task will contribute to the US DOE's identified technical needs in waste characterization, low-level mixed-waste processing, disposition technology, and improved waste forms. The proposed work was to proceed over 4 years in the following steps: Literature surveys to aid in the selection and characterization of optimized vitrified test wastes using advanced leaching protocols, and Refinement and demonstration of vitrification methods leading to commercialization. Literature surveys have been completed, and computer modeling has been performed to determine the feasibility of removing heavy metals from a waste during vitrification, possibly producing a commercial metal concentrate. This report describes the following four subtasks: (1) Survey of vitrification technologies; (2) Survey of cleanup sites; (3) Selection and characterization of test mixtures for vitrification and crystallization; and (4) Selection of crystallization methods based on thermochemistry modeling.

\section{$3562 \quad$ V18/022551}

Statistical Methods for Determination of Background Levels for Naturally Occurring Radionuclides in Soil at a RCRA Facility

Guha, S.; Taylor, J.H.

International Technology Corporation, Knoxville, TN

CONF-9607135; Proceedings of the 4Ist Annual Meeting of the Heaith Physics Society, Seattle, WA, July 21-25, 1996; Health Physics 70(6):53a (June 1996)

It is critical that summary statistics on background data, or background levels, be computed based on standardized and defensible statistical methods because background leveis are frequently used in subsequent analyses and comparisons performed by separate analysts over time. The final background for naturally occurring radionuclide concentrations in soil at a RCRA facility, and the associated statistical methods used to estimate these concentrations, are presented. The primary objective is to describe, via a case study, the statistical methods used to estimate $95 \%$ upper tolerance limits (UTL) on radionuclide background soil data sets. A 95\% UTL on background samples can be used as a screening level concentration in the absence of definitive soil cleanup criteria for naturally occurring radionuclides. The statistical methods are based exclusively on EPA guidance. This paper includes an introduction, a discussion of the analytical results for the radionuclides and a detailed description of the statistical analyses leading to the determination of $95 \%$ UTLs. Soil concentrations reported are based on validated data. Data sets are categorized as surficial soil; samples collected at depths from zero to one-half foot; and deep soil, samples collected from 3 to 5 feet. These data sets were tested for 
statistical outliers and underlying distributions were determined by using the chi-squared test for goodness-of-fit. UTLs for the data sets were then computed based on the percentage of non-detects and the appropriate best-fit distribution (lognormal, normal, or non-parametric). For data sets containing greater than approximately $50 \%$ nondetects, nonparametric UTLs were computed.

\section{$3563 \quad V 18 / 022553$}

Statistical and Cost-Benefit Enhancements to the DQO Process for Characterization Decisions

Goodman, D.

Montana State University, Environmental Statistics Group, Bozeman, MT

DOE/EM-0316; 35 pp. (September 12, 1996)

The costs of characterization can comprise a sizeable fraction of a remediation program budget. The Data Quality Objectives (DQO) Process has been instituted at DOE to ensure that the investment in characterization adds net value to each remediation project. Thoughtful characterization can be very important to minimizing the total cost of a remediation. Strategic information gained by characterization can reduce the remediation costs by reducing the unproductive investment in unnecessary remediation of portions of a site that really don't need to be remediated, and strategic information can reduce remediation costs by reducing the frequency of expensive rework or emergency action that result when remediation has not been pursued to the extent that really is needed. The $\mathrm{DQO}$ process attempts to create a rigorous, objective, stepwise framework for precisely defining the remediation problem at a site, identifying the type of data that might best resolve any questions about the remediation, and determining whether (and how much) collection of new data is warranted. Existing guidance documents approach the formalization of the DQO process by use of statistical hypothesis testing. In the present document, the tool kit for the DQO process is extended to include statistical decision theory.

\section{4}

\section{V18/023200}

\section{Strategy for Environmental Cleanup Under Tight} Funding Constraints

Jump, R.A.

\section{U.S. Department of Energy, Washington, DC}

CONF-9210194; Proceedings of an International Symposium on Environmental Contamination in Central and Eastern Europe, Budapest, Hungary, October 12-16, 1992, 968 pp.; (pp. 314-316) (1992)

This study proposes a strategy for planning and implementing an environmental restoration program in Central and Eastern Europe that borrows some features from the programs in the United States but also points out which features a Central or Eastern European country may wish to avoid. Careful thought and planning is essential to target those projects that will yield the maximum reduction in morbidity as swifly as possible. As a consequence, the environmental cleanup actions in Central and Eastern Europe will necessarily be different in character than in the U.S. where sites are often subjected to three or more years of exhaustive characterization prior to actual cleanup. The question "How can an environmental cleanup be effectively accomplished under tight funding constraints?" is addressed and some key features of a proposed strategy are presented. The study focuses on maximizing the benefit to be gained per unit of cleanup cost and presents an approach for setting budget priorities based upon reduction of risk to human health and the environment. The study also presents an analysis of resources needed to implement an effective environmental restoration program, including issues regarding sources of funds. Specifically, the study examines strategies for harmonizing privatization of state-owned industries with the assignment or liquidation of the liability for cleanup costs.

\section{5}

V18/021138

Streamlined Site Characterization Approach in Support of Remediation of U.S. Nuclear Regulatory Commission Licensed Facilities

Nalluswami, $M$.

U.S. Nuclear Regulatory Commission, Office of Nuclear Material Safety and Safeguards, Washington, DC

CONF-960212; Waste Management '96: Working Towards a Cleaner Environment, Proceedings of a Conference on $\mathrm{HLW}$, LLW, Mixed Wastes and Environmental Restoration, Tucson, AZ, February 25-29, 1996; (11 pp.) (1996)

Under the U.S. Nuclear Regulatory Commission's (NRC's) requirements for decommissioning, radiological and environmental characteristics provide the basis for preparation of an appropriate decommissioning (remediation) plan for decontamination and decommissioning (D\&D). Because of reduced Federal resources, a proposed streamlined approach to review site characterization information has been adopted. NRC's 1992 "Action Plan," D\&D process, and the streamlined site characterization approach are discussed and summarized.

\section{6}

V18/023180

Successful Application of X-Ray Fluorescence Spectroscopy for Field Screening

Sackman, A.R; Hoffman, J.

Ecology and Environment, Inc., Lancaster, NY

CONF-9210194; Proceedings of an Intemational Symposium on Environmental Contamination in Central and Eastern Europe, Budapest, Hungary, October 12-16, 1992, 968 pp.; (pp. 219-221) (1992)

A recent field investigation has demonstrated the successful use of $\mathrm{X}$-ray fluorescence spectroscopy (XRF) screening analysis for elemental concentrations in soils and sediments at a mine tailings hazardous waste site in New Mexico, United States of America. Using minimal sample preparation and commercially available standards, approximately 300 samples were analyzed on location for eight elements, including iron, copper, nickel, zinc, lead, arsenic, silver, and cadmium. Instrument detection limits achieved were five to fifteen parts per million (ppm). Statistical and graphical methods of analysis were used to show a statistically significant correlation between XRF results and laboratory results using atomic absorption (AA) and inductively coupled plasma (ICP) methods of analysis. Arsenic detection limits were found to be between $10 \%$ and $30 \%$ of the corresponding lead concentrations. The results of the XRF field 
screening analysis provided valuable information used for the completion of a Remedial Investigation/Feasibility Study (RI/FS) and a quantitative health-based risk assessment.

3567 V18/023209

Superfund Site Assessment in the United States: Efficiencies Gained Through the Use of the Hazard Ranking System Model

Courreye, P.L.; Nalipinski, $M$.

U.S. Environmental Protection Agency, San Francisco, CA; U.S. Environmental Protection Agency, Boston, MA

CONF-9210194; Proceedings of an International Symposium on Environmental Contamination in Central and Eastem Europe, Budapest, Hungary, October 12-16, 1992, 968 pp.; (pp. 380-382) (1992)

This paper describes how the United States Environmental Protection Agency (U.S. Environmental Protection Agency) assesses and prioritizes hazardous waste sites in its Superfund hazardous waste site cleanup program. The Hazard Ranking System developed by the U.S. Environmental Protection Agency is particularly important to our program since it allows us to both construct efficient sampling investigations and to prioritize hazardous waste sites.

\section{8 \\ V18/024117}

System Modeling: Manufacturing, Technology, and Policy Alternatives

Los Alamos National Laboratory, Los Alamos, NM

LALP-95-18; 1 p. (1995)

Developing environmental solutions to complex problems often requires diverse constituencies to collaborate. There is a tendency not to acknowledge the validity of other stakeholder views - such tension sometimes leads to confrontation and seldom creates mutually acceptable solutions to problems. This research offers an opportunity to use system dynamics modeling to build consensus among diverse constituencies by understanding the influences of stakeholders and by evaluating various stakeholder solutions to a problem. One type of research that illustrates this problem is lead-based paint poisoning, a serious pediatric health problem.

\section{9}

V18/023575

Technical Basis for EPA's Proposed Regulation on the Cleanup of Sites Contaminated with Radioactivity

Wolbarst, A.B.; Clark, M.E.; Doehnert, M.

U.S. Environmental Protection Agency, Washington, DC

Health Physics 71(5):644-660 (November 1996)

The US Environmental Protection Agency (EPA) is proposing a regulation for the protection of the public and radioactive contamination at sites that are to be cleaned up and released for public use. The rule will apply to sites under the control of Federal agencies and will impose limits on radiation doses to individuals living or working on a site following cleanup; it will thereby provide site owners and managers with uniform, consistent cleanup criteria for planning and carrying out remediation. This paper presents an overview of EPA's approach to assessing some of the beneficial and adverse effects associated with various possible values for the annual dose limit. In particular, it discusses the method developed to determine how the choice of cleanup criterion affects: (1) the time-integrated potential numbers of non-fatal and fatal radiogenic cancers averted among future populations, (2) the occurrence of radiogenic cancers among remediation workers and the public caused by the cleanup process itself, and (3) the volumes of contaminated soil that may require remediation. The analytic methods described here were used to provide input data and assumptions for the Reguiatory Impact Analysis (RIA) that supports the proposed regulation; the RIA also considered non-radiological benefits and costs (i.e., public health, economic, and ecological) of the standards.

3570

V18/022298

Technical Specification for Transferring Environmental Surveillance Surface Water Data, Y-12 Sanitary Sewer Data, Radiological Monitoring Plan Data, and Storm Water Data to the Oak Ridge Environmental Information System (OREIS)

Lockheed Martin Energy Systems, Inc., Environmental Restoration Division, Oak Ridge, TN

ES/ER/TM-175; 90 pp. (September 1996)

In November 1995, a team was formed to develop, document, and implement a technical specification for transmitting environmental surveillance surface water data, sanitary sewer data, radiological monitoring plan data, and storm water data to the Oak Ridge Environmental Information System (OREIS). This document describes the requirements, responsibilities, criteria, and format for transmitting these data to OREIS as determined by the team. The approach used to transmit this data is documented in the Plan for Integrating Environmental Compliance and Monitoring Data into OREIS. This plan addresses the consolidated data requirements defined by the Federal Facility Agreement (FFA) and the Tennessee Oversight Agreement (TOA) as they pertain to environmental compliance and monitoring data maintained by the Oak Ridge environmental management organizations of Energy Systems and Energy Research.

3571

V18/022356

Technical Specifications for Transferring National Pollutant Discharge Elimination System Water Data to the Oak Ridge Environmental Information System

Oak Ridge National Laboratory, Oak Ridge, TN

ES/ER/TM-144; 60 pp. (November 1996)

In May 1994, a team was formed to develop, document, and implement technical specifications for transmitting National Pollutant Discharge Elimination System (NPDES) environmental compliance and monitoring surface water data to the Oak Ridge Environmental Information System (OREIS). The approach used to transmit this data is documented in the Plan for Integrating Environmental Compliance and Monitoring Data into OREIS. This plan addresses the consolidated data requirements defined by the Federal Facility Agreement (FFA) and the Tennessee Oversight Agreement (TOA) as they pertain to environmental compliance and monitoring data maintained by Energy Systems' Oak Ridge Environmental Management organizations. This document describes the requirements, responsibilities, criteria and format for 
transmitting NPDES compliance and monitoring surface water data to the OREIS.

3572 V18/023217

Technology Risk Management

Brown, E.B.; Whitehurst, C.A.; Plumblee, H.E.

Lockheed Environmental Systems and Technologies Company, Houston, TX

CONF-9210194; Proceedings of an International Symposium on Environmental Contamination in Central and Eastern Europe, Budapest, Hungary, October 12-16, 1992, 968 pp.; (pp. 443-445)

(1992)

As the environmental remediation industry begins the transition in the 90's from basically a "hog and haul" approach to another high-tech industry, many new technologies will have to be developed, or else modified from other industrial applications. The approach taken in this transition phase could be the key to success for many companies either entering this new opportunistic industry, or else attempting the transition from the old way to the new. Technology development can be, and usually is, a very risky endeavor. In order to minimize and manage this risk associated with the development of new environmental technologies, we have adapted a methodology developed within Lockheed to control the risk associated with introducing new, developing technologies into large complex programs. The method, as presented in this paper, accounts for all the requirements involved in the CERCLA process. A Technology Risk Factor, that is dependant on the Probability of Failure and Consequence of Failure, is calculated. This is used to develop a Technology Risk Reduction profile for management tracking and control. An example is presented, based on a new soil remediation technology that is currently under development.

3573

V18/022664

Tension Permeameter for Deep Borehole Characterization

Sisson, J.B.; Honeycutt, T.K.

Idaho National Engineering Laboratory, Idaho Falls, ID

CONF-941124; Insitu Remediation: Scientific Basis for Current and Future Technologies, G.W. Gee and N.R. Wing (eds.), Proceedings of the 33rd Hanford Symposium on Health and the Environment, Pasco, WA, November 7-11, 1994. Battelle Press, Columbus, OH, Part 2, 605 pp.; (pp. 1263-1268) (1994)

The permeability of geologic materials is an important variable for estimating the rate of transport of contaminants from waste sites. To date, permeability has been estimated in the laboratory from measurements made on small cores, under hydrologic conditions far removed from those of the field. Available field instruments cannot estimate permeabilities at depth under ambient conditions. The authors have constructed a borehole tension permeameter that is capable of operating at near field conditions and at depths of more than $30 \mathrm{~m}$. The tension permeameter consists of a syringe pump, lightweight packer, semipermeable membrane, and pressure transducer, all controlled by a programmable logic controller. Water is metered at a fixed rate through the membrane while monitoring tension. The permeability is estimated from the steady pumping rate for the membrane geometry used at the measured water tension. The permeameter was used to estimate the permeability of Pancheri sandy loam at tensions of 0 to $150 \mathrm{~cm}$.

3574

V18/024875

Test of the Insitu Permeable Flow Sensor at Savannah River, SC

Ballard, S.; Barker, G.T.; Nichols, R.L.

Sandia National Laboratories, Geophysics Department, Albuquerque, NM; Savannah River Technology Center, Environmental Sciences Section, Aiken, SC

Groundwater 34(3):389-396 (May-June 1996)

A test of the In Situ Permeable Flow Sensor was conducted in which groundwater flow velocity measurements made by the flow sensors were directly compared to velocity estimates obtained using standard hydrologic techniques. Two flow sensors were deployed in a confined aquifer in close proximity to a well which was screened over the entire vertical extent of the aquifer. When the well was pumped at four different pumping rates, the horizontal component of the flow velocity measured by the flow sensors was directed toward the pumping well, within the uncertainty in the measurements, and the magnitude of the horizontal component of the velocity increased linearly with pumping rate, as predicted by theoretical considerations. The measured magnitudes differed from predicted values, calculated with the assumption that the hydraulic properties of the aquifer were homogeneous and isotropic, by less than a factor of two. Vertical components of groundwater flow observed with the flow sensors are qualitatively consistent with the vertical distribution of hydraulic conductivity estimated from grain-size analysis but are significantly larger in magnitude than predicted. This is likely due to the creation of a vertical conduit of increased hydraulic conductivity during emplacement of the probes. The results suggest that while the flow sensors measured the local groundwater flow velocity vector during the test quite accurately, care must be exercised to disturb the formation as little as possible during emplacement. The technology has many potential uses, particularly in the area of environmental site characterization and remediation process monitoring.

3575 .

V18/021058

Third Party Superfund Lawsuit Defense Influenced by the Choice of Remediation Method

Haddad, B.I.; Parish, G.B.

Graef, Anhalt, Schloemer \& Associates, Environmental Services Division, Milwaukee, WI

CONF-940499 (Vol. 1); Proceedings of the 1994 Federal Environmental Restoration III and Waste Minimization II Conference and Exhibition, New Orleans, LA, April 27-29, 1994. Hazardous Materials Control Resources Institute, Rockville, MD, Vol. 1, 783 pp.; (pp. 476-484) (1994)

Paper Company A was sued in a third party action suit initiated by a local utility who was a potential responsible party (PRP) to a contaminated site regulated under the Comprehensive Environmental Response, Compensation and Liability Act (CERCLA) program. In addition to Paper Company $A$, other parties to the third party suit included Paper Company $B$ and Contractor $\mathrm{C}$, a demolition contractor/waste hauler. Other PRPs 
included land owners where the contaminated debris was dumped, Mr. and Mrs. D. Based on background information, Paper Company A dumped coal ash, off quality feed stock, wood and trash north of the D-property. Paper Company B admitted dumping material north of the D-property. Samples of industrial sludges on the D-property had properties characteristic of the Paper Company B's sludges. Paper Company B dumped ash, chromium contaminated gypsum sludge and other waste. The utility company dumped ash on the D-property. Contractor $C$ hauled demolition debris to the $\mathrm{D}$ property. A third PRP, Company E was the original owner of the buildings that were demolished. This PRP settled with the EPA as part of a bankruptcy settlement. Remediation of the site was divided into two separate phases. The first phase included dredging of PCB, lead and chromium contaminated debris from a pond located on the D-property. The second phase was capping and long term groundwater monitoring of the rest of the site. The defense position taken was that liability for environmental restoration cost should be based on the location where various parties dumped wastes containing hazardous substances and the particular remedy implemented to deal with those wastes rather than on the waste volumes disposed on-site. The expert opinion was that Paper Company A should only be liable for their share of the investigative cost and 20 to 40 percent of the cost of the second phase remedy because only 40 percent of the cap covered areas where Paper Company A disposed of material containing hazardous substances. paper Company A was sued for $\$ 2,500,000$, which was 75 percent of the remaining costs; the suit settled for $\$ 1,000,000$.

\section{6}

\section{V18/024043}

Three-Dimensional Digital Imaging of Environmental Data: Selection of Gridding Parameters

Eddy, C.A.; Looney, B.B.

Westinghouse Savannah River Company, Aiken, SC

International Journal of Geographical Information Systems 7(2):165-172 (1993)

Three-dimensional imaging is a powerful technique for the visualization and interpretation.of environmental data. The success of the process is linked to careful, technically-justifiable selection of variable parameters during the gridding and imaging process. The impacts of various approaches to gridding and possible setting of parameters on the final image and volume calculations were examined by generating alternative images for a very well characterized contaminated site in layered coastal plain sediments. To image properly scattered data collected at close intervals in wells from layered geological media, a higher grid density in the $z$ direction is required along with a weighting factor to emphasise the influence of data in the $x$ and $y$ directions. For steeply-varying contaminant concentration data, the best results were obtained by gridding the log of the property value; an anti-log transformation is carried out to restore property values to the correct value before the visualization is prepared. The techniques and recommendations made in this article were designed for modeling contaminant values with very steep gradients dispersed in a strongly anisotropic media. These recommendations may not apply directly to other sites but the process of selecting parameters should be similar. of Potential Concern for Effects on Sediment-Associated Biota: 1996 Revision [Rev. 2]

Jones, D.S.; Hull, R.N.; Suter, G.W., II

U.S. Department of Energy, Oak Ridge Operations Office, Oak Ridge, TN; Lockheed Martin Energy Systems, Inc., Health Sciences Research Division, Oak Ridge, TN

ES/ER/TM-95/R2; 35 pp. (June 1996)

The purpose of this report is to present sediment benchmark data and discuss their use as benchmarks for determining the level of toxicological effects on sediment-associated biota and to briefly describe three categories of approaches to the development of sediment quality benchmarks. These approaches are based on analytical chemistry, toxicity test results, and field survey data. A fourth integrative approach incorporated all three types of data. The use of multiple benchmarks is recommended for screening chemicals of concem in sediments. Equilibrium partitioning benchmarks are included for screening nonionic organic chemicals. Publication of this document meets a milestone for the Environmental Restoration (ER) Risk Assessment program. This report is an update of a prior report. It contains an expanded list of National Oceanic and Atmospheric Administration and Ontario Ministry of the Environment values, an additional set of benchmarks from the Florida Department of Environmental Protection, an expanded list of benchmarks calculated for selected nonionic organic chemicals using equilibrium partitioning, and the U.S. Environmental Protection Agency Region IV and Office of Solid Waste and Emergency Response sediment screening values.

V18/020999

Toxicological Benchmarks for Wildlife: 1996 Revision [Rev. 3]

Sample, B.E.; Opresko, D.M.; Suter, G.W., II

U.S. Department of Energy, Oak Ridge Operations Office, Oak Ridge, TN; Lockheed Martin Energy Systems, Inc., Health Sciences Research Division, Oak Ridge, TN

ES/ER/TM-86/R3; 215 pp. (June 1996)

The purpose of this report is to present toxicological benchmarks for assessment of effects of certain chemicals on mammalian and avian wildlife species. This document provides the ER Program with toxicological benchmarks that may be used as comparative tools in screening assessments as well as lines of evidence to support or refute the presence of ecological effects in ecological risk assessments. The process of evaluating ecological risks of environmental contaminants comprises two tiers. The first is a screening assessment where concentrations of contaminants in the environment are compared to no observed adverse effects level (NOAEL)-based toxicological benchmarks that represent concentrations of chemicals in environmental media; these concentrations are presumed to be nonhazardous to the surrounding biota. The second tier is a baseline ecological risk assessment where toxicological benchmarks are one of several lines of evidence used to support or refute the presence of ecological effects. This report presents NOAEL- and lowest observed adverse effects level (LOAEL)-based toxicological benchmarks for assessment of effects of 85 chemicals on 9 representative mammalian wildlife species or Il avian wildlife species. The chemicals considered are some that occur at U.S. Department of Energy waste sites, and the wildlife 
species evaluated herein were chosen because they are widely distributed and represent a range of body sizes and diets.

\section{9}

V18/023218

Toxicological Risk Assessment in the Application of Health-Based Target Concentrations to Site Remediation

Teaf, C.M.; Kuperberg, J.M.; Herndon, R.C.; Moerlins, J.E.

Florida State University, Center for Biomedical and Toxicological Research, Tallahassee, FL

CONF-9210194; Proceedings of an International Symposium on Environmental Contamination in Central and Eastern Europe, Budapest, Hungary, October 12-16, 1992, 968 pp.; (pp. 461-464) (1992)

In order to determine whether, or to what extent, remediation is required at a contaminated site, it is important to establish clearly the magnitude and distribution of contamination for evaluation of the potential environmental or human health hazards. Toxicologists have demonstrated that it is possible to calculate risk-based cleanup targets at concentrations which are well above detection limits, while still satisfying the requirement to protect the public health. This becomes an important consideration as analytical chemists improve detection limits to sub part per billion (ppb) levels for many organic and inorganic analytes. Legislative and regulatory requirements which influence the need for, or the extent of, remedial actions differ among countries. Existing statutes and the accompanying rules for their implementation recently have recognized the value and applicability of risk-based remedial goals. A major advantage of using risk-based target concentrations is the ability to identify those sites which represent significant risks to public health. In this way, the higher risk sites can be given a higher clean-up priority, while ensuring that financial and technical resources are effectively used.

\section{$3580 \quad$ V18/024690}

\section{Treatability Studies, Chapter 10}

Cookson, J.T., Jr.

International Network for Environmental Training, Inc., Potomac, MD

Bioremediation Engineering: Design and Application, G.F. Nalven (ed.), McGraw-Hill, Inc., New York, NY, 539 pp.; (pp. 433-459) (1995)

This is a chapter in the book titled Bioremediation Engineering: Design and Application. For many bioremediation projects, treatability studies become a required prerequisite. Few, if any, contaminated sites are identical, and identical responses are unlikely. Experience significantly aids in the design of a bioremediation project, but experience can only be applied within limits. Many variables are a function not only of the contaminated media and the contaminants, but also of the genetic variability of microbial species. Microorganisms acquire genetic material or undergo changes that may be directed by specific environmental conditions. These effects are not subtle and can determine the success or failure of a bioremediation project. They are both site-specific and microbial-specific. The same contaminant can respond differently under what appears to be identical bioremediation techniques and microorganisms.

3581

V18/022103

Treatability Study Design for Solidification and Stabilization Technologies

Dean, P.V.; Brecker, C.M.

PRC Environmental Management, Inc., McLean, VA

CONF-951139 (Vol. 1); Superfund 16: Proceedings of a Hazardous Waste Conference and Exhibition, Washington, DC, November 6-8, 1995. E.J. Krause and Associates, Bethesda, MD, Vol. 1, 828 pp.; (pp. 629-637) (1994)

Solidification and stabilization technologies have been recommended as the best demonstrated available technology for a variety of hazardous wastes. From 1982 until 1994, solidification and stabilization technologies were specified as the treatment remedy for source control in from 20 to 25 percent of records of decision (ROD) being addressed under the Comprehensive Environmental Restoration, Compensation, and Liability Act (CERCLA). Solidification and stabilization technologies also have been used for a comparable percentage of corrective actions conducted under Resources Conservation and Recovery Act (RCRA). Treatability studies often are employed to assist the site manager in screening, selecting, and fine-tuning solidification and stabilization technologies as potential remedies. This paper presents an overview of treatability testing of solidification and stabilization technologies. In addition, the paper recommends specific performance goals and treatability study designs that should be considered before additional testing, selection, or implementation is conducted. For each type of treatability study presented, the priorities of performance goals are established and recommended treatability tests are discussed. The paper also discusses the advantages and limitations of commonly used leaching and physical stability tests, with respect to specific types of contaminants and postremediation management scenarios.

3582

V18/022796

Tribal Environmental Remediation Technology Decision-Making Matrix

Baptiste, K.L.; Tano, M.L.; Tallbear, K.

Nez Perce Tribe, Environmental Restoration and Waste Management, Lapwai, D; Council of Energy Resource Tribes, Denver, CO

CONF-960804 (Vol. 2); Spectrum '96: Nuclear and Hazardous Waste Management, Proceedings of an International Topical Meeting, Seattle, WA, August 18-23, 1996. American Nuclear Society, La Grange Park, II, Vol. 2, 873 pp.; (pp. 1668-1671) (1996)

The Nez Perce Tribe's Environmental Restoration and Waste Management program, in coordination with the Council of Energy Resource Tribes, has developed an environmental remediation technology matrix for tribal decision-makers. The matrix plots on the vertical axis, technologies being considered by the U.S. Department of Energy (DOE) for facility decommissioning and waste characterization, retrieval, treatment and containment/stabilization. On the horizontal axis, the matrix plots the implications for Tribes from such technologies. Implications for 
Tribes include both burdens and opportunities resulting from the implementation of remediation technologies. A Tribal dialogue cannot take place without presenting the technical and political considerations against the array of tribal legal, cultural, political, and natural resource considerations. These include implications for Tribal treaty rights, the Federal/Tribal trust relationship, Tribal emergency response and regulatory programs, and for religious and cultural resources. Tribal interests also include opportunities for Tribes and Tribal colleges to participate in technology research, development and implementation, thereby garnering economic and educational benefits for Tribes. It is also expected that the recommended process can also contribute to tribal efforts to pursue economic development strategies. The matrix will aid Tribal decision-makers in identifying the risks and potential benefits to tribes from the development and implementation of remediation technologies. Specifically, Tribal decision-makers can use the matrix to guide their assessments of how technologies will require Tribes to build their regulatory and environmental protection capacity, their capacity to respond to emergencies, defend treaty rights and protect Tribal resources. Tribal decision-makers can also use the matrix to focus on identifying opportunities to partner with industry, universities, and laboratories to participate in the research, development and demonstration of appropriate technologies. After identifying the potential impacts of technologies, Tribal decision-makers can assess which technologies are acceptable from the Tribal point of view.

\section{$3583 \quad$ V18/024149}

\section{USDOE Remote Sensing Laboratory Multisensor} Surveys

Tinney, L; Christel, L.; Clark, H.; Mackey, H.E., Jr.

U.S. Department of Energy, Nevada Operations Office, Remote Sensing Laboratory, Las Vegas, NV; Westinghouse Savannah River Company, Aiken, SC

CONF-960613 (Vol. 2); Technology, Measurement \& Analysis, Proceedings of the Second International Airbome Remote Sensing Conference and Exhibition, San Francisco, CA, June 24-27, 1996, Vol. 2, 774 pp.; (pp. II122) (1996)

The United States Department of Energy (USDOE) maintains a Remote Sensing Laboratory (RSL) to support nuclear related programs of the US Government. The mission of the organization includes both emergency response and routine environmental assessments of nuclear facilities. The unique suite of equipment used by RSL for multisensor surveys of nuclear facilities include gamma radiation sensors, mapping quality aerial cameras, video cameras, thermal imagers, and multispectral scanners. Results for RSL multisensor surveys that have been conducted at the Savannah River Site (SRS) located in South Carolina are presented. The RSL maintains a small fleet of specially equipped aircraft that are used as platforms for remote sensor systems. The aircraft include helicopters, light aircraft, and a small business jet suitable for high altitude acquisitions. In addition to airborne sampling and mapping systems, various in-situ equipment are also used for ground measurements. The primary mission of the RSL organization is to provide emergency response support to nuclear related incidents. Accident response examples include airborne plume tracking, intensity and spectral mapping of radionuclide depositions, finding lost radioactive sources, and the detection of vegetation damage related to spills or releases of hazardous material. To maintain technical and operational proficiency to accomplish this mission, the RSL also uses the equipment to support more routine environmental surveys. These surveys provide RSL staff with field experience and opportunities to evaluate the use of various sensor systems under different environmental conditions. The Savannah River Site is a USDOE facility that encompasses an area of approximately 77,700 hectares near Aiken, SC. The site has been in use since the 1950's in support of nuclear materials production. Five nuclear reactors, a coal-fired power plant, and extensive support facilities are present on the site. RSL has conducted annual multisensor surveys of the site since 1981 in support of various environmental assessment and monitoring programs. Applications of multisensor data collected at SRS that illustrate integration issues associated with multiple data types (aerial film, digital scanner imagery, and contours derived from airborne gamma spectra) are presented. (Complete text)

\section{4}

\section{V18/022555}

Use of Technical and Economic Analysis for Optimizing Technology Selection and Remedial Design for Contaminated Sites

Hardisty, P.E.; Brown, A.

Komex-H2O Science, Huntington Beach, $\mathrm{CA}$

CONF-960393 (Part 2); Contaminated Soils and Groundwater: Analysis, Fate, Environmental and Public Health Effects, and Remediation, Proceedings of the Sixth Annual West Coast Conference, Newport Beach, CA, March 11-14, 1996. Association for the Environmental Health of Soils, Amherst, MA, Part 2, 226 pp.; (p. 14) (1996)

The decision to remediate a contaminated site can be seen from the macroeconomic and microeconomic viewpoints. Macroeconomics can be used to plan and account for the overall cost of pollution as part of a firm's production, and thus make overall decisions on the real cost of pollution and the level of clean-up which may be called for. Valuation of damaged resources, option values and intrinsic worth is an important part of this process. Once the decision to remediate has been taken, the question becomes how best to remediate. Microeconomic analysis deals with providing efficient allocative decisions for reaching specified goals. It is safe to say that cost is one of the single most important factors in site clean-up decision making. A basic rule of remediation is often taken to be the maximization of contaminant mass removed per dollar spent. However, remediation may also be governed by other objectives and constraints. In some situations, minimization of time, rather than cost, could be the constraint. Or perhaps the objective could be to achieve a set level of clean-up for the lowest possible cost, even if a large program would result in unit-cost reductions. Evaluation of the economics of a clean-up project is directly linked to the objectives of the site owner, and the constraints within which the remediation is to be performed.

\section{5} V18/022104

Use of a Remedial Removal Integrated Investigation/Feasibility Study to Characterize a Developed Former Landfill: A Novel SACM Approach

Geraghty, C.A.; Oskvarek, J.D.; Quina, C.L.; Carroll, C.G.; 
Lennox, U.R.; Mullins, J.R.

Ecology and Environment, Inc., Dallas, TX; U.S. Environmental Protection Agency, Dallas, TX

CONF-951139 (Vol. 1); Superfund 16: Proceedings of a Hazardous Waste Conference and Exhibition, Washington, DC, November 6-8, 1995. E.J. Krause and Associates, Bethesda, MD, Vol. 1, 828 pp.; (pp. 609-618) (1994)

The Superfund Accelerated Cleanup Model (SACM) is being implemented by the United States Environmental Protection Agency (EPA) to increase the timeliness and efficiency of Superfund activities and cleanup actions. By providing for cross-program coordination of response planning, prompt risk reduction through early action and appropriate cleanup of long-term environmental problems, can be achieved. To encourage and promote this type of effort, EPA Region 6 introduced the concept of a Remedial Removal Integrated Investigation (RRI) to concurrently evaluate data requirements for early and long-term actions. The purpose of the RRII is to determine the nature and distribution of hazardous substances released at a National Priorities List (NPL) caliber site and to assess the potential risks to human health and the environment. The EPA Removal Program uses this information to determine the appropriateness of a time-critical or non-time-critical removal action based on the type of situation, the urgency and threat of the release, and the time frame in which action must be initiated. The EPA Remedial Program uses this information, which includes data appropriate for a Remedial Investigation (RD), in support of a Feasibility Study (FS). The FS is conducted to develop and evaluate options for a long-term remedial action. Using this type of combined investigate approach, EPA can select short-term actions or early actions consistent with any long-term actions that might be required. This type of integrated investigation was successfully used in Region 6 to rapidly characterize the Agriculture Street Landfill (ASL) site in New Orleans, Orleans Parish, Louisiana. Information generated throughout the course of the RRII was used by both EPA programs to support time-critical removal actions as well as remedial actions for the final site remedy.

\section{6}

V18/023859

Use of the ASTM Standard for Risk-Based Corrective Action to Support No Further Action at Petroleum-Impacted Sites

Robles, H.; Halffman, B.; Manweiler, D.

Environmental Science \& Engineering, Inc., Fountain Valley, CA

CONF-960154; PETRO-SAFE '96, Proceedings of a Conference Held as Part of the Energy Week ' 96 Conference and Exhibition, Houston, TX, January 29-February 2, 1996. PennWell Conferences and Exhibitions, Houston, TX, 291 pp.; (pp. 146-150) (1996)

In July 1994, the American Society for Testing and Materials (ASTM) published their Emergency Standard Guide for Risk-Based Corrective Action Applied to Petroleum Release Sites (ES 38-94). This document is a decision-making tool designed to help standardize, simplify, and expedite the restoration and closure of sites contaminated with petroleum hydrocarbons. To achieve these objectives, ES 38-94 directs the response efforts - site assessment and remediation - toward protection of human health and the environment. This is done using a tiered approach that advances from (1) evaluation of site-specific conditions and risks, to (2) screening risk assessment, to (3) sophisticated risk assessment. Sites already in remediation often require sophisticated risk assessment (Tier III) to advance the restoration/closure process. To aid such assessment, ES 38-94 provides the fate-and-transport models and exposures equations best designed for the evaluation of risks from petroleum release sites. This paper explains the ES 38-94 process, describes the application of the risk assessment models at two leaking underground fuel tanks in Califomia, and offers suggestions for the future use of risk-based corrective action methodology to support requests for no further action.

V18/022821

Using DOE Decommissioning Benchmarking Results for the Development of a Preferred Decommissioning Technologies Guide

Warren, S.W.; Daniel, P.R.

U.S. Department of Energy, Office of Environmental Restoration, Washington, DC; Booz-Allen \& Hamilton, Inc., Germantown, MD

CONF-960804 (Vol. 3); Spectrum '96: Nuclear and Hazardous Waste Management, Proceedings of an Intemational Topical Meeting, Seattle, WA, August 18-23, 1996. American Nuclear Society, La Grange Park, IL, Vol. 3, 841 pp.; (pp. 1852-1859) (1996)

The Department of Energy's (DOE) Office of Environmental Restoration is initiating a benchmarking study and the development of a preferred decommissioning technologies guide to ultumately improve the performance of its decommissioning program The benchmarking study will evaluate the cost and performance of the decommissioning program and identify best practices The preferred decommissioning technologies guide will assist planners in selecting decommissioning technologies. The guide will feature qualitative comparisons among technologies for specific tasks. Although previous studies will be used to establish initial ratings, the benchmarking data will provide the most recent data. This paper will discuss the purpose and methodology of the benchmarking study. The paper will also discuss the purpose and structure of the preferred decommissioning technologies guide and how the results of the benchmarking study will be applied to the development of the guide.

\section{8 \\ V18/022728}

Using Electronic Templates and a Centralized Document Production Network to Reduce Cost and Improve Consistence Between Technical Reports

Bymes, M.E.

Science Applications International Corporation, Richland, WA

CONF-960804 (Vol. 1); Spectrum '96: Nuclear and Hazardous Waste Management, Proceedings of an International Topical Meeting, Seattle, WA, August 18-23, 1996. American Nuclear Society, La Grange Park, II, Vol. 1, 887 pp.; (pp. 665-666) (1996)

In an effort to reduce the cost and improve the accuracy and consistency between technical reports being written by large 
companies or large Federal installations, SAIC has recently developed the Centralized Document Production Network (CDPN) Software. The CDPN Software is loaded with standardized electronic document templates along with standardized site-specific background text, tables, and figures. While users across the network are able to retrieve electronic templates and site-specific background text to support their report writing activities, modifications to the network text can only be made by designated experts who are assigned individual passwords. At this time, the CDPN software is being Beta Tested by Kaiser-Hill and Rocky Mountain Remediation Services at the U.S. Department of Energy's Rocky Flats Plant, in addition to multiple private sector corporations.

\section{9}

\section{V18/023780}

Using Fate, Transport, and Risk Assessment Modeling to Evaluate Cleanup Options

Day, R.W.; Davenport, C.W.; Kalmes, R.

McLaren/Hart Environmental Engineering, Alameda, CA

CONF-9504134; HAZMACON '95, T. Bursztynsky and M.L. Loss

(eds.), Proceedings of the Twelfth Hazardous Materials

Management Annual Conference and Exhibition, San Jose, CA, April 4-6, 1995. Association of Bay Area Govemments, Oakland, CA, 790 pp.; (pp. 113-125) (1995)

This paper discusses a quantitative methodology developed to assess the potential health risks associated with a site impacted by volatile organic compounds (VOCs). Application of this methodology resulted in "no-action" altematives for both soil and groundwater approved by the regulatory oversight agency and the site's early inclusion in the "Non-Attainment Area" program as the first pre-remediation implementation selectee. Three fate and transport models were used to evaluate contaminant transport at a site impacted primarily by trichloroethene (TCE). The models linearly linked soil and groundwater concentrations, which allowed easy assessment of the impact different soil concentrations would have on groundwater at a defined downgradient "compliance point". The linked model relationships were then used to "back-calculate" from a given groundwater concentration at the compliance point to a residual concentration in source area soils. An equilibrium leachate model predicted leachate generation from unsaturated soils to groundwater. A mass balance aquifer box model quantified mixing of leachate with the underlying aquifer. MYGRT2 predicted the maximum groundwater concentration at the compliance point. Each model produced a concentration reduction factor, which when combined result in a site reduction factor. The site reduction factor was first used to demonstrate that a uniform total VOC concentration of $1 \mathrm{mg} / \mathrm{kg}$ in source area soils would not result in a "significant health risk" (defined as $1 \times 10[\mathrm{E}-5]$ for carcinogens and Hazard Index of 1 for non-carcinogens) assuming exposure to groundwater at the compliance point. Then, to elevate actual site conditions, a site-specific "risk envelope" approach was developed to assess the cumulative effects of a localized "hot spot" of relatively high concentration and lower concentrations present in the remainder of the source area. Application of the risk envelope approach indicated that (assuming exposure to groundwater at the compliance point) potential health risks associated with the combined "chemical flux" theoretically entering the water table from source area soils (including the hot spot) was less than the potential risk associated with $1 \mathrm{mg} / \mathrm{kg}$ of VOCs uniformly distributed throughout the source area. Therefore, a "no-action" altemative for site soils was proposed to and accepted by the regulatory oversight agency. Based on the quantitative approach and identification of protective groundwater concentrations at the compliance point, the "no-action" groundwater alternative was accepted with the site placed on "Non-Attainment Area" status. The approach counts for concern over adverse impact to the environment, calibration to actual site conditions, obvious economic advantage to the affected party, and can easily be adjusted to model different chemical types and sources areas.

3590

V18/022496

\section{Using Geostatistics to Evaluate Cleanup Goals}

Marcon, M.F.; Hopkins, L.P.

CONF-950333; SPE-29690; Government and Industry Working Together to Find Cost Effective Approaches to Protecting the Environment, Proceedings of the Society of Petroleum Engineers (SPE)/U.S. Environmental Protection Agency (EPA) Exploration Production Environmental Conference, Houston, TX, March 27-29, 1995. SPE, Richardson, TX, 797 pp.; (pp. 19-29) (1995)

Geostatistical analysis is a powerful predictive tool typically used to define spatial variability in environmental data. The information from a geostatistical analysis using kriging, a geostatistical tool, can be taken a step further to optimize sampling location and frequency and help quantify sampling uncertainty in both the remedial investigation and remedial design at a hazardous waste site. Geostatistics were used to quantify sampling uncertainty in attainment of a risk-based cleanup goal and determine the optimal sampling frequency necessary to delineate the horizontal extent of impacted soils at a Gulf Coast waste site.

3591

V18/023219

Using Regression Analysis in Site Evaluation and Monitoring at U.S. Superfund Sites

King, M.K.; Haller, S.

Theta Technologies, Inc., Oak Ridge, IN

CONF-9210194; Proceedings of an International Symposium on Environmental Contamination in Central and Eastern Europe, Budapest, Hungary, October 12-16, 1992, 968 pp.; (pp. 469-471)

Site evaluations and monitoring involve many different techniques and academic areas, including mathematics. The example given illustrates how regression analysis can help in evaluating a site. Suppose we have several bermed storage tanks which either leak or give off some gas. (Research has shown that nearly all underground storage tanks leak.) Gas measurements were collected at the enclosure boundaries and weather data were obtained at a nearby meteorological station. Both sets of data were to be recorded each hour. Our problem was to somehow relate the gas measurements to the weather data. Because pressure measurements were not available from inside the tanks or on the berms surrounding them, we used dropping atmospheric pressure at the meteorological station to simulate "the pressure outside the tank is less than the pressure inside the tank". Stepwise regression and time series analyses produced low correlation coefficients using linear combinations of the meteorological variables. Consequently we used products (for 
example, current atmospheric pressure times the current gas measurement) as independent variables to predict the gas measurement for the next hour. We reasoned: If a temperature inversion did not occur, then even if the gas were released it dispersed before reaching the monitors, i.e., it never got measured. Thus the meteorological variables could be split into two categories - those influencing the release of the gas and those facilitating measurement of the gas. Consequently, the final regressions were run on a contrived (censored) data set.

\section{2 \\ V18/022108}

Using Risk-Based Remedy Selection to Minimize Remedial Response Costs: A Case History

Cox, S.A.; Hochreiter, J.J., Jr;; Stout, D.J.

Blasland, Bouck \& Lee, Inc., Cranbury, NJ

CONF-951139 (Vol. 1); Superfund 16: Proceedings of a Hazardous Waste Conference and Exhibition, Washington, DC, November 6-8, 1995. E.J. Krause and Associates, Bethesda, MD, Vol. 1, 828 pp.; (pp. 378-385) (1994)

Risk-based remedy selection is widely accepted by regulatory agencies under a variety of regulatory programs. Commonly, site-specific environmental quality data are used for a series of calculations yielding a "forward projection" of potential carcinogenic risks to human health under existing site conditions. If calculated numerical risks are not within a range of "acceptable" cancer risks (generally $1 \times 10[\mathrm{E}-4]$ to $1 \times 10[\mathrm{E}-6]$ ), subsequent remedial activities are required. Basing remedy selection on "forward projections" of cancer risk can result in selection of costly remedies, which offer little additional protectiveness for each incremental increase in cost of implementation.

V18/022079

Utilizing Pathway Analysis Methodology to Compare DOE and EPA Risk Assessment

Tan, Z.; Eckart, R.E.

University of Cincinnati, Department of Mechanical, Industrial, and Nuclear Engineering, Cincinnati, $\mathrm{OH}$

CONF-941148 (Vol. 2); DDER-'94: Decommissioning,

Decontamination, and Environmental Restoration at Contaminated Nuclear Sites, M.G. White (ed.), Proceedings of an Embedded Topical Symposium of the American Nuclear Society Winter Meeting, Washington, DC, November 13-18, 1994. American Nuclear Society, Inc., La Grange Park, IL, Vol. 2, 241 pp.; (pp. 495-499) (1994)

There is considerable debate between the DOE and the EPA concerning risk level goals for site restoration. The EPA frequently cites $10(E-6)$ as the desired lifetime risk level, while the DOE believes that $10(E-4)$ is a more reasonable and achievable goal. This paper will show that if and when agreement is reached on a risk level, the EPA risk assessment methodology will yield risk assessment results that are considerably different than the DOE methodology. Thus, the same risk level could result in cleanup standards that are two orders of magnitude different ( $1 \mathrm{pCi}$ vs. 100 pCi). The risk levels compared in this paper are for the DOE methodology exemplified by the RESRAD computer program and the EPA methodology given by the Risk Assessment for Superfund
(RAGS) documents and the PRESTO computer program. The example in this paper is for the food ingestion pathway, based on a comparison of important input parameters for these pathways. The analysis was conducted for $\mathrm{Am}-241, \mathrm{Pu}-239$, (soluble and insoluble), Sr-90, Ra-226, Cs-137 and U-238 (soluble and insoluble). The results are presented in terms of dose-to-source ratios and the corresponding lifetime risk for these radionuclides in the food ingestion pathways. The results of this study and previous work done by University of Cincinnati (UC) indicate that agreement must be reached by the DOE and EPA on risk assessment parameters and methodology.

\section{$3594 \quad$ V18/023779}

\section{VLEACH Screening for Multiple-Site Closures}

Toh, Y.K.; Ho, J.N.

Jacobs Engineering Group Inc., Martinez, CA

CONF-9504134; HAZMACON '95, T. Bursztynsky and M.L. Loss (eds.), Proceedings of the Twelfth Hazardous Materials Management Annual Conference and Exhibition, San Jose, CA April 4-6, 1995. Association of Bay Area Governments, Oakland, CA, 790 pp.; (pp. 102-112) (1995)

Numerous soil and soil gas samples have been collected to locate potentially contaminated areas (subsites) in an on-going remedial investigation ( $R D$ at a Superfund site in the Central Valley of California. As a result of the RI, the vertical and horizontal extent of contaminant plumes at many subsites were delineated. The next step in the process was to differentiate between subsites that warranted feasibility studies and areas that required no further action. As in most RI projects, the major issue of concern here involved contaminants percolating through vadose zone soils and the impact of leachate migrating to the underlying aquifer. Therefore, the fate and transport of the identified contaminants were evaluated to assist in the decision-making process. Normally, modeling is conducted for each individual subsite using subsite-specific contaminant and soil stratigraphic data. However, both limited budget and tight schedule imposed constraints on that time-consuming approach. To overcome this problem, a screening approach that included the use of a less complicated but physically-based model was developed. In this paper, we will introduce this screening methodology and the results associated with the application of this approach to the Superfund site.

3595

$\mathrm{V} 18 / 024137$

Value of Information Analysis - Nevada Test Site

Nulty, G.; Deshler, B.; Dove, H.; Rehfeldt, K.; Fryer, W.; Bangerter, R., Jr.

International Technology Corporation, Albuquerque, NM; GeoTrans, Inc., Las Vegas, NV; U.S. Department of Energy, Nevada Operations Office, Las Vegas, NV

CONF-970335; Waste Management '97: Working Towards a Cleaner Environment, Proceedings of a Conference on HLW, LLW, Mixed Wastes and Environmental Restoration, Tucson, AZ, March 2-6, 1997; (12 pp.) (1997)

This paper presents an innovative use of decision analysis to perform a Value of Information Analysis that compares the cost of acquiring environmental information during a corrective action 
investigation with a benefit. The benefit has been defined as the percent reduction in the uncertainty of a groundwater plume boundary. The decision analysis incorporate many of the detailed elements of flow and transport modeling with some simplification. the decision model uses the flow and transport model to calculate the plume boundary, defined as the 95 percent confidence level for a 4 millirem/year organ dose, to evaluate the benefit not only of various field data acquisition and analysis tasks, but also the importance of uncertainties in the conceptual flow model. The results indicate that vertical flow, not the currently assumed horizontal flow model, may actually control the site characterization effort for the corrective action unit in question. Furthermore, the results indicate that a sizeable investment on the order of several millions of dollars is required to either resolve the likelihood of a vertical flux to the highly conductive carbonate aquifer or improve uncertainty in the plume boundary associated with horizontal flow by only a few percent. If the new information shows that a vertical flux to the carbonate aquifer actually does exist, the boundary location may change significantly and extend well into the carbonate aquifer. The likelihood of resolving the presence or absence of this important pathway can be increased with expenditures similar to those expected for the major uncertainty reductions in the source term and minor ones in the horizontal flux.

\section{6}

V18/021256

Verification Process

Abelquist, E.W.

Oak Ridge Institute for Science and Education, Environmental Survey and Site Assessment Program, Oak Ridge, TN

CONF-941148 (Vol. 1); DDER-'94: Decommissioning, Decontamination, and Environmental Restoration at Contaminated Nuclear Sites, M.G. White (ed.), Proceedings of an Embedded Topical Symposium of the American Nuclear Society Winter Meeting, Washington, DC, November 13-18, 1994. American Nuclear Society, Inc., La Grange Park, IL, Vol. 1, 323 pp.; (pp. 245-252) (1994)

It is the policy of the Department of Energy and the Nuclear Regulatory Commission to perform independent, third party verification of the adequacy and effectiveness of remedial actions. The Environmental Survey and Site Assessment Program (ESSAP) of the Oak Ridge Institute for Science and Education (ORISE) is one of the organizations responsible for this task. Verification activities may be implemented at two different levels depending on the complexity of the project, the objective of the remedial action (e.g., restricted or unrestricted release), the nature of the radiological contaminants and their form, and results of previous verification activities, if any. The simpler type of verification is called a Type A (or "limited") verification. Activities comprising a Type $A$ verification include document reviews, data validation, and confirmatory analyses. A Type B (or "full") verification includes independent survey activities, in addition to those activities included in the Type A verification. All documents associated with decommissioning activities, including decommissioning plans, characterization reports, survey and sampling plans, and decommissioning reports, may be reviewed as part of the verification process. Document reviews are performed to ensure that survey procedures, instrumentation and established residual radioactivity guidelines for the site are appropriate for the expected radioactive contaminants. The site operational history is reviewed to assure that all potential contamination pathways have been addressed by the remedial action contractor. Survey data interpretation is reviewed to ensure that results of survey measurements and sampling were in compliance with the guidelines, that grid block averaging was correctly performed, when necessary, and that all guidelines were satisfied with the specified statistical accuracy. Data validation and confirmatory analyses are also discussed as they relate to the verification process. Independent survey activities include measurements for total and removable surface activity, exposure rate, and radionuclide concentrations in media (e.g., soil, water, etc.). The verification survey typically addresses from 1 to $10 \%$ of the site, but may be extended, if questions develop or problems are identified. The tasks and sequence of events associated with the verification process are discussed, along with a description of the problems ESSAP has observed and solutions which have been implemented. General deficiencies observed have included poorly defined survey scopes, contaminants not being identified, inaccessible areas not being addressed, use of inappropriate survey instrumentation, and misapplication of release guidelines.

\section{7}

\section{V18/020837}

Volatile Organic Compound Sensing Devices Lancaster, G.D.; Moore, G.A.; Stone, M.L.; Reagen, W.K. U.S. Department of Energy, Washington, DC U.S. Patent 05445795; 14 pp. (August 8, 1995)

This invention relates generally to the optical detection of chemical species and is particularly directed to apparatus for detection of volatile organic compounds (VOCs), VOC aqueous matrix detection, and selective VOC vapor detection. The apparatus employs vapochromic materials in the form of inorganic double complex salts which change color reversibly when exposed to volatile organic compound (VOC) vapors. It is adapted for VOC vapor detection, VOC aqueous matrix detection, and selective VOC vapor detection. The basic VOC vapochromic sensor is incorporated in various devices such as a ground probe sensor, a wristband sensor, a periodic sampling monitor, a soil/water penetrometer, an evaporative purge sensor, and various vacuum-based sensors which are particularly adapted for reversible/reusable detection, remote detection, continuous monitoring, or rapid screening of environmental remediation and waste management sites. The vapochromic sensor is used in combination with various fiber optic arrangements to provide a calibrated qualitative and/or quantitative indication of the presence of VOCs.

\section{8 V18/023761}

Waste Minimization in Analytical Methods

Green, D.W.; Smith, L.L.; Crain, J.S.; Boparai, A.S.; Kiely, J.T.; Yaeger, J.S.; Schilling, J.B.

Argonne National Laboratory, Argonne, II CONF-9505111; Shaping the Future Through Pollution Prevention: Involvement - Commitment - Progress, Proceedings of the Eleventh DOE Pollution Prevention Conference, Knoxville, TN, 
May 16-18, 1995, 495 pp.; (pp. 144-150) (November 1995)

The characterization phase of site remediation is an important and costly part of the process. In addition, it is a new source of waste, including mixed waste, because toxic solvents and other hazardous materials are used in common analytical methods. The DOE expects to require a large number of characterizations over a 30-year period to accomplish its goals in environmental restoration. Thus, if analytical methods can be modified so they produce less waste, a large payback can be realized. Alternative methods can reduce the volume or form of hazardous waste produced either in the sample preparation step or in the measurement step. Generally, changes in methods must not compromise the detection levels, although in some cases less sensitive methods may meet the data quality objectives. Our research is divided into three tasks in the area of inorganic, radiological, and organic analysis. For determining inorganic constituents, alternative methods were studied for sample introduction into inductively-coupled plasma spectrometers. Data were obtained comparing figures of merit and waste volumes associated with the conventional and the new high-efficiency approaches. In the radiological area, data were obtained comparing conventional methods for gross alpha/beta measurements of soil samples in which we used high-pressure microwave dissolution. Liquid waste was reduced by a factor of nine ( $200 \mathrm{~mL} / \mathrm{sample})$, dry active waste was reduced by a factor of two, and analysis time was reduced by a factor of three. Preliminary measurements on other matrices (i.e., oils, greases, sludges), and for the use of alternative, nonhazardous solvents for the preparation of soils indicate additional reduction in waste volumes is possible. For determination of organic constituents, microwave-assisted extraction was studied for RCRA-regulated semivolatile organics in a variety of solid matrices, including spiked samples in blank soil; polyaromatic hydrocarbons in soils, sludges, and sediments; and semivolatile organics in soil. Extraction efficiencies were determined under varying conditions of time, temperature, microwave power, moisture content, and extraction solvent. Solvent usage was cut from the $300 \mathrm{~mL}$ used in conventional extraction methods to about $30 \mathrm{~mL}$. Extraction results varied from one matrix to another. In most cases, the microwave-assisted extraction technique was as efficient as the more common Soxhlet or sonication extraction techniques.

\section{9}

V18/022231

\section{Worldwide Markets for Bioremediation Offer Opportunities for Growth}

Glass, D.J.; Raphael, T.; Valo, R.; Van Eyk, J.

D. Glass Associates, Inc., Needham, MA; Umweltberatung Dr. Raphael, Schwerte, Germany; Soil and Water Limited, Helsinki, Finland; Delft Geotechnics, Delft, Netherlands

CONF-951139 (Vol. 2); Superfund 16: Proceedings of a Hazardous Waste Conference and Exhibition, Washington, DC, November 6-8, 1995. E.J. Krause and Associates, Bethesda, MD, Vol. 2, 817 pp.; (pp. 1181-1190) (1994)

Bioremediation, the use of living organisms to detoxify or destroy hazardous contaminants, continues to play an increasingly important role in remediation of the world's hazardous wastes, and is becoming a widely accepted tool of mainstream remediation firms. International markets should grow faster than the United States market because most other countries are only beginning to duplicate the extensive regulatory framework that drives the United States remediation market, and many are only now beginning to inventory and prioritize their waste sites. Bioremediation should grow dramatically along with the overall world remediation market, and may be positioned more favorably than in the United States, due to the existing track record of success and an increased willingness to try innovative technologies in light of the limitations of existing methods. 


\section{ENVIRONMENTAL MANAGEMENT ISSUES}


3600

V18/022335

\section{Accelerated Retraining Curriculum for Environmental Management}

U.S. Department of Energy, Office of Worker and Community Transition, Washington, DC; Rust Geotech, Inc., Grand Junction, $\mathrm{CO}$

DOE/ID/12584-273; GJPO-121; 575 pp. (July 23, 1996)

As a result of the Cold War and the United States' decision to cease nuclear weapons production and reduce weapons stockpiles, the U.S. Department of Energy (DOE) began a transition from nuclear weapons development and production to cleanup and stabilization of its weapons production facilities. Section 3161 of the National Defense Authorization Act of 1993 directed DOE to retrain defense workers who helped maintain the nation's nuclear deterrent during the Cold War to meet the workforce needs of its new cleanup mission. Under the guidance of the DOE Office of Worker and Community Transition, an Accelerated Retraining Curriculum (ARC) for Environmental Management was designed to retrain DOE's defense workers to meet the qualifications of environmental technicians and other environmental restoration and waste-management-related jobs at former DOE production sites. This curriculum was developed by members of the DOE Community College Network (C2NET), an informal consortium of 20 colleges located near DOE facilities with environmental management missions and programs. In developing ARC, members of C2NET worked toward two primary goals: (1) The curriculum should contain the technical competencies of an associate's degree program for a generalist or broad-based environmental technician. (2) The curriculum should be constructed so that it can be completed in a 16-week period, if required.

3601

V18/025462

\section{Buying Time: Franchising Hazardous and Nuclear} Waste Cleanup

Hale, D.R.

\section{U.S. Department of Energy, Washington, DC}

Energy Joumal 18(2):63-87 (1997)

This paper describes a private franchise approach to long-term custodial care, monitoring and eventual cleanup of hazardous and nuclear waste sites. The franchise concept could be applied to Superfund sites, decommissioning commercial reactors and safeguarding their wastes and to Department of Energy sites. Privatization would reduce costs by enforcing efficient operations and capital investments during the containment period, by providing incentives for successful innovation and by sustaining containment until the cleanup's net benefits exceed its costs. The franchise system would also permit local governments and citizens to demand and pay for more risk reduction than provided by the federal government. In principle, they would have the option of taking over site management. The major political drawback of the idea is that it requires society to be explicit about what it is willing to pay for now to protect current and future generations. Hazardous waste sites are enduring legacies of energy development. Abandoned mines, closed refineries, underground storage tanks and nuclear facilities have often become threats to human health and water quality. The policy of the United States government is that such sites should quickly be made nonpolluting and safe for unrestricted use. That is, the policy of the United States is prompt cleanup. Orphaned commercial hazardous waste sites are addressed by the US Environmental Protection Agency's Superfund program.

3602 V18/025534

Challenges of Technology Transfer for Economic Development in the Central Savannah River Area

Gorden, M.E.; Claire, E.J.; Bakr, A.A.

Southeastern Technology Center, Augusta, GA

CONF-960804 (Vol. 2); Spectrum '96: Nuclear and Hazardous

Waste Management, Proceedings of an International Topical Meeting, Seattle, WA, August 18-23, 1996. American Nuclear Society, La Grange Park, IL, Vol. 2, 873 pp.; (pp. 1473-1477) (1996)

Technology transfer initiatives are becoming increasingly important in today's market place. A combination of accelerating technological changes, increasing competitiveness in the national and international market, and increasing participation of educational institutions in assisting industry have all contributed to the need for programs which focus on technology transfer. Added to these forces is the end of the cold war and the changing mission and structure of Department Of Energy (DOE) facilities. Many technologies which were developed in support, or as a byproduct, of the DOE cold war efforts may have applications in the private sector. Despite all of this technological development, small and small/disadvantaged businesses generally have difficulty in investing in new and innovative technologies due to the risk associated with technology development. Many companies also do not have the knowledge or resources to work within the DOE framework for gaining access to DOE's technologies. An opportunity exists in which small and smaly/disadvantaged businesses can be targeted in the commercialization of new technologies in such a way as to minimize the risks and help position these businesses as a leaders in their field. Further, technology commercialization strategies can be regionally focused to impact the economic growth of a small geographic area.

\section{$3603 \quad \mathrm{~V} 18 / 021303$}

\section{Closing the Circle on the Splitting of the Atom}

U.S. Department of Energy, Office of Environmental Management, Washington, DC

DOE/EM-0266; 100 pp. (January 1996)

In the grand scheme of things we are a little more than halfway through the cycle of splitting the atom for weapons purposes. If we visualize this historic cycle as the full sweep of a clock face, at zero hour we would find the first nuclear chain reaction by Enrico Fermi, followed immediately by the Manhattan Project and the explosion of the first atomic bombs. From two o'clock until five, the United States built and ran a massive industrial complex that produced tens of thousands of nuclear weapons. At half past, the Cold War ended, and the United States shut down most of its nuclear weapons factories. The second haif of this cycle involves dealing with the waste and contamination from nuclear weapons production - a task that had, for the most part, been postponed into the indefinite future. That future is now upon us. 
3604

V18/022765

\section{Consolidation of the Landfill Stabilization and} Contaminant Plumes Focus Areas

Brown, J.P.; Wright, J.; Chamberlain, G.S.

U.S. Department of Energy, Savannah River Operations Office, Aiken, SC; U.S. Department of Energy, Germantown, MD

CONF-960804 (Vol. 2); Spectrum '96: Nuclear and Hazardous Waste Management, Proceedings of an International Topical Meeting, Seattle, WA, August 18-23, 1996. American Nuclear Society, La Grange Park, IL, Vol. 2, 873 pp.; (pp. 1173-1178) (1996)

The Assistant Secretary of the Office of Environmental Management (EM) on January 25, 1994, formally established five focus areas to implement A New Approach to Environmental Research and Technology Development at the U.S. Department of Energy (DOE) - Action Plan. The goal of this new approach was to conduct a research and technology development program that is focused on overcoming the major obstacles to cleaning up DOE sites and ensuring that the best talent within the Department and the national science communities is used. Two of the five focus areas established were Landfill Stabilization Focus Area (LSFA) and Contaminant Plumes Containment and Remediation Focus Area (PFA), which were located at the Savannah River Operations Office (SR).

V18/021015

Cost Management Improvement in the Office of Environmental Management 1991-1995: A Progress Report

U.S. Department of Energy, Office of Engineering and Cost Management, Washington, DC

DOE/EM-0274; 40 pp. (December 1995)

The Department of Energy's (DOE's) Office of Environmental Management (EM) has been proactive in meeting the cost management challenges of environmental management activities. EM recognized the need for defining and establishing good cost management practices and has, during the first half of the $1990 \mathrm{~s}$, initiated more than a dozen major cost-management-related activities that have resulted in: (1) Measurable improvement in cost- and cost-related management practices; (2) Improved communications between field and Headquarters and among field sites; (3) Deveiopment of cost management tools; (4) Hiring of cost professionals; and (5) Involving regulators and stakeholders early in the planning process. Most significantly, these initiatives are instilling and encouraging a cost-conscious culture throughout EM. The purposes of this progress report are to summarize EM's cost management initiatives, report on the results of its proactive approach to cleaning up the environment at reasonable cost, and identify future cost management needs.

\section{$3606 \quad$ V18/023686}

Current Issues in DOE's Environmental Management Program

Werner, J.D.
U.S. Department of Energy, Office of Environmental Management, Washington, DC

CONF-961032; Proceedings of the 1996 TLG Decommissioning Conference, Captiva Island, FL, October 13-16, 1996. TLG Services, Inc., Bridgewater, CT, 478 pp.; (29 pp.) (1996)

This paper was presented as the keynote address at the TLG Decommissioning Conference. The presentation covered these four major areas: Key elements of the EM program, the 10 year cleanup plan, the scope of $D \& D$, and new ways of doing business via contract reform and privatization. Appropriations and budget allocations are presented in charts and graphs. Additionally, an attached chart provides DOE environmental management budget appropriations arranged by sites and by state. Another attachment contains the policy on recycling radioactively contaminated carbon steel.

3607

V18/022182

Defense Programs Industrial Partnerships at Los Alamos National Laboratory

Freese, K.B.

Los Alamos National Laboratory, Industrial Partnership Office, Los Alamos, NM

LA-UR-96-2325; CONF-9607134; Proceedings of the Tenth American Glovebox Society Annual Conference, San Diego, CA, July 22-25, 1996; (13 pp.) (1996)

The US Department of Energy's Defense Programs faces unprecedented challenges of stewardship for an aging nuclear stockpile, cessation of nuclear testing, reduced federal budgets, and a smaller manufacturing complex. Partnerships with industry are essential in developing technology, modernizing the manufacturing complex, and maintaining the safety and reliability of the nation's nuclear capability. The past decade of federal support for industrial partherships has promoted benefits to US industrial competitiveness. Recent shifts in government policy have re-emphasized the importance of industrial partnerships in accomplishing agency missions. Nevertheless, abundant opportunities exist for dual-benefit, mission-driven partnerships between the national laboratories and industry. Experience at Los Alamos National Laboratory with this transition is presented.

3608 V18/023021

Developing Necessary and Sufficient Sets of Environmental, Safety, and Health Standards at the Department of Energy

Nelson, D.B.; Troy, A.W.

CONF-951006; Proceedings of an American Nuclear Society (ANS) Winter Meeting, San Francisco, CA, October 29-November 1, 1995. ANS, La Grange Park, IL, 522 pp.; Transactions of the American Nuclear Society 73:131-132 (1995)

The U.S. Department of Energy (DOE) is committed to protect its workers, the public, and the environment. To do this, we must understand our work and its potential hazards and tailor our protection to those hazards. Until now, the DOE has regulated environmental, safety, and health aspects of our work through orders and, more recently, through rules. However, it has become apparent that our current approach suffers from several 
disadvantages. Most notably, it has been difficult to craft orders that recognize and deal effectively with the wide diversity in our work; this can lead to inappropriate requirements and can even compromise safety. Also, the current approach does not easily incorporate the benefits of experience; our practices can become obsolete or ineffectual. This report describes efforts of DOE towards the development of an integrated standards program as the basis for ensuring the protection of workers, public and the environment.

\section{9}

V18/025535

Developing an Integrated Ecological Resource Management and Monitoring Plan as Part of an Environmental Management System

Michael, D.; Hooten, M.; Kelly, E.J.; Roy-Harrison, W. Neptune and Company, Inc., Los Alamos, NM; Los Alamos National Laboratory, Los Alamos, NM; U.S. Department of Energy, Washington, DC

LA-UR-97-519; CONF-970335; Waste Management '97: Working Towards a Cleaner Environment, Proceedings of a Conference on HLW, LLW, Mixed Wastes and Environmental Restoration, Tucson, AZ, March 2-6, 1997; (10 pp.) (1997)

Recent interest in defining the appropriate content of an Environmental Management System (EMS) as specified by ISO 14001 prompted a study to determine how ecological concerns should be integrated into an EMS and subsequently implemented. This paper describes an approach for developing objectives, targets, and processes for ecological resource management at those Department of Energy (DOE) facilities where an ecological resource management approach that goes beyond simple regulatory compliance is warranted. A major goal of this approach is to position DOE facilities so that they can proactively address ecological concerns, rather than being forced to respond retroactively to damage claims, restoration requirements, and/or bad publicity. Although DOE is not requiring ISO 14001 implementation at its facilities, it is recommending ISO 14001 as a voluntary approach to encourage good environmental practices, such as pollution prevention and sustainable development, by adopting an integrated systems approach. The DOE position is that existing DOE orders and policy statements are consistent with, and have elements of, the ISO 14001 EMS approach.

3610

V18/021103

Documenting Cost and Performance for Environmental Remediation Projects

U.S. Department of Energy, Office of Environmental Management, Washington, DC

DOE/EM-0302; 20 pp. (August 8, 1996)

The purpose of this DOE guide is to facilitate the use of consistent procedures to document cost and performance information for projects involving the remediation of media contaminated with hazardous and radioactive waste. It provides remedial action project managers with a standardized set of data to document completed remediation projects. Standardized reporting of data will broaden the utility of the information, increase confidence in the effectiveness of future remedial technologies, and enhance the organization, storage, and retrieval of relevant information for future cleanup projects.

$3611 \quad$ V18/024273

EM International Activities: February 1997 Highlights

U.S. Department of Energy, Office of Environmental Management, Washington, DC

DOE/EM-0324; 25 pp. (February 1997)

EM Intemational Highlights is a brief summary of on-going international projects within the Department of Energy's Office of Environmental Management (EM). This document contains sections on: Global Issues, activities in Western Europe, activities in central and Eastern Europe, activities in Russia, activities in Asia and the Pacific Rim, activities in South America, activities in North America, and International Organizations.

3612

V18/024272

EPA Issues Guidance on Changes in RCRA Enforcement for Federal Facilities

Hazardous Waste Consultant 11(6):2.19 (November-December 1993)

The Federal Facility Compliance Act (FFCA), which went into effect on October 6, 1992, amends the sovereign immunity waiver formerly granted to federal facilities under the Resource Conservation and Recovery Act (RCRA). Basically, FFCA mandates that federal facilities are subject to the same requirements and enforcement procedures as any other "person" as defined by RCRA. EPA recently issued guidance clarifying the enforcement of RCRA in light of FFCA. The guidance was published in the Federal Register on September 21, 1993 (58 FR 49044-49046). Prior to FFCA, EPA was not authorized to issue administrative compliance orders against other federal agencies. Instead, EPA negotiated federal facility compliance agreements. In addition, states authorized to administer RCRA were not allowed to impose punitive fines against federal facilities for hazardous waste violations.

3613

V18/022307

Environmental Management: Progress and Plans of the Environmental Management Program

U.S. Department of Energy, Washington, DC

DOE/EM-0317; 150 pp. (November 1996)

The Department of Energy's Environmental Management program is responsible for addressing immediate, urgent risks to human health and the environment, as well as managing long-term contamination and safety threats. As the Nation's environmental stewardship program, Environmental Management's mission is to manage the nuclear waste and clean up the contamination at Departmental sites across the country. Beyond this mission, Environmental Management performs a variety of stabilization, deactivation and decommissioning, and technology development activities throughout the Nation. The program is responsible for both the short- and long-term disposal and treatment of nuclear and chemical wastes generated during nearly 50 years of nuclear weapons production and nuclear research at 137 Departmental sites in 33 States and 1 Territory. A 1996 study by the Department, the Baseline Environmental Management Report, estimates that the costs of addressing the environmental legacy of the Cold War will 
total approximately $\$ 227$ billion over the next 75 years.

3614

V18/020863

Environmental Restoration Acceleration Report: Expediting the Cleanup

U.S. Department of Energy, Washington, DC

DOE/S-0116; 40 pp. (May 1, 1996)

The Department of Energy (DOE) has made considerable progress in accelerating the pace of cleanup over the past few years. The 1995 Baseline Environmental Management Report (BEMR) estimated that the cleanup program would take 75 years to complete, stretching ahead to the year 2065. The most current estimates show that $80 \%$ of the Environmental Management site cleanups will be completed by the year 2021 . These changes reflect a more focused technical baseline - oriented towards results and fueled by performance-based contracts - and a fundamental change in the strategy of the Environmental Management Program. This strategy involves: (1) addressing urgent risks first; (2) stabilizing sites; (3) investing in technology development and basic science; (4) reducing mortgage costs; and (5) basing decisions on future land use considerations. With this approach, DOE's Environmental Management Program will succeed in completing cleanup at most sites within the next 20 years. The Department intends to increase the pace of acceleration so that risk and fixed management costs are substantially lower and only surveillance and maintenance tasks remain.

3615

V18/023045

Executive Order 12898, Federal Actions to Address Environmental Justice in Minority and Low-Income Populations

U.S. Department of Energy, Office of Environmental Policy and Assistance, Washington, DC

EH-411-097/0001; 4 pp. (February 1997)

On February 11, 1994, President Clinton signed Executive Order (EO) 12898, Federal Actions to Address Environmental Justice in Minority Populations and Low-Income Populations. The Order is designed to focus federal attention on the environmental and human health conditions in minority communities and low-income communities with the goal of achieving environmental justice. The Order is also intended to promote nondiscrimination in federal programs substantialiy affecting human health and the environment. In addition it places emphasis on providing minority communities and low-income communities access to public information on, and an opportunity for public participation in, matters relating to human health or the environment. This information brief provides an overview of the requirements of $E O$ 12898 and their implications for the conduct of DOE activities. In addition, it calls attention to ongoing environmental justice activities within the Department in an effort to raise staff awareness of what is already being done.

3616

V18/023298

Federal Radiological Monitoring and Assessment Center (FRMAC): Overview of FRMAC Operations [Rev. 3]
Bechtel Nevada Corporation, Las Vegas, NV; U.S. Department of Energy, Nevada Operations Office, Las Vegas, NV

DOE/NV-358 (Rev. 3); 35 pp. (February 1996)

In the event of a major radiological emergency, 17 federal agencies with various statutory responsibilities have agreed to coordinate their efforts at the emergency scene under the umbrella of the Federal Radiological Emergency Response Plan (FRERP). These agencies are listed in Appendix A. This cooperative effort will assure the designated Lead Federal Agency (LFA) and the state(s) that all federal radiological assistance fully supports their efforts to protect the public. The mandated federal cooperation ensures that each agency can obtain the data critical to its specific responsibilities. This Overview of the Federal Radiological Monitoring and Assessment Center (FRMAC) Operations describes the FRMAC response activities to a major radiological emergency. It also describes the federal assets and subsequent operational activities which provide federal radiological monitoring and assessment of the off-site areas. These off-site areas may include one or more affected states.

\section{$3617 \quad \mathrm{~V} 18 / 021312$}

Guide to Tribal and Community Involvement in Innovative Technology Assessment

Western Governors' Association, Denver, CO; Federal Advisory Committee to Develop Onsite Innovative Technologies, Washington, DC

Report; 15 pp. (June 1995)

The Federal Advisory Committee to Develop Onsite Innovative Technologies (DOIT), through its Interstate Technology and Regulatory Cooperation Subgroup, is developing a draft framework for interstate cooperation in exploring mechanisms to streamline the regulatory process for deploying technologies. In order to recognize and integrate the interests of tribal governments and communities into this and other technology assessment efforts, the Western Governors' Association (WGA), in conjunction with the U.S. Department of Energy (DOE), organized a Forum to discuss and develop guidance for working with communities on technology assessment issues. Hundreds of representatives from tribes, universities, advisory boards, local govermments, and various public interest organizations were invited to participate in this Forum.

3618

V18/021367

How Can I Find Information?

U.S. Department of Energy, Office of Environmental Management, Washington, DC

DOE/EM-0203; 40 pp. (November 1994)

This guide contains a list (similar to a phone book) of information sources to help members of the public find DOE-related information. The guide is divided into three sections: (1) Listing of DOE Sites by State; (2) Public Information Directory; and (3) Other Information.

How Can I Get Involved?

U.S. Department of Energy, Office of Environmental 
Management, Washington, DC

DOE/EM-0205; 12 pp. (November 1994)

The Department of Energy is changing the way it does business. Employees are empowered to make changes that will help meet the goal of cleaning up and managing wastes at $\mathrm{DOE}$ sites. Taxpayers also have a stake in the future of DOE's sites and projects. DOE invites members of the public to become involved in Environmental Management decision making if they are concemed about the environment, live near a DOE site, care about the health and safety of workers and the public, and/or want a say in how their tax dollars are spent. This brochure is part of the "starter kit" provided to facilitate the reader's becoming involved.

V18/021131

Incentives for Recycling in the U.S. Department of Energy

Short, J.J.; West, H.

U.S. Department of Energy, Office of Pollution Prevention, Washington, DC; BDM Federal, Inc., Gaithersburg, MD

CONF-960212; Waste Management '96: Working Towards a Cleaner Environment, Proceedings of a Conference on $\mathrm{HLW}$, LLW, Mixed Wastes and Environmental Restoration, Tucson, AZ, February 25-29, 1996; (5 pp.) (1996)

A 1994 change in public law (P.L. 103-329, Section 608) enables Federal agencies to receive and use funds from the sale of materials recovered through recycling or waste prevention programs. The law states that these funds must be used for specified environmental programs or other authorized employee programs. Numerous recycling programs exist across the complex; however, revenues generated from these programs are either not captured or managed, are being used to fund unrelated programs (e.g., employee incentive programs), or are being donated to charities. This change in public law provides a valuable incentive for agencies to maximize the recycling of wastes otherwise bound for disposal, especially in light of recent and projected Federal budget cuts. This paper discusses the provisions of the public law, the Department of Energy (DOE) recycling progress, and incentives for recycling within DOE.

\section{1 \\ V18/023943}

Integrated Data Base Report - 1995: U.S. Spent Nuclear Fuel and Radioactive Waste Inventories, Projections, and Characteristics [Rev. 12]

U.S. Department of Energy, Washington, DC; Oak Ridge National Laboratory, Oak Ridge, TN

DOE/RW-0006 (Rev. 12); 275 pp. (December 1996)

The information in this report summarizes the U.S. Department of Energy (DOE) data base for inventories, projections, and characteristics of domestic spent nuclear fuel and radioactive waste. This report is updated annually to keep abreast of continual waste inventory and projection changes in both the government and commercial sectors. Baseline information is provided for $\mathrm{DOE}$ program planning purposes and to support DOE program decisions. Although the primary purpose of this document is to provide background information for program planning within the DOE community, it has also been found useful by state and local governments, the academic community, and some private citizens.
To sustain the objectives of this program in providing accurate and complete data in this field of operation, comments and suggestions to improve the quality and coverage are encouraged.

3622

V18/021324

Involving Stakeholders in Waste Cleanup

Initiatives in Environmental Technology Investment 3(April 1996):1,3-4 (April 1996)

For decades, radioactive, hazardous, mixed, and solid wastes have been accumulating and contaminating the environment. Some of the waste directly affects the public in the communities where it has accumulated. These interested and affected parties, or stakeholders, have a direct concern in how and when the waste in their area is cleaned up. Therefore, the U.S. Department of Energy has formed several groups that involve the public in the decision-making process more than ever before. The Community Leaders Network, the Federal Advisory Committee to Develop Onsite Innovative Technologies, Site Specific Advisory Board, and Site Technology Coordination Groups are intended to reach the public and get them involved with cleanup of waste sites and the deployment of new remediation technologies.

3623

V18/021370

\section{Is DOE Serious? Our Commitment to Public} Participation

U.S. Department of Energy, Office of Environmental Management, Washington, DC

DOE/EM-0206; 8 pp. (November 1994)

The Department of Energy defines stakeholders as "individuals and groups in the public and private sectors who are interested in and/or affected by DOE's activities and decisions. " DOE invites stakeholders to become involved in Environmental Management decision making if they are concerned about the environment, live near a DOE site, care about the health and safety of workers and the public, and/or want a say in how their tax dollars are spent. This brochure is part of the "starter kit" provided to facilitate the reader's becoming involved. It describes DOE's goals and emphasizes DOE's commitment to public participation.

3624

V18/021091

Joint LLNL/Russian Cooperation in Environmental Technologies and Waste Management

Heywood, A.C.; Adamson, M.G.; Kusubov, A.; Myers, B.R.

Lawrence Livermore National Laboratory, Livermore, CA

UCRL-LR-1 12400-92-2/93-1; Environmental Restoration/Waste Management - Applied Technology, Semiannual Report for July 1992-June 1993 - Volume 1, Number 2 and Volume 2, Number 1; (pp. 23-32) (1993)

The realignment of the former Soviet Union into the Commonwealth of Independent States created an excellent opportunity for us to establish mutually beneficial alliances through which to explore and implement new environmental restoration and waste management technologies. In June 1992, seven senior managers and scientists from LLNL visited fourteen Russian institutes and identified several areas of common interest. They 
later placed more than twenty small procurements for state-of-the-art research reports, and they organized a joint CIS-LLNL workshop at Livermore in February 1993 to discuss potential collaborations. As a follow-up, they visited eight institutes and facilities in Russia during a two-week trip in August 1993. The objectives for this second trip were as follows: Evaluate CIS laboratories, facilities, technical personnel, and analytical capabilities; Identify opportunities for accessing key environmental technologies and data sources and for conducting mutually beneficial research and development in ways that facilitate the conversion of Russian scientists and engineers from military to environmental endeavors; Initiate technology-development projects with various Russian institutions to assess the state of the art in selected waste-management technical areas; Discuss and finalize the scope of a joint Russia/US mixed-waste (MW) treatment demonstration proposal to the International Science and Technology Center (ISTC) in Moscow. In this paper the authors briefly evaluate each of the Russian institutes and facilities visited, describe the topics covered in the discussions and specify any agreements reached for future work.

3625

V18/022185

MAC Waste Assay Team

Zebarth, M.; Miller, J.

Canberra Industries, Inc., Meriden, CT

Nuclear Engineering International 40(495):17-18 (October 1995)

The MAC Team, formed by a consortium of three companies in the USA, provides mobile rapid response radioactive waste characterization and treatment on or off site. Privatizing characterization by employing the MAC Team could assist the US DOE in its efforts to cut costs in its program of environmental management of former nuclear weapons installations. Potential applications for MAC Team services include: sorting or segregating low-level waste from transuranic waste; sorting or segregating low-level waste from free-release uranium-bearing waste; sorting of bulk samples in environmental restoration projects; sorting or segregating low-level and free-release/activation products; characterization of transuranic waste for disposal at the Waste Isolation Pilot Plant.

\section{6}

V18/021229

Measuring the Success of Public Participation Efforts Associated with the U.S. Department of Energy's Environmental Management Activities

Schweitzer, M.; Carnes, S.A.; Peelle, E.B.; Wolfe, A.K.; Munro, J.F.

Oak Ridge National Laboratory, Oak Ridge, TN

CONF-960648; Practical Environmental Directions - A Changing Agenda, Proceedings of the 21st Annual National Association of Environmental Professionals Conference, Houston, TX, June 2-6, 1996; (14 pp.) (June 2, 1996)

For the last several years, U.S. DOE's Office of Environmental Restoration and Waste Management (EM) has actively pursued a policy of involving local stakeholders in the planning and implementation of environmental management activities at contaminated sites throughout the DOE complex. An ongoing
ORNL study is focusing on how to measure the success of the public participation efforts. Five DOE facilities were selected for intensive site visits; 4 or 5 additional sites were covered by telephone interviews. Key stakeholder groups were interviewed. Based on the data collection and preliminary analysis, 17 definitions of success were developed for public participation programs. Objective and subjective indicators of the success of the public participation efforts are discussed.

3627

V18/025287

More Can Be Done to Better Control Environmental Restoration Costs

U.S. General Accounting Office, Washington, DC GAO/RCED-92-71; 46 pp. (April 1992)

For more than 40 years, the Department of Energy's (DOE) nuclear weapons complex has disposed of large quantities of hazardous and/or radioactive wastes at numerous sites across the United States. DOE environmental restoration is a process for assessing and cleaning up previously used sites and facilities to meet prescribed stancards derived from federal and state laws. DOE estimated, in 1988 , that it may take from $\$ 35$ billion to $\$ 64$ billion to clean up the weapons complex. Since 1988 the Department has not revised these overall cost projections but has acknowledged that the overall cleanup cost has been growing. As a result, the Chairman, Senate Committee on Governmental Affairs, asked the General Accounting Office (GAO) to examine the (1) degree of cost growth associated with DOE's environmental restoration program and (2) steps DOE can take to better manage, and thereby control, cost growth. By cost growth, GAO is referring to the percent deviation between an estimated cost and a revised estimated cost (or actual cost). Indications are that considerable environmental restoration cost growth is occurring. This study concluded that most cost growth is controllable, primarily by better defining the scope of the cleanup and better determining the contamination problems present. In some instances insufficient DOE management oversight has led to poor contractor performance and cost growth.

3628

V18/023946

\section{Office of Nuclear and Facility Safety FY 1996 Activity} Summary

U.S. Department of Energy, Office of Nuclear and Facility Safety, Washington, DC

DOE/EH-0548; 20 pp. (1996)

The Office of Nuclear and Facility Safety provides nuclear safety policy, independent technical evaluation and technical support in the Department of Energy through an integrated program of analysis of facility operations, assistance in implementing nuclear safety programs, and development of regulations, orders and standards. In FY 1996, the office also carried out the Department's responsibilities under the Price-Anderson Amendments Act of 1988 for setting nuclear safety requirements and investigating and enforcing instances of noncompliance.

3629

V18/021593

Overview of the DOE's Environmental Restoration and Waste Management Program: Hearing Before the Subcommittee on Energy of the Committee on Science, 
Space, and Technology, U.S. House of Representatives, One Hundred Third Congress, First Session, July 15, 1993

Government Printing Office Report No. 63; 201 pp. (1993)

The hearing addresses the Department of Energy's (DOE) environmental restoration and waste management program. Federal facility compliance activities are examined and the overlap in regulatory activities. The national program plans are presented by an official of the DOE. The planned programs, projects and activities are examined.

\section{0}

V18/021366

\section{Public Participation Starter Kit}

U.S. Department of Energy, Office of Environmental Management, Washington, DC

Report; 87 pp. (November 1994)

Information is presented to the public, encouraging public participation and involvement. The publication consists of a series of four booklets addressed to the public: (1) How Can I Find Information?; (2) What Have We Accomplished Together? - Public participation highlights; (3) How Can I Get Involved?; and (4) Is DOE Serious? - Our commitment to public participation. Information resources to the public are listed. Information provided in these booklets includes: DOE sites, by state; Public information directory; and, Highlights of participatory events at several DOE sites.

\section{1}

\section{V18/021946}

\section{Radioactive Waste}

Thomson, B.M.

University of New Mexico, Department of Civil Engineering, Albuquerque, NM

Water Environment Research 64(4):479-492 (June 1992)

This paper is a year-in-review report on the status of radioactive waste management. With increasing recognition of potentially global impacts of other forms of energy generation, there appeared to be an intemational resurgence of interest in nuclear power as a viable alternative with the least number of environmental drawbacks. However, the future of this technology is dependent to a large extent on resolving complex waste management issues. This paper discusses national programs, waste repositories, waste processing and decommissioning, environmental occurrence and transport of radionuclides, and remedial actions and treatment.

\section{2}

\section{V18/025536}

Regional Impact of Federal Nuclear Facilities: The Need for Adjoining States to Have a Role in Decisions at the U.S. Department of Energy's Nuclear Facilities

Grainey, M.W.

Oregon Department of Energy, Salem, OR

CONF-960804 (Vol. 2); Spectrum '96: Nuclear and Hazardous Waste Management, Proceedings of an International Topical Meeting, Seattle, WA, August 18-23, 1996. American Nuclear Society, La Grange Park, IL, Vol. 2, 873 pp.; (pp. 1672-1677) (1996)
The U.S. Department of Energy's (US DOE) nuclear facilities affect not only the state where the facility is located, but may also affect an entire region. States which border states with US DOE facilities and which are impacted by those facilities should play a meaningful role in decisions on waste management and on environmental restoration of those facilities. Federal law currently limits state participation in review and oversight of federal decision-making to the state where the federal facility is located. Federal law should be changed to provide affected bordering states with a role in decisions made at US DOE nuclear facilities.

3633

V18/021953

Role of Risk and Cost Benefit in Program Budgeting Henry, C.J.; Alchowiak, J.

U.S. Department of Energy, Office of Environmental Management, Washington, DC; U.S. Department of Energy, Office of Integrated Risk Management, Washington, DC CONF-951209; Proceedings of the 17th Annual U.S. Department of Energy Low-Level Radioactive Waste Management Conference, D. Lake (ed.), Phoenix, AZ, December 12-14, 1995, 480 pp.; (8 pp.) (1995)

The primary Environmental Management (EM) program mission is protecting human health and the environment. EM is currently facing a decreasing budget while still having to deal with competing requirements and risks to workers, public, and environment. There has been no consistent framework for considering in an integrated fashion the multiple types of risks and hazards present in the nuclear weapons complex. Therefore, to allocate resources during the budget process, EM is using risk, long term costs. mongage reduction, compliance issues, and stakeholders concerns to prioritize the funding of activities. Risk and cost-benefit analysis are valuable tools to help make decisions to reduce risks to health, safery, and the environment in a sensible and cost-effective manner. Principles for priority setting using risk analysis are to seck to compare risks by grouping them into broad categories of concem (e.g., high, medium, and low); to set priorities in managing risks to account for relevant management and social considerations; to inform priorities by as broad a range of views as possible, ideally with consensus; and, to try to coordinate risk reduction efforts among programs. The Draft Risk Report to Congress - Risks and the Risk Debate: Searching for Common Gound "The First Step," provides the first link between budget, compliance requirements, and risk reduction/pollution prevention activities. The process used for the report provides an initial framework to capture the spectrum of risks associated with environmental management activities and to link these risks in a qualitative fashion to compliance and the budget

3634

V18/021228

Standardization and Integration of Ecological and Human Risk Assessments at Department of Energy National Laboratories

Breckenridge, R.P.; Berry, D.L.

Idaho National Engineering Laboratory, Idaho Falls, ID; Sandia National Laboratories, Albuquerque, NM

CONF-9511137; Global Environmental Protection: Science, 
Politics, and Common Sense, Proceedings of the Second Society of Environmental Toxicology and Chemistry (SETAC) World Congress and 16th Annual Meeting, Vancouver, British Columbia, Canada, November 5-9, 1995. Society of Environmental Toxicology and Chemistry, Pensacola, FL, 378 pp.; (p. 169) (1995)

In 1990, the directors of twelve national laboratories operated by the U.S. Department of Energy (DOE) chartered a steering group to address DOE's concems about the effectiveness of any regulations driving the cost of environmental restoration and waste management. The goal of this presentation is to inform and to seek collaboration on the challenge of standardizing ecological and human health risk assessment approaches and development of an approach to address the differences between environmental remediation and restoration activities at DOE's waste management sites across the country. Recent changes in risk related regulations and budget cuts have prompted significant changes in DOE's approach to conducting and standardizing risk-based approaches for waste management. The steering group was established in 1990 to organize a broad, long-term educational outreach and research program focused on better science and public understanding of the risks associated with hazardous agents (chemical, biological, radiological, and physical) in the environment and the workplace. This presentation discusses the group's goal to (1) act as one resource for providing the technical basis for health and environmental standards; (2) catalyze a national effort to improve public understanding of risk and the importance of cost benefit analysis in evaluating mitigation of risk; (3) catalyze improvements in understanding of health and environmental effects of hazardous agents; and (4) analyze with regulatory agencies, industry, and the public the potential for evolution of risk-based consensus standard into federal and state environmental and occupational/public health regulations. Major accomplishments will be presented along with the group's agenda for standardizing risk, environmental, and occupational/public health standards. (Complete text)

\section{5}

V18/022795

Taking Stock: An Overview of Public Participation Lessons Learned by the U.S. Department of Energy 1990-1995

Swartz, G.

Swartz and Associates, Inc., Boulder, CO

CONF-960804 (Vol. 2); Spectrum '96: Nuclear and Hazardous Waste Management, Proceedings of an International Topical Meeting, Seattle, WA, August 18-23, 1996. American Nuclear Society, La Grange Park, IL, Vol. 2, 873 pp.; (pp. 1629-1635) (1996)

The U.S. Department of Energy (DOE) has produced a large volume of work in the area of public involvement during the years from 1990-1995. Despite this fact, public perception has been that DOE has done little to establish a clear and coordinated definition or role for public involvement. In summary, the public reports they do not believe DOE is actively trying to involve "stakeholders" in its decision making processes at either the local or national level. Lack of coordination among DOE public involvement efforts; functional overlaps from group-to-group; lack of a clear definition of the DOE decision-making process; and lack of a clear accounting of how tribes and the public are actually involved in decision making, have been cited as primary roadblocks to problem solution. Beginning in July of 1995, DOE's Mixed Waste Focus Area (MWFA) convened a core group of staff and contract personnel for the purpose of designing an innovative approach to meeting collaborative decision making needs within DOE's Mixed Waste arena. The objective of the effort was to complete a general overview of lessons that DOE has leamed in working with the public since 1990 and to demonstrate how those lessons could be utilized in designing meaningful public participation plans to serve DOE into the future.

3636

$$
\mathrm{V} 18 / 021328
$$

\section{U.S. Department of Energy Environmental Justice} Strategy: Executive Order 12898

\section{U.S. Department of Energy, Washington, DC \\ Report; 20 pp. (April 1995)}

This document provides a structured framework of the Department of Energy's efforts to integrate feasible environmental justice principles set forth in Executive Order 12898 into its operations. The strategy is structured in the spirit of the Administration's principles for reinventing government and is consistent with the principles set forth in the National Performance Review as it emphasizes a more responsive government and accountability by employees for achieving results. Individual strategies reflect a refocusing of policies and programs by Departmental elements, more meaningful dialogue with stakeholders to address the impact of operations on communities, and the continuation of on-going programmatic activities with the infusion of a heightened sensitivity to the principles by environmental justice.

Implementation of the strategy will be carried out mainly within current programmatic and budgetary provisions of existing Departmental elements. As current budgetary situations change, the Department will work with stakeholders to prioritize strategies for implementation.

3637

\section{V18/023202}

\section{U.S. Department of Energy Integrated Demonstrations and Integrated Programs for Environmental Remediation and Waste Management}

Lankford, J.M.; Strauch, H.J.

U.S. Department of Energy, Germantown, MD; BDM International, Inc., Germantown, MD

CONF-9210194; Proceedings of an International Symposium on Environmental Contamination in Central and Eastern Europe, Budapest, Hungary, October 12-16, 1992, 968 pp.; (pp. 326-328) (1992)

The United States Department of Energy (DOE) has the responsibility to carry out various government related programs. This requires the continued operation of facilities, resulting in the generation of radioactive and hazardous waste. The Office of Environmental Restoration and Waste Management was created within the DOE to manage this waste, as well as to remediate sites and manage wastes produced in earlier decades. This paper describes the management concept of Integrated Programs and Integrated Demonstrations and some of the technologies associated with them which were developed to assist in this undertaking. These demonstrations and programs are pursued to provide faster, better, safer, and cheaper systems than are now available. 
3638

V18/021368

What Have We Accomplished Together? Public Participation Highlights

U.S. Department of Energy, Office of Environmental Management, Washington, DC

DOE/EM-0204; 12 pp. (November 1994)

Examples are given of public participation endeavors at DOE sites or projects such as the Waste Isolation Pilot Plant (WIPP), Oak Ridge Operations Office, Fernald, Formerly Utilized Sites Remedial Action Program (FUSRAP), Rocky Flats, Oakland Operations Office, Weldon Spring Site, UMTRA Project, and the Idaho Operations Office. DOE encourages the public to become involved by providing a toll-free information service, working with several national advisory groups, traveling with exhibits to inform the public, and making it uncomplicated for individuals to express their interests and concerns. 